UNIVERSIDADE DE BRASÍLIA

FACULDADE DE AGRONOMIA E MEDICINA VETERINÁRIA

PROGRAMA DE PÓS-GRADUAÇÃO EM AGRONOMIA

DESENVOLVIMENTO, VALIDAÇÃO, TRANSFERIBILIDADE E APLICAÇÃO DE MARCADORES MICROSSATÉLITES EM ESTUDOS GENÉTICOS DAS PASSIFLORAS

SUSAN ARAYA

TESE DE DOUTORADO

EM AGRONOMIA

BRASÍLIA/DF

NOVEMBRO/2016 


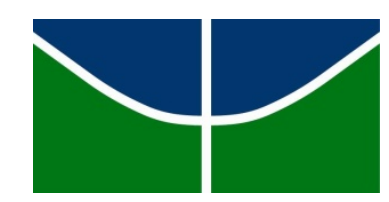

UNIVERSIDADE DE BRASÍLIA

FACULDADE DE AGRONOMIA E MEDICINA VETERINÁRIA PROGRAMA DE PÓS-GRADUAÇÃO EM AGRONOMIA

DESENVOLVIMENTO, VALIDAÇÃO, TRANSFERIBILIDADE E APLICAÇÃO DE MARCADORES MICROSSATÉLITES EM ESTUDOS GENÉTICOS DAS PASSIFLORAS

SUSAN ARAYA

ORIENTADOR: FÁBIO GELAPE FALEIRO

CO-ORIENTADOR: MÁRCIO ELIAS FERREIRA

TESE DE DOUTORADO EM AGRONOMIA

PUBLICAÇÃO: 052D/2016

BRASÍLIA/DF

NOVEMBRO/2016 
UNIVERSIDADE DE BRASÍLIA

FACULDADE DE AGRONOMIA E MEDICINA VETERINÁRIA PROGRAMA DE PÓS-GRADUAÇÃO EM AGRONOMIA

DESENVOLVIMENTO, VALIDAÇÃO, TRANSFERIBILIDADE E APLICAÇÃO DE MARCADORES MICROSSATÉLITES EM ESTUDOS GENÉTICOS DAS PASSIFLORAS

SUSAN ARAYA

TESE DE DOUTORADO SUBMETIDA AO PROGRAMA DE PÓSGRADUAÇÃO EM AGRONOMIA, COMO PARTE DOS REQUISITOS NECESSÁRIOS À OBTENÇÃO DO GRAU DE DOUTOR EM AGRONOMIA.

APROVADA POR:

Fábio Gelape Faleiro, D.Sc., Embrapa Cerrados, CPF: 739.634.706-82, fabio.faleiro@embrapa.br (Orientador)

Nilton Tadeu Vilela Junqueira, D.Sc., Embrapa Cerrados, CPF: 309.620.646-53, nilton.junqueira@embrapa.br (Examinador interno)

Jose Ricardo Peixoto, Dr., Universidade de Brasília, CPF: 354.356.236-34, peixoto@unb.br (Examinador interno)

Ana Maria Costa, Dra., Embrapa Cerrados, CPF: 308.371.701-68, ana-maria.costa@embrapa.br (Examinador externo)

Marco Aurélio Caldas de Pinho Pessoa Filho, Dr., Embrapa Cerrados, CPF: 836.127.693-91, marco.pessoa@embrapa.br (Examinador externo) 


\section{FICHA CATALOGRÁFICA}

Araya, Susan

Desenvolvimento, validação, transferibilidade e aplicação de marcadores microssatélites em estudos genéticos das Passifloras.

Susan Araya; orientação de Fábio Gelape Faleiro. - Brasília, 2016.

283 p. : il.

Tese de Doutorado (D) - Universidade de Brasília/Faculdade de Agronomia e Medicina Veterinária, 2016.

1. Passiflora edulis Sims. 2. Marcadores microssatélites.

3. Transferibilidade 4. Modo de reprodução.

5. Cruzamentos. 6. Teste de paternidade.

I. Faleiro, F. G. II. Doutor.

CDD ou CDU

Agris / FAO

\section{REFERÊNCIA BIBLIOGRÁFICA}

ARAYA, S. Desenvolvimento, validação, transferibilidade e aplicação de marcadores microssatélites em estudos genéticos das Passifloras. Brasília: Faculdade de Agronomia e Medicina Veterinária, Universidade de Brasília, 2016, 283 p. Tese de Doutorado.

\section{CESSÃO DE DIREITOS}

NOME DO AUTOR: SUSAN ARAYA

TÍTULO DA TESE: Desenvolvimento, validação, transferibilidade e utilização de marcadores microssatélites em estudos genéticos das Passifloras.

GRAU: Doutor $\quad$ ANO: 2016

É concedida à Universidade de Brasília de Brasília permissão para reproduzir cópias desta tese de doutorado para única e exclusivamente propósitos acadêmicos e científicos. $\mathrm{O}$ autor reserva para si os outros direitos autorais, de publicação. Nenhuma parte desta tese de doutorado pode ser reproduzida sem a autorização por escrito do autor. Citações são estimuladas, desde que citada à fonte.

Nome: SUSAN ARAYA

CPF: 749.345.381-00

Endereço: SGAS 611 L3 Sul, Conjunto D, Parte C, Asa Sul, Brasília CEP 70.200-710

Telefone: (61) 9-8124-0221_ E-mail: susan_araya@hotmail.com 


\section{SUMÁRIO}

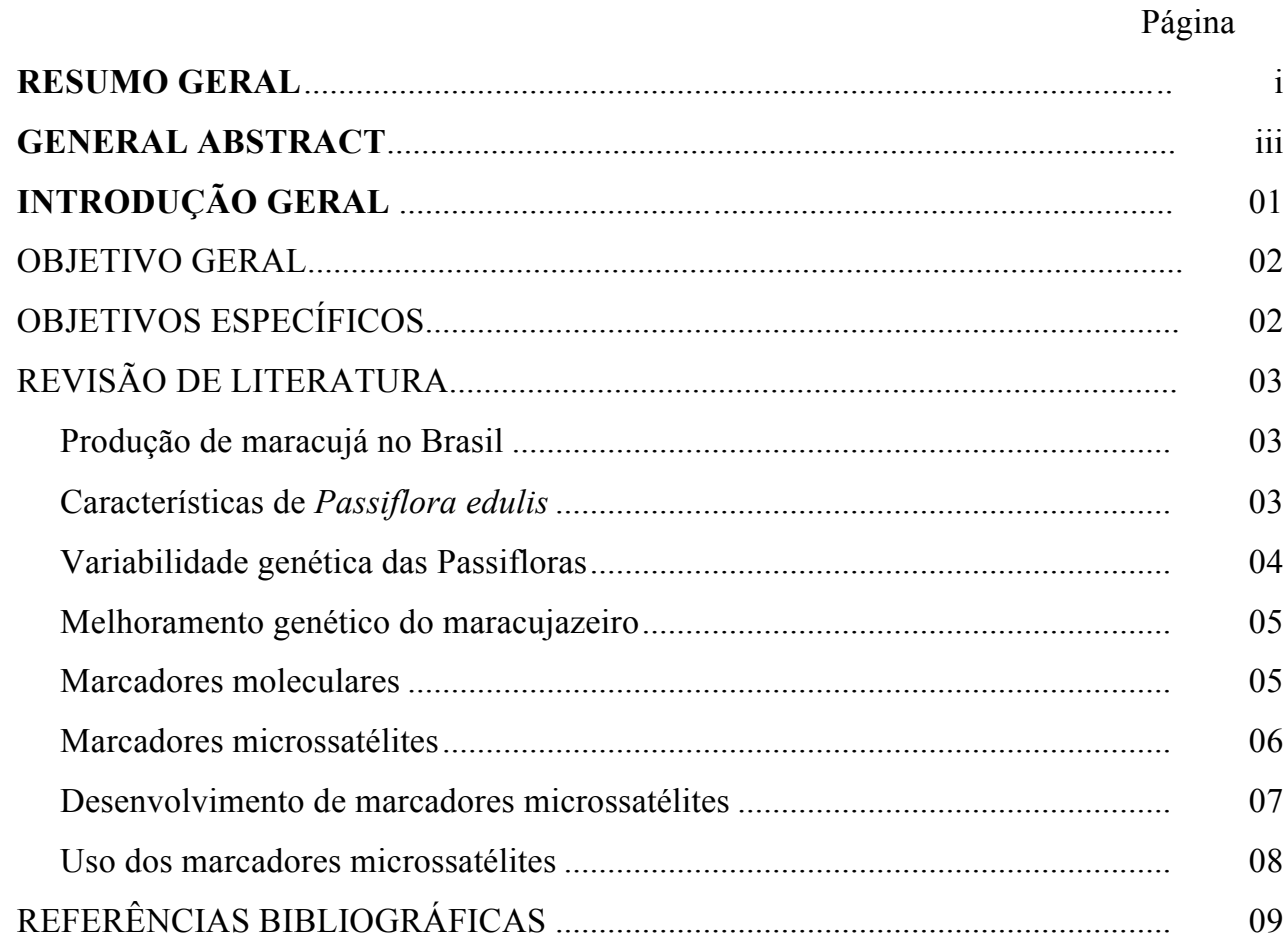

CAPÍTULO 1. DESENVOLVIMENTO DE MARCADORES

MICROSSATÉLITES POR MEIO DO SEQUENCIAMENTO PARCIAL DO

GENOMA DE MARACUJÁ-AMARELO Passiflora edulis Sims E

TRANSFERIBILIDADE PARA 78 ESPÉCIES DO GÊNERO Passiflora.......... 21

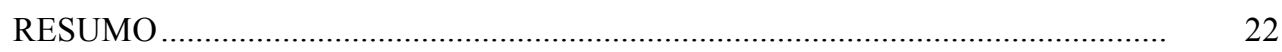

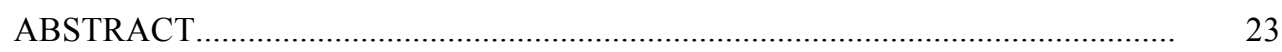

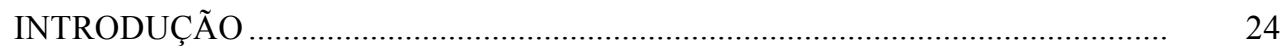

MATERIAL E MÉTODOS ................................................................................. 26

Extração de DNA e sequenciamento do genoma...................................................... 26

Montagem de novo do genoma ...................................................................... 26

Identificação de microssatélites e desenvolvimento de marcadores........................ 27

Testes de PCR dos marcadores microssatélites .................................................. 28

Material vegetal e descrição estatística dos marcadores microssatélites ................ 28

Transferibilidade de marcadores microssatélites de P. edulis .............................. 32

RESULTADOS E DISCUSSÃO ……………………...................................... 33

Sequenciamento parcial e montagem de novo do genoma de Passiflora edulis

Sims para a deteç̧ão de microssatélites .............................................................. 33

Estatística descritiva dos marcadores microssatélites....................................... 36

Transferibilidade dos marcadores microssatélites em espécies de Passiflora....... $\quad 39$

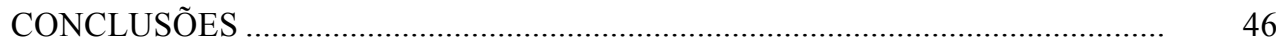


CAPÍTULO 2. ESTIMATIVA DAS TAXAS DE AUTOGAMIA E ALOGAMIA NA CULTIVAR BRS MARACUJÁ JABOTICABA DE Passiflora edulis Sims UTILIZANDO MARCADORES MICROSSATÉLITES 56 RESUMO

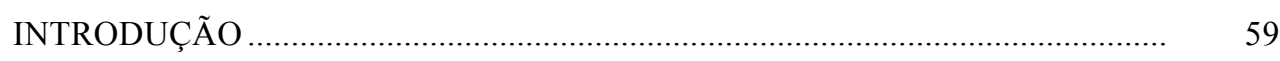

MATERIAL E MÉTODOS ....................................................................................

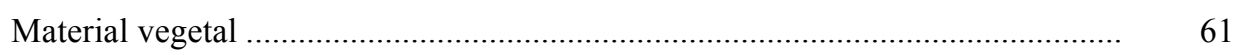

Extração de DNA e genotipagem ........................................................................ 63

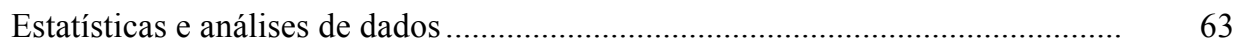

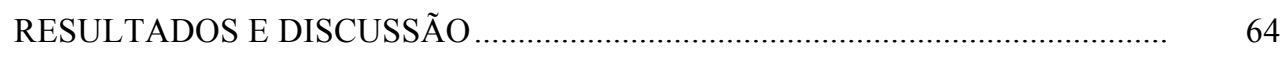

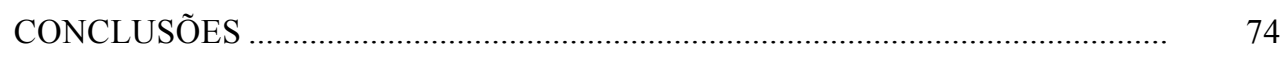

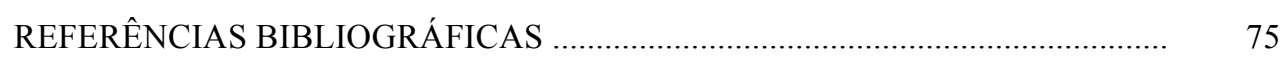

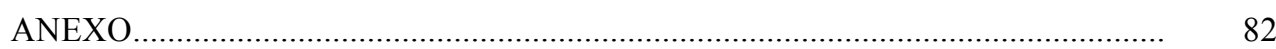

CAPÍTULO 3. ANÁLISE DE PATERNIDADE EM GENÓTIPOS DE

PASSIFLORA OBTIDOS A PARTIR DE CRUZAMENTOS

INTERESPECÍFICOS UTILIZANDO MARCADORES

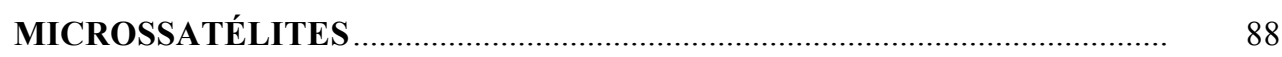

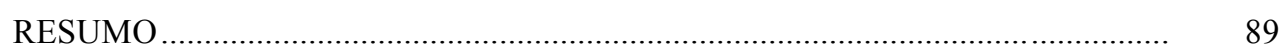

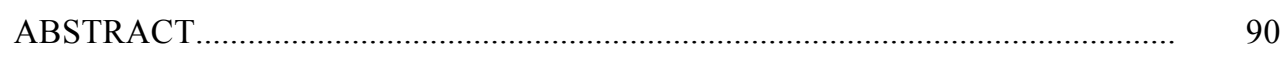

INTRODUÇÃ

MATERIAL E MÉTODOS ................................................................................. 92

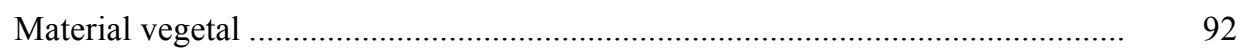

Extração de DNA e genotipagem .................................................................. 94

Binagem e frequências alélicas ..................................................................... 95

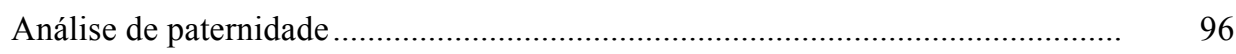

RESULTADOS E DISCUSSÃO .......................................................................... 97

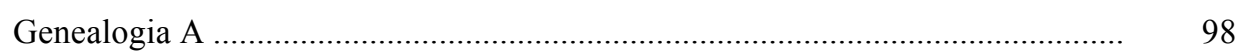

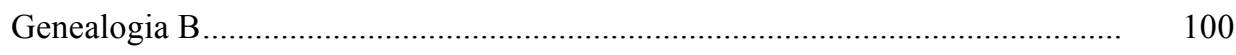

Genealogia C .................................................................................. 104

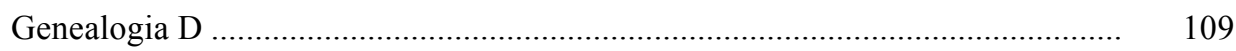

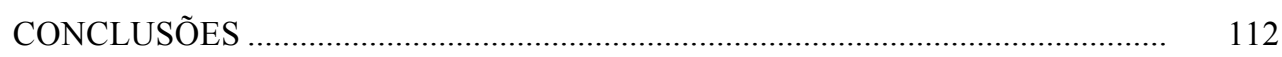

REFERÊNCIAS BIBLIOGRÁFICAS …............................................................. 112

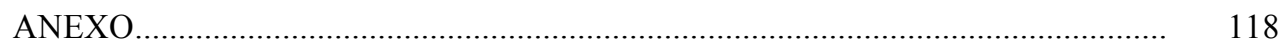

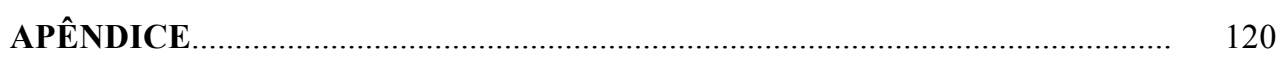




\title{
DESENVOLVIMENTO, VALIDAÇÃO, TRANSFERIBILIDADE E APLICAÇÃO DE MARCADORES MICROSSATÉLITES EM ESTUDOS GENÉTICOS DAS PASSIFLORAS
}

\author{
RESUMO GERAL
}

O gênero Passiflora compreende centenas de espécies silvestres e cultivadas de maracujá que possuem diversos usos na alimentação, na indústria, na medicina e também no paisagismo. Esforços para desenvolver ferramentas de análises genéticas em Passiflora edulis Sims, a espécie mais importante do gênero Passiflora, ainda são incipientes. Nessa pesquisa, é descrito o uso do Sequenciamento de Nova Geração para a montagem parcial do genoma de P. edulis com o intuito de desenvolver centenas de novos marcadores microssatélites. Um total de 14,11 Gpb de reads de sequências paired-end de Illumina foram analisadas para detectar sequências simples repetidas no genoma de maracujá. Uma amostra de 1.300 contigs que continham sequencias de microssatélites foram selecionadas para o desenvolvimento de primers para PCR. Os painéis para os marcadores di- e tri-nucleotídeos selecionados, foram testados em acessos de $P$. edulis para a sua validação. Polimorfismo foi detectado em $74 \%$ dos marcadores ( $\mathrm{PIC}=0,16-0,77$; número de alelos/loco=2-7). Os marcadores mais polimórficos $(\mathrm{PIC}=0,46-0,77)$ foram usados em análises de transferibilidade, modo de reprodução e confirmação de cruzamentos. Os marcadores foram testados em 78 espécies de Passiflora, onde aproximadamente $71 \%$ da combinação marcador/espécie foi positiva para a amplificação em todas as espécies testadas. No estudo do modo de reprodução da cultivar BRS Maracujá Jaboticaba de $P$. edulis, nas populações de polinização aberta, a taxa de cruzamento multiloco $\left(t_{m}\right)$ variou entre 0,409 e 0,566 , evidenciando modo de reprodução misto por meio de autogamia e alogamia. Na confirmação de cruzamentos, foram analisados os genitores de quatro genealogias para a Inclusão ou Exclusão Categóricas para cada loco, e então calculados os Índice de Paternidade (PI) e a Probabilidade de Paternidade (W) para os verdadeiros genitores. Os marcadores microssatélites testados auxiliaram na exclusão de 7 supostos genitores de 6 cruzamentos em 4 genealogias, e confirmaram como genitores verdadeiros 5 dos supostos genitores, onde W variou entre 95,137 e 99,999\%. Nossos estudos confirmaram a obtenção dos híbridos sexuais do 
cruzamentos interespecífico $P$. edulis $\mathrm{GA} 2 \times \mathrm{x} \quad P$. incarnata. Os marcadores moleculares microssatélites desenvolvidos, validados e utilizados nesse trabalho serão de grande utilidade para diferentes estudos genéticos das Passifloras por diferentes grupos de pesquisa no Brasil e no mundo.

Palavras-chave: Passiflora edulis, montagem do genoma de novo, microssatélites, modo de reprodução, cruzamentos interespecíficos 


\title{
DEVELOPMENT, VALIDATION, TRANSFERABILITY AND APPLICATION OF MICROSATELLITE MARKERS IN GENETIC STUDIES OF PASSIFLORAS
}

\author{
GENERAL ABSTRACT
}

The Passiflora genus comprises hundreds of wild and cultivated species of passion fruit used for food, industrial, ornamental and medicinal purposes. Efforts to develop genomic tools for genetic analysis of $P$. edulis, the most important of the Passiflora species, are still incipient. We describe the use of NGS technology to partially assemble the $P$. edulis genome in order to develop hundreds of new microsatellite markers. A total of 14.11 Mbp of Illumina paired-end sequence reads were analyzed to detect simple sequence repeat sites in the sour passion fruit genome. A sample of 1,300 contigs containing perfect repeat microsatellite sequences was selected for PCR primer development. A panel of di- and tri-nucleotide repeat markers selected were then tested in $P$. edulis germplasm accessions for validation. DNA polymorphism was detected in $74 \%$ of the markers $(\mathrm{PIC}=0.16$ to 0.77 ; number of alleles/locus $=2$ to 7$)$. A core panel of highly polymorphic markers $(\mathrm{PIC}=0.46$ to 0.77$)$ was used in analysis of cross-amplify, matting system and confirmation crosses in Passiflora. The markers tested in 78 species of Passiflora resulted in $71 \%$ of the marker/species combinations for positive amplicons in all species tested. In the study of matting system in the cultivar BRS Maracujá Jaboticaba of $P$. edulis, in three of the offspring that comes from commercial orchards of $P$. edulis allogamy were confirmed with multilocus outcrossing rate $\left(t_{m}\right) 0,409$ to 0,566 , that is an evidence of the mixed mating system through autogamy and allogamy. For the confirmation of crosses we analyzed the genitors from crosses of four genealogies by Categorical Inclusion or Exclusion for each loci, and then, estimated the Paternity Index (PI) and the Probability of Paternity (W) for the true genitor. Microsatellite markers tested assist for the exclusion of 7 alleged genitors of 6 crossings in 4 genealogies, and confirmed as a true genitors 5 alleged genitors, where W was rated between 95.137 and 99.999\%. Our research confirms the achievement of sexual hybrid for interspecific crossing of P. edulis GA2 x P. incarnata. The new microsatellite markers, validated and used in this research, 
will be useful for different genetic studies of Passiflora by different research groups in Brazil and worldwide.

Key words: Passiflora edulis, de novo genome assembly, microsatellite, mating system, interspecific crosses 


\section{INTRODUÇÃO GERAL}

O maracujazeiro pertence à família Passifloraceae, a qual possui mais de 500 espécies distribuídas em regiões tropicais da América, Ásia e África (FEUILLET, 2004; MACDOUGAL; FEUILLET, 2004; VANDERPLANK, 1996). Brasil e Colômbia são os maiores centros de diversidade (FERREIRA, 1994; OCAMPO; D’EECKENBRUGGE; JARVIS, 2010). Dentro dessa família, a espécie mais importante é Passiflora edulis Sims $(2 \mathrm{n}=2 \mathrm{x}=18)$, que representa uma produção mundial de 1.270.000 toneladas (FAO, 2011) onde o destino dos frutos é principalmente para a fabricação de sucos e concentrados, e o consumo in natura. Atualmente, o Brasil é o maior produtor e consumidor de maracujá no mundo (FAO, 2011), onde a cultura apresenta uma franca expansão, mas que ainda enfrenta problemas no sistema de produção devido em parte, à uma carência de cultivares adaptadas aos diferentes agroecossistemas e com adequado nível de resistência às principais doenças (MELETTI et al., 2005).

A espécie $P$. edulis apresenta uma ampla variedade de cores de casca nos seus frutos, começando desde o amarelo, passando pelo vermelho e chegando até o roxo. $\mathrm{O}$ maracujazeiro-amarelo é considerado como uma mutação do maracujazeiro-roxo ou como um híbrido natural entre o roxo e outras espécies relacionadas (AKAMINE; GIROLAMI, 1959). A diferença tem separado a espécie, tradicionalmente, em duas formas: flavicarpa e edulis (maracujazeiro-amarelo e maracujazeiro-roxo, respectivamente). Entretanto, em termos taxonômicos, segundo BERNACCI et al. (2008), a maneira correta é utilizar Passiflora edulis Sims para toda e qualquer planta e cor de fruto do maracujazeiro-azedo, seguido do nome da cultivar.

Maracujazeiro-amarelo é utilizado principalmente na fabricação de sucos e polpas (SOUZA; MELETTI, 1997). Já maracujazeiro-roxo possui características físicas e organolépticas interessantes para o mercado de frutas exóticas (MELETTI, 1999).

Considerando a importância dessa cultura e seus principais usos, programas de melhoramento genético têm realizado cruzamentos inter e intraespecíficos para obtenção de híbridos utilizando espécies como Passiflora setacea, Passiflora quadrifaria, Passiflora incarnata, entre outras espécies compatíveis com a espécie comercial, para a introdução de características desejáveis (MELETTI et al., 2005). Certamente ainda existem muitas outras espécies que devem ser devidamente 
caracterizadas para seu uso em programas de melhoramento (CERQUEIRA-SILVA et al., 2014a).

Marcadores moleculares têm sido utilizados como ferramentas auxiliares nas diferentes etapas do melhoramento genético, desde a caracterização de germoplasma até as etapas finais de desenvolvimento e seleção de plantas melhoradas (FERREIRA; FALEIRO, 2008; FERREIRA; GRATTAPAGLIA, 1998). Dentro da ampla gama de marcadores moleculares utilizados, marcadores microssatélites apresentam grandes vantagens como a alta reprodutibilidade, codominância, alto conteúdo de polimorfismo e alelismo múltiplo (CHEN et al., 1997; LITT; LUTY, 1989).

Dentro da família Passifloraceae, algumas pesquisas têm desenvolvido marcadores microssatélites (CERQUEIRA-SILVA et al., 2012, 2014b; OLIVEIRA, 2006; OLIVEIRA et al., 2005; PADUA et al., 2005; PENHA et al., 2013), mas os resultados obtidos para os locos descobertos, têm sido insatisfatórios em relação ao polimorfismo detectado, principalmente em $P$. edulis, que é uma espécie autoincompatível e de grande importância econômica e social.

\section{OBJETIVO GERAL}

Desenvolver e validar marcadores microssatélites por meio do sequenciamento parcial do genoma de Passiflora edulis Sims, e utilizar esses marcadores em análises da variabilidade genética, do modo de reprodução de uma cultivar de maracujazeiroroxo e na confirmação de cruzamentos inter e intraespecíficos realizados no programa de melhoramento genético das Passifloras realizado na Embrapa Cerrados.

\section{OBJETIVOS ESPECÍFICOS}

- Desenvolver e validar marcadores microssatélites por meio do sequenciamento parcial do genoma de P. edulis.

- Analisar a transferibilidade dos marcadores microssatélites desenvolvidos e validados em $P$. edulis para outras espécies do gênero Passiflora.

- Analisar a autocompatibilidade e taxas de alogamia e autogamia na cultivar BRS Maracujá Jaboticaba de maracujazeiro-roxo ( $P$. edulis) utilizando marcadores microssatélites. 
- Realizar análises de paternidade utilizando marcadores microssatélites, para a confirmação de cruzamentos realizados no programa de melhoramento das Passifloras.

\section{REVISÃO DE LITERATURA}

\section{Produção de maracujá no Brasil}

A produção de maracujá vem ganhando grande importância no Brasil a partir das últimas três décadas, o que coloca o País em uma situação de destaque no ranking mundial. A área plantada de maracujazeiro-azedo no Brasil, segundo o Instituto Brasileiro de Geografia e Estatística, corresponde a 51.187 ha alcançando uma produção de 921.275 t (IBGE, 2015). As maiores regiões produtoras de maracujazeiro no Brasil são o Nordeste e o Sudeste, e o Estado com maior produção é a Bahia, seguido por Ceará e Sergipe (IBGE, 2014). O rendimento nacional de aproximadamente 14 toneladas por hectare é baixo, considerando que o potencial da cultura é superior a 50 toneladas por hectare (MELETTI et al., 2005). Entre as causas da baixa produtividade estão o uso de cultivares inadequadas (JUNQUEIRA et al., 1999), a carência na utilização de tecnologias no sistema de produção, as condições edáficas e climáticas desfavoráveis para a cultura, e a ocorrência de fatores bióticos e abióticos que diminuem a produção e a longevidade das plantas (LIMA; BORGES, 2002). Portanto, o melhoramento genético enfocado no desempenho agronômico torna-se fundamental, assim como para a obtenção de cultivares resistentes a fitopatógenos (FALEIRO; JUNQUEIRA; COSTA, 2015).

\section{Características de Passiflora edulis}

O maracujazeiro-azedo ou Passiflora edulis Sims é uma planta trepadeira sublenhosa que apresenta grande vigor vegetativo e que pertence à família Passifloraceae. É uma espécie diploide $(2 \mathrm{n}=2 \mathrm{x}=18)$, onde seu genoma é de tamanho médio entre 3.096 e $3.126 \mathrm{Mpb}$ (SOUZA et al., 2004).

Seu caule é cilíndrico ou subanguloso e estriado. Suas folhas são trilobadas, trinervadas com lóbulos oblongo-ovados ou ovados, com ápice agudo e, às vezes um par de glândulas sésseis nos sinus dos lóbulos. A margem é serreada ou serreado- 
glandular. Possui gavinhas axilares, solitárias e bem desenvolvidas e robustas. (CERVI, 1997).

A flor de $P$. edulis é hermafrodita, grande, vistosa e protegida na base por brácteas foliares. $\mathrm{O}$ ovário encontra-se sobre o androginóforo. Os três estiletes são livres e conatos na base, com estigmas capitados. $\mathrm{O}$ androceu é formado por cinco estames, com filetes livres inseridos abaixo do ovário e anteras dorsifixas e versáteis (BRUCKNER, 1997; VANDERPLANK, 1996). Embora a flor de P. edulis seja hermafrodita, ela é incapaz de produzir zigotos após autopolinização, devido à autoincompatibilidade, isto faz que o produtor precise ter um grande número de plantas geneticamente distintas em seu pomar. BRUCKNER et al. (1995) concluíram que a autoincompatibilidade em maracujazeiro-amarelo é do tipo homomórfica esporofítica, de herança monofatorial, entretanto, estudos realizados por SUASSUNA et al. (2003), sugerem a existência de um gene de efeito gametofítico associado ao sistema esporofítico. Por outro lado, na mesma espécie, mas em maracujazeiro-roxo, tem sido observada a autocompatibilidade (CHANG, 1974, 1981; ISHIHATA, 1981; RÊGO, 1997).

Os frutos de $P$. edulis são globosos ou ovoides, que apresentam grande variação de cores como amarelo-pálido, amarelo, amarelo-alaranjado, vermelhorosado, vermelho, roxo-avermelhado, roxo-esverdeado, roxo e roxo-escuro (CERVI, 1997). Característica de herança complexa e que não apresenta dominância, existindo, portanto, várias cores intermediárias (BERNACCI et al., 2008).

\section{Variabilidade genética das Passifloras}

O gênero Passiflora está composto por mais de 500 espécies (VANDERPLANK, 1996), sendo que mais de 150 são originárias do Brasil, um dos principais centros de diversidade genética, observando uma ampla diversidade no Centro-Norte do País (FERREIRA, 1994). Segundo CUNHA (1997), dessas espécies, cerca de 70 produzem frutos comestíveis e segundo VIEIRA e CARNEIRO (2004), mais de 50 apresentam potencial comercial. Por exemplo, FALEIRO; JUNQUEIRA e COSTA (2015) e FALEIRO et al. (2013) relatam o potencial agronômico na produção de frutos das espécies $P$. alata, $P$. setacea, $P$. nitida, $P$. tenuifila, $P$. cincinnata, $P$. quadrangularis e P. maliformis para o mercado de frutas frescas, na produção de matéria-prima para doces e sorvetes e também substâncias bioativas com propriedades medicinais. 


\section{Melhoramento genético do maracujazeiro}

As primeiras cultivares híbridas de maracujazeiro-azedo, obtidas a partir do melhoramento genético, foram lançadas em 1999 pelo Instituto Agronômico (IAC) para atender à especialização do mercado que buscava frutos de menor espessura da casca e homogeneidade (MELETTI, 2011). Com o passar do tempo, o foco mudou devido ao aumento da ocorrência de doenças nessa cultura, as quais depreciam a qualidade do fruto, diminuindo seu valor comercial e reduzindo a produtividade e a longevidade do pomar (FALEIRO; JUNQUEIRA; COSTA, 2015). Sendo assim, o melhoramento buscou selecionar genótipos superiores que fossem resistentes às doenças dentro e fora da espécie $P$. edulis, realizando hibridações intra e interespecíficas, e por sua vez retrocuzamentos, os quais têm sido utilizados com sucesso na incorporação de genes de resistência e outros genes de interesse em materiais comerciais ( JUNQUEIRA et al., 2005; FALEIRO et al., 2008; FALEIRO; JUNQUEIRA, 2009; FONSECA et al., 2009).

\section{Marcadores moleculares}

Marcadores moleculares podem ser definidos como marcadores genéticos baseados na detecção de isoenzimas ou sequências de DNA. Entre as vantagens dos marcadores moleculares, estão a obtenção de um numero praticamente ilimitado de polimorfismos genéticos; a identificação direta do genótipo sem influência do ambiente; a possibilidade de detecção de tais polimorfismos em qualquer estádio do desenvolvimento da planta ou do animal, ou a partir de cultura de células ou tecidos, e a possiblidade de gerar maior quantidade de informação genética por loco no caso de marcadores codominantes (FERREIRA; GRATTAPAGLIA, 1997).

A disponibilidade de marcadores genéticos é fundamental na biologia e no melhoramento de plantas para a caracterização e seleção de plantas, para o mapeamento de genes e para a avaliação e análises de diversidade genética (RUDD et al., 2005).

Marcadores moleculares podem ser separados em dois grupos principais: a) marcadores moleculares loco-específicos codominantes, como RFLP (Restriction Fragment Length Polymorphism, GRODZICKER et al., 1974) e SSR ou microssatélites (Sequências Simples Repetidas, LITT; LUTY, 1989) e b) marcadores loco não-específicos dominantes, como RAPD (Random Amplified Polymorphic 
DNA, WELSH; McCLELLAND, 1990) e AFLP (Amplified Fragment Length Polymorphism, VOS et al., 1995), ambos baseados na PCR (Polymerase Chain Reaction). Há outros marcadores que têm por base a PCR, porém um ou ambos os primers são assentados em sequências alvo, como RGA (Resistance Gene Analogs, LOPEZ et al., 2003; PFLIEGER et al., 2001; VALLAD et al., 2001; VAN DER LINDEN et al., 2004) e TRAP (Target Region Amplification Polymorphism, HU; VICK, 2003).

Para estudos de diversidade genética no gênero Passiflora têm sido usados marcadores RAPD (CROCHEMORE et al., 2003; FAJARDO et al., 1998; VIANA et al., 2003), cpDNA (SÁNCHEZ et al., 1999), Isoenzimas (SEGURA et al., 2003), AFPL (SEGURA, et al., 2002), SSR (OLIVEIRA et al., 2005; PADUA et al., 2005) e ISSR (SANTOS et al., 2011).

\section{Marcadores microssatélites}

Microssatélites ou SSR (Sequências Simples Repetidas) são sequências de 1 a 6 nucleotídeos, chamados de motivos, repetidos em tandem (LITT; LUTY, 1989) e que se encontram presentes em regiões codificadoras e não codificadoras dos genomas eucarióticos e procarióticos (FIELD; WILLS, 1996). Inicialmente, microssatélites foram desenvolvidos em humanos (LITT; LUTY, 1989; WEISSENBACH et al., 1992) e então, estudos realizados em plantas demonstraram que são amplamente distribuídos nos seus genomas (BRUNEL, 1994).

As vantagens do uso de microssatélites sobre outros marcadores moleculares nos estudos genéticos são a reprodutibilidade, simplicidade e rapidez, pequena quantidade de DNA requerida, baixo custo de utilização, grande poder de resolução e altos níveis de polimorfismo (CHEN et al., 1997; LITT; LUTY, 1989). Além disso, os marcadores microssatélites podem ser usados para análises de transferibilidade, pedigrees e populações (BRONDANI et al., 1998).

Sequências que flanqueiam os microssatélites são bastante conservadas e são utilizadas para o desenho de primers e a amplificação dos microssatélites. A diferença de tamanho entre os fragmentos amplificados permite detectar o polimorfismo. Essa diferença se deve ao número de repetições dentro dos microssatélites. Além disso, os microssatélites parecem ter uma distribuição frequente e aleatória, permitindo uma cobertura completa do genoma (RALLO et al., 2000). As principais desvantagens são o alto custo requerido no desenvolvimento de primers específicos, quando eles não 
estão disponíveis para a espécie a ser estudada (LITT; LUTY, 1989; MORGANTE; OLIVIERI, 1993; QUELLER et al., 1993).

\section{Desenvolvimento de marcadores microssatélites}

A estratégia de desenvolvimento de microssatélite, inicialmente proposta, envolvia a construção de biblioteca genômica, hibridização com sondas contendo microssatélite, sequenciamento dos clones hibridizados positivamente e desenho dos primers flanqueando os microssatélites encontrados (CAIXETA et al., 2006). O número de clones positivos, contendo os microssatélites, que podem ser obtidos com essa técnica, varia entre $12 \%$ a menos do que $0,04 \%$ do total de clones analisados (ZANE et al., 2002).

Atualmente, a aplicação de tecnologias de sequenciamento de nova geração é capaz de gerar informação sobre milhões de pares de bases em uma única corrida (CARVALHO; SILVA, 2010), o que gera dados sequenciados para a identificação de microssatélites em regiões aleatórias do genoma para o desenho de primers (ABDELKRIM et al., 2009; ZHU et al., 2012). Dentro das vantagens da técnica está o maior tamanho das leituras e a grande capacidade de gerar informação, o que torna o projeto de montagem mais fácil e permite trabalhar com coberturas genômicas mais amplas, favorecendo o processo de montagem (CARVALHO; SILVA, 2010).

O impacto no uso desta técnica no desenvolvimento de marcadores microssatélites é evidente: avaliações do genoma parcial utilizando até mesmo fracções de uma corrida de sequenciamento de nova geração permitem a descoberta de milhares de regiões de microssatélites potencialmente amplificáveis, as que podem ser selecionadas para o desenho de primers (CASTOE et al., 2010). Esta é uma abordagem promissora para espécies com informação genômica limitada, cujos programas de melhoramento se beneficiariam muito com o uso de ferramentas genômicas (SILVA et al., 2013).

Em Passifloras, vários trabalhos têm sido realizados para desenvolver microssatélites usando o método de bibliotecas enriquecidas, mas os microssatélites tem sido, em sua maioria, imperfeitos e compostos, o que tem afetado o nível de

polimorfismo observado (CAZÉ et al., 2012; CERQUEIRA-SILVA et al., 2014; OLIVEIRA et al., 2005; PADUA et al., 2005; PENHA et al., 2013). 


\section{Uso dos marcadores microssatélites}

Em geral, marcadores microssatélites têm sido utilizados para a construção de mapas de ligação (BRONDANI et al., 2002; HAMWIEH et al., 2005; LESPINASSE et al., 2000; PUGH et al., 2004; TEMNYKH et al., 2000), proteção de cultivares (PRIOLLI et al., 2004), fingerprinting (MOTILAL et al., 2011), caracterização e conservação de germoplasma (MASON et al., 2005), análise de pedigree (KOTZAMANIDIS et al., 2011) e estudos de diversidade genética (COLLEVATTI et al., 1999).

Já no gênero Passiflora, diversos são os trabalhos relacionados ao desenvolvimento e utilização de marcadores microssatélites em diferentes estudos genéticos. Em P. edulis, OLIVEIRA et al. (2005a) trabalharam em estudos de diversidade genética no desenvolvimento do primeiro conjunto de locos de microssatélites isolados a partir de uma biblioteca genômica. Em Passiflora alata, PADUA et al. (2005) desenvolveram um conjunto de marcadores microssatélites para analisar a estrutura genética da população silvestre e o modo de reprodução da espécie. Em 2009, KRIEDT trabalhou no desenvolvimento de marcadores microssatélites em Passiflora ovalis. PEREIRA (2010) utilizou marcadores microssatélites, M-AFLP e SNP visando à integração de mapas genético-moleculares em P. alata. FERREIRA et al. (2010) caracterizaram aspectos do sistema reprodutivo da mesma espécie usando RAPD e microssatélites. Em 2011, REIS et al. estimaram a variabilidade genética em dois ciclos de seleção recorrente do maracujazeiro-amarelo (P. edulis) e avaliaram o impacto da seleção nas progênies selecionadas via alterações nas frequências alélicas, detectadas com uso de marcadores microssatélites. Em Passiflora contracta, CAZÉ et al. (2012) desenvolveram uma biblioteca de microssatélites para estudos mais detalhados da estrutura genética da espécie, para contribuir em estudos de genética populacional. Em 2012, ORTIZ et al. avaliaram a variação intraespecífica do DNA de acessos de P. edulis usando marcadores AFLPs e SSR. CASTRO (2012) realizou um trabalho usando marcadores microssatélites para monitorar possíveis perdas de alelos e variações da frequência no ciclo de regeneração do germoplasma em espécies de Passiflora. Mais tarde, em 2013, PEREIRA et al., trabalharam para construir e integrar o mapa genético da espécie $P$. alata utilizando marcadores moleculares AFLP, microssatélites-AFLP, SSR, RGA e TRAP. Em um dos últimos trabalhos publicados sobre o assunto, CERQUEIRASILVA et al. (2014) desenvolveram os primeiros microssatélites para Passiflora 
setacea e caracterizaram novos marcadores para P. edulis e Passiflora cincinnata, apresentando 42 novos microssatélites polimórficos para as três espécies.

\section{REFERÊNCIAS BIBLIOGRÁFICAS}

ABDELKRIM, J.; ROBERTSON, B. C.; STANTON, J.; GEMMELL, N. Fast, costeffective development of species-specific microsatellite markers by genomic sequencing. BioTechniques, v. 46, n. 3, p. 185-92, 2009.

AKAMINE, E. K.; GIROLAMI, G. Pollination and fruit set in the yellow passion fruit. Hawaii Agricultural Experiment Station. Technical Bulletin, v. 39, p. 44, 1959.

BERNACCI, L. C.; SOARES-SCOTT, M. D.; JUNQUEIRA, N. T. V.; JUNQUEIRA, N. T. V.; PASSOS, I. R. S.; MELETTI, L. M. M. Passiflora edulis Sims: the correct taxonomic way to cite the yellow passion fruit (and other colors). Revista Brasileira de Fruticultura, v. 30, n. 2, p. 566-576, 2008.

BOT. MAG. Self-incompatibility in passion fruit: evidence of gametophyticsporophytic control. Theoretical and Applied Genetics, v. 106, p. 298-302, 2003.

BRONDANI, R. P. V. BRONDANI, C.; TARCHINI, R.; GRATTAPAGLIA, D. Development, characterization and mapping of microsatellite markers in Eucalyptus grandis and E. urophylla. Theoretical and Applied Genetics, v. 97, n. 5-6, p. 816$827,1998$.

BRONDANI, R. P. V; BRONDANI, C.; GRATTAPAGLIA, D. Towards a genuswide reference linkage map for Eucalyptus based exclusively on highly informative microsatellite markers. Molecular Genetics and Genomics, v. 267, n. 3, p. 338-47, 2002.

BRUCKNER, C. H.; CASALI, V. W. D.; MORAES, C. F.; REGAZZI, A. J.; SILVA, E. A. M. Self-incompatibility in passion fruit (Passiflora eduis Sims). Acta 
Horticulturae, n. 370, p. 45-57, 1995.

BRUCKNER, C. H. Perspectivas do melhoramento genético do maracujazeiro. In: ABEL, R. S. et al. (Eds.). Melhoramento, morte prematura, polinização, taxonomia. Porto Alegre: Cinco Continentes, 1997. p. 70.

BRUNEL, D. A microsatellite marker in Helianthus annuus L. Plant Molecular Biology, v. 24, p. 397-400, 1994.

CAIXETA, E. T.; OLIVEIRA, A.C.B.; BRITO, G. G.; SAKIYAMA, N. S. Tipos de marcadores moleculares. In: BORÉM, A.; CAIXETA, E. T. (Eds.). Marcadores moleculares. Viçosa, MG: Jard, 2006. p. 374.

CARVALHO, M. C.; SILVA, D. Sequenciamento de DNA de nova geração e suas aplicações na genômica de plantas. Ciência Rural, v. 3, p. 735-744, 2010.

CASTOE, T. A.; POOLE, A. W.; KONING, A. P. J.; JONES, K.; TOMBACK, D. F.; OYLER-MCCANCE, S. J.; FIKE, J. A.; LANCE, S. L.; STREICHER, J. W.; SMITH, E. N.; POLLOCK, D. D. Rapid identification of thousands of copperhead snake (Agkistrodon contortrix) microsatellite loci from modest amounts of 454 shotgun genome sequence. Molecular Ecology Resources, v. 10, n. 2, p. 341-7, 2010.

CASTRO, J. Conservação dos recursos genéticos de Passiflora e seleção de descritores mínimos para caracterização de maracujazeiro. Universidade Federal do Recôncavo da Bahia, 2012.

CAZÉ, A. L. R.; KRIEDT, R. A.; BEHEREGARAY, L. B.; BONATTO, S. L.; FREITAS, L. B. Isolation and Characterization of Microsatellite Markers for Passiflora contracta. International Journal of Molecular Science, v. 13, n. 9, p. $11343-8,2012$.

CERQUEIRA-SILVA, C. B.; SANTOS, E. S . L.; SOUZA, A. M.; MORI, G. M.; OLIVEIRA, E. J.; CORRÊA, R. X.; SOUZA, A. P. Development and characterization 
of microsatellite markers for the wild South American Passiflora cincinnata (Passifloraceae). American Journal of Botany, v. 99, n. 4, p. e170-2, 2012.

CERQUEIRA-SILVA, C. B.; JESUS, O. N.; SANTOS, E. S. L.; CORRÊA, R. X.; SOUZA, A. P. Genetic Breeding and Diversity of the Genus Passiflora: Progress and Perspectives in Molecular and Genetic Studies. International Journal of Molecular Sciences, v. 15, n. 8, p. 14122-14152, 2014a.

CERQUEIRA-SILVA, C. B.; SANTOS, E. S. L.; VIEIRA, J. G. P.; MORI, G. M.; JESUS, O. N.; CORRÊA, R. X.; SOUZA, A. P. New Microsatellite Markers for Wild and Commercial Species of Passiflora (Passifloraceae) and Cross-Amplification. Applications in Plant Sciences, v. 2, n. 2, p. 1300061, 2014b.

CERVI, A. C. Passifloraceae do Brasil. Estudo do gênero Passiflora L., subgênero Passiflora. Fontqueria, v. 45, p. 1-92, 1997.

CHANG, C. C. Studies on unfruitfulines of the yellow passion fruits growing in Taiwan. Taiwan Agriculture Quarterly, v. 10, n. 2, p. 78-89, 1974.

CHANG, C. C. Breeding of passion fruit. Plant Breeding Abstracts, v. 51, n. 6, p. $480,1981$.

CHEN, X.; TEMNYKH, S.; XU, Y.; CHO, Y. G.; MCCOUCH, S. R. Development of a microsatellite framework map providing genome-wide coverage in rice ( Oryza sativa L.). Theoretical and Applied Genetics, v. 95, n. 4, p. 553-567, 1997.

COLlEVATTI, R. G.; BRONDANI, R. V; GRATTAPAGLIA, D. Development and characterization of microsatellite markers for genetic analysis of a Brazilian endangered tree species Caryocar brasiliense. Heredity, v. 83, p. 748-56, 1999.

CROCHEMORE, M. L.; MOLINARI, H. B. C.; VIEIRA, L. G. E. Genetic Diversity in Passion Fruit (Passiflora spp.) Evaluated by RAPD Markers. Brazilian Archives of Biology and Technology, v. 46, n. 4, p. 521-527, 2003. 
CUNHA, M. A. P. Prioridades de pesquisa por subárea e objetivo. Reunião técnica de pesquisa em maracujazeiro no Brasil. Cruz das Almas: EMBRAPA-CNPMF. Anais...Cruz das Almas, BA: EMBRAPA/CNPMF. Documentos 77, 1997

FAJARDO, D.; ANGEL, F.; GRUM, M.; TOHME, J.; LOBO, M.; ROCA, W. M. Genetic variation analysis of the genus Passiflora L. using RAPD markers. Euphytica, v. 101, p. 341-347, 1998.

FALEIRO, F. G. JUNQUEIRA, N. T. V.; BRAGA, M. F.; PEIXOTO, J. R. Caracterização de germoplasma e melhoramento genético do maracujazeiro assistidos por marcadores moleculares: resultados de pesquisa 2005-2008. Boletim de Pesquisa e Desenvolvimento, $\mathbf{N}^{\mathbf{0}} \mathbf{2 0 7}$, p. 59, 2008.

FALEIRO, F. G. JUNQUEIRA, N. T. V.; JESUS, O. N.; COSTA, A. M. Avances y perspectivas del fitomejoramiento de las pasifloráceas en Brasil. Congreso Latinoamericano de Passifloras 2. Anais...Neiva: Corporación Cepass Colombia, 2013.

FALEIRO, F. G.; JUNQUEIRA, N. T. V. Passion fruit (Passiflora spp.) improvement using wild species. In: MARIANTE, A. S.; SAMPAIO, M. J. S.; INGLIS, M. C. (Eds.). The state of Brazil's plant genetic resources. Second national report. Conservation and sustainable utilization for food and agriculture. p. 101-106.

FALEIRO, F. G.; JUNQUEIRA, N. T. V. Recursos genéticos: conservação, caracterização e uso. In: FALEIRO, F. G.; ANDRADE, S. R. M.; REIS JÚNIOR, F. B. (Eds.). Biotecnologia: estado da arte e aplicações na agropecuária. Planaltina, DF: Embrapa Cerrados, 2011. p. 513-551.

FALEIRO, F. G.; JUNQUEIRA, N. T. V.; COSTA, A. M. Ações de Pesquisa e Desenvolvimento para o Uso Diversificado de Espécies Comerciais e Silvestres de Maracujá (Passiflora spp.). Planaltina, DF: Embrapa Cerrados, 2015.

FAO. Intergovernmental Group on Bananas and Tropical Fruits. Commitee on Commodity Problems, Fifth Session. Anais...Yaoundé, Cameroon: 2011. Disponível 
em: <http://www.fao.org/docrep/meeting/022/am481t.pdf

FERREIRA, F. R. Germoplasma de Passiflora no Brasil. In: Maracujá: produção e mercado. Vitória da Conquista: Universidade Estadual do Sudoeste da Bahia. São Jose, ed. São Jose. 1991. p. 24-26.

FERREIRA, M. E.; FALEIRO, F. G. Biotecnologia: avanços e aplicações no melhoramento genético vegetal. In: FALEIRO, F. G.; FARIAS NETO, A. L. (Eds.). Savanas: desafíos e estratégias para o equilíbrio entre sociedade, agronegócio e recursos naturais. Planaltina, DF: Embrapa Cerrados, 2008. p. 765-792.

FERREIRA, M. E.; GRATTAPAGLIA, D. Introdução ao uso de marcadores moleculares em análise genética. $3^{\circ}$ ed. Brasília, DF: EMBRAPA-CENARGEN, 1998.

FERREIRA, T. G. T. PENHA, H. A.; ZUCCHI, M. I.; SANTOS, A. A.; HANAI, L. R.; JUNQUEIRA, N.; BRAGA, M. F.; VENCOVSKY, R.; VIEIRA, M. L. C. Outcrossing rate in sweet passion fruit based on molecular markers. Plant Breeding, v. 129, n. 6, p. 727-730, 2010.

FEUILLET, C. Passifloraceae (passion flower family). In: SMITH, N.; MORI, S. A.; HENDERSON, A.; STEVENSON, D. W.; HELD, S. V. (Eds.). Flowering Plants on the Neotropics. New York: Princeton University Press, 2004. p. 286-287.

FIELD, D.; WILLS, C. Long, polymorphic microsatellites in simple organisms. Proceedings. Biological sciences / The Royal Society, v. 263, n. 1367, p. 209-15, 1996.

FONSECA, G. K.; FALEIRO, F. G.; PEIXOTO, J. R.; JUNQUEIRA, N. T. V.; SILVA, M. S.; BELlON, G.; JUNQUEIRA, K. P.; VAZ, C. F. Análise da recuperação do genitor recorrente em maracujazeiro-azedo por meio de marcadores RAPD. Revista Brasileira de Fruticultura, v. 31, n. 1, p. 145-153, 2009.

GRODZICKER, T.; WILLIAMS, J.; SHARP, P.; SAMBROOK, J. Physical mapping 
of temperature-sensitive mutations of adenoviruses. Cold Spring Harbor Symposia on Quantitative Biology, v. 39, p. 439-446, 1974.

HAMWIEH, A.; UDUPA, S. M.; CHOUMANE, W.; SARKER, A.; DREYER, F.; JUNG, C.; BAUM, M. A genetic linkage map of Lens sp. based on microsatellite and AFLP markers and the localization of fusarium vascular wilt resistance. Theoretical and Applied Genetics, v. 110, n. 4, p. 669-77, 2005.

HU, J.; VICK, B. A. Target Region Amplification Polymorphism: A Novel Marker Technique for Plant Genotyping. Plant Molecular Biology Reporter, v. 21, p. 289294, 2003.

IBGE. Séries históricas e estatísticas: lavoura permanente - quantidade produzida. Disponível em:

$<$ http://www.sidra.ibge.gov.br/bda/tabela/protabl.asp?c=1613\&z=p\&o=30\&i=P $>$. Acesso em: 28 nov. 2016.

ISHIHATA, K. Studies on the morphology of flowering organs and the fruit bearing in purple passion fruit, Passiflora edulis Sims. Bulletin of the Faculty of Agriculture-Kagoshima University, v. 31, p. 7-11, 1981.

JUNQUEIRA, N. T. V.; ANJOS, J. R. N.; SHARMA, R. D.; SANZONWICZ, C.; ANDRADE, J. R. M. Doenças do Maracujazeiro. III Encontro de Fitopatologia: Doenças de fruteiras tropicais. Anais...Viçosa: 1999.

JUNQUEIRA, N. T. V.; BRAGA, M. F.; FALEIRO, F. G.; PEIXOTO, J. R.; BERNACCI, J. C. Potencial de espécies silvestres de maracujazeiro como fonte de resistência a doenças. In: FALEIRO, F. G.; JUNQUEIRA, N. T. V.; BRAGA, M. F. (Eds.). Maracujá: germoplasma e melhoramento genético. Embrapa Cerrados, 2005. p. 81-108.

KOTZAMANIDIS, S.; IPSILANDIS, C.; MAVROMATIS, A.; KORKOVELOS, A.; LITHOURGIDIS, A.; IRAKLI, M. Prediction of pedigree relationships in durum wheat varieties based on agronomic, morphological and molecular traits. Australian 
Journal of Crop Science, v. 5, n. 7, p. 809-814, 2011.

KRIEDT, R. Isolamento de marcadores microssatélites para Petunia integrifolia subesp. depauperata (Solanaceae) e Passiflora ovalis (Passifloraceae). Universidade Federal do Rio Grande do Sul, 2009.

LESPINASSE, D. RODIER-GOUD, M.; GRIVET, L.; LECONTE, G. A.; LEGNATE, H.; SEGUIN, M. A. saturated genetic linkage map of rubber tree (Hevea spp .) based on RFLP, AFLP, microsatellite, and isozyme markers. Theoretical and Applied Genetics, v. 100, p. 127-138, 2000.

LIMA, A. DE A.; BORGES, A. L. Solo e clima. In: LIMA, A. DE A. (Ed.). Maracujá: produção, aspectos técnicos. Brasília: Embrapa-SPI, 2002. p. 25-28.

LITT, M.; LUTY, J. A. A Hypervariable Microsatellite Revealed by In Vitro Amplification of a Dinucleotide Repeat within the Cardiac Muscle Actin Gene. American Journal of Human Genetics, v. 44, p. 397-401, 1989.

LÓPEZ, C. E.; ACOSTA, I. F.; JARA, C.; PREZADA, F.; GAITÁN-SOLÍS, E.; GALLEGO, G.; BEEBE, S.; TOHME, J. Identifying resistance gene analogs associated with resistances to different pathogens in common bean. Phytopathology, v. 93, n. 1, p. 88-95, 2003.

MACDOUGAL, J.; FEUILlET, C. Systematics. In: ULMER, T.; MACDOUGAL, J. (Eds.). Passiflora: Passionflowers of the World. Portland, OR, USA: Timber Press, 2004. p. 27-31.

MASON, S. L.; STEVENS, M. R.; JELLEN, E. N.; BONAFACIO, A.; FAIRBANKS, D. J.; COLEMAN, C. E.; MCCARTY, R. R.; RASMUSSEN, A. G.; MAUGHAN, P. J. Development and use of microsatellite markers for germplasm characterization in quinoa (Chenopodium quinoa Willd.). Crop Science, v. 45, n. 4, p. 1618-1630, 2005.

MELETTI, L. M. M. Maracujá-roxo. Revista Brasileira de Fruticultura, v. 27, n. 2, 
p. 194-348, 1999.

MELETTI, L. M. M.; SOARES-SCOTT, M. D.; BERNACCI, L. C.; PASSOS, I. R. S. Melhoramento genético do maracujá: passado e futuro. In: FALEIRO, F. G.; JUNQUEIRA, N. T. V.; BRAGA, M. F. (Eds.). Maracujá: germoplasma e melhoramento genético. Planaltina, DF. p. 55-78.

MELETTI, L. M. M. Avanços na cultura do maracujá no Brasil. Revista Brasileira de Fruticultura, v. 33, p. 83-91, 2011.

MORGANTE, M.; OLIVIERI, A. M. PCR-amplified microsatellites as markers in plant genetics. The Plant Journal, v. 3, n. 1, p. 175-82, 1993.

MOTILAL, L. A.; LAMBERT, A.; ZHANG, D.; UMAHARAN, P.; MISCHKE, S.; PINNEY, S.; MEINHARDT, L. W. Microsatellite fingerprinting in the International Cocoa Genebank, Trinidad: accession and plot homogeneity information for germplasm management. Plant Genetic Resources, v. 9, n. 3, p. 430-438, 2011.

OCAMPO, J.; D'EECKENBRUGGE, G.; JARVIS, A. Distribution of the genus Passiflora L. diversity in Colombia and its potential as an indicator for biodiversity management on the coffee growing zone. Diversity, v. 2, p. 1158-1180, 2010.

OLIVEIRA, E. J.; PÁDUA, J. G.; ZUCCHI, M. I.; CAMARGO, L. E. A.; FUNGARO, M. H. P.; VIEIRA, M. L. C. Development and characterization of microsatellite markers from the yellow passion fruit (Passiflora edulis f. flavicarpa). Molecular Ecology Notes, v. 5, n. 2, p. 331-333, 2005.

OLIVEIRA, E. J. Desenvolvimento e uso de marcadores microssatélites para construção e integração de mapas genéticos de maracujá-amarelo (Passiflora edulis Sims f . flavicarpa Deg.). Universidade de São Paulo, 2006.

ORTIZ, D. C.; BOHÓRQUEZ, A.; DUQUE, M. C.; TOHME, J.; CUÉLlAR, D.; MOSQUERA, T. Evaluating purple passion fruit (Passiflora edulis Sims f. edulis) genetic variability in individuals from commercial plantations in Colombia. Genetic 
Resources and Crop Evolution, v. 59, n. 6, p. 1089-1099, 2012.

PADUA, J. G.; OLIVEIRA, E. J.; ZUCCHI, M. I.; OlIVEIRA, G. C. X.; CAMARGO, L. E. A.; VIEIRA, M. L. C. Isolation and characterization of microsatellite markers from the sweet passion fruit (Passiflora alata Curtis: Passifloraceae). Molecular Ecology Notes, v. 5, n. 4, p. 863-865, 2005.

PENHA, H. A.; PEREIRA, G. S.; ZUCCHI, M. I.; DINIZ, A. L.; VIEIRA, M. L. C. Development of microsatellite markers in sweet passion fruit, and identification of length and conformation polymorphisms within repeat sequences. Plant Breeding, v. 132, n. 6, p. 731-735, 2013.

PEREIRA, G. S. Desenvolvimento de marcadores SSR, M-AFLP e SNP visando à integração de mapas genético-moleculares de Passiflora alata Curtis. Universidade de São Paulo, 2010.

PEREIRA, G. S.; NUNES, E. S.; LAPERUTA, L. D. C.; BRAGA, M. F.; PENHA, H. A.; DINIZ, A. L. MUNHOZ, C. F.; CAZAFFI, R.; GARCIA, A. A. F.; VIEIRA, M. L. C. Molecular polymorphism and linkage analysis in sweet passion fruit, an outcrossing species. Annals of Applied Biology, v. 162, n. 3, p. 347-361, 2013.

PFlieGER, S.; PALlOIX, A.; CARANTA, C.; BLATTES, A.; LEFEBVRE. V. Defense response genes co-localize with quantitative disease resistance loci in pepper. Theoretical and Applied Genetics, v. 103, n. 6-7, p. 920-929, 2001.

PRIOLLI, R. H. G.; MENDES-JUNIOR, C. T.; SOUSA, S. M. B.; SOUSA, N. E. A.; CONTEL, E. P. B. Diversidade genética da soja entre períodos e entre programas de melhoramento no Brasil. Pesquisa Agropecuária Brasileira, v. 39, n. 10, p. 967975, 2004.

PUGH, T.; FOUET, O.; RISTERUCCI, A. M.; BROTTIER, P.; ABOULADZE, M.; DELETREZ, C.; COURTOIS, B.; CLEMENT, D.; LARMANDE, P.; N'GORAN, J. A. K.; LANAUD, C. A new cacao linkage map based on codominant markers: development and integration of 201 new microsatellite markers. Theoretical and 
Applied Genetics, v. 108, n. 6, p. 1151-61, 2004.

QUELlER, D. C.; STRASSMANN, J. E.; HUGHES, C. R. Microsatellites and Kinship. Trends in Ecology and Evolution, v. 8, n. 8, p. 285-288, 1993.

RALLO, P.; DORADO, G.; MARTIN, A. Development of simple sequence repeats (SSRs) in olive tree (Olea europaea L .). Theoretical and Applied Genetics, v. 101, p. 984-989, 2000.

RÊGO, M. M. DO. Genética, interação pólen-pistilo e expressão de proteínas na auto-incompatibilidade do maracujazeiro (Passiflora edulis Sims). Universidade Federal de Viçosa, 1997.

REIS, R. V.; OLIVEIRA, E. J.; VIANA, A. P.; PEREIRA, T. N. S.; PEREIRA, M. G.; SILVA, M. G. M. Diversidade genética em seleção recorrente de maracujazeiro amarelo detectada por marcadores microssatélites. Pesquisa Agropecuária Brasileira, v. 46, n. 1, p. 51-57, 2011.

RUDD, S.; SCHOOF, H.; MAYER, K. PlantMarkers--a database of predicted molecular markers from plants. Nucleic Acids Research, v. 33, p. 628-632, 2005.

SÁNCHEZ, I.; ANGEL, F.; GRUM, M.; DUQUE, M.; LOBO, M.; TOHME, J.; ROCA, W. Variability of chloroplast DNA in the genus Passiflora L. Euphytica, v. 106, p. 15-26, 1999.

SANTOS, L. F.; OLIVEIRA, E. J.; SILVA, A. S.; CARVALHO, F. M.; COSTA, J. L.; PÁDUA, J. G. ISSR markers as a tool for the assessment of genetic diversity in Passiflora. Biochemical Genetics, v. 49, n. 7-8, p. 540-54, 2011.

SEGURA, S.; LOPEZ, L.; GRUM, M.; GUARINO, L. Mapping the potential distribution of five species of Passiflora in Andean. Genetic Resources and Crop Evolution, v. 50, p. 555-566, 2003.

SEGURA, S. D.; COPPENS, G.; OCAMPO, H. Isozyme variation in Passiflora 
subgenera Tacsonia and Manicata. Relationships between cultivated and wild species.

Genetic Resources and Crop Evolution, v. 50, p. 417-427, 2002.

SILVA, P. I.; MARTINS, A. M.; GOUVEA, E. G.; PESSOA-FILHO, M.; FERREIRA, M. E. Development and validation of microsatellite markers for Brachiaria ruziziensis obtained by partial genome assembly of Illumina single-end reads. BMC Genomics, v. 14, n. 1, p. 17, 2013.

SOUZA, J.; MELETTI, L. Maracujá: Espécies, Variedades, Cultivo. Piracicaba, Brasil: Fealq, 1997.

SOUZA, M. M.; PALOMINO, G.; PEREIRA, T. N. S.; PEREIRA, M. G.; VIANA, A. P. Flow cytometric analysis of genome size variation in some Passiflora species. Hereditas, v. 141, p. 31-38, 2004.

TEMNYKH, S.; PARK, W. D.; AYRES, N.; CARTINHOUR, S.; HAUCK, N.; LIPOVICH, L.; CHO, Y. G.; ISHII, T.; MCCOUCH, S. R. Mapping and genome organization of microsatellite sequences in rice (Oryza sativa L.). Theoretical and Applied Genetics, v. 100, n. 5, p. 697-712, 2000.

VALLAD, G.; RIVKIN, M.; VALLEJOS, C.; MCCLEAN, P. Cloning and homology modelling of a Pto-like protein kinase family of common bean (Phaseolus vulgaris L.). Theoretical and Applied Genetics, v. 103, n. 6-7, p. 1046-1058, 2001.

VAN DER LINDEN, C. G.; WOUTERS, D. C. A. E.; MHALKA, V.; KOCHIEVA, E. Z.; SMULDERS, M. J. M.; VOSMAN, B. Efficient targeting of plant disease resistance loci using NBS profiling. Theoretical and Applied Genetics, v. 109, n. 2, p. 384-93, 2004.

VANDERPLANK, J. Passion flowers. Massachusetts: MIT Press, 1996. p. 224.

VIANA, A. P.; PEREIRA, T. N. S.; PEREIRA, M. G.; SOUSA, M. M.; MALDONADO, J. F. M.; JUNIOR, A. T. A. Diversidade genética entre genótipos comerciais de maracujazeiro-amarelo (Passiflroa edulis f. flavicarpa) e entre espécies 
de Passifloras nativas determinada por marcadores RAPD. Revista Brasileira de Fruticultura, v. 25, n. 3, p. 489-493, 2003.

VIEIRA, M. L. C.; CARNEIRO, M. C. Passifloraceae. In: LITZ, R. (Ed.). Biotechnology of fruit and nut crops. Oxford, 2004. p. 436-453.

VOS, P.; HOGERS, R.; BLEEKER, M.; REIJANS, M.; LEE, T. V.; FRIJTERS, A.; POT, J.; PELEMAN, J.; KUIPER, M.; ZABEAU, M.; KEYGENE, N. V.; BOX, P. O. AFLP : a new technique for DNA fingerprinting. Nucleic Acids Research v. 23, n. 21, p. 4407-4414, 1995.

WEISSENBACH, J.; GYAPAY, G.; DIB, C.; VIGNAL, A.; MORISSETTE, J.; MILLASSEAU, P.; VAYSSEIX, G.; LATHROP, M. A second-generation linkage map of the human genome. Nature, v. 359, p. 794-801, 1992.

WELSH, J.; MCCLELLAND, M. Fingerprinting genomes using PCR with arbitrary primers. Nucleic Acids Research, v. 18, n. 24, p. 7213-7218, 1990.

ZANE, L.; BARGELLONI, L.; PATARNELLO, T. Strategies for microsatellite isolation: a review. Molecular Ecology, v. 11, p. 1-16, 2002.

ZHU, H.; SENALIK, D.; MCCOWN, B. H.; ZELDIN, E. L.; HYMAN, J.; BASSIL, N.; HUMMER, K.; SIMON, P. W.; ZALAPA, J. E. Mining and validation of pyrosequenced simple sequence repeats (SSRs) from American cranberry (Vaccinium macrocarpon Ait.). Theoretical and Applied Genetics, v. 124, n. 1, p. 87-96, 2012. 
CAPÍTULO 1. DESENVOLVIMENTO DE MARCADORES MICROSSATÉLITES POR MEIO DO SEQUENCIAMENTO PARCIAL DO GENOMA DE MARACUJÁ-AZEDO (Passiflora edulis Sims) E TRANSFERIBILIDADE PARA 78 ESPÉCIES DO GÊNERO Passiflora

CHAPTER 1. MICROSATELLITE MARKER DEVELOPMENT BY PARTIAL SEQUENCING OF THE SOUR PASSION FRUIT GENOME (Passiflora edulis Sims) AND TRANSFERABILITY TO 78 SPECIES OF THE Passiflora GENUS 


\section{RESUMO}

O gênero Passiflora compreende centenas de espécies silvestres e cultivadas de maracujazeiro utilizadas na alimentação, na indústria, na medicina e também utilizadas como plantas ornamentais. Esforços para desenvolver ferramentas de análise genética em $P$. edulis, a espécie mais importante do gênero Passiflora, ainda são incipientes. Marcadores microssatélites em P. edulis são, geralmente, limitados em número, apresentando reduzido polimorfismo, onde a maioria está baseada em repetições nucleotídicas compostas ou imperfeitas. Além disso, marcadores microssatélites foram desenvolvidos apenas para algumas espécies de Passiflora. Nessa pesquisa, é descrito o uso do sequenciamento de nova geração (NGS) para a montagem parcial do genoma de $P$. edulis com o intuito de desenvolver novos marcadores microssatélites. Um total de $14,11 \mathrm{Gpb}$ de reads de sequências paired-end de Illumina foram analisadas para detectar sequências simples repetidas (SSR) que foram selecionadas para o desenvolvimento de combinações de primers para PCR. Os painéis para os marcadores di e tri-nucleotídeos foram testados em acessos do germoplasma de $P$. edulis para a sua validação. Polimorfismo foi detectado em $74 \%$ dos marcadores $(\mathrm{PIC}=0,16-0,77$; número de alelos/loco $=2-7)$. Os marcadores mais polimórficos $(\mathrm{PIC}=0,46-0,77)$ foram usados em análises de transferibilidade em 78 espécies de Passiflora, pertencentes a quatro subgêneros (Astrophea, Decaloba, Distephana e Passiflora). Aproximadamente $71 \%$ da combinação marcador/espécie foi positiva para a amplificação em todas as espécies testadas. Polimorfismo foi detectado nos acessos de seis espécies de Passiflora relacionadas entre si (P. edulis, $P$. alata, $P$. maliformis, $P$. nitida, $P$. quadrangularis e $P$. setacea), e os dados foram usados para a diferenciação entre acessos e espécies. O novo conjunto de marcadores microssatélites está pronto para seu uso em análises de polimorfismo de $P$. edulis e em outras espécies da família Passifloraceae.

Palavras-chave: Passiflora edulis, montagem do genoma de novo, microssatélites 


\begin{abstract}
The Passiflora genus comprises hundreds of wild and cultivated species of passion fruit used for food, industrial, ornamental and medicinal purposes. Efforts to develop genomic tools for genetic analysis of $P$. edulis, the most important commercial Passiflora species, are still incipient. Microsatellite markers in P. edulis are usually limited in number, show reduced polymorphism, and are mostly based on compound or imperfect repeats. Furthermore, microsatellite markers are confined to only a few Passiflora species. We describe the use of NGS technology to partially assemble the $P$. edulis genome in order to develop new microsatellite markers. A total of 14.11 Gbp of Illumina paired-end sequence reads were analyzed to detect simple sequence repeat sites in the sour passion fruit genome. A sample of 1,300 contigs containing perfect repeat microsatellite sequences was selected for PCR primer development. A panel of di- and tri-nucleotide repeat markers were then tested in P. edulis germplasm accessions for validation. DNA polymorphism was detected in $74 \%$ of the markers $(\mathrm{PIC}=0.16$ to 0.77 ; number of alleles/locus $=2$ to 7$)$. A core panel of highly polymorphic markers $(\mathrm{PIC}=0.46$ to 0.77$)$ was used to cross-amplify PCR products in 78 species of Passiflora, belonging to four subgenera (Astrophea, Decaloba, Distephana and Passiflora). Approximately $71 \%$ of the marker/species combinations resulted in positive amplicons in all species tested. DNA polymorphism was detected in germplasm accessions of six closely related Passiflora species (P. edulis, P. alata, P. maliformis, P. nitida, P. quadrangularis and P. setacea) and the data used for accession discrimination and species assignment. The new set of microsatellite markers can be readily used for DNA polymorphism analysis of $P$. edulis and other Passifloracea.
\end{abstract}

Key words: Passiflora edulis, de novo genome assembly, microsatellites 


\section{INTRUDUÇÃO}

O gênero Passiflora apresenta ampla variabilidade com aproximadamente 500 espécies distribuídas, predominantemente, nas regiões tropicais da América, sendo também encontrados exemplares na Ásia e na África (MACDOUGAL; FEUILLET, 2004). Apesar da incerteza taxonômica, aproximadamente $96 \%$ das espécies de Passiflora são encontradas na América do Sul e Centro-América (CERQUEIRASILVA et al., 2014a). Os maiores centros de diversidade são o Brasil e a Colômbia (FERREIRA; OLIVEIRA, 1991; OCAMPO; D’EECKENBRUGGE; JARVIS, 2010), onde centenas de espécies tem sido catalogadas. Apesar do grande número de espécies, somente algumas são usadas comercialmente, principalmente para a produção de frutos para o mercado in natura ou na produção do suco, e de folhas para a produção de fitoterápicos.

O maracujazeiro-azedo ( $P$. edulis) é a espécie comercial mais importante dentro das espécies de Passiflora a nível mundial. É uma espécie alógama que apresenta variabilidade na forma, cor e morfologia de frutos, flores e plantas. A variabilidade genética em $P$. edulis tem sido estimada por descritores morfológicos (CROCHEMORE; MOLINARI; STENZEL, 2003; PLOTZE et al., 2005; VIANA et al., 2010) e características agronômicas (ABREU et al., 2009; CERQUEIRA-SILVA et al., 2008; MELETTI; SOARES-SCOTT; BERNACCI, 2005). A detecção de polimorfismo do DNA em $P$. edulis tem sido estudada com diferentes tipos de marcadores moleculares, como ISSR (SANTOS et al., 2011), RAPD (BELLON et al., 2007; CROCHEMORE; MOLINARI; VIEIRA, 2003; FAJARDO et al., 1998), AFLP (ORTIZ et al., 2012; SEGURA et al., 2002) e microssatélites (CERQUEIRA-SILVA et al., 2014b; OLIVEIRA et al., 2005). Altos níveis de variabilidade genética têm sido relatados em avaliações morfológicas e agronômicas, como também na maioria dos sistemas de marcadores. No entanto, o uso de marcadores microssatélites em análises genéticas de $P$. edulis tem apresentado baixo nível de polimorfismo (CERQUEIRASILVA et al., 2012, 2014b; OLIVEIRA et al., 2005; ORTIZ et al., 2012), o que é contraditório, considerando que a espécie apresenta ampla diversidade.

As vantagens dos marcadores microssatélites quando comparados com outras tecnologias são a alta reprodutibilidade, codominância, alto conteúdo de informação polimórfica (PIC) e alelismo múltiplo (BRONDANI et al., 1998; LITT; LUTY, 1989; POWELL et al., 1996). Menos de 200 marcadores microssatélites foram 
desenvolvidos para P. edulis (CERQUEIRA-SILVA et al., 2014b; OLIVEIRA, 2006; OLIVEIRA et al., 2005), mas somente uma pequena fração deles foi validada e usada em estudos genéticos (OLIVEIRA, 2006; OLIVEIRA et al., 2013; ORTIZ et al., 2012; REIS et al., 2011). Os poucos marcadores microssatélites polimórficos em $P$. edulis estão baseados, principalmente, em repetições nucleotídicas imperfeitas e compostas, o que dificulta a interpretação da genotipagem de rotina devido às dificuldades da binagem dos alelos (DOMANIÇ, 2007; PREPARATA, 2007; LIM et al., 2013). Isso poderia ser uma limitação para algumas aplicações, especialmente para estudos genéticos populacionais (GOLDSTEIN; CLARK, 1995; MA; RÖDER; SORRELLS, 1996). Microssatélites perfeitos (com repetições nucleotídicas perfeitas, sem interrupção ou variação) são mais adequados, mas eles estão disponíveis em uma pequena fração (aproximadamente 10\%) do total dos marcadores disponíveis para $P$. edulis (CERQUEIRA-SILVA et al., 2014b; OLIVEIRA, 2006; OLIVEIRA et al., 2005). O uso de marcadores microssatélites em Passiflora tem sido limitado a poucas espécies, tais como P. edulis (OLIVEIRA, 2006; OLIVEIRA et al., 2005), P. alata (PADUA et al., 2005; PENHA et al., 2013), P. cincinnata (CERQUEIRA-SILVA et al., 2012, 2014b), P. setacea (CERQUEIRA-SILVA et al., 2014b), e P. contracta (CAZÉ et al., 2012). Isso representa uma pequena porção (aproximadamente 1\%) das espécies conhecidas de Passiflora. Restrições semelhantes à disponibilidade e utilização de marcadores microssatélite também tem sido observadas em outras espécies de Passiflora.

Desenvolvimento de marcadores microssatélites em Passiflora tem sido baseado na construção de bibliotecas genômicas enriquecidas para sequências simples repetidas (CAZÉ et al., 2012; CERQUEIRA-SILVA et al., 2012, 2014b; OLIVEIRA, 2006; OLIVEIRA et al., 2005; PADUA et al., 2005; PENHA et al., 2013). Esta é uma técnica eficaz, mas requer muito tempo $\mathrm{e}$ trabalho para a descoberta $\mathrm{e}$ desenvolvimento de marcadores microssatélites. Contudo, novas abordagens tais como o sequenciamento de nova geração (NGS) podem fornecer um grande número de sequências do genoma de alta qualidade, as que podem ser obtidas mais rapidamente e a custos reduzidos, facilitando a detecção de milhares de microssatélites no genoma de uma espécie-alvo (ABDELKRIM et al., 2009; CASTOE et al., 2010; CSENCSICS; BRODBECK; HOLDEREGGER, 2010; SILVA et al., 2013). 
No presente estudo, foi utilizada a técnica NGS para sequenciar o genoma de $P$. edulis. As sequências dos contigs que foram obtidas pela montagem parcial de novo do genoma foram analisadas para detectar microssatélites perfeitos. Esses dados foram utilizados no desenvolvimento e validação dos marcadores microssatélites utilizados nos acessos de P. edulis do Banco de Germoplasma das Passifloras 'Flor da Paixão', da Embrapa Cerrados. Marcadores foram avaliados em qualidade e polimorfismo em $P$. edulis e em cinco espécies próximas de Passiflora, e também para transferibilidade em 78 espécies de Passiflora pertencentes a quatro subgêneros (Astrophea, Decaloba, Distephana e Passiflora), que foram coletadas no Brasil.

\section{MATERIAL E MÉTODOS}

\section{Extração de DNA e sequenciamento do genoma}

Folhas frescas do acesso Passiflora edulis CPGA1 (matriz da cultivar de maracujazeiro-azedo BRS Gigante Amarelo - BRS GA1), foram usadas para a extração de DNA sob o protocolo CTAB (DOYLE; DOYLE, 1987), com modificações descritas por FALEIRO et al. (2003). A construção da biblioteca de fragmentos de DNA genômico e o sequenciamento massivo paralelo pair-end foram realizados no sequenciador Illumina GAII seguindo o protocolo Illumina.

\section{Montagem de novo do genoma}

A presença de sequências de DNA não nuclear e/ou exógeno na base de dados de DNA de maracujazeiro foi verificada com BLASTing para DNA de cloroplasto, mitocôndria e possíveis contaminantes (fungos, bactérias e vírus). Sequências extrínsecas foram removidas das análises. A ferramenta de correção short-read de SOAPdenovo (Lançamento 1.05), foi utilizada para corrigir os reads de Illumina GA para genomas de plantas e animais (LI et al., 2008), aplicada nos arquivos formatados de FASTQ contendo os reads sequenciados de DNA. A função de ajuste CLC (limite padrão=0,05) (software CLC Genomics Workbench v.4.1, CLC Bio, Aarhus, Dinamarca) foi usada para eliminar os adaptadores do sequenciamento Illumina e a baixa qualidade dos reads. Rotinas de ErrorCorrection e KmerFreq foram aplicadas com os parâmetros padrão (seed length $=17$, quality cutoff $=5$ ). Arquivos finais de FASTQ foram submetidos à montagem de novo utilizando o tamanho bubble de $50 \mathrm{pb}$ 
no software CLC Genomics Workbench (Assembly Length Fraction=0,5; Similarity= 0,8). Parâmetros de discordância, supressão e inserção foram fixados em 2, 3 e 3, respectivamente. O tamanho k-mer da montagem CLC Bio foi fixada em 25 pb e o limite da cobertura em 10X. Durante a montagem, o parâmetro do tamanho padrão foi ajustado para 25 usando a informação de sobreposição k-mer (grafo De Bruijn) para assegurar as vias inequívocas dos contigs obtidos. Para as análises, foram considerados os contigs maiores que 160 pb. Sobreposições entre as sequências foram representadas pelo grafo de estruturas De Bruijn (ZERBINO; BIRNEY, 2008).

\section{Identificação de microssatélites e desenvolvimento de marcadores}

A montagem de novo do sequenciamento parcial foi utilizada para a identificação dos locos de sequências simples repetidas (SSR) no genoma de maracujazeiro-azedo utilizando o software PHOBOS (MAYER, 2006-2011). Foram listados e quantificados os dados de locação e número de di, tri ou tetra-nucleotídeos de SSR obtidos da montagem parcial de novo. Sequências repetidas localizadas em regiões de genes putativos foram identificadas com o modelo de gene versão TAIR 9 utilizando os contigs de P. edulis e comparando-os com os transcritos de Arabidopsis thaliana (AtGDB171). A predição ab intio das regiões de expressão foram realizadas utilizando o software geneid (GUIGÓ et al., 1992). Ambas as análises foram consideradas para a seleção dos microssatélites localizados em regiões de genes. Microssatélites localizados exclusivamente em regiões genômicas com um mínimo de $15 \mathrm{X}$ de cobertura foram considerados para o desenvolvimento de marcadores. Foi criada uma base de dados com as sequências simples repetidas com quatro ou mais repetições de di, tri ou tetra-nucleotídeos. Locos de microssatélites que apresentaram motivos simples repetidos em tandem (“microssatélites perfeitos") foram listados e aqueles que foram compostos (mais de um motivo) ou com repetições imperfeitas, foram deixados à parte. O grupo de marcadores selecionados foi formado por microssatélites perfeitos com um mínimo de 3 repetições no motivo e localizados em contigs com um mínimo de tamanho de $2,5 \mathrm{~Kb}$ e cobertura média de $20 \mathrm{X}$, em uma tentativa de maximizar a independência do loco e a qualidade do marcador. Finalmente, foram desenvolvidos 816 pares de primers de microssatélites com o software Primer3Plus (UNTERGASSER et al., 2007). 


\section{Testes de PCR dos marcadores microssatélites}

Foram desenhados painéis multiplex para a avaliação simultânea de marcadores microssatélites mediante o software Multiplex Manager (HOLLELEY; GEERTS, 2009). Os testes de PCR foram realizados em um volume final de $5 \mu \mathrm{L}$ que continham 5 n g de DNA genômico, 1X de QIAGEN Multiplex PCR Kit Master Mix (QIAGEN), 0,5X de Q-Solution (QIAGEN), e 0,2 $\mu \mathrm{M}$ de cada primer. Reações de PCR foram realizadas no termocilador $\operatorname{Veriti}^{\mathrm{TM}}$ (Applied Biosystems, USA) utilizando o seguinte programa de amplificação: $95^{\circ} \mathrm{C}$ por 15 minutos; 35 ciclos a $94^{\circ} \mathrm{C}$ por 30 segundos, 55,57 ou $60^{\circ} \mathrm{C}$ por 90 segundos, e $72^{\circ} \mathrm{C}$ por 60 segundos; seguidos por uma extensão final a $60^{\circ} \mathrm{C}$ por 60 minutos. Foram adicionados $9 \mu \mathrm{L}$ de formamida $\mathrm{Hi}^{-\mathrm{Di}^{\mathrm{TM}}}$ (Applied Biosystems, USA) mais $1 \mu \mathrm{L}$ de ROX-labeled de tamanho padrão no produto da $\mathrm{PCR}$, e então desnaturado a $94^{\circ} \mathrm{C}$ por 5 minutos. $\mathrm{O}$ produto desnaturado foi injetado no sequenciador automático ABI3730 (Applied Biosystems, USA). A chamada dos alelos segundo o tamanho, e a genotipagem foram realizadas com o software GeneMapper ${ }^{\circledR}$ v.4.1 (Applied Biosystems, USA). A binagem dos alelos foi realizada com o software Tandem (MATSCHINER; SALZBURGER, 2009). Foi utilizado o Teste Exato de Fisher para provar a associação entre o nível de polimorfismo do marcador e do tamanho da repetição (di ou tri-nucleotídeo) usando o software MedCalc Statistical v.12.7.7 (http://www.medcalc.org; 2013).

\section{Material vegetal e descrição estatística dos marcadores microssatélites}

Dez acessos de maracujazeiro-azedo ( $P$. edulis Sims), mantidos no Banco Ativo de Germoplasma da Embrapa Cerrados, Planaltina, DF, foram usados para avaliar se o novo conjunto de marcadores era adequado para as análises genéticas em maracujazeiro-azedo. Os dados dos acessos de maracujazeiro utilizados no presente estudo estão descritos na Tabela 1 (linhas 1 - 10). Esses acessos representam um grupo diverso de cultivares e variedades coletadas em diferentes regiões do Brasil. A única exceção é o acesso Gulupa procedente da Colômbia. Porém, acredita-se que esse acesso foi originalmente coletado no Brasil e então introduzido na Colômbia (FONSECA-TRUJILLO et al., 2009; RENDÓN; OCAMPO; URREA, 2013) e portanto, foi utilizado nas análises. Os dez acessos de $P$. edulis foram genotipados com uma amostra aleatória de 60 marcadores microssatélites di e tri-nucleotídeos. Foram estimados o polimorfismo, o número de alelos, a heterozigosidade e o 
conteúdo de informação polimórfica para os marcadores utilizando o software Cervus v.3.0.3 (MARSHALL et al., 1998)

Tabela 1. Acessos do germoplasma de maracujazeiro (Passiflora spp.) coletados em diferentes regiões do Brasil e genotipados com os novos marcadores microssatélites.

\begin{tabular}{|c|c|c|c|}
\hline $\mathrm{N}^{\mathrm{o}}$ & Espécie & Subgênero & Origem \\
\hline 1 & Passiflora edulis Sims & Passiflora & Seleção Embrapa CPGA1, Distrito Federal \\
\hline 2 & Passiflora edulis Sims & Passiflora & Seleção Embrapa CPMSC1, Paraná \\
\hline 3 & Passiflora edulis Sims & Passiflora & Seleção Maguary, Minas Gerais \\
\hline 4 & Passiflora edulis Sims & Passiflora & Cafuringa, Distrito Federal \\
\hline 5 & Passiflora edulis Sims & Passiflora & Niquelândia, Goiás \\
\hline 6 & Passiflora edulis Sims & Passiflora & Oliveira, Minas Gerais \\
\hline 7 & Passiflora edulis Sims & Passiflora & Búzios, Rio de Janeiro \\
\hline 8 & Passiflora edulis Sims & Passiflora & Criciúma, Santa Catarina \\
\hline 9 & Passiflora edulis Sims & Passiflora & Jundiaí, São Paulo \\
\hline 10 & Passiflora edulis Sims & Passiflora & Gulupa, Colômbia (original do Brasil) \\
\hline 11 & Passiflora edulis Sims & Passiflora & BRS Maracujá Jaboticaba, Distrito Federal \\
\hline 12 & Passiflora actinia Hook. & Passiflora & Curitiba, Paraná \\
\hline 13 & Passiflora acuminata DC. & Passiflora & Manaus, Amazonas \\
\hline 14 & Passiflora alata Curtis & Passiflora & Monte Verde, Minas Gerais \\
\hline 15 & Passiflora alata Curtis & Passiflora & Seleção Embrapa, Distrito Federal \\
\hline 16 & Passiflora alata Curtis & Passiflora & Seleção Embrapa, Distrito Federal \\
\hline 17 & Passiflora alata Curtis & Passiflora & Seleção Embrapa, Distrito Federal \\
\hline 18 & Passiflora alata Curtis & Passiflora & Trancoso, Bahia \\
\hline 19 & Passiflora ambigua Hemsl. & Passiflora & Confresa, Mato Grosso \\
\hline 20 & Passiflora amethystina Mikan & Passiflora & Monte Verde, Minas Gerais \\
\hline 21 & Passiflora araujoi Sacco & Distephana & Santarém, Pará \\
\hline 22 & Passiflora auriculata Kunth & Decaloba & Manaus, Amazonas \\
\hline 23 & Passiflora bahiensis Klotzsch & Passiflora & Lençóis, Bahia \\
\hline 24 & Passiflora biflora Lam. & Decaloba & Novo Airão, Amazonas \\
\hline 25 & Passiflora boticarioana Cervi & Passiflora & Conceição do Mato Dentro, Minas Gerais \\
\hline 26 & Passiflora caerulea $\mathrm{L}$. & Passiflora & Bento Gonçalves, Rio Grande do Sul \\
\hline 27 & Passiflora capsularis $\mathrm{L}$. & Decaloba & Planaltina, Distrito Federal \\
\hline 28 & Passiflora cerasina Annonay \& Feuillet & Passiflora & Presidente Figueiredo, Amazonas \\
\hline 29 & Passiflora cerradense Sacco & Astrophea & Planaltina, Distrito Federal \\
\hline
\end{tabular}




\begin{tabular}{|c|c|c|c|}
\hline $\mathrm{N}^{\mathrm{o}}$ & Espécie & Subgênero & Origem \\
\hline 30 & Passiflora cervii Milward-de-Azevedo & Decaloba & Caeté, Minas Gerais \\
\hline 31 & Passiflora chlorina L. K. Escobar & Astrophea & Caeté, Minas Gerais \\
\hline 32 & Passiflora cincinnata Mast. & Passiflora & Rio Pardo de Minas, Minas Gerais \\
\hline 33 & Passiflora coccinea Aubl. & Passiflora & Pontes e Lacerda, Mato Grosso \\
\hline 34 & Passiflora decaisneana G. Nicholson & Passiflora & Planaltina, Distrito Federal \\
\hline 35 & Passiflora edmundoi Sacco & Passiflora & Rio Pardo, Minas Gerais \\
\hline 36 & Passiflora eichleriana Mast. & Passiflora & Criciúma, Santa Catarina \\
\hline 37 & Passiflora elegans Mast. & Passiflora & Patos de Minas, Minas Gerais \\
\hline 38 & Passiflora ferruginea Mast. & Decaloba & Rio Branco, Acre \\
\hline 39 & Passiflora foetida $\mathrm{L}$. & Passiflora & Belém, Pará \\
\hline 40 & Passiflora galbana Mast. & Passiflora & Ponte Nova, Minas Gerais \\
\hline 41 & Passiflora gardneri Mast. & Passiflora & Silvania, Goiás \\
\hline 42 & Passiflora gibertii Brown & Passiflora & Poconé, Mato Grosso \\
\hline 43 & Passiflora glandulosa Cav. & Passiflora & Igarapé-açú, Pará \\
\hline 44 & Passiflora haematostigma Mart. ex Mast. & Astrophea & Natividade, Tocantins \\
\hline 45 & Passiflora hatschbachii Cervi & Passiflora & Jaíba, Minas Gerais \\
\hline 46 & Passiflora hypoglauca Harms & Passiflora & Ouro Preto, Minas Gerais \\
\hline 47 & Passiflora incarnata L. & Passiflora & Centroflora, Botucatu, São Paulo \\
\hline 48 & Passiflora jilekii Wawra & Passiflora & Manhuaçu, Minas Gerais \\
\hline 49 & Passiflora junqueirae Imig \& Cervi & Passiflora & Caparaó, Minas Gerais \\
\hline 50 & Passiflora kermesina Link \& Otto & Passiflora & São José do Laranjal, Minas Gerais \\
\hline 51 & Passiflora laurifolia $\mathrm{L}$. & Passiflora & Picos, Piauí \\
\hline 52 & Passiflora ligularis Juss. & Passiflora & Pomar comercial \\
\hline 53 & Passiflora loefgrenii Vitta & Passiflora & Criciúma, Santa Catarina \\
\hline 54 & Passiflora luetzelburgii Harms & Passiflora & Rio Pardo de Minas, Minas Gerais \\
\hline 55 & Passiflora malacophylla Spruce ex Mast. & Passiflora & Rio das Ostras, Rio de Janeiro \\
\hline 56 & Passiflora maliformis L. & Passiflora & Seleção Embrapa, Distrito Federal \\
\hline 57 & Passiflora maliformis L. & Passiflora & Boa Vista, Roraima \\
\hline 58 & Passiflora maliformis L. & Passiflora & Guajará Mirim, Rondônia \\
\hline 59 & Passiflora mendoncaei Harms & Passiflora & Monte Verde, Minas Gerais \\
\hline 60 & Passiflora micropetala Mast. & Decaloba & Iranduba, Amazonas \\
\hline 61 & Passiflora miersii Mast. in Mart. & Passiflora & Monte Verde, Minas Gerais \\
\hline 62 & Passiflora misera Kunth & Decaloba & Trancoso, Bahia \\
\hline 63 & Passiflora morifolia Mast. in Mart. & Decaloba & Lavras, Minas Gerais \\
\hline 64 & Passiflora mucronata Lam. & Passiflora & Campos dos Goytacazes, Rio de Janeiro \\
\hline
\end{tabular}




\begin{tabular}{|c|c|c|c|}
\hline $\mathrm{N}^{\mathrm{o}}$ & Espécie & Subgênero & Origem \\
\hline 65 & Passiflora nitida Kunth & Passiflora & Presidente Figueiredo, Amazonas \\
\hline 66 & Passiflora nitida Kunth & Passiflora & Planaltina, Distrito Federal \\
\hline 67 & Passiflora nitida Kunth & Passiflora & Marabá, Pará \\
\hline 68 & Passiflora odontophylla Harms ex Glaz. & Passiflora & Caeté, Minas Gerais \\
\hline 69 & Passiflora organensis Gardn. & Decaloba & Serra dos Órgãos, Rio de Janeiro \\
\hline 70 & Passiflora pedata $\mathrm{L}$. & Passiflora & Manaus, Amazonas \\
\hline 71 & Passiflora picturata Ker & Passiflora & Álter do Chão, Pará \\
\hline 72 & Passiflora pohlii Mast. in Mart. & Decaloba & Planaltina, Distrito Federal \\
\hline 73 & Passiflora porophylla Vell. & Decaloba & Caeté, Minas Gerais \\
\hline 74 & Passiflora quadrangularis $\mathrm{L}$. & Passiflora & Silvania, Goiás \\
\hline 75 & Passiflora quadrangularis $\mathrm{L}$. & Passiflora & Pomar comercial \\
\hline 76 & Passiflora quadrifaria Vanderpl. & Distephana & Manaus, Amazonas \\
\hline 77 & Passiflora quadriglandulosa Rodschied & Distephana & Porto Velho, Rondônia \\
\hline 78 & Passiflora racemosa Brot. & Passiflora & Búzios, Rio de Janeiro \\
\hline 79 & Passiflora recurva Mast. in Mart. & Passiflora & Rio Pardo de Minas, Minas Gerais \\
\hline 80 & Passiflora rhamnifolia Mast. & Astrophea & Caeté, Minas Gerais \\
\hline 81 & Passiflora riparia Mart. & Passiflora & Confresa, Mato Grosso \\
\hline 82 & Passiflora rubra $\mathrm{L}$. & Decaloba & Monte Verde, Minas Gerais \\
\hline 83 & Passiflora saxicola Gontsch. & Decaloba & Porto Seguro, Bahia \\
\hline 84 & Passiflora sclerophylla Harms & Astrophea & Manaus, Amazonas \\
\hline 85 & Passiflora setacea DC. & Passiflora & Tapiramutá, Bahia \\
\hline 86 & Passiflora setacea DC. & Passiflora & Planaltina, Distrito Federal \\
\hline 87 & Passiflora setacea DC. & Passiflora & Manhuaçu, Minas Gerais \\
\hline 88 & Passiflora setacea DC. & Passiflora & Janaúba, Minas Gerais \\
\hline 89 & Passiflora sidaefolia M. Roemer & Passiflora & Caparaó, Minas Gerais \\
\hline 90 & Passiflora speciosa Gardn. & Passiflora & Manhuaçu, Minas Gerais \\
\hline 91 & Passiflora suberosa L. & Decaloba & Macapá, Amapá \\
\hline 92 & Passiflora subrotunda Mast. in Mart. & Passiflora & Natal, Rio Grande do Norte \\
\hline 93 & Passiflora tenuifila Killip & Passiflora & Patos de Minas, Minas Gerais \\
\hline 94 & Passiflora tholozanii Sacco & Distephana & Girau, Rondônia \\
\hline 95 & Passiflora tricuspis Mast. in Mart. & Decaloba & Planaltina, Distrito Federal \\
\hline 96 & Passiflora triloba Ruiz \& Pav. ex DC. & Passiflora & Cruzeiro do Sul, Acre \\
\hline 97 & Passiflora trintae Sacco & Passiflora & Rio Pardo, Minas Gerais \\
\hline 98 & Passiflora variolata Poepp. \& Endl. & Distephana & Manaus, Amazonas \\
\hline 99 & Passiflora vespertilio L. & Decaloba & Manaus, Amazonas \\
\hline
\end{tabular}




\begin{tabular}{llll}
$\mathrm{N}^{\circ}$ & Espécie & Subgênero & Origem \\
\hline 100 & Passiflora villosa Vell. & Passiflora & Alto Paraíso, Goiás \\
101 & Passiflora vitifolia Kunth & Passiflora & Poconé, Mato Grosso \\
\hline
\end{tabular}

\section{Transferibilidade de marcadores microssatélites de $\boldsymbol{P}$. edulis}

Com o intuito de testar a transferibilidade em outras espécies de Passiflora, os marcadores microssatélites desenvolvidos para P. edulis que apresentaram PIC maior que 0,45 foram genotipados em 90 acessos pertencentes a 78 espécies de Passiflora (Tabela 1, filas 12 - 101), mantidos no Banco Ativo de Germoplasma de Passifloras da Embrapa Cerrados, Planaltina, DF. Essas espécies de Passiflora fazem parte de quatro subgêneros (Astrophea, Decaloba, Distephana e Passiflora). Os acessos foram genotipados com 18 dos marcadores polimórficos dentro do conjunto de 60 marcadores inicialmente selecionados da validação. Quando a amplificação de PCR foi exitosa, foi registrada a presença ou ausência de fragmentos amplificados se o tamanho dos alelos fora detectado no intervalo esperado.

Para a maioria das espécies de Passiflora, somente um acesso estava representado no Banco Ativo de Germoplasma. Para as espécies com dois ou mais acessos disponíveis, a amplificação cruzada e o polimorfismo dos marcadores foram computados (Tabela 1). A frequência observada em 27 acessos de seis espécies $(P$. edulis, P. alata, P. maliformis, P. nitida, P. quadrangularis e P. setacea) mais o acesso 11 (Tabela 1, BRS Maracujá Jaboticaba) foi usado para estimar a distância genética utilizando o coeficiente Band (LYNCH, 1990). BRS Maracujá Jaboticaba é uma cultivar autógama de maracujazeiro-azedo de filogenia desconhecida a que produz pequenos frutos de casca roxa. A similaridade genética detectada pelos marcadores microssatélites foi explorada com Análises de Coordenadas Principais (PCoA) utilizando o software NTSYSpc v.2.10 (ROHLF, 1990). As análises de estrutura da população e ancestralidade dos 28 acessos com base na estatística Bayesiana, sem nenhuma atribuição prévia às espécies, foi realizada utilizando o software Structure v.2.3.4 (PRITCHARD; STEPHENS; DONNELLY, 2000; PRITCHARD; WEN; FALUSH, 2010). Foi considerado o modelo de frequências alélicas correlacionadas e independentes entre os grupos inferidos, com base nos parâmetros do modelo de mistura (Admixture model) com 250.000 repetições iniciais (burnin) com um tamanho na corrida de 500.000 (run-length). Para identificar o 
número de grupos na amostra dos acessos de Passiflora, o valor de $\ln \mathrm{P}(\mathrm{D})$ foi obtido por meio do teste de K variando entre 1 a 10 usando 20 corridas independentes para cada valor de K (duração do período de repetições iniciais: 50.000; número de MCMC repetições após as repetições iniciais: 50.000). Os valores mais prováveis de K para cada teste foram detectados pelo Delta K (EVANNO; REGNAUT; GOUDET, 2005). Os acessos de Passiflora testados foram divididos em grupos segundo os valores de Q maiores ou iguais a 0,70 , ou sendo considerados como intermediários ou misturados. A extração e quantificação de DNA de todos os acessos de Passiflora seguiram os procedimentos descritos anteriormente.

\section{RESULTADOS E DISCUSSÃO}

\section{Sequenciamento parcial e montagem de novo do genoma de Passiflora edulis Sims para a detecção de microssatélites}

A montagem foi baseada em 225.293.527 reads curtos de sequências de DNA (média do tamanho=62,65 pb), compreendendo uma base de dados de 14.113.860.125 pb (Tabela 2), a que correspondeu aproximadamente a 4,4X de cobertura do genoma de maracujá, supondo que o tamanho do genoma é de 3.126 Mpb (SOUZA et al., 2004). O total de 234.239 segmentos de contigs mostrou variação de tamanho de 166 a $45.662 \mathrm{pb}$, com média de 707 pb e cobertura de 165.702.691 pb. O conjunto dos segmentos foi revisado para identificar a presença de sítios de microssatélites.

Tabela 2. Resumo dos dados dos reads das sequências pair-end de Illumina, montagem de novo e detecção de repetições de microssatélites no genoma de $P$. edulis.

\begin{tabular}{lrrrr} 
Informação do sequenciamento & \multicolumn{2}{c}{ Variação em } & Média do & \\
& \multicolumn{1}{c}{ Total \# } & tamanho $(\mathrm{pb})$ & tamanho $(\mathrm{pb})$ & Total $(\mathrm{pb})$ \\
Reads de paired-end de llumina & 225.293 .527 & $52-76$ & 62,65 & 14.113 .860 .125 \\
Contigs & 234.239 & $166-45.662$ & 707 & 165.702 .691 \\
& & & \\
Sequências de microssatélites & Total \# & $>5$ repetições & - \\
Microssatélites imperfeitos e/o compostos & 1.544 .549 & 13.391 & \\
Di-nucleotídeos perfeitos & 360.162 & 1.436 & \\
Tri-nucleotídeos perfeitos & 60.669 & 186 & \\
Tetra-nucleotídeos perfeitos & 7.463 & - & \\
Total & 1.972 .843 & & \\
\hline
\end{tabular}


O conjunto de 1.972 .843 sítios de microssatélites ajustaram-se aos critérios estabelecidos para o descobrimento de sequências simples repetidas na montagem dos segmentos dos contigs (Tabela 2). Microssatélites perfeitos incluíram 360.162 repetições de di-nucleotídeos com um número de repetições que variou de 3 até 20 (13.391 > 5 repetições). Repetições perfeitas de tri-nucleotídeos incluíram 60.669 sítios de 3 até 14 repetições $(1.436>5$ repetições). Para tetra-nucleotídeos as repetições perfeitas incluíram 7.463 sítios com 3 até 13 repetições $(186>5$ repetições).

Análises de sequências dos contigs de $P$. edulis permitiram 37.761 anotações de genes e identificaram 5.947 sequências repetidas localizadas em regiões de genes putativos, dos quais 2.990 hits foram não redundantes. A predição $a b$ initio para as regiões de expressão resultou em uma compilação de 101.361 hits em regiões de éxons dos 47.706 dos scaffolds avaliados. Usando o mínimo de 15X de cobertura média como corte, um total de 1.300 sítios de microssatélites perfeitos foram selecionados em regiões genômicas funcionais e estruturais de maracujazeiro-azedo. Nessa amostra de sítios de microssatélites, as repetições de tri-nucleotídeos foram a classe mais abundante (534 sítios), seguida pelos tetra-nucleotídeos (475) e dinucleotídeos (294) (Figura 1a). Os tipos de sequências de microssatélites mais frequentes em cada classe foram AT/TA, GAA/TCC e AAAT/ATTT (Figura 1b). A repetição do motivo de di-nucleotídeo mais frequente (AT) também foi a mais abundante, correspondendo a 5,3\% da região de microssatélites perfeitos detectados nos contigs com pelo menos $15 \mathrm{X}$ de cobertura. Por outro lado, motivos das repetições de tri e tetra-nucleotídeos apresentaram uma distribuição mais balanceada entre as diferentes classes.

A lista de 1.300 sítios de microssatélites foi ainda analisada para o desenvolvimento de primers para PCR. Pares de primers flanqueando as repetições de DNA puderam ser desenvolvidos para 816 sítios de microssatélites, os que foram adequados para o desenho dentro de cada contig, que não apresentaram locos de sequências simples repetidas adjacentes e que atenderam os requisitos previamente descritos (Apêndice). Aos novos marcadores microssatélites lhes foi dado o prefixo "BrPe". A lista de marcadores incluiu 149 di, 329 tri e 338 tetra-nucleotídeos. Aproximadamente $56 \%$ dos marcadores estavam localizados em regiões funcionais do genoma de $P$. edulis (60 repetições de di, 263 de tri e 139 de tetra-nucleotídeos) e o restante em regiões estruturais. 

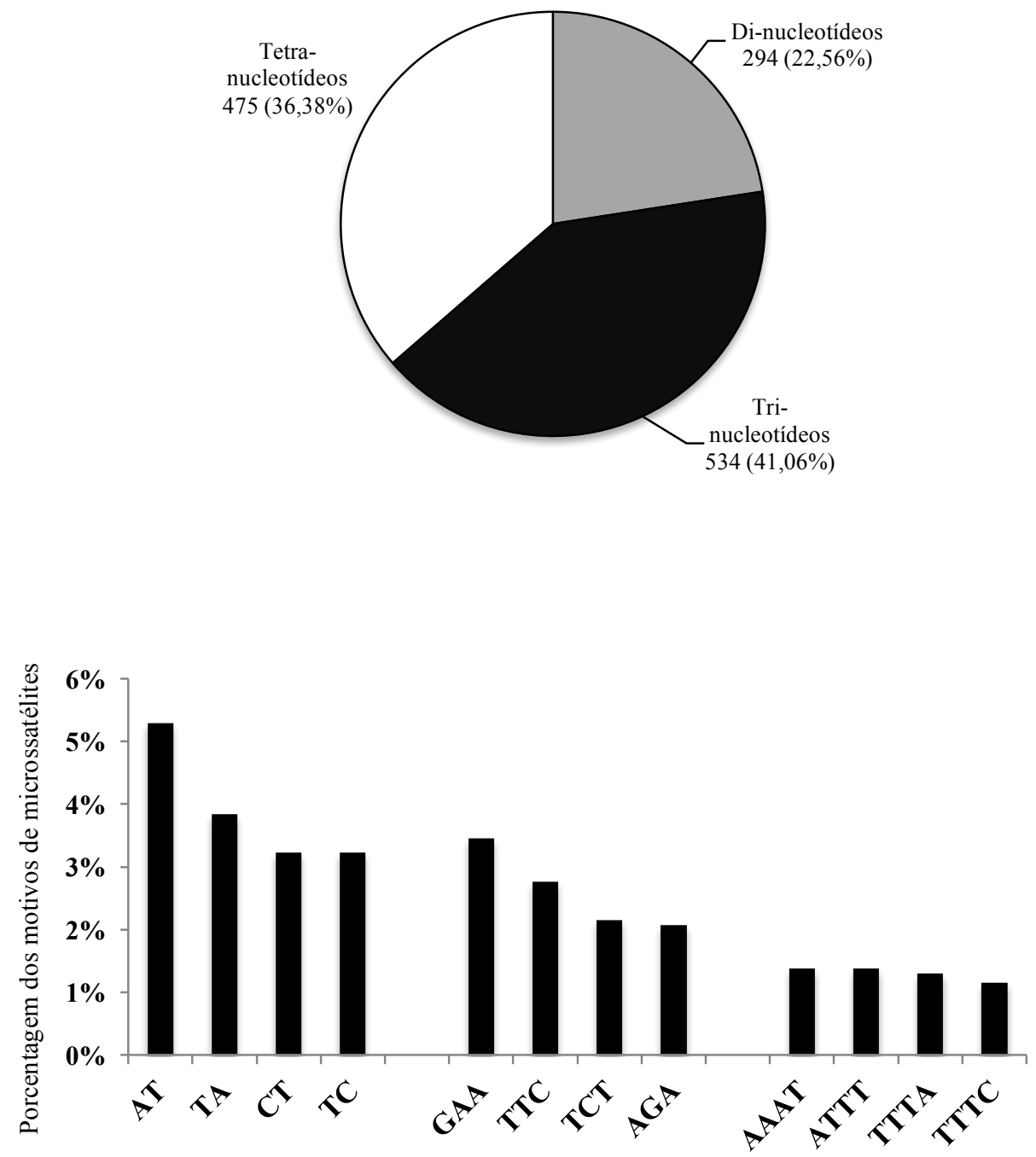

Quatro classes mais abundantes dos motivos de microssatélites

Figura 1. (a) Distribuição dos microssatélites perfeitos de di, tri e tetra-nucleotídeos em contigs com um mínimo de $15 \mathrm{X}$ de cobertura (b) Distribuição dos motivos mais frequentes com um mínimo de $15 \mathrm{X}$ de cobertura.

Foi escolhida uma amostra de 60 marcadores (50 di e 10 tri-nucleotídeos) que foram marcados com pigmentos fluorescentes e combinados para a amplificação simultânea em duplas ou trios para testar a eficiência de genotipagem e o polimorfismo dos marcadores nos acessos de maracujazeiro. Foram testados 25 painéis, que geralmente continham dois marcadores cada um para a amplificação 
simultânea dos alelos. Dos 60 marcadores, 52 amplificaram produto em todos os 25 painéis, sem ajuste nas condições de PCR (Figura 2). Cinco marcadores funcionaram melhor na amplificação individual (BrPe0014, BrPe0021, BrPe0033, BrPe0042, BrPe0043). Não foram obtidos fragmentos amplificados de PCR em três marcadores (5\%) (BrPe0004, BrPe0005, BrPe0048), embora não tenham sido testados ajustes na PCR. Isto representa uma taxa de sucesso mais elevada na amplificação por PCR de marcadores microssatélites que foram obtidos por qualquer outro método.
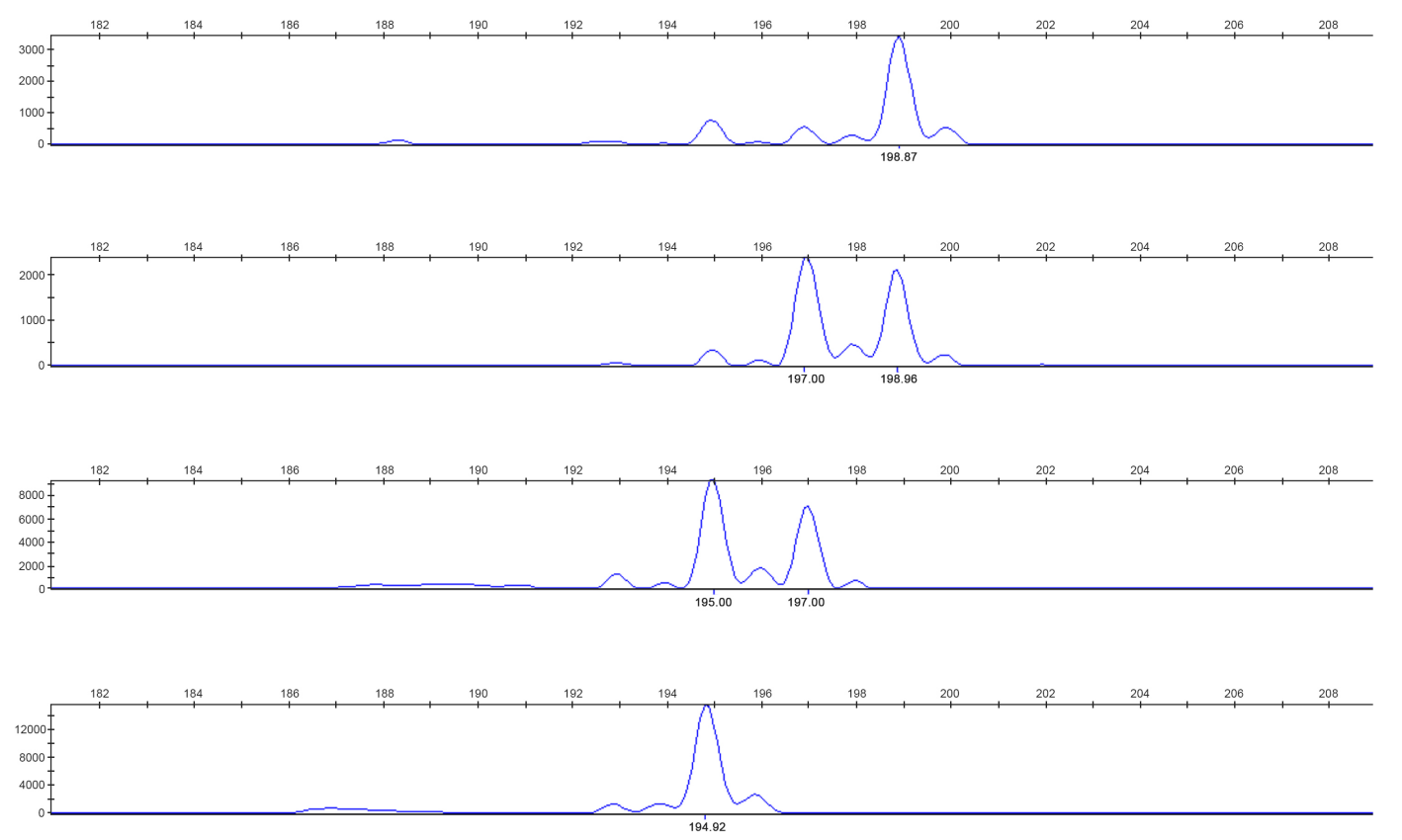

Figura 2. Eletroferograma do marcador BrPe0006 mostrando os padrões de amplificação e o polimorfismo do DNA em quatro acessos de $P$. edulis $(1,3,4,5)$ (Eixo $\mathrm{Y}=$ pfu; Eixo $\mathrm{X}=$ tamanho do alelo).

\section{Estatística descritiva dos marcadores microssatélites}

Dentro dos 57 marcadores que produziram fragmentos amplificados, 42 (aproximadamente 74\%) foram polimórficos quando testados em uma amostra de dez acessos do germoplasma de $P$. edulis, que permitiram a detecção de 137 alelos (Tabela 3). Quinze marcadores não foram polimórficos (nove repetições de dinucleotídeos e seis de tri-nucleotídeos) (Apêndice). O número de alelos observados para todos os marcadores microssatélites polimórficos variou entre 2 a 7 , com uma 
média de 3,26 alelos por loco (Tabela 3). Os valores para a heterozigosidade esperada (He) foram entre 0,19 e 0,84 com uma média de 0,55. A heterozigosidade observada (Ho) variou entre 0,00 e 1,00 com uma média de 0,45 (Tabela 3 ).

Foi conferido se o tamanho dos locos polimórficos correspondia ao tamanho esperado dos fragmentos de $P$. edulis. O tamanho esperado para cada marcador microssatélites está baseado na informação de sequenciamento gerada pelo processo da montagem de novo. A proporção de marcadores que geraram fragmentos amplificados dentro do $5 \%$ do tamanho esperado foi de 100\% (42 de 42). Aproximadamente $55 \%$ dos marcadores polimórficos geraram fragmentos amplificados com produto exato ao esperado (23 de 42)

Além dos 50 marcadores de di-nucleotídeos testados para polimorfismo, 17 foram localizados nas regiões genômicas estruturais e 53 em sítios funcionais putativos do genoma de $P$. edulis (Apêndice). Não foi achada associação significativa (Teste Exato de Fisher $\mathrm{P}=0,64)$ entre o nível de polimorfismo do marcador e o tamanho da repetição (di ou tri-nucleotídeo).

Tabela 3. Estatísticas descritivas dos novos marcadores microssatélites de Passiflora edulis

\begin{tabular}{|c|c|c|c|c|c|c|c|c|c|}
\hline $\mathrm{N}^{\mathrm{o}}$ & Marcador & Sequência do primer 5'-3' & $\begin{array}{l}\text { Motivo } \\
\text { repetido }\end{array}$ & $\mathrm{T}_{\mathrm{a}}$ & $\begin{array}{c}\mathrm{N} \\
\text { alelos }\end{array}$ & $\begin{array}{c}\text { Faixa } \\
\text { tamanho } \\
\text { do alelo } \\
\text { (pb) }\end{array}$ & $\mathrm{He}$ & Ho & PIC \\
\hline 1 & $\mathrm{BrPe} 0032$ & $\begin{array}{l}\text { F:TTGCACAATGACCAATGTTGT } \\
\text { R:CTGAGCACCTTGTCAAAATACA }\end{array}$ & $(\mathrm{AT})_{13}$ & $60^{\circ} \mathrm{C}$ & 7 & $137-157$ & 0,84 & 1,00 & 0,77 \\
\hline 2 & $\mathrm{BrPe} 0028$ & $\begin{array}{l}\text { F:CAAAAGGAACAGGGAAGA } \\
\text { R:GAAAGAGAGAAAGACAGAGA }\end{array}$ & $(\mathrm{TA})_{6}$ & $55^{\circ} \mathrm{C}$ & 5 & $90-110$ & 0,80 & 0,50 & 0,72 \\
\hline 3 & $\mathrm{BrPe} 0024$ & $\begin{array}{l}\text { F:CCCTACCTTTCTCTGCTT } \\
\text { R:CATCTCCTCTATCTCCTTC }\end{array}$ & $(\mathrm{TC})_{7}$ & $55^{\circ} \mathrm{C}$ & 4 & $221-231$ & 0,76 & 0,70 & 0,68 \\
\hline 4 & $\mathrm{BrPe} 0031$ & $\begin{array}{l}\text { F:AGGTCGGTGGGTGTGTTTAG } \\
\text { R:CATTCAACTCCCCAAAAGGT }\end{array}$ & $(\mathrm{TA})_{9}$ & $60^{\circ} \mathrm{C}$ & 5 & $134-150$ & 0,77 & 0,67 & 0,67 \\
\hline 5 & $\mathrm{BrPe} 0014$ & $\begin{array}{l}\text { F:AATATGGCTGGGGAAAAC } \\
\text { R:TTCCTGTCTTTGGACCTT }\end{array}$ & $(\mathrm{AG})_{7}$ & $57^{\circ} \mathrm{C}$ & 5 & $215-227$ & 0,75 & 0,50 & 0,67 \\
\hline 6 & $\mathrm{BrPe} 0033$ & $\begin{array}{l}\text { F:GCCATGAGAGACTTGGGAGA } \\
\text { R:CGGTTGCCAAAAAGAAGAGA }\end{array}$ & $(\mathrm{AT})_{8}$ & $60^{\circ} \mathrm{C}$ & 5 & $237-249$ & 0,72 & 0,30 & 0,65 \\
\hline 7 & $\mathrm{BrPe} 0038$ & $\begin{array}{l}\text { F:TTTCAACTTTTCGTGTGTGC } \\
\text { R:TGTTGTTGCTTGGAAGGATG }\end{array}$ & $(\mathrm{AT})_{6}$ & $60^{\circ} \mathrm{C}$ & 5 & $154-176$ & 0,73 & 0,60 & 0,64 \\
\hline 8 & $\mathrm{BrPe} 0042$ & $\begin{array}{l}\text { F:CATGCATTCATTTGTTTTTCTTG } \\
\text { R:GATGCTGGGAAAAAGAGTGC }\end{array}$ & $(\mathrm{AT})_{8}$ & $60^{\circ} \mathrm{C}$ & 6 & $142-160$ & 0,71 & 0,80 & 0,63 \\
\hline 9 & $\mathrm{BrPe} 0003$ & $\begin{array}{l}\text { F:CTTTCTCTCCСТАТАCCC } \\
\text { R:СССТCСАТААТСАСАТАAC }\end{array}$ & $(\mathrm{TC})_{11}$ & $55^{\circ} \mathrm{C}$ & 5 & $277-291$ & 0,70 & 0,40 & 0,62 \\
\hline 10 & $\mathrm{BrPe} 0043$ & $\begin{array}{l}\text { F:TCATACATGGATGTCAAATCGATAC } \\
\text { R:GCGGACCAAGAAAATTCAAA }\end{array}$ & $(\mathrm{AT})_{8}$ & $60^{\circ} \mathrm{C}$ & 4 & $199-207$ & 0,71 & 0,50 & 0,60 \\
\hline 11 & $\mathrm{BrPe} 0006$ & $\begin{array}{l}\text { F:AAGGAAAAGAACAGCCTCA } \\
\text { R:CGCTCTCAAATCAGTCAAA }\end{array}$ & $(\mathrm{TC})_{10}$ & $55^{\circ} \mathrm{C}$ & 4 & 193-199 & 0,68 & 0,40 & 0,59 \\
\hline 12 & $\mathrm{BrPe} 0002$ & $\begin{array}{l}\text { F:AAAGCCCAGATGAAGTGAA } \\
\text { R:GGCTCCAATCAGAAGTGT }\end{array}$ & $(\mathrm{AG})_{12}$ & $55^{\circ} \mathrm{C}$ & 3 & $177-185$ & 0,69 & 0,56 & 0,58 \\
\hline 13 & $\mathrm{BrPe} 0021$ & $\begin{array}{l}\text { F:ACTTCCTCATCATTCG } \\
\text { R:GCTATGCCTCTTTTTG }\end{array}$ & $(\mathrm{TA})_{7}$ & $55^{\circ} \mathrm{C}$ & 3 & $158-164$ & 0,67 & 0,25 & 0,56 \\
\hline 14 & $\mathrm{BrPe} 0036$ & $\begin{array}{l}\text { F:TCGGACCTTAAAACCGAGAA } \\
\text { R:CAGCACCAAAATTTGACGAG }\end{array}$ & $(\mathrm{TC})_{6}$ & $60^{\circ} \mathrm{C}$ & 4 & $197-203$ & 0,65 & 0,10 & 0,54 \\
\hline 15 & $\mathrm{BrPe} 0023$ & $\begin{array}{l}\text { F:AGATACCACACCCAATAG } \\
\text { R:TTGGAGTTGTTGGGGA }\end{array}$ & $(\mathrm{CT}) 7$ & $55^{\circ} \mathrm{C}$ & 6 & $118-132$ & 0,57 & 0,40 & 0,52 \\
\hline
\end{tabular}




\begin{tabular}{|c|c|c|c|c|c|c|c|c|c|}
\hline $\mathrm{N}^{\circ}$ & Marcador & Sequência do primer $5^{\prime}-3$ ' & $\begin{array}{l}\text { Motivo } \\
\text { repetido }\end{array}$ & $\mathrm{T}_{\mathrm{a}}$ & $\begin{array}{c}\mathrm{N} \\
\text { alelos }\end{array}$ & $\begin{array}{c}\text { Faixa } \\
\text { tamanho } \\
\text { do alelo } \\
(\mathrm{pb})\end{array}$ & $\mathrm{He}$ & Ho & PIC \\
\hline 16 & $\mathrm{BrPe} 3011$ & $\begin{array}{l}\text { F:CCGGTCTTCCTGATTGACTC } \\
\text { R:CCTCTCTCACCTGGAACTGC }\end{array}$ & $(\mathrm{TTC})_{4}$ & $60^{\circ} \mathrm{C}$ & 3 & $157-163$ & 0,62 & 0,30 & 0,50 \\
\hline 17 & $\mathrm{BrPe} 0037$ & $\begin{array}{l}\text { F:TGATAATGCAGCGAAAGAGC } \\
\text { R:TCACACTCCATTTGCTCTGC }\end{array}$ & (TG)6 & $60^{\circ} \mathrm{C}$ & 3 & $227-231$ & 0,61 & 0,20 & 0,49 \\
\hline 18 & $\mathrm{BrPe} 0010$ & $\begin{array}{l}\text { F:GAAGAAAAAAGGGCTTG } \\
\text { R:GTTAGGGTTTGGAGGA }\end{array}$ & $(\mathrm{TC})_{9}$ & $55^{\circ} \mathrm{C}$ & 3 & $200-204$ & 0,60 & 0,40 & 0,48 \\
\hline 19 & $\mathrm{BrPe} 0001$ & $\begin{array}{l}\text { F:GTTGAGAGGATTGTGTTTG } \\
\text { R:ATGGTAGAGGAGGAGAGA }\end{array}$ & $(\mathrm{CT})_{14}$ & $55^{\circ} \mathrm{C}$ & 3 & $143-157$ & 0,56 & 0,14 & 0,46 \\
\hline 20 & $\mathrm{BrPe} 0012$ & $\begin{array}{l}\text { F:AGAGAGAGAGAGAGAG } \\
\text { R:ACATCATACTCCTCATCC }\end{array}$ & $(\mathrm{AG}) 8$ & $55^{\circ} \mathrm{C}$ & 3 & 214-218 & 0,58 & 0,13 & 0,45 \\
\hline 21 & $\mathrm{BrPe} 0008$ & $\begin{array}{l}\text { F:TTTTCAGCCTCCACTCTT } \\
\text { R:TACACCACCAACACTCAC }\end{array}$ & $(\mathrm{AG}) 9$ & $55^{\circ} \mathrm{C}$ & 3 & 264-274 & 0,57 & 1,00 & 0,44 \\
\hline 22 & $\mathrm{BrPe} 0025$ & $\begin{array}{l}\text { F:CAAGGAACCAGAACAAGAAGAA } \\
\text { R:GAAGAACAAGCCAGCCCA }\end{array}$ & $(\mathrm{GA}) 6$ & $55^{\circ} \mathrm{C}$ & 3 & 114-126 & 0,57 & 0,11 & 0,44 \\
\hline 23 & $\mathrm{BrPe} 0039$ & $\begin{array}{l}\text { F:GCTGCTCCACTGTGAATGTC } \\
\text { R:AACCTAGCCCCGTCACAGTA }\end{array}$ & $(\mathrm{AT}) 6$ & 60 & 3 & $193-203$ & 0,57 & 0,10 & 0,44 \\
\hline 24 & $\mathrm{BrPe} 0050$ & $\begin{array}{l}\text { F:TCAAGGGTATCTTTGGTGCTG } \\
\text { R:AGCTTCAGCGAGACAAAACC }\end{array}$ & (TG)7 & $60^{\circ} \mathrm{C}$ & 3 & $197-205$ & 0,56 & 0,20 & 0,44 \\
\hline 25 & $\mathrm{BrPe} 0013$ & $\begin{array}{l}\text { F:GATCGAGGTGAGGTACTG } \\
\text { R:GGTTTGGCTTTAATGGAGG }\end{array}$ & $(\mathrm{AG}) 8$ & $55^{\circ} \mathrm{C}$ & 2 & $169-171$ & 0,53 & 0,00 & 0,38 \\
\hline 26 & $\mathrm{BrPe} 0020$ & $\begin{array}{l}\text { F:TAAAGCATCAGGTCAG } \\
\text { R:TAGATAGATTTGACGGG }\end{array}$ & $(\mathrm{GT}) 7$ & $55^{\circ} \mathrm{C}$ & 2 & 295-297 & 0,53 & 0,00 & 0,38 \\
\hline 27 & $\mathrm{BrPe} 0034$ & $\begin{array}{l}\text { F:CCTGTGGTGAAAATGGAACC } \\
\text { R:GAGCCCTGGACTGACACATT }\end{array}$ & $(\mathrm{CT})_{15}$ & $60^{\circ} \mathrm{C}$ & 2 & $217-227$ & 0,56 & 1,00 & 0,38 \\
\hline 28 & $\mathrm{BrPe} 0049$ & $\begin{array}{l}\text { F:GGGAATCAAAACCATGCAGT } \\
\text { R:CTCCCAGCTTCCACTCACTC }\end{array}$ & $(\mathrm{TA}) 9$ & $60^{\circ} \mathrm{C}$ & 2 & $189-191$ & 0,53 & 0,11 & 0,38 \\
\hline 29 & $\mathrm{BrPe} 3012$ & $\begin{array}{l}\text { F:CGCCCTTTCTGAAGATAATCC } \\
\text { R:GCAATGCTAAGAAGGCCAAG }\end{array}$ & $(\mathrm{TCT}) 4$ & $60^{\circ} \mathrm{C}$ & 2 & 181-183 & 0,53 & 0,11 & 0,38 \\
\hline 30 & $\mathrm{BrPe} 0018$ & $\begin{array}{l}\text { F:TCCTTCCTTCTCCTCC } \\
\text { R:ACACTTGTCTCTCATCT }\end{array}$ & $(\mathrm{CT}) 7$ & $55^{\circ} \mathrm{C}$ & 3 & $135-149$ & 0,43 & 0,30 & 0,37 \\
\hline 31 & $\mathrm{BrPe} 0022$ & $\begin{array}{l}\text { F:GGCATAGAAGTGGAAGGG } \\
\text { R:GGAAGGGAAGTGAAGGGA }\end{array}$ & $(\mathrm{AG}) 7$ & $55^{\circ} \mathrm{C}$ & 2 & $98-104$ & 0,51 & 0,20 & 0,37 \\
\hline 32 & $\mathrm{BrPe} 0047$ & $\begin{array}{l}\text { F:TGGGCCATTTCTTTTCTCTC } \\
\text { R:GAATCCTGCATGAGTTGAGGA }\end{array}$ & $(\mathrm{CT}) 9$ & $60^{\circ} \mathrm{C}$ & 2 & $186-192$ & 0,48 & 0,30 & 0,35 \\
\hline 33 & $\mathrm{BrPe} 3014$ & $\begin{array}{l}\text { F:CGGAAGCGTGCTCATAAAGT } \\
\text { R:AAGCCTGTGAGGTTGATTCG }\end{array}$ & $(\mathrm{AGA}) 5$ & $60^{\circ} \mathrm{C}$ & 2 & $218-220$ & 0,48 & 0,30 & 0,35 \\
\hline 34 & $\mathrm{BrPe} 0007$ & $\begin{array}{l}\text { F:AAAGCCCAGATGAAGTGAA } \\
\text { R:GGCTCCAATCAGAAGTGT }\end{array}$ & $(\mathrm{AG}) 9$ & $55^{\circ} \mathrm{C}$ & 2 & $177-179$ & 0,40 & 0,50 & 0,31 \\
\hline 35 & $\mathrm{BrPe} 0027$ & $\begin{array}{l}\text { F:TCCAATCTTCTCAACC } \\
\text { R:CAAACTAGTAAACCCC } \\
\end{array}$ & (TA)6 & $46^{\circ} \mathrm{C}$ & 3 & $97-101$ & 0,35 & 0,20 & 0,30 \\
\hline 36 & $\mathrm{BrPe} 3027$ & $\begin{array}{l}\text { F:CCAAAATGCCCAAAATGTCT } \\
\text { R:GTCCGTGAGGAGATGTCGAT }\end{array}$ & (GGT)4 & $60^{\circ} \mathrm{C}$ & 3 & 178-202 & 0,35 & 0,40 & 0,30 \\
\hline 37 & $\mathrm{BrPe} 0019$ & $\begin{array}{l}\text { F:AAAGAGAAGGATGGATG } \\
\text { R:AAAAAGGACGAGGAAGA }\end{array}$ & (TC)7 & $55^{\circ} \mathrm{C}$ & 2 & $210-214$ & 0,36 & 0,14 & 0,28 \\
\hline 38 & $\mathrm{BrPe} 0044$ & $\begin{array}{l}\text { F:GGACGCTAAGAGACCCATTG } \\
\text { R:TAAAAGCCCCACTTGCAATC }\end{array}$ & (TA)6 & $60^{\circ} \mathrm{C}$ & 2 & $217-219$ & 0,33 & 0,38 & 0,26 \\
\hline 39 & $\mathrm{BrPe} 0016$ & $\begin{array}{l}\text { F:TGGTTGGTGGGTCTTGT } \\
\text { R:CTCTTTCCTCTCTCTCTCTCT }\end{array}$ & $(\mathrm{AG}) 7$ & $55^{\circ} \mathrm{C}$ & 2 & $277-279$ & 0,21 & 0,22 & 0,18 \\
\hline 40 & $\mathrm{BrPe} 0045$ & $\begin{array}{l}\text { F:CGCTTCCACTTTACCAGCTC } \\
\text { R:GACCAACAACAGGCACAATG }\end{array}$ & $(\mathrm{GT}) 8$ & $60^{\circ} \mathrm{C}$ & 2 & $183-185$ & 0,21 & 0,22 & 0,18 \\
\hline 41 & $\mathrm{BrPe} 0011$ & $\begin{array}{l}\text { F:GTTCTACTCCCTCATT } \\
\text { R:CTTCTTAACATCCCCA }\end{array}$ & $(\mathrm{CT}) 8$ & $53^{\circ} \mathrm{C}$ & 2 & $74-80$ & 0,19 & 0,20 & 0,16 \\
\hline 42 & $\mathrm{BrPe} 0017$ & $\begin{array}{l}\text { F:TTGTCTCTCGGTTCTCT } \\
\text { R:CAAACACAAAACCCCC }\end{array}$ & $(\mathrm{AG}) 7$ & $55^{\circ} \mathrm{C}$ & 2 & $86-90$ & 0,19 & 0,00 & 0,16 \\
\hline & MÉDIA & & & & 3,26 & & 0,55 & 0,35 & 0,45 \\
\hline
\end{tabular}

$\mathrm{F}$ : primer forward; R: primer reverse; $\mathrm{T}_{\mathrm{a}}$ : temperatura de anelamento; Ho: heterozigosidade observada; He: heterozigosidade esperada; PIC: conteúdo de informação polimórfica. 


\section{Transferibilidade dos marcadores microssatélites em espécies de Passiflora}

Marcadores foram classificados segundo os valores de PIC obtidos para avaliar a amplificação cruzada em 78 espécies de Passiflora. A média do PIC para os marcadores selecionados foi de 0,60, variando entre 0,46 e 0,77 (Tabela 3, marcadores 1-16, 18, 19). Foi realizada uma avaliação do potencial da amplificação cruzada desses marcadores microssatélites em espécies de Passiflora mostrando que $72 \%$ da combinação marcador/espécie resultou em amplificação positiva (Tabela 4), com valores entre 33 a 89\% (Tabela 4). Essa alta proporção de transferibilidade dos marcadores não era esperada. Três marcadores amplificaram em todas as 79 espécies de Passiflora, incluindo P. edulis (BrPe0032, BrPe0038, BrPe3011). BrPe0032 apresentou o mais alto valor do PIC e do número de alelos nos acessos de $P$. edulis testados. Primers BrPe0001, BrPe0034 e BrPe0042 também funcionaram na maioria das espécies testadas, com exceção de $P$. porophylla (BrPe0001), P. triloba e $P$. vitifolia (BrPe0034), P. capsularis e P. gibertii (BrPe0042). Interessante notar que, pelo menos 14 marcadores (BrPe0032, BrPe0038, BrPe3011, BrPe0001, BrPe0034, BrPe0042, BrPe0036, BrPe0006, BrPe0010, BrPe002, BrPe0031, BrPe0021, BrPe0003, BrPe0033) podem amplificar produtos de PCR em P. alata, P. bahiensis, P. laurifolia, P. ligularis, P. luetzelburgii, $P$. maliformis, $P$. mendoncaei, $P$. nitida, $P$. odontophylla, P. pedata, $P$. racemosa, $P$. recurva, $P$. setacea, $P$. speciosa e $P$. tenuifila. Cinquenta por cento dos marcadores produziram fragmentos amplificados em todas espécies testadas, exceto P. pohlii (Decaloba) e P. sclerophylla (Astrophea).

Tabela 4. Transferibilidade de 18 marcadores microssatélites de P. edulis a 78 espécies de Passiflora.

\begin{tabular}{|c|c|c|c|c|c|c|c|c|c|c|c|c|c|c|c|c|c|c|c|c|}
\hline $\mathrm{N}^{\circ}$ & & $\begin{array}{l}\text { f } \\
8 \\
0 \\
0 \\
0 \\
0\end{array}$ & 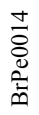 & 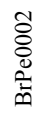 & 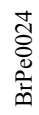 & 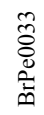 & 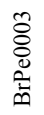 & 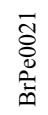 & 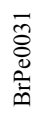 & 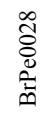 & 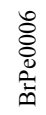 & $\begin{array}{l}\circ \\
\frac{0}{8} \\
0 \\
\stackrel{0}{0}\end{array}$ & 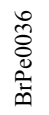 & 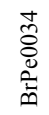 & 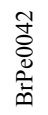 & 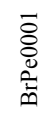 & 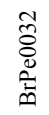 & 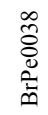 & 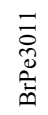 & $\%$ \\
\hline 72 & P. pohlii & - & - & - & - & - & - & - & - & - & - & - & - & + & + & + & + & + & + & $33 \%$ \\
\hline 84 & P. sclerophylla & - & - & - & - & + & - & - & - & + & - & - & - & + & + & + & + & + & + & $44 \%$ \\
\hline 91 & P. suberosa & - & - & - & - & - & - & - & - & + & + & + & - & + & + & + & + & + & + & $50 \%$ \\
\hline 36 & P. eichleriana & - & - & - & - & + & - & + & - & - & + & + & - & + & + & + & + & + & + & $56 \%$ \\
\hline 45 & P. hatschbachii & - & - & - & - & + & + & - & + & - & - & - & + & + & + & + & + & + & + & $56 \%$ \\
\hline 58 & P. picturata & - & - & - & - & - & - & - & - & + & + & + & + & + & + & + & + & + & + & $56 \%$ \\
\hline 71 & P. porophylla & - & + & - & - & - & - & - & + & + & + & - & + & + & + & - & + & + & + & $56 \%$ \\
\hline 73 & P. saxicola & - & - & - & - & - & - & - & + & + & - & + & + & + & + & + & + & + & + & $56 \%$ \\
\hline 83 & P. tricuspis & - & - & - & - & - & + & - & - & + & + & - & + & + & + & + & + & + & + & $56 \%$ \\
\hline 95 & P. araujoi & - & - & - & - & - & - & + & + & + & + & - & + & + & + & + & + & + & + & $61 \%$ \\
\hline 21 & P. auriculata & - & - & - & - & - & - & - & + & + & + & + & + & + & + & + & + & + & + & $61 \%$ \\
\hline 22 & P. edmundoi & - & - & - & - & - & + & - & - & + & + & + & + & + & + & + & + & + & + & $61 \%$ \\
\hline
\end{tabular}




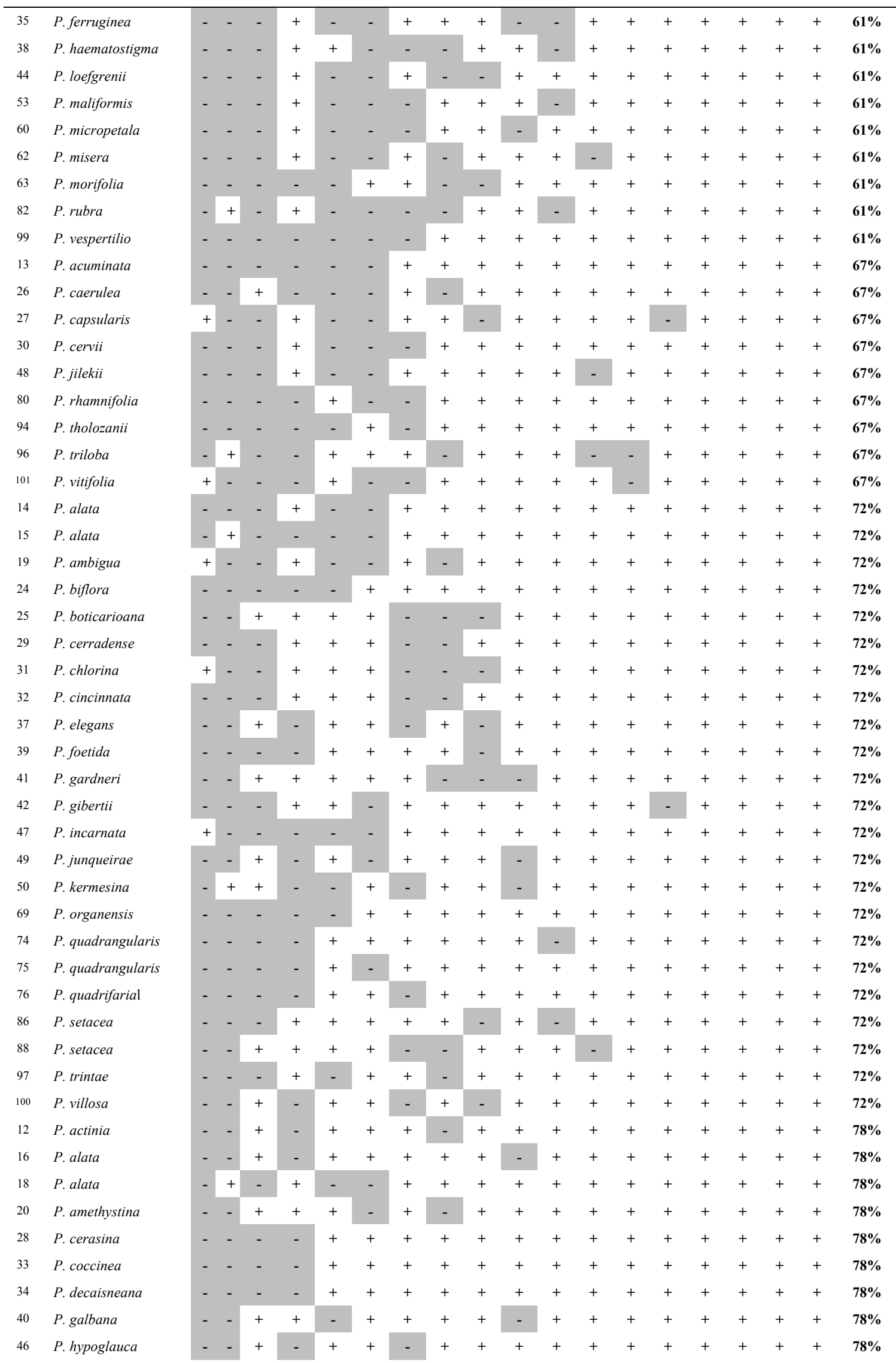




\begin{tabular}{|c|c|c|c|c|c|c|c|c|c|c|c|c|c|c|c|c|c|c|c|c|}
\hline $\mathrm{N}^{\circ}$ & & 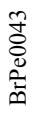 & 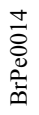 & $\begin{array}{l}\text { ¿ } \\
8 \\
0 \\
0 \\
\stackrel{0}{0}\end{array}$ & 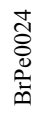 & $\begin{array}{l}\hat{\overbrace{}} \\
\delta \\
0 \\
\hat{0}\end{array}$ & 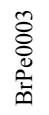 & $\begin{array}{l}\overline{\widetilde{\Omega}} \\
\delta \\
\stackrel{0}{0} \\
\stackrel{0}{0}\end{array}$ & $\begin{array}{l}\overline{0} \\
8 \\
0 \\
\stackrel{0}{0}\end{array}$ & $\begin{array}{l}\stackrel{\infty}{\widetilde{Q}} \\
\stackrel{0}{0} \\
\stackrel{0}{0}\end{array}$ & 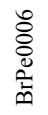 & $\begin{array}{l}0 \\
0 \\
0 \\
0 \\
01 \\
0\end{array}$ & 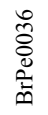 & 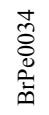 & 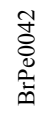 & $\begin{array}{l}\overline{8} \\
8 \\
0 \\
\stackrel{0}{0}\end{array}$ & 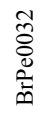 & 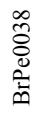 & 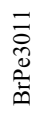 & $\%$ \\
\hline 55 & P. malacophylla & - & - & + & + & + & + & + & - & - & + & + & + & + & + & + & + & + & + & $78 \%$ \\
\hline 56 & P. maliformis & - & - & + & - & + & + & - & + & + & + & + & + & + & + & + & + & + & + & $78 \%$ \\
\hline 61 & P. miersii & - & - & + & - & + & + & + & + & + & - & + & + & + & + & + & + & + & + & $78 \%$ \\
\hline 64 & P. mucronata & - & - & - & + & + & + & + & + & - & + & + & + & + & + & + & + & + & + & $78 \%$ \\
\hline 66 & P. nitida & - & - & - & - & + & + & + & + & + & + & + & + & + & + & + & + & + & + & $78 \%$ \\
\hline 67 & P. nitida & - & - & - & - & + & + & + & + & + & + & + & + & + & + & + & + & + & + & $78 \%$ \\
\hline 77 & P. quadriglandulosa & + & - & - & - & + & + & + & + & + & + & + & - & + & + & + & + & + & + & $78 \%$ \\
\hline 81 & P. riparia & - & - & - & - & + & + & + & + & + & + & + & + & + & + & + & + & + & + & $78 \%$ \\
\hline 85 & P. setacea & - & - & - & + & + & + & + & + & - & + & + & + & + & + & + & + & + & + & $78 \%$ \\
\hline 89 & P. sidaefolia & - & - & - & + & + & + & - & + & + & + & + & + & + & + & + & + & + & + & $78 \%$ \\
\hline 92 & P. subrotunda & - & - & - & + & + & - & + & + & + & + & + & + & + & + & + & + & + & + & $78 \%$ \\
\hline 98 & P. variolata & - & - & - & - & + & + & + & + & + & + & + & + & + & + & + & + & + & + & $78 \%$ \\
\hline 17 & P. alata & - & + & - & + & + & + & + & - & + & + & + & + & + & + & + & + & + & + & $83 \%$ \\
\hline 23 & P. bahiensis & + & - & - & + & - & + & + & + & + & + & + & + & + & + & + & + & + & + & $83 \%$ \\
\hline 54 & P. luetzelburgii & - & - & + & + & + & + & + & - & + & + & + & + & + & + & + & + & + & + & $83 \%$ \\
\hline 57 & P. maliformis & - & - & + & + & - & + & + & + & + & + & + & + & + & + & + & + & + & + & $83 \%$ \\
\hline 59 & P. mendoncaei & - & - & + & - & + & + & + & + & + & + & + & + & + & + & + & + & + & + & $83 \%$ \\
\hline 65 & P. nitida & - & + & - & - & + & + & + & + & + & + & + & + & + & + & + & + & + & + & $83 \%$ \\
\hline 78 & P. racemosa & - & - & + & - & + & + & + & + & + & + & + & + & + & + & + & + & + & + & $83 \%$ \\
\hline 79 & P. recurva & - & - & + & - & + & + & + & + & + & + & + & + & + & + & + & + & + & + & $83 \%$ \\
\hline 87 & P. setacea & - & + & + & + & + & + & + & - & - & + & + & + & + & + & + & + & + & + & $83 \%$ \\
\hline 90 & P. speciosa & + & + & - & - & + & + & + & - & + & + & + & + & + & + & + & + & + & + & $83 \%$ \\
\hline 43 & P. glandulosa & + & + & - & + & - & + & + & + & + & + & + & + & + & + & + & + & + & + & $89 \%$ \\
\hline 51 & P. laurifolia & + & - & + & + & - & + & + & + & + & + & + & + & + & + & + & + & + & + & $89 \%$ \\
\hline 52 & P. ligularis & - & - & + & + & + & + & + & + & + & + & + & + & + & + & + & + & + & + & $89 \%$ \\
\hline 68 & P. odontophylla & - & + & - & + & + & + & + & + & + & + & + & + & + & + & + & + & + & + & $89 \%$ \\
\hline 70 & P. pedata & - & - & + & + & + & + & + & + & + & + & + & + & + & + & + & + & + & + & $89 \%$ \\
\hline 93 & P. tenuifila & - & - & + & + & + & + & + & + & + & + & + & + & + & + & + & + & + & + & $89 \%$ \\
\hline 1 & P. edulis & + & + & + & + & + & + & + & + & + & + & + & + & + & + & + & + & + & + & $100 \%$ \\
\hline
\end{tabular}

Os novos marcadores microssatélites revelaram diversidade genética em $P$. edulis (Figura 2, Tabela 3) e também em outras espécies relacionadas (Figura 3). A análise PCoA baseada no polimorfismo dos 18 marcadores avaliados em 28 acessos de seis espécies (P. edulis, P. alata, P. maliformis, P. nitida, P. quadrangularis e $P$. setacea) permitiu a separação em quatro grupos principais. A variação detectada pelo valor eigen foi para o eixo $1=32,08 \%$, eixo $2=14,20 \%$ e eixo $3=11,10 \%$. Curiosamente os acessos de P. edulis formaram dois grupos (Figura 3a) e poderiam ser facilmente separados dos acessos de outras espécies de Passiflora. A única exceção foi BRS Maracujá Jaboticaba (Tabela 1, acesso 11), que não foi incluído em nenhum dos dois grupos de $P$. edulis e sim no grupo de $P$. setacea. O quarto grupo incluiu acessos de P. nitida, P. quadrangularis, $P$. alata e $P$. maliformis. Embora os 
acessos dessas quatro espécies possam ser discriminados dentro desse conjunto de marcadores microssatélites, todos eles estão incluídos no mesmo grupo. Uma análise de estrutura de população e ancestralidade desses 28 acessos, sem nenhuma atribuição prévia de espécie, também inferiu a existência de quatro grupos principais, estimados pela plotagem dos valores de K versus Delta K, para K variando de 1 para 10 (Figura 3b). Novamente os acessos de P. edulis foram colocados em dois grupos, os acessos de $P$. setacea foram separados em um terceiro grupo, enquanto os acessos de $P$. nitida, $P$. quadrangularis, $P$. alata e $P$. maliformis formaram um quarto grupo. Todos os acessos foram colocados em um a quatro grupos com um valor para $\mathrm{Q}$ de $\geq 70$, com exceção do BRS Maracujá Jaboticaba (acesso e11), o que apresentou um perfil misturado ou intermediário.

(a)
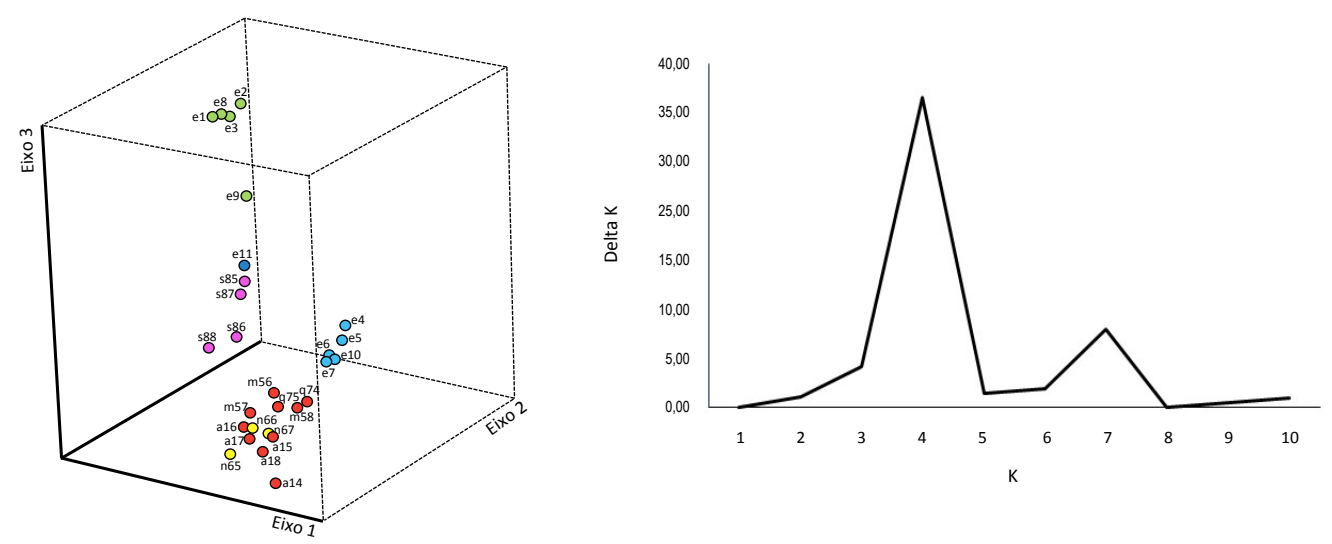

(c)

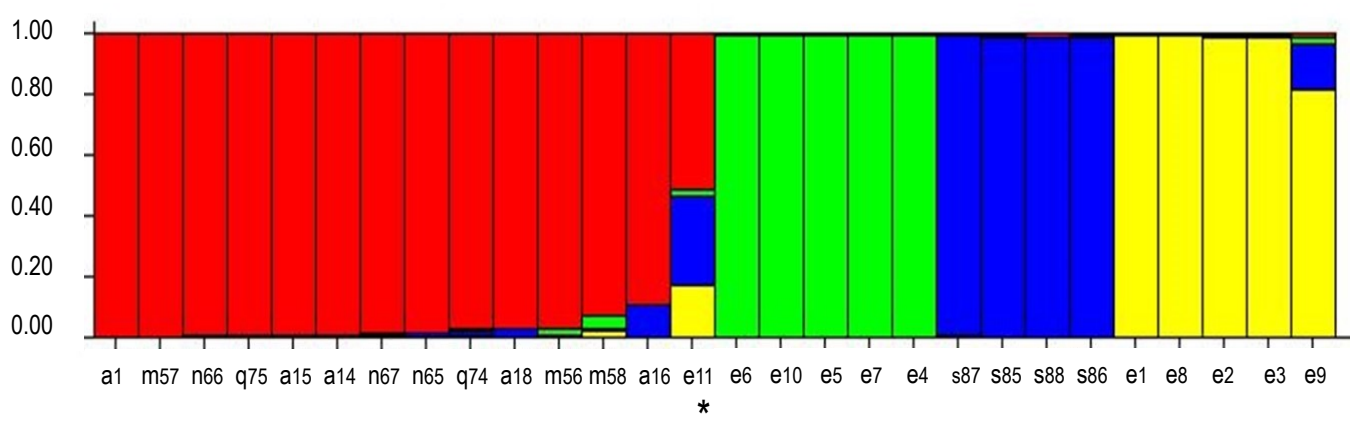

Figura 3. (a) Análises das coordenadas principais de 28 acessos de Passiflora pertencentes a seis espécies de maracujazeiro relacionadas com base no polimorfismo de microssatélites. As amostras foram identificadas segundo o número de acesso da Tabela 1, precedido pela inicial: P. edulis (amostras e1 até e11); P. alata (amostras a14 até a18); P. maliformis (amostras m56 até m58); P. nitida (amostras n65 até n67) e P. setacea (amostras s85 até s88); (b) Plotagem dos valores de K vs Delta K para 
definir o número mais provável de grupos nas análises de estrutura da população e ancestralidade de 28 acessos de Passiflora sem nenhuma atribuição prévia de espécie; (c) os acessos de Passiflora foram separados por grupos com base nos valores de Q $(\mathrm{Q}>0,70)$ para $\mathrm{K}=4$. As amostras misturadas ou intermédias foram identificadas com asterisco.

A maioria dos marcadores microssatélites de $P$. edulis e outras espécies de Passiflora tem sido obtidas mediante o sequenciamento de bibliotecas enriquecidas com regiões de sequências simples repetidas (CAZÉ et al., 2012; CERQUEIRASILVA et al., 2012, 2014b; OLIVEIRA, 2006; OLIVEIRA et al., 2005; PADUA et al., 2005; PENHA et al., 2013). Existem, apenas, aproximadamente 200 marcadores microssatélites di-nucleotídeos disponíveis para $P$. edulis (CERQUEIRA-SILVA et al., 2014b; OLIVEIRA, 2006; OLIVEIRA et al., 2005). Nesse trabalho foi descrito o eficiente uso da tecnologia NGS, que além de obter uma grande quantidade de dados sequenciados mediante a aplicação de ferramentas de bioinformática, permitiu a geração de 816 marcadores microssatélites para a espécie.

A maioria dos marcadores microssatélites desenvolvidos para $P$. edulis detectaram baixo polimorfismo, variando entre 15\% (CERQUEIRA-SILVA et al., 2014b) a 24,7\% (OLIVEIRA, 2006). Esses resultados tem sido interpretados como evidência de baixa diversidade genética em P. edulis (CERQUEIRA-SILVA et al., 2012, 2014b), contrastando com a alta diversidade morfológica (CROCHEMORE; MOLINARI; STENZEL, 2003) e agronômica (CERQUEIRA-SILVA et al., 2008; MELETTI; SOARES-SCOTT; BERNACCI, 2005) observada na espécie. Com o intuito de verificar quão polimórfico era o novo conjunto de marcadores microssatélites, foi testada uma amostra de 60 marcadores em dez acessos de $P$. edulis coletados em diferentes regiões do Brasil e estimados os parâmetros genéticos como Ho, PIC e número de alelos. Aproximadamente $74 \%$ dos marcadores de di e trinucleotídeos que apresentaram fragmentos amplificados foram polimórficos, onde o PIC, Ho e o número de alelos foram altos. Os valores do PIC para 80,9\% (38/47) dos marcadores de di-nucleotídeos variaram entre 0,26 e 0,77 , e para o $40 \%(4 / 10)$ dos marcadores de tri-nucleotídeos entre 0,30 e 0,50. Utilizando fingerprinting de DNA baseado em somente dois marcadores (BrPe0028 e BrPe0032), poderíamos discriminar todos os acessos de $P$. edulis utilizados no presente estudo. Essas estimativas são similares aos valores encontrados para outras espécies alógamas onde 
a tecnologia NGS foi utilizada no desenvolvimento de marcadores microssatélites, como é o caso da forrageira Brachiaria ruziziensis (SILVA et al., 2013) ou do rabanete Raphanus sativus (ZHAI et al., 2014). Portanto, não foi achada evidência de baixo polimorfismo dos microssatélites em $P$. edulis mediante a avaliação do novo conjunto de marcadores microssatélites. Muito pelo contrário, a maioria dos marcadores testados foi altamente polimórfico. É possível que o baixo polimorfismo encontrado em $P$. edulis nos estudos prévios com marcadores microssatélites deve ter ocorrido por causa de parentesco genético nas amostras de maracujazeiro utilizadas nos testes, ou simplesmente porque os marcadores testados foram localizados em regiões mais conservadas do genoma de maracujazeiro-azedo.

Marcadores microssatélites perfeitos representam somente uma fração (aproximadamente 10\%) do número de marcadores disponíveis, até agora, para $P$. edulis. A ampla maioria é de marcadores com motivos compostos ou imperfeitos, os que são difíceis de interpretar em trabalhos de genotipagem de rotina devido à dificuldade na binagem dos alelos (DOMANIÇ; PREPARATA, 2007; LIM et al., 2013). Além disso, na maioria dos estudos em P. edulis, marcadores microssatélites tem sido baseados na discriminação alélica em géis de agarose (CASTRO, 2012; PAIVA et al., 2014) ou poliacrilamida (CERQUEIRA-SILVA et al., 2014b, 2015, OLIVEIRA et al., 2005, 2008; ORTIZ et al., 2012), o que adiciona ainda mais desafios na análise de marcadores microssatélites compostos e imperfeitos. Isso pode ser um obstáculo para algumas aplicações, especialmente em estudos genéticos de populações (MA; RÖDER; SORRELLS, 1996). Todos os novos marcadores estão baseados na repetição do mesmo motivo de nucleotídeo sem interrupção ou variação, o que facilita a análise genética.

Foram testados os novos marcadores microssatélites de P. edulis em outras 78 espécies. A porcentagem de transferibilidade em outras espécies do subgênero Passiflora foi alta $(75,4 \%)$, similar a Distephana $(71,11 \%)$. Mas, diminuiu nas espécies do gênero Astrophea (63,33) e Decaloba (59,72\%). OLIVEIRA et al. (2013) obtiveram resultados similares para transferibilidade de marcadores microssatélites de P. edulis para o subgênero Passiflora (>73\%) e Decaloba (54\%). É interessante notar que o produto da amplificação da PCR de P. edulis foi obtido para pelo menos $50 \%$ dos marcadores testados em todos os 90 acessos de outras espécies de Passiflora, com exceção de P. pohlii (Decaloba) e P. sclerophylla (Astrophea). Isso indica que uma proporção substancial dos novos marcadores microssatélites de P. edulis pode, 
potencialmente, ser usada em estudos genéticos de um amplo número de espécies de Passiflora.

Uma análise combinada de 28 acessos de seis espécies de Passiflora ( $P$. edulis, $P$. alata, $P$. maliformis, $P$. nitida, $P$. quadrangularis e $P$. setacea) utilizando os novos marcadores microssatélites demostrou ser eficiente na descoberta de diversidade genética em maracujazeiro. $P$. edulis formou dois grupos que podem ser facilmente separados dos acessos de outras espécies. Esses acessos de P. edulis foram obtidos em diferentes regiões do Brasil, mas não foi achada correlação genética entre os grupos e a origem geográfica (dados não apresentados). Porém, um dos grupos está composto por acessos de maracujazeiro-azedo (Tabela 1, acessos 1-3 e 8), os que têm sido utilizados comercialmente (ex. acessos Maguary, CPGA1 e CPMSC1) e possivelmente derivados de populações de ancestralidade comum (MONTEIRO et al., 2010; OLIVEIRA, 2006). O acesso 8 (Criciúma, Santa Catarina) foi originalmente coletado em uma área próxima de pomares de Passiflora, e seus frutos pôdem ter sido derivados de polinização cruzada com cultivares comerciais. Embora o acesso BRS Maracujá Jaboticaba seja classificado como P. edulis (Tabela 1, acesso 11) ele não foi agrupado dentro dos dois grupos de $P$. edulis. BRS Maracujá Jaboticaba parece estar associado ao terceiro grupo formado pelos acessos de $P$. setacea (Figura 3a), apesar da probabilidade estimada de inclusão dentro de esse grupo ser baixa $(\mathrm{Q}=0,52)$ (Figura 3c). Análises do modo de reprodução de BRS Maracujá Jaboticaba no Capítulo 2, indicam que a cultivar é autocompatível apresentando altos níveis de autogamia, enquanto a maioria dos acessos são alógamos, o que poderia explicar a distância genética com os outros acessos de maracujazeiro-azedo. Análises adicionais relacionadas aos diferentes modos de reprodução e à plasticidade do sistema reprodutivo na diversidade genética de $P$. edulis devem ser realizados.

O quarto grupo incluiu acessos de $P$. nitida, $P$. quadrangularis, $P$. alata e $P$. maliformis. Análises moleculares de filogenia em espécies de Passiflora utilizando polimorfismo de nrITS, trnL-trnF e rps4 agrupou $P$. alata, $P$. quadrangularis, $P$. maliformis, $P$. setacea e $P$. edulis (MUSCHNER et al., 2003). Análises de DNA plastidial também encontraram que $P$. alata, $P$. nitida, $P$. edulis e $P$. maliformis estão proximamente relacionadas (HANSEN et al., 2006). PAIVA et al. (2014), utilizando os marcadores microssatélites de OLIVEIRA (2006) e PADUA et al. (PADUA et al., 2005 ) encontraram similaridade molecular entre $P$. edulis e $P$. setacea. De fato, a filogenia em Passiflora é muito complexa, com mais de 520 espécies distribuídas em 
vários continentes. Marcadores microssatélites podem ajudar a entender os relacionamentos genéticos dentro das espécies e entre os acessos de espécies próximas.

A pressão antrópica em centros de diversidade está contribuindo para a erosão genética de muitas plantas, incluindo Passiflora (FERREIRA, 2005; MYERS et al., 2000; RODRIGUES et al., 2009). Conservação in situ da flora nativa, assim como os esforços na coleta de espécies silvestres, populações crioulas e variedades locais de maracujazeiro para sua conservação ex situ são necessárias para seu uso atual como no futuro.

A viabilidade de sementes a curto prazo segue sendo uma importante limitação na conservação (DOBSON; BRADSHAW; BAKER, 1997; KHURANA, E.;SINGH, 2001) e a maioria das coleções dependem da propagação vegetativa para seu armazenamento. É um desafio manter um grande número de acessos de maracujazeiro mediante propagação vegetativa na coleção de germoplasma com as restrições de recursos humanos e financeiros. Como a propagação vegetativa é a principal maneira de conservação, cada acesso de maracujazeiro é composto por uma ou poucas plantas por espécie ou variedade, colocando limites para a conservação da diversidade genética ex situ. Atividades de rotina na conservação do germoplasma e melhoramento requerem aplicação de tecnologia genômica, incluindo marcadores microssatélites, na conservação e uso dos recursos genéticos do maracujazeiro.

\section{CONCLUSÕES}

A tecnologia NGS foi utilizada para a obtenção de uma grande quantidade de sequências genômicas, as quais foram aplicadas no desenvolvimento de centenas de marcadores microssatélites para $P$. edulis. Os novos marcadores detectaram altos níveis de polimorfismo em $P$. edulis e podem ser utilizado para avaliar a diversidade genética em acessos de maracujazeiro-azedo e em espécies próximas. A porcentagem de transferibilidade dos marcadores microssatélites desenvolvidos variou entre $33 \%$ e 89\% para 78 espécies de Passiflora pertencentes a quatro subgêneros (Passiflora, Distephana, Astrophea e Decaloba). Dessa forma, vários marcadores microssatélites de $P$. edulis podem ser utilizados potencialmente em análises genética em outras espécies do gênero Passiflora. Esse novo conjunto de marcadores microssatélites 
pode ser prontamente utilizado em muitas aplicações na conservação de germoplasma, programas de melhoramento e estudos genéticos do maracujazeiro.

\section{REFERÊNCIAS BIBLIOGRÁFICAS}

ABDELKRIM, J.; ROBERTSON, B. C.; STANTON, J.; GEMMELL, N. Fast, costeffective development of species-specific microsatellite markers by genomic sequencing. BioTechniques, v. 46, n. 3, p. 185-92, 2009.

ABREU, S. P. M.; PEIXOTO, J. R.; VILELA, N. T.; FIGUEREIDO, M. A. Características agronômicas de seis genótipos de maracujazeiro-azedo cultivados no Distrito Federal. Revista Brasileira de Fruticultura, v. 31, n. 3, p. 920-924, 2009.

BELlON, G.; FALEIRO, F. G.; JUNQUEIRA, K. P.; JUNQUEIRA, N. T. V.; SANTOS, E. C.; BRAGA, M. F.; GUIMARÃES, C. T. Variabilidade genética de acessos silvestres e comerciais de Passiflora edulis Sims. com base em marcadores RAPD. Revista Brasileira de Fruticultura, v. 29, n. 1, p. 124-127, 2007.

BRONDANI, R. P. V. BRONDANI, C.; TARCHINI, R.; GRATTAPAGLIA, D. Development, characterization and mapping of microsatellite markers in Eucalyptus grandis and E. urophylla. Theoretical and Applied Genetics, v. 97, n. 5-6, p. 816$827,1998$.

CASTOE, T. A.; POOLE, A. W.; KONING, A. P. J.; JONES, K.; TOMBACK, D. F.; OYLER-MCCANCE, S. J.; FIKE, J. A.; LANCE, S. L.; STREICHER, J. W.; SMITH, E. N.; POLLOCK, D. D. Rapid identification of thousands of copperhead snake (Agkistrodon contortrix) microsatellite loci from modest amounts of 454 shotgun genome sequence. Molecular Ecology Resources, v. 10, n. 2, p. 341-7, 2010.

CASTRO, J. Conservação dos recursos genéticos de Passiflora e seleção de descritores mínimos para caracterização de maracujazeiro. Universidade Federal do Recôncavo da Bahia, 2012. 
CAZÉ, A. L. R.; KRIEDT, R. A.; BEHEREGARAY, L. B.; BONATTO, S. L.; FREITAS, L. B. Isolation and Characterization of Microsatellite Markers for Passiflora contracta. International Journal of Molecular Science, v. 13, n. 9, p. $11343-8,2012$.

CERQUEIRA-SILVA, C. B.; SANTOS, E. S . L.; SOUZA, A. M.; MORI, G. M.; OLIVEIRA, E. J.; CORREAA, R. X.; SOUZA, A. P. Development and characterization of microsatellite markers for the wild South American Passiflora cincinnata (Passifloraceae). American Journal of Botany, v. 99, n. 4, p. e170-2, 2012.

CERQUEIRA-SILVA, C. B.; JESUS, O. N.; SANTOS, E. S. L.; CORRÊA, R. X.; SOUZA, A. P. Genetic Breeding and Diversity of the Genus Passiflora: Progress and Perspectives in Molecular and Genetic Studies. International Journal of Molecular Sciences, v. 15, n. 8, p. 14122-14152, 2014a.

CERQUEIRA-SILVA, C. B.; SANTOS, E. S. L.; VIEIRA, J. G. P.; MORI, G. M.; JESUS, O. N.; CORRÊA, R. X.; SOUZA, A. P. New Microsatellite Markers for Wild and Commercial Species of Passiflora (Passifloraceae) and Cross-Amplification. Applications in Plant Sciences, v. 2, n. 2, p. 1300061, 2014b.

CERQUEIRA-SILVA, C. B. M.; MOREIRA, C. N.; FIGUEIRA, A. R.; CORRÊA, R. X.; OLIVEIRA, A. C. Detection of a resistance gradient to Passion fruit woodiness virus and selection of "yellow" passion fruit plants under field conditions. Genetics and Molecular Research, v. 7, n. 4, p. 1209-1216, 2008.

CERQUEIRA-SILVA, C. B. M.; JESUS, O. N.; OLIVEIRA, E. J.; SANTOS, E. S. L.; SOUZA, A. P. Characterization and selection of passion fruit (yellow and purple) accessions based on molecular markers and disease reactions for use in breeding programs. Euphytica, v. 202, n. 3, p. 345-359, 2015.

CROCHEMORE, M. L.; MOLINARI, H. B. C.; VIEIRA, L. G. E. Genetic Diversity in Passion Fruit (Passiflora spp.) Evaluated by RAPD Markers. Brazilian Archives of Biology and Technology, v. 46, n. 4, p. 521-527, 2003. 
CROCHEMORE, M. L.; MOLINARI, H. B.; STENZEL, N. M. C. Caracterização agromorfológica do maracujazeiro (Passiflora spp.). Revista Brasileira de Fruticultura, v. 25, n. 1, p. 5-10, 2003.

CSENCSICS, D.; BRODBECK, S.; HOLDEREGGER, R. Cost-Effective, SpeciesSpecific Microsatellite Development for the Endangered Dwarf Bulrush (Typha minima) Using Next-Generation Sequencing Technology. Journal of Heredity, v. 101, n. 6, p. 789-793, 2010.

DOBSON, A. P.; BRADSHAW, A. D.; BAKER, A. J. M. Hopes for the Future: Restoration Ecology and Conservation Biology. Scandinavian Journal of Statistics, v. 277, p. 515-522, 1997.

DOMANIÇ, N. O.; PREPARATA, F. P. A novel approach to the detection of genomic approximate tandem repeats in the levenshtein metric. Journal of Computational Biology, v. 14, n. 7, p. 873-891, 2007.

DOYLE, J.; DOYLE, J. L. Genomic plant DNA preparation from fresh tissue-CTAB method. Phytochem Bull, v. 19, n. 11, p. 11-15, 1987.

EVANNO, G.; REGNAUT, S.; GOUDET, J. Detecting the number of clusters of individuals using the software STRUCTURE: a simulation study. Molecular Ecology, v. 14, n. 8, p. 2611-2620, 2005.

FAJARDO, D.; ANGEL, F.; GRUM, M.; TOHME, J.; LOBO, M.; ROCA, W. M. Genetic variation analysis of the genus Passiflora L. using RAPD markers. Euphytica, v. 101, p. 341-347, 1998.

FALEIRO, F. G.; FALEIRO, A. S. G.; CORDEIRO, M. C. R.; KARIA, C. T. Metodologia para operacionalizar a extração de DNA de espécies nativas do cerrado. Comunicado Téncnico. Planaltina, DF: Embrapa Cerrados, 2003.

FERREIRA, F. Recursos genéticos de Passiflora. In: FALEIRO, F. G.; JUNQUEIRA, N. T. V.; BRAGA, M. F. (Eds.). Maracujá: germoplasma e melhoramento 
genético. Planaltina, DF: Embrapa Cerrados, 2005. p. 41-52.

FERREIRA, F. R.; OLIVEIRA, J. C. Germoplasma de Passiflora no Brasil. In: SÃO JOSÉ, A. R. (Ed.). A cultura do maracujá no Brasil. Jaboticabal: FUNEP, 1991. p. 187-200.

FONSECA-TRUJILLO, N.; MÁRQUEZ-CARDONA, M. P.; MORENO-OSORIO, J. H.; TERÁN-PÉREZ, W.; SCHULER-GARCÍA, I. Caracterización molecular de materiales cultivados de gulupa (Passiflora edulis f. edulis). Universitas Scientiarum, v. 14, p. 135-140, 2009.

GOLDSTEIN, D. B.; CLARK, A. G. Microsatellite variation in North American populations of Drosophila melanogaster. Nucleic Acids Research, v. 23, n. 19, p. 3882-3886, 1995.

GUIGÓ, R.; KNUDSEN, S.; DRAKE, N.; SMITH, T. Prediction of gene structure. Journal of Molecular Biology, v. 226, n. 1, p. 141-157, 1992.

HANSEN, A. K.; GILBERT, L. E.; SIMPSON, B. B.; DOWNIE, S.; CERVI, A. C.; JANSEN, R. K. Phylogenetic Relationships and Chromosome Number Evolution in Passiflora. Systematic Botany, v. 31, n. 1, p. 138-150, 2006.

HOLLELEY, C. E.; GEERTS, P. G. Multiplex Manager 1.0: a cross-platform computer program that plans and optimizes multiplex PCR. BioTechniques, v. 46, n. 7, p. 511-517, 2009.

KHURANA, E.; SINGH, J. S. Ecology of seed and seedling growth for conservation and restoration of tropical dry forest : a review. Environmental Conservation, v. 28, n. 1, p. 39-52, 2001.

LI, R.; LI. Y.; KRISTIANSEN, K.; WANG, J. SOAP: Short oligonucleotide alignment program. Bioinformatics, v. 24, n. 5, p. 713-714, 2008.

LIM, K. G.; KWOH, C. K.; HSU, L. Y.; WIRAWAN, A. Review of tandem repeat 
search tools: A systematic approach to evaluating algorithmic performance. Briefings in Bioinformatics, v. 14, n. 1, p. 67-81, 2013.

LITT, M.; LUTY, J. A. A Hypervariable Microsatellite Revealed by In Vitro Amplification of a Dinucleotide Repeat within the Cardiac Muscle Actin Gene. American Journal of Human Genetics, v. 44, p. 397-401, 1989.

LYNCH, M. The similarity index and DNA fingerprinting. Molecular Biology and Evolution, v. 7, n. 5, p. 478-84, 1990.

MA, Z. Q.; RÖDER, M.; SORRELLS, M. E. Frequencies and sequence characteristics of di-, tri-, and tetra-nucleotide microsatellites in wheat. Genome, v. 39, n. 1, p. 123-30, 1996.

MACDOUGAL, J.; FEUILLET, C. Systematics. In: ULMER, T.; MACDOUGAL, J. (Eds.). Passiflora: Passionflowers of the World. Portland, OR, USA: Timber Press, 2004. p. 27-31.

MARSHALL, T. C.; SLATE, J.; KRUUK, L. E. B.; PEMBERTON, J. M. Statistical confidence for likelihood-based paternity inference in natural populations. Molecular Ecology, v. 7, p. 639-655, 1998.

MATSCHINER, M.; SALZBURGER, W. TANDEM: Integrating automated allele binning into genetics and genomics workflows. Bioinformatics, v. 25, n. 15, p. 19821983, 2009.

MAYER, C. Phobos 3.3.11 edn., 2006-2010.

MELETTI, L. M. M.; SOARES-SCOTT, M. D.; BERNACCI, L. C. Caracterização fenotípica de três seleções de maracujazeiro-roxo (Passiflora edulis Sims). Revista Brasileira de Fruticultura, v. 27, n. 2, p. 268-272, 2005.

MONTEIRO, S. R.; FONSECA, L. P.; SILVA, M. S.; FALEIRO, F. G.; JUNQUEIRA, N. T. V. Estudos preliminares para o uso de termoterapia ex vitro 
em maracujazeiro-azedo visando à eliminação de vírus-do-endurecimento-dosfrutos. Embrapa Cerrados. Planaltina, DF. 2010. p. 18

MUSCHNER, V. C.; LORENZ, A. P.; CERVI, A. C.; BONATTO, S. C.; SOUZACHIES, T. T.; SALZANO, F. M.; FREITAS, L. B. A first molecular phylogenetic analysis of Passiflora (Passifloraceae). American Journal of Botany, v. 90, n. 8, p. 1229-1238, 2003.

MYERS, N.; MITTERMEIER, R. A.; MITTERMEIER, C. G.; FONSECA, G. A. B.; KENT, J. Biodiversity hotspots for conservation priorities. Nature, v. 403, n. 6772, p. 853-858, 2000.

OCAMPO, J.; D'EECKENBRUGGE, G.; JARVIS, A. Distribution of the genus Passiflora L. diversity in Colombia and its potential as an indicator for biodiversity management on the coffee growing zone. Diversity, v. 2, p. 1158-1180, 2010.

OLIVEIRA, E. J.; PÁDUA, J. G.; ZUCCHI, M. I.; CAMARGO, L. E. A.; FUNGARO, M. H. P.; VIEIRA, M. L. C. Development and characterization of microsatellite markers from the yellow passion fruit (Passiflora edulis f. flavicarpa). Molecular Ecology Notes, v. 5, n. 2, p. 331-333, 2005.

OLIVEIRA, E. J. Desenvolvimento e uso de marcadores microssatélites para construção e integração de mapas genéticos de maracujá-amarelo (Passiflora edulis Sims f . flavicarpa Deg.). Universidade de São Paulo, 2006.

OLIVEIRA, E. J.; VIEIRA, M. L.; GARCIA, A. A. F.; MUNHOZ, C. F.; MARGARIDO, G. R. A.; CONSOLI, L.; MATTA, F. P.; MORAES, M. C.; BOX, P. O.; ZUCCHI, M. I.; FUNGARO, M. H. P. An Integrated Molecular Map of Yellow Passion Fruit Based on Simultaneous Maximum-likelihood Estimation of Linkage and Linkage Phases. Journal of the American Society for Horticultural Science, v. 133, n. 1, p. 35-41, 2008.

OLIVEIRA, G. A. F.; PÁDUA, J. G.; COSTA, J. L.; JESUS, O. N.; CARVALHO, F. M.; OLIVEIRA, E . J. Cross-species Amplification of Microsatellite Loci Developed 
for Passiflora edulis Sims. in Related Passiflora Species. Brazilian Archives of Biology and Technology, v. 56, p. 785-792, 2013.

ORTIZ, D. C.; BOHÓRQUEZ, A.; DUQUE, M. C.; TOHME, J.; CUÉLlAR, D.; MOSQUERA, T. Evaluating purple passion fruit (Passiflora edulis Sims f. edulis) genetic variability in individuals from commercial plantations in Colombia. Genetic Resources and Crop Evolution, v. 59, n. 6, p. 1089-1099, 2012.

PADUA, J. G.; OLIVEIRA, E. J.; ZUCCHI, M. I.; OLIVEIRA, G. C. X.; CAMARGO, L. E. A.; VIEIRA, M. L. C. Isolation and characterization of microsatellite markers from the sweet passion fruit (Passiflora alata Curtis: Passifloraceae). Molecular Ecology Notes, v. 5, n. 4, p. 863-865, 2005.

PAIVA, C., VIANA, A. P.; SANTOS, E. A.; FREITAS, J. C. O.; SILVA, R. N. O.; OLIVEIRA, E. J. Genetic variability assessment in the genus Passiflora by SSR marker. Chilean Journal of Agricultural Research, v. 74, n. 3, p. 355-360, 2014.

PENHA, H. A.; PEREIRA, G. S.; ZUCCHI, M. I.; DINIZ, A. L.; VIEIRA, M. L. C. Development of microsatellite markers in sweet passion fruit, and identification of length and conformation polymorphisms within repeat sequences. Plant Breeding, v. 132, n. 6, p. 731-735, 2013.

PLOTZE, R. O.; FALVO, M.; PÁDUA, J. G.; BERNACCI, L. C.; VIEIRA, M. L. C.; OLIVEIRA, G. C. X.; BRUNO, O. M. Leaf shape analysis using the multiscale Minkowski fractal dimension, a new morphometric method: A study with Passiflora (Passifloraceae). Canadian Journal of Botany, v. 83, p. 287-301, 2005.

POWELL, W.; MORGANTE, M.; ANDRE, C.; HANAFEY, M.; VOGEL, J.; TINGEY, S.; RAFALSKI, A. The comparision of RFLP, RAPD, AFLP and SSR (microsatellite) markers for germplasm analysis. Molecular Breeding, v. 13, p. 391393, 1996.

PRITCHARD, J. K.; STEPHENS, M.; DONNELLY, P. Inference of Population Structure Using Multilocus Genotype Data. Genetics, v. 155, n. 2, p. 945-959, 2000. 
PRITCHARD, J. K.; WEN, X.; FALUSH, D. Documentation for structure software: Version 2.3, Chicago, IL. University of Chicago, 2010.

REIS, R. V.; OLIVEIRA, E. J.; VIANA, A. P.; PEREIRA, T. B. S.; PEREIRA, M. G.; SILVA, M. G. M. Diversidade genética em seleção recorrente de maracujazeiro amarelo detectada por marcadores microssatélites. Pesquisa Agropecuária Brasileira, v. 46, n. 1, p. 51-57, 2011.

RENDÓN, J. S.; OCAMPO, J.; URREA, R. Estudio sobre polinización y biología floral en Passiflora edulis f. edulis Sims, como base para el premejoramiento genético. Acta Agronómica, v. 62, n. 3, p. 232-241, 2013.

RODRIGUES, R. R.; LIMA, R. A. F.; GANDOLFI, S.; NAVE, A. G. On the restoration of high diversity forests: 30 years of experience in the Brazilian Atlantic Forest. Biological Conservation, v. 142, n. 6, p. 1242-1251, 2009.

ROHLF, F. Numerical taxonomy and multivariate analysis system (NTSYS-pc). New York, Departament of Ecology and Evolution, 1990.

SANTOS, L. F. et al. ISSR markers as a tool for the assessment of genetic diversity in Passiflora. Biochemical genetics, v. 49, n. 7-8, p. 540-54, 2011.

SEGURA, S.; D'EECKENBRUGGE, G. C.; BOHORQUEZ, A.; OLLITRAUTL, P.; TOHME, J. An AFLP diversity study of the genus Passiflora focusing on subgenus Tacsonia. Genetic Resources and Crop Evolution, v. 00, p. 1-10, 2002.

SILVA, P. I.; MARTINS, A. M.; GOUVEA, E. G.; PESSOA-FILHO, M.; FERREIRA, M. E. Development and validation of microsatellite markers for Brachiaria ruziziensis obtained by partial genome assembly of Illumina single-end reads. BMC Genomics, v. 14, n. 1, p. 17, 2013.

SOUZA, M. M.; PALOMINO, G.; PEREIRA, T. N. S.; PEREIRA, M. G.; VIANA, A. P. Flow cytometric analysis of genome size variation in some Passiflora species. 
Hereditas, v. 141, p. 31-38, 2004.

UNTERGASSER, A.; NIJVEEN, H.; RAO, X.; BISSELING, T.; GEURTS, R.; LAUNISSEN, J. A. M. Primer3Plus, an enchanced web interface to Primer3. Nucleic Acids Research, v. 35, p. W71-W74, 2007.

VIANA, A. J. C.; SOUZA, M. M.; ARAÚJO, I. S.; CORRÊA, R. X.; AHNERT, D. Genetic diversity in Passiflora species determined by morphological and molecular characteristics. Biologia Plantarum, v. 54, n. 3, p. 535-538, 2010.

ZERBINO, D. R.; BIRNEY, E. Velvet: Algorithms for de novo short read assembly using de Bruijn graphs. Genome Research, v. 18, n. 5, p. 821-829, 2008.

ZHAI, L.; XU, L.; WANG, Y.; CHENG, H.; CHEN, Y.; GONG, Y.; LIU, L. Novel and useful genic-SSR markers from de novo transcriptome sequencing of radish (Raphanus sativus L.). Molecular Breeding, v. 33, n. 3, p. 611-624, 2014. 
CAPÍTULO 2. ESTIMATIVA DAS TAXAS DE AUTOGAMIA E ALOGAMIA NA CULTIVAR BRS MARACUJÁ JABOTICABA DE

Passiflora edulis Sims UTILIZANDO MARCADORES MICROSSATÉLITES

CHAPTER 2. ESTIMATED RATES OF AUTOGAMY AND ALOGAMY IN THE CULTIVAR BRS MARACUJÁ JABOTICABA OF Passiflora edulis Sims USING MICROSATELLITE MARKERS 


\section{RESUMO}

Maracujazeiro-azedo (Passiflora edulis Sims) possui flores hermafroditas, mas, de maneira geral, elas são incapazes de produzir zigotos após autopolinização devido à autoincompatibilidade. Pelo contrário, observações em relação ao modo de reprodução da cultivar BRS Maracujá Jaboticaba (BRS MJ) evidenciaram a autocompatibilidade, mas ainda não foram publicados dados conclusivos sobre o modo de reprodução dessa cultivar. Neste trabalho, foram estimadas as taxas de autogamia e alogamia na cultivar BRS MJ utilizando 16 marcadores microssatélites polimórficos. Frutos provenientes de três plantas com polinização aberta e de uma planta com polinização controlada (autofecundação), deram origem a quatro progênies de 21 a 23 indivíduos cada uma. Amostras de DNA de cada um dos indivíduos foram extraídas e genotipadas para obtenção de fragmentos amplificados. Autogamia e alogamia foram estimadas com base na taxa de cruzamento multiloco $\left(t_{m}\right)$. Nas três progênies obtidas a partir da polinização aberta, a taxa de cruzamento multiloco variou entre 0,409 e 0,566 , evidenciando o modo de reprodução misto por meio da autogamia e alogamia. Na progênie obtida a partir da autofecundação, a autogamia foi de 99,99\% confirmando autocompatibilidade na cultivar BRS MJ. Análises de variabilidade genética da cultivar BRS MJ em relação ao outros acessos da espécie $P$. edulis com base em marcadores microssatélites, mostraram uma clara diferenciação entre elas, corroborando as diferenças fenotípicas e diferentes modos de reprodução.

Palavras-chave: Passiflora edulis Sims, maracujá-roxo, modo de reprodução, microssatélites, autocompatibilidade, autofecundação 


\begin{abstract}
Different cultivars of passion fruit (Passiflora edulis Sims) have hermaphrodite flowers, but, in general, cannot produce zygotes after selfing, due to because selfincompatibility. On the other hand, observations regarding the mating system of the cultivar BRS Maracujá Jaboticaba (BRS MJ) evidenced self-compatibility, but conclusive data has not been published. In this research, allogamy and autogamy rates were estimated for $P$. edulis cultivar BRS MJ by 16 polymorphic microsatellite markers. Fruits from three plants with open pollination and one plant with controlled pollination (selfing) have originated four populations with 21 to 23 individuals each. DNA samples from each individual were extracted and genotyped with microsatellite markers. Autogamy and allogamy were estimated based on multilocus outcrossing rates $\left(t_{m}\right)$. All three offspring obtained from open-pollinated, allogamy was confirmed with multilocus rate of 0.409 to 0.566 , that is an evidence of the mixed mating system through autogamy and allogamy. The offspring coming from selfing, autogamy was in $99.99 \%$ which confirms auto-compatibility on the BRS MJ cultivar. Analysis of genetic variability with BRS MJ and other accessions of the P. edulis species based on microsatellite markers showed a clear differentiation between them, corroborating the phenotypic differences and different mating system.
\end{abstract}

Keywords: Passiflora edulis, purple passion fruit, mating system, microsatellite, selfcompatibility, selfing 


\section{INTRODUÇÃO}

Numerosas são as espécies do gênero Passiflora que produzem frutos comestíveis, as que no Brasil são chamadas de maracujás. Dentro desse grupo, a espécie mais conhecida e de importância comercial é Passiflora edulis Sims (FALEIRO et al,, 2011; OCAMPO et al,, 2007), a que é chamada de maracujazeiroazedo. Seus frutos podem ser amarelos, vermelhos e roxos, os quais são utilizados para o processamento industrial e também para consumo in natura. O maracujazeiroamarelo é cultivado principalmente em Brasil, Equador e Colômbia e o maracujazeiro-roxo é mais cultivado na Austrália, África, no Sudeste Asiático e também na Colômbia. Maracujazeiro-roxo e amarelo são nativos da América tropical, onde o maracujazeiro-amarelo tem sido considerado como uma variação do maracujazeiro-roxo, sendo ambas as formas da mesma espécie (OLIVEIRA; RUGGIERO, 2005).

O maracujazeiro-roxo possui características físicas e organolépticas interessantes para o mercado de frutas especiais, mas a baixa produtividade e a falta de cultivares com características agronômicas desejáveis que se adaptem às diferentes áreas de produção vem limitando a produção comercial no Brasil (MELETTI; SOARES-SCOTT; BERNACCI, 2005)

Com o intuito de gerar uma cultivar de maracujazeiro-roxo mais adaptada às condições de produção no Cerrado o programa de melhoramento genético das Passifloras da Embrapa Cerrados, desenvolveu a cultivar BRS Maracujá Jaboticaba (BRS MJ), por meio da seleção massal, visando ao aumento de produtividade e aceitação comercial das características físicas e químicas dos frutos, e menor dependência da polinização manual. O programa de melhoramento começou com os primeiros ciclos de seleção e recombinação em 1999, utilizando acessos e populações silvestres de Passiflora edulis Sims. Entre 1999 e 2013, foram realizados seis ciclos de seleção massal e então selecionadas as matrizes superiores para a geração da nova cultivar, a qual apresenta flores pequenas, com diâmetro entre 3 e $5 \mathrm{~cm}$ com antese matutina, podendo estender-se durante o período da tarde, dependendo das condições climáticas. Possui comprimento do androginóforo curto $(0,5$ a $1,0 \mathrm{~cm})$ o que permite a polinização por pequenos insetos. Os frutos são roxos, arredondados e pequenos (diâmetros transversal de $45 \mathrm{~mm}$ e longitudinal de $43 \mathrm{~mm}$ ), com uma massa média de 40 gramas. Sua polpa é alaranjado clara, levemente ácida, com alto teor de sólidos 
solúveis totais (acima de $15^{\circ}$ Brix), especial para consumo in natura, o que a faz uma seleção muito atrativa para a diversificação do mercado das Passifloras.

Autocompatibilidade tem sido observada para a espécie $P$. edulis, principalmente para o maracujazeiro-roxo (CHANG, 1974, 1981; ISHIHATA, 1981; RÊGO, 1997), embora existam evidências que a autocompatibilidade também possa ocorrer em alguns acessos de maracujazeiro-amarelo (SHIVANNA, 2012). De maneira geral, considera-se que $P$. edulis é uma espécie autoincompatível (BRUCKNER et al., 1995). O mecanismo da autoincompatibilidade, segundo BRUCKNER et al., (1995), é do tipo homomórfica esporofítica, e de herança monofatorial porém, estudos posteriores de SUASSUNA et al. (2003), sugerem a existência de um gene de efeito gametofítico associado ao sistema esporofítico.

No gênero Passiflora a autocompatibilidade também tem sido observada em outras espécies, como Passiflora elegans, Passiflora tenuifila, Passiflora vilosa, Passiflora suberosa, Passiflora foetida (JUNQUEIRA et al., 2005), Passiflora capsularis e Passiflora rubra (AMORIM et al., 2011).

Até o momento, observações em relação ao modo de reprodução da cultivar BRS MJ evidenciaram a autocompatibilidade, mas ainda não foram publicados dados conclusivos sobre o modo de reprodução dessa cultivar. Pesquisas sobre o modo de reprodução em populações autocompatíveis são conduzidas por meio de diferentes metodologias, como o cálculo da porcentagem de frutificação obtida por polinização natural, autopolinização natural, autopolinização manual e polinização cruzada (ex. RENDÓN; OCAMPO; URREA, 2013; SHIVANNA, 2012). Segundo BAYE e BECKER (2004), a melhor maneira de calcular a taxa de alogamia, parâmetro fundamental para a estimação do modo de reprodução, é por meio do uso de marcadores moleculares aplicados em progênies de plantas.

Marcadores moleculares microssatélites têm sido usados amplamente para investigar os modos de reprodução em populações naturais, assim como em análise de paternidade e construção de mapas genéticos (CHASE; KESSELI; BAWA, 1996). Estes marcadores apresentam várias vantagens como a simplicidade, efetividade, abundância no genoma, hipervariabilidade, reprodutibilidade e herança codominante (LITT; LUTY, 1989; POWELL et al., 1996), além de apresentar altos níveis de polimorfismo e heterozigosidade esperada, sendo muito utilizados para entender em detalhe os padrões de composição de parentesco e para a discriminação individual na identificação de clones (COLLEVATTI; BRONDANI; GRATTAPAGLIA, 1999; DE 
LORENZIS et al., 2013; SCHUELER et al., 2003; VOUILLAMOZ; MAIGRE; MEREDITH, 2003).

Nesse trabalho, o objetivo principal foi estudar o modo de reprodução da cultivar BRS Maracujá Jaboticaba da espécie P. edulis utilizando marcadores microssatélites. Neste contexto, os marcadores microssatélites foram utilizados para (a) confirmar ocorrência de autofecundação, (b) determinar as taxas de autogamia e alogamia em diferentes plantas da cultivar e (c) avaliar se existem cruzamentos entre indivíduos aparentados de outras cultivares de maracujazeiro.

\section{MATERIAL E MÉTODOS}

\section{Material vegetal}

Foram escolhidas quatro plantas da cultivar BRS MJ (Figura 1) para a formação de quatro progênies. Duas plantas (P1RJ-RC e P2RJ-RC) cultivadas em um pomar comercial de BRS Rubi do Cerrado (P. edulis) plantado a 1,5 m x $2 \mathrm{~m}$ (Figura 2); uma planta (P3RJ-GA) cultivada em um pomar comercial misto de BRS Rubi do Cerrado, BRS Gigante Amarelo e BRS Sol do Cerrado (1,5 m x 2 m) (Figura 2). Os dois pomares estavam localizados em Planaltina do DF (15 $25^{\prime} 23^{\prime}$ S, $47^{\circ} 32^{\prime} 33^{\prime}$ ' W, 1039 m.s.n.m.). A quarta planta (P4RJ-CV) foi cultivada de forma isolada em uma casa de vegetação na Embrapa Cerrados, Planaltina do DF ( $5^{\circ} 35^{\prime} 30^{\prime \prime} \mathrm{S}, 47^{\circ} 42^{\prime} 30^{\prime}$ " W, 1100 m.s.n.m.).

Não foi controlada a polinização nas três plantas que se encontravam nos pomares, permitindo a polinização natural para testar alogamia e autogamia espontâneas. No caso da planta cultivada em casa de vegetação, foi realizada a autopolinização para avaliar a possibilidade de autofecundação. Após a frutificação, foi coletado um fruto por planta. As sementes de cada fruto foram germinadas em bandejas de poliestireno com um substrato de turfa, perlita e solo. Após 8 semanas, foram coletadas folhas para a extração de DNA. 


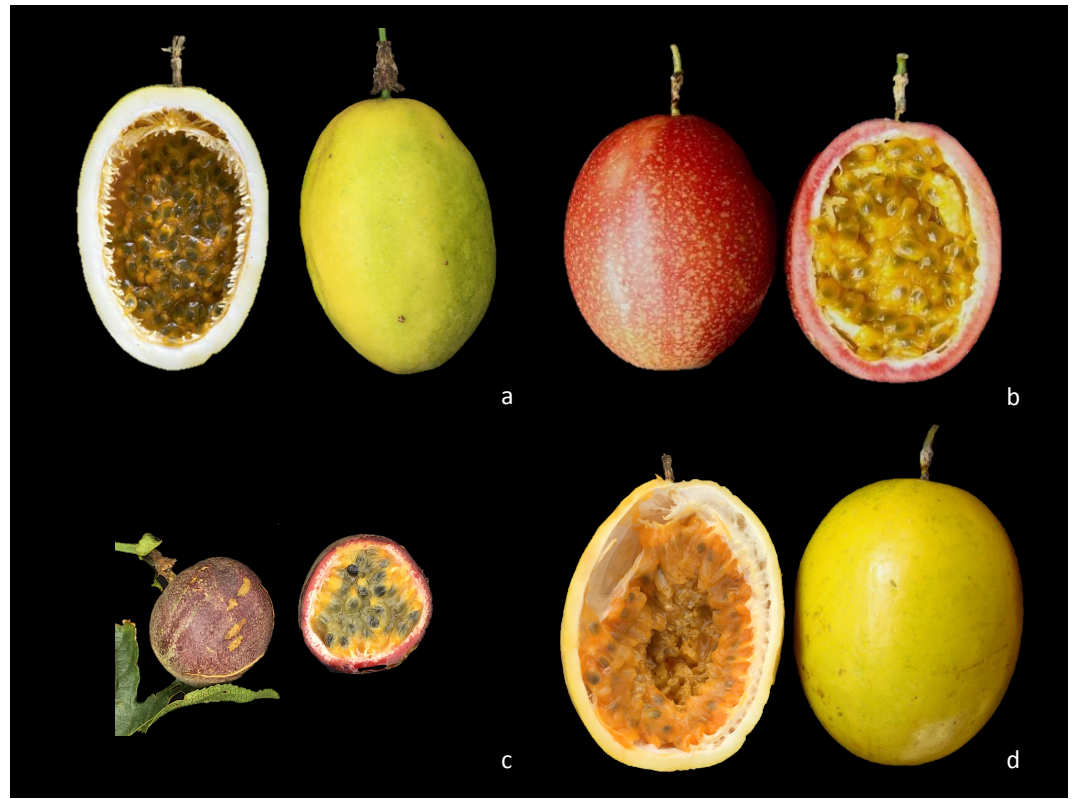

Figura 1. Imagem comparativa do tamanho e da cor dos frutos de três cultivares desenvolvidas pela Embrapa e parceiros, a) e b) BRS Rubi do Cerrado, c) BRS Maracujá Jaboticaba e d) BRS Gigante Amarelo.

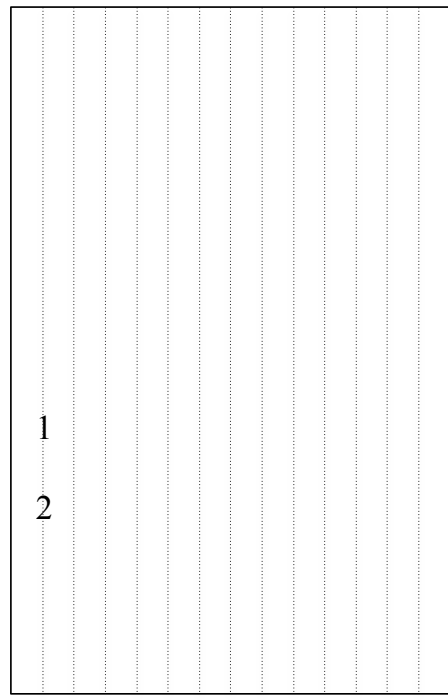

Pomar comercial BRS Rubi do Cerrado
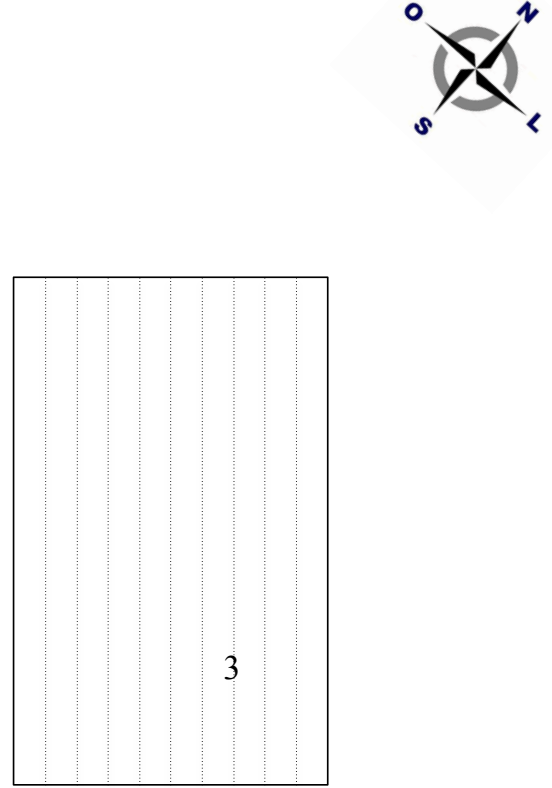

Pomar comercial misto

Figura 2. Croqui da distribuição das plantas de BRS Maracujá Jaboticaba (1) P1RJRC e (2) P2RJ-RC no pomar comercial de BRS Rubi do Cerrado, e (3) P3RJ-GA no pomar comercial misto de BRS Rubi do Cerrado, BRS Gigante Amarelo e BRS Sol do Cerrado. 


\section{Extração de DNA e genotipagem}

Amostras de DNA de cada uma das quatro plantas de P. edulis cv. BRS MJ e suas respectivas progênies (21 a 23 indivíduos por progênie) foram extraídas utilizando o método CTAB (DOYLE; DOYLE, 1987) com modificações de FALEIRO et al., (2003). A concentração de DNA de cada amostra foi estimada utilizando o espectofotômetro Nanodrop 2000 (Thermo Scientific, USA), e as amostras foram diluídas em TE $\mathrm{pH}$ 8,0 para uma concentração final de $5 \eta \mathrm{g} / \mu \mathrm{L}$. Foram testados 18 pares de primers de microssatélites polimórficos desenhados e validados para $P$. edulis no Capítulo 1 (Tabela 1$)$.

As reações em cadeia da polimerase (PCR) foram realizadas em um volume total de $5 \mu \mathrm{L}$ que continham $5 \eta \mathrm{g}$ de DNA genômico, $1 \mathrm{X}$ de QIAGEN Multiplex PCR Kit Master Mix (QIAGEN), 0,5X Q-Solution (QIAGEN), e 0,2 $\mu \mathrm{M}$ de cada primer. As reações de PCR foram realizadas no termociclador Veriti ${ }^{\mathrm{TM}}$ (Applied Biosystems, USA) usando o seguinte programa de amplificação: $95^{\circ} \mathrm{C}$ por 15 minutos; 35 ciclos a $94^{\circ} \mathrm{C}$ por 30 segundos, 55,57 ou $60^{\circ} \mathrm{C}$ por 90 segundos, e $72^{\circ} \mathrm{C}$ por 60 segundos; extensão final a $60^{\circ} \mathrm{C}$ por 60 minutos. Para $1 \mu \mathrm{L}$ do produto da amplificação de cada amostra, foram adicionados $9 \mu \mathrm{L}$ de $\mathrm{Hi}^{-D i}{ }^{\mathrm{TM}}$ Formamida (Applied Biosystems, USA) contendo um padrão de tamanho, marcado com o fluoróforo ROX, e então o DNA foi desnaturado a $94^{\circ} \mathrm{C}$ por 5 minutos. Após a desnaturação, as amostras foram injetadas no sequenciador automático ABI3730 (Applied Biosystems, USA). As análises de genotipagem foram realizadas no software GeneMapper ${ }^{\circledR}$ (Applied Biosystems, USA) e os dados foram binados no software Tandem (MATSCHINER; SALZBURGER, 2009).

\section{Estatísticas e análises de dados}

Foram estimados o número de alelos, a heterozigosidade esperada $(\mathrm{He}) \mathrm{e}$ observada (Ho), e o conteúdo de informação polimórfica (PIC) dos marcadores microssatélites em cada uma das quatro progênies utilizando o software Cervus v.3.0.3 (Tristan Marshall 1998-2014) (MARSHALL et al., 1998)

A herança Mendeliana dos locos de microssatélites foi analisada com o Teste

Exato de Fisher de 2x3 no software VassarStats (LOWRY, 2001-2016) [http://vassarstats.net/fisher2x3.html] que baseia-se no procedimento descrito por FREEMAN e HALTON (1951) para a obtenção da probabilidade da hipótese nula 
acontecer. Foi assumido que os locos heterozigotos em uma população autógama segregam em uma proporção 1:2:1.

O modo de reprodução foi analisado sob o modelo misto ou modelo de cruzamentos correlacionados (RITLAND, 1989) utilizado o software MLTR v.3.2 (RITLAND, 2002). Foram calculadas a taxa de cruzamento multiloco $\left(\boldsymbol{t}_{\boldsymbol{m}}\right)$, a taxa de cruzamento uniloco $\left(\boldsymbol{t}_{s}\right)$, a taxa de cruzamento entre indivíduos aparentados $\left(\boldsymbol{t}_{p}=\left(\boldsymbol{t}_{\boldsymbol{m}}\right.\right.$ $\left.\boldsymbol{t}_{\boldsymbol{s}}\right)$ ), a correlação multiloco de paternidade $\left(\boldsymbol{r}_{\boldsymbol{p}}\right)$, a correlação uniloco de paternidade $\left(\boldsymbol{r}_{s}\right)$, os cruzamentos correlacionados $\left(\boldsymbol{t}_{m} \times \boldsymbol{r}_{p}\right)$, cruzamentos aleatórios $\left(\boldsymbol{t}_{\boldsymbol{m}}\left(\mathbf{1}-\boldsymbol{r}_{p}\right)\right)$ e a taxa de autogamia $\left(\mathbf{1}-\boldsymbol{t}_{\boldsymbol{m}}\right)$. O Desvio Padrão foi obtido a partir de 100 repetições da reamostragem de indivíduos dentro de cada progênie.

Foi realizada a Análise de Coordenadas Principais (PCoA) utilizando o software NTSYSpc v.2.10 (ROHLF, 1990), onde foram considerados 103 indivíduos (10 acessos de P. edulis e 93 indivíduos do acesso P. edulis cv. BRS MJ. Também foi realizada um análise de estrutura e ancestralidade com base na estatística Bayesiana, sem nenhuma atribuição prévia às espécies, utilizando o software Structure v.2.3.4 (PRITCHARD; STEPHENS; DONNELLY, 2000; PRITCHARD; WEN; FALUSH, 2010). Foi considerado o modelo de frequências alélicas correlacionadas e independentes entre os grupos inferidos, com base nos parâmetros do modelo de mistura (Admixture model) com 250.000 repetições iniciais (burnin) com um tamanho na corrida de 500.000 (run-length). Para identificar o número de grupos dos 103 genótipos, o valor de $\ln \mathrm{P}(\mathrm{D})$ foi obtido pelo teste de $\mathrm{K}$ variando entre 1 a 10 , usando 20 corridas independentes para cada valor de K (duração do período de repetições iniciais: 50.000; número de MCMC repetições após as repetições iniciais: 50.000). Os valores mais prováveis de $\mathrm{K}$ para cada teste foram detectados pelo Delta $\mathrm{K}$ (EVANNO; REGNAUT; GOUDET, 2005). Os acessos testados foram divididos em grupos segundo os valores de Q maiores ou iguais a 0,70 , ou sendo considerados como intermediários ou misturados. A extração e quantificação de DNA dos 10 acessos de $P$. edulis seguiram os procedimentos descritos anteriormente.

\section{RESULTADOS E DISCUSSÃO}

Dos 18 pares de primers de microssatélites testados, 16 amplificaram satisfatoriamente $(88,9 \%$ ) (excluídos BrPe0014 e BrPe0036). Nem todos os locos 
foram polimórficos quando avaliados em cada progênie, o que era esperado considerando a menor variabilidade genética dentro das progênies de cada planta e devido à possibilidade de autogamia. Na família P1RJ-RC, dos 16 locos, 12 foram polimórficos, apresentando entre 2 a 4 alelos por loco. As médias da He para esses locos polimórficos foi de 0,16, da Ho de 0,21 e do PIC de 0,13 (Tabela 2). Na família P2RJ-RC, 14 locos foram polimórficos com o mesmo número de alelos por loco que na família P1RJ-RC, e valores similares para a He, Ho e PIC (Tabela 3). Já para a família proveniente da planta P3RJ-GA, a que se encontrava em um pomar misto de BRS Gigante Amarelo, BRS Rubi do Cerrado e BRS Sol do Cerrado, o número de locos polimórficos foi de 15 (93,8\%), apresentando 2 a 4 alelos por loco e maiores médias de Ho e He que nas outras progênies, e PIC de 0,33 (Tabela 4). Para a família proveniente da planta que se encontrava isolada na casa de vegetação (P4RJ-CV), os valores caíram para somente 2 locos polimórficos (12,5\%) com dois alelos por loco (Tabela 5).

Tabela 1. Estatísticas da seleção de 18 marcadores microssatélites polimórficos que foram validados em $P$. edulis no Capítulo 1.

\begin{tabular}{|c|c|c|c|c|c|c|c|c|c|c|}
\hline Painel & Marcador & Dye & Sequência do primer 5'-3' & Motivo & $\mathrm{Ta}$ & $\mathrm{N}$ & $\begin{array}{l}\text { Tamanho } \\
\text { alelos bp }\end{array}$ & $\mathrm{He}$ & Ho & PIC \\
\hline \multirow[t]{2}{*}{1} & $\mathrm{BrPe} 0001$ & 6-Fam & $\begin{array}{l}\text { F:GTTGAGAGGATTGTGTTTG } \\
\text { R: ATGGTAGAGGAGGAGAGA }\end{array}$ & $(\mathrm{CT})_{14}$ & $55^{\circ} \mathrm{C}$ & 3 & $143-157$ & 0,56 & 0,14 & 0,46 \\
\hline & $\mathrm{BrPe} 0028$ & Hex & $\begin{array}{l}\text { F:CAAAAGGAACAGGGAAGA } \\
\text { R: GAAAGAGAGAAAGACAGAGA }\end{array}$ & $(\mathrm{TA})_{6}$ & $55^{\circ} \mathrm{C}$ & 5 & $90-110$ & 0,80 & 0,50 & 0,72 \\
\hline \multirow[t]{2}{*}{2} & $\mathrm{BrPe} 0002$ & Hex & $\begin{array}{l}\text { F:AAAGCCCAGATGAAGTGAA } \\
\text { R:GGCTCCAATCAGAAGTGT }\end{array}$ & $(\mathrm{AG})_{12}$ & $55^{\circ} \mathrm{C}$ & 3 & $177-185$ & 0,69 & 0,56 & 0,58 \\
\hline & $\overline{\mathrm{BrPe} 0024}$ & 6-Fam & $\begin{array}{l}\mathrm{F}: \text { CCCTACCTTTCTCTGCTT } \\
\mathrm{R}: \mathrm{CATCTCCTCTATCTCCTTC}\end{array}$ & $(\mathrm{TC})_{7}$ & $55^{\circ} \mathrm{C}$ & 4 & $221-231$ & 0,76 & 0,70 & 0,68 \\
\hline \multirow[t]{3}{*}{3} & $\mathrm{BrPe} 0003$ & 6-Fam & $\begin{array}{l}\mathrm{F}: \text { CTTTCTCTCCCTATACCC } \\
\mathrm{R}: \text { CCCTCCATAATCACATAAC } \\
\end{array}$ & $(\mathrm{TC})_{11}$ & $55^{\circ} \mathrm{C}$ & 5 & $277-291$ & 0,70 & 0,40 & 0,62 \\
\hline & $\overline{\mathrm{BrPe} 0006}$ & 6-Fam & $\begin{array}{l}\text { F:AAGGAAAAGAACAGCCTCA } \\
\text { R:CGCTCTCAAATCAGTCAAA }\end{array}$ & $(\mathrm{TC})_{10}$ & $55^{\circ} \mathrm{C}$ & 4 & 193-199 & 0,68 & 0,40 & 0,59 \\
\hline & $\mathrm{BrPe} 0010$ & Hex & $\begin{array}{l}\text { F:GAAGAAAAAAGGGCTTG } \\
\text { R:GTTAGGGTTTGGAGGA }\end{array}$ & $(\mathrm{TC})_{9}$ & $55^{\circ} \mathrm{C}$ & 4 & $199-207$ & 0,71 & 0,50 & 0,60 \\
\hline \multirow[t]{2}{*}{4} & $\mathrm{BrPe} 0031$ & 6-Fam & $\begin{array}{l}\text { F:AGGTCGGTGGGTGTGTTTAG } \\
\text { R:CATTCAACTCCCCAAAAGGT }\end{array}$ & $(\mathrm{TA})_{9}$ & $60^{\circ} \mathrm{C}$ & 5 & $134-150$ & 0,77 & 0,67 & 0,67 \\
\hline & $\mathrm{BrPe} 0036$ & Hex & $\begin{array}{l}\text { F:TCGGACCTTAAAACCGAGAA } \\
\text { R:CAGCACCAAAATTTGACGAG }\end{array}$ & $(\mathrm{TC})_{6}$ & $60^{\circ} \mathrm{C}$ & 4 & $197-203$ & 0,65 & 0,10 & 0,54 \\
\hline \multirow[t]{2}{*}{5} & $\mathrm{BrPe} 0032$ & 6-Fam & $\begin{array}{l}\text { F:TTGCACAATGACCAATGTTGT } \\
\text { R:CTGAGCACCTTGTCAAAATACA }\end{array}$ & $(\mathrm{AT})_{13}$ & $60^{\circ} \mathrm{C}$ & 7 & $137-157$ & 0,84 & 1,00 & 0,77 \\
\hline & $\mathrm{BrPe} 0034$ & Hex & $\begin{array}{l}\text { F:CCTGTGGTGAAAATGGAACC } \\
\text { R:GAGCCCTGGACTGACACATT }\end{array}$ & $(\mathrm{CT})_{15}$ & $60^{\circ} \mathrm{C}$ & 2 & $217-227$ & 0,56 & 1,00 & 0,38 \\
\hline \multirow[t]{2}{*}{6} & $\mathrm{BrPe} 0038$ & 6-Fam & $\begin{array}{l}\text { F:TTTCAACTTTTCGTGTGTGC } \\
\text { R:TGTTGTTGCTTGGAAGGATG }\end{array}$ & $(\mathrm{AT})_{6}$ & $60^{\circ} \mathrm{C}$ & 5 & $154-176$ & 0,73 & 0,60 & 0,64 \\
\hline & $\overline{\mathrm{BrPe} 3011}$ & Hex & $\begin{array}{l}\text { F:CCGGTCTTCCTGATTGACTC } \\
\text { R:CCTCTCTCACCTGGAACTGC }\end{array}$ & $(\mathrm{TTC})_{4}$ & $60^{\circ} \mathrm{C}$ & 3 & $157-163$ & 0,62 & 0,30 & 0,50 \\
\hline \multirow{2}{*}{ NP } & $\mathrm{BrPe} 0014$ & 6-Fam & $\begin{array}{l}\text { F:AATATGGCTGGGGAAAAC } \\
\text { R:TTCCTGTCTTTGGACCTT }\end{array}$ & $(\mathrm{AG}) 7$ & $57^{\circ} \mathrm{C}$ & 5 & $215-227$ & 0,75 & 0,50 & 0,67 \\
\hline & $\mathrm{BrPe} 0021$ & 6-Fam & $\begin{array}{l}\text { F:ACTTCCTCATCATTCG } \\
\text { R:GCTATGCCTCTTTTTG }\end{array}$ & $(\mathrm{TA})_{7}$ & $55^{\circ} \mathrm{C}$ & 3 & $158-164$ & 0,67 & 0,25 & 0,56 \\
\hline
\end{tabular}




\begin{tabular}{|c|c|c|c|c|c|c|c|c|c|}
\hline Painel & Marcador Dye & Sequência do primer 5'-3' & Motivo & $\mathrm{Ta}$ & $\mathrm{N}$ & $\begin{array}{l}\text { Tamanho } \\
\text { alelos bp }\end{array}$ & $\mathrm{He}$ & Ho & PIC \\
\hline \multirow[t]{3}{*}{ NP } & BrPe0033 Hex & $\begin{array}{l}\text { F:GCCATGAGAGACTTGGGAGA } \\
\text { R:CGGTTGCCAAAAAGAAGAGA }\end{array}$ & $(\mathrm{AT})_{8}$ & $60^{\circ} \mathrm{C}$ & 5 & $237-249$ & 0,72 & 0,30 & 0,65 \\
\hline & BrPe0042 6-Fam & $\begin{array}{l}\text { F:CATGCATTCATTTGTTTTTCTTG } \\
\text { R:GATGCTGGGAAAAAGAGTGC }\end{array}$ & $(\mathrm{AT})_{8}$ & $60^{\circ} \mathrm{C}$ & 6 & $142-160$ & 0,71 & 0,80 & 0,63 \\
\hline & $\mathrm{BrPe} 0043 \mathrm{Hex}$ & $\begin{array}{l}\text { F:TCATACATGGATGTCAAATCGATAC } \\
\text { R:GCGGACCAAGAAAATTCAAA }\end{array}$ & $(\mathrm{AT})_{8}$ & $60^{\circ} \mathrm{C}$ & 4 & 199-207 & 0,71 & 0,50 & 0,60 \\
\hline & & & Média & & & & 0,70 & 0,51 & 0,60 \\
\hline
\end{tabular}

$\mathrm{F}$ : primer forward; R: primer reverse; $\mathrm{T}_{\mathrm{a}}$ : temperatura de anelamento; $\mathrm{N}$ : número de alelos; Ho: heterozigosidade observada; He: heterozigosidade esperada; PIC: conteúdo de informação polimórfica, NP: não painel.

Tabela 2. Estatísticas descritivas dos 12 locos de microssatélites polimórficos testados na progênie P1RJ-RC.

\begin{tabular}{cccccc} 
Loco & $\mathrm{N}$ & Tamanho alelos pb & Ho & He & PIC \\
\hline BrPe0001 & 3 & $154-160$ & 0,57 & 0,49 & 0,38 \\
\hline BrPe0002 & 2 & $171-187$ & 0,05 & 0,05 & 0,04 \\
\hline BrPe0003 & 2 & $279-289$ & 0,04 & 0,04 & 0,04 \\
\hline BrPe0006 & 2 & $193-197$ & 0,04 & 0,04 & 0,04 \\
\hline BrPe0021 & 3 & $162-172$ & 0,10 & 0,09 & 0,09 \\
\hline BrPe0028 & 2 & $99-105$ & 0,09 & 0,09 & 0,08 \\
\hline BrPe0031 & 3 & $143-147$ & 0,29 & 0,27 & 0,24 \\
\hline BrPe0032 & 2 & $151-153$ & 1,00 & 0,51 & 0,38 \\
\hline BrPe0038 & 2 & $155-157$ & 0,13 & 0,12 & 0,11 \\
\hline BrPe0042 & 4 & $148-156$ & 0,13 & 0,12 & 0,12 \\
\hline BrPe0043 & 2 & $200-206$ & 0,05 & 0,05 & 0,04 \\
\hline BrPe3011 & 2 & $159-165$ & 0,04 & 0,04 & 0,04 \\
\hline Média & 2,42 & 0,21 & 0,16 & 0,13
\end{tabular}

N: número de alelos; Ho: heterozigosidade observada; He: heterozigosidade esperada; PIC: conteúdo de informação polimórfica

Tabela 3. Estatísticas descritivas dos 14 locos de microssatélites polimórficos testados na progênie P2RJ-RC.

\begin{tabular}{cccccc} 
Loco & $\mathrm{N}$ & Tamanho alelos $\mathrm{pb}$ & Ho & He & PIC \\
\hline $\mathrm{BrPe} 0001$ & 4 & $154-162$ & 0,81 & 0,55 & 0,44 \\
\hline $\mathrm{BrPe} 0002$ & 2 & $175-187$ & 0,05 & 0,05 & 0,05 \\
\hline $\mathrm{BrPe} 0003$ & 2 & $287-289$ & 0,04 & 0,04 & 0,04 \\
\hline $\mathrm{BrPe} 0006$ & 2 & $191-197$ & 0,05 & 0,05 & 0,04 \\
\hline $\mathrm{BrPe} 0010$ & 3 & $197-207$ & 0,09 & 0,09 & 0,08
\end{tabular}




\begin{tabular}{cccccc} 
Loco & $\mathrm{N}$ & Tamanho alelos pb & Ho & He & PIC \\
\hline BrPe0024 & 2 & $226-232$ & 0,04 & 0,04 & 0,04 \\
\hline BrPe0028 & 2 & $99-105$ & 0,04 & 0,04 & 0,04 \\
\hline BrPe0031 & 4 & $135-147$ & 0,48 & 0,46 & 0,41 \\
\hline BrPe0032 & 2 & $151-153$ & 1,00 & 0,51 & 0,38 \\
\hline BrPe0033 & 2 & $242-252$ & 0,05 & 0,05 & 0,04 \\
\hline BrPe0034 & 2 & $213-227$ & 0,05 & 0,05 & 0,04 \\
\hline BrPe0038 & 2 & $155-157$ & 0,04 & 0,04 & 0,04 \\
\hline BrPe0042 & 2 & $150-156$ & 0,04 & 0,04 & 0,04 \\
\hline BrPe3011 & 2 & $159-165$ & 0,04 & 0,04 & 0,04 \\
\hline Média & 2,36 & & 0,20 & 0,15 & 0,12
\end{tabular}

N: número de alelos; Ho: heterozigosidade observada; He: heterozigosidade esperada; PIC: conteúdo de informação polimórfica

Tabela 4. Estatísticas descritivas dos 15 locos de microssatélites polimórficos testados na progênie P3RJ-GA.

\begin{tabular}{cccccc} 
Loco & $\mathrm{N}$ & Tamanho alelos pb & Ho & He & PIC \\
\hline BrPe0001 & 3 & $154-162$ & 0,33 & 0,45 & 0,36 \\
\hline BrPe0002 & 2 & $181-187$ & 0,48 & 0,37 & 0,30 \\
\hline BrPe0003 & 4 & $279-293$ & 0,42 & 0,35 & 0,31 \\
\hline BrPe0006 & 3 & $195-199$ & 0,21 & 0,20 & 0,18 \\
\hline BrPe0010 & 3 & $203-207$ & 0,50 & 0,41 & 0,36 \\
\hline BrPe0021 & 2 & $164-172$ & 0,50 & 0,38 & 0,31 \\
\hline BrPe0024 & 3 & $226-232$ & 0,50 & 0,41 & 0,35 \\
\hline BrPe0028 & 3 & $99-105$ & 0,52 & 0,43 & 0,37 \\
\hline BrPe0032 & 2 & $151-153$ & 1,00 & 0,51 & 0,38 \\
\hline BrPe0033 & 3 & $242-252$ & 0,42 & 0,35 & 0,29 \\
\hline BrPe0034 & 3 & $213-225$ & 0,50 & 0,41 & 0,35 \\
\hline BrPe0038 & 2 & $155-157$ & 0,50 & 0,38 & 0,31 \\
\hline BrPe0042 & 3 & $150-156$ & 0,52 & 0,43 & 0,37 \\
\hline BrPe0043 & 5 & $200-220$ & 0,50 & 0,42 & 0,38 \\
\hline BrPe3011 & 2 & $159-165$ & 0,50 & 0,38 & 0,31 \\
\hline Média & 2,87 & 0,49 & 0,39 & 0,33
\end{tabular}

N: número de alelos; Ho: heterozigosidade observada; He: heterozigosidade esperada; PIC: conteúdo de informação polimórfica 
Tabela 5. Estatísticas descritivas dos 2 locos de microssatélites polimórficos testados na progênie P4RJ-CV.

\begin{tabular}{cccccc} 
Loco & $\mathrm{N}$ & Tamanho alelos pb & Ho & He & PIC \\
\hline BrPe0001 & 2 & $154-156$ & 0,55 & 0,50 & 0,37 \\
\hline BrPe0032 & 2 & $151-153$ & 1,00 & 0,51 & 0,38 \\
\hline Média & 2 & & 0,77 & 0,50 & 0,37
\end{tabular}

N: número de alelos; Ho: heterozigosidade observada; He: heterozigosidade esperada; PIC: conteúdo de informação polimórfica

Quando comparados os alelos dos indivíduos de cada progênie com os alelos do genitor feminino, um total de 57 indivíduos $(63,3 \%)$ apresentaram somente alelos do genitor feminino. Na família P1RJ-RC, 13 indivíduos apresentaram somente alelos do genitor feminino (56,5\%); na família P2RJ-RC, 13 indivíduos (59,1\%); na família P3RJ-GA, 10 indivíduos (43,4\%); e na família P4RJ-CV, todos os 21 indivíduos $(100 \%)$ tiveram somente alelos do genitor feminino. Segundo a segregação Mendeliana, locos heterozigotos do genitor feminino resultarão em 50\% de progênie heterozigota para esse mesmo loco, na ocorrência de autopolinização. Considerando somente os indivíduos com alelos provenientes do genitor feminino, foi calculada a probabilidade de segregação na proporção 1:2:1 utilizando o Teste Exato de Fisher, onde a maioria dos locos apresentaram uma probabilidade maior que $P=0,05$ não existindo diferença significativa entre a segregação esperada e a observada. A exceção foi para o loco $\mathrm{BrPe} 0032$ nas progênies P1RJ-RC e P4RJ-CV, que apresentou diferença significativa $(0,0441<P=0,05$ e $0,025<P=0,05$, respectivamente), rejeitando a hipótese nula de 1:2:1 (Tabela 6; Figura 3).

Tabela 6. Probabilidade da segregação independente mediante o Teste Exato de Fisher em quatro progênies provenientes de autopolinização de quatro plantas da cultivar BRS Maracujá Jaboticaba.

\begin{tabular}{cccccc} 
Família & Loco & $\begin{array}{c}\text { Fenótipo genitor } \\
\text { feminino } a b\end{array}$ & $\begin{array}{c}\text { Segregação F1 } \\
a a: a b: b b\end{array}$ & $\begin{array}{c}\text { Taxa esperada } \\
a a: a b: b b\end{array}$ & $P$ \\
\hline \multirow{2}{*}{ P1RJ-RC } & BrPe0001 & $154 / 156$ & $1: 5: 6$ & $1: 2: 1$ & 0,7576 \\
\cline { 2 - 6 } & BrPe0032 & $151 / 153$ & $0: 13: 0$ & $1: 2: 1$ & 0,0441
\end{tabular}




\begin{tabular}{cccccc} 
Família & Loco & $\begin{array}{c}\text { Fenótipo genitor } \\
\text { feminino } a b\end{array}$ & $\begin{array}{c}\text { Segregação F1 } \\
a a: a b: b b\end{array}$ & $\begin{array}{c}\text { Taxa esperada } \\
a a: a b: b b\end{array}$ & $P$ \\
\hline \multirow{3}{*}{ P2RJ-RC } & BrPe0001 & $154 / 156$ & $0: 10: 2$ & $1: 2: 1$ & 0,2445 \\
\cline { 2 - 6 } & BrPe0031 & $145 / 147$ & $10: 3: 0$ & $1: 2: 1$ & 0,0987 \\
\cline { 2 - 6 } & BrPe0032 & $151 / 153$ & $0: 12: 0$ & $1: 2: 1$ & 0,0500 \\
\hline \multirow{2}{*}{ P3RJ-GA } & BrPe0001 & $154 / 156$ & $0: 6: 4$ & $1: 2: 1$ & 0,4406 \\
\cline { 2 - 6 } & BrPe0032 & $151 / 153$ & $0: 10: 0$ & $1: 2: 1$ & 0,0659 \\
\hline \multirow{2}{*}{ P4RJ-CV } & BrPe0001 & $154 / 156$ & $2: 12: 7$ & $1: 2: 1$ & 0,5684 \\
\cline { 2 - 6 } & $\mathrm{BrPe} 0032$ & $151 / 153$ & $0: 18: 0$ & $1: 2: 1$ & 0,0259
\end{tabular}

Desvios na segregação Mendeliana podem ocorrer por várias causas como mutações, as que variam entre $10^{-2}$ a $10^{-6}$ nucleotídeos por loco por geração (SIA et al., 2000; TACHIDA; IIZUKA, 1992), mudanças no modo de reprodução como apomixia (BRESSAN et al., 2013; NASSAR; COLLEVATTI, 2005), epistasia (MONTAGUTELLI; TURNER; NADEAU, 1996), barreiras reprodutivas (HARUSHIMA et al., 2001), dominância completa e incompleta (DAVIES; COATES; NIELSEN, 1985), entre outros. No presente estudo, considerando que somente um dos dois locos heterozigotos não segregaram de maneira Mendeliana em duas progênies, o desvio poderia ser atribuído ao tamanho pequeno da progênie testada, portanto seria necessário aumentar o número de indivíduos testados, assim como o número de locos heterozigotos.

Nossos resultados foram obtidos a partir da genotipagem com uma seleção de 18 marcadores microssatélites mais informativos que foram validados em 10 acessos de $P$. edulis, que apresentaram PIC entre 0,38 e 0,77 , Ho 0,14 a 1,00, e entre 2 a 7 alelos por loco (Tabela 1). Considerando os mesmos marcadores utilizados nas quatro progênies da cultivar BRS MJ, o PIC foi entre 0,04 e 0,44, a Ho de 0,04 a 1,00, e foram observados entre 2 a 5 alelos por loco, afirmando que a técnica é eficiente e os marcadores desenvolvidos são informativos (Tabelas 2-5) (Figuras 3 e 4). 

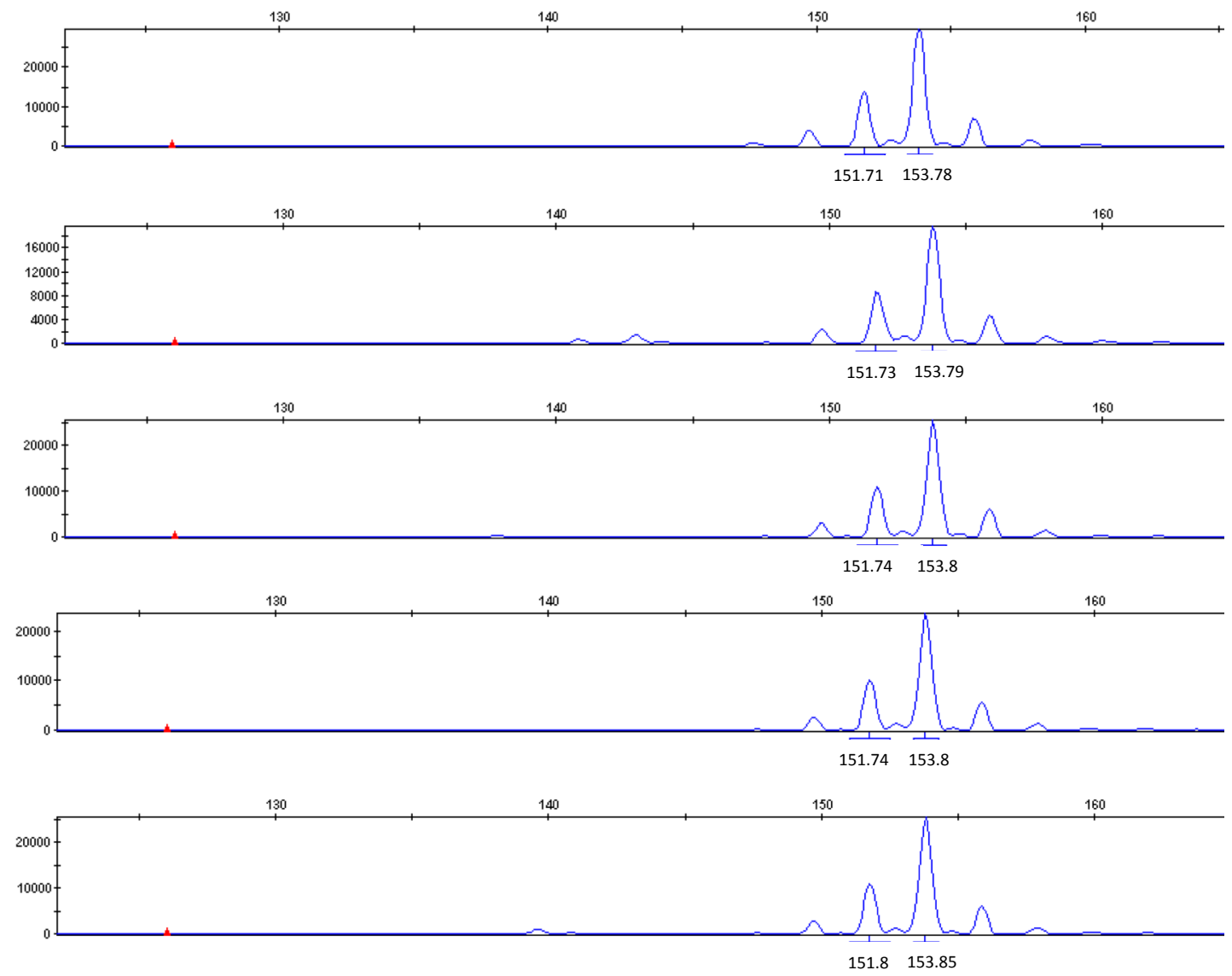

Figura 3. Eletroferograma do loco BrPe0032 nos acessos P4RJ-CV (151/153), P4RJCV-2 (151/153), P4RJ-CV-4 (151/153), P4RJ-CV-5 (151/153) e P4RJ-CV-6 (151/153). Alelos em parêntese.

Os resultados das análises do modo de reprodução variaram dependendo do local onde se encontravam as plantas. Para as progênies das plantas P1RJ-RC e P2RJRC que estavam no pomar de BRS Rubi do Cerrado, a porcentagem de alogamia foi de $43,5 \%$ e $40,9 \%\left(t_{m}=0,435\right.$ e $\left.t_{m}=0,409\right)$ respectivamente. Na progênie da planta P3RJ-GA que se encontrava em um pomar misto (BRS Gigante Amarelo, BRS Rubi do Cerrado e BRS Sol do Cerrado) a alogamia aumentou para 56,6\% $\left(t_{m}=0,566\right)$. Esses resultados indicam que em condições naturais, a cultivar BRS MJ apresenta modo de reprodução misto. Pelo contrário, a progênie da planta $\mathrm{P} 4 \mathrm{RJ}-\mathrm{CV}$ que se encontrava isolada na casa de vegetação apresentou $0 \%$ de alogamia $\left(t_{m}=0,001\right)$ (Tabela 7) o que confirma as observações previamente feitas de que essa cultivar é autocompatível. 

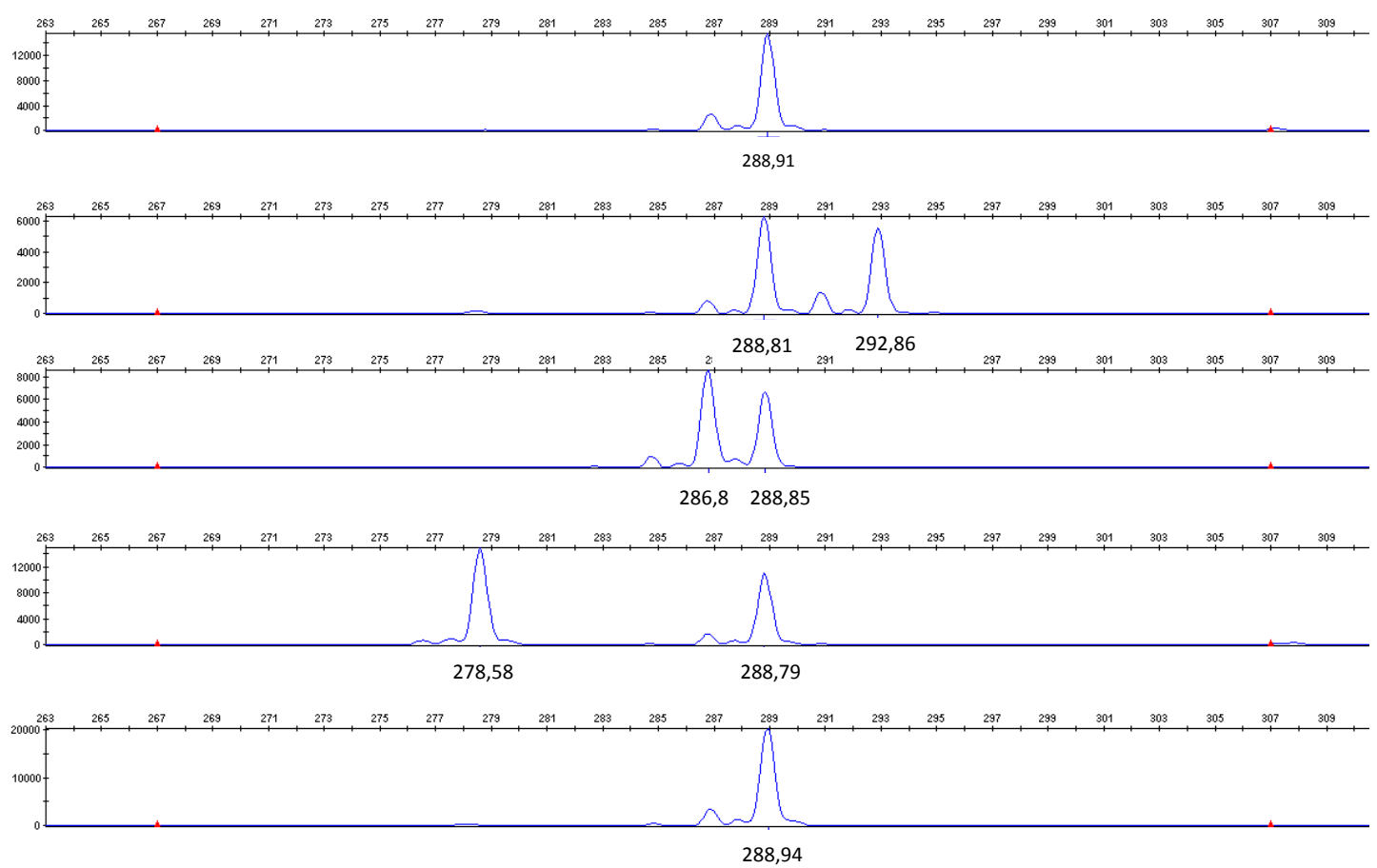

Figura 4. Eletroferograma do loco BrPe0003, acessos P3RJ-GA (289/289), P3RJ-GA3 (289/293), P3RJ-GA-4 (287/289), P3RJ-GA-7 (279/289), P3RJ-GA-11 (289/289). Alelos em parêntese.

É interessante notar que a maior porcentagem de alogamia foi observada na progênie P3RJ-RC, a que estava no pomar misto. As porcentagens de alogamia foram menores nas progênies das plantas P1RJ-RC e P2RJ-RC localizadas próximas entre si em um pomar da cultivar BRS Rubi do Cerrado.

Os resultados da taxa de cruzamentos entre indivíduos aparentados para as duas progênies P1RJ-RC e P2RJ-RC foi de 26,2\% $\left(t_{m}-t_{s}=0,262\right)$, evidenciando uma baixa ocorrência de cruzamentos entre indivíduos aparentados. A correlação multiloco de paternidade $\left(r_{p(m)}\right)$ foi muito alta para a progênie P4RJ-RC $(0,999)$ o que confirma que não houve genitores masculinos contribuindo com pólen, e que a progênie está composta por irmãos-completos. Os resultados para a correlação de multiloco de paternidade $\left(r_{p(m)}\right)$ foi alta para as progênies P2RJ-RC e P3RJ-GA, $(0,766$ e 0,701$)$ indicando que o número de fontes de pólen foi restrito (RITLAND, 1989). 
Tabela 7. Estimação do modo de reprodução de $P$. edulis cultivar BRS MJ em quatro progênies.

\begin{tabular}{cccccc} 
Família & $t_{m}$ & $t_{s}$ & $\left(t_{m}-t_{s}\right)$ & $r_{p(m)}$ & $1-t_{m}$ \\
& & & & & \\
\hline P1RJ-RC & $0,435 \pm 0,097$ & $0,172 \pm 0,058$ & $0,262 \pm 0,061$ & $0,314 \pm 0,243$ & 0,565 \\
\hline P2RJ-RC & $0,409 \pm 0,094$ & $0,148 \pm 0,069$ & $0,262 \pm 0,073$ & $0,766 \pm 0,214$ & 0,591 \\
\hline P3RJ-GA & $0,566 \pm 0,102$ & $1,156 \pm 0,114$ & $-0,59 \pm 0,086$ & $0,701 \pm 0,159$ & 0,434 \\
\hline P4RJ-CV & $0,001 \pm 0,000$ & $0,001 \pm 0,000$ & $0,000 \pm 0,000$ & $0,999 \pm 0,000$ & 0,999
\end{tabular}

$\boldsymbol{t}_{\boldsymbol{m}}=$ taxa de cruzamento multiloco, $\boldsymbol{t}_{\boldsymbol{s}}=$ taxa de cruzamento uniloco, $\left(\boldsymbol{t}_{\boldsymbol{m}}-\boldsymbol{t}_{\boldsymbol{s}}\right)=$ taxa de cruzamento entre indivíduos aparentados, $\boldsymbol{r}_{p(\boldsymbol{m})}=$ correlação multiloco de paternidade, $\mathbf{1}-\boldsymbol{t}_{\boldsymbol{m}}=$ taxa de autogamia.

Análises similares com marcadores moleculares RAPD em Passiflora alata confirmaram, pelo contrário, a ocorrência de autoincompatibilidade, com uma taxa de cruzamento multiloco de $t_{m}=0,940$ (FERREIRA et al., 2010).

Considerando a frutificação em maracujazeiro-amarelo, em uma cultivar autocompatível, a autogamia resultou em $60 \%$ de autopolinização natural mediante insetos, e entre 83\% e 92\% mediante autopolinização manual (SHIVANNA, 2012). Por outro lado, em maracujazeiro-amarelo autoincompatível, DAS et al. (2013) encontraram que a formação de frutos por autogamia foi de 1,71\% a 4,51\%, confirmando a autoincompatibilidade.

Na cultivar Gulupa de $P$. edulis RENDÓN et al. (2013) observaram que a formação de frutos por autopolinização natural foi de $28 \%$, e por polinização cruzada, um $68 \%$

Já em outras espécies, como $P$. capsularis e $P$. rubra foi descrito que ambas as espécies apresentam modo de reprodução misto, mas foi determinado 62,5\% e 67,2\% de autogamia, respectivamente, utilizando polinização controlada (AMORIM et al., 2011). Em $P$. coccinea foi reportado que não houve frutificação por autogamia (STORTI, 2002).

A análise PCoA mostrou que os 103 indivíduos formaram dois grupos (Figura 5b), o primeiro com os acessos de $P$. edulis utilizados na validação dos marcadores microssatélites (ver Capítulo 1), e o segundo grupo com todos os indivíduos do acesso P. edulis cv. BRS MJ (genitores e progênies). Na figura 3c é possível identificar facilmente os indivíduos oriundos de fecundação cruzada de BRS MJ. 
Chama a atenção a formação de dois grupos, considerando que todos os acessos pertencem à mesma espécie $P$. edulis. Segundo os resultados dessa pesquisa para o modo de reprodução, a cultivar BRS MJ é autocompatível, podendo apresentar uma taxa de autogamia até de 99,9\%. Por outro lado, 9 dos 10 acessos de $P$. edulis utilizados na validação dos marcadores microssatélites apresentam autoincompatibilidade (exceto Gulupa), o que os poderia ter colocado em um grupo diferente. Certamente essas características são importantes na diferenciação dos materiais genéticos, o que levaria a pensar na possibilidade de que a cultivar BRS MJ fosse de uma outra espécie. No gênero Solanum seção Lycopersicum, por exemplo, em análises filogenéticas com marcadores moleculares tem sido observada uma diferenciação correspondente ao sistema de reprodução (autocompatibilidade versus incompatibilidade) e outra à coloração dos frutos (vermelho versus verde) (MARSHALL et al., 2001; MILLER; TANKSLEY, 1990)

Por outro lado, a transição de uma espécie alógama para autógama precisa de mutações no sistema de autoincompatibilidade, assim como na morfologia floral (HERMANN; KUHLEMEIER, 2011), cuja herança é controlada por vários genes (CHEN; TANKSLEY, 2004; RICK; DEMPSEY, 1969).

No gênero Passiflora, vários estudos taxonômicos foram feitos para atribuir nomes às classes de $P$. edulis que tinham sido observadas segundo a coloração dos frutos (CERVI, 1997; DEGENER, 1932; MASTERS, 1872; SIMS, 1818), mas, finalmente, BERNACCI et al. (2008) concluíram que a nível taxonômico, P. edulis é o nome a utilizar para qualquer tipo de planta e cor do maracujazeiro-azedo junto com o nome da cultivar. Entretanto, segundo as evidências obtidas na presente pesquisa, mais estudos são necessários para tentar esclarecer a separação da cultivar BRS MJ do grupo dos acessos de P. edulis, considerando que o maracujazeiro-azedo apresenta plantas autocompatíveis quanto autoincompatíveis o que poderia ser uma característica de distinção entre uma espécie para outra. 
(a)

(c)

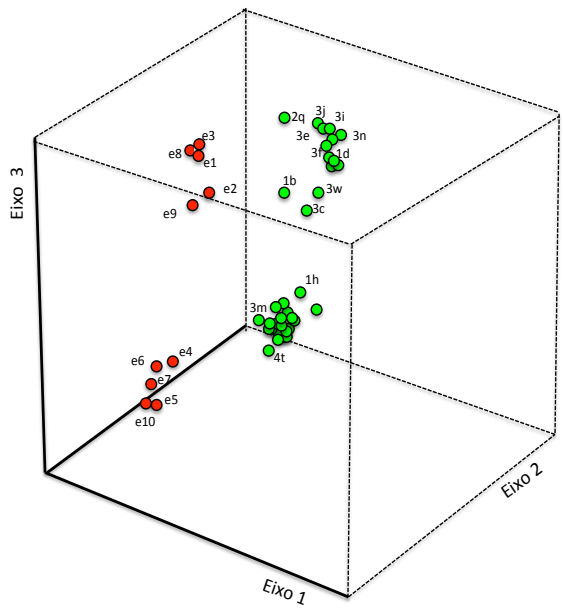

(b)

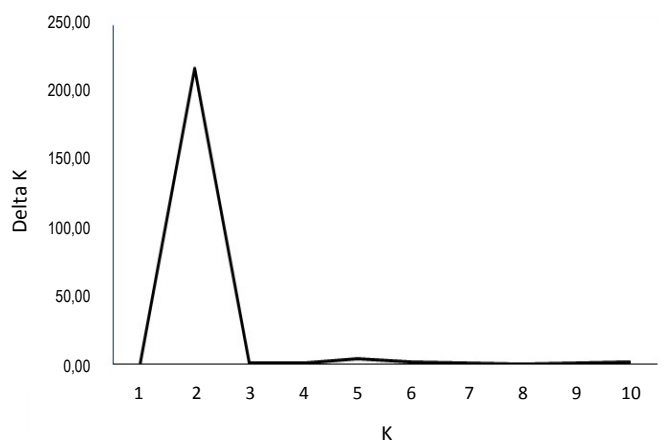

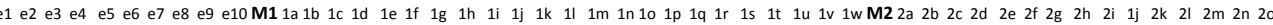

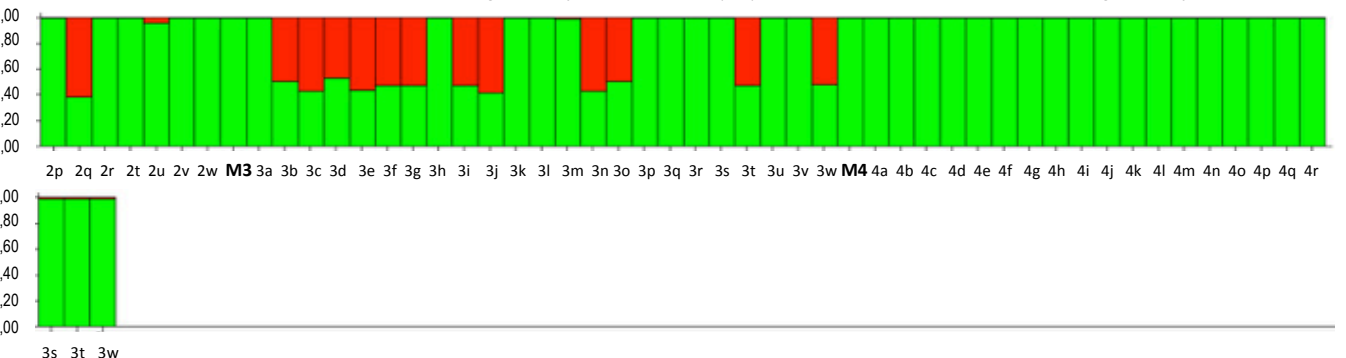

Figura 5. (a) Análise de coordenadas principais de 103 indivíduos (11 acessos) de $P$. edulis baseados no polimorfismo de marcadores microssatélites. Foram avaliados os quatro genitores femininos de BRS MJ (M1, M2, M3, M4) e seus respectivas progênies identificadas com o número do genitor (1-4) em ordem alfabética; (b) Gráfico dos valores $\mathrm{K}$ versus Delta K para definir o número mais provável de grupos (K) na análise da estrutura da população e coeficiente de ancestralidade dos acessos de P. edulis; (c) Acessos foram distribuídos por grupos baseados nos valores de Q $(\mathrm{Q}>0,70)$ para $\mathrm{K}=2$. As amostras misturadas foram identificadas com duas cores (vermelho e verde).

\section{CONCLUSÕES}

Os marcadores microssatélites utilizados foram polimórficos, informativos e eficientes no estudo do modo de reprodução da cultivar BRS MJ, confirmando que a cultivar é autocompatível e que o modo de reprodução seria misto, combinando autogamia e alogamia. Também foi observado que em condições naturais, existe 
cruzamento entre indivíduos aparentados, mas que o número de fontes de pólen foi pequeno.

A separação de dois grupos dentro de $P$. edulis nas análises de similaridade, evidencia variabilidade genética intraespecífica e poderia estar relacionada também com o modo de reprodução dos acessos testados.

\section{REFERÊNCIAS BIBLIOGRÁFICAS}

AMORIM, J. S.; SOUZA, M. M.; VIANA, A. J. C.; FREITAS, J. C. O. Self-, crossand interespecific pollinations in Passiflora capsularis and P. rubra. Revista Brasileira de Botânica, v. 34, n. 4, p. 537-544, 2011.

BAYE, T.; BECKER, H. C. Natural outcrossing rate in Vernonia galamensis. Plant Breeding, v. 123, n. 4, p. 398-399, 2004.

BERNACCI, L. C.; SOARES-SCOTT, M. D.; JUNQUEIRA, N. T. V.; JUNQUEIRA, N. T. V.; PASSOS, I. R. S.; MELETTI, L. M. M. Passiflora edulis Sims: the correct taxonomic way to cite the yellow passion fruit (and other colors). Revista Brasileira de Fruticultura, v. 30, n. 2, p. 566-576, 2008.

BRESSAN, E. A.; SEBBEN, A. M.; FERREIRA, R. R.; LEE, T. S. G.; FIGUEIRA, A. Jatropha curcas L. (Euphorbiaceae) exhibits a mixed mating system, high correlated mating and apomixis. Tree Genetics and Genomes, v. 9, n. 4, p. 1089$1097,2013$.

BRUCKNER, C. H.; CASALI, V. W. D.; MORAES, C. F.; REGAZZI, A. J.; SILVA, E. A. M. Self-incompatibility in passion fruit (Passiflora eduis Sims). Acta Horticulturae, n. 370, p. 45-57, 1995.

CERVI, A. C. Passifloraceae do Brasil. Estudo do gênero Passiflora L., subgênero Passiflora. Fontqueria, v. 45, p. 1-92, 1997.

CHANG, C. C. Studies on unfruitfulines of the yellow passion fruits growing in 
Taiwan. Taiwan Agriculture Quarterly (Tai-Wan nung-yeh), v. 10, n. 2, p. 78-89, 1974.

CHANG, C. C. Breeding of passion fruit. Plant Breeding Abstracts, v. 51, n. 6, p. 480, 1981.

CHASE, M.; KESSELI, R.; BAWA, K. Microsatellite Markers for Population and Conservation Genetics of Tropical Trees. American Journal of Botany, v. 83, p. 51$57,1996$.

CHEN, K.; TANKSLEY, S. D. High-Resolution Mapping and Functional Analysis of se2.1 : A Major Stigma Exsertion Quantitative Trait Locus Associated With the Evolution From Allogamy to Autogamy in the Genus Lycopersicon. Genetics, v. 168, p. 1563-1573, 2004.

COLlEVATTI, R. G.; BRONDANI, R. V; GRATTAPAGLIA, D. Development and characterization of microsatellite markers for genetic analysis of a Brazilian endangered tree species Caryocar brasiliense. Heredity, v. 83 n. August, p. 748-56, 1999.

DAS, M. R.; HOSSAIN, T.; MIA, M. A. B.; AHMED, J. U.; KARIMAN, A. J. M. S.; HOSSAIN, M. M. Fruit Setting Behaviour of Passion Fruit. American Journal of Plant Sciences, v. 4, n. May, p. 1066-1073, 2013.

DAVIES, C. S.; COATES, J. B.; NIELSEN, N. C. Inheritance and biochemical analysis of four electrophoretic variants of $\$ \beta \$$-conglycinin from soybean. Theoretical and Applied Genetics, v. 71, n. 2, p. 351-358, 1985.

DE LORENZIS, G.; IMAZIO, S.; BIAGINI, B.; FAILlA, O.; SCIENZA, A. Pedigree reconstruction of the Italian grapevine aglianico (Vitis vinifera L.) from Campania. Molecular Biotechnology, v. 54, n. 2, p. 634-642, 2013.

DEGENER, O. Passiflora edulis. Flora Hawaiiensis. Honolulu, family 250, 1932. 
DOYLE, J.; DOYLE, J. L. Genomic plant DNA preparation from fresh tissue-CTAB method. Phytochemical Bulletin, v. 19, n. 11, p. 11-15, 1987.

EVANNO, G.; REGNAUT, S.; GOUDET, J. Detecting the number of clusters of individuals using the software STRUCTURE: a simulation study. Molecular Ecology, v. 14, n. 8, p. 2611-2620, 2005.

FALEIRO, F. G.; FALEIRO, A. S. G.; CORDEIRO, M. C. R.; KARIA, C. T. Metodologia para operacionalizar a extração de DNA de espécies nativas do cerrado. Comunicado Téncnico. Planaltina, DF, 2003.

FALEIRO, F. G.; JUNQUEIRA, N. T. V.; BRAGA, M. F.; OLIVEIRA, E. J.; PEIXOTO, J. R.; COSTA, A. M. Germoplasma e melhoramento do maracujazeiro histórico e perspectivas. Embrapa Cerrados, Planaltina, DF. 2011.

FERREIRA, T. G. T.; PENHA, H. A.; ZUCCHI, M. I.; SANTOS, A. A.; HANAI, L. R.; JUNQUEIRA, N. T. V.; BRAGA, M. F.; VENCOVSKY, R.; VIEIRA, M. L. C. Outcrossing rate in sweet passion fruit based on molecular markers. Plant Breeding, v. 129, n. 6, p. $727-730,2010$.

FREEMAN, G. H.; HALTON, J. H. Note on exact treatment of contingency, goodness of fit and other problems of significance. Biometrika, v. 34, p. 141-149, 1951.

HARUSHIMA, Y.; NAKAGAHRA, M.; YANO, M.; SASAKI, T.; KURATA, N. A genome-wide survey of reproductive barriers in an intraspecific hybrid. Genetics, v. 159, n. 2, p. 883-892, 2001.

HERMANN, K.; KUHLEMEIER, C. The genetic architecture of natural variation in flower morphology. Current Opinion in Plant Biology, v. 14, n. 1, p. 60-65, 2011.

ISHIHATA, K. Studies on the morphology of flowering organs and the fruit bearing in purple passion fruit, Passiflora edulis Sims. Japanese Journal of Tropical Agriculture v. 31, p. 7-11, 1981. 
JUNQUEIRA, N. T. V.; BRAGA, M. F.; FAlEIRO, F. G.; PEIXOTO, J. R.; BERNACCI, J. C.; Potencial de espécies silvestres de maracujazeiro como fonte de resistência a doenças. In: FALEIRO, F. G.; JUNQUEIRA, N. T. V.; BRAGA, M. F. (Eds.). Maracujá: germoplasma e melhoramento genético. Planaltina DF: Embrapa Cerrados, 2005. p. 81-108.

LITT, M.; LUTY, J. A. A Hypervariable Microsatellite Revealed by In Vitro Amplification of a Dinucleotide Repeat within the Cardiac Muscle Actin Gene. American Journal of Human Genetics, v. 44, p. 397-401, 1989.

LOWRY, R. VassarStats: website for statistical computation. Vassar College, 2004.

MARSHALL, J. A.; KNAPP, S.; DAVEY, M. R.; POWER, J. B.; COCKING, E. C.; BENNETT, M. D.; COX, A. V. Molecular systematics of Solanum section Lycopersicum (Lycopersicon) using nuclear ITS rDNA region. Theoretical and Applied Genetics, v. 103, p. 1216-1222, 2001.

MARSHALL, T. C.; SLATE, J.; KRUUK, L. E. B.; PEMBERTON, J. M. Statistical confidence for likelihood-based paternity inference in natural populations. Molecular Ecology, v. 7, p. 639-655, 1998.

MASTERS, M. T. Passifloraceae. In: MARTIUS, C. F. P.; EICHLER, A. G.; URBAN, I. (Eds.). Flora Brasiliensis. Lipsiae: Fed. p. v.13, 527-628.

MATSCHINER, M.; SALZBURGER, W. TANDEM: Integrating automated allele binning into genetics and genomics workflows. Bioinformatics, v. 25, n. 15, p. $1982-$ 1983, 2009.

MELETTI, L. M. M.; SOARES-SCOTT, M. D.; BERNACCI, L. C. Caracterização fenotípica de três seleções de maracujazeiro-roxo (Passiflora edulis Sims). Revista Brasileira de Fruticultura, v. 27, n. 2, p. 268-272, 2005.

MILLER, J. C.; TANKSLEY, S. D. RFLP analysis of phylogenetic relationships and 
genetic variation in the genus Lycopersicon. Theoretical and Applied Genetics, v. 80, n. 4, p. 437-448, 1990.

MONTAGUTELLI, X.; TURNER, R.; NADEAU, J. H. Epistatic control of nonMendelian inheritance in mouse interspecific crosses. Genetics, v. 143, n. 4, p. 1739 1752,1996

NASSAR, N. M. A.; COLLEVATTI, R. G. Microsatellite markers confirm high apomixis level in cassava bred clones. Hereditas, v. 142, n. 33-37, 2005.

OCAMPO, J. D'EECKENRUGGE, J. C.; RESTREPO, M.; JARVIS, A.; SALAZAR, M.; CAETANO, C. Diversity of Colombian Passifloraceae: biogeography and updated list for conservation. Biota Colombiana, v. 8, n. 1, p. 1-45, 2007.

OLIVEIRA, J. C.; RUGGIERO, C. Espécies de maracujá com potencial agronômico. In: FALEIRO, F. G.; JUNQUEIRA, N. T. V.; BRAGA, M. F. (Eds.). Maracujá: germoplasma e melhoramento genético. Planaltina, DF: Embrapa Cerrados, 2005. p. $143-158$.

POWELL, W.; MORGANTE, M.; ANDRE, C.; HANAFEY, M.; VOGEL, J.; TINGEY, S.; RAFALSKI, A. The comparision of RFLP, RAPD, AFLP and SSR (microsatellite) markers for germplasm analysis. Molecular Breeding, v. 13, p. 391393, 1996

PRITCHARD, J. K.; STEPHENS, M.; DONNELLY, P. Inference of Population Structure Using Multilocus Genotype Data. Genetics, v. 155, n. 2, p. 945-959, 2000.

PRITCHARD, J. K.; WEN, X.; FALUSH，D. Documentation for structure software: Version 2.3. Chicago, IL. University of Chicago, 2010. Disponível em: $<$ http://pritch.bsd.uchicago.edu/software/readme_structure2.pdf $>$

RÊGO, M. M. Genética, interação pólen-pistilo e expressão de proteínas na autoincompatibilidade do maracujazeiro (Passiflora edulis Sims). Universidade Federal de Viçosa, 1997. 
RENDÓN, J. S.; OCAMPO, J.; URREA, R. Estudio sobre polinización y biología floral en Passiflora edulis f. edulis Sims, como base para el premejoramiento genético. Acta Agronómica, v. 62, n. 3, p. 232-241, 2013.

RICK, C. M.; DEMPSEY, W. H. Position of the stigma in relation to fruit setting of tomato. Botanical Gazette, v. 130, p. 180-186, 1969.

RITLAND, K. Correlated mating in the partial selfer Mimulus guttatus. Evolution, v. 43, n. 4, p. 848-859, 1989.

RITLAND, K. Systems Using N Independent Loci. Heredity, v. 88, p. 221-228, 2002.

ROHLF, F. Numerical taxonomy and multivariate analysis system (NTSYS-pc). New York Departament of Ecology and Evolution, 1990.

SCHUELER, S.; TUSCH, A.; SCHUSTER, M.; ZIEGENHAGEN, B. Characterization of microsatellites in wild and sweet cherry (Prunus avium L.)-markers for individual identification and reproductive processes. Genome, v. 46, p. 95-102, 2003.

SHIVANNA, K. R. Reproductive assurance through unusual autogamy in the absence of pollinators in Passiflora edulis (passion fruit). Current Science, v. 103, p. 10911096, 2012.

SIA, E. A. BUTLER, C. A.; DOMINSKA, M.; GREENWELl, P.; FOX, T. D.; PETES, T. D. Analysis of microsatellite mutations in the mitochondrial DNA of Saccharomyces cerevisiae. Proceedings of the National Academy of Sciences, v. 97 , n. 1, p. 250-255, 2000.

SIMS, J. Passiflora edulis. Botanical Magazine, Londres, v. 45, 1818.

STORTI, E. F. Biologia da polinização e sistema reprodutivo de Passiflora coccinea Aubl. em Manaus, Amazonas, Brasil. Acta Amazonica, v. 32, n. 3, p. 421-429, 2002. 
SUASSUNA, T. M. F.; BRUCKNER, C. H.; CARVALHO, C. R.; BORÉM, A. Selfincompatibility in passion fruit: evidence of gametophytic-sporophytic control. Theoretical and Applied Genetics, v. 106, p. 298-302, 2003.

TACHIDA, H.; IIZUKA, M. Persistence of repeated sequences that evolve by replication slippage. Genetics, v. 131, n. 2, p. 471-478, 1992.

VOUILLAMOZ, J.; MAIGRE, D.; MEREDITH, C. P. Microsatellite analysis of ancient alpine grape cultivars: Pedigree reconstruction of Vitis vinifera L. "Cornalin du Valais". Theoretical and Applied Genetics, v. 107, n. 3, p. 448-454, 2003. 


\section{ANEXO}

Alelos dos 16 locos de microssatélites utilizados na análise do modo de reprodução da cultivar BRS Maracujá Jaboticaba de $P$. edulis. Alelos em pb.

\begin{tabular}{|c|c|c|c|c|c|c|c|c|c|c|c|c|c|c|c|c|}
\hline Indivíduo & 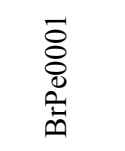 & 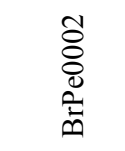 & 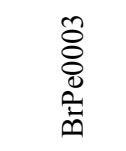 & 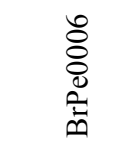 & 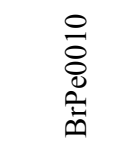 & 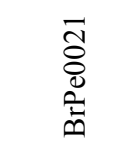 & 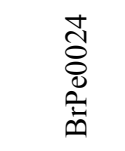 & 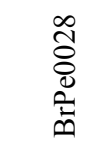 & 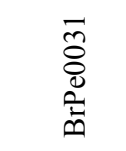 & 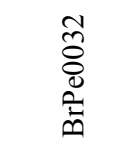 & 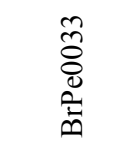 & 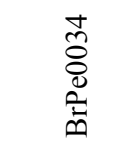 & 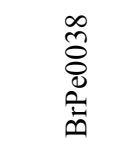 & 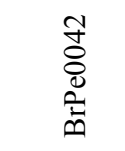 & 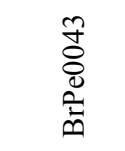 & $\begin{array}{l}\bar{D} \\
\overline{0} \\
\infty \\
\stackrel{0}{\bar{n}} \\
\end{array}$ \\
\hline P1RJ-RC & $154 / 156$ & $187 / 187$ & $289 / 289$ & $197 / 197$ & $205 / 205$ & $172 / 172$ & $226 / 226$ & 99/99 & $145 / 145$ & $151 / 153$ & $252 / 252$ & $213 / 213$ & $155 / 155$ & $156 / 156$ & $206 / 206$ & $165 / 165$ \\
\hline P1RJ-RC-1 & $156 / 156$ & $187 / 187$ & $289 / 289$ & $197 / 197$ & $205 / 205$ & $172 / 172$ & $226 / 226$ & 99/99 & $145 / 145$ & $151 / 153$ & $252 / 252$ & $213 / 213$ & $155 / 155$ & $156 / 156$ & $206 / 206$ & $165 / 165$ \\
\hline P1RJ-RC-2 & $154 / 154$ & $0 / 0$ & $279 / 289$ & $193 / 197$ & $0 / 0$ & $0 / 0$ & $0 / 0$ & $99 / 105$ & $145 / 145$ & $0 / 0$ & $0 / 0$ & $0 / 0$ & $155 / 157$ & $148 / 156$ & $0 / 0$ & $159 / 165$ \\
\hline P1RJ-RC-3 & $154 / 156$ & $187 / 187$ & $289 / 289$ & $197 / 197$ & $205 / 205$ & $172 / 172$ & $226 / 226$ & 99/99 & $145 / 145$ & $151 / 153$ & $252 / 252$ & $213 / 213$ & $155 / 155$ & $154 / 156$ & $206 / 206$ & $165 / 165$ \\
\hline P1RJ-RC-4 & $156 / 156$ & $0 / 0$ & $0 / 0$ & $0 / 0$ & $0 / 0$ & $0 / 0$ & $0 / 0$ & $99 / 105$ & $145 / 147$ & $0 / 0$ & $0 / 0$ & $0 / 0$ & $155 / 157$ & $150 / 156$ & $0 / 0$ & $165 / 165$ \\
\hline P1RJ-RC-5 & $154 / 156$ & 187/187 & $289 / 289$ & 197/197 & $205 / 205$ & $172 / 172$ & $226 / 226$ & 99/99 & $145 / 145$ & $151 / 153$ & $252 / 252$ & $213 / 213$ & $155 / 155$ & $156 / 156$ & $206 / 206$ & $165 / 165$ \\
\hline P1RJ-RC-6 & $154 / 156$ & $187 / 187$ & $289 / 289$ & 197/197 & $205 / 205$ & $172 / 172$ & $226 / 226$ & 99/99 & $145 / 145$ & $151 / 153$ & $252 / 252$ & $213 / 213$ & $155 / 155$ & $156 / 156$ & $206 / 206$ & $165 / 165$ \\
\hline P1RJ-RC-7 & $154 / 156$ & $187 / 187$ & 289/289 & 197/197 & $205 / 205$ & $172 / 172$ & $226 / 226$ & 99/99 & $145 / 147$ & $151 / 153$ & $252 / 252$ & $213 / 213$ & $155 / 155$ & $156 / 156$ & $206 / 206$ & $165 / 165$ \\
\hline P1RJ-RC-8 & $154 / 156$ & 187/187 & $289 / 289$ & 197/197 & $205 / 205$ & $0 / 0$ & $226 / 226$ & 99/99 & $145 / 147$ & $151 / 153$ & $252 / 252$ & $213 / 213$ & $155 / 157$ & $156 / 156$ & $206 / 206$ & $165 / 165$ \\
\hline P1RJ-RC-9 & $154 / 156$ & $187 / 187$ & $289 / 289$ & 197/197 & $205 / 205$ & $172 / 172$ & $226 / 226$ & 99/99 & $145 / 145$ & $151 / 153$ & $252 / 252$ & $213 / 213$ & $155 / 155$ & $156 / 156$ & $206 / 206$ & $165 / 165$ \\
\hline P1RJ-RC-10 & $154 / 154$ & 187/187 & $289 / 289$ & 197/197 & $205 / 205$ & $172 / 172$ & $226 / 226$ & 99/99 & $145 / 145$ & $151 / 153$ & $252 / 252$ & $213 / 213$ & $155 / 155$ & $156 / 156$ & $206 / 206$ & $165 / 165$ \\
\hline P1RJ-RC-11 & $0 / 0$ & $187 / 187$ & $289 / 289$ & 197/197 & $205 / 205$ & $172 / 172$ & $226 / 226$ & 99/99 & $145 / 145$ & $151 / 153$ & $0 / 0$ & $213 / 213$ & $155 / 155$ & $156 / 156$ & $206 / 206$ & $165 / 165$ \\
\hline P1RJ-RC-12 & $156 / 156$ & $187 / 187$ & 289/289 & $197 / 197$ & $205 / 205$ & $172 / 172$ & $226 / 226$ & 99/99 & $145 / 145$ & $151 / 153$ & $252 / 252$ & $213 / 213$ & $155 / 155$ & $156 / 156$ & $206 / 206$ & $165 / 165$ \\
\hline P1RJ-RC-13 & $154 / 156$ & $187 / 187$ & $289 / 289$ & $197 / 197$ & $205 / 205$ & $172 / 172$ & $226 / 226$ & 99/99 & $145 / 145$ & $151 / 153$ & $252 / 252$ & $213 / 213$ & $155 / 155$ & $156 / 156$ & $206 / 206$ & $165 / 165$ \\
\hline
\end{tabular}




\begin{tabular}{|c|c|c|c|c|c|c|c|c|c|c|c|c|c|c|c|c|}
\hline Indivíduo & $\begin{array}{l}\overline{8} \\
0 \\
0 \\
0 \\
01\end{array}$ & 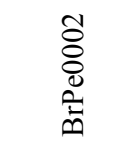 & 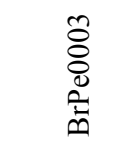 & 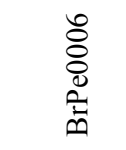 & 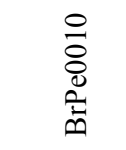 & 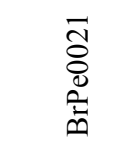 & 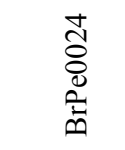 & 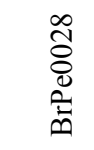 & $\begin{array}{l}\overrightarrow{0} \\
\overline{0} \\
0 \\
\stackrel{0}{0}\end{array}$ & 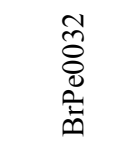 & 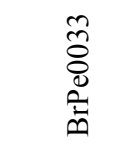 & 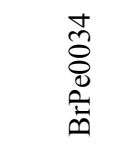 & 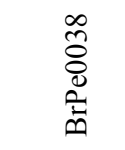 & 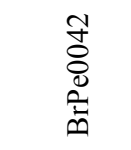 & 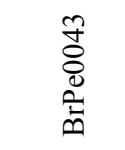 & $\begin{array}{l}\bar{D} \\
\bar{D} \\
0 \\
\overline{0}\end{array}$ \\
\hline P1RJ-RC-14 & $54 / 156$ & $187 / 187$ & $289 / 289$ & $197 / 197$ & $205 / 205$ & $172 / 172$ & $226 / 226$ & 99/99 & $143 / 145$ & $151 / 153$ & $252 / 252$ & $213 / 213$ & $155 / 155$ & $156 / 156$ & $206 / 206$ & $165 / 165$ \\
\hline P1RJ-RC-15 & $156 / 156$ & $187 / 187$ & $289 / 289$ & $197 / 197$ & $205 / 205$ & $172 / 172$ & $226 / 226$ & 99/99 & $145 / 145$ & $151 / 153$ & $252 / 252$ & $213 / 213$ & $155 / 155$ & $156 / 156$ & $206 / 206$ & $165 / 165$ \\
\hline P1RJ-RC-16 & $154 / 156$ & $187 / 187$ & $289 / 289$ & $197 / 197$ & $205 / 205$ & $172 / 172$ & $226 / 226$ & 99/99 & $145 / 145$ & $151 / 153$ & $252 / 252$ & $213 / 213$ & $155 / 155$ & $156 / 156$ & $206 / 206$ & $165 / 165$ \\
\hline P1RJ-RC-17 & $156 / 156$ & $187 / 187$ & $289 / 289$ & $197 / 197$ & $205 / 205$ & $172 / 172$ & $226 / 226$ & 99/99 & $145 / 147$ & $151 / 153$ & $252 / 252$ & $213 / 213$ & $155 / 155$ & $156 / 156$ & $206 / 206$ & $165 / 165$ \\
\hline P1RJ-RC-18 & $154 / 156$ & $187 / 187$ & $289 / 289$ & $197 / 197$ & $205 / 205$ & $172 / 172$ & $226 / 226$ & 99/99 & $143 / 145$ & $151 / 153$ & $252 / 252$ & $213 / 213$ & $155 / 155$ & $156 / 156$ & $206 / 206$ & $165 / 165$ \\
\hline P1RJ-RC-19 & $156 / 156$ & $187 / 187$ & $289 / 289$ & $197 / 197$ & $205 / 205$ & $172 / 172$ & $226 / 226$ & 99/99 & $145 / 145$ & $151 / 153$ & $252 / 252$ & $213 / 213$ & $155 / 155$ & $156 / 156$ & $206 / 206$ & $165 / 165$ \\
\hline P1RJ-RC-20 & $156 / 156$ & $187 / 187$ & $289 / 289$ & $197 / 197$ & $205 / 205$ & $172 / 172$ & $226 / 226$ & 99/99 & $145 / 145$ & $151 / 153$ & $252 / 252$ & $213 / 213$ & $155 / 155$ & $156 / 156$ & $206 / 206$ & $165 / 165$ \\
\hline P1RJ-RC-21 & $156 / 156$ & $187 / 187$ & $289 / 289$ & $197 / 197$ & $205 / 205$ & $172 / 172$ & $226 / 226$ & 99/99 & $145 / 145$ & $151 / 153$ & $252 / 252$ & $213 / 213$ & $155 / 155$ & $156 / 156$ & $206 / 206$ & $165 / 165$ \\
\hline P1RJ-RC-22 & $156 / 160$ & $187 / 187$ & $289 / 289$ & $197 / 197$ & $205 / 205$ & $172 / 172$ & $226 / 226$ & $0 / 0$ & $145 / 145$ & $151 / 153$ & $252 / 252$ & $213 / 213$ & $155 / 155$ & $156 / 156$ & $200 / 206$ & $165 / 165$ \\
\hline P1RJ-RC-23 & $154 / 156$ & $171 / 187$ & $289 / 289$ & $197 / 197$ & $205 / 205$ & $162 / 172$ & $226 / 226$ & 99/99 & $143 / 145$ & $0 / 0$ & $0 / 0$ & $213 / 213$ & $155 / 155$ & $156 / 156$ & $206 / 206$ & $165 / 165$ \\
\hline P2RJ-RC & $54 / 156$ & $187 / 187$ & $289 / 289$ & $197 / 197$ & $05 / 205$ & $172 / 172$ & $226 / 226$ & 99 & 47 & 53 & $252 / 252$ & $213 / 213$ & $155 / 155$ & $156 / 156$ & $206 / 206$ & $165 / 165$ \\
\hline P2RJ-RC-1 & $154 / 156$ & $187 / 187$ & $289 / 289$ & $197 / 197$ & $05 / 205$ & $172 / 172$ & $226 / 226$ & 99/99 & $145 / 145$ & $151 / 153$ & $252 / 252$ & $213 / 213$ & $155 / 155$ & $156 / 156$ & $206 / 206$ & $165 / 165$ \\
\hline P2RJ-RC-2 & $154 / 160$ & $187 / 187$ & $289 / 289$ & $197 / 197$ & $205 / 205$ & $172 / 172$ & $226 / 226$ & 99/99 & $145 / 145$ & $151 / 153$ & $252 / 252$ & $213 / 213$ & $155 / 155$ & $156 / 156$ & $206 / 206$ & $165 / 165$ \\
\hline P2RJ-RC-3 & $154 / 156$ & $187 / 187$ & $289 / 289$ & $197 / 197$ & $205 / 205$ & $172 / 172$ & $226 / 226$ & 99/99 & $135 / 145$ & $151 / 153$ & $252 / 252$ & $213 / 213$ & $155 / 155$ & $156 / 156$ & $206 / 206$ & $165 / 165$ \\
\hline P2RJ-RC-4 & $154 / 156$ & $187 / 187$ & $289 / 289$ & $197 / 197$ & $205 / 205$ & $172 / 172$ & $226 / 226$ & $99 / 9$ & $145 / 145$ & $151 / 153$ & $252 / 252$ & $213 / 213$ & $155 / 155$ & $156 / 156$ & $206 / 206$ & $165 / 165$ \\
\hline P2RJ-RC-5 & $154 / 156$ & $187 / 187$ & $289 / 289$ & 197/197 & $205 / 205$ & $172 / 172$ & $226 / 226$ & 99/99 & $145 / 145$ & $151 / 153$ & $252 / 252$ & $213 / 213$ & $155 / 155$ & $156 / 156$ & $206 / 206$ & $165 / 165$ \\
\hline P2RJ-RC-6 & $54 / 156$ & $187 / 187$ & $89 / 289$ & $197 / 197$ & $205 / 205$ & $172 / 172$ & $26 / 226$ & $9 / 99$ & $135 / 145$ & $151 / 153$ & $252 / 252$ & $213 / 213$ & $155 / 155$ & $156 / 156$ & $206 / 206$ & $165 / 165$ \\
\hline
\end{tabular}




\begin{tabular}{|c|c|c|c|c|c|c|c|c|c|c|c|c|c|c|c|c|}
\hline Indivíduo & $\begin{array}{l}\overline{8} \\
0 \\
0 \\
0 \\
0\end{array}$ & 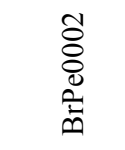 & $\begin{array}{l}0 \\
8 \\
0 \\
0 \\
0 \\
\dot{0}=1\end{array}$ & 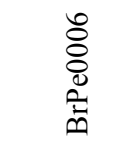 & $\begin{array}{l}0 \\
0 \\
0 \\
0 \\
0 . \overline{0}\end{array}$ & 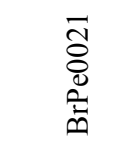 & 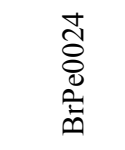 & 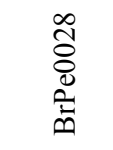 & $\begin{array}{l}\overline{0} \\
0 \\
0 \\
\stackrel{0}{0} \\
0\end{array}$ & 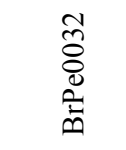 & 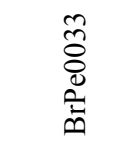 & 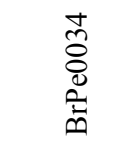 & 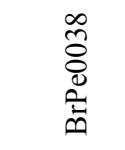 & $\begin{array}{l}\text { ₹ } \\
8 \\
0 \\
0 \\
01\end{array}$ & 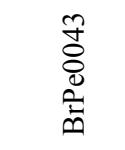 & 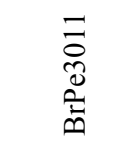 \\
\hline P2RJ-RC-7 & $156 / 156$ & $187 / 187$ & $289 / 289$ & $197 / 197$ & $205 / 205$ & $172 / 172$ & $226 / 226$ & 99/99 & $145 / 145$ & $151 / 153$ & $252 / 252$ & $213 / 213$ & $155 / 155$ & $156 / 156$ & $206 / 206$ & $165 / 165$ \\
\hline P2RJ-RC-8 & $156 / 162$ & $187 / 187$ & $289 / 289$ & $197 / 197$ & $205 / 205$ & $172 / 172$ & $226 / 226$ & 99/99 & $135 / 145$ & $151 / 153$ & $252 / 252$ & $213 / 213$ & $155 / 155$ & $156 / 156$ & $206 / 206$ & $165 / 165$ \\
\hline P2RJ-RC-9 & $154 / 156$ & $187 / 187$ & $289 / 289$ & $197 / 197$ & $205 / 205$ & $172 / 172$ & $226 / 226$ & 99/99 & $145 / 145$ & $151 / 153$ & $252 / 252$ & $213 / 213$ & $155 / 155$ & $156 / 156$ & $206 / 206$ & $165 / 165$ \\
\hline P2RJ-RC-10 & $154 / 156$ & $187 / 187$ & $289 / 289$ & $197 / 197$ & $205 / 205$ & $172 / 172$ & $226 / 226$ & 99/99 & $145 / 147$ & $151 / 153$ & $252 / 252$ & $213 / 213$ & $155 / 155$ & $156 / 156$ & $0 / 0$ & $165 / 165$ \\
\hline P2RJ-RC-11 & $154 / 156$ & $187 / 187$ & $289 / 289$ & $197 / 197$ & $205 / 205$ & $172 / 172$ & $226 / 226$ & 99/99 & $145 / 145$ & $151 / 153$ & $252 / 252$ & $213 / 213$ & $155 / 155$ & $156 / 156$ & $206 / 206$ & $165 / 165$ \\
\hline P2RJ-RC-12 & $154 / 156$ & $187 / 187$ & $289 / 289$ & 191/197 & $197 / 205$ & $172 / 172$ & $226 / 226$ & 99/99 & $145 / 147$ & $151 / 153$ & $252 / 252$ & $213 / 213$ & $155 / 155$ & $156 / 156$ & $206 / 206$ & $165 / 165$ \\
\hline P2RJ-RC-13 & $154 / 156$ & $187 / 187$ & $289 / 289$ & $197 / 197$ & $205 / 205$ & $172 / 172$ & $226 / 226$ & 99/99 & $143 / 145$ & $151 / 153$ & $252 / 252$ & $213 / 213$ & $155 / 155$ & $156 / 156$ & $206 / 206$ & $165 / 165$ \\
\hline P2RJ-RC-14 & $0 / 0$ & $187 / 187$ & $289 / 289$ & $197 / 197$ & $205 / 205$ & $172 / 172$ & $226 / 226$ & 99/99 & $145 / 145$ & $151 / 153$ & $252 / 252$ & $213 / 213$ & $155 / 155$ & $156 / 156$ & $206 / 206$ & $165 / 165$ \\
\hline P2RJ-RC-15 & $154 / 156$ & $187 / 187$ & $289 / 289$ & $197 / 197$ & $205 / 205$ & $172 / 172$ & $226 / 226$ & 99/99 & $145 / 145$ & $151 / 153$ & $252 / 252$ & $213 / 213$ & $155 / 155$ & $156 / 156$ & $206 / 206$ & $165 / 165$ \\
\hline P2RJ-RC-16 & $0 / 0$ & $0 / 0$ & $289 / 289$ & $197 / 197$ & $205 / 205$ & $172 / 172$ & $226 / 226$ & 99/99 & $143 / 145$ & $0 / 0$ & $252 / 252$ & $0 / 0$ & $155 / 155$ & $156 / 156$ & $206 / 206$ & $165 / 165$ \\
\hline P2RJ-RC-17 & $154 / 154$ & $0 / 0$ & $287 / 289$ & $0 / 0$ & $205 / 207$ & $0 / 0$ & $226 / 232$ & $99 / 105$ & $147 / 147$ & $0 / 0$ & $242 / 252$ & $213 / 227$ & $155 / 157$ & $150 / 156$ & $0 / 0$ & $159 / 165$ \\
\hline P2RJ-RC-18 & $154 / 156$ & $187 / 187$ & $289 / 289$ & $197 / 197$ & $205 / 205$ & $172 / 172$ & $226 / 226$ & 99/99 & $145 / 147$ & $0 / 0$ & $252 / 252$ & $213 / 213$ & $155 / 155$ & $156 / 156$ & $206 / 206$ & $165 / 165$ \\
\hline P2RJ-RC-20 & $154 / 156$ & $187 / 187$ & $289 / 289$ & 197/197 & $205 / 205$ & $172 / 172$ & $226 / 226$ & $99 / 99$ & $145 / 145$ & $151 / 153$ & $252 / 252$ & $213 / 213$ & $155 / 155$ & $156 / 156$ & $206 / 206$ & $165 / 165$ \\
\hline P2RJ-RC-21 & $156 / 156$ & $175 / 187$ & $289 / 289$ & $197 / 197$ & $205 / 205$ & $172 / 172$ & $226 / 226$ & 99/99 & $145 / 147$ & $151 / 153$ & $252 / 252$ & $213 / 213$ & $155 / 155$ & $156 / 156$ & $206 / 206$ & $165 / 165$ \\
\hline P2RJ-RC-22 & $156 / 156$ & $187 / 187$ & $289 / 289$ & $197 / 197$ & $205 / 205$ & $172 / 172$ & $226 / 226$ & $99 / 99$ & $145 / 145$ & $151 / 153$ & $252 / 252$ & $213 / 213$ & $155 / 155$ & $156 / 156$ & $206 / 206$ & $165 / 165$ \\
\hline P2RJ-RC-23 & $154 / 156$ & $187 / 187$ & $289 / 289$ & 197/197 & $205 / 205$ & $172 / 172$ & $226 / 226$ & 99/99 & $145 / 147$ & $151 / 153$ & $0 / 0$ & $213 / 213$ & $155 / 155$ & $156 / 156$ & $206 / 206$ & $165 / 165$ \\
\hline P3RJ-GA & $4 / 156$ & $187 / 187$ & $39 / 289$ & $197 / 197$ & $05 / 205$ & $172 / 172$ & $226 / 226$ & 99/99 & $0 / 0$ & $151 / 153$ & $252 / 252$ & $3 / 213$ & $155 / 155$ & $156 / 156$ & $206 / 206$ & $165 / 165$ \\
\hline
\end{tabular}




\begin{tabular}{|c|c|c|c|c|c|c|c|c|c|c|c|c|c|c|c|c|}
\hline Indivíduo & $\begin{array}{l}\overline{8} \\
0 \\
0 \\
0 \\
01\end{array}$ & 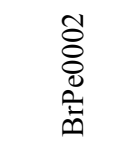 & 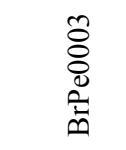 & 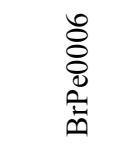 & 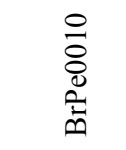 & 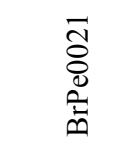 & 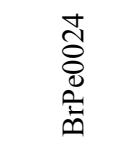 & $\begin{array}{l}\infty \\
\widetilde{\delta} \\
0 \\
0 \\
\stackrel{0}{1} \\
0\end{array}$ & 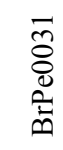 & 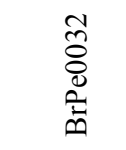 & 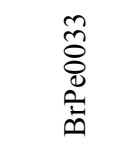 & 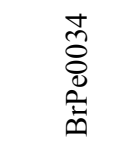 & 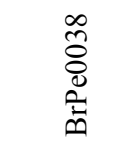 & 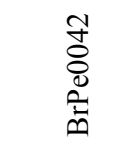 & 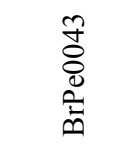 & 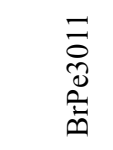 \\
\hline P3RJ-GA-1 & $154 / 156$ & $187 / 187$ & $289 / 289$ & $197 / 197$ & $205 / 205$ & $172 / 172$ & $226 / 226$ & 99/99 & $0 / 0$ & $151 / 153$ & $252 / 252$ & $213 / 213$ & $155 / 155$ & $0 / 0$ & $206 / 206$ & $165 / 165$ \\
\hline P3RJ-GA-2 & $156 / 156$ & $181 / 187$ & $289 / 289$ & $197 / 197$ & $205 / 207$ & $164 / 172$ & $226 / 232$ & $99 / 105$ & $0 / 0$ & $151 / 153$ & $242 / 252$ & $213 / 217$ & $155 / 157$ & $152 / 156$ & $200 / 206$ & $159 / 165$ \\
\hline P3RJ-GA-3 & $156 / 156$ & $181 / 187$ & $289 / 293$ & $195 / 197$ & $203 / 205$ & $164 / 172$ & $226 / 232$ & $99 / 103$ & $0 / 0$ & $151 / 153$ & $244 / 252$ & $213 / 225$ & $155 / 157$ & $152 / 156$ & $206 / 220$ & $159 / 165$ \\
\hline P3RJ-GA-4 & $154 / 154$ & $181 / 187$ & $287 / 289$ & $197 / 197$ & $203 / 205$ & $164 / 172$ & $226 / 230$ & $99 / 105$ & $0 / 0$ & $151 / 153$ & $252 / 252$ & $213 / 217$ & $155 / 157$ & $152 / 156$ & $200 / 206$ & $159 / 165$ \\
\hline P3RJ-GA-5 & $154 / 154$ & $181 / 187$ & $287 / 289$ & $197 / 199$ & $205 / 207$ & $164 / 172$ & $226 / 230$ & $99 / 105$ & $0 / 0$ & $151 / 153$ & $242 / 252$ & $213 / 217$ & $155 / 157$ & $150 / 156$ & $200 / 206$ & $159 / 165$ \\
\hline P3RJ-GA-6 & $156 / 156$ & $181 / 187$ & $287 / 289$ & $197 / 197$ & $203 / 205$ & $164 / 172$ & $226 / 230$ & $99 / 103$ & $0 / 0$ & $151 / 153$ & $242 / 252$ & $213 / 217$ & $155 / 157$ & $152 / 156$ & $206 / 214$ & $159 / 165$ \\
\hline P3RJ-GA-7 & $156 / 156$ & $181 / 187$ & $279 / 289$ & $197 / 197$ & $203 / 205$ & $164 / 172$ & $226 / 230$ & $99 / 105$ & $0 / 0$ & $151 / 153$ & $242 / 252$ & $213 / 225$ & $155 / 157$ & $150 / 156$ & $200 / 206$ & $159 / 165$ \\
\hline P3RJ-GA-8 & $156 / 156$ & $187 / 187$ & $289 / 289$ & $197 / 197$ & $205 / 205$ & $172 / 172$ & $226 / 226$ & 99/99 & $0 / 0$ & $151 / 153$ & $252 / 252$ & $213 / 213$ & $155 / 155$ & $156 / 156$ & $206 / 206$ & $165 / 165$ \\
\hline P3RJ-GA-9 & $156 / 156$ & $181 / 187$ & $287 / 289$ & $197 / 197$ & $205 / 207$ & $164 / 172$ & $226 / 230$ & $99 / 105$ & $0 / 0$ & $151 / 153$ & $242 / 252$ & $213 / 217$ & $155 / 157$ & $150 / 156$ & $200 / 206$ & $159 / 165$ \\
\hline P3RJ-GA-10 & $154 / 154$ & $181 / 187$ & $287 / 289$ & $197 / 199$ & $205 / 207$ & $164 / 172$ & $226 / 230$ & $99 / 105$ & $0 / 0$ & $0 / 0$ & $242 / 252$ & $213 / 217$ & $155 / 157$ & $150 / 156$ & $200 / 206$ & $159 / 165$ \\
\hline P3RJ-GA-11 & $154 / 156$ & $187 / 187$ & $289 / 289$ & $197 / 197$ & $205 / 205$ & $172 / 172$ & $226 / 226$ & 99/99 & $0 / 0$ & $151 / 153$ & $252 / 252$ & $213 / 213$ & $155 / 155$ & $156 / 156$ & $206 / 206$ & $165 / 165$ \\
\hline P3RJ-GA-12 & $156 / 156$ & $187 / 187$ & $289 / 289$ & $197 / 197$ & $205 / 205$ & $172 / 172$ & $226 / 226$ & 99/99 & $0 / 0$ & $151 / 153$ & $252 / 252$ & $213 / 213$ & $155 / 155$ & $156 / 156$ & $206 / 206$ & $165 / 165$ \\
\hline P3RJ-GA-13 & $154 / 162$ & $187 / 187$ & $289 / 289$ & $197 / 197$ & $205 / 205$ & $172 / 172$ & $226 / 226$ & $0 / 0$ & $0 / 0$ & $151 / 153$ & $252 / 252$ & $213 / 213$ & $155 / 155$ & $156 / 156$ & $206 / 206$ & $165 / 165$ \\
\hline P3RJ-GA-14 & $156 / 156$ & $181 / 187$ & $287 / 289$ & 197/199 & $203 / 205$ & $164 / 172$ & $226 / 230$ & $99 / 105$ & $0 / 0$ & $151 / 153$ & $242 / 252$ & $213 / 217$ & $155 / 157$ & $152 / 156$ & $200 / 206$ & $159 / 165$ \\
\hline P3RJ-GA-15 & $156 / 156$ & $181 / 187$ & $289 / 289$ & $197 / 197$ & $203 / 205$ & $164 / 172$ & $226 / 230$ & $99 / 105$ & $0 / 0$ & $151 / 153$ & $242 / 252$ & $213 / 225$ & $155 / 157$ & $152 / 156$ & $206 / 208$ & $159 / 165$ \\
\hline P3RJ-GA-16 & $154 / 156$ & $187 / 187$ & $289 / 289$ & 197/197 & $205 / 205$ & $172 / 172$ & $226 / 226$ & 99/99 & $0 / 0$ & $151 / 153$ & $252 / 252$ & $213 / 213$ & $155 / 155$ & $156 / 156$ & $206 / 206$ & $165 / 165$ \\
\hline P3RJ-GA-17 & $154 / 156$ & $187 / 187$ & $289 / 289$ & $197 / 197$ & $205 / 205$ & $172 / 172$ & $226 / 226$ & 99/99 & $0 / 0$ & $151 / 153$ & $252 / 252$ & $213 / 213$ & $155 / 155$ & $156 / 156$ & $206 / 206$ & $165 / 165$ \\
\hline
\end{tabular}




\begin{tabular}{|c|c|c|c|c|c|c|c|c|c|c|c|c|c|c|c|c|}
\hline Indivíduo & $\begin{array}{l}\overline{8} \\
0 \\
0 \\
0 \\
01\end{array}$ & 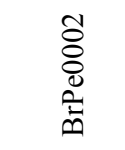 & 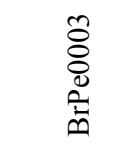 & 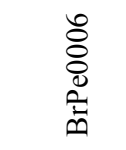 & 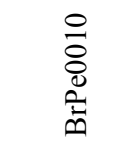 & 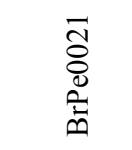 & 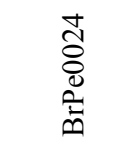 & $\begin{array}{l}\infty \\
\widetilde{\delta} \\
0 \\
0 \\
\stackrel{0}{1} \\
0\end{array}$ & $\begin{array}{l}\overrightarrow{0} \\
\overline{0} \\
0 \\
\stackrel{0}{0}\end{array}$ & 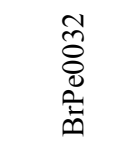 & 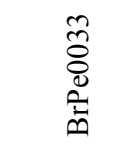 & 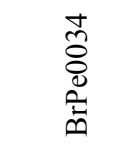 & 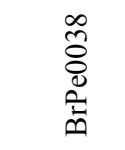 & 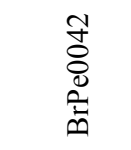 & 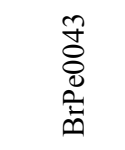 & $\begin{array}{l}\bar{D} \\
\bar{D} \\
0 \\
\overline{0}\end{array}$ \\
\hline P3RJ-GA-18 & $54 / 156$ & $187 / 187$ & $289 / 289$ & $197 / 197$ & $205 / 205$ & $172 / 172$ & $226 / 226$ & 99/99 & $0 / 0$ & $151 / 153$ & $252 / 252$ & $213 / 213$ & $155 / 155$ & $156 / 156$ & $206 / 206$ & $165 / 165$ \\
\hline P3RJ-GA-19 & $154 / 156$ & $187 / 187$ & $289 / 289$ & $197 / 197$ & $205 / 205$ & $172 / 172$ & $226 / 226$ & $99 / 99$ & $0 / 0$ & $151 / 153$ & $252 / 252$ & $213 / 213$ & $155 / 155$ & $156 / 156$ & $206 / 206$ & $165 / 165$ \\
\hline P3RJ-GA-20 & $156 / 156$ & $181 / 187$ & $287 / 289$ & $197 / 197$ & $203 / 205$ & $164 / 172$ & $226 / 230$ & $99 / 103$ & $0 / 0$ & $151 / 153$ & $242 / 252$ & $213 / 217$ & $155 / 157$ & $152 / 156$ & $206 / 214$ & $159 / 165$ \\
\hline P3RJ-GA-21 & $156 / 156$ & $187 / 187$ & $289 / 289$ & $197 / 197$ & $205 / 205$ & $172 / 172$ & $226 / 226$ & 99/99 & $0 / 0$ & $151 / 153$ & $252 / 252$ & $213 / 213$ & $155 / 155$ & $156 / 156$ & $206 / 206$ & $165 / 165$ \\
\hline P3RJ-GA-22 & $156 / 156$ & $187 / 187$ & $289 / 289$ & $197 / 197$ & $205 / 205$ & $172 / 172$ & $226 / 226$ & $99 / 99$ & $0 / 0$ & $151 / 153$ & $252 / 252$ & $213 / 213$ & $155 / 155$ & $156 / 156$ & $206 / 206$ & $165 / 165$ \\
\hline P3RJ-GA-23 & $156 / 156$ & $0 / 0$ & $287 / 289$ & $195 / 197$ & $203 / 205$ & $164 / 172$ & $226 / 232$ & $99 / 103$ & $0 / 0$ & $151 / 153$ & $252 / 252$ & $213 / 217$ & $155 / 157$ & $152 / 156$ & $206 / 214$ & $159 / 165$ \\
\hline P4RJ-CV & $154 / 156$ & $187 / 187$ & $289 / 289$ & $197 / 197$ & $205 / 205$ & $172 / 172$ & $226 / 226$ & 99/99 & $45 / 145$ & $151 / 153$ & $252 / 252$ & $213 / 213$ & $155 / 155$ & $156 / 156$ & $206 / 206$ & $165 / 165$ \\
\hline P4RJ-CV-1 & $154 / 156$ & $187 / 187$ & $289 / 289$ & $197 / 197$ & $205 / 205$ & $172 / 172$ & $226 / 226$ & $99 / 9$ & $5 / 145$ & $151 / 153$ & $252 / 252$ & $213 / 213$ & $155 / 155$ & $156 / 156$ & $206 / 206$ & $165 / 165$ \\
\hline P4RJ-CV-2 & $154 / 156$ & $187 / 187$ & $289 / 289$ & $197 / 197$ & $205 / 205$ & $172 / 172$ & $226 / 226$ & 99/99 & $145 / 145$ & $151 / 153$ & $252 / 252$ & $213 / 213$ & $155 / 155$ & $156 / 156$ & $206 / 206$ & $165 / 165$ \\
\hline P4RJ-CV-3 & $154 / 156$ & $187 / 187$ & $289 / 289$ & $197 / 197$ & $205 / 205$ & $172 / 172$ & $226 / 226$ & 99/99 & $145 / 145$ & $151 / 153$ & $252 / 252$ & $213 / 213$ & $155 / 155$ & $156 / 156$ & $206 / 206$ & $165 / 165$ \\
\hline P4RJ-CV-4 & $54 / 156$ & $187 / 187$ & $289 / 289$ & $197 / 197$ & $05 / 205$ & $172 / 172$ & $226 / 226$ & $99 / 99$ & $45 / 145$ & $151 / 153$ & $252 / 252$ & $213 / 213$ & $155 / 155$ & $156 / 156$ & $200 / 206$ & $165 / 165$ \\
\hline P4RJ-CV-5 & $156 / 156$ & $187 / 187$ & $289 / 289$ & $197 / 197$ & $205 / 205$ & $172 / 172$ & $226 / 226$ & 99/99 & $145 / 145$ & $151 / 153$ & $252 / 252$ & $213 / 213$ & $155 / 155$ & $156 / 156$ & $206 / 206$ & $165 / 165$ \\
\hline P4RJ-CV-6 & $154 / 156$ & $187 / 187$ & $289 / 289$ & $197 / 197$ & $205 / 205$ & $172 / 172$ & $226 / 226$ & 99/99 & $145 / 145$ & $151 / 153$ & $252 / 252$ & $213 / 213$ & $155 / 155$ & $156 / 156$ & $206 / 206$ & $165 / 165$ \\
\hline P4RJ-CV-7 & $156 / 156$ & $187 / 187$ & $289 / 289$ & $197 / 197$ & $205 / 205$ & $172 / 172$ & $226 / 226$ & 99/99 & $145 / 145$ & $151 / 153$ & $252 / 252$ & $213 / 213$ & $155 / 155$ & $156 / 156$ & $206 / 206$ & $165 / 165$ \\
\hline P4RJ-CV-8 & $154 / 156$ & $187 / 187$ & $289 / 289$ & $197 / 197$ & $205 / 205$ & $172 / 172$ & $226 / 226$ & $99 /$ & $145 / 145$ & $151 / 153$ & $252 / 252$ & $213 / 213$ & $155 / 155$ & $156 / 156$ & $206 / 206$ & $165 / 165$ \\
\hline P4RJ-CV-9 & $154 / 156$ & $187 / 187$ & $289 / 289$ & 197/197 & $205 / 205$ & $172 / 172$ & $226 / 226$ & 99/99 & $145 / 145$ & $151 / 153$ & $252 / 252$ & $213 / 213$ & $155 / 155$ & $156 / 156$ & $206 / 206$ & $165 / 165$ \\
\hline P4RJ-CV-10 & $156 / 156$ & $187 / 187$ & $289 / 289$ & $197 / 197$ & $205 / 205$ & $172 / 172$ & $226 / 226$ & 99/99 & $145 / 145$ & $151 / 153$ & $252 / 252$ & $213 / 213$ & $155 / 155$ & $156 / 156$ & $206 / 206$ & $165 / 165$ \\
\hline
\end{tabular}




\begin{tabular}{|c|c|c|c|c|c|c|c|c|c|c|c|c|c|c|c|c|}
\hline Indivíduo & 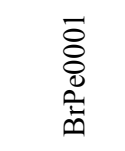 & 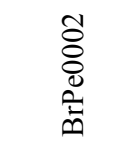 & 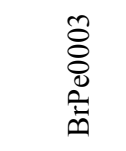 & 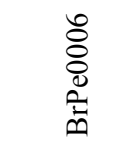 & $\begin{array}{l}0 \\
0 \\
0 \\
0 \\
0 \\
0\end{array}$ & 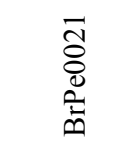 & 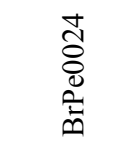 & 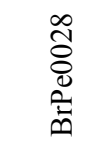 & 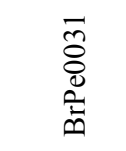 & 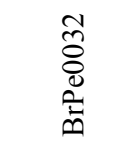 & 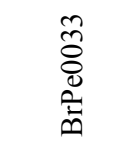 & 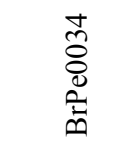 & 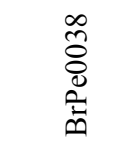 & 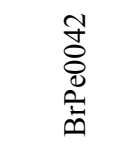 & 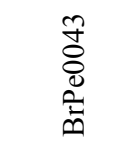 & 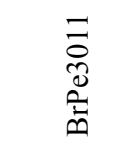 \\
\hline P4RJ-CV-11 & $156 / 156$ & $187 / 187$ & $289 / 289$ & $197 / 197$ & $205 / 205$ & $172 / 172$ & $226 / 226$ & 99/99 & $145 / 145$ & $151 / 153$ & $252 / 252$ & $213 / 213$ & $155 / 155$ & $156 / 156$ & $206 / 206$ & $165 / 165$ \\
\hline P4RJ-CV-12 & $154 / 156$ & $187 / 187$ & $289 / 289$ & $197 / 197$ & $205 / 205$ & $172 / 172$ & $226 / 226$ & 99/99 & $145 / 145$ & $151 / 153$ & $252 / 252$ & $213 / 213$ & $155 / 155$ & $156 / 156$ & $206 / 206$ & $165 / 165$ \\
\hline P4RJ-CV-13 & $154 / 154$ & $187 / 187$ & $289 / 289$ & $197 / 197$ & $205 / 205$ & $172 / 172$ & $226 / 226$ & 99/99 & $145 / 145$ & $151 / 153$ & $252 / 252$ & $213 / 213$ & $155 / 155$ & $156 / 156$ & $206 / 206$ & $165 / 165$ \\
\hline P4RJ-CV-14 & $154 / 156$ & $187 / 187$ & $289 / 289$ & $197 / 197$ & $205 / 205$ & $172 / 172$ & $226 / 226$ & 99/99 & $145 / 145$ & $151 / 153$ & $252 / 252$ & $213 / 213$ & $155 / 155$ & $156 / 156$ & $206 / 206$ & $165 / 165$ \\
\hline P4RJ-CV-15 & $154 / 156$ & $187 / 187$ & $289 / 289$ & $197 / 197$ & $205 / 205$ & $172 / 172$ & $226 / 226$ & 99/99 & $145 / 145$ & $151 / 153$ & $252 / 252$ & $213 / 213$ & $155 / 155$ & $156 / 156$ & $206 / 206$ & $165 / 165$ \\
\hline P4RJ-CV-16 & $154 / 156$ & $187 / 187$ & $289 / 289$ & $197 / 197$ & $205 / 205$ & $172 / 172$ & $226 / 226$ & 99/99 & $145 / 145$ & $151 / 153$ & $252 / 252$ & $213 / 213$ & $155 / 155$ & $156 / 156$ & $206 / 206$ & $165 / 165$ \\
\hline P4RJ-CV-17 & $156 / 156$ & $187 / 187$ & $289 / 289$ & $197 / 197$ & $205 / 205$ & $172 / 172$ & $226 / 226$ & 99/99 & $143 / 145$ & $0 / 0$ & $252 / 252$ & $213 / 213$ & $155 / 155$ & $156 / 156$ & $206 / 206$ & $165 / 165$ \\
\hline P4RJ-CV-18 & $156 / 156$ & $187 / 187$ & $289 / 289$ & $197 / 197$ & $205 / 205$ & $172 / 172$ & $226 / 226$ & 99/99 & $145 / 145$ & $151 / 153$ & $252 / 252$ & $213 / 213$ & $155 / 155$ & $156 / 156$ & $206 / 206$ & $165 / 165$ \\
\hline P4RJ-CV-19 & $156 / 156$ & $187 / 187$ & $289 / 289$ & $197 / 197$ & $205 / 205$ & $172 / 172$ & $226 / 226$ & 99/99 & $145 / 145$ & $0 / 0$ & $252 / 252$ & $213 / 213$ & $155 / 155$ & $156 / 156$ & $206 / 206$ & $165 / 165$ \\
\hline P4RJ-CV-20 & $154 / 154$ & $187 / 187$ & $289 / 289$ & $197 / 197$ & $205 / 205$ & $172 / 172$ & $226 / 226$ & 99/99 & $145 / 145$ & $0 / 0$ & $0 / 0$ & $213 / 213$ & $155 / 155$ & $156 / 156$ & $206 / 206$ & $165 / 165$ \\
\hline P4RJ-CV-23 & $154 / 154$ & $187 / 187$ & $289 / 289$ & $197 / 197$ & $205 / 205$ & $172 / 172$ & $226 / 226$ & 99/99 & $145 / 145$ & $151 / 153$ & $252 / 252$ & $213 / 213$ & $155 / 155$ & $156 / 156$ & $206 / 206$ & $165 / 165$ \\
\hline
\end{tabular}


CAPÍTULO 3. ANÁLISE DE PATERNIDADE EM GENÓTIPOS DE PASSIFLORA OBTIDOS A PARTIR DE CRUZAMENTOS INTERESPECÍFICOS UTILIZANDO MARCADORES MICROSSATÉLITES

CHAPTER 3. PATERNITY ANALYSIS OF PASSIFLORA GENOTYPES OBTAINED FROM INTERESPECIFIC CROSSES USING MICROSATELLITE MARKERS 


\section{RESUMO}

Espécies silvestres de Passiflora têm um grande potencial na utilização de cruzamentos interespecíficos para a introdução de características desejáveis nas cultivares comerciais. Considerando que a confirmação de cruzamentos é parte importante de um programa de melhoramento, o objetivo desse trabalho foi comprovar as genealogias de cruzamentos interespecíficos em Passifloras realizando análises de paternidade com o auxílio de marcadores microssatélites. Foram analisados os genitores de cruzamentos de quatro genealogias (A, B, C e D) segundo a Inclusão ou Exclusão Categóricas para cada loco, e então calculados os Índice de Paternidade (PI) e a Probabilidade de Paternidade (W) para os verdadeiros genitores segundo o trio genitor feminino, progênie e suposto genitor masculino, e na ausência de um dos genitores, os mesmos índices foram calculados segundo o duo genitor e progênie. Os marcadores microssatélites testados auxiliaram na exclusão de 7 supostos genitores de 6 cruzamentos em 4 genealogias, e confirmaram como genitores verdadeiros a 5 dos supostos genitores, onde $\mathrm{W}$ foi entre 95,137 e 99,999\%. Neste estudo foi confirmada a obtenção do híbrido P. edulis GA2 x P. incarnata.

Palavras-chave: Passiflora, microssatélites, paternidade, cruzamentos interespecíficos, melhoramento de plantas 


\begin{abstract}
Wild species of Passiflora have great potential for use in interspecific crosses to introduce desirable traits in commercial cultivars. Considering that the verification of crossing is essential in a breeding program, the target of this work was to confirm the genealogies of interspecific crosses in Passiflora, making paternity tests using SSR markers. We analyzed the genitors from interspecific crosses of four genealogies (A, B, $\mathrm{C}$ and D) by Categorical Inclusion or Exclusion for each loci, and then, estimated the Paternity Index (PI) and the Probability of Paternity (W) for the true genitor, according to the trio female genitor, progeny and alleged masculine genitor, and in the absence of one of the parents, the same values were calculated according to the duo genitor and progeny. Microsatellite markers tested assisted for the exclusion of 7 alleged genitors of 6 crossings in 4 genealogies, and confirmed as true genitors 5 alleged genitors, where $\mathrm{W}$ was rated between 95.137 and $99.999 \%$. This research confirms the achievement of sexual hybrids for interspecific crossing of $P$. edulis GA2 x P. incarnata.
\end{abstract}

Key words: Passiflora, microsatellites, paternity, interspecific crosses, plant breeding. 


\section{INTRODUÇÃO}

O gênero Passiflora, amplamente distribuído no mundo, tem sido encontrado nas Américas, na Índia, nas Ilhas Galápagos, na Austrália, nas Filipinas e em muitas outras ilhas do Oceano Pacífico. Entretanto, 95\% das espécies endêmicas encontram-se na América do Sul (VANDERPLANK, 2000). No total, estima-se que o número de espécies do gênero Passiflora seja maior do que 500 (FEUILLET, 2004), mas ainda novas espécies continuam sendo identificadas (CERVI, 2005; CERVI; LINSINGEN, 2010; IMIG; CERVI, 2014).

Dentro das muitas espécies de Passiflora, a que possui maior destaque é Passiflora edulis Sims, devido a seu uso na produção de frutos, tanto para consumo in natura, quanto para a indústria alimentar na fabricação de sucos e polpas (SOUZA; MELETTI, 1997). As passifloras também tem sido usadas para propósitos ornamentais (PEIXOTO, 2005), medicinais (COSTA; TUPINAMBÁ, 2005) e como fonte de óleos para a indústria cosmética (ZERAIK et al., 2010).

Considerando a importância dessa cultura e seus principais usos, programas de melhoramento genético tem realizado cruzamentos inter e intraespecíficos utilizando espécies como P. setacea, P. quadrifaria, P. incarnata, entre outras, para a introdução de características desejáveis nas cultivares comerciais (MELETTI et al., 2005). Alguns dos híbridos interespecíficos obtidos tem apresentado problemas de desenvolvimento, esterilidade masculina, baixa viabilidade polínica ou dificuldade em florescer, o que dificulta a realização de ciclos de retrocruzamento para recompor o vigor natural das plantas e as características interessantes para comercialização, o que no fim torna o programa de melhoramento mais demorado (MELETTI; BRUCKNER, 2001).

No melhoramento genético, marcadores moleculares têm sido uma excelente ferramenta para auxiliar na seleção de genótipos, na redução de ciclos de melhoramento, na caracterização do germoplasma, na análise de diversidade, na confirmação de cruzamentos e nos testes de paternidade. Por exemplo, no programa de melhoramento das Passifloras, FALEIRO et al., (2005) utilizaram marcadores moleculares RAPD para confirmar o sucesso da fecundação cruzada e a recuperação do genoma recorrente em sucessivos retrocruzamentos com $P$. edulis após a geração de 
híbridos. Também, RAPD tem sido usado na confirmação de hibridações interespecíficas entre várias espécies de Passifloras (JUNQUEIRA et al., 2008).

Contudo, marcadores microssatélites ou SSR (Sequências Simples Repetidas) são os marcadores mais utilizados em testes de paternidade (LEE et al., 2000; YAMAMOTO et al., 2003), reconstituição de pedigree (VOUILLAMOZ; MAIGRE; MEREDITH, 2003), mapeamento físico e genético de genomas (PUGH et al., 2004), como também em análises de variabilidade genética de populações (SIMIC et al., 2009), devido a que microssatélites encontram-se localizados em diferentes cromossomo, o que permite assegurar a distribuição aleatória e a herança Mendeliana (Lei da Segregação Independente) (BUCKLETON; CLAYTON; TRIGSS, 2005).

Microssatélites são sequências de 1 a 6 nucleotídeos, chamados de motivos, repetidos em tandem (LITT; LUTY, 1989) e estão presentes em regiões codificadoras e não codificadoras dos genomas eucarióticos e procarióticos (FIELD; WILLS, 1996). Inicialmente, marcadores microssatélites foram desenvolvidos em humanos (LITT; LUTY, 1989) e então, vários estudos foram realizados em plantas que demonstraram que são amplamente distribuídos nos seus genomas (BRUNEL, 1994). As vantagens do uso de microssatélites sobre outros marcadores moleculares nas análises de paternidade é que estes são codominantes, têm alta reprodutibilidade, a PCR é simples e rápida, é preciso uma pequena quantidade de DNA, têm baixo custo de utilização, grande poder de resolução e altos níveis de polimorfismo onde, por exemplo, um loco pode apresentar vários alelos, e na maioria dos casos, um indivíduo pode ser excluído como genitor verdadeiro usando poucos locos (BUCKLETON; CLAYTON; TRIGSS, 2005).

O objetivo principal desse trabalho foi confirmar as genealogias de cruzamentos interespecíficos em Passifloras realizando análises de paternidade com auxílio de marcadores microssatélites.

\section{MATERIAL E MÉTODOS}

\section{Material vegetal}

Os cruzamentos foram realizados no Banco Ativo de Germoplasma 'Flor da Paixão’ da Embrapa Cerrados e as análises moleculares no Laboratório de Genética 
Vegetal da Embrapa Recursos Genéticos e Biotecnologia, Cenargen. Foram analisadas quatro genealogias (A, B, C e D), com seus respectivos cruzamentos (Tabela 1) e seus prováveis genitores.

Nos casos em que não se encontrava disponível algum dos acessos, se fez uma reconstituição dos genótipos segundo herança Mendeliana, para determinar o genótipo esperado.

Os genitores iniciais das genealogias foram: o híbrido interespecífico BRS Rósea Púrpura proveniente de cruzamentos entre as espécies $P$. setacea, P. quadrifaria e $P$. incarnata, o híbrido interespecífico BRS Céu do Cerrado, proveniente de cruzamentos entre as espécies $P$. incarnata e $P$. edulis GA2, os acessos de $P$. edulis GA2 e $P$. edulis MA provenientes de seleção massal, um acesso da espécie $P$. incarnata e um acesso de Passiflora aff. amethystina "macrocarpa", ambos silvestres (Tabela 1).

Tabela 1. Cruzamentos e prováveis genitores de quatro genealogias.

\begin{tabular}{|c|c|c|c|c|c|c|c|}
\hline G & $\mathrm{C}$ & CA & Genitor Feminino & & Yenitor Masculino & & Progênie \\
\hline \multirow{2}{*}{ A } & $1^{\mathrm{o}}$ & & BRS Rósea púrpura & $\mathbf{x}$ & P. edulis GA2 & $=$ & F1RPGA2_R \\
\hline & $2^{\circ}$ & $*$ & F1RPGA2_R & $\mathbf{x}$ & P. edulis MA & $=$ & F1RPGA2MA \\
\hline \multirow{3}{*}{ B } & $1^{\mathrm{o}}$ & & P. edulis GA2 & $\mathbf{x}$ & P. incarnata & $=$ & F1GA2Pi_R \\
\hline & $2^{\circ}$ & $*$ & F1GA2Pi_R & $\mathbf{x}$ & P. edulis GA2 & $=$ & F1GA2PiRC1 \\
\hline & $3^{\circ}$ & $*$ & F1GA2PiRC1 & $\mathbf{x}$ & P. edulis GA2 & $=$ & F1GA2PiRC2 \\
\hline \multirow{3}{*}{$\mathrm{C}$} & $1^{\mathrm{o}}$ & & $P$. aff. amethystina & $\mathbf{x}$ & P. edulis GA2 & $=$ & F1PAGA2_R \\
\hline & $2^{\circ}$ & $*$ & F1PAGA2_R & $\mathbf{x}$ & P. edulis GA2 & $=$ & F1PAGA2RC1 \\
\hline & $3^{\circ}$ & * & F1PAGA2RC1 & $\mathbf{x}$ & P. edulis GA2 & $=$ & F1PAGA2RC2 \\
\hline $\mathrm{D}$ & $1^{o}$ & $*$ & BRS Céu Do Cerrado & $\mathbf{x}$ & P. edulis MA & $=$ & F1CCMA \\
\hline
\end{tabular}

G: genealogia; C: cruzamento; CA: cruzamentos analisados para teste de paternidade; R: reconstituído

Os cruzamentos foram realizados no BAG da Embrapa Cerrados. Os botões florais das plantas que foram escolhidas como genitores femininos, foram protegidos com sacos de papel branco antes da antese, e então emasculados. Na manhã seguinte foi coletado o pólen do genitor masculino e realizada a hibridação artificial. As flores foram novamente protegidas até o desenvolvimento completo do fruto. Assim que os 
frutos ficaram amadurecidos, eles foram coletados e retiradas as sementes para serem semeadas em bandejas de poliestireno. Foi selecionada somente uma planta por cruzamento com as características desejáveis para a continuação da etapa de melhoramento. As plantas foram clonadas para a manutenção dos acessos.

\section{Extração de DNA e genotipagem}

Folhas em estágio intermediário de maturação de cada genótipo foram coletadas para a extração de DNA utilizando o método CTAB (DOYLE; DOYLE, 1987) com modificações de FALEIRO et al. (2003). As concentrações de DNA foram medidas no espectrofotômetro Nanodrop 2000 (Thermo Scientific, USA), e as amostras de DNA foram diluídas em TE $\mathrm{pH}$ 8,0 para uma concentração final de $5 \eta \mathrm{g} / \mu \mathrm{L}$. Para os testes de paternidade, foram utilizados 18 marcadores microssatélites polimórficos que foram previamente desenhados e validados para $P$. edulis no Capítulo 1(Tabela 2).

As reações de PCR foram realizadas em um volume total de $5 \mu \mathrm{L}$ que

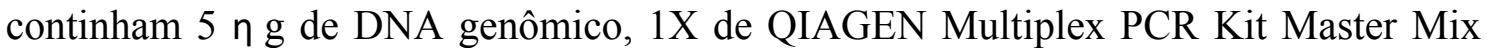
(QIAGEN), 0,5X Q-Solution (QIAGEN), e 0,2 $\mu \mathrm{M}$ de cada primer. As reações de PCR foram realizadas no termociclador Veriti ${ }^{\mathrm{TM}}$ (Applied Biosystems, USA) usando o seguinte programa de amplificação: $95^{\circ} \mathrm{C}$ por 15 minutos; 35 ciclos a $94^{\circ} \mathrm{C}$ por 30 segundos, 55,57 ou $60^{\circ} \mathrm{C}$ por 90 segundos, e $72^{\circ} \mathrm{C}$ por 60 segundos; e uma extensão final a $60^{\circ} \mathrm{C}$ por 60 minutos.

Foram adicionados $9 \mu \mathrm{L}$ de $\mathrm{Hi}-\mathrm{Di}^{\mathrm{TM}}$ Formamida (Applied Biosystems, USA) mais um padrão de tamanho marcado com o fluoróforo ROX, para $1 \mu \mathrm{L}$ do produto da PCR, e então desnaturado a $94^{\circ} \mathrm{C}$ por 5 minutos, para logo ser injetado no sequenciador automático ABI3730 (Applied Biosystems, USA). As análises da genotipagem foram realizadas no software GeneMapper® (Applied Biosystems, USA).

Tabela 2. Estatísticas da seleção de 18 marcadores microssatélites polimórficos que foram validados em $P$. edulis no Capítulo 1.

\begin{tabular}{|c|c|c|c|c|c|c|c|c|c|c|}
\hline Painel & Marcador & Dye & Sequência do primer 5'-3' & Motivo & $\mathrm{Ta}$ & $\mathrm{N}$ & $\begin{array}{l}\text { Tamanho } \\
\text { alelos bp }\end{array}$ & $\mathrm{He}$ & Нo & PIC \\
\hline \multirow[t]{2}{*}{1} & $\mathrm{BrPe} 0001$ & 6-Fam & $\begin{array}{l}\text { F:GTTGAGAGGATTGTGTTTG } \\
\text { R: ATGGTAGAGGAGGAGAGA }\end{array}$ & $(\mathrm{CT})_{14}$ & $55^{\circ} \mathrm{C}$ & 3 & $143-157$ & 0,56 & 0,14 & 0,46 \\
\hline & $\mathrm{BrPe} 0028$ & Hex & $\begin{array}{l}\text { F:CAAAAGGAACAGGGAAGA } \\
\text { R: GAAAGAGAGAAAGACAGAGA }\end{array}$ & $(\mathrm{TA})_{6}$ & $55^{\circ} \mathrm{C}$ & 5 & $90-110$ & 0,80 & 0,50 & 0,72 \\
\hline
\end{tabular}




\begin{tabular}{|c|c|c|c|c|c|c|c|c|c|}
\hline Painel & Marcador Dye & Sequência do primer $5^{\prime}-3$ ' & Motivo & $\mathrm{Ta}$ & $\mathrm{N}$ & $\begin{array}{l}\text { Tamanho } \\
\text { alelos bp }\end{array}$ & $\mathrm{He}$ & Ho & $\mathrm{PIC}$ \\
\hline \multirow[t]{2}{*}{2} & $\mathrm{BrPe} 0002 \mathrm{Hex}$ & $\begin{array}{l}\text { F:AAAGCCCAGATGAAGTGAA } \\
\text { R:GGCTCCAATCAGAAGTGT }\end{array}$ & $(\mathrm{AG})_{12}$ & $55^{\circ} \mathrm{C}$ & 3 & $177-185$ & 0,69 & 0,56 & 0,58 \\
\hline & $\mathrm{BrPe0024}$ 6-Fam & $\begin{array}{l}\text { F:CCCTACCTTTCTCTGCTT } \\
\text { R:CATCTCCTCTATCTCCTTC }\end{array}$ & $(\mathrm{TC})_{7}$ & $55^{\circ} \mathrm{C}$ & 4 & $221-231$ & 0,76 & 0,70 & 0,68 \\
\hline \multirow[t]{3}{*}{3} & $\mathrm{BrPe} 0003$ 6-Fam & $\begin{array}{l}\mathrm{F}: \text { CTTTCTCTCCСТATACCC } \\
\text { R:CCCTCCATAATCACATAAC }\end{array}$ & $(\mathrm{TC})_{11}$ & $55^{\circ} \mathrm{C}$ & 5 & $277-291$ & 0,70 & 0,40 & 0,62 \\
\hline & BrPe0006 6-Fam & $\begin{array}{l}\text { F:AAGGAAAAGAACAGCCTCA } \\
\text { R:CGCTCTCAAATCAGTCAAA } \\
\end{array}$ & $(\mathrm{TC})_{10}$ & $55^{\circ} \mathrm{C}$ & 4 & 193-199 & 0,68 & 0,40 & 0,59 \\
\hline & $\mathrm{BrPe} 0010 \mathrm{Hex}$ & $\begin{array}{l}\text { F:GAAGAAAAAAGGGCTTG } \\
\text { R:GTTAGGGTTTGGAGGA }\end{array}$ & $(\mathrm{TC})_{9}$ & $55^{\circ} \mathrm{C}$ & 4 & $199-207$ & 0,71 & 0,50 & 0,60 \\
\hline \multirow[t]{2}{*}{4} & BrPe0031 6-Fam & $\begin{array}{l}\text { F:AGGTCGGTGGGTGTGTTTAG } \\
\text { R:CATTCAACTCCCCAAAAGGT }\end{array}$ & $(\mathrm{TA})_{9}$ & $60^{\circ} \mathrm{C}$ & 5 & $134-150$ & 0,77 & 0,67 & 0,67 \\
\hline & $\mathrm{BrPe} 0036 \mathrm{Hex}$ & $\begin{array}{l}\text { F:TCGGACCTTAAAACCGAGAA } \\
\text { R:CAGCACCAAAATTTGACGAG }\end{array}$ & $(\mathrm{TC})_{6}$ & $60^{\circ} \mathrm{C}$ & 4 & $197-203$ & 0,65 & 0,10 & 0,54 \\
\hline \multirow[t]{2}{*}{5} & $\mathrm{BrPe} 0032$ 6-Fam & $\begin{array}{l}\text { F:TTGCACAATGACCAATGTTGT } \\
\text { R:CTGAGCACCTTGTCAAAATACA }\end{array}$ & $(\mathrm{AT})_{13}$ & $60^{\circ} \mathrm{C}$ & 7 & $137-157$ & 0,84 & 1,00 & 0,77 \\
\hline & $\mathrm{BrPe} 0034 \mathrm{Hex}$ & $\begin{array}{l}\text { F:CCTGTGGTGAAAATGGAACC } \\
\text { R:GAGCCCTGGACTGACACATT }\end{array}$ & $(\mathrm{CT})_{15}$ & $60^{\circ} \mathrm{C}$ & 2 & $217-227$ & 0,56 & 1,00 & 0,38 \\
\hline \multirow[t]{3}{*}{6} & BrPe0038 6-Fam & $\begin{array}{l}\text { F:TTTCAACTTTTCGTGTGTGC } \\
\text { R:TGTTGTTGCTTGGAAGGATG }\end{array}$ & $(\mathrm{AT})_{6}$ & $60^{\circ} \mathrm{C}$ & 5 & $154-176$ & 0,73 & 0,60 & 0,64 \\
\hline & BrPe3011 Hex & $\begin{array}{l}\text { F:CCGGTCTTCCTGATTGACTC } \\
\text { R:CCTCTCTCACCTGGAACTGC }\end{array}$ & $(\mathrm{TTC})_{4}$ & $60^{\circ} \mathrm{C}$ & 3 & $157-163$ & 0,62 & 0,30 & 0,50 \\
\hline & $\mathrm{BrPe0014}$ 6-Fam & $\begin{array}{l}\text { F:AATATGGCTGGGGAAAAC } \\
\text { R:TTCCTGTCTTTGGACCTT }\end{array}$ & $(\mathrm{AG}) 7$ & $57^{\circ} \mathrm{C}$ & 5 & $215-227$ & 0,75 & 0,50 & 0,67 \\
\hline \multirow[t]{5}{*}{ NP } & $\mathrm{BrPe0021}$ 6-Fam & $\begin{array}{l}\text { F:ACTTCCTCATCATTCG } \\
\text { R:GCTATGCCTCTTTTTG }\end{array}$ & $(\mathrm{TA})_{7}$ & $55^{\circ} \mathrm{C}$ & 3 & $158-164$ & 0,67 & 0,25 & 0,56 \\
\hline & $\mathrm{BrPe} 0033 \mathrm{Hex}$ & $\begin{array}{l}\text { F:GCCATGAGAGACTTGGGAGA } \\
\text { R:CGGTTGCCAAAAAGAAGAGA } \\
\end{array}$ & $(\mathrm{AT})_{8}$ & $60^{\circ} \mathrm{C}$ & 5 & $237-249$ & 0,72 & 0,30 & 0,65 \\
\hline & $\mathrm{BrPe0042}$ 6-Fam & $\begin{array}{l}\text { F:CATGCATTCATTTGTTTTTCTTG } \\
\text { R:GATGCTGGGAAAAAGAGTGC }\end{array}$ & $(\mathrm{AT})_{8}$ & $60^{\circ} \mathrm{C}$ & 6 & $142-160$ & 0,71 & 0,80 & 0,63 \\
\hline & $\mathrm{BrPe} 0043 \mathrm{Hex}$ & $\begin{array}{l}\text { F:TCATACATGGATGTCAAATCGATAC } \\
\text { R:GCGGACCAAGAAAATTCAAA }\end{array}$ & $(\mathrm{AT})_{8}$ & $60^{\circ} \mathrm{C}$ & 4 & $199-207$ & 0,71 & 0,50 & 0,60 \\
\hline & & & Média & & 4,24 & & 0,70 & 0,51 & 0,60 \\
\hline
\end{tabular}

$\mathrm{F}$ : primer forward; $\mathrm{R}$ : primer reverse; $\mathrm{T}_{\mathrm{a}}$ : temperatura de anelamento; $\mathrm{N}$ : número de alelos; Ho: heterozigosidade observada; He: heterozigosidade esperada; PIC: conteúdo de informação polimórfica, NP: não painel.

\section{Binagem e frequências alélicas}

Para a binagem e o cálculo de frequências alélicas foram utilizados 22 acessos (10 de P. edulis utilizados na validação dos marcadores microssatélites no Capítulo 1, e 12 indivíduos dos cruzamentos que foram analisados nesse Capítulo). Os alelos foram binados no software Tandem (MATSCHINER; SALZBURGER, 2009) e as frequências alélicas dos locos foram obtidas mediante o software Cervus (Tristan Marshall 19982014) (MARSHALL et al., 1998) 


\section{Análise de paternidade}

Alelos de todos os locos analisados foram comparados entre o suposto genitor feminino e a progênie, e entre o suposto genitor masculino e a progênie para cada cruzamento, segundo herança Mendeliana, determinando-se a sua Inclusão ou Exclusão Categóricas. Quando houve duas ou mais Exclusões Categóricas, o suposto genitor foi eliminado como o verdadeiro genitor segundo protocolo da AMERICAN ASSOCIATION OF BLOOD BANKS (AABB, 2004). Quando houve uma ou nenhuma Exclusão Categórica, isto é, quando tivemos Inclusões Categóricas para todos os locos ou todos os locos menos um, foram calculados: o Índice de Paternidade (PI) e a Probabilidade de Paternidade (W) para o genitor masculino segundo o trio genitor feminino, progênie e suposto genitor masculino (Tabela 3). $\mathrm{Na}$ ausência de um dos genitores, foi calculado o PI e a W segundo o duo genitor e progênie (Tabela 4).

Tabela 3. Distribuição do Índice de Paternidade (PI) para todas as combinações que não excluem os genótipos maternos e paternos (LEE et al., 2000).

\begin{tabular}{|c|c|c|c|}
\hline $\begin{array}{c}\text { Genótipo genitor } \\
\text { feminino }\end{array}$ & Genótipo progênie & $\begin{array}{l}\text { Genótipo do suposto } \\
\text { genitor masculino }\end{array}$ & PI \\
\hline$a a$ & & \multirow{4}{*}{$a a$} & \multirow{4}{*}{$1 / P_{a}$} \\
\hline$a b$ & a & & \\
\hline$b b$ & \multirow{2}{*}{$a b$} & & \\
\hline$c b$ & & & \\
\hline$a a$ & \multirow{3}{*}{$a a$} & \multirow{6}{*}{$a b$} & \multirow{6}{*}{$1 / 2 P_{a}$} \\
\hline$a b$ & & & \\
\hline$a c$ & & & \\
\hline$b b$ & \multirow{2}{*}{$a b$} & & \\
\hline$b c$ & & & \\
\hline$b c$ & $a c$ & & \\
\hline$c c$ & & & \\
\hline \multirow[t]{2}{*}{$c d$} & & & \\
\hline & \multirow{3}{*}{$a b$} & $a a$ & \multirow{2}{*}{$1 /\left(P_{a}+P_{b}\right)$} \\
\hline \multirow[t]{2}{*}{$a b$} & & $a b$ & \\
\hline & & $\overline{a c}$ & $1 / 2\left(P_{a}+P_{b}\right)$ \\
\hline
\end{tabular}

* $P$ é a frequência do alelo $a$ ou $b$ de um específico loco calculado em uma população aleatória. 
O Índice de Paternidade é usado para descrever a taxa de probabilidade baseada em duas hipóteses, a que o suposto genitor é o verdadeiro genitor, e que o suposto genitor não é o verdadeiro genitor. Após o cálculo do Índice de Paternidade, foi calculado o Índice de Paternidade Combinada, que é o produto das probabilidades obtidas para cada loco $\left(\mathrm{CPI}=\mathrm{PI}_{\mathrm{i}} \times \mathrm{PI}_{\mathrm{j}} \mathrm{x} \ldots \mathrm{PI}_{\mathrm{n}}\right)$. Também foi calculada a Probabilidade de Paternidade (W= CPI/(CPI+1)) (LEE et al., 2000) .

Tabela 4. Formulas do Índice de Paternidade (PI) para situações onde o genótipo de um dos genitores encontra-se disponível como amostra de referência (LEE et al., 2000)

\begin{tabular}{ccc} 
Genitor & Progênie & PI \\
\hline$a a$ & $a a$ & $1 / P_{a}$ \\
\cline { 2 - 3 } & $a b$ & $1 / 2 P_{a}$ \\
\hline$a b$ & $a a$ & $1 / 2 P_{a}$ \\
\hline$a b$ & $P_{a}+P_{b} / 4 P_{a} P_{b}$ \\
\hline & $a c$ & $1 / 4 P_{a}$
\end{tabular}

* $P$ é a frequência do alelo $a$ ou $b$ de um específico loco calculado em uma população aleatória.

\section{RESULTADOS E DISCUSSÃO}

Os marcadores microssatélites foram boas ferramentas para confirmar a ocorrência ou não dos cruzamentos testados. Os números de locos analisados para cada genealogia variou entre 14 e 18, dependendo da obtenção de fragmentos amplificados. Dos 18 locos testados, 13 foram utilizados em todos os cruzamentos (BrPe0001, BrPe0003, BrPe0006, BrPe0010, BrPe0014, BrPe0031， BrPe0032， BrPe0033, BrPe0034, BrPe0036, BrPe0038, BrPe0042, BrPe3011). 


\section{Genealogia A}

Para a confirmação da Genealogia A (Figura 1), foi reconstituída a progênie F1RPGA2_R do $1^{\circ}$ Cruzamento entre BRS Rósea Púrpura x P. edulis GA2, e foi utilizada como genitor feminino no $2^{\circ}$ Cruzamento (F1RPGA2_R x P. edulis MA) onde a progênie foi denominada F1RPGA2MA. Considerando nenhuma Exclusão Categórica nos 16 locos analisados (Tabela 5), o suposto genitor feminino F1RPGA2_R é o verdadeiro genitor feminino do acesso F1RPGA2MA com 99,442\% de Probabilidade de Paternidade (Tabela 5.1). Já para na análise de Inclusão ou Exclusão Categóricas, considerando 3 Exclusões Categóricas nos locos considerados, o suposto genitor masculino P. edulis MA é, portanto, excluído como o verdadeiro genitor masculino do acesso F1RPGA2MA (Tabela 5).

$1^{\mathrm{o}}$

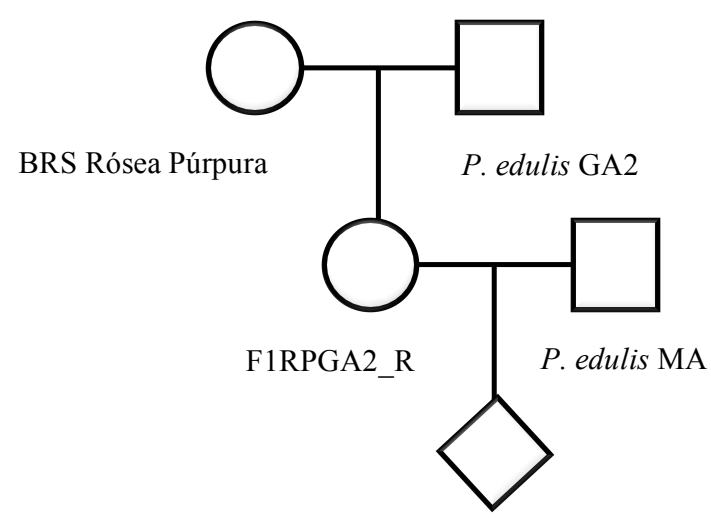

F1RPGA2MA

Figura 1. Genealogia A com dois cruzamentos: $1^{\circ}$ BRS Rósea Púrpura x P. edulis GA2; $2^{\circ}$ F1RPGA2_R x P. edulis MA.

Tabela 5. Análise de Inclusão ou Exclusão Categóricas do $2^{\circ}$ Cruzamento da Genealogia A.

\begin{tabular}{|c|c|c|c|c|c|c|c|c|c|c|c|}
\hline \multirow{2}{*}{ Locos } & \multirow{2}{*}{$\begin{array}{c}\text { Genitor } \\
\text { Fem. } \\
\text { BRS Rósea } \\
\text { Púrpura }\end{array}$} & \multicolumn{2}{|r|}{$\begin{array}{c}\text { Genitor } \\
\text { Masc. }\end{array}$} & \multicolumn{2}{|r|}{$\begin{array}{c}\text { Progênie/ } \\
\text { Genitor Fem. }\end{array}$} & \multicolumn{2}{|r|}{$\begin{array}{l}\text { Genitor } \\
\text { Masc. }\end{array}$} & \multicolumn{2}{|r|}{ Progênie } & \multicolumn{2}{|c|}{$\begin{array}{l}\text { Inclusão/ } \\
\text { Exclusão }\end{array}$} \\
\hline & & $\mathrm{x}$ & $\begin{array}{c}\text { P. edulis } \\
\text { GA2 }\end{array}$ & $=$ & F1RPGA2 (R) & $\mathrm{x}$ & $\begin{array}{c}\text { P. edulis } \\
\text { MA }\end{array}$ & $=$ & F1RPGA2MA & $\begin{array}{c}\text { G. } \\
\text { Fem }\end{array}$ & $\begin{array}{c}\text { G. } \\
\text { Masc }\end{array}$ \\
\hline $\mathrm{BrPe} 0001$ & $156 / 156$ & & $156 / 158$ & & $156 / 158$ & & $156 / 158$ & & $156 / 158$ & I & I \\
\hline $\mathrm{BrPe} 0003$ & $275 / 275$ & & $287 / 289$ & & $275 / 287$ & & $279 / 287$ & & $287 / 287$ & I & I \\
\hline $\mathrm{BrPe} 0006$ & $196 / 196$ & & $188 / 192$ & & $192 / 196$ & & $200 / 200$ & & $196 / 196$ & I & $\mathrm{E}$ \\
\hline
\end{tabular}




\begin{tabular}{|c|c|c|c|c|c|c|c|}
\hline \multirow{2}{*}{ Locos } & \multirow{2}{*}{$\begin{array}{c}\text { Genitor } \\
\text { Fem. } \\
\text { BRS Rósea } \\
\text { Púrpura }\end{array}$} & \multirow{2}{*}{$\begin{array}{c}\text { Genitor } \\
\text { Masc. } \\
\text { P. edulis } \\
\text { GA2 }\end{array}$} & \multirow{2}{*}{$\begin{array}{c}\text { Progênie/ } \\
\text { Genitor Fem. }\end{array}$} & \multirow{2}{*}{$\begin{array}{c}\text { Genitor } \\
\text { Masc. } \\
\text { P. edulis } \\
\text { MA }\end{array}$} & \multirow{2}{*}{$\begin{array}{c}\text { Progênie } \\
\text { F1RPGA2MA }\end{array}$} & \multicolumn{2}{|c|}{$\begin{array}{l}\text { Inclusão/ } \\
\text { Exclusão }\end{array}$} \\
\hline & & & & & & $\begin{array}{c}\text { G. } \\
\text { Fem }\end{array}$ & $\begin{array}{c}\text { G. } \\
\text { Masc }\end{array}$ \\
\hline $\mathrm{BrPe} 0010$ & $196 / 198$ & $202 / 204$ & $196 / 204$ & $202 / 204$ & $204 / 204$ & I & I \\
\hline $\mathrm{BrPe} 0014$ & $216 / 216$ & $216 / 216$ & $216 / 216$ & $216 / 216$ & $216 / 216$ & I & I \\
\hline $\mathrm{BrPe} 0021$ & $152 / 152$ & $164 / 164$ & $152 / 164$ & $164 / 164$ & $164 / 164$ & I & I \\
\hline $\mathrm{BrPe} 0024$ & $231 / 231$ & $233 / 233$ & $231 / 233$ & $231 / 233$ & $231 / 233$ & I & I \\
\hline $\mathrm{BrPe} 0028$ & $99 / 99$ & $105 / 105$ & $99 / 105$ & $105 / 105$ & $105 / 105$ & I & I \\
\hline $\mathrm{BrPe} 0031$ & $149 / 149$ & $149 / 151$ & $149 / 151$ & $151 / 151$ & $151 / 153$ & I & $\mathrm{E}$ \\
\hline $\mathrm{BrPe} 0032$ & $139 / 139$ & $149 / 149$ & $139 / 149$ & $149 / 149$ & $149 / 149$ & I & I \\
\hline $\mathrm{BrPe} 0033$ & $243 / 243$ & $245 / 251$ & $243 / 251$ & $243 / 251$ & $251 / 263$ & I & $\mathrm{E}$ \\
\hline $\mathrm{BrPe} 0034$ & $223 / 237$ & $219 / 231$ & $219 / 223$ & $219 / 231$ & $219 / 231$ & I & I \\
\hline $\mathrm{BrPe} 0036$ & $198 / 204$ & $198 / 200$ & $198 / 200$ & $200 / 200$ & $200 / 200$ & I & I \\
\hline $\mathrm{BrPe} 0038$ & $156 / 156$ & $158 / 158$ & $156 / 158$ & $158 / 158$ & $158 / 158$ & I & I \\
\hline $\mathrm{BrPe} 0042$ & $134 / 140$ & $156 / 156$ & $134 / 156$ & $154 / 156$ & $154 / 156$ & I & I \\
\hline BrPe3011 & $163 / 165$ & $159 / 165$ & $159 / 163$ & $159 / 165$ & $159 / 165$ & I & I \\
\hline
\end{tabular}

Tabela 5.1. Cálculo do Índice de Paternidade (PI), do Índice de Probabilidade Combinado (CPI) e da Probabilidade de Paternidade (W) considerando o duo genitor e progênie para o $2^{\circ}$ Cruzamento da Genealogia A.

\begin{tabular}{|c|c|c|c|c|c|}
\hline Loco & $\begin{array}{c}\text { Genitor Feminino } \\
\text { F1RPGA2 (R) }\end{array}$ & $\begin{array}{c}\text { Progênie } \\
\text { F1RPGA2MA }\end{array}$ & $\begin{array}{l}\text { Frequência dos } \\
\qquad \text { alelos* } \\
\left(P_{a} \text { e/ou } P_{b}\right)\end{array}$ & $\begin{array}{c}\text { PI } \\
\text { (fórmula) }\end{array}$ & PI \\
\hline $\mathrm{BrPe} 0001$ & $\begin{array}{c}156 / 158 \\
a / b\end{array}$ & $\begin{array}{c}156 / 158 \\
a / b\end{array}$ & $\begin{array}{l}P_{a}=0,500 \\
P_{b}=0,300\end{array}$ & $P_{a}+P_{b} / 4 P_{a} P_{b}$ & 1,333 \\
\hline $\mathrm{BrPe} 0003$ & $\begin{array}{c}275 / 287 \\
b / a\end{array}$ & $\begin{array}{c}287 / 287 \\
a / a\end{array}$ & $P_{a}=0,273$ & $1 /\left(2 P_{a}\right)$ & 1,832 \\
\hline $\mathrm{BrPe} 0006$ & $\begin{array}{c}192 / 196 \\
b / a\end{array}$ & $\begin{array}{c}196 / 196 \\
a / a\end{array}$ & $P_{a}=0,318$ & $1 /\left(2 P_{a}\right)$ & 1,572 \\
\hline $\mathrm{BrPe} 0010$ & $\begin{array}{c}196 / 204 \\
b / a\end{array}$ & $\begin{array}{c}204 / 204 \\
a / a\end{array}$ & $P_{a}=0,159$ & $1 /\left(2 P_{a}\right)$ & 3,145 \\
\hline $\mathrm{BrPe} 0014$ & $\begin{array}{c}216 / 216 \\
a / a\end{array}$ & $\begin{array}{c}216 / 216 \\
a / a\end{array}$ & $P_{a}=0,546$ & $1 / P_{a}$ & 1,832 \\
\hline BrPe0021 & $\begin{array}{c}152 / 164 \\
b / a\end{array}$ & $\begin{array}{c}164 / 164 \\
a / a\end{array}$ & $P_{a}=0,611$ & $1 /\left(2 P_{a}\right)$ & 0,818 \\
\hline $\mathrm{BrPe} 0024$ & $\begin{array}{c}231 / 233 \\
a / b\end{array}$ & $\begin{array}{c}231 / 233 \\
a / b\end{array}$ & $\begin{array}{l}P_{a}=0,325 \\
P_{b}=0,300\end{array}$ & $P_{a}+P_{b} / 4 P_{a} P_{b}$ & 1,603 \\
\hline $\mathrm{BrPe} 0028$ & $\begin{array}{c}99 / 105 \\
b / a\end{array}$ & $\begin{array}{c}105 / 105 \\
a / a\end{array}$ & $P_{a}=0,381$ & $1 /\left(2 P_{a}\right)$ & 1,312 \\
\hline
\end{tabular}




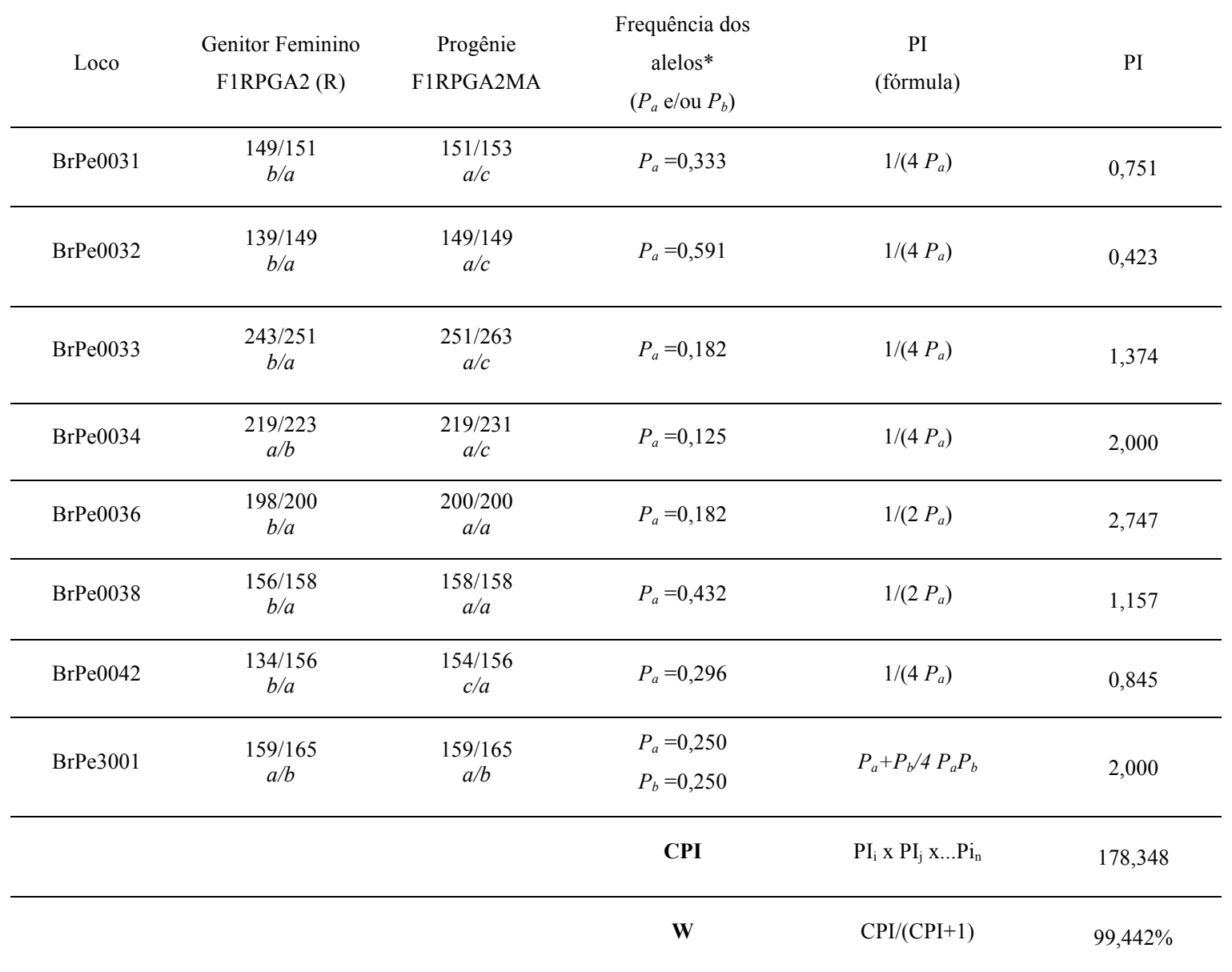

*Ver frequência dos alelos para cada loco no Anexo.

\section{Genealogia B}

$\mathrm{Na}$ Genealogia B (Figura 2), foi reconstituída a progênie do $1^{\circ}$ Cruzamento $P$. edulis GA2 $x$ P. incarnata, F1GA2Pi_R que foi utilizada como genitor feminino no $2^{\circ}$ Cruzamento entre F1GA2Pi_R x P. edulis GA2, ou primeiro retrocruzamento com o genitor recorrente $P$. edulis GA2, onde a progênie desse cruzamento foi denominada F1GA2PiRC1.

Para as análises de paternidade para o $2^{\circ}$ Cruzamento da Genealogia B, considerando somente uma Exclusão Categórica, o que não excluiu o suposto genitor masculino (Tabela 6), e após o cálculo da Probabilidade de Paternidade dos 14 locos que apresentaram Inclusões Categóricas, foi confirmando que o suposto genitor masculino $P$. edulis GA2, é o verdadeiro genitor masculino de F1GA2PiRC1 com uma Probabilidade de Paternidade de 99,997\% (Tabela 6.1). 


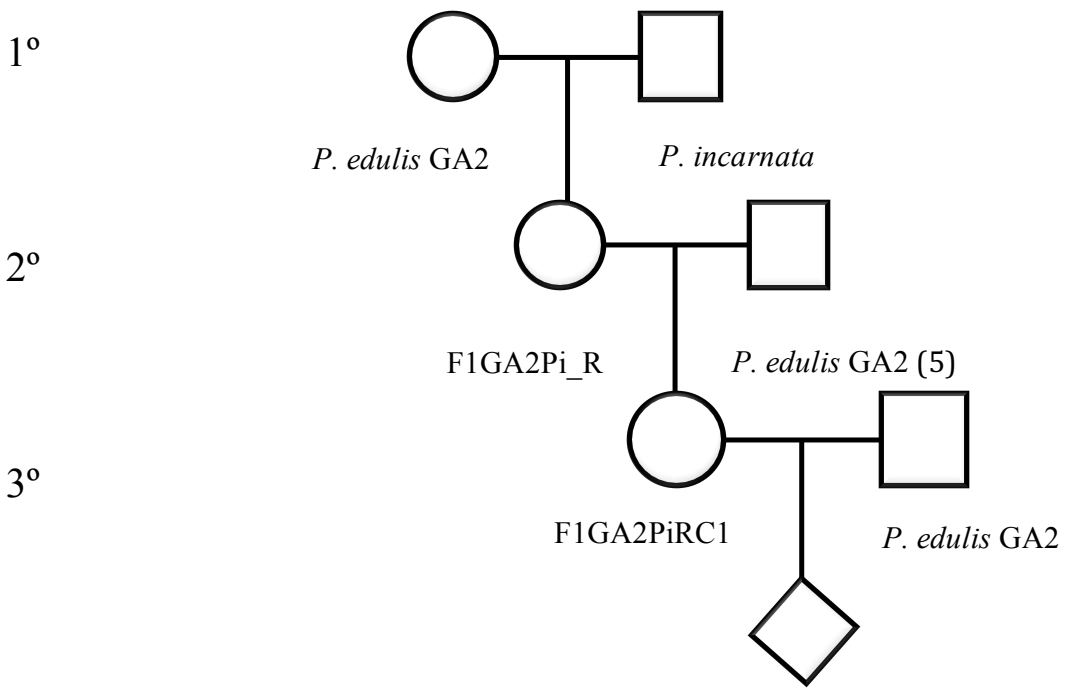

F1GA2PiRC2

Figura 2. Genealogia B com três cruzamentos: $1^{\circ} P$. edulis GA2 $\times$ P. incarnata; $2^{\circ}$ F1GA2Pi_R x P. edulis GA2; 3º F1GA2PiRC1 x P. edulis GA2.

Para as análises de paternidade para o $2^{\circ}$ Cruzamento da Genealogia B, considerando somente uma Exclusão Categórica, o que não excluiu o suposto genitor masculino (Tabela 6), e após o cálculo da Probabilidade de Paternidade dos 14 locos que apresentaram Inclusões Categóricas, foi confirmando que o suposto genitor masculino $P$. edulis GA2, é o verdadeiro genitor masculino de F1GA2PiRC1 com uma Probabilidade de Paternidade de 99,997\% (Tabela 6.1).

Tabela 6. Análise de Inclusão e Exclusão Categóricas do $2^{\circ}$ Cruzamento na Genealogia B.

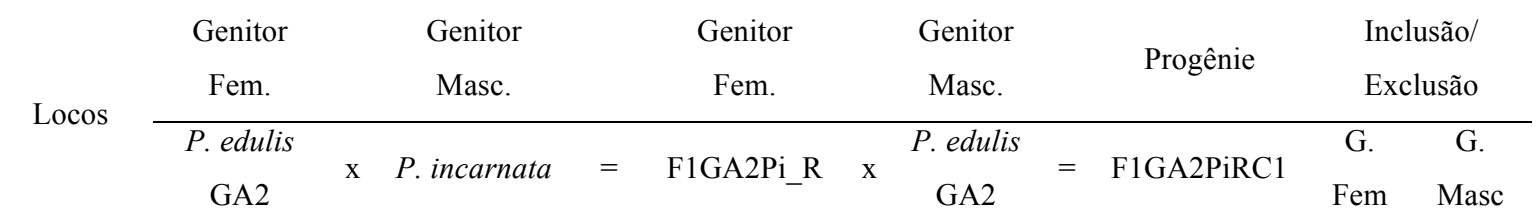

\begin{tabular}{llllllll}
\hline BrPe0001 & $156 / 158$ & $146 / 156$ & $156 / 159$ & $156 / 158$ & $156 / 158$ & I & I \\
\hline BrPe0003 & $287 / 289$ & $279 / 279$ & $279 / 289$ & $287 / 289$ & $287 / 289$ & I & I \\
\hline BrPe0006 & $188 / 192$ & $194 / 194$ & $188 / 194$ & $188 / 192$ & $188 / 188$ & I & I \\
\hline BrPe0010 & $202 / 204$ & $192 / 196$ & $196 / 202$ & $202 / 204$ & $202 / 204$ & I & I \\
\hline BrPe0014 & $216 / 216$ & $216 / 216$ & $216 / 216$ & $216 / 216$ & $216 / 216$ & I & I \\
\hline
\end{tabular}




\begin{tabular}{|c|c|c|c|c|c|c|c|c|c|c|}
\hline $\mathrm{BrPe} 0028$ & $105 / 105$ & & $101 / 101$ & & $101 / 105$ & & $105 / 105$ & $105 / 105$ & I & I \\
\hline \multirow{2}{*}{ Locos } & $\begin{array}{c}\text { Genitor } \\
\text { Fem. }\end{array}$ & & $\begin{array}{l}\text { Genitor } \\
\text { Masc. }\end{array}$ & & $\begin{array}{c}\text { Genitor } \\
\text { Fem. }\end{array}$ & & $\begin{array}{l}\text { Genitor } \\
\text { Masc. }\end{array}$ & Progênie & \multicolumn{2}{|c|}{$\begin{array}{l}\text { Inclusão/ } \\
\text { Exclusão }\end{array}$} \\
\hline & $\begin{array}{c}\text { P. edulis } \\
\text { GA2 }\end{array}$ & $\mathrm{x}$ & P. incarnata & $=$ & F1GA2Pi_R & $\mathrm{x}$ & $\begin{array}{c}\text { P. edulis } \\
\text { GA2 }\end{array}$ & $=$ F1GA2PiRC1 & $\begin{array}{c}\text { G. } \\
\text { Fem }\end{array}$ & $\begin{array}{c}\text { G. } \\
\text { Masc }\end{array}$ \\
\hline $\mathrm{BrPe} 0031$ & $149 / 151$ & & $149 / 151$ & & $149 / 151$ & & $149 / 151$ & $137 / 149$ & I & $\mathrm{E}$ \\
\hline $\mathrm{BrPe} 0032$ & $149 / 149$ & & $135 / 149$ & & $135 / 149$ & & $149 / 149$ & $149 / 149$ & I & I \\
\hline $\mathrm{BrPe} 0033$ & $245 / 251$ & & $243 / 243$ & & $243 / 251$ & & $245 / 251$ & $251 / 251$ & I & I \\
\hline $\mathrm{BrPe} 0034$ & $219 / 231$ & & $223 / 223$ & & $223 / 231$ & & $219 / 231$ & $219 / 231$ & I & I \\
\hline $\mathrm{BrPe} 0036$ & $198 / 200$ & & $198 / 204$ & & $198 / 204$ & & $198 / 200$ & $198 / 204$ & I & I \\
\hline $\mathrm{BrPe} 0038$ & $158 / 158$ & & $156 / 158$ & & $156 / 158$ & & $158 / 158$ & $158 / 158$ & I & I \\
\hline $\mathrm{BrPe} 0042$ & $156 / 156$ & & $154 / 164$ & & $156 / 164$ & & $156 / 156$ & $156 / 156$ & I & I \\
\hline $\mathrm{BrPe} 3011$ & $159 / 165$ & & $163 / 165$ & & $159 / 165$ & & $159 / 165$ & $159 / 165$ & I & I \\
\hline
\end{tabular}

Tabela 6.1. Cálculo do Índice de Probabilidade (PI), do Índice de Probabilidade Combinado (CPI), e da Probabilidade de Paternidade (W) considerando o trio genitor feminino, progênie e suposto genitor masculino do $2^{\circ}$ Cruzamento na Genealogia B.

\begin{tabular}{|c|c|c|c|c|c|c|}
\hline Loco & $\begin{array}{c}\text { Genitor } \\
\text { Feminino } \\
\text { F1GA2Pi_R }\end{array}$ & $\begin{array}{c}\text { Progênie } \\
\text { F1GA2PiRC1 }\end{array}$ & $\begin{array}{c}\text { Genitor } \\
\text { Masculino } \\
\text { P. edulis } \\
\text { GA2 }\end{array}$ & $\begin{array}{l}\text { Frequência dos } \\
\text { alelos* } \\
\left(P_{a} \text { e/ou } P_{b}\right)\end{array}$ & $\begin{array}{c}\text { PI } \\
\text { (fórmula) }\end{array}$ & PI \\
\hline $\mathrm{BrPe} 0001$ & $\begin{array}{c}156 / 159 \\
a / b\end{array}$ & $\begin{array}{c}156 / 158 \\
a / b\end{array}$ & $\begin{array}{c}156 / 158 \\
a / b\end{array}$ & $\begin{array}{l}P_{a}=0,500 \\
P_{b}=0,300\end{array}$ & $1 /\left(P_{a}+P_{b}\right)$ & 1,250 \\
\hline $\mathrm{BrPe} 0003$ & $\begin{array}{c}279 / 289 \\
c / b\end{array}$ & $\begin{array}{c}287 / 289 \\
a / b\end{array}$ & $\begin{array}{c}287 / 289 \\
a / b\end{array}$ & $P_{a}=0,273$ & $1 /\left(2 P_{a}\right)$ & 1,832 \\
\hline $\mathrm{BrPe} 0006$ & $\begin{array}{c}188 / 194 \\
a / c\end{array}$ & $\begin{array}{c}188 / 188 \\
a / a\end{array}$ & $\begin{array}{c}188 / 192 \\
a / b\end{array}$ & $P_{a}=0,205$ & $1 /\left(2 P_{a}\right)$ & 2,439 \\
\hline $\mathrm{BrPe} 0010$ & $\begin{array}{c}196 / 202 \\
c / b\end{array}$ & $\begin{array}{c}202 / 204 \\
b / a\end{array}$ & $\begin{array}{c}202 / 204 \\
b / a\end{array}$ & $P_{a}=0,159$ & $1 /\left(2 P_{a}\right)$ & 3,145 \\
\hline $\mathrm{BrPe} 0014$ & $\begin{array}{c}216 / 216 \\
a / a\end{array}$ & $\begin{array}{c}216 / 216 \\
a / a\end{array}$ & $\begin{array}{c}216 / 216 \\
a / a\end{array}$ & $P_{a}=0,546$ & $1 / P_{a}$ & 1,832 \\
\hline $\mathrm{BrPe} 0028$ & $\begin{array}{c}101 / 105 \\
b / a\end{array}$ & $\begin{array}{c}105 / 105 \\
a / a\end{array}$ & $\begin{array}{c}105 / 105 \\
a / a\end{array}$ & $P_{a}=0,381$ & $1 / P_{a}$ & 2,625 \\
\hline $\mathrm{BrPe} 0032$ & $\begin{array}{c}135 / 149 \\
b / a\end{array}$ & $\begin{array}{c}149 / 149 \\
a / a\end{array}$ & $\begin{array}{c}149 / 149 \\
a / a\end{array}$ & $P_{a}=0,591$ & $1 / P_{a}$ & 1,692 \\
\hline $\mathrm{BrPe} 0033$ & $\begin{array}{c}243 / 251 \\
c / a\end{array}$ & $\begin{array}{c}251 / 251 \\
a / a\end{array}$ & $\begin{array}{c}245 / 251 \\
b / a\end{array}$ & $P_{a}=0,182$ & $1 /\left(2 P_{a}\right)$ & 2,747 \\
\hline
\end{tabular}




\begin{tabular}{|c|c|c|c|c|c|c|}
\hline Loco & $\begin{array}{c}\text { Genitor } \\
\text { Feminino } \\
\text { F1GA2Pi_R }\end{array}$ & $\begin{array}{c}\text { Progênie } \\
\text { F1GA2PiRC1 }\end{array}$ & $\begin{array}{c}\text { Genitor } \\
\text { Masculino } \\
\text { P. edulis } \\
\text { GA2 }\end{array}$ & $\begin{array}{c}\text { Frequência dos } \\
\text { alelos* } \\
\left(P_{a} \text { e/ou } P_{b}\right)\end{array}$ & $\begin{array}{c}\text { PI } \\
\text { (fórmula) }\end{array}$ & PI \\
\hline $\mathrm{BrPe} 0034$ & $\begin{array}{c}223 / 231 \\
c / b\end{array}$ & $\begin{array}{c}219 / 231 \\
a / b\end{array}$ & $\begin{array}{c}219 / 231 \\
a / b\end{array}$ & $P_{a}=0,125$ & $1 /\left(2 P_{a}\right)$ & 4,000 \\
\hline $\mathrm{BrPe} 0036$ & $\begin{array}{c}198 / 204 \\
a / b\end{array}$ & $\begin{array}{c}198 / 204 \\
a / b\end{array}$ & $\begin{array}{c}198 / 200 \\
a / c\end{array}$ & $\begin{array}{l}P_{a}=0,273 \\
P_{b}=0,136\end{array}$ & $1 /\left[2\left(P_{a}+P_{b}\right)\right]$ & 1,222 \\
\hline $\mathrm{BrPe} 0038$ & $\begin{array}{c}156 / 158 \\
b / a\end{array}$ & $\begin{array}{c}158 / 158 \\
a / a\end{array}$ & $\begin{array}{c}158 / 158 \\
a / a\end{array}$ & $P_{a}=0,432$ & $1 / P_{a}$ & 2,315 \\
\hline $\mathrm{BrPe} 0042$ & $\begin{array}{c}156 / 164 \\
a / b\end{array}$ & $\begin{array}{c}156 / 156 \\
a / a\end{array}$ & $\begin{array}{c}156 / 156 \\
a / a\end{array}$ & $P_{a}=0,296$ & $1 / P_{a}$ & 3,378 \\
\hline \multirow[t]{3}{*}{ BrPe3001 } & $\begin{array}{c}159 / 165 \\
a / b\end{array}$ & $\begin{array}{c}159 / 165 \\
a / b\end{array}$ & $\begin{array}{c}159 / 165 \\
a / b\end{array}$ & $\begin{array}{l}P_{a}=0,250 \\
P_{b}=0,250\end{array}$ & $1 /\left(P_{a}+P_{b}\right)$ & 2,000 \\
\hline & & & & CPI & $P I_{i} \times P_{j} \times \ldots i_{n}$ & 30009,664 \\
\hline & & & & W & $\mathrm{CPI} /(\mathrm{CPI}+1)$ & $99,997 \%$ \\
\hline
\end{tabular}

*Ver frequência dos alelos para cada loco no Anexo.

No $3^{\circ}$ Cruzamento da Genealogia B (Figura 3), que corresponderia no segundo ciclo de retrocruzamento (F1GA2PiRC1 x P. edulis GA2), e considerando 4 Exclusões Categóricas em 17 locos testados, o suposto genitor feminino F1GA2PiRC1 foi excluído como o verdadeiro genitor feminino do acesso F1GA2PiRC2 (Tabela 7). Da mesma maneira, e considerando 5 Exclusões Categóricas, o suposto genitor masculino P. edulis GA2 também foi excluído como o verdadeiro genitor masculino do mesmo acesso (Tabela 7).

Tabela 7. Análise de Inclusão e Exclusão Categóricas do $3^{\circ}$ Cruzamento da Genealogia B.

\begin{tabular}{|c|c|c|c|c|c|c|c|}
\hline \multirow[t]{2}{*}{ Locos } & \multicolumn{2}{|l|}{ Genitor Feminino } & \multicolumn{2}{|l|}{ Genitor Masculino } & Progênie & \multicolumn{2}{|c|}{$\begin{array}{l}\text { Inclusão/ } \\
\text { Exclusão }\end{array}$} \\
\hline & F1GA2PiRC1 & $\mathrm{x}$ & P. edulis GA2 & $=$ & F1GA2PiRC2 & G. Fem & G. Masc \\
\hline $\mathrm{BrPe} 0001$ & $156 / 158$ & & $156 / 158$ & & $158 / 158$ & I & I \\
\hline $\mathrm{BrPe} 0002$ & $181 / 181$ & & $181 / 181$ & & $181 / 181$ & $\mathrm{I}$ & $\mathrm{I}$ \\
\hline $\mathrm{BrPe} 0003$ & $287 / 289$ & & $287 / 289$ & & $287 / 287$ & $\mathrm{I}$ & $\mathrm{I}$ \\
\hline $\mathrm{BrPe} 0006$ & $188 / 188$ & & $188 / 192$ & & $200 / 200$ & $\mathrm{E}$ & $E$ \\
\hline
\end{tabular}




\begin{tabular}{|c|c|c|c|c|c|c|c|}
\hline \multirow[t]{2}{*}{ Locos } & \multirow{2}{*}{$\begin{array}{l}\text { Genitor Feminino } \\
\text { F1GA2PiRC1 }\end{array}$} & \multicolumn{3}{|c|}{ Genitor Masculino } & \multirow{2}{*}{$\begin{array}{c}\text { Progênie } \\
\text { F1GA2PiRC2 }\end{array}$} & \multicolumn{2}{|c|}{$\begin{array}{l}\text { Inclusão/ } \\
\text { Exclusão }\end{array}$} \\
\hline & & $\mathrm{x}$ & P. edulis GA2 & $=$ & & G. Fem & G. Masc \\
\hline $\mathrm{BrPe} 0010$ & $202 / 204$ & & $202 / 204$ & & $202 / 204$ & I & I \\
\hline $\mathrm{BrPe} 0014$ & $216 / 216$ & & $216 / 216$ & & $216 / 216$ & $\mathrm{I}$ & I \\
\hline $\mathrm{BrPe} 0021$ & $164 / 164$ & & $164 / 164$ & & $164 / 164$ & I & I \\
\hline $\mathrm{BrPe} 0024$ & $233 / 233$ & & $233 / 233$ & & $231 / 231$ & $\mathrm{E}$ & $\mathrm{E}$ \\
\hline $\mathrm{BrPe} 0028$ & $105 / 105$ & & $105 / 105$ & & $103 / 105$ & I & $\mathrm{E}$ \\
\hline $\mathrm{BrPe} 0031$ & $137 / 149$ & & $149 / 151$ & & $151 / 153$ & $\mathrm{E}$ & I \\
\hline $\mathrm{BrPe} 0032$ & $149 / 149$ & & $149 / 149$ & & $149 / 149$ & I & I \\
\hline $\mathrm{BrPe} 0033$ & $251 / 251$ & & $245 / 251$ & & $241 / 251$ & I & $\mathrm{E}$ \\
\hline $\mathrm{BrPe} 0034$ & $219 / 231$ & & $219 / 231$ & & $231 / 231$ & I & I \\
\hline $\mathrm{BrPe} 0036$ & $198 / 204$ & & $198 / 200$ & & $200 / 200$ & $\mathrm{E}$ & I \\
\hline $\mathrm{BrPe} 0038$ & $158 / 158$ & & $158 / 158$ & & $158 / 158$ & I & I \\
\hline $\mathrm{BrPe} 0042$ & $156 / 156$ & & $156 / 156$ & & $150 / 156$ & I & $\mathrm{E}$ \\
\hline \multirow[t]{2}{*}{$\mathrm{BrPe} 3011$} & $159 / 165$ & & $159 / 165$ & & $159 / 165$ & I & I \\
\hline & & & & & Exclusões & 4 & 5 \\
\hline
\end{tabular}

\section{Genealogia C}

Para a Genealogia C (Figura 3), o $1^{\circ}$ Cruzamento (cruzamento interespecífico) entre $P$. aff. amethystina $x \quad P$. edulis GA2, onde a progênie F1PaGA2_R foi reconstituída, e que teria sido utilizada como genitor feminino no $2^{\circ}$ Cruzamento (retrocruzamento) com $P$. edulis GA2, considerando 14 locos, o suposto genitor masculino $P$. edulis GA2 foi excluído como o verdadeiro genitor masculino com 2 Exclusões Categóricas (Tabela 8). Pelo contrário, considerando nenhuma Exclusão Categórica em 14 locos, o suposto genitor feminino F1PaGA2_R seria o verdadeiro genitor feminino do acesso $\mathrm{F} 1 \mathrm{PaGA} 2 \mathrm{RC} 1$, e na análise do duo genitor e progênie a probabilidade de paternidade seria de um 95,137\% (Tabela 8.1 ). 


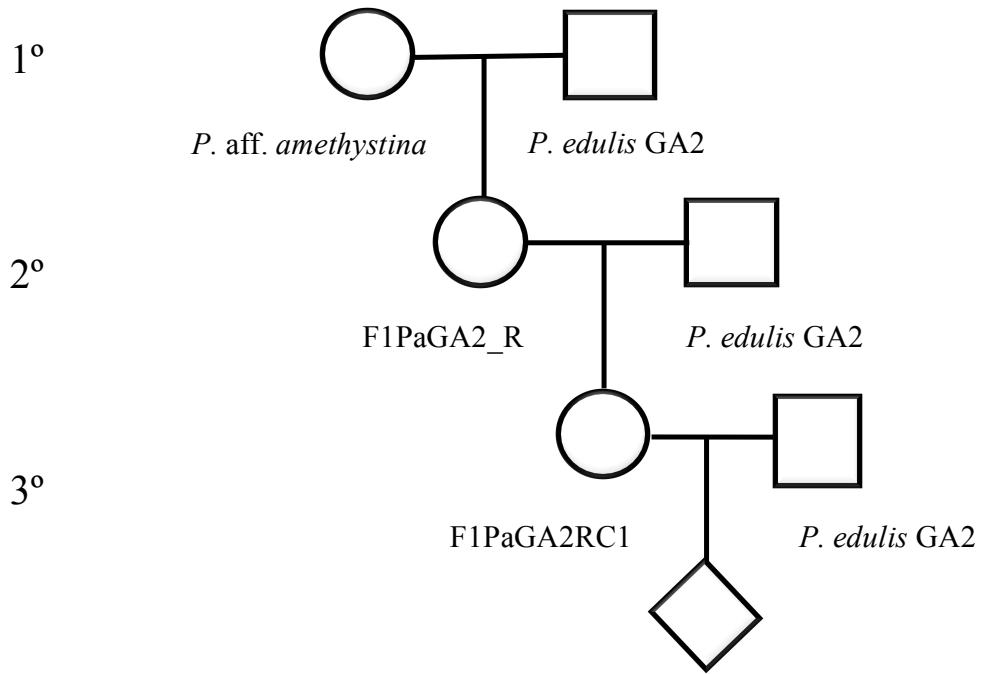

F1PaGA2RC2

Figura 3. Genealogia $\mathrm{C}$ com três cruzamentos: $1^{\mathrm{o}} P$. aff. amethystina $\mathrm{x} P$. edulis GA2; $2^{\circ}$ F1PaGA2_R x P. edulis GA2; $3^{\circ}$ F1PaGA2RC1 x P. edulis GA2.

Tabela 8. Análise de Inclusão e Exclusão Categóricas do $2^{\circ}$ Cruzamento da Genealogia C.

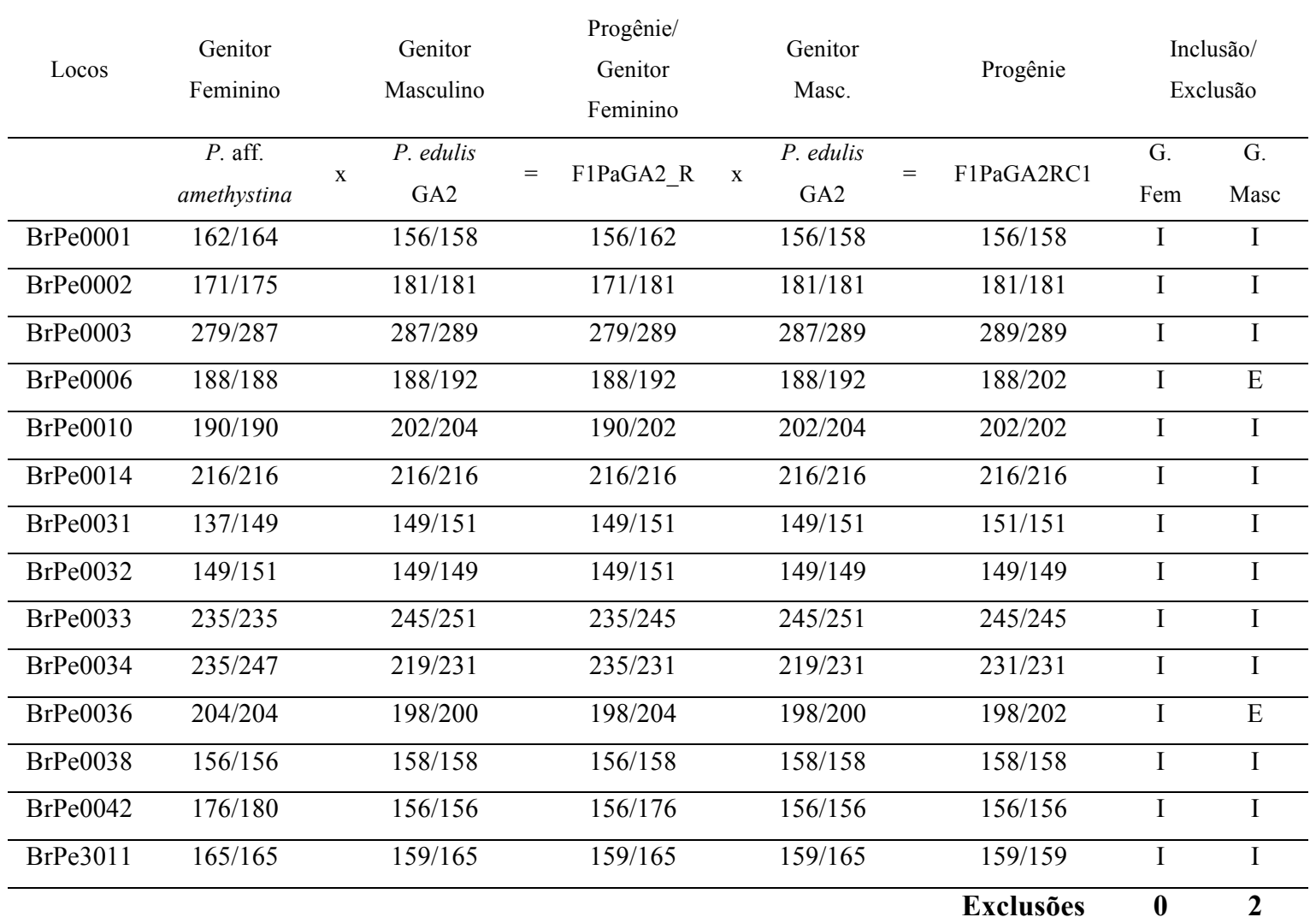


Tabela 8.1. Cálculo do Índice de Probabilidade (PI), do Índice de Probabilidade Combinado (CPI) e da Probabilidade de Paternidade (W) considerando o duo genitor e progênie para o $2^{\circ}$ Cruzamento da Genealogia C.

\begin{tabular}{|c|c|c|c|c|c|}
\hline Loco & $\begin{array}{c}\text { Gen. Fem. } \\
\text { F1PaGA2 (R) }\end{array}$ & $\begin{array}{c}\text { Progênie } \\
\text { F1PaGA2RC1 }\end{array}$ & $\begin{array}{l}\text { Frequência dos alelos* } \\
\qquad\left(P_{a} \text { e/ou } P_{b}\right)\end{array}$ & $\begin{array}{c}\text { IP } \\
\text { (fórmula) }\end{array}$ & IP \\
\hline $\mathrm{BrPe} 0001$ & $\begin{array}{c}156 / 162 \\
a / b\end{array}$ & $\begin{array}{c}156 / 158 \\
a / b\end{array}$ & $P_{a}=0,500$ & $1 /\left(4 P_{a}\right)$ & 0,500 \\
\hline $\mathrm{BrPe} 0002$ & $\begin{array}{c}171 / 181 \\
b / a\end{array}$ & $\begin{array}{c}181 / 181 \\
a / a\end{array}$ & $P_{a}=0,474$ & $1 /\left(2 P_{a}\right)$ & 1,055 \\
\hline $\mathrm{BrPe} 0003$ & $\begin{array}{c}279 / 289 \\
b / a\end{array}$ & $\begin{array}{c}289 / 289 \\
a / a\end{array}$ & $P_{a}=0,364$ & $1 /\left(2 P_{a}\right)$ & 1,374 \\
\hline $\mathrm{BrPe} 0006$ & $\begin{array}{c}188 / 192 \\
a / b\end{array}$ & $\begin{array}{c}188 / 202 \\
a / c\end{array}$ & $P_{a}=0,205$ & $1 /\left(4 P_{a}\right)$ & 1,220 \\
\hline $\mathrm{BrPe} 0010$ & $\begin{array}{c}190 / 202 \\
b / a\end{array}$ & $\begin{array}{c}202 / 202 \\
a / a\end{array}$ & $P_{a}=0,364$ & $1 /\left(2 P_{a}\right)$ & 1,374 \\
\hline $\mathrm{BrPe} 0014$ & $\begin{array}{c}216 / 216 \\
a / a\end{array}$ & $\begin{array}{c}216 / 216 \\
a / a\end{array}$ & $P_{a}=0,546$ & $1 / P_{a}$ & 1,832 \\
\hline $\mathrm{BrPe} 0031$ & $\begin{array}{c}149 / 151 \\
b / a\end{array}$ & $\begin{array}{c}151 / 151 \\
a / a\end{array}$ & $P_{a}=0,333$ & $1 /\left(2 P_{a}\right)$ & 1,502 \\
\hline $\mathrm{BrPe} 0032$ & $\begin{array}{c}149 / 151 \\
a / b\end{array}$ & $\begin{array}{c}149 / 149 \\
a / a\end{array}$ & $P_{a}=0,591$ & $1 /\left(2 P_{a}\right)$ & 0,846 \\
\hline $\mathrm{BrPe} 0033$ & $\begin{array}{c}235 / 245 \\
b / a\end{array}$ & $\begin{array}{c}245 / 245 \\
a / a\end{array}$ & $P_{a}=0,318$ & $1 /\left(2 P_{a}\right)$ & 1,572 \\
\hline $\mathrm{BrPe} 0034$ & $\begin{array}{c}235 / 231 \\
a / b\end{array}$ & $\begin{array}{c}231 / 231 \\
a / a\end{array}$ & $P_{a}=0,406$ & $1 /\left(2 P_{a}\right)$ & 1,231 \\
\hline $\mathrm{BrPe} 0036$ & $\begin{array}{c}198 / 204 \\
a / b\end{array}$ & $\begin{array}{c}198 / 202 \\
a / c\end{array}$ & $P_{a}=0,273$ & $1 /\left(4 P_{a}\right)$ & 0,916 \\
\hline $\mathrm{BrPe} 0038$ & $\begin{array}{c}156 / 158 \\
b / a\end{array}$ & $\begin{array}{c}158 / 158 \\
a / a\end{array}$ & $P_{a}=0,432$ & $1 /\left(2 P_{a}\right)$ & 1,157 \\
\hline $\mathrm{BrPe} 0042$ & $\begin{array}{c}156 / 176 \\
a / b\end{array}$ & $\begin{array}{c}156 / 156 \\
a / a\end{array}$ & $P_{a}=0,296$ & $1 /\left(2 P_{a}\right)$ & 1,689 \\
\hline \multirow[t]{3}{*}{ BrPe3001 } & $\begin{array}{c}159 / 165 \\
a / b\end{array}$ & $\begin{array}{c}159 / 159 \\
a / a\end{array}$ & $P_{a}=0,250$ & $1 /\left(2 P_{a}\right)$ & 2,000 \\
\hline & & & CPI & $P I_{i} \times P_{j} \times \ldots i_{n}$ & 19,563 \\
\hline & & & $\mathbf{W}$ & $\mathrm{CPI} /(\mathrm{CPI}+1)$ & $95,137 \%$ \\
\hline
\end{tabular}

*Ver frequência dos alelos para cada loco no Anexo.

No $3^{\circ}$ Cruzamento da Genealogia C, que correspondente no segundo ciclo de retrocruzamento, F1PaGA2RC1 $\mathrm{x} P$. edulis GA2, o suposto genitor feminino 
F1PaGA2RC1 do acesso F1PaGA2RC2 seria o verdadeiro genitor feminino considerando somente 1 Exclusão Categórica em 17 locos (Tabela 9) e com uma probabilidade de paternidade de 99,999\% (Tabela 9.1). Pelo contrário, o suposto genitor masculino $P$. edulis GA2 não corresponderia ao verdadeiro genitor masculino observando 4 Exclusões Categóricas (Tabela 9).

Tabela 9. Análise de Inclusão e Exclusão Categóricas do $3^{\circ}$ Cruzamento da Genealogia C.

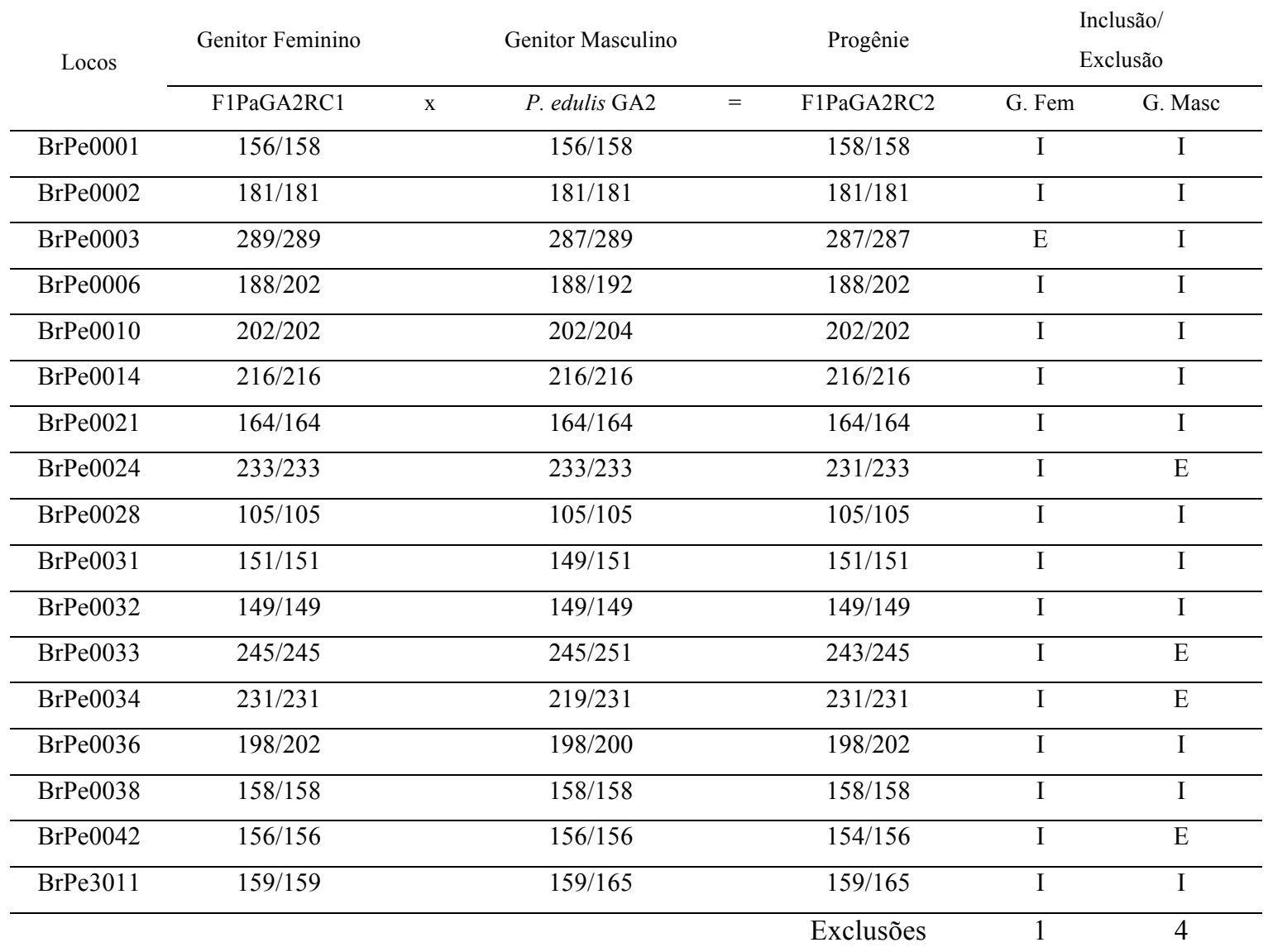


Tabela 9.1 Cálculo do Índice de Probabilidade (PI), do Índice de Probabilidade Combinado (CPI) e da Probabilidade de Paternidade (W) considerando o duo genitor e progênie para o $3^{\circ}$ Cruzamento da Genealogia $\mathrm{C}$

\begin{tabular}{|c|c|c|c|c|c|}
\hline Loco & $\begin{array}{c}\text { Gen. Fem. } \\
\text { F1PaGA2RC1 }\end{array}$ & $\begin{array}{c}\text { Progênie } \\
\text { F1PaGA2RC2 }\end{array}$ & $\begin{array}{l}\text { Frequência dos alelos* } \\
\qquad\left(P_{a} \text { e/ou } P_{b}\right)\end{array}$ & $\begin{array}{c}\text { PI } \\
\text { (fórmula) }\end{array}$ & PI \\
\hline $\mathrm{BrPe} 0001$ & $\begin{array}{c}156 / 158 \\
b / a\end{array}$ & $\begin{array}{c}158 / 158 \\
a / a\end{array}$ & $P_{a}=0,300$ & $1 / 2 P_{a}$ & 1,667 \\
\hline $\mathrm{BrPe} 0002$ & $\begin{array}{c}181 / 181 \\
a / a\end{array}$ & $\begin{array}{c}181 / 181 \\
a / a\end{array}$ & $P_{a}=0,474$ & $1 / P_{a}$ & 2,110 \\
\hline $\mathrm{BrPe} 0006$ & $\begin{array}{c}188 / 202 \\
a / b\end{array}$ & $\begin{array}{c}188 / 202 \\
a / b\end{array}$ & $\begin{array}{l}P_{a}=0,205 \\
P_{b}=0,091\end{array}$ & $P_{a}+P_{b} / 4 P_{a} P_{b}$ & 3,967 \\
\hline $\mathrm{BrPe} 0010$ & $\begin{array}{c}202 / 202 \\
a / a\end{array}$ & $\begin{array}{c}202 / 202 \\
a / a\end{array}$ & $P_{a}=0,364$ & $1 / P_{a}$ & 2,747 \\
\hline $\mathrm{BrPe} 0014$ & $\begin{array}{c}216 / 216 \\
a / a\end{array}$ & $\begin{array}{c}216 / 216 \\
a / a\end{array}$ & $P_{a}=0,546$ & $1 / P_{a}$ & 1,832 \\
\hline $\mathrm{BrPe} 0021$ & $\begin{array}{c}164 / 164 \\
a / a\end{array}$ & $\begin{array}{c}164 / 164 \\
a / a\end{array}$ & $P_{a}=0,611$ & $1 / P_{a}$ & 1,637 \\
\hline $\mathrm{BrPe} 0024$ & $\begin{array}{c}233 / 233 \\
a / a\end{array}$ & $\begin{array}{c}231 / 233 \\
b / a\end{array}$ & $P_{a}=0,300$ & $1 / 2 P_{a}$ & 1,667 \\
\hline $\mathrm{BrPe} 0028$ & $\begin{array}{c}105 / 105 \\
a / a\end{array}$ & $\begin{array}{c}105 / 105 \\
a / a\end{array}$ & $P_{a}=0,381$ & $1 / P_{a}$ & 2,625 \\
\hline $\mathrm{BrPe} 0031$ & $\begin{array}{c}151 / 151 \\
a / a\end{array}$ & $\begin{array}{c}151 / 151 \\
a / a\end{array}$ & $P_{a}=0,333$ & $1 / P_{a}$ & 3,003 \\
\hline BrPe0032 & $\begin{array}{c}149 / 149 \\
a / a\end{array}$ & $\begin{array}{c}149 / 149 \\
a / b\end{array}$ & $P_{a}=0,591$ & $1 / 2 P_{a}$ & 0,846 \\
\hline BrPe0033 & $\begin{array}{c}245 / 245 \\
a / a\end{array}$ & $\begin{array}{c}243 / 245 \\
b / a\end{array}$ & $P_{a}=0,318$ & $1 / 2 P_{a}$ & 1,572 \\
\hline $\mathrm{BrPe} 0034$ & $\begin{array}{c}231 / 231 \\
a / a\end{array}$ & $\begin{array}{c}231 / 231 \\
a / a\end{array}$ & $P_{a}=0,406$ & $1 / P_{a}$ & 2,463 \\
\hline $\mathrm{BrPe} 0036$ & $\begin{array}{c}198 / 202 \\
a / b\end{array}$ & $\begin{array}{c}198 / 202 \\
a / b\end{array}$ & $\begin{array}{l}P_{a}=0,273 \\
P_{b}=0,296\end{array}$ & $P_{a}+P_{b} / 4 P_{a} P_{b}$ & 1,760 \\
\hline BrPe0038 & $\begin{array}{c}158 / 158 \\
a / a\end{array}$ & $\begin{array}{c}158 / 158 \\
a / a\end{array}$ & $P_{a}=0,432$ & $1 / P_{a}$ & 2,315 \\
\hline $\mathrm{BrPe} 0042$ & $\begin{array}{c}156 / 156 \\
a / a\end{array}$ & $\begin{array}{c}154 / 156 \\
b / a\end{array}$ & $P_{a}=0,296$ & $1 / 2 P_{a}$ & 1,689 \\
\hline \multirow[t]{3}{*}{$\mathrm{BrPe} 3001$} & $\begin{array}{c}159 / 159 \\
a / a\end{array}$ & $\begin{array}{c}159 / 165 \\
a / b\end{array}$ & $P_{a}=0,250$ & $1 / 2 P_{a}$ & 2,000 \\
\hline & & & CPI & $\mathrm{PI}_{\mathrm{i}} \times \mathrm{PI}_{\mathrm{j}} \mathrm{x} \ldots \mathrm{Pi}_{\mathrm{n}}$ & 68057,033 \\
\hline & & & $\mathbf{W}$ & $\mathrm{CPI} /(\mathrm{CPI}+1)$ & $99,999 \%$ \\
\hline
\end{tabular}

*Ver frequência dos alelos para cada loco no Anexo. 


\section{Genealogia D}

Para a Genealogia D (Figura 4), o cruzamento entre o híbrido interespecífico BRS Céu do Cerrado x P. edulis MA, o suposto genitor masculino foi eliminado como o verdadeiro genitor masculino do acesso F1CCMA com 5 Exclusões Categóricas nos 14 locos considerados. Da mesma maneira, o genitor feminino para o mesmo acesso também foi eliminado como o verdadeiro genitor feminino, mas agora com 2 Exclusões Categóricas (Tabela 10).

$1^{\mathrm{o}}$

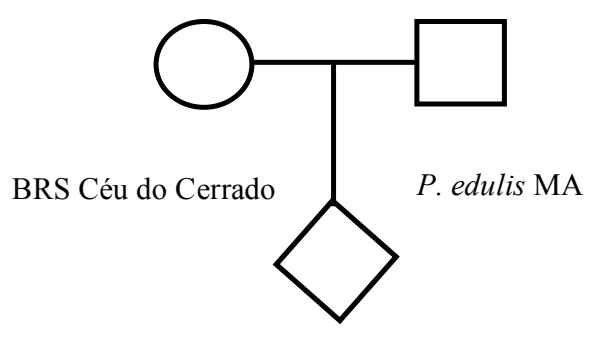

F1CCMA

Figura 4. Genealogia D, cruzamento entre BRS Céu do Cerrado x P. edulis MA.

Tabela 9. Análise de Inclusão e Exclusão Categóricas do $1^{\circ}$ Cruzamento da Genealogia D.

\begin{tabular}{|c|c|c|c|c|c|c|c|}
\hline \multirow[t]{2}{*}{ Locos } & \multicolumn{2}{|l|}{ Genitor Fem. } & \multicolumn{2}{|l|}{ Genitor Masc. } & Progênie & \multicolumn{2}{|c|}{$\begin{array}{l}\text { Inclusão/ } \\
\text { Exclusão }\end{array}$} \\
\hline & BRS Céu Do Cerrado & $\mathrm{x}$ & P. edulis MA & $=$ & F1CCMA & G. Fem & G. Masc \\
\hline BrPe0001 & $156 / 158$ & & $156 / 158$ & & $158 / 158$ & $\mathrm{I}$ & I \\
\hline $\mathrm{BrPe} 0002$ & $181 / 181$ & & $181 / 181$ & & $181 / 181$ & I & I \\
\hline $\mathrm{BrPe} 0003$ & $287 / 293$ & & $279 / 287$ & & $289 / 289$ & $\mathrm{E}$ & $\mathrm{E}$ \\
\hline $\mathrm{BrPe} 0006$ & $188 / 202$ & & $200 / 200$ & & $188 / 202$ & $\mathrm{I}$ & $\mathrm{E}$ \\
\hline $\mathrm{BrPe} 0010$ & $202 / 202$ & & $202 / 204$ & & $202 / 204$ & I & I \\
\hline $\mathrm{BrPe} 0014$ & $216 / 216$ & & $216 / 216$ & & $216 / 216$ & I & I \\
\hline $\mathrm{BrPe} 0021$ & $164 / 164$ & & $164 / 164$ & & $164 / 164$ & I & I \\
\hline $\mathrm{BrPe} 0024$ & $231 / 233$ & & $231 / 233$ & & $233 / 233$ & I & I \\
\hline $\mathrm{BrPe} 0028$ & $105 / 105$ & & $105 / 105$ & & $103 / 105$ & I & $\mathrm{E}$ \\
\hline $\mathrm{BrPe} 0031$ & $149 / 151$ & & $151 / 151$ & & $151 / 151$ & $\mathrm{I}$ & I \\
\hline $\mathrm{BrPe} 0032$ & $147 / 149$ & & $149 / 149$ & & $149 / 149$ & I & I \\
\hline $\mathrm{BrPe} 0033$ & $243 / 243$ & & $243 / 251$ & & $251 / 251$ & $\mathrm{E}$ & I \\
\hline $\mathrm{BrPe} 0034$ & $229 / 231$ & & $219 / 231$ & & $231 / 231$ & I & I \\
\hline
\end{tabular}




\begin{tabular}{|c|c|c|c|c|c|c|c|}
\hline \multirow[t]{2}{*}{ Locos } & \multirow{2}{*}{$\begin{array}{c}\text { Genitor Fem. } \\
\text { BRS Céu Do Cerrado }\end{array}$} & & \multirow{2}{*}{$\begin{array}{l}\text { Genitor Masc. } \\
\text { P. edulis MA }\end{array}$} & & \multirow{2}{*}{$\begin{array}{c}\text { Progênie } \\
\text { F1CCMA }\end{array}$} & \multicolumn{2}{|c|}{$\begin{array}{l}\text { Inclusão/ } \\
\text { Exclusão }\end{array}$} \\
\hline & & $\mathrm{x}$ & & $=$ & & G. Fem & G. Masc \\
\hline $\mathrm{BrPe} 0036$ & $198 / 202$ & & $200 / 200$ & & $198 / 198$ & I & $\mathrm{E}$ \\
\hline $\mathrm{BrPe} 0038$ & $158 / 158$ & & $158 / 158$ & & $158 / 158$ & I & I \\
\hline $\mathrm{BrPe} 0042$ & $152 / 156$ & & $154 / 156$ & & $156 / 156$ & I & I \\
\hline $\mathrm{BrPe} 0043$ & $202 / 222$ & & $196 / 202$ & & $222 / 222$ & I & $\mathrm{E}$ \\
\hline BrPe3011 & $159 / 165$ & & $159 / 165$ & & $159 / 159$ & I & I \\
\hline
\end{tabular}

Considerando o grande potencial do uso das espécies silvestres no melhoramento genético e devido à compatibilidade existente entre muitas das espécies de Passiflora, o que tem permitido a obtenção de híbridos interespecíficos (MELETTI et al., 2005), se faz fundamental a utilização de marcadores moleculares para auxiliar na detecção de cruzamentos, análise de paternidade, reconstrução de pedigree e identificação de cultivares, de tal modo que seja possível encurtar os tempos do programa de melhoramento para a obtenção de novas cultivares.

Marcadores microssatélites demonstraram ser uma excelente ferramenta no esclarecimento de alguns cruzamentos e a paternidade dos acessos, seja confirmando os genitores como verdadeiros genitores ou excluindo-os como os verdadeiros genitores.

$\mathrm{Na}$ análise de Inclusão e Exclusão Categóricas realizada nos 12 genitores de 6 cruzamentos analisados, os resultados confirmaram como genitores verdadeiros a 5 deles, onde a Probabilidade de Paternidade (W) calculada para o único genitor masculino foi de 99,997\%. As análises também demonstraram que 7 dos supostos genitores foram excluídos como os genitores verdadeiros das progênies, apresentando Exclusões Categóricas em 2, 3, 4 e 5 locos.

Dois dos 5 genitores que foram confirmados como genitores verdadeiros, apresentaram somente uma Exclusão Categórica em um dos locos testados, o que não os excluiu como genitores verdadeiros. Para o genitor masculino P. edulis GA2 do $2^{\circ}$ Cruzamento da Genealogia B, a única exclusão categórica foi no loco BrPe0031, que apresentou uma discrepância de 12 pares de bases ou 6 repetições a mais do motivo do microssatélite TA entre o genitor $P$. edulis GA2 (149 pb) e a progênie F1GA2PiRC1 (137 pb) (Tabela 5). E para o $3^{\circ}$ Cruzamento da Genealogia C, a única Exclusão Categórica foi no loco BrPe0003, com uma discrepância de 2 pares de bases ou uma 
repetição a mais do motivo $\mathrm{TC}$, entre o genitor feminino $P$. edulis GA2 (289 pb) e a progênie F1PaGA2RC2 (287 pb) (Tabela 9).

Diferença no número de repetições dentro do microssatélite entre uma geração e outra pode ser atribuída ao fenômeno de slippage do DNA durante a replicação (TACHIDA; IIZUKA, 1992) ou à recombinação entre as fitas de DNA causada por um crossing-over desigual (BROHEDE; ELLEGREN, 1999; HARDING; BOYCE; CLEGG, 1992).

No caso da diferença entre 2 pares de base no loco BrPe0003, entre o genitor feminino $P$. edulis GA2 (289 pb) e a progênie F1PaGA2RC2 (287 pb) seria um exemplo de slippage na variação de um número pequeno de pares de base, seja por inserção ou deleção, causado pela pausa da DNA polimerase durante a dissociação da polimerase do DNA, onde em esse momento somente a parte terminal da nova fita sintetizada é separada da fita original, emparelhando-se a outra unidade de repetição do microssatélite (HILE; ECKERT, 2004). Esse fenômeno tem sido previamente documentado em algumas espécies como Arabidopsis (SYMONDS; LLOYD, 2003), grão-de-bico (SETHY et al., 2006) e soja (PEAKALL et al., 1998).

No caso da diferença de 12 pares de base no loco BrPe0031, entre o genitor masculino P. edulis GA2 (149 pb) e a progênie F1GA2PiRC1 (137 pb), poderia ser causada pela recombinação das fitas de DNA na meiose, onde se tem observado sequências maiores de adição ou perda devido a um crossing-over desigual (BERG et al., 2003).

$\mathrm{Na}$ Genealogia B, o genitor feminino F1GA2Pi_R foi confirmado como o genitor feminino verdadeiro do acesso F1GA2PiRC1, da mesma maneira para o genitor masculino $P$. edulis GA2. Isso demonstra que é possível obter híbridos interespecíficos sexuados entre $P$. edulis GA2 x P. incarnata e que tem sido reportado anteriormente por FALEIRO et al. (2015). Em estudos anteriores feitos por KNIGHT (1991) e OTONI et al. (1995) foi observado que quando $P$. edulis era cruzada sexualmente com $P$. incarnata os híbridos F1 eram macho-estéreis e não conseguiam frutificar, portanto a obtenção de plantas férteis deveria ser através da duplicação cromossômica, mediante o uso de colchicina, ou bem pela fusão de protoplastos. No cruzamento entre $P$. edulis GA2 e $P$. incarnata realizado neste estudo, o vingamento foi exitoso na maioria dos casos (dados não apresentados). 
Os marcadores microssatélites testados auxiliaram na exclusão de 7 supostos genitores de 6 cruzamentos em 4 genealogias. Erros na identificação dos acessos, polinização tardia das flores, contaminação do pólen, problemas mecânicos na hora de ensacar as flores polinizadas, poderiam ter sido algumas das razões pelas quais 7 dos supostos genitores foram excluídos como os verdadeiros genitores dos cruzamentos analisados.

\section{CONCLUSÕES}

Os novos marcadores microssatélites polimórficos foram eficientes na análise de paternidade dos cruzamentos testados, confirmando a obtenção do híbrido interespecífico entre $P$. edulis GA2 x P. incarnata.

\section{REFERÊNCIAS BIBLIOGRÁFICAS}

AMERICAN ASSOCIATION OF BLOOD BANKS. Guidance for Standars for Parentage Testing Laboratories. 6th. ed. Bethesda, MD, 2004. p.144.

BERG, I.; NEUMANN, R.; CEDERBERG, H.; RANNUNG, U.; JEFFREYS, A.J. Two modes of germline instability at human minisatellite MS1 (locus D1S7): complex rearrangements and paradoxical hyperdeletion. American Journal of Human Genetics, v. 72, p. 1436-47, 2003.

BROHEDE, J.; ELLEGREN, H. Microsatellite evolution: polarity of substitutions within repeats and neutrality of flanking sequences. Proceedings: Biological Sciences, v. 266, n. 1421, p. 825-833, 1999.

BRUNEL, D. A microsatellite marker in Helianthus annuus L. Plant Molecular Biology, v. 24, p. 397-400, 1994. 
BUCKLETON, J.; CLAYTON, T.; TRIGSS, C. Parentage Testing. In: BUCKLETON, J.; TRIGSS, C.; WALSH, S. J. (Eds.). Forensic DNA Evidence Interpretation. Washington, DC: CRC Press, 2005. p. 531.

CERVI, A. C. Espécies de Passiflora L. (Passifloraceae) publicadas e descritas nos últimos 55 anos (1950-2005) na América do Sul e principais publicações brasileiras. Estudos de Biologia, v. 27, n. 61, p. 19-24, 2005.

CERVI, A. C.; LINSINGEN, L. VON. Passiflora kikiana, a new species of Passifloraceae from the Brazilian Amazon. Acta Botanica Brasilica, v. 24, n. 4, p. 1062-1064, 2010.

COSTA, A. M.; TUPINAMBÁ, D. D. O maracujá e suas propriedades medicinais estado da arte. In: FALEIRO, F. G.; JUNQUEIRA, N. T. V. (Eds.). Maracujá: germoplasma e melhoramento genético. Planaltina, DF: Embrapa Cerrados, 2005. p. 475-506.

DOYLE, J.; DOYLE, J. L. Genomic plant DNA preparation from fresh tissue-CTAB method. Phytochemical Bulletin, v. 19, n. 11, p. 11-15, 1987.

FALEIRO, F. G.; FALEIRO, A. S. G.; CORDEIRO, M. C. R.; KARIA, C. T. Metodologia para operacionalizar a extração de DNA de espécies nativas do cerrado. Comunicado Téncnico. Planaltina, DF, 2003.

FALEIRO, F. G.; JUNQUEIRA, N. T. V.; BRAGA, M. F.; BELLON, G.; PEIXOTO, J. R.; BARros, A. M.; BORGES, T. A.; ALMEIDA, D. A.; COSTA, B. Obtenção de populações de retrocruzamentos e confirmação da fecundação cruzada no maracujazeiro com base em marcadores moleculares. Congresso Brasileiro de Melhoramento de Plantas. Embrapa Trigo, Gramado, RS. 2005.

FAleiro, F. G.; JUnQueIRA, N. T. V.; COSTA, A. M. Ações de Pesquisa e Desenvolvimento para o Uso Diversificado de Espécies Comerciais e Silvestres de 
Maracujá (Passiflora spp.). Embrapa Cerrados, Planaltina, DF. 2105.

FEUILLET, C. Passifloraceae (passion flower family). In: SMITH, N.; MORI, S. A.; HENDERSON, A.; STEVENSON, D. W.; HELD, S. V. (Eds.). Flowering Plants on the Neotropics. New York: Princeton University Press, 2004. p. 286-287.

FIELD, D.; WILLS, C. Long, polymorphic microsatellites in simple organisms. Proceedings. Biological sciences / The Royal Society, v. 263, n. 1367, p. 209-15, 1996.

HARDING, R. M.; BOYCE, A. J.; CLEGG, J. B. The evolution of tandemly repetitive DNA: Recombination rules. Genetics, v. 132, n. 3, p. 847-859, 1992.

HILE, S. E.; ECKERT, K. A. Positive Correlation Between DNA Polymerase $\alpha$ Primase Pausing and Mutagenesis within Polypyrimidine/Polypurine Microsatellite Sequences. Journal of Molecular Biology, v. 335, p. 745-759, 2004.

IMIG, D. C.; CERVI, A. C. A new species of Passiflora (Passifloraceae) from Minas Gerais, Brazil. Phytotaxa, v. 186, n. 5, p. 292-296, 2014.

JUNQUEIRA, K. P.;JUNQUEIRA, N. T.; BELLON, G.; BRAGA, M. F.; SOUZA, L. S. D. E. Confirmação de híbridos interespecíficos artificiais no gênero Passiflora por meio de marcadores RAPD. Revista Brasileira de Fruticultura, v. 30, n. 1, p. 191196, 2008.

KNIGHT, R. J. Development of Tetraploid Hybrid Passion Fruit Clones with Potential for the North Temperate Zone. HortScience, v. 26, n. 12, p. 1541-1543, 1991.

LEE, H. S.; LEE, J. W.; HAN, G. R.; HWANG, J. J. Motherless case in paternity testing. Forensic Science International, v. 114, p. 57-65, 2000.

LITT, M.; LUTY, J. A. A. Hypervariable Microsatellite Revealed by In Vitro 
Amplification of a Dinucleotide Repeat within the Cardiac Muscle Actin Gene. American Journal of Human Genetics, v. 44, p. 397-401, 1989.

MARSHALL, T. C.; SLATE, J.; KRUUK, L. E. B.; PEMBERTON, J. M. Statistical confidence for likelihood-based paternity inference in natural populations. Molecular Ecology, v. 7, p. 639-655, 1998.

MATSCHINER, M.; SALZBURGER, W. TANDEM: Integrating automated allele binning into genetics and genomics workflows. Bioinformatics, v. 25, n. 15, p. 19821983, 2009.

MELETTI, L. M. M.; SOARES-SCOTT, M. D.; BERNACCI, L. C.; BERNACCI, L. C.; PASSOS, I. R. S. Melhoramento genético do maracujá: passado e futuro. In: FALEIRO, F. G.; JUNQUEIRA, N. T. V.; BRAGA, M. F. (Eds.). Maracujá: germoplasma e melhoramento genético. Planaltina, DF: Embrapa Cerrados, 2005. p. $55-78$.

MELETTI, L. M. M.; BRUCKNER, C. H. Melhoramento genético. In: BRUCKNER, C. H.; PICANÇO, M. C. (Eds.). Maracujá: tecnologia de produção, pós-colheita, agroindústria, mercado. Porto Alegre: Cinco Continentes, 2001. p. 345-385.

OTONI, W. C.; BLACKHALL, N.W.; D'ULTRA VAZ, F. B.; CASALI, V. W.; POWER, J. B.; DAVEY, M. R. Somatic hybridization of the Passiflora species, P. edulis f. flavicarpa Degener and P. incarnata L. Journal of Experimental Botany, v. 46, n. 7, p. 777-785, 1995.

PEAKALL, R.; GILMORE, S.; KEYS, W.; MORGANTE, M.; RAFALSKI, A. Crossspecies amplification of soybean (Glycine max) simple sequence repeats (SSRs) within the genus and other legume genera: implications for the transferability of SSRs in plants. Molecular Biology and Evolution, v. 15, n. 10, p. 1275-87, 1998.

PEIXOTO, M. Problemas e perspectivas do maracujá ornamental. In: FALEIRO, F. G.; 
JUNQUEIRA, N. T. V.; BRAGA, M. F. (Eds.). Maracujá: germoplasma e melhoramento genético. Planaltina, DF: Embrapa Cerrados, 2005. p. 457-463.

PUGH, T.; FOUET, O.; RISTERUCCI, A. M.; BROTTIER, P.; ABOULADZE, M.; DELETREZ, C.; COURTOIS, B.; CLEMENT, D.; LARMANDE, P.; N'GORAN, J. A. K.; LANAUD, C. A new cacao linkage map based on codominant markers: development and integration of 201 new microsatellite markers. Theoretical and Applied Genetics, v. 108, n. 6, p. 1151-61, 2004.

SETHY, N. K.; SHOKEEN, B.; EDWARDS, K. J.; BAHATIA, S. Development of microsatellite markers and analysis of intraspecific genetic variability in chickpea (Cicer arietinum L.). Theoretical and Applied Genetics, v. 112, n. 8, p. 1416-1428, 2006.

SIMIC, D.; LEDENCAR, T.; JAMBROVIC, A.; ZDUNIC, Z.; BRKIC, J.; BRKIC, A.; MLADENOVIC-DRINIC, S.; BRKIC, I. SNP and SSR marker analysis and mapping of a maize population. Genetika, v. 41, n. 3, p. 237-246, 2009.

SOUZA, J.; MEletTI, L. Maracujá: Espécies, Variedades, Cultivo. Piracicaba, Brasil: Fealq, 1997.

SYMONDS, V. V.; LLOYD, A. M. An Analysis of Microsatellite Loci in Arabidopsis thaliana: Mutational Dynamics and Application. Genetics, v. 165, n. 3, p. 1475-1488, 2003.

TACHIDA, H.; IIZUKA, M. Persistence of repeated sequences that evolve by replication slippage. Genetics, v. 131, n. 2, p. 471-478, 1992.

VANDERPLANK, J. Passion flowers. Cambridge: The MIT Press, 2000.

VOUILlamOZ, J.; MAIGRE, D.; MEREDITH, C. P. Microsatellite analysis of ancient alpine grape cultivars: Pedigree reconstruction of Vitis vinifera L. "Cornalin du 
Valais". Theoretical and Applied Genetics, v. 107, n. 3, p. 448-454, 2003.

WEBER, J. L.; WONG, C. Mutation of human short tandem repeats. Human Molecular Genetics, v. 2, n. 8, p. 1123-8, 1993.

WEISSENBACH, J.; GYAPAY, G; DIB, C.; VIGNAL, A.; MORISSETTE, J.; MILLASSEU, P.; VAYSSEIX, G.; LATHROP, M. A second-generation linkage map of the human genome. Nature, v. 359, p. 794-801, 1992.

YAMAMOTO, T.; MOCHIDA, K.; IMAII, T.; HAJII, T.; YAEGAKII, H.; MATSUTAI, N.; HAYASHIT, T. Parentage Analysis in Japanese Peaches using SSR Markers. Breeding Science, v. 53, p. 35-40, 2003.

ZERAIK, M. L.; PEREIRA, C. A. M.; ZUIN, V. G.; Maracujá: Um alimento funcional? Revista Brasileira de Farmacognosia, v. 20, p. 459-471, 2010. 


\section{ANEXO}

Frequências alélicas dos 18 locos testados em 22 acessos do gênero Passiflora (A: alelo, F: frequência alélica)

\begin{tabular}{|c|c|c|c|c|c|c|c|c|}
\hline Loco & $\mathrm{A}$ & $\mathrm{F}$ & Loco & $\mathrm{A}$ & $\mathrm{F}$ & Loco & $\mathrm{A}$ & $\mathrm{F}$ \\
\hline \multirow[t]{8}{*}{$\mathrm{BrPe} 0001$} & 144 & 0,050 & \multirow[t]{8}{*}{$\mathrm{BrPe} 0002$} & 171 & 0,026 & \multirow[t]{8}{*}{$\mathrm{BrPe} 0003$} & 275 & 0,046 \\
\hline & 146 & 0,025 & & 175 & 0,026 & & 277 & 0,046 \\
\hline & 154 & 0,075 & & 179 & 0,211 & & 279 & 0,091 \\
\hline & 156 & 0,500 & & 181 & 0,474 & & 285 & 0,114 \\
\hline & 158 & 0,300 & & 183 & 0,105 & & 287 & 0,273 \\
\hline & 162 & 0,025 & & 187 & 0,158 & & 289 & 0,364 \\
\hline & \multirow[t]{2}{*}{164} & \multirow[t]{2}{*}{0,025} & & & & & 291 & 0,046 \\
\hline & & & & & & & 293 & 0,023 \\
\hline Loco & A & $\bar{F}$ & Loco & $\mathrm{A}$ & $\mathrm{F}$ & Loco & $\mathrm{A}$ & $F$ \\
\hline \multirow[t]{7}{*}{$\mathrm{BrPe0006}$} & 188 & 0,205 & \multirow[t]{7}{*}{$\mathrm{BrPe} 0010$} & 190 & 0,046 & \multirow[t]{7}{*}{$\mathrm{BrPe} 0014$} & 214 & 0,182 \\
\hline & 192 & 0,023 & & 192 & 0,023 & & 216 & 0,546 \\
\hline & 194 & 0,068 & & 196 & 0,046 & & 218 & 0,068 \\
\hline & 196 & 0,318 & & 198 & 0,023 & & 220 & 0,046 \\
\hline & 198 & 0,114 & & 200 & 0,341 & & 224 & 0,136 \\
\hline & 200 & 0,182 & & 202 & 0,364 & & 226 & 0,023 \\
\hline & 202 & 0,091 & & 204 & 0,159 & & & \\
\hline Loco & A & $\mathrm{F}$ & Loco & $\mathrm{A}$ & $\mathrm{F}$ & Loco & $\mathrm{A}$ & $F$ \\
\hline \multirow[t]{7}{*}{$\mathrm{BrPe} 0021$} & 152 & 0,056 & \multirow[t]{7}{*}{$\mathrm{BrPe} 0024$} & 221 & 0,175 & \multirow[t]{7}{*}{$\mathrm{BrPe} 0028$} & 89 & 0,048 \\
\hline & 158 & 0,111 & & 223 & 0,075 & & 99 & 0,048 \\
\hline & 162 & 0,222 & & 229 & 0,125 & & 101 & 0,238 \\
\hline & \multirow[t]{4}{*}{164} & \multirow[t]{4}{*}{0,611} & & 231 & 0,325 & & 103 & 0,167 \\
\hline & & & & 233 & 0,300 & & 105 & 0,381 \\
\hline & & & & 233 & 0,308 & & 107 & 0,071 \\
\hline & & & & & & & 109 & 0,048 \\
\hline Loco & A & $\mathrm{F}$ & Loco & A & $\mathrm{F}$ & Loco & A & $\mathrm{F}$ \\
\hline \multirow[t]{8}{*}{ BrPe0031 } & 135 & 0,095 & \multirow[t]{8}{*}{$\mathrm{BrPe} 0032$} & 135 & 0,023 & \multirow[t]{8}{*}{$\mathrm{BrPe} 0033$} & 235 & 0,046 \\
\hline & 137 & 0,048 & & 137 & 0,068 & & 237 & 0,068 \\
\hline & 143 & 0,024 & & 139 & 0,046 & & 241 & 0,091 \\
\hline & 147 & 0,143 & & 145 & 0,023 & & 243 & 0,227 \\
\hline & 149 & 0,310 & & 147 & 0,114 & & 245 & 0,318 \\
\hline & 151 & 0,333 & & 149 & 0,591 & & 249 & 0,046 \\
\hline & 153 & 0,048 & & 151 & 0,046 & & 251 & 0,182 \\
\hline & & & & 153 & 0,091 & & 263 & 0,023 \\
\hline
\end{tabular}




\begin{tabular}{|c|c|c|c|c|c|c|c|c|}
\hline Loco & $\mathrm{A}$ & $\mathrm{F}$ & Loco & $\mathrm{A}$ & $\mathrm{F}$ & Loco & $\mathrm{A}$ & $\mathrm{F}$ \\
\hline \multirow[t]{8}{*}{$\mathrm{BrPe} 0034$} & 217 & 0,125 & \multirow[t]{8}{*}{$\mathrm{BrPe} 0036$} & 196 & 0,114 & \multirow[t]{8}{*}{$\mathrm{BrPe} 0038$} & 154 & 0,023 \\
\hline & 219 & 0,125 & & 198 & 0,273 & & 156 & 0,318 \\
\hline & 223 & 0,094 & & 200 & 0,182 & & 158 & 0,432 \\
\hline & 229 & 0,156 & & 202 & 0,296 & & 168 & 0,023 \\
\hline & 231 & 0,406 & & \multirow[t]{4}{*}{204} & \multirow[t]{4}{*}{0,136} & & 178 & 0,091 \\
\hline & 235 & 0,031 & & & & & 180 & 0,114 \\
\hline & 237 & 0,031 & & & & & & \\
\hline & 247 & 0,031 & & & & & & \\
\hline Loco & $\mathrm{A}$ & $\mathrm{F}$ & Loco & $\bar{A}$ & $\mathrm{~F}$ & Loco & $\bar{A}$ & $F$ \\
\hline \multirow[t]{12}{*}{$\mathrm{BrPe} 0042$} & 134 & 0,023 & \multirow[t]{12}{*}{$\mathrm{BrPe} 0043$} & 194 & 0,063 & \multirow[t]{12}{*}{ BrPe3011 } & 157 & 0,205 \\
\hline & 140 & 0,023 & & 196 & 0,031 & & 159 & 0,250 \\
\hline & 142 & 0,023 & & 200 & 0,188 & & 163 & 0,296 \\
\hline & 150 & 0,046 & & 202 & 0,219 & & 165 & 0,250 \\
\hline & 152 & 0,068 & & 204 & 0,063 & & & \\
\hline & 154 & 0,296 & & 206 & 0,031 & & & \\
\hline & 156 & 0,296 & & 210 & 0,063 & & & \\
\hline & 160 & 0,023 & & 212 & 0,031 & & & \\
\hline & 162 & 0,136 & & \multirow[t]{4}{*}{222} & \multirow[t]{4}{*}{0,313} & & & \\
\hline & 164 & 0,023 & & & & & & \\
\hline & 176 & 0,023 & & & & & & \\
\hline & 180 & 0,023 & & & & & & \\
\hline
\end{tabular}


APÉNDICE

Marcadores microssatélites desenhados a partir do sequênciamento parcial e da montagem de novo do genoma de P. edulis

\begin{tabular}{|c|c|c|c|c|c|c|c|c|c|c|c|c|c|c|c|c|c|c|c|c|}
\hline $\mathbf{N}^{\circ}$ & Primer & Contig I & Motivo & Início & Fim & pb & $\begin{array}{c}\mathbf{N}^{\circ} \\
\text { Repet }\end{array}$ & Score & Sequência do contig & Unidade & G/S & Cobertura & pb & Sequência Forward & $\begin{array}{l}\mathrm{T}^{\circ} \mathrm{C} \\
F w d \\
F\end{array}$ & Sequência Reverse & $\begin{array}{l}\mathrm{T}^{\circ} \mathrm{C} \\
\operatorname{Rev} \\
\end{array}$ & $\begin{array}{c}\% \mathrm{GC} \\
F w d \\
\end{array}$ & $\begin{array}{c}\% \mathrm{GC} \\
R e v \\
\end{array}$ & $\mathbf{P} / \mathbf{M}$ \\
\hline 1 & BrPe0001 & $\begin{array}{l}\text { Maracuja_ } \\
\text { NoIndex_L } \\
003 \text { R1_00 } \\
\text { 1_contig_3 } \\
4580\end{array}$ & 2 & 1881 & 1908 & 28 & 14 & 26 & $\begin{array}{l}\text { GCTACAAGCTGTAATCCTTGGAGAATTTTCTTTAGCTGTTGAGAGGA } \\
\text { TTGTGTTTGGTTAAGGAGTTCAATCTCTAACCACCAGTTGGTGGACC } \\
\text { TAAAACCCTCTCTTAAACCTCTCCAGAATCACCCACAAGCATCATCT } \\
\text { TCCTCTCCACTCTCTCTCTCTCTCTCTCTCTCTCTCTGTTTCTCTCCTC } \\
\text { CTCTACCATGGAAGGTCTGGTCTTGCTGCAATATCCACAATATAAGC } \\
\text { ATATTCTTCCTCTCTTTTGTTTTTTCTCTGAAATCTCTTTCTTTCCGTA } \\
\text { TTATTCTAATAATACAATTACTTATTTATTTTATTTGCCAGG }\end{array}$ & CT & $\mathrm{G}$ & 18,34 & 162 & $\begin{array}{l}\text { GTTGAGAGGATTGTG } \\
\text { TTTG }\end{array}$ & 53,84 & $\begin{array}{l}\text { ATGGTAGAGGAGGA } \\
\text { GAGA }\end{array}$ & 53,89 & 44 & 41 & $\mathrm{P}$ \\
\hline 2 & BrPe0002 & $\begin{array}{l}\text { Maracuja_ } \\
\text { NoIndex_L } \\
\text { 003_R1_00 } \\
\text { 1_contig_3 } \\
\text { 2851 }\end{array}$ & 2 & 6549 & 6572 & 24 & 12 & 22 & $\begin{array}{l}\text { GCGCAAGGGAGAATTGTCAGCAATTTTGGTTTCAATGCCTCATCTAC } \\
\text { CATGGGAGCAATAGTGCGTATAACCTGCAAAGATGAATTGTATAAA } \\
\text { GCCCAGATGAAGTGAATAAAAAATGAACAGCAAAGCATGACATCTG } \\
\text { GAGCTTTAAAAAGAGAGAGAGAGAGAGAGAGAGAGTGAGAAAGGA } \\
\text { TATGAAGAAACCAATGATAGTGCTAACAATTACTAATACTGAATAA } \\
\text { TTATGCTGCCACAAGAACACTATTAACACTTCTGATTGGAGCCCAAG } \\
\text { TCCTTTAAACGATCGCAACTAGTGATTGCACTTGGCTCAGATATTCA }\end{array}$ & AG & G & 18,49 & 183 & $\begin{array}{l}\text { AAAGCCCAGATGAAG } \\
\text { TGAA }\end{array}$ & 56,56 & $\begin{array}{l}\text { GGCTCCAATCAGAA } \\
\text { GTGT }\end{array}$ & 56,43 & 42 & 50 & $\mathrm{P}$ \\
\hline 3 & BrPe0003 & $\begin{array}{l}\text { Maracuja_ } \\
\text { NoIndex_L } \\
003 \text { R1_00 } \\
\text { 1_contig_1 } \\
0654\end{array}$ & 2 & 2214 & 2235 & 22 & 11 & 20 & $\begin{array}{l}\text { CAAGAGCCTCCATGCTTTCTCTCCCTATACCCCTTTCCCCAAATGCC } \\
\text { AAGCCTCTTGGCAATTTCAAGAACTCCGCTGCTTTCAACCACCGTCC } \\
\text { TGGATTTTCCATGCCAAGCAGGCTCCTCATCAGACGTCAGTATCAAC } \\
\text { CACCTTCGTTCTCTCTCTCTCTCTCTCTCTCCTTTCTTTTTTTTGGGCA } \\
\text { TTTTACTTCTTTATTTTCAAACACATGAGATGGATGGTCAGTATCTTG } \\
\text { GGCGGTTGTAGTGAAGAGAGCTATAGTCTAAGTGTCTCTATTTTGTT } \\
\text { ATGTGATTATGGAGGGCGAAAGAATTTAATTGCTATG }\end{array}$ & $\mathrm{TC}$ & G & 20,52 & 287 & $\begin{array}{l}\text { СТTТСТСТСССТАТАC } \\
\text { СC }\end{array}$ & 51,64 & $\begin{array}{l}\text { СССТCCATAATCAC } \\
\text { ATAAC }\end{array}$ & 51,58 & 50 & 42 & $\mathrm{P}$ \\
\hline 4 & BrPe0004 & $\begin{array}{l}\text { Maracuja_ } \\
\text { NoIndex_L } \\
003 \text { R1_00 } \\
\text { 1_contig_3 } \\
\text { 3460 }\end{array}$ & 2 & 3256 & 3277 & 22 & 11 & 20 & $\begin{array}{l}\text { TCCTCCCTCCTCTTCCTTTGTATATAATCCCTCCACCCCCGAATTTTC } \\
\text { CATTTCCCACCCTCTCTCCCGTGACCGTACACCAGTCACCACTTGTC } \\
\text { ACTCTTATTTTCCTCTCTCTCCTATTTCCACCGTCTCTCTCGCTCTCG } \\
\text { CTCTCGCTCTCTCTCTCTCTCTCTCTCTATATCTCCGTCTCATCCTCTT } \\
\text { CCCTCTCATCGCTCCCTCTCTTGTCCTCCCATCATTTCAGTTTCTCA } \\
\text { AGTGTAACTCGTCTCCCGTCGCCATATCTTCCGCTGTTGGCGGCGAG } \\
\text { TTCTTCTTTGTTCTTTTGCTTTAATTACTGCTTT }\end{array}$ & Ст & G & 16,08 & 192 & $\begin{array}{l}\text { ТСТСТСТССТАТTTCC } \\
\text { САСС }\end{array}$ & 55,34 & $\begin{array}{l}\text { AACAAAGAAGAACT } \\
\text { CGCC }\end{array}$ & 54,77 & 50 & 44 & $\mathrm{NA}$ \\
\hline 5 & BrPe0005 & $\begin{array}{l}\text { Maracuja_ } \\
\text { NoIndex_L } \\
\text { 003_R1_00 } \\
\text { 1_contig_2 } \\
\text { 2047 }\end{array}$ & 2 & 1950 & 1969 & 20 & 10 & 18 & $\begin{array}{l}\text { ATTAATTCTTTTCCTTCTTCTCTTCAAACTCTTCGTTGCTTGCCTGCAC } \\
\text { TCTACAAGTCTCCTCTCTCGTATCAGAAAGCAGAAACAGAAAGAC } \\
\text { CACCATGAGAGCACGCGCAGGAACTGAGAGTGGGTGGATGAAGAA } \\
\text { GAAGCACAGTAGAGAGAGAGAGAGAGAGAGTGTGCGTGCTTGTTC } \\
\text { GTGGTGGTAAGTGTAAATGAAGCCTGAGGGGGTCTTGTGTATTATT } \\
\text { T }\end{array}$ & AG & G & 11,35 & 192 & $\begin{array}{l}\text { ССТТСТTСТСТTСAAA } \\
\text { с }\end{array}$ & 50,36 & $\begin{array}{l}\text { САТTTACACTTACC } \\
\text { ACC }\end{array}$ & 50,35 & 41 & 44 & $\mathrm{NA}$ \\
\hline
\end{tabular}


APÉNDICE

Marcadores microssatélites desenhados a partir do sequênciamento parcial e da montagem de novo do genoma de P. edulis

\begin{tabular}{|c|c|c|c|c|c|c|c|c|c|c|c|c|c|c|c|c|c|c|c|c|}
\hline $\mathbf{N}^{\circ}$ & Primer & Contig I & Motivo & Início & Fim & pb & $\begin{array}{c}\mathbf{N}^{\circ} \\
\text { Repet }\end{array}$ & Score & Sequência do contig & Unidade & G/S & Cobertura & pb & Sequência Forward & $\begin{array}{l}\mathrm{T}^{\circ} \mathrm{C} \\
F w d \\
\end{array}$ & Sequência Reverse & $\begin{array}{l}\mathrm{T}^{\circ} \mathrm{C} \\
\operatorname{Rev} \\
\end{array}$ & $\begin{array}{c}\% \mathrm{GC} \\
F w d \\
\end{array}$ & $\begin{array}{c}\% \mathrm{GC} \\
R e v \\
\end{array}$ & $\mathbf{P} / \mathbf{M}$ \\
\hline 6 & $\begin{array}{ll}\text { BrPe0006 } \\
\end{array}$ & $\begin{array}{l}\text { Maracuja_ } \\
\text { NoIndex_L } \\
\text { 003_R1_00 } \\
\text { 1_contig_4 } \\
\text { 1864 }\end{array}$ & 2 & 1512 & 1531 & 20 & 10 & 18 & $\begin{array}{l}\text { AACCCATTTCTTTTAAGCTTGAGATGAGCCCAGATAGGGAAAATCC } \\
\text { ACAAGGAAAAGAACAGCCTCAGAGATAAGTAGAGTAGAGTACCGA } \\
\text { AAAGGGTCAATTTAATCACTGGAATTAATATCTGAAGAGCATCGGC } \\
\text { CATCTCTACGTCTTCTCTCTCTCTCTCTCTCTCCTTCAATTTCTGAGA } \\
\text { GTCAGAAGCTAGCTAGTATATAGCGAATGCCGGTATATTCTTTGACT } \\
\text { GATTTGAGAGCGATGCCCAAGCGAGGTATTTATAGACGAGATATGG } \\
\text { GTCGGCCTGGTTCGAGAATGTCGGAGCTATGACTGGGGATTA }\end{array}$ & TC & $\mathrm{G}$ & 13,3 & 196 & $\begin{array}{l}\text { AAGGAAAAGAACAG } \\
\text { CCTCA }\end{array}$ & 55,14 & $\begin{array}{l}\text { CGCTCTCAAATCAG } \\
\text { TCAAA }\end{array}$ & 55,18 & 42 & 42 & $P$ \\
\hline 7 & BrPe0007 & $\begin{array}{l}\text { Maracuja_ } \\
\text { NoIndex_L } \\
003 \text { R1_00 } \\
\text { 1_contig_1 } \\
0263\end{array}$ & 2 & 11920 & 11937 & 18 & 9 & 16 & $\begin{array}{l}\text { CTTTAAGGATCTTAGGTTTTGATTGATCCATTTCCCATATGGATTTGA } \\
\text { CAATGCCACTCTCTTTTTGACATCAGTATTCTCATAAACCTGTAAAT } \\
\text { GGAAATACTCAGTATACAATTCGATAGAGCAAGGACAGGGATATA } \\
\text { TATATACACAGAGAGAGAGAGAGAGAGGCAAGACACTGTGTTACA } \\
\text { AGAACCGGGACGTTCTATGGCACTAGATGTCAGAAAAAGGGCGTTC } \\
\text { TTGAAACATTCCAAAACATAAACAGAAAGAAGCGAACGAGACCTGT } \\
\text { GACCAAACCCCACAAAGCCTCGGAATAGTCCCTATGGAAA }\end{array}$ & $\mathrm{AG}$ & $\mathrm{s}$ & 18,69 & 183 & $\begin{array}{l}\text { AAAGCCCAGATGAAG } \\
\text { TGAA }\end{array}$ & 56,56 & $\begin{array}{l}\text { GGCTCCAATCAGAA } \\
\text { GTGT }\end{array}$ & 56,43 & 42 & 50 & $\mathrm{P}$ \\
\hline 8 & BrPe0008 & $\begin{array}{l}\text { Maracuja_ } \\
\text { NoIndex_L } \\
\text { 003_R1_00 } \\
\text { 1_contig_1 } \\
9143\end{array}$ & 2 & 2100 & 2117 & 18 & 9 & 16 & $\begin{array}{l}\text { GCCTTTTTTCAGCCTCCACTCTTATAGTTTCTTGGCTTGACACCTGGG } \\
\text { AACCCTTTCCTGGTGCTGAGTGGCACATGACCATGCCCACCAGCCA } \\
\text { GCCAACCCTTGGGGAAAAACTTCTTTCCTTCATTTGTAAGAAAATTA } \\
\text { TGTGTGTGAAGAGAGAGAGAGAGAGAGTTGAGAGCTTTTGTGTGAG } \\
\text { CTTGAGTGTGCTTTTGTGACCTTGAGACTTTGCTAGAGCTGAGATTG } \\
\text { GAGTGGTAGGAGAGTAACCTAAGGCTTCGTGGTGAGTGTTGGTGGT } \\
\text { GTAGTGCATGCATGTTTTATGTTTTATCATTTGATTT }\end{array}$ & $\mathrm{AG}$ & G & $22,55 \quad 2$ & 278 & $\begin{array}{l}\text { TTTTCAGCCTCCACTC } \\
\text { TT }\end{array}$ & 54,88 & $\begin{array}{l}\text { TACACCACCAACAC } \\
\text { TCAC }\end{array}$ & 54,89 & 44 & 50 & $\mathrm{P}$ \\
\hline 9 & BrPe0009 & $\begin{array}{l}\text { Maracuja_ } \\
\text { NoIndex_L } \\
\text { 003_R1_00 } \\
\text { 1_contig_4 } \\
1230\end{array}$ & 2 & 4237 & 4254 & 18 & 9 & 16 & $\begin{array}{l}\text { ATTTGCTGAGTTTCTGTCTCTTTCAGCAATCAAGAAGGATCTGCTTTT } \\
\text { GATTTTGGGGGCTAGAAGCAGCAATTGTACTTCAAGGAGTTAAGA } \\
\text { TTAGGAATGATGAAGCCAAAGCACGTATGATTCCCTCTCCTCTCCTC } \\
\text { TTCTCTCCCCTCTCTCTCTCTCTCTCTACTCATTTCTGCTTTTCTGACG } \\
\text { TTTGACAAGTATAACCAACTCTCCAAAAGCAAAGGGTGTGAAAGGT } \\
\text { TTGAATATGTCTGATGAGGGTACAACAGAGAGGGGGTACCATTTC } \\
\text { CAATACAGTAATCATGCTGAGCATCAGAATTGAATG }\end{array}$ & СТ & G & 17,89 & 113 & $\begin{array}{l}\text { стСТССТСТССТСТTC } \\
\text { тC }\end{array}$ & 54,05 & $\begin{array}{l}\text { TTCAAACCTTTCAC } \\
\text { ACCC }\end{array}$ & 53,39 & 56 & 44 & M \\
\hline 10 & BrPe0010 & $\begin{array}{l}\text { Maracuja_ } \\
\text { NoIndex_L } \\
003 \text { R1_00 } \\
\text { 1_contig_6 } \\
7275\end{array}$ & 2 & 1693 & 1710 & 18 & 9 & 16 & $\begin{array}{l}\text { ACAAAAACCCAGAACATTTTACGGCTGGAACAGCGAGTGATACCAG } \\
\text { CTAGTATAAAGAAGAAAAAAGGGCTTGTATGAAAGATAGATACTCC } \\
\text { TTGTCTACATCTGTTGACGGAAATGATTCTTCTCTCAAGGAAAAAGA } \\
\text { GCTCCTATCGATCTCTCTCTCTCTCTCTCCATTCAATGCGGTTTTTTCT } \\
\text { TTCTTTCCTTTTTTTTGTTGTATCTGTGTAGCTTTTAACAGTGTGTCTC } \\
\text { TGATCTTTCCTCCAAACCCTAACATGTGTCCCTTGAAAGGGATAGTA } \\
\text { TTGATTTTATCCTCTCCTCTATGTTTATTCTCCC }\end{array}$ & $\mathrm{TC}$ & G & 15,3 & 204 & $\begin{array}{l}\text { GAAGAAAAAAGGGCT } \\
\text { TG }\end{array}$ & 51,56 & $\begin{array}{l}\text { GTTAGGGTTTGGAG } \\
\text { GA }\end{array}$ & 51,06 & 41 & 50 & $\mathrm{P}$ \\
\hline
\end{tabular}

G: genoma funcional

S: genoma estructural

P: polimórfico

M: monomórfico 
APÉNDICE

Marcadores microssatélites desenhados a partir do sequênciamento parcial e da montagem de novo do genoma de P. edulis

\begin{tabular}{|c|c|c|c|c|c|c|c|c|c|c|c|c|c|c|c|c|c|c|c|c|}
\hline $\mathbf{N}^{\circ}$ & Primer & Contig I & Motivo & Início & Fim & pb & $\begin{array}{c}\mathbf{N}^{\circ} \\
\text { Repet }\end{array}$ & Score & Sequência do contig & Unidade & G/S & Cobertura & pb & Sequência Forward & $\begin{array}{l}\mathbf{T}^{\circ} \mathrm{C} \\
F w d\end{array}$ & Sequência Reverse & $\begin{array}{r}\mathrm{T}^{\circ} \mathrm{C} \\
\operatorname{Rev}\end{array}$ & $\begin{array}{c}\% \mathrm{GC} \\
F w d\end{array}$ & $\begin{array}{c}\% \mathrm{GC} \\
\operatorname{Rev}\end{array}$ & $\mathbf{P} / \mathbf{M}$ \\
\hline 11 & BrPe0011 & $\begin{array}{l}\text { Maracuja_ } \\
\text { NoIndex_L } \\
\text { 003_R1_00 } \\
\text { 1_contig_2 } \\
\text { 1881 }\end{array}$ & 2 & 1767 & 1782 & 16 & 8 & 14 & $\begin{array}{l}\text { TTATGTAACCCACTACATGTCGTATTGCAGGATAACCCTCTTCTATT } \\
\text { CGACTACAATGTCGAGAATCGAGTTAATGATTTTGTTAATGCAGCTA } \\
\text { TGATCCAAGTAAACTCTGAGATCAACTTGTTCTACTCCCTCATTTTTT } \\
\text { CTGATTCCCTCTCTCTCTCTCTCTGTGCTTTTAATCTGGTTCTTGGGG } \\
\text { ATGTTAAGAAGACAACTATCAAAACTTTTGGAAAGAATCTATATGC } \\
\text { AAATGACGCTGTCCTTTTCTACAGGTAAATGTGACAAGGACAAACC } \\
\text { ATGTGATGTGGACCATGGGTGATGATTTCCAGTA }\end{array}$ & CT & $\mathrm{G}$ & 16,92 & 79 & GTTCTACTCCCTCATT & 49,2 & $\begin{array}{l}\text { CTTCTTAACATCCCC } \\
\text { A }\end{array}$ & 49,24 & 44 & 44 & $P$ \\
\hline 12 & BrPe0012 & $\begin{array}{l}\text { Maracuja_ } \\
\text { NoIndex_L } \\
\text { 003_R1_00 } \\
\text { 1_contig_2 } \\
\text { 3916 }\end{array}$ & 2 & 1717 & 1732 & 16 & 8 & 14 & $\begin{array}{l}\text { TCAACGGAAAGAAGGCCACTGAGAATGCATTCTTTGAGGCCAGTCC } \\
\text { CAAGAACAATGACATCATACTCCTCATCCATGGCTTACGTACAGTG } \\
\text { ATGAGAGAGAACCCAAGGTGGAAGAGATCAGTTTTGATCGGTGGAG } \\
\text { AAAGTGATCGACAGAGAGAGAGAGAGAGGGAATGGAGAGGCAATG } \\
\text { GACAGAGTCAGGATTTTATGTTCTTGATGAAGCTGTGGAGCAGGTCT } \\
\text { TTAGCGGGGGCTAAGTAACGATAATAACGCAGAGCACAACACAGA } \\
\text { CTAATTGCCATATACCATTCTAAAGCATGAACGTAATTGTA }\end{array}$ & AG & G & 16,72 & 222 & $\begin{array}{l}\text { ACATCATACTCCTCA } \\
\text { TCC }\end{array}$ & 52,42 & $\begin{array}{l}\text { TTAGTCTGTGTTGTG } \\
\text { CTC }\end{array}$ & 52,67 & 44 & 44 & $\mathrm{P}$ \\
\hline 13 & BrPe0013 & $\begin{array}{l}\text { Maracuja_ } \\
\text { NoIndex_L } \\
\text { 003_R1_00 } \\
\text { 1_contig_4 } \\
6638\end{array}$ & 2 & 2068 & 2083 & 16 & 8 & 14 & $\begin{array}{l}\text { TAAAAAACCAAACTTGCAGAGGCTTCCAAAGGCAACATTTTTAAAT } \\
\text { GCTTTGGTCTCTGATCGAGGTGAGGTACTGATCATTACTCGTTGAGA } \\
\text { AAATGCACAGAATCCAGAACATCTCGCATCATACAAGTTCATTATG } \\
\text { CATGCAGGTGCAGAGAGAGAGAGAGAGTGATGGAGCTCACGATCA } \\
\text { TCAACAAAATTCAGAGGGTCTACCCGATTCCTCCATTAAAGCCAAA } \\
\text { CCCAGATTTGGATTTGTTCCTCCTCACACAAGGATATGTAATCCTA } \\
\text { TTTATGGACAAATAAAAATTTGATGTTGAATGTATTTGA }\end{array}$ & $\mathrm{AG}$ & G & 12,69 & 174 & $\begin{array}{l}\text { GATCGAGGTGAGGTA } \\
\text { CTG }\end{array}$ & 56,1 & $\begin{array}{l}\text { GGTTTGGCTTTAATG } \\
\text { GAGG }\end{array}$ & 55,62 & 56 & 47 & $\mathrm{P}$ \\
\hline 14 & BrPe0014 & $\begin{array}{l}\text { Maracuja_ } \\
\text { NoIndex_L } \\
\text { 003_R1_00 } \\
\text { 1_contig_1 } \\
0551\end{array}$ & 2 & 2151 & 2164 & 14 & 7 & 12 & $\begin{array}{l}\text { ACAATCGATAGATGAGACATCAAATATGGCTGGGGAAAACAGTAAC } \\
\text { CATACAAACAGGGGAAATCTACAAGGAAACAATCCATTCCTATGAC } \\
\text { ACATCCCAATTTGATGAGTGTGTTAATCAATTTCATCAGATCATGTT } \\
\text { TTCATGAAAAAAAGAGAGAGAGAGAGGGAGACAAAGGTAATCAAA } \\
\text { AGATACCATACATCATAAGTTCATGTTTACATAATATAAAAAGGTCC } \\
\text { AAAGACAGGAAATACTCAAAAGCATCATTCTCAATAAACTAAACAC } \\
\text { AAAGCCAGAAGAATCATAACTGAGAAAATTGTTCATC }\end{array}$ & AG & G & 16,3 & 220 & $\begin{array}{l}\text { AATATGGCTGGGGAA } \\
\text { AAC }\end{array}$ & 54,76 & $\begin{array}{l}\text { TTCCTGTCTTTGGAC } \\
\text { СTT }\end{array}$ & 54,96 & 44 & 44 & $\mathrm{P}$ \\
\hline 15 & BrPe0015 & $\begin{array}{l}\text { Maracuja_ } \\
\text { NoIndex_L } \\
003 \text { R1_00 } \\
\text { 1_contig_1 } \\
\text { 3562 }\end{array}$ & 2 & 2273 & 2286 & 14 & 7 & 12 & $\begin{array}{l}\text { AAACCTGGAAACTCCATTCAGCATTTCAAGAGAAACCCATCTCAGT } \\
\text { CAGATTCAGAGGGAAATGCAAAACAGGCTACCACATGAAGTTGGAG } \\
\text { GGAAGAGAAAACCAAGTGATCCAGAAACCAAAGACCCACGTCAAA } \\
\text { AGAAAACCAAAAAAGAGAGAGAGAGAGCCAGAACAAGAAAAAGC } \\
\text { AAACAAAAGAGGCTTCAAGGAAAGAAGTGCATTATTAGGAAAACG } \\
\text { GGACGTATATGAACCTACTACGCTCGGTGTTTATATGAATGTCGAAC } \\
\text { CAACGAACAACAGCATGAGTCCAGGAGCAAAGCCCTACGGG }\end{array}$ & AG & G & 16,44 & 203 & $\begin{array}{l}\text { AAGTTGGAGGGAAGA } \\
\text { G }\end{array}$ & 51,93 & $\begin{array}{l}\text { CTGTTGTTCGTTGGT } \\
\mathrm{T}\end{array}$ & 51,76 & 50 & 44 & M \\
\hline
\end{tabular}

G: genoma funcional

S: genoma estructural

P: polimórfico

M: monomórfico 
APÉNDICE

Marcadores microssatélites desenhados a partir do sequênciamento parcial e da montagem de novo do genoma de $P$. edulis

\begin{tabular}{|c|c|c|c|c|c|c|c|c|c|c|c|c|c|c|c|c|c|c|c|c|}
\hline $\mathrm{N}^{\circ}$ & Primer & Contig $\mathrm{I}$ & Motivo & Início & Fim & pb & $\begin{array}{c}\mathbf{N}^{\circ} \\
\text { Repet }\end{array}$ & Score & Sequência do contig & Unidade & G/S & Cobertura & pb & Sequência Forward & $\begin{array}{l}\mathrm{T}^{\circ} \mathrm{C} \\
F w d\end{array}$ & Sequência Reverse & $\begin{array}{r}\mathrm{T}^{\circ} \mathrm{C} \\
\operatorname{Rev}\end{array}$ & $\begin{array}{c}\% \mathrm{GC} \\
F w d\end{array}$ & $\begin{array}{c}\% \mathrm{GC} \\
\operatorname{Rev}\end{array}$ & $\mathbf{P} / \mathbf{M}$ \\
\hline 16 & BrPe0016 & $\begin{array}{l}\text { Maracuja_ } \\
\text { NoIndex_L } \\
\text { 003_R1_00 } \\
\text { 1_contig_1 } \\
4816\end{array}$ & 2 & 2784 & 2797 & 14 & 7 & 12 & $\begin{array}{l}\text { AAATAAAGGCAGAGAAAGGTAAAATGGTTGGTGGGTCTTGTGAGTA } \\
\text { TGTGGAAAGTGGGAGAGGGACAGAGACAGAGAGAGGGACCTTTCA } \\
\text { AAAAACCTGGAAAGGAAGCTTTGTTTGCAATGGAGGAAACCACAGT } \\
\text { GAGGAAAACCAAAAGAGAGAGAGAGAGCAGTCAAGGGAAAGCAA } \\
\text { GAATTAAGTGCACGGATAGGCCAGGACTCATAACTATGTAAAAGTA } \\
\text { AAGAAAACACACATAATGAGAACCCAACATAAAGCAAGCACAAAA } \\
\text { AAACTGGACACAGAGAGAGAGAGAGAGAGGAAAGAGTCGGTA }\end{array}$ & $\overline{\mathrm{AG}}$ & $\bar{G}$ & 16,99 & 284 & $\begin{array}{l}\text { TGGTTGGTGGGTCTT } \\
\text { GT }\end{array}$ & 56,29 & $\begin{array}{l}\text { СТСТTTCСТСТСТCT } \\
\text { СТСТС }\end{array}$ & 56,47 & 53 & 48 & $P$ \\
\hline 17 & BrPe0017 & $\begin{array}{l}\text { Maracuja_ } \\
\text { NoIndex_L } \\
\text { 003_R1_00 } \\
\text { 1_contig_1 } \\
8007\end{array}$ & 2 & 1170 & 1183 & 14 & 7 & 12 & $\begin{array}{l}\text { CCAACAACACTCAGTCGATTCGAGAGCGAAACTAGCATTGATCTGC } \\
\text { AACGGATGCTCCCATGTTTATAGCGACCACGAACCTGAGTATTGTCT } \\
\text { CTCGGTTCTCTTTTGCATAGCTATAAAGAGGAAACATATAGAGAGA } \\
\text { AAGAGATATATAGAGAGAGAGAGAGGGGGGGTTTGTGTTTGGAGA } \\
\text { GTGAAACCCAGATGGCTATCCAGATAGAGATCTAGTGCAGTCCAT } \\
\text { TAAATCGAAGGTTAGAGCCTGAAGAAGTCGAAGAAGCCGTACATC } \\
\text { AAAATGGACAAGAGTGCGAGCGTCAAGGTCGAGATCC }\end{array}$ & AG & G & 15,07 & 94 & $\begin{array}{l}\text { TTGTCTCTCGGTTCTC } \\
\text { T }\end{array}$ & 52,47 & $\begin{array}{l}\text { CAAACACAAAACCC } \\
\text { CC }\end{array}$ & 52,44 & 47 & 50 & $\mathrm{P}$ \\
\hline 18 & BrPe0018 & $\begin{array}{l}\text { Maracuja_ } \\
\text { NoIndex_L } \\
\text { 003_R1_00 } \\
\text { 1_contig_2 } \\
\text { 5472 }\end{array}$ & 2 & 3884 & 3897 & 14 & 7 & 12 & $\begin{array}{l}\text { CCTCGAACAACATCTGTTTCTATGCAGTAAAGCCTCATGACTCTGTT } \\
\text { GGTGCTGCAGAATCTGCTGCTGCTGGTGCTGTTCCTTGCCCATCGAA } \\
\text { ATTGCATCTGGAAAAATCACTTGTCCTTCCTTCTCCTCCGAACTTC } \\
\text { ACTCACTAACTCTCTCTCTCTCTTTCTCTTCCTCCCTAATAAAAAGAT } \\
\text { TGAAACTTCATGTGATCCTCTCTCTCTAAAAATCGAACCGACACAA } \\
\text { CCAATGAGATGACATAGATGAGAGACAAGTGTTCATGAGTGCACAT } \\
\text { TACTTTTGATTTGCTGCCTACCTCTCTCTTTC }\end{array}$ & СT & G & 17,3 & 150 & ТССТTCСТTСТССТСC & 51,16 & $\begin{array}{l}\text { АСАCTTGTCTCTCAT } \\
\text { СТ }\end{array}$ & 51,47 & 56 & 41 & $\mathrm{P}$ \\
\hline 19 & BrPe0019 & $\begin{array}{l}\text { Maracuja_ } \\
\text { NoIndex_L } \\
\text { 003_R1_00 } \\
\text { 1_contig_2 } \\
9060\end{array}$ & 2 & 3671 & 3684 & 14 & 7 & 12 & $\begin{array}{l}\text { GAACAAACGGGCCAAAATGAGGAACCAATTAAAAGGAGAAGGATGGA } \\
\text { TGCTTACCTCTCTGCCACAAGGTGACTGAAAAAACGGCATCACAGT } \\
\text { TTAGTAACTTCTCCTCTCACGTACCATTGTTTGTCTCTACCTAACACT } \\
\text { CTCTCCTCTCTTCTCTCTCTCTCTCGGATTGTTCTTGCACTTGTGTCTT } \\
\text { CCTTGCTTTCTCTTCCATGCATCAGCACATTTTGTACTCTTCCTCGTC } \\
\text { CTTTTTGGCTTTTGATTGCACTGTTTTAGTGCTTTTTTGGGCCTTCCTT } \\
\text { TTTCGAAAATTTCACTGTCTGAGTCTCTG }\end{array}$ & $\mathrm{TC}$ & G & 17,47 & 212 & $\begin{array}{l}\text { AAAGAGAAGGATGG } \\
\text { ATG }\end{array}$ & 50,59 & $\begin{array}{l}\text { AAAAAGGACGAGG } \\
\text { AAGA }\end{array}$ & 51,08 & 41 & 41 & $\mathrm{P}$ \\
\hline 20 & BrPe0020 & $\begin{array}{l}\text { Maracuja_ } \\
\text { NoIndex_L } \\
003 \_R 1 \_00 \\
\text { 1_contig_4 } \\
0022\end{array}$ & 2 & 6276 & 6289 & 14 & 7 & 12 & $\begin{array}{l}\text { CGGACGAATAAAGCATCAGGTCAGATGAGGTGACATCAAAGGACCT } \\
\text { ACATAGGAACCTTTTTTGCTTTACAATCCAGATATCCACGGTGGTGA } \\
\text { TGGGGCTGTCACCAATGCATGGTCACGGCAGTAATGTGACGCACCA } \\
\text { CCATTAGTGGAGTGTGTGTGTGTGTATTCAAAGCTGTAAACCAAATT } \\
\text { GGAGCAGTATTTAAGTGGAAGGAAAAACAACAGATATAAATTGGA } \\
\text { TTGCAGAGTGGCTCAGAAGCAGTGTACTGTCTGAAGTGACTGGAGG } \\
\text { GGCAAATGTCCTGCCCGTCAAATCTATCTAAGTCCT }\end{array}$ & GT & G & 16,19 & 300 & $\begin{array}{l}\text { TAAAGCATCAGGTCA } \\
\text { G }\end{array}$ & 48,17 & $\begin{array}{l}\text { TAGATAGATTTGAC } \\
\text { GGG }\end{array}$ & 48,99 & 44 & 41 & $\mathrm{P}$ \\
\hline
\end{tabular}

G: genoma funcional

S: genoma estructural

P: polimórfico

M: monomórfico 
APÉNDICE

Marcadores microssatélites desenhados a partir do sequênciamento parcial e da montagem de novo do genoma de P. edulis

\begin{tabular}{|c|c|c|c|c|c|c|c|c|c|c|c|c|c|c|c|c|c|c|c|c|}
\hline $\mathbf{N}^{\circ}$ & Primer & Contig $\mathrm{I}$ & Motivo & Início & Fim & pb & $\begin{array}{c}\mathbf{N}^{\circ} \\
\text { Repet }\end{array}$ & Score & Sequência do contig & Unidade & $G / S$ & Cobertura & pb & Sequência Forward & $\begin{array}{l}\mathrm{T}^{\circ} \mathrm{C} \\
F w d\end{array}$ & Sequência Reverse & $\begin{array}{r}\mathrm{T}^{\circ} \mathrm{C} \\
\operatorname{Rev}\end{array}$ & $\begin{array}{c}\% \mathrm{GC} \\
F w d\end{array}$ & $\begin{array}{c}\% \mathrm{GC} \\
\operatorname{Rev}\end{array}$ & $\mathbf{P} / \mathbf{M}$ \\
\hline 21 & BrPe0021 & $\begin{array}{l}\text { Maracuja_ } \\
\text { NoIndex_L } \\
003 \text { R1_00 } \\
\text { 1_contig_4 } \\
5867\end{array}$ & 2 & 1667 & 1680 & 14 & 7 & 12 & $\begin{array}{l}\text { CGAGAGATACGAGAGAGCCCAGCATGCATCAGTCAAGACTTCCTCA } \\
\text { TCATTCGAATGGATAAGACGTGCAAGAGCTGGAAGTGCAGGCCTAA } \\
\text { CCTGTTAGGCATACATAAAGGACAAATCCTAAGATTGTGCAACACA } \\
\text { AAACTATATATGTATATATATATATACCAACAAAGATTCTAAAGAA } \\
\text { AAATGCAAAAAGAGGCATAGCTCCTACGAAGGTAAATTCTTTCCCA } \\
\text { TAATTAAAATTACTTAAAAAGGAGTGTCTTAACAGGTAGGCCACAA } \\
\text { ACCGGTGATCATATTCTCATCAAAGTTTAATAACTACA }\end{array}$ & $\overline{\mathrm{TA}}$ & $\bar{G}$ & 16,28 & 168 & ACTTCCTCATCATTCG & 50,06 & $\begin{array}{l}\text { GCTATGCCTCTTTTT } \\
\text { G }\end{array}$ & 49,96 & 44 & 44 & $P$ \\
\hline 22 & BrPe0022 & $\begin{array}{l}\text { Maracuja_ } \\
\text { NoIndex_L } \\
\text { 003_R1_00 } \\
\text { 1_contig_5 } \\
2201\end{array}$ & 2 & 1309 & 1322 & 14 & 7 & 12 & $\begin{array}{l}\text { AAGTTAAAGAATTCCCATTTTAACATTATTTTGTTTTCAGTTAAATTT } \\
\text { TCAGAATTGCGAATTTCAGCATATATTCTCTCCAATTTTTCATGTGG } \\
\text { GCAGAATGTTGGATCTGTTTAGAATGTCACTAAGTGGCATAGAAGT } \\
\text { GGAAGGGCTAGAGAGAGAGAGAGGGACAGATGAGGCCGTGAAATT } \\
\text { GTTCCAAGATTTACCATTGTTTTCTCTATTCCCTTCACTTCCCTTCCA } \\
\text { AAAGAAAGCCAACAAAAAGCACGAAACAGAGGATTCTCCCAAATA } \\
\text { TTTCCTGATACTTTCTGATAGTGATGGCCTCTCTC }\end{array}$ & AG & G & 15,08 & 103 & $\begin{array}{l}\text { GGCATAGAAGTGGAA } \\
\text { GGG }\end{array}$ & 57,09 & $\begin{array}{l}\text { GGAAGGGAAGTGAA } \\
\text { GGGA }\end{array}$ & 57,09 & 56 & 56 & $\mathrm{P}$ \\
\hline 23 & BrPe0023 & $\begin{array}{l}\text { Maracuja_ } \\
\text { NoIndex_L } \\
003 \text { R1_00 } \\
\text { 1_contig_7 } \\
76\end{array}$ & 2 & 3993 & 4006 & 14 & 7 & 12 & $\begin{array}{l}\text { GGAAAATTCCCCTCGCATTGTTAACCTCATTGTAAATCATGTATCCA } \\
\text { CGGTGAGATACCACACCCAATAGGCCCAATAGCACAGGACTGGACA } \\
\text { GAACCATAAAGAGGCATAAATAACCCTAGATCTGAAACCTGAGAGC } \\
\text { AAGATAACCCCCTCTCTCTCTCTCTTTCCCCAACAACTCCAAGCTCT } \\
\text { CTAAGCCCCATCACCAGCGGTTGAGTCTCCCATCGACAACAACCAG } \\
\text { AGCCCTTTGACCCTTCCTCTTGTGCATGTATTAACTAGACTCTCATGA } \\
\text { GCATGCAAACATACAAATTTACTAAACTAAGTAT }\end{array}$ & СT & G & 16,93 & 129 & $\begin{array}{l}\text { AGATACCACACCCAA } \\
\text { TAG }\end{array}$ & 52,38 & $\begin{array}{l}\text { TTGGAGTTGTTGGG } \\
\text { GA }\end{array}$ & 51,95 & 44 & 50 & $\mathrm{P}$ \\
\hline 24 & BrPe0024 & $\begin{array}{l}\text { Maracuja_ } \\
\text { NoIndex_L } \\
\text { 003_R1_00 } \\
\text { 1_contig_8 } \\
8799\end{array}$ & 2 & 1857 & 1870 & 14 & 7 & 12 & $\begin{array}{l}\text { CTCGCTTGACTATGTTATTGATACTGTCCCAGTGTTTCACCCTCTTGA } \\
\text { GCCCTACCTTTCTCTGCTTAAACTCGACGGCAAGCTGATCTTGATGG } \\
\text { GTGTTATCAATACACCACTGCAGTTCCTTACACCTATGGTTATGATT } \\
\text { GGTCAGTATCTCTCTCTCTCTCACTCTCTCTCTCGTTAGTCTTTTAAA } \\
\text { CAGGAGTACCAGTAGTCTTGATGCAATTTTGTTCAGGGAGGAAGAC } \\
\text { GATCACCGGGAGCTTCATAGGGAGCATGAAGGAGATAGAGGAGAT } \\
\text { GCTTCAGTTCTGCAAGGAAAAGGGATTAACCTC }\end{array}$ & $\mathrm{TC}$ & G & 14,63 & 233 & $\begin{array}{l}\text { СССТАССТTTCTCTGC } \\
\text { тT }\end{array}$ & 54,82 & $\begin{array}{l}\text { САТСТССТСТАТСТC } \\
\text { СТTC }\end{array}$ & 52,22 & 50 & 47 & $\mathrm{P}$ \\
\hline 25 & BrPe0025 & $\begin{array}{l}\text { Maracuja_ } \\
\text { NoIndex_L } \\
003 \text { R1_00 } \\
\text { 1_contig_1 } \\
0103\end{array}$ & 2 & 1683 & 1694 & 12 & 6 & 10 & $\begin{array}{l}\text { TGCTCAGGTTCTGGAGACTTCTCGTGGATCTGGGTCAGCTTTACCTT } \\
\text { GGCTCCCCGAAGGTTCATCAACTTAATCTGGCGACGAAAAGAACAG } \\
\text { ATTTGCAATCAACAAGCATAATCAGACATGCCAAGGAACCAGAACA } \\
\text { AGAAGAAGAAGGAGAGAGAGAGAAAGAAAGAAAGAGACCTTGGG } \\
\text { ATAGGTACAGCCGGTAGTTGGGGCAGACAGAGGAAGCTCAGGTGG } \\
\text { GCTGGCTTGTTCTTCTTGACCATCCATGTAAACGCTAAGGCAAAGGT } \\
\text { CACAGAGGTTTTCGTTCGAGGTCGTTCGCTGTTTGTC }\end{array}$ & GA & G & 17,74 & 119 & $\begin{array}{l}\text { CAAGGAACCAGAACA } \\
\text { AGAAGAA }\end{array}$ & 56,52 & $\begin{array}{l}\text { GAAGAACAAGCCAG } \\
\text { CCCA }\end{array}$ & 56,87 & 41 & 56 & $\mathrm{P}$ \\
\hline
\end{tabular}

G: genoma funcional

S: genoma estructural

P: polimórfico

M: monomórfico 
APÉNDICE

Marcadores microssatélites desenhados a partir do sequênciamento parcial e da montagem de novo do genoma de P. edulis

\begin{tabular}{|c|c|c|c|c|c|c|c|c|c|c|c|c|c|c|c|c|c|c|c|c|}
\hline $\mathbf{N}^{\circ}$ & Primer & Contig I & Motivo & Início & Fim & pb & $\begin{array}{c}\mathbf{N}^{\circ} \\
\text { Repet }\end{array}$ & Score & Sequência do contig & Unidade & G/S & Cobertura & pb & Sequência Forward & $\begin{array}{l}\mathrm{T}^{\circ} \mathrm{C} \\
F w d\end{array}$ & Sequência Reverse & $\begin{array}{r}\mathrm{T}^{\circ} \mathrm{C} \\
\operatorname{Rev}\end{array}$ & $\begin{array}{c}\% \mathrm{GC} \\
F w d\end{array}$ & $\begin{array}{c}\% \mathrm{GC} \\
\operatorname{Rev}\end{array}$ & $\mathbf{P} / \mathbf{M}$ \\
\hline 26 & BrPe0026 & $\begin{array}{l}\text { Maracuja_ } \\
\text { NoIndex_L } \\
003 \text { R1_00 } \\
\text { 1_contig_1 } \\
1032\end{array}$ & 2 & 1793 & 1804 & 12 & 6 & 10 & $\begin{array}{l}\text { TCCATTTTGCTCAGAATAGAAAACAGAAAAAGAGAGTAAGGGTTTGC } \\
\text { AATGCTTCTATCACAACATTCTATATTCGTCAGTTTTCCTTCGTTTTT } \\
\text { TCCTGTAGTGTCTACACAACCAAACGGGCCATGTTTCCTCCATTTGA } \\
\text { GAAAAGGAAAGAGAGAGAGAGCGGCGGAAAGAACTAATATCAGAG } \\
\text { AAATTGACGGATTTCACCCAAAAAAAATATGAATACTCGACATTTG } \\
\text { GTGGAAGCATGAAAAGATAACTTACAGCGAATAGAAGATGGATAA } \\
\text { ATTGGCAAACGCAGTGAAGAAAGCAGAATCAAAAC }\end{array}$ & $\overline{\mathrm{AG}}$ & $\mathrm{G}$ & 19,39 & 217 & $\begin{array}{l}\text { CCTTCGTTTTTTCCTG } \\
\mathrm{T}\end{array}$ & 53,16 & $\begin{array}{l}\text { CTTTCTTCACTGCGT } \\
\text { TT }\end{array}$ & 52,29 & 41 & 41 & $\mathrm{M}$ \\
\hline 27 & BrPe0027 & $\begin{array}{l}\text { Maracuja_ } \\
\text { NoIndex_L } \\
003 \text { R1_00 } \\
\text { 1_contig_1 } \\
\text { 21386 }\end{array}$ & 2 & 1635 & 1646 & 12 & 6 & 10 & $\begin{array}{l}\text { TACATATCTGATTTACGACCGAGTTGCTTCTGCGGAAGAATCACTTG } \\
\text { TGCAGAGTGAGAATCACTGGTGTCTGGAATAGGATGGCTCATTATA } \\
\text { CATATAGCACGAGCAACTTTTCCAATCTTCTCAACCTGTTGCATTAG } \\
\text { ACCATATATGTATATATATATAGCTGTCATGATCATTTCAGCATATC } \\
\text { AATTCATGTCAAAGGGGTTACTAGTTTGATAGAAGTTACTTTGTCT } \\
\text { GGCAAATATGATGGATCGCAGACAACTTTCTTGCATTTGGCGGTTTC } \\
\text { TCCTTCAGAGGTCACACCGATGGCCTTCCCA }\end{array}$ & TA & G & 17,17 & 103 & TCCAATCTTCTCAACC & 049 & $\begin{array}{l}\text { CAAACTAGTAAACC } \\
\text { CC }\end{array}$ & 49,12 & 44 & 44 & $\mathrm{P}$ \\
\hline 28 & BrPe0028 & $\begin{array}{l}\text { Maracuja_ } \\
\text { NoIndex_L } \\
003 \text { 121_00 } \\
\text { 1_contig_1 } \\
65927\end{array}$ & 2 & 1325 & 1336 & 12 & 6 & 10 & $\begin{array}{l}\text { TACGCTTTCGTCTCACACACTACCAGAACCAAAAACAACAGCACCC } \\
\text { TCATGACCCAAGTGTTTATTTTCCTCCTGCCCCCACAAGCCATTGGG } \\
\text { AGCTACCTTATCTGAGCAATATCCAAGAACCAAAAGGAACAGGGAA } \\
\text { GATACGGTTGCTATATATATATAAATATATGATGGGCTTAGATGACG } \\
\text { CCTCAACAAGAAAATGCAAGTATATCTCTGTCTTTCTCTCTTTCTGTG } \\
\text { CGGTTTCAGTGGGTGTACTTCTCGCAAGGAAAATGCATGTGTATTGT } \\
\text { TTTGAGGCCAAAGCCAAAGTATATAAGCAGT }\end{array}$ & TA & G & 14,16 & 107 & $\begin{array}{l}\text { CAAAAGGAACAGGG } \\
\text { AAGA }\end{array}$ & 53,67 & $\begin{array}{l}\text { GAAAGAGAGAAAG } \\
\text { ACAGAGA }\end{array}$ & 53,42 & 44 & 40 & $\mathrm{P}$ \\
\hline 29 & BrPe0029 & $\begin{array}{l}\text { Maracuja_ } \\
\text { NoIndex_L } \\
\text { 003_R1_00 } \\
\text { 1_contig_1 } \\
885\end{array}$ & 2 & 5660 & 5671 & 12 & 6 & 10 & $\begin{array}{l}\text { ATTCTTATTTTTTTATGGTTTGGGAAATTTTTCCGATCGAAAACATGT } \\
\text { CGGTAGAACCTTCTACTGAGAATATCAGTATGGTCGGAGTCCGACC } \\
\text { CGAGACTTGAATATAAATAAAATGAATATGATTCGAATTTTAATTTT } \\
\text { CCATCCTTACTCTCTCTCTCTTCTCTGCACCCCCTCTCTCCCCTCGCG } \\
\text { ATTCTTCTTCATCGCGATTCATCTCCCTCCCTCCCCTCTGAACCCTTT } \\
\text { CTTCTCCTTCCCCTTCTCTTCTCTTCTTCTCCTTCTC }\end{array}$ & СТ & G & 17,88 & 187 & $\begin{array}{l}\text { ATATCAGTATGGTCG } \\
\text { GAGT }\end{array}$ & 54,82 & $\begin{array}{l}\text { AGAGAAGGGGAAG } \\
\text { GAGAA }\end{array}$ & 54,85 & 42 & 50 & M \\
\hline 30 & BrPe0030 & $\begin{array}{l}\text { Maracuja_ } \\
\text { NoIndex_L } \\
003 \text { R1_00 } \\
\text { 1_contig_7 } \\
592\end{array}$ & 2 & 2640 & 2651 & 12 & 6 & 10 & $\begin{array}{l}\text { ACCTGTTTTGTATGGTTTTGATATTCTAGGGCTTGTGCAGTGGGCCA } \\
\text { TGTCCTCCATGTGCCTGCATGTGCTGTGTCTTTCCGGGAGAGGCCCA } \\
\text { CCTCTTGCTTTCCCAGAGCAAATAAATGGCAGGCACATTCTTCTTCT } \\
\text { CTTCATTCGTCTCTCTCTCTCAACTTGATTCTAAGATTCCTAAACACT } \\
\text { TTCTTGGATCTGCGGAAGACTTTGAACTACTGCATCATTCTGCAGCT } \\
\text { TGTCTTGTAATTTCTCATCAGGTATGTGTTCTTTTACTACATTACTCT } \\
\text { AATTCACATGTTTTTGCGTGCAATGATT }\end{array}$ & TC & G & 14,58 & 91 & $\begin{array}{l}\text { GCACATTCTTCTTCTC } \\
\text { TTCA }\end{array}$ & 54,75 & $\begin{array}{l}\text { AGTTCAAAGTCTTC } \\
\text { CGCA }\end{array}$ & 55,21 & 40 & 44 & M \\
\hline
\end{tabular}

G: genoma funcional

S: genoma estructural

P: polimórfico

M: monomórfico 
APÉNDICE

Marcadores microssatélites desenhados a partir do sequênciamento parcial e da montagem de novo do genoma de P. edulis

\begin{tabular}{|c|c|c|c|c|c|c|c|c|c|c|c|c|c|c|c|c|c|c|c|c|}
\hline $\mathbf{N}^{\circ}$ & Primer & Contig 1 & Motivo & Início & Fim & pb & $\begin{array}{c}\mathbf{N}^{\circ} \\
\text { Repet }\end{array}$ & Score & Sequência do contig & Unidade & G/S & Cobertura & pb & Sequência Forvard & $\begin{array}{l}\mathrm{T}^{\circ} \mathrm{C} \\
F w d\end{array}$ & Sequência Reverse & $\begin{array}{r}\mathrm{T}^{\circ} \mathrm{C} \\
\operatorname{Rev}\end{array}$ & $\begin{array}{c}\% \mathrm{GC} \\
F w d\end{array}$ & $\begin{array}{c}\% \mathrm{GC} \\
\operatorname{Rev}\end{array}$ & $\mathbf{P} / \mathbf{M}$ \\
\hline 31 & BrPe0031 & $\begin{array}{l}\text { Maracuja_ } \\
\text { NoIndex_L } \\
\text { 003_R1_00 } \\
\text { 1_contig_2 } \\
718\end{array}$ & 2 & 3664 & 3681 & 18 & 9 & 16 & $\begin{array}{l}\text { AGTATTTTTGGTACACTGACAACATCCTGGGTCGAGTCCTAGCATTT } \\
\text { GATTTTTGGATTTTTGACGATTTTATGGTTATTAGAGGTCGGTGGGT } \\
\text { GTGTTTAGTTAGTAAAATTATCGGAATTAGAATTGGTTTGAAGATA } \\
\text { AAAATAAATTATATATATATATATATAAAAAGGATGTATCCAGTCAA } \\
\text { AGACCAAGTATAGAGAGTCTGCCGATAACCTTTTGGGGAGTTGAAT } \\
\text { GTTCTAGTTTACTCCAAACTAATTTCAAAGTAATCATTTGATGTTGT } \\
\text { GACTTTGAGAACTAATGGGATTTCACCTAACTAATGAG }\end{array}$ & TA & $\bar{G}$ & 22,84 & 152 & $\begin{array}{l}\text { AGGTCGGTGGGTGTG } \\
\text { TTTAG }\end{array}$ & 59,9 & $\begin{array}{l}\text { CATTCAACTCCCCA } \\
\text { AAAGGT }\end{array}$ & 58,9 & 55 & 45 & $P$ \\
\hline 32 & BrPe0032 & $\begin{array}{l}\text { Maracuja_ } \\
\text { NoIndex_L } \\
\text { 003_R1_00 } \\
\text { 1_contig_8 } \\
614\end{array}$ & 2 & 1940 & 1965 & 26 & 13 & 24 & $\begin{array}{l}\text { TTCGATTCGATTCAACCTAACCACCTTCTTTATCTCTTGAAAACAAT } \\
\text { GTTTAATTTATCTTATAGACAGCTGATTGCACAATGACCAATGTTGT } \\
\text { CCATCAGGAAGTTGGTAGAGACAATAATTGGGAAAAAAGAAATCCT } \\
\text { GAATCAGTCAATATATATATATATATATATATATATTGTACGTCTGC } \\
\text { GAAGCTACTTGTGCTCTAGTTGTATTTGACAAGGTGCTCAGCTTCT } \\
\text { CCTTCTCCAAAGCAAGCAGTGACCATGGAAGTG }\end{array}$ & $\mathrm{AT}$ & G & 20,44 & 156 & $\begin{array}{l}\text { TTGCACAATGACCAA } \\
\text { TGTTGT }\end{array}$ & 59,9 & $\begin{array}{l}\text { CTGAGCACCTTGTC } \\
\text { AAAATACA }\end{array}$ & 58 & 38 & 41 & $\mathrm{P}$ \\
\hline 33 & BrPe0033 & $\begin{array}{l}\text { Maracuja_ } \\
\text { NoIndex_L } \\
003 \text { R1_00 } \\
\text { 1_contig_1 } \\
\text { 3192 }\end{array}$ & 2 & 691 & 706 & 16 & 8 & 14 & $\begin{array}{l}\text { TTTTGGTCTCTTTGGAAACCTTTGTTACATATCTCACATAAGAATCTG } \\
\text { TTTGTAGCCATGAGAGACTTGGGAGATAGAGCAATAACTTCAGCAT } \\
\text { CTGGATCTGTTAACGTTAATTGTTATAAGACATATACGAAAGCTCTG } \\
\text { AGTTAGTAGATATATATATATATATTCAACTGTAATTAAAGCTTTTA } \\
\text { TTTCAAGAAACAAATATGTATCAACACAAATAATAAAAGAGAGATA } \\
\text { GTATAATGAGCATGGTGTTAATTACCTGGTGTTCCTGGTAAATTTCT } \\
\text { CTTCTTTTTGGCAACCGGATTTGCTGTATGTTTAG }\end{array}$ & АТ & G & 18,35 & 244 & $\begin{array}{l}\text { GCCATGAGAGACTTG } \\
\text { GGAGA }\end{array}$ & 60,3 & $\begin{array}{l}\text { CGGTTGCCAAAAAG } \\
\text { AAGAGA }\end{array}$ & 60,4 & 55 & 45 & $\mathrm{P}$ \\
\hline 34 & BrPe0034 & $\begin{array}{l}\text { Maracuja_ } \\
\text { NoIndex_L } \\
\text { 003_R1_00 } \\
\text { 1_contig_2 } \\
0319\end{array}$ & 2 & 1319 & 1348 & 30 & 15 & 28 & $\begin{array}{l}\text { CATTGCTCATACAAGCTGGAGCCATATGGATTTAACAACACCTGTGG } \\
\text { TGAAAATGGAACCCACAATATCTACGCAAGCAAGGTTGCTGTTTCC } \\
\text { CCTCCTCTTTTTTGCTCTTATAAAATGAAAGATTGTCTTGGCCTTCAG } \\
\text { ATATTTAACCTCTCTCTCTCTCTCTCTCTCTCTCTCTCTTACCATGAA } \\
\text { GAATACACTCTTTGAATATGTTGACTAAGTCGGAAAAATTGAGAAA } \\
\text { CCAACATAAGCAGCCAATGTGTCAGTCCAGGGCTCAGCATTGATA } \\
\text { ACAATTGACAGTGTGTGTGAAAGCAGAGCTCGAAACTCCATCTGAT }\end{array}$ & Ст & $\mathrm{s}$ & 17,2 & 230 & $\begin{array}{l}\text { CCTGTGGTGAAAATG } \\
\text { GAACC }\end{array}$ & 60,2 & $\begin{array}{l}\text { GAGCCCTGGACTGA } \\
\text { CACATT }\end{array}$ & 60,1 & 50 & 55 & $\mathrm{P}$ \\
\hline 35 & BrPe0035 & $\begin{array}{l}\text { Maracuja_ } \\
\text { NoIndex_L } \\
\text { 003_R1_00 } \\
\text { 1_contig_2 } \\
\text { 5978 }\end{array}$ & 2 & 838 & 849 & 12 & 6 & 10 & $\begin{array}{l}\text { TCAGGGGGAAAGTGAATGGAGCCATGGGGGCAATTGAGAATGCGCAT } \\
\text { CAAGAACAAGAACAAGTACAAGCCAACGCTGTTTATAAAAATGGAG } \\
\text { ATTATGTTCCTCACGATGAAGGGGTTATTTTGGGTCTGGATGGTGGC } \\
\text { ACCACATCCACTGTGTGTGTGTGCATTCCTTTCTTCCCTTCCTCAACT } \\
\text { ACCCACCTCCCCGATCCTCTCCCCGTTCTTAGTCGTGCTGTTGCTGGT } \\
\text { TGTTCCAATCACAATAGCGTTGGAGGTATACAGCGACCATCACCAC } \\
\text { TCTTTTGTGTTGATCCTCTGATTTGGTGTTT }\end{array}$ & TG & G & 17,1 & 172 & $\begin{array}{l}\text { AGGGGTTATTTTGGG } \\
\text { TCTGG }\end{array}$ & 60,0 & $\begin{array}{l}\text { GAGTGGTGATGGTC } \\
\text { GCTGTA }\end{array}$ & 59,7 & 50 & 55 & M \\
\hline
\end{tabular}


APÉNDICE

Marcadores microssatélites desenhados a partir do sequênciamento parcial e da montagem de novo do genoma de $P$. edulis

\begin{tabular}{|c|c|c|c|c|c|c|c|c|c|c|c|c|c|c|c|c|c|c|c|c|}
\hline $\mathbf{N}^{\circ}$ & Primer & Contig I & Motivo & Início & Fim & pb & $\begin{array}{c}\mathbf{N}^{\circ} \\
\text { Repet }\end{array}$ & Score & Sequência do contig & Unidade & G/S & Cobertura & pb & Sequência Forward & $\begin{array}{l}\mathrm{T}^{\circ} \mathrm{C} \\
F w d \\
\end{array}$ & Sequência Reverse & $\begin{array}{l}\mathrm{T}^{\circ} \mathrm{C} \\
\operatorname{Rev} \\
\end{array}$ & $\begin{array}{c}\% \mathrm{GC} \\
F w d \\
\end{array}$ & $\begin{array}{c}\% \mathrm{GC} \\
\operatorname{Rev} \\
\end{array}$ & $\mathbf{P} / \mathbf{M}$ \\
\hline 36 & BrPe0036 & $\begin{array}{l}\text { Maracuja_ } \\
\text { NoIndex_L } \\
\text { 003_R1_00 } \\
\text { 1_contig_2 } \\
\text { 8091 }\end{array}$ & 2 & 1713 & 1724 & 12 & 6 & 10 & $\begin{array}{l}\text { TTGGCTTACCGAATATCATTTAGCTTATTTTTAAGAATTTTGATATTT } \\
\text { TATTTCATGGATTCATCTTTCGTGCCAATATTTTTTGAAATTGGTCTC } \\
\text { GGACCTTAAAACCGAGAATTTGAAAATTCGAAAATTATCATTCCTCA } \\
\text { GGCTTCATCTCTCTCTCTCATCCAATATTAAAATTGACATATTTCCTT } \\
\text { CCAAACTCAACCAATTAAAAGAATCTTATCACATTAGAACTATCTC } \\
\text { TTTGTCATCGCTCTTTTCTAACTAGACTCGTCGGCTATCTCGTCAAAT } \\
\text { TTTGGTGCTGGTGAGTATTTTTTAT }\end{array}$ & TC & $\mathrm{s}$ & 19,1 & 202 & $\begin{array}{l}\text { TCGGACCTTAAAACC } \\
\text { GAGAA }\end{array}$ & 59,7 & $\begin{array}{l}\text { CAGCACCAAAATTT } \\
\text { GACGAG }\end{array}$ & 59,3 & 45 & 45 & $\bar{P}$ \\
\hline 37 & BrPe0037 & $\begin{array}{l}\text { Maracuja_ } \\
\text { NoIndex_L } \\
\text { 003_R1_00 } \\
\text { 1_contig_2 } \\
\text { 8141 }\end{array}$ & 2 & 2106 & 2117 & 12 & 6 & 10 & $\begin{array}{l}\text { CCGGAAGAATTAATTAATCATGATTCTAATGGTTGACACATGTTGTG } \\
\text { CATTATTTTAAGAGACATAGAAGGTTCTGATAATGCAGCGAAAGAG } \\
\text { CTTAAAAAAAGGAAGCATGATCTTCTTACATGATCACTAATTCATGC } \\
\text { AAGTCATGTCTGTGTGTGTGTGAGACCCAGACATGCAAATTTCTCCC } \\
\text { CTTGTCTAATAGAAAAGGTAGACAAGATTGCTCTCCATCGATCAATG } \\
\text { TGGCTCACGAGCCGCATTCTTCTTTGGGAACGGCTTTAATTACCCAA } \\
\text { GTTGCAGAGCAAATGGAGTGTGATCTTTATT }\end{array}$ & TG & $\mathrm{s}$ & 16,55 & 230 & $\begin{array}{l}\text { TGATAATGCAGCGAA } \\
\text { AGAGC }\end{array}$ & 59,2 & $\begin{array}{l}\text { TCACACTCCATTTGC } \\
\text { TCTGC }\end{array}$ & 60 & 45 & 50 & $\mathrm{P}$ \\
\hline 38 & BrPe0038 & $\begin{array}{l}\text { Maracuja_ } \\
\text { NoIndex_L } \\
\text { 003_R1_00 } \\
\text { 1_contig_3 } \\
\text { 2014 }\end{array}$ & 2 & 6095 & 6106 & 12 & 6 & 10 & $\begin{array}{l}\text { TTATCTAATTGAAGGAATTTCCTTTTGTTTTGATATTATTGATATTAC } \\
\text { CATTAAATCATTTGATACCTCTAAATCATATTTATGAAATATGATAT } \\
\text { CCATTATCTAAAAGTTTTCTCCTAAATATCGTATATTTCAACTTTTCG } \\
\text { TGTGTGCATATATATATATTGTTCATGTACAAATGCATAGAAAGTGA } \\
\text { AGAATTACAAGCCACAAATCTCCAAAAACAAGAAAACGTGAACCACT } \\
\text { GTTTTTGAAAACATCAAGCTTCTGGAAAATTCAGTTCATCCTTCCAA } \\
\text { GCAACAACAGCATGTATTATATGTGTTTG }\end{array}$ & АT & $\mathrm{s}$ & 16,1 & 162 & $\begin{array}{l}\text { TTTCAACTTTTCGTGT } \\
\text { GTGC }\end{array}$ & 57,4 & $\begin{array}{l}\text { TGTTGTTGCTTGGAA } \\
\text { GGATG }\end{array}$ & 59,7 & 40 & 45 & $\mathrm{P}$ \\
\hline 39 & BrPe0039 & $\begin{array}{l}\text { Maracuja_ } \\
\text { NoIndex_L } \\
\text { 003_R1_00 } \\
\text { 1_contig_6 } \\
9859\end{array}$ & 2 & 1362 & 1373 & 12 & 6 & 10 & $\begin{array}{l}\text { GTTAAGATCTTCTGGTTTTCATTCTTCCAATTATGTTCCCACGCATTG } \\
\text { GTCCCTACTTTCTGTTGTATATATATGCAAGTTGATCGGCTGCTCCAC } \\
\text { TGTGAATGTCTTTAATATTATTCTCGTGAATCTTCATATGCTGCATTT } \\
\text { GCAGAGATATATATATATGCATATATCGCCTCATACATCAGAGCCAT } \\
\text { GCTTCCTTGCAAGGACATCAGAGTACATAAATAATTGCAATGCAGG } \\
\text { CTCTGCACGGTTTGTCTACGTAATTTCTACTGTGACGGGGCTAGGTT } \\
\text { TTGAAGATACTATACGCATGCTTTTACA }\end{array}$ & AT & $\mathrm{s}$ & 20,23 & 198 & $\begin{array}{l}\text { GCTGCTCCACTGTGA } \\
\text { ATGTC }\end{array}$ & 59,4 & $\begin{array}{l}\text { AACCTAGCCCCGTC } \\
\text { ACAGTA }\end{array}$ & 59,6 & 55 & 55 & $\mathrm{P}$ \\
\hline 40 & BrPe0040 & $\begin{array}{l}\text { Maracuja_ } \\
\text { NoIndex_L } \\
003 \text { R1_00 } \\
\text { 1_contig_6 } \\
4549\end{array}$ & 2 & 5670 & 5681 & 12 & 6 & 10 & $\begin{array}{l}\text { CAGATGAAAGAGAAGTACAATCAGATGCCCCATCCATCAACTGTAG } \\
\text { AAAAACAAATTGATCACTAATTACACAAAATAACATTTCTTGCATTT } \\
\text { CAAAATGTTTCTTGAAAACAAAAGATTGAATATTTTGAGAATTAAG } \\
\text { AAAAGGTTTGTTATATATATATACATAGTTAGATGGATAATATGGGT } \\
\text { CATGAATCATCTACTTGTGTAACACCATATGTCTCAGTATAGATTCT } \\
\text { CCATGCAAAGCACACACCGTAATTATAAGGAGAAAACGGATACAA } \\
\text { AAATCACAACGATCGAGTTTGAACAATATGCAGC }\end{array}$ & $\mathrm{TA}$ & $\mathrm{s}$ & 17,12 & 229 & $\begin{array}{l}\text { GCCCCATCCATCAAC } \\
\text { TGTAG }\end{array}$ & 60,3 & $\begin{array}{l}\text { TTACGGTGTGTGCTT } \\
\text { TGCAT }\end{array}$ & 60,2 & 55 & 45 & $\mathrm{M}$ \\
\hline
\end{tabular}


APÉNDICE

Marcadores microssatélites desenhados a partir do sequênciamento parcial e da montagem de novo do genoma de P. edulis

\begin{tabular}{|c|c|c|c|c|c|c|c|c|c|c|c|c|c|c|c|c|c|c|c|c|}
\hline $\mathbf{N}^{\circ}$ & Primer & Contig $\mathrm{I}$ & Motivo & Início & Fim & pb & $\begin{array}{c}\mathbf{N}^{\circ} \\
\text { Repet }\end{array}$ & Score & Sequência do contig & Unidade & G/S & Cobertura & pb & Sequência Forward & $\begin{array}{l}\mathrm{T}^{\circ} \mathrm{C} \\
F w d\end{array}$ & Sequência Reverse & $\begin{array}{l}\mathrm{T}^{\circ} \mathrm{C} \\
\operatorname{Rev}\end{array}$ & $\begin{array}{c}\% \mathrm{GC} \\
F w d\end{array}$ & $\begin{array}{c}\% \mathrm{GC} \\
\operatorname{Rev}\end{array}$ & $\mathbf{P} / \mathbf{M}$ \\
\hline 41 & BrPe0041 & $\begin{array}{l}\text { Maracuja_ } \\
\text { NoIndex_L } \\
\text { 003_R1_00 } \\
\text { 1_contig_5 } \\
558\end{array}$ & 2 & 2068 & 2079 & 12 & 6 & 10 & $\begin{array}{l}\text { ACTTTTCAAAACTATGGTTGGATGCTGTAACTACCATCATTCTCGCG } \\
\text { TACCAGACCATCAAATTTATAGCAGCTGAAGATCAATAGATCATTG } \\
\text { ATTCTCTTTATCTTGTGCATCTTTACCCTCTTTCTGTGAACATATCCC } \\
\text { AAGAAACAAAGAGAGAGAGAGCGGACCAGACAAGCATAGATGTAA } \\
\text { AAGAAAATGCTGACAGCTATAGATATTGACATGGAGGGAATATGGT } \\
\text { TGGACTATTAAAGCAGTGTGGGGGGCAAGAAAGTTGAGTGAAAAG } \\
\text { GAAAGGTCTGCTTGTTGGATGAGGGTAGAGGGTCA }\end{array}$ & $\overline{\mathrm{AG}}$ & $\bar{s}$ & 14,57 & 194 & $\begin{array}{l}\text { CGCGTACCAGACCAT } \\
\text { CAAAT }\end{array}$ & 60,9 & $\begin{array}{l}\text { GTCCAACCATATTC } \\
\text { ССТCCA }\end{array}$ & 59,6 & 50 & 50 & $\mathrm{M}$ \\
\hline 42 & BrPe0042 & $\begin{array}{l}\text { Maracuja_ } \\
\text { NoIndex_L } \\
\text { 003_R1_00 } \\
\text { 1_contig_9 } \\
73\end{array}$ & 2 & 951 & 966 & 16 & 8 & 14 & $\begin{array}{l}\text { TGTGTTCTATGTTACTCGCATCGGTATTCGGTCAAACTTTATCAACA } \\
\text { GGAATCAGTGTTAATCCGCTTTCTCTATCCCGAAGTTTTAATTAATT } \\
\text { ATTATAGTCTCTCACACATGCATTCATTTGTTTTCTTGAAGGTTACA } \\
\text { TCATACGGATATATATATATATATCTATACATGTCTACAGGATTAAA } \\
\text { GCCGAGGAAGGCTAGAGATGGGAGAGCCAAACCAGTCGTATATGC } \\
\text { ATTAGCAAGTACTGCACTCTTTTTCCCAGCATCGCATGGGAAACCT } \\
\text { TTTGTTGTGCTACCATGTATGATATGACTGTAACA }\end{array}$ & АT & $\mathrm{s}$ & 20,92 & 157 & $\begin{array}{l}\text { CATGCATTCATTTGTT } \\
\text { TTTCTTG }\end{array}$ & 59,5 & $\begin{array}{l}\text { GATGCTGGGAAAAA } \\
\text { GAGTGC }\end{array}$ & 59,8 & 30 & 50 & $\mathrm{P}$ \\
\hline 43 & BrPe0043 & $\begin{array}{l}\text { Maracuja_ } \\
\text { NoIndex_L } \\
\text { 003_R1_00 } \\
\text { 1_contig_1 } \\
764\end{array}$ & 2 & 655 & 670 & 16 & 8 & 14 & $\begin{array}{l}\text { AATCATGATTTATTACTTATCTAATATAAAAATATATTATTCATGGTC } \\
\text { ATCATATTCTAACATGGAAAAAATTATAATTATTCATACATGGATGT } \\
\text { CAAATCGATACTGAATTAAATATTTATAAATAAAAATAATTTATCAT } \\
\text { ATTGGTATAATATATATATATATATTCCGGTAAAGTATATATGAAGC } \\
\text { ACGTGAGTACTTGGCCTACTAGGCTATTAGTACATGTGGAATTCTAT } \\
\text { AATAAAAGGTGACAACGCGTAATGAGGTTGGAATTTTCTTGGTCCGC } \\
\text { TTGTGCTGATGCTTGAACATTGACTTCCAGGTTC }\end{array}$ & AT & $\mathrm{s}$ & 15,05 & 202 & $\begin{array}{l}\text { TCATACATGGATGTC } \\
\text { AAATCGATAC }\end{array}$ & 60,0 & $\begin{array}{l}\text { GCGGACCAAGAAAA } \\
\text { TTCAAA }\end{array}$ & 60,1 & 36 & 40 & $P$ \\
\hline 44 & BrPe0044 & $\begin{array}{l}\text { Maracuja_ } \\
\text { NoIndex_L } \\
\text { 003_R1_00 } \\
\text { 1_contig_9 } \\
106\end{array}$ & 2 & 637 & 648 & 12 & 6 & 10 & $\begin{array}{l}\text { CAACTGTAATGCAACAAAGTATACCTGAGGACGCTAAGAGACCCAT } \\
\text { TGCAAACAAACAGCAAAAGAAGAGGCTAGCCTTCATGGTTAATGTG } \\
\text { TTCAGGATTTGAACGATTATTGCCACTGTGTATATAGAGATGTAAGT } \\
\text { AAGCTCTTATGTATATATATATACATCCAGAGAGGGGATATTTAGAC } \\
\text { AAAAATCCACCAACATTCGGTGGTCCATATATAGTGCCAAAGAAAG } \\
\text { ATTGCAAGTGGGGCTTTTACTTCATCATTGCACTACCTCTACAAAAT } \\
\text { CTGGAAACCCGTGTGCGGGTTTTAGTCTTTTTT }\end{array}$ & TA & $\mathrm{s}$ & 15,74 & 223 & $\begin{array}{l}\text { GGACGCTAAGAGACC } \\
\text { CATTG }\end{array}$ & 59,7 & $\begin{array}{l}\text { TAAAAGCCCCACTT } \\
\text { GCAATC }\end{array}$ & 60,1 & 55 & 45 & $\mathrm{P}$ \\
\hline 45 & BrPe0045 & $\begin{array}{l}\text { Maracuja_ } \\
\text { NoIndex_L } \\
\text { 003_R1_00 } \\
\text { 1_contig_1 } \\
0566\end{array}$ & 2 & 5675 & 5690 & 16 & 8 & 14 & $\begin{array}{l}\text { ATGAATTGTGCTATCCGCTTCCACTTTACCAGCTCTTCCGGACCTCA } \\
\text { AACAATTTGGTTCCTGTGAGAGATTCATACTAGTGGTCGAAACTATG } \\
\text { ACGAAGATTATAGAAATTTACCAGAGATCTTCTTGCCGTTGGATAAA } \\
\text { TAGAGAACAGTGTGTGTGTGTGTGTAATGTATATCTACACACATTGT } \\
\text { GCCTGTTGTTGGTCCTCTAGTTTTCAGTTAGCTGATCTCTGTTGGCTT } \\
\text { TGCATGAAAGTATGTGAAAAATTGCCTTTTTCACGCCTTCCTGCCTC } \\
\text { ATTAATATGCATTTATATCTAGGCAACTTTTAG }\end{array}$ & GT & $\mathrm{s}$ & 18,41 & 187 & $\begin{array}{l}\text { CGCTTCCACTTTACCA } \\
\text { GCTC }\end{array}$ & 60,0 & $\begin{array}{l}\text { GACCAACAACAGGC } \\
\text { ACAATG }\end{array}$ & 60 & 55 & 50 & $\mathrm{P}$ \\
\hline
\end{tabular}


APÉNDICE

Marcadores microssatélites desenhados a partir do sequênciamento parcial e da montagem de novo do genoma de P. edulis

\begin{tabular}{|c|c|c|c|c|c|c|c|c|c|c|c|c|c|c|c|c|c|c|c|c|}
\hline $\mathrm{N}^{\circ}$ & Primer & Contig I & Motivo & Ińcio & Fim & pb & $\begin{array}{c}\mathbf{N}^{\mathbf{o}} \\
\text { Repet }\end{array}$ & Score & Sequência do contig & Unidade & G/S & Cobertura & pb & Sequência Forward & $\begin{array}{l}\mathrm{T}^{\circ} \mathrm{C} \\
F w d\end{array}$ & Sequência Reverse & $\begin{array}{l}\mathrm{T}^{\circ} \mathrm{C} \\
\operatorname{Rev}\end{array}$ & $\begin{array}{c}\% \mathrm{GC} \\
F w d\end{array}$ & $\begin{array}{c}\% \mathrm{GC} \\
\operatorname{Rev}\end{array}$ & $\mathbf{P} / \mathbf{M}$ \\
\hline 46 & BrPe0046 & $\begin{array}{l}\text { Maracuja_ } \\
\text { NoIndex_L } \\
003 \_R 1 \_00 \\
\text { 1_contig_1 } \\
4107\end{array}$ & 2 & 1996 & 2009 & 14 & 7 & 12 & $\begin{array}{l}\text { CTATATGCATTAACAATATTTATCCATCCATTAACACACATGATTAA } \\
\text { CTTGTTATTAACATATATAATTAATTTCAAAAACATGTGACACAATA } \\
\text { GTGAGTTAACGAACTAAAATGCAAACATTCAATATACACTTCAATA } \\
\text { TGTGAACAGCCACACACACACACATCATGCACAAGCATGCTCAACA } \\
\text { AGCAAGATTAACATACAACTCCACCTCACATATATTTAATTTGAACA } \\
\text { AGATCAAACCTCAACCAAAAATTAACACAAGAAGAACACCACATA } \\
\text { AACCATCCCATAAGATCAACCAAACAACACAATAAC }\end{array}$ & $\mathrm{CA}$ & $\overline{\mathrm{s}}$ & 21,95 & 185 & $\begin{array}{l}\text { CGAACTAAAATGCAA } \\
\text { ACATTCAA }\end{array}$ & 59,2 & $\begin{array}{l}\text { TGGGATGGTTTATG } \\
\text { TGGTGTT }\end{array}$ & 60,0 & 30 & 43 & $\mathrm{M}$ \\
\hline 47 & BrPe0047 & $\begin{array}{l}\text { Maracuja_ } \\
\text { Nolndex_L } \\
\text { 003_R1_00 } \\
\text { 1_contig_1 } \\
9032\end{array}$ & 2 & 1868 & 1885 & 18 & 9 & 16 & $\begin{array}{l}\text { CAACTCAAATGGGCCATTTCTTTTCTCTCATTTTGACTGACTTCTGGC } \\
\text { ATATTAATCTGCAGTCTACAGAAAAGCTGAAGATATGAATTATCACT } \\
\text { CAGTTTGCTTGCATGTTCTTGCGGATTCCATTCGTAGGTTTGCTCCAC } \\
\text { CACCCCTTCTCTCTCTCTCTCTCTCGCTGCCAGCAGCATTTCCTCAAC } \\
\text { TCATGCAGGATTCTGTTTGGTTTGATCTTTATGTATGCATGTTAAGTT } \\
\text { GGTGTGCTGTTGTTGTTTCTCAGTGCAGGCTTGATATTGGCTTCCTGG } \\
\text { TTTTTGTCCCTTGGGTATTTTGCTTGCAATT }\end{array}$ & CT & $\mathrm{s}$ & 18,22 & 195 & $\begin{array}{l}\text { TGGGCCATTTCTTTTC } \\
\text { TCTC }\end{array}$ & 59,2 & $\begin{array}{l}\text { GAATCCTGCATGAG } \\
\text { TTGAGGA }\end{array}$ & 60,0 & 45 & 48 & $\mathrm{P}$ \\
\hline 48 & BrPe0048 & $\begin{array}{l}\text { Maracuja_ } \\
\text { NoIndex_L } \\
\text { 003_R1_00 } \\
\text { 1_contig_2 } \\
\text { 2454 }\end{array}$ & 2 & 1160 & 1181 & 22 & 11 & 20 & $\begin{array}{l}\text { TGTTTAGAATGAACCAGATTTAACTACTTTAAACTAAACTCTACATC } \\
\text { ATTAATTCTTTACGTTATCTCGAAACACTCAATAAGTGAGATTTATA } \\
\text { ATTTGATATTATTAATCTATTGTTCAAATTGAGAGACCTTAATTATTA } \\
\text { TACTTTCTTATATATATATATATATATATACCAAAACTCGGGTTGCTT } \\
\text { AAAATAATTGACCTTCTTTAACGAAATTTTCCACTAAAATGTAGTTT } \\
\text { GGTGTTTTTTTAGAAAAAATTCAAAACGTAAAATAGGATTAAGTGG } \\
\text { AGGCCCTATGAAGATGACCTGGTTGGCAGGATTCGAACC }\end{array}$ & $\mathrm{TA}$ & $\mathrm{s}$ & 16,83 & 150 & $\begin{array}{l}\text { ACATCATTAATTCTTT } \\
\text { ACGTTATCTCG }\end{array}$ & 58,3 & $\begin{array}{l}\text { TTAAGCAACCCGAG } \\
\text { TTTTGG }\end{array}$ & 60,1 & 30 & 45 & NA \\
\hline 49 & BrPe0049 & $\begin{array}{l}\text { Maracuja_ } \\
\text { Nolndex_L } \\
\text { 003_R1_00 } \\
\text { 1_contig_2 } \\
\text { 2555 }\end{array}$ & 2 & 1496 & 1513 & 18 & 9 & 16 & $\begin{array}{l}\text { AAACTCTGCAGTACTGATCAAAAGCTTACTTGTTCATTTGTAAAAGC } \\
\text { TTGATGACTTCTTGGTGAGCAAATTGCGTTATGGTGGACTATCTTGA } \\
\text { GTAATCTGGGAATCAAAACCATGCAGTGTCGCTGCAAGCCACTGGG } \\
\text { GGAGTACTGTTATATATATATATATATAAGGATATCCGATTCTTTTG } \\
\text { CCTCTTCCTTAACTCTTTTATATGTAACGATGTTATTCAAAAAATATA } \\
\text { TGTGACGATGTTCGCAAGTGCGTGGGTCTTCTAACTCAGGAGTGAGT } \\
\text { GGAAGCTGGGAGTTTGCTTTCCTGGCTGCAATATGA }\end{array}$ & TA & $\mathrm{s}$ & 16,88 & 193 & $\begin{array}{l}\text { GGGAATCAAAACCAT } \\
\text { GCAGT }\end{array}$ & 59,8 & $\begin{array}{l}\text { СTCCCAGCTTCCACT } \\
\text { CACTC }\end{array}$ & 60,0 & 45 & 60 & $\mathrm{P}$ \\
\hline 50 & BrPe0050 & $\begin{array}{l}\text { Maracuja_ } \\
\text { NoIndex_L } \\
\text { 003_R1_00 } \\
\text { 1_contig_2 } \\
\text { 2748 }\end{array}$ & 2 & 930 & 943 & 14 & 7 & 12 & $\begin{array}{l}\text { AAGCTCTGCTCAGGTTGACCTGCAGCAAAGGTGTTGCATCGATAGT } \\
\text { ATTTGGTTTTCTAACCATAGATTCAAGGGTATCTTGGTGCTGTTTCT } \\
\text { AGTCTGCTTCTGACAAGATTTATTGGTGCATTCCTGGGGTCGAGTGT } \\
\text { TCAGTTGGCTGTGTGTGTGTGTGGGACTCATTGGTCACTACATTGCT } \\
\text { AATCTTTTATCATGACTGCCAAACTGTATACTTTTATCTAGATGAGT } \\
\text { ATAGCTTTTTCTGGTTTTGTCTCGCTGAAGCTTTATGTTAGAACTACC } \\
\text { GTTGGCTTAAAGATTTGATTGCATGAAATAA }\end{array}$ & TG & $\mathrm{s}$ & 14,59 & 199 & $\begin{array}{l}\text { TCAAGGGTATCTTTG } \\
\text { GTGCTG }\end{array}$ & 60,1 & $\begin{array}{l}\text { AGCTTCAGCGAGAC } \\
\text { AAAACC }\end{array}$ & 59,6 & 48 & 50 & $\mathrm{P}$ \\
\hline
\end{tabular}

G: genoma funcional

S: genoma estructural

P: polimórfico

M: monomórfico 
APÉNDICE

Marcadores microssatélites desenhados a partir do sequênciamento parcial e da montagem de novo do genoma de P. edulis

\begin{tabular}{|c|c|c|c|c|c|c|c|c|c|c|c|c|c|c|c|c|c|c|c|}
\hline $\mathrm{N}^{\circ}$ & Primer & Contig $\mathrm{I}$ & Motivo & Início & Fim & pb & $\begin{array}{c}\mathbf{N}^{\circ} \\
\text { Repet }\end{array}$ & Score & Sequência do contig & Unidade & G/S & Cobertura & pb & Sequência Forward & $\begin{array}{l}\mathrm{T}^{\circ} \mathrm{C} \\
F w d\end{array}$ & Sequência Reverse & $\begin{array}{l}\mathrm{T}^{\circ} \mathrm{C} \\
\operatorname{Rev}\end{array}$ & $\begin{array}{r}\% \mathrm{GC} \\
F w d\end{array}$ & $\begin{array}{c}\% \mathrm{GC} \\
\operatorname{Rev}\end{array} \quad \mathrm{P} / \mathbf{M}$ \\
\hline 51 & BrPe0051 & $\begin{array}{l}\text { Maracuja_ } \\
\text { NoIndex_L } \\
003 \text { R1_00 } \\
\text { 1_contig_1 } \\
6\end{array}$ & 2 & 2628 & 2639 & 12 & 6 & 10 & $\begin{array}{l}\text { TATCAAATGCTGATTAAGTGTGGAGGATATAGGTTGTTTAAGAAAGA } \\
\text { GAAAATCGTTGGTTCCTTATAGTCATTTCTCTTTCCTATCGTGACAAC } \\
\text { TCTTGTCTTGTTCCCCCACCTTTTTAGCGTTCTGGGGCCCTACTTCAC } \\
\text { TATATAACTATATATATATAATCACTATATACCTTTCTTCTACCTTCG } \\
\text { AAGGATGGAGGGGTTCTACAGCGAAAAAAGCGTCGAAGGGGTCAT } \\
\text { CCTGGGTTACTGAAAAGTCGTCCGACTGCTCGGTGACCAAATCAGA } \\
\text { GAGGTTTTGACCGCTTTCTCTTCTCTCCAGC }\end{array}$ & $\overline{\mathrm{AT}}$ & $\mathrm{G}$ & $3.892,26$ & 198 & $\begin{array}{l}\text { GTCTTGTTCCCCCACC } \\
\text { TTTT }\end{array}$ & 60,2 & $\begin{array}{l}\text { AGCGGTCAAAACCT } \\
\text { CTCTGA }\end{array}$ & 60,0 & 50 & 50 \\
\hline 52 & BrPe0052 & $\begin{array}{l}\text { Maracuja_ } \\
\text { NoIndex_L } \\
003 \text { R1_00 } \\
\text { 1_contig_1 } \\
43\end{array}$ & 2 & 393 & 406 & 14 & 7 & 12 & $\begin{array}{l}\text { GAAATGGGGAATGAATATGATGAAGCCATTCAAGGTCTACAGAAAC } \\
\text { TCCTCAGGTAAAAATATCGCTCGTCTAAAATGTAACTAGCTAGCCTT } \\
\text { TTGTTTTCTTAATCTCGGACCCGACCTTCTTCAGACATATGTGGTCTT } \\
\text { GAACTTGAAATATATATATATATGACTTCAAGTACCGTCTGCTACGT } \\
\text { TATTAAACTGCTGTCTCTAGCTAGGTTCATCAGACTGTACTTTTGAA } \\
\text { TGATGTGTGGTTGCAGTGAGAAGACAGAGTTGAGGGCCAGTGCCGC } \\
\text { TGCTAAAGTGTCCAAGGTTACTGCTGAGTTAAA }\end{array}$ & AT & $\mathrm{s}$ & 16,44 & 182 & $\begin{array}{l}\text { TGATGAAGCCATTCA } \\
\text { AGGTC }\end{array}$ & 58,6 & $\begin{array}{l}\text { GCAGTTTAATAACG } \\
\text { TAGCAGACG }\end{array}$ & 58,2 & 45 & 45 \\
\hline 53 & BrPe0053 & $\begin{array}{l}\text { Maracuja_ } \\
\text { NoIndex_L } \\
\text { 003_R1_00 } \\
\text { 1_contig_2 } \\
38\end{array}$ & 2 & 10514 & 10525 & 12 & 6 & 10 & $\begin{array}{l}\text { CCTTGCAACTTTCATAGCATAAACCTTAGCGACTTCACTCTATTCCT } \\
\text { ACCTTGGGTCACGAGCTCAGCTCGGAAGTAACGGAACTCTCTTCTTT } \\
\text { TGCTCCAACAGTTAAGTCAAGGGCTACGAAAAAACCTTCCTCCGTA } \\
\text { AGTTCCTTTACTCTCTCTCTCTTTAGAGCTTTCAGGTGAAATGAACCA } \\
\text { ATTCACCATTGAGTTCGATTTGAACTAGTTTCAAAGGCTGGATTTCC } \\
\text { CTTAGGGAGAACTAGAATCCTATCCTCATCTCTTTCCCTCTTATGTCA } \\
\text { TTTTGAGACAAAAAGAAGTAGGGATTTGA }\end{array}$ & СT & $\mathrm{s}$ & 288,74 & 197 & $\begin{array}{l}\text { TTCCTACCTTGGGTCA } \\
\text { CGAG }\end{array}$ & 60,1 & $\begin{array}{l}\text { TAAGGGAAATCCAG } \\
\text { CCTTTG }\end{array}$ & 59,2 & 55 & 45 \\
\hline 54 & BrPe0054 & $\begin{array}{l}\text { Maracuja_ } \\
\text { NoIndex_L } \\
003 \text { R1_00 } \\
\text { 1_contig_2 } \\
91\end{array}$ & 2 & 1431 & 1444 & 14 & 7 & 12 & $\begin{array}{l}\text { GCCTGGAAAATTTCTGCATGGGATCAGACGGGTTAGATTTTTCCACA } \\
\text { CCAACCATGCCCACTTCAGTTACCTTTTTCTTTAATATGGTAGCGTGT } \\
\text { TAAGAACGATATGCAATGGGATTCATAGTTAAAAAGATGAATATAT } \\
\text { TACATTACAAGAGAGAGAGAGAGCAGACCTGCACAGTTGCATGGAT } \\
\text { TATAGAGTTGGAAACTTCTATTGTAAGCAAGAAATGATATGCTCCGT } \\
\text { TTTGACATTCTGCAATCTGAACGTATAATTGCATGCTGCTTTCCTTTA } \\
\text { TCAATTATACTGCATAAAGTATCTTTTTTTCT }\end{array}$ & AG & $\mathrm{s}$ & 15,97 & 230 & $\begin{array}{l}\text { CATGGGATCAGACGG } \\
\text { GTTAG }\end{array}$ & 60,3 & $\begin{array}{l}\text { CAGAATGTCAAAAC } \\
\text { GGAGCA }\end{array}$ & 59,8 & 55 & 45 \\
\hline 55 & BrPe0055 & $\begin{array}{l}\text { Maracuja_ } \\
\text { NoIndex_L } \\
003 \_R 1 \_00 \\
\text { 1_contig_3 } \\
50\end{array}$ & 2 & 4214 & 4229 & 16 & 8 & 14 & $\begin{array}{l}\text { ATTATACATATGTATGACAGATAATAACATTTTTCCAGTAGAAAATA } \\
\text { CAAAGATGGATTTTTGAAAAAGATAAGAGTATACGTTGGATATAAA } \\
\text { ATAATTATATATTTAGCATTATTAATTAAAGATCTAATTAGTATATA } \\
\text { TAGATATATATGTGTGTGTGTGTGTGGATCCAGCACGCATTAGGTTC } \\
\text { CCCTCCGTTGGATTATTTTATCGCGTTTGCTGTTGTCATGTTATATGC } \\
\text { TTTCAGCCAAGCAAAACCTTGACTTTCAGTTCTGACTTTTATATTAG } \\
\text { ATCCATCTCACAAAAGCAATCGGTTTTCCTTCTA }\end{array}$ & TG & $\mathrm{s}$ & 16,03 & 172 & $\begin{array}{l}\text { TTTCCAGTAGAAAAT } \\
\text { ACAAAGATGGA }\end{array}$ & 59,5 & $\begin{array}{l}\text { ATAATCCAACGGAG } \\
\text { GGGAAC }\end{array}$ & 60,0 & 30,8 & 50 \\
\hline
\end{tabular}


APÉNDICE

Marcadores microssatélites desenhados a partir do sequênciamento parcial e da montagem de novo do genoma de P. edulis

\begin{tabular}{|c|c|c|c|c|c|c|c|c|c|c|c|c|c|c|c|c|c|c|c|c|}
\hline $\mathbf{N}^{\circ}$ & Primer & Contig & Motivo & Início & Fim & pb & $\begin{array}{c}\mathbf{N}^{\mathbf{o}} \\
\text { Repet }\end{array}$ & Score & Sequência do contig & Unidade & G/S & Cobertura & pb & Sequência Forward & $\begin{array}{l}\mathrm{T}^{\circ} \mathrm{C} \\
F w d \\
F\end{array}$ & Sequência Reverse & $\begin{array}{l}\mathrm{T}^{\circ} \mathrm{C} \\
\operatorname{Rev} \\
\end{array}$ & $\begin{array}{r}\% \mathbf{G C} \\
F w d \\
\end{array}$ & $\begin{array}{c}\% \mathrm{GC} \\
\operatorname{Rev} \\
\end{array}$ & $\mathbf{P} / \mathbf{M}$ \\
\hline 56 & BrPe056 & $\begin{array}{l}\text { Maracuja_ } \\
\text { NoIndex_L } \\
\text { 003_R1_00 } \\
\text { 1_contig_7 } \\
60\end{array}$ & 2 & 4588 & 4599 & 12 & 6 & 10 & $\begin{array}{l}\text { CTTCTCCTGTGTTCATGTGAAGGATTTGGGACACTTCCATGGTCACT } \\
\text { GCTTGCTTTGGAGAAGGAGAAGCTGAGCACCTTGTCAAAATACAAC } \\
\text { TAGAGCATACAAGTAGTTTCGCAGACGTTCAACAAATATATATATTG } \\
\text { GAGATTAATCATATATATATATTGGAAAAATTGTATAAGTCACGTCA } \\
\text { TCTGACTGTTACCCTGTCATTTATTTTGCTGTTAGAAAAAAATTATCA } \\
\text { CCAAACCTAATAAAATTTATTCTTTCCAAAATCATAAAAAGATTCC } \\
\text { TTCTCATTTTCGAAAACCCAATCCCTTGGT }\end{array}$ & 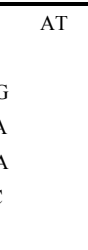 & $\bar{G}$ & 442,47 & 204 & $\begin{array}{l}\text { GTTTCGCAGACGTTC } \\
\text { AACAA }\end{array}$ & 59,9 & $\begin{array}{l}\text { ACCAAGGGATTGGG } \\
\text { TTTTC }\end{array}$ & 58,7 & 45 & 47,4 & \\
\hline 57 & BrPe0057 & $\begin{array}{l}\text { Maracuja_ } \\
\text { NoIndex_L } \\
003 \text { R1_00 } \\
\text { 1_contig_1 } \\
372\end{array}$ & 2 & 581 & 596 & 16 & 8 & 14 & $\begin{array}{l}\text { TTTTTTAATGCAATGTGAAAGGTAATATGTGTCTACCAGCTCGAGTC } \\
\text { CTGATTGCCAGCTTACAAGTTGTTGGGAGCAAACATGGGGTCGGAC } \\
\text { ATAATTTATGATATTGATAAAATTTTCCAAAAAGTCGCGGATGGAA } \\
\text { ACTTCATCCTTATATATATATATATAAAGAAAGTAAAATATGTTAAT } \\
\text { TAACAAAAAGAATGACTTGGTCTCCGTCTTTATGTTAAAATTTTATA } \\
\text { TGTAAAAACAACAAAACACGTAAATGACATGACTAATACGCAGAGT } \\
\text { ATGAGATGGGTTAGAATATTCAACCCAGTATCCAAT }\end{array}$ & TA & $\mathrm{s}$ & 48,01 & 179 & $\begin{array}{l}\text { ACCAGCTCGAGTCCT } \\
\text { GATTG }\end{array}$ & 60,4 & $\begin{array}{l}\text { CGGAGACCAAGTCA } \\
\text { TTCTTTTT }\end{array}$ & 59,6 & 55 & 40 & \\
\hline 58 & BrPe0058 & $\begin{array}{l}\text { Maracuja_ } \\
\text { NoIndex_L } \\
003 \text { R1_00 } \\
\text { 1_contig_2 } \\
\text { 177 }\end{array}$ & 2 & 3899 & 3922 & 24 & 12 & 22 & $\begin{array}{l}\text { TTAAAAATAAGCTGAAAAATGAGAAATCCACACACAGGCTAACTCT } \\
\text { AGATGACAGTAAACCGATCGAGTAAATGAGGGGATTGTACCTTATA } \\
\text { TTCTGATGATATCGAAGTTGTTTTGACGAAGACACTGATAGTTCTCT } \\
\text { GAGGCAGATATTATATATATATATATATATATATACACACATACATA } \\
\text { TATATATTTATCTGAAATTAATTTACTGCATAGTTGGGTCACAAGT } \\
\text { TAACCCGAATTCAAGTTTCTTATCATAATTTGACCAAAATGCTGGA } \\
\text { TACACATACCCATATGTAGCCATGCTAATTTTGGTATGCTCCGG }\end{array}$ & TA & G & 16,13 & 186 & $\begin{array}{l}\text { GATCGAGTAAATGAG } \\
\text { GGGATTG }\end{array}$ & 59,8 & $\begin{array}{l}\text { TGGAATTCGGGTTA } \\
\text { ACTTGTG }\end{array}$ & 59,8 & 45,5 & 42,9 & \\
\hline 59 & BrPe0059 & $\begin{array}{l}\text { Maracuja_ } \\
\text { NoIndex_L } \\
003 \text { R1_00 } \\
\text { 1_contig_3 } \\
888\end{array}$ & 2 & 3583 & 3598 & 16 & 8 & 14 & $\begin{array}{l}\text { AAAAAGGTATATGGTAGAGGAAACAGCTTCACACACAGGAGAGGA } \\
\text { TGACACAGTTTCATATATACCAGTAAACATGGAATGGCCAAGCTAT } \\
\text { ACTGTAAATGTGCAGTATTTTTTGCACGAACCGATCCCAAAATTTA } \\
\text { AGATATCTCCGTTATATATATATATATAAATCAAATACTCGCTTTTG } \\
\text { ATTAAAAAAAATAAAAAGAGTAAGAAATTTACCTTTCCAGCATATT } \\
\text { TAATTTAAATCGGAGATTTCCAATTAATCGGCCATACTGTAGTGAAG } \\
\text { ATGAATCTGTAGCCGTAGCCAGCAAACCGTGCTTACC }\end{array}$ & TA & $\mathrm{s}$ & 16,62 & 153 & $\begin{array}{l}\text { TGGAATGGCCAAGCT } \\
\text { ATACTG }\end{array}$ & 60,1 & $\begin{array}{l}\text { TGCTGGAAAGGTAA } \\
\text { АTTTCTTACTC }\end{array}$ & 59,3 & 47,6 & 36 & \\
\hline 60 & BrPe0060 & $\begin{array}{l}\text { Maracuija_ } \\
\text { NoIndex_L } \\
003 \text { 121_00 } \\
\text { 1_contig_3 } \\
995\end{array}$ & 2 & 2250 & 2273 & 24 & 12 & 22 & $\begin{array}{l}\text { AGGTGTGAAGTTGCCTCTTTTAATTCCTGGTCTCAGGTAGTTGGTCC } \\
\text { ATCTAAGCCTGCAACTTTTGCTGCATCTTAACAACCCTTTTTGCAGA } \\
\text { CAGAAACAAATAGATTGATCAATTGAACAAAGAGTAATTTATGATT } \\
\text { CATATTGAACATATATATATATATATATATATATGTTCATGTTGCAG } \\
\text { AGTTTTTACCAGTGTTGGTAGGCACTGATCTCCAGTTTCCTGGACCA } \\
\text { TGTTCTTGGATGTAAGACACTAGGATGATGTCCTCCTCAGGGGTCCA } \\
\text { TGGACCTTTCTTGACGCCAACTTTGTCGCAACAAGGAGGTCTT }\end{array}$ & AT & G & 16,49 & 173 & $\begin{array}{l}\text { GGTCCATCTAAGCCT } \\
\text { GCAAC }\end{array}$ & 59,7 & $\begin{array}{l}\text { TCAGTGCCTACCAA } \\
\text { CACTGG }\end{array}$ & 59,7 & 55 & 55 & \\
\hline
\end{tabular}


APÉNDICE

Marcadores microssatélites desenhados a partir do sequênciamento parcial e da montagem de novo do genoma de P. edulis

\begin{tabular}{|c|c|c|c|c|c|c|c|c|c|c|c|c|c|c|c|c|c|c|c|}
\hline $\mathbf{N}^{\circ}$ & Primer & Contig & Motivo & Início & Fim & pb & $\begin{array}{c}\mathbf{N}^{\circ} \\
\text { Repet }\end{array}$ & Score & Sequência do contig & Unidade & G/S & Cobertura & pb & Sequência Forward & $\begin{array}{l}\mathrm{T}^{\circ} \mathrm{C} \\
F w d \\
\end{array}$ & Sequência Reverse & $\begin{array}{l}\mathrm{T}^{\circ} \mathrm{C} \\
\operatorname{Rev} \\
\end{array}$ & $\begin{array}{c}\% \mathrm{GC} \\
F w d \\
\end{array}$ & $\begin{array}{r}\% \mathrm{GC} \\
\operatorname{Rev} \\
\end{array}$ \\
\hline 61 & BrPe0061 & $\begin{array}{l}\text { Maracuja_ } \\
\text { NoIndex_L } \\
003 \text { 121_00 } \\
\text { 1_contig_4 } \\
067\end{array}$ & 2 & 2561 & 2572 & 12 & 6 & 10 & $\begin{array}{l}\text { AAAGCAGCCAAGGACTTCTCAAAAATTTAAACAGCATGATCATTTT } \\
\text { GCCGGTGTACATATATTTTTTTTCTAGTAAGAACATTATACTTTTCAG } \\
\text { GTTGATGCAACTTAAATTATTTTAGTCATGCCCGCAGAATGTACTGC } \\
\text { TTAGTTTTCATATATATATATTTTTTCTATTTAAATTATTGGTTCCTA } \\
\text { GGATGAGTAATTCCATCAGATAATATTAGTCAATATCATATTAAAAT } \\
\text { GCACGCTATTCACGAAGGTCACAGAAGAAACACTTCATCAGCATCC } \\
\text { CATACAAGCTTCCATGTGAACTAACCTTCC }\end{array}$ & AT & $\mathrm{s}$ & 16,64 & 171 & $\begin{array}{l}\text { CCCGCAGAATGTACT } \\
\text { GCTTA }\end{array}$ & 58,9 & $\begin{array}{l}\text { GGAAGCTTGTATGG } \\
\text { GATGCT }\end{array}$ & 59,2 & 50 & 50 \\
\hline 62 & BrPe0062 & $\begin{array}{l}\text { Maracuja_ } \\
\text { NoIndex_L } \\
003 \text { R1_00 } \\
\text { 1_contig_4 } \\
320\end{array}$ & 2 & 3141 & 3158 & 18 & 9 & 16 & $\begin{array}{l}\text { GCCTTTCTATATATATACATATATGGGTTTTTAGGTGTTGTGCTTACA } \\
\text { ACGGGTCATTCGCTTGCAATCACTAGGAACTTATATCATTAAATATA } \\
\text { TTGTTGTGGACCATTTGAACCATGTAAAATAATAATAATAATAATAC } \\
\text { GAAATTAGCTCTCTCTCTCTCTCTCTTTAAAATTATGTCTTATAAAAT } \\
\text { TATATATTAATACATACGGATTACAACAGGTTCGATCCAAGTAATGC } \\
\text { CAACTAGGGTCTTGCTATTTTTTTCTTGATAAGAAGGGTCTTCCAAT } \\
\text { TCTAAACATGCAGGTCTCCTATATGGTTAGAAG }\end{array}$ & CT & G & 15,28 & 216 & $\begin{array}{l}\text { GTTGTGCTTACAACG } \\
\text { GGTCA }\end{array}$ & 59,6 & $\begin{array}{l}\text { GCAAGACCCTAGTT } \\
\text { GGCATT }\end{array}$ & 59,2 & 50 & 50 \\
\hline 63 & BrPe0063 & $\begin{array}{l}\text { Maracuja_ } \\
\text { NoIndex_L } \\
003 \text { 121_00 } \\
\text { 1_contig_4 } \\
859\end{array}$ & 2 & 610 & 627 & 18 & 9 & 16 & $\begin{array}{l}\text { AAACAGTTGCTGGAAGAGCTAGAAGACCTTAGAACTTTGGCTCTCA } \\
\text { ATGAACTGAGAGGTTTTGACCAGGCAAAGGTTGAGAAAATTCAAG } \\
\text { TATAATTGACCTCCATTGACCTCCAAAGGGCATTGGATCGTCACTTG } \\
\text { TTCTCAAGAGATCTCTCTCTCTCTCTCTCCTTTTCCACTGATACCGCA } \\
\text { TGGTTTAAAGTCGTTTGTTGTTGGGTAATTATTAGTTTTAGTTTTTA } \\
\text { AAATGATCGATTAGAATTTGTTGGATATAGAATATCTCTTACTTCCA } \\
\text { TCAGGAAGGAAAAAAATCATCCAGTTGATCATCGTA }\end{array}$ & $\mathrm{TC}$ & $\mathrm{s}$ & 16,09 & 183 & $\begin{array}{l}\text { TTGCTGGAAGAGCTA } \\
\text { GAAGACC }\end{array}$ & 60,2 & $\begin{array}{l}\text { CATGCGGTATCAGT } \\
\text { GGAAAA }\end{array}$ & 59,5 & 50 & 45 \\
\hline 64 & BrPe0064 & $\begin{array}{l}\text { Maracuja_ } \\
\text { NoIndex_L } \\
003 \text { 121_00 } \\
\text { 1_contig_7 } \\
951\end{array}$ & 2 & 162 & 173 & 12 & 6 & 10 & $\begin{array}{l}\text { ATATATACAGACTGCTCCAGATTCCAAGGAGCTAGTTTTCATCGGTA } \\
\text { TAAGTACAGAGAAACCTGATTACGAAGTAGGAGTTGTCTCAGGTAC } \\
\text { TATATATATATATCTTACAAATACAAGCATCATTTTTATTTCTTATTC } \\
\text { ATCATATATTATATATATATAATGGATACTTAATGCAGCTGATGGGA } \\
\text { AGAAGCTACTGCACAAGACGGATCTCAGGACAGATCGCTGTGTCCT } \\
\text { CAGCCACGAGATGGGCGTTACACAAAAGTATGGTACTATATACGGG } \\
\text { GAGTCTGTCTCATCAACAGTTAATTATGAAAT }\end{array}$ & $\mathrm{TA}$ & G & 24,54 & 179 & $\begin{array}{l}\text { CAAGCATCATTTTTAT } \\
\text { TTCTTATTCA }\end{array}$ & 058 & $\begin{array}{l}\text { TGATGAGACAGACT } \\
\text { CCCCGTA }\end{array}$ & 60,7 & 23,1 & 52,4 \\
\hline 65 & BrPe0065 & $\begin{array}{l}\text { Maracuja_ } \\
\text { NoIndex_L } \\
003 \text { R1_00 } \\
\text { 1_contig_8 } \\
380\end{array}$ & 2 & 2009 & 2020 & 12 & 6 & 10 & $\begin{array}{l}\text { AATACATTTACATGAAATTGTAACCTGCTGATAAAGACATCTCTGCA } \\
\text { GCAAACCACTCAGCTCCTGGAAGAGACCTTGGCCCATGCCACGTGG } \\
\text { AATTTCAACTTGCTGGCTAGAACTTGCTTGGCTTGAAGAGTCTTGAA } \\
\text { GAGAAAAGGGTCTCTCTCTCTCAGATTGCTTTTCGGCTAGTACAAGA } \\
\text { TTGATAATGGCATTTGCTGCTGCTTGACGAACTGTGTCTTCTCGTCTA } \\
\text { AACATGGCTTTATGCACAACCACTATGCAGTAATCCTGTGCTATCAG } \\
\text { GGGAAAAAGGTTAACAATTTAATAATGGAA }\end{array}$ & TC & G & 17,23 & 152 & $\begin{array}{l}\text { GACATCTCTGCAGCA } \\
\text { AACCA }\end{array}$ & 60,0 & $\begin{array}{l}\text { TCTTGTACTAGCCG } \\
\text { AAAAGCAA }\end{array}$ & 59,2 & 50 & 40,9 \\
\hline
\end{tabular}


APÉNDICE

Marcadores microssatélites desenhados a partir do sequênciamento parcial e da montagem de novo do genoma de P. edulis

\begin{tabular}{|c|c|c|c|c|c|c|c|c|c|c|c|c|c|c|c|c|c|c|c|}
\hline $\mathbf{N}^{\circ}$ & Primer & Contig & Motivo & Início & Fim & pb & $\begin{array}{c}\mathbf{N}^{\circ} \\
\text { Repet }\end{array}$ & Score & Sequência do contig & Unidade & G/S & Cobertura & pb & Sequência Forward & $\begin{array}{l}\mathrm{T}^{\circ} \mathrm{C} \\
F w d \\
\end{array}$ & Sequência Reverse & $\begin{array}{l}\mathrm{T}^{\circ} \mathrm{C} \\
\operatorname{Rev} \\
\end{array}$ & $\begin{array}{c}\% \mathrm{GC} \\
F w d \\
\end{array}$ & $\begin{array}{r}\% \mathrm{GC} \\
\operatorname{Rev} \\
\end{array}$ \\
\hline 66 & BrPe0066 & $\begin{array}{l}\text { Maracuja_ } \\
\text { Nolndex_L } \\
\text { 003_R1_00 } \\
\text { 1_contig_8 } \\
705\end{array}$ & 2 & 4428 & 4445 & 18 & 9 & 16 & $\begin{array}{l}\text { CAAAAGGTTATCCGATCTTAAATCTTGATAAAGAAATAGATTAATTT } \\
\text { CAACAAAACACAACTTGATTCCCCCTACCACCTTTGGCATATCAAAG } \\
\text { CAAACATGCAGCTTGAAATCCAACTTTAATGAGGAAATTTGAAGTA } \\
\text { TTCTTGAAAGCACACACACACACACACATCTTAAATCTTTCTTTTGC } \\
\text { ACTAAATCCGTCAATAGATCCTCAATTAGCTATATCCTTGATATCAA } \\
\text { AGGACACAAAAATTCTTCTGCTGCTTCTGCAACTGAGAAGAGAACT } \\
\text { AACATGAAAATAGCAATCAAGTTAGACTCATAAAGGAC }\end{array}$ & $\begin{array}{ll} & \text { CA } \\
& \\
& \end{array}$ & $\mathrm{s}$ & 18,55 & 206 & $\begin{array}{l}\text { CTTGATTCCCCCTACC } \\
\text { ACCT }\end{array}$ & 60,2 & $\begin{array}{l}\text { TTGCAGAAGCAGCA } \\
\text { GAAGAA }\end{array}$ & 60,0 & 55 & 45 \\
\hline 67 & BrPe0067 & $\begin{array}{l}\text { Maracuja_ } \\
\text { NoIndex_L } \\
003 \_R 1 \text { 00 } \\
\text { 1_contig_1 } \\
\text { 1724 }\end{array}$ & 2 & 757 & 770 & 14 & 7 & 12 & $\begin{array}{l}\text { GTTGGTGCGTATCCTTATACTGTAAAAATCAGAAAAGCAAATATAGA } \\
\text { ATTAGAACAAAATGTAATAGAAGGTGACCATTTAATATGATGAAAT } \\
\text { GCCTTGTATATAAGTGGTAATCTAATGATATAATGTCATTTAAAATT } \\
\text { GATAGTTGCATTATATATATATATAATATTGTTTTATGAATAATGTA } \\
\text { ATTTTGTTATATGTGATACAACATTGAATATAAAGAATATACAATGG } \\
\text { TAAGAATAAAAAATTTAAGAATGTGGAGTGTGGGATTTAAACCCAC } \\
\text { GCCCTTTCGGA }\end{array}$ & 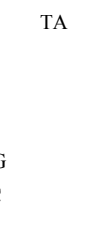 & G & 15,83 & 224 & $\begin{array}{l}\text { GAACAAAATGTAATA } \\
\text { GAAGGTGACCA }\end{array}$ & 59,7 & $\begin{array}{l}\text { TTCAAATCCCACAC } \\
\text { TCCACA }\end{array}$ & 59,9 & 34,6 & 45 \\
\hline 68 & BrPe0068 & $\begin{array}{l}\text { Maracuja_ } \\
\text { Nolndex_L } \\
003 \_R 1 \text { 00 } \\
\text { 1_contig_1 } \\
\text { 1772 }\end{array}$ & 2 & 829 & 846 & 18 & 9 & 16 & $\begin{array}{l}\text { AGCCGAAATTATCACGGTTGAACTGCCTTCAATTTTAATGGTGCCTA } \\
\text { CTTATCACAAGAGTGACGGATTCTCCCTAATATTTGCCCAAGCATA } \\
\text { ACTTGAATATTCAATTCATATCAATAATGAAATATTACTTAGTGTTG } \\
\text { GTTAATATATGTGTGTGTGTGTGTGTGGAAAGAGATGCGGCTAGTTC } \\
\text { AATTATTTAAAGAATTCCTTGATATAGCATAAATAAATATATGGGAA } \\
\text { AAAATAGAATAAGATAAAACAGTACAGATAAAATGTAGGGCTTCA } \\
\text { ATTTTTTCTTACGATGCCATTATTTGTGCTACTATTG }\end{array}$ & TG & $\mathrm{s}$ & 21,3 & 190 & $\begin{array}{l}\text { AGCCGAAATTATCAC } \\
\text { GGTTG }\end{array}$ & 60,0 & $\begin{array}{l}\text { TTGAACTAGCCGCA } \\
\text { TCTCTTT }\end{array}$ & 59,1 & 45 & 42,9 \\
\hline 69 & BrPe0069 & $\begin{array}{l}\text { Maracuja_ } \\
\text { NoIndex_L } \\
003 \_R 1 \text { 00 } \\
\text { 1_contig_1 } \\
2360\end{array}$ & 2 & 414 & 429 & 16 & 8 & 14 & $\begin{array}{l}\text { CGAAAGGTTCGTTTACATTGTTCGAATCCTGATATTTGATTAAGAAA } \\
\text { AAATGAGCCCTAGTCACTCCACCATTCATTTCTTGATACAACTATTC } \\
\text { TTATTCATAAATTGACTAAAATATTTTGTAGGAAAGGAACCCGTCTT } \\
\text { CATAAAATGATATATATATATATATTCCCAGCATCTCCATTAAAACG } \\
\text { GCATAAATCAAGGTTTAATTAGAGCTACATCATTTCTACTTAATAGT } \\
\text { CCAAAAGTTATTATTAAGTAGGCTGATGTATTTTGGACTTGTTGTTC } \\
\text { TTTGAATACAACTTTTATCACAGTTCCACTAAAA }\end{array}$ & AT & $\mathrm{s}$ & 13,24 & 153 & $\begin{array}{l}\text { GAGCCCTAGTCACTC } \\
\text { CACCA }\end{array}$ & 60,3 & $\begin{array}{l}\text { AAACCTTGATTTAT } \\
\text { GCCGTTTT }\end{array}$ & 59 & 60,0 & 31,8 \\
\hline 70 & BrPe0070 & $\begin{array}{l}\text { Maracuja_ } \\
\text { Nolndex_L } \\
003 \_R 1 \text { 00 } \\
\text { 1_contig_1 } \\
3447\end{array}$ & 2 & 508 & 519 & 12 & 6 & 10 & $\begin{array}{l}\text { ATCAGTTCAGGCAAAGTTTACAATCAACTCATCCATGAACACAAGG } \\
\text { ACCCCTGAATAGCAAAAATCAGTACTTATTTGGAAAAATAAAAGAA } \\
\text { TCAAGGAAACCACTCACCTTTTATTTATCTTACCAGAATGAAAAGAG } \\
\text { AAAAAGGGAACAGAGAGAGAGAGCTAGCTTTCACGGCTTCACCTGT } \\
\text { ATTTTCACGTCCAGGATGGTCTTTAAGCCTCAAGCAGACACATAATC } \\
\text { CAAGAAAATGAAATACAAAAGGTAATCAAAGACAAAACAATGAGC } \\
\text { CATCCATGATATAAGGCGGGTCAATCAGAGGCAGC }\end{array}$ & $\mathrm{AG}$ & G & 017 & 166 & $\begin{array}{l}\text { CAAGGACCCCTGAAT } \\
\text { AGCAA }\end{array}$ & 60,1 & $\begin{array}{l}\text { AGACCATCCTGGAC } \\
\text { GTGAAA }\end{array}$ & 60,5 & 50,0 & 50 \\
\hline
\end{tabular}


APÉNDICE

Marcadores microssatélites desenhados a partir do sequênciamento parcial e da montagem de novo do genoma de P. edulis

\begin{tabular}{|c|c|c|c|c|c|c|c|c|c|c|c|c|c|c|c|c|c|c|c|}
\hline $\mathbf{N}^{\circ}$ & Primer & Contig N & Motivo & Início & Fim & pb & $\begin{array}{c}\mathbf{N}^{\circ} \\
\text { Repet }\end{array}$ & Score & Sequência do contig & Unidade & G/S & Cobertura & pb & Sequência Forward & $\begin{array}{l}\mathrm{T}^{\circ} \mathrm{C} \\
F w d \\
F\end{array}$ & Sequência Reverse & $\begin{array}{l}\mathrm{T}^{\circ} \mathrm{C} \\
\operatorname{Rev} \\
\end{array}$ & $\begin{array}{c}\% \mathrm{GC} \\
F w d \\
\end{array}$ & $\begin{array}{r}\% \mathrm{GC} \\
\operatorname{Rev} \\
\end{array}$ \\
\hline 71 & BrPe0071 & $\begin{array}{l}\text { Maracuja_ } \\
\text { NoIndex_L } \\
\text { 003_R1_00 } \\
\text { 1_contig_1 } \\
4006\end{array}$ & 2 & 745 & 760 & 16 & 8 & 14 & $\begin{array}{l}\text { TTTTTTCTTTTTAATTTTGGGCAGCTGCATGCAATAATAAGGCACGTCT } \\
\text { ACCCAGAAAAAGAAAGAATTTAATGAAATAAGCATATTGAATCTA } \\
\text { CAATAGTTTATAATTGTGGGAAAGGCGATCAATGATGGAAAGACTT } \\
\text { TGGTTTCTTGATATATATATATATATTCATGTTAACTATGCAGTACA } \\
\text { AAATCAAGGGTCGAATTAATCATTTCCTTTAAACAGTGATTTTGATT } \\
\text { GATTTTGATTTAGCCCTTCCGCATGCGTAAGTTTGTCGTTGGTAGAT } \\
\text { GACTACCAAATTCATGCATTAAACCAGGTTTATCA }\end{array}$ & \begin{tabular}{|ll}
$\mathrm{AT}$ \\
\end{tabular} & $\mathrm{s}$ & 18,82 & 107 & $\begin{array}{l}\text { ATTGTGGGAAAGGCG } \\
\text { ATCA }\end{array}$ & 61,4 & $\begin{array}{l}\text { GAAATGATTAATTC } \\
\text { GACCCTTGA }\end{array}$ & 59,3 & 47,4 & 34,8 \\
\hline 72 & BrPe0072 & $\begin{array}{l}\text { Maracuja_ } \\
\text { NoIndex_L } \\
\text { 003_R1_00 } \\
\text { 1_contig_1 } \\
4239\end{array}$ & 2 & 640 & 655 & 16 & 8 & 14 & $\begin{array}{l}\text { CTCGAAATCAATGGTTTCTCCTATATATCATCAATCCTCATGGGTCT } \\
\text { AATAATACATATTGGTTTTGTTGTCATCTATACGGTTTCGTGAGACT } \\
\text { CAAGCTTTCAATTCAGTGTATGCTTCGGGGTTTTAGATTAGTTAGGT } \\
\text { TTCTTGGTAATATATATATATATATCGTTAATCTTCATTTTTCGTGGG } \\
\text { AGTCTTCAGGTAATAATTCGCACTTCAGATAATTGCTGCCAGAAGAT } \\
\text { ACTTTTTTAAAGCTGCATCTATAATATGATACAATGCACGACCAAAT } \\
\text { CCTGCTGCAGAGATACATAGGATATCAAGGAAA }\end{array}$ & АТ & $\mathrm{s}$ & 12,19 & 179 & $\begin{array}{l}\text { CAGTGTATGCTTCGG } \\
\text { GGTTT }\end{array}$ & 60,0 & $\begin{array}{l}\text { AGGATTTGGTCGTG } \\
\text { CATTGT }\end{array}$ & 60,4 & 50 & 45 \\
\hline 73 & BrPe0073 & $\begin{array}{l}\text { Maracuja_ } \\
\text { NoIndex_L } \\
\text { 003_R1_00 } \\
\text { 1_contig_1 } \\
5030\end{array}$ & 2 & 3113 & 3134 & 8 & 4 & 6 & $\begin{array}{l}\text { ATGAATTTGAATAGAAAGCTGGTTGATATAGCTTACTATAAGAAGGA } \\
\text { ACAGCTGTTGCTCAAGATATACTACTTAGATCCCCAATCTTCATCAC } \\
\text { CCTCCTGATATTTTACATTACTCGATCTTCTCTACCATAATTCTGGTA } \\
\text { TCATATCATGAGAGAGAGAGAGAGAGAGAGATCAACCAATAAAGA } \\
\text { ACTTTCTAGCTAATTATCTTTAACTGGTGATCGCCAAAATCATGGCT } \\
\text { ACAGCTGCTTATACCCATGGAACAAGTTCCATCAAGTGCTTTTATAT } \\
\text { ATATGAGCAAGCAACTCTAGCTTGCAAGGATCATAAAATTAA }\end{array}$ & TA & $\mathrm{s}$ & 14,54 & 111 & $\begin{array}{l}\text { AACTGGTGATCGCCA } \\
\text { AAATC }\end{array}$ & 59,9 & $\begin{array}{l}\text { TTTTATGATCCTTGC } \\
\text { AAGCTAGA }\end{array}$ & 58,2 & 45 & 34,8 \\
\hline 74 & BrPe0074 & $\begin{array}{l}\text { Maracuja_ } \\
\text { NoIndex_L } \\
\text { 003_R1_00 } \\
\text { 1_contig_1 } \\
6503\end{array}$ & 2 & 3503 & 3520 & 18 & 9 & 16 & $\begin{array}{l}\text { AATAAAATTATGGTATCTGAAAAAAAATGATCAAGCTTTGTATCTTGC } \\
\text { CAGTTTTTCTTCTCAACCATAAAAAATAAAGGAGCAATCTCGAGTCCA } \\
\text { TTCATATAAATTTCCTGAAGCGCTCGATTTCATCTCGTGAGCAGCTT } \\
\text { ATAAACGGAATATATATATATATATATCATAATCCCTGCAAGAGAA } \\
\text { ATAAGATTTCCATCAGGAAATAATATATGCCATGATTTAATATTAATA } \\
\text { CAGTAACAACACCCACTACATAGATTGCACATCTTTCATATCCGACC } \\
\text { CGTTATATTGCGTGTCCAAACCATATAACATCAGGAT }\end{array}$ & AT & $\mathrm{s}$ & 16,17 & 209 & $\begin{array}{l}\text { AAGGAGCAATCTCGA } \\
\text { GTCCA }\end{array}$ & 60,0 & $\begin{array}{l}\text { CGGGTCGGATATGA } \\
\text { AAGATG }\end{array}$ & 60,3 & 50 & 50 \\
\hline 75 & BrPe0075 & $\begin{array}{l}\text { Maracuja_ } \\
\text { NoIndex_L } \\
\text { 003_R1_00 } \\
\text { 1_contig_1 } \\
6622\end{array}$ & 2 & 5152 & 5163 & 12 & 6 & 10 & $\begin{array}{l}\text { ATTTGGTGATTTTCCTGGTACCAATGGCACACATCATGAAAACAGGA } \\
\text { AAAAAATCCCTTTTGGGGATAGTTTACAAGTCTGAGTGTTTAACTTG } \\
\text { AACAAGTTACCTCATCTTTTCTTGACTGATAAACATTATGGAGAAGC } \\
\text { TTCAATTAGTATATATATATACACACAGACTCAAACATACATATTAC } \\
\text { AGAATTATGTCCAGTTTGATAGGATGGAACAAAATTGAGAAAGTCA } \\
\text { TTCAGTATGATGATCCTACAAAGTATTGTATAGTAATACTTAGCAGT } \\
\text { TATATCTTGTAGCATTATTTAAGATAGTTAA }\end{array}$ & TA & $\mathrm{s}$ & 15,73 & 164 & $\begin{array}{l}\text { TCCCTTTTGGGGATA } \\
\text { GTTTACA }\end{array}$ & 59,7 & $\begin{array}{l}\text { TTCCATCCTATCAA } \\
\text { ACTGGACA }\end{array}$ & 59,4 & 40,9 & 40,9 \\
\hline
\end{tabular}


APÉNDICE

Marcadores microssatélites desenhados a partir do sequênciamento parcial e da montagem de novo do genoma de P. edulis

\begin{tabular}{|c|c|c|c|c|c|c|c|c|c|c|c|c|c|c|c|c|c|c|c|}
\hline $\mathbf{N}^{\circ}$ & Primer & Contig N & Motivo & Início & Fim & pb & $\begin{array}{c}\mathbf{N}^{\circ} \\
\text { Repet }\end{array}$ & Score & Sequência do contig & Unidade & G/S & Cobertura & pb & Sequência Forward & $\begin{array}{l}\mathrm{T}^{\circ} \mathrm{C} \\
F w d \\
\end{array}$ & Sequência Reverse & $\begin{array}{l}\mathrm{T}^{\circ} \mathrm{C} \\
\operatorname{Rev} \\
\end{array}$ & $\begin{array}{c}\% \mathrm{GC} \\
F w d \\
\end{array}$ & $\begin{array}{r}\% \mathrm{GC} \\
\operatorname{Rev} \\
\end{array}$ \\
\hline 76 & BrPe0076 & $\begin{array}{l}\text { Maracuja_ } \\
\text { NoIndex_L } \\
\text { 003_R1_00 } \\
\text { 1_contig_1 } \\
6875\end{array}$ & 2 & 717 & 728 & 12 & 6 & 10 & $\begin{array}{l}\text { CGATCGAGTAGCTCTATGTCTTCTCCTTCGACTGTAAAGAAATGGAC } \\
\text { AGGGTAAAGGATACAAAAACGGCGCCGTTTTATGGTCTCCTTCGA } \\
\text { GAAACCCATCGTTTTACGTTCTTCTTACGGCTCAACTCGAAGGATTC } \\
\text { AAGCTTAATCCACACACACACAGAGCTCTGTACAGCAGATTGATAG } \\
\text { AATCATCTGTCTTTCAGTGCAACTATTCATTCGGTAAATATAACCGT } \\
\text { TCCTACTCTCCTGGTGGTTCCTTATTCATCAGGTTAACCGCTGTCGGA } \\
\text { AACCTTGTGAATTGAGGTTTTTATGAAAACA }\end{array}$ & CA & $\bar{G}$ & 14,78 & 167 & $\begin{array}{l}\text { TCTCCTTCGAGAAAC } \\
\text { CCATC }\end{array}$ & 59,2 & $\begin{array}{l}\text { CCACCAGGAGAGTA } \\
\text { GGAACG }\end{array}$ & 59,7 & 50,0 & 60,0 \\
\hline 77 & BrPe0077 & $\begin{array}{l}\text { Maracuja_ } \\
\text { NoIndex_L } \\
\text { 003_R1_00 } \\
\text { 1_contig_1 } \\
\text { 7080 }\end{array}$ & 2 & 6105 & 6116 & 12 & 6 & 10 & $\begin{array}{l}\text { GAACACCCTTTCCAATGCAATTACTAGTAAACTGCTTTCAGATTTCA } \\
\text { ACAGCATCAACCATAAATTTTTTTTTTGTATGTACCATTATTAAAGT } \\
\text { TGAATTTGCTTCAAACAAGGCTCAACAAGATCACACTTCTGTCAAAA } \\
\text { GCAAAATCTGTGTGTGTGTGGCTCCTTTATTTTCCTTGTTGATTAACC } \\
\text { ATTGAGAAGTAATATGACCAATTCACCAACCAACAATCAATAAAAA } \\
\text { TATTATAAAAAATAGACCTGCAGCTGGAATGATTTGTGTTCAACATG } \\
\text { GAAAGAGAACTCTCTTGTTTCAAAACTTC }\end{array}$ & TG & $\mathrm{s}$ & 18,45 & 169 & $\begin{array}{l}\text { TTGCTTCAAACAAGG } \\
\text { CTCAA }\end{array}$ & 59,6 & $\begin{array}{l}\text { ATCATTCCAGCTGC } \\
\text { AGGTCT }\end{array}$ & 59,8 & 40,0 & 50,0 \\
\hline 78 & BrPe0078 & $\begin{array}{l}\text { Maracuja_ } \\
\text { NoIndex_L } \\
\text { 003_R1_00 } \\
\text { 1_contig_1 } \\
\text { 7923 }\end{array}$ & 2 & 2256 & 2269 & 14 & 7 & 12 & $\begin{array}{l}\text { GGAAAAGATAGCTGTGCCCTACAATAGATTAGTACTAGTTAAAAGAA } \\
\text { AGTACACCAAGTCCAAAAAAGCAAATATTCACTTAGAACTAGGGAT } \\
\text { ACGGCAATTGATCAATTCATTCAACAACATCCATTCATATTGGACCA } \\
\text { GGATGAATGACGAGAGAGAGAGAGATTAAAAAGCTAGATTAGTAG } \\
\text { TTAAAGAATTCCTTTGAGAATATCGAGTTGAATCCTTGACCCTCGGT } \\
\text { TGCTAAAATGACCCACCATTCATGGCATTCTTCTCCTGGCAGTTAGC } \\
\text { TCAAACTTGCATCGCCGATATCATGTCGATAATCTC }\end{array}$ & GA & $\mathrm{s}$ & 16,13 & 179 & $\begin{array}{l}\text { TCCATTCATATTGGAC } \\
\text { CAGGA }\end{array}$ & 60,1 & $\begin{array}{l}\text { GATATCGGCGATGC } \\
\text { AAGTTT }\end{array}$ & 60,1 & 42,9 & 45 \\
\hline 79 & BrPe0079 & $\begin{array}{l}\text { Maracuja_ } \\
\text { NoIndex_L } \\
\text { 003_R1_00 } \\
\text { 1_contig_1 } \\
8054\end{array}$ & 2 & 2529 & 2548 & 20 & 10 & 18 & $\begin{array}{l}\text { AAAAAAAAAAAAACTTACTATACATTTCTGGCTTTCTCATCTTACAA } \\
\text { GATGTGCTTCACATATAAGAAAGCAATGATTACTTTGTAGCATTTCA } \\
\text { TAAAGACCATTATCCTGCAACGTACTAGTGAAATTGAATATAATGAT } \\
\text { CTTACTAAAAGAGAGAGAGAGAGAGAGAGTTACTGTTTTCATTTGC } \\
\text { CTTGTTTCCTCTTACATTTTTTTTTTAAAAACTGTGTGCAGTGTGATG } \\
\text { AAGTAACAAACAATGGCAAGACCACTACACCTGTAAAATTTCAGGT } \\
\text { TCATTGTGCTAATCTATTTTTGATTTCCAGTGTTTACTG }\end{array}$ & $\mathrm{AG}$ & $\mathrm{s}$ & 19,28 & 176 & $\begin{array}{l}\text { САTTTCTGGCTTTCTC } \\
\text { ATCTTACA }\end{array}$ & 59,8 & $\begin{array}{l}\text { GAGGAAACAAGGC } \\
\text { AAATGAAA }\end{array}$ & 59,2 & 37,5 & 38,1 \\
\hline 80 & BrPe0080 & $\begin{array}{l}\text { Maracuja_ } \\
\text { NoIndex_L } \\
\text { 003_R1_00 } \\
\text { 1_contig_1 } \\
\text { 8293 }\end{array}$ & 2 & 6147 & 6164 & 18 & 9 & 16 & $\begin{array}{l}\text { AACAAAAGCAAAAGCCAAACATTTTAAACAAAATGGAAGATGCTTT } \\
\text { CATCTACAAAATAAATGAGATACATCTCGGCAACCTGTCACTCATC } \\
\text { AACTCACGGCATATGAGGAATGCCAAGAGAAATGTCCACTAACATT } \\
\text { TATGTAACTCAAGTGTGTGTGTGTGTGTGTAACTATAACAAACAACT } \\
\text { ATTCTCCATATATTTCAAGCTATATCACAGGCAGGAAGCATAGAGA } \\
\text { AGTTGTCGGCTTAAACTTACAGGCTAACCAAGTCAGACAAAAGAGT } \\
\text { AATCTGGTCACTAATACTCCCTCTTAATCCTTGACTTCCAA }\end{array}$ & GT & $\mathrm{s}$ & 17,61 & 163 & $\begin{array}{l}\text { TACATCTCGGCAACC } \\
\text { TGTCA }\end{array}$ & 60,3 & $\begin{array}{l}\text { TCTATGCTTCCTGCC } \\
\text { TGTGA }\end{array}$ & 59,5 & 50 & 50 \\
\hline
\end{tabular}


APÉNDICE

Marcadores microssatélites desenhados a partir do sequênciamento parcial e da montagem de novo do genoma de $P$. edulis

\begin{tabular}{|c|c|c|c|c|c|c|c|c|c|c|c|c|c|c|c|c|c|c|c|}
\hline $\mathbf{N}^{\circ}$ & Primer & Contig & Motivo & Início & Fim & pb & $\begin{array}{c}\mathbf{N}^{\circ} \\
\text { Repet }\end{array}$ & Score & Sequência do contig & Unidade & G/S & Cobertura & pb & Sequência Forward & $\begin{array}{l}\mathrm{T}^{\circ} \mathrm{C} \\
F w d\end{array}$ & Sequência Reverse & $\begin{array}{l}\mathrm{T}^{\circ} \mathrm{C} \\
\operatorname{Rev}\end{array}$ & $\begin{array}{c}\% \mathrm{GC} \\
F w d\end{array}$ & $\begin{array}{c}\% \mathrm{GC} \\
\operatorname{Rev}\end{array}$ \\
\hline \multirow[t]{5}{*}{81} & BrPe0081 & Maracuja_ & 2 & 1484 & 1501 & 18 & 9 & 16 & $\begin{array}{l}\text { CCGGAGTTGGGTATTTCTTTGCAAAGAAATGCAAGCACATGGTTGTA } \\
\end{array}$ & $\mathrm{CT}$ & $\mathrm{S}$ & 16,93 & 181 & TTGCAAAGAAATGCA & 60,0 & CCACGCAGCATCAT & 60,8 & 40 & 50 \\
\hline & & NoIndex_L & & & & & & & ATTATACAGGAAAAAAGATTGCGTGTAATTCCATTTCCGAGCAGGC & & & & & AGCAC & & AGATCA & & & \\
\hline & & 003_R1_00 & & & & & & & CAGAAAGGTCAAAGCTCCTGTCAGAGGGAAAAAATAAAGCCCTGTG & & & & & & & & & & \\
\hline & & 1_contig_1 & & & & & & & AACAAAAAGTCCTCTCTCTCTCTCTCTCTGCGCTGGTGGATGATCTA & & & & & & & & & & \\
\hline & & 8583 & & & & & & & TGATGCTGCGTGGC & & & & & & & & & & \\
\hline
\end{tabular}

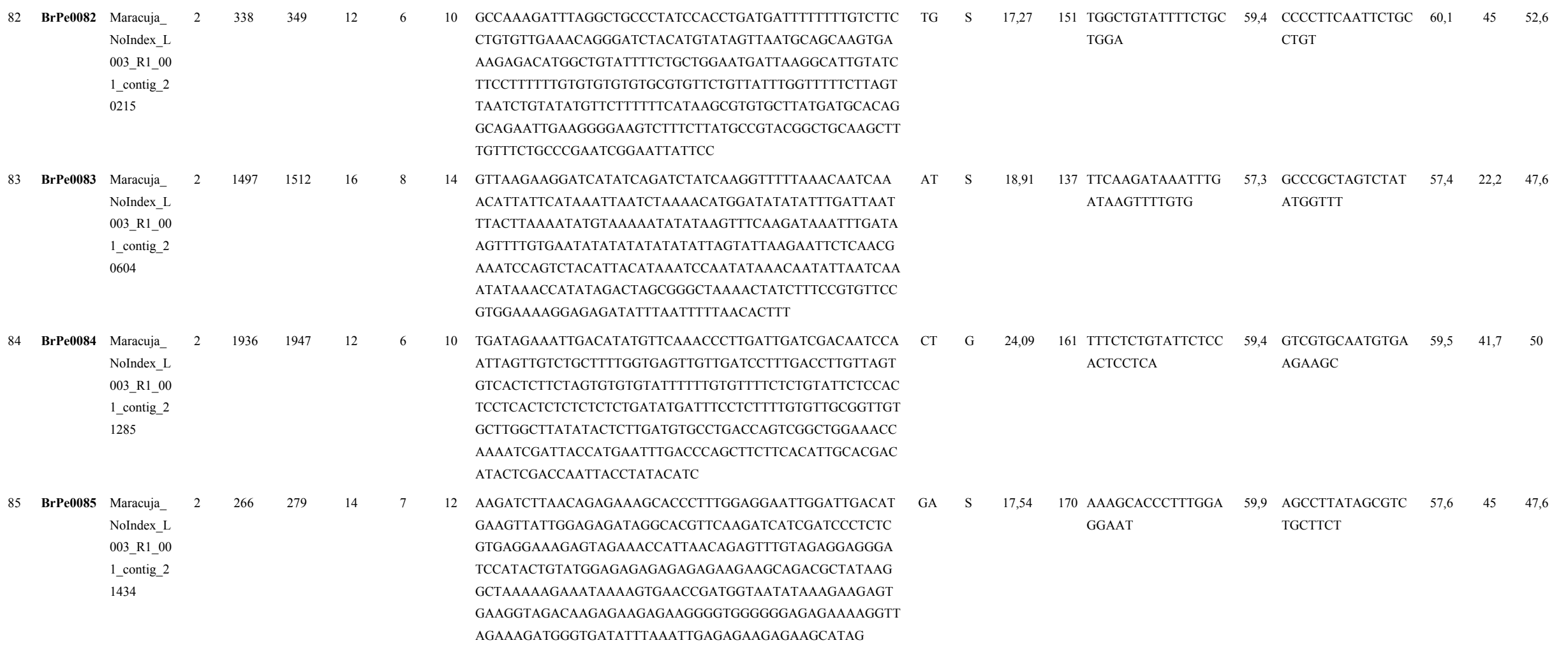

\footnotetext{
G: genoma funcional

S: genoma estructural

P: polimórfico

M: monomórfico
} 
APÉNDICE

Marcadores microssatélites desenhados a partir do sequênciamento parcial e da montagem de novo do genoma de $P$. edulis

\begin{tabular}{|c|c|c|c|c|c|c|c|c|c|c|c|c|c|c|c|c|c|c|c|c|}
\hline $\mathbf{N}^{\circ}$ & Primer & Contig & Motivo & Início & Fim & pb & $\begin{array}{c}\mathbf{N}^{\circ} \\
\text { Repet }\end{array}$ & Score & Sequência do contig & Unidade & G/S & Cobertura & pb & Sequência Forward & $\begin{array}{l}\mathrm{T}^{\circ} \mathrm{C} \\
F w d \\
\end{array}$ & Sequência Reverse & $\begin{array}{l}\mathrm{T}^{\circ} \mathrm{C} \\
\operatorname{Rev} \\
\end{array}$ & $\begin{array}{r}\% \mathrm{GC} \\
F w d \\
\end{array}$ & $\begin{array}{c}\% \mathrm{GC} \\
R e v \\
\end{array}$ & $\mathbf{P} / \mathbf{M}$ \\
\hline 86 & BrPe0086 & $\begin{array}{l}\text { Maracuja_ } \\
\text { NoIndex_L } \\
003 \text {-R1_00 } \\
\text { 1_contig_2 } \\
4018\end{array}$ & 2 & 2356 & 2375 & 20 & 10 & 18 & $\begin{array}{l}\text { TTGGATATCTACCCCATCGATCTCGGATCTATGCTTGAGGACCAAGT } \\
\text { CAATTTCCCAATTTCAATGGCTCCGTAACTGAATTTTCTATGTACA } \\
\text { AATAGGTCAATTACGTGCCAAAAATTCTGTTAATTTTATTATTCATC } \\
\text { ATTAACCTTTATATATATATATATATATAAAGATCCTATAGGTTATA } \\
\text { TTTTACTGTGCCTGTCTCCGGGTGCTTCGTTCAACTATTATAATCCTC } \\
\text { AAATCTTGCGCTATTAACATATATCACGTACCAAGGACAATGTCATT } \\
\text { AAAACTTAATAGTTAAACTAGAATTAAACGGAATTAG }\end{array}$ & TA & $\mathrm{s}$ & 11,1 & 153 & $\begin{array}{l}\text { CAAATTTCAATGGCT } \\
\text { CCGTAA }\end{array}$ & 60,0 & $\begin{array}{l}\text { CGGAGACAGGCACA } \\
\text { GTAAAA }\end{array}$ & 58,9 & 38,1 & 50 & \\
\hline 87 & BrPe0087 & $\begin{array}{l}\text { Maracuja_ } \\
\text { NoIndex_L } \\
\text { 003_R1_00 } \\
\text { 1_contig_2 } \\
4110\end{array}$ & 2 & 2769 & 2782 & 14 & 7 & 12 & $\begin{array}{l}\text { TGCATTTTGCAAATTGCTTAAGTGGAACATGCAATACATCTCTTAAC } \\
\text { CACATACTTTTTGCTTGCAGGGGAAAATGGATGCTGCGTTGAGCATG } \\
\text { ATTGAGAAAGCTATAATTGCAAATCCCACATATGCGGAAGCTTATA } \\
\text { ACAACTTAGGTCTCTCTCTCTCTCACTCCTTGAACAAAAGATTTACC } \\
\text { CTCTAGTGTCATCAGATTGGTTTTAATGTTCAGAGATTTCAAGGTCT } \\
\text { AATGTGTTTAGTTTATAGTAATTACTATTGATTGCTTATGATTGGGCT } \\
\text { CACTGATATTCAATGAAGCAACTATCTTTATC }\end{array}$ & TC & $\mathrm{s}$ & 17,89 & 206 & $\begin{array}{l}\text { GCGTTGAGCATGATT } \\
\text { GAGAA }\end{array}$ & 60,0 & $\begin{array}{l}\text { TCAGTGAGCCCAAT } \\
\text { CATAAGC }\end{array}$ & 60,2 & 45 & 47,6 & \\
\hline 88 & BrPe0088 & $\begin{array}{l}\text { Maracuja_ } \\
\text { NoIndex_L } \\
003 \text { BR1_00 } \\
\text { 1_contig_2 } \\
5627\end{array}$ & 2 & 1616 & 1631 & 16 & 8 & 14 & $\begin{array}{l}\text { TTGATGCAACAGGAGGCCATCGTTATTTGTGATTGCTGATTCTTGCT } \\
\text { TTATTTTATTGACTTTATTCCTTGGTTCAATATTATTTTCTCTTCCTCA } \\
\text { TCAGGGTTGGGCTATTGGGTGGCAAAAGAAGCAATTTTTTGAACATT } \\
\text { TTAACTGCTCTCTCTCTCTCTCTGTGAAATTGGATACTTTCAAAGTAT } \\
\text { TAACAAGCATTCCATCTTATGCTAAGTATGTTTTATGAGCTTTCTTCT } \\
\text { CAAAGATTTCTAAATTCTTCACACTCCCATTTACAGCATTTGCACAG } \\
\text { ATCTTATCATGCTTTGTTTTATCATTGATT }\end{array}$ & СT & $\mathrm{s}$ & 18,91 & 180 & $\begin{array}{l}\text { GCTATTGGGTGGCAA } \\
\text { AAGAA }\end{array}$ & 60,1 & $\begin{array}{l}\text { CTGTGCAAATGCTG } \\
\text { TAAATGG }\end{array}$ & 59,2 & 45 & 42,9 & \\
\hline 89 & BrPe0089 & $\begin{array}{l}\text { Maracuja_ } \\
\text { Nolndex_L } \\
\text { 003_R1_00 } \\
\text { 1_contig_2 } \\
5926\end{array}$ & 2 & 1482 & 1495 & 14 & 7 & 12 & $\begin{array}{l}\text { CACTGAATTTTTCCCTTTGCAGATATGCAATCGTAATGAAGATACTG } \\
\text { CAAGTAAGCGGGGTGCTCTTCAGCAGTTAATTGAAGCTTCTTCTGCT } \\
\text { AACGAACACTCTGTTTGGTCCAAAGTATAGTAATTTGTCTCCCTCCA } \\
\text { TAATCTCTTTCTCTCTCTCTCTCATGCGAATATTGCTATGGTGATACT } \\
\text { GCAGTGAAATGTTTTTTTAAAGTTTTGTGATGCCTTATGCACATATT } \\
\text { GCTACCACTATACTGCAGAGCAATGTGTTTGGATTCTTTGTTATGAC } \\
\text { TGCAGGTTGATAACTTTTGGTTACCGTTGC }\end{array}$ & $\mathrm{TC}$ & $\mathrm{s}$ & 17,32 & 150 & $\begin{array}{l}\text { AAGTAAGCGGGGTGC } \\
\text { TCTTC }\end{array}$ & 60,8 & $\begin{array}{l}\text { TTTCACTGCAGTATC } \\
\text { ACCATAGC }\end{array}$ & 59,3 & 55 & 43,5 & \\
\hline 90 & BrPe0090 & $\begin{array}{l}\text { Maracuja_ } \\
\text { NoIndex_L } \\
003 \text { _R1_00 } \\
\text { 1_contig_2 } \\
6137\end{array}$ & 2 & 545 & 556 & 12 & 6 & 10 & $\begin{array}{l}\text { AGAGTAGTTACCACCAAAACCAGTTGAATGATTTGAACATTGAAAA } \\
\text { ATATATCAGAAAATCTGCATTCACGCTCAGCTAGTGGAGATCAAGA } \\
\text { ACATCGCCAGTGATTTAGAGGAAAGAGGACCAAATCATACTTAGGA } \\
\text { TTCAAGTTATATAGAGAGAGAGAGTCGACACAGAGAGAAGGCTGA } \\
\text { AGAAATCAAGTGGGTTTTACGCAAAATTTAAGCTGCTTCTTTTGCAT } \\
\text { TGGACTGGATTGGTCTTTAAGATATCTCTGTCTGCAATAGATATCGA } \\
\text { TGAAGAGCAATTTAATGTGCGAAAAAACAAACTGT }\end{array}$ & AG & $\mathrm{s}$ & 14,92 & 185 & $\begin{array}{l}\text { TGCATTCACGCTCAG } \\
\text { CTAGT }\end{array}$ & 59,8 & $\begin{array}{l}\text { AGACCAATCCAGTC } \\
\text { CAATGC }\end{array}$ & 59,9 & 50 & 50 & \\
\hline
\end{tabular}


APÉNDICE

Marcadores microssatélites desenhados a partir do sequênciamento parcial e da montagem de novo do genoma de P. edulis

\begin{tabular}{|c|c|c|c|c|c|c|c|c|c|c|c|c|c|c|c|c|c|c|c|}
\hline $\mathbf{N}^{\circ}$ & Primer & Contig & Motivo & Início & Fim & pb & $\begin{array}{c}\mathbf{N}^{\circ} \\
\text { Repet }\end{array}$ & Score & Sequência do contig & Unidade & G/S & Cobertura & pb & Sequência Forward & $\begin{array}{l}\mathrm{T}^{\circ} \mathrm{C} \\
F w d \\
F\end{array}$ & Sequência Reverse & $\begin{array}{l}\mathrm{T}^{\circ} \mathrm{C} \\
\operatorname{Rev} \\
\end{array}$ & $\begin{array}{c}\% \mathrm{GC} \\
F w d \\
\end{array}$ & $\begin{array}{r}\% \mathrm{GC} \\
\operatorname{Rev} \\
\end{array}$ \\
\hline 91 & BrPe0091 & $\begin{array}{l}\text { Maracuja_ } \\
\text { NoIndex_L } \\
\text { 003_R1_00 } \\
\text { 1_contig_2 } \\
7830\end{array}$ & 2 & 1454 & 1473 & 20 & 10 & 18 & $\begin{array}{l}\text { ATTAAGATCGAGTTATGATCCCTAGGGAAACACTCAAATCAAGGAG } \\
\text { CAAAAAGTGATTCAGCATTAATGATGGCCCTTCCACATAATACTTAT } \\
\text { TTTCTTCTCTGGTTCGTTTAGATATACTATACATTTCTTCTGGATATT } \\
\text { TGTGAGTTCATATATATATATATATATATGGAGATTAGAAAAAGAC } \\
\text { GAGGGAGACAAAATAATGGAAGAATTTTGGGTGGTTCAGGTAATTA } \\
\text { TGCACCAGGAGACAATTCCTTAGCTTTAAACTATATAATTAATTCTG } \\
\text { ATAGGTTGTGCTAAACCATGAGCGACTTGAGAGAAAATAT }\end{array}$ & AT & $\mathrm{s}$ & 15,91 & 186 & $\begin{array}{l}\text { ATGATGGCCCTTCCA } \\
\text { CATAA }\end{array}$ & 60,2 & $\begin{array}{l}\text { GGAATTGTCTCCTG } \\
\text { GTGCAT }\end{array}$ & 59,9 & 45 & 50 \\
\hline 92 & BrPe0092 & $\begin{array}{l}\text { Maracuja_ } \\
\text { NoIndex_L } \\
003 \text { R1_00 } \\
\text { 1_contig_2 } \\
8274\end{array}$ & 2 & 2283 & 2296 & 14 & 7 & 12 & $\begin{array}{l}\text { CTTTTGGAAATCTGTTATACCAGAAAGTGGAAACCTGATACCGAGT } \\
\text { GGATTATAGTTTTTTATACCAGTACGTACAATAATGTAATGGAAGC } \\
\text { GTCATTAGTGGAGTACTTTATGATTTGTATATCTATACGACCTCAAG } \\
\text { ATCTGGAATCTATATATATATATACATTGGTCGGCAAAAAATATATC } \\
\text { TTCCCTATAATTTCTCACTGCAACTGGTATATTTTTCAACCTTATTTA } \\
\text { TCTCTATGCTCGTAAATTGAAAGCTGAATCGACTGATATACTTGTA } \\
\text { TTGAAGGAACCAGAGAATCCAGGTTTGATGGA }\end{array}$ & TA & $\mathrm{s}$ & 16,49 & 219 & $\begin{array}{l}\text { TGGAAGCGTCATTAG } \\
\text { TGGAG }\end{array}$ & 58,9 & $\begin{array}{l}\text { CCTGGATTCTCTGGT } \\
\text { TCCTTC }\end{array}$ & 60,1 & 50 & 52,4 \\
\hline 93 & BrPe0093 & $\begin{array}{l}\text { Maracuja_ } \\
\text { NoIndex_L } \\
\text { 003_R1_00 } \\
\text { 1_contig_2 } \\
8317\end{array}$ & 2 & 249 & 262 & 14 & 7 & 12 & $\begin{array}{l}\text { CAGTTTCTATTTTAACTTTTTCTTTTCTGTGTACTTGTCTTTTGCTAGT } \\
\text { TTAAGTGGAAATTGGAGAAGAAAGCTGCACAAGTGTTTATTTGCA } \\
\text { TTTTGCGTTGAAGAAACGAGCAATTGTCGAGGAGATTCAGGAGAAG } \\
\text { CAGGAACAGGTGTGTGTGTGTGTCTGAAAACTGAAGATGTTTAAGC } \\
\text { TCGTTTATGTTTGAGCATTTACTGCTGCTTGGCAATGTGTGGTTTTTG } \\
\text { ATGTATTCTCGTTGGAACATTATTATATTAAAGGTTAAAGAATGGCT } \\
\text { TCAAAATCTAGGAATAGGAGATCATGCACCGA }\end{array}$ & GT & G & 17,9 & 163 & $\begin{array}{l}\text { TGGAGAAGAAAGCTG } \\
\text { CACAA }\end{array}$ & 59,7 & $\begin{array}{l}\text { CATTGCCAAGCAGC } \\
\text { AGTAAA }\end{array}$ & 60,0 & 45 & 45 \\
\hline 94 & BrPe0094 & $\begin{array}{l}\text { Maracuja_ } \\
\text { NoIndex_L } \\
003 \text { 121_00 } \\
\text { 1_contig_2 } \\
9830\end{array}$ & 2 & 2305 & 2318 & 14 & 7 & 12 & $\begin{array}{l}\text { GCACCTTGGAAATGCCTTTGAAGATTCAATTGAAGAAGCAACCAAG } \\
\text { AAAAACACCGTCACCTATTCCCATTACCATTTTTTAATACTTTTCATT } \\
\text { CGTGTTTTTCTTCGTGGAAGCCAAAAAAGCGTGTGAGATTTGTTTG } \\
\text { TCAGTTTGCCTCTCTCTCTCTCTTCTTATCTCCTCAGATGACTAAAAT } \\
\text { ATAAGTGGGCTTTTTATACTAATTTGTTTTTCTTTCTTCCTTTGGTGCT } \\
\text { GCTACCTAGCTAGAGCTGCCTTCTCAAGTTTTCTAGAACCCACGTCG } \\
\text { CTTTCTGCGACCTCCTTCTCCCTCTTTAT }\end{array}$ & Ст & $\mathrm{s}$ & 17,58 & 158 & $\begin{array}{l}\text { CCAAGAAAAACACCG } \\
\text { TCACC }\end{array}$ & 60,4 & $\begin{array}{l}\text { GCCCACTTATATTTT } \\
\text { AGTCATCTGAG }\end{array}$ & 58,8 & 50 & 38,5 \\
\hline 95 & BrPe0095 & $\begin{array}{l}\text { Maracuia_ } \\
\text { NoIndex_L } \\
003 \text { R1_00 } \\
\text { 1_contig_3 } \\
0748\end{array}$ & 2 & 630 & 643 & 14 & 7 & 12 & $\begin{array}{l}\text { AACTTCCTCTGTAGAGAGTCAATAACATGGCACCTACAACACAGAC } \\
\text { AAGTGTACCAAGTACTTTCGCTCTTCCGCTGTGAGATTTTATGTCAA } \\
\text { CAGTCTCCAATCTGAAATGTGTATGAACCCACATTATAAAGAAGCTC } \\
\text { AAATTCAAACTATATATATATATAATCCGGCATCTAGATAAACGCAT } \\
\text { CCATACCCCATTGGCAGTGCCATAACGAAGGTGATCACAGGCACGA } \\
\text { TGTTGATGAAGGCGCACGCAAATGTAGCAGATGTGTATTGAATGCC } \\
\text { AAGCAGGAAGAAGTATTGCGTTAACGATGCCCTGC }\end{array}$ & TA & $\mathrm{s}$ & 16,01 & 234 & $\begin{array}{l}\text { TACTTTCGCTCTTCCG } \\
\text { CTGT }\end{array}$ & 60,2 & $\begin{array}{l}\text { CTTCTTCCTGCTTGG } \\
\text { CATTC }\end{array}$ & 60,0 & 50 & 50 \\
\hline
\end{tabular}


APÉNDICE

Marcadores microssatélites desenhados a partir do sequênciamento parcial e da montagem de novo do genoma de $P$. edulis

\begin{tabular}{|c|c|c|c|c|c|c|c|c|c|c|c|c|c|c|c|c|c|c|c|c|}
\hline $\mathbf{N}^{o}$ & Primer & Contig N & Motivo & Início & Fim & pb & $\begin{array}{c}\mathbf{N}^{\circ} \\
\text { Repet }\end{array}$ & Score & Sequência do contig & Unidade & G/S & Cobertura & pb & Sequência Forward & $\begin{array}{l}\mathrm{T}^{\circ} \mathrm{C} \\
F w d \\
\end{array}$ & Sequência Reverse & $\begin{array}{l}\mathrm{T}^{\circ} \mathrm{C} \\
\operatorname{Rev} \\
\end{array}$ & $\begin{array}{r}\% \mathrm{GC} \\
F w d \\
\end{array}$ & $\begin{array}{c}\% \mathrm{GC} \\
R e v \\
\end{array}$ & $\mathbf{P} / \mathbf{M}$ \\
\hline 96 & $\begin{array}{l}\text { BrPe0096 } \\
\end{array}$ & $\begin{array}{l}\text { Maracuja__ } \\
\text { NoIndex_L } \\
\text { 003_R1_00 } \\
\text { 1_contig_3 } \\
0934\end{array}$ & 2 & 731 & 754 & 24 & 12 & 22 & $\begin{array}{l}\text { ATGGAACCTCAAGATCATGACAACATAAAGGAACAGTCAACAAAA } \\
\text { CAAACAAAACTCCATTCATAAGCAAACAAAGGTAGGTAACCAACAA } \\
\text { GAAGGTAAAAAGCACAAATGGACGGGGAGGCTCCTTTTTACGGTGA } \\
\text { TTCATTTTCATGCAGAGAGAGAGAGAGAGAGAGAGAGCGGTGTAAA } \\
\text { CAAGAGGGGATGGAGAGGGGATCATCGGGACATTTTTGGGGAATGG } \\
\text { GAGAGCACAGGAAAGGGACGGCTCGCAATCACAACAGAGAAACAG } \\
\text { CTTTGGATGCCAGGTCCGTATGACTTTACACGCAAAACTATGGCATT }\end{array}$ & 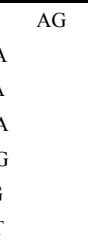 & $\mathrm{s}$ & 14,41 & 182 & $\begin{array}{l}\text { GAGGCTCCTTTTTACG } \\
\text { GTGA }\end{array}$ & 59,3 & $\begin{array}{l}\text { AGTCATACGGACCT } \\
\text { GGCATC }\end{array}$ & 60,0 & 50 & 55 & \\
\hline 97 & BrPe0097 & $\begin{array}{l}\text { Maracuja_ } \\
\text { NoIndex_L } \\
\text { 003_R1_00 } \\
\text { 1_contig_3 } \\
0981\end{array}$ & 2 & 377 & 396 & 20 & 10 & 18 & $\begin{array}{l}\text { TCATTTTTAATATATTAATATCGCTTATAACTATTTTCTTTCCCATTGT } \\
\text { TTAGACTGTTGCTACTAAGGAGAACACTGAATTATTATGGCTGATTG } \\
\text { TGATTGCCGTACCTCTCCATCCTTGGCTGCTCTCACTTCCCAAGTTGC } \\
\text { TTCTTGCATATATATATATATATATATTCATCCCCGCACTTGGACTTT } \\
\text { TTAACGTAGGCATGACAGAATTTTCGGTGTCAAGTGATACTAATGAT } \\
\text { GCCTAAATATAGAATGCTCCTCGTAGATCGATTCAGCCAAAGTTACA } \\
\text { ACGGCGTCTCTGGAAAACCAAACTCAATATACAAA }\end{array}$ & AT & G & 14,86 & 155 & $\begin{array}{l}\text { GCTCTCACTTCCCAA } \\
\text { GTTGC }\end{array}$ & 60,0 & $\begin{array}{l}\text { TTGGCTGAATCGAT } \\
\text { CTACGA }\end{array}$ & 59,4 & 55 & 45 & \\
\hline 98 & BrPe0098 & $\begin{array}{l}\text { Maracuja__ } \\
\text { NoIndex_L } \\
\text { 003_R1_00 } \\
\text { 1_contig_3 } \\
1480\end{array}$ & 2 & 947 & 960 & 14 & 7 & 12 & $\begin{array}{l}\text { GAAATCGGCGCTAGCTGGGGGGCTTCAAATGATGTTTTATCGTATTC } \\
\text { GAAAAGGCTTTAGACAATTAATGTATTTTAACCTTATTTGGTTGTTT } \\
\text { GATGTGCCGCCTAATCATGGACATTTTTGTTTGCCTCCACATCTCC } \\
\text { ACGCCCAACCTCTCTCTCTCTCTTCTTCATGGCCACAAACATTGGGC } \\
\text { CTTTAGCTTCTTTCTCTCTCACAATTACCTACACGACAGGGAACCAA } \\
\text { CTCTTGCAAACAAAAAATTTTTTTAGTTCTGCTGACTTGCGTATTAAT } \\
\text { TTATCTTTTCTGTGTTTTTTTCGTTGCAAAA }\end{array}$ & CT & G & 14,97 & 176 & $\begin{array}{l}\text { GGGGGCTTCAAATGA } \\
\text { TGTTT }\end{array}$ & 61,1 & $\begin{array}{l}\text { TAAAGGCCCAATGT } \\
\text { TTGTGG }\end{array}$ & 60,7 & 45 & 45 & \\
\hline 99 & BrPe0099 & $\begin{array}{l}\text { Maracuja_ } \\
\text { NoIndex_L } \\
\text { 003_R1_00 } \\
\text { 1_contig_3 } \\
\text { 3103 }\end{array}$ & 2 & 1293 & 1314 & 22 & 11 & 20 & $\begin{array}{l}\text { TAACCAGGAATTTCAAAATGGGCCGGCCCAGTTGGAGCCCATGTAG } \\
\text { TTTGTGGTTCCACTCTCATCTTGCTTGAAGTAGCCCAATTACGACTA } \\
\text { AGGTGGAAAAGCCCAATGGGCTTTTATTTCAGTACTTGCATGGATTC } \\
\text { TTCTTTAATCCTCTCTCTCTCTCTCTCTCTCTGATGATGTGTATATAA } \\
\text { GGAGAGCAAGTCCAGATGACATAAATTGCTGCTCAAAAATCAAGAA } \\
\text { TGAAAAGGAGGAGGAGGAGAAGTAAATGCAGTCAATCAACATCAA } \\
\text { CCCATGAAGGAAGAAGCATTACGTGTATTGCAGCAACTATATT }\end{array}$ & $\mathrm{CT}$ & G & 16,32 & 182 & $\begin{array}{l}\text { CCAGTTGGAGCCCAT } \\
\text { GTAGT }\end{array}$ & 60,0 & $\begin{array}{l}\text { TGTCATCTGGACTTG } \\
\text { СTCTCC }\end{array}$ & 60,4 & 55 & 52,4 & \\
\hline 100 & BrPe0100 & $\begin{array}{l}\text { Maracuja_ } \\
\text { NoIndex_L } \\
\text { 003_R1_00 } \\
\text { 1_contig_3 } \\
\text { 3911 }\end{array}$ & 2 & 158 & 181 & 24 & 12 & 22 & $\begin{array}{l}\text { CTATGAATAGATCTGACTTTCGGGTAAGAGTAACATATCTATATGCC } \\
\text { TTGATATAGCTTAGGTGTATGAGAATCTGAAAATTTTATTGAAATAA } \\
\text { ATTTTTTTTAGATAAGTATAAATATCTCTACGTGGTTCGATCAACCA } \\
\text { TCGAATTTAATATATATATATATATATATATATTAACAAGAATTGAT } \\
\text { GAAATTAAAGAAAAATTATACTACAAAGACGATATTTGTAAGAAAA } \\
\text { CAGATATAGATAGGGCTGCGCATCAGTCAGAACGGTAATTTCTGA } \\
\text { CCGATAATTTTTTTATTTTTTTCCTGATAGTTTTATTTTTGA }\end{array}$ & AT & $\mathrm{s}$ & 18,22 & 155 & $\begin{array}{l}\text { TTCGATCAACCATCG } \\
\text { AATTT }\end{array}$ & 058 & $\begin{array}{l}\text { TCGGTCAGAAAATT } \\
\text { ACCGTTC }\end{array}$ & 59,1 & 35 & 42,9 & \\
\hline
\end{tabular}


APÉNDICE

Marcadores microssatélites desenhados a partir do sequênciamento parcial e da montagem de novo do genoma de P. edulis

\begin{tabular}{|c|c|c|c|c|c|c|c|c|c|c|c|c|c|c|c|c|c|c|c|}
\hline $\mathbf{N}^{\circ}$ & Primer & Contig I & Motivo & Início & Fim & pb & $\begin{array}{c}\mathbf{N}^{\circ} \\
\text { Repet }\end{array}$ & Score & Sequência do contig & Unidade & G/S C & Cobertura & pb & Sequência Forward & $\begin{array}{l}\mathrm{T}^{\circ} \mathrm{C} \\
F w d \\
\end{array}$ & Sequência Reverse & $\begin{array}{r}\mathrm{T}^{\circ} \mathrm{C} \\
\operatorname{Rev} \\
\end{array}$ & $\begin{array}{c}\% \mathrm{GC} \\
F w d \\
\end{array}$ & $\begin{array}{cc}\% \mathrm{GC} & \mathrm{P} / \mathrm{M} \\
\operatorname{Rev} & \end{array}$ \\
\hline 101 & BrPe0101 & $\begin{array}{l}\text { Maracuja_ } \\
\text { NoIndex_L } \\
003 \text { R1_00 } \\
\text { 1_contig_3 } \\
4325\end{array}$ & 2 & 1225 & 1240 & 16 & 8 & 14 & $\begin{array}{l}\text { GACGCTTTTAAGGCAGCACTCTTGAAAGTGATAATCCTATGATAATG } \\
\text { ATTAGTACCAATCCTTATTATTAGCTTTCTCTTTTGCACGAGTGGGTT } \\
\text { TAATTTAAGTGATACTAAAAAGTGGTGATTTGATCTTCCATCCTTTC } \\
\text { CACAAACGCACACACACACACACATTACAGAAATTGGTGGCATGTT } \\
\text { TCATTGGGGTCCCTGTATAGATGAAAGGAGTCAAAAGACAGGCGTG } \\
\text { GATAAACATAACCACTCTCGATCTACCCCAAAAAGAAGATCTTATTT } \\
\text { GCTTTTTTTTCTATAAATAATGTGAAGAACAATTG }\end{array}$ & $\mathrm{CA}$ & $\mathrm{s}$ & 14,66 & 189 & $\begin{array}{l}\text { TCTTTTGCACGAGTG } \\
\text { GGTTT }\end{array}$ & 60,7 & $\begin{array}{l}\text { TTGGGGTAGATCGA } \\
\text { GAGTGG }\end{array}$ & 60,1 & 45 & 55 \\
\hline 102 & BrPe0102 & $\begin{array}{l}\text { Maracuja_ } \\
\text { NoIndex_L } \\
\text { 003_R1_00 } \\
\text { 1_contig_3 } \\
5410\end{array}$ & 2 & 1707 & 1724 & 18 & 9 & 16 & $\begin{array}{l}\text { ATTAAATTAATGAGGTTGGGCTGTAATAGAGATAGTGATTTTATGAT } \\
\text { CATATAGATTAAAGTAATAAATCCACTGACTACGTTTTCACATTCAA } \\
\text { ACCGTCGTGGTTTCACGACCCATAAATAGTTATTTTAAAACATTAAT } \\
\text { TTCTCCATCTATATATATATATATATAGGTATTACCAATGTCGGTGT } \\
\text { CATTTAGGACATTGGACGTTGTTATTTTATTACTGAGTTTACTTATT } \\
\text { TTGGAGGTTGGGGGGTTAGTCATTAAGGACATCTAACATGTAGATGT } \\
\text { GGTAATTTCTGAAATCAAAGTGAATCCTGAATAA }\end{array}$ & TA & $\mathrm{s}$ & 17,25 & 168 & $\begin{array}{l}\text { TTCACATTCAAACCG } \\
\text { TCGTG }\end{array}$ & 60,6 & $\begin{array}{l}\text { CCCCCAACCTCCAA } \\
\text { AATAAG }\end{array}$ & 60,5 & 45 & 50 \\
\hline 103 & BrPe0103 & $\begin{array}{l}\text { Maracuja_ } \\
\text { NoIndex_L } \\
\text { 003_R1_00 } \\
\text { 1_contig_3 } \\
6398\end{array}$ & 2 & 226 & 237 & 12 & 6 & 10 & $\begin{array}{l}\text { AAGGACTCATGCATGCAACACCATAACCATACTTAAACATGCATGG } \\
\text { ATAACACTTCTTCTTCATACCTCCTTCACAATTTCTTTCTTTAAACAC } \\
\text { TTAATCAAGCTTACTAGAAGGTTGAAGGTAGTCTGAAGCTAAAGAA } \\
\text { AAAGCTGAGTTCTCTCTCTCTCAATGCTCTCCCTTCTCTCTATCTCTT } \\
\text { TTCTCTCACTTCAAATGCAAAAATGAATTAAAAAATGAAAGAAAGG } \\
\text { CTTATAAAGGGTGGCTGATGTCTCTAGAGGTCGTGGGTGGCTGCCA } \\
\text { GGTATCTTGTTAAGTGGCAATGAGGTGTCAAA }\end{array}$ & $\mathrm{TC}$ & $\mathrm{s}$ & 40,34 & 201 & $\begin{array}{l}\text { GAAGGTTGAAGGTAG } \\
\text { TCTGAAGC }\end{array}$ & 58,6 & $\begin{array}{l}\text { TTGACACCTCATTG } \\
\text { CCACTT }\end{array}$ & 59,1 & 47,8 & 45 \\
\hline 104 & BrPe0104 & $\begin{array}{l}\text { Maracuja_ } \\
\text { NoIndex_L } \\
\text { 003_R1_00 } \\
\text { 1_contig_3 } \\
6910\end{array}$ & 2 & 2709 & 2720 & 12 & 6 & 10 & $\begin{array}{l}\text { CACCAGACTTTCTCACCATCAGATGGGAGCTTCACTTTGAGGAACTT } \\
\text { GGCAGCAAGGAAAATAGCACCTGCCGCAATATGATGGGGCTTAAAT } \\
\text { TGCAGGCAGAGCGATGTCCTCAGCCTGCAAAGCCGCTTTCTTGTATG } \\
\text { TAAAGAAAATAGAGAGAGAGAGGGGAAACCACAGAGCTGGAAACT } \\
\text { TAAAAAGTTTGAGGGAAACATAGTAAAATGCATACCCATCATTAAC } \\
\text { AAAATTCCATGCAACTTGAGCAAGGGCATTCTGTGCAACCTTAAATT } \\
\text { TCTTTATTGCTTCGACAAGTGGCTTGTAAGGGTG }\end{array}$ & AG & G & 16,69 & 219 & $\begin{array}{l}\text { GGCTTAAATTGCAGG } \\
\text { CAGAG }\end{array}$ & 60,0 & $\begin{array}{l}\text { AAGCCACTTGTCGA } \\
\text { AGCAAT }\end{array}$ & 59,9 & 50 & 45 \\
\hline 105 & BrPe0105 & $\begin{array}{l}\text { Maracuja_ } \\
\text { NoIndex_L } \\
\text { 003_R1_00 } \\
\text { 1_conti__3 } \\
7090\end{array}$ & 2 & 612 & 627 & 16 & 8 & 14 & $\begin{array}{l}\text { TTTCCCATGCATTTAACAAATCTAATCATGGCCTCGAACTGGTATCA } \\
\text { TAGCTAGTTCTAGGGTCAACTAATTTCCACATCACAACACTCACAAG } \\
\text { AAAATAGTAAAGCACATTAGAATTATGCTAAAAAATGGCTCAAAGC } \\
\text { ACTCGCAATGGTGTGTGTGTGTGTGTAAATATGACCTCAAGTAATCA } \\
\text { AAATCTGACTGTCAACATAACTTACTTATCATGGTACAAAAGGAAAA } \\
\text { ATCATGAAATTCATCAAATCAAAGTCCATACAATCTGGAAAAATAA } \\
\text { TCGTGACAAAGTGGGAGAATCATCAATATTAGCATA }\end{array}$ & GT & $\mathrm{s}$ & 60,6 & 214 & $\begin{array}{l}\text { CATGGCCTCGAACTG } \\
\text { GTATC }\end{array}$ & 60,5 & $\begin{array}{l}\text { TCATGATTTTTCTTT } \\
\text { TGTACCATGA }\end{array}$ & 59,8 & 55 & 28 \\
\hline
\end{tabular}


APÉNDICE

Marcadores microssatélites desenhados a partir do sequênciamento parcial e da montagem de novo do genoma de $P$. edulis

\begin{tabular}{|c|c|c|c|c|c|c|c|c|c|c|c|c|c|c|c|c|c|c|c|}
\hline $\mathbf{N}^{\circ}$ & Primer & Contig I & Motivo & Início & Fim & pb & $\begin{array}{c}\mathbf{N}^{\circ} \\
\text { Repet }\end{array}$ & Score & Sequência do contig & Unidade & G/S & Cobertura & pb & Sequência Forward & $\begin{array}{l}\mathrm{T}^{\circ} \mathrm{C} \\
F w d \\
\end{array}$ & Sequência Reverse & $\begin{array}{r}\mathrm{T}^{\circ} \mathrm{C} \\
\operatorname{Rev} \\
\end{array}$ & $\begin{array}{c}\% \mathrm{GC} \\
F w d \\
\end{array}$ & $\begin{array}{c}\% \mathrm{GC} \\
\operatorname{Rev}\end{array} \quad \mathrm{P} / \mathrm{M}$ \\
\hline 106 & BrPe0106 & $\begin{array}{l}\text { Maracuja_ } \\
\text { NoIndex_L } \\
\text { 003_R1_00 } \\
\text { 1_contig_3 } \\
8277\end{array}$ & 2 & 1501 & 1516 & 16 & 8 & 14 & $\begin{array}{l}\text { CAAAATTTCTCTGACCATTTGTCTCCTATTTGTAAAACAAAGATGAA } \\
\text { CTTGATCTCCCGTTTGCGACTGTTACTTCTTTCTCTGTTACCTGTATC } \\
\text { CCTATCCATTTTCTACCAGAGATATATTTTAGGCTACTTGGGTTTCCC } \\
\text { TCTCTGGATATATATATATATATTTGCACTTAGACACTCAACTTACTT } \\
\text { TCAAGTGGAAAAGGCGTTTCGTGTTGCTGTTTTGTTGTAGCGGTTTG } \\
\text { TTATATTGACTTTTTGTTGCAATTATACTCTTTCAGGAAGAGATTCT } \\
\text { GGCCTGAGCAAAGGACTATCTAGGTATAGT }\end{array}$ & $\overline{\mathrm{AT}}$ & $\mathrm{s}$ & 15,87 & 179 & $\begin{array}{l}\text { CCCGTTTGCGACTGTT } \\
\text { ACTT }\end{array}$ & 60,2 & $\begin{array}{l}\text { CCGCTACAACAAAA } \\
\text { CAGCAA }\end{array}$ & 59,9 & 50 & 45 \\
\hline 107 & BrPe0107 & $\begin{array}{l}\text { Maracuja_ } \\
\text { NoIndex_L } \\
\text { 003_R1_00 } \\
\text { 1_contig_3 } \\
9890\end{array}$ & 2 & 860 & 873 & 14 & 7 & 12 & $\begin{array}{l}\text { TTCTTCTACCGTTTTCCAGATCAATGTATTTACCTCCTTTTCAAGACT } \\
\text { CCATATCTGCTTATGGTTCTCGCTGGGGTAAAGCCTGCTCCGGCATT } \\
\text { AATAAACAACCGAAGGATTATTACATTCTGAATTCCAAAGAGTCAG } \\
\text { AGCAATTACATATATATATATATTCTGCTATAAACACATACCTAAAA } \\
\text { CTCATGACATCGAAAAGGACACTGTGCTTGGTGAGGAGTTTTTGAA } \\
\text { GCTTCTTGATTTTGGAGAAAATGTGTTTGCCGTTTAAATAAGAGCTC } \\
\text { CCAAAACAAGTTCTCGCAATGACCTCTCCTGAA }\end{array}$ & АТ & $\mathrm{s}$ & 12,1 & 208 & $\begin{array}{l}\text { TATGGTTCTCGCTGG } \\
\text { GGTAA }\end{array}$ & 60,5 & $\begin{array}{l}\text { ACGGCAAACACATT } \\
\text { TTCTCC }\end{array}$ & 60,0 & 50 & 45 \\
\hline 108 & BrPe0108 & $\begin{array}{l}\text { Maracuja_ } \\
\text { NoIndex_L } \\
\text { 003_R1_00 } \\
\text { 1_contig_4 } \\
0474\end{array}$ & 2 & 2522 & 2533 & 12 & 6 & 10 & $\begin{array}{l}\text { AGTTTCTTGGGTATAAGTTTAGATCTGCTCAACAATGCTAAATAAGT } \\
\text { TTATAGATCTGCAAGAATTAGGCCATTGGAACAGATGAGAAAGACT } \\
\text { AGCAAATACAAGGTGAAAATACGGTACTGCTAGTTACCACTGTGAC } \\
\text { ATTCGCTCAGGATATATATATATCCACATATTGGTGGTCCTACTTTA } \\
\text { GTGGGTGTGCTTTATAAATGTAGTTCACTGAACAGGATGACATATC } \\
\text { AAACCCCTCCCAGAAGAAAGCAATTTTGCAATTAGCAAGTACTCAC } \\
\text { AACCAACAAAATCTTTTAAGTGAAAGTTAGAAA }\end{array}$ & АТ & $\mathrm{s}$ & 17,99 & 190 & $\begin{array}{l}\text { GCAAGAATTAGGCCA } \\
\text { TTGGA }\end{array}$ & 60,0 & $\begin{array}{l}\text { TCTGGGAGGGGTTT } \\
\text { GATATG }\end{array}$ & 59,7 & 45 & 50 \\
\hline 109 & BrPe0109 & $\begin{array}{l}\text { Maracuja_ } \\
\text { NoIndex_L } \\
\text { 003_R1_00 } \\
\text { 1_contig_4 } \\
0585\end{array}$ & 2 & 5769 & 5784 & 16 & 8 & 14 & $\begin{array}{l}\text { ACAAGTTTTTCACACTGGATACACTAAGGGACAGCAAAGGTGAAGA } \\
\text { TGCAAAAAATAAGGAAATCCACATCATACTGTCCAGAAACTTGAAT } \\
\text { ATAACAAAAAACAAATGAATAAAAGTAAATGGAGATGACAAGCAT } \\
\text { AGTTGGACCAACAGTGTGTGTGTGTGTGTAAAAGCTTCAAATGACA } \\
\text { AAGGTAAGTACAACCTTAGTCCAATAATCAAAAAGTAAAAAATTTG } \\
\text { AAGATGAAGCATACCATTGATCTGAGAGAGTTGGCTTATATAAGC } \\
\text { ATAGTAATGACCGCCATGCACACCTCCACTGTGAACTAAGA }\end{array}$ & GT & $\mathrm{s}$ & 18,87 & 235 & $\begin{array}{l}\text { CAGCAAAGGTGAAGA } \\
\text { TGCAA }\end{array}$ & 60,0 & $\begin{array}{l}\text { AGGCCAACTCTCTC } \\
\text { AGATCAA }\end{array}$ & 59 & 45 & 47,6 \\
\hline 110 & BrPe0110 & $\begin{array}{l}\text { Maracuja_ } \\
\text { NoIndex_L } \\
\text { 003_R1_00 } \\
\text { 1_contig_4 } \\
1713\end{array}$ & 2 & 348 & 363 & 16 & 8 & 14 & $\begin{array}{l}\text { CTGGTACTTGATGAAGGTTGTGTGGGTGAAACTGGCTACGAATCCC } \\
\text { AATTCATACGCTTGTGTTATTGGTCTTGCTTGGGCTTTGTAGCCAGC } \\
\text { AGGTAATTTTATTACAACATTGGCGGATTTAATCATTACTTAATTAC } \\
\text { TACACGTCAATATATATATATATATGTTCTTATTGTCTTATCAATTGT } \\
\text { TAGATGGCATTTTGGGATGCCAAGCATCATGGAGGGATCCGTATCG } \\
\text { ATTATGGCAAAAGCTGGCACGGGGACTGCAATGTTCAGTATGGGTG } \\
\text { AGATTATGATTCCTATATAATTCGCCATTTATAAA }\end{array}$ & АТ & $\mathrm{s}$ & 15,46 & 185 & $\begin{array}{l}\text { CTTGCTTGGGCTTTTG } \\
\text { TAGC }\end{array}$ & 60,0 & $\begin{array}{l}\text { GTGCCAGCTTTTGC } \\
\text { CATAAT }\end{array}$ & 60,1 & 50 & 45 \\
\hline
\end{tabular}


APÉNDICE

Marcadores microssatélites desenhados a partir do sequênciamento parcial e da montagem de novo do genoma de P. edulis

\begin{tabular}{|c|c|c|c|c|c|c|c|c|c|c|c|c|c|c|c|c|c|c|c|}
\hline $\mathbf{N}^{\circ}$ & Primer & Contig I & Motivo & Início & Fim & pb & $\begin{array}{c}\mathbf{N}^{\circ} \\
\text { Repet }\end{array}$ & Score & Sequência do contig & Unidade & G/S & Cobertura & pb & Sequência Forward & $\begin{array}{l}\mathrm{T}^{\circ} \mathrm{C} \\
F w d \\
F w\end{array}$ & Sequência Reverse & $\begin{array}{r}\mathrm{T}^{\circ} \mathrm{C} \\
\operatorname{Rev}\end{array}$ & $\begin{array}{c}\% \mathrm{GC} \\
F w d\end{array}$ & $\begin{array}{c}\% \mathrm{GC} \\
\operatorname{Rev}\end{array} \quad \mathrm{P} / \mathrm{M}$ \\
\hline 111 & BrPe0111 & $\begin{array}{l}\text { Maracuja_ } \\
\text { NoIndex_L } \\
\text { 003_R1_00 } \\
\text { 1_contig_4 } \\
\text { 2689 }\end{array}$ & 2 & 365 & 380 & 16 & 8 & 14 & $\begin{array}{l}\text { CTTAGCGGAAACCAATTTCTGGGAATTGACTATTATTACATCTCCCA } \\
\text { TTAAGCTTTAATTTGCCAACTATTACCAGGAAATCCACAAAACCATG } \\
\text { CCTCAAATGGTAAGTCAAATATTGCAAATATTTTCTGAAAATAGAAT } \\
\text { ATCAAGCACATATATATATATATATGTACTAATGAATCGTCAAACTG } \\
\text { AAGAGGCTATTGAACTATGCAAGTGAAGAAGGTGTCTCCACCTCTT } \\
\text { CGGTCCATTCAGAGTTGGGTTCACTCCAGGACCTGGGTCGCACCCCA } \\
\text { ATCTTAAAGTAAAACACCATCTCCAACGCTTCAAA }\end{array}$ & $\overline{\mathrm{AT}}$ & $\mathrm{s}$ & 14,33 & 190 & $\begin{array}{l}\text { GGAAATCCACAAAAC } \\
\text { CATGC }\end{array}$ & 60,2 & $\begin{array}{l}\text { TCCTGGAGTGAACC } \\
\text { CAACTC }\end{array}$ & 60,1 & 45 & 55 \\
\hline 112 & BrPe0112 & $\begin{array}{l}\text { Maracuja_ } \\
\text { NoIndex_L } \\
003 \text { R1_00 } \\
\text { 1_contig_4 } \\
3125\end{array}$ & 2 & 2697 & 2712 & 22 & 11 & 20 & $\begin{array}{l}\text { GGTTTGATCGATCTATATGCTCAAGGAATCAACAGATTTTACAGATT } \\
\text { ATAATAAGATTTATAAGCTCCACAAATCCAACCAGATCATGTCCTT } \\
\text { AAAAAGATGAGGAAAAAAGAGAGAGTAAAAGTGAGTGGCACAGAT } \\
\text { TATATATATTCATATATATATATATATCCGTCACGATATCGGTGAGA } \\
\text { TTAATCTTACGATCGGTTGGGATAGTCACCACCCTTAAAATATATAT } \\
\text { ATATATATATATATCAGCCAGTCGATTTACAAGTTGGAAGGGAATT } \\
\text { TAATCAACTTTTTTTTTATTTTTCACTGCCTAAAG }\end{array}$ & АТ & $\mathrm{s}$ & 17,42 & 100 & $\begin{array}{l}\text { AATCTTACGATCGGT } \\
\text { TGGGATA }\end{array}$ & 59,7 & $\begin{array}{l}\text { GTTGATTAAAATTC } \\
\text { CCTTCCAA }\end{array}$ & 57,2 & 40,9 & 31,8 \\
\hline 113 & BrPe0113 & $\begin{array}{l}\text { Maracuja_ } \\
\text { NoIndex_L } \\
\text { 003_R1_00 } \\
\text { 1_contig_4 } \\
\text { 3818 }\end{array}$ & 2 & 7866 & 7883 & 18 & 9 & 16 & $\begin{array}{l}\text { AGCCATACACAGTCCTTTTCAGCCTGCCATGCAATTTAAAAAAAAAA } \\
\text { ACAAGGTGGACCAAAATCAGTAGCAAAAATGGGGATTCTGAGTTT } \\
\text { CGATGTTTGATTGAAAGATAGCCTCTGGAAACTTGTTAATGGTTCAA } \\
\text { ATTAATTTCTGATATATATATATATATATGCCAGTTGTGTACAAAGT } \\
\text { GTTAACATTAGGATACCCTCCAATGACATTAATATACTGGGTTGTAG } \\
\text { ATGGTTATGCATGCTTTCGTAACCTTACAGTGCAAAGTGTTTCTGG } \\
\text { ACTTTCTGCTGTGAAACTATTAGTTGCAGTGCAAAGAG }\end{array}$ & АT & $\mathrm{s}$ & 16,33 & 183 & $\begin{array}{l}\text { GCAAAAATGGGGATT } \\
\text { CTGAG }\end{array}$ & 59,5 & $\begin{array}{l}\text { CGAAAGCATGCATA } \\
\text { ACCATC }\end{array}$ & 59,1 & 45 & 45 \\
\hline 114 & BrPe0114 & $\begin{array}{l}\text { Maracuja_ } \\
\text { NoIndex_L } \\
003 \text { R1_00 } \\
\text { 1_contig_4 } \\
4175\end{array}$ & 2 & 334 & 345 & 12 & 6 & 10 & $\begin{array}{l}\text { GGCACGGTGGCCGGTGGTGGAGAGATGCTCAAATGCTCCATGACAT } \\
\text { TGAAAGGCTGAGCTGCTTCTCCCATTTTGATGAGGTGGTCCAAGTCC } \\
\text { TCCTGTATGGTATCTGGTGGCAACTCTGATGTAGAAGTGCAATTCAT } \\
\text { GGCCGGGTTTTATATATATATAGCCGTTGCTAATTTCTTTATTAATTA } \\
\text { CTATTCTACCATACAAGTAGTAAATGCGAATGAATCTTCTATAGAA } \\
\text { AGGAAAAATATATTAAAAAATTTAGACAACAATGTCATTTCTAATC } \\
\text { AGACTCTTTATTCTTTACCAAAAAATTTTC }\end{array}$ & TA & $\mathrm{s}$ & 12,7 & 165 & $\begin{array}{l}\text { AGCTGCTTCTCCCATT } \\
\text { TTGA }\end{array}$ & 60,0 & $\begin{array}{l}\text { CATTCGCATTTTACT } \\
\text { ACTTGTATGG }\end{array}$ & 59,1 & 45 & 36 \\
\hline 115 & BrPe0115 & $\begin{array}{l}\text { Maracuja_ } \\
\text { NoIndex_L } \\
\text { 003_R1_00 } \\
\text { 1_contig_4 } \\
4276\end{array}$ & 2 & 4863 & 4878 & 16 & 8 & 14 & $\begin{array}{l}\text { ATAAAAAATAAAAACAAATCCAATAGGTGTATGAAATTTCAATATG } \\
\text { CTCACTTTTTTAATGAAACATGGGTTATTTTATTAAAAATAAAGCA } \\
\text { AATTTATCCACTCATTAAGCGATTGACCGGAAGCACATAGAAAGAC } \\
\text { AAAAGCATATGTATATATATATATATAATTTTGATAAAGTTTTAGTA } \\
\text { ATTATATATCGACATTGTGATAAATGTATAATTTGTTGGAATGATGG } \\
\text { GAATTTCAGATTAGACTAAGGTCCAATTTGGTTTAGAGAG }\end{array}$ & TA & G & 16,85 & 157 & $\begin{array}{l}\text { TGACCGGAAGCACAT } \\
\text { AGAAA }\end{array}$ & 59,3 & $\begin{array}{l}\text { TCTCTAAAAACCAAA } \\
\text { TTGGACCTT }\end{array}$ & 58,3 & 45 & 34,8 \\
\hline
\end{tabular}


APÉNDICE

Marcadores microssatélites desenhados a partir do sequênciamento parcial e da montagem de novo do genoma de P. edulis

\begin{tabular}{|c|c|c|c|c|c|c|c|c|c|c|c|c|c|c|c|c|c|c|c|}
\hline $\mathbf{N}^{\circ}$ & Primer & Contig $\mathrm{I}$ & Motivo & Início & Fim & pb & $\begin{array}{c}\mathbf{N}^{\circ} \\
\text { Repet }\end{array}$ & Score & Sequência do contig & Unidade & G/S & Cobertura & pb & Sequência Forward & $\begin{array}{l}\mathrm{T}^{\circ} \mathrm{C} \\
F w d \\
\end{array}$ & Sequência Reverse & $\begin{array}{l}\mathrm{T}^{\circ} \mathrm{C} \\
\operatorname{Rev} \\
\end{array}$ & $\begin{array}{r}\% \mathrm{GC} \\
F w d \\
\end{array}$ & $\begin{array}{cc}\% \mathrm{GC} & \mathrm{P} / \mathrm{M} \\
\operatorname{Rev} & \end{array}$ \\
\hline 116 & BrPe0116 & $\begin{array}{l}\text { Maracuja_ } \\
\text { NoIndex_L } \\
\text { 003_R1_00 } \\
\text { 1_contig_4 } \\
4519\end{array}$ & 2 & 2456 & 2467 & 12 & 6 & 10 & $\begin{array}{l}\text { AAGAAAGAAAGAGTCCACACATGACGTGGATAATGTTATATATGTA } \\
\text { ATAGCGCATGGGATTCATAATGGATATACATGCAAATCAAGAGATC } \\
\text { ATATAAGCTCAATGGAATGCTCGGTACACATTTCCAAAGAATAAGC } \\
\text { AATAAATATATGGAGAGAGAGAGACCCTAGTGCCACAACTGGAATG } \\
\text { TGGCAGAATAAAAGAAACATCTTACCATGTGTTTTAATTTCTGATAG } \\
\text { TAAATTGGACCCATAAAAATATACGCCTGCAGTGGACAACCTGTTA } \\
\text { TACCTGGACAAACATAAGAGATAGTAAGGTGATAG }\end{array}$ & GA & $\overline{\mathrm{s}}$ & 18,46 & 171 & $\begin{array}{l}\text { TCAATGGAATGCTCG } \\
\text { GTACA }\end{array}$ & 60,1 & $\begin{array}{l}\text { GTTGTCCACTGCAG } \\
\text { GCGTAT }\end{array}$ & 61,1 & 45 & 55 \\
\hline 117 & BrPe0117 & $\begin{array}{l}\text { Maracuja_ } \\
\text { NoIndex_L } \\
\text { 003_R1_00 } \\
\text { 1_contig_4 } \\
5267\end{array}$ & 2 & 3113 & 3124 & 12 & 6 & 10 & $\begin{array}{l}\text { GGTGGAGAAGGAAACTTGAAATCATCCAACCTGTAGAAATCCACTC } \\
\text { TTTTGCAGCTGACTGCAATACAGATGACCTTCTCTGTGTTCTGATAA } \\
\text { AGGTGCGCGTTTAAGACTCATTCTGCCAGGTTTTATGATATATGCAC } \\
\text { TCCTGGTTGCATATATATATATTTATATCCATTAGGATATATTTGAT } \\
\text { ATCAGTTTTTAGAATATCCCGTCTCATAATTGATTTTAAACTCCATGC } \\
\text { AGAACATATCTCCTGCACATATGCCTGATATTGTGATATACATAGAT } \\
\text { GCTATATCTGTTGTTTTTGAGGAAGCTTC }\end{array}$ & АT & G & 17,33 & 170 & $\begin{array}{l}\text { GGTGCGCGTTTAAGA } \\
\text { CTCAT }\end{array}$ & 60,3 & $\begin{array}{l}\text { TCAGGCATATGTGC } \\
\text { AGGAGA }\end{array}$ & 60,4 & 50 & 50 \\
\hline 118 & BrPe0118 & $\begin{array}{l}\text { Maracuja_ } \\
\text { NoIndex_L } \\
\text { 003_R1_00 } \\
\text { 1_contig_4 } \\
\text { 7034 }\end{array}$ & 2 & 3748 & 3759 & 12 & 6 & 10 & $\begin{array}{l}\text { ACATGTTATTCATATATTGCACACTAATCTATGGATTTTCCTTACGTT } \\
\text { GATGTTTCCAGTGATTTGTTATATGACTTTCTCACCATGCTGAGCAA } \\
\text { GCAGTTGACAGAGATTGATGTTGCTATTATCTTGACTGTTCTACAAT } \\
\text { GTAAGTGTACACACACACACGCACTCACTATCCATAAGGTGGCAAA } \\
\text { GGATTGCTTTTTATACTTTTGAATATATTTTATAATATAGCCGTCAAT } \\
\text { TAGATGACATCAATGACCATTCTCCATCTCATTCTACAGAAAATATG } \\
\text { ATATTGGGATGTCTGGGACCAATTTATGT }\end{array}$ & $\mathrm{AC}$ & $\mathrm{s}$ & 17,03 & 218 & $\begin{array}{l}\text { GCTGAGCAAGCAGTT } \\
\text { GACAG }\end{array}$ & 59,9 & $\begin{array}{l}\text { TGGTCCCAGACATC } \\
\text { CCAATA }\end{array}$ & 61,1 & 55 & 50 \\
\hline 119 & BrPe0119 & $\begin{array}{l}\text { Maracuja_ } \\
\text { NoIndex_L } \\
\text { 003_R1_00 } \\
\text { 1_contig_4 } \\
7902\end{array}$ & 2 & 3111 & 3122 & 12 & 6 & 10 & $\begin{array}{l}\text { CTACAAAACCTGGTGTCCCACCAGGCTAGCCCCATGTGAAAGAAAG } \\
\text { CTACACCTGCACTGCCACTTTTTTGCCACAAGCATTGTTACAAGATC } \\
\text { ATGTGAATCATAATCTACCAATCCGATACATGTCTCTTCCCTTTCTTT } \\
\text { TTCGATTCAATATATATATATGTGTCTTTGTCAGGTTGGAAAACCGA } \\
\text { AGCACCGACGAATTTTAGCAGTGTTCAACAAAAAGTACCAAGAGCA } \\
\text { AGGGGTCAGACTTCCACGCCAATTACTGACAACAGCGTATATATGA } \\
\text { ACTGCACCATGCTGTATAGATTCTGTGCAGGA }\end{array}$ & АТ & $\mathrm{s}$ & 14,99 & 241 & $\begin{array}{l}\text { GCTAGCCCCATGTGA } \\
\text { AAGAA }\end{array}$ & 60,2 & $\begin{array}{l}\text { TGTCAGTAATTGGC } \\
\text { GTGGAA }\end{array}$ & 60,1 & 50 & 45 \\
\hline 120 & BrPe0120 & $\begin{array}{l}\text { Maracuja_ } \\
\text { NoIndex_L } \\
\text { 003_R1_00 } \\
\text { 1_contig_4 } \\
8684\end{array}$ & 2 & 379 & 390 & 12 & 6 & 10 & $\begin{array}{l}\text { CAATGGCATGTGTGGACAAGGCATTGGTTGTCGACGTCCAAAGACT } \\
\text { TGCATTGCATACCATTGCATACTCTATTCATGACATGGCACTACACA } \\
\text { CGAGTCACCCAGTTCCAACCATGGACTCTATATTGTTGATGCTTCGT } \\
\text { GATTGTATATTGTGTGTGTGTGGTGAATATGAGAATACTAGTACAGG } \\
\text { CCCGAGATGAGTGTCAGGACGTACGTGTGAAAATATGAGAAATATC } \\
\text { AGGATGGGTCCGAGGTGA }\end{array}$ & TG & $\mathrm{s}$ & 98,66 & 170 & $\begin{array}{l}\text { TGACATGGCACTACA } \\
\text { CACGA }\end{array}$ & 59,7 & $\begin{array}{l}\text { TCGGACCCATCCTG } \\
\text { ATATTT }\end{array}$ & 59,2 & 50 & 45 \\
\hline
\end{tabular}


APÉNDICE

Marcadores microssatélites desenhados a partir do sequênciamento parcial e da montagem de novo do genoma de $P$. edulis

\begin{tabular}{|c|c|c|c|c|c|c|c|c|c|c|c|c|c|c|c|c|c|c|c|}
\hline $\mathbf{N}^{\mathbf{o}}$ & Primer & Contig $\mathrm{I}$ & Motivo & Início & Fim & pb & $\begin{array}{c}\mathbf{N}^{\mathbf{o}} \\
\text { Repet }\end{array}$ & Score & Sequência do contig & Unidade & G/S & Cobertura & pb & Sequência Forward & $\begin{array}{l}\mathrm{T}^{\circ} \mathrm{C} \\
F w d\end{array}$ & Sequência Reverse & $\begin{array}{r}\mathrm{T}^{\circ} \mathrm{C} \\
\operatorname{Rev}\end{array}$ & $\begin{array}{c}\% \mathrm{GC} \\
F w d\end{array}$ & $\begin{array}{c}\% \mathrm{GC} \\
\operatorname{Rev}\end{array} \quad \mathrm{P} / \mathbf{M}$ \\
\hline 121 & BrPe0121 & $\begin{array}{l}\text { Maracuja_ } \\
\text { NoIndex_L } \\
\text { 003_R1_00 } \\
\text { 1_contig_5 } \\
1052\end{array}$ & 2 & 165 & 192 & 28 & 14 & 26 & $\begin{array}{l}\text { GCAGAAGCTGAATATCAGACCAACCAACAAACCAGGCACCAGTAC } \\
\text { AAGTAATGAGAGAGAGAAGACAGAAAAGCCATGGATTGGAAGAA } \\
\text { GCCAAGACACCTGTACTTATGAGGTTATGAGACAGACAAAGTCACA } \\
\text { GGTGGCCGTTCATGATATATATATATATATATATATATATATTTTTCC } \\
\text { ATACAACCTGAAAATTTATTATACTATTTTAAATTAATTCATCTCTT } \\
\text { TTTAATATAATAAAAGAAGCCTTTGATATTTTGGTACCTGAAATTT } \\
\text { ATATTAAAAAAAGAGGGGATAAATAAAAAGCGGGTATTGATCATT }\end{array}$ & $\overline{\mathrm{AT}}$ & $\mathrm{s}$ & 28,68 & 207 & $\begin{array}{l}\text { ACAGAAAAGCCCATG } \\
\text { GATTG }\end{array}$ & 59,9 & $\begin{array}{l}\text { GGTACCAAAAATAT } \\
\text { CAAAGGCTTC }\end{array}$ & 59,3 & 45 & 37,5 \\
\hline 122 & BrPe0122 & $\begin{array}{l}\text { Maracuja_ } \\
\text { NoIndex_L } \\
\text { 003_R1_00 } \\
\text { 1_contig_5 } \\
\text { 2441 }\end{array}$ & 2 & 392 & 405 & 14 & 7 & 12 & $\begin{array}{l}\text { AACCGGGGATGATTTTACAAAACCACTTCCAGATGTTTCACCAATTCG } \\
\text { CCTTTCAAACAAAAGGGTCGTCATCCTAAGAAACACTATTCCTTTAC } \\
\text { AATTTGTGAATAAAAATTTGTCTGGCTTGCCTGGACATGCCTTGGCT } \\
\text { TAAACTCTCCTCTCTCTCTCTCTGTCGGCCATATAGGTTTTTGTCCCT } \\
\text { TGTGAGCTGCAGAGGGAGGTCGCAATCTTGATGTTCCTCTTCCCTCT } \\
\text { CTGCTTTTTAGTGGATTGGCTGTTCCGATAAACTCTTGTCTTGAGCCT } \\
\text { ACCACATTAATGTCACTGACCCATAAATTC }\end{array}$ & СT & G & 17,05 & 235 & $\begin{array}{l}\text { GTTTCACCAATTCGC } \\
\text { CTTTC }\end{array}$ & 59,6 & $\begin{array}{l}\text { TTTATCGGAACAGC } \\
\text { CAATCC }\end{array}$ & 59,9 & 45 & 45 \\
\hline 123 & BrPe0123 & $\begin{array}{l}\text { Maracuja_ } \\
\text { NoIndex_L } \\
\text { 003_R1_00 } \\
\text { 1_contig_5 } \\
\text { 3461 }\end{array}$ & 2 & 2500 & 2511 & 12 & 6 & 10 & $\begin{array}{l}\text { GTGATTCTGGTTACTTGGTCAGGAGTATAAATCGTGGATATATTTTC } \\
\text { TTCTGACACTTCACAGATACAGTTGTATAGTCCCAGAATTCATTTAC } \\
\text { GCAAAATTGGCTGGATTGTATTGTGCTTGCAATTCCCTTAAAATGTT } \\
\text { TTGCTTATGATATATATATATTTCGAATTTGCTAATCCCTTTCCTATT } \\
\text { CTCCTCTAGGAACATGAGAGCTCCTCTGATGAATTTTTGAATCTTTC } \\
\text { TGATACTTGGGAATTCAAGAAAATGAGATAATGAATGCGCAGGAT } \\
\text { AAACTAAGGTCAATACGGGCAAAATTAGCA }\end{array}$ & AT & $\mathrm{s}$ & 17,7 & 180 & $\begin{array}{l}\text { TTGGCTGGATTGTATT } \\
\text { GTGC }\end{array}$ & 59,5 & $\begin{array}{l}\text { CCTGCGCATTCATT } \\
\text { ATCTCA }\end{array}$ & 59,8 & 45 & 45 \\
\hline 124 & BrPe0124 & $\begin{array}{l}\text { Maracuja_ } \\
\text { NoIndex_L } \\
003 \text { 1_1_00 } \\
\text { 1_contig_5 } \\
\text { 3714 }\end{array}$ & 2 & 2725 & 2742 & 18 & 9 & 16 & $\begin{array}{l}\text { AATAATCAATTACTATAAAAGTTGGAAAAAAAGTATAGATTCAGAG } \\
\text { ATCGAATAATAAATGAAGCAAAAAGAATGAGATGAGTTGTTGGTGG } \\
\text { TTAGATCAAGGAAAGGAAATGGAGATCAGCTACGAAGGAGACCTC } \\
\text { GAATCTGAGAGATAGAGAGAGAGAGAGAGAGCACGGTTGGAAGTG } \\
\text { ATGCCAAGATCCGATTTGAATAATTTTGGTCAGGTTTTGTTTTGGA } \\
\text { GGGGAAGGCAAGAATGTTACGGATACCGTTCGATATACAATATAT } \\
\text { TGTGCATGTATTATATGGTGCAACTGTT }\end{array}$ & AG & $\mathrm{s}$ & 18,61 & 152 & $\begin{array}{l}\text { TGGAGATCAGCTACG } \\
\text { AAGGAG }\end{array}$ & 59,6 & $\begin{array}{l}\text { TCGAACGGTATCCG } \\
\text { TAACATT }\end{array}$ & 59,4 & 52,4 & 42,9 \\
\hline 125 & BrPe0125 & $\begin{array}{l}\text { Maracuja_ } \\
\text { NoIndex_L } \\
\text { 003_R1_00 } \\
\text { 1_contig_5 } \\
3838\end{array}$ & 2 & 520 & 531 & 12 & 6 & 10 & $\begin{array}{l}\text { TGAGAAGTTTAGACGAGTACTGACAGAACAACCAAGCTGCATTGAA } \\
\text { AAACATGCAAACCATTTGGCGTAAGTATGCTATGGAGCTAGGAACT } \\
\text { TGTTTAGAATCCATCGAAGGCCTGCTCTACGAGGCGTTGTTTCAAG } \\
\text { TTCTCACCAGGTATATATATATAACATAGTTCCCTAGAAACTGAGC } \\
\text { TTGAATTCACAGGTAGTACTGACAAGTAAAACTAGCAATTGCAGGT } \\
\text { ATGCTCCTCTTTACTTTCTGTTTACTGTTGTCTACTTGTGTTTCGTAA } \\
\text { GATCCAACAAAAGGTTATTCAATGGTTTTGCA }\end{array}$ & $\mathrm{TA}$ & $\mathrm{s}$ & 16,9 & 192 & $\begin{array}{l}\text { GCAAACCATTTGGCG } \\
\text { TAAGT }\end{array}$ & 60,0 & $\begin{array}{l}\text { AAAGAGGAGCATAC } \\
\text { CTGCAA }\end{array}$ & 57,6 & 45 & 45 \\
\hline
\end{tabular}


APÉNDICE

Marcadores microssatélites desenhados a partir do sequênciamento parcial e da montagem de novo do genoma de $P$. edulis

\begin{tabular}{|c|c|c|c|c|c|c|c|c|c|c|c|c|c|c|c|c|c|c|c|}
\hline $\mathbf{N}^{\circ}$ & Primer & Contig I & Motivo & Início & Fim & pb & $\begin{array}{c}\mathbf{N}^{\mathbf{o}} \\
\text { Repet }\end{array}$ & Score & Sequência do contig & Unidade & G/S & Cobertura & pb & Sequência Forward & $\begin{array}{l}\mathrm{T}^{\circ} \mathrm{C} \\
F w d \\
\end{array}$ & Sequência Reverse & $\begin{array}{r}\mathrm{T}^{\circ} \mathrm{C} \\
\operatorname{Rev} \\
\end{array}$ & $\begin{array}{c}\% \mathrm{GC} \\
F w d \\
\end{array}$ & $\begin{array}{cc}\% \mathrm{GC} & \mathrm{P} / \mathrm{M} \\
\operatorname{Rev} & \end{array}$ \\
\hline 126 & BrPe0126 & $\begin{array}{l}\text { Maracuja_ } \\
\text { NoIndex_L } \\
\text { 003_R1_00 } \\
\text { 1_contig_5 } \\
4356\end{array}$ & 2 & 995 & 1006 & 12 & 6 & 10 & $\begin{array}{l}\text { CGTGGGTCCCATTAGCACGTCAGGATTAGATCTGTATTGGATTCTTC } \\
\text { CTTTTTCCGCTCGCACCAAATGGCGGCTTGTTAATTTACTTATATTTT } \\
\text { ATAAAGGTTTTGACTTCTTTTCCACAAAATCAAGATTGATTAGATGG } \\
\text { TATGTGAAATATATATATATTATTGTTTTGAATCATTAATAAAACTA } \\
\text { TTATTAATAATGGAATTATATCTACATGAATTATATGACAGAAGAG } \\
\text { TTCATACAATGAGTTAATTAATAATTTATTTGAAATTAATCAAAGAC } \\
\text { ATGTTTCCAAAATTCAATAAATTAAATTG }\end{array}$ & $\mathrm{AT}$ & $\mathrm{s}$ & 17,62 & 235 & $\begin{array}{l}\text { AAATGGCGGCTTGTT } \\
\text { AATTT }\end{array}$ & 58,6 & $\begin{array}{l}\text { TGAATTTTGGAAAC } \\
\text { ATGTCTTTG }\end{array}$ & 59 & 34 & 30,4 \\
\hline 127 & BrPe0127 & $\begin{array}{l}\text { Maracuja_ } \\
\text { NoIndex_L } \\
003 \text { R1_00 } \\
\text { 1_contig_5 } \\
4506\end{array}$ & 2 & 619 & 636 & 18 & 9 & 16 & $\begin{array}{l}\text { TCTGTGTCCTATCACGGTGAGTGATGCATATAACTAATGTGCCCCTC } \\
\text { TATCGGGCTCCGTTCTGTATAATCTATGTACGTCATATGTCGTTATA } \\
\text { ATGGTGCAATTGAGAAATTCTTTTCAAACTTAGCTTCAAATCAGATC } \\
\text { CTTTGTACCTCTCTCTCTCTCTCTCTACCATTTTCTTTATATACAAACT } \\
\text { GAACTTGTGGATTTTACATGAAATAATTAGATAGCCTTATCTGTTGT } \\
\text { TTACCTGAAGGCTAAAACATGAAGCAGTAACAATAATTGTTGCAAA } \\
\text { TTTTTGCTGAAGCAGTAACATTAATGCAGTATTC }\end{array}$ & СТ & $\mathrm{s}$ & 15,01 & 244 & $\begin{array}{l}\text { CGGGCTCCGTTTCTGT } \\
\text { ATAA }\end{array}$ & 60,1 & $\begin{array}{l}\text { TCAGCAAAAATTTG } \\
\text { CAACAA }\end{array}$ & 58 & 50 & 30 \\
\hline 128 & BrPe0128 & $\begin{array}{l}\text { Maracuja_ } \\
\text { NoIndex_L } \\
003 \text { R1_00 } \\
\text { 1_contig_5 } \\
4674\end{array}$ & 2 & 466 & 479 & 14 & 7 & 12 & $\begin{array}{l}\text { GCAAGGAATTCAAGAATCTGAACAAATGAAAACTCTTTGACGATCA } \\
\text { ATACCTTATAACATGACACACCAATACCACGCTAAGAAAAACCAAT } \\
\text { CATCTGGAACACGAGGAATTGCGCACCATTGGTCAGAAGCTAACCC } \\
\text { AACATTTTCTTTGAGAGAGAGAGAGAAAGAAGCTTCCTTGGGGCTA } \\
\text { CCACCAAACTAAACTTCTCTTTTCAATGTGGTTACTTTGCTTCTTTGT } \\
\text { CTTTGGGTTGTTCACTATATTTTCTGCAGGTCTACACCAACTTTTCTG } \\
\text { ACTATATTGTCACTGCCACTTGACATGGTCCAAG }\end{array}$ & GA & G & 16,47 & 162 & $\begin{array}{l}\text { CACACCAATACCACG } \\
\text { CTAAGAA }\end{array}$ & 60,1 & $\begin{array}{l}\text { GCAAAGTAACCACA } \\
\text { TTGAAAAGA }\end{array}$ & 58,4 & 45,5 & 34,8 \\
\hline 129 & BrPe0129 & $\begin{array}{l}\text { Maracuja_ } \\
\text { NoIndex_L } \\
003 \text { R1_00 } \\
\text { 1_contig_5 } \\
7617\end{array}$ & 2 & 977 & 988 & 12 & 6 & 10 & $\begin{array}{l}\text { ATATTTCTCTTCCCCAAATACTAAAGATGGATCGCCCTCAGTGCATA } \\
\text { AAATGGAAATAGTCCGACCTCCTAAGCGATAGTTTGGATCCCCTATT } \\
\text { CTGTTCTCGAAACAGGTTTTAGGGGATCTACAGACACGAGAATTGG } \\
\text { AATTTGGTAGCTCTCTCTCTCTATGTATTTCCATCCAACAAGAAGGG } \\
\text { AAACCAATATCACAGCATGGCCAGCCTTCGAGTTCAACAAGGTTCC } \\
\text { CTACAGGCATCTGAAGCAATTTCTTGGAGCGAATATCTGATTCAGGA } \\
\text { GAAGCAAGTAGCCTTGGTCTTGCAACAGCGTG }\end{array}$ & СТ & G & 13,05 & 174 & $\begin{array}{l}\text { CTAAAGATGGATCGC } \\
\text { CCTCA }\end{array}$ & 60,2 & $\begin{array}{l}\text { TTGGTTTCCCTTCTT } \\
\text { GTTGG }\end{array}$ & 59,9 & 50 & 45 \\
\hline 130 & BrPe0130 & $\begin{array}{l}\text { Maracuja_ } \\
\text { NoIndex_L } \\
003 \text { R1_00 } \\
\text { 1_contig_5 } \\
9911\end{array}$ & 2 & 232 & 245 & 14 & 7 & 12 & $\begin{array}{l}\text { AGGAACACATACATGCATAGCATGCATGAAACAACCCTACCTTTCC } \\
\text { TCTTCCTCCTTCTCCTCTTCTCTTCCTTCTTCTCTCAGCCAACCCAAG } \\
\text { CCTCACAAGAATTCAGCTGCTCACACCCACAAGAGCTCTCCCTTCTC } \\
\text { TCCTCTTCACTCTCTCTCTCTCTTCTTTACTTCACAATTTGCACAAAT } \\
\text { GAAAGCAAAAGGTAAGGAGAGTGGGTTTTGATCTGGAAAAAGGCA } \\
\text { TGGCTAGCTGGCATCAGGTGCTAGGGAAAATGTCCAGGTGCACAAG } \\
\text { AAAATTGCAAACTTTAGGTAGTTGGAAAAATATG }\end{array}$ & CT & G & 140,27 & 172 & $\begin{array}{l}\text { CTTCTCTCAGCCAAC } \\
\text { CCAAG }\end{array}$ & 60,0 & $\begin{array}{l}\text { CAGCTAGCCATGCC } \\
\text { TTTTTC }\end{array}$ & 60,0 & 55 & 50 \\
\hline
\end{tabular}


APÉNDICE

Marcadores microssatélites desenhados a partir do sequênciamento parcial e da montagem de novo do genoma de $P$. edulis

\begin{tabular}{|c|c|c|c|c|c|c|c|c|c|c|c|c|c|c|c|c|c|c|c|}
\hline $\mathbf{N}^{\mathbf{o}}$ & Primer & Contig $\mathrm{I}$ & Motivo & Início & Fim & pb & $\begin{array}{c}\mathbf{N}^{\mathbf{o}} \\
\text { Repet }\end{array}$ & Score & Sequência do contig & Unidade & G/S & Cobertura & pb & Sequência Forward & $\begin{array}{l}\mathrm{T}^{\circ} \mathrm{C} \\
F w d\end{array}$ & Sequência Reverse & $\begin{array}{r}\mathrm{T}^{\circ} \mathrm{C} \\
\operatorname{Rev}\end{array}$ & $\begin{array}{c}\% \mathrm{GC} \\
F w d\end{array}$ & $\begin{array}{c}\% \mathrm{GC} \\
\operatorname{Rev}\end{array} \quad \mathrm{P} / \mathbf{M}$ \\
\hline 131 & BrPe0131 & $\begin{array}{l}\text { Maracuja_ } \\
\text { NoIndex_L } \\
\text { 003_R1_00 } \\
\text { 1_conti__6 } \\
0595\end{array}$ & 2 & 3270 & 3281 & 12 & 6 & 10 & $\begin{array}{l}\text { TACTACATTAGGTTGGTAAAAAGACAAGAGTACAACGTTTGTTGAAG } \\
\text { CGTCTCTATAGTTGTTTGCAGGAGTTATCCATCTTCGCATTGAAGAA } \\
\text { GAAAACAAAGATAATTAGCGATGATTAGGATATGCTAACACTGATA } \\
\text { TTTTCCTTAAAATATATATATATTATCAAGAAAATTAAAGGGTTTCA } \\
\text { CAAGAATGAAAAATCATCATTAACCCTTTTTGGAAAGTATAACCATT } \\
\text { ACGATCCGCAAGCAAATAAAAGAGGAAGTGGAAACCAATAATAAT } \\
\text { AATATTTTTCATTTTATTTTTGTATTAATTTTTT }\end{array}$ & $\overline{\mathrm{AT}}$ & $\mathrm{s}$ & 16,71 & 155 & $\begin{array}{l}\text { CAAAGATAATTAGCG } \\
\text { ATGATTAGGA }\end{array}$ & 58,1 & $\begin{array}{l}\text { TTTATTTGCTTGCGG } \\
\text { ATCGT }\end{array}$ & 60,6 & 32 & 40 \\
\hline 132 & BrPe0132 & $\begin{array}{l}\text { Maracuja_ } \\
\text { NoIndex_L } \\
\text { 003_R1_00 } \\
\text { 1_contig_6 } \\
\text { 2779 }\end{array}$ & 2 & 1521 & 1534 & 14 & 7 & 12 & $\begin{array}{l}\text { ATGATTCCCTGACACATTGACGAATTTAACTTTTCCAGCTTCATCCA } \\
\text { AGCTTCTCAAACCAATCCAGTCATCAATGTAGAGCTCAGTCTGTAAT } \\
\text { GAATACAGCATATGCGTTACTTGATACAATCAAATGGAAGATGGAC } \\
\text { TTCAACCATCATATATATATATATGCACACTTGCAAGACTGCAGACG } \\
\text { CATGAACTAGAACAATATATCACCTCTTGAACAGGCAAAATGCGAA } \\
\text { CAAATGAGCCGTCTGGGTAGTAACCAAACCATGAGGTTTCCTTTGGT } \\
\text { ATCAAAACTTTATCATGCTCAAACTGATAACCAT }\end{array}$ & АТ & $\mathrm{s}$ & 16,05 & 209 & $\begin{array}{l}\text { CCAGCTTCATCCAAG } \\
\text { СТTCT }\end{array}$ & 59,6 & $\begin{array}{l}\text { GGCTCATTTGTTCGC } \\
\text { ATTTT }\end{array}$ & 60,1 & 50 & 40 \\
\hline 133 & BrPe0133 & $\begin{array}{l}\text { Maracuja_ } \\
\text { NoIndex_L } \\
\text { 003_R1_00 } \\
\text { 1_contig_6 } \\
\text { 2965 }\end{array}$ & 2 & 2646 & 2661 & 16 & 8 & 14 & $\begin{array}{l}\text { ACCAATCATTATTCCCCATAACATGGAATACTGCATTATGCCACTGA } \\
\text { TGAGTACATTTCTTGGACCTGCAGTAGAAATGAGAACAGGTGATGG } \\
\text { GAATCTGCAGGTGCTGCAATCTTCATATCCCCTTGTGTTAAATCTAC } \\
\text { AAATCTTTACATATATATATATATATTTGCAGACGAACCCGTTAGAC } \\
\text { TGAAGCGTAACAGCATATATCAATGATAGCTTTCTAGCTTATTTAGA } \\
\text { TGCCTTATGTCCCTTCTTCTGGTCAAAAATTTCCAGAGACTAAAAAT } \\
\text { TCAATCCATTCAATTAACTATTAGGCCTCCTAATG }\end{array}$ & АТ & $\mathrm{s}$ & 18,08 & 181 & $\begin{array}{l}\text { AACAGGTGATGGGAA } \\
\text { TCTGC }\end{array}$ & 59,9 & $\begin{array}{l}\text { TTTTGACCAGAAGA } \\
\text { AGGGACA }\end{array}$ & 59,7 & 50 & 42,9 \\
\hline 134 & BrPe0134 & $\begin{array}{l}\text { Maracuja_ } \\
\text { NoIndex_L } \\
003 \text { R1_00 } \\
\text { 1_contig_6 } \\
3110\end{array}$ & 2 & 3428 & 3443 & 16 & 8 & 14 & $\begin{array}{l}\text { GCAAGAATACTTCCAGAATCAGTCATTACAGATTGAAAGAAATATA } \\
\text { GCAAAAAATTAGTCCTATTCTACCCATGGATTAGCCATGCCAAAGC } \\
\text { ACCACAATACTTATAACACTCGGGATTAGACGAAAGGGGTTAGGAC } \\
\text { TTGGATATAGACATATATATATATATATTTATATACAAGGTTCTGTA } \\
\text { TCCTGGTCAAAATAGCTAAACCATAGACACCGACATAGACAGAAAC } \\
\text { CAGTAGAGATTTTACTACTATAGCATCAACAAGAGTTAATTTCAGG } \\
\text { ATTTTGGGCTGCTTATGGAGCTTTTAAGATATGCAGGC }\end{array}$ & АТ & $\mathrm{s}$ & 18,6 & 216 & $\begin{array}{l}\text { CATGCCAAAGCACCA } \\
\text { CAATA }\end{array}$ & 60,5 & $\begin{array}{l}\text { TCCATAAGCAGCCC } \\
\text { AAAATC }\end{array}$ & 60,0 & 45 & 45 \\
\hline 135 & BrPe0135 & $\begin{array}{l}\text { Maracuja_ } \\
\text { NoIndex_L } \\
003 \_R 1 \_00 \\
\text { 1_contig_6 } \\
4475\end{array}$ & 2 & 704 & 715 & 12 & 6 & 10 & $\begin{array}{l}\text { TTGATCGAAGAAACGATAAGTTTTGCCGTCTTGTTTGCCACTCCTCC } \\
\text { CTTCTTTGGTTCTTTTATGGTACTTGTACACGTTCTCGAACTTCTCTTT } \\
\text { GCACTTCTTGGCGCTTCGATTATAGCCAAGTTCTTTTAGCTTCCTGCT } \\
\text { CATCAGTATATATATATAACATCAGTTACAACTCGAGTAACTACGCT } \\
\text { TTCTTTATCTTAATTTCCCTTCCTAACAGGTTACTTCACGAGAGAGA } \\
\text { AAACAAAACATTTGAAGGCATTGGCACATAAAATAAAATTAAAAAA } \\
\text { AGCAGATAAGTTAACAAGGCAAAGGCAA }\end{array}$ & $\mathrm{TA}$ & G & 13,98 & 210 & $\begin{array}{l}\text { AGTTTTGCCGTCTTGT } \\
\text { TTGC }\end{array}$ & 60,3 & $\begin{array}{l}\text { GAAGTAACCTGTTA } \\
\text { GGAAGGGAAA }\end{array}$ & 59,1 & 45 & 41,7 \\
\hline
\end{tabular}


APÉNDICE

Marcadores microssatélites desenhados a partir do sequênciamento parcial e da montagem de novo do genoma de $P$. edulis

\begin{tabular}{|c|c|c|c|c|c|c|c|c|c|c|c|c|c|c|c|c|c|c|c|}
\hline $\mathbf{N}^{\circ}$ & Primer & Contig I & Motivo & Início & Fim & pb & $\begin{array}{c}\mathbf{N}^{\circ} \\
\text { Repet }\end{array}$ & Score & Sequência do contig & Unidade & G/S & Cobertura & pb & Sequência Forward & $\begin{array}{l}\mathrm{T}^{\circ} \mathrm{C} \\
F w d \\
\end{array}$ & Sequência Reverse & $\begin{array}{r}\mathrm{T}^{\circ} \mathrm{C} \\
\operatorname{Rev} \\
\end{array}$ & $\begin{array}{c}\% \mathrm{GC} \\
F w d \\
\end{array}$ & $\begin{array}{c}\% \mathrm{GC} \\
\operatorname{Rev}\end{array} \quad \mathrm{P} / \mathrm{M}$ \\
\hline 136 & $\begin{array}{l}\text { BrPe0136 } \\
\end{array}$ & $\begin{array}{l}\text { Maracuja_ } \\
\text { NoIndex_L } \\
\text { 003_R1_00 } \\
\text { 1_conti__6 } \\
5330\end{array}$ & 2 & 3980 & 3991 & 12 & 6 & 10 & $\begin{array}{l}\text { GTTTCCCCCAAAAACCTCTATTTACTATATTTACACTCTTTAACAAAT } \\
\text { GGGTGGATCTTCCCAGTTGAATTGGATTTTATTGGATTGTGTCCAA } \\
\text { TAACTTAATCAAATGGAAACAAAGAGCAAAGCATGGAGAGCTCATT } \\
\text { TCCCCATCTTCTCTCTCTCTCCAAATGGTTGTCGGTAGCCCCTCCATG } \\
\text { TGTAGCCTTTTTTTCCCCTTCCTGCAAGTTGAGGGTTATATTATAATC } \\
\text { CCAATCCAGGTAAAATTGTTCTTTTAAGTATGAATTCTGATTCTACA } \\
\text { AAGTTGTTTGGATTTTTTGATTATATCT }\end{array}$ & $\mathrm{TC}$ & $\mathrm{s}$ & 17,37 & 195 & $\begin{array}{l}\text { GTTTCCCCCAAAAAC } \\
\text { CTCTA }\end{array}$ & 058 & $\begin{array}{l}\text { GCTACACATGGAGG } \\
\text { GGCTAC }\end{array}$ & 59,6 & 45 & 60 \\
\hline 137 & BrPe0137 & $\begin{array}{l}\text { Maracuja_ } \\
\text { NoIndex_L } \\
\text { 003_R1_00 } \\
\text { 1_contig_6 } \\
\text { 7544 }\end{array}$ & 2 & 1424 & 1443 & 20 & 10 & 18 & $\begin{array}{l}\text { GACCCACTTGGTTCAAGTGTTCAATGAAACAAAGGTGTGGAAAGTC } \\
\text { AGTCATTATTTTTGGTCATATACATAAAAATAATTCCAATTGACAA } \\
\text { AAGAAGAGATTGTTTTGGATATCCCAGCATTGCATACTTTGCTTTTA } \\
\text { CATGAGCAATAGAGAGAGAGAGAGAGAGAGGGAGGTAACTATTC } \\
\text { AGTGTGCAAGTCTAGTTGATGCCTGAATTGTGTCAAATGCCAGCAAC } \\
\text { GGTAAGAAATTAGGATAAGTAAATCAAGGAGGAAGCAAAAAAAGT } \\
\text { GACCCTGAGCAGCTTCTTTTGTTTGATAACTAATCAACATCTA }\end{array}$ & AG & $\mathrm{s}$ & 18,24 & 219 & $\begin{array}{l}\text { TCAATGAAACAAAGG } \\
\text { TGTGGA }\end{array}$ & 059 & $\begin{array}{l}\text { TCTTACCGTTGCTGG } \\
\text { CATTT }\end{array}$ & 60,6 & 38,1 & 45 \\
\hline 138 & BrPe0138 & $\begin{array}{l}\text { Maracuja_ } \\
\text { NoIndex_L } \\
\text { 003_R1_00 } \\
\text { 1_contig_6 } \\
8408\end{array}$ & 2 & 471 & 482 & 12 & 6 & 10 & $\begin{array}{l}\text { CTCGATCTTTTAAGACAAAACATATGAGATCACTGTGTTTTCAATGG } \\
\text { AGTGGAATTTCTTGACAAGACATTTTTGGAGGAAGCTCCAAGGAAG } \\
\text { AGATGATCATGACCCAGATACCATTGTGATAGCTCAACTGCCACGTT } \\
\text { CAGGTAGCACTATATATATATAAATACAATAAGACATCCAAATGGA } \\
\text { TGAAGAATTATGATAATGAAGAATAAAGATGTCACTGTCCCCTGAA } \\
\text { ATGAGAGACAAATACTCAAGGGAAAACCCAACTAACTGTAATATTA } \\
\text { TAGATTTAAAGAACGAATTATCATATAGTTTAGT }\end{array}$ & TA & $\mathrm{s}$ & 17,74 & 161 & $\begin{array}{l}\text { GGAGGAAGCTCCAAG } \\
\text { GAAGA }\end{array}$ & 60,8 & $\begin{array}{l}\text { CATTTCAGGGGACA } \\
\text { GTGACA }\end{array}$ & 59,5 & 55 & 50 \\
\hline 139 & BrPe0139 & $\begin{array}{l}\text { Maracuja_ } \\
\text { NoIndex_L } \\
003 \text { 1_1_00 } \\
\text { 1_contig_6 } \\
8563\end{array}$ & 2 & 900 & 917 & 18 & 9 & 16 & $\begin{array}{l}\text { ACTACAAGAAAGTGAGGGTGGTGCACTTTGTGGACACAATTCCAAA } \\
\text { ATCACCTTCAGGGAAGATCATGCGCAGGGTTATTAAAGAAAAGATG } \\
\text { GTCGAGAAGATGAGAACCAAATGATTAAGACTGTCCAATTCACAGC } \\
\text { CTCAAGTCTCTCATATATATATATATATATGTAAAAGATGCATTCAT } \\
\text { CTTCAATCATTAAGGTGGCAACAACTAATACACGCACAGCCTGAGA } \\
\text { AACCACCCAAGTACGTAATCCAAAGATACTGTACAAGTACAACAAC } \\
\text { AGTCGCCATCCACAGTTCACGAGTGGAATAATAAAAAAACAA }\end{array}$ & AT & $\mathrm{s}$ & 15,68 & 242 & $\begin{array}{l}\text { AGATCATGCGCAGGG } \\
\text { TTATT }\end{array}$ & 59,6 & $\begin{array}{l}\text { CACTCGTGAACTGT } \\
\text { GGATGG }\end{array}$ & 60,2 & 45 & 55 \\
\hline 140 & BrPe0140 & $\begin{array}{l}\text { Maracuja_ } \\
\text { NoIndex_L } \\
003 \text { 181_00 } \\
\text { 1_conti__6 } \\
9143\end{array}$ & 2 & 1300 & 1313 & 14 & 7 & 12 & $\begin{array}{l}\text { CATGTGGCTTCTTGTCTGAATCTTGTGTCATTTTGCAATTAATGTGGA } \\
\text { ATCACATCCCGCAGCTGCTAATCAAAGAGTGGACCTCTGTTGCTTCA } \\
\text { CCTGGGTAATAAATACTTGGTTAAGGATTACCACACGTATTCTCTTA } \\
\text { AAGTTGTTTATATATATATATAGACCGTCTCTCCTTTTAAATATTATA } \\
\text { AGAAAGATTTGGTCAAAGTTTGCTTGAAAATTAATAGGTCTTCCAC } \\
\text { TTAATCTTCATCTGATGTTAATTATTCGTCGGTGGTGTTCTATACATC } \\
\text { TATGCTTAGTTTCTATATAAAAGGACATA }\end{array}$ & TA & $\mathrm{s}$ & 17,65 & 200 & $\begin{array}{l}\text { GGACCTCTGTTGCTTC } \\
\text { АСCT }\end{array}$ & 59,3 & $\begin{array}{l}\text { AGAACACCACCGAC } \\
\text { GAATAA }\end{array}$ & 58,1 & 55 & 45 \\
\hline
\end{tabular}


APÉNDICE

Marcadores microssatélites desenhados a partir do sequênciamento parcial e da montagem de novo do genoma de $P$. edulis

\begin{tabular}{|c|c|c|c|c|c|c|c|c|c|c|c|c|c|c|c|c|c|c|c|}
\hline $\mathbf{N}^{\circ}$ & Primer & Contig I & Motivo & Início & Fim & pb & $\begin{array}{c}\mathbf{N}^{\circ} \\
\text { Repet }\end{array}$ & Score & Sequência do contig & Unidade & G/S C & Cobertura & pb & Sequência Forward & $\begin{array}{l}\mathrm{T}^{\circ} \mathrm{C} \\
F w d \\
\end{array}$ & Sequência Reverse & $\begin{array}{l}\mathrm{T}^{\circ} \mathrm{C} \\
\operatorname{Rev} \\
\end{array}$ & $\begin{array}{c}\% \mathrm{GC} \\
F w d \\
\end{array}$ & $\begin{array}{cc}\% \mathrm{GC} & \mathrm{P} / \mathrm{M} \\
\operatorname{Rev} & \end{array}$ \\
\hline 141 & BrPe0141 & $\begin{array}{l}\text { Maracuja_ } \\
\text { NoIndex_L } \\
\text { 003_R1_00 } \\
\text { 1_conti__6 } \\
9605\end{array}$ & 2 & 805 & 824 & 20 & 10 & 18 & $\begin{array}{l}\text { AAGTGCATTACAGCACCATTGGGAAGACAAAGAAGAGAAGCTACTT } \\
\text { GGGTTGTGCTTAAAAAGCTCGTGTTCTTACCGCATTGGTGTTCCTG } \\
\text { AGATAAGAAGAAGAAGAAGAGTAGATTGTGTATAAATCTCTTGGAT } \\
\text { AACACCGAGGAAGAGAGAGAGAGAGAGAGAGTGCAGGAAGGGAA } \\
\text { AATGTTGGAAGGTAAAGCTCTGTTAGAAGACACCGACATGCCATTG } \\
\text { AAGATGCAGATCCAAGCCATGGCTTCTGCTTCTCAGGCCTTGGATCT } \\
\text { CTATGATGTACTTGACTGCAAATCTATAGCTGCGCATATCAAAA }\end{array}$ & $\overline{\mathrm{AG}}$ & $\bar{G}$ & 16,41 & 109 & $\begin{array}{l}\text { TCTCTTGGATAACAC } \\
\text { CGAGGA }\end{array}$ & 59,7 & $\begin{array}{l}\text { CTGCATCTTCAATG } \\
\text { GCATGT }\end{array}$ & 59,7 & 47,6 & 45,5 \\
\hline 142 & BrPe0142 & $\begin{array}{l}\text { Maracuja_ } \\
\text { NoIndex_L } \\
003 \text { R1_00 } \\
\text { 1_contig_7 } \\
0250\end{array}$ & 2 & 3178 & 3197 & 20 & 10 & 18 & $\begin{array}{l}\text { CAGGTCATCGCACCTTACTTCTCGACCTTGTACTTCTATTGCGGGCA } \\
\text { ATGTGATAGTGATGCCTTTAACCCAAAGACAGAAGTGACCACAAAT } \\
\text { CTACTTTTGTCCTTTTTCTTTTCTTTCTTCCTCACTTTGAATAGATCCC } \\
\text { TATTGAACTATATATATATATATATATACATATCAGTGGTTTTCTTCT } \\
\text { TTGGATTCAGAGTCCTCACCTCTAGCATAGCCTAGACCTCTCATGAA } \\
\text { ATCCATTGATTCGATTGCATGCATGTTACTCCCCTTCTGTGCAGCCG } \\
\text { AATTTGACAGAGACATGGGTGGAAGGAACAGTCATG }\end{array}$ & TA & $\mathrm{s}$ & 16,64 & 190 & $\begin{array}{l}\text { TTCCTCACTTTGAATA } \\
\text { GATCCCTA }\end{array}$ & 58,4 & $\begin{array}{l}\text { ССTTCCACCCATGTC } \\
\text { TCTGT }\end{array}$ & 60,0 & 37,5 & 55 \\
\hline 143 & BrPe0143 & $\begin{array}{l}\text { Maracuja_ } \\
\text { NoIndex_L } \\
003 \text { R1_00 } \\
\text { 1_contig_7 } \\
1490\end{array}$ & 2 & 5014 & 5037 & 24 & 12 & 22 & $\begin{array}{l}\text { TTTTTAATTATAAGATCCTAAAATCATATCTTTCGGCGAAGATATAT } \\
\text { ATCTAAAATTCAATTCTCTGTTCATCGATGTTTTTATTATAAGATCA } \\
\text { TTAGGATTTGATCGAACTTTGGCGAAGATATTTATTATTTTGAATAA } \\
\text { GTAAATGTTATATATATATATATATATATATACTTAAAACACAATGA } \\
\text { TCATGATTGTTCAGAACTGGATAGGTAAGTGTCATCCTGGTCGTCGC } \\
\text { CCTTGGAATATTTGCTGTCTAATCAAGGAAATAAAAACCATAGTAG } \\
\text { AGAAACTTCGTGGAAGACTAAACTAAACTATAGAATAAACAA }\end{array}$ & TA & $\mathrm{s}$ & 15,38 & 152 & $\begin{array}{l}\text { TTAGGATTTGATCGA } \\
\text { ACTTTGG }\end{array}$ & 58,2 & $\begin{array}{l}\text { ATATTCCAAGGGCG } \\
\text { ACGAC }\end{array}$ & 59,9 & 36,4 & 52,6 \\
\hline 144 & BrPe0144 & $\begin{array}{l}\text { Maracuja_ } \\
\text { NoIndex_L } \\
\text { 003_R1_00 } \\
\text { 1_contig_7 } \\
1785\end{array}$ & 2 & 2349 & 2366 & 18 & 9 & 16 & $\begin{array}{l}\text { TATTGCACCCATCTAAATGAAATGAATAGACATCCATCTCTATAAAG } \\
\text { AAGATTTTGGGTAGTACATGCTGGATCGTTTTTTATCTTTCGCTCTAA } \\
\text { CCAAAACCCACCTGCATCATGGCTGTGGGTACAGCAGTCGATCGGC } \\
\text { AACTATATTTATATATATATATATATACACGGTCACTAATTAAGACC } \\
\text { CACAAGCACGCATACACATATATTTCATCAACCCTATCCCTGATCAG } \\
\text { AATCTCAGACTAGAAGATATGACATCGATCAGATGGCATTCCAACA } \\
\text { AGAAAATCGATCTAGATATATTATATAAACTATTAAA }\end{array}$ & TA & $\mathrm{s}$ & 15,2 & 157 & $\begin{array}{l}\text { AGCAGTCGATCGGCA } \\
\text { ACTAT }\end{array}$ & 59,9 & $\begin{array}{l}\text { TCTTGTTGGAATGCC } \\
\text { ATCTG }\end{array}$ & 59,6 & 50 & 45 \\
\hline 145 & BrPe0145 & $\begin{array}{l}\text { Maracuja_ } \\
\text { NoIndex_L } \\
\text { 003_R1_00 } \\
\text { 1_contig_7 } \\
\text { 2514 }\end{array}$ & 2 & 241 & 252 & 12 & 6 & 10 & $\begin{array}{l}\text { ACAAAAAATAACAATAATATATAATAATGGAAGGTAATCAGGACCA } \\
\text { CTCTTGATTTGAAGCTTCTGGAACAGGGCTTAGTTTAATTATTAACA } \\
\text { CTTACTAACTCGCATAGTTTTGAGGAAAAGCCAGAGAAACTGGCAG } \\
\text { CTGACGATGCCATATATATATATTGTGCCAATATTATCTTTTTGTGG } \\
\text { GCAATGCATGTTTTCTAGCTATGTAAGAAGAGTACAGACCTAAAAA } \\
\text { AGTAAACTAAAAATGTACAGATGGAGGAAAGGTGAGGGTCATGTAT } \\
\text { AGATCTGGGCCAAATGATAGGGATTGCTCAACTG }\end{array}$ & AT & G & 14,69 & 213 & $\begin{array}{l}\text { AGCTTCTGGAACAGG } \\
\text { GCTTA }\end{array}$ & 59,1 & $\begin{array}{l}\text { АСССТСАССТTТССТ } \\
\text { ССАТС }\end{array}$ & 60,3 & 50 & 55 \\
\hline
\end{tabular}


APÉNDICE

Marcadores microssatélites desenhados a partir do sequênciamento parcial e da montagem de novo do genoma de $P$. edulis

\begin{tabular}{|c|c|c|c|c|c|c|c|c|c|c|c|c|c|c|c|c|c|c|c|}
\hline $\mathbf{N}^{\circ}$ & Primer & Contig I & Motivo & Início & Fim & pb & $\begin{array}{c}\mathbf{N}^{\circ} \\
\text { Repet }\end{array}$ & Score & Sequência do contig & Unidade & G/S & Cobertura & pb & Sequência Forward & $\begin{array}{l}\mathrm{T}^{\circ} \mathrm{C} \\
F w d \\
\end{array}$ & Sequência Reverse & $\begin{array}{l}\mathrm{T}^{\circ} \mathrm{C} \\
\operatorname{Rev} \\
\end{array}$ & $\begin{array}{c}\% \mathrm{GC} \\
F w d \\
\end{array}$ & $\begin{array}{cc}\% \mathrm{GC} & \mathrm{P} / \mathrm{M} \\
\operatorname{Rev} & \end{array}$ \\
\hline 146 & BrPe0146 & $\begin{array}{l}\text { Maracuja_ } \\
\text { NoIndex_L } \\
\text { 003_R1_00 } \\
\text { 1_contig_7 } \\
\text { 3344 }\end{array}$ & 2 & 694 & 717 & 24 & 12 & 22 & $\begin{array}{l}\text { TGCGGAAAAAAGGAGAAAATCTTCAGAGACCATAAATAGCAAAAAA } \\
\text { CAGAACAAAAATCCAACAGAAAAAGTCAGGAAAATAAGCCGGTTT } \\
\text { CTACAGGTAGCCCCCCTATTCCAACGTTGAGTCTGTTGTTTCTCTTGC } \\
\text { ACTCTTGAGATGGAGAGAGAGAGAGAGAGAGAGAGAATCAGATAG } \\
\text { ACATCACAAAGGATTGCTAACACCAGGCATCAGTAACCCACACAGC } \\
\text { TAACCACAACAATAGCAACAAGAAGAAAGTCAAGTTTGGCGTGTGC } \\
\text { TTGTGTTCACTCTTACGGTACATTTGTTAACTTTGGACCAAACAAGT }\end{array}$ & $\overline{\mathrm{GA}}$ & $\mathrm{s}$ & 14,52 & 151 & $\begin{array}{l}\text { CAGGAAAATAAGCCC } \\
\text { GTTTC }\end{array}$ & 58,7 & $\begin{array}{l}\text { GGGTTACTGATGCC } \\
\text { TGGTGT }\end{array}$ & 59,9 & 45 & 55 \\
\hline 147 & BrPe0147 & $\begin{array}{l}\text { Maracuja_ } \\
\text { NoIndex_L } \\
\text { 003_R1_00 } \\
\text { 1_contig_7 } \\
3624\end{array}$ & 2 & 412 & 429 & 18 & 9 & 16 & $\begin{array}{l}\text { GAAAATTATAAAAAAAAGACCAATAATGCTTTTAAAATTTGGAGACT } \\
\text { TTTGGGTGCTTGGTAGGTGGGGACGCGTGAAAGCTACGTGGGAACT } \\
\text { TACCGCATCCACTCATATACGTGGCACTCATATACCCTGCCATTTGG } \\
\text { CACGTAACCCTTCTCTCTCTCTCTCTCTCCAAGTAGTCAATTTTCTCA } \\
\text { TCCCAAGCACATGCAAGCCTCAATGTCATTCCCATTATCAAATCCAC } \\
\text { AATTCAATGTTCAAATTTACAATTGCGTTAATTCAACAAGTCTTTTTT } \\
\text { GTCAAATACTTAATTTATTTTAACAAGTCAATATTT }\end{array}$ & TC & G & 14,76 & 164 & $\begin{array}{l}\text { TTTGGAGACTTTTGG } \\
\text { GTGCT }\end{array}$ & 59,7 & $\begin{array}{l}\text { CATGTGCTTGGGAT } \\
\text { GAGAAA }\end{array}$ & 59,6 & 45 & 45 \\
\hline 148 & BrPe0148 & $\begin{array}{l}\text { Maracuja_ } \\
\text { NoIndex_L } \\
\text { 003_R1_00 } \\
\text { 1_contig_7 } \\
3686\end{array}$ & 2 & 1477 & 1490 & 14 & 7 & 12 & $\begin{array}{l}\text { TGGATGTGTCACAGTCATTGGCATTGGCTCACGCCGACATATCTGAG } \\
\text { GGGAAGGTGGTGTTTGTCCCATGGGTGGAAACTGATTTCAGAACTG } \\
\text { GAGATGCTCCATGGTGGGCTTAAGCCTGCTCTCTATGTGATGATCTT } \\
\text { CGACCTCCTCTATATATATATATACTGCATTCATGTTCAAGATTGCA } \\
\text { GGAAGCAGCTTGCTCTGCACAGATGCTTCAAGCAAGTTCATTATTTC } \\
\text { TGTTGAATTTATTCTTTTTTTTTCTTTTTGGTACCTTGTTTATTACATC } \\
\text { ATCATCATGAACTATGTTCCTGTGCAAGAAT }\end{array}$ & TA & $\mathrm{s}$ & 16,45 & 177 & $\begin{array}{l}\text { TATCTGAGGGGAAGG } \\
\text { TGGTG }\end{array}$ & 59,9 & $\begin{array}{l}\text { GAAGCATCTGTGCA } \\
\text { GAGCAA }\end{array}$ & 60,3 & 55 & 50 \\
\hline 149 & BrPe0149 & $\begin{array}{l}\text { Maracuja_ } \\
\text { NoIndex_L } \\
\text { 003_R1_00 } \\
\text { 1_contig_7 } \\
\text { 8274 }\end{array}$ & 2 & 2378 & 2389 & 12 & 6 & 10 & $\begin{array}{l}\text { GCTGGTAAAGCACTTGCTTGCCCTCATCGAGATACCATGGTAAATGG } \\
\text { TAATGTTTCGAGTAACATATACTAGCTACTCATATATACCATGAACA } \\
\text { ATCCTCTTCGAAGAGGCCCAAACCTAGCTAGAAGTATATAGTTACTA } \\
\text { GCACTCTCTTCTCTCTCTCTCGAAGAGAAGAAAGAACTAAAAGTGAT } \\
\text { CAGTTTCTGACATCATGGTACAGTCAAAGAAGTTCAGAGGTGTCAG } \\
\text { GCAACGCCACTGGGGCTCTTGGGTCTCCGAGATTCGTCACCCCTTGC } \\
\text { TGTACTCTCAACAACTTAACCAAGTCTTTAC }\end{array}$ & $\mathrm{TC}$ & G & 14,03 & 184 & $\begin{array}{l}\text { TCGAAGAGGCCCAAA } \\
\text { CCTA }\end{array}$ & 60,7 & $\begin{array}{l}\text { TACAGCAAGGGGTG } \\
\text { ACGAAT }\end{array}$ & 60,5 & 52,6 & 50 \\
\hline 150 & BrPe3001 & $\begin{array}{l}\text { Maracuja_ } \\
\text { NoIndex_L } \\
003 \text { R1_00 } \\
\text { 1_contig_1 } \\
02\end{array}$ & 3 & 3926 & 3943 & 18 & 6 & 15 & $\begin{array}{l}\text { TAACAGACTAAGATTTTCCAAATGAAGTGAAATATGGGATTCCTTGC } \\
\text { ATATATACTGTGTTGAAATACAAAGTATTATTATAACCAATTATCAT } \\
\text { ATGACCATATGAAAATGAAGATTGAAGGATCCATGACCAGTGTTCT } \\
\text { ACAGACATTCCTGCTGCTGCTGCTGCTGTTGGGAAAGATTCAAAGTT } \\
\text { AAATGGTTCAAAAAACCCACCTTTTTCTTCTGTCCAATTATTACACTT } \\
\text { GTTATTGGGAGTTTGGGATCCAAGAATTCCCTTACTTTCATGCAGAA } \\
\text { ATCCTCCACACTAGAAAGAGCAGCTATAAATATACC }\end{array}$ & CTG & G & 18,03 & 178 & $\begin{array}{l}\text { TGAAGGATCCATGAC } \\
\text { CAGTG }\end{array}$ & 59,5 & $\begin{array}{l}\text { AGTGTGGAGGATTT } \\
\text { CTGCAT }\end{array}$ & 57,2 & 50 & 45 \\
\hline
\end{tabular}


APÉNDICE

Marcadores microssatélites desenhados a partir do sequênciamento parcial e da montagem de novo do genoma de P. edulis

\begin{tabular}{|c|c|c|c|c|c|c|c|c|c|c|c|c|c|c|c|c|c|c|c|}
\hline $\mathbf{N}^{\circ}$ & Primer & Contig I & Motivo & Início & Fim & pb & $\begin{array}{c}\mathbf{N}^{\circ} \\
\text { Repet }\end{array}$ & Score & Sequência do contig & Unidade & G/S & Cobertura & pb & Sequência Forward & $\begin{array}{l}\mathrm{T}^{\circ} \mathrm{C} \\
F w d \\
\end{array}$ & Sequência Reverse & $\begin{array}{l}\mathrm{T}^{\circ} \mathrm{C} \\
\operatorname{Rev} \\
\end{array}$ & $\begin{array}{c}\% \mathrm{GC} \\
F w d \\
\end{array}$ & $\begin{array}{cc}\% \mathrm{GC} & \mathrm{P} / \mathrm{M} \\
\operatorname{Rev} & \end{array}$ \\
\hline 151 & BrPe3002 & $\begin{array}{l}\text { Maracuja_ } \\
\text { NoIndex_L } \\
003 \text { R1_00 } \\
\text { 1_contig_2 } \\
\text { 215 }\end{array}$ & 3 & 807 & 818 & 12 & 4 & 9 & $\begin{array}{l}\text { TCACTTTCCCTGAAAAATCAATGCAGGACTCTGATATAACTGCTTTT } \\
\text { GTGCTTAGTAATTCATCCTGAAAAACCCATCAACAAGGTTTTGATGA } \\
\text { TTCTTACCTTTTCCCTTTCTTTTCTTGCTCCATAATGTACACAGCACC } \\
\text { AAGCCTAAGATGATGATGATTCCTGACATGGTTGGACTATGATTGT } \\
\text { CTCTAGCCTTTTCTTCTTGTTTGAATGGAGTGGTTCTAAAAAAAGAG } \\
\text { AGATAGTTAATGATTCTGCTCCTGGATCCAATGGAAGAGAACAGAG } \\
\text { GGAAGAACCATCATAAATCTGAAGAAATGC }\end{array}$ & GAT & $\bar{G}$ & 15,58 & 205 & $\begin{array}{l}\text { TCCTGAAAAACCCAT } \\
\text { CAACA }\end{array}$ & 58,9 & $\begin{array}{l}\text { TTGGATCCAGGAGC } \\
\text { AGAATC }\end{array}$ & 60,2 & 40 & 50 \\
\hline 152 & BrPe3003 & $\begin{array}{l}\text { Maracuja_ } \\
\text { NoIndex_L } \\
003 \text { R1_00 } \\
\text { 1_contig_3 } \\
042\end{array}$ & 3 & 490 & 501 & 12 & 4 & 9 & $\begin{array}{l}\text { TTCTCTAATCTGAGGCAGTCTTTGGGCCCTGGAGTTGATGGCTGGGC } \\
\text { TATCTCCCTCAAGGAATGATGAGCATTGTGGTGCTGATGGGATTT } \\
\text { CGATCTGTTTCCTTTACTGGTGGGTGAATGCTTTTGTTCCTCTTCCAA } \\
\text { CCCGTAGCAAGAAGAAGAAGGTAAGCTTCTACAAGAATGGTATTTT } \\
\text { CTCTTTGTCATGTATTTTACCAGAATGATTGATTTTGAGAATGAGTC } \\
\text { AACTTGATTACCCTTGATTATGGTCAACATGGCTCCCACAAGATGAT } \\
\text { TTTATAGATCATAAATCTAGCTAGATATC }\end{array}$ & AAG & G & 17,3 & 190 & $\begin{array}{l}\text { GATGGGATTTGCGAT } \\
\text { CTGTT }\end{array}$ & 59,9 & $\begin{array}{l}\text { GGGAGCCATGTTGA } \\
\text { CCATAA }\end{array}$ & 60,7 & 45 & 50 \\
\hline 153 & BrPe3004 & $\begin{array}{l}\text { Maracuja_ } \\
\text { NoIndex_L } \\
003 \text { R1_00 } \\
\text { 1_contig_5 } \\
\text { 254 }\end{array}$ & 3 & 690 & 701 & 12 & 4 & 9 & $\begin{array}{l}\text { GGTGGACCTAGGATAGGGGATGATACCCTACTTGAGCAGATGTTTCC } \\
\text { GTGACTGATGTCATACCCAGAGACGTATCTTGATGGATCATGGTTGC } \\
\text { GATGTATTTTATAGGGCAGTTGCCATTGCTGATTTTGAGACTATCCT } \\
\text { CAATAGCCTAATGATGATGATGCAAGAGTTCCATTTGCATGATTGGT } \\
\text { GACGTGATTGGTACTAGATGATGGGCGACCGTTTGACATGAGAGTT } \\
\text { GATGGAGATACGATGACATGATCATGGTAGGTGATTTGCCAGCAGG } \\
\text { GAGATGTAGTGAGGTATACGGGATTGGTATGCA }\end{array}$ & ATG & G & 19,4 & 245 & $\begin{array}{l}\text { TGAGCAGATGTTTCC } \\
\text { GTGAC }\end{array}$ & 59,8 & $\begin{array}{l}\text { GCTGGCAAATCACC } \\
\text { TACCAT }\end{array}$ & 60,0 & 50 & 50 \\
\hline 154 & BrPe3005 & $\begin{array}{l}\text { Maracuja_ } \\
\text { NoIndex_L } \\
\text { 003_R1_00 } \\
\text { 1_contig_5 } \\
822\end{array}$ & 3 & 4146 & 4157 & 12 & 4 & 9 & $\begin{array}{l}\text { ATTATCTTCTCATAATCCTTGATTAAAAAAAACCCAAATACCTACCTC } \\
\text { ACCTGGCCAAACTGATGTGAAATTAATTAGCACACCAAGAAACTCC } \\
\text { AAAAAAGGGAATAAAAAGAAACAAAAAGCAACCCAGAATTGTCAG } \\
\text { GCCATTGGAAGAAGCAGCAGCAGCTTTATCTGTAATCTGATGAAGT } \\
\text { TTCTTCCTTCCAATATACCTAACCCCCTCCCTCACAATCTTTTCATGG } \\
\text { TAATGATTCTTTAGCTCCTCCACCCATCCTCTTCCTTCTCTCTCTCTCT } \\
\text { CTGTCTTTTTCTCCAACTCTTTTCTCAATGA }\end{array}$ & $\mathrm{AGC}$ & G & 16,81 & 173 & $\begin{array}{l}\text { CTGGCCAAACTGATG } \\
\text { TGAAA }\end{array}$ & 59,7 & $\begin{array}{l}\text { ATTGTGAGGGAGGG } \\
\text { GGTTAG }\end{array}$ & 60,2 & 45 & 55 \\
\hline 155 & BrPe3006 & $\begin{array}{l}\text { Maracuja_ } \\
\text { NoIndex_L } \\
\text { 003_R1_00 } \\
\text { 1_contig_7 } \\
006\end{array}$ & 3 & 865 & 876 & 12 & 4 & 9 & $\begin{array}{l}\text { TTTGGACCAAATTCTCTTCATCAACGCCCCTCGTTTCCTGCCATTTAT } \\
\text { ATTGCTCATGTCGCCTGATCCGGTCCCTCAAATCTCAGGAAGCAAC } \\
\text { CGGTGGGACATCCACTGCTCTGCATCTCTCCTTTTAACTCTCATTTCC } \\
\text { TCCAATCTAGTAGTAGTAGATTGCAAATATGTCTGCCTCAGAAAAAC } \\
\text { AACTCGAAGTTCATCAAATGCAGAACAATATGAGCTCAAAAAGTAC } \\
\text { AAAATTTTCATCCAAATTTTTAACCAAGAAGCAACTAGGCTCTGACG } \\
\text { ATATACCGAAAAGCAAAGCAGTAAAAAGT }\end{array}$ & TAG & G & 18,91 & 219 & $\begin{array}{l}\text { ATCCGGTCCCTCAAA } \\
\text { TTCTC }\end{array}$ & 60,3 & $\begin{array}{l}\text { TCGTCAGAGCCTAG } \\
\text { TTGCTTC }\end{array}$ & 59,8 & 50 & 52 \\
\hline
\end{tabular}


APÉNDICE

Marcadores microssatélites desenhados a partir do sequênciamento parcial e da montagem de novo do genoma de $P$. edulis

\begin{tabular}{|c|c|c|c|c|c|c|c|c|c|c|c|c|c|c|c|c|c|c|c|c|}
\hline $\mathbf{N}^{\circ}$ & Primer & Contig I & Motivo & Início & Fim & pb & $\begin{array}{c}\mathbf{N}^{\circ} \\
\text { Repet }\end{array}$ & Score & Sequência do contig & Unidade & $\mathbf{G} / \mathbf{S}$ & Cobertura & pb & Sequência Forward & $\begin{array}{l}\mathrm{T}^{\circ} \mathrm{C} \\
F w d \\
\end{array}$ & Sequência Reverse & $\begin{array}{r}\mathrm{T}^{\circ} \mathrm{C} \\
\operatorname{Rev} \\
\end{array}$ & $\begin{array}{c}\% \mathrm{GC} \\
F w d \\
\end{array}$ & $\begin{array}{c}\% \mathrm{GC} \\
\operatorname{Rev} \\
\end{array}$ & $\mathbf{P} / \mathbf{M}$ \\
\hline 156 & BrPe3007 & $\begin{array}{l}\text { Maracuja_ } \\
\text { NoIndex_L } \\
003 \text { R1_00 } \\
\text { 1_contig_8 } \\
481\end{array}$ & 3 & 5431 & 5442 & 12 & 4 & 9 & $\begin{array}{l}\text { CTTCAGCTGGAAAGGCACCTGATGGCCGTTTTGGCAAACTACTGCC } \\
\text { GGAGACTGATCTGGAGGATTTGGCAGCTGATTCGATCATCTTTGTGT } \\
\text { TTGTGGCCTCAAGGTCTGTAAGGGAAGTGGATGAAGCACGGCGGGT } \\
\text { GTGCGTGTTTATGGTGGTGGTGGAGTCATGGTCACTATGAGTTCTGT } \\
\text { GATTGCTGGTGTTGGCAGCTGGTTGGGCATACTTTGAAAACGGATTT } \\
\text { GCATGAGCATCGAAGGGCTCAATCACTGCCTTCTCCATCCTGTTGTG } \\
\text { CATCCAGCTACTTGTGTTGTTGAGCTTCTATA }\end{array}$ & TGG & $\bar{G}$ & 19,52 & 170 & $\begin{array}{l}\text { AAGGGAAGTGGATGA } \\
\text { AGCAC }\end{array}$ & 59,1 & $\begin{array}{l}\text { TGCACAACAGGATG } \\
\text { GAGAAG }\end{array}$ & 59,8 & 50 & 50 & $\mathrm{M}$ \\
\hline 157 & BrPe3008 & $\begin{array}{l}\text { Maracuja_ } \\
\text { NoIndex_L } \\
\text { 003_R1_00 } \\
\text { 1_contig_8 } \\
671\end{array}$ & 3 & 473 & 484 & 12 & 4 & 9 & $\begin{array}{l}\text { CATTATGTCCAGTAATCAAAATACTATTAAAGAAAATCCTAGAAAA } \\
\text { GAGGTCCCACCTTAGAGTTGGTTCATCCACTTCCATGTAGTTAGCAA } \\
\text { GCTTCCCAAGGGATATGGTTGAATAAACTTTCAGGAAGGCACGGAC } \\
\text { ACTGGCTAACAGCTGCTGCTGCTTAACTTCATATAGAAAGAGCTTTA } \\
\text { ACTGCAGTCTGTAAGCATCCTGTAAAAGACAAACAGAACAAATCA } \\
\text { AGGAAATGTCAGCACAAAAAAAACAAGAGGCTAGGATGCATAGGG } \\
\text { AAAACCAACCATATTAATGGCCATGCTAAATGGAA }\end{array}$ & GCT & G & 16,36 & 190 & $\begin{array}{l}\text { TTCCCAAGGGATATG } \\
\text { GTTGA }\end{array}$ & 60,1 & $\begin{array}{l}\text { TTGGTTTTCCCTATG } \\
\text { CATCC }\end{array}$ & 59,8 & 45 & 45 & \\
\hline 158 & BrPe3009 & $\begin{array}{l}\text { Maracuja_ } \\
\text { NoIndex_L } \\
\text { 003_R1_00 } \\
\text { 1_contig_9 } \\
\text { 349 }\end{array}$ & 3 & 1858 & 1869 & 12 & 4 & 9 & $\begin{array}{l}\text { TAACATGTTTAGTTCACGACACAGACAAGGTCCTGAGCTACTTTCTT } \\
\text { CAGTCCCATAACCACTTTCTTCATCAAGGGAGTAGAGTATATTTAAG } \\
\text { AGTTCATCTTTATCCTCTTCTAATTTTAGGTCTTTTAGCTTTTGCAGT } \\
\text { AAAGGGTGTTCTTCTTCTTCAGAGGGATACATTAAGTTCAATAGTTC } \\
\text { AGCTTTTTCTTCCTCTCCTATGTTCACATTTTAATTTCTTGATTAG } \\
\text { GGGGCAATCCCTCTTATAGTGTCCTTCTTTTCTGCACTTATAGCATAT } \\
\text { TAGCTTAGTTCCCTTCCTTTTCAACCT }\end{array}$ & TTC & G & 27,95 & 228 & $\begin{array}{l}\text { CGACACAGACAAGGT } \\
\text { CCTGA }\end{array}$ & 59,9 & $\begin{array}{l}\text { TTGCCCCCTAATCA } \\
\text { AGAAAA }\end{array}$ & 59,5 & 55 & 40 & M \\
\hline 159 & BrPe3010 & $\begin{array}{l}\text { Maracuja_ } \\
\text { NoIndex_L } \\
\text { 003_R1_00 } \\
\text { 1_contig_1 } \\
\text { 1840 }\end{array}$ & 3 & 4066 & 4080 & 15 & 5 & 12 & $\begin{array}{l}\text { AGATGGCCTAAAAGATCCCCTAGTTAAACTTGGATCGGGAACAATC } \\
\text { TCAATTTCAAACATAACCATTTCAAACTTGCAGAAAAAGAAATTAC } \\
\text { AAATTACTTACAGCAGCTACCATTCGGTACCAATTCTGCGAGCACT } \\
\text { TTCAGAAGAAACATCATCATCATCATTGGCATTATCCATTTCATCAT } \\
\text { CTACAAACAAAAGAAAAACATACTAAAAAGAAGGTCCAGAAAAAC } \\
\text { CAACCAGAGGGTATTTGTGAGGGAGAAGACTAATACTCCTCAACTG } \\
\text { TTCCTACAAATTATATACCAATTCGTCTGCAACTGCAC }\end{array}$ & CAT & G & 17,86 & 194 & $\begin{array}{l}\text { ACCAATTCTGCGAGC } \\
\text { АСТTT }\end{array}$ & 59,9 & $\begin{array}{l}\text { GTGCAGTTGCAGAC } \\
\text { GAATTG }\end{array}$ & 60,5 & 45 & 50 & \\
\hline 160 & BrPe3011 & $\begin{array}{l}\text { Maracuja_ } \\
\text { NoIndex_L } \\
003 \text { R1_00 } \\
\text { 1_contig_1 } \\
4729\end{array}$ & 3 & 506 & 517 & 12 & 4 & 9 & $\begin{array}{l}\text { ATTTGTCGTTGCCTGTCATAATCTTACAAACTTATGCAGTAATGAGT } \\
\text { TGAAACGTCAAATAAAGTGTACCGGTCTTCCTGATTGACTCTTTCCA } \\
\text { CTCATTGACTATGTTGGCATCTCCAGAAAAGTTCCGTCTGTGAAGAC } \\
\text { ATAGCACAATTCTTCTTCTTCCCTCAACAGAGAGGTAAGAATTAAGA } \\
\text { TTTAGGCTTCACATGCAGATAGGTTGCAGTTCCAGGTGAGAGAGGT } \\
\text { GTCTTTGCAGCATACTCTCTGTTGATCTTGATATCAGATTGCTCTATC } \\
\text { ACAGGGTACGTACCCACCAGTCTTATTTAT }\end{array}$ & тTC & G & 15,26 & 165 & $\begin{array}{l}\text { CCGGTCTTCCTGATTG } \\
\text { ACTC }\end{array}$ & 59,7 & $\begin{array}{l}\text { ССТСТСТСАССТGG } \\
\text { ААСТGC }\end{array}$ & 60,0 & 55 & 60,0 & $P$ \\
\hline
\end{tabular}

G: genoma funcional

S: genoma estructural

P: polimórfico

M: monomórfico 
APÉNDICE

Marcadores microssatélites desenhados a partir do sequênciamento parcial e da montagem de novo do genoma de $P$. edulis

\begin{tabular}{|c|c|c|c|c|c|c|c|c|c|c|c|c|c|c|c|c|c|c|c|c|}
\hline $\mathbf{N}^{\circ}$ & Primer & Contig I & Motivo & Início & Fim & pb & $\begin{array}{c}\mathbf{N}^{\circ} \\
\text { Repet }\end{array}$ & Score & Sequência do contig & Unidade & G/S & Cobertura & pb & Sequência Forward & $\begin{array}{l}\mathrm{T}^{\circ} \mathrm{C} \\
F w d\end{array}$ & Sequência Reverse & $\begin{array}{r}\mathrm{T}^{\circ} \mathrm{C} \\
\operatorname{Rev}\end{array}$ & $\begin{array}{c}\% \mathrm{GC} \\
F w d\end{array}$ & $\begin{array}{c}\% \mathrm{GC} \\
\operatorname{Rev}\end{array}$ & $\mathbf{P} / \mathbf{M}$ \\
\hline 161 & BrPe3012 & $\begin{array}{l}\text { Maracuja_ } \\
\text { NoIndex_L } \\
003 \_R 1 \_00 \\
\text { 1_contig_1 } \\
6160\end{array}$ & 3 & 177 & 188 & 12 & 4 & 9 & $\begin{array}{l}\text { ACATTAGCACTTCGCCCTTTCTGAAGATAATCCTTTTTCTTCTTATCT } \\
\text { CTGGGTTTTCTGGGCACTTGAACTCGCTCGGATGGATAGATTGCATT } \\
\text { ACACTCACTCTTCTTTCTCTCTGAATGTTGAAATCTTGGCCTTGCTCA } \\
\text { GACTCCCTCTTCTTCTTCTCTAGATGTTGAAATCTTGGCCTTCTTAGC } \\
\text { ATTGCCTATAATGAGAAGAAAGTTAAAAAGTTTCTGGCCACCAGAA } \\
\text { GATATAGAGTCACAGTAGATTTTCTATCCACCAGATTTTTTGAGATT } \\
\text { CTGTATAATAAATTGAGATTTGACTCTT }\end{array}$ & TCT & $\mathrm{G}$ & 24,96 & 184 & $\begin{array}{l}\text { CGCCCTTTCTGAAGA } \\
\text { TAATCC }\end{array}$ & 60,0 & $\begin{array}{l}\text { GCAATGCTAAGAAG } \\
\text { GCCAAG }\end{array}$ & 60,0 & 48 & 50 & $P$ \\
\hline 162 & BrPe3013 & $\begin{array}{l}\text { Maracuja_ } \\
\text { NoIndex_L } \\
003 \text { R1_00 } \\
\text { 1_contig_1 } \\
9157\end{array}$ & 3 & 1534 & 1548 & 15 & 5 & 12 & $\begin{array}{l}\text { TTGTGTGCTGTTATTCCTCATTGAATCTTTATGTTTTATTAAGGTTTTT } \\
\text { ATGGAATAGTATTTGTGTTTTACTTGATGTAGAGAATCCAGTATGCA } \\
\text { AAAACAAAATCAGATTGCCTTGTAGAGGCAGAAGGAATCTATGATC } \\
\text { CTAATGCAAAGAAGAAGAAGAAGCAAGAAGAGAAAGGTGAGTACT } \\
\text { CAAATATATCATTGCTTAACAGTAGATTGCATGCTGTGATAGGGGA } \\
\text { ACCACATAGTAGAGTGAGTAGTACTAAGGTCTTTGTCTGGTAGTTCT } \\
\text { ATGTTCGTATCTTGACATGTTTAGTGAGTAATCC }\end{array}$ & AAG & $\mathrm{s}$ & 17,16 & 237 & $\begin{array}{l}\text { TTGTGTGCTGTTATTC } \\
\text { CTCATTG }\end{array}$ & 60,0 & $\begin{array}{l}\text { TGGTTCCCCTATCAC } \\
\text { AGCAT }\end{array}$ & 60,3 & 39 & 50 & \\
\hline 163 & BrPe3014 & $\begin{array}{l}\text { Maracuja_ } \\
\text { NoIndex_L } \\
\text { 003_R1_00 } \\
\text { 1_contig_2 } \\
\text { 1891 }\end{array}$ & 3 & 1171 & 1185 & 15 & 5 & 12 & $\begin{array}{l}\text { CCACGCCGGTGACCGAGACGGAAGCGTGCTCATAAAGTCCATGCAC } \\
\text { TTGCAAAAATTTTGGATATGTAGAACTCCGAAGAAGCGAAACGGGT } \\
\text { GGAGTTGCGTTCGGGGTGAGGTAGCTACAACCCAGGGGAACGACGA } \\
\text { TAACCGCCCTCTAGAAGAAGAAGAAGACGACCCCCTTAAGCTCTTT } \\
\text { CGACCAACAATAGCTGGGACAGTACTGCAGATATTATACGAATCA } \\
\text { ACCTCACAGGCTTAGGTAGCAAACTTCACTGTAAGAGACGACTAAG } \\
\text { CGCTCCCTTGTATCACAGGAGCAATTTTCTGGTCGGCGA }\end{array}$ & AGA & G & 19,94 & 225 & $\begin{array}{l}\text { CGGAAGCGTGCTCAT } \\
\text { AAAGT }\end{array}$ & 60,4 & $\begin{array}{l}\text { AAGCCTGTGAGGTT } \\
\text { GATTCG }\end{array}$ & 60,3 & 50 & 50 & $\mathrm{P}$ \\
\hline 164 & BrPe3015 & $\begin{array}{l}\text { Maracuja_ } \\
\text { NoIndex_L } \\
003 \text { R1_00 } \\
\text { 1_contig_2 } \\
\text { 2335 }\end{array}$ & 3 & 2937 & 2948 & 12 & 4 & 9 & $\begin{array}{l}\text { AGAAAAGAGAAAACATAATATGCTCCACAATAATTCACACGTTGCG } \\
\text { CTCTGAGAAAGAAAAAAAAAAGAAAAAATACCTGCTTGATTTCGG } \\
\text { AGGAGCAGGAACCTCAGGAGCCAAATCTTCCCGTTCCTCAGGATCA } \\
\text { TTCCCAACAGCTTCATCATCATCAGTGAAAATTTGTTCATGCTCCCA } \\
\text { ATCATCACCTACAACAAGCATATGTATTTTCATGACGAAGTACTCAA } \\
\text { ATAAAAAATGAAGATTCTGGATAAGGTTAAAGAAAGTCGTTATGCA } \\
\text { ACATTCTAGGGATGAAAAATGATGCAAGTGTTT }\end{array}$ & TCA & G & 16,71 & 192 & $\begin{array}{l}\text { AGGAACCTCAGGAGC } \\
\text { CAAAT }\end{array}$ & 60,1 & $\begin{array}{l}\text { TCCCTAGAATGTTG } \\
\text { CATAACGA }\end{array}$ & 59,6 & 50 & 41 & M \\
\hline 165 & BrPe3016 & $\begin{array}{l}\text { Maracuja_ } \\
\text { NoIndex_L } \\
\text { 003_R1_00 } \\
\text { 1_contig_2 } \\
4907\end{array}$ & 3 & 2101 & 2112 & 12 & 4 & 9 & $\begin{array}{l}\text { TGCTAATGAGATGGCAAAATTTTCTGTTTCATTTGGATCGATATCAA } \\
\text { TACAAACAAGCTTCTCACGACAAGACTGACAAACACCATTCTCATT } \\
\text { CATATGAGTCCTTGCTACTTTCCACTGCCCGCTACCCAACCATCCTT } \\
\text { GCCCATGCCATCCTCCTCCTCCCTTCACAACTGCTTCCTCCATCTTGT } \\
\text { TCACTTCCCATTTCTCTTCTCCAATACTGGCAGCGACCTCAGACTTG } \\
\text { AACCAATCTTCAATAATCCC }\end{array}$ & TCC & G & 18,18 & 158 & $\begin{array}{l}\text { CGACAAGACTGACAA } \\
\text { ACACCA }\end{array}$ & 59,8 & $\begin{array}{l}\text { CGCTGCCAGTATTG } \\
\text { GAGAAG }\end{array}$ & 60,9 & 48 & 55 & \\
\hline
\end{tabular}

G: genoma funcional

S: genoma estructural

P: polimórfico

M: monomórfico 
APÉNDICE

Marcadores microssatélites desenhados a partir do sequênciamento parcial e da montagem de novo do genoma de $P$. edulis

\begin{tabular}{|c|c|c|c|c|c|c|c|c|c|c|c|c|c|c|c|c|c|c|c|c|}
\hline $\mathbf{N}^{\circ}$ & Primer & Contig I & Motivo & Início & Fim & pb & $\begin{array}{c}\mathbf{N}^{\mathbf{o}} \\
\text { Repet }\end{array}$ & Score & Sequência do contig & Unidade & G/S & Cobertura & pb & Sequência Forward & $\begin{array}{l}\mathrm{T}^{\circ} \mathrm{C} \\
F w d \\
\end{array}$ & Sequência Reverse & $\begin{array}{l}\mathrm{T}^{\circ} \mathrm{C} \\
\operatorname{Rev} \\
\end{array}$ & $\begin{array}{c}\% \mathrm{GC} \\
F w d \\
\end{array}$ & $\begin{array}{c}\% \mathrm{GC} \\
\operatorname{Rev} \\
\end{array}$ & $\mathbf{P} / \mathbf{M}$ \\
\hline 166 & BrPe3017 & $\begin{array}{l}\text { Maracuja_ } \\
\text { NoIndex_L } \\
003 \text { R1_00 } \\
\text { 1_contig_2 } \\
8853\end{array}$ & 3 & 210 & 221 & 12 & 4 & 9 & $\begin{array}{l}\text { TATTAAATTTTACAGGAATTTTGACGCATGGTTGATACGTGATAAAG } \\
\text { TCACTCATACATCAGACCTGAAAGGGTGCGTGATCAATACATGGGC } \\
\text { ACGTCGATCCTGCAAACACAAGTGAAGTAAGGCATGGGCACAGAA } \\
\text { GCGAGACATTCAAACAACAACAACCTGTGGATCTTCTATGGATTTCC } \\
\text { AGTGGATATTTCGGAACCAACTTTGACCTATGATCTTTTCAATTTTA } \\
\text { AACATCGACTTATGTATCTTGGATGTTTCTATTTAAAGTCCTCAATAT } \\
\text { TTTGAGAAGCGGCAAATATTATTAGCTTAGAT }\end{array}$ & $\mathrm{AAC}$ & $\mathrm{s}$ & 32,43 & 190 & $\begin{array}{l}\text { GAATTTTGACGCATG } \\
\text { GTTGA }\end{array}$ & 59,5 & $\begin{array}{l}\text { TTGGTTCCGAAATA } \\
\text { TCCACTG }\end{array}$ & 59,8 & 48 & 43 & \\
\hline 167 & BrPe3018 & $\begin{array}{l}\text { Maracuja_ } \\
\text { NoIndex_L } \\
003 \text { R1_00 } \\
\text { 1_contig_3 } \\
4233\end{array}$ & 3 & 8781 & 879 & 15 & 5 & 12 & $\begin{array}{l}\text { CTGATACGGCAAATGATGTTTGATTAATTACAACAGGAGCATCATC } \\
\text { GATCGCGACAGACATCAGAATGGGACTCTTTAATCAGTTTAAGTAC } \\
\text { ATAGAAATCAAGGGGAAAAAAAGCATTCCAAGACTAAAATGTAGA } \\
\text { GCTCTAAGATTTGAAGAAGAAGAAGAAAAACAAAATCAAAAGTGTT } \\
\text { TGTTCGCTTGTTGTTTTATATGTGGAGAGTGCATCAATCAAACGCAC } \\
\text { ACCTTCGAATTTTATAATCCCTCGCGTGATGACTTGTCAGCAGATCT } \\
\text { GCACCTGTGGTCCACACGGCCCCGGTGGTG }\end{array}$ & GAA & $\mathrm{s}$ & 16,72 & 185 & $\begin{array}{l}\text { GATCGCGACAGACAT } \\
\text { CAGAA }\end{array}$ & 069 & $\begin{array}{l}\text { GTGCGTTTGATTGAT } \\
\text { GCACT }\end{array}$ & 59,7 & 50 & 45 & \\
\hline 168 & BrPe3019 & $\begin{array}{l}\text { Maracuja_ } \\
\text { NoIndex_L } \\
\text { 003_R1_00 } \\
\text { 1_contig_3 } \\
7596\end{array}$ & 3 & 6465 & 6479 & 15 & 5 & 12 & $\begin{array}{l}\text { ATCTTTTCCAACAAAAACTCTGAGTAGAGCTGAGTTTGAGTTAGAAG } \\
\text { CTCCTCCAACTTCGTATACTGAGTATCATTAAGCTGGGCTGCATCCT } \\
\text { TTGTCATTTTCTCAAGCTCGGCTTCTTCCTCTTTCACCCGAGCTTCTA } \\
\text { TGAGCTTTTCCTCCTCCTCCTCCATTGTTTTTGAGATAAGTGCAGAAG } \\
\text { CCCCCTTTTTCACATCTAGTATAGCATCATCTTCCACTTTTACCTCTG } \\
\text { TTTTATCCCCACTTGTTGTCTTCACACCACAGTTACAGGGAATAAAA } \\
\text { AAGATAAACTCAGGAATAGACAGAGTATAA }\end{array}$ & TCC & G & 20,69 & 184 & $\begin{array}{l}\text { GGCTGCATCCTTTGTC } \\
\text { ATTT }\end{array}$ & 60,1 & $\begin{array}{l}\text { TGGTGTGAAGACAA } \\
\text { CAAGTGG }\end{array}$ & 59,6 & 45 & 48 & \\
\hline 169 & BrPe3020 & $\begin{array}{l}\text { Maracuja_ } \\
\text { NoIndex_L } \\
003 \text { R1_00 } \\
\text { 1_contig_3 } \\
8802\end{array}$ & 3 & 887 & 901 & 15 & 5 & 12 & $\begin{array}{l}\text { AGGTATAATTGATTTCTTGTTCTGGCTTCTGGGTTTTAGTTGAATCTT } \\
\text { TTTGTTGTTGCAGTGACCTGTGTGGAATCTGGGGATAAAGCTTTGGA } \\
\text { GTACCTGGGTCTGCTTGATAACATAGAAAATGCTTCTCCACCTTCTT } \\
\text { CACCTTCGTCTTCTTCTTCTTCTACGTTTTCTTCACATTCACCAGAAG } \\
\text { AGGTGAGGTTATTTCTGCACTGTACATGTGGTGTCTTTCTTCATCAAT } \\
\text { CCTTGAAGCTATATTTCTATCTTTGATGCTTGGATAATGAAGAGATT } \\
\text { TGTCCTTACTCAACCAAAATGTGAGATTCA }\end{array}$ & ТСТ & G & 19,3 & 181 & $\begin{array}{l}\text { TGTTCTGGCTTCTGGG } \\
\text { TTTT }\end{array}$ & 59,7 & $\begin{array}{l}\text { ССТСACСTCTTCTGG } \\
\text { TGAATG }\end{array}$ & 59,7 & 45 & 52 & M \\
\hline 170 & BrPe3021 & $\begin{array}{l}\text { Maracuja_ } \\
\text { NoIndex_L } \\
003 \text { R1_00 } \\
\text { 1_contig_4 } \\
6530\end{array}$ & 3 & 1134 & 1145 & 12 & 4 & 9 & $\begin{array}{l}\text { ACTGAAATGAAAATTTTTTCTCTGGAAAGATCTCTACCACAAACTTT } \\
\text { AATGTGACTAAACAGATGGAGTACTGCTTGACCAGGTCAATGTGAA } \\
\text { TTCTTCTGCTGATGGACCAAGTACCTCCTCAGCACCAGATAATGACA } \\
\text { ACAATGCTCTTGATGATGATGACGATCTGGACATGGATGAGTTAAA } \\
\text { TGAGCTCGAAGCAAGCTTAGCAAAAACATCAATCCGAATTCAGTAG } \\
\text { CCTGGAAGGTACTGATTAATTTTGAGAGGCGGTGTATGTGTTTTAAT } \\
\text { GCCTTTCCACTATCCTGCTGCAAATGCATAATC }\end{array}$ & TGA & G & 15,16 & 207 & $\begin{array}{l}\text { TTCTTCTGCTGATGGA } \\
\text { CCAA }\end{array}$ & 59,4 & $\begin{array}{l}\text { GCAGCAGGATAGTG } \\
\text { GAAAGG }\end{array}$ & 59,8 & 45 & 55 & \\
\hline
\end{tabular}


APÉNDICE

Marcadores microssatélites desenhados a partir do sequênciamento parcial e da montagem de novo do genoma de $P$. edulis

\begin{tabular}{|c|c|c|c|c|c|c|c|c|c|c|c|c|c|c|c|c|c|c|c|}
\hline $\mathbf{N}^{\circ}$ & Primer & Contig I & Motivo & Início & Fim & pb & $\begin{array}{c}\mathbf{N}^{\circ} \\
\text { Repet }\end{array}$ & Score & Sequência do contig & Unidade & G/S & Cobertura & pb & Sequência Forward & $\begin{array}{l}\mathrm{T}^{\circ} \mathrm{C} \\
F w d \\
\end{array}$ & Sequência Reverse & $\begin{array}{r}\mathrm{T}^{\circ} \mathrm{C} \\
\operatorname{Rev} \\
\end{array}$ & $\begin{array}{c}\% \mathrm{GC} \\
F w d \\
\end{array}$ & $\begin{array}{c}\% \mathrm{GC} \\
\operatorname{Rev}\end{array} \quad \mathrm{P} / \mathrm{M}$ \\
\hline 171 & BrPe3022 & $\begin{array}{l}\text { Maracuja_ } \\
\text { NoIndex_L } \\
\text { 003_R1_00 } \\
\text { 1_contig_4 } \\
7174\end{array}$ & 3 & 597 & 611 & 15 & 5 & 12 & $\begin{array}{l}\text { AGGCATACATATCTTACATAATCAACAACACAACATAAGAAAAGGG } \\
\text { TCCACATGACAAAATCACATTCACATACATGATGCATCATATACAA } \\
\text { AAGGCAAAGATGGCACATACGGATCAAATCACTTCCCACAACAGAA } \\
\text { GTAAAAAGAATGATAATAATAATAATAGCACGTAGGACGATGGCA } \\
\text { ATGTTGGGCAAACTACACTAAATTTTACAAACAGGACCGCATACAA } \\
\text { AATGCACAAATTGATGCAAGGATTAGGAAATGACAGGACAAAATC } \\
\text { ATTAACACCTCATACACAAAATAATTTCCAGATACAGAG }\end{array}$ & $\overline{\text { ATA }}$ & $\mathrm{s}$ & 15,28 & 160 & $\begin{array}{l}\text { GGCACATACGGATCA } \\
\text { AATCA }\end{array}$ & 59,4 & $\begin{array}{l}\text { CAATTTCCTAATCCT } \\
\text { TGCATCA }\end{array}$ & 59,1 & 45 & 36 \\
\hline 172 & BrPe3023 & $\begin{array}{l}\text { Maracuja_ } \\
\text { NoIndex_L } \\
\text { 003_R1_00 } \\
\text { 1_contig_4 } \\
8019\end{array}$ & 3 & 338 & 349 & 12 & 4 & 9 & $\begin{array}{l}\text { TGTTGCCTGTGCTATTTTGATCAAAAATAAAAAAAGAATACATTCAAT } \\
\text { TTCCTTCCCTCTGGCCATTCTTCTAAAAACAGCATGTCTTCCGCTAG } \\
\text { TTTGATAGAACTCTGGCTTCGATCAAGCTCTCGTTACATTAATTCTTC } \\
\text { ATATATACTCCTCCTCCTCGTCAATCCTTCCCATAAATCTCATTCCTA } \\
\text { CGCTGCAACTCTTTGGCAACACGTTGGAAGAACTGTTGGATTGTTGC } \\
\text { ACCATCAGCAGTCGCCGCTGCCTTAATTGTATTACATTCATGCCTAA } \\
\text { TTCATTGATGTTGCCAGGGCTCCTGAC }\end{array}$ & СтС & G & 29,96 & 192 & $\begin{array}{l}\text { СТTCCCTCTGGCCATT } \\
\text { TCTT }\end{array}$ & 60,6 & $\begin{array}{l}\text { TGGTGCAACAATCC } \\
\text { AACAGT }\end{array}$ & 60,0 & 50 & 45 \\
\hline 173 & BrPe3024 & $\begin{array}{l}\text { Maracuja_ } \\
\text { NoIndex_L } \\
\text { 003_R1_00 } \\
\text { 1_contig_6 } \\
\text { 5896 }\end{array}$ & 3 & 2081 & 2095 & 15 & 5 & 12 & $\begin{array}{l}\text { GAACATTGGAAACAGTAAAAAGAAACGCTGCAATACATAAAGTGA } \\
\text { CTTCCTCACATCATAACCTACAGATTTAGTGGGAAGAAATAGAAA } \\
\text { ATGAGAAACTATCACTATGTCCGTGATAACTACATGAGAAAGTGAT } \\
\text { CCTTCAAAGGAAACATCATCATCATCATGCTAATGAGATGGCTTTTG } \\
\text { GCAGATAAATTTTAATGACACTAGTGAATTAAATGGGCCTCGAAGT } \\
\text { AATCAACCCACAACAAGTGCTTTTCTATCAGTGTCATTCCCCAAGAG } \\
\text { CACCAGAGAAAACACCCACCACATTTACCTCTCAAGGT }\end{array}$ & CAT & $\mathrm{s}$ & 19,28 & 215 & $\begin{array}{l}\text { CAGTAAAAAGAAACG } \\
\text { CTGCAA }\end{array}$ & 58,3 & $\begin{array}{l}\text { TCGAGGCCCATTTA } \\
\text { ATTCAC }\end{array}$ & 59,9 & 38 & 45 \\
\hline 174 & BrPe3025 & $\begin{array}{l}\text { Maracuja_ } \\
\text { NoIndex_L } \\
\text { 003_R1_00 } \\
\text { 1_contig_6 } \\
8409\end{array}$ & 3 & 251 & 262 & 12 & 4 & 9 & $\begin{array}{l}\text { TATGCTGTATATAAGTGAAATAACTGATTGAGAGTGCCATCTGACA } \\
\text { ATTCACTACCCACACAAGGCATGTGTACATAGTAGTCCCCAGGATCT } \\
\text { CCAAGCCAACAACTTCTCCGCCTTTTCGGAAAGCTTGATACTCCATT } \\
\text { GCGCGGATGCAGAAGAAGAAGATCAACGTAGCACTCACTACGCCAT } \\
\text { TAAATGCCCATCCGAAGATTCGTAACCAGCTAAACAGGAGGTTCTG } \\
\text { AACACCTTCTTGGTATAGTAGTGGGACTGAAGTACAGAGAAACAT } \\
\text { GTTCAGGAATATGAAAATTCTAATCCTGATGTAA }\end{array}$ & $\mathrm{AGA}$ & G & 16,49 & 163 & $\begin{array}{l}\text { TGCCATCTGACAATT } \\
\text { CACTACC }\end{array}$ & 60,0 & $\begin{array}{l}\text { ATGGGCATTTAATG } \\
\text { GCGTAG }\end{array}$ & 59,8 & 45 & 45 \\
\hline 175 & BrPe3026 & $\begin{array}{l}\text { Maracuja_ } \\
\text { NoIndex_L } \\
\text { 003_R1_00 } \\
\text { 1_contig_7 } \\
\text { 2670 }\end{array}$ & 3 & 1024 & 1035 & 12 & 4 & 9 & $\begin{array}{l}\text { TTATCATAGGAACAGCACCTCCAAAAGCAAAATTCAACCAAAAATT } \\
\text { CAAACCCAAGCAAATATTAACTTGCTTTTCCATGCCGTTTACAGACC } \\
\text { GCGAAATTTTCAACCTTCGGCGAAGGCATAACACAGTCATCAAATA } \\
\text { CAATCATACAATATTATTATTATCCATATTCATCGAAGAGATAACA } \\
\text { TCTCACTTAATTTCCAATCCACATCTTCACCTATCCAACACAATTTA } \\
\text { ACAGCTCAAACATCTAACACAAACTTACTTTCTCAAATGGAATTTC } \\
\text { TCCTCTTCTCCTCGGGGCTATTCCCTTCTGAA }\end{array}$ & TAT & $\mathrm{s}$ & 19,47 & 190 & $\begin{array}{l}\text { GCGAAGGCATAACAC } \\
\text { AGTCA }\end{array}$ & 59,9 & $\begin{array}{l}\text { AATAGCCCCGAGGA } \\
\text { GAAGAG }\end{array}$ & 59,8 & 50 & 55 \\
\hline
\end{tabular}


APÉNDICE

Marcadores microssatélites desenhados a partir do sequênciamento parcial e da montagem de novo do genoma de $P$. edulis

\begin{tabular}{|c|c|c|c|c|c|c|c|c|c|c|c|c|c|c|c|c|c|c|c|c|}
\hline $\mathbf{N}^{\circ}$ & Primer & Contig N & Motivo & Início & Fim & pb & $\begin{array}{c}\mathbf{N}^{\circ} \\
\text { Repet }\end{array}$ & Score & Sequência do contig & Unidade & G/S & Cobertura & pb & Sequência Forward & $\begin{array}{l}\mathrm{T}^{\circ} \mathrm{C} \\
F w d \\
\end{array}$ & Sequência Reverse & $\begin{array}{l}\mathrm{T}^{\circ} \mathrm{C} \\
\operatorname{Rev} \\
\end{array}$ & $\begin{array}{c}\% \mathrm{GC} \\
F w d \\
\end{array}$ & $\begin{array}{c}\% \mathrm{GC} \\
\operatorname{Rev} \\
\end{array}$ & $\mathbf{P} / \mathbf{M}$ \\
\hline 176 & BrPe3027 & $\begin{array}{l}\text { Maracuja_ } \\
\text { NoIndex_L } \\
\text { 003_R1_00 } \\
\text { 1_contig_7 } \\
\text { 3273 }\end{array}$ & 3 & 184 & 195 & 12 & 4 & 9 & $\begin{array}{l}\text { ACTAGCTGAACTGGCATAGGTGGTACCTCAACTCTCACATTGGGCAT } \\
\text { CGCTGGCTCAATTCTCGGCTTAGGGGTTACTGGTGTCTGTGTGGTC } \\
\text { CCGCTACACCATGCATTGCAGTCCAAAATGCCCAAAATGTCTGATA } \\
\text { AACTCTTGGAGGTGGTGGTGGTACATTTGGTGGGATAGCGGTAGCC } \\
\text { CTTCCCACTAGTTCATGGCTCTACTCATGCACTGACTCTACGGTTGG } \\
\text { CTCAAGTTGAGCCTGAGGCTCACCTCTATCTTGGCCCTCATCGCCCT } \\
\text { GATGCCTAGCCATCGACATCTCCTCACGGACA }\end{array}$ & GGT & $\bar{G}$ & 32,05 & 195 & $\begin{array}{l}\text { CCAAAATGCCCAAAA } \\
\text { TGTCT }\end{array}$ & 59,8 & $\begin{array}{l}\text { GTCCGTGAGGAGAT } \\
\text { GTCGAT }\end{array}$ & 60,1 & 40 & 55 & $\bar{P}$ \\
\hline 177 & BrPe3028 & $\begin{array}{l}\text { Maracuja_ } \\
\text { NoIndex_L } \\
\text { 003_R1_00 } \\
\text { 1_contig_1 } \\
\text { 71544 }\end{array}$ & 3 & 468 & 479 & 12 & 4 & 9 & $\begin{array}{l}\text { CAGACTGAGCCTGCTGAATCACATCAAGACCCTTGCAGAATGGAAC } \\
\text { AATTCCTCTTTGTTGGATTGCAGAAGGCTTCTCAAAACCTTGAAAA } \\
\text { AAATTTAAGAAAACATAGGCAACATTCAACAAAGAAATTAAGCATA } \\
\text { CAGTAAGGGGAAGTAGTAGTAGTTCACATAAAAATGGTATAGCAAG } \\
\text { GAAATAACAAAAACCAAAACTTGAATAATCCACAAGTTGGATGACA } \\
\text { GTCAGTTTTTACAACAAGAAAATTGATATTTAAGAACATCGTGAACT } \\
\text { ATTCAAGAACCAAGAACAAAATATGCAAATAAAA }\end{array}$ & AGT & G & 21,52 & 230 & $\begin{array}{l}\text { TGAGCCTGCTGAATC } \\
\text { ACATC }\end{array}$ & 60,0 & $\begin{array}{l}\text { TGACTGTCATCCAA } \\
\text { CTTGTGG }\end{array}$ & 59,6 & 50 & 48 & \\
\hline 178 & BrPe3029 & $\begin{array}{l}\text { Maracuja_ } \\
\text { NoIndex_L } \\
\text { 003_R1_00 } \\
\text { 1_contig_8 } \\
63\end{array}$ & 3 & 3450 & 3461 & 12 & 4 & 9 & $\begin{array}{l}\text { AATGAGTAAGCCAACTGTTCATGCGTCTCATACTATAGGTTGGCAAA } \\
\text { TTCAAAACCAACAGAGTCTTTGTGCATCTGGTCCTCCTGTCACTCTC } \\
\text { TCAGCTATCAGCAGAATAAGAAATGGAAACAGTGGCTGGAGAGGC } \\
\text { ACTGTAACTGGTGCTGCTGCTGCAACCTGCAGGCTGAGCTCCTTTTC } \\
\text { AGGCACTATTGCTTCATCTTTTCACAACTTTGGAGGCAATAATGATG } \\
\text { TCTATGTGAATGGAACTTCTTCAAAGAGAAAGTATCACCTTTTGGTT } \\
\text { TTTTCTCCTTCTGGTTCTATGATACAATATGC }\end{array}$ & $\mathrm{TGC}$ & G & 16,87 & 152 & $\begin{array}{l}\text { TGGCAAATTCAAAAC } \\
\text { CAACA }\end{array}$ & 59,9 & $\begin{array}{l}\text { GTGCCTGAAAAGGA } \\
\text { GCTCAG }\end{array}$ & 60,1 & 35 & 55 & M \\
\hline 179 & BrPe3030 & $\begin{array}{l}\text { Maracuja_ } \\
\text { NoIndex_L } \\
\text { 003_R1_00 } \\
\text { 1_contig_1 } \\
000\end{array}$ & 3 & 282 & 293 & 12 & 4 & 9 & $\begin{array}{l}\text { TCAGGACAGGAGATACAATCTGGAATGTCAGGACAGAACCTGTTGG } \\
\text { GAGAAGATTTTGCAGATGAGCTGTTCCTTTGAAGGTCTTCTTATTG } \\
\text { CCTTCTGTGCAGGTTTCTTGGGTGGCTTTTGTGCTGCTGGTGCATTTT } \\
\text { CCAGCAGGGGCTGCTGCTGCTCCTCTTGAATTTCTCCCCTGGTTCCTT } \\
\text { CTTGTTCCACCTTAATATCCATAACTTCAATATCTCCGGTCTTTCAGG } \\
\text { ATTAATCTTTTCTCGAACTTCTGATTGGATAGATTCTCTTTAGTCTTC } \\
\text { GATGAAAGCTCTGGAAGGATTGCTTGG }\end{array}$ & GCT & G & 15,69 & 161 & $\begin{array}{l}\text { GGACAGAACCTGTTG } \\
\text { GGAGA }\end{array}$ & 60,1 & $\begin{array}{l}\text { AGAAGGAACCAGG } \\
\text { GGAGAAA }\end{array}$ & 60,0 & 55 & 50 & \\
\hline 180 & BrPe3031 & $\begin{array}{l}\text { Maracuja_ } \\
\text { NoIndex_L } \\
\text { 003_R1_00 } \\
\text { 1_contig_1 } \\
024\end{array}$ & 3 & 3744 & 3755 & 12 & 4 & 9 & $\begin{array}{l}\text { TTAGCACTCTGAACTACCTCTGCAAAGGAACGGTGATCCCTCTTAGC } \\
\text { CTCCAAAATCCCCACTGGTCTATGCTCCTTGTTGCGAGTAGTTGACT } \\
\text { CGGGACTGACCACTCTATACCTATCATTATGATACGCATGTTGAAAC } \\
\text { AACCTACCACTCCTCCTCCTCATCCCATCTCTTCCCACATTGTTCACA } \\
\text { CCATACTTTGCTTCGTTAAATCTAAGACGTTGAGATCCGATCGAAAT } \\
\text { GGAGTTCAATCTTCTGCATCTAGCTTCCTCCTGTCTCCCGCTTCTCAG } \\
\text { AAAACGCACAAACGCAAATTTTGCACCC }\end{array}$ & СTC & G & 29,56 & 209 & $\begin{array}{l}\text { AAAGGAACGGTGATC } \\
\text { ССТCT }\end{array}$ & 59,9 & $\begin{array}{l}\text { CGATCGGATCTCAA } \\
\text { CGTCTT }\end{array}$ & 60,2 & 50 & 50 & \\
\hline
\end{tabular}

G: genoma funcional

S: genoma estructural

P: polimórfico

M: monomórfico 
APÉNDICE

Marcadores microssatélites desenhados a partir do sequênciamento parcial e da montagem de novo do genoma de $P$. edulis

\begin{tabular}{|c|c|c|c|c|c|c|c|c|c|c|c|c|c|c|c|c|c|c|c|}
\hline $\mathbf{N}^{\circ}$ & Primer & Contig I & Motivo & Início & Fim & pb & $\begin{array}{c}\mathbf{N}^{\circ} \\
\text { Repet }\end{array}$ & Score & Sequência do contig & Unidade & G/S & Cobertura & pb & Sequência Forward & $\begin{array}{l}\mathrm{T}^{\circ} \mathrm{C} \\
F w d\end{array}$ & Sequência Reverse & $\begin{array}{r}\mathrm{T}^{\circ} \mathrm{C} \\
\operatorname{Rev}\end{array}$ & $\begin{array}{r}\% \mathrm{GC} \\
F w d\end{array}$ & $\begin{array}{cc}\% \mathrm{GC} & \\
\operatorname{Rev} & \mathrm{P} / \mathrm{M}\end{array}$ \\
\hline 181 & BrPe3032 & $\begin{array}{l}\text { Maracuja_ } \\
\text { NoIndex_L } \\
\text { 003_R1_00 } \\
\text { 1_contig_1 } \\
\text { 291 }\end{array}$ & 3 & 318 & 329 & 12 & 4 & 9 & $\begin{array}{l}\text { GGCTGGTAATGCAGGCACTGACGATGCACATGGTGAGCTATGAAGG } \\
\text { AAGAGCTAACATGCAAATCCAGGTGGCCAAAGACCTTATTCCTGAT } \\
\text { CCAGAGTTTCTTGCCAAGTGCTTTGAAGACGCCTTGCTTGAAATGAA } \\
\text { GGAAGCAGCTACTGCTGCTGCTGTGTAAATGCCTCTCAGATCAAATT } \\
\text { TTCTGCGTTTGTGATGTAATTGTTAGCTCATAGATTAGTTGAGTA } \\
\text { GAGAACGAAGAATGACTATAGCTCATAGATTTCATTGGAGAATAAA } \\
\text { GACTCCTCATACATGAATGTTGTACAATTAGTA }\end{array}$ & CTG & $\mathrm{G}$ & 16,53 & 180 & $\begin{array}{l}\text { ACGATGCACATGGTG } \\
\text { AGCTA }\end{array}$ & 60,3 & $\begin{array}{l}\text { TCACAAACGCAGAA } \\
\text { AATTTGA }\end{array}$ & 59,3 & 50 & 33 \\
\hline 182 & BrPe3033 & $\begin{array}{l}\text { Maracuja_ } \\
\text { NoIndex_L } \\
003 \text { R1_00 } \\
\text { 1_contig_1 } \\
782\end{array}$ & 3 & 3765 & 3776 & 12 & 4 & 9 & $\begin{array}{l}\text { TTCAGAATCAAATAACTCCAACAGCTTGAGGATGAAGGGATTGATCA } \\
\text { ATAAATCTTTTAGCTAATTTTGCATCTGTCTCAGGTGATGCCACAAA } \\
\text { CCTTAAGAAAAGTTCGTAGACAATTTGCAAGTGAGGCCAAGCAGCA } \\
\text { TCCATCAAAGGCTCCTCCTCCTCTAATTCAACGCCATCTACAACTTT } \\
\text { GTTCTCGCGTGGTTGCGGAGTGCGAGTCCTAAACAAATTTGTGGACA } \\
\text { CCATTTTTACAACTTCTTGCATAGCAGATTCTGTGAATTTCCCACTCA } \\
\text { CAGAAGTTACATATTCTACAAGCTCTAGCAA }\end{array}$ & СтС & G & 17,42 & 184 & $\begin{array}{l}\text { TCCAACAGCTTGAGG } \\
\text { ATGAA }\end{array}$ & 59,4 & $\begin{array}{l}\text { AACCACGCGAGAAC } \\
\text { AAAGTT }\end{array}$ & 59,8 & 45 & 45 \\
\hline 183 & BrPe3034 & $\begin{array}{l}\text { Maracuja_ } \\
\text { NoIndex_L } \\
\text { 003_R1_00 } \\
\text { 1_contig_2 } \\
\text { 145 }\end{array}$ & 3 & 3804 & 3815 & 12 & 4 & 9 & $\begin{array}{l}\text { GAACAGCCTGATTTAATTCTGGCAATGCAGGAAAATCGGCTTCTTCA } \\
\text { AACATCATGCACTCGGCAATGATTGTTGTTCAGGAGTCACTCTGAGG } \\
\text { TCTCGATTTCCCTGTCTGCACGTAAAATGATCTCGATCTTCCTGCAAT } \\
\text { ATTTCCAGAATAATAATAATCTAAGAGAGGATTTCAAGGGTGAAGG } \\
\text { CAATGTTTTCCAGTGTTTCCTTGTCTTCGTTGAACGAGGAGACAGAG } \\
\text { ATCTATCACGTGGGTGACTTGCGCAAATGGTAGAAGGATGAGTTTG } \\
\text { CCTTTGATGACCTTTTTGTCGATCATTGATG }\end{array}$ & AAT & G & 17,1 & 169 & $\begin{array}{l}\text { CAGGAAAATCGGCTT } \\
\text { CTTCA }\end{array}$ & 60,3 & $\begin{array}{l}\text { AAACATTGCCTTCA } \\
\text { CCCTTG }\end{array}$ & 60,0 & 45 & 45 \\
\hline 184 & BrPe3035 & $\begin{array}{l}\text { Maracuja_ } \\
\text { NoIndex_L } \\
\text { 003_R1_00 } \\
\text { 1_contig_2 } \\
802\end{array}$ & 3 & 552 & 566 & 15 & 5 & 12 & $\begin{array}{l}\text { AAAGATCACATGGCTAATGAATCCTTTATTGCAAAAGATTTTCATGC } \\
\text { TGTCAGTTTGATGTGGCCTTTCTTTATGTAGATAGATTCCGTTGAAG } \\
\text { GGCCAATGCCACAGACAAAATTTGTTTTGAAAAAGGCTCTGGAGTT } \\
\text { TGGCCATGCTGTTGTTGTTGTTGTCAATAAGATTGATAGACCTTCTG } \\
\text { CTCGTCCAGACTATGTCGTCAATTCCACTTTTGAATTATTTATCGAAC } \\
\text { TGAATGCGACAGATGAACAGGTAAATTACTGATAGCTAACTCTCTG } \\
\text { AGTTGGGGTTTTAGAGTTGTTCTTAATTGCTAG }\end{array}$ & TGT & G & 19,65 & 150 & $\begin{array}{l}\text { TCAGTTTGATGTGGC } \\
\text { CTTTTC }\end{array}$ & 60,1 & $\begin{array}{l}\text { GTCTGGACGAGCAG } \\
\text { AAGGTC }\end{array}$ & 60,0 & 43 & 60,0 \\
\hline 185 & BrPe3036 & $\begin{array}{l}\text { Maracuja_ } \\
\text { NoIndex_L } \\
003 \text { R1_00 } \\
\text { 1_contig_3 } \\
150\end{array}$ & 3 & 1227 & 1247 & 21 & 7 & 18 & $\begin{array}{l}\text { CTGTCCCGAACAGGGGAGGTATTATGCGCTCTTTATTATTTTGGAAA } \\
\text { TTGCCAGTGACAAGTGATTGAATGTTGTCATTCTTCTAGTTGTGATT } \\
\text { GAGGAGATAGTGGATGAAGACAAACCAACAAATGGAGATGGGCAG } \\
\text { CCCGAACGACCGAAGAAGAAGAAGAAGAAGAAATCTAGTGACAAT } \\
\text { GGTGATGGAAATCAAAATAACTCTGAACGCAAATTGTTGTCAAGA } \\
\text { GAGACAGTGGTGCAGATTTGTTGCAAAGTGAAGATGAAGATGGCTT } \\
\text { TCCTATTTCTCCTGCCCATAAAAGCGAGGAAATGGTGCAGGAGCT }\end{array}$ & GAA & G & 15,48 & 243 & $\begin{array}{l}\text { GGGGAGGTATTATGC } \\
\text { GCTCT }\end{array}$ & 60,4 & $\begin{array}{l}\text { TGCAACAAATCTGC } \\
\text { ACCACT }\end{array}$ & 60,3 & 55 & 45 \\
\hline
\end{tabular}


APÉNDICE

Marcadores microssatélites desenhados a partir do sequênciamento parcial e da montagem de novo do genoma de $P$. edulis

\begin{tabular}{|c|c|c|c|c|c|c|c|c|c|c|c|c|c|c|c|c|c|c|c|c|}
\hline $\mathbf{N}^{\circ}$ & Primer & Contig I & Motivo & Início & Fim & pb & $\begin{array}{c}\mathbf{N}^{\circ} \\
\text { Repet }\end{array}$ & Score & Sequência do contig & Unidade & G/S & Cobertura & pb & Sequência Forward & $\begin{array}{l}\mathrm{T}^{\circ} \mathrm{C} \\
F w d\end{array}$ & Sequência Reverse & $\begin{array}{r}\mathrm{T}^{\circ} \mathrm{C} \\
\operatorname{Rev}\end{array}$ & $\begin{array}{r}\% \mathrm{GC} \\
F w d\end{array}$ & $\begin{array}{c}\% \mathrm{GC} \\
\operatorname{Rev}\end{array}$ & $\mathbf{P} / \mathbf{M}$ \\
\hline 186 & $\overline{\text { BrPe3037 }}$ & $\begin{array}{l}\text { Maracuja_ } \\
\text { NoIndex_L } \\
\text { 003_R1_00 } \\
\text { 1_contig_3 } \\
\text { 598 }\end{array}$ & 3 & 1813 & 1824 & 12 & 4 & 9 & $\begin{array}{l}\text { CCCTGATCCATCAGAGTCGTACATTGTTTCCTTCTTATGGGAAGACC } \\
\text { CACCATGACCATCGTGGTCATTGTCCTGAGATTCAATTCTCGAGAGC } \\
\text { TTAACAGCCGCTCTGGCAGCGACTGCAGCATAAGCTGCTGATTCAA } \\
\text { AGGCCTCTTGAGCAGCAGCAGCTACATCTCTGTACTTCTTCCTTGCT } \\
\text { CTTACGGATTCAGACAGTTCCTCAAGGTAGATCTCCTCGTCGACAAC } \\
\text { CTTAGTTTCTCCTCGAGGATCAACATTATCCACCTCGTCAGCTGGTTT } \\
\text { ATTAGATTCTTCCTGTTGCTCCAGGCTGAC }\end{array}$ & $\mathrm{AGC}$ & $\mathrm{G}$ & 15,13 & 191 & $\begin{array}{l}\text { AGAGCTTAACAGCCG } \\
\text { CTCTG }\end{array}$ & 59,9 & $\begin{array}{l}\text { ACCAGCTGACGAGG } \\
\text { TGGATA }\end{array}$ & 60,7 & 55 & 55 & \\
\hline 187 & BrPe3038 & $\begin{array}{l}\text { Maracuja_ } \\
\text { NoIndex_L } \\
003 \text { R1_00 } \\
\text { 1_contig_3 } \\
917\end{array}$ & 3 & 1135 & 1146 & 12 & 4 & 9 & $\begin{array}{l}\text { CACCGTTGTTGCAGATACGGGAATGCCACTGTGGCAGAGAATACGG } \\
\text { AGAGAGGGTGGCGGGATCTTATATTAAACAAGATACGTGCTGTATT } \\
\text { TGGTTTTGGCATCTAACCTGTTTATATCGTTTTTTCTGCAATTGTGA } \\
\text { AACTTTTATCCATCATCATCATATTTGCGTCGTTGCATGCTGGTGACT } \\
\text { GTTTCCAGAACCTTTGTGCTATCTGTTAGAAGACCATTCATGTGGTC } \\
\text { GTAATCTCTTTTCGTCGGATTAAATGGGTTACTTTTTGGGTTCAAGC } \\
\text { AAGTGCTTTCTTGAAGTAAAGACTTCGACA }\end{array}$ & CAT & $\mathrm{s}$ & 17,57 & 212 & $\begin{array}{l}\text { GGGTGGCGGGATCTT } \\
\text { ATATT }\end{array}$ & 60,0 & $\begin{array}{l}\text { CCCATTTAATCCGA } \\
\text { CGAAAA }\end{array}$ & 59,8 & 50 & 40 & M \\
\hline 188 & BrPe3039 & $\begin{array}{l}\text { Maracuja_ } \\
\text { NoIndex_L } \\
003 \text { R1_00 } \\
\text { 1_contig_4 } \\
228\end{array}$ & 3 & 224 & 235 & 12 & 4 & 9 & $\begin{array}{l}\text { ATCACAGATGCCGTCTGGAGATATTTTCACTTTCTGGCACTCATATT } \\
\text { ACTGCATCCAATAATTTTGCTTGATTACTGCAATATATACGTTACAG } \\
\text { GCAAAAGCTTTCCGTCCACACGATTCAGATGATGACGATTCAGATG } \\
\text { ATGACCTAAGTGATGATGATGAGTTGCAATCACCCATCGATGAGGT } \\
\text { GGATCCATTTATTTACTTTGTGGACACTGTGAAAGGTGAAGGAGGCC } \\
\text { TCTTACCTTAGTGTGTATAATAATGTCGAACTAAGTATTTGGACACC } \\
\text { GTTTAACTTGTTTTTGTTCTTCCAAATGAAGT }\end{array}$ & $\mathrm{TGA}$ & G & 17,23 & 230 & $\begin{array}{l}\text { CACAGATGCCGTCTG } \\
\text { GAGAT }\end{array}$ & 61,3 & $\begin{array}{l}\text { GCCTCCTTCACCTTT } \\
\text { CACAG }\end{array}$ & 59,8 & 55 & 55 & \\
\hline 189 & BrPe3040 & $\begin{array}{l}\text { Maracuja_ } \\
\text { NoIndex_L } \\
\text { 003_R1_00 } \\
\text { 1_contig_4 } \\
495\end{array}$ & 3 & 7388 & 7399 & 12 & 4 & 9 & $\begin{array}{l}\text { AGGCATTTCGACTCCATATTCTGATCACAACTTTGGCTTGTGCATGC } \\
\text { ATCAGGGACTGCCATAAAAGAACGAATTCAAGAGCAGCTGACAA } \\
\text { AGCAGCAGTTAATGGGGTGATCTATGATAAAGATATCGAATATTA } \\
\text { CTACGATGAAGGTGATGATGATGAAAAGGAGAAGGGTGATGAAGA } \\
\text { GGAATATAGTGATGAAGACGACATATCTACCTTGATTTAAGTGGGA } \\
\text { ATTCTATGGTTTGTGCATGATTCATAATGTAGATAATATTATTTGTTT } \\
\text { CCATATAGGATATTCTGTGTTCTTGCACCTAAAAG }\end{array}$ & TGA & G & 15,99 & 160 & $\begin{array}{l}\text { CACAACTTTGGCTTGT } \\
\text { GCAT }\end{array}$ & 59,8 & $\begin{array}{l}\text { ССТСТTСATСАСССТ } \\
\text { ТСТССТ }\end{array}$ & 59,7 & 45 & 52 & \\
\hline 190 & BrPe3041 & $\begin{array}{l}\text { Maracuja_ } \\
\text { NoIndex_L } \\
\text { 003_R1_00 } \\
\text { 1_contig_4 } \\
880\end{array}$ & 3 & 4737 & 4748 & 12 & 4 & 9 & $\begin{array}{l}\text { ATGAGCTGTCTCCAGGAAACATCAGGTGATTTCTGTGCACATCCTTT } \\
\text { AAAAGCAACATCTTCTCAAAATGCTTAGGAGACGTGCTGGTTCCAA } \\
\text { TGTAGGGTTCTTCCTCTGAAGAAGGCGGCTAAAGAGAAAGCTCAAG } \\
\text { CTGAACGTGCAGCTGCTGCTGCTAGTTTTAAGTCTATGCTTCAGGAA } \\
\text { AAAGGACATATAACCATCAACTCCATTTGGTCCAGGGTATGGTGTTC } \\
\text { AAATGTTTAAATTAGATTATTTGGAGTAATGTATAGAGGAATCGTAA } \\
\text { GTAGTGGCATTTTGACAATGCTGTTATGCGTT }\end{array}$ & GCT & G & 17,38 & 162 & $\begin{array}{l}\text { GCTTAGGAGACGTGC } \\
\text { TGGTT }\end{array}$ & 60,1 & $\begin{array}{l}\text { ACACCATACCCTGG } \\
\text { ACCAAA }\end{array}$ & 59,5 & 55 & 50 & \\
\hline
\end{tabular}

G: genoma funcional

S: genoma estructural

P: polimórfico

M: monomórfico 
APÉNDICE

Marcadores microssatélites desenhados a partir do sequênciamento parcial e da montagem de novo do genoma de $P$. edulis

\begin{tabular}{|c|c|c|c|c|c|c|c|c|c|c|c|c|c|c|c|c|c|c|c|}
\hline $\mathbf{N}^{\circ}$ & Primer & Contig I & Motivo & Início & Fim & pb & $\begin{array}{c}\mathbf{N}^{\circ} \\
\text { Repet }\end{array}$ & Score & Sequência do contig & Unidade & G/S & Cobertura & pb & Sequência Forward & $\begin{array}{l}\mathrm{T}^{\circ} \mathrm{C} \\
F w d\end{array}$ & Sequência Reverse & $\begin{array}{r}\mathrm{T}^{\circ} \mathrm{C} \\
\operatorname{Rev}\end{array}$ & $\begin{array}{r}\% \mathrm{GC} \\
F w d\end{array}$ & $\begin{array}{c}\% \mathrm{GC} \\
\operatorname{Rev}\end{array}$ \\
\hline 191 & BrPe3042 & $\begin{array}{l}\text { Maracuja_ } \\
\text { NoIndex_L } \\
\text { 003_R1_00 } \\
\text { 1_contig_4 } \\
890\end{array}$ & 3 & 438 & 449 & 12 & 4 & 9 & $\begin{array}{l}\text { CTTTTAATAGCTGTATGAAAAGTCAACAGCTCTTGGCGATTTATGACT } \\
\text { AACCTGAATTCCAGAAAGGACAAAGTTAGAACAAGCAAACCATAA } \\
\text { GTTATAACAAAGCAACACCAGACATTATCCATAACAGAACTAGATA } \\
\text { ATTACCTTGTTTTTCTTCTTCTTCCCAAGTAACACAGAGCAACAGCT } \\
\text { AACTGTTGGCATTTTGAGAGATGGACACAATGAAACTTCTGTGAAA } \\
\text { AGCCCAAATGACCTATGCACTCTTTCCTCTTTTTTTTCCTTGCACTT } \\
\text { CTTGCTTGTTTCTGGTTCTAATCAATCTATGCC }\end{array}$ & TTC & $\mathrm{G}$ & 18,68 & 222 & $\begin{array}{l}\text { GTCAACAGCTCTTGG } \\
\text { CGATT }\end{array}$ & 60,4 & $\begin{array}{l}\text { TCATTTGGGCTTTTC } \\
\text { ACAGA }\end{array}$ & 59,2 & 50 & 40 \\
\hline 192 & BrPe3043 & $\begin{array}{l}\text { Maracuja_ } \\
\text { NoIndex_L } \\
003 \text { 1_1_00 } \\
\text { 1_contig_6 } \\
230\end{array}$ & 3 & 686 & 697 & 12 & 4 & 9 & $\begin{array}{l}\text { GGATCTTGATATGATTCCCTTCGCTACCCCGAACAGAAGGTCTTCCT } \\
\text { TGATTGAATCGGTGAAGAGATTGTTGTCCTAAGCGGCTAGGAGAAT } \\
\text { TCTGTGAGATGTGAGGTGTCAAATGAGAAGCCTTTGACGAGGAACG } \\
\text { ACCATATCCAAGATGATGATGATCATAGATTGGATTGCTCTTCACCT } \\
\text { CTACATTTGAAAATGATTGAATCTGCCCATTTTGTCTGGCACATACC } \\
\text { ACAAGCTATCAATATATAGTAAGAGATATTCAAATGGATACCCCTT } \\
\text { GCAATTTCAACTTCACAAAACATAAGGAATCAC }\end{array}$ & GAT & G & 20,15 & 202 & $\begin{array}{l}\text { GCGGCTAGGAGAATT } \\
\text { CTGTG }\end{array}$ & 60,0 & $\begin{array}{l}\text { GCAAGGGGTATCCA } \\
\text { TTTGAA }\end{array}$ & 59,8 & 55 & 45 \\
\hline 193 & BrPe3044 & $\begin{array}{l}\text { Maracuja_ } \\
\text { NoIndex_L } \\
\text { 003_R1_00 } \\
\text { 1_contig_6 } \\
\text { 399 }\end{array}$ & 3 & 5935 & 5946 & 12 & 4 & 9 & $\begin{array}{l}\text { TCCTTGCCTGTGGAATTTTTTGGTACCCCAACAGAACCTGTTATGGC } \\
\text { GCTCTCCTTGCTGGTTTTCATTTTTGATTTCGCCCTCTGCAAGTCCTC } \\
\text { TTTCATGCTTCTTCTGTGGTCTGCTTCAGCCTCCTCGACTGAGTTAAC } \\
\text { TGCAAATGCAGCAGCAGCAACAGCAGCTGCAAACTGCTTTCTTGG } \\
\text { ACATCATAATCCTGATTCACCTGCCAATAGAACTGACCAGTAGCCCT } \\
\text { GCGGGTAAATGGTCCATACAGTTAGTTCACAGAGAAATCAGTGTTC } \\
\text { TTCCAATTCTCTTATACATGCTTCTGCTAA }\end{array}$ & $\mathrm{GCA}$ & G & 16,16 & 205 & $\begin{array}{l}\text { GAACCTGTTATGGCG } \\
\text { CTCTC }\end{array}$ & 59,9 & $\begin{array}{l}\text { GCAGGGCTACTGGT } \\
\text { CAGTTC }\end{array}$ & 59,8 & 55 & 60 \\
\hline 194 & BrPe3045 & $\begin{array}{l}\text { Maracuja_ } \\
\text { NoIndex_L } \\
003 \text { _R1_00 } \\
\text { 1_contig_6 } \\
761\end{array}$ & 3 & 6660 & 6671 & 12 & 4 & 9 & $\begin{array}{l}\text { CTCTTATAACTATGCACTCTGACTGAGAATAGTATGAAACCTGTAGA } \\
\text { AACGTTCAAGATTAAAGGTTGCCACCCCTACAATCCGATGGAGAT } \\
\text { TCGAGCTGAGAAGGCACTTGAGGCAATTCATGTGTGCTGTTTTGGA } \\
\text { AGGATCCCATAGAAGAAGAAGATAAAAGACTGCTCTCTGCCATGTT } \\
\text { GGGTGCTGTTTTCCCATCAGTGGATAAACCAGAAATACAAAGGATT } \\
\text { GTTGAAGATAAGGCGAGGAGAGTGGCTGAAGGCAAGGACAATGTC } \\
\text { AAGGTTCGTGGGCCGAAGCCTTTGCCAAAAGAAGC }\end{array}$ & AGA & G & 16,1 & 174 & $\begin{array}{l}\text { GAAGGCACTTGAGGC } \\
\text { AATTC }\end{array}$ & 59,8 & $\begin{array}{l}\text { ACATTGTCCTTGCCT } \\
\text { TCAGC }\end{array}$ & 60,3 & 50 & 50 \\
\hline 195 & BrPe3046 & $\begin{array}{l}\text { Maracuja_ } \\
\text { NoIndex_L } \\
003 \text { R1_00 } \\
\text { 1_contig_7 } \\
222\end{array}$ & 3 & 173 & 184 & 12 & 4 & 9 & $\begin{array}{l}\text { CTTTGACATCAGCCAGCATGTCAGCATCAGCTTCATTGCCAGCAAGA } \\
\text { TTTAAGGTTCTATCTTCAACAAAATCTCCAGCATTTGAACTCGGCCC } \\
\text { ATTATCTCTATTGCAAATTGTCATTTCGGGGTCCACAGGTTCATCAA } \\
\text { CCTTCATCACATCATCATCATTCACAAGCTCATCATCTTCCAACTTCC } \\
\text { CAATGGCTTCTTCTGTAAATTCTTGGTTGTCAACAGCCTCTTCCTGTT } \\
\text { CAACTTTCTTCAATGCCATGTAATCTGCTTCATCTTCTGCATATTTCA } \\
\text { AAGCAGCCTCCACATCATCATTGGACA }\end{array}$ & CAT & G & 16,88 & 191 & $\begin{array}{l}\text { CAGCATGTCAGCATC } \\
\text { AGCTT }\end{array}$ & 60,2 & $\begin{array}{l}\text { CAGAAGAAGCCATT } \\
\text { GGGAAG }\end{array}$ & 59,8 & 50 & 50 \\
\hline
\end{tabular}


APÉNDICE

Marcadores microssatélites desenhados a partir do sequênciamento parcial e da montagem de novo do genoma de $P$. edulis

\begin{tabular}{|c|c|c|c|c|c|c|c|c|c|c|c|c|c|c|c|c|c|c|c|}
\hline $\mathbf{N}^{\circ}$ & Primer & Contig I & Motivo & Início & Fim & pb & $\begin{array}{c}\mathbf{N}^{\circ} \\
\text { Repet }\end{array}$ & Score & Sequência do contig & Unidade & G/S & Cobertura & pb & Sequência Forward & $\begin{array}{l}\mathrm{T}^{\circ} \mathrm{C} \\
F w d \\
\end{array}$ & Sequência Reverse & $\begin{array}{r}\mathrm{T}^{\circ} \mathrm{C} \\
\operatorname{Rev} \\
\end{array}$ & $\begin{array}{c}\% \mathrm{GC} \\
F w d \\
\end{array}$ & $\begin{array}{c}\% \mathrm{GC} \\
\operatorname{Rev}\end{array} \quad \mathrm{P} / \mathrm{M}$ \\
\hline 196 & BrPe3047 & $\begin{array}{l}\text { Maracuja_ } \\
\text { NoIndex_L } \\
003 \text { R1_00 } \\
\text { 1_contig_7 } \\
424\end{array}$ & 3 & 273 & 284 & 12 & 4 & 9 & $\begin{array}{l}\text { CACGGACTTAAGTTTGGCGGAATCGCACTGGGAATGTACTTTTTGGA } \\
\text { TTGCACGTGATTGCCAAATATGTGCTCCTACGCGTATGGAAGGATAT } \\
\text { GAAGGCCGTAAGAAAATCAAATGGACTGCACCCATTACGAGATCAA } \\
\text { GATGTCAGACCATCATCATCATGACAAGGACCAGATCGGAATCTGA } \\
\text { TGATCAGGAGCATATATGCTCTCGTTTTGAAACCGGTTTGATTCTAA } \\
\text { ATTTCTAATGTTTGGAGGGCGAAATGATTTCAAATTTAAAGGTACCA } \\
\text { CGTACTGTACAGTATCAAAATAACCGTACGCC }\end{array}$ & CAT & $\mathrm{s}$ & 15,11 & 214 & $\begin{array}{l}\text { TTTTGGATTGCACGTG } \\
\text { ATTG }\end{array}$ & 60,5 & $\begin{array}{l}\text { CGCCCTCCAAACAT } \\
\text { TAGAAA }\end{array}$ & 60,1 & 40 & 45 \\
\hline 197 & BrPe3048 & $\begin{array}{l}\text { Maracuja_ } \\
\text { NoIndex_L } \\
003 \text { R1_00 } \\
\text { 1_contig_1 } \\
\text { 2707 }\end{array}$ & 3 & 4122 & 4133 & 12 & 4 & 9 & $\begin{array}{l}\text { CCAAATATTACTTTGAAACCGAAAGTATTATAGAGAATCATTATTAA } \\
\text { AAATAGAGAAGAAGACGATTTTCTTCTTACCATATCATGCTGAGGA } \\
\text { ATGCCTTCAGTAATGCACACGATCAAATCCAGTTCAGCTTCCAAACC } \\
\text { CTCCATAATTGCAGCAGCAGCAAACGGTGGAGGAACATAAATCACA } \\
\text { GAGGCATTAGCCTTCGTTTCAGCTTTCGCTTCTGCGACCGTGTTGAA } \\
\text { AACAGGAAGCCCCAAGTGCTCAGTGCCACCCTTCTTAGGTGTCACTC } \\
\text { CACC }\end{array}$ & GCA & G & 17,14 & 168 & $\begin{array}{l}\text { AATGCACACGATCAA } \\
\text { ATCCA }\end{array}$ & 60,2 & $\begin{array}{l}\text { CCTAAGAAGGGTGG } \\
\text { СACTGA }\end{array}$ & 59,9 & 40 & 55 \\
\hline 198 & BrPe3049 & $\begin{array}{l}\text { Maracuja_ } \\
\text { NoIndex_L } \\
003 \text { R1_00 } \\
\text { 1_contig_1 } \\
4263\end{array}$ & 3 & 840 & 851 & 12 & 4 & 9 & $\begin{array}{l}\text { AGGTAACCTTTAAAGGCTGAGGACACTCACGACCCAAATAACCATC } \\
\text { CAATGTCTCATCATTGTCTTCAAGTTCATCTCCTCCAGTGAAGACCA } \\
\text { CAATCATGTAGTCAATTATTTTGCTTCCAAACAGTGTCTGTAAGCTA } \\
\text { CGAAGTGCAGCTTCTTCTTCTTGTGAAAATCGAGTCCTAACTGAGAA } \\
\text { AACTACAAGGACGGCATGGATCCCATCCTTGGCATGTTAATACATT } \\
\text { TAACAATTTCTTTGCCAACAAATTCTGATCCAGCAGAGAAATCAAAT } \\
\text { AGACCTGCAATGACTCCTCATGTTAGTCTCT }\end{array}$ & СТT & G & 16,86 & 179 & $\begin{array}{l}\text { CACGACCCAAATAAC } \\
\text { CATCC }\end{array}$ & 60,1 & $\begin{array}{l}\text { CCATGCCGTCCTTGT } \\
\text { AGTTT }\end{array}$ & 60 & 50 & 50 \\
\hline 199 & BrPe3050 & $\begin{array}{l}\text { Maracuja_ } \\
\text { NoIndex_L } \\
003 \text { R1_00 } \\
\text { 1_contig_1 } \\
5273\end{array}$ & 3 & 8002 & 8013 & 12 & 4 & 9 & $\begin{array}{l}\text { TTGGTTGAGCAGAGAGCCACACGACTTTGATGTCATAGGTTCGAATC } \\
\text { CCGAGCTGGACTGCTAACATGGGAAACCTAGGCTGGTTAAGTCTAA } \\
\text { AAAATTCTTTGTGAACTTACGTCAAAGTTACAGCCAAGGGAAGCCC } \\
\text { TTCCGGTACAGCAACAACAACAATGGTAACCTGCAATATGTCAGAT } \\
\text { ATAAATAAATGAAAGAAACATGAAAGGGAGACTAATTCATGTCAGA } \\
\text { TATAAATAAATGAAAGAAACATGAAAGGGAGACTAAGTCAAAGCC } \\
\text { CACATACCGCAACAGTGAGAATCTTTATAACATCAT }\end{array}$ & $\mathrm{CAA}$ & G & 17,82 & 177 & $\begin{array}{l}\text { AGCAGAGAGCCACAC } \\
\text { GACTT }\end{array}$ & 60,2 & $\begin{array}{l}\text { TCTGACATATTGCA } \\
\text { GGTTACCA }\end{array}$ & 58,2 & 55 & 41 \\
\hline 200 & BrPe3051 & $\begin{array}{l}\text { Maracuja_ } \\
\text { NoIndex_L } \\
\text { 003_R1_00 } \\
\text { 1_contig_1 } \\
85703\end{array}$ & 3 & 325 & 336 & 12 & 4 & 9 & $\begin{array}{l}\text { GGAGTGGTGAGAGAGGATATTCCACTCGCTGGAAAGGTTAATATGA } \\
\text { ATGGCGGGTATTTTGGCGATTTATCAAGTGTAGCAGTGAATGGTACT } \\
\text { GGCTTAGGAATCGGATTTCAGCAGAATAAGGGTGGTGGATTGAATA } \\
\text { ATGTTAGCATCAATAATAATAATTCTAATCAGATTTCTTTACAGTCC } \\
\text { TCGAATTTGCCTTTGAATGTCAATGGGATTAGATCAAGCCAAGGAC } \\
\text { AGGTACAGCAGCAGCAAATATATCCTAAGCAGCCTAATGTGGGATA } \\
\text { TGTGCCCCAGATACCTTTGCAAAGCAGTCCTGGG }\end{array}$ & AAT & G & 9,13 & 185 & $\begin{array}{l}\text { TATTCCACTCGCTGG } \\
\text { AAAGG }\end{array}$ & 60,2 & $\begin{array}{l}\text { TCAAAGGCAAATTC } \\
\text { GAGGAC }\end{array}$ & 60,2 & 50 & 45 \\
\hline
\end{tabular}


APÉNDICE

Marcadores microssatélites desenhados a partir do sequênciamento parcial e da montagem de novo do genoma de $P$. edulis

\begin{tabular}{|c|c|c|c|c|c|c|c|c|c|c|c|c|c|c|c|c|c|c|c|}
\hline $\mathbf{N}^{\circ}$ & Primer & Contig $\mathrm{I}$ & Motivo & Início & Fim & pb & $\begin{array}{c}\mathbf{N}^{\circ} \\
\text { Repet }\end{array}$ & Score & Sequência do contig & Unidade & G/S & Cobertura & pb & Sequência Forward & $\begin{array}{l}\mathrm{T}^{\circ} \mathrm{C} \\
F w d\end{array}$ & Sequência Reverse & $\begin{array}{r}\mathrm{T}^{\circ} \mathrm{C} \\
\operatorname{Rev}\end{array}$ & $\begin{array}{r}\% \mathrm{GC} \\
F w d\end{array}$ & $\begin{array}{c}\% \mathrm{GC} \\
\operatorname{Rev}\end{array} \quad \mathrm{P} / \mathbf{M}$ \\
\hline 201 & BrPe3052 & $\begin{array}{l}\text { Maracuja_ } \\
\text { NoIndex_L } \\
\text { 003_R1_00 } \\
\text { 1_conti__8 } \\
02\end{array}$ & 3 & 15122 & 15133 & 12 & 4 & 9 & $\begin{array}{l}\text { GAGGGATAAGAAAGAGAAACTTCAGTCAAATAGAACAATACATAG } \\
\text { TAGCTCAAAGAAAGGAAAGTACGTCGTGAGCTGTAGGCAGGAAAG } \\
\text { AGAAAATAGAGCGATTGGTAAGCTGACCCTACAAGGAATTCTTTAG } \\
\text { TTTCCGTTTAGTGGGAAGAAGAAGAAAGGGGAAAGACTTCTGATC } \\
\text { TTTGCGAGCACGAGTGAGTTATACACTACCTTCCCACCCCGGTCAGA } \\
\text { GAGAATTGCGTAAGGGGCGAGGCGTAGGCGGGAACTTGAAGCTTCT } \\
\text { CAGTCCTTACTCAACTATCAGTACAGTAAGGCTTCGC }\end{array}$ & GAA & $\mathrm{G}$ & 358,52 & 178 & $\begin{array}{l}\text { CGTGAGCTGTAGGCA } \\
\text { GGAA }\end{array}$ & 60,1 & $\begin{array}{l}\text { GCCCCTTACGCAAT } \\
\text { TCTCTC }\end{array}$ & 61,1 & 57,9 & 55 \\
\hline 202 & BrPe3053 & $\begin{array}{l}\text { Maracuja_ } \\
\text { NoIndex_L } \\
003 \text { R1_00 } \\
\text { 1_contig_1 } \\
638\end{array}$ & 3 & 1418 & 1429 & 12 & 4 & 9 & $\begin{array}{l}\text { TGGGGTAGATATAGGTGCCTGGAAATTCACCGGTATAAACTCACCA } \\
\text { GTACTCTCTTCTTGGTGTTCCCAATCCATAGCAGAGGACTTGCTAAT } \\
\text { TTGAGAGTCTCCAACTTCTCGATCCACATTACCAACAGCCGTAGCAG } \\
\text { CATGATCAAAATCATCATCATCTTCATCATCACTTTCTTCTAATTCTT } \\
\text { CCACATAGGCATTAGCAAAATCCTCATCAATGTCCTGGAAAGGAAG } \\
\text { ATTATCCCAAACAATT }\end{array}$ & ATC & G & 18,95 & 165 & $\begin{array}{l}\text { TTCCCAATCCATAGC } \\
\text { AGAGG }\end{array}$ & 60,0 & $\begin{array}{l}\text { TTCCAGGACATTGA } \\
\text { TGAGGA }\end{array}$ & 59 & 50 & 45 \\
\hline 203 & BrPe3054 & $\begin{array}{l}\text { Maracuja_ } \\
\text { NoIndex_L } \\
\text { 003_R1_00 } \\
\text { 1_contig_2 } \\
175\end{array}$ & 3 & 2882 & 2893 & 12 & 4 & 9 & $\begin{array}{l}\text { AACCTTGTGTCCGGATTAGCTGGAGCAAAAATGAACCAAACAACAT } \\
\text { TCATTTAATAACCAAGCATGCAAGCGTTTGATAACAATAATCAGAC } \\
\text { CATGCTTTGAACAAGTTGAAAGTAAAGCGAAATGTAACCCGGCGAC } \\
\text { GGAAGTGCAGGCGGAGGAGGAGGAACTGGTGGAGCTAAGGCGGAA } \\
\text { GGTGGTGGTGGATTTGGGAGTTGGAGTTGAGAGATTGGTGAAACTC } \\
\text { GTGCATCCATCCGGTTGTTTGGCGTCTGAAGCGAGAAAACCGCCTCC } \\
\text { GCTGTCTAGAGAGAGGTTAGTAAACATTCGAGCGAA }\end{array}$ & GGA & G & 13,38 & 178 & $\begin{array}{l}\text { CCTTGTGTCCGGATTA } \\
\text { GCTG }\end{array}$ & 60,6 & $\begin{array}{l}\text { CGCCTTAGCTCCAC } \\
\text { CAGT }\end{array}$ & 59 & 55 & 61,1 \\
\hline 204 & BrPe3055 & $\begin{array}{l}\text { Maracuja_ } \\
\text { NoIndex_L } \\
\text { 003_R1_00 } \\
\text { 1_contig_2 } \\
811\end{array}$ & 3 & 2059 & 2070 & 12 & 4 & 9 & $\begin{array}{l}\text { GGATATTTTGACTCTACAAACAGAGATGGAGTTTGCGCAGAGCATA } \\
\text { TCTGAACGATGCCATGCGAAGTGCCGCGGGATTGAAGATCAGATAA } \\
\text { ATGAGAAGCAAGGGAAAATCAGCAACTTACAAGATGAGTTTGGTAT } \\
\text { TGGCAAAGCTATTGATGATGATGAAGCTCGAACTTTGATGGCAGCC } \\
\text { ACAGCACTGAAGTCATGCAAGGATAGCTTGGTTAAGTTGCAAGAGA } \\
\text { AGCAGGAGCAGTCAGCTCAAGAGGCTCAAATAGAGCAGCAGAGGA } \\
\text { TCAAGGGAGTCCACCATAAAATCACCTCCCTTAAAGG }\end{array}$ & TGA & G & 13,68 & 207 & $\begin{array}{l}\text { CGCAGAGCATATCTG } \\
\text { AACGA }\end{array}$ & 60,1 & $\begin{array}{l}\text { АСTGCTCCTGCTTCT } \\
\text { CTTGC }\end{array}$ & 59,9 & 50 & 55 \\
\hline 205 & BrPe3056 & $\begin{array}{l}\text { Maracuja_ } \\
\text { NoIndex_L } \\
003 \text { 181_00 } \\
\text { 1_conti__3 } \\
173\end{array}$ & 3 & 4282 & 4293 & 12 & 4 & 9 & $\begin{array}{l}\text { TACTGTTGGATCTTAATGACAAAGACTTCCTTTCTCAAGGCTAGAAA } \\
\text { TAGATGTCTGAAGATCTACGAAGGGTTCGGGTTGTCAGTCCAGAGC } \\
\text { GGGACCTTTTTTCTTTTTAGTTATGAGTCCTATCCTTATTTGAATTTT } \\
\text { ACACAGCAACATCATCATCATACTATTCGGGAGACATGGTCCAAGC } \\
\text { CCGGTGAAATGATCACCCATGACTTCTTTGTACCGGGTCCCATTACT } \\
\text { TTCTTTCTTTTTCCAAAGGACGAGTAAGAGTGATATAAATCCGTTC } \\
\text { CCAACCAAACGTCGATACCGGCCCACATCAG }\end{array}$ & CAT & G & $1.010,54$ & 160 & $\begin{array}{l}\text { AGGGTTCGGGTTGTC } \\
\text { AGTC }\end{array}$ & 60,0 & $\begin{array}{l}\text { GGGACCCGGTACAA } \\
\text { AGAAGT }\end{array}$ & 60,2 & 57,9 & 55 \\
\hline
\end{tabular}

G: genoma funcional

S: genoma estructural

P: polimórfico

M: monomórfico 
APÉNDICE

Marcadores microssatélites desenhados a partir do sequênciamento parcial e da montagem de novo do genoma de $P$. edulis

\begin{tabular}{|c|c|c|c|c|c|c|c|c|c|c|c|c|c|c|c|c|c|c|c|}
\hline $\mathbf{N}^{\circ}$ & Primer & Contig I & Motivo & Início & Fim & pb & $\begin{array}{c}\mathbf{N}^{\circ} \\
\text { Repet }\end{array}$ & Score & Sequência do contig & Unidade & G/S & Cobertura & pb & Sequência Forward & $\begin{array}{l}\mathrm{T}^{\circ} \mathrm{C} \\
F w d \\
\end{array}$ & Sequência Reverse & $\begin{array}{r}\mathrm{T}^{\circ} \mathrm{C} \\
\operatorname{Rev} \\
\end{array}$ & $\begin{array}{c}\% \mathrm{GC} \\
F w d \\
\end{array}$ & $\begin{array}{cc}\% \mathrm{GC} & \mathrm{P} / \mathrm{M} \\
\operatorname{Rev} & \end{array}$ \\
\hline 206 & BrPe3057 & $\begin{array}{l}\text { Maracuja_ } \\
\text { NoIndex_L } \\
003 \text { R1_00 } \\
\text { 1_contig_3 } \\
173\end{array}$ & 3 & 4364 & 4375 & 12 & 4 & 9 & $\begin{array}{l}\text { CAGTCCAGAGCGGGACCTTTTTTCTTTTTAGTTATGAGTCCTATCCTT } \\
\text { ATTTGAATTTTACACAGCAACATCATCATCATACTATTCGGGAGACA } \\
\text { TGGTCCAAGCCCGGTGAAATGATCACCCATGACTTCTTTGTACCGGG } \\
\text { TCCCATTACTTTCTTTCTTTTTCCAAAGGACGAGTAAGAGTGATATA } \\
\text { AATCCGTTTCCCAACCAAACGTCGATACCGGCCACATCAGGAAAG } \\
\text { GGATCGCCATGATCAGCATCAAGCTTAATGGTGAATCCATAGGAGT } \\
\text { ATCAACAGGGCGAGCACCGAGAAAGCCAGTC }\end{array}$ & CAT & $\mathrm{G}$ & $1.010,54$ & 145 & $\begin{array}{l}\text { AGTCCAGAGCGGGAC } \\
\text { CTTT }\end{array}$ & 61,2 & $\begin{array}{l}\text { GGGACCCGGTACAA } \\
\text { AGAAGT }\end{array}$ & 60,2 & 57,9 & 55 \\
\hline 207 & BrPe3058 & $\begin{array}{l}\text { Maracuja_ } \\
\text { NoIndex_L } \\
\text { 003_R1_00 } \\
\text { 1_contig_3 } \\
\text { 575 }\end{array}$ & 3 & 278 & 289 & 12 & 4 & 9 & $\begin{array}{l}\text { ATACAAAAAGTTTGTAAGATGGAACCAAGAGAGAAAGCACAATAA } \\
\text { GACTTCAAAAGGTAAGAATGTAGTTACTTGTTATGAATGTGGAAAT } \\
\text { GCAGGTCACATTAAACCTGAATGTCCAAATCTCAAGAACAAGAAAG } \\
\text { GATTCAACAACTTGAAGAAGAAGAAAGCCTTACAAGTCACATGGGA } \\
\text { TGATCTAAATTCGGATTCAAGTGACAGTGAAAGTGTAGAAGAAAAT } \\
\text { GTCAACCTATGCTTGATGGCCAATGAAGAACATGATGAAGTAAGTT } \\
\text { CTAATTGCTCTTCCTCTCAATCTGATTTCGAATTTGA }\end{array}$ & GAA & G & $11.078,00$ & 177 & $\begin{array}{l}\text { GAATGTGGAAATGCA } \\
\text { GGTCA }\end{array}$ & 59,5 & $\begin{array}{l}\text { TTCATTGGCCATCA } \\
\text { AGCATA }\end{array}$ & 60 & 45 & 40 \\
\hline 208 & BrPe3059 & $\begin{array}{l}\text { Maracuja_ } \\
\text { NoIndex_L } \\
\text { 003_R1_00 } \\
\text { 1_contig_3 } \\
995\end{array}$ & 3 & 1819 & 1830 & 12 & 4 & 9 & $\begin{array}{l}\text { ATCCAACCTTCAAGAAGACGTGAGATGTTCTCAGTGCTTGATGCGTA } \\
\text { TGTAGAGCTTGTGGTGTGGTTAAACCCGAGATTTGAAGGAGTAGTG } \\
\text { GTGAGATCTAAGGTGGTTCTTCTGTCGCTGAAACACTTTGATGAGAC } \\
\text { AAACTGAGTACTGCTGCTGCTGGTTGAGTCTTGTGTCAGAGGGTCA } \\
\text { AAGATGACTGGAACTTCTTTAGCTTCTTCTTCAGGTGGGTGTTCCAG } \\
\text { TAGTTCTTTATATCATTATCTGTTCTCTGTGGAAGGTATGAAGCTATG } \\
\text { GCCGCCCATCTGCTCGGAGAGAACGAAGGA }\end{array}$ & CTG & G & 16,49 & 180 & $\begin{array}{l}\text { TGGTTCTTCTGTCGCT } \\
\text { GAAA }\end{array}$ & 59,6 & $\begin{array}{l}\text { CGGCCATAGCTTCA } \\
\text { TACCTT }\end{array}$ & 59,2 & 45 & 50 \\
\hline 209 & BrPe3060 & $\begin{array}{l}\text { Maracuja_ } \\
\text { NoIndex_L } \\
\text { 003_R1_00 } \\
\text { 1_contig_4 } \\
352\end{array}$ & 3 & 2758 & 2769 & 12 & 4 & 9 & $\begin{array}{l}\text { GTGCTTTTATCTTCATATTGCTAATATCTACCACATAAAAATTAAAC } \\
\text { ACTCCTAAACAGGGAGTATATGGCATCTTCTATATCTCTAAAATCGG } \\
\text { AAAAAGAGCTGGCCTAGCTGGGTACCTCGAGCACGGAAGTTGGTG } \\
\text { ACTGGCTTTCTAGTAGTAGTAGATTTGTTGTTAGAAGTGAACCAGTC } \\
\text { CTCAAAGAACCTAGCGGCAGCACCTTTGTTGTCACCACTAATAAGCT } \\
\text { TATTATCTCTGCTCATAGAAGTTCATGAGTAGCATACCAGTTGAAT } \\
\text { GCTCCTATGCTCTTGCCACTTGCACTGTCTA }\end{array}$ & TAG & G & 12,18 & 183 & $\begin{array}{l}\text { GAGCACGGAAGTTGG } \\
\text { TGACT }\end{array}$ & 60,3 & $\begin{array}{l}\text { GTGCAAGTGGCAAG } \\
\text { AGCATA }\end{array}$ & 50 & 55 & 50 \\
\hline 210 & BrPe3061 & $\begin{array}{l}\text { Maracuja_ } \\
\text { NoIndex_L } \\
\text { 003_R1_00 } \\
\text { 1_contig_4 } \\
386\end{array}$ & 3 & 717 & 728 & 12 & 4 & 9 & $\begin{array}{l}\text { ACCAACATATATTCAGCTTGCCACACTTTGGATGATAGTCAAAACCC } \\
\text { TGGGCCTCAATAGCCCTTTTGGAGAGAAAAGCAATTTGACACTTCA } \\
\text { AACCAACCCTCGAAGAAGGGTCAATACCATTTGGGTACGAAGCGAC } \\
\text { TCGAGATCTCTTTCTTCTTCTTCAAATGGCGAAAGAGATCTCGAAGC } \\
\text { GACTAGTCTGATCTGGTACGATTTAGGTTGGGGGTTTTGAGTCATAG } \\
\text { CATAGAGAGTCTGTATTTGATTGGATATAGATGACTTATAAGTTA } \\
\text { AGGAGGATTCAAGACATCTACCTTATGTTTTG }\end{array}$ & TTC & G & 294,18 & 184 & $\begin{array}{l}\text { AAAACCCTGGGCCTC } \\
\text { AATAG }\end{array}$ & 60,3 & $\begin{array}{l}\text { AAAACCCCCAACCT } \\
\text { AAATCG }\end{array}$ & 60 & 50 & 45 \\
\hline
\end{tabular}

G: genoma funcional

S: genoma estructural

P: polimórfico

M: monomórfico 
APÉNDICE

Marcadores microssatélites desenhados a partir do sequênciamento parcial e da montagem de novo do genoma de $P$. edulis

\begin{tabular}{|c|c|c|c|c|c|c|c|c|c|c|c|c|c|c|c|c|c|c|c|}
\hline $\mathbf{N}^{\mathbf{o}}$ & Primer & Contig $\mathrm{I}$ & Motivo & Início & Fim & pb & $\begin{array}{c}\mathbf{N}^{\circ} \\
\text { Repet }\end{array}$ & Score & Sequência do contig & Unidade & G/S & Cobertura & pb & Sequência Forward & $\begin{array}{l}\mathrm{T}^{\circ} \mathrm{C} \\
F w d\end{array}$ & Sequência Reverse & $\begin{array}{r}\mathrm{T}^{\circ} \mathrm{C} \\
\operatorname{Rev}\end{array}$ & $\begin{array}{c}\% \mathrm{GC} \\
F w d\end{array}$ & $\begin{array}{c}\% \mathrm{GC} \\
\operatorname{Rev}\end{array} \quad \mathrm{P} / \mathbf{M}$ \\
\hline 211 & BrPe3062 & $\begin{array}{l}\text { Maracuja_ } \\
\text { NoIndex_L } \\
003 \text { R1_00 } \\
\text { 1_contig_5 } \\
103\end{array}$ & 3 & 162 & 176 & 15 & 5 & 12 & $\begin{array}{l}\text { GGCATGTAAATCTAGGTCCTTTTCTAGGCAAAAAAATTAAAAATACG } \\
\text { CTTCCCTGTGCCCTAATATGATTAGATCTGAAATTGCCTAGATTTCC } \\
\text { ATCAGTAGAAGGACCAGCAATTGAGTAAGTGGAAGAACCAGTAGTG } \\
\text { CAGCTAGATGTACCACCACCACCACCTCTAGGAGCCTATGAGGTGT } \\
\text { TCATAGCATTTCGAGCTGCTATGCATGGTGCAACAAGACCAGAACA } \\
\text { GGTAGCCACAGTCCCTGAGCCGGGAGTAGAGACGGCGATTCCGAAG } \\
\text { CTTCAAGTTGAGGTTCCACCAATGCCAGTTCAGCCGGT }\end{array}$ & $\mathrm{ACC}$ & $\mathrm{G}$ & 133,8 & 157 & $\begin{array}{l}\text { CCATCAGTAGAAGGA } \\
\text { CCAGCA }\end{array}$ & 60,3 & $\begin{array}{l}\text { CAGGGACTGTGGCT } \\
\text { ACCTGT }\end{array}$ & 60,2 & 52,4 & 60 \\
\hline 212 & BrPe3063 & $\begin{array}{l}\text { Maracuja_ } \\
\text { NoIndex_L } \\
003 \text { 11_00 } \\
\text { 1_contig_6 } \\
024\end{array}$ & 3 & 1770 & 1781 & 12 & 4 & 9 & $\begin{array}{l}\text { TTCTGGGAACTCGCAAGAGAAAGATGTATCCTCTAACACAGTCAAT } \\
\text { GATTCTGATGCTGGCGAAAACCAGCAAGTTAATCCTTCAAACCCCC } \\
\text { AAGAGAATGACGGGTCCTCAAACTCCCAAGAGAAAGACATGTCCTC } \\
\text { GAACTCAAGTGGCAACAACAACAATGCTGATGCTGGCGACAACACG } \\
\text { AATGAGAGTTCTACAAGTCCCAACAAAGAAAATGATAGCGATGCCA } \\
\text { AGGATAGCAGTAACGCCGACCAAAATGGACAAGTCGATTCAAATGA } \\
\text { TGCTGGGGGAAATGAAGGCAACAATCATGTTCACAG }\end{array}$ & CAA & G & 17,08 & 155 & $\begin{array}{l}\text { GAGAATGACGGGTCC } \\
\text { TCAAA }\end{array}$ & 60,0 & $\begin{array}{l}\text { TCGGCGTTACTGCT } \\
\text { ATCCTT }\end{array}$ & 59,9 & 50 & 50 \\
\hline 213 & BrPe3064 & $\begin{array}{l}\text { Maracuja_ } \\
\text { NoIndex_L } \\
003 \text { _R1_00 } \\
\text { 1_contig_6 } \\
092\end{array}$ & 3 & 3493 & 3504 & 12 & 4 & 9 & $\begin{array}{l}\text { GGGATGTCTAAGTTATGATCCAAATTTTGAAGAAGATGATGATGAG } \\
\text { TACGTTTTCGTAGTTCAAATAAGCATATACATAATGCTTGATGATA } \\
\text { CCTCTGCTTATATCCAGCGAATTGCTGCTTTGCAGTGAATGTGCAGG } \\
\text { TGAACATGCAGATGATGATGATTATGATAGCTGGAAAGTTCGCAGG } \\
\text { GCAGCGACCAAATGCTTGTCTGCTTTCATTGTTTCTCGTCCTGAACTT } \\
\text { CTCTCCAAGCTTTATGATGAGAAGGTATCTCTGTATAAATCTAAGT } \\
\text { TACGCTATGTTGAGAATGTTTTTTCTTGATT }\end{array}$ & GAT & G & 16,41 & 150 & $\begin{array}{l}\text { ACCTCTGCTTATATCC } \\
\text { AGCGAAT }\end{array}$ & 60,5 & $\begin{array}{l}\text { TTGGAGAGAAGTTC } \\
\text { AGGACGA }\end{array}$ & 60 & 43,5 & 47,6 \\
\hline 214 & BrPe3065 & $\begin{array}{l}\text { Maracuja_ } \\
\text { NoIndex_L } \\
003 \text { R1_00 } \\
\text { 1_contig_6 } \\
135\end{array}$ & 3 & 1930 & 1941 & 12 & 4 & 9 & $\begin{array}{l}\text { CTCCTGCAAAAGTGGAGCTCTTTGGACACTGAAGGAGACAATAAAC } \\
\text { AATCTTCAGGGAAGGCAAAAAACTATGCCTGTGGAATCAAAGGCAA } \\
\text { AAGAACAAGTAAGAACAGGAGTGATGCAAAGAAGAGACAAAGAGA } \\
\text { AGGATGGACAATGGAAGAAGAAGAATGACTTGAGGGACAAACAAT } \\
\text { GATACGTGAAAGAAGTTGTCATGTCATGGAGTTAGTCATGTCCTGT } \\
\text { TTTTGTGATGAGCATTAACTATTTGGCCATTTTATACTGTCTTGTCT } \\
\text { TAAAATGACATATCTTAAAACCATGCACCTTTTTT }\end{array}$ & GAA & G & 18,23 & 171 & $\begin{array}{l}\text { TGGAGCTCTTTGGAC } \\
\text { ACTGA }\end{array}$ & 59,5 & $\begin{array}{l}\text { CATTGTTTGTCCCTC } \\
\text { AAGTCA }\end{array}$ & 58,6 & 50 & 42,9 \\
\hline 215 & BrPe3066 & $\begin{array}{l}\text { Maracuja_ } \\
\text { NoIndex_L } \\
\text { 003_R1_00 } \\
\text { 1_contig_6 } \\
\text { 189 }\end{array}$ & 3 & 5494 & 5505 & 12 & 4 & 9 & $\begin{array}{l}\text { ACCAACCCCAAGGTATGGGTGGTGGTGTTGGGCGTGACGGTGGCTG } \\
\text { GAGTGGTGCTGGTGGCAGAGGTTAAGCGGAGGAGACGGGAAGTGA } \\
\text { CTGACAAGGAGGATCATGGAGCGTTTCTGGAAAGATTTGAGATTCT } \\
\text { TCCTTTCCCTCAGCCTCCTCCTCCTGCTGCGAAGCTGAGCCTCTCTGG } \\
\text { TCTTACTTTTGCCATCAAAGACATGTTTGTATTTGCTTTCCTCCTTTC } \\
\text { TGCTCCATTATATTTATCAACATCTGGTCTCTAGTGGATTCGTAGCTT } \\
\text { TCATAAAGTTTTGAAGCCTTTCACTTGACTC }\end{array}$ & $\mathrm{CCT}$ & G & 13,9 & 158 & $\begin{array}{l}\text { ACGGGAAGTGACTGA } \\
\text { CAAGG }\end{array}$ & 60,2 & $\begin{array}{l}\text { GAGCAGAAAGGAG } \\
\text { GAAAGCA }\end{array}$ & 59,7 & 55 & 50 \\
\hline
\end{tabular}

G: genoma funcional

S: genoma estructural

P: polimórfico

M: monomórfico 
APÉNDICE

Marcadores microssatélites desenhados a partir do sequênciamento parcial e da montagem de novo do genoma de $P$. edulis

\begin{tabular}{|c|c|c|c|c|c|c|c|c|c|c|c|c|c|c|c|c|c|c|c|}
\hline $\mathbf{N}^{\circ}$ & Primer & Contig M & Motivo & Início & Fim & pb & $\begin{array}{c}\mathbf{N}^{\mathbf{o}} \\
\text { Repet }\end{array}$ & Score & Sequência do contig & Unidade & G/S & Cobertura & pb & Sequência Forward & $\begin{array}{l}\mathrm{T}^{\circ} \mathrm{C} \\
F w d \\
\end{array}$ & Sequência Reverse & $\begin{array}{l}\mathrm{T}^{\circ} \mathrm{C} \\
\operatorname{Rev} \\
\end{array}$ & $\begin{array}{c}\% \mathrm{GC} \\
F w d \\
\end{array}$ & $\begin{array}{cc}\% \mathrm{GC} & \mathbf{P} / \mathrm{M} \\
\operatorname{Rev} & \end{array}$ \\
\hline 216 & BrPe3067 & $\begin{array}{l}\text { Maracuja_ } \\
\text { NoIndex_L } \\
\text { 003_R1_00 } \\
\text { 1_contig_6 } \\
\text { 267 }\end{array}$ & 3 & 1702 & 1713 & 12 & 4 & 9 & $\begin{array}{l}\text { CCATTACTGGTATAAGACCTCGCTTGTGATTGTGTGTGTGTTTTTTTT } \\
\text { TTTTTTTGCTCTTTTTAGCTTGAAACTGTCATTGAAGCGGAGAAAA } \\
\text { AAGCTGCTAAAGACTTGATTCGTGAGAACAGGAAAGACAGGGCCTT } \\
\text { GTTGGCACTGAAGAAGAAGAAAACCCAGGAAGAGTTGTTGAAGCA } \\
\text { AGTGGATACCTGGCTCATTAATGTTGAGCAGCAGGTACTGTTTGCAA } \\
\text { GAATTGGGAATCTCATACCCATCTATGTTTTGTTTCAATAGCCTTTT } \\
\text { CCAGGGGTTTTGTTACTGTAATGCTCGTTCC }\end{array}$ & $\overline{\mathrm{GAA}}$ & $\mathrm{s}$ & 18,13 & $217 \mathrm{~T}$ & $\begin{array}{l}\text { TGTCATTGAAGCGGA } \\
\text { GAAAA }\end{array}$ & 59,4 & $\begin{array}{l}\text { AAAACCCCTGGAAA } \\
\text { AGGCTA }\end{array}$ & 59,9 & 40 & 40 \\
\hline 217 & BrPe3068 & $\begin{array}{l}\text { Maracuja_ } \\
\text { NoIndex_L } \\
\text { 003_R1_00 } \\
\text { 1_contig_6 } \\
409\end{array}$ & 3 & 240 & 251 & 12 & 4 & 9 & $\begin{array}{l}\text { AGGTTGAGAGATCACTAGGGATACTAATGATGATCTGGTTAGGCAA } \\
\text { TTAAACACAATAATAAAATAACTAACGCATTGAATATCTGGATTCA } \\
\text { GGTGAAGTCAGAACCCTAGGCCTTTAACTCTGCTGATTTCTTTATTA } \\
\text { CTTCGTTCACAATTATTATTATTGAATTGATTCAACTAGAAAAGACA } \\
\text { AAAGGTAAGTTCTGGTCAATACATGCTCGTTGTGGGTTCAATATCTA } \\
\text { AACTATTACTTCATTAGTGTGAACTTGCACCGTTACGTATGTGAATT } \\
\text { GGAAAACACAACAACAACTAGATCAACCAAAG }\end{array}$ & ATT & G & 73,76 & $\begin{aligned} 165 \mathrm{C} \\
\mathrm{T}\end{aligned}$ & $\begin{array}{l}\text { CCCTAGGCCTTTAAC } \\
\text { TCTGCT }\end{array}$ & 59,1 & $\begin{array}{l}\text { CGTAACGGTGCAAG } \\
\text { TTCACA }\end{array}$ & 60,8 & 52,4 & 50 \\
\hline 218 & BrPe3069 & $\begin{array}{l}\text { Maracuja_ } \\
\text { NoIndex_L } \\
\text { 003_R1_00 } \\
\text { 1_contig_7 } \\
471\end{array}$ & 3 & 5707 & 5718 & 12 & 4 & 9 & $\begin{array}{l}\text { TGAATTAGTTGAACAAACGATCTTAACGTTATAGGTTCGAAACCCA } \\
\text { AAACGGATTGCACTAACCTAGGTGAGGGTCACCTGATTGAAATGTT } \\
\text { GGTGGTGGTATGGCAGGGATTTCATAGTCATTGATCGATCTATATTC } \\
\text { TTGGGTCTACCTGATGATGATGAGCATGAAGGCATGCGCATGGATG } \\
\text { TGGACAACATGTCTTATGAGGTAATGCGATTGAAATAAATAAAATA } \\
\text { AAGGACACTTACTGTGTTGTTAACTTTATAGCAATATCAACAGGAGC } \\
\text { TGCTGGCCCTGGAAGAGAAGATTGGAAATGTTAG }\end{array}$ & TGA & G & 15,83 & $100 \mathrm{~T}$ & $\begin{array}{l}\text { TGGCAGGGATTTCAT } \\
\text { AGTCA }\end{array}$ & 59,1 & $\begin{array}{l}\text { ATAAGACATGTTGT } \\
\text { CCACATCCA }\end{array}$ & 59,2 & 45 & 39,1 \\
\hline 219 & BrPe3070 & $\begin{array}{l}\text { Maracuja_ } \\
\text { NoIndex_L } \\
\text { 003_R1_00 } \\
\text { 1_contig_8 } \\
\text { 243 }\end{array}$ & 3 & 2234 & 2251 & 18 & 6 & 15 & $\begin{array}{l}\text { ACCAATGCTTGTTGTGGTTGCAGGAGGATTATGTTGTTGGAGACGAA } \\
\text { CTGAGCAAGTTGAAATGCGAGCACAGCTATCATGCTGTCTGCATTCA } \\
\text { ACAATGGCTTAGAATGAAGAACTGGTGTCCCATTTGCAAGGCGTCA } \\
\text { GCATCTACAGCATCATCATCATCATCATGATGGTCGTCCTCGTAATC } \\
\text { AACTAATAGATTGGATCACGCTGGAGACTGAGACTTTCATTTGTACA } \\
\text { AAATTAAGTCTGCTCCTTTTTTCTCTTCCTAATTTCATTTCATGTAC } \\
\text { ATACCGTATGCCTCTTCCTTTTCAATAGAATAACAA }\end{array}$ & САT & G & 15,02 & $181 \mathrm{C}$ & $\begin{array}{l}\text { GTTGTGGTTGCAGGA } \\
\text { GGATT }\end{array}$ & 60,0 & $\begin{array}{l}\text { AGTTGATTACGAGG } \\
\text { ACGACCA }\end{array}$ & 59,6 & 50 & 47,6 \\
\hline 220 & BrPe3071 & $\begin{array}{l}\text { Maracuja_ } \\
\text { NoIndex_L } \\
\text { 003_R1_00 } \\
\text { 1_contig_8 } \\
449\end{array}$ & 3 & 229 & 243 & 15 & 5 & 12 & $\begin{array}{l}\text { GAGTTCTAAGTTAAGTCAAGCTAACCCATTGGGCCCGGACTGCACT } \\
\text { CGAACTAGATGAGTATGACAGCAAGACATCTTGAGTTGTAATTATT } \\
\text { ATGTTCGACGTGTATTGGTGTAATAAATAGGTTCATTAATATGCGGG } \\
\text { GAAAATGAAAGGGAGGAGGAGGAGGATGATATGATGGAATTGGGC } \\
\text { AAGGTGAGTGAGGTGGTTGGCTGGGCACGTTGCTTTAGTTTATAGGC } \\
\text { ACATGAATTCACAACTATGCTGGCAGTTGATTCATCATTTAGCACAT } \\
\text { GGCAACTGCACCATTTGTTTGTTTTATGTTTCATAA }\end{array}$ & $\mathrm{GGA}$ & G & 16,82 & $169 \mathrm{C}$ & $\begin{array}{l}\text { CGGACTGCACTCGAA } \\
\text { CTAGA }\end{array}$ & 59,2 & $\begin{array}{l}\text { CСАACCACCTCACT } \\
\text { САССТT }\end{array}$ & 60 & 55 & 55 \\
\hline
\end{tabular}

G: genoma funcional

S: genoma estructural

P: polimórfico

M: monomórfico 
APÉNDICE

Marcadores microssatélites desenhados a partir do sequênciamento parcial e da montagem de novo do genoma de $P$. edulis

\begin{tabular}{|c|c|c|c|c|c|c|c|c|c|c|c|c|c|c|c|c|c|c|c|}
\hline $\mathbf{N}^{\mathbf{o}}$ & Primer & Contig $\mathrm{I}$ & Motivo & Início & Fim & pb & $\begin{array}{c}\mathbf{N}^{\mathbf{o}} \\
\text { Repet }\end{array}$ & Score & Sequência do contig & Unidade & G/S & Cobertura & pb & Sequência Forward & $\begin{array}{l}\mathrm{T}^{\circ} \mathrm{C} \\
F w d\end{array}$ & Sequência Reverse & $\begin{array}{r}\mathrm{T}^{\circ} \mathrm{C} \\
\operatorname{Rev}\end{array}$ & $\begin{array}{c}\% \mathrm{GC} \\
F w d\end{array}$ & $\begin{array}{c}\% \mathrm{GC} \\
\operatorname{Rev}\end{array} \quad \mathrm{P} / \mathbf{M}$ \\
\hline 221 & BrPe3072 & $\begin{array}{l}\text { Maracuja_ } \\
\text { NoIndex_L } \\
\text { 003_R1_00 } \\
\text { 1_conti__8 } \\
522\end{array}$ & 3 & 960 & 971 & 12 & 4 & 9 & $\begin{array}{l}\text { ATGGTCATTGTCTTTGCCAACAATATATGGGTATATTCAGTCTTGAA } \\
\text { ATTCATCAACGGAGTTGGTCGTTCGACCATCATAACTTGTGCGCTTG } \\
\text { TGCTATCCACAGAGCTCGTAGGGAAGAGGTGGAGAGGCCAGGTCGG } \\
\text { AGTGATAGGTTTCTTCTTCTTCACTGCAGGGTTTTGTCTTTGCCAAT } \\
\text { CATAGCTTACATAAACAGAGATTCTTCTTGGAGGACGATTTACCTGT } \\
\text { GGACATCCGTGCCAATCATCTTCTATTCCGTGTTGGTTCATTTTTTCG } \\
\text { TTCATGAGTCTCCAAGATGGCTATTTGTG }\end{array}$ & TTC & $\bar{G}$ & 12,17 & 157 & $\begin{array}{l}\text { CCACAGAGCTCGTAG } \\
\text { GGAAG }\end{array}$ & 60,0 & $\begin{array}{l}\text { AAGATGATTGGCAC } \\
\text { GGATGT }\end{array}$ & 60 & 60 & 45 \\
\hline 222 & BrPe3073 & $\begin{array}{l}\text { Maracuja_ } \\
\text { NoIndex_L } \\
\text { 003_R1_00 } \\
\text { 1_contig_8 } \\
601\end{array}$ & 3 & 382 & 393 & 12 & 4 & 9 & $\begin{array}{l}\text { TGCACTGGCGCTTGAGCTGACCTATTTCTTTTTCTCTGCGGATATTGC } \\
\text { ACTTCATTCAAAACATAAAGAAAAAGAATAGAGGGCAAAAACAAA } \\
\text { GGCAAAAGACAAACATTAAGTCTTTTTACATTTGATCGGTGATGAT } \\
\text { ATTGACTCCATTGTTGTTGTTGCCAGAAGAAACTGAAGATGAGTCAC } \\
\text { TGCATGTTACCGCAGATCTTTGAGTGGCAGCTCTTGAGACGTCACCA } \\
\text { TAGAGTAAAAATTCATTTTCATTCTGACAACCACCGAAACAAAGCA } \\
\text { TCTTGGAAGATTTTCCAGTGGATGAGCAGTGA }\end{array}$ & TTG & G & 10,39 & 153 & $\begin{array}{l}\text { GGCAAAAACAAAGG } \\
\text { CAAAAAG }\end{array}$ & 59,7 & $\begin{array}{l}\text { TGGTGACGTCTCAA } \\
\text { GAGCTG }\end{array}$ & 60,2 & 40 & 55 \\
\hline 223 & BrPe3074 & $\begin{array}{l}\text { Maracuja_ } \\
\text { NoIndex_L } \\
\text { 003_R1_00 } \\
\text { 1_contig_8 } \\
708\end{array}$ & 3 & 1018 & 1029 & 12 & 4 & 9 & $\begin{array}{l}\text { GTAACTCTATAGCTGTAGGTTTATGGCGATGTGGTGGAGGGTTATCT } \\
\text { GCAACTACGACTACAGAGGATGATGAGCTAGCACGAGTCGACGAGC } \\
\text { CCCCAGTGGAAAGCGATGGCTGCGGAGAAGCCGATCGAGAAACCA } \\
\text { AGGTCTACAAGAGTTGTTGTTGTTCGACAAAGCATTTAGACTGTTCG } \\
\text { GCAAAGAGTTTAGTCTGCTCATCAAGTGTTGAGGTAAGGGCAGCAA } \\
\text { TATCAGATTGCATTTTCGAGTTGGCCTCTTTGATTGCCGTGACTTCCG } \\
\text { AATCCAACTTGCCAAACCGAGTTTCTGCCATCT }\end{array}$ & GTT & G & 51,2 & 242 & $\begin{array}{l}\text { CGATGTGGTGGAGGG } \\
\text { TTATC }\end{array}$ & 60,2 & $\begin{array}{l}\text { GCAATCAAAGAGGC } \\
\text { CAACTC }\end{array}$ & 59,8 & 55 & 50 \\
\hline 224 & BrPe3075 & $\begin{array}{l}\text { Maracuja_ } \\
\text { NoIndex_L } \\
\text { 003_R1_00 } \\
\text { 1_contig_9 } \\
\text { 298 }\end{array}$ & 3 & 1660 & 1671 & 12 & 4 & 9 & $\begin{array}{l}\text { GAGGGCATAAAGCACGCTTCAGAGTCATGGGGTTTCTTTCAAATTGT } \\
\text { GAACCATGGAGTGCCAAAGGATGTTATGGAAGAAATGATAGATGGG } \\
\text { ATTCGTCAGTTTCATGAGCAGAGTGCTGCACTGAAAGCTGAGTATTA } \\
\text { CTCAAGAGACAAGAAGAAGAAGGTTATCTACAACAGCAACATCGAT } \\
\text { CTTTATGCCAGAGAGGTTGCAAATTGGAGAGACACTTGTATTTTTT } \\
\text { CATGCCGCCAGAAGGGACGGATCCTGAAGAATATCCACCTGTTTGC } \\
\text { AGGTAATTCTTGGTTTCTTTGTTTATCTACCAA }\end{array}$ & AAG & G & 15,9 & 210 & $\begin{array}{l}\text { ATGGAGTGCCAAAGG } \\
\text { ATGTT }\end{array}$ & 59,4 & $\begin{array}{l}\text { CTTCAGGATCCGTC } \\
\text { CСTTCT }\end{array}$ & 60,6 & 45 & 55 \\
\hline 225 & BrPe3076 & $\begin{array}{l}\text { Maracuja_ } \\
\text { NoIndex_L } \\
\text { 003_R1_00 } \\
\text { 1_contig_9 } \\
407\end{array}$ & 3 & 443 & 454 & 12 & 4 & 9 & $\begin{array}{l}\text { AAAATGAATAACCTTATAGTGAGGCGATTCTGAAGGGTCAAAGGCA } \\
\text { AGAAAAGCAAATGGTCTGTAATCCTTCCTGGACTTGAGAGTAGGGT } \\
\text { GAGATAGAGTCCTGAACTGTCTTGTGGTAGGGTTACAAACGTACAA } \\
\text { CCTGAATCCACAATCATCATCATCCACCACAGACCTGCAATAATCTG } \\
\text { CAATATAGTCATCGTCATAGTGTTTTTTCCTGTTTCTTTTCTTATTGG } \\
\text { TCAAGAATGTGGAAGTGCAGAGCATTAATCCATTGCAAGAATGCAG } \\
\text { TATCTCAATCCGAGGAACACTCAAGTGATCCAA }\end{array}$ & АTC & G & 14,48 & 165 & $\begin{array}{l}\text { GCGATTCTGAAGGGT } \\
\text { CAAAG }\end{array}$ & 59,8 & $\begin{array}{l}\text { TTGCAGATTATTGC } \\
\text { AGGTCTGT }\end{array}$ & 59,8 & 50 & 40,9 \\
\hline
\end{tabular}

G: genoma funcional

S: genoma estructural

P: polimórfico

M: monomórfico 
APÉNDICE

Marcadores microssatélites desenhados a partir do sequênciamento parcial e da montagem de novo do genoma de $P$. edulis

\begin{tabular}{|c|c|c|c|c|c|c|c|c|c|c|c|c|c|c|c|c|c|c|c|c|}
\hline $\mathbf{N}^{\circ}$ & Primer & Contig I & Motivo & Início & Fim & pb & $\begin{array}{c}\mathbf{N}^{\mathbf{o}} \\
\text { Repet }\end{array}$ & Score & Sequência do contig & Unidade & G/S & Cobertura & pb & Sequência Forward & $\begin{array}{l}\mathrm{T}^{\circ} \mathrm{C} \\
F w d\end{array}$ & Sequência Reverse & $\begin{array}{r}\mathrm{T}^{\circ} \mathrm{C} \\
\operatorname{Rev}\end{array}$ & $\begin{array}{r}\% \mathrm{GC} \\
F w d\end{array}$ & $\begin{array}{r}\% \mathrm{GC} \\
\operatorname{Rev}\end{array}$ & $\mathbf{P} / \mathbf{M}$ \\
\hline 226 & BrPe3077 & $\begin{array}{l}\text { Maracuja_ } \\
\text { NoIndex_L } \\
\text { 003_R1_00 } \\
\text { 1_contig_9 } \\
\text { 535 }\end{array}$ & 3 & 6648 & 6659 & 9 & 3 & 6 & $\begin{array}{l}\text { GGAGTTAAAGTATCATTTAATATTTTCATTTGGAAAAGAGCACTGAG } \\
\text { GAAAGATGTCAAATGAGAGAATAAGAATGGGGCTGATATTTTAATG } \\
\text { TTCTCACTTTGCCGTTTTTCTTTTGAGTTTTTCTTATATTCGTTTTTGC } \\
\text { CAATAATGTTATTTATTTATCAAAATTAAGAAACAAGGAAAAAGGC } \\
\text { TGAACAGATAGGAAAATCATTTCCCATTATAAATGCTATAGTTTGAT } \\
\text { TTATCAGGATGTTTCTCTTCCTTTCCCGGTCTTTTCTCCAATTTCTGC } \\
\text { TTCTCTCCTGAGGTTTTACCTTATTCTT }\end{array}$ & 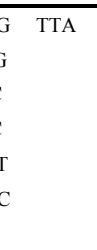 & $\mathrm{s}$ & 18,71 & 235 & $\begin{array}{l}\text { TGGAAAAGAGCACTG } \\
\text { AGGAAA }\end{array}$ & 60,0 & $\begin{array}{l}\text { CCGGGAAAGGAAG } \\
\text { AGAAAAC }\end{array}$ & 60 & 42,9 & 50 & \\
\hline 227 & BrPe3078 & $\begin{array}{l}\text { Maracuja_ } \\
\text { NoIndex_L } \\
\text { 003_R1_00 } \\
\text { 1_contig_9 } \\
735\end{array}$ & 3 & 536 & 547 & 12 & 4 & 9 & $\begin{array}{l}\text { ACGGTATACCGGGTCGGGTTATGGTTCATCCTTTCAAATCAGAGGTG } \\
\text { GGTTCCATATAGCCAGTAAAGACAAGCAGGACCACCATCAGGTTTC } \\
\text { TATCAACTGCCTACATTCCAGCAATAGTTCAGCGGAGGAAGCCTT } \\
\text { ATTTCCAACAGCCACCACCACCAGCACTAGAGCTAAAGAAACTAAA } \\
\text { AATGGAGGACTTGATGCAACATATCATCATATCAACATATGCAGGA } \\
\text { ATGAAAGCCCTGGAGAGACAGGTGAGCCAGTTGGTTAGGCATTGT } \\
\text { AGAGTAGGCCAAAAGGAGCATTGCCTTCAGACATC }\end{array}$ & GCA & G & 42,78 & 242 & $\begin{array}{l}\text { AGACAAGCAGGACCA } \\
\text { CCATC }\end{array}$ & 60,1 & $\begin{array}{l}\text { TCTGAAGGCAATGC } \\
\text { TCCTTT }\end{array}$ & 60 & 55 & 45 & \\
\hline 228 & BrPe3079 & $\begin{array}{l}\text { Maracuja_ } \\
\text { NoIndex_L } \\
\text { 003_R1_00 } \\
\text { 1_contig_1 } \\
0088\end{array}$ & 3 & 1761 & 1772 & 12 & 4 & 9 & $\begin{array}{l}\text { TCTGCGTGTGTTCTATGATTTGAAAGAATGATAAGTGGTTCGTTATT } \\
\text { CATGGCCATGACTGCAGGTGGGTAACAGGATCATCAGGAAGAGGAT } \\
\text { CCATGTACGCATAGAGCATCTACAGCCTTCGAGGTGCACTGAGGAG } \\
\text { TTCCGTCTGAGGAAGAAGAAGAATGACGAGCTAAAGGCAGAAGCA } \\
\text { AAGACAAGAGGTGAAGTTATCAGCACCAAGAGACAGCCAGAAGGA } \\
\text { CCAAAACCTGGATTTATGGTGGAAGGTGCAACATTAGAAACTGTGA } \\
\text { CTCCCATTCCCTACGATGTCGTGAACGATCTCAAGGG }\end{array}$ & GAA & G & 56,82 & 174 & $\begin{array}{l}\text { CTGCAGGTGGGTAAC } \\
\text { AGGAT }\end{array}$ & 60,0 & $\begin{array}{l}\text { TGGTCCTTCTGGCTG } \\
\text { тCTCT }\end{array}$ & 60 & 55 & 55 & \\
\hline 229 & BrPe3080 & $\begin{array}{l}\text { Maracuja_ } \\
\text { NoIndex_L } \\
003 \text { R1_00 } \\
\text { 1_contig_1 } \\
0513\end{array}$ & 3 & 356 & 367 & 12 & 4 & 9 & $\begin{array}{l}\text { GAAAATTGAAAATTTTCGTCCAATTAGTTTATGTAACGTTCCATACA } \\
\text { AAATCATTACTAAGCTTTTGGTTAATCGCATTAAGCCTTTATGCCTT } \\
\text { CTTTGGTTGCAGAAAATCAAGCTAGCTTTATTCCTGGGCGTGTTTCC } \\
\text { TCAGATAATATTATTATTATCCAGGAGGTAATCCATTTAATGAGGAG } \\
\text { GAAGAAAGGTAGAAAAGGATGGATGACTATCAAGATCGATTTGGA } \\
\text { AAAGGCGTATGACCATATTAAATGGAGTTTATCAAGGACACATTA } \\
\text { TTAGCTGCTGGGTTTTCTAACATTCTTACTAA }\end{array}$ & TAT & G & 34,07 & 160 & $\begin{array}{l}\text { GCCTTCTTTGGTTGCA } \\
\text { GAAA }\end{array}$ & 60,4 & $\begin{array}{l}\text { ATGGTCATACGCCT } \\
\text { TTTCCA }\end{array}$ & 60,3 & 45 & 45 & \\
\hline 230 & BrPe3081 & $\begin{array}{l}\text { Maracuja_ } \\
\text { NoIndex_L } \\
\text { 003_R1_00 } \\
\text { 1_contig_1 } \\
1075\end{array}$ & 3 & 195 & 206 & 12 & 4 & 9 & $\begin{array}{l}\text { TCAGAATCACTGACCCCATCATCATCACTTTCATCAATATTATCAGG } \\
\text { TTTCCGAGCAACTCCACGCCCCGAACTACTCTTTAATTTTTTACTGG } \\
\text { GAGTGACATCAACTGAATTTTTCTTTTTATTGGGCATAATAAAGTCT } \\
\text { TCATCCTCTTCATCATCATCAACTTTGTGAGCCTTTTTCGAAGGTGGA } \\
\text { TGTTTCACTGACTGATCACTATCACTTTGATGTTTTCTCTTTGCTGAA } \\
\text { GGATCCTTCGGTTCTTTATCATCTTTAGGCTTCTCCTTATCTGTGGCA } \\
\text { AAATACTTGCTAGTTTTCCTTCTGGCT }\end{array}$ & TCA & G & 12,42 & 158 & $\begin{array}{l}\text { ATCAGGTTTCCGAGC } \\
\text { AACTC }\end{array}$ & 59,3 & $\begin{array}{l}\text { CAGTGAAACATCCA } \\
\text { CCTTCG }\end{array}$ & 59,2 & 50 & 50 & \\
\hline
\end{tabular}

G: genoma funcional

S: genoma estructural

P: polimórfico

M: monomórfico 
APÉNDICE

Marcadores microssatélites desenhados a partir do sequênciamento parcial e da montagem de novo do genoma de $P$. edulis

\begin{tabular}{|c|c|c|c|c|c|c|c|c|c|c|c|c|c|c|c|c|c|c|c|}
\hline $\mathbf{N}^{\circ}$ & Primer & Contig I & Motivo & Início & Fim & pb & $\begin{array}{c}\mathbf{N}^{\circ} \\
\text { Repet }\end{array}$ & Score & Sequência do contig & Unidade & G/S & Cobertura & pb & Sequência Forward & $\begin{array}{l}\mathrm{T}^{\circ} \mathrm{C} \\
F w d \\
\end{array}$ & Sequência Reverse & $\begin{array}{l}\mathrm{T}^{\circ} \mathrm{C} \\
\operatorname{Rev} \\
\end{array}$ & $\begin{array}{c}\% \mathrm{GC} \\
F w d \\
\end{array}$ & $\begin{array}{cc}\% \mathrm{GC} & \mathrm{P} / \mathrm{M} \\
\operatorname{Rev} & \end{array}$ \\
\hline 231 & $\overline{B r P e 3082}$ & $\begin{array}{l}\text { Maracuja_ } \\
\text { NoIndex_L } \\
\text { 003_R1_00 } \\
\text { 1_contig_1 } \\
\text { 1391 }\end{array}$ & 3 & 3276 & 3287 & 12 & 4 & 9 & $\begin{array}{l}\text { TTATAACCTATTTTGCATCATAGATAATATGGTTATTTAGTTTATATT } \\
\text { CTAACTGCAATAAGACACCACTAGTTTAGATAATTATTCGAACCCAA } \\
\text { GATTTCTCCTATAACTCAAATCTTAAGATCTGGAGAGGTACCAGTTG } \\
\text { AGTTTTGGCATCATCATCATTATCCCTATCTAGTTGAACAATCTCGA } \\
\text { CATTTATTATGAAGCAACGCATCATGGATATCACGTCTAAGACATTG } \\
\text { CTGTTAAAGCTTCACATCAAATCTTCATAAAATATACAAAAAAAGGG } \\
\text { AAAGAGTCATCGTCTGTGTTAGTATAATAT }\end{array}$ & CAT & $\mathrm{s}$ & 17,13 & 168 & $\begin{array}{l}\text { TTCGAACCCAAGATT } \\
\text { TCTCC }\end{array}$ & 59,1 & $\begin{array}{l}\text { TGTGAAGCTTTAAC } \\
\text { AGCAATGTC }\end{array}$ & 59,5 & 45 & 39,1 \\
\hline 232 & BrPe3083 & $\begin{array}{l}\text { Maracuja_ } \\
\text { NoIndex_L } \\
\text { 003_R1_00 } \\
\text { 1_contig_1 } \\
\text { 1466 }\end{array}$ & 3 & 494 & 505 & 12 & 4 & 9 & $\begin{array}{l}\text { TGATGCATGTGAAGTTTCTCTACAAGGTTTATTGATATTCTCAAGCT } \\
\text { TCTTAACTTCCTGCATCGGTTGTGCCGGTGCAGGAAAACAAGAACC } \\
\text { AATATAATCATCCAACGCCAAACAATTTAACTTCGATGGTGGTGGG } \\
\text { CCTTGTTCTTCCTGCTGCTGCTGTTGCTGCTTCTTTTTGTAGAAACCC } \\
\text { ATGTTACCTTGATAAGCACCATATTCAGAACACAGAGGATAAACAT } \\
\text { GTCCCAAGTCTTCCATCGAAAACGAAAGGTTTTGTTTCCCTTTGATC } \\
\text { ACTTCCTCCTCCTCCTCCTCAGAACCATCAAC }\end{array}$ & СTG & G & 14,87 & 154 & $\begin{array}{l}\text { TAATCATCCAACGCC } \\
\text { AAACA }\end{array}$ & 59,9 & $\begin{array}{l}\text { CGATGGAAGACTTG } \\
\text { GGACAT }\end{array}$ & 59,9 & 40 & 50 \\
\hline 233 & BrPe3084 & $\begin{array}{l}\text { Maracuja_ } \\
\text { NoIndex_L } \\
\text { 003_R1_00 } \\
\text { 1_contig_1 } \\
1585\end{array}$ & 3 & 1595 & 1609 & 15 & 5 & 12 & $\begin{array}{l}\text { TTAAATGACTGATGTATACAAAGTAGGGATGACTTCCTTTCATTCTAG } \\
\text { TAATGAATCTGGTTTATTATTGCTAAAGATTATTTGAGGCTTTGTTTT } \\
\text { CTCATGGATTTTCCCCCCTTTTTCCCTCTGGTAAATAATCAACCATGC } \\
\text { ATTTATCAATAATAATAATAATTGTGTTTGTGGCTATTCTTCATTCTG } \\
\text { AGTTTCCTTGCAAACACTTGTTGCACTTGACAGTTTCTGTTTATAATT } \\
\text { ATAGCTTTTGTACTTTTCAGGTTGCTGTATTTGCTGGTGGTGTCGATA } \\
\text { CATCTGCTACTGAAACCAAAGGAACTGT }\end{array}$ & АAT & $\mathrm{s}$ & 18,29 & 181 & $\begin{array}{l}\text { CССCTTTTTCCСTCTG } \\
\text { GTAA }\end{array}$ & 60,3 & $\begin{array}{l}\text { ATGTATCGACACCA } \\
\text { CCAGCA }\end{array}$ & 60 & 50 & 50 \\
\hline 234 & BrPe3085 & $\begin{array}{l}\text { Maracuja_ } \\
\text { NoIndex_L } \\
003 \text { R1_00 } \\
\text { 1_contig_1 } \\
1622\end{array}$ & 3 & 163 & 174 & 12 & 4 & 9 & $\begin{array}{l}\text { TAATGTCAGTATGAAGCTTGTCACTAATATTATAGCCACCCGTTTGA } \\
\text { AGGCAGTCATGGCTTACTTGATTAGCCCCGCTCAAACTGCCTTTGTA } \\
\text { CCGGGGTGACATGGTATGGATAATGTCTTGATTGTGTAGGAAGCTAT } \\
\text { CCACTCACTGAAGAAGAAGAAAGGGAGATATGGGTGGATGATTATT } \\
\text { AAAGTTGATCTTGAAAAAGTATATGATATGCTTAGTCGGAAGTTCAT } \\
\text { CCGTGATACTCTAAAGGATATTGGTATTCTTGATTTCTTAACTGACG } \\
\text { TCATTTTTAATATTTTGAAATCAGAAATTTT }\end{array}$ & GAA & G & 17,11 & 210 & $\begin{array}{l}\text { TATAGCCACCCGTTT } \\
\text { GAAGG }\end{array}$ & 60,0 & $\begin{array}{l}\text { TCACGGATGAACTT } \\
\text { CCGACT }\end{array}$ & 60,7 & 50 & 50 \\
\hline 235 & BrPe3086 & $\begin{array}{l}\text { Maracuja_ } \\
\text { NoIndex_L } \\
\text { 003_R1_00 } \\
\text { 1_contig_1 } \\
1692\end{array}$ & 3 & 350 & 361 & 12 & 4 & 9 & $\begin{array}{l}\text { GCACTCCTCCGACGACCTTTTCCTCATAGCCTGCACCCGGAGCTTCT } \\
\text { ACTGCCATATCACGAATTCAAATAAAAAAACAAGAACTAAAGATAT } \\
\text { TTGGATATATATATCAGCTAAAAACGCCATCCCACTCCACAAAATTA } \\
\text { TCCAGAGTAGCATCATCATCATTCAAAGCCAGTGATAGAAATGACA } \\
\text { TCAGACACTATTAGTTGAATTTCAAAACAATTTAAACAAATAAGAA } \\
\text { AGAAATAATTCAATAAGAAATTATCTTTTACTTCTCAAAATAGAAAA } \\
\text { CTTGTTAACTTTATTACGGTAATACCTGAAATA }\end{array}$ & CAT & $\mathrm{s}$ & 32,34 & 100 & $\begin{array}{l}\text { CTAAAAACGCCATCC } \\
\text { CACTC }\end{array}$ & 59,6 & $\begin{array}{l}\text { TGAAATTCAACTAA } \\
\text { TAGTGTCTGATGT }\end{array}$ & 57,6 & 50 & 29,6 \\
\hline
\end{tabular}


APÉNDICE

Marcadores microssatélites desenhados a partir do sequênciamento parcial e da montagem de novo do genoma de $P$. edulis

\begin{tabular}{|c|c|c|c|c|c|c|c|c|c|c|c|c|c|c|c|c|c|c|c|}
\hline $\mathbf{N}^{\circ}$ & Primer & Contig M & Motivo & Início & Fim & pb & $\begin{array}{c}\mathrm{N}^{\mathbf{o}} \\
\text { Repet }\end{array}$ & Score & Sequência do contig & Unidade & G/S & Cobertura & pb & Sequência Forward & $\begin{array}{l}\mathrm{T}^{\circ} \mathrm{C} \\
F w d \\
\end{array}$ & Sequência Reverse & $\begin{array}{l}\mathrm{T}^{\circ} \mathrm{C} \\
\operatorname{Rev} \\
\end{array}$ & $\begin{array}{c}\% \mathrm{GC} \\
F w d \\
\end{array}$ & $\begin{array}{cc}\% \mathrm{GC} & \mathbf{P} / \mathrm{M} \\
\operatorname{Rev} & \end{array}$ \\
\hline 236 & $\overline{\text { BrPe3087 }}$ & $\begin{array}{l}\text { Maracuja_ } \\
\text { NoIndex_L } \\
003 \_R 1 \_00 \\
\text { 1_contig_1 } \\
1812\end{array}$ & 3 & 634 & 645 & 12 & 4 & 9 & $\begin{array}{l}\text { AAGAAGGAAGAACAGAAAACAAAAATTTTCTGGCAATTTGGATTAC } \\
\text { CTCTTGATGCGCAGAACTTGATGCAGGCTGAGGATCCTTGCTCGAAT } \\
\text { CCCTCTTTTGGTATCCACACAAACTCCGTCACATGGCTGGATTGACA } \\
\text { ATCAGATGGCAGGAGGAGGAGGCGGCTACAGAGCAAAACTGTTTTT } \\
\text { GCTCCTGCTTTTCCTATGTACGTGCGTGTAATGTGATTCAGTTATTGA } \\
\text { CTAAATCTAACATATCTGATTATATCAGATATATCTGATTAGGTATC } \\
\text { CGTTTCGCTAAATGGATATGGGTCGACCCA }\end{array}$ & $\overline{\mathrm{AGG}}$ & $\bar{G}$ & 82,24 & $157 \mathrm{~A}$ & $\begin{array}{l}\text { ACCTCTTGATGCGCA } \\
\text { GAACT }\end{array}$ & 60,0 & $\begin{array}{l}\text { AGGAAAAGCAGGA } \\
\text { GCAAAAA }\end{array}$ & 59,1 & 50 & 40 \\
\hline 237 & BrPe3088 & $\begin{array}{l}\text { Maracuja_ } \\
\text { NoIndex_L } \\
\text { 003_R1_00 } \\
\text { 1_contig_1 } \\
\text { 2011 }\end{array}$ & 3 & 2641 & 2652 & 12 & 4 & 9 & $\begin{array}{l}\text { TAGAACGAACAGTAAAGTTAGAAAAACCAACACAAACAGGGATTCA } \\
\text { ACAAAACACATATGACTATGTGATTCCCAATCCTCTCAAAACATTAC } \\
\text { CTGTTGCTCAACATTAATGAGCCAGGTATCCACTTGCTTCAACAATT } \\
\text { CTTCTTGCGTTTTCTTCTTCTTCAGTGCCAACAAGGCCCTGTCTTTTC } \\
\text { TCTTCTCCCGGATCAAGTCTCTAGCAGCTTTTTTCTCCGCTTCAA }\end{array}$ & TTC & G & 18,14 & $177 \mathrm{C}$ & $\begin{array}{l}\text { CCAACACAAACAGGG } \\
\text { ATTCA }\end{array}$ & 59,4 & $\begin{array}{l}\text { TGATCCGGGAGAAG } \\
\text { AGAAAA }\end{array}$ & 59,7 & 45 & 45 \\
\hline 238 & BrPe3089 & $\begin{array}{l}\text { Maracuja_ } \\
\text { NoIndex_L } \\
\text { 003_R1_00 } \\
\text { 1_contig_1 } \\
\text { 2049 }\end{array}$ & 3 & 600 & 611 & 12 & 4 & 9 & $\begin{array}{l}\text { TTTTCCCCTTCCTAAACTCAATGCAAACCACACCTGAAACATGATCA } \\
\text { ACCATGGCCAAAACCTAAGGCATGAGAACACAACCTAGAACACA } \\
\text { AAGAAGGAAGACATGATGCATGAATACCATAGACACATGCATAAAC } \\
\text { AACCTTCCTCACCTTCTTCTTCTTTTTATTTTCCTCTCTCAACTGATGA } \\
\text { TCAAGGAGTAAGGAAGGATGAAAATGGCTGGCTGAAGGAGATGGT } \\
\text { GTCGACAACAAGGGAGGGGAGAGGGAATCGATGGCCAAAAGAAAG } \\
\text { AAATGGCTCACCC }\end{array}$ & СTT & G & $1.076,59$ & $194 \mathrm{C}$ & $\begin{array}{l}\text { CTCAATGCAAACCAC } \\
\text { ACCTG }\end{array}$ & 60,2 & $\begin{array}{l}\text { TTTCATCCTTCCTTA } \\
\text { CTCCTTGA }\end{array}$ & 59,3 & 50 & 39,1 \\
\hline 239 & BrPe3090 & $\begin{array}{l}\text { Maracuja_ } \\
\text { NoIndex_L } \\
\text { 003_R1_00 } \\
\text { 1_contig_1 } \\
\text { 2485 }\end{array}$ & 3 & 283 & 297 & 15 & 5 & 12 & $\begin{array}{l}\text { AGATACAAAAAGTTCATCAAGTGGAACAAAGACAAGAAAAAATTTCA } \\
\text { AAGCTACAAAAGGTAAGAATATTATAACCTGTTATGAGTGTGGTAA } \\
\text { TGCAGGCCATATCAAAACTGAATGCCCAAATCTTAAGAACAAGAAA } \\
\text { GACTATGATAAAAAGAAGAAGAAGAAGGCACTTCAAGTCACTTGGG } \\
\text { ATGACTTAAATTCGGATTCAAGTGAAGAAGAAAGCTC }\end{array}$ & AAG & G & 461,67 & $188 \mathrm{~T}$ & $\begin{array}{l}\text { TTCATCAAGTGGAAC } \\
\text { AAAGACAA }\end{array}$ & 59,6 & $\begin{array}{l}\text { TCCGAATTTAAGTC } \\
\text { ATCCCAAG }\end{array}$ & 60,3 & 34,8 & 40,9 \\
\hline 240 & BrPe3091 & $\begin{array}{l}\text { Maracuja_ } \\
\text { NoIndex_L } \\
003 \_R 1 \_00 \\
\text { 1_contig_1 } \\
\text { 2758 }\end{array}$ & 3 & 828 & 839 & 9 & 3 & 6 & $\begin{array}{l}\text { GCAACGGTTGGATATTGTGGTTGTTCTGATTTTTATTTTTTTTTTCAA } \\
\text { TTATCCAGAAAGGAGGCTATGCCATATCATTTTTTAATGTAATCAAG } \\
\text { GCATGTGAAAATGAGTCTGTCAGTTTGAATTTCAGGTCACCAATAGA } \\
\text { CTCGGTAGTCATCATCATCACCTGCAAATGAGCCGGGAAGATATAC } \\
\text { AGGAAGAATAGAAAGTCCTAAAACGCCAAGCGGGACCCAATGGTT } \\
\text { AATTGTTGCCAGAGAAGGCCGAGAAAAAAACAAACCAGTTGCCCCT } \\
\text { GTGTCCGTGAACAAGCTCGACTACAAAAGCCCA }\end{array}$ & TCA & $\mathrm{s}$ & 12,3 & $203 \mathrm{~A}$ & $\begin{array}{l}\text { ATCCAGAAAGGAGGC } \\
\text { TATGC }\end{array}$ & 58,4 & $\begin{array}{l}\text { GGCCTTCTCTGGCA } \\
\text { ACAAT }\end{array}$ & 60,2 & 50 & 52 \\
\hline
\end{tabular}

G: genoma funcional

S: genoma estructural

P: polimórfico

M: monomórfico 
APÉNDICE

Marcadores microssatélites desenhados a partir do sequênciamento parcial e da montagem de novo do genoma de P. edulis

\begin{tabular}{|c|c|c|c|c|c|c|c|c|c|c|c|c|c|c|c|c|c|c|c|}
\hline $\mathbf{N}^{\circ}$ & Primer & Contig $\mathrm{I}$ & Motivo & Início & Fim & pb & $\begin{array}{c}\mathbf{N}^{\circ} \\
\text { Repet }\end{array}$ & Score & Sequência do contig & Unidade & G/S & Cobertura & pb & Sequência Forward & $\begin{array}{l}\mathrm{T}^{\circ} \mathrm{C} \\
F w d\end{array}$ & Sequência Reverse & $\begin{array}{r}\mathrm{T}^{\circ} \mathrm{C} \\
\operatorname{Rev}\end{array}$ & $\begin{array}{c}\% \mathrm{GC} \\
F w d\end{array}$ & $\begin{array}{cc}\% \mathrm{GC} & \\
\operatorname{Rev} & \mathrm{P} / \mathrm{M}\end{array}$ \\
\hline 241 & $\begin{array}{c}\text { BrPe3092 } \\
\end{array}$ & $\begin{array}{l}\text { Maracuja_ } \\
\text { NoIndex_L } \\
\text { 003_R1_00 } \\
\text { 1_contig_1 } \\
\text { 3095 }\end{array}$ & 3 & 3173 & 3184 & 12 & 4 & 9 & $\begin{array}{l}\text { AAAATATTAGACAACAATAATTTAAAAAACAAAAAAGGAGACAACC } \\
\text { AAAAAGATTCTGATTCACAGCAAAAGATAGTTCTCGAGTGCACACA } \\
\text { CAGTAAGTTAGTTCTTGCGGAAAGCATACCAGAACCCATGAAACCA } \\
\text { GAAGCAGCAGGCAATGATGATGATGGTAAGAGAGACAGCACCAAC } \\
\text { AGAATAAGTGCAAGAAGCGACATGTTAGACATGGACAACCTCTTGT } \\
\text { GTGCCGTGGACGGTGGTTCTTCCATGCAGCACAAACG }\end{array}$ & ATG & $\mathrm{G}$ & 15,27 & 158 & $\begin{array}{l}\text { TGCGGAAAGCATACC } \\
\text { AGAAC }\end{array}$ & 61,2 & $\begin{array}{l}\text { GTTTGTGCTGCATG } \\
\text { GAAGAA }\end{array}$ & 59,8 & 50 & 45 \\
\hline 242 & BrPe3093 & $\begin{array}{l}\text { Maracuja_ } \\
\text { NoIndex_L } \\
\text { 003_R1_00 } \\
\text { 1_contig_1 } \\
\text { 3144 }\end{array}$ & 3 & 682 & 693 & 12 & 4 & 9 & $\begin{array}{l}\text { AAACCCATAATCTTCATTCTGATTGATTGGGTGCACTTCAAACTTTG } \\
\text { CAGGGTGTCTGGGCAGAGCTTCAGTCGATTATACTTGACAAAGGCA } \\
\text { TTGCATGAGAATTGAATTTATGCGAAATGTTTATAGGCCTGAAGTGT } \\
\text { CTGGCAGAAATGTTGTTGTTGTGTTAATGAAGAACGCCATATACGTG } \\
\text { CTGAAGATGGTTTTGCTGTTCAGAGTTTGAAATATTGTGATTATGAA } \\
\text { AAAAATAAGAGAAAAAAAGAAAGAAATGTGCATGTGATTTTGTAGC } \\
\text { ATTTGCTTCTTATTTTTATTTTTTTTCCATT }\end{array}$ & TGT & $\mathrm{s}$ & 14,77 & 152 & $\begin{array}{l}\text { GTCTGGGCAGAGCTT } \\
\text { CAGTC }\end{array}$ & 60,1 & $\begin{array}{l}\text { CAGCAAAACCATCT } \\
\text { TCAGCA }\end{array}$ & 60 & 60 & 45 \\
\hline 243 & BrPe3094 & $\begin{array}{l}\text { Maracuja_ } \\
\text { NoIndex_L } \\
\text { 003_R1_00 } \\
\text { 1_contig_1 } \\
3336\end{array}$ & 3 & 596 & 613 & 18 & 6 & 15 & $\begin{array}{l}\text { CAGAAACTACTCTCAGCTCTGGCAATTCAGTGGTTGCAATAACAGTA } \\
\text { ACTGCAAACTGTTTTAAGATTTCTTAACGACTCAGGTGCCATTTTTT } \\
\text { AACAGGCTATACTCCCCCCTAATAAAGTCTACCAGAATTGGTAGCT } \\
\text { TATAGAATGGAAGAAGAAGAAGAAGAATGCAGTGTTTTTCTTCCAA } \\
\text { ATAATGAGGAAGACATTTCGAGTTAAGACGCATGAGTACTCAGACA } \\
\text { AATTGATAAATTACACAGGTGCCAAACTAGAAAGAGCCTAGAACG } \\
\text { GCCACAAATTTGCTGATTAGGACAACCTCTAAGGATCTC }\end{array}$ & GAA & $\mathrm{s}$ & 16,35 & 217 & $\begin{array}{l}\text { ACGACTCAGGTGCCA } \\
\text { TTTTT }\end{array}$ & 59,6 & $\begin{array}{l}\text { ACATTTGTGGCCGTT } \\
\text { CTAGG }\end{array}$ & 60 & 45 & 50 \\
\hline 244 & BrPe3095 & $\begin{array}{l}\text { Maracuja_ } \\
\text { NoIndex_L } \\
\text { 003_R1_00 } \\
\text { 1_contig_1 } \\
\text { 3411 }\end{array}$ & 3 & 775 & 789 & 15 & 5 & 12 & $\begin{array}{l}\text { AGGACATCCGTCTCATTGTTCAGGTTCGGCGAGAACTCGGAAAACC } \\
\text { ATTCCAGGACAAGAATTGAAGAAACCTGGACCATTGAAGAGATCGA } \\
\text { TTTTAACATAAGAGGATTGTCATAGATTGCTTTTTACCACCTAGTG } \\
\text { ATCTCAAGAAGGAAGAAGAAGAAGAATGTGGTACAGTGAGTGGTA } \\
\text { ATGCAAAGTTACCTCCAAAGATCCGTTCTGCATCGTTTAGGATTAGT } \\
\text { ACATCCAAGGTAGTTGCCATCGATCATGTTGATTACCCAGACTACTT } \\
\text { GAAAGGTGATCACGAAGATGTGTAGCCATTTTTTCAT }\end{array}$ & GAA & G & 13,17 & 221 & $\begin{array}{l}\text { GAACTCGGAAAACCA } \\
\text { TTCCA }\end{array}$ & 59,9 & $\begin{array}{l}\text { CGATGGCAACTACC } \\
\text { TTGGAT }\end{array}$ & 60 & 45 & 50 \\
\hline 245 & BrPe3096 & $\begin{array}{l}\text { Maracuja_ } \\
\text { NoIndex_L } \\
\text { 003_R1_00 } \\
\text { 1_contig_1 } \\
3673\end{array}$ & 3 & 1047 & 1058 & 12 & 4 & 9 & $\begin{array}{l}\text { CATTCCTTCGTATCGCAACTCGAATTTGAGGAAGAGGTGATCAAAAT } \\
\text { ACTCTTGAATTTTGATGGAGCTGAGATCAAACAGCATGCTGTGATTC } \\
\text { CATTCCGGGTTCGCTCCACCTTCCCTGTCCACAGACGTCTTTTGCCG } \\
\text { CTGCAGACTCTGCTGCTGCTGGTCATGCTTCTTCCCGGGTTCA }\end{array}$ & CTG & G & 12,24 & 180 & $\begin{array}{l}\text { TCCTTCGTATCGCAA } \\
\text { CTCG }\end{array}$ & 60,0 & $\begin{array}{l}\text { GAACCCGGGAAGAA } \\
\text { GCAT }\end{array}$ & 60 & 52,6 & 55,6 \\
\hline
\end{tabular}


APÉNDICE

Marcadores microssatélites desenhados a partir do sequênciamento parcial e da montagem de novo do genoma de $P$. edulis

\begin{tabular}{|c|c|c|c|c|c|c|c|c|c|c|c|c|c|c|c|c|c|c|c|}
\hline $\mathbf{N}^{\circ}$ & Primer & Contig I & Motivo & Início & Fim & pb & $\begin{array}{c}\mathbf{N}^{\circ} \\
\text { Repet }\end{array}$ & Score & Sequência do contig & Unidade & G/S & Cobertura & pb & Sequência Forward & $\begin{array}{l}\mathrm{T}^{\circ} \mathrm{C} \\
F w d \\
\end{array}$ & Sequência Reverse & $\begin{array}{l}\mathrm{T}^{\circ} \mathrm{C} \\
\operatorname{Rev} \\
\end{array}$ & $\begin{array}{c}\% \mathrm{GC} \\
F w d \\
\end{array}$ & $\begin{array}{c}\% \mathrm{GC} \\
\operatorname{Rev}\end{array} \quad \mathrm{P} / \mathrm{M}$ \\
\hline 246 & BrPe3097 & $\begin{array}{l}\text { Maracuja_ } \\
\text { NoIndex_L } \\
\text { 003_R1_00 } \\
\text { 1_contig_1 } \\
\text { 3881 }\end{array}$ & 3 & 551 & 562 & 12 & 4 & 9 & $\begin{array}{l}\text { ATCTTTGCAAATGGAAGATGTTGTAGACCAGGAATTACAAGAGGAA } \\
\text { CCGAAAATTGAAGAAAAGGAAGAACCCCCCATTACCATACCTTCAC } \\
\text { ATCCAGAGACAAAAACCATGGAACCTGTTCAAGTTGAAACCGAGAA } \\
\text { AGAGATGATTCCAGAAGAAGAAGATAAAAGCAAGAAGCATCCTGC } \\
\text { AATGCAGGATGAGGATGAGAAACTGGAAACGTTAGATGCCGATGA } \\
\text { AGCACGCCTTCCTCCTGACTCGGCAAACCAAGAATCGACAGAAACA } \\
\text { ATCATGGCTGAATCTGAAAGTCCTGTAGAAGAAAGCCA }\end{array}$ & $\mathrm{AGA}$ & $\mathrm{G}$ & 12,22 & 182 & $\begin{array}{l}\text { TCTTTGCAAATGGAA } \\
\text { GATGTTG }\end{array}$ & 60,1 & $\begin{array}{l}\text { GCAGGATGCTTCTT } \\
\text { GCTTTT }\end{array}$ & 59,6 & 36,4 & 45 \\
\hline 247 & BrPe3098 & $\begin{array}{l}\text { Maracuja_ } \\
\text { NoIndex_L } \\
003 \text { R1_00 } \\
\text { 1_contig_1 } \\
4352\end{array}$ & 3 & 234 & 245 & 12 & 4 & 9 & $\begin{array}{l}\text { TCAACACCACAATTTAGAGATGCAGGCTACATGCAAAGTCGAGACA } \\
\text { ATTCACTCACCGGAGGCACCAGTTTCTGTGTGGTACTTTCCAGA } \\
\text { AAGAAAGATTCGGGGTAAAAAATTGGAGGGGCAACCATCAAAGAA } \\
\text { TCTTATGGCTGAGAGGAGGAGGAGAAAAAGGTTAAATGACCGGCTG } \\
\text { TCAATGCTCAGATCAATCGTTCCAAAGATAAGCAAGGTAAACATTG } \\
\text { ACCCAATTAATGGCTTATGCAGTTGATTTTACATTTAGATTTGGAGG } \\
\text { TTCATTTGCCAGACTTGACCCCCCCTCCCCCTCTC }\end{array}$ & GAG & G & 9,06 & 169 & $\begin{array}{l}\text { AGGGGCAACCATCAA } \\
\text { AGAAT }\end{array}$ & 60,7 & $\begin{array}{l}\text { TGGCAAATGAACCT } \\
\text { CCAAAT }\end{array}$ & 60,3 & 45 & 40 \\
\hline 248 & BrPe3099 & $\begin{array}{l}\text { Maracuja_ } \\
\text { NoIndex_L } \\
003 \text { R1_00 } \\
\text { 1_contig_1 } \\
4634\end{array}$ & 3 & 160 & 171 & 12 & 4 & 9 & $\begin{array}{l}\text { TCCATCGTGTTCATCCTGTGTGACAACAAATGCGAGAGAAACCATG } \\
\text { ATCATACGAACAGCAATCAACAAACACAAGCAATGGACCAACGATT } \\
\text { CCTAAACACCCACGTTAAACTACTAGCCTTCGATCTTCTCTCCCTCA } \\
\text { CGCCAACCGCTTCCTCCTCCTCCACAGACGCGACGTCTTTCTCCCGC } \\
\text { AGAGGCGCGCTCCTAGCACGCGCCGAAACGCTGGGCATCGTTACGT } \\
\text { CCCGAGACCATAAACCGAACAAGTTCCTCAAGTTTACCATTGACGA } \\
\text { CGGAACCGGATGCGTCAGTTGCATGCTCTGGCTC }\end{array}$ & TCC & G & 6,41 & 212 & $\begin{array}{l}\text { AAGCAATGGACCAAC } \\
\text { GATTC }\end{array}$ & 59,9 & $\begin{array}{l}\text { GGTTCCGTCGTCAA } \\
\text { TGGTAA }\end{array}$ & 60,8 & 45 & 50 \\
\hline 249 & BrPe3100 & $\begin{array}{l}\text { Maracuja_ } \\
\text { NoIndex_L } \\
003 \text { R1_00 } \\
\text { 1_contig_1 } \\
4793\end{array}$ & 3 & 1610 & 1621 & 12 & 4 & 9 & $\begin{array}{l}\text { GCAGCTTCCTTAGTTCCTCAACTAATCTCATTTACTTCCCTTCATTAA } \\
\text { ATGCTTGAATTTAAGACCCTCCCTCCTTTGCCAGCAAAATTAGGTGT } \\
\text { TATGGAGAGGCAAATATCATTCTTTACTTAGACATTTGCAAGAGACA } \\
\text { AAGTAAAGGAAGAAGAAGAACGAAGAAAGAAGATGGCCGTTTTTA } \\
\text { CCCTTCAAAGTAGCCTCAACGACCTCACAGAGCATTATAGTCCTGC } \\
\text { ATGATCTTGTTAGAAGGGAAGAAAAATACAGAGAGATAGAGAGAG } \\
\text { AGATGGTGCAATTTCAAGAAACCAGTCTGGCCT }\end{array}$ & GAA & $\mathrm{s}$ & 15,21 & 237 & $\begin{array}{l}\text { TTGCCAGCAAAATTA } \\
\text { GGTGTT }\end{array}$ & 59,6 & $\begin{array}{l}\text { AGGCCAGACTGGTT } \\
\text { TCTTGA }\end{array}$ & 59,8 & 38,1 & 50 \\
\hline 250 & BrPe3101 & $\begin{array}{l}\text { Maracuja_ } \\
\text { NoIndex_L } \\
\text { 003_R1_00 } \\
\text { 1_contig_1 } \\
4899\end{array}$ & 3 & 616 & 627 & 12 & 4 & 9 & $\begin{array}{l}\text { GTAAGAATGTTGACTTCCAGGCCATGATATCAACTTGGTGTTTTCCA } \\
\text { TGTATTTCTAAGAGTTCAACAACAAAAAGGTATACATGATCATCTCC } \\
\text { TTTTTTTTCCCCTGAGTTTGATGTTGCAAATGTCGTATTTCTTAGGTT } \\
\text { CATAATCCTATTATTATTATAATGTATCTAAGGTACAAGGAAAAGAA } \\
\text { TATGCATGTACTGAACTCATGAAGACAAGATACCAAATAGCACCGG } \\
\text { CAAAATTTGGATTCCTACTTAAGTATATAAATGTTATGCAGGTAATG } \\
\text { ATAAGAGGCACTCATTTGAAAGCCAATGTG }\end{array}$ & ТАТ & $\mathrm{s}$ & 18,65 & 204 & $\begin{array}{l}\text { CCCCTGAGTTTGATGT } \\
\text { TGC }\end{array}$ & 59,1 & $\begin{array}{l}\text { GGCTTTCAAATGAG } \\
\text { TGCCTCT }\end{array}$ & 60,8 & 52,6 & 47,6 \\
\hline
\end{tabular}

G: genoma funcional

S: genoma estructural

P: polimórfico

M: monomórfico 
APÉNDICE

Marcadores microssatélites desenhados a partir do sequênciamento parcial e da montagem de novo do genoma de $P$. edulis

\begin{tabular}{|c|c|c|c|c|c|c|c|c|c|c|c|c|c|c|c|c|c|c|c|}
\hline $\mathbf{N}^{\circ}$ & Primer & Contig N & Motivo & Início & Fim & pb & $\begin{array}{c}\mathbf{N}^{\circ} \\
\text { Repet }\end{array}$ & Score & Sequência do contig & Unidade & G/S & Cobertura & pb & Sequência Forward & $\begin{array}{l}\mathrm{T}^{\circ} \mathrm{C} \\
F w d \\
\end{array}$ & Sequência Reverse & $\begin{array}{l}\mathrm{T}^{\circ} \mathrm{C} \\
\operatorname{Rev} \\
\end{array}$ & $\begin{array}{c}\% \mathrm{GC} \\
F w d \\
\end{array}$ & $\begin{array}{r}\% \mathrm{GC} \\
\operatorname{Rev} \\
\end{array}$ \\
\hline 251 & BrPe3102 & $\begin{array}{l}\text { Maracuja_ } \\
\text { NoIndex_L } \\
\text { 003_R1_00 } \\
\text { 1_contig_1 } \\
4975\end{array}$ & 3 & 188 & 199 & 12 & 4 & 9 & $\begin{array}{l}\text { AGTCGGTTGTTATTAAGTCGGAGATTCTCGAGGGATGAAAGATGTTT } \\
\text { TAGAGATAAAAAAATACTGTTATCGAAGGGTTGTCATTCAAGTAG } \\
\text { AGCAATCGTAACTTGTTCAATTGCAAGAGTCCTTGTCCACCTGAAGG } \\
\text { AAGTCATTAAAATAATAATAATTTCATTGTATTTCTGCAATTGACTA } \\
\text { ACAAACACAAACCATAAGCTTGAAATGAAATATTTTACCTGTGGAT } \\
\text { GACACGAATTGGTCAATCCCATTGCCATCCAAGTACAATACCTCCA } \\
\text { AGTTGCTTAAAGCATTCAGTTCTGGATTGTAAG }\end{array}$ & $\begin{array}{ll}\text { ATT } \\
\end{array}$ & $\mathrm{s}$ & 89,31 & 156 & $\begin{array}{l}\text { GCAAGAGTCCTTGTC } \\
\text { CACCT }\end{array}$ & 59,3 & $\begin{array}{l}\text { TTGTACTTGGATGG } \\
\text { CAATGG }\end{array}$ & 59,4 & 55 & 45 \\
\hline 252 & BrPe3103 & $\begin{array}{l}\text { Maracuja_ } \\
\text { NoIndex_L } \\
\text { 003_R1_00 } \\
\text { 1_contig_1 } \\
4994\end{array}$ & 3 & 2577 & 2588 & 12 & 4 & 9 & $\begin{array}{l}\text { GGAAGGCGTGCAGCAGACCATAAGACTCACAAAACCTGACACATA } \\
\text { GGACCGCCAAGTGGCCAGTCACAACCAAGAGAAATTTTCCCATCA } \\
\text { AGTGCACTTGCTAGAAATTCCATATGCATGCCAAGATTCTTGGACG } \\
\text { CCGCTTTGACACTGATGATGATGAATCGATTCCCCAGGCAAATGCTC } \\
\text { CACAGAGAACTGCAAAGTAGGCAAGTGTGTATCCCCCAAGCATGGA } \\
\text { GACAATCCCGTCAGGTCCGTTTCCTTCTCTGACCTTTGAACAGCTA } \\
\text { TAAACCAAGATGGCAGAGTCTCTTTGAACAGTGA }\end{array}$ & TGA & G & 13,74 & 185 & $\begin{array}{l}\text { GACACATAGGACCGC } \\
\text { CAAGT }\end{array}$ & 60,0 & $\begin{array}{l}\text { GGGGGATACACACT } \\
\text { TGCCTA }\end{array}$ & 59,8 & 55 & 55 \\
\hline 253 & BrPe3104 & $\begin{array}{l}\text { Maracuja_ } \\
\text { NoIndex_L } \\
\text { 003_R1_00 } \\
\text { 1_contig_1 } \\
\text { 5525 }\end{array}$ & 3 & 4240 & 4251 & 12 & 4 & 9 & $\begin{array}{l}\text { AATTGACATGAATACATGAATCAATGAAAAACATAGCATAAGATGA } \\
\text { TGCAATGTGAGTAGGATATGACATGGTTACCAATACAAAAATACAT } \\
\text { CCTTGATGTGCGTTTAAGCATATAATAAAGCAATGTCCTTGTTCTTC } \\
\text { ACTTCAATAGTGAAGAAGAAGAATCGTATAGCAGTAGAAGGTGACA } \\
\text { ATGATTTTAGTATATTTTATGTGTCATTGCTTTTATCATCATCTCCTT } \\
\text { GTTTGTGTTAACTGAAGAAAATATGTTGTTTGTTGTTATCCTTTTAAC } \\
\text { ACGACTCTGTTTGCCATTCAATAATATGAGG }\end{array}$ & GAA & $\mathrm{s}$ & 17,27 & 210 & $\begin{array}{l}\text { CCTTGATGTGCGTTTA } \\
\text { AGCAT }\end{array}$ & 60,1 & $\begin{array}{l}\text { TTGAATGGCAAACA } \\
\text { GAGTCG }\end{array}$ & 59,8 & 42,9 & 45 \\
\hline 254 & BrPe3105 & $\begin{array}{l}\text { Maracuja_ } \\
\text { NoIndex_L } \\
\text { 003_R1_00 } \\
\text { 1_contig_1 } \\
\text { 5709 }\end{array}$ & 3 & 740 & 751 & 12 & 4 & 9 & $\begin{array}{l}\text { GTTAAGAAATTGTAATTAACTAAGCTATGGATCACCACAGCATTTAG } \\
\text { GACCATTTCCTTCTTGAAGTTTCTGCCACAGACAAAGCATCTCCCTA } \\
\text { GGACCCTGGTAGTGAGCAACAACATAGCCATCCTTGCACCCTTCATT } \\
\text { ATAGATTCTCTCCTCCTCCTCGTATTTAACTTCTAAACCTTCCTTCTT } \\
\text { CATGTCTGCAATCCAGATACCCATGGCTACATCTTCTAACTTAAACA } \\
\text { TCTGCCACATCAACCATGAAGATTTTCAAACGACAAATAAAACATT } \\
\text { GATGATCTGTACATGGTTTCTGGACCAGTA }\end{array}$ & СТC & $\mathrm{G}$ & 17,58 & 159 & $\begin{array}{l}\text { AGGACCCTGGTAGTG } \\
\text { AGCAA }\end{array}$ & 59,7 & $\begin{array}{l}\text { TGGTTGATGTGGCA } \\
\text { GATGTT }\end{array}$ & 60 & 55 & 45 \\
\hline 255 & BrPe3106 & $\begin{array}{l}\text { Maracuja_ } \\
\text { NoIndex_L } \\
\text { 003_R1_00 } \\
\text { 1_contig_1 } \\
5768\end{array}$ & 3 & 1363 & 1374 & 12 & 4 & 9 & $\begin{array}{l}\text { GAGTAAACCAGATGGTAATACTACTGAGAATATGAAAGAGATCATT } \\
\text { GAACTTATGGTTGGCTACTATAAAGACCTCTTGGGAACTGACAATCA } \\
\text { CAACAAAACCCATATTGTCCATGATTATCTAATAAACAGCAGAGCT } \\
\text { CTGATCACTTGGGAGGAGGAGGAATCATTAAATGCTAACATATCTC } \\
\text { AGGATGAGATCAAAGCAGCATTATGGAGTATTAATAAGAAGATGGC } \\
\text { TTTTATTGTGAATGGATTCAATTCATCTTTGTTTCATTCATGTTGGGA } \\
\text { TATTATCAAGGA }\end{array}$ & $\begin{array}{l}\mathrm{GGA} \\
{ }^{2}\end{array}$ & G & 19,15 & 202 & $\begin{array}{l}\text { TGGGAACTGACAATC } \\
\text { ACAACA }\end{array}$ & 60,0 & $\begin{array}{l}\text { TCCCAACATGAATG } \\
\text { AAACAAA }\end{array}$ & 58,9 & 42,9 & 33,3 \\
\hline
\end{tabular}


APÉNDICE

Marcadores microssatélites desenhados a partir do sequênciamento parcial e da montagem de novo do genoma de $P$. edulis

\begin{tabular}{|c|c|c|c|c|c|c|c|c|c|c|c|c|c|c|c|c|c|c|c|}
\hline $\mathbf{N}^{\circ}$ & Primer & Contig I & Motivo & Início & Fim & pb & $\begin{array}{c}\mathbf{N}^{\circ} \\
\text { Repet }\end{array}$ & Score & Sequência do contig & Unidade & G/S & Cobertura & $\mathrm{pb}$ & Sequência Forward & $\begin{array}{l}\mathrm{T}^{\circ} \mathrm{C} \\
F w d \\
\end{array}$ & Sequência Reverse & $\begin{array}{r}\mathrm{T}^{\circ} \mathrm{C} \\
\operatorname{Rev} \\
\end{array}$ & $\begin{array}{c}\% \mathrm{GC} \\
F w d \\
\end{array}$ & $\begin{array}{cc}\% \mathrm{GC} & \mathrm{P} / \mathrm{M} \\
\operatorname{Rev} & \end{array}$ \\
\hline 256 & BrPe3107 & $\begin{array}{l}\text { Maracuja_ } \\
\text { NoIndex_L } \\
003 \text { R1_00 } \\
\text { 1_contig_1 } \\
6115\end{array}$ & 3 & 288 & 299 & 12 & 4 & 9 & $\begin{array}{l}\text { AAAAATGGCAGAAACCAATAGACACAAACTGAGAATCAGGACAAA } \\
\text { AACACATCTAAAATTGAGCTCTTTACGAACGCTTCTCCACAGTATCC } \\
\text { CCACCGAACAACATCCGTATCTATAGAAACCTTCATGGTTCTGTTGT } \\
\text { TGCCGCAGATTCTGCTGCTGCTGGTGCTGTTCTTTGCCCATAGAAAT } \\
\text { TGCATCTGGAAATCACTTGATTCCCTTTTTTTTTGCTCTTACTCTACA } \\
\text { GACACACTCTCCCTCTCTCTCTCTCTCTAGCGCATTGAGAATTTGTAT } \\
\text { GTTTCTCTCTTTAAAAAAAAACAAACTGGG }\end{array}$ & CTG & $\bar{G}$ & 19,13 & 178 & $\begin{array}{l}\text { TGGCAGAAACCAATA } \\
\text { GACACA }\end{array}$ & 59,2 & $\begin{array}{l}\text { TCTATGGGCAAAGA } \\
\text { ACAGCA }\end{array}$ & 59,4 & 42,9 & 45 \\
\hline 257 & BrPe3108 & $\begin{array}{l}\text { Maracuja_ } \\
\text { NoIndex_L } \\
\text { 003_R1_00 } \\
\text { 1_contig_1 } \\
6268\end{array}$ & 3 & 2725 & 2736 & 12 & 4 & 9 & $\begin{array}{l}\text { GAATATCAGGGCATTGGCTTGTTAAACTTTAATGATACTGAGATTGA } \\
\text { TAATTGGAAGCAGCTATTACCAGATATTGAGCATGTTGTTCTGCAAC } \\
\text { TGGATAATCTAGCAAAAAATGTAACTTGGGAATCCATTTACCCAGA } \\
\text { ATGGATAGATGAAGAAGAAGAATTTGAGGTTCCCACTTGCCCTCTTT } \\
\text { TTCCTAAAATTAAAGTTCCTGGTAAACCTCGAATTGATGTTGTTGCT } \\
\text { GTCAAGCTTCCTTGCAATAAGTCAGGGAGCTGGTCTAGAGACGTTG } \\
\text { CTCGATTGCACTTGCAACTTGCGGTGGCAAAT }\end{array}$ & GAA & G & 15,8 & 190 & $\begin{array}{l}\text { GCATGTTGTTCTGCA } \\
\text { ACTGG }\end{array}$ & 60,3 & $\begin{array}{l}\text { CCAGCTCCCTGACT } \\
\text { TATTGC }\end{array}$ & 59,8 & 50 & 55 \\
\hline 258 & BrPe3109 & $\begin{array}{l}\text { Maracuja_ } \\
\text { NoIndex_L } \\
\text { 003_R1_00 } \\
\text { 1_contig_1 } \\
6350\end{array}$ & 3 & 2839 & 2850 & 12 & 4 & 9 & $\begin{array}{l}\text { TGGATGCAACAGCACCCCAGTTGCAGTCTCCAACTGGGTTGCATAT } \\
\text { GCGTCAGAACATTAACCAGCAGCTCCGCTCGAGCTACCCAAACACC } \\
\text { TTCTCATCCTCTCCAGGGAGGTCATCAACATCATATAGCATTGATCA } \\
\text { ATCTGGAGTGTCAGCAGCAGCAGTTTTGAGTTCCAGGTCTGCTGCTT } \\
\text { TTGCTAAGCGCAGTCAGAGCTTCATCGAACGAAGTGCAGTGAATCG } \\
\text { CCATTCAGGATTTTCTTCACCAACTCTATCAAATACCATGATGTCTC } \\
\text { CAAACCTGTCAGATTGGGGTTCTCCTGATGGAA }\end{array}$ & CAG & G & 14,94 & 180 & $\begin{array}{l}\text { AGTCTCCAACTGGGT } \\
\text { TGCAT }\end{array}$ & 59,6 & $\begin{array}{l}\text { TCTGACTGCGCTTA } \\
\text { GCAAAA }\end{array}$ & 59,9 & 50 & 45 \\
\hline 259 & BrPe3110 & $\begin{array}{l}\text { Maracuja_ } \\
\text { NoIndex_L } \\
\text { 003_R1_00 } \\
\text { 1_contig_1 } \\
7399\end{array}$ & 3 & 10730 & 10741 & 12 & 4 & 9 & $\begin{array}{l}\text { TGAGGACTTAGGCGATAGTGAAACCGATTCAGGCAGCGGCACCGTT } \\
\text { GACGAAGGGGGCCATGATGAAGAAGATTTGGATGAAGAATGTGGG } \\
\text { GCTGAATGTGACACAGGGGAAGACGACGATGATGTTGATGGTGCAG } \\
\text { GTGAACCTGCTTCTGATGATGATGAAGTCCATGTTAGACAAAAGGT } \\
\text { ACTGGAGGTGGATCCTCAGGAAGCAGCTGATTTTGAGCAGGAGCTG } \\
\text { AGGGCTGTAATGCAGGCAAGATTGAGAATACCCAGTGCTGATTATA } \\
\text { TTTCTAATTAGGAATGCTTTTCTTGGTTAATGTTGCA }\end{array}$ & TGA & G & 18,53 & 151 & $\begin{array}{l}\text { GAAGAATGTGGGGCT } \\
\text { GAATG }\end{array}$ & 60,5 & $\begin{array}{l}\text { TCAGCTCCTGCTCA } \\
\text { AAATCA }\end{array}$ & 59,7 & 50 & 45 \\
\hline 260 & BrPe3111 & $\begin{array}{l}\text { Maracuja_ } \\
\text { NoIndex_L } \\
\text { 003_R1_00 } \\
\text { 1_contig_1 } \\
7440\end{array}$ & 3 & 2781 & 2798 & 18 & 6 & 15 & $\begin{array}{l}\text { CTTGAACTCTTGATTATCCTCAGGAATTTCTAACTACGAGAAATGGT } \\
\text { AGAAGAGAAGAAAAGGAAGACTAACCTATTGACGCCTCGATATATTG } \\
\text { AAGTCTTTTTACCACGTAGCAATTCCATGTCTATGAAATCTGAATTC } \\
\text { TTACTCATATCAGCAGCAGCAGCAGCAGAATTAAGATCCATGCTTG } \\
\text { GATTGATGAAGGACATCTATGAGAAAAATCTTAATATGATAATATG } \\
\text { CAATGCAAGAATACTTATTGTTTCTGACAAGTTCTTAGAATCAAGTC } \\
\text { AACCAAAGTATCTTAGTGTTCTTAGAAGTTTCTTAATGT }\end{array}$ & CAG & G & 16,56 & 102 & $\begin{array}{l}\text { TTTTTACCACGTAGCA } \\
\text { ATTCCA }\end{array}$ & 59,5 & $\begin{array}{l}\text { GTCCTTCATCAATCC } \\
\text { AAGCA }\end{array}$ & 58,6 & 36,4 & 45 \\
\hline
\end{tabular}

G: genoma funcional

S: genoma estructural

P: polimórfico

M: monomórfico 
APÉNDICE

Marcadores microssatélites desenhados a partir do sequênciamento parcial e da montagem de novo do genoma de $P$. edulis

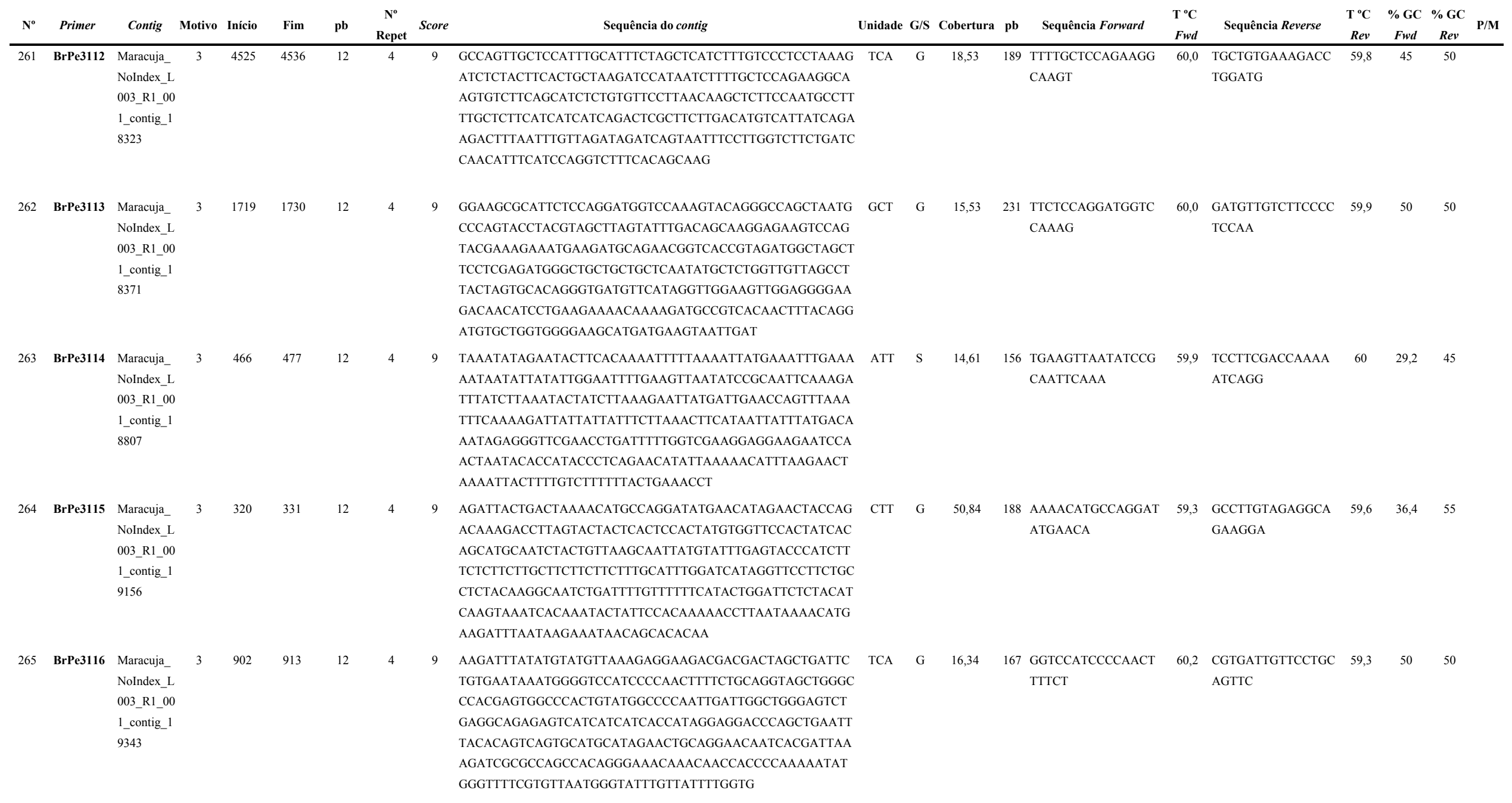

G: genoma funcional

S: genoma estructural

P: polimórfico

M: monomórfico 
APÉNDICE

Marcadores microssatélites desenhados a partir do sequênciamento parcial e da montagem de novo do genoma de $P$. edulis

\begin{tabular}{|c|c|c|c|c|c|c|c|c|c|c|c|c|c|c|c|c|c|c|c|}
\hline $\mathbf{N}^{\circ}$ & Primer & Contig I & Motivo & Início & Fim & pb & $\begin{array}{l}\mathbf{N}^{o} \\
\text { Repet }\end{array}$ & Score & Sequência do contig & Unidade & G/S & Cobertura & pb & Sequência Forward & $\begin{array}{l}\mathrm{T}^{\circ} \mathrm{C} \\
F w d\end{array}$ & Sequência Reverse & $\begin{array}{l}\mathrm{T}^{\circ} \mathrm{C} \\
R e v\end{array}$ & $\begin{array}{c}\% \mathrm{GC} \\
F w d\end{array}$ & $\begin{array}{c}\% \mathrm{GC} \\
\operatorname{Rev}\end{array}$ \\
\hline 266 & BrPe3117 & $\begin{array}{l}\text { Maracuja_ } \\
\text { NoIndex_L } \\
003 \text { R1_00 } \\
\text { 1_contig_1 } \\
9688\end{array}$ & 3 & 6790 & 6807 & 18 & 6 & 15 & $\begin{array}{l}\text { CCCACTCGCTTGCAGGGAGATTGGAAGTAACATTACCAATCGTCTCC } \\
\text { CTTTAATAACCCATTGTGGTCCTGTGCTTTGTAACGCTCAAAACAAT } \\
\text { CTGCAGCAGCAGCAGGGAGGTTCTTCATGGGATTCAACGAACAGC } \\
\text { AAAAGCAAGGAGAAGAAGAAGAAGAAGAGTATCGGGTGGTGTCGG } \\
\text { CTGTAAGAAGCAGCTACAACGATATTGTC }\end{array}$ & $\mathrm{AGA}$ & G & 18,31 & 102 & $\begin{array}{l}\text { GGTTCTTCATGGGATT } \\
\text { CCAAC }\end{array}$ & 60,6 & $\begin{array}{l}\text { GACAATATCGTTGT } \\
\text { AGCTGCTTCT }\end{array}$ & 59 & 47,6 & 41,7 \\
\hline 267 & BrPe3118 & $\begin{array}{l}\text { Maracuja_ } \\
\text { NoIndex_L } \\
\text { 003_R1_00 } \\
\text { 1_contig_2 } \\
0151\end{array}$ & 3 & 7988 & 7999 & 12 & 4 & 9 & $\begin{array}{l}\text { ACCGAAGAATCACTCACACAGAAAAATCGTTTTTATTTTTCTTTTCC } \\
\text { ACCGGGTGGTGTCTTTTTGTTGGTCGCTTAAGAGATGGTGGACGACA } \\
\text { GTTTTGTTGGCAAAACCAGTGAAGAGACTCCGAAGAAGGGGAAGGA } \\
\text { TAAGAAGAGAAAGAAGAAGAAGCGTGGAGGCAGCGCGAAGAAGAT } \\
\text { GACAGCCGAGCAGGTTTGGGCTTTCAAGGCGGTTAATGAATGGGTG } \\
\text { TGTTTGGGTCAGCAACAGCAGCAGCAGCAGCAGAATTCTTTTGTGGT } \\
\text { TGATGATTTTGGGGTACAAAAGTGTAAAGGGAGA }\end{array}$ & AAG & G & 15,93 & 190 & $\begin{array}{l}\text { GGGTGGTGTCTTTTTG } \\
\text { TTGG }\end{array}$ & 60,2 & $\begin{array}{l}\text { ACCCAAACACACCC } \\
\text { ATTCAT }\end{array}$ & 60 & 50 & 45 \\
\hline 268 & BrPe3119 & $\begin{array}{l}\text { Maracuja_ } \\
\text { NoIndex_L } \\
\text { 003_R1_00 } \\
\text { 1_contig_2 } \\
0244\end{array}$ & 3 & 2426 & 2437 & 12 & 4 & 9 & $\begin{array}{l}\text { TCCGGCTATGTAGTCACATTTATAGAATCCACTGTTATTATATTCTA } \\
\text { GAGCAAGTCTTATACCGGTCATGATTCTTATCTTTATTTGTCCTCAAT } \\
\text { ATATATATAGGTGGCTGGGTTGGTTATTTTTCATACGATACAGTCCG } \\
\text { CTATGTCGAGAAGAAGAAGATCCCATTTTCAGGAGCTGATCCTGCC } \\
\text { GAGGACAGAAATCTTCCGGACATTCACCTGGGCCCATATGATGATG } \\
\text { TGATCATATTCGATCATGTGGAGAAGGTATTCTCATCTTAGATTGCT } \\
\text { AATATTGTTTAAACTCATCATATGATGCATG }\end{array}$ & AGA & G & 22,94 & 208 & $\begin{array}{l}\text { TCCGGCTATGTAGTC } \\
\text { ACATTT }\end{array}$ & 57,3 & $\begin{array}{l}\text { TCCGGAAGATTTCT } \\
\text { GTCCTC }\end{array}$ & 59,2 & 42,9 & 50 \\
\hline 269 & BrPe3120 & $\begin{array}{l}\text { Maracuja_ } \\
\text { NoIndex_L } \\
\text { 003_R1_00 } \\
\text { 1_contig_2 } \\
0286\end{array}$ & 3 & 714 & 725 & 12 & 4 & 9 & $\begin{array}{l}\text { AAATAAGGACATACAAAAAACAATAGCCTTAGCCATTCGTAAGGGA } \\
\text { CCCAAAACCCAGACGTGACGCCCTGTTTTGGTTTCACATGCATGAT } \\
\text { CCATTATTCTCTATAACTATTACTATTTCTTCTGTCGTCACGATCCCA } \\
\text { CAGCTTCTTCTCCTCCTCCTCAGCTAGCAGGTTCCAGTCCCCGAGAT } \\
\text { TGTGTTTCTCATCATGTGATCTACCAGAAAAAGGTAGTAACACAGA } \\
\text { AATTGATGGAGGTCTAATTATAATAACATGATGCTTGGGAGGGTTG } \\
\text { CGTTAATTATCTTAATAAGTGTAATAAAATGG }\end{array}$ & стC & G & 14,72 & 158 & $\begin{array}{l}\text { GTCACGATCCCACAG } \\
\text { CTTCT }\end{array}$ & 60,3 & $\begin{array}{l}\text { ATTAACGCAACCCT } \\
\text { CCCAAG }\end{array}$ & 61,2 & 55 & 50 \\
\hline 270 & BrPe3121 & $\begin{array}{l}\text { Maracuja_ } \\
\text { NoIndex_L } \\
\text { 003_R1_00 } \\
\text { 1_contig_2 } \\
0399\end{array}$ & 3 & 2435 & 2446 & 12 & 4 & 9 & $\begin{array}{l}\text { GGCACTGACTTTTTATTTTCCGCAGAGGCAAAAAGAAGACCTTCAC } \\
\text { AGTAAAATCATCCGATTGGAGAAACAATTGGATGCAAAGCAAGCGC } \\
\text { TGGAGTTGGAAATAGAGCAACTCAAAGGGTCATTAAATGTGATGAA } \\
\text { GCACATGGAAAATGATGATGATGTGGAAATGTTGAGAAAGATGGAT } \\
\text { GCAATGATGAAAGATTTGAGGGAAAAGGAAGGAGAACTTCAAGAT } \\
\text { ATAGATGCTTTGAATCAAACTCTTATTGTAAGGGAGCGCATGAGCA } \\
\text { ATGAAGAGCTCCAGGAAGCCCGCAAAGAACTAATTA }\end{array}$ & ATG & G & 16,85 & 205 & $\begin{array}{l}\text { AAGCGCTGGAGTTGG } \\
\text { AAATA }\end{array}$ & 59,8 & $\begin{array}{l}\text { TCCTGGAGCTCTTC } \\
\text { ATTGCT }\end{array}$ & 60,1 & 45 & 50 \\
\hline
\end{tabular}

G: genoma funcional

S: genoma estructural

P: polimórfico

M: monomórfico 
APÉNDICE

Marcadores microssatélites desenhados a partir do sequênciamento parcial e da montagem de novo do genoma de $P$. edulis

\begin{tabular}{|c|c|c|c|c|c|c|c|c|c|c|c|c|c|c|c|c|c|c|c|}
\hline $\mathbf{N}^{\circ}$ & Primer & Contig $\mathrm{I}$ & Motivo & Início & Fim & pb & $\begin{array}{c}\mathbf{N}^{\mathbf{o}} \\
\text { Repet }\end{array}$ & Score & Sequência do contig & Unidade & G/S & Cobertura & pb & Sequência Forward & $\begin{array}{l}\mathrm{T}^{\circ} \mathrm{C} \\
F w d\end{array}$ & Sequência Reverse & $\begin{array}{r}\mathrm{T}^{\circ} \mathrm{C} \\
\operatorname{Rev}\end{array}$ & $\begin{array}{c}\% \mathrm{GC} \\
F w d\end{array}$ & $\begin{array}{c}\% \mathrm{GC} \\
\operatorname{Rev}\end{array} \quad \mathrm{P} / \mathbf{M}$ \\
\hline 271 & BrPe3122 & $\begin{array}{l}\text { Maracuja_ } \\
\text { NoIndex_L } \\
003 \text { R1_00 } \\
\text { 1_contig_2 } \\
0513\end{array}$ & 3 & 258 & 269 & 12 & 4 & 9 & $\begin{array}{l}\text { ATTAAAAAAAGGACAAAACAAAAAAGATTGTGAAAAGGGAAAAAACC } \\
\text { TCAAATAATGGAGGAGAAGCATTGGATGTTACTGCACATGAAAGAA } \\
\text { AGAGAAAAGGTGTAATAAAATTTAGCACCATTTTTGCTGTGTCTATT } \\
\text { ACTAGGCAGAGGAGAAGAAGAAGAGGCATGGAGAATCCCAATGCT } \\
\text { CATCAGTCTATCAGACATCACAGCCTGCACTTGACACCCTCTTGTCA } \\
\text { CCAATTCTCCTACTAAAACCACC }\end{array}$ & AGA & G & 11,15 & 100 & $\begin{array}{l}\text { AGCACCATTTTTGCTG } \\
\text { TGTCT }\end{array}$ & 59,8 & $\begin{array}{l}\text { AGTGCAGGCTGTGA } \\
\text { TGTCTG }\end{array}$ & 60,1 & 42,9 & 55 \\
\hline 272 & BrPe3123 & $\begin{array}{l}\text { Maracuja_ } \\
\text { NoIndex_L } \\
\text { 003_R1_00 } \\
\text { 1_contig_2 } \\
0572\end{array}$ & 3 & 177 & 191 & 15 & 5 & 12 & $\begin{array}{l}\text { GAGACGGTCTACCCTTCGGCCAGTCGTTGTTCCTTAATACACACAAT } \\
\text { TTACTCTTCTCCTTCCTCTTCCATTCCTCCACCATCCACGACCCATCT } \\
\text { GATAACCATCCCCATGAAACCTGGAAGAGGAAGTTTATACCTTGA } \\
\text { CGCATGCTGACCACCACCACCACCTTCTCTCTTGTTACTTACATTCA } \\
\text { ATGTTCCCTGGTCTCTGACTATTCTGTCATTGCCGTCCCTACCTTCAT } \\
\text { TAAACCTATTGTTCCATTCGTCACAGTCATTTCCCCATCCACATGAA } \\
\text { TCATCCCACCAATTTCCCCATCCATTACTTTC }\end{array}$ & $\mathrm{ACC}$ & G & 16,82 & 185 & $\begin{array}{l}\text { CCATGAAACCTGGAA } \\
\text { GAGGA }\end{array}$ & 60,0 & $\begin{array}{l}\text { TGGGATGATTCATG } \\
\text { TGGATG }\end{array}$ & 60,1 & 50 & 45 \\
\hline 273 & BrPe3124 & $\begin{array}{l}\text { Maracuja_ } \\
\text { NoIndex_L } \\
\text { 003_R1_00 } \\
\text { 1_contig_2 } \\
0685\end{array}$ & 3 & 7138 & 7152 & 15 & 5 & 12 & $\begin{array}{l}\text { AATTCACTGTATCTTGTTATGTGTAACTTTCAGTCTGGACTCTGTTAA } \\
\text { GCTTGGCTTATGCTTTTGTAATTTATCCACGTACGTATGTAACTTCCA } \\
\text { ACATTGACATTTGCTTCCCTAATCACAAAGCATCAAGCATGCGTGTT } \\
\text { TGGTTCAATTATTATTATTATTTTAATTATTTTTTCGGGTTTCAATCA } \\
\text { GAGTCTCTTTCTATAATCCTATCAACTTAGTTTCATTAAGATTTTTGG } \\
\text { GAGGTTTTCATTACCATGAATTTTAAGACCAAAAAGATATTGTGATT } \\
\text { GCATTTTACGATAGTTTAATTAGTTATAA }\end{array}$ & АTT & $\mathrm{s}$ & 14,24 & 162 & $\begin{array}{l}\text { CCAACATTGACATTT } \\
\text { GCTTCC }\end{array}$ & 60,4 & $\begin{array}{l}\text { TGGTAATGAAAACC } \\
\text { TCCCAAA }\end{array}$ & 59,3 & 42,9 & 38,1 \\
\hline 274 & BrPe3125 & $\begin{array}{l}\text { Maracuja_ } \\
\text { NoIndex_L } \\
\text { 003_R1_00 } \\
\text { 1_contig_2 } \\
0931\end{array}$ & 3 & 1853 & 1864 & 12 & 4 & 9 & $\begin{array}{l}\text { AAAGGGTTACTCCAGCCCAGGAACGACTGAATTAACAAAAATTAAA } \\
\text { ACTTTGGCGTAAAAAAAAGAAGAAAAACAGGGATTTAACATGACT } \\
\text { TACATTTTTGAGCATTGAAGAAGAGGAGAGCCTTGTGGAGGGCAAC } \\
\text { AGTGTAATTGTCAGGAGGAGGAGGGTGAGGCTTATGCTTAGGCAAA } \\
\text { GTCTTGACGATGATGGTGGGGAGTGCAATGAATAGAAAGCCACACA } \\
\text { CAATGGCGTAAAGAGTATACTTGAGGGCCTTGTGGCTGCAAACAAT } \\
\text { GCAACCCAAGTCTACGTACTTTTTCCTCTTGGCCTC }\end{array}$ & AGG & G & 15,48 & 150 & $\begin{array}{l}\text { GAAGAAAAACAGGG } \\
\text { ATTTTAACATGA }\end{array}$ & 60,9 & $\begin{array}{l}\text { CATTGCACTCCCCA } \\
\text { CCAT }\end{array}$ & 60,3 & 30,8 & 55,6 \\
\hline 275 & BrPe3126 & $\begin{array}{l}\text { Maracuja_ } \\
\text { NoIndex_L } \\
\text { 003_R1_00 } \\
\text { 1_contig_2 } \\
0980\end{array}$ & 3 & 3656 & 3670 & 15 & 5 & 12 & $\begin{array}{l}\text { TTCTGCATTGCACACATTGACTATGCTTTCATGTTCCAGGGCCTTGG } \\
\text { CAAAACTATCTCAATGATCGCCCTTATACAAATGCAAAAGTCTTTGC } \\
\text { AGTCAAAATCAAACTCTGAAGATCAATCTAATCCCAGAACTGAAGC } \\
\text { ATTGAATTTGGATGATGATGATGATAATGGCGGTCTACCTCAGGTA } \\
\text { AGGCCAAGGAGACTGCAGAATCTTCTGATGTTAAGCCAGTCCCAGA } \\
\text { AGTTACTACTTCTTCAGGGACATTTAGCAGAAGAAGACCAGCTGCT } \\
\text { GGCACACTGGTTGTGTGTCCTGCTAGTGTTCTCCGA }\end{array}$ & GAT & G & 17,89 & 204 & $\begin{array}{l}\text { TTCTGCATTGCACAC } \\
\text { ATTGA }\end{array}$ & 59,8 & $\begin{array}{l}\text { TGCAGTCTCCTTGG } \\
\text { CCTTAC }\end{array}$ & 60,4 & 40 & 55 \\
\hline
\end{tabular}

G: genoma funcional

S: genoma estructural

P: polimórfico

M: monomórfico 
APÉNDICE

Marcadores microssatélites desenhados a partir do sequênciamento parcial e da montagem de novo do genoma de P. edulis

\begin{tabular}{|c|c|c|c|c|c|c|c|c|c|c|c|c|c|c|c|c|c|c|c|}
\hline $\mathbf{N}^{\mathbf{o}}$ & Primer & Contig $\mathrm{I}$ & Motivo & Início & Fim & pb & $\begin{array}{c}\mathbf{N}^{\circ} \\
\text { Repet }\end{array}$ & Score & Sequência do contig & Unidade & G/S & Cobertura & pb & Sequência Forward & $\begin{array}{l}\mathrm{T}^{\circ} \mathrm{C} \\
F w d\end{array}$ & Sequência Reverse & $\begin{array}{r}\mathrm{T}^{\circ} \mathrm{C} \\
\operatorname{Rev}\end{array}$ & $\begin{array}{c}\% \mathrm{GC} \\
F w d\end{array}$ & $\begin{array}{c}\% \mathrm{GC} \\
\operatorname{Rev}\end{array} \quad \mathrm{P} / \mathbf{M}$ \\
\hline 276 & BrPe3127 & $\begin{array}{l}\text { Maracuja_ } \\
\text { NoIndex_L } \\
003 \text { R1_00 } \\
\text { 1_contig_2 } \\
1092\end{array}$ & 3 & 262 & 273 & 12 & 4 & 9 & $\begin{array}{l}\text { AAACGATATCCTATATAAAAGACCCATTGAAAAGAAGGTCACAATT } \\
\text { GAGGATCTTAAGTCTGAAGTTAAAGATTTGAAAGATGAAGTAAGGG } \\
\text { ACATTAAAGCCGACATAGAAATATTAAAAAATAGCAAAGGAAACA } \\
\text { GGGTGGTTAGTTCAGAAGAAGAAGATACAGATAATGAGGACATTAA } \\
\text { TGTAATATCTAAGGTAAATTATCATAAATGGTATTCTTTAATCACCA } \\
\text { TAGTAATAAAAGATT }\end{array}$ & AGA & G & 204,04 & 210 & $\begin{array}{l}\text { GACCCATTGAAAAGA } \\
\text { AGGTCA }\end{array}$ & 059 & $\begin{array}{l}\text { TGGTGATTAAAGAA } \\
\text { TACCATTTATGA }\end{array}$ & 58,1 & 42,9 & 26,9 \\
\hline 277 & BrPe3128 & $\begin{array}{l}\text { Maracuja_ } \\
\text { NoIndex_L } \\
\text { 003_R1_00 } \\
\text { 1_contig_2 } \\
1293\end{array}$ & 3 & 1388 & 1408 & 21 & 7 & 18 & $\begin{array}{l}\text { TTGAAGCTCAGATCTGTAACTCAAAGGATAGGCTTATAAAATAAGT } \\
\text { TCACCCAATTAAATGATTATATTTCTTAAATTTCAAGCTTTCATTTCT } \\
\text { GAGAATACAATATATTTTTGTTTTCAAATTTAGTTTAGAGGAATAAA } \\
\text { GGTTATAATTAATAATAATAATAATAATAAGCATAACCTTGTCTACC } \\
\text { ATGCATTACGTCGCTATGGACGCATTAAGTAATGGGAATGATAGC } \\
\text { AAACTCATCAAAAGTTGGCTTACCAACTAATCATAGAAAATTTGGCT } \\
\text { AATTCAGGTAAACTAATTGGGTATTTCCGTGGAATTCCCA }\end{array}$ & TAA & $\mathrm{s}$ & 16,47 & 204 & $\begin{array}{l}\text { GAAGCTCAGATCTGT } \\
\text { AACTCAAAGG }\end{array}$ & 60,0 & $\begin{array}{l}\text { CATAGCGACGTAAT } \\
\text { GCATGG }\end{array}$ & 60,1 & 44 & 50 \\
\hline 278 & BrPe3129 & $\begin{array}{l}\text { Maracuja_ } \\
\text { NoIndex_L } \\
\text { 003_R1_00 } \\
\text { 1_contig_2 } \\
1435\end{array}$ & 3 & 1140 & 1151 & 12 & 4 & 9 & $\begin{array}{l}\text { TGCTGCGAATCACACCAGTTTGGGAACCCAGTAAGATAAAAAGAAA } \\
\text { GTACATTGTCAGGAAGAAAATAAAGGTTAAGGTTGACGGTTGAGGT } \\
\text { TTTAGATTTTGGAAATACAGGGTTTTGATATGAAAGGGGTTATGACG } \\
\text { GTTGTTGGGGCGGTGGTGGTGGTCCTATTCCAAGCTCAAGATGGAA } \\
\text { GGTGGGGGACATAGAAAAGAGAGGGACGAGGGGAGGGAGGTTAGG }\end{array}$ & GTT & G & 62,05 & 106 & $\begin{array}{l}\text { CGGTTGAGGTTTTAG } \\
\text { ATTTTGG }\end{array}$ & 59,9 & $\begin{array}{l}\text { ACCTTCCATCTTGA } \\
\text { GCTTGG }\end{array}$ & 59,3 & 40,9 & 50 \\
\hline 279 & BrPe3130 & $\begin{array}{l}\text { Maracuja_ } \\
\text { NoIndex_L } \\
\text { 003_R1_00 } \\
\text { 1_contig_2 } \\
1663\end{array}$ & 3 & 5438 & 5449 & 12 & 4 & 9 & $\begin{array}{l}\text { GGCCCAGAGGATAAATATTTGAGCAATCTGACTATTACCTCAGCCTA } \\
\text { CTTTTCTCATATGCAAGCAATTTCTCATACTCAATCTCATCATCATTG } \\
\text { TCTTCGTCATTTTCATCATTATTGTCATCATCGAACAAGCCAACAGG } \\
\text { ACCACGAACTTCTTCTTCTTTCATACGCTGAAGTCCAAATTCGGATG } \\
\text { GATAGACAGCCAC }\end{array}$ & СТT & G & 17,82 & 106 & $\begin{array}{l}\text { TGTCTTCGTCATTTTC } \\
\text { ATCATT }\end{array}$ & 57,2 & $\begin{array}{l}\text { GCTGTCTATCCATCC } \\
\text { GAATTT }\end{array}$ & 58,1 & 31,8 & 42,9 \\
\hline 280 & BrPe3131 & $\begin{array}{l}\text { Maracuja_ } \\
\text { NoIndex_L } \\
\text { 003_R1_00 } \\
\text { 1_contig_2 } \\
\text { 1966 }\end{array}$ & 3 & 5081 & 5092 & 12 & 4 & 9 & $\begin{array}{l}\text { TGTCCAATGGACAGAAAGGGATTGTATATGCAGTAAGAAAAAAAATT } \\
\text { CCCAAGTTCTTCTCATGCTTTCTGCATGCGCCATTTGAGTGAAAGCA } \\
\text { TTGGAAAAGAATTTAGAAACTCAAGGCTTGTAAATCTGCTCTGGAA } \\
\text { AGCTGCTTATGCCACCACCACCATTGCTTTCAAGGAAAAGATGAAC } \\
\text { GAAATTTCAGAGGTCTCCTCTGAAGCTGCAAAGTGGCTGCAACAGT } \\
\text { TTCCTCCCTCCTGCTGGGCCTTGGTTTATTTTGAAGGAACAAGGTAC } \\
\text { GGTCATCTGTCCTCCAACATTGATGAATTTAATA }\end{array}$ & $\mathrm{CCA}$ & G & 16,09 & 172 & $\begin{array}{l}\text { CGCCATTTGAGTGAA } \\
\text { AGCAT }\end{array}$ & 61,2 & $\begin{array}{l}\text { AGCAGGAGGGAGG } \\
\text { AAACTGT }\end{array}$ & 60,3 & 45 & 55 \\
\hline
\end{tabular}

G: genoma funcional

S: genoma estructural

P: polimórfico

M: monomórfico 
APÉNDICE

Marcadores microssatélites desenhados a partir do sequênciamento parcial e da montagem de novo do genoma de $P$. edulis

\begin{tabular}{|c|c|c|c|c|c|c|c|c|c|c|c|c|c|c|c|c|c|c|c|}
\hline $\mathbf{N}^{\circ}$ & Primer & Contig & Motivo & Ińcio & Fim & pb & $\begin{array}{c}\mathbf{N}^{\circ} \\
\text { Repet }\end{array}$ & Score & Sequência do contig & Unidade & G/S & Cobertura & pb & Sequência Forward & $\begin{array}{l}\mathrm{T}^{\circ} \mathrm{C} \\
F w d\end{array}$ & Sequência Reverse & $\begin{array}{l}\mathrm{T}^{\circ} \mathrm{C} \\
\operatorname{Rev}\end{array}$ & $\begin{array}{c}\% \mathrm{GC} \\
F w d\end{array}$ & $\begin{array}{c}\% \mathrm{GC} \\
\operatorname{Rev}\end{array}$ \\
\hline 281 & BrPe3132 & $\begin{array}{l}\text { Maracuja_ } \\
\text { NoIndex_L } \\
\text { 003_R1_00 } \\
\text { 1_contig_2 } \\
\text { 2331 }\end{array}$ & 3 & 1612 & 1623 & 12 & 4 & 9 & $\begin{array}{l}\text { GGTAGAAAGACATGGAAAGAGGCTACTGAAACTTCCCTTCCCAAGA } \\
\text { TGGTTGGTGAAGGGGTTTATGGAGTAGGTCCTGTTTTAGCCGCATTA } \\
\text { TCTGCTGCAAGGAGAGAATTTTATGCGTTGTATGTTCAAGAAGGATT } \\
\text { GGATATTAATAAGAAGAAGAAGGACAAGAAAGGGTTTGAGAAAAGT } \\
\text { GTTGATGATGGCTCAGAAGCTTGGGTAAGGCACTAAGGAAGTCACA } \\
\text { AAGCATGACCTCAATATGATTGCAGATAACCGCCCTCATCAGGGAC } \\
\text { TTGTGCTTGATGCTTCTCCTTTGGAGATGGTGAAA }\end{array}$ & AAG & $\bar{G}$ & 13,45 & 237 & $\begin{array}{l}\text { TTGGTGAAGGGGTTT } \\
\text { ATGGA }\end{array}$ & 60,2 & $\begin{array}{l}\text { CAAGCACAAGTCCC } \\
\text { TGATGA }\end{array}$ & 59,8 & 45 & 50 \\
\hline 282 & BrPe3133 & $\begin{array}{l}\text { Maracuja_ } \\
\text { Nolndex_L } \\
003 \_R 1 \_00 \\
\text { 1_contig_2 } \\
\text { 2370 }\end{array}$ & 3 & 763 & 774 & 12 & 4 & 9 & $\begin{array}{l}\text { ACATGCATGAATGGAGCTTTCGTGATCGTGAGTATGGAAGATTTATT } \\
\text { AATTTTTTTAGTGGGTTTGGTGCCATTTCTTTATTGATGGCAGTTGCT } \\
\text { GATTCCCAAGGTGGGGAGGGATTTGTTTCGTTAATATTTTTGTGTGC } \\
\text { GAAGAAGGAGAAGAAGAAGAGAGCCAAGGGAAGATGAAAATATTG } \\
\text { CTGCGAGTCATGGAGTGAGAAGCAAGTGGGGTGATGCAAAATTCAA } \\
\text { TGGCGGCATTGATTGTTGAACAGAAGAGGTGGGACCCCTTGATTAT } \\
\text { GCCCGGGAGAGAAGAAGAAGTGCAGAGACTTTC }\end{array}$ & AGA & $\mathrm{s}$ & 11,64 & 182 & $\begin{array}{l}\text { CAGTTGCTGATTCCC } \\
\text { AAGGT }\end{array}$ & 60,1 & $\begin{array}{l}\text { GGTCCCACCTCTTCT } \\
\text { GTTCA }\end{array}$ & 60,1 & 50 & 55 \\
\hline 283 & BrPe3134 & $\begin{array}{l}\text { Maracuja_ } \\
\text { NoIndex_L } \\
003 \_R 1 \text { 00 } \\
\text { 1_contig_2 } \\
\text { 2454 }\end{array}$ & 3 & 382 & 396 & 15 & 5 & 12 & $\begin{array}{l}\text { AATTCTCGCATAGCAAGGTTCATCATAGAGGTCGCACCACCTCAGT } \\
\text { ATATCAGTGTCATGAGGCGCAGAACATGCAAGATGATGGACACAAT } \\
\text { AAAGGAAGAGGATAGAGAAGTGGTTGTAAGCGATTCTCTAGCTTCG } \\
\text { TATCCCAAGTCGTCTTCTTCTTCTTCTGCAAGTGCAACTATAGGCGCT } \\
\text { GCTTCTGCTGCTGCTGTTACTGGTTCCAAGTTCTTTTTTCATCAGAGG } \\
\text { CATTGAAAGAACCTTTTCCAATCTTTTTTTTTTTTTTTCATTTTCACA } \\
\text { AAAAATAAGAGAACTCCTGAAGGTCTTCATGA }\end{array}$ & TCT & G & 16,83 & 170 & $\begin{array}{l}\text { TCATCATAGAGGTCG } \\
\text { CACCA }\end{array}$ & 60,2 & $\begin{array}{l}\text { AGCAGCGCCTATAG } \\
\text { TTGCAC }\end{array}$ & 60,2 & 50 & 55 \\
\hline 284 & BrPe3135 & $\begin{array}{l}\text { Maracuja_ } \\
\text { Nolndex_L } \\
003 \_R 1 \text { 00 } \\
\text { 1_contig_2 } \\
\text { 2586 }\end{array}$ & 3 & 527 & 538 & 12 & 4 & 9 & $\begin{array}{l}\text { ATATCTGATCATCACTCCAATACAAACTAGTATGCATAAGACAGTG } \\
\text { AGTAAACTACTCATCAGGCATCACCCCATGTTGAAGGCCCGCCCATT } \\
\text { CCCACTTCAACTGCTGGAGGCAATCGCACCGTAGTTCCTACCACATG } \\
\text { TTTATTACTTTTCTTCTTCTTCATGGACACAGCAACCAAGCCACTCTG } \\
\text { TGACTTTTTGACATCAGCAACTTTATCAACGATCTTTTTTCGACTACC } \\
\text { ATGTTTGGGACTTTCTGAAGCATCAGCAGCAAAAAATTCAGCAAAT } \\
\text { GACGCTTCGGCATTATCAATAATGTCAAGT }\end{array}$ & $\begin{array}{l}\text { TTC } \\
7 \\
7\end{array}$ & G & 145,74 & 167 & $\begin{array}{l}\text { CСATTCCCACTTCAA } \\
\text { CTGCT }\end{array}$ & 60,1 & $\begin{array}{l}\text { TTCAGAAAGTCCCA } \\
\text { AACATGG }\end{array}$ & 60 & 50 & 42,9 \\
\hline 285 & BrPe3136 & $\begin{array}{l}\text { Maracuja_ } \\
\text { NoIndex_L } \\
003 \_R 1 \_00 \\
\text { 1_contig_2 } \\
\text { 2962 }\end{array}$ & 3 & 859 & 870 & 12 & 4 & 9 & $\begin{array}{l}\text { AAGCAATGAGGATGAAGATCAAGTTCTGAAGGTAGAGGACCAGACT } \\
\text { GGACATTTCAACAAAGCCACTATTGAATGTTATAAATGTCACAACTT } \\
\text { AGGACATTTCCAATATGAATATCCAAAGTGGAATAAGGAGGCAAAT } \\
\text { TATGCAGAGTTAGAAGAAGAAGATGAGCTGTTGTTAATGACATATG } \\
\text { TAGAACTATATGGAGCAAAGAGAGGTGATGTGTGGTTCATAGACTC } \\
\text { TGGATATGTGTAGGAATCAAGGAATATTTTCAAGTTTGGATACAACT } \\
\text { TTTTCACACATTGTCAAGCTTGGAATCGATACTA }\end{array}$ & AGA & $\mathrm{s}$ & 32,43 & 180 & $\begin{array}{l}\text { AGGACCAGACTGGAC } \\
\text { ATTTCA }\end{array}$ & 59,6 & $\begin{array}{l}\text { САТСАССТСТСТTTG } \\
\text { СТССA }\end{array}$ & 50 & 47,6 & 50 \\
\hline
\end{tabular}

G: genoma funcional

S: genoma estructural

P: polimórfico

M: monomórfico 
APÉNDICE

Marcadores microssatélites desenhados a partir do sequênciamento parcial e da montagem de novo do genoma de $P$. edulis

\begin{tabular}{|c|c|c|c|c|c|c|c|c|c|c|c|c|c|c|c|c|c|c|c|}
\hline $\mathbf{N}^{\mathbf{o}}$ & Primer & Contig $\mathrm{I}$ & Motivo & Início & Fim & pb & $\begin{array}{c}\mathbf{N}^{\circ} \\
\text { Repet }\end{array}$ & Score & Sequência do contig & Unidade & $G / S$ & Cobertura & pb & Sequência Forward & $\begin{array}{l}\mathrm{T}^{\circ} \mathrm{C} \\
F w d\end{array}$ & Sequência Reverse & $\begin{array}{l}\mathrm{T}^{\circ} \mathrm{C} \\
\operatorname{Rev}\end{array}$ & $\begin{array}{c}\% \mathrm{GC} \\
F w d\end{array}$ & $\begin{array}{c}\% \mathrm{GC} \\
\operatorname{Rev}\end{array}$ \\
\hline 286 & BrPe3137 & $\begin{array}{l}\text { Maracuja_ } \\
\text { NoIndex_L } \\
\text { 003_R1_00 } \\
\text { 1_contig_2 } \\
3037\end{array}$ & 3 & 721 & 732 & 12 & 4 & 9 & $\begin{array}{l}\text { TCCTTTGATTCTGAAGGTTGCTGGAGGTTGAGGTAATGTTGAATATT } \\
\text { GGTTATGGTTGGTTAAGAGTGGAGGAGAGGCTTCATGTATAAGTTTT } \\
\text { CATGCATAGCCATGCAAATTCATCTTTTGATCATTTGTGTTTATTAG } \\
\text { GGTTTGCATGTTGTTGTTGTAGGAGGTGTTTCTTCTGGTCA }\end{array}$ & TGT & $\bar{G}$ & 43,36 & 168 & $\begin{array}{l}\text { GGTTGCTGGAGGTTG } \\
\text { AGGTA }\end{array}$ & 60,1 & $\begin{array}{l}\text { TGACCAGAAGAAAC } \\
\text { ACCTCCT }\end{array}$ & 58,8 & 55 & 47,6 \\
\hline 287 & BrPe3138 & $\begin{array}{l}\text { Maracuja_ } \\
\text { NoIndex_L } \\
\text { 003_R1_00 } \\
\text { 1_contig_2 } \\
3217\end{array}$ & 3 & 6580 & 6594 & 15 & 5 & 12 & $\begin{array}{l}\text { ATCAAACTTGCAGTGTCTCCAAACATAGTACAATTGCAGGTAATGCT } \\
\text { AAACCAAAATGTAGCTATCAGATAAACCCAGAACACCCTGACAAAC } \\
\text { AGATCCCAGGACAGACCGTCCATCATTACAAAAGACAGAATAAAAC } \\
\text { AGTTCAAAAGGGAAGAAGAAGAAGAAAAAATCGAACTTTGCACAA } \\
\text { CACAAGCACTAAAACGAAACCCCAATATTGCAAAAACGAAAAAAG } \\
\text { AGAATGAACGAGACACCGGTAGCAAAAGAAACCACGAGAGTTAAA } \\
\text { AAAACAGACCCACCAGTGTCAAAGACATGAACTTGGTTGGT }\end{array}$ & GAA & $\mathrm{s}$ & 16,67 & 180 & $\begin{array}{l}\text { ACCCAGAACACCCTG } \\
\text { ACAAA }\end{array}$ & 60,4 & $\begin{array}{l}\text { GCTACCGGTGTCTC } \\
\text { GTTCAT }\end{array}$ & 60,1 & 50 & 55 \\
\hline 288 & BrPe3139 & $\begin{array}{l}\text { Maracuja_ } \\
\text { NoIndex_L } \\
\text { 003_R1_00 } \\
\text { 1_contig_2 } \\
3352\end{array}$ & 3 & 596 & 610 & 15 & 5 & 12 & $\begin{array}{l}\text { AGACTAGCTTCTGAAGATTCCACACCAGCTAGCCAACATCAAGAGA } \\
\text { AACAACATGAACACAATATGCAATTCACACAAACACATAAATCAAC } \\
\text { TAAAGAGGAGCAAAGAGACATGCATGAACACCACCTACCTCCTTCT } \\
\text { TCATTTCTCTCCTCTTCTTCTTCTTCTCCAACCTTAGCCAACTCTCAT } \\
\text { GATGCCCTAGCTCTTTCCTGTTTTCTCTTTTCCTTTCCTCACTTCACC } \\
\text { ATATTTTCTCTTTTATTTTATGCAATGAAAGAAAAATAATAAAAAGT } \\
\text { GGGATGATTTGGGTCAAAAG }\end{array}$ & ТСТ & G & 47,14 & 184 & $\begin{array}{l}\text { CACCAGCTAGCCAAC } \\
\text { ATCAA }\end{array}$ & 59,9 & $\begin{array}{l}\text { CAGGAAAGAGCTAG } \\
\text { GGCATC }\end{array}$ & 59 & 50 & 55 \\
\hline 289 & BrPe3140 & $\begin{array}{l}\text { Maracuja_ } \\
\text { NoIndex_L } \\
\text { 003_R1_00 } \\
\text { 1_contig_2 } \\
3729\end{array}$ & 3 & 6745 & 6756 & 12 & 4 & 9 & $\begin{array}{l}\text { TCTCTCCTCACTGCTTGTGAGAACGAGGTCCATTATGTGGGAAATTG } \\
\text { TATCTTTAGGTGGATCAATAATGCCAGAAGAGATTCGTTTCAGAATC } \\
\text { GTTGTGACCCCAATACCTTCATTCTGCAGTCGCAGAACTGAAGTGAC } \\
\text { CACCTTTTGTTCTTCTTCTTCCCCAACCCATGGAACTGCTTCTAAATA } \\
\text { TTCTAAGCATGACTGTATGCAGAACTTGAAGCCAATAAGTTCTGCAA } \\
\text { CCTGTGAAACAGATTATGCAAGGGTTCATTTATGCTAAAAAATGT } \\
\text { TCCCTTCAGATACATTGAAAGCTTAAAAG }\end{array}$ & TTC & G & 30,33 & 179 & $\begin{array}{l}\text { ССTCACTGCTTGTGA } \\
\text { GAACG }\end{array}$ & 59,6 & $\begin{array}{l}\text { AGAAGCAGTTCCAT } \\
\text { GGGTTG }\end{array}$ & 60,1 & 55 & 50 \\
\hline 290 & BrPe3141 & $\begin{array}{l}\text { Maracuja_ } \\
\text { NoIndex_L } \\
\text { 003_R1_00 } \\
\text { 1_contig_2 } \\
3783\end{array}$ & 3 & 4373 & 4384 & 12 & 4 & 9 & $\begin{array}{l}\text { TCGCAAAACCAGAAACGAAAACACAGAGAAGCTCACCAGAAAACT } \\
\text { ACTGAAAAATTGATCCAATCTCCAGGACAAAATTAAACCACTAGAC } \\
\text { ATTAGATATGATAGAAGTCTCAATCTGTGAAGGGGTTATCTTGAAC } \\
\text { CTGTAGACAAGTTTCTTCTTCTTCGAGGTAGGATTGTTAATTGTGAG } \\
\text { CAATATTTTACCCAGCTCAGAAACTTTGAAGCTGCTAGACACCACTG } \\
\text { GTGCATCAGTTGAGGTCATTTTCGTTGGTTTTGTATGATTATCGTAT } \\
\text { ATGCATCCTTAGCATCAGGAACAAACTCAGCA }\end{array}$ & TTC & G & 18,01 & 187 & $\begin{array}{l}\text { TGTGAAGGGGTTGAT } \\
\text { CTTGA }\end{array}$ & 59,1 & $\begin{array}{l}\text { TGTTCCTGATGCTAA } \\
\text { GGATGC }\end{array}$ & 60,2 & 45 & 47,6 \\
\hline
\end{tabular}

G: genoma funcional

S: genoma estructural

P: polimórfico

M: monomórfico 
APÉNDICE

Marcadores microssatélites desenhados a partir do sequênciamento parcial e da montagem de novo do genoma de $P$. edulis

\begin{tabular}{|c|c|c|c|c|c|c|c|c|c|c|c|c|c|c|c|c|c|c|c|}
\hline $\mathbf{N}^{\circ}$ & Primer & Contig I & Motivo & Início & Fim & pb & $\begin{array}{c}\mathbf{N}^{\circ} \\
\text { Repet }\end{array}$ & Score & Sequência do contig & Unidade & G/S C & Cobertura & $\mathrm{pb}$ & Sequência Forward & $\begin{array}{l}\mathrm{T}^{\circ} \mathrm{C} \\
F w d \\
\end{array}$ & Sequência Reverse & $\begin{array}{r}\mathrm{T}^{\circ} \mathrm{C} \\
\operatorname{Rev} \\
\end{array}$ & $\begin{array}{c}\% \mathrm{GC} \\
F w d \\
\end{array}$ & $\begin{array}{cc}\% \mathrm{GC} & \mathrm{P} / \mathrm{M} \\
\operatorname{Rev} & \end{array}$ \\
\hline 291 & BrPe3142 & $\begin{array}{l}\text { Maracuja_ } \\
\text { NoIndex_L } \\
\text { 003_R1_00 } \\
\text { 1_contig_2 } \\
4634\end{array}$ & 3 & 271 & 285 & 15 & 5 & 12 & $\begin{array}{l}\text { CTTTTTGCCTTGTTATACATAGACACGTAGAGGGTAGTAACATGCTT } \\
\text { CGGTCTGAGGATCTCTTATTTGATTGAAATCAGACAAATAGAACAA } \\
\text { GAAAAAACTGAATCTTCAAAGGTCCAAGAAGAAGTGGCATCCACCA } \\
\text { AGAAGTATGTTTTCTTCTTCTTCTTCATCTTCTTTCTCTGTGTGAGTGT } \\
\text { TGATATTACTAACTAAACACATTGACAATGGTAGCCACCTTCTTCAC } \\
\text { AACAATGGTCGATGGGGTCTCCTGATATCTACAGAAACTGGATGGT } \\
\text { TTTTGTCTGTTTTGGTGATCATCTCGTGTACATA }\end{array}$ & TTC & $\bar{G}$ & 18,01 & 182 & $\begin{array}{l}\text { TGGCATCCACCAAGA } \\
\text { AGTATG }\end{array}$ & 60,9 & $\begin{array}{l}\text { CACGAGATGATCAC } \\
\text { CAAAACA }\end{array}$ & 59,6 & 47,6 & 42,9 \\
\hline 292 & BrPe3143 & $\begin{array}{l}\text { Maracuja_ } \\
\text { NoIndex_L } \\
\text { 003_R1_00 } \\
\text { 1_contig_2 } \\
4688\end{array}$ & 3 & 1426 & 1437 & 12 & 4 & 9 & $\begin{array}{l}\text { CATCTGAAAGGCCCAGGACAGAGCGTTTACAGACTTGGGGCTTGAG } \\
\text { CTTTTTGGTGGCGTACCAGAGGCTTGGAGGCTCGGAGCAGTTCGCTC } \\
\text { TTGGTGAACCGGACTGGACTGGGACAAAAGGTGGTTTTGGGTCAA } \\
\text { TCTTAAGGAAATATTATTATTATCAGATTATTTGCCCTGGGCAATTTT } \\
\text { TTAATCTCAATTTGTCTTTTCCTTATAAATTGTATACAAATTATTTAA } \\
\text { AAATATCTTATTTTATTTTATTTTAAAATAAATTATAATTATGACAAT } \\
\text { TCTATTTAAAAGAAAAAAAAAATAAATGG }\end{array}$ & TAT & $\mathrm{s}$ & 12,65 & 101 & $\begin{array}{l}\text { AAAAGGTGGTTTTTG } \\
\text { GGTCA }\end{array}$ & 59,3 & $\begin{array}{l}\text { CAATTTATAAGGAA } \\
\text { AAGACAAATTGA }\end{array}$ & 57,2 & 40 & 23 \\
\hline 293 & BrPe3144 & $\begin{array}{l}\text { Maracuja_ } \\
\text { NoIndex_L } \\
003 \text { R1_00 } \\
\text { 1_contig_2 } \\
\text { 5276 }\end{array}$ & 3 & 897 & 908 & 12 & 4 & 9 & $\begin{array}{l}\text { ATGAAGAAGATGACGAGGATGAAGTAAGATTCATAACCATAACCAT } \\
\text { AACCTTCTGGGAAAAGAAAAAAAAAGTTTCCGTTTTCTCACTTGTT } \\
\text { CTAACGGACTAATAAAATTGCTTCCTGACGTTCTTTCCCCTGCAGAT } \\
\text { AACAGTGAAGGAAGAAGAAGAAATGGTTGATTCTGCAGATATATTT } \\
\text { GCTCACATCAGCGGTGTTAACTCCTTCAAATGCAATTATTCTATCCA } \\
\text { CTCCTGGATTTAGTGAAACGTCTCTACAATTTTGAAGGGTCCATAT } \\
\text { CTGCCAGGATGGTCTGTCCGGGTCTAGTCAAA }\end{array}$ & GAA & $\mathrm{s}$ & 14,6 & 164 & $\begin{array}{l}\text { CGTTCTTTCCCCTGCA } \\
\text { GATA }\end{array}$ & 60,2 & $\begin{array}{l}\text { GGCAGATATTGGAC } \\
\text { CCTTCA }\end{array}$ & 59,9 & 50 & 50 \\
\hline 294 & BrPe3145 & $\begin{array}{l}\text { Maracuja_ } \\
\text { NoIndex_L } \\
\text { 003_R1_00 } \\
\text { 1_contig_2 } \\
\text { 5298 }\end{array}$ & 3 & 661 & 684 & 24 & 8 & 21 & $\begin{array}{l}\text { GTAAAGATTTGTCGTGTTCTAACACAGTGATTTTCTTCTTCTTTTTCC } \\
\text { AATATTTTATCGGAACAGTGCATCTTTGGCATCCTTAACAAGAGAAA } \\
\text { CTGGACCCAAGGTTGTGAAAGGAGACCCAGCGAACAAGATCCAGCC } \\
\text { CACCAATGTTCATCATCATCATCATCATCATCACGTTGAGGCACCTA } \\
\text { CCATCAGCGTCAGTGACAGCTCCCTCAAGTTCACTCATGTGCTCTAT } \\
\text { AACCTCTCTCCTGCAGGTTAATATTTTCTCTTAATTTCAAATGAACA } \\
\text { AATATGTGACTTTGGTATCAAGAAAATGACCAGAAAAAAAAAG }\end{array}$ & TCA & G & 14,4 & 157 & $\begin{array}{l}\text { AGTGCATCTTTGGCA } \\
\text { TCCTT }\end{array}$ & 59,7 & $\begin{array}{l}\text { TGAACTTGAGGGAG } \\
\text { CTGTCA }\end{array}$ & 59,5 & 45 & 50 \\
\hline 295 & BrPe3146 & $\begin{array}{l}\text { Maracuja_ } \\
\text { NoIndex_L } \\
\text { 003_R1_00 } \\
\text { 1_contig_2 } \\
5397\end{array}$ & 3 & 3000 & 3011 & 12 & 4 & 9 & $\begin{array}{l}\text { TGTCAAGCCCGCCAACTCCCAGACTTGGTCCCCCGATGCTTGCAAAT } \\
\text { GCCTTTAGACAGCGTGCAGCAGCTATTCTGACGACCGATGATTTATC } \\
\text { CCCGACACCAAAGCGGGTGATAAGACGAAATGCCTCAGTATATGCT } \\
\text { GAGCCATTAGCACCACCACCACAGCCTTCCAGAGCCTTTTGAAGCA } \\
\text { TAAGCAGGGCCTCTTGTCTCACAAAATCCTGGAATTCGATGCCAAAT } \\
\text { GACATCATTTAAAAATAAATGAAAAAATCGAGAAACGCGATGATGAA } \\
\text { AAAGAAAACATCCCGCCAACTCCGTTAAAAGA }\end{array}$ & $\mathrm{CAC}$ & $\mathrm{s}$ & 17,78 & 197 & $\begin{array}{l}\text { ACACCAAAGCGGGTG } \\
\text { ATAAG }\end{array}$ & 60,0 & $\begin{array}{l}\text { CGGGATGGTTTTCTT } \\
\text { TTTCA }\end{array}$ & 59,9 & 50 & 40 \\
\hline
\end{tabular}

G: genoma funcional

S: genoma estructural

P: polimórfico

M: monomórfico 
APÉNDICE

Marcadores microssatélites desenhados a partir do sequênciamento parcial e da montagem de novo do genoma de $P$. edulis

\begin{tabular}{|c|c|c|c|c|c|c|c|c|c|c|c|c|c|c|c|c|c|c|c|}
\hline $\mathbf{N}^{\circ}$ & Primer & Contig I & Motivo & Início & Fim & pb & $\begin{array}{c}\mathbf{N}^{\circ} \\
\text { Repet }\end{array}$ & Score & Sequência do contig & Unidade & G/S & Cobertura & pb & Sequência Forward & $\begin{array}{l}\mathrm{T}^{\circ} \mathrm{C} \\
F w d \\
\end{array}$ & Sequência Reverse & $\begin{array}{l}\mathrm{T}^{\circ} \mathrm{C} \\
\operatorname{Rev} \\
\end{array}$ & $\begin{array}{c}\% \mathrm{GC} \\
F w d \\
\end{array}$ & $\begin{array}{c}\% \mathrm{GC} \\
\operatorname{Rev}\end{array} \quad \mathrm{P} / \mathrm{M}$ \\
\hline 296 & BrPe3147 & $\begin{array}{l}\text { Maracuja_ } \\
\text { NoIndex_L } \\
\text { 003_R1_00 } \\
\text { 1_contig_2 } \\
\text { 5576 }\end{array}$ & 3 & 1527 & 1541 & 15 & 5 & 12 & $\begin{array}{l}\text { AAACAGAGTATTAGCGAGTTAATGAGTCAATTACCAACCTTGTAAA } \\
\text { CACCATAATTACCAGCAGAAGGGTCTCATATGGGATGATTGATTTTA } \\
\text { ACTTTTCTGGGTCTTCATAAGTGAGTGATGTAGGTAGTAAGTAGTAT } \\
\text { ATTGCTTATTTTATTATTATTATTACAGTGTATGGTTGAGGGTACAA } \\
\text { AGCTTTCAAGTGTTGGGTTGTCCCCTGTTTTGCTGGTGCTGCCAGTCC } \\
\text { CCACTAATCCCTTCCGGTGAATAAACTTCTCAGAATTTGATTCTTCT } \\
\text { GCAGGCCACTCACCATGTTGTCTCCTTCTAAT }\end{array}$ & TTA & $\mathrm{s}$ & 17,72 & 202 & $\begin{array}{l}\text { TTACCAGCAGAAGGG } \\
\text { TCTCA }\end{array}$ & 58,4 & $\begin{array}{l}\text { TTCACCGGAAGGGA } \\
\text { TTAGTG }\end{array}$ & 59,9 & 50 & 50 \\
\hline 297 & BrPe3148 & $\begin{array}{l}\text { Maracuja_ } \\
\text { NoIndex_L } \\
\text { 003_R1_00 } \\
\text { 1_contig_2 } \\
\text { 5741 }\end{array}$ & 3 & 2424 & 2435 & 12 & 4 & 9 & $\begin{array}{l}\text { TAACTCTTATTGTTCAGTACAATAAACTTCTCAGCTGTTGTCAAATA } \\
\text { CCTTCATGGATAAACTGCAATCTGGAGGGGAATGGCATGGATTTGT } \\
\text { ATAATGATGATTTCATCAGTTCATCGGTCGAAATGGACGTTTATGAA } \\
\text { ACCTCCATTCATGATGATGATGGAAAATTATCTTCCAAAAGTGAGG } \\
\text { AAATTTTAGTCGCTTTCTTCTCATCTGACAAATACTTCATATCCGTTT } \\
\text { TATGTTCACTTGGAACTGTTTGCTAATTGTCTGGAATTGATGCAGGT } \\
\text { TTTATTTACCCTGCATCATGCCAACTTACTG }\end{array}$ & ATG & G & 18,11 & 174 & $\begin{array}{l}\text { CATCAGTTCATCGGT } \\
\text { CGAAA }\end{array}$ & 59,6 & $\begin{array}{l}\text { CCTGCATCAATTCC } \\
\text { AGACAA }\end{array}$ & 59,6 & 45 & 45 \\
\hline 298 & BrPe3149 & $\begin{array}{l}\text { Maracuja_ } \\
\text { NoIndex_L } \\
\text { 003_R1_00 } \\
\text { 1_contig_2 } \\
\text { 5801 }\end{array}$ & 3 & 2846 & 2857 & 12 & 4 & 9 & $\begin{array}{l}\text { ACAATGCCTGAGATAAATTTAAAAGGCACTATGGCAATCTCCACAAA } \\
\text { TTCTGAGATTTTTTATGATTCTTATAGGCACTCCAGGAGGGATAGAT } \\
\text { ATTAGGCCAAATGCTAGAGCAATTTTCTCGCTGTGCTCCCCAACTTC } \\
\text { AGTTATTTTCTCTTCTTCTTCTAAATCAAATAGTGCATAGTTGGTGTC } \\
\text { AGGAATGTACCCGGCCGCCTTCATTTCTGTCCTCATCTTGACCAGCA } \\
\text { TTGCTTGAATCTCACTGTTCCTTTCATGTGATGCATCTTTTGCTCGGA } \\
\text { AAACATGGACCCTATCCTTTACAGTGAGC }\end{array}$ & ТСТ & G & 17,4 & 177 & $\begin{array}{l}\text { AGCAATTTTCTCGCTG } \\
\text { TGCT }\end{array}$ & 60,2 & $\begin{array}{l}\text { GTTTTCCGAGCAAA } \\
\text { AGATGC }\end{array}$ & 59,8 & 45 & 45 \\
\hline 299 & BrPe3150 & $\begin{array}{l}\text { Maracuja_ } \\
\text { NoIndex_L } \\
\text { 003_R1_00 } \\
\text { 1_contig_2 } \\
6297\end{array}$ & 3 & 416 & 427 & 12 & 4 & 9 & $\begin{array}{l}\text { GTTTCAATGATTTGCATTGCCCAGGTAAGTTTTTAGAGTGATTCTTG } \\
\text { AAGGCATGGAGCCGTGGTGATGGTTCATGCATATTTATGCATGTGGT } \\
\text { GTATTTTCTCCATTTTTGTGCATTGTGTGACTGTTGGCTGTTTGGTGT } \\
\text { TTAGGTAGTGTTGTTGTTGTCCAGAATCCTTCTCCTAGTGCACAAGA } \\
\text { GGAGCAAAATCAGGTGAGGATGCTTTCATATTTGCTTGGAATTGGTT } \\
\text { TTTGTTTTTAAATTGATTTATGTGAATTTTGATTTAAAAGCATGGCA } \\
\text { TGTTGATTGAAAATGTGATTGAATGATC }\end{array}$ & TGT & G & 67,77 & 199 & $\begin{array}{l}\text { ATTTGCATTGCCCAG } \\
\text { GTAAG }\end{array}$ & 60,0 & $\begin{array}{l}\text { ССТСАССTGATTTTG } \\
\text { СТССT }\end{array}$ & 59,3 & 45 & 50 \\
\hline 300 & BrPe3151 & $\begin{array}{l}\text { Maracuja_ } \\
\text { NoIndex_L } \\
\text { 003_R1_00 } \\
\text { 1_contig_2 } \\
6606\end{array}$ & 3 & 3005 & 3016 & 12 & 4 & 9 & $\begin{array}{l}\text { CCGCACAAATTACGTACCTTCTCCCGCTGGACACGTTTTGGAGTTCC } \\
\text { TAAATTTGTCAGATCAGGCAATCTGGCATTAGACAAGGTGATCACT } \\
\text { GAATTTTATTTCCGCATGGTTTTTTCTACACCCACTCGTATAAAATAT } \\
\text { ATGCCTCCAGATGATGATGATCCAGCAAAGGGACTGACTTTTAATAT } \\
\text { GGCAAAGCTGAAGTATGAACTCTGTTATAGCCGGGGCAAGCAGATC } \\
\text { TATACTTTTGAATGCAAGCGTGATAGTCTTGATCTTGTTTACCAGGG } \\
\text { CCTTGACCTTCATATACCCAAGGCTATCTTG }\end{array}$ & GAT & G & 16,8 & 235 & $\begin{array}{l}\text { TGTCAGATCAGGCAA } \\
\text { TCTGG }\end{array}$ & 59,8 & $\begin{array}{l}\text { GTCAAGGCCCTGGT } \\
\text { AAACAA }\end{array}$ & 60 & 50 & 50 \\
\hline
\end{tabular}


APÉNDICE

Marcadores microssatélites desenhados a partir do sequênciamento parcial e da montagem de novo do genoma de $P$. edulis

\begin{tabular}{|c|c|c|c|c|c|c|c|c|c|c|c|c|c|c|c|c|c|c|c|}
\hline $\mathbf{N}^{\circ}$ & Primer & Contig I & Motivo & Início & Fim & pb & $\begin{array}{c}\mathbf{N}^{\circ} \\
\text { Repet }\end{array}$ & Score & Sequência do contig & Unidade & G/S & Cobertura & pb & Sequência Forward & $\begin{array}{l}\mathrm{T}^{\circ} \mathrm{C} \\
F w d\end{array}$ & Sequência Reverse & $\begin{array}{r}\mathrm{T}^{\circ} \mathrm{C} \\
\operatorname{Rev}\end{array}$ & $\begin{array}{r}\% \mathrm{GC} \\
F w d\end{array}$ & $\begin{array}{cc}\% \mathrm{GC} & \\
\operatorname{Rev} & \mathrm{P} / \mathrm{M}\end{array}$ \\
\hline 301 & BrPe3152 & $\begin{array}{l}\text { Maracuja_ } \\
\text { NoIndex_L } \\
\text { 003_R1_00 } \\
\text { 1_contig_2 } \\
7044\end{array}$ & 3 & 11172 & 11183 & 12 & 4 & 9 & $\begin{array}{l}\text { CTATAAGTCGCAAAGAATATATTGAAGCAATAAAAAATCGATAGGC } \\
\text { TTGACAGGTAATTAATGAGACGCAAATATTGACTCACGTAATAAGC } \\
\text { AGCAGAATCCATGGTCCATAATTGACAACAGTATTATCATCATTTG } \\
\text { CAAGCACTGTTTCATCATCATCAGAATCCCCTGCACTCTCGAAAGCA } \\
\text { TTTGCACTTGGTGATCGGGGAGTCATTAGTCTTCTCGTAATAGAACT } \\
\text { AGAGTAGTTCACACTCTTATCCTCTCCTGCCCAAAACAAAGAAGAA } \\
\text { AAAGAAAAGCCAGCAACGAAATTGAACTTCAGT }\end{array}$ & $\mathrm{TCA}$ & $\mathrm{G}$ & 18,88 & 186 & $\begin{array}{l}\text { AAGCAGCAGAATCCA } \\
\text { TGGTC }\end{array}$ & 60,2 & $\begin{array}{l}\text { CTTTGTTTTGGGCAG } \\
\text { GAGAG }\end{array}$ & 59,8 & 50 & 50 \\
\hline 302 & BrPe3153 & $\begin{array}{l}\text { Maracuja_ } \\
\text { NoIndex_L } \\
\text { 003_R1_00 } \\
\text { 1_contig_2 } \\
7138\end{array}$ & 3 & 9031 & 9042 & 12 & 4 & 9 & $\begin{array}{l}\text { GCAACAGTGAGATGGATGATCCAGAAGCAGAGAGACACCAGAATG } \\
\text { AGAGAGAACCACATCATTGGGGAGCAGGAAACTCTCATTACTCAAC } \\
\text { TTCCCTTGATGAGCCAAGCTCTTCATATTCTCCTTACCTTCCCCCTGT } \\
\text { TCTTGAAGAACCTTCTTCTTCTTTTTCTGAGGGTGAGATTGTCGTGAT } \\
\text { CTTAGAAGCCTGGCCTAGTTTTCTCCAAGTGAATCCAGTTTTCATT } \\
\text { GTTATTGATCTTCATTTCTACATATTATGATATGCAGCTGCAGATGA } \\
\text { TGATCCACTGCCGGCCATAGAGGGCCTCCAA }\end{array}$ & СТт & G & 19,01 & 172 & $\begin{array}{l}\text { ATTGGGGAGCAGGAA } \\
\text { АСТCT }\end{array}$ & 60,1 & $\begin{array}{l}\text { TGGAAAACTGGATT } \\
\text { CACTTGG }\end{array}$ & 60 & 50 & 42,9 \\
\hline 303 & BrPe3154 & $\begin{array}{l}\text { Maracuja_ } \\
\text { NoIndex_L } \\
\text { 003_R1_00 } \\
\text { 1_contig_2 } \\
7138\end{array}$ & 3 & 2841 & 2852 & 12 & 4 & 9 & $\begin{array}{l}\text { TATATGCGGCTGGTAGGTGTAACTCTCTTTCCAATTCTTATCTTCACA } \\
\text { TCGAGGTCTCCTGTGTCTTCTAGCATTTTGGATCTAATTTTTATTCTG } \\
\text { TATGGAATTGTTCCTTGCAACTCTAATAGACCTCCTTGCCAACAGGC } \\
\text { TTTTGATCAACAACAACAAGATCTGGTAGACGCCGCATCCAAAGCT } \\
\text { CTCTCATACAGGCAGGACATAATTGAGGAAAACATACGTCTTACAT } \\
\text { ATGAATTACAGGCAAGTACCATATGTGGTTGGTTTTATCTCTTTTG } \\
\text { GTTGTGAATTTGCATTCTTTTATATTAAGT }\end{array}$ & $\mathrm{CAA}$ & $\mathrm{s}$ & 19,01 & 203 & $\begin{array}{l}\text { ATGCGGCTGGTAGGT } \\
\text { GTAAC }\end{array}$ & 60,0 & $\begin{array}{l}\text { TCCTGCCTGTATGA } \\
\text { GAGAGC }\end{array}$ & 58,1 & 55 & 55 \\
\hline 304 & BrPe3155 & $\begin{array}{l}\text { Maracuja_ } \\
\text { NoIndex_L } \\
\text { 003_R1_00 } \\
\text { 1_contig_2 } \\
7174\end{array}$ & 3 & 2112 & 2123 & 12 & 4 & 9 & $\begin{array}{l}\text { TGCAAGATGTCAGTGGATATGCCGAGTTTTTTGTGGCTGGTTCCTCG } \\
\text { GAACCCCAGCCAAGATCTTCAAACCACACCGTTTCTAAGTCTTATAC } \\
\text { AGATGGTTGTTCATCTCCTCCTGAAAATTTTACTGCTGATGCATCCC } \\
\text { CTACTATCCGAAGAAGAAGAACGTTTGATGCCAGGACGGAATTACT } \\
\text { AGTAAATACAAGATATGAAGTTATAGAAACTAGTTACAATCATCCA } \\
\text { TTCTCCTTCATTATTAAAGCGTAATTGTCTTTTTCACTTGACTTAAGC } \\
\text { ATACCATAAATTGTATAGATATGATGTGCCA }\end{array}$ & GAA & G & 17,38 & 179 & $\begin{array}{l}\text { TGTCAGTGGATATGC } \\
\text { CGAGT }\end{array}$ & 59,1 & $\begin{array}{l}\text { GTAATTCCGTCCTG } \\
\text { GCATCA }\end{array}$ & 60,9 & 50 & 50 \\
\hline 305 & BrPe3156 & $\begin{array}{l}\text { Maracuja_ } \\
\text { NoIndex_L } \\
\text { 003_R1_00 } \\
\text { 1_contig_2 } \\
7388\end{array}$ & 3 & 2045 & 2056 & 12 & 4 & 9 & $\begin{array}{l}\text { GCTGGTTGATTTGGATTTTGATTTGTAGTTTTCTCTGGCTCAAGGTGG } \\
\text { AGCTTCCGGAAAAATTCCACAGTTAAGTAGCTAGATTCATATCCAC } \\
\text { AAGCCGTAAAACTGTTTTCCGACTTTCATCACGGAATCTCTCCAGAG } \\
\text { CTTCATTTGCAGCAGCAGCAATGTCGGCAGTAAGAGTTGGAAAGCG } \\
\text { CTTTAGTTCCTGCAATTGCCAGAAAAAATAAAAAGGAACAAGTGAA } \\
\text { CTAGCTTATTTTTCATCTTTGGCATCCTAGTTCTTTTATGACCACAAC } \\
\text { AATACAAGAGACATCTTGTTAGATCTCAAA }\end{array}$ & $\mathrm{GCA}$ & G & 40,5 & 161 & $\begin{array}{l}\text { CTTCCGGAAAAATTC } \\
\text { CACAG }\end{array}$ & 59,5 & $\begin{array}{l}\text { TCTGGCAATTGCAG } \\
\text { GAACTA }\end{array}$ & 59,4 & 45 & 45 \\
\hline
\end{tabular}


APÉNDICE

Marcadores microssatélites desenhados a partir do sequênciamento parcial e da montagem de novo do genoma de $P$. edulis

\begin{tabular}{|c|c|c|c|c|c|c|c|c|c|c|c|c|c|c|c|c|c|c|c|}
\hline $\mathrm{N}^{\circ}$ & Primer & Contig M & Motivo & Início & Fim & pb & $\begin{array}{c}\mathbf{N}^{\circ} \\
\text { Repet }\end{array}$ & Score & Sequência do contig & Unidade & $\mathbf{G} / \mathbf{S}$ & Cobertura & pb & Sequência Forward & $\begin{array}{l}\mathrm{T}^{\circ} \mathrm{C} \\
F w d \\
F w\end{array}$ & Sequência Reverse & $\begin{array}{l}\mathrm{T}^{\circ} \mathrm{C} \\
\mathrm{Rev} \\
\end{array}$ & $\begin{array}{c}\% \mathbf{G C} \\
F w d \\
\end{array}$ & $\begin{array}{l}\% \text { GC } \\
\text { Rev } \\
\end{array}$ \\
\hline 306 & BrPe3157 & $\begin{array}{l}\text { Maracuja_ } \\
\text { NoIndex_L } \\
\text { 003_R1_00 } \\
\text { 1_contig_2 } \\
7834\end{array}$ & 3 & 1580 & 1591 & 12 & 4 & 9 & $\begin{array}{l}\text { ACGTGTGCGGACATGCCGTTCAGGAGTCTTGACATTTGCATACCTGA } \\
\text { TTAGCGATCAGGAAACTTGCAATAAGTAATTTTAAAATAAGAAAGA } \\
\text { ACAATAAATCAGAAGGTTTAGATATTACTTTGGATCCAAACGGTACT } \\
\text { TGGTCTCTTTATCATCATCATCCTCTTGATCCGTTGATACTTCACTTG } \\
\text { TTGTGCTAGTTCTTCTTCCGTCTTCATTTTTTGCGACAAGCTTTGATT } \\
\text { GATAATCTATATCCTTCCTTTCAGCCTTCATTGCGTTTGGATGCTGAT } \\
\text { CTTGATTACCCTTTAATTCAGCAACACT }\end{array}$ & ATC & G & 18,29 & 185 & $\begin{array}{l}\text { GACATGCCGTTCAGG } \\
\text { AGTCT }\end{array}$ & 60,3 & $\begin{array}{l}\text { GCACAACAAGTGAA } \\
\text { GTATCAACG }\end{array}$ & 59,7 & 55 & 43,5 \\
\hline 307 & BrPe3158 & $\begin{array}{l}\text { Maracuja_ } \\
\text { NoIndex_L } \\
\text { 003_R1_00 } \\
\text { 1_contig_2 } \\
\text { 7966 }\end{array}$ & 3 & 1416 & 1427 & 12 & 4 & 9 & $\begin{array}{l}\text { TTCCTTCTTGTGTTCGGTGCTTGTAAGTTTCTCCCCCCACCCATTGCC } \\
\text { TGGACTGTTCCATGGTGTGTGTAAACTGAGTCCCATTTGTTTTATATT } \\
\text { TCCAAGTGGTGATCCAGTCGTCAGCTTTATTACACCTCGTGCTTTGA } \\
\text { AACAGACAAGAAGAAGAAGTTAAAAGGAGATTGGAACTGCTATTT } \\
\text { GAAAAAAACATTTCATAGTTCTTCGTTGAATTCCAGTAGATCAAGAA } \\
\text { GCTTTACTGTCTCCCCTTGTAATGAAAAACATCCTATAAACTATTAC } \\
\text { ATCAGGCACAGAATCATAAACGTGCGAAA }\end{array}$ & AAG & G & 16,69 & 105 & $\begin{array}{l}\text { CCCATTTGTTTTATAT } \\
\text { TTCCAAGTG }\end{array}$ & 59,9 & $\begin{array}{l}\text { GCAGGTTCCAATCT } \\
\text { CСTTTT }\end{array}$ & 58,2 & 32 & 45 \\
\hline 308 & BrPe3159 & $\begin{array}{l}\text { Maracuja_ } \\
\text { NoIndex_L } \\
003 \_R 1 \_00 \\
\text { 1_contig_2 } \\
8050\end{array}$ & 3 & 2866 & 2877 & 12 & 4 & 9 & $\begin{array}{l}\text { TTAATCCATATATCATTGTGAGAGAAGAAAAGAATACCTTTAGCAA } \\
\text { ATCAAAGACCTTCTCAGCAATGTATTTTGTTGAAAGGTGGCACCTT } \\
\text { TTTGTTGCACTTTATCAGGATGGATGCATAAAGTTGCTTTCCTATAA } \\
\text { ACCTTCTTAACAGCAGCAGCAGTGATCAAATCAGTTAAGGAAACAG } \\
\text { GCTGCCAACCACATTCTGGCCAGAGTACCTGATCATAGTGCAATAG } \\
\text { AACTTAGCATCAGGGACAGGGAGGCGTAAAACAGTAATGCCTTCCC } \\
\text { ATACATGTTACGGAGCTTATTATATAATAGGTAA }\end{array}$ & CAG & G & 17,29 & 151 & $\begin{array}{l}\text { GCAAATCAAAGACCT } \\
\text { TCTCAGC }\end{array}$ & 60,4 & $\begin{array}{l}\text { TGGCAGCCTGTTTC } \\
\text { CTTAAC }\end{array}$ & 60,2 & 45,5 & 50 \\
\hline 309 & BrPe3160 & $\begin{array}{l}\text { Maracuja_ } \\
\text { NoIndex_L } \\
\text { 003_R1_00 } \\
\text { 1_contig_2 } \\
8317\end{array}$ & 3 & 421 & 432 & 12 & 4 & 9 & $\begin{array}{l}\text { TGAAGATGTTTAAGCTCGTTTATGTTTGAGCATTTACTGCTGCTTGG } \\
\text { CAATGTGTGGTTTTTGATGTATTCTCGTTGGAACATTATTATATTAAA } \\
\text { GGTTAAAGAATGGCTTCAAAATCTAGGAATAGGAGATCATGCACCG } \\
\text { ATTGTGCACGATGATGATGATCCAGATGACGAGACCATTCCCTTGCA } \\
\text { TCATGAGGAAACTGCAAAAAATAGGTGAAAAACTAGTACATTGTTA } \\
\text { CACGAATTCTTAACATTATCAATCCCTTATCTCCGCTTTCTATATTGG } \\
\text { TTCTTATATATGGGTTCTTTTGTGCAGGGA }\end{array}$ & GAT & G & 17,9 & 154 & $\begin{array}{l}\text { TTTACTGCTGCTTGGC } \\
\text { AATG }\end{array}$ & 60,0 & $\begin{array}{l}\text { CAAGGGAATGGTCT } \\
\text { CGTCAT }\end{array}$ & 59,9 & 45 & 50 \\
\hline 310 & BrPe3161 & $\begin{array}{l}\text { Maracuja_ } \\
\text { NoIndex_L } \\
\text { 003_R1_00 } \\
\text { 1_contig_2 } \\
8704\end{array}$ & 3 & 1084 & 1095 & 12 & 4 & 9 & $\begin{array}{l}\text { AATAGTTGCAAAGCTGATGGAGATAAGGAATCATGTGGTAGAAAGT } \\
\text { TTCCAAGCTCATTTTAGTAGGAAAGAGACGGGGTGGTTCTCTTTTGA } \\
\text { TGGTCTCAGCTTTACTAAATTGAAGGTAGAAGAAAGGGAGATGCTT } \\
\text { GAGGCTCCTTTTGATGATGATGAAATTAAAGAAGCAGTGAAATATT } \\
\text { GTGGGAGTTTCAAAGCACCGAGACCGGATGGATTTAATTTTAACTTC } \\
\text { ACAAAAAAGGCATGGGAGGTGATTGGGGATGAGGTCATTGTCTTTG } \\
\text { TTAAGGAGTTCTTTAAATCCGGTGCAAACAAGAT }\end{array}$ & TGA & G & 21,97 & 201 & $\begin{array}{l}\text { AGACGGGGTGGTTCT } \\
\text { СТTTT }\end{array}$ & 60,0 & $\begin{array}{l}\text { CAATGACCTCATCC } \\
\text { CCAATC }\end{array}$ & 60,1 & 50 & 50 \\
\hline
\end{tabular}

G: genoma funcional

S: genoma estructural

P: polimórfico

M: monomórfico 
APÉNDICE

Marcadores microssatélites desenhados a partir do sequênciamento parcial e da montagem de novo do genoma de P. edulis

\begin{tabular}{|c|c|c|c|c|c|c|c|c|c|c|c|c|c|c|c|c|c|c|c|}
\hline $\mathbf{N}^{\circ}$ & Primer & Contig & Motivo & Início & Fim & pb & $\begin{array}{c}\mathbf{N}^{\circ} \\
\text { Repet }\end{array}$ & Score & Sequência do contig & Unidade & G/S & Cobertura & pb & Sequência Forward & $\begin{array}{l}\mathrm{T}^{\circ} \mathrm{C} \\
F w d\end{array}$ & Sequência Reverse & $\begin{array}{l}\mathrm{T}^{\circ} \mathrm{C} \\
\operatorname{Rev}\end{array}$ & $\begin{array}{c}\% \mathrm{GC} \\
F w d\end{array}$ & $\begin{array}{c}\% \mathrm{GC} \\
\operatorname{Rev}\end{array} \quad \mathrm{P} / \mathbf{M}$ \\
\hline 311 & $\begin{array}{ll}\text { BrPe3162 } \\
\end{array}$ & $\begin{array}{l}\text { Maracuja_ } \\
\text { NoIndex_L } \\
003 \_R 1 \_00 \\
\text { 1_contig_2 } \\
9121\end{array}$ & 3 & 1157 & 1168 & 12 & 4 & 9 & $\begin{array}{l}\text { CAGACATGTATAGTTGCTTGGTTAAGGGGTACTGTGAAGCAGGGAA } \\
\text { CGAGGAAATGGCAACAAAGGTTTTTCTTGAATCAGTTGAGAAGAGG } \\
\text { TACATCATCACTGCCGAGAGCTTTTCGACTCTTGTCTACCAATTATG } \\
\text { TGAAAAGGGCAAAGAAGAAGAAGCTGAGAAAATATTTGAGAACAT } \\
\text { GAGTAGGAGATGCCCTGTATTGGATTTAAACAGCTACCGGAGGGTT } \\
\text { CTAGATGGAGCAATTATGCATACATCTGCAGAAAGATCCAAAGGCA } \\
\text { GTCAGTATATCGAGTAGCATCGACTAAAGGAGAACG }\end{array}$ & AAG & G & 15,48 & $182 \mathrm{~A}$ & $\begin{array}{l}\text { ATCATCACTGCCGAG } \\
\text { AGCTT }\end{array}$ & 60,0 & $\begin{array}{l}\text { CTGCCTTTGGATCTT } \\
\text { TCTGC }\end{array}$ & 60 & 50 & 50 \\
\hline 312 & BrPe3163 & $\begin{array}{l}\text { Maracuja_ } \\
\text { NoIndex_L } \\
\text { 003_R1_00 } \\
\text { 1_contig_2 } \\
9359\end{array}$ & 3 & 2956 & 2967 & 12 & 4 & 9 & $\begin{array}{l}\text { TCATATACACCTGTTATTCTATATTTCTTGCAGAATTTGGCATCTTTG } \\
\text { TATGAAGAGAAAGCAGTCCCTCTAATTAAAGGAATTTTCAGTAAT } \\
\text { ACCAGTCCTGGAATGTCTACATAATTTCACAATTGAATCACTCTATA } \\
\text { CGCTCATCTTCCTCCTCCTCCAACCAAAAATAGAATGTCTGCAACCA } \\
\text { AAAAGATTCTACCAAAAAAAAGATTCTAATCACAAAGCTTGAATAT } \\
\text { ATTAATTAATACCAGCTGCACTATTATAAAATTCTGTTGCAAGTCAT } \\
\text { AGATCATCCAGACGGAAAAGACAAAATGTTT }\end{array}$ & TCC & $\mathrm{s}$ & 16,92 & $159 \mathrm{~T}$ & $\begin{array}{l}\text { TGCAGAATTTGGCAT } \\
\text { CTTTG }\end{array}$ & 59,8 & $\begin{array}{l}\text { GGTTGCAGACATTC } \\
\text { TATTTTTGG }\end{array}$ & 59,9 & 40 & 39,1 \\
\hline 313 & BrPe3164 & $\begin{array}{l}\text { Maracuja_ } \\
\text { NoIndex_L } \\
\text { 003_R1_00 } \\
\text { 1_contig_2 } \\
9520\end{array}$ & 3 & 456 & 467 & 12 & 4 & 9 & $\begin{array}{l}\text { GGGAAGCTAACATTTTTTTTTTAAAAAAAAAAAAGAAGAAAATAACA } \\
\text { TGTGTGGGAGATAACCTATCTATCCATCCAAATGGTTAGATATGCTA } \\
\text { TAACCTAGAAGCGTGTCAAGGTAATAGGGTCGTTTCCACAATCAGA } \\
\text { CTTCAGCAGGTTTGTTGTTGTTGATAGTGGAACGTGATCGATTATCG } \\
\text { GCCTAGCACTTCCTGTGTTTTGTTTTCGGCATTCAAACTGTTTATCCA } \\
\text { ATGGTCTAACATCAAGTGTCCACTCAAACATTTTTTAAGGAATAAAA } \\
\text { AAGAGATGAGTAATATTGCATTTTAGATAAA }\end{array}$ & TTG & $\mathrm{s}$ & 14,56 & $\begin{aligned} 154 \mathrm{C} \\
\mathrm{T}\end{aligned}$ & $\begin{array}{l}\text { GAAGAAAATAACATG } \\
\text { TGTGGGAGA }\end{array}$ & 59,4 & $\begin{array}{l}\text { CCGATAATCGATCA } \\
\text { CGTTCC }\end{array}$ & 60,3 & 37,5 & 50 \\
\hline 314 & BrPe3165 & $\begin{array}{l}\text { Maracuja__ } \\
\text { NoIndex_L } \\
003 \_ \text {R1_00 } \\
\text { 1_contig_2 } \\
9677\end{array}$ & 3 & 4576 & 4587 & 12 & 4 & 9 & $\begin{array}{l}\text { CGTTCTTGGCGTTCCTGCACAAATGGCAATATAACAGCCATATTAGA } \\
\text { ACCAGGAACAATGATTTGACTGAATAAATATACCGCACCTTTTCAAT } \\
\text { AGCAATTTTTCTTTTGGTTTCTCTCCTAATCAGCATCATCAAGGAT } \\
\text { CCTCCGAATCTTCTTCTTCTGCTGCTTTCTCTTAAAGCTGATTTGGAA } \\
\text { AAAAATGGAGGGGGAAATTTTCAGAATGATGACAAAGAAACAGAT } \\
\text { ACCACAACAAATCTTCAAGAGGAATTGTTGCATGTAGGAAATTTTTT } \\
\text { TTGTAGAACGAAACTGTAAAGAGGCCATAG }\end{array}$ & TCT & G & 18,57 & $176 \mathrm{~T}$ & $\begin{array}{l}\text { TTCCTGCACAAATGG } \\
\text { CAATA }\end{array}$ & 60,1 & $\begin{array}{l}\text { CAAATCAGCTTTAA } \\
\text { GAGAAAGCA }\end{array}$ & 58 & 40 & 34,8 \\
\hline 315 & BrPe3166 & $\begin{array}{l}\text { Maracuja_ } \\
\text { NoIndex_L } \\
003 \text { R1_00 } \\
1 \text { _contig_3 } \\
0504\end{array}$ & 3 & 369 & 380 & 12 & 4 & 9 & $\begin{array}{l}\text { CGATGTTTACACATGCACATGCATACTTCTTCACTAATCGACAAAAC } \\
\text { TTAAACCATCTTACAGATAATAACATGTTAACGTGAGCACAATCTCC } \\
\text { AGCCCAACAGCTAAAGCCAGTTGATGACGACATTGAACCTCAATCA } \\
\text { GATCCCAATATTCTTCTTCTTCACCTTTTCGTGACAATGTCCCCTTTG } \\
\text { TTTCACTGTTAGTAAATGAATTATGG }\end{array}$ & тTC & G & 11,34 & $154 \mathrm{~T}$ & $\begin{array}{l}\text { TCACTAATCGACAAA } \\
\text { ACTTAAACCA }\end{array}$ & 59,2 & $\begin{array}{l}\text { GGGGACATTGTCAC } \\
\text { GAAAAG }\end{array}$ & 60,4 & 32 & 50 \\
\hline
\end{tabular}


APÉNDICE

Marcadores microssatélites desenhados a partir do sequênciamento parcial e da montagem de novo do genoma de $P$. edulis

\begin{tabular}{|c|c|c|c|c|c|c|c|c|c|c|c|c|c|c|c|c|c|c|c|}
\hline $\mathbf{N}^{\circ}$ & Primer & Contig I & Motivo & Início & Fim & pb & $\begin{array}{c}\mathbf{N}^{\circ} \\
\text { Repet }\end{array}$ & Score & Sequência do contig & Unidade & G/S & Cobertura & pb & Sequência Forward & $\begin{array}{l}\mathrm{T}^{\circ} \mathrm{C} \\
F w d \\
\end{array}$ & Sequência Reverse & $\begin{array}{l}\mathrm{T}^{\circ} \mathrm{C} \\
\operatorname{Rev} \\
\end{array}$ & $\begin{array}{c}\% \mathrm{GC} \\
F w d \\
\end{array}$ & $\begin{array}{cc}\% \mathrm{GC} & \mathrm{P} / \mathrm{M} \\
\operatorname{Rev} & \end{array}$ \\
\hline 316 & BrPe3167 & $\begin{array}{l}\text { Maracuja_ } \\
\text { NoIndex_L } \\
003 \text { R1_00 } \\
\text { 1_contig_3 } \\
1210\end{array}$ & 3 & 1320 & 1331 & 12 & 4 & 9 & $\begin{array}{l}\text { AGACTTCGTTGTAGATCGCAGACGAGTGAAACGTGAGTATGATGAG } \\
\text { TTCAAAGTAAGTCTCAATGGGCTCTCCGATTCAATCGTCGGCGTTC } \\
\text { GGATGCTTATAATAGTCAGCAGGAACTCAAGGCAATGAAGAATCTA } \\
\text { AGAGAGAAGGGTGATGATGATGAGCCAATGGAAAGATTGAAGATC } \\
\text { CCAAAAGCCACTTGGATGTCTAATGGAACCCAATGGCCTGGCTACT } \\
\text { GGACAGTTCCAGCACCTGAGCACACTAGAGGAGATCATTCAAGCAT } \\
\text { AATACAGGTTATTAGATACATACTAGTTCCTTTACA }\end{array}$ & $\mathrm{TGA}$ & $\bar{G}$ & 12,23 & 179 & $\begin{array}{l}\text { GCAGACGAGTGAAAC } \\
\text { GTGAG }\end{array}$ & 59,6 & $\begin{array}{l}\text { AGTGGCTTTTGGGA } \\
\text { TCTTCA }\end{array}$ & 59,7 & 55 & 45 \\
\hline 317 & BrPe3168 & $\begin{array}{l}\text { Maracuja_ } \\
\text { NoIndex_L } \\
\text { 003_R1_00 } \\
\text { 1_contig_3 } \\
\text { 1579 }\end{array}$ & 3 & 358 & 375 & 18 & 6 & 15 & $\begin{array}{l}\text { CAAACCTATGAAGGGCAACCAAATTGGTGTCCATTGTTTCAAAGGAA } \\
\text { ACCAATCTTCCTCTTTCAGAAGTGATATTGAATCTCTCTACTCGGA } \\
\text { ACAAGATGAACCGGATGAAATGACTGTTTTTGGCCTTAATTTGTCCT } \\
\text { CATCTGAGACTGATGATGATGATGATGAAGAGAATGATGACAAGGC } \\
\text { TGAAACACATACAAATGAAGAGTATTTCCCATACTCCAGGTGCAA } \\
\text { CGGTCTCCAAATTTTACCCAACCTTCAGTCTCTCTTCAGATATTGCC } \\
\text { GGATAAGTATGAGAGACCAATCCAAGTAATTGGATTCCT }\end{array}$ & TGA & G & 23,49 & 156 & $\begin{array}{l}\text { GGAACAAGATGAACC } \\
\text { GGATG }\end{array}$ & 60,3 & $\begin{array}{l}\text { AAATTTGGAGACCG } \\
\text { TTGCAC }\end{array}$ & 60 & 50 & 45 \\
\hline 318 & BrPe3169 & $\begin{array}{l}\text { Maracuja_ } \\
\text { NoIndex_L } \\
\text { 003_R1_00 } \\
\text { 1_contig_3 } \\
1839\end{array}$ & 3 & 1192 & 1203 & 12 & 4 & 9 & $\begin{array}{l}\text { AAGCTGCAGTAGCAGAAGCTGCTGAAGATGAGGGATCTTGCTCTTTTT } \\
\text { CTGAAGCCTGATGATATTTTGGCCGGTGAAATTCGACGGAAGGTACT } \\
\text { GTTTCCTGGATGTCTATTATTGTCTTTTAAAGCTGCAATAATTTAACT } \\
\text { TATTCTGTATAATAATAATATTCATCATTTGTTCTATTCATATCTATC } \\
\text { GTTCCAGATTAGATGCGTTGATCCTACTCTAGATATGGAAGCTGACC } \\
\text { AAGGCGATGATTATACACATCTTCCAGTAAGTTGAATAGTATCATTC } \\
\text { TGCATGTTAGACTGTGAAGCATGTCTTT }\end{array}$ & ATA & $\mathrm{s}$ & 16,17 & 193 & $\begin{array}{l}\text { ATGATATTTTGGCCC } \\
\text { GTGAA }\end{array}$ & 60,2 & $\begin{array}{l}\text { TAATCATCGCCTTG } \\
\text { GTCAGC }\end{array}$ & 61,1 & 40 & 50 \\
\hline 319 & BrPe3170 & $\begin{array}{l}\text { Maracuja_ } \\
\text { NoIndex_L } \\
\text { 003_R1_00 } \\
\text { 1_contig_3 } \\
\text { 1879 }\end{array}$ & 3 & 1201 & 1221 & 21 & 7 & 18 & $\begin{array}{l}\text { TAGTTGCAAAACCAAAAAAATTATCAGACCATGTGACAATTATAACT } \\
\text { TACGAATCATCTGTTCATCAACCTAATTCCAAAGGAATTCAAAGTTA } \\
\text { GAAAGACACAACATCAGAAGGAAATTCATGTACGCACCATTCAAAG } \\
\text { GCATGCGAACTTTCTTCTTCTTCTTCTTCTTCACTGAAAAAAGAATTG } \\
\text { GCCATCAATCAGTTAGATCGCTATCATGTTGCATGTGTGATCAACAA } \\
\text { CCCGACATTTCTGGTAGAAATGAATAGATCTTTACCTGCCTCACCAG } \\
\text { AAGCAAGTTTCTGCTGCACTTCTTCCTCAACCAGAGGAGC }\end{array}$ & TTC & G & 16,01 & 198 & $\begin{array}{l}\text { GGAAATTCATGTACG } \\
\text { CACCA }\end{array}$ & 59,4 & $\begin{array}{l}\text { TGAGGAAGAAGTGC } \\
\text { AGCAGA }\end{array}$ & 59,9 & 45 & 50 \\
\hline 320 & BrPe3171 & $\begin{array}{l}\text { Maracuja_ } \\
\text { NoIndex_L } \\
\text { 003_R1_00 } \\
\text { 1_conti__3 } \\
1889\end{array}$ & 3 & 2061 & 2072 & 12 & 4 & 9 & $\begin{array}{l}\text { TCTCACTTTTATTGGTTTGTAGGTGCTTCCTATGCATTATTTACTCAA } \\
\text { AGTGGCCATGATTAGTTTTGAATTAAATTAGCGCAGAGCTATCTGTC } \\
\text { GAAACTGAAAATCTGATTGTTGCTTAGTGGATTTGTCACTATAGTTC } \\
\text { ACAATGTATTCTTCTTCTTCCTAATTTCTGGCAGAGTCTCCGGATTCT } \\
\text { GTACTTTCTTCCAAATGGTTTTTAAGTCTTCAAGATCGAAAATCACT } \\
\text { ACTGCGACTAATAATATATTCTTATTGTTTTAGTTGGTAGAACTCAA } \\
\text { GTGTAAGCGGTCCATGTAAATGTGAAAT }\end{array}$ & TTC & G & 14,79 & 221 & $\begin{array}{l}\text { CGCAGAGCTATCTGT } \\
\text { CGAAAC }\end{array}$ & 60,2 & $\begin{array}{l}\text { CATGGACCGCTTAC } \\
\text { ACTTGA }\end{array}$ & 50,7 & 52,4 & 50 \\
\hline
\end{tabular}

G: genoma funcional

S: genoma estructural

P: polimórfico

M: monomórfico 
APÉNDICE

Marcadores microssatélites desenhados a partir do sequênciamento parcial e da montagem de novo do genoma de $P$. edulis

\begin{tabular}{|c|c|c|c|c|c|c|c|c|c|c|c|c|c|c|c|c|c|c|c|}
\hline $\mathbf{N}^{\circ}$ & Primer & Contig & Motivo & Início & Fim & pb & $\begin{array}{c}\mathbf{N}^{\circ} \\
\text { Repet }\end{array}$ & Score & Sequência do contig & Unidade & G/S & Cobertura & pb & Sequência Forward & $\begin{array}{l}\mathrm{T}^{\circ} \mathrm{C} \\
F w d\end{array}$ & Sequência Reverse & $\begin{array}{l}\mathrm{T}^{\circ} \mathrm{C} \\
\operatorname{Rev}\end{array}$ & $\begin{array}{c}\% \mathrm{GC} \\
F w d\end{array}$ & $\begin{array}{c}\% \mathrm{GC} \\
\operatorname{Rev}\end{array}$ \\
\hline 321 & $\overline{\text { BrPe3172 }}$ & $\begin{array}{l}\text { Maracuja_ } \\
\text { Nolndex_L } \\
\text { 003_R1_00 } \\
\text { 1_contig_3 } \\
\text { 2287 }\end{array}$ & 3 & 1207 & 1218 & 12 & 4 & 9 & $\begin{array}{l}\text { AGAATTCACCAACGAAGAAGTGCACGCCCTTTAACTGATAAATTGC } \\
\text { GCTTCTCTAGCCAGACCTTGTCAAGCATTCATGGGCAACCAGTTAGT } \\
\text { TTCATTATGTCTCGGAGACCTTCCTTTTTATGCTTATCTACAAAAACT } \\
\text { TGTAAAACTGAAGAAGAAGAATGCACAAGACCTTGCTCTGACTTGT } \\
\text { CCAGGTTAGATTTTTTAATAGTTATTTCATTCATCATTCAGTCTAC } \\
\text { AGCACATGCTAAAGACCTTTCAGCTTTATTTGTAGACATTTTGCTA } \\
\text { TTGCTTTGTGAGGTTTATGATTTGGTTCTA }\end{array}$ & GAA & $\bar{G}$ & 15,43 & 175 & $\begin{array}{l}\text { GTGCACGCCCTTTAA } \\
\text { CTGAT }\end{array}$ & 60,1 & $\begin{array}{l}\text { AACCTGGACAAGTC } \\
\text { AGAGCAA }\end{array}$ & 59,9 & 50 & 47,6 \\
\hline 322 & BrPe3173 & $\begin{array}{l}\text { Maracuja_ } \\
\text { Nolndex_L } \\
003 \_R 1 \text { 00 } \\
\text { 1_contig_3 } \\
2429\end{array}$ & 3 & 1518 & 1529 & 12 & 4 & 9 & $\begin{array}{l}\text { GCTGCCACTGCTGTAGTCCCACAGAGGTTACGCAAGGGTGACTCAA } \\
\text { TTCTAAAACTTGGCCGATCAGGAGGGAGAAAGGAGGCATCTAGTGG } \\
\text { GCTAGACTCCTCACTTTTGGAGACCAATGTCAACACAGCAATGCTG } \\
\text { AATCAAGTTTCGGATGATGATGATAGATTCTTGATCTCCGTTATTGA } \\
\text { TGAAGGTTCTACTTCAGCTAAGAAATCTGGTGGCTTTATCCCGTCAC } \\
\text { TTCTTTTGGCTCCAAGAATGGATTGCAGAAAAACTTTAAAGCAGGC } \\
\text { AGATGATTTTGTCAAGTTTGGCACTGATTCTCCT }\end{array}$ & GAT & $\mathrm{G}$ & 13,63 & 200 & $\begin{array}{l}\text { ACGCAAGGGTGACTC } \\
\text { AATTC }\end{array}$ & 60,1 & $\begin{array}{l}\text { ACGGGATAAAGCCA } \\
\text { CCAGAT }\end{array}$ & 60,7 & 50 & 50 \\
\hline 323 & BrPe3174 & $\begin{array}{l}\text { Maracuja_ } \\
\text { NoIndex_L } \\
003 \text { O1_00 } \\
\text { 1_contig_3 } \\
\text { 2463 }\end{array}$ & 3 & 197 & 211 & 15 & 5 & 12 & $\begin{array}{l}\text { CAAAGCCTATTCTCCTTGGGGAAAATTACTCGAGGCAAGAGAAATA } \\
\text { CAAGAAGCGGAAGAATCTGCAGGACACAGAGATGTTAAAAATTTGT } \\
\text { GATCTTCTTGAGGTGGTGGGAGAGAAAAAGAAGACAAACGCTTGCA } \\
\text { AAAAGAAGGATGTAATAATAATAATAAGGGAACACTTTGGTAAAGA } \\
\text { GGACAAGGGGGTTACGAGGAGGTTATGAACTGACTAAATATGGTAG } \\
\text { ATTGCTGTTTTAGAGTTGTTATCTAAGATCAGATGCAAGAAAAAAA } \\
\text { AAAGAAGATATTTACTCTTTTATCGGGGATCATTCTGCG }\end{array}$ & 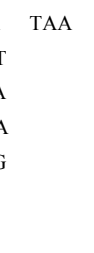 & G & 17,29 & 186 & $\begin{array}{l}\text { AACGCTTGCAAAAAG } \\
\text { AAGGA }\end{array}$ & 60,0 & $\begin{array}{l}\text { GCAGAATGATCCCC } \\
\text { GATAAA }\end{array}$ & 59,9 & 40 & 45 \\
\hline 324 & BrPe3175 & $\begin{array}{l}\text { Maracuja_ } \\
\text { Nolndex_L } \\
003 \_R 1 \text { 00 } \\
\text { 1_contig_3 } \\
\text { 2479 }\end{array}$ & 3 & 1032 & 1043 & 12 & 4 & 9 & $\begin{array}{l}\text { ACATCCATGGTGGTTGAATGGTTTTATTTGCTATGTTCCTCAGTTTCT } \\
\text { TATGTGTATAATGTAGGTGTCCTTAAGTTTCCGTTGTGACTTTGACAT } \\
\text { AGAGCAGAATTTCAAGACTTGGTCAGTAAAAGTAAAGGTCATTGGT } \\
\text { ATTGAGGCTGTTGTTGTTGTCTTATTTCCCCTTCCTTTGCTCTTTCTTC } \\
\text { AGTGTTAACTCAGTTCCCGAAGTACTTTCTGGCAGCATGAATTAGTG } \\
\text { GCTAGAAATTACACTTTTTTGGTCCACCGAAAGTTGTTGGGAAGAAG } \\
\text { GATTATGAGTTCTCTGCTCTTAAGATT }\end{array}$ & TGT & $\mathrm{s}$ & 20,8 & 184 & $\begin{array}{l}\text { ATCCATGGTGGTTGA } \\
\text { ATGGT }\end{array}$ & 59,9 & $\begin{array}{l}\text { AAGAGCAAAGGAA } \\
\text { GGGGAAA }\end{array}$ & 60,2 & 45 & 45 \\
\hline 325 & BrPe3176 & $\begin{array}{l}\text { Maracuja_ } \\
\text { NoIndex_L } \\
003 \text { 1_R1_00 } \\
\text { 1_contig_3 } \\
\text { 2698 }\end{array}$ & 3 & 232 & 243 & 12 & 4 & 9 & $\begin{array}{l}\text { TAACGACTTTTGGTATGCCTTGTCTACATTTAAAAGATCATCCCTTAT } \\
\text { GAAAGGAAGACAAGAGGATCGATGGGTTAGGTGGATTCCTCCCATT } \\
\text { ACAGGATGGCTTAAACTGAACAGCGATGGTTCCTTTAATAGCTTTTC } \\
\text { CGGAAAAGCAGGAGGAGGAGGCTTGTTCCGTGACCAGAAAGGTAG } \\
\text { ATGGATCCTTGGATTTGCAAAGCAGCTAGACTGTAATTCCAGTTGGG } \\
\text { AGGTTGAGATCTGGAGCATTAACGAAGGACTGCAGATTGCCATTAA } \\
\text { TAATAGCTGGAATTCTATTGTTGTGGAGTCAGA }\end{array}$ & AGG & $\mathrm{G}$ & 18,55 & 210 & $\begin{array}{l}\text { TCGATGGGTTAGGTG } \\
\text { GATTC }\end{array}$ & 59,8 & $\begin{array}{l}\text { ATGGCAATCTGCAG } \\
\text { TCCTTC }\end{array}$ & 60,2 & 50 & 50 \\
\hline
\end{tabular}

G: genoma funcional

S: genoma estructural

P: polimórfico

M: monomórfico 
APÉNDICE

Marcadores microssatélites desenhados a partir do sequênciamento parcial e da montagem de novo do genoma de $P$. edulis

\begin{tabular}{|c|c|c|c|c|c|c|c|c|c|c|c|c|c|c|c|c|c|c|c|}
\hline $\mathbf{N}^{\circ}$ & Primer & Contig I & Motivo & Início & Fim & pb & $\begin{array}{c}\mathbf{N}^{\circ} \\
\text { Repet }\end{array}$ & Score & Sequência do contig & Unidade & G/S & Cobertura & $\mathrm{pb}$ & Sequência Forward & $\begin{array}{l}\mathrm{T}^{\circ} \mathrm{C} \\
F w d \\
\end{array}$ & Sequência Reverse & $\begin{array}{l}\mathrm{T}^{\circ} \mathrm{C} \\
\operatorname{Rev} \\
\end{array}$ & $\begin{array}{r}\% \mathrm{GC} \\
F w d \\
\end{array}$ & $\begin{array}{cc}\% \mathrm{GC} & \mathrm{P} / \mathrm{M} \\
\operatorname{Rev} & \end{array}$ \\
\hline 326 & BrPe3177 & $\begin{array}{l}\text { Maracuja_ } \\
\text { NoIndex_L } \\
003 \text { R1_00 } \\
\text { 1_contig_3 } \\
\text { 2725 }\end{array}$ & 3 & 249 & 260 & 12 & 4 & 9 & $\begin{array}{l}\text { TTTTGCCAATTCTCTTGGCCACCACCGGGTACATCTTGCCCTTATCCT } \\
\text { TATTTTTTTATCACTTTACCTTTATGTAAAAGAAAAAAACCAAAACA } \\
\text { AAAGAAAGAAAAGAAGAGGGAGGCTTCGGGAGAAGAGTGGCGCAA } \\
\text { GGAGAAGGGGGAGAAGAAGAAAGAAGAGAGAAAGAGGAAGAAG } \\
\text { GTAGGTTGGTGAAGGGTTTTGTGTTGGTTTTGAAGTGTAAGAAAGA } \\
\text { GTTCATGCATGGATTTCATACATGTACATGCATATCCTCATGTTTTGT } \\
\text { GTATTTTGATCTTGTGATGTCTTGTTGTGCATGT }\end{array}$ & GAA & $\bar{G}$ & 378,78 & 197 & $\begin{array}{l}\text { GAGGCTTCGGGAGAA } \\
\text { GAGTG }\end{array}$ & 61,4 & $\begin{array}{l}\text { CATGCACAACAAGA } \\
\text { CATCACA }\end{array}$ & 59,2 & 60 & 42,9 \\
\hline 327 & BrPe3178 & $\begin{array}{l}\text { Maracuja_ } \\
\text { NoIndex_L } \\
\text { 003_R1_00 } \\
\text { 1_contig_3 } \\
\text { 3178 }\end{array}$ & 3 & 4059 & 4070 & 12 & 4 & 9 & $\begin{array}{l}\text { TTTGGATACAAGAGGCAGAGAGGAAAAAGGTGCAGGAAAAGAATC } \\
\text { TTCGAGAAAAAATCAAAGCATCCCACACTCCCGAGAAGATGTGAT } \\
\text { GCACCTTTGCAAAGTGGAATTGTGCGTGTTTTTGAGCAACCGGGCAT } \\
\text { AGAAGCTCCTAGTGATGATGATGACTTTATTGAGGTTAGGTCAAAG } \\
\text { AGGCAAATGCTGAATGATCGGCGTGAACAGAGAGAAAGAGAAATC } \\
\text { AAGGCAAAGTCTCGGATCCCAAAGGTTCTATCATACTCTCATCGAA } \\
\text { ATTATTTCTTGTGCTTTCCCATTATTGCAAAATAGCA }\end{array}$ & TGA & G & 14,38 & 200 & $\begin{array}{l}\text { ATCAAAGCATCCCAC } \\
\text { ACTCC }\end{array}$ & 59,9 & $\begin{array}{l}\text { AACCTTTGGGATCC } \\
\text { GAGACT }\end{array}$ & 59,9 & 50 & 50 \\
\hline 328 & BrPe3179 & $\begin{array}{l}\text { Maracuja_ } \\
\text { NoIndex_L } \\
\text { 003_R1_00 } \\
\text { 1_contig_3 } \\
\text { 3182 }\end{array}$ & 3 & 2437 & 2448 & 18 & 6 & 15 & $\begin{array}{l}\text { AAAGATGGGGTCCAAGTTGATTTCATCACTTCCTTTTTTCCGTCTCTT } \\
\text { TCTTTATCCCTCTCCTTTTCCTTGGAGCTGCTTGAACCACTCAAGATT } \\
\text { TGATTATGTGCTTCCCGAACATTTCTGACCAAAGCGTAAAAGGGCATT } \\
\text { TATCTTCTCTTCTTCTTCTCCTCCTTCTTTATCAACGGACTGCCTTTCT } \\
\text { TCTATCTCTCCTTCCATTCTTCTCTTCATCGATGATCTTCTTCTAGCTT } \\
\text { TTGAAGGGAATATGACCAAATAAATTAGAAATGAAATGAGCCAACT } \\
\text { AAACATATAAAATAAAGTAGTACCT }\end{array}$ & ТСТ & G & 15,88 & 194 & $\begin{array}{l}\text { AAAGATGGGGTCCAA } \\
\text { GTTGA }\end{array}$ & 59,4 & $\begin{array}{l}\text { GAAGAAAGGCAGTC } \\
\text { CGTTGA }\end{array}$ & 60,4 & 45 & 50 \\
\hline 329 & BrPe3180 & $\begin{array}{l}\text { Maracuja_ } \\
\text { NoIndex_L } \\
\text { 003_R1_00 } \\
\text { 1_contig_3 } \\
3368\end{array}$ & 3 & 4351 & 4362 & 12 & 4 & 9 & $\begin{array}{l}\text { GCTTCAAGTGGAGATACTAGTTCCTTCCAGGATGATCAGAGCTCTTT } \\
\text { GCATGGTAGCTCTCAAATTCAGAAAAGTGTGGAAGTTGAATCAGTT } \\
\text { GGAGAATTTGAGAAGCACTTATCATATGACTGTGCAGAAACATCAG } \\
\text { CTAAGCCTAAAAAAGAAGAAGAAGGAAAAGCATTTGGTACATAGAA } \\
\text { ATTCTTATGCTTCTGTAGTTACTGATCAGTTGCTTGACGATAGAGTTT } \\
\text { GTGATTGTATTCTCCCGTATATTTTTCTTCCTCTGGTGTTTATGTTGCT } \\
\text { TGGTTTTATATGGTTGCAGGGTTTTGCCAAC }\end{array}$ & AAG & G & 17,33 & 183 & $\begin{array}{l}\text { TGACTGTGCAGAAAC } \\
\text { ATCAGC }\end{array}$ & 60,0 & $\begin{array}{l}\text { CСCTGCAACCATAT } \\
\text { AAAACCA }\end{array}$ & 59,7 & 47,6 & 42,9 \\
\hline 330 & BrPe3181 & $\begin{array}{l}\text { Maracuja_ } \\
\text { NoIndex_L } \\
\text { 003_R1_00 } \\
\text { 1_conti__3 } \\
4767\end{array}$ & 3 & 227 & 238 & 12 & 4 & 9 & $\begin{array}{l}\text { CCAAGCATTGCCAACCGATCTCTGCGCACTAATTGCTCACAACACCC } \\
\text { TTCTTTTTCACCACCTGCTTTACTTGCTGTGATTCCATTGATAGTCCG } \\
\text { ATCTCCATCCTCATCAGTTTCCGGCGGGTAAGCAGCTCTTTATGTA } \\
\text { GTTCCAGGTCATCATCATCAACAAGAAGGAAGCCAGAGCCATCAAG } \\
\text { ACTGAAACTAGAATGAATGGCGTATCGAAACCAATCTCTAGCATAG } \\
\text { ATAACTCCCGGGATGCATAAGGGGAAGATGAGAAGAAAGATTGCTC } \\
\text { CACCGAAGAATAGCCGAGCTCTTGTTGTACCA }\end{array}$ & TCA & G & 16,37 & 167 & $\begin{array}{l}\text { GCGCACTAATTGCTC } \\
\text { ACAAC }\end{array}$ & 59,5 & $\begin{array}{l}\text { GTCTTGATGGCTCTG } \\
\text { GCTTC }\end{array}$ & 60 & 50 & 55 \\
\hline
\end{tabular}

G: genoma funcional

S: genoma estructural

P: polimórfico

M: monomórfico 
APÉNDICE

Marcadores microssatélites desenhados a partir do sequênciamento parcial e da montagem de novo do genoma de $P$. edulis

\begin{tabular}{|c|c|c|c|c|c|c|c|c|c|c|c|c|c|c|c|c|c|c|c|}
\hline $\mathbf{N}^{\circ}$ & Primer & Contig $\mathrm{I}$ & Motivo & Início & Fim & pb & $\begin{array}{c}\mathbf{N}^{\circ} \\
\text { Repet }\end{array}$ & Score & Sequência do contig & Unidade & G/S & Cobertura & pb & Sequência Forward & $\begin{array}{l}\mathrm{T}^{\circ} \mathrm{C} \\
F w d\end{array}$ & Sequência Reverse & $\begin{array}{r}\mathrm{T}^{\circ} \mathrm{C} \\
\operatorname{Rev}\end{array}$ & $\begin{array}{c}\% \mathrm{GC} \\
F w d\end{array}$ & $\begin{array}{c}\% \mathrm{GC} \\
\operatorname{Rev}\end{array} \quad \mathrm{P} / \mathbf{M}$ \\
\hline 331 & $\overline{B r P e 3182}$ & $\begin{array}{l}\text { Maracuja_ } \\
\text { NoIndex_L } \\
003 \text { R1_00 } \\
\text { 1_contig_3 } \\
\text { 5142 }\end{array}$ & 3 & 380 & 391 & 12 & 4 & 9 & $\begin{array}{l}\text { AGAACCAACTTGAAAATGAAAACTACTTATCAAGATATCATCCTGA } \\
\text { AACCAAGTAGAGGTGTGATATATGAAGTAATGTTTAATTGTGAATA } \\
\text { TAATTGGCATTATTGTCTTAAGAGTGATTTCGGAAGTGATATTGATT } \\
\text { CTATGAAGCTGCAACAACAACAATGCGAATTCACAGGATCTTCTAA } \\
\text { AAGATCTGAATGATCTTTACACAGTAAGAGATGAAAAGCATTCCTC } \\
\text { GTGGACAAGTCCATCAAATGATACATAGCAACCAGAAATTACCTGA } \\
\text { TTTTCTGCAGTCACTCCAAATCATCTCTCAACTTC }\end{array}$ & $\mathrm{CAA}$ & $\mathrm{s}$ & 16,84 & 197 & $\begin{array}{l}\text { CATCCTGAAACCAAG } \\
\text { TAGAGGTG }\end{array}$ & 60,0 & $\begin{array}{l}\text { CCACGAGGAATGCT } \\
\text { TTTCAT }\end{array}$ & 60,1 & 47,8 & 45 \\
\hline 332 & BrPe3183 & $\begin{array}{l}\text { Maracuja_ } \\
\text { NoIndex_L } \\
\text { 003_R1_00 } \\
\text { 1_contig_3 } \\
5433\end{array}$ & 3 & 2693 & 2707 & 15 & 5 & 12 & $\begin{array}{l}\text { GAAGTTGGAAGCTGAGAGGCAGAATTATATTCCCTGTCCATACCCA } \\
\text { TTCTTTATCTGCATGGGCTTCCTTATTCCAGAAAATCTTATTCATATC } \\
\text { TACTTTGTCTTCCGAGAACAAATTTGAGAGTGCTTTTCTGGTCTCTTT } \\
\text { GCATCAACAGAAGAAGAAGAAGACCTGTCATTGTTTCCAATGCTTC } \\
\text { CTTTTTTTGCTCCTTTTTTCTGAATAAATACCATTCTACAGCAGTGGCC } \\
\text { TTTTGCACTGCCCTACCGTTAAGTCTACTTTGCACCTCAACCTTTAAT } \\
\text { TCAACGAAAGCAAAAGGCAAGACAGAATAGTC }\end{array}$ & AGA & G & 14,94 & 231 & $\begin{array}{l}\text { TGGAAGCTGAGAGGC } \\
\text { AGAAT }\end{array}$ & 60,1 & $\begin{array}{l}\text { GGCCACTGCTGTAG } \\
\text { AATGGT }\end{array}$ & 60,1 & 50 & 55 \\
\hline 333 & BrPe3184 & $\begin{array}{l}\text { Maracuja_ } \\
\text { NoIndex_L } \\
\text { 003_R1_00 } \\
\text { 1_contig_3 } \\
\text { 5579 }\end{array}$ & 3 & 965 & 976 & 12 & 4 & 9 & $\begin{array}{l}\text { AGAAACCATGACAGTTTTAAGAGAGAATAACAAGAAGATTGTGGAT } \\
\text { CTTGAAAACAGTGACGATTGCTCTAATGACTTGTCTATTATGCATAG } \\
\text { CAAATACCAAAAACCTCCAAAACCATTGGATTTTGAAAGCAATGGT } \\
\text { CTTATCTGGTTTCCTCCTCCTCCCGAGGATGAAAATGATGAGGCAAA } \\
\text { TGCTAGTTTCTTTGCATATGATGATGATGACGATGATGATAATGTTG } \\
\text { GGATCTCGGGTGCAATTTTTTCATCGAGCAATGATCTCTCTAATACT } \\
\text { TTTCCATCAAAGGAGAAGCAAAATGAGGGTAG }\end{array}$ & TCC & G & 15,05 & 155 & $\begin{array}{l}\text { TGGATCTTGAAAACA } \\
\text { GTGACG }\end{array}$ & 58,8 & $\begin{array}{l}\text { GAAACTAGCATTTG } \\
\text { CCTCATCA }\end{array}$ & 59,4 & 42,9 & 40,9 \\
\hline 334 & BrPe3185 & $\begin{array}{l}\text { Maracuja_ } \\
\text { NoIndex_L } \\
003 \text { R1_00 } \\
\text { 1_contig_3 } \\
5783\end{array}$ & 3 & 3953 & 3964 & 12 & 4 & 9 & $\begin{array}{l}\text { TTCATCGGTTTTCAATCCTCAAAATCATGAATCATCGGACCTCCGAA } \\
\text { TTGCCGACCAAGCTGGTTTTCATGTTCCTGCAATTGCTGTCGATGCT } \\
\text { GTTGTGCATTTTCGACACCATGCTGCAGTCCTAATGTCAGGGAAACG } \\
\text { GCTCCATGTCCACCACCACCATCAAACCCATTCTCTGAAATGGCAC } \\
\text { GAAGTTCATCAGTGATCCGTCAATGCTACTTGGAACCTGAAACTCTA } \\
\text { CTCTTGACCTCTTCTCTTGATTCCACTGATCCGCATCCGGTTGTTCTT } \\
\text { CATGTAACAAAGAAGAGCTCGTTCCTGAG }\end{array}$ & $\mathrm{CCA}$ & G & 16,01 & 176 & $\begin{array}{l}\text { TTGTGCATTTTCGACA } \\
\text { CCAT }\end{array}$ & 60,0 & $\begin{array}{l}\text { ATGCGGATCAGTGG } \\
\text { AATCA }\end{array}$ & 60 & 40 & 40 \\
\hline 335 & BrPe3186 & $\begin{array}{l}\text { Maracuja_ } \\
\text { NoIndex_L } \\
\text { 003_R1_00 } \\
\text { 1_conti__3 } \\
6463\end{array}$ & 3 & 2796 & 2807 & 12 & 4 & 9 & $\begin{array}{l}\text { TCACCCTAAGCATGATGGTCCAAAGGTAATTGATTTACTTCATTCTG } \\
\text { AGCAAACTTTTGCTAGATGAATTTTGGGAGAACTTAGGTGAGGTTTA } \\
\text { CATATCCTTGTTGTGCTTACTTTTGCTACTACTGTATTCAGGTTCCAT } \\
\text { TTTTCTCTGAAGAAGAAGAAACACCCAGCACACCAAAAGCAGATGC } \\
\text { TTTTTTCATTCCCCGGGAAAATCCAAGAGCTCTGGTCATTGGTCCCA } \\
\text { TGGACCAACGGCCATCAAGGACTAGTGTGGATAAAACATCTCCATC } \\
\text { GAAGGATCCATCAACTTCCTCTCCAGTGCAT }\end{array}$ & GAA & G & 16,34 & 180 & $\begin{array}{l}\text { AAGCATGATGGTCCA } \\
\text { AAGGT }\end{array}$ & 59,4 & $\begin{array}{l}\text { CATCTGCTTTTGGTG } \\
\text { TGCTG }\end{array}$ & 60,4 & 45 & 50 \\
\hline
\end{tabular}

G: genoma funcional

S: genoma estructural

P: polimórfico

M: monomórfico 
APÉNDICE

Marcadores microssatélites desenhados a partir do sequênciamento parcial e da montagem de novo do genoma de $P$. edulis

\begin{tabular}{|c|c|c|c|c|c|c|c|c|c|c|c|c|c|c|c|c|c|c|c|}
\hline $\mathbf{N}^{\circ}$ & Primer & Contig I & Motivo & Início & Fim & pb & $\begin{array}{c}\mathbf{N}^{\circ} \\
\text { Repet }\end{array}$ & Score & Sequência do contig & Unidade & G/S & Cobertura & $\mathrm{pb}$ & Sequência Forward & $\begin{array}{l}\mathrm{T}^{\circ} \mathrm{C} \\
F w d \\
\end{array}$ & Sequência Reverse & $\begin{array}{l}\mathrm{T}^{\circ} \mathrm{C} \\
\operatorname{Rev} \\
\end{array}$ & $\begin{array}{c}\% \mathrm{GC} \\
F w d \\
\end{array}$ & $\begin{array}{cc}\% \mathrm{GC} & \mathrm{P} / \mathrm{M} \\
\operatorname{Rev} & \end{array}$ \\
\hline 336 & BrPe3187 & $\begin{array}{l}\text { Maracuja_ } \\
\text { NoIndex_L } \\
\text { 003_R1_00 } \\
\text { 1_contig_3 } \\
7785\end{array}$ & 3 & 211 & 222 & 12 & 4 & 9 & $\begin{array}{l}\text { GGAACATTCACTCTCTCCTGCTCCGAAATGTTGAGTGATTGTACCTG } \\
\text { CCAAATGGTTTTTTGAAGAGACAGAATTTTAGAGTAGAACACTTGC } \\
\text { GATGATGATTGATTATGTATTACTTACCTATATTCATCGCAGGAGGA } \\
\text { ACCGCATACTGAAGAAGAAGAACAAATTGATACAAGGGATCGGGA } \\
\text { GGAATGAAACCCACACGATTTGCTCCTTGCACTATGAATAACCCTAT } \\
\text { CACGGGCAATACTATATAACGGACTATTACGATCCCCAGAACCAGA } \\
\text { GACTTGTGCGTTCCTGACCCTTGCAAACCTATAG }\end{array}$ & GAA & $\bar{G}$ & 16,01 & 156 & $\begin{array}{l}\text { TATTCATCGCAGGAG } \\
\text { GAACC }\end{array}$ & 60,0 & $\begin{array}{l}\text { CTCTGGTTCTGGGG } \\
\text { ATCGTA }\end{array}$ & 60,1 & 50 & 55 \\
\hline 337 & BrPe3188 & $\begin{array}{l}\text { Maracuja_ } \\
\text { NoIndex_L } \\
\text { 003_R1_00 } \\
\text { 1_contig_3 } \\
8082\end{array}$ & 3 & 2074 & 2085 & 12 & 4 & 9 & $\begin{array}{l}\text { ACTGAATAGATAAAATTTAGTTGAACCAAACTTCTTATAATATTCAAT } \\
\text { ATTTTAGTCAAGTAGAAGTAAATTTATTGTTGTTAACATTTAAACTC } \\
\text { TATAAGATAGAAATTGCTACTAAAAAAGTTAGCTTGTCTTTTTGTGT } \\
\text { TGTTTAATTATAATAATAATATTAGTTTTAATACTTAAAATTTCTGT } \\
\text { GTTGGAATTATAACTAGAGTTGAGGTTGATGTGAAGTAAATATGTAT } \\
\text { ATACTTCTCTCCTAATGTTTGTCGACATTTGGAATTGCTTAATCGTAC } \\
\text { ACAATATTCACTAATTTAATCTCTTTAA }\end{array}$ & ATA & $\mathrm{s}$ & 18,42 & 163 & $\begin{array}{l}\text { AAAAGTTAGCTTGTC } \\
\text { TTTTTGTGTTG }\end{array}$ & 59,4 & $\begin{array}{l}\text { GATTAAGCAATTCC } \\
\text { AAATGTCG }\end{array}$ & 58,6 & 30,8 & 36,4 \\
\hline 338 & BrPe3189 & $\begin{array}{l}\text { Maracuja_ } \\
\text { NoIndex_L } \\
\text { 003_R1_00 } \\
\text { 1_contig_3 } \\
8153\end{array}$ & 3 & 238 & 252 & 15 & 5 & 12 & $\begin{array}{l}\text { TACCAGCTTCGATATCCTCACCGAAATCTTATCGGTTTCTTGCACTG } \\
\text { CTAGTTGCGCTGGTGGAACTCTAATCTTAGCTATTGGTGCCTGTGCT } \\
\text { GGTCTTGGTGCACCATGCATAGCGGACCAAAATGCCATGAACGTAT } \\
\text { CATAAGCTCCTGGTGGTGGTGGTGGCAATTCTGGCTCATGGCCTGAC } \\
\text { TCAACTGCTGGTCCCTTTACTAATCCAGCTCTTGGCTCATGAGCTAG } \\
\text { CTCAATCAAAACTTGTGAAGGATGTCTCTCAGGTCCTTCACTCGATT } \\
\text { GCTGTCTAGCCATAGACATCTCATCTCTAACTGC }\end{array}$ & TGG & G & 98,83 & 226 & $\begin{array}{l}\text { CCAGCTTCGATATCC } \\
\text { TCACC }\end{array}$ & 59,7 & $\begin{array}{l}\text { CATGAGCCAAGAGC } \\
\text { TGGATT }\end{array}$ & 60,4 & 55 & 50 \\
\hline 339 & BrPe3190 & $\begin{array}{l}\text { Maracuja_ } \\
\text { NoIndex_L } \\
\text { 003_R1_00 } \\
\text { 1_conti__3 } \\
8227\end{array}$ & 3 & 1312 & 1323 & 12 & 4 & 9 & $\begin{array}{l}\text { GGATCTCAACGGATACCTCAGCTTCGACTTCCCCAACCCACCTATTG } \\
\text { TCCATAAAGGCATAACTCATACGAAAACTAACAAAAAACAGAACAC } \\
\text { AGGAAACGTTAACACAGAAAGCTAAGCATATTATTTTACCAGAAGC } \\
\text { AACAACTGCTGGCTGCTGCTGCTCTTTCACGCTATCTTCCATGATAC } \\
\text { CTGTCTTTTTGAAGGCAGT }\end{array}$ & GCT & G & 15,57 & 158 & $\begin{array}{l}\text { GACTTCCCCAACCCA } \\
\text { CCTAT }\end{array}$ & 60,1 & $\begin{array}{l}\text { TCATGGAAGATAGC } \\
\text { GTGAAAG }\end{array}$ & 58 & 55 & 42,9 \\
\hline 340 & BrPe3191 & $\begin{array}{l}\text { Maracuja_ } \\
\text { NoIndex_L } \\
\text { 003_R1_00 } \\
\text { 1_contig_3 } \\
8484\end{array}$ & 3 & 267 & 278 & 12 & 4 & 9 & $\begin{array}{l}\text { GAGGCTATTGAGGGATAGCAGTAGAGGTGAGGGTAAAGGGGAGGC } \\
\text { TAAAGGTGAGGATGAGGAGTTCACATCTGGCTCAGAAGGGTTTTTC } \\
\text { AAGCGGTTGTTTCGTGATGGAAAGAGTAACGTTGATGAAAAATCAA } \\
\text { TTTTGAAATCTCTGGAGGAGGAGGAAAAAGAGGGTTTCTTTAAAAA } \\
\text { ATTATTTAAGGATAAGTCTGACGACAAAAGAGATGGGAGTCTTAGG } \\
\text { AATTCAGTTGAAGAAAACTATTCAAGATCTGTTGAGGATGATGATA } \\
\text { GAGAGGGCTTTTTCCGCAAACTGTTCAAGGATAAATC }\end{array}$ & GGA & G & 16,28 & 153 & $\begin{array}{l}\text { CATCTGGCTCAGAAG } \\
\text { GGTTT }\end{array}$ & 59,3 & $\begin{array}{l}\text { TCCCATCTCTTTTGT } \\
\text { CGTCAG }\end{array}$ & 60,2 & 50 & 47,6 \\
\hline
\end{tabular}

G: genoma funcional

S: genoma estructural

P: polimórfico

M: monomórfico 
APÉNDICE

Marcadores microssatélites desenhados a partir do sequênciamento parcial e da montagem de novo do genoma de $P$. edulis

\begin{tabular}{|c|c|c|c|c|c|c|c|c|c|c|c|c|c|c|c|c|c|c|c|}
\hline $\mathbf{N}^{\circ}$ & Primer & Contig M & Motivo & Início & Fim & pb & $\begin{array}{c}\mathrm{N}^{\mathbf{o}} \\
\text { Repet }\end{array}$ & Score & Sequência do contig & Unidade & G/S & Cobertura & pb & Sequência Forward & $\begin{array}{l}\mathrm{T}^{\circ} \mathrm{C} \\
F w d \\
\end{array}$ & Sequência Reverse & $\begin{array}{l}\mathrm{T}^{\circ} \mathrm{C} \\
\operatorname{Rev} \\
\end{array}$ & $\begin{array}{c}\% \mathrm{GC} \\
F w d \\
\end{array}$ & 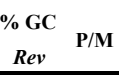 \\
\hline 341 & BrPe3192 & $\begin{array}{l}\text { Maracuja_ } \\
\text { NoIndex_L } \\
\text { 003_R1_00 } \\
\text { 1_contig_3 } \\
\text { 9256 }\end{array}$ & 3 & 849 & 860 & 12 & 4 & 9 & $\begin{array}{l}\text { CAGCAAGAAACAGCGACATATATTCCTGACAAGGATAAACGAGATG } \\
\text { GTGGTTCTTATTTAGTGAGACAAGGAATGACAGAGATCAGTTCTTCC } \\
\text { AACGTACTAACACAGGATAAATCCATCAGTCAGGACAACTTTTTG } \\
\text { CTGCAAATATGAATAATAATAATCATACTGCTGTAATTGATGATGTG } \\
\text { CAAAGTCAGCCCATTTATATTCGGATGCCAAATGGTTCTCTATTTAC } \\
\text { TGAGAATTCAGTAGAAGGTGGATGGACTAGTAGTTCATTACTGCGT } \\
\text { ACAGCAGATGACCAGACACAGGTGCATCCCATT }\end{array}$ & AAT & $\bar{G}$ & 17,87 & $\begin{array}{r}167 \mathrm{C} \\
\mathrm{T}\end{array}$ & $\begin{array}{l}\text { CAAGGATAAACGAGA } \\
\text { TGGTGGT }\end{array}$ & 60,2 & $\begin{array}{l}\text { GCTGACTTTGCACA } \\
\text { TCATCAA }\end{array}$ & 59,9 & 45,5 & 42,9 \\
\hline 342 & BrPe3193 & $\begin{array}{l}\text { Maracuja_ } \\
\text { NoIndex_L } \\
\text { 003_R1_00 } \\
\text { 1_contig_3 } \\
9306\end{array}$ & 3 & 942 & 953 & 12 & 4 & 9 & $\begin{array}{l}\text { CAATCATACACAGAATATGCATTTGCATGCTTAATTTGTTTTCGTAA } \\
\text { TTCATTCGATGGTTATGCACTTGCAGATGGTTCTTGCACTTTTTCGC } \\
\text { CATCGCCACTGAATCGATCTACGATTGAAGCTTCCGTAAGCGATCCA } \\
\text { ATCTGGGGTGATGATGATGAACATCTATCCACTGGAGGAAATCCTTC } \\
\text { CATTCCTCAGGTCTCGGATGCAAGCATATCTTAAATGGGGATCATGC } \\
\text { TCCTGATGCTACAATCAATGTTGGAGTAGAATGCGAGTTGTGATTGT } \\
\text { AGGTTATAGATTTGGTGATTATACGTTAG }\end{array}$ & TGA & G & 13,07 & $152 \mathrm{~T}$ & $\begin{array}{l}\text { TTCCGTAAGCGATCC } \\
\text { AATCT }\end{array}$ & 59,7 & $\begin{array}{l}\text { CACAACTCGCATTC } \\
\text { TACTCCA }\end{array}$ & 58,9 & 45 & 47,6 \\
\hline 343 & BrPe3194 & $\begin{array}{l}\text { Maracuja_ } \\
\text { NoIndex_L } \\
\text { 003_R1_00 } \\
\text { 1_contig_3 } \\
\text { 9349 }\end{array}$ & 3 & 3134 & 3145 & 12 & 4 & 9 & $\begin{array}{l}\text { CAAAATTCTTATCATTACATTGGATTTTTTTCCGTCTACTTGGATCTC } \\
\text { ATATGCCATTACTAAGAATCTGTATCTGATTCTGAACCTGACTCATC } \\
\text { TGATTGAAACTCTGATGGCTTGATTCTGTTCATATTGGCTTCTAATG } \\
\text { GAGGCAGGTCATCATCATCACTAGACCCCAGCTCATTCGTGTTTTCA } \\
\text { CGGGGATTATTACTGTCCGGATTTCTATCGAAACCCTCCAAGGCTGT } \\
\text { AGATTTAAAGATTTCAGGCCTGCAACCGATTATTAATACGAGGAAT } \\
\text { ACATGAGAATACTCCAGCACTAGAAAAAAA }\end{array}$ & TCA & G & 16,68 & $\begin{array}{rl}158 & \mathrm{~T} \\
\mathrm{~T}\end{array}$ & $\begin{array}{l}\text { TGAACCTGACTCATC } \\
\text { TGATTGAA }\end{array}$ & 59,7 & $\begin{array}{l}\text { CTACAGCCTTGGAG } \\
\text { GGTTTC }\end{array}$ & 58,8 & 39,1 & 55 \\
\hline 344 & BrPe3195 & $\begin{array}{l}\text { Maracuja_ } \\
\text { NoIndex_L } \\
\text { 003_R1_00 } \\
\text { 1_contig_3 } \\
9365\end{array}$ & 3 & 406 & 420 & 15 & 5 & 12 & $\begin{array}{l}\text { CTCACAACCTCCATAAAAAAACCCTCCAGGCGAAGAGTTTAAGTTTC } \\
\text { ATGTCATGAATGAAAATCGCCGAGTTCAGGAGGTAGCGTTGGACCT } \\
\text { CTTAAAGAAATACCACAGGAAGAATGAAGATTTGGACATGACAGAC } \\
\text { CTTCACAGTGAGGAAGAAGAAGAAGAATATGATGACGACGAGGCA } \\
\text { AGTTGTGCAAGTTCCGATTTGTTTGAATTGGATAACCTTTCTTCCATC } \\
\text { GGAATCGATAGGTACCGAGAAGAGCTACCTGTGTATGAAACAACCT } \\
\text { ATCTTGGTACTACTAATCGAGCCATTGCCAATGGCTTA }\end{array}$ & GAA & G & 17,02 & $240 \mathrm{C}$ & $\begin{array}{l}\text { GTTCAGGAGGTAGCG } \\
\text { TTGGA }\end{array}$ & 60,3 & $\begin{array}{l}\text { ATTGGCAATGGCTC } \\
\text { GATTAG }\end{array}$ & 60,1 & 55 & 45 \\
\hline 345 & BrPe3196 & $\begin{array}{l}\text { Maracuja_ } \\
\text { NoIndex_L } \\
\text { 003_R1_00 } \\
\text { 1_contig_4 } \\
0253\end{array}$ & 3 & 4915 & 4926 & 12 & 4 & 9 & $\begin{array}{l}\text { ATCTCTTTCCAAAAAACAGGGGGTGACAATATCGTGTTAACTACGTGC } \\
\text { CACCCTTCATTATATACGTTTTCAAGAATCTCAAAACACTGGAGTTT } \\
\text { CAGTGCTTAATCTTTTCTCTCCATAAAAAGGTCATCAATCATCCAGT } \\
\text { GAAAATAAGATAATAATAATAGATTGATGACATAATGCTCACGCCA } \\
\text { TTGTTAGCGTATGTTTTCCATGAAATTTCAAGCAACAAATCTCATAA } \\
\text { TTCTTTTGGTGGGATGGTGACAGGTTCCATCAGGTCCTCTTTTCCTGA } \\
\text { TTCCTGAGGCATAGATTTCTCATCTCCTT }\end{array}$ & ATA & $\mathrm{s}$ & 15,27 & $\begin{aligned} 189 \mathrm{C} \\
\mathrm{A}\end{aligned}$ & $\begin{array}{l}\text { CAAAAACAGGGGGTG } \\
\text { ACAAT }\end{array}$ & 59,7 & $\begin{array}{l}\text { TACGCTAACAATGG } \\
\text { CGTGAG }\end{array}$ & 59,9 & 45 & 50 \\
\hline
\end{tabular}


APÉNDICE

Marcadores microssatélites desenhados a partir do sequênciamento parcial e da montagem de novo do genoma de $P$. edulis

\begin{tabular}{|c|c|c|c|c|c|c|c|c|c|c|c|c|c|c|c|c|c|c|c|}
\hline $\mathbf{N}^{\circ}$ & Primer & Contig I & Motivo & Início & Fim & pb & $\begin{array}{c}\mathbf{N}^{\circ} \\
\text { Repet }\end{array}$ & Score & Sequência do contig & Unidade & G/S & Cobertura & pb & Sequência Forward & $\begin{array}{l}\mathrm{T}^{\circ} \mathrm{C} \\
F w d \\
\end{array}$ & Sequência Reverse & $\begin{array}{r}\mathrm{T}^{\circ} \mathrm{C} \\
\operatorname{Rev} \\
\end{array}$ & $\begin{array}{c}\% \mathrm{GC} \\
F w d \\
\end{array}$ & $\begin{array}{cc}\% \mathrm{GC} & \mathrm{P} / \mathrm{M} \\
\operatorname{Rev} & \end{array}$ \\
\hline 346 & BrPe3197 & $\begin{array}{l}\text { Maracuja_ } \\
\text { NoIndex_L } \\
\text { 003_R1_00 } \\
\text { 1_contig_4 } \\
0316\end{array}$ & 3 & 1928 & 1939 & 12 & 4 & 9 & $\begin{array}{l}\text { CATGTATGTAGTCAAATCAACAGTGACCTGTACAGTTTAACCTTCTA } \\
\text { GATGCTTTCATATTGATTTCCACAAAAGGCCCAACATCGCCGTCAAC } \\
\text { GCGCAAGATTCAGCGACTGGTACAGTTTGTTGGTCGGAAAAAGAG } \\
\text { AAACAAATATTTATTATTATTACCAGGTTCGAAGCCATTACTTCCAG } \\
\text { GAAATTGCAGCACCCAATCAATGAATTGTTCGAATCCATTATTCAAT } \\
\text { TGTGTTCCTCTTCCACTTCCACGTAAGTTTACTTTCTCAATTCTTTCC } \\
\text { AGTTTGATCGATTCTTTTGGAATATGGCTA }\end{array}$ & TTA & $\mathrm{s}$ & 18,34 & 152 & $\begin{array}{l}\text { ATTTCCACAAAAGGC } \\
\text { CCAAC }\end{array}$ & 61,1 & $\begin{array}{l}\text { AATTCATTGATTGG } \\
\text { GTGCTG }\end{array}$ & 58,4 & 45 & 40 \\
\hline 347 & BrPe3198 & $\begin{array}{l}\text { Maracuja_ } \\
\text { NoIndex_L } \\
\text { 003_R1_00 } \\
\text { 1_contig_4 } \\
0492\end{array}$ & 3 & 729 & 743 & 15 & 5 & 12 & $\begin{array}{l}\text { AACATGTGGCAAAGGTTCTCCATTATTGGATCATATCTTCCAAAATC } \\
\text { ATTGACTGTGGGAGGACAAAGGTCAATGGAAGAAAAAGCAGATCC } \\
\text { AGGACATCCAACGATGCCAGTGCTGAGGGAATAAAGCATTTTTAGT } \\
\text { TTAATCGTCTCCTTATTATTATTATTAGATGATATAATCTTGTAGATC } \\
\text { CTCTAAAACTTATTAACAGTATTTTAATCATTTTGGACTGCTGCGAT } \\
\text { TTGTATGGTGCAGGACTGTCTGAATATCAGACCATACTTAGATTAGT } \\
\text { ATGACAATTGATTGGAATACTCGCCTCTCTCAAA }\end{array}$ & TTA & G & 16,22 & 243 & $\begin{array}{l}\text { ACATGTGGCAAAGGT } \\
\text { TCTCC }\end{array}$ & 60,0 & $\begin{array}{l}\text { CACCATACAAATCG } \\
\text { CAGCAG }\end{array}$ & 60,3 & 50 & 50 \\
\hline 348 & BrPe3199 & $\begin{array}{l}\text { Maracuja_ } \\
\text { NoIndex_L } \\
\text { 003_R1_00 } \\
\text { 1_contig_4 } \\
0589\end{array}$ & 3 & 893 & 904 & 12 & 4 & 9 & $\begin{array}{l}\text { GACTGCTTGGTTATTCACCCAAATGACTCTTTAGTTTGCTGCTCGTTA } \\
\text { CGTTTATTCTGAAGATAGCCATGTTAATAAACTATTATCTGCTGTTT } \\
\text { GTTGGGTACAATTGCAGAGGAATCCAACCAAGAAGACTCCAAACTG } \\
\text { GATTTCAGCGAGGAGGAGGAGACCCTTATTACTAGGATGTTTAATCT } \\
\text { GGTTGGTGAGAGGTGGGTTCATATTCTTCATTTCCCTTACCTTTCTCT } \\
\text { TTTCAAATTTCTAAAAACATCAAGGACCTTAACGATCTGGGTCCGAT } \\
\text { CACCTTTAGGTGGGCTCTGATTGCTGGGA }\end{array}$ & GAG & G & 13,35 & 200 & $\begin{array}{l}\text { GCAGAGGAATCCAAC } \\
\text { CAAGA }\end{array}$ & 60,2 & $\begin{array}{l}\text { AGCAATCAGAGCCC } \\
\text { ACCTAA }\end{array}$ & 59,8 & 50 & 50 \\
\hline 349 & BrPe3200 & $\begin{array}{l}\text { Maracuja_ } \\
\text { NoIndex_L } \\
\text { 003_R1_00 } \\
\text { 1_contig_4 } \\
0784\end{array}$ & 3 & 1287 & 1298 & 12 & 4 & 9 & $\begin{array}{l}\text { GTTGCTATTATATAAAAGGAAACAAAGCAAGCTCTGCTCAGGAATG } \\
\text { AAGCTCTGTGCAGAGTACATTTATGTGTTTGATACTTTTTTATAATGC } \\
\text { TTACACATCAGTTAAACCATCTACCTCTCCTAACTCCCTGCAGGACT } \\
\text { ACACCAGAGGAAGAAGAAGAATATAATAACAACGTACCAAAACAC } \\
\text { AAATAAATTCTTCTAACCCAGACCAGGATAATGTAAACCTATAAAA } \\
\text { TATATACAGTTTCAGGTTCATCTAAAACAGTCTAAATGGACGGCTT } \\
\text { ATTTGAAAATGTCTGAGAGATCAGTACCAAGAA }\end{array}$ & GAA & $\mathrm{s}$ & 13,25 & 164 & $\begin{array}{l}\text { ACTCCCTGCAGGACT } \\
\text { ACACC }\end{array}$ & 59,2 & $\begin{array}{l}\text { CATTTTCAAATAAG } \\
\text { CCGTCCA }\end{array}$ & 60 & 60 & 38,1 \\
\hline 350 & BrPe3201 & $\begin{array}{l}\text { Maracuja_ } \\
\text { NoIndex_L } \\
\text { 003_R1_00 } \\
\text { 1_contig_4 } \\
0868\end{array}$ & 3 & 4663 & 4674 & 12 & 4 & 9 & $\begin{array}{l}\text { GTTGACATCAAAAGAGAATATTGAGGACACCGACAATAAAGATAGA } \\
\text { TAGAGAACAATCCCACATGTAGCAAAAATTAGTAAGCTAGAATACG } \\
\text { TCCCTACCTAGCCATGCCCTTCTCGTCTGGAAGTGTTTCATCATCGA } \\
\text { TTTCAGGCATCTCTTCTTCTTCTAAAGCCATTGCTTGCAGCACGGCGT } \\
\text { AGTGTCTTTGCAAGCCTGCAATAATTATTTTGGTAAAAAGATCTGAG } \\
\text { AAATTGAAAGCCGTAACCAAGTTCACGTCCCACAAGTGAAGCCAGG } \\
\text { TAATACAGATGCAGACAAGGTATGAATATTGG }\end{array}$ & ТСТ & G & 17,93 & 156 & $\begin{array}{l}\text { CCCTTCTCGTCTGGA } \\
\text { AGTGT }\end{array}$ & 59,3 & $\begin{array}{l}\text { GGACGTGAACTTGG } \\
\text { TTACGG }\end{array}$ & 60,4 & 55 & 55 \\
\hline
\end{tabular}


APÉNDICE

Marcadores microssatélites desenhados a partir do sequênciamento parcial e da montagem de novo do genoma de $P$. edulis

\begin{tabular}{|c|c|c|c|c|c|c|c|c|c|c|c|c|c|c|c|c|c|c|c|}
\hline $\mathbf{N}^{\mathbf{o}}$ & Primer & Contig $\mathrm{I}$ & Motivo & Início & Fim & pb & $\begin{array}{c}\mathbf{N}^{\mathbf{o}} \\
\text { Repet }\end{array}$ & Score & Sequência do contig & Unidade & G/S & Cobertura & pb & Sequência Forward & $\begin{array}{l}\mathrm{T}^{\circ} \mathrm{C} \\
F w d\end{array}$ & Sequência Reverse & $\begin{array}{r}\mathrm{T}^{\circ} \mathrm{C} \\
\operatorname{Rev}\end{array}$ & $\begin{array}{r}\% \mathrm{GC} \\
F w d\end{array}$ & $\begin{array}{c}\% \mathrm{GC} \\
\operatorname{Rev}\end{array} \quad \mathrm{P} / \mathbf{M}$ \\
\hline 351 & BrPe3202 & $\begin{array}{l}\text { Maracuja_ } \\
\text { NoIndex_L } \\
\text { 003_R1_00 } \\
\text { 1_contig_4 } \\
0963\end{array}$ & 3 & 4524 & 4535 & 12 & 4 & 9 & $\begin{array}{l}\text { ATTAATCAAACGTGAAACTTTACTACATCAATCGAGTAACAAAAAG } \\
\text { TAGAAAAATTTAAATGTAATGTTGAGTAATTTTAAAAATAAAGAAG } \\
\text { TACAAGAGCAAGCATGACAATTAAAAGAAAGTACACCTGGGCAAA } \\
\text { ATGACAAGTTAAAAACAACAACAACCAAAACACATTAGCTTTAGAA } \\
\text { AAAATTGCAGAAGGTGGCTGGGGACTGATCATCGTCATCATAAATT } \\
\text { TATTACTCAAGAACATAAAGAACAATCAATCAAATTAAGAAGTACA } \\
\text { CAACTGCCCAAAACCCTAATATACTGCAGTATATGCG }\end{array}$ & AAC & $\bar{s}$ & 18,76 & 167 & $\begin{array}{l}\text { CCTGGGCAAAATGAC } \\
\text { AAGTT }\end{array}$ & 60,0 & $\begin{array}{l}\text { TTAGGGTTTTGGGC } \\
\text { AGTTGT }\end{array}$ & 59,5 & 45 & 45 \\
\hline 352 & BrPe3203 & $\begin{array}{l}\text { Maracuja_ } \\
\text { NoIndex_L } \\
003 \text { R1_00 } \\
\text { 1_contig_4 } \\
1012\end{array}$ & 3 & 4307 & 4318 & 12 & 4 & 9 & $\begin{array}{l}\text { AGTTATTTTTAATGAACCTGACAGGACCAGAAGGAGCGGAAAAGAA } \\
\text { GAAAGGGTTCGAGCTCTAGACTTGAAAAATCAGAGTCACCAAAATC } \\
\text { AAATGGTGTCCAACTTAGCATTACAGAATTTTACCGCTCAACCAAAT } \\
\text { TACAGTTTTCTGAAGAAGAAGAAAAAAGATGTAGCCAGTAATTCAGA } \\
\text { GAATCAAGTTGATGAGCCGCCAGCTTTAAAGAGGAAGCTATCAAGC } \\
\text { TCAAACCTTCCAAAGTCTGCAAGGCGTCGCCTTTGTTCAAATAGGA } \\
\text { AGAGGCTTAACAACCTCAAAAACAAACATGTAAA }\end{array}$ & GAA & G & 14,65 & 230 & $\begin{array}{l}\text { CCTGACAGGACCAGA } \\
\text { AGGAG }\end{array}$ & 59,8 & $\begin{array}{l}\text { CTTTGGAAGGTTTG } \\
\text { AGCTTGA }\end{array}$ & 59,5 & 60 & 42,9 \\
\hline 353 & BrPe3204 & $\begin{array}{l}\text { Maracuja_ } \\
\text { NoIndex_L } \\
\text { 003_R1_00 } \\
\text { 1_contig_4 } \\
1210\end{array}$ & 3 & 1867 & 1878 & 12 & 4 & 9 & $\begin{array}{l}\text { CTCTTTTCACTGCCATCGCTGTGATTAAGAGTCCATACATGTTGTTCA } \\
\text { AGGGCTGGTATCGACTTACCCAGGATCTAATCAGCCGAGAAGGGCC } \\
\text { GTTTCTTGAAACAGCTTGCATCCCCATTGCTGGCTTGACGATCCTTCT } \\
\text { GTGGCCACTTGTTGTTGTTGGGAGCATATTGGCCACAATTTTCAGTA } \\
\text { GCATTTTCATTGGATTGTATGCAGCAGTTGTTGTGTATCAGGTTGGT } \\
\text { CTGACTTTCACTACTACTTTTGCAGTTGTTGTGTATCTTTGATTGCAA } \\
\text { TCATCATTTGCATTCTAACATGTGCAGG }\end{array}$ & TTG & G & 13,49 & 170 & $\begin{array}{l}\text { TCAAGGGCTGGTATC } \\
\text { GACTT }\end{array}$ & 59,7 & $\begin{array}{l}\text { TGCTGCATACAATC } \\
\text { CAATGAA }\end{array}$ & 60,1 & 50 & 38,1 \\
\hline 354 & BrPe3205 & $\begin{array}{l}\text { Maracuja_ } \\
\text { NoIndex_L } \\
\text { 003_R1_00 } \\
\text { 1_contig_4 } \\
1240\end{array}$ & 3 & 1445 & 1456 & 12 & 4 & 9 & $\begin{array}{l}\text { TCTCTCCCATGCATGTTTCTTTATTATGAAATAAAAACCATTGTTATAA } \\
\text { TTGTTTCTTTATTTTTATGTCACTAAAAAATTGAGAACCAAAATAGG } \\
\text { CACCGGAAAAATTAAAAACCTAATTTTATATTTATGAATCATTTAGT } \\
\text { TACTCTTATATTATTATTATAAATCATTTATAACGGAGTATAAACTT } \\
\text { AACATAGAAGGACTGTGTGCAGGTATAAAAGGGACTTATAATACAA } \\
\text { AAATATTTTATATATTTTTCTTTCATGTGTCAGTAGTACATCGAGGA } \\
\text { ATTCTGACGTTTGATGGATAGTGGTGCCTC }\end{array}$ & TAT & $\mathrm{s}$ & 16,33 & 223 & $\begin{array}{l}\text { CAAAATAGGCACCGG } \\
\text { AAAAA }\end{array}$ & 59,9 & $\begin{array}{l}\text { GCACCACTATCCAT } \\
\text { CAAACG }\end{array}$ & 59 & 40 & 50 \\
\hline 355 & BrPe3206 & $\begin{array}{l}\text { Maracuja_ } \\
\text { NoIndex_L } \\
\text { 003_R1_00 } \\
\text { 1_contig_4 } \\
\text { 1756 }\end{array}$ & 3 & 1639 & 1650 & 12 & 4 & 9 & $\begin{array}{l}\text { GCCTGTGTCTACCACTGACTGACTTCAGGTTCATGAAGTTGACAGAT } \\
\text { TCAGGTGAACAAACGGATATCACAGAAAAAATATTGGAGTATATGA } \\
\text { GGGACAAAGCTCCAGAAATGCTAGAGTTGCTCGCTTGCAGCGAAGT } \\
\text { ATTTGACAGCAGTGGTGGTGGTGCAGCACAAATGTGCAGTGATATG } \\
\text { GAGGTTCCTTTTCTTGGAAAGGTACCATTAGACCCACAACTTTGCAA } \\
\text { GGCAGCTGAAGAGGGTAGGTCCTGTTTTGCAGATCAGAAATGCGGG } \\
\text { GTGAGTGCCCCCGCCCTGAAGAGAATCGTAGAAA }\end{array}$ & GTG & G & 15,61 & 170 & $\begin{array}{l}\text { GGACAAAGCTCCAGA } \\
\text { AATGC }\end{array}$ & 59,8 & $\begin{array}{l}\text { CTGCAAAACAGGAC } \\
\text { CTACCC }\end{array}$ & 59,6 & 50 & 55 \\
\hline
\end{tabular}


APÉNDICE

Marcadores microssatélites desenhados a partir do sequênciamento parcial e da montagem de novo do genoma de $P$. edulis

\begin{tabular}{|c|c|c|c|c|c|c|c|c|c|c|c|c|c|c|c|c|c|c|c|}
\hline $\mathbf{N}^{\circ}$ & Primer & Contig I & Motivo & Início & Fim & pb & $\begin{array}{c}\mathbf{N}^{\circ} \\
\text { Repet }\end{array}$ & Score & Sequência do contig & Unidade & G/S & Cobertura & pb & Sequência Forward & $\begin{array}{l}\mathrm{T}^{\circ} \mathrm{C} \\
F w d \\
\end{array}$ & Sequência Reverse & $\begin{array}{l}\mathrm{T}^{\circ} \mathrm{C} \\
\operatorname{Rev} \\
\end{array}$ & $\begin{array}{c}\% \mathrm{GC} \\
F w d \\
\end{array}$ & $\begin{array}{cc}\% \mathrm{GC} & \mathrm{P} / \mathrm{M} \\
\operatorname{Rev} & \end{array}$ \\
\hline 356 & BrPe3207 & $\begin{array}{l}\text { Maracuja_ } \\
\text { NoIndex_L } \\
\text { 003_R1_00 } \\
\text { 1_contig_4 } \\
1864\end{array}$ & 3 & 1285 & 1296 & 12 & 4 & 9 & $\begin{array}{l}\text { CACCTGTCTATTATTCAAAAATAGCTAGGCTGGGTGATGAAAAAAGG } \\
\text { AAATCCAGCCAGATCGAAGAATTAATTACCGTGAGATTTTGGCCACT } \\
\text { GAGAAAAGTATGGAAACACTGTGGAATGGATGTCATGGGAGATCTC } \\
\text { TGAAGATCCGAAAGAAGAAGAAGCTTCTGTAGCGATGCTTTTCATC } \\
\text { TCCTTGATATTTCCGAGAGGGAAAGTGGGAGATGGACCTCCAAACC } \\
\text { CATTTCTTTTAAGCTTGAGATGAGCCCAGATAGGGAAAATCCACAA } \\
\text { GGAAAAGAACAGCCTCAGAGATAAGTAGAGTAGAG }\end{array}$ & $\overline{A A G}$ & $\bar{G}$ & 13,3 & 238 & $\begin{array}{l}\text { GCTGGGTGATGAAAA } \\
\text { AGGAA }\end{array}$ & 60,1 & $\begin{array}{l}\text { CCCTATCTGGGCTC } \\
\text { ATCTCA }\end{array}$ & 60,2 & 45 & 55 \\
\hline 357 & BrPe3208 & $\begin{array}{l}\text { Maracuja_ } \\
\text { NoIndex_L } \\
\text { 003_R1_00 } \\
\text { 1_contig_4 } \\
\text { 1950 }\end{array}$ & 3 & 1889 & 1900 & 12 & 4 & 9 & $\begin{array}{l}\text { GGATGTAATGCACTCACACTCCCATGTGGTTCTGCTGAAATATTTAG } \\
\text { CAGATGCTAACGAGGTTCCAACTGCCATCCAACATGTAAAACAAAT } \\
\text { ACAAGAAACCTGTTCTTCCATGTTGCAAGTCATTTTTACTGAGCTCC } \\
\text { TGGCCTTGCTTTCTTCTTCTTCAAAACCTGAACCTATCCTACAGTTGC } \\
\text { TTCAAGCGCTGTCTGAAGAATCCACTGATTTGAACAACAACACTCTG } \\
\text { AGGCAGATATCCACTGATAGTTCAATTCTATATACTTAAACCAGAG } \\
\text { GTGGTGA }\end{array}$ & TTC & G & 14,37 & 153 & $\begin{array}{l}\text { GCAGATGCTAACGAG } \\
\text { GTTCC }\end{array}$ & 59,8 & $\begin{array}{l}\text { CAGCGCTTGAAGCA } \\
\text { ACTGTA }\end{array}$ & 60,3 & 55 & 50 \\
\hline 358 & BrPe3209 & $\begin{array}{l}\text { Maracuja_ } \\
\text { NoIndex_L } \\
\text { 003_R1_00 } \\
\text { 1_contig_4 } \\
\text { 2157 }\end{array}$ & 3 & 2404 & 2421 & 18 & 6 & 15 & $\begin{array}{l}\text { GAAAGGAAGAGAAACCGGCAAAGGAGCTCCATCAGCTGATTTGTTA } \\
\text { GTATGCTTTCCTTCCAGAGCTCACCTAACCTTAATGCCCAAGCCCAT } \\
\text { TTGCAGTCCTGCAAGGCCATCCGAGGTCAGCAAGCACCATCACACT } \\
\text { CAAAACTACCTCCACCACCACCACCACCAGCATCACCAGCACCACA } \\
\text { AAAAGAAATCTAGCACCAGAGGTGGAGGTAGCCAAGCCAGTCCGCT } \\
\text { TTTATGGTCAAGAACTAAACAAATGGAGTCAGAAATCGTGGACCA } \\
\text { ACCTCACCGGAGGTCACCTGCGCTGGGCAGATCAAAGTAAG }\end{array}$ & $\mathrm{CCA}$ & G & 18,77 & 166 & $\begin{array}{l}\text { GTCAGCAAGCACCAT } \\
\text { CACAC }\end{array}$ & 60,3 & $\begin{array}{l}\text { GTGAGGTTGGTTCC } \\
\text { ACGATT }\end{array}$ & 59,8 & 55 & 50 \\
\hline 359 & BrPe3210 & $\begin{array}{l}\text { Maracuja_ } \\
\text { NoIndex_L } \\
\text { 003_R1_00 } \\
\text { 1_contig_4 } \\
2510\end{array}$ & 3 & 1206 & 1220 & 15 & 5 & 12 & $\begin{array}{l}\text { AGTACAAGTTCTACTACTAAGCACATCTCAGTAGCACACTACACAA } \\
\text { GTCAAACAGTCAACTCTCTCTATGACACATATCATACATACCATCTG } \\
\text { TCATATCCTACAACTCATGTGGCTGGGGTCGCTCATATCTCCTCATA } \\
\text { TGAGTCCTCGTCATCATCATCATCACTGCTGTAAACCTCGCTCCCGA } \\
\text { TTCGACCCAGTTCGG }\end{array}$ & TCA & $\mathrm{s}$ & 28,99 & 100 & $\begin{array}{l}\text { СТGTCATATCCTACA } \\
\text { ACTCATGTGG }\end{array}$ & 59,8 & $\begin{array}{l}\text { GAATCGGGAGCGAG } \\
\text { GTTTAC }\end{array}$ & 61 & 44 & 55 \\
\hline 360 & BrPe3211 & $\begin{array}{l}\text { Maracuja_ } \\
\text { NoIndex_L } \\
\text { 003_R1_00 } \\
\text { 1_contig_4 } \\
\text { 2576 }\end{array}$ & 3 & 2127 & 2138 & 12 & 4 & 9 & $\begin{array}{l}\text { CAAAATAGTCTCATGTACATCAGTCACACAAACAAAGGTAATCCAA } \\
\text { CCAAACATAACAGCCAAAAAACAACATAAGCTACAACCAATAAGC } \\
\text { ACAATCAAGATTTGTGCACACACGACACCACACTCTCAAACCGAAC } \\
\text { CAAATCCAACCAACACCACCACCACTCCGCAACATACATCAACATA } \\
\text { GCTAACACAACAAAACATCCATCGATCTATCTAATAAGAGGATGAC } \\
\text { AAACACCAAGTTGAACCTCAATACAATACCACAAGAAAACAAAACT } \\
\text { AGCTACCACCTAAGCACTCACCTCAAACCGCAAGCAA }\end{array}$ & CAC & G & 21,5 & 201 & $\begin{array}{l}\text { CAACCAAACATAACA } \\
\text { GCCAAAA }\end{array}$ & 59,9 & $\begin{array}{l}\text { TTCAACTTGGTGTTT } \\
\text { GTCATCC }\end{array}$ & 59,9 & 36,4 & 40,9 \\
\hline
\end{tabular}

G: genoma funcional

S: genoma estructural

P: polimórfico

M: monomórfico 
APÉNDICE

Marcadores microssatélites desenhados a partir do sequênciamento parcial e da montagem de novo do genoma de $P$. edulis

\begin{tabular}{|c|c|c|c|c|c|c|c|c|c|c|c|c|c|c|c|c|c|c|c|}
\hline $\mathbf{N}^{\mathbf{o}}$ & Primer & Contig $\mathrm{I}$ & Motivo & Início & Fim & pb & $\begin{array}{c}\mathbf{N}^{\mathbf{o}} \\
\text { Repet }\end{array}$ & Score & Sequência do contig & Unidade & G/S & Cobertura & pb & Sequência Forward & $\begin{array}{l}\mathrm{T}^{\circ} \mathrm{C} \\
F w d\end{array}$ & Sequência Reverse & $\begin{array}{r}\mathrm{T}^{\circ} \mathrm{C} \\
\operatorname{Rev}\end{array}$ & $\begin{array}{c}\% \mathrm{GC} \\
F w d\end{array}$ & $\begin{array}{c}\% \mathrm{GC} \\
\operatorname{Rev}\end{array} \quad \mathrm{P} / \mathbf{M}$ \\
\hline 361 & BrPe3212 & $\begin{array}{l}\text { Maracuja_ } \\
\text { NoIndex_L } \\
\text { 003_R1_00 } \\
\text { 1_contig_4 } \\
\text { 2621 }\end{array}$ & 3 & 1439 & 1450 & 12 & 4 & 9 & $\begin{array}{l}\text { TAACTAGAAATATAGTAGAAAAAAGAAGAGTGGGGGTGCTACCGAT } \\
\text { AATGTCTGAAGGGACTTTTCCATCGCAGAACCTTCCAGTGGGGATTC } \\
\text { TCCCTTTGAAATCAACACCATATGGAGGAAAGTTGCACTTAATTAGT } \\
\text { GTTTTTGAGATTGTTGTTGTTGCCTTTATCAACAACGGAATCCCCAA } \\
\text { AGACGAGGATGGCAGGGATGGTAACATTTGGAGGTAGCTTTACCAA } \\
\text { AGCTTGGGTGGTGGGAACTAGTAGAAGAAAGAGCAACAATGGCAA } \\
\text { ACCGAACTGCATTAATGGGCTAATATTTCTTTCC }\end{array}$ & TTG & $\mathrm{G}$ & 16,47 & 207 & $\begin{array}{l}\text { AACCTTCCAGTGGGG } \\
\text { ATTCT }\end{array}$ & 59,8 & $\begin{array}{l}\text { GGTTTGCCATTGTTG } \\
\text { CTCTT }\end{array}$ & 60,1 & 50 & 45 \\
\hline 362 & BrPe3213 & $\begin{array}{l}\text { Maracuja_ } \\
\text { NoIndex_L } \\
\text { 003_R1_00 } \\
\text { 1_contig_4 } \\
\text { 3068 }\end{array}$ & 3 & 373 & 384 & 12 & 4 & 9 & $\begin{array}{l}\text { TCCTGCGAGAAACAATCTCCGAAGGTGTATCTAAAGCTCCATTTCTT } \\
\text { GTTTTCATGGGAGTGGCACTTTCTATCACCGCTTTCCCTGTCTTGGCT } \\
\text { CGAATTTTGGCCGAACTGAAGCTTTTGACAACCGATGTTGGTCGTAT } \\
\text { GGCAATGTCAGCAGCAGCAGTCAATGATGTAGCTGCGTGGATTCTA } \\
\text { TTGGCTCTTGCGATTGCCCTGTCAGGATCAGGGCATTCTGCTCTTGT } \\
\text { ATCTTTGTGGGTTTTCTTTGTGGAGCTGGATTTGTTATAGCATGCAC } \\
\text { GTTCCTTGTTCCTCCTATTTTTAAATGGA }\end{array}$ & $\mathrm{CAG}$ & G & 13,27 & 181 & $\begin{array}{l}\text { CGAGAAACAATCTCC } \\
\text { GAAGG }\end{array}$ & 59,8 & $\begin{array}{l}\text { GAATCCACGCAGCT } \\
\text { ACATCA }\end{array}$ & 59,8 & 50 & 50 \\
\hline 363 & BrPe3214 & $\begin{array}{l}\text { Maracuja_ } \\
\text { NoIndex_L } \\
\text { 003_R1_00 } \\
\text { 1_contig_4 } \\
\text { 3125 }\end{array}$ & 3 & 1910 & 1924 & 15 & 5 & 12 & $\begin{array}{l}\text { AACTTATCAGTTGAGCTTGGTATCCAGATAGTTTCAACAACAATATT } \\
\text { GAAGTACTTTTACCTGTAGTAGCTCCTGGGATAATACTGAGAACTTG } \\
\text { CATAAGGAGGATAAGAAGATGAATTAAGGTTATCCTGAAGAGCTCT } \\
\text { AGCTAGTTCTTCATCATCATCATCAGTTCCCCATCTATATCCTGAATA } \\
\text { ACAAATACACATAGCCAATTATCAAATGTGAGAGACAGGACTAGAG } \\
\text { AATTGGTATGCCTTGCCTTTGCCTTTACCACTTGGTTTCTTCAAATCT } \\
\text { TCAGCTAGAGAAAGGGCAATAGCATGATCTAAC }\end{array}$ & TCA & G & 17,42 & 163 & $\begin{array}{l}\text { CTGAGAACTTGCATA } \\
\text { AGGAGGA }\end{array}$ & 58,6 & $\begin{array}{l}\text { GGCATACCAATTCT } \\
\text { CTAGTCCTG }\end{array}$ & 59,2 & 45,5 & 47,8 \\
\hline 364 & BrPe3215 & $\begin{array}{l}\text { Maracuja_ } \\
\text { NoIndex_L } \\
\text { 003_R1_00 } \\
\text { 1_contig_4 } \\
\text { 3254 }\end{array}$ & 3 & 2257 & 2268 & 12 & 4 & 9 & $\begin{array}{l}\text { ACTGTTTAAAAAAGTTTTTATTTGATTCCCGATATGAAGGAAATATACT } \\
\text { GGAGTGTGAATCTTATTTTGTAAAAATTGCAGTGATGGCTTTTGGGA } \\
\text { TGTCATTAGTGCTAGAAAAGCATATCAGCTAGTCCTCCAGGTACATC } \\
\text { CACTACCTTTTCTTCTTCTTCACTCCCTTCGAGTTTGTTAAAAATAAT } \\
\text { CTGATGACATACTAATAGCGTGCTTGATTATTTGACCCACACAGATG } \\
\text { AGAGAGAAGTACTCTGTGGATGGGGAGAATCTGGCTACAAAGATTG } \\
\text { CAGATTTATTGTTGAGTGAGGCTAGAACAC }\end{array}$ & TTC & $\mathrm{s}$ & 18,54 & 152 & $\begin{array}{l}\text { GTGATGGCTTTTGGG } \\
\text { ATGTC }\end{array}$ & 60,3 & $\begin{array}{l}\text { TGTGGGTCAAATAA } \\
\text { TCAAGCA }\end{array}$ & 59 & 50 & 38,1 \\
\hline 365 & BrPe3216 & $\begin{array}{l}\text { Maracuja_ } \\
\text { NoIndex_L } \\
\text { 003_R1_00 } \\
\text { 1_contig_4 } \\
3330\end{array}$ & 3 & 468 & 479 & 12 & 4 & 9 & $\begin{array}{l}\text { GTTTATGCTCTGCTGGGGTTTTATGATAGAAGAAAAATCTATCTATT } \\
\text { TGAAACAGCCACCCCAATACGTTTTCACCATTAAAAAAAGGAATTT } \\
\text { CCAACTTGGGAACTCTTGGATACGTCACTCCAACCAGATCACTTGTG } \\
\text { CCTGTGTGAAAAAGAAGAAGAAGCCCCATGCTGTATCGGCATTGGAG } \\
\text { GAGTTGGCAATAAGGGAGGTAGAGGCGAGCTAGTTGTCAGTTGTAA } \\
\text { AGAAAAACTTGTTTCATGTTGTGGTGAAGAGGACGATGCCTTTTCTG } \\
\text { CATTAGAGCTTGAAGCTTGCTGCTTTTCCATTC }\end{array}$ & AAG & G & 8,41 & 167 & $\begin{array}{l}\text { TGGATACGTCACTCC } \\
\text { AACCA }\end{array}$ & 60,0 & $\begin{array}{l}\text { AAAAGGCATCGTCC } \\
\text { TCTTCA }\end{array}$ & 59,8 & 50 & 45 \\
\hline
\end{tabular}

G: genoma funcional

S: genoma estructural

P: polimórfico

M: monomórfico 
APÉNDICE

Marcadores microssatélites desenhados a partir do sequênciamento parcial e da montagem de novo do genoma de $P$. edulis

\begin{tabular}{|c|c|c|c|c|c|c|c|c|c|c|c|c|c|c|c|c|c|c|c|}
\hline $\mathbf{N}^{\circ}$ & Primer & Contig I & Motivo & Início & Fim & pb & $\begin{array}{c}\mathbf{N}^{\circ} \\
\text { Repet }\end{array}$ & Score & Sequência do contig & Unidade & G/S & Cobertura & pb & Sequência Forward & $\begin{array}{l}\mathrm{T}^{\circ} \mathrm{C} \\
F w d\end{array}$ & Sequência Reverse & $\begin{array}{r}\mathrm{T}^{\circ} \mathrm{C} \\
\operatorname{Rev}\end{array}$ & $\begin{array}{r}\% \mathrm{GC} \\
F w d\end{array}$ & $\begin{array}{cc}\% \mathrm{GC} & \\
\operatorname{Rev} & \mathrm{P} / \mathrm{M}\end{array}$ \\
\hline 366 & $\overline{B r P e 3217}$ & $\begin{array}{l}\text { Maracuja_ } \\
\text { NoIndex_L } \\
\text { 003_R1_00 } \\
\text { 1_contig_4 } \\
3353\end{array}$ & 3 & 1690 & 1701 & 12 & 4 & 9 & $\begin{array}{l}\text { CATCCGTGTGCAATTGAAAAGTTGATCATTAAGTATGGCCTTGTTTT } \\
\text { GGTACATCTTGTTGTTGGAAAAGCAATAATGTTTCTACTGGACATTT } \\
\text { GTTTGTATTCCCAACGCGTTTTCAAACTATGGATCCATTTTTCCGGTC } \\
\text { TGAAGCTAGCTGCTGCTGCTATGATTATGAGGATGACGTCTGACTTC } \\
\text { TGTCCCTCTGACATCTGCACTCGTGGATGCTCTTTGCACCTCTAAAC } \\
\text { GTATTTGAAAGTTTGACTGTTCAGCTACCCACAAAGCTTCATCCAC } \\
\text { ATCCAAAGACACCTAGGCCGTGCCAGCCA }\end{array}$ & GCT & $\mathrm{s}$ & 14,69 & 211 & $\begin{array}{l}\text { GATCCATTTTTCCGGT } \\
\text { CTGA }\end{array}$ & 59,9 & $\begin{array}{l}\text { AGCTTTGTGGGTAG } \\
\text { CTGAACA }\end{array}$ & 59,9 & 45 & 47,6 \\
\hline 367 & BrPe3218 & $\begin{array}{l}\text { Maracuja_ } \\
\text { NoIndex_L } \\
\text { 003_R1_00 } \\
\text { 1_contig_4 } \\
3647\end{array}$ & 3 & 2040 & 2051 & 12 & 4 & 9 & $\begin{array}{l}\text { AGGAACTCATTGACAGGTTACCACCACTTCCCTTTTCAAAGGATGAT } \\
\text { GCAAAATTATTCTGGGAGAGTGTTCAGTCACAGATAGCTCTGGCA } \\
\text { GAAACTCAGAACAGTAATCATGTTGCAGAGATTCAATAGGACTCAA } \\
\text { CCAAGGTACCACATCATCATCATGACCGGTACCCATTTCAACAGAG } \\
\text { GGAACAGAGAGTGGAACTTCATTCAGTACAGAATCCATCGTCCCAC } \\
\text { ACTTCCCCATTCTCGCAGGACAACCACTGTTATGTCTTCTCCTCCA } \\
\text { GTCCTGGAGGCGTGAGAAGGTACAGTGTTACAAG }\end{array}$ & CAT & G & 14,24 & 207 & $\begin{array}{l}\text { CCCTTTTCAAAGGAT } \\
\text { GATGC }\end{array}$ & 59,5 & $\begin{array}{l}\text { GAAGTGTGGGACGA } \\
\text { TGGATT }\end{array}$ & 59,8 & 45 & 50 \\
\hline 368 & BrPe3219 & $\begin{array}{l}\text { Maracuja_ } \\
\text { NoIndex_L } \\
\text { 003_R1_00 } \\
\text { 1_contig_4 } \\
3650\end{array}$ & 3 & 3073 & 3087 & 15 & 5 & 12 & $\begin{array}{l}\text { GAGAAGTATATTTCGGAGGAGATCAGATCCATGGTGTCTCTAAATT } \\
\text { GTGCACCAAGATCTGTTTCCGAATTAGTGCAGTTGTCACAGAGCCT } \\
\text { TTGGCTTGGCATAGTCTTATAATCCAATCTTGCGTTAGATCGTCTCTT } \\
\text { CCATCTGGAAAGAAGAAGAAGAAGGGTGGCTCTGCAGTAAACTCAG } \\
\text { CCTCTCTACATGATGCAATTCGGAATTCCATAGAGTCCTTGTGCCGT } \\
\text { GTAGTTGAAGAGGTTACAAAATGGTTAAGAGAACAGATAAGCCGAT } \\
\text { CGGAGGATGAGAGGATGGAAAATATTCTCTTATCT }\end{array}$ & AAG & G & 18,36 & 198 & $\begin{array}{l}\text { СCTTTGGCTTGGCATA } \\
\text { GTCT }\end{array}$ & 59,3 & $\begin{array}{l}\text { ATCCTCCGATCGGC } \\
\text { TTATCT }\end{array}$ & 60 & 50 & 50 \\
\hline 369 & BrPe3220 & $\begin{array}{l}\text { Maracuja_ } \\
\text { NoIndex_L } \\
\text { 003_R1_00 } \\
\text { 1_contig_4 } \\
3836\end{array}$ & 3 & 1730 & 1744 & 15 & 5 & 12 & $\begin{array}{l}\text { TCTCTACCTCCCCGTCACAGTGTTATTTGTTTGCAACAGCCGCAGCA } \\
\text { ACATGCTTCCTACAGACCATTCTCCTCCAAACCATCCGGCGCCGGCC } \\
\text { CCAAAATCAACACCAAAGTAAACTTCTCACTTTCGGACTCCGAAGA } \\
\text { AGAGGAGGATGACGACGACGACGACAAGCCCAAGAAAGAACTCGA } \\
\text { CAAGACCAAGCTCCCTCCACCTTACAATCCCTTCGACAAAAAACCA } \\
\text { GTTATCGAAGAAGCCGGTGATCCCAAAGACTTGCCAAAAACCTTCC } \\
\text { ACGACATGCG }\end{array}$ & $\mathrm{GAC}$ & G & 13,77 & 179 & $\begin{array}{l}\text { GCAGCAACATGCTTC } \\
\text { CTACA }\end{array}$ & 60,0 & $\begin{array}{l}\text { CGAAGGGATTGTAA } \\
\text { GGTGGA }\end{array}$ & 59,9 & 50 & 50 \\
\hline 370 & BrPe3221 & $\begin{array}{l}\text { Maracuja_ } \\
\text { NoIndex_L } \\
\text { 003_R1_00 } \\
\text { 1_contig_4 } \\
3868\end{array}$ & 3 & 5865 & 5876 & 12 & 4 & 9 & $\begin{array}{l}\text { CTTGTGGTGCTCTAACATATTCTCTGCGCAGGTTGTTGACAATGATG } \\
\text { CTGATAGTGTCAGTGCAGCATTGCGAGAGAGGTTAACCGGTGATGA } \\
\text { TCCGAATCTCACCGGAGAGGAAAGGTTGAAGATAAGACATTTTCTT } \\
\text { GAAGCTTGCCCTGATGATGATGACGAATGAATCTCGTCTCTGGCAGC } \\
\text { CGAGTCATGTATCATATCATTACGTGATGATTATTAGTCAAGAAACA } \\
\text { ATAAGCAGTAATAAGGGTGCGTTTGGTTGCCGGAATTGTTGGATGC } \\
\text { GGAAAAGGAAATAGATATAAAATAATTCCTGAT }\end{array}$ & TGA & G & 18,5 & 158 & $\begin{array}{l}\text { CGCAGGTTGTTGACA } \\
\text { ATGAT }\end{array}$ & 59,6 & $\begin{array}{l}\text { TGCCAGAGACGAGA } \\
\text { TTCATTC }\end{array}$ & 60,4 & 45 & 47,6 \\
\hline
\end{tabular}

G: genoma funcional

S: genoma estructural

P: polimórfico

M: monomórfico 
APÉNDICE

Marcadores microssatélites desenhados a partir do sequênciamento parcial e da montagem de novo do genoma de $P$. edulis

\begin{tabular}{|c|c|c|c|c|c|c|c|c|c|c|c|c|c|c|c|c|c|c|c|}
\hline $\mathbf{N}^{\mathbf{o}}$ & Primer & Contig $\mathrm{I}$ & Motivo & Início & Fim & pb & $\begin{array}{c}\mathbf{N}^{\mathbf{o}} \\
\text { Repet }\end{array}$ & Score & Sequência do contig & Unidade & G/S & Cobertura & pb & Sequência Forward & $\begin{array}{l}\mathrm{T}^{\circ} \mathrm{C} \\
F w d\end{array}$ & Sequência Reverse & $\begin{array}{r}\mathrm{T}^{\circ} \mathrm{C} \\
\operatorname{Rev}\end{array}$ & $\begin{array}{c}\% \mathrm{GC} \\
F w d\end{array}$ & $\begin{array}{c}\% \mathrm{GC} \\
\operatorname{Rev}\end{array} \quad \mathrm{P} / \mathbf{M}$ \\
\hline 371 & BrPe3222 & $\begin{array}{l}\text { Maracuja_ } \\
\text { NoIndex_L } \\
\text { 003_R1_00 } \\
\text { 1_contig_4 } \\
\text { 3925 }\end{array}$ & 3 & 320 & 331 & 12 & 4 & 9 & $\begin{array}{l}\text { CTTAATGGATCAAGCTGGAATATTGAGATTTCTCTTAATAGATTAAT } \\
\text { CACGTGAAAGAAAAGAACCTGCTTGTTGATTGTTGTTTTGTGGGCT } \\
\text { GGACTAGGAAACAAATGAGTTAGGTCTGTACATGTGGAAAGTTGCC } \\
\text { ACGTTTCGTTGGAGGAGGAGGACGGGATGTAGGATGATGACCCAAC } \\
\text { ACCATATCTGTCGCATTCCCATTTAAACTAACTTCGAGCTTGCTACG } \\
\text { GCACCTTCCACAGACAGACACCTGTATGCGGAGAAGATGAATCTAT } \\
\text { TGAAAGGTGGCAGCTTTACAGGGCTTGCGTTTT }\end{array}$ & GGA & $\mathrm{G}$ & 14,23 & 153 & $\begin{array}{l}\text { GTGGGCTGGACTAGG } \\
\text { AAACA }\end{array}$ & 60,1 & $\begin{array}{l}\text { AAGGTGCCGTAGCA } \\
\text { AGCTC }\end{array}$ & 60,6 & 55 & 57,9 \\
\hline 372 & BrPe3223 & $\begin{array}{l}\text { Maracuja_ } \\
\text { NoIndex_L } \\
\text { 003_R1_00 } \\
\text { 1_contig_4 } \\
4069\end{array}$ & 3 & 1590 & 1607 & 18 & 6 & 15 & $\begin{array}{l}\text { AGGTAGCAGATGAGGAGAATTAGCAGGATCTCTGCTGGAGAAGTAG } \\
\text { ACTGGAAGTGTTTTTCCAACTCTTAGATCATCTAAGGTAAAGAAAAT } \\
\text { GTTATCTGCAGCTTCTACGTGCTCCATTTGTGAATGATAATGTGCAT } \\
\text { GCTTTCGAAGATCATCATCATCATCATCTCGGGTGTGCTTTTTGTTAA } \\
\text { GGTGATCCTCATATTTGGAATAAATCCATGAACTGTCATCAACAGAA } \\
\text { TGTTCTTGCAGATGTTTTGGATCATCATCCTCTTCTTTCAACGTCGTG } \\
\text { CCGATCAACATTCTGGCCCTTCTACCACCAGCATA }\end{array}$ & ATC & G & 13,63 & 150 & $\begin{array}{l}\text { TCTGCAGCTTCTACGT } \\
\text { GCTC }\end{array}$ & 59,5 & $\begin{array}{l}\text { TCTGCAAGAACATC } \\
\text { CTGTTGA }\end{array}$ & 59,4 & 55 & 42,9 \\
\hline 373 & BrPe3224 & $\begin{array}{l}\text { Maracuja_ } \\
\text { NoIndex_L } \\
\text { 003_R1_00 } \\
\text { 1_contig_4 } \\
4319\end{array}$ & 3 & 2335 & 2346 & 12 & 4 & 9 & $\begin{array}{l}\text { TTTGATGATTTTATGAACTGGATATGGTTTAAAGGTGGAATGTTTTC } \\
\text { AAAAGCGGAACAAAGCTGGGAAACTTGGTGGTATGAGGAGCAAGA } \\
\text { CCATCTGAGGACCACTGGTCTATGGGGAAAGCTGTTGGAGATTATTC } \\
\text { TAGATCTTCGTTTCTTCTTCTTCCAATATGGTGTCGTGTATCATCTAA } \\
\text { AAATTACTGGTGGAGATACTAGTATAGCTGTTTACTTGCTTTCTTGG } \\
\text { ATTTACATGATTGTAGCGGTTGGGATTTATATCATTATAGCATATGC } \\
\text { CCATGATAAATATGCTGCAAAGGAGCATATC }\end{array}$ & TTC & G & 014 & 150 & $\begin{array}{l}\text { CTATGGGGAAAGCTG } \\
\text { TTGGA }\end{array}$ & 60,1 & $\begin{array}{l}\text { AATCCCAACCGCTA } \\
\text { CAATCA }\end{array}$ & 60,3 & 50 & 45 \\
\hline 374 & BrPe3225 & $\begin{array}{l}\text { Maracuja_ } \\
\text { NoIndex_L } \\
\text { 003_R1_00 } \\
\text { 1_contig_4 } \\
4409\end{array}$ & 3 & 435 & 446 & 12 & 4 & 9 & $\begin{array}{l}\text { TTATACTATAGCAATAAAAACTCCTCTAACAATATACCAGCACGAC } \\
\text { AAAAAGAACGAGGAGTTGAAACCATCTAAGCCTGATACTTTATCTT } \\
\text { TATCAATCCCTAATAAAGCTTGTCTAATTTCATCAACAGTCACTGGT } \\
\text { TTACATAGTAGCTCCTCCTCCTCTGCGGATACTCTCGGCCCATCCTC } \\
\text { CATGATCCGAGAATCAATATGTTTCTGTAGCTGACATCTACTCTCA } \\
\text { AAATACTGTGGTAGTAATCCACTATTAGGTTAGAGATTCTGTTGGT } \\
\text { TTAGACACAGTGCTGCCATCCTCCTTTCAGAT }\end{array}$ & СТC & G & 15,78 & 181 & $\begin{array}{l}\text { TTCATCAACAGTCAC } \\
\text { TGGTTTACA }\end{array}$ & 59,6 & $\begin{array}{l}\text { GGATGGCAGCACTG } \\
\text { TGTCTA }\end{array}$ & 59,9 & 37,5 & 55 \\
\hline 375 & BrPe3226 & $\begin{array}{l}\text { Maracuja_ } \\
\text { NoIndex_L } \\
\text { 003_R1_00 } \\
\text { 1_contig_4 } \\
5039\end{array}$ & 3 & 1607 & 1618 & 12 & 4 & 9 & $\begin{array}{l}\text { GGAAGAAGAGGATGCTTTACCTGGTGAATTGGTGTCGAAGCTTTAC } \\
\text { TTGGTTGCTAGAAATCCCCTTAGAAGGTGCAACGTTTTGGAATCTTT } \\
\text { GGTTAGTTTCTTTGTGGAGTTCCGTGATTCGGTTTGCCCAGATCATC } \\
\text { ACAGTTTACTGGAGGAGGAGGACTTGCCGGTTGAAGATGCCTCTCG } \\
\text { AGATAATATTGTGGAAGAAGCAAACGAGGTGGAATCTGGAACACCC } \\
\text { GATACAGAGGTTGTAAAAGAATTTCGCGGGTCAGATATTATAATTC } \\
\text { AGAGCAACCCAGAAGACCAGTCAACAGTTGAAAC }\end{array}$ & GGA & G & 11,91 & 198 & $\begin{array}{l}\text { GGTGCAACGTTTTGG } \\
\text { AATCT }\end{array}$ & 60,0 & $\begin{array}{l}\text { TATCTGACCCGCGA } \\
\text { AATTCT }\end{array}$ & 59,7 & 45 & 45 \\
\hline
\end{tabular}

G: genoma funcional

S: genoma estructural

P: polimórfico

M: monomórfico 
APÉNDICE

Marcadores microssatélites desenhados a partir do sequênciamento parcial e da montagem de novo do genoma de $P$. edulis

\begin{tabular}{|c|c|c|c|c|c|c|c|c|c|c|c|c|c|c|c|c|c|c|c|}
\hline $\mathbf{N}^{\circ}$ & Primer & Contig I & Motivo & Início & Fim & pb & $\begin{array}{c}\mathbf{N}^{\circ} \\
\text { Repet }\end{array}$ & Score & Sequência do contig & Unidade & G/S & Cobertura & pb & Sequência Forward & $\begin{array}{l}\mathrm{T}^{\circ} \mathrm{C} \\
F w d \\
\end{array}$ & Sequência Reverse & $\begin{array}{r}\mathrm{T}^{\circ} \mathrm{C} \\
\operatorname{Rev} \\
\end{array}$ & $\begin{array}{c}\% \mathrm{GC} \\
F w d \\
\end{array}$ & $\begin{array}{cc}\% \mathrm{GC} & \mathrm{P} / \mathrm{M} \\
\operatorname{Rev} & \end{array}$ \\
\hline 376 & BrPe3227 & $\begin{array}{l}\text { Maracuja_ } \\
\text { NoIndex_L } \\
\text { 003_R1_00 } \\
\text { 1_contig_4 } \\
\text { 5466 }\end{array}$ & 3 & 2148 & 2159 & 12 & 4 & 9 & $\begin{array}{l}\text { CTTAACAAAAATATGAAAATGTTTCGCAAATCGAATCACAGATAAA } \\
\text { CAATTCAAGACTTTTCTAACAAAAAATAAGCATGTTAAACTCTATAA } \\
\text { TTTAGAAGTTTAACACTCAACCCGAAAAGAAAACCAACCACTCAAA } \\
\text { CCAAGCAACACACAACAACAACACAACCGCTAGAGCCAAACCTAA } \\
\text { CGAACAAAACAACTCAGACTCACTCAGAAACTCAAGACACACATCA } \\
\text { ATACATCTCAAAAATCAAACTCCTCAGAGTCATGCCAAACTCGTAC } \\
\text { CAAAGGTGCAGCACAACATGAGTAACATAACCTTA }\end{array}$ & $\mathrm{ACA}$ & $\mathrm{s}$ & 48,21 & 163 & $\begin{array}{l}\text { CAACCCGAAAAGAAA } \\
\text { ACCAA }\end{array}$ & 59,9 & $\begin{array}{l}\text { CGAGTTTGGCATGA } \\
\text { CTCTGA }\end{array}$ & 60 & 40 & 50 \\
\hline 377 & BrPe3228 & $\begin{array}{l}\text { Maracuja_ } \\
\text { NoIndex_L } \\
\text { 003_R1_00 } \\
\text { 1_contig_4 } \\
\text { 5495 }\end{array}$ & 3 & 2512 & 2523 & 12 & 4 & 9 & $\begin{array}{l}\text { GCATAGCCGCATAGGTTCCAACAGGAGATACCAAACTTGATGCGCT } \\
\text { TTAATGACTTCTTGGACAAGGCATGGACAAGCATGGTGGTTATTCTG } \\
\text { AAGATGTTTATTGGACCAAGAACGAAAAGCGATAAGACATGCCAT } \\
\text { TGGGATTACACACTACTACTACTTGTGTTGTTTTTTCCATGCCTCTAT } \\
\text { AGCTGGAGCTCATAGGGTGTAGAAATTGCCTGCAGCTCAATAAACC } \\
\text { CTTTCCCTATGCAAGACAATTTTCACCCACTTTACTCTAACAGACTA } \\
\text { ACACACTAATTTAAACCCAAAAACTCAGAAAT }\end{array}$ & ACT & G & 18,1 & 174 & $\begin{array}{l}\text { ACTTCTTGGACAAGG } \\
\text { CATGG }\end{array}$ & 60,1 & $\begin{array}{l}\text { TGAGCTGCAGGCAA } \\
\text { TTTCTA }\end{array}$ & 59,7 & 50 & 45 \\
\hline 378 & BrPe3229 & $\begin{array}{l}\text { Maracuja_ } \\
\text { NoIndex_L } \\
\text { 003_R1_00 } \\
\text { 1_contig_4 } \\
\text { 5961 }\end{array}$ & 3 & 1638 & 1649 & 12 & 4 & 9 & $\begin{array}{l}\text { AAAAGTAGCGCACACAGAAATGTGAGGAAACATAAATAAAAATAC } \\
\text { TACAACTAAATCATACCCGAGGAAGAAGAAGAAGAAGACGACGAC } \\
\text { GAATTGTGTTGCCACTTCAGCCTTCAACCTCAATCTCAGCGTGCTGA } \\
\text { AGACGAAGCATCGGAAGAAGAAGAATATGGCTATGCCCTCCGAGTT } \\
\text { TTCTCCGACTGCAGTGACCAACGGTGGTTGTGCCCCTTTTGCTACAA } \\
\text { AGGTAAATTAAAATTTCGTGGTGGGGTCATTAATTAATTAATTATT } \\
\text { TATTTGGCTGAGGACAAAAATGAGATGTAAGTT }\end{array}$ & GAA & G & 12,41 & 151 & $\begin{array}{l}\text { CСАCTTCAGCCTTCA } \\
\text { ACCTC }\end{array}$ & 59,8 & $\begin{array}{l}\text { CCACGAAAATTTTA } \\
\text { ATTTACCTTTGTA }\end{array}$ & 60 & 55 & 25,9 \\
\hline 379 & BrPe3230 & $\begin{array}{l}\text { Maracuja_ } \\
\text { NoIndex_L } \\
\text { 003_R1_00 } \\
\text { 1_contig_4 } \\
6027\end{array}$ & 3 & 212 & 223 & 12 & 4 & 9 & $\begin{array}{l}\text { AAGATGAAGAACAGGCCAAAAACAAAAATTTTTGGCGAACCGGATT } \\
\text { ACCTGTTGACGTGCAGAAACAGATGCAGACGGCAGATTCTTGTTTA } \\
\text { GAACCCTCTTCTGGTATCCACACAAACACTTCGCATGGCTGGATCGA } \\
\text { TGGCTGGTTTTAGGAGGAGGAGGCGGCTTGTACAGAGAAAACGTCT } \\
\text { TTTCTCTCTTCTGCCTGTTTTTCCTGAATACGTGCGTCTATTTTGGTTC } \\
\text { AGTTACTGACTGAATCAAGACCACATATTTTAATCTGACTTAATCAG } \\
\text { ATTACTAGTATCCATTTCTCTAAACGGATA }\end{array}$ & AGG & G & 142,33 & 158 & $\begin{array}{l}\text { ACGTGCAGAAACAGA } \\
\text { TGCAG }\end{array}$ & 60,1 & $\begin{array}{l}\text { TCAGGAAAAACAGG } \\
\text { CAGAAGA }\end{array}$ & 60 & 50 & 42,9 \\
\hline 380 & BrPe3231 & $\begin{array}{l}\text { Maracuja_ } \\
\text { NoIndex_L } \\
\text { 003_R1_00 } \\
\text { 1_contig_4 } \\
6076\end{array}$ & 3 & 12533 & 12544 & 12 & 4 & 9 & $\begin{array}{l}\text { ATATCAAGTCCCTTACGTTCAATGACCTAGAAGAGGGAAGTCAGTC } \\
\text { CATTTCTTTTCTGTAGTAGATAACAAAAAGTTCAGATTGAGAGTACT } \\
\text { TGTAAAAGCACCTCATACGGCGTCCCATCCTTAACCTCCACCTTGAC } \\
\text { AGCAGCATATTTCTTCTTCTTCAGAAGCAGCATTCTCTTGTACAAAC } \\
\text { CATCAAGATCTATTTCTAGACACCTGTACTTCTTATTAACCTAAATG } \\
\text { GAAAAAAAGAAAAAAAAAAAGATGAGATTGAAGAAACATATGTCAT } \\
\text { AGCACCACAGTGAGAAAATGTCCGTACCCATAT }\end{array}$ & TTC & G & 18,82 & 181 & $\begin{array}{l}\text { TCССTTACGTTCAATG } \\
\text { АСCT }\end{array}$ & 57,1 & $\begin{array}{l}\text { TGGTTTGTACAAGA } \\
\text { GAATGCTG }\end{array}$ & 58 & 45 & 40,9 \\
\hline
\end{tabular}

G: genoma funcional

S: genoma estructural

P: polimórfico

M: monomórfico 
APÉNDICE

Marcadores microssatélites desenhados a partir do sequênciamento parcial e da montagem de novo do genoma de $P$. edulis

\begin{tabular}{|c|c|c|c|c|c|c|c|c|c|c|c|c|c|c|c|c|c|c|c|}
\hline $\mathbf{N}^{\circ}$ & Primer & Contig I & Motivo & Início & Fim & pb & $\begin{array}{c}\mathbf{N}^{\circ} \\
\text { Repet }\end{array}$ & Score & Sequência do contig & Unidade & G/S & Cobertura & pb & Sequência Forward & $\begin{array}{l}\mathrm{T}^{\circ} \mathrm{C} \\
F w d \\
\end{array}$ & Sequência Reverse & $\begin{array}{l}\mathrm{T}^{\circ} \mathrm{C} \\
\operatorname{Rev} \\
\end{array}$ & $\begin{array}{c}\% \mathrm{GC} \\
F w d \\
\end{array}$ & $\begin{array}{c}\% \mathrm{GC} \\
\operatorname{Rev}\end{array} \quad \mathrm{P} / \mathrm{M}$ \\
\hline 381 & $\overline{B r P e 3232}$ & $\begin{array}{l}\text { Maracuja_ } \\
\text { NoIndex_L } \\
\text { 003_R1_00 } \\
\text { 1_contig_4 } \\
6743\end{array}$ & 3 & 3770 & 3781 & 12 & 4 & 9 & $\begin{array}{l}\text { TTTGAAGCTGTAGCTGTGCAAGATTTTGCAACTTAAAACTTTTTGTA } \\
\text { GGTTATTATGAATTTTGTGAAACTGTACTCTTGTTCTGCTTTATGCTT } \\
\text { AACTCCTGACATTCACAGAAACTGTGCCCTTGAGTATGAAAGTCAC } \\
\text { GGGGATATGGCTGCTGCTGCTTTAGCATATAAATGTTTGGAGGTTGC } \\
\text { ATGCTGGAGAGTAGTTTACTGCAAAACTCTACCTCAATCAGAGACC } \\
\text { ACAGTGAATTACAAGCATGTTTTCAAATGAGTGCCCAAGGTAATGT } \\
\text { AGTGGTATCTATTTATCTGGGTATATTGTTT }\end{array}$ & $\mathrm{GCT}$ & $\bar{G}$ & 16,17 & 164 & $\begin{array}{l}\text { CACAGAAACTGTGCC } \\
\text { CTTGA }\end{array}$ & 59,9 & $\begin{array}{l}\text { TGGGCACTCATTTG } \\
\text { AAAACA }\end{array}$ & 60,1 & 50 & 40 \\
\hline 382 & BrPe3233 & $\begin{array}{l}\text { Maracuja_ } \\
\text { NoIndex_L } \\
\text { 003_R1_00 } \\
\text { 1_contig_4 } \\
6975\end{array}$ & 3 & 160 & 171 & 12 & 4 & 9 & $\begin{array}{l}\text { AGAAAAAAAGAAAAAAATCTTAAATCTTTCTTAAATTAAAAAAAAA } \\
\text { AGAAGTTGTTTCGCATAAGATTAATGAGAAGAATCTAAAATATAAA } \\
\text { ATAGCATAAAACAACTTAAGCATTGGATAGGCACTGGTAAGTACAA } \\
\text { GGCAGGTCATTGGAAGAAGAAGAACGGAAGAAAAACCCAAAGCAA } \\
\text { AAGCGGAAACGCAATAATGGATTTTGGATTGACGATTGCGGAAGTG } \\
\text { ATGGTGGCTCTGATCCTGTTGGTGCCTTCACTGTTGCTATTTGCAATC } \\
\text { CTCTTCCAATCCTACGATAGAAGACACCACAACAC }\end{array}$ & GAA & G & 13,36 & 152 & $\begin{array}{l}\text { AAGCATTGGATAGGC } \\
\text { ACTGG }\end{array}$ & 60,1 & $\begin{array}{l}\text { AGTGAAGGCACCAA } \\
\text { CAGGAT }\end{array}$ & 59,6 & 50 & 50 \\
\hline 383 & BrPe3234 & $\begin{array}{l}\text { Maracuja_ } \\
\text { NoIndex_L } \\
\text { 003_R1_00 } \\
\text { 1_contig_4 } \\
7119\end{array}$ & 3 & 5076 & 5087 & 12 & 4 & 9 & $\begin{array}{l}\text { СTTCCTTTTCAACAACGACAGGATCCTACAGCACACGTAGTTCGATT } \\
\text { GAAGAAACTCAAGCAATCAATGAAAAAAAAAGGGTACAAGCAAAT } \\
\text { AACAGATGATAAAAATTAACCGTACCGTTGGCTTGGTTCTTGCAGA } \\
\text { AAGGCAGTAGCAGAAGAAGAAGACGAAGAAGAGGCGCGAACTCTG } \\
\text { GCTCCCGCCAAACTGCGTTGGAAAGCAATGGGGGGTTCGAGAA } \\
\text { AAGAGAGTCTGGAGTTGGAAAGTTGTTTAGGAAGAAATAGGCACGA } \\
\text { GAGATTGATGACCGCTGCGGTGGTGGCCATGGTTCT }\end{array}$ & AGA & G & 15,12 & 178 & $\begin{array}{l}\text { TACCGTTGGCTTGGTT } \\
\text { TCTT }\end{array}$ & 59,6 & $\begin{array}{l}\text { AGCGGTCATCAATC } \\
\text { TCTCGT }\end{array}$ & 59,8 & 45 & 50 \\
\hline 384 & BrPe3235 & $\begin{array}{l}\text { Maracuja_ } \\
\text { NoIndex_L } \\
\text { 003_R1_00 } \\
\text { 1_contig_4 } \\
7435\end{array}$ & 3 & 1815 & 1826 & 12 & 4 & 9 & $\begin{array}{l}\text { CCATCAGACCATAAAAAATGGGAAAAGCTACAAACAGAGTTTCAAA } \\
\text { AAGGTAAACACTCAGAGAAAATAGACAGCAACAAACTGTGGAGCA } \\
\text { AATATCTAATAAGGGTCAGAATAGTTACTGCAGAGCACATACCCAA } \\
\text { TCAAGCAACATGACATCATCATCATTGGCAAGCCGAGCAAGGTCAA } \\
\text { AGGCCCTCTGTCCAGTAATTAGCTCCAGAAGCATGATCCCATAACC } \\
\text { AAAAACATCGGTCTTCTCAGATGATTTGCCTGTAGAGAGATATTCAG } \\
\text { GGGCAATGTGGCCTATTGTACCACGGACAGCAGTAG }\end{array}$ & CAT & G & 16,03 & 152 & $\begin{array}{l}\text { GCAACAAACTGTGGA } \\
\text { GCAAA }\end{array}$ & 59,9 & $\begin{array}{l}\text { ATGGGATCATGCTT } \\
\text { CTGGAG }\end{array}$ & 60 & 45 & 50 \\
\hline 385 & BrPe3236 & $\begin{array}{l}\text { Maracuja_ } \\
\text { NoIndex_L } \\
\text { 003_R1_00 } \\
\text { 1_contig_4 } \\
7795\end{array}$ & 3 & 2907 & 2918 & 12 & 4 & 9 & $\begin{array}{l}\text { AGCACGCATCCTGAAAATGATGACAAATCAAACCAGTGATGGATAC } \\
\text { CATTAGACTCTCAAAAGGGGAACCATGAATAAAAAAATAAATGGAG } \\
\text { TATAAAGCAAAATATACCAAAGTGCACGGAAGTCCGCAGACAAGG } \\
\text { AACCTCATTATCACATCATCATCATATATTTTATGGCAGGAAGTGC } \\
\text { TCCAGATGACCCTTCTTCATCCTGATCATCAGCCTCAGGCATGGTAA } \\
\text { TATCAATCTTTGGAGGGTCACCAAGTAACCGTGGTCCAGGTTTACCA } \\
\text { CCAGGTTTCAGGCCAGTAGAAGCTACAGCGTTGT }\end{array}$ & CAT & G & 16,41 & 171 & $\begin{array}{l}\text { GAAGTCCGCAGACAA } \\
\text { GGAAC }\end{array}$ & 59,9 & $\begin{array}{l}\text { GCCTGAAACCTGGT } \\
\text { GGTAAA }\end{array}$ & 60 & 55 & 50 \\
\hline
\end{tabular}

G: genoma funcional

S: genoma estructural

P: polimórfico

M: monomórfico 
APÉNDICE

Marcadores microssatélites desenhados a partir do sequênciamento parcial e da montagem de novo do genoma de $P$. edulis

\begin{tabular}{|c|c|c|c|c|c|c|c|c|c|c|c|c|c|c|c|c|c|c|c|}
\hline $\mathbf{N}^{\circ}$ & Primer & Contig I & Motivo & Início & Fim & pb & $\begin{array}{c}\mathbf{N}^{\circ} \\
\text { Repet }\end{array}$ & Score & Sequência do contig & Unidade & G/S & Cobertura & $\mathrm{pb}$ & Sequência Forward & $\begin{array}{l}\mathrm{T}^{\circ} \mathrm{C} \\
F w d \\
\end{array}$ & Sequência Reverse & $\begin{array}{l}\mathrm{T}^{\circ} \mathrm{C} \\
\operatorname{Rev} \\
\end{array}$ & $\begin{array}{c}\% \mathrm{GC} \\
F w d \\
\end{array}$ & $\begin{array}{cc}\% \mathrm{GC} & \mathrm{P} / \mathrm{M} \\
\operatorname{Rev} & \end{array}$ \\
\hline 386 & BrPe3237 & $\begin{array}{l}\text { Maracuja_ } \\
\text { NoIndex_L } \\
\text { 003_R1_00 } \\
\text { 1_contig_4 } \\
7960\end{array}$ & 3 & 186 & 197 & 12 & 4 & 9 & $\begin{array}{l}\text { CTTCAGCATGCCAGCTTAGAAAAACAAAAAGAAAGAGAAGAAAATA } \\
\text { CCAGAAAGTACCCACATACTTGTGGCTGGTCTTAATTAATTAAGACT } \\
\text { TAGATAGTAGATAGCAAGACATCGTTGTCACTTGGCAAAAACAGAC } \\
\text { CAACTTGTTCAAATGATGATGATGTTTCGTAAAATCAAAGGCCAGTG } \\
\text { AGGAATACTAGTAGGAGCTTCTATCATACTTGCTGGGGCATTCATAT } \\
\text { TTTGCGTAATAAATATAGCCGTAATCCCAACATTTACACTGCGTCGC } \\
\text { AGTTTTACTGTATGTATATTAACCATGAAGTGC }\end{array}$ & ATG & $\mathrm{s}$ & 15,73 & 158 & $\begin{array}{l}\text { CACTTGGCAAAAACA } \\
\text { GACCA }\end{array}$ & 59,7 & $\begin{array}{l}\text { CGACGCAGTGTAAA } \\
\text { TGTTGG }\end{array}$ & 60,2 & 45 & 50 \\
\hline 387 & BrPe3238 & $\begin{array}{l}\text { Maracuja_ } \\
\text { NoIndex_L } \\
\text { 003_R1_00 } \\
\text { 1_contig_4 } \\
8027\end{array}$ & 3 & 165 & 179 & 15 & 5 & 12 & $\begin{array}{l}\text { AGATGGAATTGAATGGGGCACCGCCTTTTGGGTATCGACAGAGAAC } \\
\text { AAGAAAGCGCAACAGAATGACAGTACAAGACTTGTCTTGCAGCTGA } \\
\text { AGGAGAAGAATAAATAGAGGCAGCAAGACTCAATCACTGGACATCT } \\
\text { TGGATTGCCAAAGAGGAGGAGGAGGAGAAAAGCAAAGGCAACAAG } \\
\text { GGACAAAATAGAAAGCAAAAGTACAAAAAGAAAAGAGGAATTGT }\end{array}$ & GAG & G & 9,55 & 169 & $\begin{array}{l}\text { GCCTTTTGGGTATCG } \\
\text { ACAGA }\end{array}$ & 60,1 & $\begin{array}{l}\text { TTTTGTCCCTTGTTG } \\
\text { CCTTT }\end{array}$ & 59,6 & 50 & 40 \\
\hline 388 & BrPe3239 & $\begin{array}{l}\text { Maracuja_ } \\
\text { NoIndex_L } \\
\text { 003_R1_00 } \\
\text { 1_contig_4 } \\
8814\end{array}$ & 3 & 1473 & 1484 & 12 & 4 & 9 & $\begin{array}{l}\text { TATGGTGATTGGCTTGATGACCTGCCAATAGCGCATAACTTGACAAA } \\
\text { CCAAGTGGAGAACTTGGTCTGAATGCGGGATGAGAATTTTGTTCGT } \\
\text { TTGTGCTTTCTTGAGTTCAGAATTTAGAAGATTTTTGGGTGTTCAAA } \\
\text { AGGCATACATGATGATGATGGCACAGGAAATTTTCTTTTTGTTTATA } \\
\text { GGCTTTTGAAGTTTATTTCCTTTTCCTTATGGCCCTTATCACAGAAGA } \\
\text { AGTGGAGATACATGCTGCTATGATAACAATTCTCTCCGTTGGCAAAA } \\
\text { GAAATAAAGCTTCATTTATTTCACAGAA }\end{array}$ & ATG & $\mathrm{s}$ & 16,01 & 196 & $\begin{array}{l}\text { GGTGATTGGCTTGAT } \\
\text { GACCT }\end{array}$ & 59,9 & $\begin{array}{l}\text { TTCAAAAGCCTATA } \\
\text { AACAAAAAAGAAAA }\end{array}$ & 60 & 50 & 22,2 \\
\hline 389 & BrPe3240 & $\begin{array}{l}\text { Maracuja_ } \\
\text { NoIndex_L } \\
\text { 003_R1_00 } \\
\text { 1_contig_4 } \\
9041\end{array}$ & 3 & 1523 & 1534 & 12 & 4 & 9 & $\begin{array}{l}\text { CCATGGATCCTGCCCATTTAAAATTCAAATGTCTACTTGATTGCAAT } \\
\text { ACTTGGTTGCAATTATGAAAAAGTTTTTATCTTAGATCGTGTCAGGA } \\
\text { AAATATACAAGTTGTTTCCTCGGGTTCCTCTTCCACACCACTTGGGA } \\
\text { GATGTAGGAGATGATGATGATATTCAAGAACTTAATGAAGCTCTTG } \\
\text { GGGCTGCAAAAACACGTGTAGAATGCTGCTCATCATTCTTAAAAGC } \\
\text { TGCTATTAGGTGAGACATGTCTTCTGTGTTTGCAAATTATCCTTTAGT } \\
\text { TTTGCCTGCATGAGTTGTTATCCTGTGTTCT }\end{array}$ & GAT & G & 18,45 & 197 & $\begin{array}{l}\text { AGTTGTTTCCTCGGGT } \\
\text { TCCT }\end{array}$ & 60,0 & $\begin{array}{l}\text { AACAACTCATGCAG } \\
\text { GCAAAA }\end{array}$ & 59,3 & 50 & 40 \\
\hline 390 & BrPe3241 & $\begin{array}{l}\text { Maracuja_ } \\
\text { NoIndex_L } \\
\text { 003_R1_00 } \\
\text { 1_contig_4 } \\
9622\end{array}$ & 3 & 460 & 480 & 21 & 7 & 18 & $\begin{array}{l}\text { CACAAAAACTGTGACTCCATCTACTCCCTCGGAAACAAGAAAGTCT } \\
\text { GTTGTGTTGTCATCAGCGAGTAAGAGTTCAAGGACATCAGCTGCATC } \\
\text { TGATGTAAGCAAGCCGGAAAGTCTTAAAAAGTCCTCAGTTAAGCCA } \\
\text { ACATCGTCTGTTTCTTCTTCTTCTTCTTCTTCAAAAAGGATTAGTTCT } \\
\text { ACTTCATTGGACAGTACTGGAATTAGTGTGGGTAGAAAGATTGTCCC } \\
\text { GAAAGTTTCTTCACCATCCACTCAGTCACCTTCAGTTTCTAGCCGGC } \\
\text { TGAGAACTGGGTCTTTGGTCACTTCTCTTGACAGGAGTTC }\end{array}$ & TTC & G & 18,3 & 186 & $\begin{array}{l}\text { GATGTAAGCAAGCCG } \\
\text { GAAAG }\end{array}$ & 59,8 & $\begin{array}{l}\text { CCGGCTAGAAACTG } \\
\text { AAGGTG }\end{array}$ & 59,9 & 50 & 55 \\
\hline
\end{tabular}

G: genoma funcional

S: genoma estructural

P: polimórfico

M: monomórfico 
APÉNDICE

Marcadores microssatélites desenhados a partir do sequênciamento parcial e da montagem de novo do genoma de $P$. edulis

\begin{tabular}{|c|c|c|c|c|c|c|c|c|c|c|c|c|c|c|c|c|c|c|c|}
\hline $\mathbf{N}^{\mathrm{o}}$ & Primer & Contig & Motivo & Início & Fim & pb & $\begin{array}{c}\mathbf{N}^{\mathbf{o}} \\
\text { Repet }\end{array}$ & Score & Sequência do contig & Unidade & G/S & Cobertura & pb & Sequência Forward & $\begin{array}{l}\mathrm{T}^{\circ} \mathrm{C} \\
F w d\end{array}$ & Sequência Reverse & $\begin{array}{r}\mathrm{T}^{\circ} \mathrm{C} \\
\operatorname{Rev}\end{array}$ & $\begin{array}{r}\% \mathrm{GC} \\
F w d\end{array}$ & $\begin{array}{c}\% \mathrm{GC} \\
\operatorname{Rev}\end{array}$ \\
\hline 391 & $\begin{array}{l}\text { BrPe3242 } \\
\end{array}$ & $\begin{array}{l}\text { Maracuja_ } \\
\text { NoIndex_L } \\
\text { 003_R1_00 } \\
\text { 1_contig_4 } \\
9639\end{array}$ & 3 & 2363 & 2374 & 12 & 4 & 9 & $\begin{array}{l}\text { CGGGTTGAACGCCATTGAGTATCAAGGTAATAGCTAGAAAGGGGCT } \\
\text { GAGTTCAGCGACGGCTTGGGAGACCACTTCCCCTTCCGTGAATGCAT } \\
\text { AGCTAAGCACATTTCGCAGTGCGACCACAACGAAGGCTGCGATCAC } \\
\text { CGCAATAATGAAAGAAGAAGAAGTGACCACAACCACCGAAAAGGC } \\
\text { CGCTGATTTGGATGTGCTGCTCCAAGTTCATTGCTCACTCT }\end{array}$ & AAG & $\bar{G}$ & 15,85 & 214 & $\begin{array}{l}\text { GGGTTGAACGCCATT } \\
\text { GAGTA }\end{array}$ & 60,9 & $\begin{array}{l}\text { TGAACTTGGAGCAG } \\
\text { CACATC }\end{array}$ & 60 & 50 & 50 \\
\hline 392 & BrPe3243 & $\begin{array}{l}\text { Maracuja_ } \\
\text { NoIndex_L } \\
\text { 003_R1_00 } \\
\text { 1_contig_4 } \\
9768\end{array}$ & 3 & 1924 & 1935 & 12 & 4 & 9 & $\begin{array}{l}\text { TCCCTGAAAAATAAAACGCATCGGACAGTTTTCTGGGATTGTTCAAA } \\
\text { CCATTCAAAAACGGTCAACATAAAGAGATACCCAACCCGGAAAGGA } \\
\text { AAAAGACCTTACCTTTGCGGGTTATAGGTTGTTTTCCATGGCGATTG } \\
\text { GGAGGGATTGTCTTCTTCTTCTGCTGACCCTTGAAAAGGGCGTTCTT } \\
\text { CTGAGTCATCTCCGAGCGAATGTTTAGGGTTTTTCTAGTTTAGCCCTT } \\
\text { ACTGGTAGTATAAGGAGAAAGGTAGAGCCTTGGAGTTTATGGGATA } \\
\text { AAATAAAATATTTGACAATATCTTTCCCGAA }\end{array}$ & ТСт & G & 14,74 & 197 & $\begin{array}{l}\text { AAACGCATCGGACAG } \\
\text { TTTTC }\end{array}$ & 60,1 & $\begin{array}{l}\text { ACATTCGCTCGGAG } \\
\text { ATGACT }\end{array}$ & 59,8 & 45 & 50 \\
\hline 393 & BrPe3244 & $\begin{array}{l}\text { Maracuja_ } \\
\text { NoIndex_L } \\
003 \_ \text {R1_00 } \\
\text { 1_contig_5 } \\
0368\end{array}$ & 3 & 4782 & 4793 & 12 & 4 & 9 & $\begin{array}{l}\text { ATCTAAAAAGACACACCAGCCTTTTCTAATTGTTAAATTCTCGAATGG } \\
\text { AGTTCAGGACTGACATCATCCCTGCAATTACTCCCGAAATATTAGAA } \\
\text { AGAATCTTGAAGCGTGATCCTCGCATCTTTTCTTGGTAAGAATCCTT } \\
\text { CTGATTAGTTCCTCCTCCTCCGTTTTCCTTCCTGCGCGGCGCATGCAA } \\
\text { CCACTGACCATATTTCGATCCCATAGTTTTGTTGCTTTCATTTACTAT } \\
\text { ACTCATCGTCGATGAAGGTGATGATCTCCTCATCGCGTCATTAGTCC } \\
\text { GTTTTGATTGTATTGTCAGGTGTAGATT }\end{array}$ & TCC & G & 14,33 & 173 & $\begin{array}{l}\text { TCCTCGCATCTTTTCT } \\
\text { TGGT }\end{array}$ & 59,8 & $\begin{array}{l}\text { GGACTAATGACGCG } \\
\text { ATGAGG }\end{array}$ & 60,6 & 45 & 55 \\
\hline 394 & BrPe3245 & $\begin{array}{l}\text { Maracuja_ } \\
\text { NoIndex_L } \\
003 \_ \text {R1_00 } \\
\text { 1_contig_5 } \\
0403\end{array}$ & 3 & 167 & 178 & 12 & 4 & 9 & $\begin{array}{l}\text { GGGTCTGGTTGTCCATCAATGCGGGAGAGAAACCCTATCTTAATCCG } \\
\text { ACCCACCCCACAGAACATGGTTCCTCTCCGACATGACCCTCGACAA } \\
\text { CAGGTTTCGTTGTTGGAGATGAGTGGTAACGCCGCCTTACGGAAGC } \\
\text { AGTACTACCGCATGATGATGATGGATGAGTCTTTCATCACTGACCCC } \\
\text { ACCATGCCATTTCTTCAAATGCTGGACAAGCCCTTATCGCATGGAAC } \\
\text { TGGACTCAGGAAGAGATCTAGATCTGATGCCGACATTCTAGATTTG } \\
\text { ACGTTGAAGCTGTAGAAGTTAATAGTCTGTTGG }\end{array}$ & ATG & G & 11,79 & 171 & $\begin{array}{l}\text { ATGCGGGAGAGAAAC } \\
\text { CCTAT }\end{array}$ & 59,9 & $\begin{array}{l}\text { GGTGGGGTCAGTGA } \\
\text { TGAAAG }\end{array}$ & 60,4 & 50 & 55 \\
\hline 395 & BrPe3246 & $\begin{array}{l}\text { Maracuja_ } \\
\text { NoIndex_L } \\
\text { 003_R1_00 } \\
\text { 1_conti__5 } \\
0754\end{array}$ & 3 & 1681 & 1695 & 15 & 5 & 12 & $\begin{array}{l}\text { TATATAAATCTCACTAAATTCTGAGTGTGCATGGTTAGAATTACGTA } \\
\text { TATACAAGCTAACTTGAGGAAATTGTGTGCTTAAATCAGGTAAGAG } \\
\text { TTGCAGGTTAAGATGGTACAATCAGCTGGATCCAAGAATCAATCGA } \\
\text { AGCCCATTCACAGAAGAAGAAGAAGAGCGGCTGCTTGCTTCTCACA } \\
\text { AGATCCATGGGAATCGATGGTCTATTATCGCAAGACTTTTTCCTGGT } \\
\text { CGCACCGATAATGCTATCAAGAACCATTGGCATGTTATCATGGCAA } \\
\text { GAAGACACAGGGAAAAGATCCAGGCTTAATGCAAAAAG }\end{array}$ & AGA & G & 17,25 & 174 & $\begin{array}{l}\text { ATCAATCGAAGCCCA } \\
\text { TTCAC }\end{array}$ & 59,9 & $\begin{array}{l}\text { AAGCCTGGATCTTT } \\
\text { СССTGT }\end{array}$ & 60,1 & 45 & 50 \\
\hline
\end{tabular}


APÉNDICE

Marcadores microssatélites desenhados a partir do sequênciamento parcial e da montagem de novo do genoma de $P$. edulis

\begin{tabular}{|c|c|c|c|c|c|c|c|c|c|c|c|c|c|c|c|c|c|c|c|}
\hline $\mathbf{N}^{\circ}$ & Primer & Contig I & Motivo & Início & Fim & pb & $\begin{array}{c}\mathbf{N}^{\mathbf{o}} \\
\text { Repet }\end{array}$ & Score & Sequência do contig & Unidade & G/S & Cobertura & pb & Sequência Forward & $\begin{array}{l}\mathrm{T}^{\circ} \mathrm{C} \\
F w d \\
\end{array}$ & Sequência Reverse & $\begin{array}{l}\mathrm{T}^{\circ} \mathrm{C} \\
\operatorname{Rev} \\
\end{array}$ & $\begin{array}{r}\% \mathrm{GC} \\
F w d \\
\end{array}$ & $\begin{array}{cc}\begin{array}{c}\% \mathrm{GC} \\
\text { Rev }\end{array} & \mathbf{P} / \mathbf{M} \\
\end{array}$ \\
\hline 396 & BrPe3247 & $\begin{array}{l}\text { Maracuja_ } \\
\text { NoIndex_L } \\
003 \text { _R1_00 } \\
\text { 1_contig_5 } \\
1267\end{array}$ & 3 & 2479 & 2490 & 12 & 4 & 9 & $\begin{array}{l}\text { CATGAACCAGTTGCTTTACATAGAATCATGCATTCGGAAGATCCAG } \\
\text { AATCAAAAGCCCAAGAAAGAAAATGTTGTGCTCGGTGATCAGATTG } \\
\text { TTCATGAAACAGACTTAGAAACAGATGTCGAACTAAAGGTAGCTTG } \\
\text { ATTTTGGTACTGATCATCATCATCTTGCATAACAATTGTTAGCTTATC } \\
\text { TTACAGAAGGTTTATCCATCAATCACTGCAGGGAAACAACATCAAC } \\
\text { ACCGAGCTTGGCATCACTGCCTCTGAAGATGCAGTTCTTGACACACT } \\
\text { ATCTGAAAGAGCTGAAAAAGAAATAGTTTCTGA }\end{array}$ & ATC & $\mathrm{s}$ & 18,44 & 168 & $\begin{array}{l}\text { TGCTCGGTGATCAGA } \\
\text { TTGTT }\end{array}$ & 59,2 & $\begin{array}{l}\text { CAAGCTCGGTGTTG } \\
\text { ATGTTG }\end{array}$ & 60,3 & 45 & 50 \\
\hline 397 & BrPe3248 & $\begin{array}{l}\text { Maracuja_ } \\
\text { NoIndex_L } \\
003 \text { R1_00 } \\
\text { 1_contig_5 } \\
\text { 1977 }\end{array}$ & 3 & 1414 & 1425 & 12 & 4 & 9 & $\begin{array}{l}\text { GGCAGCCTCAAGCACGGCCGGAGCTACTTGAGGTTTCTCTTTCTGAT } \\
\text { CAAGAGGTTCCATCAGAGAGAATTCAAGCAAAGCAGATACTGCTGC } \\
\text { AGTAGTTGCCGAAGTTGTCATTATCGTATCTGTCGTAGTAGTTGATG } \\
\text { GTGTTGCAGCTGTTGTTGTTGTGGACGAGCAAGGATCTCGGCTCATC } \\
\text { CTATCAGAACTCTCCGAACCATTTGAATGGTTAGACATGTTATCATA } \\
\text { ACTCTGCTTTCTTCGTTTATATTGGAGTAAAGGGAAAGGTGCGTCGG } \\
\text { TGCTAAGCATACACACCCGAGGACTGTCCTC }\end{array}$ & TGT & G & 16,1 & 215 & $\begin{array}{l}\text { TGCAGTAGTTGCCGA } \\
\text { AGTTG }\end{array}$ & 60,0 & $\begin{array}{l}\text { GTCCTCGGGTGTGT } \\
\text { ATGCTT }\end{array}$ & 60 & 50 & 55 \\
\hline 398 & BrPe3249 & $\begin{array}{l}\text { Maracuja_ } \\
\text { NoIndex_L } \\
003 \text { 1_1_00 } \\
\text { 1_contig_5 } \\
\text { 2332 }\end{array}$ & 3 & 4125 & 4136 & 12 & 4 & 9 & $\begin{array}{l}\text { TGAATTGATCTACAATTTTTACATCTCTGACGTTGTTGTTTCATATCT } \\
\text { TACAGTTTCCTCTACTCTACCAAGAAGGGGTTCAAAACGTTCTGTTC } \\
\text { AGCTGGTACCGAATATTCGGATGGGCATTCAACGGCATAGTAAGTG } \\
\text { CCACACTGATCTTCTTCTTCTGCATCCGCGCAATGGAGTATCAAGCT } \\
\text { TTCCGTAAAGGCGGAGAAGTTGTCGGCCTGGAGATCCTGGGAACGA } \\
\text { CCATGTACTCATGCGTTGTGTGGGTTGTGAACTGTCAGATGGCACTG } \\
\text { TCAATTAGTTACTTCACCTACATACAGCATA }\end{array}$ & тСт & G & 15,89 & 161 & $\begin{array}{l}\text { AATATTCGGATGGGC } \\
\text { ATTCA }\end{array}$ & 60,1 & $\begin{array}{l}\text { AGTTCACAACCCAC } \\
\text { ACAACG }\end{array}$ & 59,5 & 40 & 50 \\
\hline 399 & BrPe3250 & $\begin{array}{l}\text { Maracuja_ } \\
\text { NoIndex_L } \\
\text { 003_R1_00 } \\
\text { 1_contig_5 } \\
\text { 2391 }\end{array}$ & 3 & 1215 & 1226 & 12 & 4 & 9 & $\begin{array}{l}\text { GATAAACTTAATCCGAGGCCTTTATGAGTATGGGCCTACTAACACCT } \\
\text { TGATGACGTTTGAGGCTCACAATCTTTTTGCGCGCCTGGGTTGTCCA } \\
\text { CACTTTGCGTCACTAGAGCAACCAAACGGTTCTAAACAACCGGGAA } \\
\text { AAAGAAGAACAAGAAGAAGAAGCCAGGCGTAAATACGAGCAGAAC } \\
\text { GAGAGTTTATCATCTTTTGTTATTTGATAGACTGGTAGCGAGAGGTT } \\
\text { TAGAGCTTTGATCGAAGATTGTTAGTTAGTTCCTTTCTGTTATGGAA } \\
\text { ATAAGGCTTGATTATTTTCTGTGTATGGGGTGG }\end{array}$ & AAG & $\mathrm{s}$ & 15,81 & 150 & $\begin{array}{l}\text { TGTCCACACTTTGCGT } \\
\text { САCT }\end{array}$ & 60,4 & $\begin{array}{l}\text { GCTCTAAACCTCTC } \\
\text { GCTACCA }\end{array}$ & 58,8 & 50 & 52,4 \\
\hline 400 & BrPe3251 & $\begin{array}{l}\text { Maracuja_ } \\
\text { NoIndex_L } \\
\text { 003_R1_00 } \\
\text { 1_contig_5 } \\
\text { 2888 }\end{array}$ & 3 & 713 & 724 & 12 & 4 & 9 & $\begin{array}{l}\text { TGGGTCATCGGATGGATGTTGTGAGCTAGAAAAATATGCCAAAACC } \\
\text { ATGCCTCTCGAGAAAAGTTGGTCATGGTCACTGTACCATTATTTTC } \\
\text { CGATGCTCCATACCGACTTCAACGGTCAGCACATTACACACCTATTC } \\
\text { ATCTGTCAATTCATCATCATCAGCCCCATCCAGTAGTTCATAAAAAG } \\
\text { CATTAATTACTTACGGACTGTAATTCACACGCTGTTGCCGCACCATA } \\
\text { CATACATACGAGCTTCGGGTAAGTTGGCATAAAACTCATAAATCAA } \\
\text { A }\end{array}$ & TCA & $\mathrm{s}$ & 17,12 & 150 & $\begin{array}{l}\text { CTGTACCATTATTTTT } \\
\text { CCGATGC }\end{array}$ & 59,8 & $\begin{array}{l}\text { GGCAACAGCGTGTG } \\
\text { AATTA }\end{array}$ & 58,3 & 39,1 & 47,4 \\
\hline
\end{tabular}

G: genoma funcional

S: genoma estructural

P: polimórfico

M: monomórfico 
APÉNDICE

Marcadores microssatélites desenhados a partir do sequênciamento parcial e da montagem de novo do genoma de $P$. edulis

\begin{tabular}{|c|c|c|c|c|c|c|c|c|c|c|c|c|c|c|c|c|c|c|c|c|}
\hline $\mathbf{N}^{\circ}$ & Primer & Contig & Motivo & Início & Fim & pb & $\begin{array}{c}\mathbf{N}^{\mathbf{o}} \\
\text { Repet }\end{array}$ & Score & Sequência do contig & Unidade & G/S & Cobertura & pb & Sequência Forward & $\begin{array}{l}\mathrm{T}^{\circ} \mathrm{C} \\
F w d\end{array}$ & Sequência Reverse & $\begin{array}{r}\mathrm{T}^{\circ} \mathrm{C} \\
\operatorname{Rev}\end{array}$ & $\begin{array}{r}\% \mathrm{GC} \\
F w d\end{array}$ & $\begin{array}{c}\% \mathrm{GC} \\
\operatorname{Rev}\end{array}$ & $\mathbf{P} / \mathbf{M}$ \\
\hline 401 & BrPe3252 & $\begin{array}{l}\text { Maracuja_ } \\
\text { NoIndex_L } \\
003 \text { R1_00 } \\
\text { 1_contig_5 } \\
3025\end{array}$ & 3 & 786 & 800 & 15 & 5 & 12 & $\begin{array}{l}\text { GTCGATCGGGAGGTGTTCTTGTGTTGGGATTTGGTCGGTGGGTTTTT } \\
\text { CGAAATCTTTGGTTTAGTGGGGGTTAAGGTTTTCCGGAAGAGAATA } \\
\text { ATGATGTTGACTTTGACGTTTGGGGTGTGAAGTACTATGGAAGTAGT } \\
\text { GGTTACAATCCAACAACAACAACAAAGACAAGAACTACAACTGAA } \\
\text { AACTTCACGAAGACAAGACCGATAACGCCTGTAGGAACGTCAACAT } \\
\text { GTCGATTTACATTGGTCGCGAAGCTTCAAAGGTTCTCTTCTCTGCTC } \\
\text { CTTATGCTTTCAAATTGTGGAAACTGTTTTAGTTTT }\end{array}$ & CAA & $\bar{G}$ & 15,83 & 210 & $\begin{array}{l}\text { GGGAGGTGTTCTTGT } \\
\text { GTTGG }\end{array}$ & 60,4 & $\begin{array}{l}\text { ACAGGCGTTATCGG } \\
\text { TCTTGT }\end{array}$ & 59,6 & 55 & 50 & \\
\hline 402 & BrPe3253 & $\begin{array}{l}\text { Maracuja_ } \\
\text { NoIndex_L } \\
\text { 003_R1_00 } \\
\text { 1_contig_5 } \\
3495\end{array}$ & 3 & 223 & 234 & 12 & 4 & 9 & $\begin{array}{l}\text { ATAATTCACAATTGCTCCTCGAAGCAATTTCCATGCCTCGTCTTCAA } \\
\text { TCTCCGACAGCTCTCTCTCAACTTTGGGAACGGTCTCATTCAATCCC } \\
\text { TTAAAATAATCTATATGTATTTTAGCTCCATTAATGTCTACAGTATTA } \\
\text { GAGCTTATTTCTTCTTCTTCAACTACGTTATTTCCAGTTTCAACCTTT } \\
\text { TCAAACACTAAGGGCTTCAAATTCAGCCCTCCTTGAATGTAAATCCT } \\
\text { CTCAAAACCCTTGTCATTAGCATTGGAATCTACAGATGTTGAATGAT } \\
\text { TCCTAAAATCAGACGCTACCTTGGGAAT }\end{array}$ & тTC & G & 16,05 & 159 & $\begin{array}{l}\text { CTTTGGGAACGGTCT } \\
\text { CATTC }\end{array}$ & 59,5 & $\begin{array}{l}\text { TTCAAGGAGGGCTG } \\
\text { AATTTG }\end{array}$ & 60,2 & 50 & 45 & \\
\hline 403 & BrPe3254 & $\begin{array}{l}\text { Maracuja_ } \\
\text { NoIndex_L } \\
003 \text { R1_00 } \\
\text { 1_contig_5 } \\
3737\end{array}$ & 3 & 243 & 254 & 12 & 4 & 9 & $\begin{array}{l}\text { TGACACTGTACTAAGCACTTTACAGAGTCGTTTTGATTAACAGGGAC } \\
\text { TTTACTATATTTACTATATTATTACGCTGATAACTTCTGAGAAATTTC } \\
\text { TGCGCTTCGCCCACATTCAGACACCTGAACGGCCACCTGATCTTGCC } \\
\text { ATGAAACTTTCTTCTTCTTCGAGCAATCTTTCCTCCAGCAATTCCTTA } \\
\text { TTGGTTTCTTCTCCACTCTCACCTGCTCCAAAACAGGGTTGCCTGGC } \\
\text { GTAGGTGAATTCTCATTCTGTCGAGGCACGATCACCGGCGCCAAAA } \\
\text { CAAGGTTGTCTGGGGTAGGTGAACTCTTA }\end{array}$ & TTC & G & 13,37 & 163 & $\begin{array}{l}\text { GCCCACATTCAGACA } \\
\text { CCTG }\end{array}$ & 60,1 & $\begin{array}{l}\text { GTGCCTCGACAGAA } \\
\text { TGAGAA }\end{array}$ & 59 & 57,9 & 50 & \\
\hline 404 & BrPe3255 & $\begin{array}{l}\text { Maracuja_ } \\
\text { NoIndex_L } \\
\text { 003_R1_00 } \\
\text { 1_contig_5 } \\
\text { 3899 }\end{array}$ & 3 & 371 & 382 & 12 & 4 & 9 & $\begin{array}{l}\text { CTCTGCTACTTCAGATTCAGTGGAGCAGTTGGGTTCTTGTAGGACAT } \\
\text { GATCAACAAGGATACCTTTATCCTTCAACTTCTCTAAGTAGTTGCTA } \\
\text { ATGTCAAAATTGGTCACAGCATTTGGTCCTCTGTACTCTATTGCTGC } \\
\text { CATATCATATGCTGCTGCTGCCTCCTCTTGTGTGTCTTTTAAGGATTA } \\
\text { AACAAACAAGACATAATAAAGTAAGAATCTGATAAAAAGCTGAAG } \\
\text { ATCTCATTAAGAAAGGCAAAGCTTTACAGTACAGAATAAACTAAAG } \\
\text { CCATCAGAATTAAACAATTAAGGGCAGAGTAG }\end{array}$ & TGC & G & 12,63 & 169 & $\begin{array}{l}\text { CAGTGGAGCAGTTGG } \\
\text { GTTCT }\end{array}$ & 60,3 & $\begin{array}{l}\text { TCCTTAAAAGACAC } \\
\text { ACAAGAGGA }\end{array}$ & 58 & 55 & 39,1 & \\
\hline 405 & BrPe3256 & $\begin{array}{l}\text { Maracuja_ } \\
\text { NoIndex_L } \\
\text { 003_R1_00 } \\
\text { 1_contig_5 } \\
3934\end{array}$ & 3 & 692 & 703 & 12 & 4 & 9 & $\begin{array}{l}\text { GATGATGAAGAAGACAATGTGGTTGAAGCAATGGCATCAGTGCATA } \\
\text { AGGGCAGAAGGAACAGACGTTGGAGGCATTGGAGTGAAGATTTTCC } \\
\text { AACAGAAGTTCAGAACGAGGAGAACGAGGAGGTTATGGAATGTGA } \\
\text { TAAACCAAAGACTAGGAGGAGGAGGGCCAGGAAAGAGAGGGCTAA } \\
\text { GAACAGTGTTGAAGAAGTTGAAAAGGATGATTTTGATGGAAATAAA } \\
\text { AGCTTCAATGAGGAAACTAATGGACTATGCGATCAGAAAATGGAAG } \\
\text { CGTCCTCATCTTCTTTTACAGAACACGGGCATGATGGT }\end{array}$ & AGG & G & 15,45 & 181 & $\begin{array}{l}\text { TGGAATGTGATAAAC } \\
\text { CAAAGACT }\end{array}$ & 57,7 & $\begin{array}{l}\text { TCATGCCCGTGTTCT } \\
\text { GTAAA }\end{array}$ & 60,1 & 34,8 & 45 & \\
\hline
\end{tabular}

G: genoma funcional

S: genoma estructural

P: polimórfico

M: monomórfico 
APÉNDICE

Marcadores microssatélites desenhados a partir do sequênciamento parcial e da montagem de novo do genoma de $P$. edulis

\begin{tabular}{|c|c|c|c|c|c|c|c|c|c|c|c|c|c|c|c|c|c|c|c|}
\hline $\mathbf{N}^{\circ}$ & Primer & Contig I & Motivo & Início & Fim & pb & $\begin{array}{c}\mathbf{N}^{\mathbf{o}} \\
\text { Repet }\end{array}$ & Score & Sequência do contig & Unidade & G/S & Cobertura & pb & Sequência Forward & $\begin{array}{l}\mathrm{T}^{\circ} \mathrm{C} \\
F w d\end{array}$ & Sequência Reverse & $\begin{array}{r}\mathrm{T}^{\circ} \mathrm{C} \\
\operatorname{Rev}\end{array}$ & $\begin{array}{c}\% \mathrm{GC} \\
F w d\end{array}$ & $\begin{array}{c}\% \mathrm{GC} \\
\operatorname{Rev}\end{array}$ \\
\hline 406 & BrPe3257 & $\begin{array}{l}\text { Maracuja_ } \\
\text { NoIndex_L } \\
003 \text { _R1_00 } \\
\text { 1_contig_5 } \\
4305\end{array}$ & 3 & 447 & 458 & 12 & 4 & 9 & $\begin{array}{l}\text { TTTCATCCGTTTCAAGTAGAAAAACAAAGACTCACCGGTACAGCGA } \\
\text { GTTCGCTGGCAAAGAAAGAATCAGAGAAAGTGCTTGAGTTGGAATT } \\
\text { AAGATCATCGTCCACTTGTTCCTGAGACGACCCAGGGAGAGAGTCT } \\
\text { TTCTCTAGTTCCTCTTCTTCTTCTATATGGTTATCTTGCTCTTGAACA } \\
\text { AGGCTTTCCTTAAGTTCACCATTAGAGAAATCGAAAAAGCAATCAA } \\
\text { CAGAGAAGTCTTCACTCGAAACAACCCCATTAGATGCTGCGGTAAA } \\
\text { ACACCAGATATCCTCGCTGTTATTCTGTTGGGTC }\end{array}$ & $\begin{array}{ll}\text { TCT } \\
\end{array}$ & $\bar{G}$ & 11,43 & 156 & $\begin{array}{l}\text { AGACGACCCAGGGAG } \\
\text { AGAGT }\end{array}$ & 60,3 & $\begin{array}{l}\text { GCAGCATCTAATGG } \\
\text { GGTTGT }\end{array}$ & 60 & 60 & 50 \\
\hline 407 & BrPe3258 & $\begin{array}{l}\text { Maracuja_ } \\
\text { NoIndex_L } \\
003 \text { R1_00 } \\
\text { 1_contig_5 } \\
4943\end{array}$ & 3 & 554 & 568 & 15 & 5 & 12 & $\begin{array}{l}\text { GTTGCTACGTTACTTAGAATCTAGGTGTATGAATAATTTAAATCCAG } \\
\text { ACACATATTTATTAATCATAAATAATTGTTAAAAAATAAAAGTCTTA } \\
\text { CGTTGATTTTCAGCTACAGATTAGACTCGAGAGATGAAGTCAAACA } \\
\text { ATGTGGGTGATGGTGGTGGTGGTGGCATTCTTAGCAAAGAGATAAT } \\
\text { CCCCTTCCTAATCAATCATCTAAAATTTCTAACCCATCTTCCTGATTT } \\
\text { CATCGGATAACAACTAAGACAGGAGCGATTCTTAAAGAAATCGGAA } \\
\text { AATCCAAACATGTACGTGGGATTAATAGCGACACA }\end{array}$ & $\begin{array}{ll}\text { TGG } \\
\text { T } \\
4\end{array}$ & G & 14,48 & 172 & $\begin{array}{l}\text { TCGAGAGATGAAGTC } \\
\text { AAACAATG }\end{array}$ & 59,4 & $\begin{array}{l}\text { CATGTTTGGATTTTC } \\
\text { CGATTT }\end{array}$ & 58,8 & 39,1 & 33,3 \\
\hline 408 & BrPe3259 & $\begin{array}{l}\text { Maracuja_ } \\
\text { NoIndex_L } \\
\text { 003_R1_00 } \\
\text { 1_contig_5 } \\
5191\end{array}$ & 3 & 802 & 813 & 12 & 4 & 9 & $\begin{array}{l}\text { AGACTGAGAGACTGCATCGAAGAGGTAACCAAGTTCACGCTGGAGT } \\
\text { CTCACGTTAATGGAACTCTAGGATTCGATTTACGTCTCTCAAAGGAC } \\
\text { TTCTGCTCCAACCTCATCAAACCCGATCCGGACGACGCCGTTCTGCC } \\
\text { CCTTCCTGAGACCACCACCACCTCCACAACCGGTACATTCCCTTTTA } \\
\text { AGTTTTAACCAATTCAGTGGTATTTTATTTCTGTGTCGGTCCTTCATG } \\
\text { TTTTATGAAATACTCCGGCAGATTGTTTTGTCGGAGTTCCGGAGTA } \\
\text { TCCTTTGTACAAGCGTTTATCTTCTGCTAT }\end{array}$ & ACC & G & 12,49 & 250 & $\begin{array}{l}\text { ACCAAGTTCACGCTG } \\
\text { GAGTC }\end{array}$ & 60,3 & $\begin{array}{l}\text { CGGAACTCCGACAA } \\
\text { AACAAT }\end{array}$ & 60 & 55 & 45 \\
\hline 409 & BrPe3260 & $\begin{array}{l}\text { Maracuja_ } \\
\text { NoIndex_L } \\
003 \text { R1_00 } \\
\text { 1_contig_5 } \\
5330\end{array}$ & 3 & 892 & 903 & 12 & 4 & 9 & $\begin{array}{l}\text { CTGTCTCGTTTCGTCTCCTTTCGTACACAAAGACCGATGAGGGACCT } \\
\text { TTCCAAAGTTGCTAAATTGAGGCTAAAGAAAACTACAGCGTCTTCAT } \\
\text { AACATGGTTCGTCTGCATCGCTTGCAGGGTTAGGAGCTTTTAAATAA } \\
\text { TTATAAATATATTATTATTATGCTTTAAATAGTTCAGATAATATTTTT } \\
\text { TACAAACGACTCTATTATACATTTACCATAATAAATAGAATAAAAG } \\
\text { AACTGAGACGTGTGAAAATTAATATAATAAAAGAATTAGAGAAATA } \\
\text { TATAAAGAAGTTGTACTATGAAACATCATGG }\end{array}$ & TAT & $\mathrm{s}$ & 15,81 & 224 & $\begin{array}{l}\text { AAGACCGATGAGGGA } \\
\text { CCTTT }\end{array}$ & 59,9 & $\begin{array}{l}\text { TTTTCACACGTCTCA } \\
\text { GTTCTTTT }\end{array}$ & 58,1 & 50 & 34,8 \\
\hline 410 & BrPe3261 & $\begin{array}{l}\text { Maracuja_ } \\
\text { NoIndex_L } \\
\text { 003_R1_00 } \\
\text { 1_contig_5 } \\
\text { 5361 }\end{array}$ & 3 & 909 & 923 & 15 & 5 & 12 & $\begin{array}{l}\text { TCCACATAAAGATTTCACATCATGAACAACAGAGAAATGATTGGTT } \\
\text { CTGTTTTCTGTCTTCTGTTTCCTTTCTCACCTGCAGTCCAGAATCAGA } \\
\text { GCTTCCGTATTAGGTCTATCACTTTTTTGTCTCGGTAAGACAACAAA } \\
\text { TAGTAGAGAAAGAAGAAGAAGAAGGCAAATCTCTGCAAGTGACAG } \\
\text { GATATGTGCCACTCCTTGACTCCCTCCCTACTCGCTTTTATAAGCTCA } \\
\text { TAAAGAAACGGAGTCGCCAAACCTTTCCAATACGTGACCCGAGTAA } \\
\text { CCCAGTTGAAAAGGGGAAGAAAAAAGCTGTCGAAGA }\end{array}$ & AAG & G & 15,95 & 151 & $\begin{array}{l}\text { TGTCTTCTGTTTCCTT } \\
\text { TCTCACC }\end{array}$ & 59,8 & $\begin{array}{l}\text { TCAAGGAGTGGCAC } \\
\text { ATATCC }\end{array}$ & 58,5 & 43,5 & 50 \\
\hline
\end{tabular}

G: genoma funcional

S: genoma estructural

P: polimórfico

M: monomórfico 
APÉNDICE

Marcadores microssatélites desenhados a partir do sequênciamento parcial e da montagem de novo do genoma de $P$. edulis

\begin{tabular}{|c|c|c|c|c|c|c|c|c|c|c|c|c|c|c|c|c|c|c|c|}
\hline $\mathbf{N}^{\mathbf{o}}$ & Primer & Contig $\mathrm{I}$ & Motivo & Início & Fim & pb & $\begin{array}{c}\mathbf{N}^{\mathbf{o}} \\
\text { Repet }\end{array}$ & Score & Sequência do contig & Unidade & G/S & Cobertura & pb & Sequência Forward & $\begin{array}{l}\mathrm{T}^{\circ} \mathrm{C} \\
F w d\end{array}$ & Sequência Reverse & $\begin{array}{r}\mathrm{T}^{\circ} \mathrm{C} \\
\operatorname{Rev}\end{array}$ & $\begin{array}{c}\% \mathrm{GC} \\
F w d\end{array}$ & $\begin{array}{c}\% \mathrm{GC} \\
\operatorname{Rev}\end{array} \quad \mathrm{P} / \mathbf{M}$ \\
\hline 411 & BrPe3262 & $\begin{array}{l}\text { Maracuja_ } \\
\text { NoIndex_L } \\
\text { 003_R1_00 } \\
\text { 1_contig_5 } \\
5868\end{array}$ & 3 & 3575 & 3586 & 12 & 4 & 9 & $\begin{array}{l}\text { TGTGACTCTCTCAGGCAGGCCGGCTTATGAGATGGAGGAGAGTTTG } \\
\text { CAGCCAGCAAGTGTTTCTTGTGAGTTTACTACTGTGGAAAGCGTGAC } \\
\text { TGATGTCATTGAAATGGAACCTGTTGGGGTGGCAGAGAGAAGGGTG } \\
\text { AGGTTTGCTGTTGATGATGATGAGTCAGAAACACATTCCACTGCTGA } \\
\text { TGTGGATATGCAATTCCAGGAAGAGATGGAGCATCTGTTGGCAGCT } \\
\text { CAACAGGCTGGTACAGCATTCATACTGGGGCATTCGCATGTTCAAA } \\
\text { CTAAACAAGGATCGTCTGTCCTGAAGAGGTTGGC }\end{array}$ & TGA & $\mathrm{G}$ & 18,54 & 167 & $\begin{array}{l}\text { TGGAAAGCGTGACTG } \\
\text { ATGTC }\end{array}$ & 59,8 & $\begin{array}{l}\text { TGTACCAGCCTGTT } \\
\text { GAGCTG }\end{array}$ & 60 & 50 & 55 \\
\hline 412 & BrPe3263 & $\begin{array}{l}\text { Maracuja_ } \\
\text { NoIndex_L } \\
\text { 003_R1_00 } \\
\text { 1_contig_5 } \\
6916\end{array}$ & 3 & 2756 & 2767 & 12 & 4 & 9 & $\begin{array}{l}\text { CCGCAGAGAGAAAGCGCAGACGGGCATGTCGAGTTTCAACAAGGA } \\
\text { AATTGATGATGTGTCAAAAGAGCGCAGTTACGGCGGTGCAAAGAGT } \\
\text { TTGAGTGATTTGGATGATGGAAACGAGGAGGGAATGAAGGAATATG } \\
\text { GCCATACTGGTGTGAAGAAGAAGAATACCGGTGATGGAGGCAACTC } \\
\text { CCGGATGGGATTGTCAAAGTATAGTAAGAAGAACGATGATTAGAA } \\
\text { AATGAAGTGAGATACGATAAAGCCAGGAAGGGAAGTACAGGTAAT } \\
\text { GGATTGGTGG }\end{array}$ & GAA & G & 14,16 & 155 & $\begin{array}{l}\text { GATGGAAACGAGGAG } \\
\text { GGAAT }\end{array}$ & 60,3 & $\begin{array}{l}\text { CСCTTCCTGGCTTTA } \\
\text { TCGTA }\end{array}$ & 59,2 & 50 & 50 \\
\hline 413 & BrPe3264 & $\begin{array}{l}\text { Maracuja_ } \\
\text { NoIndex_L } \\
\text { 003_R1_00 } \\
\text { 1_contig_5 } \\
7117\end{array}$ & 3 & 736 & 747 & 12 & 4 & 9 & $\begin{array}{l}\text { AGGAAGAGGGGCTGAGCAGGGGCGCAAAGAATCTGAGGGAGATTG } \\
\text { AAAGCAGAGCTGCATTAGGGAAGTATGATGTGAAGGTAACAAAAA } \\
\text { GAGTACCGTTGAAGGAAATGGAAGATAGGAATGATTTAGAGTGGAT } \\
\text { TAGGCATGAGCTTGAGAAGAAGAAGAGTTTGATTGGGAATGAAGCA } \\
\text { GAGTTGGATGGGAAGACTGAAGAGTCAATTCATAGTGAGAAAAGGT } \\
\text { AACGGTTTAGTTTCTGAAATGATGTTCGAATATAGTGTGGCCAGGTG } \\
\text { TTTAGAAATAGTATGACTATTGTTTCTATCTTCAATT }\end{array}$ & AGA & G & 16,46 & 176 & $\begin{array}{l}\text { CGCAAAGAATCTGAG } \\
\text { GGAGA }\end{array}$ & 60,5 & $\begin{array}{l}\text { TCTTCCCATCCAACT } \\
\text { CTGCT }\end{array}$ & 59,8 & 50 & 50 \\
\hline 414 & BrPe3265 & $\begin{array}{l}\text { Maracuja_ } \\
\text { NoIndex_L } \\
003 \text { 121_00 } \\
\text { 1_contig_5 } \\
7472\end{array}$ & 3 & 1138 & 1152 & 15 & 5 & 12 & $\begin{array}{l}\text { GTCTGAATACATCAACATAAAACTCAAGTGCACACCATACAAGTCA } \\
\text { ACCTGTCAACTCTCACTATGAGTCATACATCACACATATCATGACCC } \\
\text { ATCACTTGGAACTCACAAGGCTAGGGAGCAGCTCATATCTTCTCGG } \\
\text { ATGAGTCCTCCTCATCATCATCATCACTGCTGTCCTCAACCGTATCT } \\
\text { GTCGGGGATCTCAAAGGTCCTCCTGTCTCAAAGGTGGGAGGTCTAG } \\
\text { ACTGATGTGATGGTCCTGCCTTCTCATGAGCATAATGCTCTAACTGG } \\
\text { TATATCTTAGGGAATCCAAAACAAAACCAGCTATCC }\end{array}$ & TCA & G & 26,09 & 153 & $\begin{array}{l}\text { ACTCACAAGGCTAGG } \\
\text { GAGCA }\end{array}$ & 60,0 & $\begin{array}{l}\text { AGAAGGCAGGACCA } \\
\text { TCACAT }\end{array}$ & 59,5 & 55 & 50 \\
\hline 415 & BrPe3266 & $\begin{array}{l}\text { Maracuja_ } \\
\text { NoIndex_L } \\
\text { 003_R1_00 } \\
\text { 1_contig_5 } \\
7582\end{array}$ & 3 & 920 & 931 & 12 & 4 & 9 & $\begin{array}{l}\text { GTCCAAAATCAATGTTCGGATACATGACCGGCATATATATAAAAAA } \\
\text { TGAAATATGAATGATTATTAGCCAACAAATTGACAAAAACACTGGC } \\
\text { TTTCTTTTGTTGACGAAAGAGGTTAAACTTACACTCTTTCTTCTTTGA } \\
\text { GGATGCCTTTGCAGCAGCAGCACGTTCTTCTGCAGCCTTCTTTTCCT } \\
\text { CCTCGGTTTCCTCACCAAACAGGTCCACATCATCGTCGTCGTCGTCA } \\
\text { TCAACAGCAGCCTGAAACCAACATTATGTTACAAATCAGCCACAAG } \\
\text { CAATTATCAAAATGAACATACAAACAGACGTC }\end{array}$ & $\mathrm{GCA}$ & G & 16,92 & 153 & $\begin{array}{l}\text { GCCAACAAATTGACA } \\
\text { AAAACAC }\end{array}$ & 59,4 & $\begin{array}{l}\text { TGATGTGGACCTGT } \\
\text { TTGGTG }\end{array}$ & 60,4 & 36,4 & 50 \\
\hline
\end{tabular}

G: genoma funcional

S: genoma estructural

P: polimórfico

M: monomórfico 
APÉNDICE

Marcadores microssatélites desenhados a partir do sequênciamento parcial e da montagem de novo do genoma de $P$. edulis

\begin{tabular}{|c|c|c|c|c|c|c|c|c|c|c|c|c|c|c|c|c|c|c|c|}
\hline $\mathbf{N}^{\circ}$ & Primer & Contig I & Motivo & Início & Fim & pb & $\begin{array}{c}\mathbf{N}^{\circ} \\
\text { Repet }\end{array}$ & Score & Sequência do contig & Unidade & G/S & Cobertura & pb & Sequência Forward & $\begin{array}{l}\mathrm{T}^{\circ} \mathrm{C} \\
F w d \\
\end{array}$ & Sequência Reverse & $\begin{array}{l}\mathrm{T}^{\circ} \mathrm{C} \\
\operatorname{Rev} \\
\end{array}$ & $\begin{array}{r}\% \mathrm{GC} \\
F w d \\
\end{array}$ & $\begin{array}{cc}\% \mathrm{GC} & \mathbf{P} / \mathbf{M} \\
\operatorname{Rev} & \end{array}$ \\
\hline 416 & BrPe3267 & $\begin{array}{l}\text { Maracuja_ } \\
\text { NoIndex_L } \\
003 \text { R1_00 } \\
\text { 1_contig_5 } \\
7672\end{array}$ & 3 & 1103 & 1114 & 12 & 4 & 9 & $\begin{array}{l}\text { GCTAAAGCGTCCGTAGGCAATTTTGTGAAATCCAAAGATTCCTGTCG } \\
\text { GTTGCTTTAGATTCTTCCTACATCAACTTGAGAAATCCAGGTCTCAA } \\
\text { TTCTCTATTGCAAAATTCTTCATACTCTCTTCTATCCCCACTTTTCTTC } \\
\text { CTGACTTCCACCACCACCAGCTTTGGTGTCAGCTCAAATATCTCTGC } \\
\text { TTCGATCTCTAATGGACCCTTCAAGCCTTGACCAGACCCTTCCAAAC } \\
\text { TCACTCTACAATCCTTCTCCCTCACTGTGAAGCTCACAACTTTAGCA } \\
\text { ATCTCATCCAATTTGGATATAATATTCG }\end{array}$ & $\mathrm{CCA}$ & $\mathrm{G}$ & 15,71 & 206 & $\begin{array}{l}\text { CCAAAGATTCCTGTC } \\
\text { GGTTG }\end{array}$ & 60,5 & $\begin{array}{l}\text { GTTTGGAAGGGTCT } \\
\text { GGTCAA }\end{array}$ & 59,9 & 50 & 50 \\
\hline 417 & BrPe3268 & $\begin{array}{l}\text { Maracuja_ } \\
\text { NoIndex_L } \\
\text { 003_R1_00 } \\
\text { 1_contig_5 } \\
8535\end{array}$ & 3 & 260 & 271 & 12 & 4 & 9 & $\begin{array}{l}\text { AAAGTTCTTTAAAGTGGAAACTCTCTGCTCCATAAGTATGGACCTTA } \\
\text { CCTTGGGCTGTCATTTTGCTGTTGAAGGAAGTTCATACACTTACTGT } \\
\text { AAGGGAAAGAAGAACCCGCAATGAGCTGGGAGGCTGCAGCAAACT } \\
\text { TTTGCTGCTGTGCAGCAGCAGCATTTGACCAGAGTAGTTCCTGACAG } \\
\text { CGCTCAAATTCGTCGAGTTTACTCGGAGGACCATCAAGGGCAGCAC } \\
\text { CATCAGCCGACTCTCCGTGAAGAAACTTGCGAGTAGTAGTGTCATTT } \\
\text { TTGCTGAGCTTGTTCGCAGAATATAAGCAAGGC }\end{array}$ & GCA & G & 7,44 & 153 & $\begin{array}{l}\text { GACCTTACCTTGGGC } \\
\text { TGTCA }\end{array}$ & 60,1 & $\begin{array}{l}\text { TTGAGCGCTGTCAG } \\
\text { GAACTA }\end{array}$ & 59,7 & 55 & 50 \\
\hline 418 & BrPe3269 & $\begin{array}{l}\text { Maracuja_ } \\
\text { NoIndex_L } \\
003 \text { _R1_00 } \\
\text { 1_contig_5 } \\
8700\end{array}$ & 3 & 250 & 261 & 12 & 4 & 9 & $\begin{array}{l}\text { TGATAAGTTTGGTTTGAATTTTAACACTCCCCATCAAACCAAACTTT } \\
\text { TCATTCCAGTCTTATTTTGAGCATGTAGAATATCTCTGCTTTTAGTGG } \\
\text { CTTTGTAAAGATATCTGCCAATTGATCTTCTGTACGGCAATAGAGTA } \\
\text { ATTCCACTTTCTTCTTCTTCACTTGTTCACGAATGAACTGATACTTTG } \\
\text { TATCGATGTGTTTGCTGCGGCTATGAGACACTGGATTCTTTGCGAGT } \\
\text { GAGATAGAAGACTTATTATCGACATATATTGTAATTGGCCCTTCTTG } \\
\text { TGTAAAAGATAATTCTCCTAGAATATTT }\end{array}$ & TTC & G & 17,41 & 185 & $\begin{array}{l}\text { CACTCCCCATCAAAC } \\
\text { CAAAC }\end{array}$ & 60,2 & $\begin{array}{l}\text { CGCAGCAAACACAT } \\
\text { CGATAC }\end{array}$ & 60,3 & 50 & 50 \\
\hline 419 & BrPe3270 & $\begin{array}{l}\text { Maracuja_ } \\
\text { NoIndex_L } \\
\text { 003_R1_00 } \\
\text { 1_contig_5 } \\
9099\end{array}$ & 3 & 243 & 254 & 12 & 4 & 9 & $\begin{array}{l}\text { CAATACATCTATGTACTATGCAAAGCATGGTCCATCATCACTCGTCC } \\
\text { TTTCGAGTTGTCTTTGTGCGATGCATCTATCCCTAAAATTCTCTGACT } \\
\text { TGAACTATTTGATTCAAACCATGTCTTTCTTCATGTAACTTACCAATC } \\
\text { AGAGTGATCTTCTTCTTCTGGCCATCCATAATGTAGTATCCCAATTT } \\
\text { ACCGATTCCCGCATATCCGAGTTTCGATATTAATAATTATTACTCA } \\
\text { CAACTTCATTCTTGAACTCTCATGCCCAA }\end{array}$ & TCT & $\mathrm{s}$ & 274,56 & 179 & $\begin{array}{l}\text { GGTCCATCATCACTC } \\
\text { GTCCT }\end{array}$ & 59,9 & $\begin{array}{l}\text { GATATGCGGGAATC } \\
\text { GGTAAA }\end{array}$ & 59,8 & 55 & 45 \\
\hline 420 & BrPe3271 & $\begin{array}{l}\text { Maracuja_ } \\
\text { NoIndex_L } \\
003 \text { R1_00 } \\
\text { 1_contig_5 } \\
9329\end{array}$ & 3 & 986 & 1006 & 21 & 7 & 18 & $\begin{array}{l}\text { TATCACAAAAAAGGAGCTGAGTGATTCTTTAGAGAATCTGGGGATA } \\
\text { TTCATCCCGGACAATGAGTTGGCCAGGATGATACAGAAGGTGATG } \\
\text { TCAACGGCGATGGCTGCGTGGACGTTGATGAGTTTGGTATCCTGTAC } \\
\text { CAGTCCATCATGGAGGAGGAGGAGGAGGAGGATGAGGAAGGGGAC } \\
\text { ATGAAGGAGGCTTTTAATGTGTTTGATCGAAATGGTGATGGGTACAT } \\
\text { CACGGTTGACGAGCTCAAGTCTGTTTTGGCCTCACTTGGGCTCAAGC } \\
\text { AAGGCAGGACTTCTGAGGATTGCAAGAGGATGATCACCAAGGT }\end{array}$ & GGA & G & 013 & 236 & $\begin{array}{l}\text { GACAATGAGTTGGCC } \\
\text { AGGAT }\end{array}$ & 59,9 & $\begin{array}{l}\text { GAAGTCCTGCCTTG } \\
\text { CTTGAG }\end{array}$ & 60,1 & 50 & 55 \\
\hline
\end{tabular}

G: genoma funcional

S: genoma estructural

P: polimórfico

M: monomórfico 
APÉNDICE

Marcadores microssatélites desenhados a partir do sequênciamento parcial e da montagem de novo do genoma de $P$. edulis

\begin{tabular}{|c|c|c|c|c|c|c|c|c|c|c|c|c|c|c|c|c|c|c|c|c|}
\hline $\mathbf{N}^{\circ}$ & Primer & Contig & Motivo & Início & Fim & pb & $\begin{array}{c}\mathbf{N}^{\mathbf{o}} \\
\text { Repet }\end{array}$ & Score & Sequência do contig & Unidade & G/S & Cobertura & pb & Sequência Forward & $\begin{array}{l}\mathrm{T}^{\circ} \mathrm{C} \\
F w d \\
\end{array}$ & Sequência Reverse & $\begin{array}{l}\mathrm{T}^{\circ} \mathrm{C} \\
R e v \\
\end{array}$ & $\begin{array}{c}\% \text { GC } \\
F w d\end{array}$ & $\begin{array}{c}\% \mathrm{GC} \\
R e v\end{array}$ & $\mathbf{P} / \mathbf{M}$ \\
\hline 421 & $\begin{array}{l}\text { BrPe3272 } \\
\end{array}$ & $\begin{array}{l}\text { Maracuja_ } \\
\text { Nolndex_L } \\
003 \_ \text {R1_00 } \\
\text { 1_contig_5 } \\
9576\end{array}$ & 3 & 402 & 413 & 12 & 4 & 9 & $\begin{array}{l}\text { TTCAGAATAAAACATTATACTAGTTCGAATAGGAATTCAAAAAAAT } \\
\text { AAATTAGCACTGTAATTAAGAAAAATATTTTTGATCGATTTGAAAAA } \\
\text { AAAAACATGGAGGGAAAGGATTTACGTACGGGCTAAGTATTTTTTA } \\
\text { AACCTACCCCAATCATCATCATCCATCACTATCTTGTTGCGATGCTG } \\
\text { TTTTCACCTTTTCGTGGCTTCTAACAAACTTTAGCTTCAGCCTTTCAT } \\
\text { TATCATTATAACAACGTGGATATTACCTTTTTTTTTCTTGTATAGGTT } \\
\text { TATAATGAAATAAAACTAAAAATAAATGCC }\end{array}$ & ATC & $\mathrm{s}$ & 15,72 & 110 & $\begin{array}{l}\text { CATGGAGGGAAAGGA } \\
\text { TTTACG }\end{array}$ & 60,7 & $\begin{array}{l}\text { AGAAGCCACGAAAA } \\
\text { GGTGAA }\end{array}$ & 59,9 & 47,6 & 45 & \\
\hline 422 & BrPe3273 & $\begin{array}{l}\text { Maracuja_ } \\
\text { Nolndex_L } \\
003 \_ \text {R__00 } \\
\text { 1_contig_5 } \\
9619\end{array}$ & 3 & 2155 & 2166 & 12 & 4 & 9 & $\begin{array}{l}\text { ATTGAATAGTTACCGAATGATGAATGAAACAACTAGGTGGTTTTCA } \\
\text { CCCTTTTAGCAGTTTCTCCTGCATGCTGTCTGTTTCCTCTTGATCTAT } \\
\text { TTCGGTTAATGAATGGCTTTGTATTAATGATTTTATTTTCTTTGTTAT } \\
\text { GCAGACCATTGTTGTTGTTGCTGTTGTTCCATACGGGGTTATACAGC } \\
\text { TTGGTTCAATGAATAAAGTAATGAATATTCTCCAACACATGGCGAA } \\
\text { ATCATTTCTAGTTATAGATCTTTGAACTATAATTTTTATAAATGTTTC } \\
\text { TACAGGATTGAGAATAACTTCTTTTTTAT }\end{array}$ & TTG & G & 15,6 & 172 & $\begin{array}{l}\text { TCCTGCATGCTGTCTG } \\
\text { TTTC }\end{array}$ & 60,0 & $\begin{array}{l}\text { TCGCCATGTGTTGG } \\
\text { AGAATA }\end{array}$ & 60,1 & 50 & 45 & \\
\hline 423 & BrPe3274 & $\begin{array}{l}\text { Maracuja_ } \\
\text { NoIndex_L } \\
003 \_ \text {R1_00 } \\
\text { 1_contig_5 } \\
9700\end{array}$ & 3 & 1410 & 1424 & 15 & 5 & 12 & $\begin{array}{l}\text { AATTTGTGAACTGACTGGAGATAAAGTGTACTGCATTAATGAAAGA } \\
\text { TATCGCACTTGAGAACTGCCTTTCTCTTTATCTGCAAGTCAAGCAAG } \\
\text { AGCTAATGTGTGCCCATCATTTTATTACAGGTACGAGATGAACTTGA } \\
\text { ACAGCTACTGGATGATGATGATGATATGGCTGATCTTTATCTGTCAA } \\
\text { GGAAGTTGGCTGGTGCTATGTCTCCGGTTAGTGGGTCAGGTGGTGCC } \\
\text { AATTGGTTTCCTGCATCCCCGACAATTGGTTCAAAAATTTCTAGAGC } \\
\text { AAGCAGAGCAAGTATTGCAACAGGTCGAGGAGAT }\end{array}$ & GAT & G & 15,84 & 156 & $\begin{array}{l}\text { CGCACTTGAGAACTG } \\
\text { CСTTT }\end{array}$ & 60,6 & $\begin{array}{l}\text { TAGCACCAGCCAAC } \\
\text { TTCCTT }\end{array}$ & 59,9 & 50 & 50 & \\
\hline 424 & BrPe3275 & $\begin{array}{l}\text { Maracuja_ } \\
\text { Nolndex_L } \\
003 \_ \text {R1_00 } \\
\text { 1_contig_5 } \\
9823\end{array}$ & 3 & 485 & 499 & 15 & 5 & 12 & $\begin{array}{l}\text { ATACCATTCTAGATGGAAAAAAAAAAAGGATATTGAATTTTTTAAA } \\
\text { ACAATAAAAAATTTAACCATTAAAGAAAGATATTGAATCTATATATA } \\
\text { TATGAAAGCAAGTAAAGCAATAAGAAACTAATAATTTCGACCTCTA } \\
\text { TTTAACAATGTTAAGAAGAAGAAGGAAGTAGAAGGGAAAAACCCAA } \\
\text { ATAAGACAAAAGGATGGAAATGAACATAAATTACTGAGCTTTACTT } \\
\text { TTCTAAAATTGGCATGATTTGGGATCGTCAAAGTTTATTATATTGGG } \\
\text { TATGATTTTGCTGACTGAAATTACTTGTGGGGTATGAGA }\end{array}$ & AAG & $\mathrm{s}$ & 17,84 & 158 & $\begin{array}{l}\text { GAAAGCAAGTAAAGC } \\
\text { AATAAGAAAC }\end{array}$ & 57,2 & $\begin{array}{l}\text { TCCCAAATCATGCC } \\
\text { AATTTT }\end{array}$ & 60,1 & 32 & 35 & \\
\hline 425 & BrPe3276 & $\begin{array}{l}\text { Maracuja_ } \\
\text { Nolndex_L } \\
003 \_ \text {R1_00 } \\
\text { 1_contig_6 } \\
0402\end{array}$ & 3 & 179 & 190 & 9 & 3 & 6 & $\begin{array}{l}\text { CGTCTTCGCTTCAGAAATCTTCTCCACCATCGACGACGTGGCGGATG } \\
\text { ATAAGGAGTTCGACGACTCCATCTCAGTCGTCGTCTTCTCTCCAAAA } \\
\text { ATTAGCTCAAATTCTCCGCTACAATCATCGGACTCGGTAGCAGCCAA } \\
\text { ACGCTGGAGATCATCATCATCTCCTGATTTCTTCACAGCATTTTCTTT } \\
\text { TACCCTAGTGAAATTAGGAGAAAGCCACTTGGC }\end{array}$ & ATC & G & 6,54 & 184 & $\begin{array}{l}\text { TGGCGGATGATAAGG } \\
\text { AGTTC }\end{array}$ & 60,0 & $\begin{array}{l}\text { GCCAAGTGGCTTTC } \\
\text { TCCTAA }\end{array}$ & 59,5 & 50 & 50 & \\
\hline
\end{tabular}

G: genoma funcional

S: genoma estructural

P: polimórfico

M: monomórfico 
APÉNDICE

Marcadores microssatélites desenhados a partir do sequênciamento parcial e da montagem de novo do genoma de $P$. edulis

\begin{tabular}{|c|c|c|c|c|c|c|c|c|c|c|c|c|c|c|c|c|c|c|c|}
\hline $\mathbf{N}^{\circ}$ & Primer & Contig N & Motivo & Início & Fim & pb & $\begin{array}{c}\mathbf{N}^{\circ} \\
\text { Repet }\end{array}$ & Score & Sequência do contig & Unidade & G/S & Cobertura & pb & Sequência Forward & $\begin{array}{l}\mathrm{T}^{\circ} \mathrm{C} \\
F w d \\
\end{array}$ & Sequência Reverse & $\begin{array}{l}\mathrm{T}^{\circ} \mathrm{C} \\
\operatorname{Rev} \\
\end{array}$ & $\begin{array}{c}\% \mathrm{GC} \\
F w d \\
\end{array}$ & $\begin{array}{r}\% \mathrm{GC} \\
\operatorname{Rev} \\
\end{array}$ \\
\hline 426 & BrPe3277 & $\begin{array}{l}\text { Maracuja_ } \\
\text { NoIndex_L } \\
\text { 003_R1_00 } \\
\text { 1_contig_6 } \\
0467\end{array}$ & 3 & 3547 & 3558 & 12 & 4 & 9 & $\begin{array}{l}\text { GTTTTGTTCTCACTTGTACTGAAAGTTCATTTATTTCCTTTGCATATA } \\
\text { AGTCACCACCAACATCTCCAAAAACAAACCCTTATTTATTGCCAGTA } \\
\text { TATATCAGATGCTAACTTTTTCGTAGCTTGTGTTGCATATCTCACGCG } \\
\text { TACAACACCTCCTCCTCCTACTTGCTTCTTTTATTAGGCCTTGTAGCT } \\
\text { GGCCACATCCCATTCTCTTTCCCCGCCTTTCTTTTGCTCCATATTTCC } \\
\text { AGCTTCCCGTTGGTGATCGAGATGGGGAGGAGCCATCGAGAAACCG } \\
\text { CTTTGGTCTGTCTGCTCTTGCTTGCAT }\end{array}$ & $\begin{array}{l}\text { CCT } \\
\text { S } \\
\end{array}$ & $\bar{G}$ & 16,26 & 164 & $\begin{array}{l}\text { TCACCACCAACATCT } \\
\text { CCAAA }\end{array}$ & 59,9 & $\begin{array}{l}\text { GGGAAAGAGAATGG } \\
\text { GATGTG }\end{array}$ & 59,3 & 45 & 50 \\
\hline 427 & BrPe3278 & $\begin{array}{l}\text { Maracuja_ } \\
\text { NoIndex_L } \\
\text { 003_R1_00 } \\
\text { 1_contig_6 } \\
0587\end{array}$ & 3 & 2975 & 2986 & 12 & 4 & 9 & $\begin{array}{l}\text { ATGAGCTCTCCTGGAGGGTTAAGTGACTATTCATTGTTCAAGCTAGA } \\
\text { TGAAGCAGCACAGATTCTGGGAAACAATCAACAAGGACCCGAGAT } \\
\text { GATGCATGAACGGCTCATTGCAATGTCCAGCACTAACTCCACATGT } \\
\text { ACTGATTCTTCATCTTCTTCTTCTGTTTCTGCTACTGTTACTCGGGGA } \\
\text { ATGCTCCAATGCTCTTGGAAGAGTGGGAAACCCCATTTTATCTTCTC } \\
\text { CCTGGATGAGCAGAAGGTGGTCTATGAGGCCAAGTTGGTGAATTAT } \\
\text { GAGTTATCAGATGATAAGGCTCTGTACCATATA }\end{array}$ & TCT & G & 16,27 & 189 & $\begin{array}{l}\text { AACAAGGACCCGAGA } \\
\text { TGATG }\end{array}$ & 59,9 & $\begin{array}{l}\text { TGGCCTCATAGACC } \\
\text { ACCTTC }\end{array}$ & 60,1 & 50 & 55 \\
\hline 428 & BrPe3279 & $\begin{array}{l}\text { Maracuja_ } \\
\text { NoIndex_L } \\
\text { 003_R1_00 } \\
\text { 1_contig_6 } \\
0772\end{array}$ & 3 & 794 & 805 & 12 & 4 & 9 & $\begin{array}{l}\text { GCTGGACATCAGTAACAACCAATTTAGTGGTCCGTTTCCTTCTGTTG } \\
\text { TTCTTTGTCTTAAGTCGCTCAGGTTTCTTGATTTAAGATTCAATCGAT } \\
\text { TTGAAGGAAGCATCCATCTCAGCTTTTCGATCTCAAACTTGATGCA } \\
\text { CTTTTCATCAACAACAACAAATTCCAATCATCCTTGCCTGAAAACTT } \\
\text { TGGAAACTTGCCTGTTTCAGTGATAGTATTGGCCAATAATAACTTCA } \\
\text { CCGGTTGCTTTCCTTCGTCTCTAGCAAATATGAGAGGGCCCTTAAT } \\
\text { GAGATGATACTCATGAACATGGGACTCAA }\end{array}$ & CAA & G & 24,65 & 165 & $\begin{array}{l}\text { GGTCCGTTTCCTTCTG } \\
\text { TTGT }\end{array}$ & 059 & $\begin{array}{l}\text { TCCAAAGTTTTCAG } \\
\text { GCAAGG }\end{array}$ & 60,2 & 50 & 45 \\
\hline 429 & BrPe3280 & $\begin{array}{l}\text { Maracuja_ } \\
\text { NoIndex_L } \\
\text { 003_R1_00 } \\
\text { 1_contig_6 } \\
1121\end{array}$ & 3 & 1466 & 1477 & 12 & 4 & 9 & $\begin{array}{l}\text { AAGGAAAAATCTGTGAAGGAAACAAAGGAATCTGAGGACCAGCCT } \\
\text { CGTGGAGATGCTGGAAATGGGGCAGATGAAGCTGCTGAAAAAGAA } \\
\text { AAGGCAGAAGATTCATCTTCTGCTGATGTGAAAGAGCGTTTGAAGA } \\
\text { AGCTTGCTTCTGCAAAGAAGAAGAAGTCAAGTAAAGAAATGGATGC } \\
\text { AGCTGCCCGGGCTGCTGCTAGCGAGGCAGCTGCAAGAAACGCAAAG } \\
\text { CTTGCTGCTGCAAAGAAAAAAGAGAAAAATCACTACAATCAGCAGC } \\
\text { CTGTTCGGTAAAGCTGGCAAAATCAAGAGTTTTTTTCC }\end{array}$ & AAG & G & 16,02 & 169 & $\begin{array}{l}\text { AAACAAAGGAATCTG } \\
\text { AGGACCA }\end{array}$ & 60,0 & $\begin{array}{l}\text { GCAGCTGCATCCAT } \\
\text { TTCTTT }\end{array}$ & 60,4 & 40,9 & 45 \\
\hline 430 & BrPe3281 & $\begin{array}{l}\text { Maracuja_ } \\
\text { NoIndex_L } \\
003 \_R 1 \_00 \\
\text { 1_contig_6 } \\
1213\end{array}$ & 3 & 728 & 739 & 12 & 4 & 9 & $\begin{array}{l}\text { TTGTTTTTGTATTCAAAAGGGTGTATCTCGCAGCGGAAATCCGGTCC } \\
\text { CAGAAGGGTACTTTCAGGAGAACTTCGAGAGCAATCAAGACCAGCC } \\
\text { TGATGAAGGATCCGATTGGACTCTTCACGCGGCAGTGTAACGGCCG } \\
\text { TAGGATAAGAACTGCTGCTGCTGTCAATGCTATTACTTGAAATAAAA } \\
\text { CTACAATCTGGGCTTTCGAAATTTTCATCCAAACAAGAAAGAAATT } \\
\text { ACATGACGGAGGAGGGTATTCCTGGCCAAGGATATCATAGAAGGAT } \\
\text { TTCTCAGCCGCTTGGAGGGGTAAAGAGTCTTGC }\end{array}$ & CTG & $\mathrm{G}$ & 10,72 & 171 & $\begin{array}{l}\text { CGGTCCCAGAAGGGT } \\
\text { ACTTT }\end{array}$ & 60,4 & $\begin{array}{l}\text { GAAAATTTCGAAAG } \\
\text { CCCAGA }\end{array}$ & 59,3 & 55 & 40 \\
\hline
\end{tabular}

G: genoma funcional

S: genoma estructural

P: polimórfico

M: monomórfico 
APÉNDICE

Marcadores microssatélites desenhados a partir do sequênciamento parcial e da montagem de novo do genoma de $P$. edulis

\begin{tabular}{|c|c|c|c|c|c|c|c|c|c|c|c|c|c|c|c|c|c|c|c|}
\hline $\mathbf{N}^{\mathbf{o}}$ & Primer & Contig $\mathrm{I}$ & Motivo & Início & Fim & pb & $\begin{array}{c}\mathbf{N}^{\mathbf{o}} \\
\text { Repet }\end{array}$ & Score & Sequência do contig & Unidade & G/S & Cobertura & pb & Sequência Forward & $\begin{array}{l}\mathrm{T}^{\circ} \mathrm{C} \\
F w d\end{array}$ & Sequência Reverse & $\begin{array}{r}\mathrm{T}^{\circ} \mathrm{C} \\
\operatorname{Rev}\end{array}$ & $\begin{array}{c}\% \mathrm{GC} \\
F w d\end{array}$ & $\begin{array}{c}\% \mathrm{GC} \\
\operatorname{Rev}\end{array} \quad \mathrm{P} / \mathbf{M}$ \\
\hline 431 & BrPe3282 & $\begin{array}{l}\text { Maracuja_ } \\
\text { NoIndex_L } \\
\text { 003_R1_00 } \\
\text { 1_conti__6 } \\
\text { 1311 }\end{array}$ & 3 & 3959 & 3970 & 12 & 4 & 9 & $\begin{array}{l}\text { AAGGGAACGATAGTGCTTACGATCATTTATCAACAAGAGGCCTTAT } \\
\text { GCTCGCTAGTGCACTGTCAATGGCATTACTGACCAAATTATTTTTCA } \\
\text { TTTTTAGCAACAAAAAACTCACCTTCCACCACATGTAACAATATCCC } \\
\text { ATTGCTCCAACTGCTGCTGCTGGAATTAGATAAGATGCCAAACTTCC } \\
\text { TGTGAACACAAGAAATTGGCAAAATTACTGACATTAATCTTCCCTCA } \\
\text { AGACATATAAATATTGCCATATGTAGATAGAATATTGATGGGAAAA } \\
\text { CTAAAACTACCATGTATGTTGACATTACAACT }\end{array}$ & CTG & $\mathrm{G}$ & 22,11 & 161 & $\begin{array}{l}\text { CGCTAGTGCACTGTC } \\
\text { AATGG }\end{array}$ & 60,5 & $\begin{array}{l}\text { TTTGCCAATTTCTTG } \\
\text { TGTTCA }\end{array}$ & 59,2 & 55 & 33,3 \\
\hline 432 & BrPe3283 & $\begin{array}{l}\text { Maracuja_ } \\
\text { NoIndex_L } \\
003 \text { 11_00 } \\
\text { 1_contig_6 } \\
2119\end{array}$ & 3 & 2563 & 2574 & 12 & 4 & 9 & $\begin{array}{l}\text { TTGCTCTAGACCCGATCTGTGACATCTCTGCAACATGGGAAATGCAT } \\
\text { CACTTAAACATAGAAGGCGTATACTAAATAAACAGTTGCAGAGGTA } \\
\text { GACAACAGCAAAGAAGCCAAAGCAAACACGACGTTGGCTGTAGTT } \\
\text { AGTATAATCAGCCCACCACCACCAAAACAGACGTGCTAAATTGGTG } \\
\text { GTTCTCGAATCAGTTTTGTAGGAGGAAAAAATAAATCCAAATTGAG } \\
\text { GAATCCCCAAATTAAAACAGTAGACTTCTCATATTTGCTGTAACAA } \\
\text { TTTGACAAAACAAAGACAAAAAAATACTCTCCGAT }\end{array}$ & $\mathrm{CCA}$ & $\mathrm{s}$ & 14,14 & 214 & $\begin{array}{l}\text { TCTCTGCAACATGGG } \\
\text { AAATG }\end{array}$ & 59,6 & $\begin{array}{l}\text { GGGGATTCCTCAAT } \\
\text { TTGGAT }\end{array}$ & 60 & 45 & 45 \\
\hline 433 & BrPe3284 & $\begin{array}{l}\text { Maracuja_ } \\
\text { NoIndex_L } \\
003 \text { _R1_00 } \\
\text { 1_contig_6 } \\
\text { 2457 }\end{array}$ & 3 & 2584 & 2595 & 12 & 4 & 9 & $\begin{array}{l}\text { TGGTTGACTCTGGTTTCTTAATATTGACGAAACTATTATATTCTCTGT } \\
\text { TCATACTTCCCAATTAAATTGACCTGGGAGGAAGAACCGAGGCTGG } \\
\text { TAGTACTAGAGTAGGCTGAAAGCATGATTGCAGATCCATTTTATGAT } \\
\text { GATCTTGTAAATAATAATAATGGTACAGGTGTTCAAAACCTCTTTCA } \\
\text { AAATTCTCACACATAAGTGTCGAGCACCATTAAGGCGATGGGATAA } \\
\text { TTCAAATTTTAAACAATATTTAAATTCTAAGATATGTGCCCCGTTTTT } \\
\text { GTAAAAGAACTTGGGTTAGAATCACTGAGT }\end{array}$ & AAT & G & 14,59 & 220 & $\begin{array}{l}\text { TGACCTGGGAGGAAG } \\
\text { AACC }\end{array}$ & 60,0 & $\begin{array}{l}\text { TTTACAAAAACGGG } \\
\text { GCACAT }\end{array}$ & 60,2 & 57,9 & 40 \\
\hline 434 & BrPe3285 & $\begin{array}{l}\text { Maracuja_ } \\
\text { NoIndex_L } \\
003 \text { 1_1_00 } \\
\text { 1_contig_6 } \\
\text { 2789 }\end{array}$ & 3 & 1680 & 1691 & 12 & 4 & 9 & $\begin{array}{l}\text { GTACACCAGCCATGTCGAAATAACTAGGCAGGACTTTGCCATCTCC } \\
\text { AAGGAATTACTCCTGAAACATTCCTCCAAGGCCTTGAAGATTGATCC } \\
\text { CTTTTCATGATTGCAGAGTACAAAAGCTACTCTTTTCTCCCAAGAAC } \\
\text { TTGCAGCTTTTTCTTCTTCTTCCTGCGTCAAAATGTGTCCAAGCTTTG } \\
\text { TTAGGAGAGTCATAAATATGGAAATCCTTTTTAACTCTAAAACAACA } \\
\text { AAAATTGCAAACCATTGATTCTGCCAAATCATTTTCCTGATTCTTTGT } \\
\text { CTTCTCTGCCTTCATTAAAGCATTGTATG }\end{array}$ & TTC & G & 14,52 & 162 & $\begin{array}{l}\text { TAGGCAGGACTTTGC } \\
\text { САTCT }\end{array}$ & 59,8 & $\begin{array}{l}\text { AAGCTTGGACACAT } \\
\text { TTTGACG }\end{array}$ & 60,2 & 50 & 42,9 \\
\hline 435 & BrPe3286 & $\begin{array}{l}\text { Maracuja_ } \\
\text { NoIndex_L } \\
003 \_R 1 \_00 \\
\text { 1_contig_6 } \\
\text { 2809 }\end{array}$ & 3 & 284 & 298 & 15 & 5 & 12 & $\begin{array}{l}\text { GCAAGAGGATCCTATCTGAAGGACTCTGAGAAGGCTGAGATGTACC } \\
\text { GGTTGCATAAGCAGAATCCCGAGGTTTACACAGTCGAGAGGCTTGC } \\
\text { GAAGGACTATAGGATTATGAGGCAAAGGGTGCACGCCATTCTTTGG } \\
\text { CTGAAGGAGCTTGAGGAGGAGGAGGAGAAAAAGCTTGGTCATCCCT } \\
\text { TGGACGATTCTGTTGAGCTCTTGCTCGACACCTTCCCTGAGTAAGAA } \\
\text { CTTAATTTAGATGCTGTGATCTCGTTCTGTCTGTTGAAAACAATTGC } \\
\text { AGTAGTGTGATTATCTTGCTCTGTTGCAGATTTTTCA }\end{array}$ & GAG & G & 14,05 & 156 & $\begin{array}{l}\text { GCAGAATCCCGAGGT } \\
\text { TTACA }\end{array}$ & 60,1 & $\begin{array}{l}\text { TCGAGCAAGAGCTC } \\
\text { AACAGA }\end{array}$ & 60 & 50 & 50 \\
\hline
\end{tabular}

G: genoma funcional

S: genoma estructural

P: polimórfico

M: monomórfico 
APÉNDICE

Marcadores microssatélites desenhados a partir do sequênciamento parcial e da montagem de novo do genoma de $P$. edulis

\begin{tabular}{|c|c|c|c|c|c|c|c|c|c|c|c|c|c|c|c|c|c|c|c|}
\hline $\mathbf{N}^{\circ}$ & Primer & Contig I & Motivo & Início & Fim & pb & $\begin{array}{c}\mathbf{N}^{\circ} \\
\text { Repet }\end{array}$ & Score & Sequência do contig & Unidade & G/S & Cobertura & pb & Sequência Forward & $\begin{array}{l}\mathrm{T}^{\circ} \mathrm{C} \\
F w d \\
\end{array}$ & Sequência Reverse & $\begin{array}{l}\mathrm{T}^{\circ} \mathrm{C} \\
\operatorname{Rev} \\
\end{array}$ & $\begin{array}{c}\% \mathrm{GC} \\
F w d \\
\end{array}$ & $\begin{array}{cc}\% \mathrm{GC} & \mathrm{P} / \mathrm{M} \\
\operatorname{Rev} & \end{array}$ \\
\hline 436 & BrPe3287 & $\begin{array}{l}\text { Maracuja_ } \\
\text { NoIndex_L } \\
003 \text { R1_00 } \\
\text { 1_contig_6 } \\
\text { 3222 }\end{array}$ & 3 & 1961 & 1972 & 12 & 4 & 9 & $\begin{array}{l}\text { GTGTGAAAGAGGACTAATTAAGAGGAGGTCAGGAGGATAAAATAA } \\
\text { GAGCAAATCAAAAACCTGTAAATCTTCCTCAAGTCTACTGAGTTCAA } \\
\text { CTGCTTCCTGAATATCCAATTTTCCACGAAAGATGCCAACAGCAATC } \\
\text { ACTAAAGAGTGTGCTGCTGCTGCAATTGCATCAATTGCTGTCAGCTC } \\
\text { ACAGTCACTGGTTTTCTTAAGAAGATCTTCCATTGCTTTAACCAAGC } \\
\text { CTTCCTCCTGCATGCCGCCAAAGATACTTGAGTACACAACAGGCTTG } \\
\text { AAGCCAAATTCTGATTTAACCCAGTCAAGTAA }\end{array}$ & TGC & $\bar{G}$ & 16,65 & 152 & $\begin{array}{l}\text { CTGAGTTCAACTGCTT } \\
\text { CCTGA }\end{array}$ & 58,2 & $\begin{array}{l}\text { GGCTTGGTTAAAGC } \\
\text { AATGGA }\end{array}$ & 60,1 & 47,6 & 45 \\
\hline 437 & BrPe3288 & $\begin{array}{l}\text { Maracuja_ } \\
\text { NoIndex_L } \\
\text { 003_R1_00 } \\
\text { 1_contig_6 } \\
3389\end{array}$ & 3 & 3095 & 3106 & 12 & 4 & 9 & $\begin{array}{l}\text { TCTTGGCCTCTTGAGCCCAAAAATCTTTCATCTTTTTTTGTTCTTCCT } \\
\text { CTATCTGACGCTAGTGTTCTCTAATGGCTTCTGCGCCATCTTCAGA } \\
\text { GCTTTTGTTGTATCTCCTCAAGTTTTTATTGATGACCTATAGCCGCTG } \\
\text { CTGTTGTTGGTGGTGGTGGAGGTGATGGTCCTCTTCGTCGGAGGTTA } \\
\text { CAGGGATCTTTAGAGAAATTTCGTGTTGGCAATCTAGAATGCCTGAA } \\
\text { GACTTTAGAATTAAAGTCTTCTGAACAACCATAAGATTCTTCAGACA } \\
\text { TATCTGGATCAACATCCTTTGTGATGAG }\end{array}$ & TGG & G & 21,27 & 154 & $\begin{array}{l}\text { TTCTGCGCCATCTTCA } \\
\text { GAG }\end{array}$ & 60,2 & $\begin{array}{l}\text { CATTCTAGATTGCC } \\
\text { AACACGA }\end{array}$ & 58,8 & 52,6 & 42,9 \\
\hline 438 & BrPe3289 & $\begin{array}{l}\text { Maracuja_ } \\
\text { NoIndex_L } \\
003 \text { R1_00 } \\
\text { 1_contig_6 } \\
3400\end{array}$ & 3 & 151 & 162 & 12 & 4 & 9 & $\begin{array}{l}\text { AGCTACCCATGATGAGATGTCATCAGCTGAGCATCAGTCTAGAGAG } \\
\text { AGGTCAGAGGAAGTTATACCTCAGATGCCGATTGAACCAGTACAAG } \\
\text { GATCAGTACGAGAACCAACAGTTGAGTTTGTTCGTGAGCTAGTAGT } \\
\text { GCCGCCAAATGTACCACCACCACCTCCGGAAGCCTATGAGATGTTC } \\
\text { CTAGCAATCTGGACTACTATGCAAGGTGCAATGAGATTGGCACAAG } \\
\text { CACCAGCAAACCTCAAAAAACAACCTCGTAGCATGACTACGCCAAG } \\
\text { CTAA }\end{array}$ & $\mathrm{ACC}$ & G & 105,53 & 184 & $\begin{array}{l}\text { ACCTCAGATGCCGAT } \\
\text { TGAAC }\end{array}$ & 60,1 & $\begin{array}{l}\text { TTTGAGGTTTGCTGG } \\
\text { TGCTT }\end{array}$ & 60,8 & 50 & 45 \\
\hline 439 & BrPe3290 & $\begin{array}{l}\text { Maracuja_ } \\
\text { NoIndex_L } \\
003 \text { 121_00 } \\
\text { 1_contig_6 } \\
4198\end{array}$ & 3 & 1359 & 1370 & 12 & 4 & 9 & $\begin{array}{l}\text { TTCCTTCAACAACTGCATGAACAGCGGGTGGTTGAAGTACATCACA } \\
\text { GGAATTACAAATCTCTGTTGCTCCTCTCCCTGCCCCACCTTGATCGC } \\
\text { CAAACACCCTTTGGGTACATCTCTGGCTTGCTTCTTGTTGTTCCCATG } \\
\text { GTGTTGATTATGATGATGATGCATATGAGGCAACAAGTGTAGATGG } \\
\text { AAATTCCTCAGACTTTTCTCTCCACTACCCATAACTCGTGCCAACAA } \\
\text { ACAAAGAGAAGGCAAGAACACGAAACAAGAGAAAAAAACCAGTTT } \\
\text { TCGTC }\end{array}$ & ATG & G & 15,19 & 209 & $\begin{array}{l}\text { AACAGCGGGTGGTTG } \\
\text { AAGTA }\end{array}$ & 60,5 & $\begin{array}{l}\text { GCACGAGTTATGGG } \\
\text { TAGTGGA }\end{array}$ & 60 & 50 & 52,4 \\
\hline 440 & BrPe3291 & $\begin{array}{l}\text { Maracuja_ } \\
\text { NoIndex_L } \\
003 \text { 181_00 } \\
\text { 1_conti__6 } \\
4353\end{array}$ & 3 & 209 & 220 & 12 & 4 & 9 & $\begin{array}{l}\text { AAAAAACAAGGAGGTGAAAAGGGCAAACACTTGGAAACACCACTGT } \\
\text { CAACTTTGTTTGATTCCATGTTTGTGTCTCCATTAGCATTGCATGTCC } \\
\text { TTCTTTCACTTGGAAGGGATTTTTGCAGGCTATAGCTAGTCATGTGC } \\
\text { TAACCATTTCCATCATCATCATTAATTAGTAGTAATGACCATCCTTTC } \\
\text { AAACCTGCCTTGTTTGTCATCAAATCACCAAAGAATGATTAACAACA } \\
\text { CATGGGCTCCACACTAAACCAGCAATTAGCATTGCCTCTCTGAAAAT } \\
\text { GTCATAACATTGTCTTGGATTTGTCTGTCT }\end{array}$ & CAT & $\mathrm{s}$ & 18,42 & 170 & $\begin{array}{l}\text { CTTGGAAGGGATTTT } \\
\text { TGCAG }\end{array}$ & 59,7 & $\begin{array}{l}\text { GGCAATGCTAATTG } \\
\text { CTGGTT }\end{array}$ & 60,1 & 45 & 45 \\
\hline
\end{tabular}

G: genoma funcional

S: genoma estructural

P: polimórfico

M: monomórfico 
APÉNDICE

Marcadores microssatélites desenhados a partir do sequênciamento parcial e da montagem de novo do genoma de $P$. edulis

\begin{tabular}{|c|c|c|c|c|c|c|c|c|c|c|c|c|c|c|c|c|c|c|c|}
\hline $\mathbf{N}^{\circ}$ & Primer & Contig N & Motivo & Início & Fim & pb & $\begin{array}{c}\mathbf{N}^{\circ} \\
\text { Repet }\end{array}$ & Score & Sequência do contig & Unidade & G/S & Cobertura & pb & Sequência Forward & $\begin{array}{l}\mathrm{T}^{\circ} \mathrm{C} \\
F w d \\
\end{array}$ & Sequência Reverse & $\begin{array}{l}\mathrm{T}^{\circ} \mathrm{C} \\
\operatorname{Rev} \\
\end{array}$ & $\begin{array}{c}\% \mathrm{GC} \\
F w d \\
\end{array}$ & $\begin{array}{r}\% \mathrm{GC} \\
\operatorname{Rev} \\
\end{array}$ \\
\hline 441 & BrPe3292 & $\begin{array}{l}\text { Maracuja_ } \\
\text { NoIndex_L } \\
\text { 003_R1_00 } \\
\text { 1_contig_6 } \\
4775\end{array}$ & 3 & 3306 & 3320 & 15 & 5 & 12 & $\begin{array}{l}\text { TTATATACAGTTGAAATGGTCCTGTGAAGCCACAAACCGTACATAA } \\
\text { CTCTCCCTACCCAACTCCCAACCTCCCACAAACACCACAACCCAATT } \\
\text { TGCCAATTTGGTAAGGGATTTCCACTGCACCTTCTATGTCCATTTTCT } \\
\text { TGCTTCATACTTCTTCTTCTTCTTTTTTCTGTCATTTTGTGCGCCTAAA } \\
\text { ATTAGAAAGTTGTTAATATTGAGGGAGTGGATATCTTAATGTTTTTA } \\
\text { AAAAGTACAGATTTTTTTAGAAAAGATTGTTTTTTTTTTCAAAAATT } \\
\text { GTGATTATCTAGAGCTTTTTTTTTAATAAT }\end{array}$ & CTT & $\bar{G}$ & 16,51 & 113 & $\begin{array}{l}\text { GGATTTCCACTGCAC } \\
\text { CTTCT }\end{array}$ & 59,1 & $\begin{array}{l}\text { TCCACTCCCTCAAT } \\
\text { ATTAACAACTT }\end{array}$ & 59,4 & 50 & 36 \\
\hline 442 & BrPe3293 & $\begin{array}{l}\text { Maracuja_ } \\
\text { NoIndex_L } \\
\text { 003_R1_00 } \\
\text { 1_contig_6 } \\
\text { 4808 }\end{array}$ & 3 & 1706 & 1720 & 15 & 5 & 12 & $\begin{array}{l}\text { ATGTCTCTGCAAAGGGGATATTTGAAAATATTGCTCAGCATAAAGTT } \\
\text { ACACACATGGGTGGCGCACCAACAGTTTGAACACGATAATCAACG } \\
\text { CGTCATTAGGTGAACGAAGGCCGCTTCCAGGAAAAGTGTCGGTGAT } \\
\text { GACCGGTGGTGCACCACCACCACCACATGTTCTTCACAAGATGGAG } \\
\text { GAACTAGGATTTAATGTGACTCACTCTTATGGTTTGACAGAAACCTA } \\
\text { CGGTCCCGGCACGGTGTGCACTTGGAAACCTGAATGGGCTTCCCTGT } \\
\text { CTCGGGATGAACAAGCGAAGATCAAGGCTCGTCAGG }\end{array}$ & $\begin{array}{ll}\Gamma \\
\text { CAC } \\
+\end{array}$ & G & 16,52 & 188 & $\begin{array}{l}\text { CCAGGAAAAGTGTCG } \\
\text { GTGAT }\end{array}$ & 60,0 & $\begin{array}{l}\text { GCCTTGATCTTCGCT } \\
\text { TGTTC }\end{array}$ & 60 & 50 & 50 \\
\hline 443 & BrPe3294 & $\begin{array}{l}\text { Maracuja_ } \\
\text { NoIndex_L } \\
\text { 003_R1_00 } \\
\text { 1_contig_6 } \\
4885\end{array}$ & 3 & 2700 & 2711 & 12 & 4 & 9 & $\begin{array}{l}\text { TCTATGATTTCATCCCAGTTTCAAGTAAACTTAATAGTAACAGTAAC } \\
\text { GTTTCTTAATTAGAAACCAATTGAAGAAAAAACAGTCTTACTGGTG } \\
\text { GAGACCTTAAAACACACAGTTCATCGTGTTCCCAGTCTGTAGGGCC } \\
\text { ACAGAAGGTTCGTAGTAGTAGTACTATCACCACTTTTGCAGGCTTAC } \\
\text { TATTTGACCTACCGACATTGTAAATATATTATAGAAATTATAGATAG } \\
\text { TAATGTGTTTAAGCCTTATCTCTTGTCTTGAGATGGTTTGAACCCCA } \\
\text { AGTCAAAGTCAAGCCACAAGCCAGCACTAGCA }\end{array}$ & GTA & $\mathrm{s}$ & 14,72 & 162 & $\begin{array}{l}\text { CGTGTTCCCAGTCTGT } \\
\text { AGGG }\end{array}$ & 60,6 & $\begin{array}{l}\text { GGGGTTCAAACCAT } \\
\text { CTCAAG }\end{array}$ & 59,4 & 60 & 50 \\
\hline 444 & BrPe3295 & $\begin{array}{l}\text { Maracuja_ } \\
\text { NoIndex_L } \\
\text { 003_R1_00 } \\
\text { 1_contig_6 } \\
4902\end{array}$ & 3 & 782 & 793 & 12 & 4 & 9 & $\begin{array}{l}\text { GTATGCCTTTGACGGCCTTCTCTTATCTTCCTATATTCTGTGTGACAG } \\
\text { GTAGTATATTATCCGATATTCCTTGTGTTCCCAATAAGAAATCCACA } \\
\text { TCCGATTCTGGTCATTGAATACACGATATTTTGGAGAATCACTAATG } \\
\text { ATGGCGAGGAAGAAGAAGAATGATGCTTGTCAAAGCCATAACTACT } \\
\text { TTCTCATGAAAAATAAGAACCTTGGTCTGACTAACTGTACTTCTAAC } \\
\text { TAGCTTCTGTCTTTAAATTGAGTGCTGCAAATCCAGCAATAAAAAGC } \\
\text { ATATCCCAAGCTGGGCCCGGAAACAGACCG }\end{array}$ & GAA & G & 14,78 & 208 & $\begin{array}{l}\text { ATCCACATCCGATTC } \\
\text { TGGTC }\end{array}$ & 59,7 & $\begin{array}{l}\text { CCAGCTTGGGATAT } \\
\text { GCTTTT }\end{array}$ & 59,2 & 50 & 45 \\
\hline 445 & BrPe3296 & $\begin{array}{l}\text { Maracuja_ } \\
\text { NoIndex_L } \\
\text { 003_R1_00 } \\
\text { 1_contig_6 } \\
5273\end{array}$ & 3 & 695 & 709 & 15 & 5 & 12 & $\begin{array}{l}\text { CCCATGAAAATTTCTCAAACCTGAGAAGGAAAAGAACAACTGAGAA } \\
\text { AGAATTGAATTTACCGCTTTTACTCTTTCCTCGCTTGTGAAGAGTCAT } \\
\text { GCACTGTACTCTCTCACCTTCACCTCTTTTATTGCCTTTCTTCCGCAT } \\
\text { CACTTCACCTTCTTCTTCTTCTTGTTTCTCAAGGTCCTTCTCTTCAATG } \\
\text { ACACGCCTACTCAAATCCCTTTGGCTCGCAACAAAACCAATATGGA } \\
\text { GACGTTTTAGTTACTTGAACGTAAACTTGTGACAACAATTCAGGCAT } \\
\text { AACGCCGTGATCTCAACGAGAAAGAAATTGA }\end{array}$ & CTT & G & 15,32 & 167 & $\begin{array}{l}\text { TATTGCCTTTCTTCCG } \\
\text { CATC }\end{array}$ & 60,2 & $\begin{array}{l}\text { GGCGTTATGCCTGA } \\
\text { ATTGTT }\end{array}$ & 60 & 45 & 45 \\
\hline
\end{tabular}


APÉNDICE

Marcadores microssatélites desenhados a partir do sequênciamento parcial e da montagem de novo do genoma de P. edulis

\begin{tabular}{|c|c|c|c|c|c|c|c|c|c|c|c|c|c|c|c|c|c|c|c|}
\hline $\mathbf{N}^{\mathbf{o}}$ & Primer & Contig $\mathrm{I}$ & Motivo & Início & Fim & pb & $\begin{array}{c}\mathbf{N}^{\circ} \\
\text { Repet }\end{array}$ & Score & Sequência do contig & Unidade & G/S & Cobertura & pb & Sequência Forward & $\begin{array}{l}\mathrm{T}^{\circ} \mathrm{C} \\
F w d\end{array}$ & Sequência Reverse & $\begin{array}{l}\mathrm{T}^{\circ} \mathrm{C} \\
\operatorname{Rev}\end{array}$ & $\begin{array}{c}\% \mathrm{GC} \\
F w d\end{array}$ & $\begin{array}{c}\% \mathrm{GC} \\
\operatorname{Rev}\end{array} \quad \mathrm{P} / \mathbf{M}$ \\
\hline 446 & BrPe3297 & $\begin{array}{l}\text { Maracuja_ } \\
\text { NoIndex_L } \\
\text { 003_R1_00 } \\
\text { 1_conti__6 } \\
6375\end{array}$ & 3 & 570 & 581 & 12 & 4 & 9 & $\begin{array}{l}\text { TTGTTTTTGGTGGTGATTCTGATCTTAACCTGTGGTGGGGTTTTGTAC } \\
\text { GTAAGTAGGTTAGGCGTAGAGTTGCCTGCAAATTGTCACTTGGCTGT } \\
\text { GTACTTAAAGTTTGATTCTGACTTGTAGAGTTCGACGGAGAGTGAAA } \\
\text { GGAGTTTGTGTTGTTGTTGTGGTCGTGATGGGGAAGGGTTCCAAGTT } \\
\text { CAATTGTAAGTCTGCATCTCATAAGCTCTTCAAGGACAGGGCTAAG } \\
\text { AAACGTGTTGATGATCTACAAGGGATGTCTTGGATCTGCAGTTTGC } \\
\text { ACGGAAAGAGAGCCGCAACATCGATGTGGC }\end{array}$ & TGT & $\mathrm{G}$ & 14,82 & 215 & $\begin{array}{l}\text { ACCTGTGGTGGGGTT } \\
\text { TTGTA }\end{array}$ & 60,1 & $\begin{array}{l}\text { CACGTTTCTTAGCCC } \\
\text { TGTCC }\end{array}$ & 59,7 & 50 & 55 \\
\hline 447 & BrPe3298 & $\begin{array}{l}\text { Maracuja_ } \\
\text { NoIndex_L } \\
003 \text { 11_00 } \\
\text { 1_contig_6 } \\
6387\end{array}$ & 3 & 706 & 717 & 12 & 4 & 9 & $\begin{array}{l}\text { TGAAAAGTACATGCATTGATTTTACCTTTTGTTCTTACCACTTTGTCA } \\
\text { ATATCATTTATAATATTTTCCATTGGATGAACTTTGATTTTTGGAACC } \\
\text { TTTTGGGGAGTTGTATTTGATCATCCTTCTTTTCCTGGTATTTGATAA } \\
\text { TTGTTATTCTTCTTCTTCATCATCCATACCTGAGACATCCTTTCTTGG } \\
\text { ACAATGCAGGTTAGTCTTATCAACAATTACAAAATGTGTAATTTGCTC } \\
\text { TCCCTAAGCTAGTTATAATTATGAGTCAAACAAATTAAGATGTAAT } \\
\text { ACATTTCTTTGATTTTAACAATTCAA }\end{array}$ & TTC & $\mathrm{s}$ & 54,69 & 158 & $\begin{array}{l}\text { GGAACCTTTTGGGGA } \\
\text { GTTGT }\end{array}$ & 60,2 & $\begin{array}{l}\text { GCTTAGGGAGAGCA } \\
\text { AATTACACA }\end{array}$ & 59,8 & 50 & 43,5 \\
\hline 448 & BrPe3299 & $\begin{array}{l}\text { Maracuja_ } \\
\text { NoIndex_L } \\
\text { 003_R1_00 } \\
\text { 1_contig_6 } \\
6982\end{array}$ & 3 & 477 & 488 & 12 & 4 & 9 & $\begin{array}{l}\text { GTTTGTGATGGGGGATGTCCAGGCATATCTTTTGTTGGACGACATGTA } \\
\text { GTTCGTGTATTGGAGAACAGTTACCAAGAGATGAATTATAACATTTT } \\
\text { GTGAGATTAGTATCTTTATTTCTTATTAAGTTAGTGAAGAATCAACT } \\
\text { TATGGTTACATGATGATGATGTGCTTGCAGGGAAGTAGTCCATGAA } \\
\text { GAATCTGGTCATGTGCTGAAAGTTCATTTAGACGGGTTCATTTGTC } \\
\text { TGGTGATGAACCGAGTTTGGATAATTATGATACCAGTGGTCCTCAAA } \\
\text { ACATCAGTCCTCGAACAGGTATACATCTCAA }\end{array}$ & ATG & $\mathrm{s}$ & 16,96 & 217 & $\begin{array}{l}\text { GGCATATCTTTTGTTG } \\
\text { GACGA }\end{array}$ & 60,0 & $\begin{array}{l}\text { CCAGACAAATGAAC } \\
\text { CCGTCT }\end{array}$ & 60 & 42,9 & 50 \\
\hline 449 & BrPe3300 & $\begin{array}{l}\text { Maracuja_ } \\
\text { NoIndex_L } \\
003 \text { 121_00 } \\
\text { 1_contig_6 } \\
7121\end{array}$ & 3 & 186 & 197 & 12 & 4 & 9 & $\begin{array}{l}\text { GAAGCAGTATTTGCCTCACTACACTGCGCAGGAGCAGTGGATGGAC } \\
\text { CATTTTGGTGACAAGTGGGACCTGTTTCACAAGAGGAAGATGGAAT } \\
\text { TTGATCCCAGGCGCATTTTATCAACCGGGCAACGCATATTCAAGCCG } \\
\text { TCCTTCGTTTCTGATGATGATGAGGTGGCAGCATCTTGATAAATGGC } \\
\text { AATGATAGGATGCATAACATACTAACCTCGCTAGGAATAATCTTGT } \\
\text { GCATATAAGGGACGACCAAAAATAGTAAGCAATCGATGAACCAATA } \\
\text { ATGCCACCAATGAGTGGAAATGGAAATACCCAAA }\end{array}$ & TGA & G & 13,52 & 250 & $\begin{array}{l}\text { GGATGGACCATTTTG } \\
\text { GTGAC }\end{array}$ & 60,0 & $\begin{array}{l}\text { TTGGTGGCATTATTG } \\
\text { GTTCA }\end{array}$ & 59,8 & 50 & 40 \\
\hline 450 & BrPe3301 & $\begin{array}{l}\text { Maracuja_ } \\
\text { NoIndex_L } \\
003 \_R 1 \_00 \\
\text { 1_contig_6 } \\
7356\end{array}$ & 3 & 227 & 238 & 12 & 4 & 9 & $\begin{array}{l}\text { GGAGCCCTTGAGGCATAAAAGTGCAGCGTCATAGGCTCTAGCGGCA } \\
\text { GCTTCAGGTGTAGAATAAGAACCTAACCAAATTCTTGTTTTCTGGTT } \\
\text { TGGTGCTCTTATCTCTGACACCCAAGAACCCCAGCTTCTCATCCTCA } \\
\text { CTCCCTTGTACTTCTTCTTCTTGCATGATGTAGTAGATGAGGCTGAA } \\
\text { GATGTGGATGATGCCATTGCCTTGGATGTCTCTGATAACTGGATCTT } \\
\text { AGGCTCAGTCTTCACCATTTGTGTAGATAACACTAGCTAACAAAGAT } \\
\text { ACAATATATATATATATATAGAGCAATCAAA }\end{array}$ & СТT & G & 15,75 & 178 & $\begin{array}{l}\text { AGTGCAGCGTCATAG } \\
\text { GCTCT }\end{array}$ & 60,2 & $\begin{array}{l}\text { CATCCACATCTTCA } \\
\text { GCCTCA }\end{array}$ & 59,8 & 55 & 50 \\
\hline
\end{tabular}

G: genoma funcional

S: genoma estructural

P: polimórfico

M: monomórfico 
APÉNDICE

Marcadores microssatélites desenhados a partir do sequênciamento parcial e da montagem de novo do genoma de $P$. edulis

\begin{tabular}{|c|c|c|c|c|c|c|c|c|c|c|c|c|c|c|c|c|c|c|c|}
\hline $\mathbf{N}^{\mathbf{o}}$ & Primer & Contig $\mathrm{I}$ & Motivo & Início & Fim & pb & $\begin{array}{c}\mathbf{N}^{\circ} \\
\text { Repet }\end{array}$ & Score & Sequência do contig & Unidade & G/S & Cobertura & pb & Sequência Forward & $\begin{array}{l}\mathrm{T}^{\circ} \mathrm{C} \\
F w d\end{array}$ & Sequência Reverse & $\begin{array}{r}\mathrm{T}^{\circ} \mathrm{C} \\
\operatorname{Rev}\end{array}$ & $\begin{array}{c}\% \mathrm{GC} \\
F w d\end{array}$ & $\begin{array}{c}\% \mathrm{GC} \\
\operatorname{Rev}\end{array} \quad \mathrm{P} / \mathbf{M}$ \\
\hline 451 & BrPe3302 & $\begin{array}{l}\text { Maracuja_ } \\
\text { NoIndex_L } \\
\text { 003_R1_00 } \\
\text { 1_contig_6 } \\
7402\end{array}$ & 3 & 1760 & 1771 & 12 & 4 & 9 & $\begin{array}{l}\text { AAGGAAGTGTCCGCAACACGTGCCAAAGTAGAAATCTTCTTGATTG } \\
\text { GCTTCATTTTCTCGATCAATTTCGTCTTCACTAAATTGGTTATTGATC } \\
\text { TCTTCTTCGATCAGTTTGATTAGCAAATCGCACAATGACCATGCCTC } \\
\text { TTCTAGTTGTTCTTCTTCTTCATCTACGTCTTGATCTAAGGCAGAGTC } \\
\text { TGAATCTTCTAATGGGCAATTAGTTCCCATTTCTAGCCGCACTGGAA } \\
\text { AAAATGTTCGTTGCTCCTATGGGAAACAAATTCCAGAACTGAGTT } \\
\text { ATTGCTTTTATGATTATAATTCGCATTTA }\end{array}$ & TTC & $\mathrm{G}$ & 14,77 & 249 & $\begin{array}{l}\text { GCAACACGTGCCAAA } \\
\text { GTAGA }\end{array}$ & 59,9 & $\begin{array}{l}\text { TCCCATAGGAGCAA } \\
\text { ACGAAC }\end{array}$ & 60,1 & 50 & 50 \\
\hline 452 & BrPe3303 & $\begin{array}{l}\text { Maracuja_ } \\
\text { NoIndex_L } \\
\text { 003_R1_00 } \\
\text { 1_conti__6 } \\
7991\end{array}$ & 3 & 1129 & 1143 & 15 & 5 & 12 & $\begin{array}{l}\text { GCTACATTCCACACCACATGCTCACAGCCCCACCTACAACCGGACA } \\
\text { GCACAAGGCCAACTCATGGAGACGTGCAATTCTGATTGGGTGTTTG } \\
\text { GGTCATGCATCACCCATTTATGATTCAACCATCCGTCAAAGTATTGA } \\
\text { TTATTCCGTGTATTATTATTATTATGGAATAATAAGCAAGTAACTTA } \\
\text { CGTGTTAGATTTTATTTCCCAATTATTATTCTAAAATGGGCAGCAGA } \\
\text { TCCAATTACCTCTCCTAATTGTCATTTGCTTCCATAAGCCTAAGACGT } \\
\text { CATCCGTTACGCTACGCATGTGGGTGCTCGATT }\end{array}$ & TAT & $\mathrm{s}$ & 14,43 & 188 & $\begin{array}{l}\text { CTCACAGCCCCACCT } \\
\text { ACAAC }\end{array}$ & 60,6 & $\begin{array}{l}\text { TGGGAAATAAAATC } \\
\text { TAACACGTAA }\end{array}$ & 57 & 60 & 29,2 \\
\hline 453 & BrPe3304 & $\begin{array}{l}\text { Maracuja_ } \\
\text { NoIndex_L } \\
003 \_ \text {R1_00 } \\
\text { 1_contig_6 } \\
8009\end{array}$ & 3 & 1750 & 1761 & 12 & 4 & 9 & $\begin{array}{l}\text { TAAACAAAGTCTGATTTCACTCATTAGTGATGCTTAAATCGAATCGG } \\
\text { TGTGCTGTAGTGTTCTTCAGGTTATTGGTACTGTACGTATGTGAGCT } \\
\text { GAAGAGCTATCAAGACATACCTGTTTCCTAGCATCTCATGCAGTTTG } \\
\text { ATGATAGTGTCTTCTTCTTCTCTGGTGAAATTTCCTCGTTTAAGATCA } \\
\text { GGCCGCAAGTAATTTATCCATCTCAGTCTGCAACTCTTT }\end{array}$ & TCT & G & 15,96 & 164 & $\begin{array}{l}\text { TAAATCGAATCGGTG } \\
\text { TGCTG }\end{array}$ & 59,7 & $\begin{array}{l}\text { CTTGCGGCCTGATC } \\
\text { TTAAAC }\end{array}$ & 59,8 & 45 & 50 \\
\hline 454 & BrPe3305 & $\begin{array}{l}\text { Maracuja_ } \\
\text { NoIndex_L } \\
\text { 003_R1_00 } \\
\text { 1_conti__6 } \\
8226\end{array}$ & 3 & 261 & 272 & 12 & 4 & 9 & $\begin{array}{l}\text { TCCTCCAAATTGACTCATCACAATCGACCTTCTTCGCTTGTTCTTCAA } \\
\text { CTTCATCTTCTCCACTCGAATAGTCTTGTTCCTTTTGTGGAACTGGAG } \\
\text { CTATCAGTCTCCTGTCATCCGCATTCGAGTTTCTTGGCTTGCTTTGGC } \\
\text { TTTTATCTCCTCCTCCTCTTGACAACCCAACAAGCCATTTCTGTGCAT } \\
\text { CATCCCACTTGGAAGGAGTTGGCTTCCCTAAGGCTGTACGATGGCC } \\
\text { AGAACGACTAGCAGCATTACTTTTGTGAAACTCAAAGCTAATGGCG } \\
\text { TTGCTACTCGAAATCTCCTGAACTGGAC }\end{array}$ & СТC & G & 15,11 & 162 & $\begin{array}{l}\text { CGACCTTCTTCGCTTG } \\
\text { TTCT }\end{array}$ & 59,6 & $\begin{array}{l}\text { AGAAATGGGCTTGTT } \\
\text { GGGTTG }\end{array}$ & 60 & 50 & 45 \\
\hline 455 & BrPe3306 & $\begin{array}{l}\text { Maracuja_ } \\
\text { NoIndex_L } \\
\text { 003_R1_00 } \\
\text { 1_contig_6 } \\
8689\end{array}$ & 3 & 252 & 266 & 15 & 5 & 12 & $\begin{array}{l}\text { AACTTAGACAGTTAAGGCCTGATGAAAAAACCAAGAAAGTTCTATAA } \\
\text { AGAATGATAGGGCCATAAGATGAGAAGGTGAGCAAGCCAATTAAG } \\
\text { GGAATCAATAACATGTAAAAGAGCTGAACCCGATGGAATGAATGCA } \\
\text { TTCCATGAATGTCGATGATGATGATGATATCGAAGGAAGTGAGAGC } \\
\text { CTATGATGGCAGCTTGGACTGAATAAGAGTAAGCATCGAAAGCCAG } \\
\text { GTAGATGATAAAGGATCCGAGTGGTATCCGAGTGATGTGTTACCTG } \\
\text { TGTTAAAGGTGGACTAACCATTACAACAAAAGAATGAAAA }\end{array}$ & GAT & $\mathrm{s}$ & 24,67 & 219 & $\begin{array}{l}\text { GGCCTGATGAAAAAC } \\
\text { CAAGA }\end{array}$ & 60,1 & $\begin{array}{l}\text { TCTACCTGGCTTTCG } \\
\text { ATGCT }\end{array}$ & 60 & 45 & 50 \\
\hline
\end{tabular}

G: genoma funcional

S: genoma estructural

P: polimórfico

M: monomórfico 
APÉNDICE

Marcadores microssatélites desenhados a partir do sequênciamento parcial e da montagem de novo do genoma de $P$. edulis

\begin{tabular}{|c|c|c|c|c|c|c|c|c|c|c|c|c|c|c|c|c|c|c|c|}
\hline $\mathbf{N}^{\mathbf{o}}$ & Primer & Contig $\mathrm{I}$ & Motivo & Início & Fim & pb & $\begin{array}{c}\mathbf{N}^{\mathbf{o}} \\
\text { Repet }\end{array}$ & Score & Sequência do contig & Unidade & G/S & Cobertura & pb & Sequência Forward & $\begin{array}{l}\mathrm{T}^{\circ} \mathrm{C} \\
F w d\end{array}$ & Sequência Reverse & $\begin{array}{r}\mathrm{T}^{\circ} \mathrm{C} \\
\operatorname{Rev}\end{array}$ & $\begin{array}{c}\% \mathrm{GC} \\
F w d\end{array}$ & $\begin{array}{c}\% \mathrm{GC} \\
\operatorname{Rev}\end{array} \quad \mathrm{P} / \mathbf{M}$ \\
\hline 456 & BrPe3307 & $\begin{array}{l}\text { Maracuja_ } \\
\text { NoIndex_L } \\
\text { 003_R1_00 } \\
\text { 1_conti__6 } \\
8882\end{array}$ & 3 & 448 & 462 & 15 & 5 & 12 & $\begin{array}{l}\text { TGAATAGCCACATGAGGATGCAAAGATGACCGATGTGGCCAAGTAT } \\
\text { GGAATTCCAAATGATATTTGCTTGCCCGGTAAATGGTGTAATTCTTA } \\
\text { TTGGTGAACAGAGGGGACTGAGCTCGAAGCGTTGGATCTAAAAG } \\
\text { GAGATTGAACTAAGAAGAAGAAGAAGCATAGTCCCTATTTTTGCTC } \\
\text { CTGGTCACCCCAAAGTGCTATCGATCGAACAAGAGAACAGTGGATA } \\
\text { AAAATGAGTCTCCCGTGGAGCATACGAAAGAAGAATGCCGCTAATG } \\
\text { ATGGCCTCGAAAGTGTTGTGTGGCCATGATTGTAAAAG }\end{array}$ & $\overline{A A G}$ & $\mathrm{~s}$ & 27,44 & 237 & $\begin{array}{l}\text { TGCCCGGTAAATGGT } \\
\text { GTAAT }\end{array}$ & 60,1 & $\begin{array}{l}\text { CATGGCCACACAAC } \\
\text { ACTTTC }\end{array}$ & 60 & 45 & 50 \\
\hline 457 & BrPe3308 & $\begin{array}{l}\text { Maracuja_ } \\
\text { NoIndex_L } \\
\text { 003_R1_00 } \\
\text { 1_contig_6 } \\
9662\end{array}$ & 3 & 1108 & 1119 & 12 & 4 & 9 & $\begin{array}{l}\text { AGTAAGGGACAGTTGCTGGTGTTGCAGATTTCTGGACAAACACAAG } \\
\text { AATATTGGACCCACGGATTGTTGATCTACATCTAGAGTTTCTGCTAG } \\
\text { AGTTCCCACAATGAGATCCACCAGGAGATTTCGCTCTGATGATCTGA } \\
\text { AAATCTTTAGTATTATTATTATATTAGATTACATCAATAATGCACAT } \\
\text { TAAAATGCTTTTGCTTTCAACTAGACTGCATTTCAGAGGACAAAAAA } \\
\text { CAGGTATATGAATTACAATTATGATTACCATCCGCGCCTGGAGGAG } \\
\text { GTAAAGCAAAAATCACTCAGTGCTTTTCACTA }\end{array}$ & TAT & $\mathrm{s}$ & 16,39 & 189 & $\begin{array}{l}\text { AAGGGACAGTTGCTG } \\
\text { GTGTT }\end{array}$ & 59,6 & $\begin{array}{l}\text { TTTTAATGTGCATTA } \\
\text { TTGATGTAATCT }\end{array}$ & 57,5 & 50 & 22,2 \\
\hline 458 & BrPe3309 & $\begin{array}{l}\text { Maracuja_ } \\
\text { NoIndex_L } \\
\text { 003_R1_00 } \\
\text { 1_contig_6 } \\
9682\end{array}$ & 3 & 939 & 950 & 12 & 4 & 9 & $\begin{array}{l}\text { TAACCTATCCGTTCCCTCTTCTTGTTTCCCTCGGTCGCCGCGTAAAAC } \\
\text { AGAGATTCCAGTCCGGGTACGGTAAGCCGTTTCCTCTCAGATCCGA } \\
\text { GCGAGAGAAAGCGAGGCTAGAAGGAAAGAGAGGGGAAAAGAAAC } \\
\text { CATGAGCGGGAAAGGAGGAGGAGGCGGAGTGGGGGCGGTGAGTTA } \\
\text { CAATAATGGGAAAGCTAATAGTGGCATATCGGGGATACCGGCGGGG } \\
\text { TCGAGGAAGATTGTGCAGAGCTTGAAGGAGATGTTAACTGTCCCG } \\
\text { AGGCCGAGATCTACGCTATGCTTAAAGAGTGCAACAT }\end{array}$ & AGG & G & 13,71 & 164 & $\begin{array}{l}\text { CGAGAGAAAGCGAG } \\
\text { GCTAGA }\end{array}$ & 60,0 & $\begin{array}{l}\text { СТCСTTCAAGCTCTG } \\
\text { CACAA }\end{array}$ & 59,3 & 55 & 50 \\
\hline 459 & BrPe3310 & $\begin{array}{l}\text { Maracuja_ } \\
\text { NoIndex_L } \\
\text { 003_R1_00 } \\
\text { 1_contig_7 } \\
0044\end{array}$ & 3 & 703 & 726 & 24 & 8 & 21 & $\begin{array}{l}\text { GGTAGCTCAAACGGTATCAAAACAAGCACCAAGGGGAAATAAAAAG } \\
\text { ACCCATGCACACACTGTATATGCCCTTTACATTTGCGCACAGCACAG } \\
\text { ACCCCACCTCGCTATGTTTTTTTGAAGCCCCTTGGTAACATAACCTT } \\
\text { CTCTTTCTAGTTCCTCCTCCTCCTCCTCCTCCTCCACGATCCAATCCA } \\
\text { GTCCTGCCCGATGACGACAACAAAAGTAACTTTCCTTTTTTCTCTTC } \\
\text { CTAGTTTGACTTTTTATGCCTCTATAAAAATCTACTGCAGATCCAAA } \\
\text { AGTTTCAAAACAGAAAAGGCTGACGAGTGAGCGACTGACAGCT }\end{array}$ & TCC & G & 11,61 & 195 & $\begin{array}{l}\text { GCCCCTTGGTAACAT } \\
\text { AACCTT }\end{array}$ & 59,3 & $\begin{array}{l}\text { GCTCACTCGTCAGC } \\
\text { CTTTTC }\end{array}$ & 60,1 & 47,6 & 55 \\
\hline 460 & BrPe3311 & $\begin{array}{l}\text { Maracuja_ } \\
\text { NoIndex_L } \\
003 \_R 1 \_00 \\
\text { 1_contig_7 } \\
\text { 1314 }\end{array}$ & 3 & 2030 & 2041 & 12 & 4 & 9 & $\begin{array}{l}\text { ATGATATAATGAGAAAGAGGTTTTAATCTCTTCTTCAAACTCCTTGAA } \\
\text { GAAGAACATGGCTTTGCAAGAAGAGGAGACCCAGCAGTTTCAACAG } \\
\text { AGCTCATCGGCATTGGTTTTTGATGGGCTTTACTGCGAAGAAGACAG } \\
\text { TTTTGAGGTAGATGATGATGATAAGAGTGAAATCTGTGTTCAGCATG } \\
\text { CGAGAAAAGAGTCTTCTTTGTCTTCTGTTTGCTCGAACAAGACTTG } \\
\text { TTTTGGGAAGATGACGAGTTGAAGTCTCTAATCTCCAAAGAGAAAG } \\
\text { ATACCCATTTCAGTTTTGATAATGTAGTCTCT }\end{array}$ & GAT & $\mathrm{s}$ & 16,49 & 181 & $\begin{array}{l}\text { AGGAGACCCAGCAGT } \\
\text { TTCAA }\end{array}$ & 59,8 & $\begin{array}{l}\text { TCGTCATCTTCCCAA } \\
\text { AACAA }\end{array}$ & 59,1 & 50 & 40 \\
\hline
\end{tabular}

G: genoma funcional

S: genoma estructural

P: polimórfico

M: monomórfico 
APÉNDICE

Marcadores microssatélites desenhados a partir do sequênciamento parcial e da montagem de novo do genoma de $P$. edulis

\begin{tabular}{|c|c|c|c|c|c|c|c|c|c|c|c|c|c|c|c|c|c|c|c|}
\hline $\mathbf{N}^{\circ}$ & Primer & Contig N & Motivo & Início & Fim & pb & $\begin{array}{c}\mathbf{N}^{\circ} \\
\text { Repet } \\
\end{array}$ & Score & Sequência do contig & Unidade & $\mathbf{G} / \mathbf{S}$ & Cobertura & pb & Sequência Forward & $\begin{array}{l}\mathrm{T}^{\circ} \mathrm{C} \\
F w d \\
\end{array}$ & Sequência Reverse & $\begin{array}{l}\mathrm{T}^{\circ} \mathrm{C} \\
\operatorname{Rev} \\
\end{array}$ & $\begin{array}{c}\% \mathrm{GC} \\
F w d \\
\end{array}$ & $\begin{array}{c}\% \mathrm{GC} \\
\operatorname{Rev} \\
\end{array}$ \\
\hline 461 & BrPe3312 & $\begin{array}{l}\text { Maracuja_ } \\
\text { NoIndex_L } \\
\text { 003_R1_00 } \\
\text { 1_contig_7 } \\
\text { 1351 }\end{array}$ & 3 & 2460 & 2474 & 15 & 5 & 12 & $\begin{array}{l}\text { AAAAAAAATCAGAAGAATCTGAGAGAGAGAGGAAAGACCAGATGA } \\
\text { AGAAGAAGAAGAAGAATTCCTGCGCCAGAAATGATCCCACCAGTCC } \\
\text { GAGTCAATGGCGTTAGGGTCTACGGGAAGGTGCTTATGGTTTTGCT } \\
\text { CCTGTTCTTGTGCTTCTTCTTCTTCTTGAGTTTCTTTGAAGCTAGTTTA } \\
\text { CTTTTCTTGGGCTTCTTTGGAGAAGCCATTATGTATCCAAAATCGAA } \\
\text { ATCTTCAGATGGGAGCTCTTGATTGGGTAGTAAATCCCAGGGGAAG } \\
\text { AAAAGCAAAATGCGGTAACTTGCCTGATCGGTAAA }\end{array}$ & $\begin{array}{l}\text { CTT } \\
\end{array}$ & $\mathrm{G}$ & 25,23 & 161 & $\begin{array}{l}\text { AACGGTGCTTATGGT } \\
\text { TTTGC }\end{array}$ & 60,0 & $\begin{array}{l}\text { TCCCCTGGGATTTA } \\
\text { CTACCC }\end{array}$ & 60 & 45 & 55 \\
\hline 462 & BrPe3313 & $\begin{array}{l}\text { Maracuja_ } \\
\text { NoIndex_L } \\
\text { 003_R1_00 } \\
\text { 1_contig_7 } \\
\text { 1694 }\end{array}$ & 3 & 928 & 942 & 15 & 5 & 12 & $\begin{array}{l}\text { GGTGTTTTACTGGTTGTTTGACCAACCGGTTGTCATCAGTTATGCTCC } \\
\text { TTATTTTCGGAGTTATTGGCTCTGTTGTCTTGCCTATGAGTGCTATCA } \\
\text { ATCAAACTATCACGTTTCTTCTCGAAGTTCACATTTTCTCAATTAATG } \\
\text { GACAAACTGCTGCTGCTGCTGAGGAGAAAGCTGAGGGAAAACAATT } \\
\text { TGTGCTTGCGGGGGTTCATATTTATAGATGTGTAGGAGCATCGCAAT } \\
\text { GCTTGTGGGAGATGAATCAAAGTGGTTCAAATGAGCTGGCATGCAT } \\
\text { GGTCTACATTTTTTTTTCTGAATTGTGAAATC }\end{array}$ & СTG & $\mathrm{s}$ & 15,37 & 172 & $\begin{array}{l}\text { TGGCTCTGTTGTCTTG } \\
\text { CCTA }\end{array}$ & 59,6 & $\begin{array}{l}\text { TTGCGATGCTCCTA } \\
\text { CACATC }\end{array}$ & 59,8 & 50 & 50 \\
\hline 463 & BrPe3314 & $\begin{array}{l}\text { Maracuja_ } \\
\text { NoIndex_L } \\
\text { 003_R1_00 } \\
\text { 1_contig_7 } \\
\text { 2044 }\end{array}$ & 3 & 190 & 201 & 12 & 4 & 9 & $\begin{array}{l}\text { AGGTAAATGGCCCAAAATAGCCAAACCTTGAAGCTACCGATGCCCC } \\
\text { GATGTATCATCTCAGCAGGCCTGTACATAAGTGTGCCAGTGGCTCCC } \\
\text { CCAATCACCTGAGATAACAGGCGGCCAGCCCCCCTGGCCTATCCAC } \\
\text { CTGAGATCCCCTCATCATCATCAGCCAACAGAATCGTAACGTATAG } \\
\text { AAAATGCAGGTATCCCTCTCGGATCCTGAAAAATGATACAATACTCT } \\
\text { CATAAATCCATATACA }\end{array}$ & TCA & G & 116,13 & 206 & $\begin{array}{l}\text { GCCCAAAATAGCCAA } \\
\text { АCCTT }\end{array}$ & 60,3 & $\begin{array}{l}\text { TTCAGGATCCGAGA } \\
\text { GGGATA }\end{array}$ & 59,6 & 45 & 50 \\
\hline 464 & BrPe3315 & $\begin{array}{l}\text { Maracuja__ } \\
\text { NoIndex_L } \\
\text { 003_R1_00 } \\
\text { 1_contig_7 } \\
\text { 2204 }\end{array}$ & 3 & 1016 & 1027 & 12 & 4 & 9 & $\begin{array}{l}\text { TAATCATACTTATAAAATCCAACCACCTCACTTATGTAATCCACTAA } \\
\text { TTCACATTTCCCTGCACAGAAGTCCCCAAGATAGGGGGATTGATATG } \\
\text { CAAGAGAAAGCACAATCAATGCAAAGTTGTAAATCCGCAAGAACTT } \\
\text { AAAGATCTCATTCTTCTTCTTCAGTATCTTAAGCCTCATCCGGAAAA } \\
\text { AAAGCAAGGCAAAACCAAGATATCCAAAGTGAAGTATGTCAAATTC } \\
\text { AAGTGTCCCCGTGATTAAGACCAAAGCAAGAACAAGATCCAGTAGG } \\
\text { TGGCAATAACTGTACAGCCTCAGATAGTCAAGA }\end{array}$ & TTC & G & 16,09 & 170 & $\begin{array}{l}\text { AAAATCCAACCACCT } \\
\text { CACTTATG }\end{array}$ & 59,3 & $\begin{array}{l}\text { CCGGATGAGGCTTA } \\
\text { AGATACT }\end{array}$ & 57,5 & 39,1 & 47,6 \\
\hline 465 & BrPe3316 & $\begin{array}{l}\text { Maracuja_ } \\
\text { NoIndex_L } \\
\text { 003_R1_00 } \\
\text { 1_contig_7 } \\
\text { 2265 }\end{array}$ & 3 & 174 & 185 & 12 & 4 & 9 & $\begin{array}{l}\text { CGTAAGAACAGCTTGAATCAGGGTTTACCATCCATCACAAACCAGC } \\
\text { CGCCATCTTTAGAGGTTTGGCAGTAGCCATGTGCTTGAAAGCTGTGG } \\
\text { TGACGCCAGAACTCAGAGAGTCTATAATCCGAAGTTGGAGTTTTGG } \\
\text { GACTTGGAAAGAACAACAACAACGACAACCAATCTGACATGCAAA } \\
\text { AGTTTTTAAAGAACCAAGTTGAAAGATATGAAGAAACCGATTAATC } \\
\text { AACTCTGG }\end{array}$ & AAC & G & 10,97 & 170 & $\begin{array}{l}\text { TGAATCAGGGTTTAC } \\
\text { CATCCA }\end{array}$ & 60,2 & $\begin{array}{l}\text { TTGCATGTCAGATT } \\
\text { GGTTGTC }\end{array}$ & 59,6 & 42,9 & 42,9 \\
\hline
\end{tabular}

G: genoma funcional

S: genoma estructural

P: polimórfico

M: monomórfico 
APÉNDICE

Marcadores microssatélites desenhados a partir do sequênciamento parcial e da montagem de novo do genoma de $P$. edulis

\begin{tabular}{|c|c|c|c|c|c|c|c|c|c|c|c|c|c|c|c|c|c|c|c|}
\hline $\mathbf{N}^{\circ}$ & Primer & Contig & Motivo & Início & Fim & pb & $\begin{array}{c}\mathbf{N}^{\mathbf{o}} \\
\text { Repet }\end{array}$ & Score & Sequência do contig & Unidade & G/S & Cobertura & pb & Sequência Forward & $\begin{array}{l}\mathrm{T}^{\circ} \mathrm{C} \\
F w d\end{array}$ & Sequência Reverse & $\begin{array}{r}\mathrm{T}^{\circ} \mathrm{C} \\
\operatorname{Rev}\end{array}$ & $\begin{array}{c}\% \mathrm{GC} \\
F w d\end{array}$ & $\begin{array}{c}\% \mathrm{GC} \\
\operatorname{Rev}\end{array}$ \\
\hline 466 & BrPe3317 & $\begin{array}{l}\text { Maracuja_ } \\
\text { NoIndex_L } \\
\text { 003_R1_00 } \\
\text { 1_contig_7 } \\
2425\end{array}$ & 3 & 702 & 713 & 12 & 4 & 9 & $\begin{array}{l}\text { TTGATCACAACCTGTCAGGGATTATTTTATCAACATCAAAGGGGGCT } \\
\text { GCTGAAGTGTCAAAGGCATCTGACAAACAGAAAGTCTGACATCAAA } \\
\text { ACATTACTTTGTTCTTCTGAAGGTGAAGGAGCAAGAACAACAGGTC } \\
\text { TCGTGTAGTGGTGATGATGATGACCTCGATTTCTGAGTGATGGGGCA } \\
\text { CTGCTAGGAGTTGGGCCATAGGCTGAAATAGAAAGAGATGATGCTA } \\
\text { GTATTCTCAATGATGTACTGGAAAAATCATCAGACGTGATTATAATT } \\
\text { CATAAGTCACTACCTTGATGAGTTGGAGGAGCA }\end{array}$ & TGA & $\bar{G}$ & 16,2 & 188 & $\begin{array}{l}\text { GCAAGAACAACAGGT } \\
\text { CTCGTG }\end{array}$ & 60,9 & $\begin{array}{l}\text { GCTCCTCCAACTCA } \\
\text { TCAAGG }\end{array}$ & 59,8 & 52,4 & 55 \\
\hline 467 & BrPe3318 & $\begin{array}{l}\text { Maracuja_ } \\
\text { NoIndex_L } \\
003 \text { R1_00 } \\
\text { 1_contig_7 } \\
3180\end{array}$ & 3 & 1169 & 1180 & 12 & 4 & 9 & $\begin{array}{l}\text { TCTCCTCACTCCTCAGGACTTGGCTCTGAATGGATTGTCCCTCGACC } \\
\text { TAACTCTGGGGTCTTCCGTTACTGCTGGTTCCCTTGAAGCACAATCT } \\
\text { CATGTGCATGAATGCTGTTGCCCTGAAAGATCAAGCGATAATGTTG } \\
\text { ATTTCCCTGGTGATGATGATGAGGTGCCACTATTTGCTCGACGGAG } \\
\text { TTTCGTCTGGTGTGATTTTGTGTGTTGTTATATGCACAATCTGTTCTA } \\
\text { CCTTAATACCATCATGTACTTCTAATCAACTAATTCTCCTCCATGTTC } \\
\text { TCTTCTCTTCTTTTAGGCTACATCGGATA }\end{array}$ & TGA & G & 23,79 & 160 & $\begin{array}{l}\text { TCTGGGGTCTTCCGTT } \\
\text { ACTG }\end{array}$ & 60,1 & $\begin{array}{l}\text { CACACAAAATCACA } \\
\text { CCAGACG }\end{array}$ & 60,1 & 55 & 47,6 \\
\hline 468 & BrPe3319 & $\begin{array}{l}\text { Maracuja_ } \\
\text { NoIndex_L } \\
003 \text { R1_00 } \\
\text { 1_contig_7 } \\
3685\end{array}$ & 3 & 1665 & 1676 & 12 & 4 & 9 & $\begin{array}{l}\text { AGTAGTGGCTGAAAAAGAAAAATGTCTCAAACAAATAGGAATGGAG } \\
\text { CCATTATATACCTCTTCTGTATCCTCGTTCCCATATATTTTGTATCTA } \\
\text { AAAGCCTGGCTCAAGTTATTCGCTAGGGCTGCTACATCGTAGTCTCT } \\
\text { GTCATGAAGGTCATCATCATCACTATCCTTGGTTCTATCTTGCAATG } \\
\text { CTGTTGGACGGCTGGAAAAAAGGAATACAAAAGCTTAGCATCCCTG } \\
\text { ACAGTAACAAAGGATAATAACCTAACCCAAGTCCTAAAAGATTAA } \\
\text { CTTAACAGAATAAACCTGCGAACTTCCCCTCAC }\end{array}$ & TCA & G & 16,84 & 197 & $\begin{array}{l}\text { TTCGCTAGGGCTGCT } \\
\text { ACATC }\end{array}$ & 60,5 & $\begin{array}{l}\text { GGGGAAGTTCGCAG } \\
\text { GTTTA }\end{array}$ & 60,3 & 55 & 50 \\
\hline 469 & BrPe3320 & $\begin{array}{l}\text { Maracuja_ } \\
\text { NoIndex_L } \\
003 \text { R1_00 } \\
\text { 1_contig_7 } \\
3698\end{array}$ & 3 & 1358 & 1375 & 18 & 6 & 15 & $\begin{array}{l}\text { ACTTCAAAAGATTCAAGAACCCATCTAACAGTTCCTAGTCCCTCCTC } \\
\text { TGGTGAAGTCCAATCTTTTAGTCCATTGAAATTCGCATACGAGGTGG } \\
\text { AGGAGGCATTTTGCACTGCTGAGAATAGTCCTCAATTATACTCTGCA } \\
\text { TCATCAAGAGGTGGTGGTGGTGGTGGTAAGAGAAGTCCCTTCACTC } \\
\text { CAACTAAAAGTGATGGCTCGAGAAGCTTCTTAGTGGGTATTCGGA } \\
\text { CTACCCCAATTACATGTCGAACACGGAGTCTTCGAGGGCTAAACTT } \\
\text { AGATCTATGAGTGCTCCAAAACAAAGGCCCCAGTATGAG }\end{array}$ & GGT & G & 16,78 & 173 & $\begin{array}{l}\text { ССТССТCTGGTGAAG } \\
\text { TCCAA }\end{array}$ & 60,2 & $\begin{array}{l}\text { GCTTCTCGAGCCAT } \\
\text { CACTTT }\end{array}$ & 59,6 & 55 & 50 \\
\hline 470 & BrPe3321 & $\begin{array}{l}\text { Maracuja_ } \\
\text { NoIndex_L } \\
003 \text { R1_00 } \\
\text { 1_contig_7 } \\
4061\end{array}$ & 3 & 152 & 163 & 12 & 4 & 9 & $\begin{array}{l}\text { TTTAAATCCCTCCATGGAAAGCTCATTAATCCGTTTCAGCTTTAAATTT } \\
\text { GCACCAAATCCATGTAAAGTTTATGACTGCACACAACTGCTAATTCT } \\
\text { GAAAAAGCTCGGGCAGATGTGCATTCGTCAACTTAGTTCTCTTACTG } \\
\text { ATCTCATGCTTCTTCTTCTTTGTCGTCCGCCTGGGGCTAATGCCCTGC } \\
\text { ACCTGGGCTGCAGCCCTACGCTTGGCAGTGTTGGTAGCAGGCTTCAT } \\
\text { GCCATTCTTCAGCAGATATTTCTCTATGTCCACAAAATCACGCGGTA } \\
\text { ATTCAATTTCCCGAAACAGTAATTTCAG }\end{array}$ & СТT & G & 139,33 & 245 & $\begin{array}{l}\text { СCCTCCATGGAAGCT } \\
\text { CATTA }\end{array}$ & 60,0 & $\begin{array}{l}\text { CTGCTGAAGAATGG } \\
\text { CATGAA }\end{array}$ & 59,9 & 50 & 45 \\
\hline
\end{tabular}

G: genoma funcional

S: genoma estructural

P: polimórfico

M: monomórfico 
APÉNDICE

Marcadores microssatélites desenhados a partir do sequênciamento parcial e da montagem de novo do genoma de $P$. edulis

\begin{tabular}{|c|c|c|c|c|c|c|c|c|c|c|c|c|c|c|c|c|c|c|c|}
\hline $\mathbf{N}^{\mathbf{o}}$ & Primer & Contig $\mathrm{I}$ & Motivo & Início & Fim & pb & $\begin{array}{c}\mathbf{N}^{\mathbf{o}} \\
\text { Repet }\end{array}$ & Score & Sequência do contig & Unidade & G/S & Cobertura & pb & Sequência Forward & $\begin{array}{l}\mathrm{T}^{\circ} \mathrm{C} \\
F w d\end{array}$ & Sequência Reverse & $\begin{array}{r}\mathrm{T}^{\circ} \mathrm{C} \\
\operatorname{Rev}\end{array}$ & $\begin{array}{r}\% \mathrm{GC} \\
F w d\end{array}$ & $\begin{array}{c}\% \mathrm{GC} \\
\operatorname{Rev}\end{array} \quad \mathrm{P} / \mathbf{M}$ \\
\hline 471 & BrPe3322 & $\begin{array}{l}\text { Maracuja_ } \\
\text { NoIndex_L } \\
\text { 003_R1_00 } \\
\text { 1_contig_7 } \\
4119\end{array}$ & 3 & 673 & 684 & 12 & 4 & 9 & $\begin{array}{l}\text { CAGATATCACCTTGGATATTGATTCTTTGGACTTGCATTTCGTTCTTG } \\
\text { GGTTGAAAAGTCTTACCTGCTATGGGAGAAACAGAAAACACCCTT } \\
\text { CCACCTTCAAAGAAGAGGGCTGCTGGAAGGGAGATCTCAAGAGATA } \\
\text { ACCCTGGTCTTGATGATGATGAAGACTCAGCAGAGCAGGAGACTGG } \\
\text { AACTTTCAAGAGGGCTAGTGATGAGGTGTTGGCAAACAGAAGAATA } \\
\text { GTGAAAGTTCGTCGTAATCAAACCACATCAACTCCTTCATCAAATCC } \\
\text { ATTTGCTGGAATTCGTCTTGTCTCTCCTGCTGA }\end{array}$ & TGA & $\mathrm{G}$ & 14,81 & 210 & $\begin{array}{l}\text { CACCCTTCCACCTTCA } \\
\text { AAGA }\end{array}$ & 60,1 & $\begin{array}{l}\text { AGACGAATTCCAGC } \\
\text { AAATGG }\end{array}$ & 60,1 & 50 & 45 \\
\hline 472 & BrPe3323 & $\begin{array}{l}\text { Maracuja_ } \\
\text { NoIndex_L } \\
003 \text { R1_00 } \\
\text { 1_contig_1 } \\
11777\end{array}$ & 3 & 361 & 372 & 12 & 4 & 9 & $\begin{array}{l}\text { AAGATTGAGTGAAGATAAAGTCAAACAGTGTGTAGATCCAAAGCTG } \\
\text { AAGGGGGATTACCCACCTAAGGGAGTTGCCAAGGTATATTATCTCT } \\
\text { GCCCATATGTTGTGTATTATTCAGCATTTCAGGTTTCCATTGATATTG } \\
\text { GGTTATTTTCGTTGTTGTTGTTAGCAGCGGTGGCAGCATTATGTGTG } \\
\text { CAGTATGAAGCGGAGTTCCGGCCAAATATGAGCATTGTTGTCAAGG } \\
\text { CTCTGCAACCACTTTTAAAGTCTTCAACAGCTCCTGCTCCGGAGACG } \\
\text { ACATAAAGCAAAGAGATTGATTCCTCGTGTTG }\end{array}$ & GTT & G & 15,56 & 196 & $\begin{array}{l}\text { AAGGGGGATTACCCA } \\
\text { CCTAA }\end{array}$ & 59,5 & $\begin{array}{l}\text { GTTGCAGAGCCTTG } \\
\text { ACAACA }\end{array}$ & 60 & 50 & 50 \\
\hline 473 & BrPe3324 & $\begin{array}{l}\text { Maracuja_ } \\
\text { NoIndex_L } \\
\text { 003_R1_00 } \\
\text { 1_contig_1 } \\
17169\end{array}$ & 3 & 1949 & 1960 & 12 & 4 & 9 & $\begin{array}{l}\text { AACATATCCTAGCAATTAATGTTTGGAAAAGAATCTCAAAAACAAT } \\
\text { TCATGGACTGAATCAGGTATAGAGGTTTACTCTGGTTCAACAGTAAA } \\
\text { GTTGTACATACCGTAAATCCCGCGAACCTCCACCTCTCGCCATTCTT } \\
\text { GGACAAGGGCACAACAACAACACATGAAGTGTGAGAGGAAATCAT } \\
\text { CTACAAAGCCGCCCTGCCAATATATAATACGCTAAGAATAAAAGAA } \\
\text { TTCATGAAAACCATCAAGATTAGAAGTACATTTCCGATTTAAACCAC } \\
\text { TTGTTCAATGTTTTTTATGTTATGTACAGGTAAT }\end{array}$ & $\mathrm{ACA}$ & G & 18,09 & 181 & $\begin{array}{l}\text { ATACCGTAAATCCCG } \\
\text { CGAAC }\end{array}$ & 61,1 & $\begin{array}{l}\text { CAAGTGGTTTAAAT } \\
\text { CGGAAATG }\end{array}$ & 58,5 & 50 & 36,4 \\
\hline 474 & BrPe3325 & $\begin{array}{l}\text { Maracuja_ } \\
\text { NoIndex_L } \\
\text { 003_R1_00 } \\
\text { 1_contig_1 } \\
\text { 29553 }\end{array}$ & 3 & 2988 & 3002 & 15 & 5 & 12 & $\begin{array}{l}\text { TCAGCACGCACAGAGCTTGAATTCCATTCCAGTAAAAAGCAGTCAA } \\
\text { TAAATTGTCTCAGAACATCACCACCTTTGTCATTGAAGATATCTATT } \\
\text { ACTGACTCCATATCCAAATAAGACCTCTCTGAGCCAGATTCAGTTCC } \\
\text { ATCTTCACCTTTCTTCTTCTTCTTCGAATCCACAGATTGTGCTCCAGA } \\
\text { TTTGTTAGAATTACCTCCAGATTGATCAGCAGTTTCCACTTTCTGAG } \\
\text { ACTGAGTCATATCCTTTCCAGAATAGAATGCCAGATTTAGAAGTTTG } \\
\text { AGAGTCTGAACAACAGACTCTTCACCGAAATAA }\end{array}$ & TTC & G & 14,34 & 188 & $\begin{array}{l}\text { CTGAGCCAGATTCAG } \\
\text { TTCCA }\end{array}$ & 059 & $\begin{array}{l}\text { CGGTGAAGAGTCTG } \\
\text { TTGTTCAG }\end{array}$ & 59,9 & 50 & 50 \\
\hline 475 & BrPe3326 & $\begin{array}{l}\text { Maracuja_ } \\
\text { NoIndex_L } \\
\text { 003_R1_00 } \\
\text { 1_contig_1 } \\
\text { 32368 }\end{array}$ & 3 & 3485 & 3496 & 12 & 4 & 9 & $\begin{array}{l}\text { TTGTGTCTCTAGTCGTTGGCATAGCAACGGAAGGTTGGCCTAGGGGT } \\
\text { GCCCACGATGGACTTGGAATTGTTGCGAGCATTCTGCTTGTTGTGTT } \\
\text { TGTCACTGCCACTAGTGATTATAAGCAATCTTTGCAGTTCAAAGATT } \\
\text { TGGACAGGGAGAAGAAGAAGATAACAGTTCAGGTTAGTAGAAATG } \\
\text { GCTTGAGGCAGAAGATCTCGATATATGATCTCCTCGCCGGAGACATT } \\
\text { GTCCATCTTAGTATTGGAGACCAGGTCCTGCAGATGGACTTTTTCT } \\
\text { TTCAGGGTTTTCTTTGCTAATCAATGAATCAA }\end{array}$ & AGA & G & 14,18 & 201 & $\begin{array}{l}\text { GAATTGTTGCGAGCA } \\
\text { TTCTG }\end{array}$ & 59,4 & $\begin{array}{l}\text { CAGGGACCTGGTCT } \\
\text { CCAATA }\end{array}$ & 59,9 & 45 & 55 \\
\hline
\end{tabular}

G: genoma funcional

S: genoma estructural

P: polimórfico

M: monomórfico 
APÉNDICE

Marcadores microssatélites desenhados a partir do sequênciamento parcial e da montagem de novo do genoma de $P$. edulis

\begin{tabular}{|c|c|c|c|c|c|c|c|c|c|c|c|c|c|c|c|c|c|c|c|}
\hline $\mathbf{N}^{\circ}$ & Primer & Contig I & Motivo & Início & Fim & pb & $\begin{array}{c}\mathbf{N}^{\circ} \\
\text { Repet }\end{array}$ & Score & Sequência do contig & Unidade & G/S & Cobertura & pb & Sequência Forward & $\begin{array}{l}\mathrm{T}^{\circ} \mathrm{C} \\
F w d\end{array}$ & Sequência Reverse & $\begin{array}{l}\mathrm{T}^{\circ} \mathrm{C} \\
\operatorname{Rev} \\
\end{array}$ & $\begin{array}{r}\% \mathrm{GC} \\
F w d \\
\end{array}$ & $\begin{array}{cc}\begin{array}{c}\% \mathrm{GC} \\
\text { Rev }\end{array} & \mathrm{P} / \mathrm{M} \\
\end{array}$ \\
\hline 476 & BrPe3327 & $\begin{array}{l}\text { Maracuja_ } \\
\text { NoIndex_L } \\
\text { 003_R1_00 } \\
\text { 1_contig_1 } \\
\text { 38769 }\end{array}$ & 3 & 205 & 216 & 12 & 4 & 9 & $\begin{array}{l}\text { TACTTCAAGCACAGCCTTCTGGCTAGAATACATCTCCATTACTTTCG } \\
\text { CAGCAGACTCCAAAATACGATTCCGAGAAACACGGACTTTCTGACG } \\
\text { TTGTAGCCTTCCAACCCTTACCTCTCTTTCATTAGCTAATCCATGACC } \\
\text { ATCAGCACCCTGCTGCTGCTGAAGACGATACAATGCCCGAGACAAA } \\
\text { CCAAA }\end{array}$ & CTG & $\mathrm{G}$ & 10,47 & 150 & $\begin{array}{l}\text { TCTCCATTACTTTCGC } \\
\text { AGCA }\end{array}$ & 59,6 & $\begin{array}{l}\text { CTCGGGCATTGTAT } \\
\text { CGTCTT }\end{array}$ & 60,1 & 45 & 50 \\
\hline 477 & BrPe3328 & $\begin{array}{l}\text { Maracuja_ } \\
\text { NoIndex_L } \\
\text { 003_R1_00 } \\
\text { 1_contig_1 } \\
85703\end{array}$ & 3 & 325 & 336 & 12 & 4 & 9 & $\begin{array}{l}\text { GGAGTGGTGAGAGAGGATATTCCACTCGCTGGAAAGGTTAATATGA } \\
\text { ATGGCGGGTATTTTGGCGATTTATCAAGTGTAGCAGTGAATGGTACT } \\
\text { GGCTTAGGAATCGGATTTCAGCAGAATAAGGGTGGTGGATTGAATA } \\
\text { ATGTTAGCATCAATAATAATAATTCTAATCAGATTTCTTTACAGTCC } \\
\text { TCGAATTTGCCTTTGAATGTCAATGGGATTAGATCAAGCCAAGGAC } \\
\text { AGGTACAGCAGCAGCAAATATATCCTAAGCAGCCTAATGTGGGATA } \\
\text { TGTGCCCCAGATACCTTTGCAAAGCAGTCCTGGG }\end{array}$ & AAT & G & 9,13 & 185 & $\begin{array}{l}\text { TATTCCACTCGCTGG } \\
\text { AAAGG }\end{array}$ & 60,2 & $\begin{array}{l}\text { TCAAAGGCAAATTC } \\
\text { GAGGAC }\end{array}$ & 60,2 & 50 & 45 \\
\hline 478 & BrPe3329 & $\begin{array}{l}\text { Maracuja_ } \\
\text { NoIndex_L } \\
\text { 003_R1_00 } \\
\text { 1_contig_1 } \\
95514\end{array}$ & 3 & 154 & 167 & 21 & 7 & 18 & $\begin{array}{l}\text { GATGAGCAGTTGCGGTGCCTATGCGGTCTCGGATTTGATGCATGGTT } \\
\text { AAGGCACCCGCCTCTAGAACGTAGGTCAATATTCCAGCGGAGATGA } \\
\text { CTTCCGCATCCATCTGTAGCGGGCAAGCAATATAGATATGTATGTGT } \\
\text { GTATATAAATAGAGAGAGAGAGAGTTTGAAGAGGGACATGATGAA } \\
\text { TGAAAGAAAGAAGAGAAGGATTAGAAGGTTGTAGGCAGCAAAGTA } \\
\text { CCTGAAGATCAGCAAGGAGAAGAGCTAGGGACAAGGCCTTGGAGA } \\
\text { GAGGGGAACGACCATCAGGGGACAGAGGCAGGTCCTGAA }\end{array}$ & $\mathrm{AG}$ & G & 7,68 & 158 & $\begin{array}{l}\text { CTCGGATTTGATGCA } \\
\text { TGGTT }\end{array}$ & 60,9 & $\begin{array}{l}\text { TTCATCATGTCCCTC } \\
\text { TTCAAA }\end{array}$ & 58,1 & 45 & 38,1 \\
\hline 479 & BrPe4001 & $\begin{array}{l}\text { Maracuja_ } \\
\text { NoIndex_L } \\
003 \text { R1_00 } \\
\text { 1_contig_4 } \\
65\end{array}$ & 4 & 3399 & 3410 & 12 & 3 & 8 & $\begin{array}{l}\text { CAGACTATCCACTTTAAGAGCTTCCACAATTACACTGCAAGAACGA } \\
\text { CTTCAGGGTCAAAACAACATTCAACTAATAGTTCTTTTTCCTCTTCC } \\
\text { ATCTCAAGAGGTTCAATCTACCAAAAATAGAAACAGGGCTCTACTT } \\
\text { TCACTGCGGAAAAAATAAATAAATGTAGTCATTTTCACATTGACTGAA } \\
\text { CTTTCTAGCCCAGCTACGTAGAAAGATCAAAGATGAGTCACTACTC } \\
\text { AATAGAGACCTAAGTCAAATGTCAACAATCAACCATATCAAACT } \\
\text { TCCTAGACAAACAAAAGCAGCGAAGTTCAAAAAA }\end{array}$ & АAAT & $\mathrm{s}$ & 15,55 & 185 & $\begin{array}{l}\text { AACAGGGCTCTACTT } \\
\text { TCACTGC }\end{array}$ & 60,0 & $\begin{array}{l}\text { TTTGAACTTCGCTGC } \\
\text { TTTTG }\end{array}$ & 59,2 & 50 & 40 \\
\hline 480 & BrPe4002 & $\begin{array}{l}\text { Maracuja_ } \\
\text { NoIndex_L } \\
003 \text { R1_00 } \\
\text { 1_contig_4 } \\
67\end{array}$ & 4 & 1362 & 1373 & 12 & 3 & 8 & $\begin{array}{l}\text { CTGCAATCGATACCATCCCACAGATAGGTTTGGGGAACACACGGAT } \\
\text { CGCCTTGCCAGTTCCTGTTTATTCCATACACTGACTTGATATTTGCGA } \\
\text { CAGCATCAACTAAAACATTCATACAGATACATACAAGCAGCTCGTG } \\
\text { GTCAGGAATGATTAATTAATTAGTCTAGTATATATAACAGTACCAAG } \\
\text { ACATGCAGATTTCAATCAAGTATTACCATCCTTTTCATCTGTTTCA } \\
\text { GACTCTGAAAGCTCAACTACGTAATAGGCCTCAATTGCATTGATGA } \\
\text { GAGGTGGAAGGGTTGAGCCTCCAGTTTTATAG }\end{array}$ & ATTA & $\mathrm{s}$ & 24,73 & 163 & $\begin{array}{l}\text { TACAAGCAGCTCGTG } \\
\text { GTCAG }\end{array}$ & 60,2 & $\begin{array}{l}\text { TCCACCTCTCATCA } \\
\text { ATGCAA }\end{array}$ & 60,2 & 55 & 45 \\
\hline
\end{tabular}

G: genoma funcional

S: genoma estructural

P: polimórfico

M: monomórfico 
APÉNDICE

Marcadores microssatélites desenhados a partir do sequênciamento parcial e da montagem de novo do genoma de $P$. edulis

\begin{tabular}{|c|c|c|c|c|c|c|c|c|c|c|c|c|c|c|c|c|c|c|c|}
\hline $\mathbf{N}^{\circ}$ & Primer & Contig I & Motivo & Início & Fim & pb & $\begin{array}{c}\mathbf{N}^{\circ} \\
\text { Repet }\end{array}$ & Score & Sequência do contig & Unidade & G/S & Cobertura & pb & Sequência Forward & $\begin{array}{l}\mathrm{T}^{\circ} \mathrm{C} \\
F w d \\
\end{array}$ & Sequência Reverse & $\begin{array}{l}\mathrm{T}^{\circ} \mathrm{C} \\
\operatorname{Rev} \\
\end{array}$ & $\begin{array}{c}\% \mathrm{GC} \\
F w d \\
\end{array}$ & $\begin{array}{cc}\% \mathrm{GC} & \mathrm{P} / \mathrm{M} \\
\operatorname{Rev} & \end{array}$ \\
\hline 481 & BrPe4003 & $\begin{array}{l}\text { Maracuja_ } \\
\text { NoIndex_L } \\
\text { 003_R1_00 } \\
\text { 1_contig_3 } \\
062\end{array}$ & 4 & 805 & 816 & 12 & 3 & 8 & $\begin{array}{l}\text { TCATAAACTTACTTAAAGTTTATTAAATGATTCAAATGTGATTGGTT } \\
\text { ATATATATATATGCACTTTTGGAATTGCATGACCAAAAACAGAAAG } \\
\text { ACTGGTCGTTCCCATAACTAAAACAACACCAACAACTTCACCACCTT } \\
\text { TGACCAGAGACTAGCTAGCTAGTAACGACTCCATCTCAGTTTCTTAT } \\
\text { ATTCTTGATATTTAAAGGTTGAGTAGTACAAGCCCACATGCATTAC } \\
\text { CATCCAAATTAAAGTCCATATCCCAATTTTAAGATTCCCAGGAAGAA } \\
\text { CACTAAGCACCAAAGTCACAAGATGTTGAAG }\end{array}$ & $\begin{array}{c}\text { CTAG } \\
\end{array}$ & $\mathrm{s}$ & 18,33 & 175 & $\begin{array}{l}\text { TGGAATTGCATGACC } \\
\text { AAAAA }\end{array}$ & 59,9 & $\begin{array}{l}\text { TTGGATGGTAATGC } \\
\text { ATGTGG }\end{array}$ & 60,2 & 35 & 45 \\
\hline 482 & BrPe4004 & $\begin{array}{l}\text { Maracuja_ } \\
\text { NoIndex_L } \\
003 \text { R1_00 } \\
\text { 1_contig_3 } \\
283\end{array}$ & 4 & 214 & 225 & 12 & 3 & 8 & $\begin{array}{l}\text { GCATCCAACTCTTGAGATCCTATAGCGATTTTGTACAGTCTCATTTTT } \\
\text { GAAGCGATTGTAAGGTTTACAGTTTGTAATATTATTGTTTGGAAAGG } \\
\text { GTGAAGTGAATCATATTTATATGAGCAAATGCAGGTAAACACTTTG } \\
\text { GAGTACATGATGGATGGATGTCTACTTTTGTTTGTATTGTTCTAAGC } \\
\text { ATGGTTTTATCATATTTTTCAATAAAAATATTAACTGTTCTTCTCTAG } \\
\text { CTATCAAACCTTTTATGGCAGCGTAACTGAAAAACACTCAATTGAGT } \\
\text { AGATTTTATATATATATTTCTCATTTGT }\end{array}$ & GATG & $\mathrm{s}$ & 19,06 & 179 & $\begin{array}{l}\text { TTGTTTGGAAAGGGT } \\
\text { GAAGTG }\end{array}$ & 60,0 & $\begin{array}{l}\text { ACGCTGCCATAAAA } \\
\text { GGTTTG }\end{array}$ & 60,1 & 43 & 45 \\
\hline 483 & BrPe4005 & $\begin{array}{l}\text { Maracuja_ } \\
\text { NoIndex_L } \\
\text { 003_R1_00 } \\
\text { 1_contig_4 } \\
\text { 148 }\end{array}$ & 4 & 3630 & 3645 & 16 & 4 & 12 & $\begin{array}{l}\text { GATATGATGCCCACAGTCTAAGTTCTTCCTCTAGTTCTGGTATTTCTT } \\
\text { TGAGTTCTTCCTCACTATTACAATTTACACGTCCAAGAAAGTTGTC } \\
\text { CACTCATCTGCAAATCATGGCAGTAACTCTTAAACAAATCTTCCACT } \\
\text { AAAAGATGATAAATAAATAAATAATATTGAACTATGGATTTTTATTG } \\
\text { CGTAGCGATTTGCAGAAGAACAAAAAAATACCTGGGTAGATTTTT } \\
\text { GCAAGTAAAATAGGATAGAAACACCATCTTCATTTGGAACTTCCAG } \\
\text { ATCCCGAAGGGAAAACAACACTTCTTCTGTATAAT }\end{array}$ & ATAA & $\mathrm{s}$ & 18,65 & 197 & $\begin{array}{l}\text { TGCCCACAGTCTAAG } \\
\text { TTCTTCC }\end{array}$ & 60,7 & $\begin{array}{l}\text { CTGCAAATCGCTAC } \\
\text { GCAATA }\end{array}$ & 60 & 50 & 45 \\
\hline 484 & BrPe4006 & $\begin{array}{l}\text { Maracuja_ } \\
\text { NoIndex_L } \\
\text { 003_R1_00 } \\
\text { 1_contig_4 } \\
670\end{array}$ & 4 & 1659 & 1670 & 12 & 3 & 8 & $\begin{array}{l}\text { TCATATCGTGGATATTGAAAAGCTAAGTGCTGCAATCTGCACTACAG } \\
\text { AGCTACACGCAGTAAATGTCCCTGCAGAGCTGTGCAATAATGGAAAA } \\
\text { TAAATGCTGCGATGACGACGAGCCAATTGCCAAGGGAGGGACCAAC } \\
\text { CCTCCATGCCCAACTAACTAACTCCCTATACATCTCTCCCATGTTAA } \\
\text { TTAGCTTCCAGTTCTAGCAAAGCGTGGAAGGATTGTTGTATCCAAAA } \\
\text { ACTGTCGAAGCGAGGCTACGTACTGGCTATCTTTCTAATTTGTTTCTT } \\
\text { TTCCTTTTCTTTTCTTTTTTTAGCAGATG }\end{array}$ & АACT & G & 16,51 & 172 & $\begin{array}{l}\text { TGGAAATAAATGCTG } \\
\text { CGATG }\end{array}$ & 59,7 & $\begin{array}{l}\text { CCAGTACGTAGCCT } \\
\text { CGCTTC }\end{array}$ & 60 & 40 & 60 \\
\hline 485 & BrPe4007 & $\begin{array}{l}\text { Maracuja_ } \\
\text { NoIndex_L } \\
\text { 003_R1_00 } \\
\text { 1_contig_8 } \\
639\end{array}$ & 4 & 2687 & 2698 & 12 & 3 & 8 & $\begin{array}{l}\text { GGAACAGACCAGTACTGCTCTTGGTCTTTCCTTGATGTAACCTATGG } \\
\text { AAAAAAAAAGTTTTATATGAATGGCAGGAATACGAGCATAAGATTC } \\
\text { AACAAGATTCATGCCCCAAGCTCTCTATCACTTACTTCTTGCAAGAA } \\
\text { GTCTGCAACATTCTTTCTTTCTGGACATGTAAACCCCATCGATGAGA } \\
\text { AGAACTCAAGAGCAGTTTCACGTGGTCCTTGGTATACAATCTGGCCC } \\
\text { TCACATAGAAGAATTATATCATCAAATAGCTCATAAGTCTCAGGCG } \\
\text { CAGGCTGCAGCAAAGAGATCACAGTAGTGCCA }\end{array}$ & ТTCT & G & 17,44 & 151 & $\begin{array}{l}\text { AATGGCAGGAATACG } \\
\text { AGCAT }\end{array}$ & 59,6 & $\begin{array}{l}\text { AAGGACCACGTGAA } \\
\text { АCTGCT }\end{array}$ & 59,8 & 45 & 50 \\
\hline
\end{tabular}

G: genoma funcional

S: genoma estructural

P: polimórfico

M: monomórfico 
APÉNDICE

Marcadores microssatélites desenhados a partir do sequênciamento parcial e da montagem de novo do genoma de $P$. edulis

\begin{tabular}{|c|c|c|c|c|c|c|c|c|c|c|c|c|c|c|c|c|c|c|c|}
\hline $\mathbf{N}^{\circ}$ & Primer & Contig & Motivo & Início & Fim & pb & $\begin{array}{c}\mathbf{N}^{\mathbf{o}} \\
\text { Repet }\end{array}$ & Score & Sequência do contig & Unidade & G/S & Cobertura & pb & Sequência Forward & $\begin{array}{l}\mathrm{T}^{\circ} \mathrm{C} \\
F w d\end{array}$ & Sequência Reverse & $\begin{array}{r}\mathrm{T}^{\circ} \mathrm{C} \\
\operatorname{Rev}\end{array}$ & $\begin{array}{c}\% \mathrm{GC} \\
F w d\end{array}$ & $\begin{array}{c}\% \mathrm{GC} \\
\operatorname{Rev}\end{array}$ \\
\hline 486 & $\begin{array}{l}\text { BrPe4008 } \\
\end{array}$ & $\begin{array}{l}\text { Maracuja_ } \\
\text { NoIndex_L } \\
\text { 003_R1_00 } \\
\text { 1_contig_9 } \\
810\end{array}$ & 4 & 228 & 239 & 16 & 4 & 12 & $\begin{array}{l}\text { ATCCATCAGTTTTATTAGTTAAACCTTTCGAGTGCGTACTAAGTAAA } \\
\text { TCTCCAACGACAACAAACCGCACAGGAGATTTTGTACGGATTAAAC } \\
\text { CAGTTTAGGTTATTTTAATAGTCCACTTTATAATTTGAAGATCGTAA } \\
\text { AATTTTCCACTCAATCAATCAAATCAGTTAAAACTTTTGATCTAAGC } \\
\text { ATTGAAATAGTTAGGACTCATTGGATGTTGAATCGAATCCTTAAAAA } \\
\text { CTGTTGAGATTGTATTTACTTTTGATGTTAAAACATCAAAAATCTCG } \\
\text { AGCAAAATAACATTGATTTTGACATGGTATT }\end{array}$ & TCAA & $\mathrm{s}$ & 17,74 & 163 & $\begin{array}{l}\text { CAAACCGCACAGGAG } \\
\text { ATTTT }\end{array}$ & 60,1 & $\begin{array}{l}\text { TCGATTCAACATCC } \\
\text { AATGAGTC }\end{array}$ & 59,9 & 45 & 50 \\
\hline 487 & BrPe4009 & $\begin{array}{l}\text { Maracuja_ } \\
\text { NoIndex_L } \\
003 \text { R1_00 } \\
\text { 1_contig_1 } \\
2842\end{array}$ & 4 & 195 & 206 & 12 & 3 & 8 & $\begin{array}{l}\text { GTACCGAAGGTACGCAAACACTCACACAACGTAAAAACACTCTCAA } \\
\text { GAACATCTCCAATTACTCCGGGTTGGGAATTATGCTTACCGTCCAA } \\
\text { ACCTTCAAATGCCACGTATGCATGTGACACCCAAATTCAAAATCGA } \\
\text { AAAGGCGACTCCATGCATGCATGATATGCTCATGGACTTAACCCAA } \\
\text { CATCTTAACTCAAAAGGTCAACACTAAAGAAAATCGATCCGAGAAC } \\
\text { CTGAACCGGGTCTAACTCGGATACAGGTCCCATATCTCTCCCCTCCT } \\
\text { AATAAAGAATTTCATCCCGAAATTCTCTCTAAAT }\end{array}$ & CATG & G & 33,43 & 231 & $\begin{array}{l}\text { CGAAGGTACGCAAAC } \\
\text { ACTCA }\end{array}$ & 59,9 & $\begin{array}{l}\text { TCAGGTTCTCGGAT } \\
\text { CGATTT }\end{array}$ & 59,6 & 50 & 45 \\
\hline 488 & BrPe4010 & $\begin{array}{l}\text { Maracuja_ } \\
\text { NoIndex_L } \\
003 \text { R1_00 } \\
\text { 1_contig_2 } \\
\text { 1238 }\end{array}$ & 4 & 2716 & 2727 & 12 & 3 & 8 & $\begin{array}{l}\text { TGACAGAATCCTCTTCTTCTTTATGAGACATGTTACTCACTTTGGATT } \\
\text { CAGAAGGGGTATCCTGATCCGAGCTTGAATAAAATGTCTCGCAAAC } \\
\text { ATCACTCATCCCATTTGTCTCCAGGATAGCAAGAACATCTGCTGTTG } \\
\text { CCTTCTCTGCTTTCTTTCTTTGAAGAGAAACAATCCTTAGCTGTTCCT } \\
\text { CAAGTTCTTCAACCTAATTTTCAGATGAAGTCAACATTATGTGTCTA } \\
\text { ACTCAGGAGGACCAAACGAGAGAGAGAGTGAGCAATTATCCCTGG } \\
\text { GAAGATATCCAGGTAAAGTATACCTTTCTTG }\end{array}$ & СтTт & G & 16,51 & 196 & $\begin{array}{l}\text { GGGTATCCTGATCCG } \\
\text { AGCTT }\end{array}$ & 60,4 & $\begin{array}{l}\text { TGGTCCTCCTGAGTT } \\
\text { AGACACAT }\end{array}$ & 60 & 50 & 45 \\
\hline 489 & BrPe4011 & $\begin{array}{l}\text { Maracuja_ } \\
\text { NoIndex_L } \\
003 \text { R1_00 } \\
\text { 1_contig_2 } \\
6273\end{array}$ & 4 & 3689 & 3700 & 12 & 3 & 8 & $\begin{array}{l}\text { TCTCGCTTTCCCTTTCATTTTTTAATCTGATGGGTCCTATCGATCTTTT } \\
\text { CCCCTCTTTGTCTTTTACTTCAAAACCCTATCAAGGGTTTAGGATTGA } \\
\text { TAGCAATTTCCAATGATGAACAATGTTAAACGTGGTACATGGGACA } \\
\text { TTCACTCTTGATTGATTGAAATCATTCATAAGCTCCATTGCCTTTGGA } \\
\text { TGGATTAAAGTTGCTTTGTAGTGTACTGTGGTTATCCTGACCTGTAT } \\
\text { CTTTTCTTTTCTCTGTAGATAGACACATGTAATGGATTCTACTGTGAA } \\
\text { AACTTCAAACCGAACAAGGACTACA }\end{array}$ & TTGA & G & 15,91 & 152 & $\begin{array}{l}\text { TCGATCTTTTCCССTC } \\
\text { TTTG }\end{array}$ & 59,2 & $\begin{array}{l}\text { TCCAAAGGCAATGG } \\
\text { AGCTTA }\end{array}$ & 60,7 & 45 & 45 \\
\hline 490 & BrPe4012 & $\begin{array}{l}\text { Maracuja_ } \\
\text { NoIndex_L } \\
\text { 003_R1_00 } \\
\text { 1_contig_2 } \\
6679\end{array}$ & 4 & 486 & 497 & 12 & 3 & 8 & $\begin{array}{l}\text { CAACACCGCTGCTTTCACTATTGAAACACATTGCTTTATCAAGTTTA } \\
\text { TCCACTTCGCCCCAAAGCCGATCTTCTTCTTAACCTTAAAAAGCATT } \\
\text { CCCAATCCACGAAATCATATGCCTTTTGGAAATCGATCTTGAATAAC } \\
\text { CACCTATTTTTTCTTTCTTTCCTCATGTGATGCACCACTTCGGATGTA } \\
\text { ATCATAACTGAATCAAGCAACTTTCTTCCTTTCACAAAACCGGATTG } \\
\text { ATAGGGTGAAATAATTGAAGAAAAGACCCCTTTCAATCTATTGGCT } \\
\text { AGCAACTTTGAGATGATTTTATAAACACTA }\end{array}$ & TTTC & G & 19,04 & 150 & $\begin{array}{l}\text { ATTCCCAATCCACGA } \\
\text { AATCA }\end{array}$ & 60,1 & $\begin{array}{l}\text { CCTATCAATCCGGT } \\
\text { TTTGTGA }\end{array}$ & 59,8 & 40 & 43 \\
\hline
\end{tabular}

G: genoma funcional

S: genoma estructural

P: polimórfico

M: monomórfico 
APÉNDICE

Marcadores microssatélites desenhados a partir do sequênciamento parcial e da montagem de novo do genoma de $P$. edulis

\begin{tabular}{|c|c|c|c|c|c|c|c|c|c|c|c|c|c|c|c|c|c|c|c|}
\hline $\mathbf{N}^{\mathbf{o}}$ & Primer & Contig $\mathrm{I}$ & Motivo & Início & Fim & pb & $\begin{array}{c}\mathbf{N}^{\circ} \\
\text { Repet }\end{array}$ & Score & Sequência do contig & Unidade & G/S & Cobertura & pb & Sequência Forward & $\begin{array}{l}\mathrm{T}^{\circ} \mathrm{C} \\
F w d\end{array}$ & Sequência Reverse & $\begin{array}{r}\mathrm{T}^{\circ} \mathrm{C} \\
\operatorname{Rev}\end{array}$ & $\begin{array}{r}\% \mathrm{GC} \\
F w d\end{array}$ & $\begin{array}{c}\% \mathrm{GC} \\
\operatorname{Rev}\end{array} \quad \mathrm{P} / \mathbf{M}$ \\
\hline 491 & BrPe4013 & $\begin{array}{l}\text { Maracuja_ } \\
\text { NoIndex_L } \\
\text { 003_R1_00 } \\
\text { 1_contig_2 } \\
6847\end{array}$ & 4 & 4177 & 4192 & 16 & 4 & 12 & $\begin{array}{l}\text { AGAGCAGCCAGGAGATATATTTTATTAAAACTACCAAGTCTCGAGT } \\
\text { ATGACGGTGGGAACTACTAGACTGCTGGAAATTTTAAAAGAAGGTG } \\
\text { GTGGCGATGAAAGCTTTTGGATTTTTGTGTAGGAATCATAAGCTTTA } \\
\text { AAAATGGCGAATGATTGATTGATTGATCAGTAATCAAAATCTCAGT } \\
\text { CTCTCCTTATAAAGTCCACTTTAGTATATTATGCATTCCATTATTTTG } \\
\text { CTACATATGTCCCGTCTCTTTCCTTTTCTAATGTAACTTTCACATCG } \\
\text { CTCATTAAAAAGAATACTTTCTTTCTGTCTGAATGT }\end{array}$ & TGAT & $\bar{s}$ & 17,36 & 220 & $\begin{array}{l}\text { CGAGTATGACGGTGG } \\
\text { GAACT }\end{array}$ & 60,0 & $\begin{array}{l}\text { AAAAAGGAAAGAG } \\
\text { ACGGGACA }\end{array}$ & 60,1 & 55 & 43 \\
\hline 492 & BrPe4014 & $\begin{array}{l}\text { Maracuja_ } \\
\text { NoIndex_L } \\
\text { 003_R1_00 } \\
\text { 1_contig_2 } \\
9608\end{array}$ & 4 & 3914 & 3925 & 12 & 3 & 8 & $\begin{array}{l}\text { TAATCTAGCAAATTCAGAAAAAGAAATATATAATTCCTTCAACCTG } \\
\text { GAGGCTATCCGTCTGTACATGCTTCGTTGAATGAGAGTTATGACTAA } \\
\text { CATCCCGTTGAACTAATAGATGTTTTTGCTTTGGCATCCCATTTTACT } \\
\text { GTTGTCACTGTTAGTTAGTTAAAGGAGAGTGAGGTTTCATTATAGGT } \\
\text { TGTTTTTGTATTCTGCAGAAAGTATTTTGGATTAAAAGGAAAAGGA } \\
\text { AGAACGAGGCTGATATACTGGACTTGTCAAAATTAGATGGGAAGAA } \\
\text { ACTTGGAAATTTTCTCTTCTTGAATACAAAC }\end{array}$ & GTTA & $\mathrm{s}$ & 16,74 & 167 & $\begin{array}{l}\text { AACCTGGAGGCTATC } \\
\text { CGTCT }\end{array}$ & 60,1 & $\begin{array}{l}\text { TCTGCAGAATACAA } \\
\text { AAACAACCT }\end{array}$ & 58 & 55 & 35 \\
\hline 493 & BrPe4015 & $\begin{array}{l}\text { Maracuja_ } \\
\text { NoIndex_L } \\
\text { 003_R1_00 } \\
\text { 1_contig_3 } \\
3257\end{array}$ & 4 & 1226 & 1237 & 12 & 3 & 8 & $\begin{array}{l}\text { TTCGATGGTTCCAACCCACTCCAACGGCGAAAAGGGCAAACCAGATT } \\
\text { TAGCCTTTTGCCCAGTGCCAACCATGTGTGCCATTTTCATATTATGG } \\
\text { GCATGTGAAACTTCAAATATCCATCAGTGTGCGAAACTGCGAAGGA } \\
\text { ACCATTGCTACATTTATTTATTTTTTTAAAAATTCGCATAAACATGT } \\
\text { GCACACAGCTAATTACAAAGTTGTTCTTTACTTTCCAGCGTAG }\end{array}$ & ATTT & $\mathrm{s}$ & 15,72 & 151 & $\begin{array}{l}\text { ATTTAGCCTTTTGCCC } \\
\text { AGTG }\end{array}$ & 59,2 & $\begin{array}{l}\text { TGTGTGCCACATGTT } \\
\text { TATGC }\end{array}$ & 59 & 45 & 45 \\
\hline 494 & BrPe4016 & $\begin{array}{l}\text { Maracuja_ } \\
\text { NoIndex_L } \\
\text { 003_R1_00 } \\
\text { 1_contig_3 } \\
\text { 3301 }\end{array}$ & 4 & 1247 & 1258 & 12 & 3 & 8 & $\begin{array}{l}\text { AATAGCCACCATCGATAGCATTGCCGGTCTGTACAAGAGTGATGAT } \\
\text { CTTGCTCCACCGTGCGCTAGTTTCCGTTCGCATACCTTGCAATGCCG } \\
\text { CGGCATTATGCCAACCTTTTCTGTCTGGAAGTGCTGGATTTAGGAA } \\
\text { ACTTGACCTGTCTTTCTTTCTTGTTGGAATGGCAATCTGAGAGTGTG } \\
\text { CTAGGGATATCAAGCACCAGGTGCCTTCCTTCCAGTCTCTTGTCAAT } \\
\text { CTTCCTCTGGACTAGATGGATGTACGAGTAACGACCTTGTAAGCACG } \\
\text { CGTAATCATTAGGTGTCAGACCCGTATTGTC }\end{array}$ & TCTT & G & 15,66 & 180 & $\begin{array}{l}\text { GCCAACCTTTTCTGTC } \\
\text { TGGA }\end{array}$ & 60,2 & $\begin{array}{l}\text { GCGTGCTTACAAGG } \\
\text { TCGTTA }\end{array}$ & 59 & 50 & 50 \\
\hline 495 & BrPe4017 & $\begin{array}{l}\text { Maracuja_ } \\
\text { NoIndex_L } \\
\text { 003_R1_00 } \\
\text { 1_contig_4 } \\
0350\end{array}$ & 4 & 702 & 713 & 12 & 3 & 8 & $\begin{array}{l}\text { CCCTTCTGCAATTCAAATATTTGGTGCAGGGAAACAGTTCCAGGCAC } \\
\text { GGATGGTTTCCCAGTTTAGGGTCATGGAATTCAAGCTCTGACTGCTG } \\
\text { TGATTGGGAAAGAGTATTTTGCAAAGTACCACAACAGGTGACTAGC } \\
\text { CTTGACCTCAGCTCGCTCGCTCCCTCACTCCCCTCGGAGGATGTCTC } \\
\text { ATCTGATGTTTTAGCTCCACTCTTTCACTTGCGCACTCTTGTGTTCTT } \\
\text { GAGCGTTTCTGGGAACCATATAAGTGGTGGAATTCAAGAGCAGTT } \\
\text { TCCAATCTGACACAACTTTTAACCCTTGACT }\end{array}$ & GCTC & G & 18,34 & 176 & $\begin{array}{l}\text { CCCAGTTTAGGGTCA } \\
\text { TGGAA }\end{array}$ & 59,8 & $\begin{array}{l}\text { AACACAAGAGTGCG } \\
\text { CAAGTG }\end{array}$ & 60,1 & 50 & 50 \\
\hline
\end{tabular}

G: genoma funcional

S: genoma estructural

P: polimórfico

M: monomórfico 
APÉNDICE

Marcadores microssatélites desenhados a partir do sequênciamento parcial e da montagem de novo do genoma de $P$. edulis

\begin{tabular}{|c|c|c|c|c|c|c|c|c|c|c|c|c|c|c|c|c|c|c|c|}
\hline $\mathbf{N}^{\circ}$ & Primer & Contig & Motivo & Início & Fim & pb & $\begin{array}{c}\mathbf{N}^{\circ} \\
\text { Repet }\end{array}$ & Score & Sequência do contig & Unidade & G/S & Cobertura & pb & Sequência Forward & $\begin{array}{l}\mathrm{T}^{\circ} \mathrm{C} \\
F w d \\
\end{array}$ & Sequência Reverse & $\begin{array}{l}\mathrm{T}^{\circ} \mathrm{C} \\
\operatorname{Rev} \\
\end{array}$ & $\begin{array}{c}\% \mathrm{GC} \\
F w d \\
\end{array}$ & $\begin{array}{c}\% \mathrm{GC} \\
\operatorname{Rev}\end{array}$ \\
\hline 496 & BrPe4018 & $\begin{array}{l}\text { Maracuja_ } \\
\text { NoIndex_L } \\
\text { 003_R1_00 } \\
\text { 1_contig_4 } \\
9519\end{array}$ & 4 & 966 & 977 & 12 & 3 & 8 & $\begin{array}{l}\text { CAACCTTTACCTGCTGACATGGCAAACCTCTGGCTAATACATCCTTC } \\
\text { TCCATCCTAGGTTATCAACAACCTCATTAAAGTTAATGGACATCTTT } \\
\text { GTGCTGTTTAGAAAGAATGCCAAAGTTGAAGGATGAGTCTCTGGCA } \\
\text { TGATAAATCCATCAATCAATCATCATGAGGTAAAGAAATCATATCTC } \\
\text { ATAATGCCAACAATCTGTCAGCTCTTATCTTGAACTCTGACTCTGTTT } \\
\text { TTCTCTAAATTTCTCTATCTGACTTTAACCAACACAGGATCGCAAGC } \\
\text { ATGCCTTGCTCGACTATTCTCAAGTAATAC }\end{array}$ & ATCA & $\mathrm{s}$ & 020 & 204 & $\begin{array}{l}\text { TTACCTGCTGACATG } \\
\text { GCAAA }\end{array}$ & 60,3 & $\begin{array}{l}\text { AGCTGACAGATTGT } \\
\text { TGGCATT }\end{array}$ & 59,8 & 45 & 43 \\
\hline 497 & BrPe4019 & $\begin{array}{l}\text { Maracuja_ } \\
\text { NoIndex_L } \\
003 \_R 1 \text { 00 } \\
\text { 1_contig_5 } \\
\text { 2931 }\end{array}$ & 4 & 904 & 915 & 12 & 3 & 8 & $\begin{array}{l}\text { AACACCACTACCTTAACCATCATTCCGAAGTGCTGCTCACCTATAGG } \\
\text { ACTTGCTGATTATCGGCCAATTGCATGTTGCATAGTCTTTTATAAGA } \\
\text { CTGTGTCAAAAATATTGATAGCCAGGACATTGAGGGTGTTGTGTAG } \\
\text { AGTTATCAGCATCAATCAATCAGCCTTTGTAGCAGGGAGAAGCATC } \\
\text { ACTGACAACATACTCATGGCTCATGAGCTTGTGAGTAACTATGGAA } \\
\text { AAAGATCAGGGATACCGAATTATGCCAGCAAAGTTTACCTTCACAA } \\
\text { GGCATACGACTCAATTGCTGGGATTTTGTGAG }\end{array}$ & ATCA & G & 28,82 & 242 & $\begin{array}{l}\text { GCCAATTGCATGTTG } \\
\text { CATAG }\end{array}$ & 60,1 & $\begin{array}{l}\text { AATCCCAGCAAATT } \\
\text { GAGTCG }\end{array}$ & 60,1 & 45 & 45 \\
\hline 498 & BrPe4020 & $\begin{array}{l}\text { Maracuja_ } \\
\text { NoIndex_L } \\
\text { 003_R1_00 } \\
\text { 1_contig_5 } \\
\text { 2966 }\end{array}$ & 4 & 3440 & 3451 & 12 & 3 & 8 & $\begin{array}{l}\text { ACCTGAAACCGTTGCGGCAAAGTTTGAGGCTATGAATTGATTGGCA } \\
\text { ACCATTGGCAAGGTATTTTAGCACTACATCTGTCAACTTATGCAAGT } \\
\text { AGCAGAGATCAAGAGCGCGTAAGTTTGGACATAGTTTGCCCACAAA } \\
\text { TTTAAGTGATAAGTCAGTCAGTCTCCTGAACCATAAAAGTATCCTT } \\
\text { GTTACTAAAATGTATAGAAATGCGAAAGTAGCGCTCAGCTCATTCTT } \\
\text { ATTCTTGAAACATATGAATGCAGACTTACACACAATTAGAAAAAAC } \\
\text { AAGCTCTCTCATGTTCATTCCACATGCTTTGAC }\end{array}$ & AGTC & $\mathrm{s}$ & 15,82 & 179 & $\begin{array}{l}\text { GCAACCATTGGCAAG } \\
\text { GTATT }\end{array}$ & 59,8 & $\begin{array}{l}\text { GAGCGCTACTTTCG } \\
\text { CATTTC }\end{array}$ & 60,1 & 45 & 50 \\
\hline 499 & BrPe4021 & $\begin{array}{l}\text { Maracuja_ } \\
\text { Nolndex_L } \\
\text { 003_R1_00 } \\
\text { 1_contig_5 } \\
\text { 3009 }\end{array}$ & 4 & 1420 & 1431 & 12 & 3 & 8 & $\begin{array}{l}\text { TAATTCATTATAATTTTTTAGCCTGGGACCACTCACCAATCATCCTCT } \\
\text { TGTCTTATTGCCTGGTGAAGGTACGACAATACCATTGACCTCCAATA } \\
\text { AAGTTGTTACCTTGTGTTTGCACAATATTGCGACAAATGCTAATTTG } \\
\text { CACATAGTTTAATTAATTAAACTTATCTTATAAATATATTTTGGTTTT } \\
\text { GTATCAGGTGACGTCGGGATCAGAGCCTAAGCAAGTTCAGACAATG } \\
\text { TACGTAGATAAACAAATCGAAGAGTGGGAACACCAGAGCCACCCT } \\
\text { TTGAGACTCGTCTGAGATCCGGGCCAATGG }\end{array}$ & TTAA & $\mathrm{s}$ & 16,41 & 249 & $\begin{array}{l}\text { GGACCACTCACCAAT } \\
\text { CATCC }\end{array}$ & 60,2 & $\begin{array}{l}\text { TCTGGTGGTTCCCA } \\
\text { СTCTTC }\end{array}$ & 60,1 & 55 & 55 \\
\hline 500 & BrPe4022 & $\begin{array}{l}\text { Maracuja_ } \\
\text { Nolndex_L } \\
003 \_R 1 \text { 00 } \\
\text { 1_contig_5 } \\
3586\end{array}$ & 4 & 2424 & 2435 & 12 & 3 & 8 & $\begin{array}{l}\text { AAAGTAAAGCCATGTCCTTCAAGCTTCTTATGTTTGCCTTCTTCTTCA } \\
\text { TTTCAACGAGCTCAGGGACATCATACATGTGCTTTTTAGAGTAAACA } \\
\text { CAAATAAGATTTCTGCGTAAAGGGGAATGTTAGTTATGACTTTCTCA } \\
\text { ATTACAAAAAGATAGATAGATGCTGAAAGAATAAACATCTCGAATAC } \\
\text { ATCTAAAAGCATCATGACTACCTTCCCATACTAAATGGCTTGCAGAG } \\
\text { AGGATCTGTAATAACTCTATCCCCTGCCACATAGATCTGCACTAGTA } \\
\text { TTTATGGTTTGATGTCACCAAAAGATACC }\end{array}$ & AGAT & $\mathrm{s}$ & 18,54 & 189 & $\begin{array}{l}\text { AACGAGCTCAGGGAC } \\
\text { ATCAT }\end{array}$ & 59,7 & $\begin{array}{l}\text { GATCCTCTCTGCAA } \\
\text { GCCATT }\end{array}$ & 59,4 & 50 & 50 \\
\hline
\end{tabular}

G: genoma funcional

S: genoma estructural

P: polimórfico

M: monomórfico 
APÉNDICE

Marcadores microssatélites desenhados a partir do sequênciamento parcial e da montagem de novo do genoma de $P$. edulis

\begin{tabular}{|c|c|c|c|c|c|c|c|c|c|c|c|c|c|c|c|c|c|c|c|}
\hline $\mathbf{N}^{\circ}$ & Primer & Contig I & Motivo & Início & Fim & pb & $\begin{array}{c}\mathbf{N}^{\circ} \\
\text { Repet }\end{array}$ & Score & Sequência do contig & Unidade & G/S & Cobertura & $\mathrm{pb}$ & Sequência Forward & $\begin{array}{l}\mathrm{T}^{\circ} \mathrm{C} \\
F w d \\
\end{array}$ & Sequência Reverse & $\begin{array}{l}\mathrm{T}^{\circ} \mathrm{C} \\
\operatorname{Rev} \\
\end{array}$ & $\begin{array}{c}\% \mathrm{GC} \\
F w d \\
\end{array}$ & $\begin{array}{cc}\% \mathrm{GC} & \mathrm{P} / \mathrm{M} \\
\operatorname{Rev} & \end{array}$ \\
\hline 501 & BrPe4023 & $\begin{array}{l}\text { Maracuja_ } \\
\text { NoIndex_L } \\
\text { 003_R1_00 } \\
\text { 1_conti__6 } \\
9689\end{array}$ & 4 & 1835 & 1846 & 12 & 3 & 8 & $\begin{array}{l}\text { ATGCTCATAATCTTTGGCAAAATCTTCAGGAGCTGGTTTTCCATATA } \\
\text { TTCCCATCTGGGAGCTGTTTAGCCAATAAGGAGGAGTTTGCAATCGA } \\
\text { CGAGGCCAATCCTCCGGCCATCTAGTGCCCCTCTCATTACTGTCAAC } \\
\text { AGGCACCCGATGCATGCATGCCTGCAGAGGCACATACCTGAAAATG } \\
\text { CCATTACCTGGATGGTTACTATCTATAATAGCTATCAAGAGTTCAGT } \\
\text { ATTCATCATATTTAAAGTCATTTCCAAATTCTATGGCCACGGAGATT } \\
\text { TTGTTTGTTTAAAACCCACCAAGCTGCGTTT }\end{array}$ & ATGC & $\mathrm{G}$ & 15,85 & 175 & $\begin{array}{l}\text { GGCAAAATCTTCAGG } \\
\text { AGCTG }\end{array}$ & 60,0 & $\begin{array}{l}\text { TGGCATTTTCAGGT } \\
\text { ATGTGC }\end{array}$ & 59,5 & 50 & 45 \\
\hline 502 & BrPe4024 & $\begin{array}{l}\text { Maracuja_ } \\
\text { NoIndex_L } \\
003 \text { R1_00 } \\
\text { 1_contig_5 } \\
28\end{array}$ & 4 & 210 & 221 & 12 & 3 & 8 & $\begin{array}{l}\text { GGTAATAACAGCTTCCCGTAGTATTACATCTACTGTGTACTACATCT } \\
\text { TCGATAAGTATAAAATTTGTGTCAAGGTTTTTTTTTTATGTTTTTCTA } \\
\text { TTAATGGGAGCAAAATTATTTGGCAGAGCTCGTTAACCAGCAGAAA } \\
\text { TTAGCCGTGCAATCAATCAATAGAGAGTTGTGTGACGCTGATGAGG } \\
\text { CGAATTTGCTTGATGAAGAAGGAATATATGAGAGCTTGAAAGTTT } \\
\text { ATCATAATGGGTGGATGATTATGGTTGGTGAGGGGTCAGGCTCCTC } \\
\text { GCTTTTGGTCTGGCTATTTGTTTGATCAAAAAA }\end{array}$ & САAT & G & 18,56 & 161 & $\begin{array}{l}\text { AAATTATTTGGCAGA } \\
\text { GCTCGTT }\end{array}$ & 59,3 & $\begin{array}{l}\text { CCCCTCACCAACCA } \\
\text { TAATCA }\end{array}$ & 60,6 & 36 & 50 \\
\hline 503 & BrPe4025 & $\begin{array}{l}\text { Maracuja_ } \\
\text { NoIndex_L } \\
\text { 003_R1_00 } \\
\text { 1_contig_9 } \\
73\end{array}$ & 4 & 951 & 966 & 12 & 3 & 8 & $\begin{array}{l}\text { TTGAAACCAAGGCATAAAGTTAGGTCCTTTCAGAAAACGCCTAAAC } \\
\text { AGCAACAAAGGTCATTATTAGCTCAACAGAATTAGAGTGGCTATGA } \\
\text { GTGAAGAACCATAGGCAATTTATAGAAGCTGAAGAAACTAAAAACA } \\
\text { AAACAAGAGAAAAAATAAATAAATGAATACCAATACAAGTTTATTG } \\
\text { TTCATTACTTGTATAAGTCCAGCCAATTTGATCTCATCCGCTTTGATA } \\
\text { AAAACTTTCCCACTCCTCTTGCTGATAGGCTTGCCAGGAATTCATCA } \\
\text { GTATTAAATGAAAGGAGAGGAGGAGGGTCTACA }\end{array}$ & TTAA & $\mathrm{s}$ & 20,92 & 107 & $\begin{array}{l}\text { GCATCGGTATTCGGT } \\
\text { CAAAC }\end{array}$ & 60,3 & $\begin{array}{l}\text { CAAATGAATGCATG } \\
\text { TGTGAGAG }\end{array}$ & 59,2 & 50 & 41 \\
\hline 504 & BrPe4026 & $\begin{array}{l}\text { Maracuja_ } \\
\text { NoIndex_L } \\
\text { 003_R1_00 } \\
\text { 1_contig_1 } \\
140\end{array}$ & 4 & 654 & 665 & 12 & 3 & 8 & $\begin{array}{l}\text { ACTTACAGATGTAACACTCCACCCGCCACCAAAAATATAATCCAGT } \\
\text { GGCTCATAACCCCTGAAGTCAAATAACATCACTGGGGCATATTTCCC } \\
\text { TTGTTCACTCAATTCGTTGGTAAGCGGTTGACCTTTCCAGGGATCA } \\
\text { TTGTCACAGTTCCCTCCCTCCCACAAAATTTGCACTACGCAAAGAAA } \\
\text { GTATATGGCAAAGACATCAGTCCTGGATGATATAACTACAGATTGA } \\
\text { AGTTCTGGAGCAGAAGTTAAATTACAACCAGATGACTCCTTGGCCCT } \\
\text { AAGAATGAAGACATTCAGACGCACACCTCCCA }\end{array}$ & TCCC & G & 17,32 & 182 & $\begin{array}{l}\text { AATTCGTTGGTAAGC } \\
\text { GGTTG }\end{array}$ & 60,0 & $\begin{array}{l}\text { TTCTTAGGGCCAAG } \\
\text { GAGTCA }\end{array}$ & 59,8 & 45 & 50 \\
\hline 505 & BrPe4027 & $\begin{array}{l}\text { Maracuja_ } \\
\text { NoIndex_L } \\
\text { 003_R1_00 } \\
\text { 1_contig_1 } \\
742\end{array}$ & 4 & 1475 & 1486 & 12 & 3 & 8 & $\begin{array}{l}\text { CCCAAAAGGGCGCGAGTATATAGACAAGAAAGACACAAAACTCAG } \\
\text { AAAGACGTACAGACACATACAAATGACCATTATTGATGGAAGAACA } \\
\text { CAAGAAAACAAAACAGCCTTGTGTTGTAAGATGGAAATACAGCTGT } \\
\text { GCAAGGGGCCTATAGACAGACAGACTGTAGAGAAAGAGGTTGGTTA } \\
\text { TCATCAATCGGAGGACTTTTGCTATTTCTTCATTAAAAACCAACTGT } \\
\text { AAGTCTGTAATCGGTAAGGAACAGAAAAGCACTTTGATTGGATCAT } \\
\text { GGTTGTTGCAAAATTAAGTATCTCTTGTGGTTCAAT }\end{array}$ & AGAC & $\mathrm{s}$ & 18,76 & 163 & $\begin{array}{l}\text { GGAAATACAGCTGTG } \\
\text { CAAGG }\end{array}$ & 58,4 & $\begin{array}{l}\text { TGCAACAACCATGA } \\
\text { TCCAAT }\end{array}$ & 59,8 & 50 & 40 \\
\hline
\end{tabular}

G: genoma funcional

S: genoma estructural

P: polimórfico

M: monomórfico 
APÉNDICE

Marcadores microssatélites desenhados a partir do sequênciamento parcial e da montagem de novo do genoma de $P$. edulis

\begin{tabular}{|c|c|c|c|c|c|c|c|c|c|c|c|c|c|c|c|c|c|c|c|}
\hline $\mathbf{N}^{\circ}$ & Primer & Contig I & Motivo & Início & Fim & pb & $\begin{array}{c}\mathbf{N}^{\circ} \\
\text { Repet }\end{array}$ & Score & Sequência do contig & Unidade & G/S & Cobertura & pb & Sequência Forward & $\begin{array}{l}\mathrm{T}^{\circ} \mathrm{C} \\
F w d \\
\end{array}$ & Sequência Reverse & $\begin{array}{l}\mathrm{T}^{\circ} \mathrm{C} \\
\operatorname{Rev} \\
\end{array}$ & $\begin{array}{c}\% \mathrm{GC} \\
F w d \\
\end{array}$ & $\begin{array}{c}\% \mathrm{GC} \\
\operatorname{Rev}\end{array} \quad \mathrm{P} / \mathrm{M}$ \\
\hline 506 & BrPe4028 & $\begin{array}{l}\text { Maracuja_ } \\
\text { NoIndex_L } \\
003 \text { R1_00 } \\
\text { 1_contig_2 } \\
\text { 213 }\end{array}$ & 4 & 2780 & 2791 & 12 & 3 & 8 & $\begin{array}{l}\text { GAATGACGAGAAGTTAGCTTGTCAGGATGTTTGTCAGGAAGGGTGG } \\
\text { ACGTATATTTATATGGAGAAACATGACAGACAAAAGGAAGGTGGAA } \\
\text { AGTATACTGTTCCAGGAAGGCAACACAAAACATGATCCTTTGAAGA } \\
\text { ATTAATGGCTGCTTAATTAATTAAAAAGACATTCTCTGTGACATAGG } \\
\text { AGAGGTATGGACTGAGATGCCTGAGCCTTATACGGCAAGACTATTG } \\
\text { GGATTGTGACCATGCTATTGTTTCAGATTGCTCTCCACTGAAAGAAA } \\
\text { ATCAAAACGGCGACTCCGACTCGACTCGGGTACT }\end{array}$ & TTAA & $\mathrm{s}$ & 14,98 & 219 & $\begin{array}{l}\text { GTTTGTCAGGAAGGG } \\
\text { TGGAC }\end{array}$ & 59,4 & $\begin{array}{l}\text { AGCATGGTCACAAT } \\
\text { CCCAAT }\end{array}$ & 60,2 & 55 & 45 \\
\hline 507 & BrPe4029 & $\begin{array}{l}\text { Maracuja_ } \\
\text { NoIndex_L } \\
\text { 003_R1_00 } \\
\text { 1_contig_2 } \\
763\end{array}$ & 4 & 745 & 756 & 12 & 3 & 8 & $\begin{array}{l}\text { GGTGTTGGAGCTTCATTCCAACAGAACTAGTATGACTTCATCTGATG } \\
\text { GAGATTATGGAGCAAAGCCAGCTATGGTGAACACAAGAACATTAAA } \\
\text { GGGCCCAAGGTAGATTAGATATTAAACATTCACATATTTGGAGCTTC } \\
\text { ATTTATTAACTTATTTATTTATGTTTTAATGGAGTCGAAAATGATAC } \\
\text { GATAAGACCCTTTTATATGCAGAGATGATGTTCGAATGATCACGAC } \\
\text { ATCTTTGCCAGTATCTCCTTGTTCTAGCCCGCTACGGCAGTATGGTC } \\
\text { CTGCACATCGGAGTTGTTATCTTTCTCCTCCT }\end{array}$ & TTAT & $\mathrm{s}$ & 14,88 & 205 & $\begin{array}{l}\text { AACATTAAAGGGCCC } \\
\text { AAGGT }\end{array}$ & 59,7 & $\begin{array}{l}\text { CGATGTGCAGGACC } \\
\text { ATACTG }\end{array}$ & 60,1 & 45 & 55 \\
\hline 508 & BrPe4030 & $\begin{array}{l}\text { Maracuja_ } \\
\text { NoIndex_L } \\
\text { 003_R1_00 } \\
\text { 1_contig_3 } \\
169\end{array}$ & 4 & 3476 & 3487 & 12 & 3 & 8 & $\begin{array}{l}\text { CAAGCAACTTTTCCCCTCTCTCAAGTGTCTGCACAAAACGAAGTTCT } \\
\text { TCCCTTTCCAACTCATCAAGTATGCGAAGGCGTCTAGCTTTTACATC } \\
\text { TGGATCAATATCAGAGCTTAGTTCTATTACAGTTTCCGCAATGGATG } \\
\text { GTAAAAATGTTCCTTCCTTCCCATCTCCTTTTATACCAAGCAACCTG } \\
\text { CCAGTACGAACTGCCCGTCTGATGAGACGACGAACAACATATCCTC } \\
\text { TACCAATATTTGATGGGACTACTCCATCTGATATTAGATACACAATT } \\
\text { GCACGCATATGATCTCCTACAATCTGAAAAG }\end{array}$ & TTCC & G & 16,15 & 183 & $\begin{array}{l}\text { CССCTCTCTCAAGTGT } \\
\text { CTGC }\end{array}$ & 60,0 & $\begin{array}{l}\text { GTACTGGCAGGTTG } \\
\text { CTTGGT }\end{array}$ & 60,2 & 60 & 55 \\
\hline 509 & BrPe4031 & $\begin{array}{l}\text { Maracuja_ } \\
\text { NoIndex_L } \\
003 \text { R1_00 } \\
\text { 1_contig_3 } \\
424\end{array}$ & 4 & 3269 & 3280 & 12 & 3 & 8 & $\begin{array}{l}\text { СCTCAGGACCTCCACTGCAGCACAACGTAGCTTGATTAAAAAGGAA } \\
\text { GGATACTCAACAGAAGATGTCATGTCTCTTTTTACGTCTTTTACTGG } \\
\text { AGTTGTTTCTGAGGCTTTGCTCTTCCTCCACAATGTAAAAAATATCT } \\
\text { CTATTTTTCTGAAGGAAGGAAGTGGCCATGAGATGCAACTATTACAT } \\
\text { AGTGTGGTAAGAAACCACATTACTGAGCCAGAAAAGGAATCCACTT } \\
\text { CTGTGAGTGATTTGTTTGGTCTCATCACTGGAAGACAATGTAGTGGA } \\
\text { TTAGATAAAGATCAGTTGCTCAAAAGACTGAA }\end{array}$ & GAAG & G & 16,32 & 214 & $\begin{array}{l}\text { GCAGCACAACGTAGC } \\
\text { TTGAT }\end{array}$ & 59,1 & $\begin{array}{l}\text { TGGATTCCTTTTCTG } \\
\text { GCTCA }\end{array}$ & 60,7 & 50 & 45 \\
\hline 510 & BrPe4032 & $\begin{array}{l}\text { Maracuja_ } \\
\text { NoIndex_L } \\
003 \text { 181_00 } \\
\text { 1_conti__3 } \\
582\end{array}$ & 4 & 161 & 172 & 12 & 3 & 8 & $\begin{array}{l}\text { CAGCCGAGGATGCGATCGGTAAGTCAGAAGCCATGAAACTGAAAG } \\
\text { CGGAAAAAGCCATGCAAGATTCCAAGCAATCAGCCGAGTCATGGAA } \\
\text { GAAAGGGGCCCGTGATAAGACAATGATGGAGTAATAATCATTTTCT } \\
\text { CCCCAAGTTATTGCTATCTATCTATGTATTGATGGTGATTTGTTTCTT } \\
\text { TCTAATTTGCAAATATCTTGGGATATTACCATGCCAGTGTTTTGTCCT } \\
\text { TTCTCGTGAGAAGTGTGATTCTTATTCTCGAGTACTTAAGTATATGT } \\
\text { CATGAAACTGAACCTGAAATGAAGGGAAATGA }\end{array}$ & СТАТ & $\mathrm{s}$ & 16,79 & 221 & $\begin{array}{l}\text { GCGATCGGTAAGTCA } \\
\text { GAAGC }\end{array}$ & 60,0 & $\begin{array}{l}\text { GGACAAAACACTGG } \\
\text { CATGGT }\end{array}$ & 60,8 & 55 & 50 \\
\hline
\end{tabular}

G: genoma funcional

S: genoma estructural

P: polimórfico

M: monomórfico 
APÉNDICE

Marcadores microssatélites desenhados a partir do sequênciamento parcial e da montagem de novo do genoma de $P$. edulis

\begin{tabular}{|c|c|c|c|c|c|c|c|c|c|c|c|c|c|c|c|c|c|c|c|}
\hline $\mathbf{N}^{\circ}$ & Primer & Contig I & Motivo & Início & Fim & pb & $\begin{array}{c}\mathbf{N}^{\circ} \\
\text { Repet }\end{array}$ & Score & Sequência do contig & Unidade & G/S & Cobertura & pb & Sequência Forward & $\begin{array}{l}\mathrm{T}^{\circ} \mathrm{C} \\
F w d \\
\end{array}$ & Sequência Reverse & $\begin{array}{l}\mathrm{T}^{\circ} \mathrm{C} \\
\operatorname{Rev} \\
\end{array}$ & $\begin{array}{c}\% \mathrm{GC} \\
F w d \\
\end{array}$ & $\begin{array}{cc}\% \mathrm{GC} & \mathrm{P} / \mathrm{M} \\
\operatorname{Rev} & \end{array}$ \\
\hline 511 & BrPe4033 & $\begin{array}{l}\text { Maracuja_ } \\
\text { NoIndex_L } \\
003 \text { R1_00 } \\
\text { 1_contig_5 } \\
018\end{array}$ & 4 & 544 & 555 & 12 & 3 & 8 & $\begin{array}{l}\text { TAAGCCAGAATTGGATGGCCAAGGTATTAGAGAATGAACTGTAAAA } \\
\text { TCGACAATAATTCACTAAACCATAAGAAACATTACCAATAGCCCTA } \\
\text { GCAAGATTTAGACTGCCGTTAACACGCCCTGCATGTATGAATCCACC } \\
\text { AGCTTTTAAAATTCTTTCTTTCTCAGCCTCAAGATCAGGTTTATGATC } \\
\text { CCGAGAAAGATTGTATGCCTGCATCAAACAAAACATTGTCACAAGA } \\
\text { CCATCCATTCAAAACAAAAGACACAAAAAATCAAGATACTCAACCC } \\
\text { TTGAGGAATTTGATCAGTCACCAACAAATACCT }\end{array}$ & TTCT & $\mathrm{G}$ & 20,28 & 203 & $\begin{array}{l}\text { AGAATTGGATGGCCA } \\
\text { AGGTA }\end{array}$ & 59,4 & $\begin{array}{l}\text { GCAGGCATACAATC } \\
\text { TTTCTCG }\end{array}$ & 59,9 & 45 & 48 \\
\hline 512 & BrPe4034 & $\begin{array}{l}\text { Maracuja_ } \\
\text { NoIndex_L } \\
\text { 003_R1_00 } \\
\text { 1_contig_6 } \\
830\end{array}$ & 4 & 1699 & 1710 & 12 & 3 & 8 & $\begin{array}{l}\text { TGTGCCAATACATATAATCTGTCTGTTTCTAAGAGTATTTGCTGCAA } \\
\text { CTCACTGTAAATAAGATGCAAATAATGGTTCACCAAGCAAAATATA } \\
\text { TTGTTATGGCACATAAAGGAAATACTTTAAGTACAAAGAACAATTTC } \\
\text { ATTTCTTTAGCCCTGCCTGCCTGTGCAACCTTTACTGCATAACTTTTG } \\
\text { ACGTACAAGGGAAAATGCTCCACTGGAAAAGATAAATTCCACAATC } \\
\text { CCCTCTGCCTCAAGTAATAGGCAAATAAATGTTTGACATACCTCAAA } \\
\text { CACATGGTCCAATGGGCAGACAAAAGGTTGTC }\end{array}$ & ССТG & $\mathrm{s}$ & 18,69 & 246 & $\begin{array}{l}\text { GCAAATAATGGTTCA } \\
\text { CCAAGC }\end{array}$ & 59,5 & $\begin{array}{l}\text { CAACCTTTTGTCTGC } \\
\text { CCATT }\end{array}$ & 60 & 43 & 45 \\
\hline 513 & BrPe4035 & $\begin{array}{l}\text { Maracuja_ } \\
\text { NoIndex_L } \\
003 \text { R1_00 } \\
\text { 1_contig_7 } \\
223\end{array}$ & 4 & 3677 & 3688 & 12 & 3 & 8 & $\begin{array}{l}\text { CTTTATACAATCCAGTGTGTCAAAGGCGAAAATAACAACATAAAAA } \\
\text { GTGCGTGAAATCCAAAAACCACAGCACTGAGCTACAAAGCTTTCAA } \\
\text { AGCACAGAAGCAAAATTCTCCCCAAGCTGTCAAACACACAATTAAA } \\
\text { AGACAGGGAAATCAAGCAAGCAAGAAGCATACCTTGACAACAAAC } \\
\text { AATATGGCAAAAGCGAGAATCGCTTGAATCTCCTAAACACGCACAA } \\
\text { AAAAAAAAAAACTTAATTCCCCGGAAACAAAAATACAAATTGAGTA } \\
\text { AAGTAAAAGAGAGGCTGCGCACCCGATGGAAGAGATG }\end{array}$ & CAAG & $\mathrm{s}$ & 17,49 & 186 & $\begin{array}{l}\text { CAGTGTGTCAAAGGC } \\
\text { GAAAA }\end{array}$ & 59,9 & $\begin{array}{l}\text { CGCTTTTGCCATATT } \\
\text { GTTTG }\end{array}$ & 59,2 & 45 & 40 \\
\hline 514 & BrPe4036 & $\begin{array}{l}\text { Maracuja_ } \\
\text { NoIndex_L } \\
\text { 003_R1_00 } \\
\text { 1_contig_7 } \\
319\end{array}$ & 4 & 4331 & 4342 & 12 & 3 & 8 & $\begin{array}{l}\text { ATTGCATTCAATTATGGACTAGACTGTCAATATTCTTGTTGAAGCAT } \\
\text { TTTGTAGAATATTATCAAGCCGCAAAATTGACTTTCACGACAATGAA } \\
\text { ATATCAGAGATTCATCATTATCCAAAAGTGGAAGTACAATTCCCGC } \\
\text { AATCCATTTCCAAACAAACAAATGATACGTCAGTCTATTTCAATGCA } \\
\text { GCATCATTAAACAATGATAATGAAGCAAACATTCCAAAAGGGTAAA } \\
\text { AAAATGGGTTGGGTAGGAAAGGGGACCAAGAGCAGATGATAATCA } \\
\text { ACAGTTGTGTTTTCATTGATAACTGGGGTATAT }\end{array}$ & CAAA & $\mathrm{s}$ & 18,53 & 162 & $\begin{array}{l}\text { CGCAAAATTGACTTT } \\
\text { CACGA }\end{array}$ & 59,8 & $\begin{array}{l}\text { СССTTTTGGAATGTT } \\
\text { TGCTT }\end{array}$ & 59,1 & 40 & 40 \\
\hline 515 & BrPe4037 & $\begin{array}{l}\text { Maracuja_ } \\
\text { NoIndex_L } \\
\text { 003_R1_00 } \\
\text { 1_contig_1 } \\
0377\end{array}$ & 4 & 2208 & 2219 & 12 & 3 & 8 & $\begin{array}{l}\text { ATTCCCTTGAAAAAATAAGGGACATCACTGCAGTGACAGAGAGAAA } \\
\text { AAACTGCAAGTTTTCATGTAAAGAGCCAGTAAACATTATTATGAATT } \\
\text { GAACAAGTCAAAGAACAAGGTGCAGAACATCATACGCACAGACCT } \\
\text { GATCAGCAACATCATACATACATATGTATTTGCTGTTTCCAGCAGCT } \\
\text { AATATGTAGCTCCCGTCTGCAGAATAACATAAGGTCGTGAAGCATTT } \\
\text { TCCTGCAGTTGAATTGGCTGCAGACCTGCGATCAGTCATAAGACGTC } \\
\text { CTCCAGCGATATCCCTGCGACCCTCAATGGTGC }\end{array}$ & CATA & G & 16,6 & 176 & $\begin{array}{l}\text { TGCAGAACATCATAC } \\
\text { GCACA }\end{array}$ & 59,9 & $\begin{array}{l}\text { ATCGCTGGAGGACG } \\
\text { TCTTAT }\end{array}$ & 58,8 & 45 & 50 \\
\hline
\end{tabular}

G: genoma funcional

S: genoma estructural

P: polimórfico

M: monomórfico 
APÉNDICE

Marcadores microssatélites desenhados a partir do sequênciamento parcial e da montagem de novo do genoma de $P$. edulis

\begin{tabular}{|c|c|c|c|c|c|c|c|c|c|c|c|c|c|c|c|c|c|c|c|}
\hline $\mathbf{N}^{\circ}$ & Primer & Contig I & Motivo & Início & Fim & pb & $\begin{array}{c}\mathbf{N}^{\circ} \\
\text { Repet }\end{array}$ & Score & Sequência do contig & Unidade & G/S & Cobertura & pb & Sequência Forward & $\begin{array}{l}\mathrm{T}^{\circ} \mathrm{C} \\
F w d \\
\end{array}$ & Sequência Reverse & $\begin{array}{r}\mathrm{T}^{\circ} \mathrm{C} \\
\operatorname{Rev} \\
\end{array}$ & $\begin{array}{c}\% \mathrm{GC} \\
F w d \\
\end{array}$ & $\begin{array}{cc}\% \mathrm{GC} & \mathrm{P} / \mathrm{M} \\
\operatorname{Rev} & \end{array}$ \\
\hline 516 & BrPe4038 & $\begin{array}{l}\text { Maracuja_ } \\
\text { NoIndex_L } \\
003 \text { R1_00 } \\
\text { 1_contig_1 } \\
1101\end{array}$ & 4 & 552 & 567 & 16 & 4 & 12 & $\begin{array}{l}\text { GCGCAGGAATAAGAGGGGCATTAGGCCAGCACACCTAGGAGACTA } \\
\text { TGTGTAGTCAGGAATATCCGCCTTGTATTCCGGTCACAATAGCCTTT } \\
\text { ATCAAGTATTTAAATAGTGAATGAGAAAAGAACAGGGTAGACTACT } \\
\text { ATTCAACAATTCTCTTTCTTTCTTTCTTCTGCCTCGCCTTGATTTCTGT } \\
\text { TCTTTCCCTTGAGTCATATCACGTAACACTCTCTCCCTATCAACGG } \\
\text { AACAACAATGGCTTCCTTTGTCTTTGACTTAAATTTGACGTTCTCTCC } \\
\text { CTCTACTTTGTCTTCTTCCTTTCTTATCGATCC }\end{array}$ & TCTT & $\mathrm{s}$ & 17,85 & 244 & $\begin{array}{l}\text { GCAGGAATAAGAGGG } \\
\text { GCATT }\end{array}$ & 60,4 & $\begin{array}{l}\text { GCCATTGTTGTTCCG } \\
\text { TTGAT }\end{array}$ & 60,8 & 50 & 45 \\
\hline 517 & BrPe4039 & $\begin{array}{l}\text { Maracuja_ } \\
\text { NoIndex_L } \\
\text { 003_R1_00 } \\
\text { 1_contig_1 } \\
\text { 2042 }\end{array}$ & 4 & 512 & 523 & 12 & 3 & 8 & $\begin{array}{l}\text { ATGGGTCTTTTACAGAATATGGAAAAAAAATCATATACATGTATGA } \\
\text { AGAAGCTTAGAGACATGCATGAATATAAGCACATCTAATTAGGACT } \\
\text { GAACGCAAGTTACCTAAAACTATAGGATGCTAATGATAGGGGAAAA } \\
\text { ACAGGAGTTTGAAATGAATGAATGGAAAAAAGTCAGATTAAAATAG } \\
\text { AGGATTTATAGGGGGAGTATGGGAATCTAGAGAGGAATAGAGGGTT } \\
\text { GGTCTGTAGATAGTGCCGGAGAGCAGCATGCAATTAAATGCAGTGG } \\
\text { CACTTGTCATTAGCACAGTCATTTTGGTTCTTCCTT }\end{array}$ & AATG & $\mathrm{s}$ & 19,86 & 155 & $\begin{array}{l}\text { GGGGAAAAACAGGA } \\
\text { GTTTGA }\end{array}$ & 059 & $\begin{array}{l}\text { TGACAAGTGCCACT } \\
\text { GCATTTA }\end{array}$ & 60,3 & 45 & 43 \\
\hline 518 & BrPe4040 & $\begin{array}{l}\text { Maracuja_ } \\
\text { NoIndex_L } \\
\text { 003_R1_00 } \\
\text { 1_contig_1 } \\
\text { 2931 }\end{array}$ & 4 & 616 & 627 & 12 & 3 & 8 & $\begin{array}{l}\text { GAAAATGACTTGAATTCAAAACGAATGGGACTCCGCACGTGGCTTG } \\
\text { TTGGGTGGCTTTGGTCTGATTGTAAAAGGGGTTTTACGTGCAACAGT } \\
\text { CGGCAATATTATTTCAGACTTGTAGTCACTTTGTCTTATTTCCTTGTC } \\
\text { CTAATCCTTATTAATTAATTACCGGAAATAGTATGGATATGGTAATT } \\
\text { TCTGTGGTTGCAAATCCCTTTCAGTTTCCATATGATTATTACATCAA } \\
\text { TTTATGATGTACATATACAATGTTGTTCATGGTCTTGATTCATATTTT } \\
\text { CACAATTGCCTTTCCAAACTCGTATCC }\end{array}$ & ATTA & $\mathrm{s}$ & 18,6 & 160 & $\begin{array}{l}\text { GGTGGCTTTGGTCTG } \\
\text { ATTGT }\end{array}$ & 60,0 & $\begin{array}{l}\text { AAGGGAATTTGCAA } \\
\text { CCACAG }\end{array}$ & 60 & 50 & 45 \\
\hline 519 & BrPe4041 & $\begin{array}{l}\text { Maracuja_ } \\
\text { NoIndex_L } \\
\text { 003_R1_00 } \\
\text { 1_contig_1 } \\
4395\end{array}$ & 4 & 838 & 849 & 12 & 3 & 8 & $\begin{array}{l}\text { TAAACTATTTTGGCACATATGTCTTTCGGCCCATTAAAATTTTTCTTA } \\
\text { TTCTTCCTCGTGTTGTCGTAGCCTGGATGCAGTAGCTAGCGCCACAC } \\
\text { TTCGCGCCTCATAGCGATTGTGACTTTGCCACAGGTTGCCAATGCCA } \\
\text { TGCGACTAGTTGGTTGGTTGCTAGGACTGCCTGAGCAACCTCGATGC } \\
\text { AACTACAAATACGTCGGGGTGGTTGCTGCTCTGACGAGCATGTAAT } \\
\text { GATCACAGCTGACGGTGACCACTGATGAAATCCATAGCAATTTAAG } \\
\text { AATACTCCTTCCTTTGATATGAAAATATCTA }\end{array}$ & GTTG & $\mathrm{s}$ & 16,66 & 168 & $\begin{array}{l}\text { CATATGTCTTTCGGCC } \\
\text { CATT }\end{array}$ & 59,8 & $\begin{array}{l}\text { AGGTTGCTCAGGCA } \\
\text { GTCCTA }\end{array}$ & 60 & 45 & 55 \\
\hline 520 & BrPe4042 & $\begin{array}{l}\text { Maracuja_ } \\
\text { NoIndex_L } \\
003 \text { 181_00 } \\
\text { 1_contig_1 } \\
4543\end{array}$ & 4 & 741 & 752 & 12 & 3 & 8 & $\begin{array}{l}\text { CTGCAAGAGGTGGATGTTCCATCAACTGAGAGGGTGGAGTCACATC } \\
\text { CTCCTGATTCTGATCACCAACACTACTGGCCGGAAATCCAACCACG } \\
\text { GGGAGTGGAACCCAGCGATGTGAATCCAACACTAACTGAAGTAAAA } \\
\text { TAGGCAATTTGCAAGAAAGAAAGACATCAGATGCTAGTATATGACA } \\
\text { TAACAATTCGACACTATAGGAAAAGTATTGCACCACTATGAGAAA } \\
\text { CAAATTCAAACCGTCACTAGCCAAAAACCTGAAAATTTTCCACAGC } \\
\text { TATGCTCATGTTCTTTGAGAATAGGTTAAGAACAGC }\end{array}$ & AAGA & $\mathrm{s}$ & 16,56 & 150 & $\begin{array}{l}\text { CAGCGATGTGAATCC } \\
\text { AACAC }\end{array}$ & 60,1 & $\begin{array}{l}\text { TTGGCTAGTGACGG } \\
\text { TTTGAA }\end{array}$ & 59,3 & 50 & 45 \\
\hline
\end{tabular}

G: genoma funcional

S: genoma estructural

P: polimórfico

M: monomórfico 
APÉNDICE

Marcadores microssatélites desenhados a partir do sequênciamento parcial e da montagem de novo do genoma de $P$. edulis

\begin{tabular}{|c|c|c|c|c|c|c|c|c|c|c|c|c|c|c|c|c|c|c|c|}
\hline $\mathbf{N}^{\circ}$ & Primer & Contig M & Motivo & Início & Fim & pb & $\begin{array}{c}\mathrm{N}^{\mathbf{o}} \\
\text { Repet }\end{array}$ & Score & Sequência do contig & Unidade & G/S & Cobertura & pb & Sequência Forward & $\begin{array}{l}\mathrm{T}^{\circ} \mathrm{C} \\
F w d \\
\end{array}$ & Sequência Reverse & $\begin{array}{l}\mathrm{T}^{\circ} \mathrm{C} \\
\operatorname{Rev} \\
\end{array}$ & $\begin{array}{c}\% \mathrm{GC} \\
F w d \\
\end{array}$ & 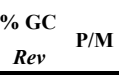 \\
\hline 521 & BrPe4043 & $\begin{array}{l}\text { Maracuja_ } \\
\text { NoIndex_L } \\
\text { 003_R1_00 } \\
\text { 1_contig_1 } \\
4659\end{array}$ & 4 & 3020 & 3031 & 12 & 3 & 8 & $\begin{array}{l}\text { CAACCCATATCCAAGGCTGATAAGCAACACTCCTCTCCACGAACCTT } \\
\text { CCCCAAGTATCCCATCTCCTATTATCATGATTCTCATAGTCGTCAGC } \\
\text { ATAAGAAAGGTCGCCAATAAACAACACAGCCTTCCCTATTCGTGGG } \\
\text { TTGTTTTCATAGTGAGTGAGTGTTTTATTGGAATCATAAGTCTGACC } \\
\text { AAGATCACCTGCAAAAACACAGAGCACAACGTGATGAGCTTATTAA } \\
\text { AGATGAACCATATTTCAAGAACATGCAAAGGGTCACTTGCATTACC } \\
\text { CATGACACCAAATGTATACGGGACATCAGGCCC }\end{array}$ & AGTG & $\bar{G}$ & 17,16 & 154 & $\begin{array}{l}\text { CCCCAAGTATCCCAT } \\
\text { СTCCT }\end{array}$ & 60,1 & $\begin{array}{l}\text { TTGCAGGTGATCTT } \\
\text { GGTCAG }\end{array}$ & 59,8 & 55 & 50 \\
\hline 522 & BrPe4044 & $\begin{array}{l}\text { Maracuja_ } \\
\text { NoIndex_L } \\
\text { 003_R1_00 } \\
\text { 1_contig_1 } \\
5486\end{array}$ & 4 & 5918 & 5929 & 12 & 3 & 8 & $\begin{array}{l}\text { AGTATGTGAAACCACCACATAATATAGCACAATGCCATAACATGCT } \\
\text { TCTAAAAGGAACACCTTTTTGCCTTAGTTTTATTACTACCCTCTTTA } \\
\text { TTTCATTACAGTACTAAATAACATATGCCTGTAACTGAACAACTTCT } \\
\text { CTTCTTTCCAAATAAATAAATGATCGTTTATAGAGCACATAGATTAT } \\
\text { TGAAAATCTTCTAAGCAAAAGAAAATGGAACAAATGGCAAGGATG } \\
\text { AACGTCAGAATGCAATGAAAAATATGTATGACAAGCTGAACAGAAA } \\
\text { TTCAACAAAAGAGAAAAGAGTTTAATCAGAGAA }\end{array}$ & AAAT & $\mathrm{s}$ & 18,85 & 214 & $\begin{array}{l}\text { AGCACAATGCCATAA } \\
\text { CATGC }\end{array}$ & 59,9 & $\begin{array}{l}\text { GACGTTCATCCTTG } \\
\text { CCATTT }\end{array}$ & 59,9 & 45 & 45 \\
\hline 523 & BrPe4045 & $\begin{array}{l}\text { Maracuja_ } \\
\text { NoIndex_L } \\
\text { 003_R1_00 } \\
\text { 1_contig_1 } \\
6779\end{array}$ & 4 & 1195 & 1206 & 12 & 3 & 8 & $\begin{array}{l}\text { AACTCGGCTTGGAAAAGTGGAGAAGGGAAGTTTGTGCAACTTACAGT } \\
\text { AGCTCGAGTGATACCGGGAAGGCAATAATCAGCATGCGGTGTGAGA } \\
\text { ACTCGGCCTTTCTTAACTAAGAACTGTGAAAATGCAAATGCAGTGTT } \\
\text { AGAAGTCGGCACTTTCTTTCTTTTCTCTTGCAGGATGTCTGGAATCA } \\
\text { ATAAGGCTAATTATGGACACCAACAAAAGCACCACCAGCATTCTTT } \\
\text { ATTTCATTCTTTTCACAACCTTTGGCTATCCATAAGATGGAATCTGA } \\
\text { AACAAGACAATGTTAGAAAGCAGAAGCTTACAA }\end{array}$ & СтTт & $\mathrm{s}$ & 18,6 & 160 & $\begin{array}{l}\text { ATAATCAGCATGCGG } \\
\text { TGTGA }\end{array}$ & 60,1 & $\begin{array}{l}\text { AGAATGCTGGTGGT } \\
\text { GCTTTT }\end{array}$ & 59,7 & 45 & 45 \\
\hline 524 & BrPe4046 & $\begin{array}{l}\text { Maracuja_ } \\
\text { NoIndex_L } \\
\text { 003_R1_00 } \\
\text { 1_contig_1 } \\
7558\end{array}$ & 4 & 1629 & 1640 & 12 & 3 & 8 & $\begin{array}{l}\text { CAGAGTCAAAACCTTGCCTCCTGCTACGCACCCTTACCGACTAACCA } \\
\text { TAAATTTGTGGTGCCTTCTTTGGCTAGTTTAATGGGTTGTAGCAGAA } \\
\text { TTTAGCTTAGTGATAAGAGTTTGCTTAACTCAACAGAGATAAGTTCA } \\
\text { AAACAGTTGTTTATTTATTTAATTTTCTTCCTTGAGGAAGGAGGAGA } \\
\text { ATGGCGCTTTTGTTATCGACAGCAGCGACCAAGTTAAACTGGAAGC } \\
\text { TTTTCAACAATGTTGGTGGTGATGTACAAGAAGTGTCGTCAGCTCTG } \\
\text { TCTAATCTTTTTACTGGTAAATATGTAGTCT }\end{array}$ & TTTA & s & 15,32 & 188 & $\begin{array}{l}\text { GCACCCTTACCGACT } \\
\text { AACCA }\end{array}$ & 60,0 & $\begin{array}{l}\text { CGCTGCTGTCGATA } \\
\text { ACAAAA }\end{array}$ & 60 & 55 & 45 \\
\hline 525 & BrPe4047 & $\begin{array}{l}\text { Maracuja_ } \\
\text { NoIndex_L } \\
\text { 003_R1_00 } \\
\text { 1_contig_1 } \\
8119\end{array}$ & 4 & 474 & 485 & 12 & 3 & 8 & $\begin{array}{l}\text { CTTAGACCACTCGGCCATCCTGACACTGTTTTGAAGGTTTGATTATC } \\
\text { TTTTATCAATGCAAAGGTCTAATTACTGAAATCTGCTTATCAATCAA } \\
\text { TGAAGTTGCTATTTAGAACCTTATATTTTGTGGCTGTCTCTGTATTGC } \\
\text { TGAGTGTGTTGTTTGTTTGTCTTTGATGGTTTCAGATTGTGTGTTATA } \\
\text { CGCGTGAGGTGTGTTGATATTCAGCTGTGAGGATTCAGGTTAGTAGA } \\
\text { TTGTGTTCTCGGAGGTTGATAGTTTACAGTTCCGCCTTGAAGTGGC } \\
\text { CATGCACCATGAGAGACCCACTGGTGTG }\end{array}$ & TTGT & G & 15,81 & 181 & $\begin{array}{l}\text { TGGCTGTCTCTGTATT } \\
\text { GCTGA }\end{array}$ & 59,6 & $\begin{array}{l}\text { GTGGGTCTCTCATG } \\
\text { GTGCAT }\end{array}$ & 61 & 48 & 55 \\
\hline
\end{tabular}

G: genoma funcional

S: genoma estructural

P: polimórfico

M: monomórfico 
APÉNDICE

Marcadores microssatélites desenhados a partir do sequênciamento parcial e da montagem de novo do genoma de $P$. edulis

\begin{tabular}{|c|c|c|c|c|c|c|c|c|c|c|c|c|c|c|c|c|c|c|c|}
\hline $\mathbf{N}^{\circ}$ & Primer & Contig I & Motivo & Início & Fim & pb & $\begin{array}{c}\mathbf{N}^{\circ} \\
\text { Repet }\end{array}$ & Score & Sequência do contig & Unidade & G/S & Cobertura & pb & Sequência Forward & $\begin{array}{l}\mathrm{T}^{\circ} \mathrm{C} \\
F w d \\
\end{array}$ & Sequência Reverse & $\begin{array}{l}\mathrm{T}^{\circ} \mathrm{C} \\
\operatorname{Rev} \\
\end{array}$ & $\begin{array}{r}\% \mathrm{GC} \\
F w d \\
\end{array}$ & $\begin{array}{cc}\% \mathrm{GC} & \mathrm{P} / \mathrm{M} \\
\operatorname{Rev} & \end{array}$ \\
\hline 526 & BrPe4048 & $\begin{array}{l}\text { Maracuja_ } \\
\text { NoIndex_L } \\
003 \text { R1_00 } \\
\text { 1_contig_1 } \\
9032\end{array}$ & 4 & 1095 & 1106 & 12 & 3 & 8 & $\begin{array}{l}\text { AGAAGAAATACTATCCTCTATATTTTGTGTTCATATCATCATATATTT } \\
\text { TGCTTTTATCCTCTGCTTACGGACTGTTTTTAGTCACTCTAAGTTTGG } \\
\text { TTGTCACACTCATGAATTTGTATGCACCGTTGTTCTGATTCTAGATTG } \\
\text { TATCTGCTGTCTGTCTGTTTTCCATATTTTTATTGTATTTCTTTTTCTT } \\
\text { TTGTTATTTAGTTTTTTACCTCATTGAAAGTTCTCAGGCTATTGTTAA } \\
\text { CTTCCTTATGCTAACATATGGAAATTCTTGATTGTGATGCATGGTGT } \\
\text { AGACAGCTGTTCCTCTTGTTCTTG }\end{array}$ & CTGT & $\mathrm{G}$ & 18,22 & 178 & $\begin{array}{l}\text { TGCACCGTTGTTCTGA } \\
\text { TTCT }\end{array}$ & 59,3 & $\begin{array}{l}\text { AGCTGTCTACACCA } \\
\text { TGCATCA }\end{array}$ & 59,3 & 45 & 48 \\
\hline 527 & BrPe4049 & $\begin{array}{l}\text { Maracuja_ } \\
\text { NoIndex_L } \\
\text { 003_R1_00 } \\
\text { 1_contig_2 } \\
0941\end{array}$ & 4 & 3562 & 3573 & 12 & 3 & 8 & $\begin{array}{l}\text { TAGTATATATTGATTATGGATGACATAAATAAGTAAATGCATATTGC } \\
\text { CTTACCATCTACAAACGTAGTCCAACAATTCAGTAAATAGAAATTTA } \\
\text { ATGTGGAAAATTAATAAAATTTCATCAAAAACTCTAGACACCACAT } \\
\text { GTGGAAATCAAAATAAATAAATCATAGCACTGATGCATTCAACTAG } \\
\text { TGATTTATTTTTGACTTTGCCACAACCCAGAGGAAAAATGAAGAATA } \\
\text { TTTCCATTTATAGAAGGAAAACTTAGTATTTCAACAAAACTTTATCA } \\
\text { ATAACATCCAAATAAATTACGATTCAAGACTG }\end{array}$ & AAAT & $\mathrm{s}$ & 22,22 & 175 & $\begin{array}{l}\text { TTGCCTTACCATCTAC } \\
\text { AAACG }\end{array}$ & 57,9 & $\begin{array}{l}\text { CTCTGGGTTGTGGC } \\
\text { AAAGTC }\end{array}$ & 60,7 & 43 & 55 \\
\hline 528 & BrPe4050 & $\begin{array}{l}\text { Maracuja_ } \\
\text { NoIndex_L } \\
003 \text { R1_00 } \\
\text { 1_contig_2 } \\
1563\end{array}$ & 4 & 1552 & 1563 & 12 & 3 & 8 & $\begin{array}{l}\text { ATGGGTGCCTCATACTTCATCCTGGATCTCAGAGATAATCTCGGTGG } \\
\text { ACTAGTACAGGTATTTATATTCTTGTGCAGCTTTTCAGTTTAATCTT } \\
\text { ACACATTCATTAATCTAGTCAGTTCTTTTTTGTAATATCCTTTGATTT } \\
\text { GAGATCTTTTATTTATTTACTCAGTTAAAATGGCATATTTTGTTTATC } \\
\text { CTTTCAATGTGATAGGATCAGCAATAATGGGTAAAAGAATGTGGAG } \\
\text { TAATCATTCTTACTTGAACATGTAGTTTCTGTGAACTTGTATTCCCTT } \\
\text { TGAGGAGAAACTGAAAAATACTTCCGG }\end{array}$ & TTTA & $\mathrm{s}$ & 17,08 & 220 & $\begin{array}{l}\text { GGGTGCCTCATACTT } \\
\text { CATCC }\end{array}$ & 59,4 & $\begin{array}{l}\text { CCCATTATTGCTGAT } \\
\text { CCTATCAC }\end{array}$ & 59,7 & 55 & 43 \\
\hline 529 & BrPe4051 & $\begin{array}{l}\text { Maracuja_ } \\
\text { NoIndex_L } \\
003 \text { R1_00 } \\
\text { 1_contig_8 } \\
2\end{array}$ & 4 & 523 & 534 & 12 & 3 & 8 & $\begin{array}{l}\text { CAAAGATCAAGCTAGCTCCTGGAAACCCTAGCTGAACAAGACCAAG } \\
\text { AGAAGTAACATGAACATCAAACTCAAACCATACATGCACATGAACA } \\
\text { TGGCAACCAAAGACAAGGATGGCATGCATGAACACCACCTACCTCT } \\
\text { TCTCCCTTCTTCTCTTTCTTTCTTCTTCTTCTTTTGCCCTAGCCAGCCC } \\
\text { TCTCACGATGGCAACTCACCTCAGCCCTCACTCTCTTTTCTTTTCTCA } \\
\text { ATTACACCACCTTTTCCATAGAGTCATTACACCACCTTTTTTATTAGG } \\
\text { GGTTGAATAGGTCTTTTGTGGG }\end{array}$ & TCTT & $\mathrm{s}$ & 37,4 & 207 & $\begin{array}{l}\text { TCCTGGAAACCCTAG } \\
\text { CTGAA }\end{array}$ & 59,8 & $\begin{array}{l}\text { AGAGAGTGAGGGCT } \\
\text { GAGGTG }\end{array}$ & 59,6 & 50 & 60 \\
\hline 530 & BrPe4052 & $\begin{array}{l}\text { Maracuja_ } \\
\text { NoIndex_L } \\
003 \text { _R1_00 } \\
\text { 1_conti__8 } \\
5\end{array}$ & 4 & 7687 & 7698 & 12 & 3 & 8 & $\begin{array}{l}\text { GAGAAAACGAAATCCGGAAAAAGTCCAATACCTATTACTGGTAAAA } \\
\text { GTAGACATATCGAAACAAAAAATTCCCGGGGCCCAGAATCAAAAA } \\
\text { AATACGAGTTTGCAGCATCAAACAGCTTGTATCCATAGAACATTTGG } \\
\text { CGTAACATGGATAATAAATAAATAGGAGTCAATATCATTCCAACTG } \\
\text { CCATTACAAAAGTAATTAGAATTTTGGGCATTAAAAGATATTTTTGG } \\
\text { CCGGTAATTATTCCAAGAAAGACTATTAATTCCGCAACAAAACCAC } \\
\text { TCATGCCCGGTAATGCAAGGGAGGCTAATGATAAG }\end{array}$ & AATA & G & $5.355,62$ & 180 & $\begin{array}{l}\text { TTTGCAGCATCAAAC } \\
\text { AGCTT }\end{array}$ & 59,6 & $\begin{array}{l}\text { GAGTGGTTTTGTTGC } \\
\text { GGAAT }\end{array}$ & 60 & 40 & 45 \\
\hline
\end{tabular}

G: genoma funcional

S: genoma estructural

P: polimórfico

M: monomórfico 
APÉNDICE

Marcadores microssatélites desenhados a partir do sequênciamento parcial e da montagem de novo do genoma de $P$. edulis

\begin{tabular}{|c|c|c|c|c|c|c|c|c|c|c|c|c|c|c|c|c|c|c|c|}
\hline $\mathbf{N}^{\mathbf{o}}$ & Primer & Contig $\mathrm{I}$ & Motivo & Início & Fim & pb & $\begin{array}{c}\mathbf{N}^{\mathbf{o}} \\
\text { Repet }\end{array}$ & Score & Sequência do contig & Unidade & G/S & Cobertura & pb & Sequência Forward & $\begin{array}{l}\mathrm{T}^{\circ} \mathrm{C} \\
F w d\end{array}$ & Sequência Reverse & $\begin{array}{r}\mathrm{T}^{\circ} \mathrm{C} \\
\operatorname{Rev}\end{array}$ & $\begin{array}{c}\% \mathrm{GC} \\
F w d\end{array}$ & $\begin{array}{c}\% \mathrm{GC} \\
\operatorname{Rev}\end{array} \quad \mathrm{P} / \mathbf{M}$ \\
\hline 531 & BrPe4053 & $\begin{array}{l}\text { Maracuja_ } \\
\text { NoIndex_L } \\
\text { 003_R1_00 } \\
\text { 1_contig_1 } \\
06\end{array}$ & 4 & 2829 & 2840 & 12 & 3 & 8 & $\begin{array}{l}\text { GTACAATAGACAGTGGAGACAATAAAGCATTTACCGTAGGTTGACA } \\
\text { GGGCCAGTCACTGTTAGATCTTTCGATGATCAAGCTACACAGCCAA } \\
\text { ACGTTGTCCTTTCAAATTCATTGCCAGCGAAAACCTTTCTGGTTACT } \\
\text { GTTAAAAAAACCAAACAAACAAAGACGATCCAGCCATGGGGAGGT } \\
\text { TGCGGGCACCTGAAGGAGAGGGAGGAAGAGAAGGCTGGGGACAAA } \\
\text { ACAATTCGTAAGCCAAAAAAACAAACAAGCATTTTCTGGAGTTTAA } \\
\text { TGCCCAAGGTGAGGTAATATCATTCTCCTAGACGCTT }\end{array}$ & CAAA & $\mathrm{G}$ & 99,39 & 156 & $\begin{array}{l}\text { TCAAGCTACACAGCC } \\
\text { AAACG }\end{array}$ & 60,0 & $\begin{array}{l}\text { GTTTTGTCCCCAGCC } \\
\text { TTCTC }\end{array}$ & 61 & 50 & 55 \\
\hline 532 & BrPe4054 & $\begin{array}{l}\text { Maracuja_ } \\
\text { NoIndex_L } \\
003 \text { R1_00 } \\
\text { 1_contig_2 } \\
42\end{array}$ & 4 & 1311 & 1322 & 12 & 3 & 8 & $\begin{array}{l}\text { AAAATATTCTTACTTACCATTCAATTATTAATAGGTACTTTTGTGTAT } \\
\text { AAAGATTTCTATTTCAAAGAACCAGCTAAGCTAGCTGTCCTCTTGTC } \\
\text { GGGAGCCAGCATTCTTTTTTTATGTATGAATAAAAGAAGTCGTTTTG } \\
\text { CTTTTCTACTTTCTTTCTTTATTTATTTCATTATCAGTATAATAATTGG } \\
\text { ATTAGTCTCTTTGCCAGGTAAAGTTACTGCGTTGGACTTGTGGGGTT } \\
\text { TATCTATTTTTGTCTTAGTACATATAATCTTTCTATGGGGGTTGCAAC } \\
\text { TTTTTATATTACCCCAGGAAAAACAA }\end{array}$ & стTт & $\mathrm{s}$ & 309,29 & 159 & $\begin{array}{l}\text { AAGCTAGCTGTCCTC } \\
\text { TTGTCG }\end{array}$ & 58,9 & $\begin{array}{l}\text { CCACAAGTCCAACG } \\
\text { CAGTAA }\end{array}$ & 59,8 & 52,4 & 50 \\
\hline 533 & BrPe4055 & $\begin{array}{l}\text { Maracuja_ } \\
\text { NoIndex_L } \\
\text { 003_R1_00 } \\
\text { 1_contig_2 } \\
84\end{array}$ & 4 & 1517 & 1532 & 16 & 4 & 12 & $\begin{array}{l}\text { ATTAGAACTCAATTAAGGCTCGATGAGTAACTCTTACGATCTATTAA } \\
\text { TGAAATTTTGAAATTATTGTTTTCATAGAATATAACACTTCATAATT } \\
\text { AGGGTAGACTCGCTCTTTCTTTTCTTTTCTTTTTTTTTTTTTTGATTAA } \\
\text { ATATATCTCTTTCTTTCTTTCTTCTTTTGTTACTAAAAATTAATTTTG } \\
\text { TTCAGGAAACATGTTGGAGTGACTATAGCTGTTTTTTTTCCTAATG } \\
\text { AATTCGTGTAGATTGTGTTGGAATGTCAATGTTATATAGCTCTGG } \\
\text { TGCTCGTTTCTTATAATTCTTAACATTGAC }\end{array}$ & ТстT & $\mathrm{s}$ & 19,41 & 206 & $\begin{array}{l}\text { GAACTCAATTAAGGC } \\
\text { TCGATGA }\end{array}$ & 58,5 & $\begin{array}{l}\text { TCCAACATGTTTCCT } \\
\text { GAACAA }\end{array}$ & 59 & 40,9 & 38,1 \\
\hline 534 & BrPe4056 & $\begin{array}{l}\text { Maracuja_ } \\
\text { NoIndex_L } \\
003 \text { R1_00 } \\
\text { 1_contig_4 } \\
23\end{array}$ & 4 & 765 & 776 & 12 & 3 & 8 & $\begin{array}{l}\text { AGCTTTGGAAAGTAAGACTAATAATAATCTTTTGATGAGGTTAAAA } \\
\text { AGCCAGTAAAAGTTCTTACTAATTATCGATGCGAATACTTAGAAACC } \\
\text { CAGTATGGCCCCAGCCTGTTGTGCTCCTGTGAACCTGAGCGCCATTT } \\
\text { TGTTTCATGGCAAACAAACAAAACCAAAGGTTCACGTGGTGATCGC } \\
\text { AGTAGTGGTTGCCCAACAATATTGTCCCAACTTTACATTTTGCGTAA } \\
\text { TCCATTCTTTTGTCACCATTCACAGCCTCAAAATTGCACCATCCTGT } \\
\text { GCAGTGACAGACAGCTGCTCCTGACAGCTACA }\end{array}$ & CAAA & G & 13,28 & 167 & $\begin{array}{l}\text { TTGTGCTCCTGTGAAC } \\
\text { CTGA }\end{array}$ & 60,4 & $\begin{array}{l}\text { AGGATGGTGCAATT } \\
\text { TTGAGG }\end{array}$ & 59,9 & 50 & 45 \\
\hline 535 & BrPe4057 & $\begin{array}{l}\text { Maracuja_ } \\
\text { NoIndex_L } \\
003 \_R 1 \_00 \\
\text { 1_contig_4 } \\
65\end{array}$ & 4 & 1592 & 1603 & 12 & 3 & 8 & $\begin{array}{l}\text { AAAGACAACACCAATATTCCTGGCATCAGCGTCATTAGGATAATAA } \\
\text { ACATAAAGCTTCCCGCTAAGAACACAAGTCTTCGCATGCTCAACAA } \\
\text { GAACATCCCACATCTTATTTGACATGCCACTTCCCAGAATCTACAGA } \\
\text { AAAATGGATAAAAATAAATAAATGAAAACAATAATGCATGAAAGA } \\
\text { AAATACTAATTTAACATCAAACTTAAATCATACATTTCTCAATCTCT } \\
\text { GCGAGTCCCTAACTACAAGACGTAGGAAGTCTTCAACTGTATATATT } \\
\text { CCAGCTTTGTTAAGCCTCTTGTGAAATGATCCAT }\end{array}$ & AAAT & G & 15,55 & 165 & $\begin{array}{l}\text { TTCGCATGCTCAACA } \\
\text { AGAAC }\end{array}$ & 60,0 & $\begin{array}{l}\text { AGGGACTCGCAGAG } \\
\text { ATTGAG }\end{array}$ & 59,6 & 45 & 55 \\
\hline
\end{tabular}

G: genoma funcional

S: genoma estructural

P: polimórfico

M: monomórfico 
APÉNDICE

Marcadores microssatélites desenhados a partir do sequênciamento parcial e da montagem de novo do genoma de $P$. edulis

\begin{tabular}{|c|c|c|c|c|c|c|c|c|c|c|c|c|c|c|c|c|c|c|c|}
\hline $\mathbf{N}^{\circ}$ & Primer & Contig I & Motivo & Início & Fim & pb & $\begin{array}{c}\mathbf{N}^{\circ} \\
\text { Repet }\end{array}$ & Score & Sequência do contig & Unidade & G/S & Cobertura & pb & Sequência Forward & $\begin{array}{l}\mathrm{T}^{\circ} \mathrm{C} \\
F w d \\
\end{array}$ & Sequência Reverse & $\begin{array}{r}\mathrm{T}^{\circ} \mathrm{C} \\
\operatorname{Rev} \\
\end{array}$ & $\begin{array}{c}\% \mathrm{GC} \\
F w d \\
\end{array}$ & $\begin{array}{c}\% \mathrm{GC} \\
\operatorname{Rev}\end{array} \quad \mathrm{P} / \mathrm{M}$ \\
\hline 536 & BrPe4058 & $\begin{array}{l}\text { Maracuja_ } \\
\text { NoIndex_L } \\
003 \text { R1_00 } \\
\text { 1_contig_5 } \\
52\end{array}$ & 4 & 1584 & 1595 & 12 & 3 & 8 & $\begin{array}{l}\text { CCTCATCCTCGGCCAGAGGTACCTCTGCGATCCATAGCCCTAGACTT } \\
\text { TGTGAAAGACTATCGGTGTAAAGACTCTCAGCTAGTCGGGAAAACC } \\
\text { CCTCTATCTTTTCAAGTCCCATTCCATTGGTCGGCTCTCTCAAAAAG } \\
\text { GGGTTCGGAATTCTTTCTTTCTCTTCCGGCCCTTTTAAGTCCAACTGC } \\
\text { TCAGATAGCAAAATCGTAAGGTTCATAGTCTGAATCTCTTACCTTAT } \\
\text { TCTCTCTTGGTAAGAGAAAAAGTCCTATCCTTCAGGGCAGTCCTTGC } \\
\text { GGAAGTTGGTGGACTCTATTTGGGATTCTA }\end{array}$ & TTCT & $\mathrm{s}$ & 298,11 & 195 & $\begin{array}{l}\text { TCGGGAAAACCCCTC } \\
\text { TATCT }\end{array}$ & 59,9 & $\begin{array}{l}\text { GACTGCCCTGAAGG } \\
\text { ATAGGA }\end{array}$ & 59,2 & 50 & 55 \\
\hline 537 & BrPe4059 & $\begin{array}{l}\text { Maracuja_ } \\
\text { NoIndex_L } \\
003 \text { R1_00 } \\
\text { 1_contig_7 } \\
68\end{array}$ & 4 & 206 & 217 & 12 & 3 & 8 & $\begin{array}{l}\text { AAAAACGGTGGGAAAGTAAGGCATATTAAAACATTTAATGCATAAA } \\
\text { ACCACATTTCGTACCTTGAGAGCTGATAACCAGTTACTCAAACATTG } \\
\text { TAATGCACGACATAATCATAATAACATATCACATGCACACATGGGC } \\
\text { AAACAGTTTCAAACCAACCAACCTCAGGCCTCCCAGAACCTCAGC } \\
\text { AGGTCATTAGACCTCCCTGGCATCACGGCTTAGTCATTTTGGTTGGT } \\
\text { TATGCATGTCATACAATCAAACCTCAGACTTCCCCAGAACCTCAGCA } \\
\text { GGTCATTAGACCTCCCTGGCATCACGGCTTGGT }\end{array}$ & AACC & G & $12.178,39$ & 222 & $\begin{array}{l}\text { CGGTGGGAAAGTAAG } \\
\text { GCATA }\end{array}$ & 60,0 & $\begin{array}{l}\text { ccaAAATGACTAAGC } \\
\text { CGTGA }\end{array}$ & 58,8 & 50 & 45 \\
\hline 538 & BrPe4060 & $\begin{array}{l}\text { Maracuja_ } \\
\text { NoIndex_L } \\
003 \text { R1_00 } \\
\text { 1_contig_8 } \\
06\end{array}$ & 4 & 658 & 669 & 12 & 3 & 8 & $\begin{array}{l}\text { CAATAAGTGCATAGTGCATGGCTCTGATATCCCCGTTGGCTTCTCTT } \\
\text { TTGCCACAAGGACATCGACTGTTGCCGGCCTTTTTCTTGTTTGATTAC } \\
\text { AGCTCTAACATCTCCCTATTACACATCGAAACATTTTCCTTTCTTACA } \\
\text { AAAAAAGAAGAAAGAAAGATGGAGGGGTTGGTCAAGCTGTCCTTGT } \\
\text { TGGGTGCTGATTCTTCTTCTTCATACTGGAAAACCTTGCGTCAGCA } \\
\text { AAGACCAAAATCAAGTCGGTGTGATCGATCGTTGCCTTAACATTTCA } \\
\text { GTTGTCTCAGTGATTAATTAATTAACAAA }\end{array}$ & AAGA & G & 17,93 & 165 & $\begin{array}{l}\text { ATATCCCCGTTGGCTT } \\
\text { CTCT }\end{array}$ & 59,9 & $\begin{array}{l}\text { CAACAAGGACAGCT } \\
\text { TGACCA }\end{array}$ & 59,9 & 50 & 50 \\
\hline 539 & BrPe4061 & $\begin{array}{l}\text { Maracuja_ } \\
\text { NoIndex_L } \\
003 \text { R1_00 } \\
\text { 1_contig_8 } \\
92\end{array}$ & 4 & 22256 & 22267 & 12 & 3 & 8 & $\begin{array}{l}\text { ATGTGAATTGCAACGAATTAATAGAACCTTTAGAGCGTACTCCTTCC } \\
\text { TTTAGAAGAATGGATTCAGAGTTCAAGAAGATGTCTTAAACAATTT } \\
\text { GCTTTTCCTTGCTCTTACTAGGAGTTCTTGCACTAAGTGACTTTTGAA } \\
\text { TGAAACTTTTGAGTGAGTGAGATGGAGATTAAGCGAGGGAAGGAAC } \\
\text { CCCGGGGTAAATAAAGTTTCGTATAACAGAACCATTAGCGATTCTC } \\
\text { GCTCTTGTCTTATCTGCTGCTGTCTCTGACTGACGAAGAAGGAGTCC } \\
\text { CACTACACGAAAAGAAAGAAGGTAGGAGCCCA }\end{array}$ & TGAG & $\mathrm{s}$ & 257,95 & 150 & $\begin{array}{l}\text { CAATTTGCTTTTCCTT } \\
\text { GCTCTT }\end{array}$ & 59,9 & $\begin{array}{l}\text { GAGCGAGAATCGCT } \\
\text { AATGGT }\end{array}$ & 59,4 & 36,4 & 50 \\
\hline 540 & BrPe4062 & $\begin{array}{l}\text { Maracuja_ } \\
\text { NoIndex_L } \\
\text { 003_R1_00 } \\
\text { 1_contig_9 } \\
46\end{array}$ & 4 & 3757 & 3768 & 12 & 3 & 8 & $\begin{array}{l}\text { TTGAAACCAAGGCATAAAGTTAGGTCCTTTCAGAAAACGCCTAAAC } \\
\text { AGCAACAAAGGTCATTATTAGCTCAACAGAATTAGAGTGGCTATGA } \\
\text { GTGAAGAACCATAGGCAATTTATAGAAGCTGAAGAAACTAAAAACA } \\
\text { AAACAAGAGAAAAAATAAATAAATGAATACCAATACAAGTTTATTG } \\
\text { TTCATTACTTGTATAAGTCCAGCCAATTTGATCTCATCCGCTTTGATA } \\
\text { AAAACTTTCCCACTCCTCTTGCTGATAGGCTTGCCAGGAATTCATCA } \\
\text { GTATTAAATGAAAGGAGAGGAGGAGGGTCTACA }\end{array}$ & АAAT & $\mathrm{s}$ & 16,21 & 219 & $\begin{array}{l}\text { CGCCTAAACAGCAAC } \\
\text { AAAGG }\end{array}$ & 60,8 & $\begin{array}{l}\text { CAGCAAGAGGAGTG } \\
\text { GGAAAG }\end{array}$ & 60 & 50 & 55 \\
\hline
\end{tabular}

G: genoma funcional

S: genoma estructural

P: polimórfico

M: monomórfico 
APÉNDICE

Marcadores microssatélites desenhados a partir do sequênciamento parcial e da montagem de novo do genoma de $P$. edulis

\begin{tabular}{|c|c|c|c|c|c|c|c|c|c|c|c|c|c|c|c|c|c|c|c|}
\hline $\mathbf{N}^{\circ}$ & Primer & Contig I & Motivo & Início & Fim & pb & $\begin{array}{c}\mathbf{N}^{\circ} \\
\text { Repet }\end{array}$ & Score & Sequência do contig & Unidade & G/S & Cobertura & pb & Sequência Forward & $\begin{array}{l}\mathrm{T}^{\circ} \mathrm{C} \\
F w d \\
\end{array}$ & Sequência Reverse & $\begin{array}{l}\mathrm{T}^{\circ} \mathrm{C} \\
\operatorname{Rev} \\
\end{array}$ & $\begin{array}{c}\% \mathrm{GC} \\
F w d \\
\end{array}$ & $\begin{array}{c}\% \mathrm{GC} \\
\operatorname{Rev}\end{array} \quad \mathrm{P} / \mathrm{M}$ \\
\hline 541 & BrPe4063 & $\begin{array}{l}\text { Maracuja_ } \\
\text { NoIndex_L } \\
\text { 003_R1_00 } \\
\text { 1_contig_1 } \\
\text { 257 }\end{array}$ & 4 & 256 & 267 & 12 & 3 & 8 & $\begin{array}{l}\text { TGGATGGAAGAAAAGGAAGTTGAGCATCTGATGAATTATCTGCATC } \\
\text { ACTACAAACATATAACGTCAGATAATATCCGCCTGATGAGTGGTAA } \\
\text { AGAAACTCTATGAAAATGTGCAGAAAAAATTGAATGACGGGCATGG } \\
\text { TCAGAAACAAACAAATAAATAAATGCAGGCAAATGAAATCAAATC } \\
\text { AATGAAAAAAGATTCAGTCACAAAATGATGGCCACTTACAGTACAT } \\
\text { CCAACAAGTAGAACAAACTAGAACAATCTAGAACAATCCAAAAGG } \\
\text { TGCCCAATTCTCCAAAAATATTACTCTTTATGGCAATT }\end{array}$ & $\overline{\text { AAAT }}$ & $\mathrm{s}$ & 16,86 & 151 & $\begin{array}{l}\text { AATATCCGCCTGATG } \\
\text { AGTGG }\end{array}$ & 59,9 & $\begin{array}{l}\text { AAGTGGCCATCATT } \\
\text { TTGTGA }\end{array}$ & 59,9 & 50 & 40 \\
\hline 542 & BrPe4064 & $\begin{array}{l}\text { Maracuja_ } \\
\text { NoIndex_L } \\
003 \text { R1_00 } \\
\text { 1_contig_1 } \\
627\end{array}$ & 4 & 5318 & 5329 & 12 & 3 & 8 & $\begin{array}{l}\text { GTTTACCGAGGTGCTTTGAGTACTTGTCACTTTCGCAATCATGTATG } \\
\text { GTGGGTTCTATTTTTTTCTCAACCTTATATTTTATCTTTTTTCTCAAAG } \\
\text { CAATATTCCCTCAATCACAGGGTACGAGAAAAAAGGTCCACAAGTT } \\
\text { CTATTTATTTAATTAATTAAATAATTATTATTTCAGGTAAAAGTATCT } \\
\text { AAACCTTGTCATACATGATTATGTGTCAGCATTATCCTATTGTAATT } \\
\text { GCGTAGGACAATGACATTTTTGTGGTGTGTTAACCAACCATTGGGCC } \\
\text { ACATGGCAGTTTATATCGTTTGTGATGA }\end{array}$ & TTAA & $\mathrm{s}$ & 17,26 & 161 & $\begin{array}{l}\text { CCCTCAATCACAGGG } \\
\text { TACGA }\end{array}$ & 60,9 & $\begin{array}{l}\text { CACCACAAAAATGT } \\
\text { CATTGTCC }\end{array}$ & 60,1 & 55 & 40,9 \\
\hline 543 & BrPe4065 & $\begin{array}{l}\text { Maracuja_ } \\
\text { NoIndex_L } \\
\text { 003_R1_00 } \\
\text { 1_contig_2 } \\
007\end{array}$ & 4 & 2824 & 2835 & 12 & 3 & 8 & $\begin{array}{l}\text { CATCATTTACCTGTTGTGAGTCGCTTCTTTTGTCCCCCAGATATGCCT } \\
\text { CGTACCATTTCATCACCCACCATAGTATCAGCACACACTTCAAGTCC } \\
\text { CAGAATCTGGATGTTTCAGAAGAAAGATAGATTAATCATTATGCAC } \\
\text { ATATATATATATGTATGTATGGATGTGTGTCCTAAGTGGGTTCTCAG } \\
\text { TTAGCTACCTTAAGAGTATAATCTGTCATTACATTAGTCTCTTGCCCT } \\
\text { TCCAGTGCTGCTGCCTGCGGATTCCAAGTATCAGAACACGCTTCACT } \\
\text { GATGAAAACAATTCAGGAATTATGGTCGC }\end{array}$ & TATG & G & 15,96 & 200 & $\begin{array}{l}\text { TGCCTCGTACCATTTC } \\
\text { ATCA }\end{array}$ & 60,1 & $\begin{array}{l}\text { caCTGGAAGGGCAA } \\
\text { GAGACT }\end{array}$ & 59,5 & 45 & 55 \\
\hline 544 & BrPe4066 & $\begin{array}{l}\text { Maracuja_ } \\
\text { NoIndex_L } \\
\text { 003_R1_00 } \\
\text { 1_contig_2 } \\
\text { 285 }\end{array}$ & 4 & 608 & 619 & 12 & 3 & 8 & $\begin{array}{l}\text { TTGCGTGACGTGAGATGGACAAAGTGAGAGTTGAAACTTAAAAGTG } \\
\text { ATGGCTCCATTTAGTTGGAGTTAACTTCATTCATGCATAGTGAATAA } \\
\text { TCACTGACAGCAGATGCATGTTGACACTGTCCCTCCATCTTCCCTG } \\
\text { CAAAAACATGTCCTTCCTTCCTCGGCCTTGACAAGAAAATACTGAAC } \\
\text { TTGATAGATAGAACCATCAGAATCAATGACCCCATTATTATTATTAT } \\
\text { TATTGTTGTTATTTCTTTCTCTCACCACAACAAAGTGGCTTCACTCCT } \\
\text { TTCCTTACTTATACCACTTGTCCGCAACGT }\end{array}$ & ТССТ & $\mathrm{s}$ & 18,62 & 217 & $\begin{array}{l}\text { CGTGACGTGAGATGG } \\
\text { ACAAA }\end{array}$ & 60,7 & $\begin{array}{l}\text { GGGGTCATTGATTC } \\
\text { TGATGG }\end{array}$ & 60,1 & 50 & 50 \\
\hline 545 & BrPe4067 & $\begin{array}{l}\text { Maracuja_ } \\
\text { NoIndex_L } \\
\text { 003_R1_00 } \\
\text { 1_contig_2 } \\
\text { 509 }\end{array}$ & 4 & 6817 & 6828 & 12 & 3 & 8 & $\begin{array}{l}\text { CTGGATGATAAAAGAACGTTCTTTCAAATTCACGTGAAAAAGAACA } \\
\text { TTTGTTTGGTTTGATAGAGCCTGGGGGCAGGGACCGTGTTCGACCCC } \\
\text { CACAAAAGGAACTGGTGGGCTCTGCATCTATTCCAGAGGCTAAAAG } \\
\text { GGAGAAGCAAGAGAAAGGAAAGAATGCCCAACTATGGACTGCAACT } \\
\text { TACTTATTATTTTATTGCCCTCAAAAAAAAGTTCCAGAGGCATCTTC } \\
\text { CATTCATATCGATTTGGGTTTTTCCGCACCATATTTTGATCTGCCTCT } \\
\text { TCTTCGATCCGGAATTCCCAGCAAATCCTTTAC }\end{array}$ & AGAA & G & 257,61 & 198 & $\begin{array}{l}\text { AAAAGGAACTGGTGG } \\
\text { GCTCT }\end{array}$ & 60,1 & $\begin{array}{l}\text { ATTCCGGATCGAAG } \\
\text { AAGAGG }\end{array}$ & 60,5 & 50 & 50 \\
\hline
\end{tabular}

G: genoma funcional

S: genoma estructural

P: polimórfico

M: monomórfico 
APÉNDICE

Marcadores microssatélites desenhados a partir do sequênciamento parcial e da montagem de novo do genoma de $P$. edulis

\begin{tabular}{|c|c|c|c|c|c|c|c|c|c|c|c|c|c|c|c|c|c|c|c|}
\hline $\mathbf{N}^{\circ}$ & Primer & Contig I & Motivo & Início & Fim & pb & $\begin{array}{c}\mathbf{N}^{\circ} \\
\text { Repet }\end{array}$ & Score & Sequência do contig & Unidade & G/S & Cobertura & pb & Sequência Forward & $\begin{array}{l}\mathrm{T}^{\circ} \mathrm{C} \\
F w d \\
\end{array}$ & Sequência Reverse & $\begin{array}{l}\mathrm{T}^{\circ} \mathrm{C} \\
\operatorname{Rev} \\
\end{array}$ & $\begin{array}{c}\% \mathrm{GC} \\
F w d \\
\end{array}$ & $\begin{array}{cc}\% \mathrm{GC} & \mathrm{P} / \mathrm{M} \\
\operatorname{Rev} & \end{array}$ \\
\hline 546 & $\begin{array}{l}\text { BrPe4068 } \\
\end{array}$ & $\begin{array}{l}\text { Maracuja_ } \\
\text { NoIndex_L } \\
\text { 003_R1_00 } \\
\text { 1_contig_2 } \\
721\end{array}$ & 4 & 385 & 396 & 12 & 3 & 8 & $\begin{array}{l}\text { CTCTATTTCTTCCACGGCTATTTTCATTTTTGTTGGTGACAGTATCAG } \\
\text { TCCCTCCTTTTCGCATATCCTGAGCATCCTGCTTAAATGCTCTGCGTG } \\
\text { TTCACAAGGATATCGTCTATGTATACGGCTATGAAATCCTCACAATC } \\
\text { TTTAAAGCATCCATCCATCTTTCTCTGGAATATAGCCGGCGCATTTTT } \\
\text { CAATCCAAATGGCATTACCAGCCATTCATACAATCCTCCTGGTGTAA } \\
\text { TGAAGGCTGTCCATGGTATACTCTCTTCGGCCATAGCTACCTGGTGA } \\
\text { AATCCACTTTCAGATCAAATTTTGAG }\end{array}$ & CATC & $\mathrm{G}$ & 284,1 & 228 & $\begin{array}{l}\text { CCTTTTCGCATATCCT } \\
\text { GAGC }\end{array}$ & 59,8 & $\begin{array}{l}\text { CAGGTAGCTATGGC } \\
\text { CGAAGA }\end{array}$ & 60,4 & 50 & 55 \\
\hline 547 & BrPe4069 & $\begin{array}{l}\text { Maracuja_ } \\
\text { NoIndex_L } \\
\text { 003_R1_00 } \\
\text { 1_contig_2 } \\
977\end{array}$ & 4 & 746 & 757 & 12 & 3 & 8 & $\begin{array}{l}\text { AAAGGCGTATGTATGTTTATATATTCGCGTTGCGTTACCCCTTCTCTG } \\
\text { CATGCACCACTGAGCTTCAAAAGAGCTCCAAGAGAAAAAAAAAAC } \\
\text { CAACAAGAAAAACAAGACAAAGCAAGGCCTAAAATTAAGATTTGCT } \\
\text { CACAGAGAAATGGAAGGAAGGAAATGTAAAAGGCAGGAGAGGGAA } \\
\text { AGAGAAAAAGGGAAGAGAGAGGGAGAAGAAAAAAAGGTAAAGAT } \\
\text { AGAACGCTATATGTGGACTACTCGAAGCCTTTCAAATGCCGAAGTA } \\
\text { CCAAAAAGGGGCTGGTTGACTCTCATCCCTCCTCTCTC }\end{array}$ & GGAA & G & 17,87 & 158 & $\begin{array}{l}\text { GTTGCGTTACCCCTTC } \\
\text { TCTG }\end{array}$ & 59,7 & $\begin{array}{l}\text { СтTTCCCTCTCCTGC } \\
\text { СTTTT }\end{array}$ & 59,8 & 55 & 50 \\
\hline 548 & BrPe4070 & $\begin{array}{l}\text { Maracuja_ } \\
\text { NoIndex_L } \\
\text { 003_R1_00 } \\
\text { 1_contig_3 } \\
019\end{array}$ & 4 & 271 & 282 & 12 & 3 & 8 & $\begin{array}{l}\text { ACAACCAACCAATTCGAACTTAGGGGCGATTGGTTGGGGCACACAA } \\
\text { CACCCTAAGAGAAAGAGAATTTGGAACACCACACGACTGACTAATC } \\
\text { GCATGAGGGCATACGATCGGTCCTACTTGTAACTCAACGTCTAAGCT } \\
\text { AATAACCAATGACCAACCAACCATAACCACAGCTCACCAAAGATTC } \\
\text { ACGACACAAGCCAACACAACCAACTCTTCAACAAAAGGCTCCAACC } \\
\text { AAACTCAAGAACACCATGCAACAACACGGAACTATCCTAGCATCTC } \\
\text { AACATCCTACTCAAGCCTACAAGGCAACACTTGTT }\end{array}$ & ACCA & $\mathrm{s}$ & 84,54 & 166 & $\begin{array}{l}\text { TTTGGAACACCACAC } \\
\text { GACTG }\end{array}$ & 60,6 & $\begin{array}{l}\text { GGTTGGAGCCTTTT } \\
\text { GTTGAA }\end{array}$ & 60,1 & 50 & 45 \\
\hline 549 & BrPe4071 & $\begin{array}{l}\text { Maracuja_ } \\
\text { NoIndex_L } \\
003 \text { R1_00 } \\
\text { 1_contig_3 } \\
173\end{array}$ & 4 & 4282 & 4293 & 12 & 3 & 8 & $\begin{array}{l}\text { TACTGTTGGATCTTAATGACAAAGACTTCCTTTCTCAAGGCTAGAAA } \\
\text { TAGATGTCTGAAGATCTACGAAGGGTTCGGGTGTCAGTCCAGAGC } \\
\text { GGGACCTTTTTTCTTTTTAGTTATGAGTCCTATCCTTATTTGAATTTT } \\
\text { ACACAGCAACATCATCATCATACTATTCGGGAGACATGGTCCAAGC } \\
\text { CCGGTGAAATGATCACCCATGACTTCTTTGTACCGGGTCCCATTACT } \\
\text { TTCTTTCTTTTTCCAAAGGACGAGTAAGAGTGATATAAATCCGTTTC } \\
\text { CCAACCAAACGTCGATACCGGCCCACATCAG }\end{array}$ & СТTT & G & $1.010,55$ & 100 & $\begin{array}{l}\text { GGTGAAATGATCACC } \\
\text { CATGA }\end{array}$ & 59,1 & $\begin{array}{l}\text { TTGGTTGGGAAACG } \\
\text { GATTTA }\end{array}$ & 60,2 & 45 & 40 \\
\hline 550 & BrPe4072 & $\begin{array}{l}\text { Maracuja_ } \\
\text { NoIndex_L } \\
003 \text { 181_00 } \\
\text { 1_conti__3 } \\
173\end{array}$ & 4 & 4364 & 4375 & 12 & 3 & 8 & $\begin{array}{l}\text { CAGTCCAGAGCGGGACCTTTTTTCTTTTTAGTTATGAGTCCTATCCTT } \\
\text { ATTTGAATTTTACACAGCAACATCATCATCATACTATTCGGGAGACA } \\
\text { TGGTCCAAGCCCGGTGAAATGATCACCCATGACTTCTTTGTACCGGG } \\
\text { TCCCATTACTTTCTTTCTTTTTCCAAAGGACGAGTAAGAGTGATATA } \\
\text { AATCCGTTTCCCAACCAAACGTCGATACCGGCCCACATCAGGAAAG } \\
\text { GGATCGCCATGATCAGCATCAAGCTTAATGGTGAATCCATAGGAGT } \\
\text { ATCAACAGGGCGAGCACCGAGAAAGCCAGTC }\end{array}$ & СтTт & G & $1.010,54$ & 191 & $\begin{array}{l}\text { GGTGAAATGATCACC } \\
\text { CATGA }\end{array}$ & 59,1 & $\begin{array}{l}\text { GTGCTCGCCCTGTT } \\
\text { GATACT }\end{array}$ & 60,3 & 45 & 55 \\
\hline
\end{tabular}

G: genoma funcional

S: genoma estructural

P: polimórfico

M: monomórfico 
APÉNDICE

Marcadores microssatélites desenhados a partir do sequênciamento parcial e da montagem de novo do genoma de $P$. edulis

\begin{tabular}{|c|c|c|c|c|c|c|c|c|c|c|c|c|c|c|c|c|c|c|c|}
\hline $\mathbf{N}^{\mathbf{o}}$ & Primer & Contig $\mathrm{I}$ & Motivo & Início & Fim & pb & $\begin{array}{c}\mathbf{N}^{\circ} \\
\text { Repet }\end{array}$ & Score & Sequência do contig & Unidade & G/S & Cobertura & pb & Sequência Forward & $\begin{array}{l}\mathrm{T}^{\circ} \mathrm{C} \\
F w d\end{array}$ & Sequência Reverse & $\begin{array}{r}\mathrm{T}^{\circ} \mathrm{C} \\
\operatorname{Rev}\end{array}$ & $\begin{array}{c}\% \mathrm{GC} \\
F w d\end{array}$ & $\begin{array}{c}\% \mathrm{GC} \\
\operatorname{Rev}\end{array} \quad \mathrm{P} / \mathbf{M}$ \\
\hline 551 & BrPe4073 & $\begin{array}{l}\text { Maracuja_ } \\
\text { NoIndex_L } \\
\text { 003_R1_00 } \\
\text { 1_contig_3 } \\
382\end{array}$ & 4 & 319 & 330 & 12 & 3 & 8 & $\begin{array}{l}\text { GAGCTATTTGAGCAGTAATTCAGGGTACCGCGAGGACGGCACGAGT } \\
\text { ATAGAATCCTATGACATCCGAGCCAAGGATGAGACTGGCAATACCA } \\
\text { AAAATGAGAGTTGAGCCACGAGTTGAGAATCAGGTTCAGACAGAGA } \\
\text { TGTCGATGCATGAGACAGACAGACTCCTAGTGCAGATATCTAAGTT } \\
\text { ACTGAAGGA }\end{array}$ & AGAC & $\mathrm{s}$ & 63,34 & 158 & $\begin{array}{l}\text { GAGGACGGCACGAGT } \\
\text { ATAGA }\end{array}$ & 57,9 & $\begin{array}{l}\text { TCAGTAACTTAGAT } \\
\text { ATCTGCACTAGGA }\end{array}$ & 57,2 & 55 & 37 \\
\hline 552 & BrPe4074 & $\begin{array}{l}\text { Maracuja_ } \\
\text { NoIndex_L } \\
\text { 003_R1_00 } \\
\text { 1_contig_3 } \\
699\end{array}$ & 4 & 1912 & 1923 & 12 & 3 & 8 & $\begin{array}{l}\text { CACTAAACAGAGAGAAGGGAAGCCTAAAACAAGTGAAAAATAGCTG } \\
\text { CTTAAGCGAACCGTTACCTTGAAAATATAGGGCTGGCTTTTTAAGAG } \\
\text { TTTCAAGGATTTTTACGCTCGCGAGTACGCTAATAGAAGGGGAAAG } \\
\text { GATAATAAATAGTTTCTTTCTTTCAAGCCCAGCTTCATCCAGTTCCGT } \\
\text { GGCCGCCGCCGTG }\end{array}$ & тTтC & $\mathrm{s}$ & 017 & 180 & $\begin{array}{l}\text { CAGAGAGAAGGAAG } \\
\text { CCTAAAACA }\end{array}$ & 59,2 & $\begin{array}{l}\text { CACGGAACTGGATG } \\
\text { AAGCTG }\end{array}$ & 61,8 & 43,5 & 55 \\
\hline 553 & BrPe4075 & $\begin{array}{l}\text { Maracuja_ } \\
\text { NoIndex_L } \\
\text { 003_R1_00 } \\
\text { 1_contig_3 } \\
747\end{array}$ & 4 & 541 & 560 & 20 & 5 & 16 & $\begin{array}{l}\text { TCTACTTCAAAACAGAAAAAGAATGACATGGTTTGAAATTTTTAAA } \\
\text { AACATGTGATACCATAAATTTATTTAATTAATTATTTAAATGAGGAA } \\
\text { ATTAATTTCCTAAGCATTCATGCCTACTAATTCCACTATTGTGGATC } \\
\text { ACTAGTATAAAGATAGATAGATAGATAGATTGAGCAACAAAGGGG } \\
\text { ACCCTTTGGACTATCTTTTAAAAAATGCTATCAAACAAATTAGAAAA } \\
\text { AAAAACAAAAAAGTGGAGTGAGAAAAAGAAAGAGGAAAAAAGTG } \\
\text { AAAAAGATGGGATGGTATGGTCCATTCATGTATAGTAAGTTTTG }\end{array}$ & AGAT & $\mathrm{s}$ & 15,22 & 194 & $\begin{array}{l}\text { GCATTCATGCCTACT } \\
\text { AATTCCA }\end{array}$ & 59,1 & $\begin{array}{l}\text { TGGACCATACCATC } \\
\text { CCATCT }\end{array}$ & 60 & 40,9 & 50 \\
\hline 554 & BrPe4076 & $\begin{array}{l}\text { Maracuja_ } \\
\text { NoIndex_L } \\
\text { 003_R1_00 } \\
\text { 1_contig_4 } \\
349\end{array}$ & 4 & 324 & 335 & 12 & 3 & 8 & $\begin{array}{l}\text { ATGGTAAATAAGTTTTTCTTTTTATTCTAATACATTAAGTATTCCAAC } \\
\text { CTATTGATTTTTTAAAAAATTCGAATTTCTTTTACAAATTTTCACTAA } \\
\text { TAATATAAAAAATATCAAATTAATTTGTTTATTAATAAATTTTGATT } \\
\text { TAGTTAATAATTAATTAATCTATCTAGATATAAACGATACAGTATTT } \\
\text { TTGTAGTAATTATTCTTTATGCTTGAACGCAACACATGCTGTTAATT } \\
\text { AATATTTAATAAATCTTGACGGTTCTTTAATGAGAGAACAAATTAT } \\
\text { CTGAAACCCGTTTCCTGGGTTTTTTTAT }\end{array}$ & TAAT & $\mathrm{s}$ & 12,81 & 159 & $\begin{array}{l}\text { TTCGAATTTCTTTTAC } \\
\text { AAATTTTCAC }\end{array}$ & 59,1 & $\begin{array}{l}\text { TGTGTTGCGTTCAA } \\
\text { GCATAA }\end{array}$ & 58,9 & 23,1 & 40 \\
\hline 555 & BrPe4077 & $\begin{array}{l}\text { Maracuja_ } \\
\text { NoIndex_L } \\
\text { 003_R1_00 } \\
\text { 1_contig_4 } \\
699\end{array}$ & 4 & 480 & 491 & 12 & 3 & 8 & $\begin{array}{l}\text { GTTCTTATAATTTAGATGAACAATACACGCTTGTAGTTCTTAATGTTT } \\
\text { TCGTGCGAATGCATCTTCAGTTGGCAAATTTCTGCTTTTGCTACAGTT } \\
\text { CATTCTTGTGGTGTCTGATGGGATTGGTTATGTTGACTGGACAAGTT } \\
\text { TGTGGTGAGGAAGGAAGGACTCAAATTTGAAAAATGGAAACTTCAA } \\
\text { GAGTTGGTCTGATCTCGGCTGCAGGCGTATCTAATCTTAGAAGGCT } \\
\text { AAACTTTATCCAGTATGTAGTTAATGTTCAATGCATAGCATTCCCGC } \\
\text { ATCTTCATGTGAGGTGCAGGGGTGAGGCC }\end{array}$ & AGGA & $\mathrm{s}$ & 13,77 & 184 & $\begin{array}{l}\text { GGTGTCTGATGGGAT } \\
\text { TGGTT }\end{array}$ & 59,6 & $\begin{array}{l}\text { GAAGATGCGGGAAT } \\
\text { GCTATG }\end{array}$ & 60,6 & 50 & 50 \\
\hline
\end{tabular}

G: genoma funcional

S: genoma estructural

P: polimórfico

M: monomórfico 
APÉNDICE

Marcadores microssatélites desenhados a partir do sequênciamento parcial e da montagem de novo do genoma de $P$. edulis

\begin{tabular}{|c|c|c|c|c|c|c|c|c|c|c|c|c|c|c|c|c|c|c|c|}
\hline $\mathbf{N}^{\circ}$ & Primer & Contig $\mathrm{I}$ & Motivo & Início & Fim & pb & $\begin{array}{c}\mathbf{N}^{\circ} \\
\text { Repet }\end{array}$ & Score & Sequência do contig & Unidade & G/S & Cobertura & pb & Sequência Forward & $\begin{array}{l}\mathrm{T}^{\circ} \mathrm{C} \\
F w d\end{array}$ & Sequência Reverse & $\begin{array}{r}\mathrm{T}^{\circ} \mathrm{C} \\
\operatorname{Rev}\end{array}$ & $\begin{array}{r}\% \mathrm{GC} \\
F w d\end{array}$ & $\begin{array}{c}\% \mathrm{GC} \\
\operatorname{Rev}\end{array} \quad \mathrm{P} / \mathbf{M}$ \\
\hline 556 & BrPe4078 & $\begin{array}{l}\text { Maracuja_ } \\
\text { NoIndex_L } \\
003 \text { R1_00 } \\
\text { 1_contig_5 } \\
100\end{array}$ & 4 & 1252 & 1263 & 12 & 3 & 8 & $\begin{array}{l}\text { GGTTCAAATGAGCATTTTAGTTCTGGTGAACCGAAGCCAAACTGCTT } \\
\text { AAGGACGATATTAATTAGGGCTAATCACAAGACGACATCTTTCGAT } \\
\text { GTCTTTCTGTCTGAAACAATTATCTTTCGAGTTATTAAATTTTCTGTA } \\
\text { TTTGTAGCTGTACGTACGTACAATATTCCGCAAAATACAACCAGCGG } \\
\text { AATCTTCCTACAGTAGTGGTGGTGGTAGTGAAGATATAACAGTTGA } \\
\text { TTATCAGCAGCAGCTAGCAGCTGTGACAGCGCCCGTGTTTCATGAC } \\
\text { AGTAATCGTGTGTTGGGTTGGGTGGGCACTG }\end{array}$ & GTAC & $\mathrm{G}$ & 17,5 & 168 & $\begin{array}{l}\text { AACCGAAGCCAAACT } \\
\text { GCTTA }\end{array}$ & 59,9 & $\begin{array}{l}\text { GGAAGATTCCGCTG } \\
\text { GTTGTA }\end{array}$ & 60,1 & 45 & 50 \\
\hline 557 & BrPe4079 & $\begin{array}{l}\text { Maracuja_ } \\
\text { NoIndex_L } \\
003 \text { R1_00 } \\
\text { 1_contig_5 } \\
867\end{array}$ & 4 & 245 & 256 & 12 & 3 & 8 & $\begin{array}{l}\text { GTCCGGACGAACCCCTACAGATCAAAAAACCTATTTTTCCAGCAACTT } \\
\text { TCGGCCCTCATTTGGGGACCCTACGGGTCTCCAAAAACTACCAAATT } \\
\text { TCATCCGCACCTAGCCTGACATACAGGCTACCAATCCCAACCAGAA } \\
\text { ACACACCAATCCAACCAACCAATCATGAGTTATGAATTTTCAAAGA } \\
\text { TGGGCATTTGAAACAAAAGTGCAAAAAACAGGGCAGTAGCCCTAATT } \\
\text { ACCAAAAATC }\end{array}$ & CCAA & $\mathrm{s}$ & $1.093,43$ & 158 & $\begin{array}{l}\text { CGGGTCTCCAAAAAC } \\
\text { TACCA }\end{array}$ & 60,0 & $\begin{array}{l}\text { AGGGCTACTGCCCT } \\
\text { GTTTTT }\end{array}$ & 60,1 & 50 & 50 \\
\hline 558 & BrPe4080 & $\begin{array}{l}\text { Maracuja_ } \\
\text { NoIndex_L } \\
003 \text { R1_00 } \\
\text { 1_contig_7 } \\
441\end{array}$ & 4 & 292 & 303 & 12 & 3 & 8 & $\begin{array}{l}\text { TTTGTACTGCCTGGGTGGATAGCATAAGCAGAACTATGAGCTTCCAT } \\
\text { CAAGATGCTCTACCTCAACTGAGGATCACTGGGTACACAAACCCTTT } \\
\text { CTTGAAACACGAGGATACCATCACCTCGTATCCGGTACTCTGCTATG } \\
\text { GTGCTATCATTGCTTGCTTGCACTTTCTCTATAATCTTGCTCAGTACT } \\
\text { AGGTCTTCTACTTGCTTAACTCGAATCTCATCCAACAACACTGGCCT } \\
\text { TGCCACAATGCGGGCTAGCAATGTTCCACGATCATCGACATCCAAT } \\
\text { GACA }\end{array}$ & TTGC & G & 131,93 & 234 & $\begin{array}{l}\text { TTTGTACTGCCTGGGT } \\
\text { GGAT }\end{array}$ & 60,4 & $\begin{array}{l}\text { GCCAGTGTTGTTGG } \\
\text { ATGAGA }\end{array}$ & 59,7 & 50 & 50 \\
\hline 559 & BrPe4081 & $\begin{array}{l}\text { Maracuja_ } \\
\text { NoIndex_L } \\
003 \text { R1_00 } \\
\text { 1_contig_7 } \\
633\end{array}$ & 4 & 3035 & 3046 & 12 & 3 & 8 & $\begin{array}{l}\text { AGCATCAATAGTCATGACAACCATAGATTTAAAAAAACCATTAAAAA } \\
\text { CACCACATTTCGTCCACATCATATAGTTGAGATGCTTATATATTATTT } \\
\text { TTATGCATTATCTAGGATTCTTTTTCTTTTTTGGACTTGTATTCTCC } \\
\text { GGATGTTAAGAAAGAAAGGAGCAAAAGAACATACTGATCCATACCAC } \\
\text { AGGGCATGGTACACAGTGCCACAAGATCCTGCAGTAATAGAAAGAT } \\
\text { ACAAACAGCAAATTAAAGATCAGAACGTCACGAAATCAGGCAAAA } \\
\text { ATCACAAAAAGAAGAAAGGATGAATAATGATCA }\end{array}$ & AAGA & $\mathrm{s}$ & 15,87 & 156 & $\begin{array}{l}\text { GGAACTTGTATTCTCC } \\
\text { GGATGT }\end{array}$ & 59,4 & $\begin{array}{l}\text { GATTTTTGCCTGATT } \\
\text { TCGTGA }\end{array}$ & 60,1 & 45,5 & 38,1 \\
\hline 560 & BrPe4082 & $\begin{array}{l}\text { Maracuja_ } \\
\text { NoIndex_L } \\
\text { 003_R1_00 } \\
\text { 1_contig_7 } \\
829\end{array}$ & 4 & 4062 & 4073 & 12 & 3 & 8 & $\begin{array}{l}\text { AAAGAGGGTTAAACGTACATCAACCCCAACAACTGCTGCTCCTACA } \\
\text { TTGTATTTCATAAGAAAGAAAAAAAAAGAAAACAACATTTGGATCAT } \\
\text { TTCTATCGCTTCCATCACCCTCTTTTTTCTATCTATGACTGCAAAAGT } \\
\text { CCAACAGCTTCTTCCTTCCTTCAACAATCTCATCAAAGAAATCATCG } \\
\text { AGTTGTCCAACAATATTCTCAGCCCCAGATCTCAAGACCTCAAAAC } \\
\text { ACCCTCTTAAGTTCTCCACTCTTTCCCTTATCCCCACCTCTGTTTCCC } \\
\text { AGTCCACCAGCATCCCTTGCCCGCACTTCCT }\end{array}$ & СтTC & G & 16,54 & 177 & $\begin{array}{l}\text { TATCGCTTCCATCACC } \\
\text { СTCT }\end{array}$ & 59,7 & $\begin{array}{l}\text { AGGTGGGGATAAGG } \\
\text { GAAAGA }\end{array}$ & 59,8 & 50 & 50 \\
\hline
\end{tabular}

G: genoma funcional

S: genoma estructural

P: polimórfico

M: monomórfico 
APÉNDICE

Marcadores microssatélites desenhados a partir do sequênciamento parcial e da montagem de novo do genoma de $P$. edulis

\begin{tabular}{|c|c|c|c|c|c|c|c|c|c|c|c|c|c|c|c|c|c|c|c|}
\hline $\mathbf{N}^{\circ}$ & Primer & Contig I & Motivo & Início & Fim & pb & $\begin{array}{c}\mathbf{N}^{\circ} \\
\text { Repet }\end{array}$ & Score & Sequência do contig & Unidade & G/S & Cobertura & pb & Sequência Forward & $\begin{array}{l}\mathrm{T}^{\circ} \mathrm{C} \\
F w d \\
F w\end{array}$ & Sequência Reverse & $\begin{array}{l}\mathrm{T}^{\circ} \mathrm{C} \\
\operatorname{Rev} \\
\end{array}$ & $\begin{array}{r}\% \mathrm{GC} \\
F w d \\
\end{array}$ & $\begin{array}{cc}\% \mathrm{GC} & \mathbf{P} / \mathbf{M} \\
\operatorname{Rev} & \end{array}$ \\
\hline 561 & BrPe4083 & $\begin{array}{l}\text { Maracuja_ } \\
\text { NoIndex_L } \\
\text { 003_R1_00 } \\
\text { 1_contig_8 } \\
\text { 365 }\end{array}$ & 4 & 5240 & 5251 & 12 & 3 & 8 & $\begin{array}{l}\text { TTTGCACTGTATGAGCCATTTATCTGTTTTCCTTTCAAGTGATTTGAA } \\
\text { TTCTATTTGCAATGGTACTGTTTTTCTTTTCTCATTTTTATTTCCCATC } \\
\text { ATACAACAAAGAGTAGCACAAACTTTCTATCAGATGTATCACATTTG } \\
\text { ATATGTCATGCATGCATGTATGGACTATATGATAATTGGTTTGTTTG } \\
\text { AGAACAAACATAATCATGTGACTTTTGATTTTGAAGCTATCAATAGA } \\
\text { TACAGGAAATTGTCCGCTCTTCGCTATGTTGCTTTTGTTCTGATGTA } \\
\text { GTAAGCTTTTGTTTCATACGTCCATG }\end{array}$ & CATG & $\mathrm{s}$ & 18,56 & 173 & $\begin{array}{l}\text { CCCATCATACAACAA } \\
\text { AGAGTAGCA }\end{array}$ & 60,4 & $\begin{array}{l}\text { TAGCGAAGAGCGGA } \\
\text { CAATTT }\end{array}$ & 60 & 41,7 & 45 \\
\hline 562 & BrPe4084 & $\begin{array}{l}\text { Maracuja_ } \\
\text { NoIndex_L } \\
\text { 003_R1_00 } \\
\text { 1_contig_8 } \\
\text { 506 }\end{array}$ & 4 & 875 & 886 & 12 & 3 & 8 & $\begin{array}{l}\text { TTCATAATTTGATTATTTTTTTTATAGTGCCCAACAGGTAGAGTTTCA } \\
\text { TTCAAGCTTTATGACTGGAACCCAGCAGAATTTCCCAGAAGGCTTG } \\
\text { GCACCAGGTATTTTAAAGACTTAACATTAGAGTTTAATGTCTGGAGG } \\
\text { AGAAAGACTTTATTTATTTAATGATCTGGAGTGTCTGGAATTGTTTT } \\
\text { GACATGATGTAAGGGTGATTGCAGATATTCCAATGGTTGGCAAGCA } \\
\text { TGCCTGTTGAGTTGGAGGGATATATTCGCCCTGGGTGTACAATCTTG } \\
\text { ACTGCTTTCATTTCCATGCCATCATTTGTG }\end{array}$ & TTTA & $\mathrm{s}$ & 19,12 & 232 & $\begin{array}{l}\text { CAGCAGAATTTCCCA } \\
\text { GAAGG }\end{array}$ & 59,8 & $\begin{array}{l}\text { GGCATGGAAATGAA } \\
\text { AGCAGT }\end{array}$ & 60 & 50 & 45 \\
\hline 563 & BrPe4085 & $\begin{array}{l}\text { Maracuja_ } \\
\text { NoIndex_L } \\
003 \text { R1_00 } \\
\text { 1_contig_8 } \\
763\end{array}$ & 4 & 687 & 698 & 12 & 3 & 8 & $\begin{array}{l}\text { ACATGAGTTGGTGCATCCCTTGTGAGGAAATGGATCCATCCTTGGAA } \\
\text { CCTTAGACTCTCCAAGACATCTTCAGGCATGTCTTGTTCCACAAGCC } \\
\text { TTCTTCCAAAAATGATTTCTTTGTTGCTAAAGGCGGCCATTGAGAGG } \\
\text { GACAAAAAGGTTTGTTTGTTTAAGAGAGCAAGAGAGTAATGAGAGT } \\
\text { TTTAGAAGGTGAGGTGAGTGTTTTGTGATGAGGTCTTGGAGTCCTTT } \\
\text { TATAGCCAAAAGTAAGTGGGAAATCCGAGATTTTGAATTTCAAACT } \\
\text { TCAAATTTCAATCTCAAAGATTGAGCATATTA }\end{array}$ & GTTT & $\mathrm{s}$ & 28,77 & 159 & $\begin{array}{l}\text { GGATCCATCCTTGGA } \\
\text { ACCTT }\end{array}$ & 60,1 & $\begin{array}{l}\text { AAAACTCTCATTAC } \\
\text { TCTCTTGCTCTC }\end{array}$ & 58,1 & 50 & 38,5 \\
\hline 564 & BrPe4086 & $\begin{array}{l}\text { Maracuja_ } \\
\text { NoIndex_L } \\
003 \text { R1_00 } \\
\text { 1_contig_9 } \\
\text { 280 }\end{array}$ & 4 & 1079 & 1090 & 12 & 3 & 8 & $\begin{array}{l}\text { ATTTTCTATTTTCTGAGAATTTCCGATTTTAAATAATAAATCCACCGA } \\
\text { CATGTGTCGCCTTGCAAATGGTGCCACATGTTATAACCAGTAGACGC } \\
\text { CTATGTTTCCTTCCTATTTATACCGGGCTGAACCTGACCCATTAAC } \\
\text { CGGAATACAGAAAGAAAGAACTCAGTTTGAGTGAACTTGACTGGGT } \\
\text { TAACAACCCAGGTTATGACAATACCGACGTTGTCGGATCGCCAAAA } \\
\text { ATTTGAACGGCCAAGTTGGCGGTTTACGACGAGACACCGAACCAAA } \\
\text { CCTATATTGAATTAAAGCTCGTTCAACAAGCA }\end{array}$ & AGAA & G & 14,7 & 171 & $\begin{array}{l}\text { ATTTATACCGGGCCT } \\
\text { GAACC }\end{array}$ & 60,0 & $\begin{array}{l}\text { GTTTGGTTCGGTGTC } \\
\text { TCGTC }\end{array}$ & 60,6 & 50 & 55 \\
\hline 565 & BrPe4087 & $\begin{array}{l}\text { Maracuja_ } \\
\text { NoIndex_L } \\
003 \text { R1_00 } \\
\text { 1_contig_9 } \\
\text { 285 }\end{array}$ & 4 & 4576 & 4587 & 12 & 3 & 8 & $\begin{array}{l}\text { ATTAATCTCGCTCAGCAACTTATTCATCAACAATGTCAATTTTCATA } \\
\text { TAACAACAGTTTCAAGCACTCACTCAAGAAAAAAAAAGCTCTTCAA } \\
\text { GAGTTTTCAATAACTAAAGAAACGCGGACCCAATAAGTTCTGTATA } \\
\text { GATTTTTATAATTATTTATTTATCATCTATGTAACAACAGTAATGCA } \\
\text { GCTAGTTTGAGTTGGCAAATCAGTTTATTGAATCCATAAACCAATGA } \\
\text { AATAAAACCATATGATACCTCAAAAAACATAATAAAACTTTCAAAC } \\
\text { TATAAAATCAACAAAAGGAGACCAATCAAATCA }\end{array}$ & TTAT & $\mathrm{S}$ & 17,69 & 196 & $\begin{array}{l}\text { AAACGCGGACCCAAT } \\
\text { AAGTT }\end{array}$ & 60,7 & $\begin{array}{l}\text { TTGATTGGTCTCCTT } \\
\text { TTGTTGA }\end{array}$ & 59,6 & 45 & 36,4 \\
\hline
\end{tabular}

G: genoma funcional

S: genoma estructural

P: polimórfico

M: monomórfico 
APÉNDICE

Marcadores microssatélites desenhados a partir do sequênciamento parcial e da montagem de novo do genoma de $P$. edulis

\begin{tabular}{|c|c|c|c|c|c|c|c|c|c|c|c|c|c|c|c|c|c|c|c|}
\hline $\mathbf{N}^{\circ}$ & Primer & Contig I & Motivo & Início & Fim & pb & $\begin{array}{c}\mathbf{N}^{\circ} \\
\text { Repet }\end{array}$ & Score & Sequência do contig & Unidade & G/S & Cobertura & $\mathrm{pb}$ & Sequência Forward & $\begin{array}{l}\mathrm{T}^{\circ} \mathrm{C} \\
F w d \\
\end{array}$ & Sequência Reverse & $\begin{array}{l}\mathrm{T}^{\circ} \mathrm{C} \\
\operatorname{Rev} \\
\end{array}$ & $\begin{array}{c}\% \mathrm{GC} \\
F w d \\
\end{array}$ & $\begin{array}{cc}\% \mathrm{GC} & \mathrm{P} / \mathrm{M} \\
\operatorname{Rev} & \end{array}$ \\
\hline 566 & BrPe4088 & $\begin{array}{l}\text { Maracuja_ } \\
\text { NoIndex_L } \\
\text { 003_R1_00 } \\
\text { 1_contig_9 } \\
\text { 361 }\end{array}$ & 4 & 4270 & 4281 & 12 & 3 & 8 & $\begin{array}{l}\text { CAGCCGTGCTGTAGATCACTTTCTTGCTGAAAATCAGATCTCCACTG } \\
\text { TAAATTACCATGGGGAGGTGCCAGCTGAACAGAGGTGAGACATGGA } \\
\text { AAATGCTTATTGTCTTCCTAGACAATTTTTTGTTAAGTAACTGAGGT } \\
\text { CAATGAGGATTCACTCACTCACCTACTCCTAGTAGTTTCTTATATTA } \\
\text { TGGAATTCATTCGTGTTCCTGGGGTTATAGTGCCGACAAGCATTGTT } \\
\text { CAGCTTGGATATATGCAGTATACTGAAATGCGTGAATTTTAACTGA } \\
\text { CTGGCAACCCATGTTGCTTTTTTAATCCCA }\end{array}$ & TCAC & $\mathrm{s}$ & 18,88 & 229 & $\begin{array}{l}\text { CCAGCTGAACAGAGG } \\
\text { TGAGA }\end{array}$ & 59,1 & $\begin{array}{l}\text { ACATGGGTTGCCAG } \\
\text { TCAGTT }\end{array}$ & 60,4 & 55 & 50 \\
\hline 567 & BrPe4089 & $\begin{array}{l}\text { Maracuja_ } \\
\text { NoIndex_L } \\
\text { 003_R1_00 } \\
\text { 1_contig_9 } \\
641\end{array}$ & 4 & 1167 & 1178 & 12 & 3 & 8 & $\begin{array}{l}\text { AACCCTTCTGTCCTGAAATAAATAGTTAGTTTCCGAAAGATCGTAAA } \\
\text { AAAACAATAGTTTTCGATCGAAATCCGAAGAGAAATTAACGAAATA } \\
\text { CCTGAGATCCAACTGTAGTTGGGAAAGGGAAAACACCCCCACAGAA } \\
\text { GCATGTTGTTGGTGAGTGAGTGATTGAAGCTGCAAGATGACCTGAT } \\
\text { GGAGCTGTATCTCATATATGGTTCTAAAACTAAGCTCAACAGTAACA } \\
\text { TATAGCCTTTCCCGTTAACATAGTACTACGCATCTTTGATGCAGCAA } \\
\text { AAGTACTACCCCCATCTCTCTTGTTATACAGCA }\end{array}$ & GTGA & $\mathrm{s}$ & 14,9 & 166 & $\begin{array}{l}\text { CCCCACAGAAGCATG } \\
\text { TTGTT }\end{array}$ & 061 & $\begin{array}{l}\text { GATGGGGGTAGTAC } \\
\text { TTTTGCTG }\end{array}$ & 59,9 & 50 & 50 \\
\hline 568 & BrPe4090 & $\begin{array}{l}\text { Maracuja_ } \\
\text { NoIndex_L } \\
\text { 003_R1_00 } \\
\text { 1_contig_9 } \\
793\end{array}$ & 4 & 4998 & 5009 & 12 & 3 & 8 & $\begin{array}{l}\text { TATTACAGTTAGAGATAAATGTTCTTTTGACTGAGAATGGTAAGTGT } \\
\text { AGAAAAATGCCCTGGAATAGTAACTCTTTCTTTCAGAATTGCTTAAT } \\
\text { TCACAACTTCCATCTTGGTGTAGATCTACCTGCCACTGGTGTTCATA } \\
\text { ACAACATTGGCAAGCAAGCAACAATACCAACTGGGTCGAGTGCTGA } \\
\text { CTTTTATGCTAATCCCTCCGTAATGTATTTTACTGTTACTTTAACCAC } \\
\text { TTTCCATTCCAGCTGTAAGCCAGTAAACAGTGGTGACTGGATCAAG } \\
\text { AAGTTGCTTAAGAAAAAAACTGATGTCGATT }\end{array}$ & GCAA & G & 18,51 & 168 & $\begin{array}{l}\text { CTACCTGCCACTGGT } \\
\text { GTTCA }\end{array}$ & 59,7 & $\begin{array}{l}\text { CAACTTCTTGATCC } \\
\text { AGTCACCA }\end{array}$ & 60,1 & 55 & 45,5 \\
\hline 569 & BrPe4091 & $\begin{array}{l}\text { Maracuja_ } \\
\text { NoIndex_L } \\
\text { 003_R1_00 } \\
\text { 1_contig_9 } \\
815\end{array}$ & 4 & 959 & 970 & 12 & 3 & 8 & $\begin{array}{l}\text { GTTGCTGTCTCTATTAGCCTCACCATTTCTCTGGCAACTGAGCTGAG } \\
\text { TTCATCTATTCCTTGCAACTCCATATCCTGAAGCTCCGAAGGCATAA } \\
\text { CAGCCTTAGAATTGATTGCTTCAGCCTCCCTAAATGAGTCTCGCAGA } \\
\text { ATAAGTTGCAATGAATGAATGGCATCCATTTCTGCATTTTCCCATGG } \\
\text { CAAACTCCGGCTCTTCACCACTTCTAAAAAAGCTATGAATGAAGAT } \\
\text { CGCGGAT }\end{array}$ & AATG & G & 16,72 & 157 & $\begin{array}{l}\text { CCGAAGGCATAACAG } \\
\text { CCTTA }\end{array}$ & 60,2 & $\begin{array}{l}\text { CCGCGATCTTCATTC } \\
\text { ATAGC }\end{array}$ & 60,7 & 50 & 50 \\
\hline 570 & BrPe4092 & $\begin{array}{l}\text { Maracuja_ } \\
\text { NoIndex_L } \\
\text { 003_R1_00 } \\
\text { 1_contig_1 } \\
0041\end{array}$ & 4 & 1593 & 1608 & 16 & 4 & 12 & $\begin{array}{l}\text { CCAAATCCTTCCCTCCAGAGAAACCACCATTACGGAAACATCATCA } \\
\text { TGATATTTACGTCTATCGCCATGCGGAATATCGAGCAACTCGTGAAA } \\
\text { ATCCATTCCTGCAACCAATAAGAAGGATTAAAGAATTGGTGCAAGG } \\
\text { GCTTTAAAATGAGAAAGAAAGAAAGAACAGTGGTTCCAGGAACCA } \\
\text { GGATGCAGGCACCTAAAATACAAGACATCATAAGGATTCATCAGTT } \\
\text { TTTGACAATTGGGTTTCTGATTAAAAGAGTAGCTATCACCCCTCCA } \\
\text { CCGTGCACAAATCAATGAGCTGACTCAGGCCTTTGTGAC }\end{array}$ & AGAA & $\mathrm{s}$ & 17,43 & 184 & $\begin{array}{l}\text { GAATTGGTGCAAGGG } \\
\text { CTTTA }\end{array}$ & 60,1 & $\begin{array}{l}\text { AGGCCTGAGTCAGC } \\
\text { TCATTG }\end{array}$ & 60,6 & 45 & 55 \\
\hline
\end{tabular}

G: genoma funcional

S: genoma estructural

P: polimórfico

M: monomórfico 
APÉNDICE

Marcadores microssatélites desenhados a partir do sequênciamento parcial e da montagem de novo do genoma de $P$. edulis

\begin{tabular}{|c|c|c|c|c|c|c|c|c|c|c|c|c|c|c|c|c|c|c|c|}
\hline $\mathbf{N}^{\circ}$ & Primer & Contig I & Motivo & Início & Fim & pb & $\begin{array}{c}\mathbf{N}^{\circ} \\
\text { Repet }\end{array}$ & Score & Sequência do contig & Unidade & G/S & Cobertura & pb & Sequência Forward & $\begin{array}{l}\mathrm{T}^{\circ} \mathrm{C} \\
F w d \\
\end{array}$ & Sequência Reverse & $\begin{array}{l}\mathrm{T}^{\circ} \mathrm{C} \\
\operatorname{Rev} \\
\end{array}$ & $\begin{array}{c}\% \mathrm{GC} \\
F w d \\
\end{array}$ & $\begin{array}{cc}\% \mathrm{GC} & \mathrm{P} / \mathrm{M} \\
\operatorname{Rev} & \end{array}$ \\
\hline 571 & $\begin{array}{l}\text { BrPe4093 } \\
\end{array}$ & $\begin{array}{l}\text { Maracuja_ } \\
\text { NoIndex_L } \\
\text { 003_R1_00 } \\
\text { 1_contig_1 } \\
0819\end{array}$ & 4 & 1329 & 1340 & 12 & 3 & 8 & $\begin{array}{l}\text { CAGTATCAGAAAGATAGAAGCAGTAGAACTACATCAGGCATTGATT } \\
\text { AGGGTAAGCATGTAAAAGTAAGATAGTTCCTATGACGTACAATTA } \\
\text { TTTCCACATATCCTTGTAAGACTGCAGGTTTGATACAAGAATATACG } \\
\text { CCATCAAAAATAAGAAAGAAAGATAGGCAACATGATGACAGTAATT } \\
\text { GGCAAAAAACCACACATACCGCAGCAACTGTTGTTTGAGAGCTAG } \\
\text { ACCATGAACACGAGGCAAGATTGCTTCTTTTACAAGCTGCAAGGAA } \\
\text { CAAAAAAAAAAAAAAAAATTCCAAGATTTATTCTCA }\end{array}$ & AAGA & $\mathrm{s}$ & 18,47 & 223 & $\begin{array}{l}\text { CAGGCATTGATTAGG } \\
\text { GTAAGC }\end{array}$ & 58,7 & $\begin{array}{l}\text { AAGCAATCTTGCCT } \\
\text { CGTGTT }\end{array}$ & 59,9 & 47,6 & 45 \\
\hline 572 & BrPe4094 & $\begin{array}{l}\text { Maracuja_ } \\
\text { NoIndex_L } \\
003 \text { R1_00 } \\
\text { 1_contig_1 } \\
0942\end{array}$ & 4 & 1854 & 1865 & 12 & 3 & 8 & $\begin{array}{l}\text { TAATAACACTGGGAGCAGTCGAGCAGCAGATTTTGATAGAGTGTAC } \\
\text { GGGCATTCAAAGGGAAACTTTTTCAGCAGGACAGTACTCAATATC } \\
\text { CGGATCTTTGGGCTAAGACTGGGAAAAATGGAATTAGCAAAGGTGG } \\
\text { TGAAAATGTGGGAACAAACAAACAGAAGTTGGTGGATTACTTTGCT } \\
\text { CAAGCTGATAGAAACCGATTCAATAGGAACCAACTGGAAAAAATCC } \\
\text { ACACAGCTTCAGGACGAGGGGCATTTCTTCTTGGTGAAGGAAAATC } \\
\text { ATTAGGTGGACTACAACATACTGGTTTCAGTTCTAG }\end{array}$ & AACA & G & 16,98 & 223 & $\begin{array}{l}\text { AGTGTACGGGCATTC } \\
\text { AAAGG }\end{array}$ & 60,0 & $\begin{array}{l}\text { AAGAAGAAATGCCC } \\
\text { CTCGTC }\end{array}$ & 60,6 & 50 & 50 \\
\hline 573 & BrPe4095 & $\begin{array}{l}\text { Maracuja_ } \\
\text { NoIndex_L } \\
003 \text { R1_00 } \\
\text { 1_contig_1 } \\
1493\end{array}$ & 4 & 3931 & 3942 & 12 & 3 & 8 & $\begin{array}{l}\text { AGCTTCCTCCAGGATTTCTCATATCACAGATCCAGAAATACGCATGG } \\
\text { CTTTCAGAAAGACTATCATCACTTATTCTCAGATTTCCCAGGGCAGC } \\
\text { CTTCACACTAAAAGAGCTTGGAAAGACCTGGTAACCAGGAAACAAA } \\
\text { TAAGGTAAACATGGATGGATGGGATTCATATGCAAGAAAAAGAGA } \\
\text { AAAAACAAAGAAGATTTTGATGGAGTCAAAAAGACCTTGATATCCG } \\
\text { TAAGCAACTTGTCTTGTGATAAAGTGGCAAGTTTAGCTTCCCTTTCA } \\
\text { TTCATCAAAAATATCTGAGCACGGGCATTTTCA }\end{array}$ & ATGG & $\mathrm{s}$ & 17,65 & 218 & $\begin{array}{l}\text { AGGGCAGCCTTCACA } \\
\text { CTAAA }\end{array}$ & 59,9 & $\begin{array}{l}\text { GCCCGTGCTCAGAT } \\
\text { ATTTTT }\end{array}$ & 59,2 & 50 & 45 \\
\hline 574 & BrPe4096 & $\begin{array}{l}\text { Maracuja_ } \\
\text { NoIndex_L } \\
\text { 003_R1_00 } \\
\text { 1_contig_1 } \\
\text { 1578 }\end{array}$ & 4 & 4248 & 4259 & 12 & 3 & 8 & $\begin{array}{l}\text { AGCACCTATCTTCTCATGACCCATCAAGTGTGCAGGTAACTCGACTA } \\
\text { AGAGTGTGAAAGTGTGTTAATGTTGATCTTGAAGTTCTTCCCTGATA } \\
\text { ATTTATGATTTCCATTCGCATAGCATGGGATGCCAACTTCTTTCGAT } \\
\text { AATGATGCTGTTGGTTGGTTGCCTGATGTTGGAGGTCAAAGCCAACC } \\
\text { ACAAACTTTTGATGCCTCTGCTTCTTTAAATGCTCTGAGGTTTGTTTT } \\
\text { AAGTTGGGTTGGAGAACAATTGCGTACTTAAACCTAATATTTTAGTT } \\
\text { TAAGAGAGTAATATTATGCAAGCCCAGA }\end{array}$ & GTTG & G & 17,46 & 175 & $\begin{array}{l}\text { CCCATCAAGTGTGCA } \\
\text { GGTAA }\end{array}$ & 59,6 & $\begin{array}{l}\text { GTTTGTGGTTGGCTT } \\
\text { TGACC }\end{array}$ & 60,4 & 50 & 50 \\
\hline 575 & BrPe4097 & $\begin{array}{l}\text { Maracuja_ } \\
\text { NoIndex_L } \\
\text { 003_R1_00 } \\
\text { 1_contig_1 } \\
\text { 1884 }\end{array}$ & 4 & 1264 & 1275 & 12 & 3 & 8 & $\begin{array}{l}\text { TCAATTATATATTCAAGGATGGCGACATGTGAGTTAGGCATTTTTCA } \\
\text { CGATTTTAAATGGGCCGGAGTTTTTAATTTGTAGGTCAAAAAACTAG } \\
\text { AAATGCACACTGATGCAAGATGTGATTCGATTAGGATTTATTAGTTC } \\
\text { TTATGCAAATAGGTAGGTAGGATGGTTAGGTCAAGAACCCATTTCA } \\
\text { CATGCATAACTAAACTAAAATTCGGATGCCAAATAGGAAGCACTAA } \\
\text { ACTTCGCCAGAGATTAATGGCCCAATGACAATCTCGTAAAACATGA } \\
\text { TGTAATTCATCCTCTTCTGCGTCTCCACAACTA }\end{array}$ & TAGG & $\mathrm{s}$ & 15,56 & 176 & $\begin{array}{l}\text { GGATGGCGACATGTG } \\
\text { AGTTA }\end{array}$ & 59,5 & $\begin{array}{l}\text { GCATGTGAAATGGG } \\
\text { TTCTTG }\end{array}$ & 59 & 50 & 45 \\
\hline
\end{tabular}

G: genoma funcional

S: genoma estructural

P: polimórfico

M: monomórfico 
APÉNDICE

Marcadores microssatélites desenhados a partir do sequênciamento parcial e da montagem de novo do genoma de $P$. edulis

\begin{tabular}{|c|c|c|c|c|c|c|c|c|c|c|c|c|c|c|c|c|c|c|c|}
\hline $\mathbf{N}^{\circ}$ & Primer & Contig I & Motivo & Início & Fim & pb & $\begin{array}{c}\mathbf{N}^{\circ} \\
\text { Repet }\end{array}$ & Score & Sequência do contig & Unidade & G/S & Cobertura & pb & Sequência Forward & $\begin{array}{l}\mathrm{T}^{\circ} \mathrm{C} \\
F w d \\
\end{array}$ & Sequência Reverse & $\begin{array}{l}\mathrm{T}^{\circ} \mathrm{C} \\
\operatorname{Rev} \\
\end{array}$ & $\begin{array}{c}\% \mathrm{GC} \\
F w d \\
\end{array}$ & $\begin{array}{cc}\% \mathrm{GC} & \mathrm{P} / \mathrm{M} \\
\operatorname{Rev} & \end{array}$ \\
\hline 576 & $\begin{array}{l}\text { BrPe4098 } \\
\end{array}$ & $\begin{array}{l}\text { Maracuja_ } \\
\text { NoIndex_L } \\
\text { 003_R1_00 } \\
\text { 1_contig_1 } \\
\text { 2468 }\end{array}$ & 4 & 2175 & 2186 & 12 & 3 & 8 & $\begin{array}{l}\text { ACAATAACATCATTCGTCCACCCAGAGGATCTTCCAACTTCATTGGA } \\
\text { GACTAAAAATCACTTTAAAGAGAAAAAAGAGGACAAATTGCGGTTT } \\
\text { TTTTTAATATAAATTTTATTGAAAATTAAGAACAACAAAGAGAAAT } \\
\text { GCACCAATCAGATCAATCAATCAGAAAAGATGAAATAAAAAGCTGA } \\
\text { CAGAGAATAGCAGTTGTTCTCTTTCCTTTTGGGAGTTAAGTGTGAGC } \\
\text { ATAGCTACTTGATTTCTTTCTATTGCTTTGTCCGGTGATGGGTAAGTG } \\
\text { AGCATAGCTACCAAACCCCACAACACAACCAC }\end{array}$ & ATCA & $\mathrm{s}$ & 16,23 & 108 & $\begin{array}{l}\text { CAACAAAGAGAAATG } \\
\text { CACCAA }\end{array}$ & 58,8 & $\begin{array}{l}\text { TGCTCACACTTAAC } \\
\text { TCCCAAAA }\end{array}$ & 59,8 & 38,1 & 40,9 \\
\hline 577 & BrPe4099 & $\begin{array}{l}\text { Maracuja_ } \\
\text { NoIndex_L } \\
\text { 003_R1_00 } \\
\text { 1_contig_1 } \\
\text { 2570 }\end{array}$ & 4 & 1883 & 1894 & 12 & 3 & 8 & $\begin{array}{l}\text { TAACCCTGTTGGTGATTTTGACTAAGCTTTTCTAGCATTTGTTACTTT } \\
\text { ATGTAGGATTCCTGGATTCTCGGGAAACAGCTTGACCTCATTTCAAA } \\
\text { TAGGAGCACTTTGTGGACTGATTATGGACTCCGATCTCTTGCAAAAA } \\
\text { CAAGGTGGTTGTTTGTTTGTGTATTTAGGCATATGTGGTTTCTTAAG } \\
\text { AGATACCCTTTATTAAATAATGGCATTCTGAATCCTTTATGCAATAG } \\
\text { TTCCTTGTACATGAAACGTAACACGGAGCATGATCCACCTTATTGGA } \\
\text { GAGGCCCGATTTGGATGAACATGAATTAC }\end{array}$ & TTGT & G & 16,9 & 231 & $\begin{array}{l}\text { ATTCTCGGGAAACAG } \\
\text { CTTGA }\end{array}$ & 59,8 & $\begin{array}{l}\text { AATCGGGCCTCTCC } \\
\text { AATAAG }\end{array}$ & 60,4 & 45 & 50 \\
\hline 578 & BrPe4100 & $\begin{array}{l}\text { Maracuja_ } \\
\text { NoIndex_L } \\
003 \text { R1_00 } \\
\text { 1_contig_1 } \\
\text { 2573 }\end{array}$ & 4 & 4564 & 4575 & 12 & 3 & 8 & $\begin{array}{l}\text { ACTTTATCCTTCACAAAGTACAAGAAAGTAAAAGAACATGCTCTTAT } \\
\text { TCATACTGTTGTTATCTTGAAAATATTTGACCTCTTTTAATTCTCAGG } \\
\text { GGCACTCTACAGAGGTACACTCTGTTTGCTGGGATGTAAATGGAGA } \\
\text { TTTCTTGGCGTCAGTCAGTCAAGAGTCTGTGAGAGTGTGGTCATTGG } \\
\text { CCTCGGGAGAATGCATTCATGAACTTAGTACCAGCGGGAACAAATT } \\
\text { TCATTCTTGTGTTTTCCATCCAAGCTATTCCACCCTCTTGGTCATTGG } \\
\text { AGGCTACCAGGTATTGCTCGTGTCTTATAG }\end{array}$ & GTCA & G & 19,11 & 150 & $\begin{array}{l}\text { GTTTGCTGGGATGTA } \\
\text { AATGGA }\end{array}$ & 59,8 & $\begin{array}{l}\text { GGTGGAATAGCTTG } \\
\text { GATGGA }\end{array}$ & 59,9 & 42,9 & 50 \\
\hline 579 & BrPe4101 & $\begin{array}{l}\text { Maracuja_ } \\
\text { NoIndex_L } \\
003 \text { R1_00 } \\
\text { 1_contig_1 } \\
\text { 2620 }\end{array}$ & 4 & 3567 & 3578 & 12 & 3 & 8 & $\begin{array}{l}\text { CGATAAACTGAACCCTCTGAAAATACTGCTTCTTGACTTCCTCGTAA } \\
\text { TCTCTTGCAGCATCAGCTCGAGAAAGGAGCTCAATAACCTGATCCA } \\
\text { AGAAGAAAGCTTCAGCTCTTTCCTTTCTATTAGCAGCTTCTTCTTTTT } \\
\text { CCCTCCTAAAGCTAGCTAGCTCTTTGCTGATCTCTGAAGGTTCTACA } \\
\text { GGGATCCCCACTGCCCTGGCTATTTCTTCAAGCATGTCATTTGCAAA } \\
\text { CCCCTGATCAAGTTTCTGATCCCGAAGGCCCTGGTTTAACTTGTCCA } \\
\text { CAATTTCAAGCTGAGAATGTGAAGTTTCAA }\end{array}$ & AGCT & G & 16,22 & 207 & $\begin{array}{l}\text { GCATCAGCTCGAGAA } \\
\text { AGGAG }\end{array}$ & 60,2 & $\begin{array}{l}\text { CCTTCGGGATCAGA } \\
\text { ААСTTG }\end{array}$ & 59,7 & 55 & 50 \\
\hline 580 & BrPe4102 & $\begin{array}{l}\text { Maracuja_ } \\
\text { NoIndex_L } \\
\text { 003_R1_00 } \\
\text { 1_contig_1 } \\
\text { 3044 }\end{array}$ & 4 & 1611 & 1622 & 12 & 3 & 8 & $\begin{array}{l}\text { GGCTAATATTTTTCGGCACGTTTTCTCACATTTCATACATAAACATG } \\
\text { ATTTTCTGTGTTTTCAACCCATGGGTTTAATGGCATGCAGGACTTTA } \\
\text { CATAAATTCTGACATTCCTTGAAGGTTAAATAACATGCAACTCATAC } \\
\text { TCCCTATGCACAGACAGACAGGACAACAGCAACAACATGCTGATAA } \\
\text { TTTCTTGAAATCACAAATTTTATACTAACAGATGAAACAGATAGTGA } \\
\text { AGCATGCGAGTTTTCTAAATATACACCATAAAACCATTAAGTATACC } \\
\text { TTCTTTTGCCTTGATAAATTTGTCATAAGTT }\end{array}$ & ACAG & $\mathrm{s}$ & 17,43 & 177 & $\begin{array}{l}\text { ATTTTTCGGCACGTTT } \\
\text { TCTC }\end{array}$ & 59,2 & $\begin{array}{l}\text { TCAGCATGTTGTTGC } \\
\text { TGTTG }\end{array}$ & 59,5 & 40 & 45 \\
\hline
\end{tabular}

G: genoma funcional

S: genoma estructural

P: polimórfico

M: monomórfico 
APÉNDICE

Marcadores microssatélites desenhados a partir do sequênciamento parcial e da montagem de novo do genoma de $P$. edulis

\begin{tabular}{|c|c|c|c|c|c|c|c|c|c|c|c|c|c|c|c|c|c|c|c|}
\hline $\mathbf{N}^{\mathbf{o}}$ & Primer & Contig $\mathrm{I}$ & Motivo & Início & Fim & pb & $\begin{array}{c}\mathbf{N}^{\mathbf{o}} \\
\text { Repet }\end{array}$ & Score & Sequência do contig & Unidade & G/S & Cobertura & pb & Sequência Forward & $\begin{array}{l}\mathrm{T}^{\circ} \mathrm{C} \\
F w d\end{array}$ & Sequência Reverse & $\begin{array}{r}\mathrm{T}^{\circ} \mathrm{C} \\
\operatorname{Rev}\end{array}$ & $\begin{array}{c}\% \mathrm{GC} \\
F w d\end{array}$ & $\begin{array}{c}\% \mathrm{GC} \\
\operatorname{Rev}\end{array} \quad \mathrm{P} / \mathbf{M}$ \\
\hline 581 & BrPe4103 & $\begin{array}{l}\text { Maracuja_ } \\
\text { NoIndex_L } \\
\text { 003_R1_00 } \\
\text { 1_contig_1 } \\
\text { 3391 }\end{array}$ & 4 & 749 & 760 & 12 & 3 & 8 & $\begin{array}{l}\text { GTCAGTCTCTTGGAGTCTGAGGAGACTATAAACGAAATCATTCTTAT } \\
\text { CAAAATCATCATTTTCAATCCTGTGCTCTTCGATCACCTGATCAAGT } \\
\text { AAATCACTTAATTCTCGGGAAGTTGCTTTCAGCTTTGGAACCAATCC } \\
\text { TGTGATGTAATCCATCCATCCCCAGCCACTATACATATCCCCAAAAC } \\
\text { TGAAAGCCGCAAATTGTTCCATCAGCTTCCTTGTCAACTCCCCGAAC } \\
\text { TTTCTCTTGCCAGCTTCTTCTTCAGCCTTTCGACCAAGAACACATCTA } \\
\text { GAAGTTACGGTGTTTGAAGTAGCAGTCAA }\end{array}$ & ATCC & $\mathrm{G}$ & 12,14 & 173 & $\begin{array}{l}\text { CCTGTGCTCTTCGATC } \\
\text { ACCT }\end{array}$ & 60,4 & $\begin{array}{l}\text { GAAAGTTCGGGGAG } \\
\text { TTGACA }\end{array}$ & 60,1 & 55 & 50 \\
\hline 582 & BrPe4104 & $\begin{array}{l}\text { Maracuja_ } \\
\text { NoIndex_L } \\
\text { 003_R1_00 } \\
\text { 1_contig_1 } \\
4068\end{array}$ & 4 & 7024 & 7035 & 12 & 3 & 8 & $\begin{array}{l}\text { AAAGTAACTTTTCTCTACAAAAATTTCCCAGTTATATTTTCATGATATC } \\
\text { TCGAATCTTTGTTTCCTTATTCCTGTAAAAAAAGCAAGCAAGGCGGT } \\
\text { GATTTTTTTTGTTAGAAAAGAAAGCCCACCTACTTTGCATTTCCTGA } \\
\text { AGTTTCTCAACAAACAAACAGAAAATCAAACCAATAACATCATCCA } \\
\text { CACCTTCACTCTGAAGAAAGAAGTTAAAGCGTGGATATTATAAAAA } \\
\text { TTAAAAATCACAAAAAGGAGGAGAAAAACCAGCTCCTTTTCATTTC } \\
\text { AGGATTTCTCAACCAACAGACACGAGACAAGA }\end{array}$ & AACA & G & 16,78 & 104 & $\begin{array}{l}\text { GCCCACCTACTTTGC } \\
\text { ATTTC }\end{array}$ & 59,9 & $\begin{array}{l}\text { CCACGCTTTAACTTC } \\
\text { TTTCTTCA }\end{array}$ & 59,9 & 50 & 39,1 \\
\hline 583 & BrPe4105 & $\begin{array}{l}\text { Maracuja_ } \\
\text { NoIndex_L } \\
\text { 003_R1_00 } \\
\text { 1_contig_1 } \\
4664\end{array}$ & 4 & 2446 & 2457 & 12 & 3 & 8 & $\begin{array}{l}\text { CCTACCATTGGTTTGTCCCTTTTCTCCTTGAATGAATCGTCTTCATTT } \\
\text { TATGCTTCCCATTATACTATGTGATTGTATAGCGTGATCTCTGTTTGG } \\
\text { ATATGAAATCATATAATCGAACAGTTCTTTGCGAACCTTTCACCGAT } \\
\text { TATTATGTTGTTTGTTTGTACTGTGGGAAGCGCTTTTGTTTGCAAGT } \\
\text { GTTGATGTAGAGGTACATACATTCATTCGTTATCCTTTACTCTTAAG } \\
\text { CTTGTGGTGATTACCCCTGTTAGCTTTCCTTCATCGGGTCTTATGTGA } \\
\text { TTTTTTGTATTTAGTGCTCACAATAC }\end{array}$ & TTGT & G & 15,14 & 160 & $\begin{array}{l}\text { TTCTTTGCGAACCTTT } \\
\text { CACC }\end{array}$ & 60,2 & $\begin{array}{l}\text { AAGACCCGATGAAG } \\
\text { GAAAGC }\end{array}$ & 60,6 & 45 & 50 \\
\hline 584 & BrPe4106 & $\begin{array}{l}\text { Maracuja_ } \\
\text { NoIndex_L } \\
003 \text { R1_00 } \\
\text { 1_contig_1 } \\
4716\end{array}$ & 4 & 156 & 167 & 12 & 3 & 8 & $\begin{array}{l}\text { AAGCCGAGTCTCGTCTGAGCATCACTATTGACGAAAACGTAGGCGA } \\
\text { CCTAAGAATTTGGGCTTGCTTTCTTATTTCTTTGGTGCTTTAGGGTTT } \\
\text { TTCTGACAGATAATTAGATTGAATTGGGATATTAATTTTTGTTGCAT } \\
\text { TTATGGAATTGAATGAATGAAGGTAAAGCTTTCAAAGGAAAGGGAG } \\
\text { TCGCTAGCATTTACTGCAAAAAAACTTGGGCGTGATTTGGCGAAGG } \\
\text { TCAGATTTTTTTCTTGCTACCGCTCAAATCTGTCAATCGAACATCAC } \\
\text { CTGTGAATAGTTTTATATGGTTACGTTTCTG }\end{array}$ & TGAA & $\mathrm{s}$ & 17,51 & 151 & $\begin{array}{l}\text { GACCTAAGAATTTGG } \\
\text { GCTTGC }\end{array}$ & 60,1 & $\begin{array}{l}\text { GCTAGCGACTCCCT } \\
\text { TTCCTT }\end{array}$ & 60 & 47,6 & 55 \\
\hline 585 & BrPe4107 & $\begin{array}{l}\text { Maracuja_ } \\
\text { NoIndex_L } \\
003 \_R 1 \_00 \\
\text { 1_contig_1 } \\
5182\end{array}$ & 4 & 960 & 971 & 12 & 3 & 8 & $\begin{array}{l}\text { TAATTCCTACACCTTCTAGAGCACGTCCTTTAAGAAAAAATGGCATC } \\
\text { TCATTCCGCCCCATTGAAGCATTTATAACGGTAAAGTGCGATGATGC } \\
\text { GATTAAGCTAGCTCATGGAAGAAGAATTCATGGCGCCAGGGCGCCT } \\
\text { GTCAAAATTCGATTGATTGATTAACCATGTTCACTGTGAATATTCGA } \\
\text { AAATGGTTTGCGCATTGGTATTTTCATTACCATCTGACAGAATATAC } \\
\text { GTAAAACTAGACAGACAGTACCAGTTTGATTAATTTGGTGGTTATTA } \\
\text { AACATCAACGTTAAACATGTGTAAAACCAGA }\end{array}$ & GATT & $\mathrm{s}$ & 15,57 & 154 & $\begin{array}{l}\text { AGGGCGCCTGTCAAA } \\
\text { ATTC }\end{array}$ & 62,4 & $\begin{array}{l}\text { TGTTTAATAACCAC } \\
\text { CAAATTAATCAAA }\end{array}$ & 59,1 & 52,6 & 22,2 \\
\hline
\end{tabular}

G: genoma funcional

S: genoma estructural

P: polimórfico

M: monomórfico 
APÉNDICE

Marcadores microssatélites desenhados a partir do sequênciamento parcial e da montagem de novo do genoma de $P$. edulis

\begin{tabular}{|c|c|c|c|c|c|c|c|c|c|c|c|c|c|c|c|c|c|c|c|}
\hline $\mathbf{N}^{\circ}$ & Primer & Contig I & Motivo & Início & Fim & pb & $\begin{array}{c}\mathbf{N}^{\circ} \\
\text { Repet }\end{array}$ & Score & Sequência do contig & Unidade & G/S & Cobertura & pb & Sequência Forward & $\begin{array}{l}\mathrm{T}^{\circ} \mathrm{C} \\
F w d \\
\end{array}$ & Sequência Reverse & $\begin{array}{r}\mathrm{T}^{\circ} \mathrm{C} \\
\operatorname{Rev} \\
\end{array}$ & $\begin{array}{c}\% \mathrm{GC} \\
F w d \\
\end{array}$ & $\begin{array}{cc}\% \mathrm{GC} & \mathrm{P} / \mathrm{M} \\
\operatorname{Rev} & \end{array}$ \\
\hline 586 & BrPe4108 & $\begin{array}{l}\text { Maracuja_ } \\
\text { NoIndex_L } \\
003 \text { R1_00 } \\
\text { 1_contig_1 } \\
\text { 5778 }\end{array}$ & 4 & 2110 & 2121 & 12 & 3 & 8 & $\begin{array}{l}\text { GACTGCAGCTCGGTTGCTATGGTCTCGAAGTAATCTACATTGAGCTC } \\
\text { CATGAAGTCATGACAATCCTGTAATGCACCATGCTCCTCTTGTGTCA } \\
\text { TTTTCGAAACATGGTTCTTGTGTGTCAGGTGATATCTGATGACCTTA } \\
\text { GACAATCTCCTTGCTTGCTTGAGACATTCTTTCACCGACAACTTGCT } \\
\text { GTAATCGTAAGGGTTGGAAGGTGATGATGATGCATTGAATGTGAC } \\
\text { AGCATAAAACGGCACAGTTTGGGGTAAAGGGTCGATTTGCATGCAA } \\
\text { GAGAAGGTGACTGTGGCTGTGTTGTTGGGGCC }\end{array}$ & CTTG & $\mathrm{G}$ & 17,78 & 204 & $\begin{array}{l}\text { TGTAATGCACCATGC } \\
\text { TCCTC }\end{array}$ & 59,7 & $\begin{array}{l}\text { ATCGACCCTTTACC } \\
\text { CCAAAC }\end{array}$ & 60,1 & 59,7 & 60,1 \\
\hline 587 & BrPe4109 & $\begin{array}{l}\text { Maracuja_ } \\
\text { NoIndex_L } \\
\text { 003_R1_00 } \\
\text { 1_contig_1 } \\
\text { 5821 }\end{array}$ & 4 & 2446 & 2457 & 12 & 3 & 8 & $\begin{array}{l}\text { TAGTTTGCATGTTAGTGATTTACGTGATAACATCACACCTTTGCAAT } \\
\text { GCCTCAAAAATGGACCAATTATGCTTTGTTTCCGATGAATTTGGTAA } \\
\text { CTGACAATTTGCCCTAACTTGTGGCTTGCTAATAGTGTTGTCTGTAT } \\
\text { AATTGCTAGAAGAAAGAAAGACATTGTCAAATTGGTTTCATTAGTA } \\
\text { TTTCTTCTTGAGTAGAGAGGGTTCTTCCATTTGAAAAGTTAAAATGT } \\
\text { CAAATAATTTACAATGGATCCATGACCGTAGCCGTCGTGGTTGAAAT } \\
\text { CTGATGCTTGTTTGACTGACAAGAATGCTTC }\end{array}$ & AAGA & G & 16,37 & 236 & $\begin{array}{l}\text { ATGCCTCAAAAATGG } \\
\text { ACCAA }\end{array}$ & 60,3 & $\begin{array}{l}\text { ATTTCAACCACGAC } \\
\text { GGCTAC }\end{array}$ & 60 & 40 & 50 \\
\hline 588 & BrPe4110 & $\begin{array}{l}\text { Maracuja_ } \\
\text { NoIndex_L } \\
\text { 003_R1_00 } \\
\text { 1_contig_1 } \\
5969\end{array}$ & 4 & 1304 & 1315 & 12 & 3 & 8 & $\begin{array}{l}\text { ACTGAATTCTGCACATCAACCAACTGCCCATTGATGTCAGCAGGAC } \\
\text { CAAAGTATCTTTCGTGAATCTTTTTATGCAATATGGATACAAAATGA } \\
\text { TTTATCTTCATTACAAGGAAACGACTGTTCAAAATGTTGTGTTTCTC } \\
\text { CTTGTGGCTGTTCTTTCTTTCTCGGTTTCCATATTACTCATGTTCCTGT } \\
\text { ACACTTCTATGCAGATATGAGTACAGATGGGCTGATGGAGTCATCA } \\
\text { TCAAGAAGCCAATTGAGGTGTCTGCTCCAAAATATGTTGACTACCTG } \\
\text { ATGGACTGGATTGAGACTCAGTTAGATGA }\end{array}$ & ттст & $\mathrm{s}$ & 16,47 & 197 & $\begin{array}{l}\text { TGATGTCAGCAGGAC } \\
\text { CAAAG }\end{array}$ & 59,8 & $\begin{array}{l}\text { TCCATCAGCCCATC } \\
\text { TGTACTC }\end{array}$ & 60,1 & 50 & 52,4 \\
\hline 589 & BrPe4111 & $\begin{array}{l}\text { Maracuja_ } \\
\text { NoIndex_L } \\
\text { 003_R1_00 } \\
\text { 1_contig_1 } \\
6166\end{array}$ & 4 & 9170 & 9181 & 12 & 3 & 8 & $\begin{array}{l}\text { AACGCGATCAAGGATCAAAATACATCCTGCAATTTAGTGCTTTATCC } \\
\text { TAAGCACTCAGTACTGATTAGTACATGAGCATTTTTCTGCATATTTTT } \\
\text { GTAAAGCCAAATGAATTAGGAGATCTCAGAGGATTAATACGAAAGA } \\
\text { ATGAAAAAGAGAAAGAAAGAATATCTTCATCAAGTATGATCAGAAT } \\
\text { ACACAATGGCACCAACAAGAAAAGGACTGTACAGATTTACGCAGTT } \\
\text { ACAAGGTTGCACAATACTCCATGCTTTTTTATATATCACCATTGACT } \\
\text { ATGTTTCTATGATAAACAAAACAAACCTCACT }\end{array}$ & AGAA & $\mathrm{s}$ & 15,8 & 206 & $\begin{array}{l}\text { ACGCGATCAAGGATC } \\
\text { AAAAT }\end{array}$ & 59,5 & $\begin{array}{l}\text { TCTTGTTGGTGCCAT } \\
\text { TGTGT }\end{array}$ & 60 & 40 & 45 \\
\hline 590 & BrPe4112 & $\begin{array}{l}\text { Maracuja_ } \\
\text { NoIndex_L } \\
003 \text { 181_00 } \\
\text { 1_contig_1 } \\
6723\end{array}$ & 4 & 3762 & 3773 & 12 & 3 & 8 & $\begin{array}{l}\text { TGCATTTGGCATGATGTCACAATCATTAAATCTTAATAGAATGGTTA } \\
\text { TTGCATTAAGAAATACAGCTAGAAGTTAATTAATGAAAATACTCGA } \\
\text { CAGTGAAGACAAAAAGTAGAAATTTGTAAACAACTGACGACAAAC } \\
\text { ATTAAACATAAGAAACAAACAAACCTGACATTCTTTCCACAATCTG } \\
\text { CATGAGCATCATAAACATAGACAGGTAGCACTCGTGGTGAATAAAC } \\
\text { TACAATGGGTGGTGAAAGGAGGACCTATAAGAACAGGCATGCAAG } \\
\text { AAATAGGGTAAAAAGGTCATTTTATACTATAAATAAA }\end{array}$ & AAAC & $\mathrm{s}$ & 17,33 & 171 & $\begin{array}{l}\text { TGAAAATACTCGACA } \\
\text { GTGAAGACA }\end{array}$ & 059 & $\begin{array}{l}\text { СTCCTTTCACCACCC } \\
\text { ATTGT }\end{array}$ & 59,8 & 37,5 & 50 \\
\hline
\end{tabular}

G: genoma funcional

S: genoma estructural

P: polimórfico

M: monomórfico 
APÉNDICE

Marcadores microssatélites desenhados a partir do sequênciamento parcial e da montagem de novo do genoma de $P$. edulis

\begin{tabular}{|c|c|c|c|c|c|c|c|c|c|c|c|c|c|c|c|c|c|c|c|}
\hline $\mathbf{N}^{\mathbf{o}}$ & Primer & Contig $\mathrm{I}$ & Motivo & Início & Fim & pb & $\begin{array}{c}\mathbf{N}^{\mathbf{o}} \\
\text { Repet }\end{array}$ & Score & Sequência do contig & Unidade & G/S & Cobertura & pb & Sequência Forward & $\begin{array}{l}\mathrm{T}^{\circ} \mathrm{C} \\
F w d\end{array}$ & Sequência Reverse & $\begin{array}{r}\mathrm{T}^{\circ} \mathrm{C} \\
\operatorname{Rev}\end{array}$ & $\begin{array}{c}\% \mathrm{GC} \\
F w d\end{array}$ & $\begin{array}{c}\% \mathrm{GC} \\
\operatorname{Rev}\end{array} \quad \mathrm{P} / \mathbf{M}$ \\
\hline 591 & BrPe4113 & $\begin{array}{l}\text { Maracuja_ } \\
\text { NoIndex_L } \\
\text { 003_R1_00 } \\
\text { 1_contig_1 } \\
7161\end{array}$ & 4 & 492 & 503 & 12 & 3 & 8 & $\begin{array}{l}\text { ACAGAAAACGGATATGGAAACGGGGTCTATACTTTTTCTCTCTAGTG } \\
\text { GAAGGAAGGTGGGAATTAAAGGGAATATATAAGAAGCAAAAGGAA } \\
\text { TATAAGGAGAGACAAACCTTAATTCTTTTGATATGTTGTTATATGGA } \\
\text { ACGGAATGGTGTGGATGGATGGACTTTTGAGTGCTGCTCTATATACT } \\
\text { CTTAAAATCTCTTGTGTGGTGGTGGGGGTGGTGAAAGAAAATGCCA } \\
\text { AAAGAAAGCAGAACTTTAGCCTTGACACTATCAAATGAATCTCCCA } \\
\text { ATCTCTTTCCACTTGGACGGGTTTCTGGTAAACG }\end{array}$ & TGGA & $\bar{s}$ & 14,01 & 107 & $\begin{array}{l}\text { GCAAAAGGAATATAA } \\
\text { GGAGAGACAA }\end{array}$ & 59,3 & $\begin{array}{l}\text { AAGAGTATATAGAG } \\
\text { CAGCACTCAAAA }\end{array}$ & 57,3 & 36 & 34,6 \\
\hline 592 & BrPe4114 & $\begin{array}{l}\text { Maracuja_ } \\
\text { NoIndex_L } \\
\text { 003_R1_00 } \\
\text { 1_contig_1 } \\
7344\end{array}$ & 4 & 2770 & 2781 & 12 & 3 & 8 & $\begin{array}{l}\text { ACATGTTATCTGTCTCCCCGTTGTTGAGATTTTTGAGACCTCTTCATC } \\
\text { CCTAGAAGACATAGCCAATATTTAGTCCCCTGTAAAAAGTAAACAA } \\
\text { AAATATTAAGTAGAAGGAGCAAGTTTCTTACATAGTTGCATGGAAA } \\
\text { CATGGAACCTCTAGCTAGCTAGTCTTGCACGACCAGTTGAGGCCTTC } \\
\text { TCGTTCTTCATGATTTTGTTGAATAATTTTAGAGTTTTAACACGGTCC } \\
\text { TCTTCCACCATCTCTCTCAGCACATCGTCCTCGATCTTTTCGGCTTGC } \\
\text { CACCGAGAAGGGTCCTCGGCAAACGCCTG }\end{array}$ & CTAG & G & 15,05 & 178 & $\begin{array}{l}\text { CCCCGTTGTTGAGATT } \\
\text { TTTG }\end{array}$ & 60,3 & $\begin{array}{l}\text { GAACGAGAAGGCCT } \\
\text { CAACTG }\end{array}$ & 60 & 45 & 55 \\
\hline 593 & BrPe4115 & $\begin{array}{l}\text { Maracuja_ } \\
\text { NoIndex_L } \\
\text { 003_R1_00 } \\
\text { 1_contig_1 } \\
7784\end{array}$ & 4 & 371 & 382 & 12 & 3 & 8 & $\begin{array}{l}\text { AAGGGAAAAACAAGGTTACATGTCTCTTCACTCTATCCTGCCCAGA } \\
\text { GGCACCAAGGTTAGCCGATATATATATCAGTATACGTAAATAGTGG } \\
\text { CTACATATTGCTTACAAATATGTGATTTGAAAATGATTATTAAGTTG } \\
\text { TTTTGGCTGGTATTGATTGATTGCAGAATGATAAGAACTCGATCATG } \\
\text { CTAATGTCAGCAATGAAAATACGCGAGCTGAGGGGTTATAAGGAGT } \\
\text { GGTTGGAGAAGAGAACAGAGAAGCTGCAAGGGAGATTGAAGGCAA } \\
\text { TGGGGAGGGAGAACCAGGGAAGTACAAAGATTACG }\end{array}$ & ATTG & $\mathrm{s}$ & 19,44 & 153 & $\begin{array}{l}\text { TGATTATTAAGTTGTT } \\
\text { TTGGCTGGT }\end{array}$ & 60,2 & $\begin{array}{l}\text { ATTGCCTTCAATCTC } \\
\text { CCTTG }\end{array}$ & 59,1 & 32 & 45 \\
\hline 594 & BrPe4116 & $\begin{array}{l}\text { Maracuja_ } \\
\text { NoIndex_L } \\
\text { 003_R1_00 } \\
\text { 1_contig_1 } \\
7859\end{array}$ & 4 & 5127 & 5138 & 12 & 3 & 8 & $\begin{array}{l}\text { AGCATTGCAAAGGATAATTCCACTCCTCAACCCAAGTCTGAACTCCT } \\
\text { CTTCTGATGGTTCAGCTGGCAAGTCTTTAGCTGCAACCACCCCGATC } \\
\text { ATTTTCCTCAACCATCCGGCCGCTTCATATCTTCTCGATGCTACAAA } \\
\text { ACAACAAAGAAATAAATAAATTTAACCTTCTCGACTTCCGATCAGC } \\
\text { AATGTAAGCAACATTGGAGAAGAAAAACCCCTATAGCCAATCTCTT } \\
\text { TGTGCCTCCTCTC }\end{array}$ & АAAT & $\mathrm{s}$ & 16,43 & 168 & $\begin{array}{l}\text { TCCACTCCTCAACCC } \\
\text { AAGTC }\end{array}$ & 60,1 & $\begin{array}{l}\text { CTGATCGGAAGTCG } \\
\text { AGAAGG }\end{array}$ & 59,9 & 55 & 55 \\
\hline 595 & BrPe4117 & $\begin{array}{l}\text { Maracuja_ } \\
\text { NoIndex_L } \\
\text { 003_R1_00 } \\
\text { 1_contig_1 } \\
7908\end{array}$ & 4 & 11318 & 11333 & 16 & 4 & 12 & $\begin{array}{l}\text { GTTCGACCCGAACTGGAAGCATATACTTTAGTCCAGGAACAAGGTG } \\
\text { AACCATAAACAGATTCATGGAGCTGACCGTTTTGAAACTTCTCTAAA } \\
\text { CCAAAAGATTCCTTTGTTGCATTCATCACAACAAAAGTTTCATGCCC } \\
\text { AGCTTTCCATTGAATGAATGAATGAAAAGCATCACATCTATAAAAG } \\
\text { TAGTCACCTGAAGAAAGCAGACTTAACATTAGAGGAAAAGCATGAA } \\
\text { GTCAGCCAAAGTCAAGCCGTAACCAAAAGCGTGTTCCAGAGAAAC } \\
\text { ATGGTAAGCAATATTACCATTTGATGCTTTCATCGTAG }\end{array}$ & TGAA & G & 18,81 & 181 & $\begin{array}{l}\text { ATTCATGGAGCTGAC } \\
\text { CGTTT }\end{array}$ & 59,6 & $\begin{array}{l}\text { GGCTGACTTCATGC } \\
\text { TTTTCC }\end{array}$ & 59,8 & 45 & 50 \\
\hline
\end{tabular}

G: genoma funcional

S: genoma estructural

P: polimórfico

M: monomórfico 
APÉNDICE

Marcadores microssatélites desenhados a partir do sequênciamento parcial e da montagem de novo do genoma de $P$. edulis

\begin{tabular}{|c|c|c|c|c|c|c|c|c|c|c|c|c|c|c|c|c|c|c|c|}
\hline $\mathbf{N}^{\circ}$ & Primer & Contig & Motivo & Início & Fim & pb & $\begin{array}{c}\mathbf{N}^{\circ} \\
\text { Repet }\end{array}$ & Score & Sequência do contig & Unidade & G/S & Cobertura & pb & Sequência Forward & $\begin{array}{l}\mathrm{T}^{\circ} \mathrm{C} \\
F w d \\
\end{array}$ & Sequência Reverse & $\begin{array}{l}\mathrm{T}^{\circ} \mathrm{C} \\
\operatorname{Rev} \\
\end{array}$ & $\begin{array}{c}\% \mathrm{GC} \\
F w d \\
\end{array}$ & $\begin{array}{r}\% \mathrm{GC} \\
\operatorname{Rev} \\
\end{array}$ \\
\hline 596 & BrPe4118 & $\begin{array}{l}\text { Maracuja_ } \\
\text { Nolndex_L } \\
\text { 003_R1_00 } \\
\text { 1_contig_1 } \\
8355\end{array}$ & 4 & 273 & 284 & 12 & 3 & 8 & $\begin{array}{l}\text { GAATCGAATTTGATATAAAGGAAAAAAACTGTTTTCGTAGGATTCGTT } \\
\text { GATCCCTTTCTTGAAAGTGACAAACCAATCGAACAAGCAACAACAA } \\
\text { GCATATTGCTTCTCCCTTTCCTTGCACTCTTTTCCCATCTCCTCCCCT } \\
\text { ACCTATATACACTCACTCACTGGTCTGCCATTTCAAACCATTTCACA } \\
\text { TATCCATTCTCGGCAAAATGGGTTCGGCCACCAGTTCCATGGGAAA } \\
\text { AGGTTTGTTTGTGACTAAATATATACATATATATCTCACTGAAAAAG } \\
\text { CCTGTTTTCTTTTATAGTCTTTTATCTTCTC }\end{array}$ & CACT & $\mathrm{s}$ & 14,94 & 121 & $\begin{array}{l}\text { TGCACTCTTTTCCCAT } \\
\text { CTCC }\end{array}$ & 60,2 & $\begin{array}{l}\text { CTTTTCCCATGGAA } \\
\text { CTGGTG }\end{array}$ & 60,3 & 50 & 50 \\
\hline 597 & BrPe4119 & $\begin{array}{l}\text { Maracuja_ } \\
\text { NoIndex_L } \\
003 \_R 1 \text { 00 } \\
\text { 1_contig_1 } \\
8435\end{array}$ & 4 & 6922 & 6933 & 12 & 3 & 8 & $\begin{array}{l}\text { ATATTAATATAATACAAATTCATAATTCTTTGATACATATTCTTTACC } \\
\text { GACGATAATAAATGTATAAATTAAGAATCCTTCTTTTATGATTTTAA } \\
\text { TATGATTTCCAATTGAAGAAAAATCTTTAAAATCCAATTATTTTTCT } \\
\text { ACATTTTTAATAAATAAATATAAATTTATAACAATGCATCTTTATAC } \\
\text { TTACTAAATTATGACTTGTCTATGAGTCAAATAACGTGTTAATAATA } \\
\text { CATTCACAACCTAGCGAAAAAGGGCAAAAAAAGAAGGAATCTCTTA } \\
\text { ATCAATCAATCAATCAAATCAATACAACAA }\end{array}$ & AATA & $\mathrm{s}$ & 17,51 & 232 & $\begin{array}{l}\text { TTTGATACATATTCTT } \\
\text { TACCGACGA }\end{array}$ & 059 & $\begin{array}{l}\text { CCCTTTTTCGCTAGG } \\
\text { TTGTG }\end{array}$ & 59,7 & 32 & 50 \\
\hline 598 & BrPe4120 & $\begin{array}{l}\text { Maracuja_ } \\
\text { NoIndex_L } \\
003 \_R 1 \text { 00 } \\
\text { 1_contig_1 } \\
8506\end{array}$ & 4 & 6651 & 6662 & 12 & 3 & 8 & $\begin{array}{l}\text { AAGGAAACTACCCCACGTACTGCAGTAAATGAATGCGAGAAGCATG } \\
\text { TACGTCTGAAACAGTTTAAAGAAACGTGGAAATAAAACCTCCCGCT } \\
\text { TTTTGCAAGCATATTTCATTCCCTTTTGAAAGGGATTCCAAATTCAA } \\
\text { CATTATCATGAAATCAATCAATCGCACAACATTAAAGCATTACATA } \\
\text { ATAAACCAACAACATAATACAATAAGAGAACAAAAGACGAGGAGA } \\
\text { AATGTCTAGATACGTCTTGTCAGATAAACGACAGGTATGAGGCTTG } \\
\text { AGTTCTTCGCTAACACCATCCACGATCACAGACGGC }\end{array}$ & AATC & $\mathrm{s}$ & 18,08 & 221 & $\begin{array}{l}\text { CCGCTTTTTGCAAGC } \\
\text { ATATT }\end{array}$ & 60,2 & $\begin{array}{l}\text { TCTGTGATCGTGGA } \\
\text { TGGTGT }\end{array}$ & 60 & 40 & 50 \\
\hline 599 & BrPe4121 & $\begin{array}{l}\text { Maracuja_ } \\
\text { Nolndex_L } \\
003 \_R 1 \text { 00 } \\
\text { 1_contig_1 } \\
8882\end{array}$ & 4 & 5059 & 5070 & 12 & 3 & 8 & $\begin{array}{l}\text { GACATTACTGCTGTTCTTACGTTTTCCTGTCCATCAGAAACACTTCTC } \\
\text { ACAACCATTACAATCAAACCAGCAAGTTGTGTACTGATCATACACC } \\
\text { TAAACAACTTGCTCAATATTATCTGCATCTGCGCGCTTTGATCTTTTG } \\
\text { TTTCAGTTCAACCAACCAACGAGACCAAAGAACCAGTCTGCGGTGG } \\
\text { TCATTACTTGTAGCTTCTGTTCTTGGTTTTCTCCATGGCTCTTGGTGC } \\
\text { TGACATTAGGAACATAAATAAAAGAAAAATCCCATCAGCATTTTA } \\
\text { CTTGGAACAGAACCAGAGATAAATATTAAT }\end{array}$ & CAAC & G & 16,17 & 151 & $\begin{array}{l}\text { GCGCTTTGATCTTTTG } \\
\text { TTTCA }\end{array}$ & 60,4 & $\begin{array}{l}\text { TGCTGATGGGAATT } \\
\text { TTTCTTTT }\end{array}$ & 60 & 38,1 & 31,8 \\
\hline 600 & BrPe4122 & $\begin{array}{l}\text { Maracuja_ } \\
\text { Nolndex_L } \\
003 \_R 1 \text { 00 } \\
\text { 1_contig_1 } \\
8975\end{array}$ & 4 & 783 & 794 & 12 & 3 & 8 & $\begin{array}{l}\text { ATGATATGGAATCAAGTTTTGCCCCTACGGCATGAGCTATGGCTTGC } \\
\text { ATAAATCGTTCATGGAAGACCTTAAAACTTTGGATCTCAGCTTGAAA } \\
\text { ACTCTCCACAGCCAGCATTCTCTAGGAAAAGGTGTCAGCAGGATGG } \\
\text { TACGTTGAAGATGCATGCATGCCCATGTCCTGATGATAAGGTCGAG } \\
\text { CAATATGGCAAGGTGCAGGTTTTTCTGGGGCAATCAGCTCAACCTTG } \\
\text { TCTTCATTCACATGGCCAACCCAATAGTGTAGAGGGTCAATGTGTT } \\
\text { AAGGGGTTTAATCTTGGCCTCCTCGACCATGA }\end{array}$ & ATGC & $\mathrm{s}$ & 60,16 & 161 & $\begin{array}{l}\text { TGGCTTGCATAAATC } \\
\text { GTTCA }\end{array}$ & 60,2 & $\begin{array}{l}\text { ACCTTGCCATATTG } \\
\text { CTCGAC }\end{array}$ & 60,1 & 40 & 50 \\
\hline
\end{tabular}

G: genoma funcional

S: genoma estructural

P: polimórfico

M: monomórfico 
APÉNDICE

Marcadores microssatélites desenhados a partir do sequênciamento parcial e da montagem de novo do genoma de $P$. edulis

\begin{tabular}{|c|c|c|c|c|c|c|c|c|c|c|c|c|c|c|c|c|c|c|c|}
\hline $\mathbf{N}^{\circ}$ & Primer & Contig & Motivo & Início & Fim & pb & $\begin{array}{c}\mathbf{N}^{\circ} \\
\text { Repet }\end{array}$ & Score & Sequência do contig & Unidade & G/S & Cobertura & pb & Sequência Forward & $\begin{array}{l}\mathrm{T}^{\circ} \mathrm{C} \\
F w d \\
\end{array}$ & Sequência Reverse & $\begin{array}{l}\mathrm{T}^{\circ} \mathrm{C} \\
\operatorname{Rev} \\
\end{array}$ & $\begin{array}{c}\% \mathrm{GC} \\
F w d \\
\end{array}$ & $\begin{array}{r}\% \mathrm{GC} \\
\operatorname{Rev} \\
\end{array}$ \\
\hline 601 & BrPe4123 & $\begin{array}{l}\text { Maracuja_ } \\
\text { Nolndex_L } \\
\text { 003_R1_00 } \\
\text { 1_contig_1 } \\
9269\end{array}$ & 4 & 479 & 490 & 12 & 3 & 8 & $\begin{array}{l}\text { CTTCTCAACAAGGTCAGTCAGTTTTATGTTAAACCTCGCAAGACATT } \\
\text { TGGGTTGTTGCCTCTTCTCTCTTTCCATTTATCTTGCTCCTGTTTGATT } \\
\text { AATAATTGTTATACTTGCAATTGCGAGGTTACTTATATATTATGATG } \\
\text { CATCACTCTAGCTAGCTAGATAGGGTTTTATATATTAATGTCGTTTTC } \\
\text { CCATTTCTTTATGATCGTATGCTTTGTTTATGATTAAGTATTAAATAG } \\
\text { TAAACTATATATCAGACTGCGATTAGCACATTTCCGAGGAACTTGTT } \\
\text { TCCTAGTTAACAGTGTGGCTTTTGTC }\end{array}$ & CTAG & $\mathrm{s}$ & 17,11 & 235 & $\begin{array}{l}\text { CATTTGGGTTGTTGCC } \\
\text { TCTT }\end{array}$ & 60,0 & $\begin{array}{l}\text { CCTCGGAAATGTGC } \\
\text { TAATCG }\end{array}$ & 60,6 & 45 & 50 \\
\hline 602 & BrPe4124 & $\begin{array}{l}\text { Maracuja_ } \\
\text { Nolndex_L } \\
003 \_R 1 \text { 00 } \\
\text { 1_contig_1 } \\
9278\end{array}$ & 4 & 2351 & 2366 & 16 & 4 & 12 & $\begin{array}{l}\text { TTTCTTTTCCCATGTGCTTCTTTAGAATTAGCAACATAAATATGATAA } \\
\text { CTAAAAGAAGAATGTAAGATTTTCTCGTGATCGATAACGAAAAGAC } \\
\text { CCGAATTAAGCAAGCACATCACATTTTCGTTTGGTTGAAGGTCGCTA } \\
\text { TCCACACCCTCCTTCCTTCCTTCCTCTTAAAGGCGACAATGATATAA } \\
\text { GAAAATGCCTTGAAGTTTCCAAGCCTAAGAAAGGGTGTCAAATAATG } \\
\text { ACAAAAGTCACATGGCAGGATGCCAAAGATTTTCTAGACTCAGAGG } \\
\text { TTTGTGAGAGACATCCAGTAGAAGTTTCATCTTCT }\end{array}$ & TCCT & G & 18,94 & 160 & $\begin{array}{l}\text { CCCGAATTAAGCAAG } \\
\text { CACAT }\end{array}$ & 60,1 & $\begin{array}{l}\text { CCTGCCATGTGACT } \\
\text { TTTGTC }\end{array}$ & 59,1 & 45 & 50 \\
\hline 603 & BrPe4125 & $\begin{array}{l}\text { Maracuja_ } \\
\text { NoIndex_L } \\
\text { 003_R1_00 } \\
\text { 1_contig_1 } \\
9330\end{array}$ & 4 & 2342 & 2353 & 12 & 3 & 8 & $\begin{array}{l}\text { CAACACTGTAATGCTGGTCTTTAATTTAGAGAAGCTATCAGCCTGCC } \\
\text { AAAATCAACTCATGATGTAGGGTTGCTGCTACTCTGAAATGCTTGCA } \\
\text { TAACCGCTTTCTTGATATTTGACCACAAACCAATGGTGCTTGGTTAT } \\
\text { AGAAATAATTTCTTTCTTTCACTCTTTTTGGAGGTCATGCTTACTGT } \\
\text { AATTTATGTTACCCCAATTTGAATTGCAATAAAAAAAAAGAGAATA } \\
\text { TTATGGAGAAGAATCTGAAGAGATAATGCCAATGTCCTACCTTCTTA } \\
\text { ATTAGTATGAATTCAATTACTATCTTTTTG }\end{array}$ & TтTC & $\mathrm{s}$ & 18,29 & 186 & $\begin{array}{l}\text { AAGCTATCAGCCTGC } \\
\text { CAAAA }\end{array}$ & 60,0 & $\begin{array}{l}\text { TGCAATTCAAATTG } \\
\text { GGGTAA }\end{array}$ & 58,9 & 45 & 35 \\
\hline 604 & BrPe4126 & $\begin{array}{l}\text { Maracuja_ } \\
\text { NoIndex_L } \\
003 \_R 1 \text { 00 } \\
\text { 1_contig_1 } \\
9433\end{array}$ & 4 & 494 & 505 & 12 & 3 & 8 & $\begin{array}{l}\text { ATTAAACGAATCGAATTGAATCTATTAAAAAGACTCAACATGACTATT } \\
\text { ACAAACTTCTCGTCTCTGCCTGACTGTGTTATTACAGCAGTAACCAT } \\
\text { TGTCTGGATAGATTCGATAAATTGTTCATTAAATATTTCTTACTACA } \\
\text { ACTAGGATTATAAATAAATAACAAACTGCCCGCACGCTTATAACAC } \\
\text { GTTACCTCATAAGAAAGAATTAGGTACTACAACAGCATTCATATTCT } \\
\text { AGAAGGAAAACATAAGGTAATATAAGGGACAAAGGGTCCGATAAT } \\
\text { ATAAACCTATTTAAACAACAAAAGTGAAACTAA }\end{array}$ & ATAA & $\mathrm{s}$ & 13,55 & 220 & $\begin{array}{l}\text { CTCGTCTCTGCCTGAC } \\
\text { TGTG }\end{array}$ & 59,8 & $\begin{array}{l}\text { TCGGACCCTTTGTCC } \\
\text { CTTAT }\end{array}$ & 60,7 & 60 & 50 \\
\hline 605 & BrPe4127 & $\begin{array}{l}\text { Maracuja_ } \\
\text { NoIndex_L } \\
003 \_R 1 \text { 00 } \\
\text { 1_contig_1 } \\
9505\end{array}$ & 4 & 747 & 758 & 12 & 3 & 8 & $\begin{array}{l}\text { TAAATGTTGTGTTTACATTGTATTGATGACCACTTGTGCAATTGTTG } \\
\text { AGTTTTGAAAGGTTTAAAATCGGATTTAATGCATGATAGGGCTCTGC } \\
\text { CCTGTTTTTCCAGTTTTCAGTTCATATGCCCTACTTTGGGCAATCATA } \\
\text { TTTGGAGATTGGTTGGTTGGATTTGTGTGATTCTTGTTGGAGTGTGA } \\
\text { AGCCTGTATGTCAGGCTATGTGCGGATGGAATTTGGTGAATTTGGA } \\
\text { GGTCCGGAGGGTCCCCAATTGTGGCTCGTAAGTTACTGAAAAATAA } \\
\text { GGTTTATGATCTG }\end{array}$ & TTGG & $\mathrm{G}$ & 767,2 & 159 & $\begin{array}{l}\text { ATAGGGCTCTGCCCT } \\
\text { GTTTT }\end{array}$ & 60,1 & $\begin{array}{l}\text { GGACCTCCAAAATT } \\
\text { CACCAA }\end{array}$ & 59,8 & 50 & 45 \\
\hline
\end{tabular}

G: genoma funcional

S: genoma estructural

P: polimórfico

M: monomórfico 
APÉNDICE

Marcadores microssatélites desenhados a partir do sequênciamento parcial e da montagem de novo do genoma de $P$. edulis

\begin{tabular}{|c|c|c|c|c|c|c|c|c|c|c|c|c|c|c|c|c|c|c|c|}
\hline $\mathbf{N}^{\circ}$ & Primer & Contig & Motivo & Início & Fim & pb & $\begin{array}{c}\mathbf{N}^{\circ} \\
\text { Repet }\end{array}$ & Score & Sequência do contig & Unidade & G/S & Cobertura & pb & Sequência Forward & $\begin{array}{l}\mathrm{T}^{\circ} \mathrm{C} \\
F w d \\
F\end{array}$ & Sequência Reverse & $\begin{array}{l}\mathrm{T}^{\circ} \mathrm{C} \\
\operatorname{Rev} \\
\end{array}$ & $\begin{array}{c}\% \mathrm{GC} \\
F w d \\
\end{array}$ & $\begin{array}{r}\% \mathrm{GC} \\
\operatorname{Rev} \\
\end{array}$ \\
\hline 606 & BrPe4128 & $\begin{array}{l}\text { Maracuja_ } \\
\text { Nolndex_L } \\
\text { 003_R1_00 } \\
\text { 1_contig_1 } \\
9917\end{array}$ & 4 & 1925 & 1936 & 12 & 3 & 8 & $\begin{array}{l}\text { GTATTTCCCCATCTTTTATTATGATAATTTCTTTTTTATTTTTCTATTT } \\
\text { TTTCTTTAGCTGTAATGCAGCTTATATCGAGAAAAGAAAATGGACAT } \\
\text { GAGCTTGTCTGTGGTGTCGTTTACCTGAATGTTTATCGATGTGCTTG } \\
\text { GCTGGCGCCAACCAACCAATACCGACAAGGTAGCATCGCGTAAGGG } \\
\text { TAGTTTCGGTAATGGAAGTGAATGTGTTTGTTATTATTATGCATTGA } \\
\text { TTACCTTTTGTACCCTTACAGAGGTTCACCAATACAACGTCAGATC } \\
\text { TAACTTGGAACCTTCACATCAGATGTGTA }\end{array}$ & CCAA & $\mathrm{s}$ & 15,93 & 101 & $\begin{array}{l}\text { GGACATGAGCTTGTC } \\
\text { TGTGG }\end{array}$ & 59,3 & $\begin{array}{l}\text { TACCCTTACGCGAT } \\
\text { GCTACC }\end{array}$ & 60,1 & 55 & 55 \\
\hline 607 & BrPe4129 & $\begin{array}{l}\text { Maracuja_ } \\
\text { NoIndex_L } \\
003 \_R 1 \text { 00 } \\
\text { 1_contig_2 } \\
0130\end{array}$ & 4 & 1340 & 1359 & 20 & 5 & 16 & $\begin{array}{l}\text { CTCATAGTAAAATCATTATCAATAATGCTTTTTTCATATCTCGTATTT } \\
\text { TTATCGGATCAAACCCGAATCGTAGACCACTATATCAACCCTCTTGA } \\
\text { TTGGCTAATGCTACGTGTAGTTTTAATAGGAAAAGGGATGACTAATT } \\
\text { TTTGTATGTATTTATTTATTTATTTATTGTTTTAATCGGATATGTATAT } \\
\text { TAAATATGTAGATATTTATTACAGTATCAATTAACAAGTCTAAACCA } \\
\text { AATAAAATATTTAATTAGAGTTAAAATAAGACTGTAATGTCGATATT } \\
\text { ATTGTAACATATTTTGACACAAAGTGGATGCCTCT }\end{array}$ & TATT & $\mathrm{s}$ & 121,5 & 233 & $\begin{array}{l}\text { СССTCTTGATTGGCTA } \\
\text { ATGCT }\end{array}$ & 60,6 & $\begin{array}{l}\text { GAGGCATCCACTTT } \\
\text { GTGTCA }\end{array}$ & 59,7 & 47,6 & 50 \\
\hline 608 & BrPe4130 & $\begin{array}{l}\text { Maracuja_ } \\
\text { NoIndex_L } \\
003 \_R 1 \text { 00 } \\
\text { 1_contig_2 } \\
0399\end{array}$ & 4 & 4512 & 4523 & 12 & 3 & 8 & $\begin{array}{l}\text { TGTCTGACTGAAAGGATTTATTTAACGTCTTGGGAAACTTGCTTTCA } \\
\text { TGTCAAAATGATATTCTATTCGTATTGTGTTAGCTTTCTTTTGTCA } \\
\text { TCTTTGATTGTCTTCCACCCTCTGTCTGCAAACTACCATATCCTGCAA } \\
\text { CTGACGTTTTCTTTCTTTCACAATATAGTTAAATTAAAATTCAATTTA } \\
\text { CTGGTGCAGGAGGTTGTTGATGATGAAGACGAAAAACTGAAAGGTT } \\
\text { TGAAGAAGGAGATGGGCGAGGGAGTGTACAATGCTGTAGCAGCAG } \\
\text { CTTTAGTGCAAATAAATGAATACAATCCCA }\end{array}$ & TTTC & $\mathrm{s}$ & 16,85 & 182 & $\begin{array}{l}\text { CGTCTTGGGAAACTT } \\
\text { GCTTT }\end{array}$ & 59,4 & $\begin{array}{l}\text { CAACCTCCTGCACC } \\
\text { AGTAAA }\end{array}$ & 58,8 & 45 & 50 \\
\hline 609 & BrPe4131 & $\begin{array}{l}\text { Maracuja_ } \\
\text { Nolndex_L } \\
\text { 003_R1_00 } \\
\text { 1_contig_2 } \\
0497\end{array}$ & 4 & 1043 & 1054 & 12 & 3 & 8 & $\begin{array}{l}\text { ACATGGAAGAGTCGGAGACAGGAAAGCATATGCCATTTTCTGTGTG } \\
\text { GAATTTTCCTTGAGATGCGTGTTTCTCTTGGACTTTGGGTCTTGTGGA } \\
\text { AATTGGGGACTGAACCAACATAAATATTGTATTTGGATCCATATCA } \\
\text { TATGTGCACATAAATAAATAATTTCAGCAGACAAATCTGTGAGCAA } \\
\text { TGCCAAAATAGATCATAAACTATATTAAAAAAAAAAGAAAAAGGA } \\
\text { ACTACAATTCCTAGTGGATGCATTTTGGGTAATTAATGTTATCATTA } \\
\text { AATAAGTGAAAATTTAGTGACCTTATTGATATT }\end{array}$ & ATAA & $\mathrm{s}$ & 29,88 & 186 & $\begin{array}{l}\text { GAGTCGGAGACAGGA } \\
\text { AAGCA }\end{array}$ & 60,5 & $\begin{array}{l}\text { TTTGGCATTGCTCAC } \\
\text { AGATT }\end{array}$ & 59,3 & 55 & 40 \\
\hline 610 & BrPe4132 & $\begin{array}{l}\text { Maracuja_ } \\
\text { Nolndex_L } \\
003 \_R 1 \text { 00 } \\
\text { 1_contig_2 } \\
0975\end{array}$ & 4 & 2002 & 2017 & 16 & 4 & 12 & $\begin{array}{l}\text { TGATTTATCCTGCAACTAATAGTGTTCTTTTGATGATTAAAATAATTT } \\
\text { TGGAGGTCTGGTGTGCTATGCGAATTTCTTTCTTCACCTGTGTACA } \\
\text { AATGTGGATGGTTGAAAAGCGCATCAAATGCGGCAATGCATTGGTA } \\
\text { CGAAGAAGGAAGCAAGCAAGCAAGCTAGAAACATATCACGGAGTA } \\
\text { GTTGGTCAGTGTTCCGGGCTGCAGATGACCACTCGCTGCTTCCTCTT } \\
\text { AAATATAAAAAATAAAAATAAAAAAGAGAAGCAAGGATGCCAATA } \\
\text { AAATCAAATCAGGTACATGCAAAGTCACAAACAGCCAC }\end{array}$ & AAGC & $\mathrm{s}$ & 16,17 & 150 & $\begin{array}{l}\text { ACCTGTGTACAAATG } \\
\text { TGGATGG }\end{array}$ & 59,6 & $\begin{array}{l}\text { TAAGAGGAAGCAGC } \\
\text { GAGTGG }\end{array}$ & 60,7 & 45,5 & 55 \\
\hline
\end{tabular}

G: genoma funcional

S: genoma estructural

P: polimórfico

M: monomórfico 
APÉNDICE

Marcadores microssatélites desenhados a partir do sequênciamento parcial e da montagem de novo do genoma de $P$. edulis

\begin{tabular}{|c|c|c|c|c|c|c|c|c|c|c|c|c|c|c|c|c|c|c|c|}
\hline $\mathbf{N}^{\circ}$ & Primer & Contig $\mathrm{I}$ & Motivo & Início & Fim & pb & $\begin{array}{c}\mathbf{N}^{\circ} \\
\text { Repet }\end{array}$ & Score & Sequência do contig & Unidade & G/S & Cobertura & pb & Sequência Forward & $\begin{array}{l}\mathrm{T}^{\circ} \mathrm{C} \\
F w d\end{array}$ & Sequência Reverse & $\begin{array}{r}\mathrm{T}^{\circ} \mathrm{C} \\
\operatorname{Rev}\end{array}$ & $\begin{array}{r}\% \mathrm{GC} \\
F w d\end{array}$ & $\begin{array}{c}\% \mathrm{GC} \\
\operatorname{Rev}\end{array} \quad \mathrm{P} / \mathbf{M}$ \\
\hline 611 & BrPe4133 & $\begin{array}{l}\text { Maracuja_ } \\
\text { NoIndex_L } \\
003 \text { R1_00 } \\
\text { 1_contig_2 } \\
\text { 1621 }\end{array}$ & 4 & 1968 & 1983 & 16 & 4 & 12 & $\begin{array}{l}\text { TAGTTAGGATCATATGGTAGATCGTTCAGGAATTAGTTATAGTAGTG } \\
\text { AGATATTCTGAGTTTTTTTTGTATCAATTGCCATCAACCAGTCTTA } \\
\text { CACCATGTACCGTTTCCTAAGTGGCTACCTATGTACACGCTAAATGC } \\
\text { TCATAAATATGAATGAATGAATGAGTATATATTTTGCTCAGAAAGA } \\
\text { AAAGGTTGAAGACAAGTTGCTTCCCGTGGACCATAAGTAAAGCTGT } \\
\text { GAAAATCGTGACCATATTGTGCACTCTTAAAACTTCATGACTCCAAA } \\
\text { GGCATGCCCTGGGTAAGTATGATAGGATCTGCAGT }\end{array}$ & ATGA & $\mathrm{s}$ & 23,62 & 154 & $\begin{array}{l}\text { CAATTTGCCATCAAC } \\
\text { CAGTCT }\end{array}$ & 60,0 & $\begin{array}{l}\text { ACTTATGGTCCACG } \\
\text { GGAAGC }\end{array}$ & 61,3 & 42,9 & 55 \\
\hline 612 & BrPe4134 & $\begin{array}{l}\text { Maracuja_ } \\
\text { NoIndex_L } \\
\text { 003_R1_00 } \\
\text { 1_contig_2 } \\
1639\end{array}$ & 4 & 257 & 268 & 12 & 3 & 8 & $\begin{array}{l}\text { TTCATATTTTCAACTCTCATGTATTCTGTGTCTGCGGCATGCAGGTTG } \\
\text { GCGAATATCAAGGTGCATATAAGGTAAGAGATGAATTTAGGCTTCT } \\
\text { GTATGTTCATTGTAAGTTATGCAGACTTTTTCTTGTCCTTGATTGTTA } \\
\text { TCCATCGTTGTATGTATGTAGATAACCAAGGGATTATTGGAGAAGTA } \\
\text { TGGCCCCGAGAGGGTTCTCGATACTCCGATTACAGAGGTAATTTTGG } \\
\text { TTACATGGCTTTACTGACATCAACATAATCACGTAGCTAAATTTATAT } \\
\text { AGTTATGTTTTTAGGCTGAACACAGATCC }\end{array}$ & TGTA & G & 17,79 & 158 & $\begin{array}{l}\text { GGTTGGCGAATATCA } \\
\text { AGGTG }\end{array}$ & 60,3 & $\begin{array}{l}\text { СTCTCGGGGCCATA } \\
\text { СТTCTC }\end{array}$ & 61,1 & 50 & 60 \\
\hline 613 & BrPe4135 & $\begin{array}{l}\text { Maracuja_ } \\
\text { NoIndex_L } \\
\text { 003_R1_00 } \\
\text { 1_contig_2 } \\
\text { 1881 }\end{array}$ & 4 & 8608 & 8619 & 12 & 3 & 8 & $\begin{array}{l}\text { AGGGGACAGTGCAGCGCAACCTTCTTCGTCGCCGCTTAGAGGTGGT } \\
\text { CCGGTTGATGACGCAGCACTCATCGTGGAGCTCGGCCCGATGGAAA } \\
\text { TTCGCACTTTTCTGCTAAAATTTTGAAGCGGAGGATTTGCGATTTGA } \\
\text { AAAGATTGACGTTTATTTATTTACACTGGACTCGTCGCGAACGAAGT } \\
\text { CGGATCCAAATAACCAGGTTCTTTCTGTGGCACGAACAAAAAAATA } \\
\text { AATAATCGGCGAGAAACATGAAAGCAGTATATTAAAAACGCGAGTT } \\
\text { TTAGCACAGCCCGTCTCCCATTCTTGTTTTATTC }\end{array}$ & TTTA & $\mathrm{s}$ & 16,92 & 187 & $\begin{array}{l}\text { CTTAGAGGTGGTCCG } \\
\text { GTTGA }\end{array}$ & 60,1 & $\begin{array}{l}\text { TCGTGCCACAGAAA } \\
\text { GAACCT }\end{array}$ & 60,8 & 55 & 50 \\
\hline 614 & BrPe4136 & $\begin{array}{l}\text { Maracuja_ } \\
\text { NoIndex_L } \\
\text { 003_R1_00 } \\
\text { 1_contig_2 } \\
\text { 2090 }\end{array}$ & 4 & 657 & 668 & 12 & 3 & 8 & $\begin{array}{l}\text { GAAATGCCACAATTGCTAACTTTTCCGTTTGCTTCAACATTCAATTCT } \\
\text { CAATTCTGGTACATACCACAAACCCTTCACAGTTCTGAGACCACCTT } \\
\text { GAATTTCGATTGTACGAGTTGGCTAAAACGACAAGTTCGACATGAA } \\
\text { AACCAATGGCACCCACCCACCTGCAGAGGAAACGGAGTATGACTTT } \\
\text { GAGAGAAATAACAATGACAGATGGATGACGAATGCATTTTGATACC } \\
\text { ACGAAGATGAAACGTTCCATTGTGGTTGATGCAGTGCGATATTATAT } \\
\text { GATGAAATACTTGGATTGTTTAACAATTGAGT }\end{array}$ & CACC & G & 16,78 & 159 & $\begin{array}{l}\text { CGAGTTGGCTAAAAC } \\
\text { GACAA }\end{array}$ & 059 & $\begin{array}{l}\text { ACTGCATCAACCAC } \\
\text { AATGGA }\end{array}$ & 60 & 45 & 45 \\
\hline 615 & BrPe4137 & $\begin{array}{l}\text { Maracuja_ } \\
\text { NoIndex_L } \\
\text { 003_R1_00 } \\
\text { 1_contig_2 } \\
2700\end{array}$ & 4 & 3802 & 3813 & 12 & 3 & 8 & $\begin{array}{l}\text { AGGTGGCTACCGATGCTGTGGGGATTATAAGAACAGTAGCTTCTTTC } \\
\text { TGTTCTGAAGAAAAAGTGATGCAACTCTACAGAAGTAAATGTGAAG } \\
\text { GACCATTGAAGGCTGGAAAAAGGCTAGGAACTGTCAGTGGCATAGG } \\
\text { ATTTGGAGTATCTTCCTTCCTTCTGTATTGCTTTGAAGCAACCAGTTT } \\
\text { CTATGCAGGAGCCCAGCTAGTTAAGGGTGGGCACGCACAATTCTCA } \\
\text { GACGTTTTCCGGGTGAGTATACCTTACCTGTCCATCAAGTCTATACC } \\
\text { ATATCTTCTTACAAGCCTACAACATTAATTCT }\end{array}$ & Сттс & G & 14,37 & 154 & $\begin{array}{l}\text { TGAAGGCTGGAAAAA } \\
\text { GGCTA }\end{array}$ & 60,0 & $\begin{array}{l}\text { ATACTCACCCGGAA } \\
\text { AACGTC }\end{array}$ & 58,9 & 45 & 50 \\
\hline
\end{tabular}

G: genoma funcional

S: genoma estructural

P: polimórfico

M: monomórfico 
APÉNDICE

Marcadores microssatélites desenhados a partir do sequênciamento parcial e da montagem de novo do genoma de $P$. edulis

\begin{tabular}{|c|c|c|c|c|c|c|c|c|c|c|c|c|c|c|c|c|c|c|c|}
\hline $\mathbf{N}^{\circ}$ & Primer & Contig I & Motivo & Início & Fim & pb & $\begin{array}{c}\mathbf{N}^{\circ} \\
\text { Repet }\end{array}$ & Score & Sequência do contig & Unidade & G/S & Cobertura & $\mathrm{pb}$ & Sequência Forward & $\begin{array}{l}\mathrm{T}^{\circ} \mathrm{C} \\
F w d \\
\end{array}$ & Sequência Reverse & $\begin{array}{l}\mathrm{T}^{\circ} \mathrm{C} \\
\operatorname{Rev} \\
\end{array}$ & $\begin{array}{c}\% \mathrm{GC} \\
F w d \\
\end{array}$ & $\begin{array}{cc}\% \mathrm{GC} & \mathrm{P} / \mathrm{M} \\
\operatorname{Rev} & \end{array}$ \\
\hline 616 & BrPe4138 & $\begin{array}{l}\text { Maracuja_ } \\
\text { NoIndex_L } \\
\text { 003_R1_00 } \\
\text { 1_contig_2 } \\
\text { 2717 }\end{array}$ & 4 & 487 & 498 & 12 & 3 & 8 & $\begin{array}{l}\text { CTGTCTTCTCCACATATGAATGTTCCTCACAATATGTTTCAGGAAGC } \\
\text { GAAGGATGACAGCAAAAATGCCCCCAATTGGACAGTTATCTCAGGG } \\
\text { TTTTCGGCTCCCAATCCTCAGATTTGAAGAATGACCAGCCCCCTGA } \\
\text { CACGTTGGATAAAGAAAGAAAGTCTGAGGCAGCCACTAGTTATCGA } \\
\text { CTATTTGGTATTGAACTCATAAATAATTCCACAAACTTGCCTCCTGC } \\
\text { TGAACGTACACCTGCACTGCCAATCAGTGTATCTAGTGGGATCACTG } \\
\text { AAGGGCATGACGTGAACGCCATATCAGCTGCT }\end{array}$ & AAAG & $\mathrm{G}$ & 12,32 & 212 & $\begin{array}{l}\text { GTTTCAGGAAGCGAA } \\
\text { GGATG }\end{array}$ & 59,8 & $\begin{array}{l}\text { CAGGTGTACGTTCA } \\
\text { GCAGGA }\end{array}$ & 58,9 & 50 & 55 \\
\hline 617 & BrPe4139 & $\begin{array}{l}\text { Maracuja_ } \\
\text { NoIndex_L } \\
\text { 003_R1_00 } \\
\text { 1_contig_2 } \\
\text { 2761 }\end{array}$ & 4 & 170 & 181 & 12 & 3 & 8 & $\begin{array}{l}\text { GGAATCCGCTCTCCACAGGTGGTACCTCTCTAATCTCTCGAGTAATC } \\
\text { GGTGTACCTGACCTGAATGATGAACTACGTGGAGGTCTCCTCGCCTG } \\
\text { GGCTCGGAGTCTGGGTCCAGATGGCCTCACAGTAACTGGCTGGCCA } \\
\text { ACTGATGGTCTCCATCCATCCAAATCTCCATCCTGGTAAACCCTATC } \\
\text { AA }\end{array}$ & TCCA & G & 642,06 & 120 & $\begin{array}{l}\text { TGATGAACTACGTGG } \\
\text { AGGTCT }\end{array}$ & 57,2 & $\begin{array}{l}\text { AGGGTTTACCAGGA } \\
\text { TGGAGA }\end{array}$ & 58,4 & 47,6 & 50 \\
\hline 618 & BrPe4140 & $\begin{array}{l}\text { Maracuja_ } \\
\text { NoIndex_L } \\
\text { 003_R1_00 } \\
\text { 1_contig_2 } \\
\text { 3088 }\end{array}$ & 4 & 174 & 185 & 12 & 3 & 8 & $\begin{array}{l}\text { GTTTTCTAATTTACCGACATCCCTCGGTCGGTAAATTTAACCGACCC } \\
\text { ACCAGCAAAATTTTCAGCAATAACCCGACCGATTTCCGACCAGAAA } \\
\text { TCAATCAGTTCGGGAAATTACCGACGGGTCGGGTTACTTTGCTCAGC } \\
\text { CCTATAGTAGCCAACCAACCAAAACTCGAAACACAACAAGACTTAC } \\
\text { GCCGGGATGACCAACAACAAAGCTTCCCGACGCACCGCAAGCGTCA } \\
\text { AACCCAATCAAGGAAGACTTCTTAAAGATCAAGCCAAGGATTACAT } \\
\text { CCAAAGACAATAACCCAAACCTAGGGTTTCAAGC }\end{array}$ & CCAA & G & 107,24 & 151 & $\begin{array}{l}\text { CACCAGCAAAATTTT } \\
\text { CAGCA }\end{array}$ & 59,8 & $\begin{array}{l}\text { GTCATCCCGGCGTA } \\
\text { AGTCT }\end{array}$ & 60,1 & 40 & 57,9 \\
\hline 619 & BrPe4141 & $\begin{array}{l}\text { Maracuja_ } \\
\text { NoIndex_L } \\
\text { 003_R1_00 } \\
\text { 1_contig_2 } \\
\text { 3090 }\end{array}$ & 4 & 337 & 348 & 12 & 3 & 8 & $\begin{array}{l}\text { GCTACTGATCATAACTTGTTTAGATTAAAATGTAATAGAACTTAATT } \\
\text { AGAAGTTTTATTCAGCTTATTTATAGAAGAGCTTTGTCTCTTTTAGCA } \\
\text { TGTTGTTGTGTCTTCGTTTTGTCGTGGGGGAACAAAGTTGAAAATGG } \\
\text { CTGATTATGTACGTACGTACCCAGACCATGCAATTTATATAAGAAAA } \\
\text { TGTTCATAATTCTTCCTGTTAAAAAAACATATTAATCTCACTTCAAA } \\
\text { GACATAAAAACGATGAATTCGGAAGCATGTTCTCCTTTTCAAACGTT } \\
\text { CTGCTACATAAGCTGACATGCAGTCTGGA }\end{array}$ & GTAC & $\mathrm{s}$ & 16,16 & 155 & $\begin{array}{l}\text { GTGGGGGAACAAAGT } \\
\text { TGAAA }\end{array}$ & 59,8 & $\begin{array}{l}\text { AAGGAGAACATGCT } \\
\text { TCCGAAT }\end{array}$ & 60,1 & 45 & 42,9 \\
\hline 620 & BrPe4142 & $\begin{array}{l}\text { Maracuja_ } \\
\text { NoIndex_L } \\
\text { 003_R1_00 } \\
\text { 1_contig_2 } \\
\text { 3346 }\end{array}$ & 4 & 4251 & 4262 & 12 & 3 & 8 & $\begin{array}{l}\text { AAGGCGTGGTGTCCGGTGTCGTATCCATATAACAATTTTAATATAAT } \\
\text { TTTAAAAGAAAACCTAATATGACCGTTACTCGGAAGCCTAACGTCTC } \\
\text { CTTAGACTTGGAAAATTTTAAATTTGAAATTAGTGAAAAGCGATAA } \\
\text { AGATGACTGGCTTTCTTTCTTTGCATTTACAGGCTTACAGCACAGGA } \\
\text { ATAAATAACCCCCTTGAATCGATAAGCTTCTTCAAAGCTTCCGACCA } \\
\text { AACTTTGAATCTCGTCTCCCTCCTTCATCTTCCTCGACAGAGCAATG } \\
\text { GCATTGAGATCCATTGATAATGCTCTTCCAG }\end{array}$ & Сттт & $\mathrm{s}$ & 17,53 & 176 & $\begin{array}{l}\text { GACCGTTACTCGGAA } \\
\text { GCCTA }\end{array}$ & 59,3 & $\begin{array}{l}\text { TTCAAAGTTTGGTC } \\
\text { GGAAGC }\end{array}$ & 60,2 & 55 & 45 \\
\hline
\end{tabular}

G: genoma funcional

S: genoma estructural

P: polimórfico

M: monomórfico 
APÉNDICE

Marcadores microssatélites desenhados a partir do sequênciamento parcial e da montagem de novo do genoma de $P$. edulis

\begin{tabular}{|c|c|c|c|c|c|c|c|c|c|c|c|c|c|c|c|c|c|c|c|}
\hline $\mathbf{N}^{\circ}$ & Primer & Contig I & Motivo & Início & Fim & pb & $\begin{array}{c}\mathbf{N}^{\circ} \\
\text { Repet }\end{array}$ & Score & Sequência do contig & Unidade & G/S & Cobertura & pb & Sequência Forward & $\begin{array}{l}\mathrm{T}^{\circ} \mathrm{C} \\
F w d \\
\end{array}$ & Sequência Reverse & $\begin{array}{l}\mathrm{T}^{\circ} \mathrm{C} \\
\operatorname{Rev} \\
\end{array}$ & $\begin{array}{c}\% \mathrm{GC} \\
F w d \\
\end{array}$ & $\begin{array}{c}\% \mathrm{GC} \\
\operatorname{Rev}\end{array} \quad \mathrm{P} / \mathrm{M}$ \\
\hline 621 & BrPe4143 & $\begin{array}{l}\text { Maracuja_ } \\
\text { NoIndex_L } \\
\text { 003_R1_00 } \\
\text { 1_contig_2 } \\
\text { 3664 }\end{array}$ & 4 & 2221 & 2232 & 12 & 3 & 8 & $\begin{array}{l}\text { ACTTAAGATGTTGGTGTTGGGGTGTTAGGTCAAGCCCATGATCATAT } \\
\text { CATTACATGCATCGAGTCCATGATCATATCATTGCATGCGTCGAGTC } \\
\text { CATGATCGTATCATTGCATGCGTTGATCGTTATTTTGATTGAGTCT } \\
\text { GTGTGATTACATGCATGCATGGTGTTTAGAGGTTCGGTGGATGAGTA } \\
\text { ATTTCCTTTATTTTTTCTGAGTGTTTGGAGCATTATTGATGCTAGGAG } \\
\text { ATGATGCTTTGGGATTCTATGTTGGAAGAGTGTAAGGATGGTGTA } \\
\text { CCGGAGGTTTGGGTCGAGTCGGACGACGT }\end{array}$ & CATG & $\mathrm{s}$ & 21,49 & 182 & $\begin{array}{l}\text { TGCATGCGTTGAGTC } \\
\text { GTTAT }\end{array}$ & 60,3 & $\begin{array}{l}\text { CCTCCGGTACACCA } \\
\text { TCCTTA }\end{array}$ & 59,8 & 45 & 55 \\
\hline 622 & BrPe4144 & $\begin{array}{l}\text { Maracuja_ } \\
\text { NoIndex_L } \\
\text { 003_R1_00 } \\
\text { 1_contig_2 } \\
\text { 3892 }\end{array}$ & 4 & 3506 & 3517 & 12 & 3 & 8 & $\begin{array}{l}\text { TCATAATTAATTATACATTATTACATAAAATCATGCTCACCTTCATG } \\
\text { TCTATAATGCCAATCGTATGTACGTGTGTCATATATAATCACATAAA } \\
\text { TTGAGATTTCTTGATATGGAAATATCAATTATTTTATGTGTGATTAA } \\
\text { ATATTTAAAATTTATTTATTTGACTTACTAAAGTATCTAATTTTGATA } \\
\text { TTGTTTATTGGAGAGAATTTTTACTTTTCAAATAAGAAGTGTTCGAA } \\
\text { CTTGAACCGTAAATATATCATATCTTGGACAGAAATTACATGTCTT } \\
\text { ATGGTGATTGAAAATTATTCCTCGATAAA }\end{array}$ & АТTT & $\mathrm{s}$ & 14,81 & 193 & $\begin{array}{l}\text { AATGCCAATCGTATG } \\
\text { TACGTG }\end{array}$ & 58,5 & $\begin{array}{l}\text { CGGTTCAAGTTCGA } \\
\text { ACACTTC }\end{array}$ & 59,8 & 42,9 & 47,6 \\
\hline 623 & BrPe4145 & $\begin{array}{l}\text { Maracuja_ } \\
\text { NoIndex_L } \\
\text { 003_R1_00 } \\
\text { 1_contig_2 } \\
4056\end{array}$ & 4 & 506 & 517 & 12 & 3 & 8 & $\begin{array}{l}\text { GAAGCAATAGATTTTTCTCCTAGGGCACACTCCACCACCAGCAGCCT } \\
\text { TTTTTCCTGTTACAAAAAAATTCCATTGTTTTTCTCTATTTCTGCCGT } \\
\text { GGTCTTTTGGGCAATGTACACTCAGTTTACATCTCAACTCATCTTAT } \\
\text { AGCATCTTCAGACAGACAGATCCGCTATAAAAGACACATAATAAGT } \\
\text { TACGCCTGAAAAGTTGCAGGATTTAAACAATGAGATTTGAAAAAAT } \\
\text { TATGAAACTAGTACTTCCAAAGACAAAATTCTAAAGATTTGAAAAC } \\
\text { TATTTCTAATATAATATCTCTCAACTAATCCA }\end{array}$ & CAGA & $\mathrm{s}$ & 18,31 & 191 & $\begin{array}{l}\text { ATTTCTGCCGTGGTCT } \\
\text { TTTG }\end{array}$ & 60,1 & $\begin{array}{l}\text { CAAATCTTTAGAAT } \\
\text { TTTGTCTTTGGA }\end{array}$ & 59,2 & 45 & 26,9 \\
\hline 624 & BrPe4146 & $\begin{array}{l}\text { Maracuja_ } \\
\text { NoIndex_L } \\
\text { 003_R1_00 } \\
\text { 1_contig_2 } \\
4093\end{array}$ & 4 & 2653 & 2664 & 12 & 3 & 8 & $\begin{array}{l}\text { CAATTGGTTTTTATTATGCTCATATTTATGTCTATTACTTAATGAGAT } \\
\text { TGCTATTATCAGTTGAATTTTTCGCGGTCAATCTATTAGTTCAAGT } \\
\text { GACTTATTGTTTTGTGTACGCCGAGTGTGGCGATCTTTCTATTAGTTC } \\
\text { ATGGAGGCCTTCCTTCCTTATTAGTTTCTTTGATTTCAGGCCTTCTCA } \\
\text { ACAGCAGCAGACAACCAGACCCAAGTTGGAATCAAGGTCCTACAAG } \\
\text { GTGAGGGTGAAATGGCATCCGACAACAAGCTCCTGGGAGAATTGA } \\
\text { ACTTGTGGGAATTCCACCAGCTCCAAGGG }\end{array}$ & ССтT & G & 13,5 & 220 & $\begin{array}{l}\text { AGTTGAATTTTTCGCG } \\
\text { GTCA }\end{array}$ & 60,6 & $\begin{array}{l}\text { TTCTCCCAGGAGCT } \\
\text { TGTTGT }\end{array}$ & 59,8 & 40 & 50 \\
\hline 625 & BrPe4147 & $\begin{array}{l}\text { Maracuja_ } \\
\text { NoIndex_L } \\
\text { 003_R1_00 } \\
\text { 1_contig_2 } \\
4288\end{array}$ & 4 & 2293 & 2304 & 12 & 3 & 8 & $\begin{array}{l}\text { CTGCATCTTTATACATCGTTTCCTGGATGATGAATACTCTTGTAGGA } \\
\text { AGTTAATCGCTAATGTGAGCTCTTGCTCACTTAACCCTTTTTCAAAT } \\
\text { CTTGGATTTCATACAGAAGTACAACTTTTAGGCAATTAGCGTTCAGT } \\
\text { TTTCACAAGTTTGTTTGTTTTATCCTATAACCATATTGGACAGTTGTG } \\
\text { TTCTCGTAGCTGGTAGATCTGCTTCAGCGGGTGCTCCGTAAGACACA } \\
\text { TTTACTGCTGTTATCTAACACGGAGATGACTACAAAGAATAAACTTC } \\
\text { CTGTTGGATGCCTTAACCACATCATGAT }\end{array}$ & GTTT & $\mathrm{s}$ & 18,52 & 249 & $\begin{array}{l}\text { TCGCTAATGTGAGCT } \\
\text { CTTGC }\end{array}$ & 59,3 & $\begin{array}{l}\text { GGTTAAGGCATCCA } \\
\text { ACAGGA }\end{array}$ & 59,9 & 50 & 50 \\
\hline
\end{tabular}

G: genoma funcional

S: genoma estructural

P: polimórfico

M: monomórfico 
APÉNDICE

Marcadores microssatélites desenhados a partir do sequênciamento parcial e da montagem de novo do genoma de $P$. edulis

\begin{tabular}{|c|c|c|c|c|c|c|c|c|c|c|c|c|c|c|c|c|c|c|c|}
\hline $\mathbf{N}^{\circ}$ & Primer & Contig I & Motivo & Início & Fim & pb & $\begin{array}{c}\mathbf{N}^{\circ} \\
\text { Repet }\end{array}$ & Score & Sequência do contig & Unidade & G/S & Cobertura & pb & Sequência Forward & $\begin{array}{l}\mathrm{T}^{\circ} \mathrm{C} \\
F w d \\
\end{array}$ & Sequência Reverse & $\begin{array}{l}\mathrm{T}^{\circ} \mathrm{C} \\
\operatorname{Rev} \\
\end{array}$ & $\begin{array}{c}\% \mathrm{GC} \\
F w d \\
\end{array}$ & $\begin{array}{cc}\% \mathrm{GC} & \mathrm{P} / \mathrm{M} \\
\operatorname{Rev} & \end{array}$ \\
\hline 626 & BrPe4148 & $\begin{array}{l}\text { Maracuja_ } \\
\text { NoIndex_L } \\
003 \text { R1_00 } \\
\text { 1_contig_2 } \\
4476\end{array}$ & 4 & 2980 & 2991 & 12 & 3 & 8 & $\begin{array}{l}\text { AAGTTAGCATTTGTTCATTAATAAGAGCATAGGACTATATAGCTAGT } \\
\text { TAGATCATGTAAGTGGGAAGCAACCCCCAGTCGATCCCAGGCTTTT } \\
\text { CTTCTTTTTGACATTCTCTCTGTGTGCGGGGAAAGTAATAGCCCGAA } \\
\text { GAAGAGGAATTACATACATACAAGGGGAATTAGCAATTCCTTGTAT } \\
\text { AGGGAGGTCTTTGTACATCTTTTTGTACATGTGCAACAGCCACCTCT } \\
\text { AAGAGGGTTCCTTAATACAAATTGTTTGCAGTACATGTTCTGTTCTC } \\
\text { CAAATGGTTCATTACAGACTTGGTCTCCAAGC }\end{array}$ & TACA & $\bar{G}$ & 16,2 & 159 & $\begin{array}{l}\text { AGTCGATCCCAGGCT } \\
\text { TTTCT }\end{array}$ & 60,2 & $\begin{array}{l}\text { TAGAGGTGGCTGTT } \\
\text { GCACAT }\end{array}$ & 59,3 & 50 & 50 \\
\hline 627 & BrPe4149 & $\begin{array}{l}\text { Maracuja_ } \\
\text { NoIndex_L } \\
\text { 003_R1_00 } \\
\text { 1_contig_2 } \\
4817\end{array}$ & 4 & 167 & 178 & 12 & 3 & 8 & $\begin{array}{l}\text { TTCGTACTGCTCAGGTGGATAGCATAAGTAGAACTGTAAGCCTCTGT } \\
\text { CAAGATGCTCTATCTCAACTGAGGATCACTGGGTACACAAACCCTTT } \\
\text { CTCAGAATACGAGGATACCATCATCTCGTATCCGGTATTCTGCTACG } \\
\text { GTGCTATCATTGCTTGCTTGCACCTTCTCCTTATCTTACTCAACACT } \\
\text { GGGTCCTCTGCTTGCTTAGCTCAAATCTCATCAAGTAATAATGGCCT } \\
\text { TGCCACAATACGAGCTATTAGCATCCCACAATCATTGGTATCCAATG } \\
\text { ATACTCTTGATGTCT }\end{array}$ & TTGC & G & 100,82 & 150 & $\begin{array}{l}\text { CGGTATTCTGCTACG } \\
\text { GTGCT }\end{array}$ & 60,3 & $\begin{array}{l}\text { TACCAATGATTGTG } \\
\text { GGATGC }\end{array}$ & 59,2 & 55 & 45 \\
\hline 628 & BrPe4150 & $\begin{array}{l}\text { Maracuja_ } \\
\text { NoIndex_L } \\
\text { 003_R1_00 } \\
\text { 1_contig_2 } \\
4981\end{array}$ & 4 & 2497 & 2508 & 12 & 3 & 8 & $\begin{array}{l}\text { ATTTTCGTTTGTATTCCTGTTTATTTCATGTTTGCTTCCTCTCCTTCTT } \\
\text { TGCAGGCTGGATACTACTGTTCCGTCTGTGAGTGTGTGGTAAAGGAC } \\
\text { TCTGCGAACTACTTGGATCACATCAATGGAAAGAAACGTATGTGGT } \\
\text { TGTTCCAATGTTTGTTTGTTGATTGAATTTACATCTTCGTCTTGAGTT } \\
\text { GCATCCGTGATCATGCTCCAAACTGTTTTTCTTAGATCAAAGGGCT } \\
\text { TTGGGGATGTCTATGCGTGCAGAGCGGGCATCTCTTCAGCAGGTATA } \\
\text { TTCTTTTCTTTTTTTAACCATCATCTCT }\end{array}$ & TGTT & $\mathrm{s}$ & 16,04 & 186 & $\begin{array}{l}\text { TCCGTCTGTGAGTGT } \\
\text { GTGGT }\end{array}$ & 60,2 & $\begin{array}{l}\text { ACGCATAGACATCC } \\
\text { CCAAAG }\end{array}$ & 60 & 55 & 50 \\
\hline 629 & BrPe4151 & $\begin{array}{l}\text { Maracuja_ } \\
\text { NoIndex_L } \\
\text { 003_R1_00 } \\
\text { 1_contig_2 } \\
\text { 5146 }\end{array}$ & 4 & 551 & 562 & 12 & 3 & 8 & $\begin{array}{l}\text { TCCTAACATTGATGGTCGAGAATTCAGATTAATTTGCAATTTGTCAA } \\
\text { TTTGGTGTATTATCTTTTTTTTTTTTGAAAAAAAATTGCTGAATTCAC } \\
\text { AGTTTAATTTGCAATTATATTCGTCATGTTTAGCCAGATTTATAAAG } \\
\text { TTTCGATGTAAATAAATAAACTATAAATATACAAACGCAAGGAAAAT } \\
\text { GCCATAACAAAAACTATATAGAAACAAAAAGCATAAGAGACATATC } \\
\text { AGGGTGTGATTATATTTGATAAGATATATAAATTACTTGATTTCGGG } \\
\text { ATTCTCAATTAAATAACTATAGGGATTATTA }\end{array}$ & TAAA & $\mathrm{s}$ & 17,45 & 175 & $\begin{array}{l}\text { TTCGTCATGTTTAGCC } \\
\text { AGATTT }\end{array}$ & 58,8 & $\begin{array}{l}\text { TTGAGAATCCCGAA } \\
\text { ATCAAGT }\end{array}$ & 58,8 & 36,4 & 38,1 \\
\hline 630 & BrPe4152 & $\begin{array}{l}\text { Maracuja_ } \\
\text { NoIndex_L } \\
\text { 003_R1_00 } \\
\text { 1_contig_2 } \\
\text { 5201 }\end{array}$ & 4 & 275 & 286 & 12 & 3 & 8 & $\begin{array}{l}\text { CATGACAACCTCGGGTGACTCAACCCGACTCTTGGGTTTACAAATAT } \\
\text { AAAAATCAAACCAAAGGACCGAATCAGGTCCAACTCGGGTATAGGT } \\
\text { TTCACAATAACTCCTTAACCCTGAATTAAAATCTATTCATTGTTCTTG } \\
\text { AATAAATTCTCTTTCTTTCTTCTCCACATACTTATTCTGAGCCTCCTT } \\
\text { AGAACAGAATCTAAAAGAGTCAAAATCTTCACTGCTGGAAGAAGAA } \\
\text { GCTCTGCTATGTCTATGTGCAGCCATTGTGGTTGCTTCAACAGCATG } \\
\text { CCTTTCCAAGAGCAATTTATCCAAAGAGCA }\end{array}$ & Тстт & G & 32,34 & 186 & $\begin{array}{l}\text { ATGACAACCTCGGGT } \\
\text { GACTC }\end{array}$ & 60,0 & $\begin{array}{l}\text { GGAGGCTCAGAATA } \\
\text { AGTATGTGG }\end{array}$ & 59,2 & 55 & 47,8 \\
\hline
\end{tabular}

G: genoma funcional

S: genoma estructural

P: polimórfico

M: monomórfico 
APÉNDICE

Marcadores microssatélites desenhados a partir do sequênciamento parcial e da montagem de novo do genoma de $P$. edulis

\begin{tabular}{|c|c|c|c|c|c|c|c|c|c|c|c|c|c|c|c|c|c|c|c|}
\hline $\mathbf{N}^{\circ}$ & Primer & Contig I & Motivo & Início & Fim & pb & $\begin{array}{c}\mathbf{N}^{\circ} \\
\text { Repet }\end{array}$ & Score & Sequência do contig & Unidade & G/S & Cobertura & pb & Sequência Forward & $\begin{array}{l}\mathrm{T}^{\circ} \mathrm{C} \\
F w d \\
\end{array}$ & Sequência Reverse & $\begin{array}{l}\mathrm{T}^{\circ} \mathrm{C} \\
\operatorname{Rev} \\
\end{array}$ & $\begin{array}{c}\% \mathrm{GC} \\
F w d \\
\end{array}$ & $\begin{array}{cc}\% \mathrm{GC} & \mathrm{P} / \mathrm{M} \\
\operatorname{Rev} & \end{array}$ \\
\hline 631 & BrPe4153 & $\begin{array}{l}\text { Maracuja_ } \\
\text { NoIndex_L } \\
\text { 003_R1_00 } \\
\text { 1_contig_2 } \\
\text { 5398 }\end{array}$ & 4 & 3315 & 3326 & 12 & 3 & 8 & $\begin{array}{l}\text { ATGGACTCATCACATAACAACATTGTTGTTTTTTGGATTTGGCCTTTT } \\
\text { GTCCTTGTGGGAGGGATTCAAAGACGAAGGGTATTGGATTTTATCTT } \\
\text { ATCACTATTCTTTGTTTATTTCCTTTCTATTCATCTACTGGCTTCAGAT } \\
\text { TCTGGAATTTATTTATTTTTTCCACGTTCAGGGAGGCTGAAGAATTG } \\
\text { GCTGAAGTTGAAGCAAAACTGGTTTGTATCAGTTGTACTTAACCTTT } \\
\text { GCTTTGAAGTGGAGTCTGGTTTCACTCTGCCCTTGTTTTATTTCTAGG } \\
\text { ATGCTGATTTAAAAGCAAACGAGGGA }\end{array}$ & ATTT & $\mathrm{G}$ & 17,15 & 241 & $\begin{array}{l}\text { TTTGGATTTGGCCTTT } \\
\text { TGTC }\end{array}$ & 59,9 & $\begin{array}{l}\text { AAGGGCAGAGTGAA } \\
\text { ACCAGA }\end{array}$ & 59,8 & 40 & 50 \\
\hline 632 & BrPe4154 & $\begin{array}{l}\text { Maracuja_ } \\
\text { NoIndex_L } \\
\text { 003_R1_00 } \\
\text { 1_contig_2 } \\
\text { 5462 }\end{array}$ & 4 & 268 & 279 & 12 & 3 & 8 & $\begin{array}{l}\text { ATGATGCATTTATATAATAGGCTTTTTGAAAAGAAAGATAATCTTAC } \\
\text { ACAAGCAAATAATGGTGCAGATGTTTATCACAGGACAGGAATGATC } \\
\text { AGCTTGACCTGTTAAAGAGTCGTACCTGTCAGGTGTGGGTCTCTTTC } \\
\text { CTAACCGTCCTATGTATGTATGCATGGTGCTATACTTTGACAATAAA } \\
\text { ACCTAAAGATAACAAACTCGATCCAATAAAAGAAATTTGCATTTTA } \\
\text { TATCCCCATAATTAAGTACTGTCTTGACGATTCCTGGTCACATGGTA } \\
\text { TCTTTACAACTGTTGAAGCTCTCTATTATTGA }\end{array}$ & TATG & G & 38,94 & 158 & $\begin{array}{l}\text { TCAGGTGTGGGTCTC } \\
\text { TTTCC }\end{array}$ & 60,1 & $\begin{array}{l}\text { ACCATGTGACCAGG } \\
\text { AATCGT }\end{array}$ & 60,2 & 55 & 50 \\
\hline 633 & BrPe4155 & $\begin{array}{l}\text { Maracuja_ } \\
\text { NoIndex_L } \\
\text { 003_R1_00 } \\
\text { 1_contig_2 } \\
\text { 5701 }\end{array}$ & 4 & 2954 & 2965 & 12 & 3 & 8 & $\begin{array}{l}\text { TGTCATGGAATTGAAGATTACCGAGTCTGCAGTGTAGGGGCAGCAG } \\
\text { TAGTAGTAGTACAAAGGAGAAACAAAATGACTGTTTTTCTTTCTTTC } \\
\text { TGCAGCTTGTGGTAATTGCAGGAACTTTATGGAACCCACCTACATCC } \\
\text { TGCGCGTATGTTCTTTCTTTCTAACTTTTTTGTTTCTAATTGTGACAA } \\
\text { TGACATCATTTCCAACTGTATGAGTTGTTGAAGATAAGTTACAAAGC } \\
\text { AAATGAATACTTATAGTGTTTTCCCGTATCAATTCTACGAAGGTCAT } \\
\text { CAATGTTCAACCATTCTTTTAGGATAGCCG }\end{array}$ & ТTCT & $\mathrm{s}$ & 16,99 & 201 & $\begin{array}{l}\text { GCAGCTTGTGGTAAT } \\
\text { TGCAG }\end{array}$ & 59,5 & $\begin{array}{l}\text { TGGTTGAACATTGA } \\
\text { TGACCTTC }\end{array}$ & 59,8 & 50 & 40,9 \\
\hline 634 & BrPe4156 & $\begin{array}{l}\text { Maracuja_ } \\
\text { NoIndex_L } \\
\text { 003_R1_00 } \\
\text { 1_contig_2 } \\
\text { 5806 }\end{array}$ & 4 & 2318 & 2329 & 12 & 3 & 8 & $\begin{array}{l}\text { TGATTGGAAATGGTTTCTCAATTCTTTTGTTATTTCTGTTGGCCTGAT } \\
\text { GACTGCTCTTCATTTTCATTGTTTTAGGCTATATGTACTGTTTTGACG } \\
\text { GCTTCTGATTACTGATTCAGTTGCAGTTTTCTCGTGGCCTTTAGTTTG } \\
\text { GTTATCTGTTTGTTTGTTCTATTGACGATTATCAGACTTGTATCAGAG } \\
\text { AAGTTTTCCTATTTTGCTTACTAATTTTCTGGCTATGAATTGTATTCT } \\
\text { GTTGGTTCTTAATTGAGGGATCTCTATGGTGTTTGGTGCATACATGG } \\
\text { TACTGTAGAACATGAGGTTCTTTT }\end{array}$ & TGTT & $\mathrm{s}$ & 16,42 & 162 & $\begin{array}{l}\text { TCTCGTGGCCTTTAGT } \\
\text { TTGG }\end{array}$ & 60,2 & $\begin{array}{l}\text { CCATGTATGCACCA } \\
\text { AACACC }\end{array}$ & 59,7 & 50 & 50 \\
\hline 635 & BrPe4157 & $\begin{array}{l}\text { Maracuja_ } \\
\text { NoIndex_L } \\
\text { 003_R1_00 } \\
\text { 1_contig_2 } \\
5899\end{array}$ & 4 & 8094 & 8105 & 12 & 3 & 8 & $\begin{array}{l}\text { CTTATCCAGGAAGCTCCAATCTGCCCTTCTCTTCCAACAATTGATTG } \\
\text { CAAACTAGGCGGTTCATCCTTAATCCTAGAGGAAAAGGGACCCAAA } \\
\text { TGTGCAGCAGATTCAGACAGGCGCATTTGAGAAAATGCCTGAAAGA } \\
\text { GAAATGTAAACATAAATAAATAAGTAAAAGAACCAGCTTCTAATAG } \\
\text { TATTGTTCATAAATTGAACAAGGTAATAGCAACAACTGACTTCAAAT } \\
\text { TTTAACACACCAAAAAGATAAGGAGTACTGATAGATGATGCAGTAA } \\
\text { ATCAATGAATGTGTACCACAAAATATCTGATTCT }\end{array}$ & ATAA & G & 17,4 & 170 & $\begin{array}{l}\text { GGCGGTTCATCCTTA } \\
\text { ATCCT }\end{array}$ & 60,3 & $\begin{array}{l}\text { TCAGTTGTTGCTATT } \\
\text { ACCTTGTTCA }\end{array}$ & 60,1 & 50 & 36 \\
\hline
\end{tabular}

G: genoma funcional

S: genoma estructural

P: polimórfico

M: monomórfico 
APÉNDICE

Marcadores microssatélites desenhados a partir do sequênciamento parcial e da montagem de novo do genoma de $P$. edulis

\begin{tabular}{|c|c|c|c|c|c|c|c|c|c|c|c|c|c|c|c|c|c|c|c|}
\hline $\mathbf{N}^{\circ}$ & Primer & Contig I & Motivo & Início & Fim & pb & $\begin{array}{c}\mathbf{N}^{\circ} \\
\text { Repet }\end{array}$ & Score & Sequência do contig & Unidade & G/S & Cobertura & pb & Sequência Forward & $\begin{array}{l}\mathrm{T}^{\circ} \mathrm{C} \\
F w d \\
\end{array}$ & Sequência Reverse & $\begin{array}{r}\mathrm{T}^{\circ} \mathrm{C} \\
\operatorname{Rev} \\
\end{array}$ & $\begin{array}{c}\% \mathrm{GC} \\
F w d \\
\end{array}$ & $\begin{array}{c}\% \mathrm{GC} \\
\operatorname{Rev}\end{array} \quad \mathrm{P} / \mathrm{M}$ \\
\hline 636 & BrPe4158 & $\begin{array}{l}\text { Maracuja_ } \\
\text { NoIndex_L } \\
\text { 003_R1_00 } \\
\text { 1_contig_2 } \\
6605\end{array}$ & 4 & 3660 & 3671 & 12 & 3 & 8 & $\begin{array}{l}\text { CCTCTTTACTTTTTTTGGACATTTGGTTTGTGCAAAGCTGGCAACCAC } \\
\text { CATAAAAACATTCCTCCTTGGGCAGATCCATGTGCACTCAGAAACT } \\
\text { GTCCTTGGAGGCTACGATGTTGAAATCCTAGTTTTAATGTACATTAG } \\
\text { ATGGACAGCAAAGAAAGAAAGTGTTATGATGCAAAATAACACTTTG } \\
\text { AGAAAAAGCAGTGCCTTGATCCATAAAGGTTTTGTCAGAGTGGGT } \\
\text { TTTGTGGATTGAGCTGTTTCAATATTTCTTGACAAGGCATGCAACAT } \\
\text { AAATAACCTCGGTTAGCAGTTACTTGTCTCTT }\end{array}$ & AAAG & $\mathrm{s}$ & 17,27 & 187 & $\begin{array}{l}\text { ACTGTCCTTGGAGGC } \\
\text { TACGA }\end{array}$ & 59,9 & $\begin{array}{l}\text { GTTGCATGCCTTGTC } \\
\text { AAGAA }\end{array}$ & 59,8 & 55 & 45 \\
\hline 637 & BrPe4159 & $\begin{array}{l}\text { Maracuja_ } \\
\text { NoIndex_L } \\
\text { 003_R1_00 } \\
\text { 1_contig_2 } \\
6705\end{array}$ & 4 & 983 & 994 & 12 & 3 & 8 & $\begin{array}{l}\text { CACTTACTCCCAGGCTACCCTACTCATACATGTTGCGATTAATATTTT } \\
\text { CCTGTTGTTTTAATCAAGATTCTAAGCAACGATGATAAGTTTCTGAT } \\
\text { TGAGGATCAACCTTCTTTTGTGTTATAACTGTCAATTCCAGGAGCTC } \\
\text { TGTTTGGGGTTTGTTTGTTTTATGACATTGATTGTGTGTTGCTTGGTC } \\
\text { TGTAGAACCATGATACAGAACATGATTAAGGAGGGAAAGATTGTGC } \\
\text { CTTCAGAGGTAACAATAAAGCTTCTTCAGAAAGCAATGCAGGAAAG } \\
\text { CGGCAATGACAAATTTCTTATCGATGGCTT }\end{array}$ & GTTT & $\mathrm{s}$ & 17,65 & 232 & $\begin{array}{l}\text { CTCCCAGGCTACCCT } \\
\text { ACTCA }\end{array}$ & 59,3 & $\begin{array}{l}\text { AGGCACAATCTTTC } \\
\text { ССТCCT }\end{array}$ & 60 & 60 & 50 \\
\hline 638 & BrPe4160 & $\begin{array}{l}\text { Maracuja_ } \\
\text { NoIndex_L } \\
\text { 003_R1_00 } \\
\text { 1_contig_2 } \\
6928\end{array}$ & 4 & 2334 & 2345 & 12 & 3 & 8 & $\begin{array}{l}\text { TCAGAGTTAACAGCACTGTTGTCGTTTAAGCCTCTTGGTTAATTTTA } \\
\text { ATAGTTCACTTCAGCTTTCCAGAATGAGTTTTCTTTTTTCTTTTTTTCA } \\
\text { GAACATGCCTCTTTTATTCTGGAAAACACATTCATCAGACAAACACC } \\
\text { AAATATTTCAGTCAGTCAGGCATGGAGGTAAAGGGCATCCATATTG } \\
\text { AGCGAATACAGACTCAGAAAACATCAAAAAAAAAAAAACAGAAGA } \\
\text { CTGTTTCGCATCTGTTCATCCTGGAGATTGACTTTCTCCTCGATGGAA } \\
\text { ACAGAACCAGCAACTTTAAAGTTGAATCTG }\end{array}$ & TCAG & G & 17,93 & 113 & $\begin{array}{l}\text { GAACATGCCTCTTTTA } \\
\text { TTCTGGA }\end{array}$ & 59,6 & $\begin{array}{l}\text { TTTCTGAGTCTGTAT } \\
\text { TCGCTCAA }\end{array}$ & 59,2 & 39,1 & 39,1 \\
\hline 639 & BrPe4161 & $\begin{array}{l}\text { Maracuja_ } \\
\text { NoIndex_L } \\
\text { 003_R1_00 } \\
\text { 1_contig_2 } \\
\text { 7565 }\end{array}$ & 4 & 182 & 193 & 12 & 3 & 8 & $\begin{array}{l}\text { GTGGCCGTGGACTGACCCAGCGGGCCCCTCAAGAATGTTATCAAGT } \\
\text { TGGAAGCTATCCCATAATACGCAAACCTCTCCGCAACTTCCACACCT } \\
\text { TAACTCAAAAAACCCACATGCACATCACAACCCAAAAGCACCATTA } \\
\text { ACCGTTAGCATCAACCAACCAACATCAAGAAAAAAGTACAACCCCA } \\
\text { CACAACGATTTCCACCACCTGAAACAAGTCATCGATTCGGACAAAG } \\
\text { AACAGGAAAAGCAACAGTCTTTCACCGTTCAACAGACATGAAAGAG } \\
\text { GGACTAACTCTGTCAACAACCTATTACTTGTCTAA }\end{array}$ & CAAC & G & 12,16 & 175 & $\begin{array}{l}\text { GGGCCCCTCAAGAAT } \\
\text { GTTAT }\end{array}$ & 60,2 & $\begin{array}{l}\text { AAATCGTTGTGTGG } \\
\text { GGTTGT }\end{array}$ & 60,1 & 50 & 45 \\
\hline 640 & BrPe4162 & $\begin{array}{l}\text { Maracuja_ } \\
\text { NoIndex_L } \\
\text { 003_R1_00 } \\
\text { 1_contig_2 } \\
7934\end{array}$ & 4 & 1276 & 1287 & 12 & 3 & 8 & $\begin{array}{l}\text { AGTCAAGTTTTGCATTGTAAAGAGAAAAACCAAGTAGGATTGATAG } \\
\text { ACAAAGAAAAAGTTTAGAATTTAGAAAAAGAAAATAACATTTGTAT } \\
\text { CAGTCTGCAAGACAAGAAACAAACCTTGATAGTTGTAATGAACCCT } \\
\text { AATTTACAAAACAGAAAGAAAGAATACTGGTAGAGAAATGGGTCC } \\
\text { AACCTGACCAGGCATGACTTCACCATTAATGCCGCTGATGTTGATAC } \\
\text { CAGCGTACAAACAGGCTTTGTAGTGGGAGTCCACGATATCTCGACC } \\
\text { GAAGGCTTTGTCAGCCCCTGTACCGCAGTAGTATGG }\end{array}$ & AGAA & $\mathrm{s}$ & 14,87 & 191 & $\begin{array}{l}\text { TCTGCAAGACAAGAA } \\
\text { ACAAACC }\end{array}$ & 59,4 & $\begin{array}{l}\text { CAAAGCCTTCGGTC } \\
\text { GAGATA }\end{array}$ & 60,3 & 40,9 & 50 \\
\hline
\end{tabular}

G: genoma funcional

S: genoma estructural

P: polimórfico

M: monomórfico 
APÉNDICE

Marcadores microssatélites desenhados a partir do sequênciamento parcial e da montagem de novo do genoma de $P$. edulis

\begin{tabular}{|c|c|c|c|c|c|c|c|c|c|c|c|c|c|c|c|c|c|c|c|}
\hline $\mathbf{N}^{\mathbf{o}}$ & Primer & Contig I & Motivo & Início & Fim & pb & $\begin{array}{c}\mathbf{N}^{\mathbf{o}} \\
\text { Repet }\end{array}$ & Score & Sequência do contig & Unidade & G/S & Cobertura & pb & Sequência Forward & $\begin{array}{l}\mathrm{T}^{\circ} \mathrm{C} \\
F w d\end{array}$ & Sequência Reverse & $\begin{array}{r}\mathrm{T}^{\circ} \mathrm{C} \\
\operatorname{Rev}\end{array}$ & $\begin{array}{r}\% \mathrm{GC} \\
F w d\end{array}$ & $\begin{array}{c}\% \mathrm{GC} \\
\operatorname{Rev}\end{array}$ \\
\hline 641 & $\overline{B r P e 4163}$ & $\begin{array}{l}\text { Maracuja_ } \\
\text { NoIndex_L } \\
\text { 003_R1_00 } \\
\text { 1_contig_2 } \\
\text { 8518 }\end{array}$ & 4 & 6475 & 6486 & 12 & 3 & 8 & $\begin{array}{l}\text { ACAGAACCCAGGAGGACAGCATTGCACAAGTTGGATCAAGACATGT } \\
\text { TTGTCCCTTGTGTAATGGATGCTTCATACAGGGTCCCAGCCACACAC } \\
\text { TAGAAATTTCTGTGTCATAGTGCACGAAGCAGACATGGATGCAGAC } \\
\text { AACAGCTCTATGCTAGCTAGCTAACTGATCAACTGTTGCATCTCCGG } \\
\text { CGATTTCTGCTGTTACATGCTGTGTATGACTAATCTCTGTTATTCTTC } \\
\text { TTCAGTTCCTGTGTAAAGTAGAGAAGCTTTGGATCGAGGATTTAGAG } \\
\text { ACAGCAGTATGAATATATAATCGCAGTGTTT }\end{array}$ & GCTA & $\mathrm{s}$ & 15,18 & 156 & $\begin{array}{l}\text { GAAGCAGACATGGAT } \\
\text { GCAGA }\end{array}$ & 60,0 & $\begin{array}{l}\text { TCCTCGATCCAAAG } \\
\text { CTTCTC }\end{array}$ & 59,5 & 50 & 50 \\
\hline 642 & BrPe4164 & $\begin{array}{l}\text { Maracuja_ } \\
\text { NoIndex_L } \\
\text { 003_R1_00 } \\
\text { 1_contig_2 } \\
8611\end{array}$ & 4 & 599 & 618 & 20 & 5 & 16 & $\begin{array}{l}\text { AGTGGTGTCTTGTCAATAAACAAACAAGGTTATTTAGCACAACACA } \\
\text { TTTCTGAGCTCGAAGTTATGAAAGCAACCTCATGTTGGTGGATTCAG } \\
\text { TTGTCTGGGACTGCTGGAAATGCTCTTTAAGATCAACCCCGCATTTA } \\
\text { GAATAGGTATTTGATTGATTGATTGATTGAGATTTCTAATCCTTTTTT } \\
\text { CTTTGTGTTTCTTGCCATTGGACGAGTCAATCATCTTACTCCAAGCTT } \\
\text { CCACACAACCAACTTTCACAATGGTGGATGAGATTTCTGTTGACCAA } \\
\text { AGGAAAAAGTGGGACTGAGATTTCTTGCATGCCATTA }\end{array}$ & TTGA & G & 16,36 & 194 & $\begin{array}{l}\text { GATCAACCCCGCATT } \\
\text { TAGAA }\end{array}$ & 59,9 & $\begin{array}{l}\text { TGGCATGCAAGAAA } \\
\text { TCTCAG }\end{array}$ & 59,9 & 45 & 45 \\
\hline 643 & BrPe4165 & $\begin{array}{l}\text { Maracuja_ } \\
\text { NoIndex_L } \\
\text { 003_R1_00 } \\
\text { 1_contig_2 } \\
9038\end{array}$ & 4 & 1841 & 1852 & 12 & 3 & 8 & $\begin{array}{l}\text { ATTTCTCAGCATATACCTACAGATTATGCAATGCTTAGCTTGTTTATT } \\
\text { GACAGCCATACCCTTACGGTTTACCAAATGTTATTTCAATACCTTGA } \\
\text { ATGCAGGATCCTCAAAAAGAACACCATCTGTAGGTAATACAAGCAA } \\
\text { GTCTTCATCCTTTCTTTCTTTAATATCCTGTATCCACGAACAAAAACA } \\
\text { TCATACAAGGTAAAAGGAGATTTGTTCAGATAGAAAGCATCTGGCT } \\
\text { TTTACGACCGACCTTAAAGTAGGAGTTATCAAACTTCAGCCACTCTG } \\
\text { CTGTCCAGGACTGCCCTCCTGGCGCTCCAG }\end{array}$ & сттт & G & 15,3 & 203 & $\begin{array}{l}\text { TGAATGCAGGATCCT } \\
\text { CAAAA }\end{array}$ & 59,2 & $\begin{array}{l}\text { CAGTCCTGGACAGC } \\
\text { AGAGTG }\end{array}$ & 59,6 & 40 & 50 \\
\hline 644 & BrPe4166 & $\begin{array}{l}\text { Maracuja_ } \\
\text { NoIndex_L } \\
\text { 003_R1_00 } \\
\text { 1_contig_3 } \\
0081\end{array}$ & 4 & 412 & 423 & 12 & 3 & 8 & $\begin{array}{l}\text { TTCTCCATATTCTTAGAGAGATTATGTTACTTTAGTGAAAGAAATCT } \\
\text { TGCTTTCTGGTAAAGTTCTGCTTACACGTAAGGTTTTGAAGTTAAAA } \\
\text { AAAAAGGGTTCCTACTGTTTGGGAACCATCTATTGGTTAAATTAGCA } \\
\text { CCTCTTTTTTCCCTCCCTCCCCTGCTTTTTAGCTTTCATTTTGTAGTTA } \\
\text { GCTTGTATGCTCTCTTGATCTATCAGTTTAGTGATGAAAACTGACAG } \\
\text { TTTTAAAGCGCATACCAGCACTATTTTTTCTTCTCTAATTATGTCCTA } \\
\text { GCTTTTCTAGTTAGCCTTTTAGATGTC }\end{array}$ & TCCC & $\mathrm{s}$ & 15,19 & 153 & $\begin{array}{l}\text { TGTTTGGGAACCATC } \\
\text { TATTGG }\end{array}$ & 59,7 & $\begin{array}{l}\text { AATAGTGCTGGTAT } \\
\text { GCGCTTT }\end{array}$ & 58,9 & 42,9 & 42,9 \\
\hline 645 & BrPe4167 & $\begin{array}{l}\text { Maracuja_ } \\
\text { NoIndex_L } \\
\text { 003_R1_00 } \\
\text { 1_contig_3 } \\
0310\end{array}$ & 4 & 2770 & 2781 & 12 & 3 & 8 & $\begin{array}{l}\text { ATCAGAACTTCTGACTCTTTATTTCTCCAAACCTTTTATTTGATAAGG } \\
\text { TCTAAAGGTGAGGCCAAAGCAATGTTTTTGCGGCATGAAGGATTTCT } \\
\text { TGGAGCGTTAGGTGCCTTTGCAAGCTATGAAAAGCACAACCCTGAT } \\
\text { AGCTTCGTCATCAATCAATCACAGCAACTCCCAGTCGTCAACTCTTC } \\
\text { CAACGCGGCTGAGATGGATTATAACAAGCTAAATGGCGGTCTTCAT } \\
\text { TGAATGACGGCGGCCAAGTTAGTCCAGACAAGTTTGTGTTAATACTC } \\
\text { TTTATCATAGGTAAGACTCATCGTGTCCAAA }\end{array}$ & ATCA & G & 16,3 & 153 & $\begin{array}{l}\text { GGCATGAAGGATTTC } \\
\text { TTGGA }\end{array}$ & 60,0 & $\begin{array}{l}\text { GAAGACCGCCATTT } \\
\text { AGCTTG }\end{array}$ & 59,8 & 45 & 50 \\
\hline
\end{tabular}

G: genoma funcional

S: genoma estructural

P: polimórfico

M: monomórfico 
APÉNDICE

Marcadores microssatélites desenhados a partir do sequênciamento parcial e da montagem de novo do genoma de $P$. edulis

\begin{tabular}{|c|c|c|c|c|c|c|c|c|c|c|c|c|c|c|c|c|c|c|c|}
\hline $\mathbf{N}^{\circ}$ & Primer & Contig $\mathrm{I}$ & Motivo & Início & Fim & pb & $\begin{array}{c}\mathbf{N}^{\circ} \\
\text { Repet }\end{array}$ & Score & Sequência do contig & Unidade & G/S & Cobertura & pb & Sequência Forward & $\begin{array}{l}\mathrm{T}^{\circ} \mathrm{C} \\
F w d\end{array}$ & Sequência Reverse & $\begin{array}{r}\mathrm{T}^{\circ} \mathrm{C} \\
\operatorname{Rev}\end{array}$ & $\begin{array}{r}\% \mathrm{GC} \\
F w d\end{array}$ & $\begin{array}{c}\% \mathrm{GC} \\
\operatorname{Rev}\end{array} \quad \mathrm{P} / \mathbf{M}$ \\
\hline 646 & BrPe4168 & $\begin{array}{l}\text { Maracuja_ } \\
\text { NoIndex_L } \\
\text { 003_R1_00 } \\
\text { 1_contig_3 } \\
0398\end{array}$ & 4 & 4292 & 4303 & 12 & 3 & 8 & $\begin{array}{l}\text { TGCCTCTAGGATGAGGGAAGAGATTGAATTCAAAAAGCAACGAGAG } \\
\text { AGAGAAAGGGAAGCTGCTCGGTCTGCTATTGAGAAGGTTTGTACAG } \\
\text { TAAATTCATGAATCTGAGGACGTCCATGTACCTTGACGATTCCTTTT } \\
\text { CCATTCTTGTTTTGGTTGGTTGGACAAAGATGACAGTAGTCTCACGT } \\
\text { GTTGGTCTTGGCTGCAGATGGAAAAAACTGCAAACATCGAGTTGAA } \\
\text { CTTGGATGTTCTAAAAGAACTAGAAAAGCTTTGCGGATGCTCCTTAA } \\
\text { CCTATAATGTATGGAGGAAGGATGTGAAGAGGG }\end{array}$ & TTGG & $\mathrm{s}$ & 15,78 & 158 & $\begin{array}{l}\text { CCTTGACGATTCCTTT } \\
\text { TCCA }\end{array}$ & 60,0 & $\begin{array}{l}\text { GTTAAGGAGCATCC } \\
\text { GCAAAG }\end{array}$ & 59,8 & 45 & 50 \\
\hline 647 & BrPe4169 & $\begin{array}{l}\text { Maracuja_ } \\
\text { NoIndex_L } \\
\text { 003_R1_00 } \\
\text { 1_contig_3 } \\
0589\end{array}$ & 4 & 1964 & 1975 & 12 & 3 & 8 & $\begin{array}{l}\text { ACATGTGATTTCAAGGCATAGGAAACAAAGAAGCCTCACTCACGTT } \\
\text { AAAAGAATTACTCGATGCTTGAACTCTTTGAACAGCCTTTAAAGCGA } \\
\text { GCAAGCCGCCATCATCGTGACCAACAAGCACCACTGAAGAGAACCC } \\
\text { CATCTCAGCACAGAAAGAAAGAAGCAGGTCAACCTGAAATTACCAA } \\
\text { ATAAAATTCAAGGATAAAGAGCTATAAAAGCAAATGTCGTTCCCCC } \\
\text { AAGAGAAAGGATAGAGTGAAAAATGCAAAACCAGTTCAAGGAGAT } \\
\text { ACTACATACGGAGCTAAGATGATACGCAAAGTCAGA }\end{array}$ & AGAA & G & 16,92 & 166 & $\begin{array}{l}\text { ACAGCCTTTAAAGCG } \\
\text { AGCAA }\end{array}$ & 60,2 & $\begin{array}{l}\text { ATCCTTTCTCTTGGG } \\
\text { GGAAC }\end{array}$ & 59,4 & 45 & 50 \\
\hline 648 & BrPe4170 & $\begin{array}{l}\text { Maracuja_ } \\
\text { NoIndex_L } \\
\text { 003_R1_00 } \\
\text { 1_contig_3 } \\
0752\end{array}$ & 4 & 316 & 327 & 12 & 3 & 8 & $\begin{array}{l}\text { TGGAGGAGCAACCTGGTTCAGCTGTTATGACTTGCCAAACGCTGCA } \\
\text { GGTTGAGGTCTCGCTTAAGGATGTCAAACAATCAGGGGAGGATAAG } \\
\text { ATCAAGAAAATCTCTCTTGGTCAAGAAAAGTCTGATGTGATTCCAGT } \\
\text { TCGGGAAAAGAAGGGAGGGAGGGGAACATGGGCGGACTTGTTCAA } \\
\text { CAACAGGAGGAAGAACCCAATGAGTGAACTGTGTTGTATTCCTCCG } \\
\text { ATCATTAAAGATGGGCATCGTATAGGAAGGTACTCTTCGAGTGACT } \\
\text { CTGCTCTTCTTGCTGAACAATGGAAGAATACTCTGA }\end{array}$ & AGGG & G & 14,16 & 201 & $\begin{array}{l}\text { AGCAACCTGGTTCAG } \\
\text { CTGTT }\end{array}$ & 59,9 & $\begin{array}{l}\text { TCATTGGGTTCTTCC } \\
\text { TCCTG }\end{array}$ & 60 & 50 & 50 \\
\hline 649 & BrPe4171 & $\begin{array}{l}\text { Maracuja_ } \\
\text { NoIndex_L } \\
\text { 003_R1_00 } \\
\text { 1_contig_3 } \\
1560\end{array}$ & 4 & 2508 & 2519 & 12 & 3 & 8 & $\begin{array}{l}\text { AGGCTTGTAAGTAAAGGTTGCAAGTTGGTTGGATGTGGCTCGGCTAT } \\
\text { ACCAAATCTTCAGATTTCAAATGATGACCTTGCAAAAATTGTTGATA } \\
\text { CTAACGATGAGTGGATATCTGTTCGCACTGGCATCGGAATCGTCGA } \\
\text { ATTCTTACAGGTTGGTTGGTTCTTGCAGAGCACCTTACTGTTGTATAT } \\
\text { CATATCGCACCGAACTTTCTGGATGTCTCAGCTTGTTTGAGCTCAAC } \\
\text { TGTGCAACCATTGCATTGAAAACTGACTTCTTTCTTAGTGAAGAGCA } \\
\text { TTCATCTTGATTTCTTTGTTTTAGTGGGA }\end{array}$ & GGTT & G & 017 & 238 & $\begin{array}{l}\text { AAAGGTTGCAAGTTG } \\
\text { GTTGG }\end{array}$ & 60,0 & $\begin{array}{l}\text { GCAATGGTTGCACA } \\
\text { GTTGAG }\end{array}$ & 60,3 & 45 & 50 \\
\hline 650 & BrPe4172 & $\begin{array}{l}\text { Maracuja_ } \\
\text { NoIndex_L } \\
\text { 003_R1_00 } \\
\text { 1_conti__3 } \\
1680\end{array}$ & 4 & 916 & 927 & 12 & 3 & 8 & $\begin{array}{l}\text { TTAATCAACAGAAAACCACATAGAAATTGAACTTGGCAAAAAAGTT } \\
\text { AAGATTCACCACATACAGGGAATGAAAAATATAGCACAACTTTCCA } \\
\text { CTCCTCCCATGATAGTGATGTTACCTGAAATACATTAGTTCCTTGTA } \\
\text { ATGTGGTGAAGAAATAAATAAATTACGCAATAAAAATCACATGGGA } \\
\text { TGGCAAGGACAGAAAACTACTTACAGAGAAAAGAACAGACAGCGG } \\
\text { ATGAATGTACAAAATCAATATGTGAAGAAGCATGGTCAGGATGATT } \\
\text { GAACCAACAAGCCATAAGTTACTCCAGGGATTGATA }\end{array}$ & АAAT & G & 16,33 & 198 & $\begin{array}{l}\text { АСТTTCСАСТССТСCC } \\
\text { ATGA }\end{array}$ & 59,5 & $\begin{array}{l}\text { TGGTTCAATCATCCT } \\
\text { GACCA }\end{array}$ & 59,9 & 50 & 45 \\
\hline
\end{tabular}

G: genoma funcional

S: genoma estructural

P: polimórfico

M: monomórfico 
APÉNDICE

Marcadores microssatélites desenhados a partir do sequênciamento parcial e da montagem de novo do genoma de $P$. edulis

\begin{tabular}{|c|c|c|c|c|c|c|c|c|c|c|c|c|c|c|c|c|c|c|c|}
\hline $\mathbf{N}^{\circ}$ & Primer & Contig I & Motivo & Início & Fim & pb & $\begin{array}{c}\mathbf{N}^{\circ} \\
\text { Repet }\end{array}$ & Score & Sequência do contig & Unidade & G/S & Cobertura & $\mathrm{pb}$ & Sequência Forward & $\begin{array}{l}\mathrm{T}^{\circ} \mathrm{C} \\
F w d \\
\end{array}$ & Sequência Reverse & $\begin{array}{l}\mathrm{T}^{\circ} \mathrm{C} \\
\operatorname{Rev} \\
\end{array}$ & $\begin{array}{c}\% \mathrm{GC} \\
F w d \\
\end{array}$ & $\begin{array}{c}\% \mathrm{GC} \\
\operatorname{Rev}\end{array} \quad \mathrm{P} / \mathrm{M}$ \\
\hline 651 & BrPe4173 & $\begin{array}{l}\text { Maracuja_ } \\
\text { NoIndex_L } \\
\text { 003_R1_00 } \\
\text { 1_contig_3 } \\
1909\end{array}$ & 4 & 328 & 339 & 12 & 3 & 8 & $\begin{array}{l}\text { TTCTAGGGATGACGTGTGTAAAGTGATTTCTAGTATGGGCAGTTTCA } \\
\text { AAGCTCCGGGATTAGATGGTCTACAGCCAGTCTTTTTCCAAAGTCAA } \\
\text { TGAAGTATAGTGGGCGAATCAGTAACTAAAGTGGTGAGTGACTTTA } \\
\text { TGAACACCGGCTTCCTTCCTTCGGGATTGAATGACACTCTGATTACT } \\
\text { TTGATTCCAAAAGTGAAGGCTCCGGAGAATTTTTCACAGTTCAGGCC } \\
\text { GATTAGCTTGTGCAATGTAGTCTATAAGGCAATTACTAAACTGATTG } \\
\text { CGAATAGACTGAGGCCGGCAATGAACCACTG }\end{array}$ & СТTC & $\mathrm{s}$ & 14,12 & 188 & $\begin{array}{l}\text { AAGCTCCGGGATTAG } \\
\text { ATGGT }\end{array}$ & 59,9 & $\begin{array}{l}\text { CGGCCTGAACTGTG } \\
\text { AAAAAT }\end{array}$ & 60,1 & 50 & 45 \\
\hline 652 & BrPe4174 & $\begin{array}{l}\text { Maracuja_ } \\
\text { NoIndex_L } \\
003 \text { R1_00 } \\
\text { 1_contig_3 } \\
2227\end{array}$ & 4 & 329 & 340 & 12 & 3 & 8 & $\begin{array}{l}\text { TCTAAACTACGTTTCAATTTCAAATGCATGAGATAAAATTTGAAACA } \\
\text { TATCATAAGTTTAATAACTCCTTGCCGTCGTCTCTCACGTATGATAA } \\
\text { AATATTAATATTTGACATATTATTTAACAAAGGAGGTTACGATTGAA } \\
\text { TTTATAGTAAAATAAATAAATGTGTATATTCAATTAGTTGTTTCCTTT } \\
\text { CAATCAATATTTAATGGATATTCAGATTAAAAAAATAATTTAATGGA } \\
\text { TATCGCAAAGAACAAAAGGAGTTCTAATATTACATACACGAAGCCA } \\
\text { GTCGAAAGCGAGCCATAGCCGTACAAATAT }\end{array}$ & AAAT & $\mathrm{s}$ & 16,26 & 227 & $\begin{array}{l}\text { TAACTCCTTGCCGTC } \\
\text { GTCTC }\end{array}$ & 60,4 & $\begin{array}{l}\text { TTCGACTGGCTTCGT } \\
\text { GTATG }\end{array}$ & 59,9 & 55 & 50 \\
\hline 653 & BrPe4175 & $\begin{array}{l}\text { Maracuja_ } \\
\text { NoIndex_L } \\
\text { 003_R1_00 } \\
\text { 1_contig_3 } \\
\text { 2317 }\end{array}$ & 4 & 865 & 876 & 12 & 3 & 8 & $\begin{array}{l}\text { AGTAAATTAAAGTTGCTCTTATTGTACTTGTGCGACGTACTTGTTCA } \\
\text { CCTACCTACAACACTTTTGCACCTTAATAATAATGATCACTACCAAT } \\
\text { TTCTCTGCTGCTAATCCCCATTAATACCACAGTAATGAATTAAACAA } \\
\text { CCAAATAACCATACATACATAACAAGCAATGCTACAACGATTCATC } \\
\text { CTCACAAAACATCACGAGTATTCGGAGTGAAAGAACCTGGGAAATG } \\
\text { GCCACACTTGGAGCATCATACAGAAGCTAAAACCATGTGAGAATGG } \\
\text { GGAGAGCACCAGCTGGCTCTGTCGAAAATCTAC }\end{array}$ & CATA & $\mathrm{s}$ & 18,69 & 186 & $\begin{array}{l}\text { СTCTGCTGCTAATCCC } \\
\text { CATT }\end{array}$ & 59,3 & $\begin{array}{l}\text { TCCCCATTCTCACAT } \\
\text { GGTTT }\end{array}$ & 60,2 & 50 & 45 \\
\hline 654 & BrPe4176 & $\begin{array}{l}\text { Maracuja_ } \\
\text { NoIndex_L } \\
\text { 003_R1_00 } \\
\text { 1_contig_3 } \\
\text { 3065 }\end{array}$ & 4 & 760 & 771 & 12 & 3 & 8 & $\begin{array}{l}\text { GTCCTACATAAAGAGTGATATTTCTCCATAAATACCATAATTTCGTA } \\
\text { GCCATTGACTTGCTTTTTGCTTCTTTTCTAATCATTTCATCCTGGGGA } \\
\text { AATGTTGGACTCCAATGTCTTTAATAGACAAAAGTTGGTCCTTGAAA } \\
\text { GAACTTGATGAGTGAGTGAGCATTAAGACTGCATGTGTGTCTTTTTG } \\
\text { GTGTATTATATATGTGGTTTGATCACTTACCTTCCAAATAAGTAAGC } \\
\text { TGATATCAAACTGCCCGCCATTATAAGAAGATGTTGGCGAGATGGC } \\
\text { GGCCTCAATTGCGATTTTATTGTTTGTTTG }\end{array}$ & TGAG & $\mathrm{s}$ & 15,93 & 234 & $\begin{array}{l}\text { GCCATTGACTTGCTTT } \\
\text { TTGC }\end{array}$ & 60,8 & $\begin{array}{l}\text { CCATCTCGCCAACA } \\
\text { TCTTCT }\end{array}$ & 60,2 & 45 & 50 \\
\hline 655 & BrPe4177 & $\begin{array}{l}\text { Maracuja_ } \\
\text { NoIndex_L } \\
003 \text { 181_00 } \\
\text { 1_conti__3 } \\
3123\end{array}$ & 4 & 1662 & 1673 & 12 & 3 & 8 & $\begin{array}{l}\text { TCAAAATGCAAACAACTGCTATGACTGTCACAGAAGAAGGCACATC } \\
\text { TAGGTCAGCTCATTAATCACATTCACTAACACCCCGAATTGTGTAGT } \\
\text { TATTCTCGTCTATTAGTTGCAAACACTGAGGCTCAATAAATAATCT } \\
\text { CACTCCATCTTAAATAAATAAAAGCAAAAGTACATCTTTGGACTCGT } \\
\text { AAGGGTCCACAGTTACCGAATCAAAGTTACCGCATTAGTCTAGACA } \\
\text { CATATTTGCAACAATGTGGTGGAGGCAGCTTTGAAAAAAAAAATAT } \\
\text { CGTTCAAAATTACTATTTACAAAACTTATAGAA }\end{array}$ & TAAA & $\mathrm{s}$ & 14,45 & 187 & $\begin{array}{l}\text { CACTAACACCCCGAA } \\
\text { TTGTG }\end{array}$ & 58,9 & $\begin{array}{l}\text { TCCACCACATTGTT } \\
\text { GCAAAT }\end{array}$ & 59,8 & 50 & 40 \\
\hline
\end{tabular}

G: genoma funcional

S: genoma estructural

P: polimórfico

M: monomórfico 
APÉNDICE

Marcadores microssatélites desenhados a partir do sequênciamento parcial e da montagem de novo do genoma de $P$. edulis

\begin{tabular}{|c|c|c|c|c|c|c|c|c|c|c|c|c|c|c|c|c|c|c|c|}
\hline $\mathbf{N}^{\circ}$ & Primer & Contig I & Motivo & Início & Fim & pb & $\begin{array}{c}\mathbf{N}^{\circ} \\
\text { Repet }\end{array}$ & Score & Sequência do contig & Unidade & G/S & Cobertura & $\mathrm{pb}$ & Sequência Forward & $\begin{array}{l}\mathrm{T}^{\circ} \mathrm{C} \\
F w d \\
\end{array}$ & Sequência Reverse & $\begin{array}{l}\mathrm{T}^{\circ} \mathrm{C} \\
\operatorname{Rev} \\
\end{array}$ & $\begin{array}{c}\% \mathrm{GC} \\
F w d \\
\end{array}$ & $\begin{array}{c}\% \mathrm{GC} \\
\operatorname{Rev}\end{array} \quad \mathrm{P} / \mathrm{M}$ \\
\hline 656 & BrPe4178 & $\begin{array}{l}\text { Maracuja_ } \\
\text { NoIndex_L } \\
\text { 003_R1_00 } \\
\text { 1_contig_3 } \\
\text { 3201 }\end{array}$ & 4 & 1813 & 1824 & 12 & 3 & 8 & $\begin{array}{l}\text { CAATACAATTCAGAAGAAATTCATGGTTGCTAGTATTGTGTTGAAAA } \\
\text { TAGATGAAGCTTTTACTGTCATTAACTCCTAGACCCGAGGTGCTATG } \\
\text { GAAACTATCCAATACTTTCCTGATCCAGGCTAGAGAAGGACCATCA } \\
\text { GCCTTTGCAAAAATAAATAAATCATCTGCGAAGCTGAGGTGAATAA } \\
\text { GTTTTTTACTGGAACAACCAGAGTGATATTTAAAATAACTAGGAACC } \\
\text { TTAGCCAGACATCTTAAAAGGTACTCAACATCAAGGAAAAATAGAA } \\
\text { GAGGAGAGACATGATCACCCTGTCTCAATCCTC }\end{array}$ & AAAT & $\mathrm{s}$ & 17,25 & 224 & $\begin{array}{l}\text { CTAGACCCGAGGTGC } \\
\text { TATGG }\end{array}$ & 59,7 & $\begin{array}{l}\text { GGGTGATCATGTCT } \\
\text { CTCCTCTT }\end{array}$ & 59,6 & 60 & 50 \\
\hline 657 & BrPe4179 & $\begin{array}{l}\text { Maracuja_ } \\
\text { NoIndex_L } \\
\text { 003_R1_00 } \\
\text { 1_contig_3 } \\
3537\end{array}$ & 4 & 153 & 164 & 12 & 3 & 8 & $\begin{array}{l}\text { CCATCAGCTATGCTACCTTCGAAAGCATCCCAGTAAATCTGGTATGC } \\
\text { CGGAAATATTGCTTTTAGGACAGTGACACTTGTCACGTATCTCCAAC } \\
\text { CCATATCTTTGTTTCTCTTTCCAACATGCAGCAGTTCAACACCAACT } \\
\text { ACATTCATCAAACAAACAAAAGAATGGAAAATTCGTGGACTCAAAT } \\
\text { AGAAACCAATATGTTCATTTCGCCATTCAAACATAGGCTTATTGTG } \\
\text { CACAAGAGGCAAACACCCCTAGGCAAACTCACCCACATACGGATAA } \\
\text { AAAAGGAATGCTAACACAAGGTGATTAGTGA }\end{array}$ & CAAA & $\mathrm{s}$ & 21,33 & 157 & $\begin{array}{l}\text { TCTTTTCCAACATGCA } \\
\text { GCAG }\end{array}$ & 60,0 & $\begin{array}{l}\text { TGAGTTTGCCTAGG } \\
\text { GGTGTT }\end{array}$ & 59,6 & 45 & 50 \\
\hline 658 & BrPe4180 & $\begin{array}{l}\text { Maracuja_ } \\
\text { NoIndex_L } \\
\text { 003_R1_00 } \\
\text { 1_contig_3 } \\
\text { 3794 }\end{array}$ & 4 & 1148 & 1159 & 12 & 3 & 8 & $\begin{array}{l}\text { CTGAGAGAGGTTTACGGTCTCTTGCTGTGGCATACCAGGTAAATCCA } \\
\text { ATCTTCTTTCCATTTCTTTTGGTATATTTGAATATTATTTGTCATGTG } \\
\text { AACCACTAACTGTCTTGTTGCTCTTGTTGGGTATCTCCTTTATGCAGG } \\
\text { AAGTTCCGGAAGGAAGGAAAGAAAGTGCTGGACGTCCATGGCAGTT } \\
\text { TATTGGCCTGATGCCTCTTTTTGATCCTCCTAGGCATGACAGCGCCG } \\
\text { AGACAATAAGGAGGGCCTTGAATCTTGGAGTTAATGTTAAGATGAT } \\
\text { TACAGGTTGGCTATGTCTTCCAGTTGGAAG }\end{array}$ & GGAA & G & 16,37 & 198 & $\begin{array}{l}\text { TTTACGGTCTCTTGCT } \\
\text { GTGG }\end{array}$ & 58,9 & $\begin{array}{l}\text { AAGAGGCATCAGGC } \\
\text { CAATAA }\end{array}$ & 59,7 & 50 & 45 \\
\hline 659 & BrPe4181 & $\begin{array}{l}\text { Maracuja_ } \\
\text { NoIndex_L } \\
003 \text { R1_00 } \\
\text { 1_contig_3 } \\
4177\end{array}$ & 4 & 9992 & 10003 & 12 & 3 & 8 & $\begin{array}{l}\text { CAAACTTAGCTGGGTCTGGCAATTCAGCGTCCTGTCCTGTGAGCTCT } \\
\text { TGTACTAGGGCTCGAAACTGGGAGGCGCTTGTCTTGAACTTCATGGG } \\
\text { ATTAGATATGTACACAACTTTCGTAGGATGTTTCTTGGTTTTCGCCCT } \\
\text { TTTTGTACTCTTTCTTTCTTGCAAACTGCTACCTACTAGATCATCCAT } \\
\text { GTACCTGAAAGAAAGACAGGAAAGATCGGAATCACAAACGAATGC } \\
\text { TGGCTAGCGCTCTCAAGTTCACATAAAAAATGATGACTGTGGAAAG } \\
\text { TTTGAGGACAGGATGGATCTAAAGGCTGCAA }\end{array}$ & ТСТТ & G & 17,87 & 150 & $\begin{array}{l}\text { GCTCTTGTACTAGGG } \\
\text { CTCGAAA }\end{array}$ & 60,0 & $\begin{array}{l}\text { ACATGGATGATCTA } \\
\text { GTAGGTAGCA }\end{array}$ & 57 & 50 & 41,7 \\
\hline 660 & BrPe4182 & $\begin{array}{l}\text { Maracuja_ } \\
\text { NoIndex_L } \\
\text { 003_R1_00 } \\
\text { 1_conti__3 } \\
4365\end{array}$ & 4 & 1866 & 1877 & 12 & 3 & 8 & $\begin{array}{l}\text { TTTTATTAACCTAAATGACAGCAAAACCCTCATAACACCTGATCACT } \\
\text { TCTCAGGCCCAATTTGCTTTGCTCAAACCAAACAATCATACAGCCTT } \\
\text { CAAGCAAAAAATTCAAAACAAGAAGCACAGCTCTCAAATGATAAA } \\
\text { GTATTGATGATGGAAGGAAGGAAAAATCAGAAATGGGAGAAGCTA } \\
\text { CATACATTATCAGGTCCTCATGGTAGCAATGACCATAAGGTTCCTGT } \\
\text { GTTTGTCATGTTGCCTCTTGATACTGTCACATTTGGGGGTAATTTGA } \\
\text { ACAAGCCAAGAGCAATGAATGCTAGCTTGATGGC }\end{array}$ & GGAA & G & 17,7 & 172 & $\begin{array}{l}\text { CCAAACAATCATACA } \\
\text { GCCTTCA }\end{array}$ & 60,0 & $\begin{array}{l}\text { GGCAACATGACAAA } \\
\text { CACAGG }\end{array}$ & 60 & 40,9 & 50 \\
\hline
\end{tabular}

G: genoma funcional

S: genoma estructural

P: polimórfico

M: monomórfico 
APÉNDICE

Marcadores microssatélites desenhados a partir do sequênciamento parcial e da montagem de novo do genoma de $P$. edulis

\begin{tabular}{|c|c|c|c|c|c|c|c|c|c|c|c|c|c|c|c|c|c|c|c|}
\hline $\mathbf{N}^{\circ}$ & Primer & Contig M & Motivo & Início & Fim & pb & $\begin{array}{c}\mathrm{N}^{\mathbf{o}} \\
\text { Repet }\end{array}$ & Score & Sequência do contig & Unidade & G/S & Cobertura & pb & Sequência Forward & $\begin{array}{l}\mathrm{T}^{\circ} \mathrm{C} \\
F w d \\
\end{array}$ & Sequência Reverse & $\begin{array}{l}\mathrm{T}^{\circ} \mathrm{C} \\
\operatorname{Rev} \\
\end{array}$ & $\begin{array}{c}\% \mathrm{GC} \\
F w d \\
\end{array}$ & $\begin{array}{cc}\% \mathrm{GC} & \mathrm{P} / \mathrm{M} \\
\operatorname{Rev} & \end{array}$ \\
\hline 661 & BrPe4183 & $\begin{array}{l}\text { Maracuja_ } \\
\text { NoIndex_L } \\
\text { 003_R1_00 } \\
\text { 1_contig_3 } \\
4960\end{array}$ & 4 & 913 & 924 & 12 & 3 & 8 & $\begin{array}{l}\text { AAGAAACCAGAAACAGACAACCAAAATTTTGATTAGCCGAAGAACT } \\
\text { ACTGAGTGTTAATAATTTGGTAAATCAGACAATACCAATGGCCCTA } \\
\text { GCAAGATTCAGACTGCCGTTAACACGCCCTGCATGTATAAAACCAC } \\
\text { CAGCTTTCAATATTCTTTCTTTCTCGACCTCAAGATCAGGTTTATGAT } \\
\text { CTCTGGAAAGATTGTATGCCTGCATCGAAAGAAGCATTGCTAAAGG } \\
\text { AAGGAAATAAATATTAGCATAATACACACAGAAAACTGATATCGTC } \\
\text { TGTTACAACCATATATATGTGAATCTGCATTCAT }\end{array}$ & TTCT & $\mathrm{G}$ & 16,7 & $\begin{array}{r}151 \mathrm{~A} \\
\mathrm{~A}\end{array}$ & $\begin{array}{l}\text { AATACCAATGGCCCT } \\
\text { AGCAA }\end{array}$ & 59,4 & $\begin{array}{l}\text { AGCAATGCTTCTTTC } \\
\text { GATGC }\end{array}$ & 60,5 & 45 & 45 \\
\hline 662 & BrPe4184 & $\begin{array}{l}\text { Maracuja_ } \\
\text { NoIndex_L } \\
\text { 003_R1_00 } \\
\text { 1_contig_3 } \\
5676\end{array}$ & 4 & 1189 & 1200 & 12 & 3 & 8 & $\begin{array}{l}\text { GTGCGCAGCAGCACTAATGGATGTACCCTGACATTTCTGCATGTAAT } \\
\text { GACTCCAATGAACAGATTTAATCCAGAACTCGCCCTTAAGAAACTC } \\
\text { AGAGGAAAGAGGATGCTGTTTGTAGGAGATTCGCTTCAAAGGGGTC } \\
\text { AATGGCAATCCTTTGTTTGTTTGGTGGAATGGATCATTCCTGAAGAC } \\
\text { AAGAAGTCCATGAAAAGGGGCCGTTCTCATTCAGTCTTCAGAGCTA } \\
\text { AGGTATAACCAGCTACTCAACTTGACAGGAGAAAAAGTTTCCAACC } \\
\text { AAACTCAACCAATTCTTGAAACTAACCATTCTCT }\end{array}$ & TTTG & G & 15,72 & $212 \mathrm{C}$ & $\begin{array}{l}\text { CCAGAACTCGCCCTT } \\
\text { AAGAA }\end{array}$ & 59,4 & $\begin{array}{l}\text { TTGGTTGAGTTTGGT } \\
\text { TGGAA }\end{array}$ & 59 & 50 & 40 \\
\hline 663 & BrPe4185 & $\begin{array}{l}\text { Maracuja_ } \\
\text { NoIndex_L } \\
\text { 003_R1_00 } \\
\text { 1_contig_3 } \\
5968\end{array}$ & 4 & 367 & 378 & 12 & 3 & 8 & $\begin{array}{l}\text { CAAGATGACCAAAGTATATGGCTTCTTTGAATGTGTGAGATATTTCT } \\
\text { TTGCTTTTCCCTTGATGAATGGATGACCGACCACAATGTCACCTTCA } \\
\text { TCAACTCCCTCACTAAATTGTTAAAACCAAGAGGGGGAACCACCAA } \\
\text { GCCAGATGAGCAATCAATCAATAGGAAAGGGGATAGTATAGGGAG } \\
\text { GTGAGAAATGAGTGTTTAAGCTTAGCAAATGTGCAAAAATGAATAA } \\
\text { AGATTCTTTGGTTGACTATTCATTCACCCGTAATTGTTTGAAAACA } \\
\text { TTGATGAACCGAATGGATAATGAAATGCATAACC }\end{array}$ & CAAT & $\mathrm{s}$ & 19,35 & $208 \mathrm{~A}$ & $\begin{array}{l}\text { AATGGATGACCGACC } \\
\text { ACAAT }\end{array}$ & 60,1 & $\begin{array}{l}\text { CAAACAATTACGGG } \\
\text { TGGAATG }\end{array}$ & 60,1 & 45 & 42,9 \\
\hline 664 & BrPe4186 & $\begin{array}{l}\text { Maracuja_ } \\
\text { NoIndex_L } \\
\text { 003_R1_00 } \\
\text { 1_contig_3 } \\
6594\end{array}$ & 4 & 702 & 713 & 12 & 3 & 8 & $\begin{array}{l}\text { CAGAACATAATTGTGCGCTTAAGGGATCATAGAATGCAATTTCCTG } \\
\text { AGAGATTCGGGAGCTATCAGTTGGTTGAATGGAACATTCAGCCTCA } \\
\text { GAGAAAGTCGTATGTGTTTCTAGCCCTCCTTTTTGTCTCCCCAACAC } \\
\text { CTTCCCTCACCATTTATTTATTTTTCTTTTGATAATCATATGATGGGT } \\
\text { TCCCTAGCTTCGTTGTCTTCAATTCCCTTCATAGGGAAACTCAACAT } \\
\text { CTTTTCTGAGTGCCAGGGAATGTTTAAAGTGCTGTCGCCAGAGATAC } \\
\text { ATGCATATTTTCATCCTTCGCGCAACTTATG }\end{array}$ & ATTT & $\mathrm{s}$ & 14,72 & $159 \mathrm{~T}$ & $\begin{array}{l}\text { TTTGTCTCCCCAACAC } \\
\text { CTTC }\end{array}$ & 59,9 & $\begin{array}{l}\text { TGTATCTCTGGCGA } \\
\text { CAGCAC }\end{array}$ & 60 & 50 & 55 \\
\hline 665 & BrPe4187 & $\begin{array}{l}\text { Maracuja_ } \\
\text { NoIndex_L } \\
\text { 003_R1_00 } \\
\text { 1_contig_3 } \\
6628\end{array}$ & 4 & 201 & 212 & 12 & 3 & 8 & $\begin{array}{l}\text { CAGGCAGAGGGAGGTAGAGGTGTTTGACACGGAGGAGGAACTTGC } \\
\text { GGTGTCTCTCGCCAAATACACTGCCGATTGTCTGATAAGTTTGCCA } \\
\text { CAGAAAGAGGCTATTTTTCTGTGGTTTTGTCTGGTGGGTCTCTCGTG } \\
\text { AAGTCGCTCAGGTGAGTGAGTGAAACAAAAACCCTCTGATGAGTTG } \\
\text { ATTACATTAAAGTATCATTCTTCAGTTAAATTTGGTCATGTTTTGATA } \\
\text { TCGGAATTTCGTTTTGTTTGTTTTCATTAGGAACTGGTAGAACCGC } \\
\text { CTTATGTTGATCAGATAGAATGGTCCAAGTGG }\end{array}$ & GTGA & $\mathrm{s}$ & 14,27 & $226 \mathrm{C}$ & $\begin{array}{l}\text { GCCAAATACACTGCC } \\
\text { GATTT }\end{array}$ & 60,0 & $\begin{array}{l}\text { GGCGGTTCTACCAG } \\
\text { TTTCCT }\end{array}$ & 60,5 & 45 & 55 \\
\hline
\end{tabular}

G: genoma funcional

S: genoma estructural

P: polimórfico

M: monomórfico 
APÉNDICE

Marcadores microssatélites desenhados a partir do sequênciamento parcial e da montagem de novo do genoma de $P$. edulis

\begin{tabular}{|c|c|c|c|c|c|c|c|c|c|c|c|c|c|c|c|c|c|c|c|}
\hline $\mathbf{N}^{\circ}$ & Primer & Contig I & Motivo & Início & Fim & pb & $\begin{array}{c}\mathbf{N}^{\circ} \\
\text { Repet }\end{array}$ & Score & Sequência do contig & Unidade & G/S & Cobertura & pb & Sequência Forward & $\begin{array}{l}\mathrm{T}^{\circ} \mathrm{C} \\
F w d \\
\end{array}$ & Sequência Reverse & $\begin{array}{l}\mathrm{T}^{\circ} \mathrm{C} \\
\operatorname{Rev} \\
\end{array}$ & $\begin{array}{c}\% \mathrm{GC} \\
F w d \\
\end{array}$ & $\begin{array}{c}\% \mathrm{GC} \\
\operatorname{Rev}\end{array} \quad \mathrm{P} / \mathrm{M}$ \\
\hline 666 & BrPe4188 & $\begin{array}{l}\text { Maracuja_ } \\
\text { NoIndex_L } \\
\text { 003_R1_00 } \\
\text { 1_contig_3 } \\
\text { 6791 }\end{array}$ & 4 & 2237 & 2248 & 12 & 3 & 8 & $\begin{array}{l}\text { GCAACATCAGTATCTCATATTCCCGTATTTCTCTGGCTGATGTAGCC } \\
\text { AAGAAGCTGAGATTGGATTCTGCAAACCCCGTTGCTGATGCGGAGA } \\
\text { GCATTGTAGCCAAGGCAATTCGAGATGGTGCTATAGATGCAACGTT } \\
\text { GGATCATGCAAATGGATGGATGGTATCAAAGGAGACGGGGGACATT } \\
\text { TACTCCACAAATGAACCTCAGGTTGCGTTCAACTCTAGGATTGCATT } \\
\text { TTGTCTTAACATGCA }\end{array}$ & ATGG & G & 12,57 & 155 & $\begin{array}{l}\text { GGCTGATGTAGCCAA } \\
\text { GAAGC }\end{array}$ & 60,0 & $\begin{array}{l}\text { AGTAAATGTCCCCC } \\
\text { GTCTCC }\end{array}$ & 60,2 & 55 & 55 \\
\hline 667 & BrPe4189 & $\begin{array}{l}\text { Maracuja_ } \\
\text { NoIndex_L } \\
\text { 003_R1_00 } \\
\text { 1_contig_3 } \\
6845\end{array}$ & 4 & 1197 & 1208 & 12 & 3 & 8 & $\begin{array}{l}\text { TACCATGTGATAAATCAGGTCTAGTACATAGCATGAGGTACATAAC } \\
\text { AGATCCAATTATTTCACAGTAGGGTACATGGGACATATCTACAATTT } \\
\text { CACTCTCAGAATTAGGAAAACAGTCGGCAGTGAATTTCATATGAGC } \\
\text { AGGTATAGGAAGGTTGGTTGGTTTTGATTTATCCATAAAAAATTGTT } \\
\text { CAAGCACCTTCCTTGCATATTCAGATTGAGATAAAGAAAGAATACC } \\
\text { TTCAGATCTGTCTCTAAAAACCCTTATACCAAGGATCTTTCTAACAG } \\
\text { GCCCTAAGTCTTTCATGGAAAAGG }\end{array}$ & GGTT & $\mathrm{s}$ & 49,77 & 150 & $\begin{array}{l}\text { TCACAGTAGGGTACA } \\
\text { TGGGACA }\end{array}$ & 60,3 & $\begin{array}{l}\text { TGAATATGCAAGGA } \\
\text { AGGTGCT }\end{array}$ & 59,7 & 50 & 42,9 \\
\hline 668 & BrPe4190 & $\begin{array}{l}\text { Maracuja_ } \\
\text { NoIndex_L } \\
\text { 003_R1_00 } \\
\text { 1_contig_3 } \\
7507\end{array}$ & 4 & 5635 & 5646 & 12 & 3 & 8 & $\begin{array}{l}\text { CAAGACACTAAAGAACAAACAGGTTAATGACGAACAACTTAAACC } \\
\text { ACAAACAACCACAACTGGCAGCCAATTACCTCTCCAAAAGTCTCAT } \\
\text { TGTGGTTGCCTCATCCAAGACATCCTTACAATCACTAAGGAATGCTC } \\
\text { GAAACTCTTGAATGATTGATTGATATTCAGAACTATGACTCTCTGTA } \\
\text { GCACCATCTTCTTCTAAAAGCAGCCGATTTATCTAAAATACCACCAA } \\
\text { TGAAACCAAATTAACCTTTTCCAATCTACAGCGCAGCATCAATTCTT } \\
\text { TATGACCTCTAGCAACGAGTCTTACCTAATAAC }\end{array}$ & TGAT & G & 19,34 & 151 & $\begin{array}{l}\text { AAACCACAAACAACC } \\
\text { ACAACTG }\end{array}$ & 59,8 & $\begin{array}{l}\text { TGGTGCTACAGAGA } \\
\text { GTCATAGTTC }\end{array}$ & 57,7 & 40,9 & 45,8 \\
\hline 669 & BrPe4191 & $\begin{array}{l}\text { Maracuja_ } \\
\text { NoIndex_L } \\
\text { 003_R1_00 } \\
\text { 1_contig_3 } \\
7949\end{array}$ & 4 & 1801 & 1812 & 12 & 3 & 8 & $\begin{array}{l}\text { GATAGGAGGACCAGTTGCCATGCTTTGCTTCGTAATTATCTCCTACA } \\
\text { TTTCTGTCCTTCTATCAGATTGCTACAGATCTCCTGACCCTGTCACCG } \\
\text { GGAAGCGAAACTACATTACATGCATGCTGTTAGAGCCTATATTGGTT } \\
\text { ACCAACCACTATCTATCTATTTTTCTTCGTTAACTTTGGGCTCGATTG } \\
\text { GTGATTTTGAAAGTTTATGTTTCGTGGATTTTGTGTTCGCGGTAATGC } \\
\text { TTGTAGAACATTTTTGGGTCATTGGACCATTTTATCTTTCGATTTTCA } \\
\text { GATCGGTTTTCGTGTATTAGGCTCTG }\end{array}$ & СТАТ & $\mathrm{s}$ & 19,49 & 250 & $\begin{array}{l}\text { GCCATGCTTTGCTTCG } \\
\text { TAAT }\end{array}$ & 60,2 & $\begin{array}{l}\text { GGTCCAATGACCCA } \\
\text { AAAATG }\end{array}$ & 60 & 45 & 45 \\
\hline 670 & BrPe4192 & $\begin{array}{l}\text { Maracuja_ } \\
\text { NoIndex_L } \\
\text { 003_R1_00 } \\
\text { 1_conti__3 } \\
8015\end{array}$ & 4 & 1756 & 1767 & 12 & 3 & 8 & $\begin{array}{l}\text { CATCATCAGTGTAAGAAACATTCTCAGGGAAAAGTAGAGAAGCCAT } \\
\text { TCTTCAGTATCTCAAACTCTCCTACAAATTATCTCCCCAAAAAGTTC } \\
\text { AGTGTGAAGAAGACCACTCCTCTCTACTCTTTATTTATAGCACCTGT } \\
\text { GCTTAATACTACTCACTCACTCTACTTAAACTTGAAGCATCGGTAGC } \\
\text { AACGCCAATGGATTTCACTTTTAATCTAGACATGGTTTCCTCTTAC } \\
\text { ATTACATTACTGGTGGAGAAAGGAGAAAAAGGACATTAATCAGTAT } \\
\text { CTGTCCACCATTACATGCTACTCACCTGTCCT }\end{array}$ & АСТC & $\mathrm{s}$ & 15,31 & 182 & $\begin{array}{l}\text { CAGGGAAAAGTAGAG } \\
\text { AAGCCATT }\end{array}$ & 60,1 & $\begin{array}{l}\text { AGTGAAATCCATTG } \\
\text { GCGTTG }\end{array}$ & 60,9 & 43,5 & 45 \\
\hline
\end{tabular}

G: genoma funcional

S: genoma estructural

P: polimórfico

M: monomórfico 
APÉNDICE

Marcadores microssatélites desenhados a partir do sequênciamento parcial e da montagem de novo do genoma de $P$. edulis

\begin{tabular}{|c|c|c|c|c|c|c|c|c|c|c|c|c|c|c|c|c|c|c|c|}
\hline $\mathbf{N}^{\circ}$ & Primer & Contig I & Motivo & Início & Fim & pb & $\begin{array}{c}\mathbf{N}^{\circ} \\
\text { Repet }\end{array}$ & Score & Sequência do contig & Unidade & G/S & Cobertura & pb & Sequência Forward & $\begin{array}{l}\mathrm{T}^{\circ} \mathrm{C} \\
F w d \\
\end{array}$ & Sequência Reverse & $\begin{array}{l}\mathrm{T}^{\circ} \mathrm{C} \\
\operatorname{Rev} \\
\end{array}$ & $\begin{array}{c}\% \mathrm{GC} \\
F w d \\
\end{array}$ & $\begin{array}{cc}\% \mathrm{GC} & \mathrm{P} / \mathrm{M} \\
\operatorname{Rev} & \end{array}$ \\
\hline 671 & BrPe4193 & $\begin{array}{l}\text { Maracuja_ } \\
\text { NoIndex_L } \\
\text { 003_R1_00 } \\
\text { 1_contig_3 } \\
8605\end{array}$ & 4 & 308 & 319 & 12 & 3 & 8 & $\begin{array}{l}\text { ACACACACTAGCCGCCACCATCATCTTCTCTCCCTTTCCTCTTACAG } \\
\text { CCAAAATCAACAAGGAGAAAAGTCTCCTTGTTGCATGCATCCCGAG } \\
\text { GCAAGAAGAACAAGAGAAAAGAGTTTTCTCTTGTTCGTGGCTGTCC } \\
\text { CTGTGATACCTGTTCGTTCGTTCTACATCATGTGGATAATAAGAGAG } \\
\text { GCCACTGGTGATTGATCGGGGTTGGATCAACATCAAGAATAGAGGA } \\
\text { GTGAAATCAGTTCTGCGCTTCAAGAGGTAAGAACAAAACCATCTGC } \\
\text { TTTCAGTTTTTGGTTGTGGTCACATGCCTAGTTT }\end{array}$ & GTTC & $\mathrm{G}$ & 540,72 & 187 & $\begin{array}{l}\text { GCCACCATCATCTTCT } \\
\text { CTCC }\end{array}$ & 59,6 & $\begin{array}{l}\text { CAATCACCAGTGGC } \\
\text { СTCTCT }\end{array}$ & 60,3 & 55 & 55 \\
\hline 672 & BrPe4194 & $\begin{array}{l}\text { Maracuja_ } \\
\text { NoIndex_L } \\
\text { 003_R1_00 } \\
\text { 1_contig_3 } \\
\text { 8702 }\end{array}$ & 4 & 854 & 865 & 12 & 3 & 8 & $\begin{array}{l}\text { CTTTTATCTTGAGCGCAGTTTCACGACGTACACCAACTTCGCTTAGT } \\
\text { AAAAATCGAGAGGAGCGAAAAAAAGCAAGTATCTTCTCTTTACAG } \\
\text { AAATGGAGGGACGCCGAACTTCTGCTGCATGTTGTGATTTTATAGTC } \\
\text { ACAGAGGTGTTCCATCCATCCAACACATCCTCTATGTCATAAGCCAC } \\
\text { GGCCTTGAGTTTATCCAACCACCGCTTGACAGTATCCTCCTGCAGTT } \\
\text { GTCTTTTTTCTGCTTGGACAAGCCCGTCTTGGATGGCCTCAAAGTTG } \\
\text { CTGGCAAGCTTTTCGACTTCTCTCTTAACAC }\end{array}$ & TCCA & G & 32,54 & 151 & $\begin{array}{l}\text { CGAACTTCTGCTGCA } \\
\text { TGTTG }\end{array}$ & 60,6 & $\begin{array}{l}\text { GGCTTGTCCAAGCA } \\
\text { GAAAAA }\end{array}$ & 60,4 & 50 & 45 \\
\hline 673 & BrPe4195 & $\begin{array}{l}\text { Maracuja_ } \\
\text { NoIndex_L } \\
\text { 003_R1_00 } \\
\text { 1_contig_3 } \\
8730\end{array}$ & 4 & 193 & 204 & 12 & 3 & 8 & $\begin{array}{l}\text { TGTGACCAAAACATATACAATTAGAACTAGTTGGTCTCAAGGCATT } \\
\text { GGTTGAGACTTTTGGTTCTATATAGGCTTTGTGAATACATGCTGGTA } \\
\text { ACTGTCGCTCTATACATCTGTACAATGTTTGTGCTTTTTGACTGGAA } \\
\text { AATGACAGAGTTTCTTTCTTTCCATACAAAGTAAACAAAGGTGACA } \\
\text { AACAATATTCTTCTGTTCCTGGCTAGTGTGCTCTTTCCACAGCTTTC } \\
\text { CTTGTAAACCAACTCACTTCGCGCCTCCAAGTGCAGGACTCCTCGT } \\
\text { GATACCTACTTTAGGCATTAGCATCTGCCAG }\end{array}$ & TTTC & G & 13,47 & 209 & $\begin{array}{l}\text { GTTGGTCTCAAGGCA } \\
\text { TTGGT }\end{array}$ & 60,0 & $\begin{array}{l}\text { CAAGGAAAGCTGTG } \\
\text { GGAAAG }\end{array}$ & 59,8 & 50 & 50 \\
\hline 674 & BrPe4196 & $\begin{array}{l}\text { Maracuja_ } \\
\text { NoIndex_L } \\
\text { 003_R1_00 } \\
\text { 1_contig_3 } \\
9079\end{array}$ & 4 & 1074 & 1085 & 12 & 3 & 8 & $\begin{array}{l}\text { GACACAATAATAACATATAGAGAGACTAGAAAGTGCTTGGCTTTTG } \\
\text { GCAGCCGGGGATATATGTTTGTTGGAACTTACGTGTGCGCGTTTGTT } \\
\text { GCGTATTGCGGACATGAAGGTAACAATAAAGGGATGCAGCCATTAC } \\
\text { TGGATGCCCTACTAGCTAGCTAGAACCGAGCAGGTCATGGCCAAAT } \\
\text { CGTCAAAGCAACTTTCCTGCTTTTAATGCTTCCTTTCTATGAGCACGT } \\
\text { GCTGGATCTTTTCTGACAGGTGCAATTCTACCTAGTTGTTAG }\end{array}$ & CTAG & $\mathrm{s}$ & 16,88 & 158 & $\begin{array}{l}\text { CAGCCGGGGATATAT } \\
\text { GTTTG }\end{array}$ & 60,2 & $\begin{array}{l}\text { GCAGGAAAGTTGCT } \\
\text { TTGACG }\end{array}$ & 60,9 & 50 & 50 \\
\hline 675 & BrPe4197 & $\begin{array}{l}\text { Maracuja_ } \\
\text { NoIndex_L } \\
\text { 003_R1_00 } \\
\text { 1_conti__3 } \\
9462\end{array}$ & 4 & 1660 & 1671 & 12 & 3 & 8 & $\begin{array}{l}\text { GGAAAGAGTAAGTCATTGTCGACAAGTTCATAAATACTCAAGTAGC } \\
\text { AATGAATATACAAATAACAACAACAGTTCCATCCAAATGACATC } \\
\text { TGCCTGCTGTATCCCTAACTAGGAGCAGAACCAATACTACATACAA } \\
\text { GGATAAATAAAGCAAACAAACAAAGAAAACTATATTTTACCTTTAG } \\
\text { TTTCTCTCGTTCTTTTAGTTCTTTTCTCTTCTTTGCATATAACCGATTC } \\
\text { AGTAGTCGAATCCGTGGATCGTCCGTAGTGTTCTTCAAAGGCTCCAA } \\
\text { CTTCTCCTCCTAAATTACGACCAAATGTTAAA }\end{array}$ & CAAA & $\mathrm{s}$ & 18,23 & 174 & $\begin{array}{l}\text { CAAATGACATCTGCC } \\
\text { TGCTG }\end{array}$ & 60,4 & $\begin{array}{l}\text { ACGATCCACGGATT } \\
\text { CGACTA }\end{array}$ & 60,5 & 50 & 50 \\
\hline
\end{tabular}

G: genoma funcional

S: genoma estructural

P: polimórfico

M: monomórfico 
APÉNDICE

Marcadores microssatélites desenhados a partir do sequênciamento parcial e da montagem de novo do genoma de $P$. edulis

\begin{tabular}{|c|c|c|c|c|c|c|c|c|c|c|c|c|c|c|c|c|c|c|c|}
\hline $\mathbf{N}^{\circ}$ & Primer & Contig I & Motivo & Início & Fim & pb & $\begin{array}{c}\mathbf{N}^{\circ} \\
\text { Repet }\end{array}$ & Score & Sequência do contig & Unidade & G/S & Cobertura & pb & Sequência Forward & $\begin{array}{l}\mathrm{T}^{\circ} \mathrm{C} \\
F w d \\
\end{array}$ & Sequência Reverse & $\begin{array}{l}\mathrm{T}^{\circ} \mathrm{C} \\
\operatorname{Rev} \\
\end{array}$ & $\begin{array}{c}\% \mathrm{GC} \\
F w d \\
\end{array}$ & $\begin{array}{cc}\% \mathrm{GC} & \mathrm{P} / \mathrm{M} \\
\operatorname{Rev} & \end{array}$ \\
\hline 676 & BrPe4198 & $\begin{array}{l}\text { Maracuja_ } \\
\text { NoIndex_L } \\
\text { 003_R1_00 } \\
\text { 1_contig_3 } \\
9544\end{array}$ & 4 & 306 & 317 & 12 & 3 & 8 & $\begin{array}{l}\text { ATTTTTGTTGATGAATTAATCATACCAGAAGTAGGGAGATCATTGTG } \\
\text { TGGTAGGTGTCATAAATCTTAATGCATAAGTCCAATTTACAAAAGA } \\
\text { AATCCTATGTTGTAGCTCTTCTTACATTTGCTTCCTGATCTTTTACAT } \\
\text { ACTATGCATGGAAGGAAGGAACAAAATTGTCAGTTTATATAAGCAG } \\
\text { TGGCGGTCTTGCCAATCTCATATCAGTTGTAGCGACTGTGATTTCC } \\
\text { CCATTAAAAAACTCCACAATGTATATTCTGGTTATCACTACTGATCA } \\
\text { ATCTGTGGCATGGGACATATAGAATTGTTC }\end{array}$ & GGAA & $\mathrm{s}$ & 16,79 & 202 & $\begin{array}{l}\text { GGGAGATCATTGTGT } \\
\text { GGTAGG }\end{array}$ & 59,3 & $\begin{array}{l}\text { GGGAAATCACAGTC } \\
\text { GCTACAA }\end{array}$ & 60,1 & 52,4 & 47,6 \\
\hline 677 & BrPe4199 & $\begin{array}{l}\text { Maracuja_ } \\
\text { NoIndex_L } \\
\text { 003_R1_00 } \\
\text { 1_contig_3 } \\
9643\end{array}$ & 4 & 1988 & 1999 & 12 & 3 & 8 & $\begin{array}{l}\text { TTACACCTTTGTGTTCAGTTTTACAGATACATTACCTGCAGTGAGCA } \\
\text { TTGTCCTTTTATGTTTTTCTGATTTGACTTCCATTGCTCCAAATTTTTA } \\
\text { CACAATTGTTTTCTTTCATCAATTATGCAGGTCTGGTTCAGTGTGCCT } \\
\text { GGATGTAATCAATCAATCTTGGAGTCCGATGTTTGGTAATTTTCTTTT } \\
\text { TTGTTTGTGCATGAAATAATGGCTTTCATGTATCTGCCATGCACACA } \\
\text { ACTTTACACATGTACAACATCCGTCAGAAATGTTGGAGGCTGCATTA } \\
\text { AAAATTGTCATGCTTCTATCTTTGCT }\end{array}$ & AATC & G & 15,88 & 249 & $\begin{array}{l}\text { TGCAGTGAGCATTGT } \\
\text { CCTTT }\end{array}$ & 59,4 & $\begin{array}{l}\text { AATGCAGCCTCCAA } \\
\text { CATTTC }\end{array}$ & 60,1 & 45 & 45 \\
\hline 678 & BrPe4200 & $\begin{array}{l}\text { Maracuja_ } \\
\text { NoIndex_L } \\
\text { 003_R1_00 } \\
\text { 1_contig_3 } \\
\text { 9644 }\end{array}$ & 4 & 3186 & 3201 & 16 & 4 & 12 & $\begin{array}{l}\text { TAAACTTTTCTGTAATGTTTCGGATTGTTATATTATGTATTAGGCTCA } \\
\text { CCATTCCTTACTCGGTAGTCCATGATGCTACCTGTGTACTTGCCAAT } \\
\text { GCTACCGATGACAAAGCTTGTATAGCTTTGTTTTTGGGGTTAATGTT } \\
\text { TTATATCTAGAAAGAAAGAAAGAAGAAAAGAGTTACATAACCAAA } \\
\text { GCTAAACTCCGACAGAATGCAGCAGTAGAAAAAAAAATTGAAAAG } \\
\text { GAGAAACTGTTTGAGTGATCTTAATAGTTAACTAAACTGGTTAGATT } \\
\text { TAGTAAACAATTCAAGCTTTGAGATGCAGACCCACCG }\end{array}$ & AGAA & $\mathrm{s}$ & 18,6 & 168 & $\begin{array}{l}\text { GGCTCACCATTCCTT } \\
\text { ACTCG }\end{array}$ & 59,7 & $\begin{array}{l}\text { GCTGCATTCTGTCG } \\
\text { GAGTTT }\end{array}$ & 60,4 & 55 & 50 \\
\hline 679 & BrPe4201 & $\begin{array}{l}\text { Maracuja_ } \\
\text { NoIndex_L } \\
\text { 003_R1_00 } \\
\text { 1_contig_3 } \\
9779\end{array}$ & 4 & 522 & 533 & 12 & 3 & 8 & $\begin{array}{l}\text { TAATGTCTTCATGATAAAAGCGTACCTGAAAGTGCAACCATATCTGT } \\
\text { GACGGAGAGACCTTGATAGAGAAACTTGGAAATGATAGATATCAGA } \\
\text { CTCTCGTCTGCTGTTGGAAGATTTGAATTTGCGAGCTCGTAGCTTGC } \\
\text { AGTTTTAGAATCCTTCCTTCCTACGGGAACATCCCAGTATGGTCCAC } \\
\text { CAACCTGACAGATACAGGAAAAGGAGAGGAACCAACGATATTCTTC } \\
\text { AGCAAGCGAAAACAAAAAGGAAATTAAACATCATTTCCTGTATTGC } \\
\text { ATGCAGTACCAGTATCACAGCATCTCTTGCAGC }\end{array}$ & ТсСт & G & 16,76 & 160 & $\begin{array}{l}\text { TCTCGTCTGCTGTTGG } \\
\text { AAGA }\end{array}$ & 59,7 & $\begin{array}{l}\text { TCCTTTTTGTTTTCG } \\
\text { CTTGC }\end{array}$ & 60,4 & 50 & 40 \\
\hline 680 & BrPe4202 & $\begin{array}{l}\text { Maracuja_ } \\
\text { NoIndex_L } \\
\text { 003_R1_00 } \\
\text { 1_contig_4 } \\
0136\end{array}$ & 4 & 2341 & 2352 & 12 & 3 & 8 & $\begin{array}{l}\text { TCAAACAAATGATAAGATGTTGCTTTATCTTTTTGACATTATGATTA } \\
\text { TTAGGACAACCATGCAAATAACCTTCCACAGTTGCATGATTAGTATA } \\
\text { ACCTTGAAATTTGAAGTATGGAGTGCCTATTGTTTCTACCAGGAATC } \\
\text { TCTTCACTTCTTGCTTGCTTGATAGTAAAGTTTTATAACTTAGCGTCT } \\
\text { TTGAAATGCTTTCTCTTCTCACAATTTATTTATCCCTGGATGCTTATC } \\
\text { ATTTCACTGTCTGGGCAATAAACTTTTGACACAAGACATACTGTTTC } \\
\text { TAGTTTACTCAGTCAGCAGATTATTATG }\end{array}$ & СтTG & $\mathrm{s}$ & 17,29 & 189 & $\begin{array}{l}\text { AACCTTCCACAGTTG } \\
\text { CATGA }\end{array}$ & 59,1 & $\begin{array}{l}\text { TTGCCCAGACAGTG } \\
\text { AAATGA }\end{array}$ & 60,2 & 45 & 45 \\
\hline
\end{tabular}

G: genoma funcional

S: genoma estructural

P: polimórfico

M: monomórfico 
APÉNDICE

Marcadores microssatélites desenhados a partir do sequênciamento parcial e da montagem de novo do genoma de $P$. edulis

\begin{tabular}{|c|c|c|c|c|c|c|c|c|c|c|c|c|c|c|c|c|c|c|c|}
\hline $\mathbf{N}^{\circ}$ & Primer & Contig I & Motivo & Início & Fim & pb & $\begin{array}{c}\mathbf{N}^{\circ} \\
\text { Repet }\end{array}$ & Score & Sequência do contig & Unidade & G/S & Cobertura & pb & Sequência Forward & $\begin{array}{l}\mathrm{T}^{\circ} \mathrm{C} \\
F w d \\
\end{array}$ & Sequência Reverse & $\begin{array}{l}\mathrm{T}^{\circ} \mathrm{C} \\
\operatorname{Rev} \\
\end{array}$ & $\begin{array}{c}\% \mathrm{GC} \\
F w d \\
\end{array}$ & $\begin{array}{cc}\% \mathrm{GC} & \mathrm{P} / \mathrm{M} \\
\operatorname{Rev} & \end{array}$ \\
\hline 681 & BrPe4203 & $\begin{array}{l}\text { Maracuja_ } \\
\text { NoIndex_L } \\
\text { 003_R1_00 } \\
\text { 1_contig_4 } \\
0399\end{array}$ & 4 & 1451 & 1462 & 12 & 3 & 8 & $\begin{array}{l}\text { AGGCCCTGCATAGCTTATCGTTAAAGTTCTAATATTTCATTTTGTCA } \\
\text { AGTCATCTTCCTAGTTAATATACTTCGAAATTAGTCTTGGACCAGAAA } \\
\text { AACCTATAAAATTAGGATTTTCAAAAACTCGAGACTGATTCCTTTGC } \\
\text { GAGCCTTCCTCTTTCTTTCTTCTCTCTATCTCTTTCCCTTTTGAACCTT } \\
\text { AAACCCCAAAATTGACAATTCTCACCAAAATTAACAATCTCCCTCC } \\
\text { ACACTCAACTATATACGACAGTTCTTGTCACTTTGGTTGTTGTTGAC } \\
\text { ATAGCAGGACTAGTTCATCGACTGTCT }\end{array}$ & TCTT & $\mathrm{s}$ & 20,83 & 243 & $\begin{array}{l}\text { GCCCTGCATAGCTTA } \\
\text { TCGTT }\end{array}$ & 59,3 & $\begin{array}{l}\text { TTGAGTGTGGAGGG } \\
\text { AGAATTG }\end{array}$ & 60,1 & 50 & 47,6 \\
\hline 682 & BrPe4204 & $\begin{array}{l}\text { Maracuja_ } \\
\text { NoIndex_L } \\
\text { 003_R1_00 } \\
\text { 1_contig_4 } \\
0680\end{array}$ & 4 & 1213 & 1224 & 12 & 3 & 8 & $\begin{array}{l}\text { GGACTACATGCTATAATTTACTTTTACAATGTTCACTTGGGGACTTTT } \\
\text { TGTCCGTTTCACCTGTTGGTATCATGATGTTTACTAAACATTTTTTGT } \\
\text { TCTTGCAGTGTCTGCTCTTAATGTATTGTTTACCAGCTTAAATTCGCC } \\
\text { ATCAGAACTGACTGACTGGAAATCAAGTGGTGGAGACCCTTGTGGT } \\
\text { GAATCTTGGGAAGGGATCACATGCTCAGGCTCTGCCGTGACTGAAA } \\
\text { TGTAGTTTGATCAGCTTACTTTAATATTTCTGGAGTAGAATTCTGAA } \\
\text { ACATAGCTACCCAAAATTTCTGACCTTTA }\end{array}$ & ACTG & G & 16,24 & 168 & $\begin{array}{l}\text { GGGACTTTTTGTCCGT } \\
\text { TTCA }\end{array}$ & 59,9 & $\begin{array}{l}\text { ATCCCTTCCCAAGA } \\
\text { TTCACC }\end{array}$ & 60,1 & 45 & 50 \\
\hline 683 & BrPe4205 & $\begin{array}{l}\text { Maracuja_ } \\
\text { NoIndex_L } \\
003 \text { R1_00 } \\
\text { 1_contig_4 } \\
1000\end{array}$ & 4 & 1305 & 1316 & 12 & 3 & 8 & $\begin{array}{l}\text { CATTCTCTTCCTATCGATCAAAGCACTTCAAGTAGAATGCAAAGTGC } \\
\text { ATCAGACCTCGTATCATTGGATGACTGGCCTCCAAAGGATCAAAAG } \\
\text { CAGGAAGTAGAACAAGATGTATTAAGTGCCAGAAACAGTGCACGG } \\
\text { GACCTTGCGTCTATGGATGGATGGCCACCTGAAATGGCAAAAGAGG } \\
\text { GAGAAGACAACGCACAACAAACGTCATTATGGGATTCGATCACTAG } \\
\text { CGAATATGATAATTGGGAGGCCGCATTAGCATGGCCTGAAAGCCTA } \\
\text { CCTATTCAATCATCACCTGATGACCAAGATTCCTCA }\end{array}$ & ATGG & G & 12,66 & 161 & $\begin{array}{l}\text { TGCAAAGTGCATCAG } \\
\text { ACCTC }\end{array}$ & 60,0 & $\begin{array}{l}\text { TGCGTTGTCTTCTCC } \\
\text { СTCTT }\end{array}$ & 60 & 50 & 50 \\
\hline 684 & BrPe4206 & $\begin{array}{l}\text { Maracuja_ } \\
\text { NoIndex_L } \\
\text { 003_R1_00 } \\
\text { 1_contig_4 } \\
\text { 1301 }\end{array}$ & 4 & 4087 & 4098 & 12 & 3 & 8 & $\begin{array}{l}\text { AGCAAAGCCAACAATCAAGAGGAGATAAGCACTACAATATATCCAT } \\
\text { TACTCTCACTGCAGTAACTCTCCTAGCACATTCTTCTCTGGTGGAA } \\
\text { CAGTCAATGTTAAATTCTTTGAAACCACAGTAAACAAAACCATGAA } \\
\text { GGAAGAGATACCATACATACATATGTACAGTCCCTACCCCCAAGAA } \\
\text { CATGTAAAAACTTTGTTAATTGTTTCTCAACAGCAAGGAGTTTCCGA } \\
\text { GGCAAAGGGTATCTGACAAGTACCAAGAACATGTTACTGCCACGCT } \\
\text { AAAGAACAAGATCCTGCAGAAGATGTGACCAGAC }\end{array}$ & CATA & G & 17,8 & 244 & $\begin{array}{l}\text { CAAAGCCAACAATCA } \\
\text { AGAGGA }\end{array}$ & 60,2 & $\begin{array}{l}\text { ATACCCTTTGCCTCG } \\
\text { GAAAC }\end{array}$ & 60,3 & 42,9 & 50 \\
\hline 685 & BrPe4207 & $\begin{array}{l}\text { Maracuja_ } \\
\text { NoIndex_L } \\
\text { 003_R1_00 } \\
\text { 1_contig_4 } \\
\text { 1850 }\end{array}$ & 4 & 2332 & 2343 & 12 & 3 & 8 & $\begin{array}{l}\text { GTGTTTTTTGGGAAGAAAACTAGATTGATTGTAAGGAATATAGGATT } \\
\text { CATGAATATATGCATATGTATGAACTGCTTTCATGCGATTTTTTTGG } \\
\text { CATGGTTCCAGTGCTGGGGCATAAACAATTGACAGGGCTGGCATAT } \\
\text { GTCTTCATATTTTATTTATTTAATATATTGTGATGTTTTCTGAAAATA } \\
\text { AGGTAGATTCTTCTTGTTATTTGGATTATGGGGCATAGAATATCTAG } \\
\text { AAGATTGAACTAAACTTATGAGAGCTAATGTCACATCTTGCTTGGTT } \\
\text { TAGTTATTCGGGCAAGTGTTCCAAAGTTGG }\end{array}$ & TTTA & $\mathrm{s}$ & 16,12 & 176 & $\begin{array}{l}\text { GGGCTGGCATATGTC } \\
\text { TTCAT }\end{array}$ & 59,9 & $\begin{array}{l}\text { GGAACACTTGCCCG } \\
\text { AATAAC }\end{array}$ & 59,4 & 50 & 50 \\
\hline
\end{tabular}

G: genoma funcional

S: genoma estructural

P: polimórfico

M: monomórfico 
APÉNDICE

Marcadores microssatélites desenhados a partir do sequênciamento parcial e da montagem de novo do genoma de $P$. edulis

\begin{tabular}{|c|c|c|c|c|c|c|c|c|c|c|c|c|c|c|c|c|c|c|c|}
\hline $\mathbf{N}^{\circ}$ & Primer & Contig I & Motivo & Início & Fim & pb & $\begin{array}{c}\mathbf{N}^{\circ} \\
\text { Repet }\end{array}$ & Score & Sequência do contig & Unidade & G/S & Cobertura & $\mathrm{pb}$ & Sequência Forward & $\begin{array}{l}\mathrm{T}^{\circ} \mathrm{C} \\
F w d \\
\end{array}$ & Sequência Reverse & $\begin{array}{l}\mathrm{T}^{\circ} \mathrm{C} \\
\operatorname{Rev} \\
\end{array}$ & $\begin{array}{c}\% \mathrm{GC} \\
F w d \\
\end{array}$ & $\begin{array}{cc}\% \mathrm{GC} & \mathrm{P} / \mathrm{M} \\
\operatorname{Rev} & \end{array}$ \\
\hline 686 & BrPe4208 & $\begin{array}{l}\text { Maracuja_ } \\
\text { NoIndex_L } \\
\text { 003_R1_00 } \\
\text { 1_contig_4 } \\
\text { 2135 }\end{array}$ & 4 & 573 & 584 & 12 & 3 & 8 & $\begin{array}{l}\text { GTTCTTGTGTTCTTTAACTATTGTTTCTCTTTACTAGCCTGGGGCGTC } \\
\text { TGTTGTTTTGGTTGTCTTCATTCTTCTTGGCTTTTGATTTGGGAGACA } \\
\text { AGTTTCTGTTATTGAGTTTTTTCTTTTCCTCCCCAGGACTAATTTGGT } \\
\text { GTCATGGTTAGTTAGTTATTACTGCGGTGTCTCCGTGATATCAATTG } \\
\text { AAACTTTTCAGAGCCAAATAAATCTTTCTGCTATGGTATCTGCGCTT } \\
\text { CGTTTTAATCTCTCTCTCTCCTTTATTATTAATTTTTTTTAAAAATCTT } \\
\text { TTAAAAGGCCTCTTCTGAAACCGTT }\end{array}$ & GTTA & $\mathrm{s}$ & 15,35 & 167 & $\begin{array}{l}\text { GGCTTTTGATTTGGG } \\
\text { AGACA }\end{array}$ & 60,1 & $\begin{array}{l}\text { AAACGAAGCGCAGA } \\
\text { TACCAT }\end{array}$ & 59,7 & 45 & 45 \\
\hline 687 & BrPe4209 & $\begin{array}{l}\text { Maracuja_ } \\
\text { NoIndex_L } \\
\text { 003_R1_00 } \\
\text { 1_contig_4 } \\
\text { 2399 }\end{array}$ & 4 & 688 & 699 & 12 & 3 & 8 & $\begin{array}{l}\text { AATTGTTATGGTATAAGTGTAAGGTTATTATGTTCAGGCTTTCCTTAT } \\
\text { TCTTGGTTTCATGGAGATCATATTCTCATGCTAAATTATCTAGCTAA } \\
\text { AGTCTGGAGATGCTTAATTTTATTCTTCATAATTGAGAGGCATATTG } \\
\text { TTTAGCATTTCTTTCTTTCATCAATGCTATAAGTGAGGTTTGGCTCTT } \\
\text { TCTTCTGTCAGGACATCTTACATCGAGGAGTGATGTGTACAGCTTCG } \\
\text { GTGTGGTT }\end{array}$ & тTтC & G & 20,03 & 209 & $\begin{array}{l}\text { TTCAGGCTTTCCTTAT } \\
\text { TCTTGG }\end{array}$ & 59,7 & $\begin{array}{l}\text { CACCGAAGCTGTAC } \\
\text { ACATCAC }\end{array}$ & 59,2 & 40,9 & 52,4 \\
\hline 688 & BrPe4210 & $\begin{array}{l}\text { Maracuja_ } \\
\text { NoIndex_L } \\
\text { 003_R1_00 } \\
\text { 1_contig_4 } \\
\text { 2416 }\end{array}$ & 4 & 1394 & 1405 & 12 & 3 & 8 & $\begin{array}{l}\text { TCCATCATATGGTCTACAAATCTTGCAGGTTGACAAAAAACTAAATC } \\
\text { CACTTTCAAATTCACTAGTCCACATACAGGATCTAAAGACCCAGCC } \\
\text { AATTCCCGAACCATGTCAAAATACCACTCAAGCATGCACAACATAT } \\
\text { GCATCCAGTGCTATTTATTTATTATATTCACTCTGAATCACCGCAAA } \\
\text { ATGAAAGGTTCAATTGATAAAATTTCTAGTCACAAATTAGGCATCAT } \\
\text { AGGCATCAAATCGTCTAATATTCATCAATTCATTCAACACATGCACA } \\
\text { TACAGAAACTGAAGCCTTGACCGAGTCTTGTA }\end{array}$ & TATT & $\mathrm{s}$ & 17,86 & 178 & $\begin{array}{l}\text { CAAATCTTGCAGGTT } \\
\text { GACAAAA }\end{array}$ & 60,1 & $\begin{array}{l}\text { CCTTTCATTTTGCGG } \\
\text { TGATT }\end{array}$ & 59,9 & 36,4 & 40 \\
\hline 689 & BrPe4211 & $\begin{array}{l}\text { Maracuja_ } \\
\text { NoIndex_L } \\
\text { 003_R1_00 } \\
\text { 1_contig_4 } \\
\text { 2614 }\end{array}$ & 4 & 2706 & 2717 & 12 & 3 & 8 & $\begin{array}{l}\text { AAAGGCTTGCATTTTCAATACAGAGATTGATACCAAATAAAAAGTG } \\
\text { GATGAAGGACCACACAAATGAAACACGCTATCTCGTTACAATGTGG } \\
\text { CTTCGTAAACCTATAATAAAATAAGAAACACGACCGGAATAATAACA } \\
\text { TGCAAACAACAAAAAGAAAGAAAGGAAAAAGCCTGCGCCTGACAA } \\
\text { TGGGACCCACAACTTTTGAAGTAATGGGATTTGGTCATAAATGAGG } \\
\text { TTGCTTCTGTGAGTTGACAATGTACGGGGACCCGAAGGGCACAGCA } \\
\text { GAAACTCTGTAGTCGTAGCTGTGTTGTTTTTGTGTCA }\end{array}$ & AAAG & $\mathrm{s}$ & 17,8 & 217 & $\begin{array}{l}\text { TGGATGAAGGACCAC } \\
\text { ACAAA }\end{array}$ & 59,9 & $\begin{array}{l}\text { GGTCCCCGTACATT } \\
\text { GTCAAC }\end{array}$ & 60,1 & 45 & 55 \\
\hline 690 & BrPe4212 & $\begin{array}{l}\text { Maracuja_ } \\
\text { NoIndex_L } \\
\text { 003_R1_00 } \\
\text { 1_contig_4 } \\
2819\end{array}$ & 4 & 1409 & 1420 & 12 & 3 & 8 & $\begin{array}{l}\text { CTACCAGTTTTTATAGGATTAACTAGTAACAAGATTGGAATAATGTA } \\
\text { ACAATTCTCATGTGTGGACATCCAGGCGCATCCAGAATTAAACAAG } \\
\text { AGTGAAAGGAAGCGGCTGTGTAGAACACTGGACTGCAAAAAACTAT } \\
\text { CTGTTGAAGCCTGCATGCATGCAGCGCAGAATGAGTTGCTCCCGCT } \\
\text { AAGGGTGGTAGTGCAAGTTCTGTTTTCTGAGCAAGCCAGAGTGGCT } \\
\text { GGTGGCAAAGTAACTGAGCTTCCTAGCAATATCAAGGCACTACTAG } \\
\text { CTTCACATTGTATTGACCCATCAAAGACCAATCCA }\end{array}$ & TGCA & G & 16,56 & 153 & $\begin{array}{l}\text { AAGGAAGCGGCTGTG } \\
\text { TAGAA }\end{array}$ & 60,0 & $\begin{array}{l}\text { AGCTCAGTTACTTTG } \\
\text { CCACCA }\end{array}$ & 59,9 & 50 & 47,6 \\
\hline
\end{tabular}

G: genoma funcional

S: genoma estructural

P: polimórfico

M: monomórfico 
APÉNDICE

Marcadores microssatélites desenhados a partir do sequênciamento parcial e da montagem de novo do genoma de $P$. edulis

\begin{tabular}{|c|c|c|c|c|c|c|c|c|c|c|c|c|c|c|c|c|c|c|c|}
\hline $\mathbf{N}^{\circ}$ & Primer & Contig I & Motivo & Início & Fim & pb & $\begin{array}{c}\mathbf{N}^{\circ} \\
\text { Repet }\end{array}$ & Score & Sequência do contig & Unidade & G/S & Cobertura & pb & Sequência Forward & $\begin{array}{l}\mathrm{T}^{\circ} \mathrm{C} \\
F w d \\
\end{array}$ & Sequência Reverse & $\begin{array}{l}\mathrm{T}^{\circ} \mathrm{C} \\
\operatorname{Rev} \\
\end{array}$ & $\begin{array}{c}\% \mathrm{GC} \\
F w d \\
\end{array}$ & $\begin{array}{r}\% \mathrm{GC} \\
\operatorname{Rev} \\
\end{array}$ \\
\hline 691 & BrPe4213 & $\begin{array}{l}\text { Maracuja_ } \\
\text { NoIndex_L } \\
\text { 003_R1_00 } \\
\text { 1_contig_4 } \\
\text { 2895 }\end{array}$ & 4 & 297 & 308 & 12 & 3 & 8 & $\begin{array}{l}\text { AGCAGAAACTTCTGTATAAAAGTAAGGTATGGTACTCCACTTGCTTCT } \\
\text { TTGAAAGAACCCTAAAATATGCTTCTGAACAAGACCCTATTCCTATT } \\
\text { CATTGCAGGCCTATTAGATTGTCAAGGATTCCAGCAGCGTCAGAAT } \\
\text { GGACGAGTCCATGCATGCATGATCTGTAATCAAATTCTGTTGCTCAA } \\
\text { CTTTCTACGTTTTAGTGAACAGAGGGAAAATATGCAATATTGATTAG } \\
\text { AGGATGTTTTGTGCAGTGTAGATTAATGATCTAATGCTTTCTTAAG } \\
\text { CTCTGTAACAGCAAAACAGAGAGAGTAACA }\end{array}$ & CATG & $\bar{G}$ & 13,98 & 154 & $\begin{array}{l}\text { TTGCAGGCCTATTAG } \\
\text { ATTGTCA }\end{array}$ & 59,7 & $\begin{array}{l}\text { TGCACAAAACATCC } \\
\text { TCTAATCAA }\end{array}$ & 59,6 & 40,9 & 34,8 \\
\hline 692 & BrPe4214 & $\begin{array}{l}\text { Maracuja_ } \\
\text { NoIndex_L } \\
003 \_R 1 \_00 \\
\text { 1_contig_4 } \\
4103\end{array}$ & 4 & 1004 & 1015 & 12 & 3 & 8 & $\begin{array}{l}\text { CCAAGTGCAGCGTCGGTCCACTACCGACTGACTGTCCATATAAAATT } \\
\text { ATATCTTCCTGACTGACTCCATACTCGGTCTGAAGACACTCATAAAC } \\
\text { TGCCTCAATATCAGCATATGTATTGGACTCGCTCGGCTGATCACCAC } \\
\text { AAAAACAACATAAATAAATAAGAATACAAGAATGTATTATCATTAC } \\
\text { TAACTACATTAAATTGGAAAGTAAAACCAAAAACAAATGTACTTCT } \\
\text { ACTTGCATTGGTCAAATTCACATATCCATGATGGGATTCAAAAAGG } \\
\text { ATTCATCCATGAAGTTCTTTAAAAATCAGCAAA }\end{array}$ & ATAA & $\mathrm{s}$ & 16,89 & 156 & $\begin{array}{l}\text { GGCTGATCACCACAA } \\
\text { AAACA }\end{array}$ & 59,5 & $\begin{array}{l}\text { TGAATCCTTTTTGAA } \\
\text { TCCCATC }\end{array}$ & 60,1 & 45 & 36,4 \\
\hline 693 & BrPe4215 & $\begin{array}{l}\text { Maracuja_ } \\
\text { Nolndex_L } \\
\text { 003_R1_00 } \\
\text { 1_contig_4 } \\
4406\end{array}$ & 4 & 4080 & 4091 & 12 & 3 & 8 & $\begin{array}{l}\text { TAATTGCAAAATCGAATTGTAAGCCTGTATGATACCAACTAATGATC } \\
\text { ACGCTTGAAGCTTAGTAGCTCTAATCACAGTAACCAAAAAAGCAAA } \\
\text { AGTCTCATGTCCTCCAACACCAAATGCCACCGTAATTAACAGATCCA } \\
\text { AAATTTACATATCAATCAATCAGTAAAGCAATAAGAACCCGCTAAA } \\
\text { GAAATTAACAATACATGAGAAACTGAATTTTCAAACAATAAATGGC } \\
\text { AATTCCAAACAGAAACCACTGTCAGTTAAACCGAAACTGAAAGCCA } \\
\text { ACCAAAACCCAGAAGTCCAAATTCAAAAGATATG }\end{array}$ & ATCA & $\mathrm{s}$ & 22,37 & 190 & $\begin{array}{l}\text { ACACCAAATGCCACC } \\
\text { GTAAT }\end{array}$ & 60,1 & $\begin{array}{l}\text { TTTGGACTTCTGGGT } \\
\text { TTTGG }\end{array}$ & 59,9 & 45 & 45 \\
\hline 694 & BrPe4216 & $\begin{array}{l}\text { Maracuja_ } \\
\text { Nolndex_L } \\
\text { 003_R1_00 } \\
\text { 1_contig_4 } \\
\text { 5006 }\end{array}$ & 4 & 1847 & 1858 & 12 & 3 & 8 & $\begin{array}{l}\text { TGGTCGATTTTGAAAGGTCCTATTGACCGACACAGATCCTTGGCGAA } \\
\text { GTTGCGAACCATCCTGGAAGCAGGTTTCTTGACTTGGATGTCATTTC } \\
\text { GAAGAAAATAGCTTACCAGGCTAGCTCTTTTGTCTGGCTATAATTAC } \\
\text { TCATAGTCTTGAATGAATGAAGCTGCAACTGCAGACTGTGTTTTATC } \\
\text { AGACGCTTTATTGGGTCGAGTACGATGGATTTGACCAACCCCTGCGG } \\
\text { TGTTTCAGTTGACGTTGAAATCAACAAATGGGATTCCGTCGTAATTG } \\
\text { GACAATAAATACGAACACATACCTTTCGCT }\end{array}$ & TGAA & G & 12,89 & 247 & $\begin{array}{l}\text { ACAGATCCTTGGCGA } \\
\text { AGTTG }\end{array}$ & 60,3 & $\begin{array}{l}\text { TACGACGGAATCCC } \\
\text { ATTTGT }\end{array}$ & 60,2 & 50 & 45 \\
\hline 695 & BrPe4217 & $\begin{array}{l}\text { Maracuja_ } \\
\text { NoIndex_L } \\
003 \_R 1 \_00 \\
\text { 1_contig_4 } \\
\text { 5016 }\end{array}$ & 4 & 3887 & 3898 & 12 & 3 & 8 & $\begin{array}{l}\text { CCATGTTGTAGCTGATTATTCAGTTTTCTTCATTTTTTTCCCATCTGA } \\
\text { CATGCACATGCAGTCATGTGCTGCTAATCAAATCCCAATATCTGCAG } \\
\text { TATATATAATCCCTGAGGAAGAGAAAAATGTTTGTCATCAGAGAGA } \\
\text { AAAGCTGCACATGCATGCATGAGCTCAACTTCGTTAATCATTAACCA } \\
\text { ATCATCCTAGTTTGTATTGGCTATTCAAAAACTCGATTCTACGAATA } \\
\text { GAACAGACATAGTCGGAAGAATATTGATATCGAATCAAGATCAGTT } \\
\text { TACATAGGATGCAGATCCTTTCTAAATATAT }\end{array}$ & CATG & $\mathrm{s}$ & 16,61 & 195 & $\begin{array}{l}\text { TCCCTGAGGAAGAGA } \\
\text { AAAATG }\end{array}$ & 58,4 & $\begin{array}{l}\text { GGATCTGCATCCTA } \\
\text { TGTAAACTGA }\end{array}$ & 59,5 & 42,9 & 41,7 \\
\hline
\end{tabular}

G: genoma funcional

S: genoma estructural

P: polimórfico

M: monomórfico 
APÉNDICE

Marcadores microssatélites desenhados a partir do sequênciamento parcial e da montagem de novo do genoma de $P$. edulis

\begin{tabular}{|c|c|c|c|c|c|c|c|c|c|c|c|c|c|c|c|c|c|c|c|}
\hline $\mathbf{N}^{\mathbf{o}}$ & Primer & Contig $\mathrm{I}$ & Motivo & Início & Fim & pb & $\begin{array}{c}\mathbf{N}^{\circ} \\
\text { Repet }\end{array}$ & Score & Sequência do contig & Unidade & G/S & Cobertura & pb & Sequência Forward & $\begin{array}{l}\mathrm{T}^{\circ} \mathrm{C} \\
F w d\end{array}$ & Sequência Reverse & $\begin{array}{l}\mathrm{T}^{\circ} \mathrm{C} \\
\operatorname{Rev}\end{array}$ & $\begin{array}{r}\% \mathrm{GC} \\
F w d\end{array}$ & $\begin{array}{c}\% \mathrm{GC} \\
\operatorname{Rev}\end{array} \quad \mathrm{P} / \mathbf{M}$ \\
\hline 696 & BrPe4218 & $\begin{array}{l}\text { Maracuja_ } \\
\text { NoIndex_L } \\
\text { 003_R1_00 } \\
\text { 1_contig_4 } \\
5254\end{array}$ & 4 & 471 & 482 & 12 & 3 & 8 & $\begin{array}{l}\text { AGCCTTTCACTTATGAAGAATTCAGAAAGCTGCGATTATCCAACAA } \\
\text { ATTCCATGCTGGTGAAGCACTTTCACTAGTACGCACCCAGAACTGA } \\
\text { AGCAAATGATATAGCATGTTGCAGCCCATCCATCAAATACTGCATCT } \\
\text { GCAAAGTAAACTACGTACGTACGCCTTGAGGATCCTGAAATAACTT } \\
\text { CACATATGAGATCAATAAA }\end{array}$ & TACG & $\bar{s}$ & 12,73 & 159 & $\begin{array}{l}\text { CAACAAATTCCATGC } \\
\text { TGGTG }\end{array}$ & 60,0 & $\begin{array}{l}\text { TGATCTCATATGTG } \\
\text { AAGTTATTTCAGG }\end{array}$ & 59,8 & 45 & 33,3 \\
\hline 697 & BrPe4219 & $\begin{array}{l}\text { Maracuja_ } \\
\text { NoIndex_L } \\
\text { 003_R1_00 } \\
\text { 1_conti__4 } \\
5348\end{array}$ & 4 & 1044 & 1055 & 12 & 3 & 8 & $\begin{array}{l}\text { GATTCTGAGTAAAATAAAGTTACATTATTCTATTTAGAACACGCGGG } \\
\text { CAACTTTTTTATGAATGTTAGGTATGATATCATTAGTCATATTAATC } \\
\text { GAGTTTATCTATTGGATTAATTTGTGTTAGAAGTCAAAAGTCATTTC } \\
\text { AACCGACTGATTTATTTATTTCGTTATATAAGTCAAATAATATTATA } \\
\text { ATCACGAACTTTACCGAAGTGGGTTAAATAGGAGTAGCTACCATTGT } \\
\text { TATCATTAAGCGGACTTATTTTCCAATTAAGCATTTATGTCTTCAATC } \\
\text { AGTGGCGAGACGACAGGTCGGTGACTTTT }\end{array}$ & ATTT & $\mathrm{s}$ & 15,26 & 180 & $\begin{array}{l}\text { ATTTAGAACACGCGG } \\
\text { GCAAC }\end{array}$ & 62,3 & $\begin{array}{l}\text { CCCACTTCGGTAAA } \\
\text { GTTCGT }\end{array}$ & 59,1 & 50 & 50 \\
\hline 698 & BrPe4220 & $\begin{array}{l}\text { Maracuja_ } \\
\text { NoIndex_L } \\
\text { 003_R1_00 } \\
\text { 1_contig_4 } \\
5560\end{array}$ & 4 & 461 & 476 & 16 & 4 & 12 & $\begin{array}{l}\text { ATGTTTCTTGCATCCCTTTTACTGTGAAAACCACGTGGACCAGGAGA } \\
\text { TGGAATACTCCTGAATGGAGGATCATGCAAGAAGAAAATCACAGAG } \\
\text { AATAAAAGACTGTTCAAAGGGTTATTACATACAAAAACAAGTTCAT } \\
\text { TAACTGCATTCTGTTTGTTTGTTTGTTGTATATCTACTAGTACAAGAT } \\
\text { ACTTGGTTTTGTATATTCCAGACTTGTACCAATCTATAGCGTAGGAT } \\
\text { TTGGCTTCCTTAGCTGATTTTTTGATTGTTTTGAGGCTCTTGCTAACT } \\
\text { GAACTGCAGGCCTTGATTCAATTTTGTATCACAC }\end{array}$ & TGTT & $\mathrm{s}$ & 16,67 & 237 & $\begin{array}{l}\text { TGGAGGATCATGCAA } \\
\text { GAAGA }\end{array}$ & 59,3 & $\begin{array}{l}\text { ATCAAGGCCTGCAG } \\
\text { TTCAGT }\end{array}$ & 59,9 & 45 & 50 \\
\hline 699 & BrPe4221 & $\begin{array}{l}\text { Maracuja_ } \\
\text { NoIndex_L } \\
\text { 003_R1_00 } \\
\text { 1_contig_4 } \\
5963\end{array}$ & 4 & 366 & 377 & 12 & 3 & 8 & $\begin{array}{l}\text { CTTAGAACGCTATAATTTCCTCCTTAATTTGGCAGTTTAGGAGTGAC } \\
\text { TGCATTTCTGCGAGCAGGTGTATATGTTTGTTTGTGTATTTTATTGCC } \\
\text { TTTTTTATTATTGCTATTGCTGTAAAAGAGAACAATAATGAGAAATA } \\
\text { AGCAAGTGAGAAAGAAAGAATGTTTAAGAGAGTGAGCAAAAGGGG } \\
\text { TTTCTATTTAGCCAGAAGACGTGCATGGTTTGGTTAAACTTGACACT } \\
\text { AATAATTTCCAGATGAAAGAGTGTTGTTATAAAGATTGTGTCTATAC } \\
\text { GACCAAGAGGCTTAACTAGTAGATAGTAGAT }\end{array}$ & AGAA & $\mathrm{s}$ & 15,42 & 167 & $\begin{array}{l}\text { GAACAATAATGAGAA } \\
\text { ATAAGCAAGTG }\end{array}$ & 57,7 & $\begin{array}{l}\text { ССTCTTGGTCGTATA } \\
\text { GACACAATCT }\end{array}$ & 60 & 30,8 & 44 \\
\hline 700 & BrPe4222 & $\begin{array}{l}\text { Maracuja_ } \\
\text { NoIndex_L } \\
\text { 003_R1_00 } \\
\text { 1_contig_4 } \\
6248\end{array}$ & 4 & 3165 & 3176 & 12 & 3 & 8 & $\begin{array}{l}\text { TGCTATCAACCAAATTAAATAGCATTGAAGACGGCTGTTTTCTTCAA } \\
\text { TGACGTGTTCCAACTACTAAAAAGATTATTGATTTTTCTCTTGGAGC } \\
\text { TCTGAATTCAAATTAAAACAGTCTTGACATCAATGGGATTGATCAAA } \\
\text { CGGGGAGGATAATTAATTAATAACAGGATTAATCATCGATTTAAAT } \\
\text { ACTAATTCTATAGCACCTAAGGCCATGAACTAGTCCTTAATGAATTA } \\
\text { ACGATTAACCTTATTCCTCCTCCTTTTATGCTCGACGATGAGCTTCA } \\
\text { CTATAGTTGCTGCTTCCAACCTATTTAGTA }\end{array}$ & TAAT & $\mathrm{s}$ & 17,92 & 250 & $\begin{array}{l}\text { AGACGGCTGTTTTCTT } \\
\text { CAATG }\end{array}$ & 59,4 & $\begin{array}{l}\text { GCTCATCGTCGAGC } \\
\text { ATAAAA }\end{array}$ & 59 & 42,9 & 45 \\
\hline
\end{tabular}

G: genoma funcional

S: genoma estructural

P: polimórfico

M: monomórfico 
APÉNDICE

Marcadores microssatélites desenhados a partir do sequênciamento parcial e da montagem de novo do genoma de $P$. edulis

\begin{tabular}{|c|c|c|c|c|c|c|c|c|c|c|c|c|c|c|c|c|c|c|c|}
\hline $\mathbf{N}^{\circ}$ & Primer & Contig I & Motivo & Início & Fim & pb & $\begin{array}{c}\mathbf{N}^{\circ} \\
\text { Repet }\end{array}$ & Score & Sequência do contig & Unidade & G/S & Cobertura & pb & Sequência Forward & $\begin{array}{l}\mathrm{T}^{\circ} \mathrm{C} \\
F w d \\
\end{array}$ & Sequência Reverse & $\begin{array}{l}\mathrm{T}^{\circ} \mathrm{C} \\
\operatorname{Rev} \\
\end{array}$ & $\begin{array}{c}\% \mathrm{GC} \\
F w d \\
\end{array}$ & $\begin{array}{c}\% \mathrm{GC} \\
\operatorname{Rev}\end{array}$ \\
\hline 701 & BrPe4223 & $\begin{array}{l}\text { Maracuja_ } \\
\text { NoIndex_L } \\
\text { 003_R1_00 } \\
\text { 1_contig_4 } \\
6356\end{array}$ & 4 & 2316 & 2327 & 12 & 3 & 8 & $\begin{array}{l}\text { CCTGAACAGGGCAAGACAATATGGATGGCAAGACACATACGTGTTC } \\
\text { ACGAAGGCCATGGGGGAAATGATGATAGATAAGATGAGAGGAAAC } \\
\text { ATACCGGTTGTCATAATCCGACCCAGTGTTATTGAGAGCACTTGCAA } \\
\text { AGAACCGTTTCCTGGATGGATGGAAGGAAATAGGTAGGCCGTATAC } \\
\text { ATTATAATACATATATCATTTTTATCTTTGCCAAACCTGAAATTATTA } \\
\text { TTATTATTTTTTAAAAATTTTTGGTCATAGGATGATGGATCCAATA } \\
\text { GTTTTATACTATGGCAAAGGGCAGCTCACAGGA }\end{array}$ & TGGA & $\mathrm{G}$ & 14,72 & 225 & $\begin{array}{l}\text { CCTGAACAGGGCAAG } \\
\text { ACAAT }\end{array}$ & 60,1 & $\begin{array}{l}\text { TTCAGGTTTGGCAA } \\
\text { AGATAAAAA }\end{array}$ & 60 & 50 & 30,4 \\
\hline 702 & BrPe4224 & $\begin{array}{l}\text { Maracuja_ } \\
\text { NoIndex_L } \\
\text { 003_R1_00 } \\
\text { 1_contig_4 } \\
6821\end{array}$ & 4 & 1492 & 1503 & 12 & 3 & 8 & $\begin{array}{l}\text { TCTTCTCTTTCCTCTAGAGAAATACTGGCTCTGAAAGGGGTGGAACT } \\
\text { TCCTGCACCTGACGTATTGATGAACACCTAACCTGCCAACTCAAAAT } \\
\text { TGCAAATTAAGAACAATAATCTGGAGGAAAATTCAGATACAGATTC } \\
\text { ATTTCTTGGGTGTATGTATGTACATGTGCGGTGTTTTTCAACAATGG } \\
\text { GCCTTTCATTATATATGTGGCTAATACATTACTTTCCGCCTAGCTACG } \\
\text { ACGAAAACAGAAGTCTCAGCGGCTACTAGCAGTTTCTTTCTTTCGCT } \\
\text { TTATGGAAAAACTGATAAGACTGCTGCATA }\end{array}$ & TGTA & $\mathrm{s}$ & 15,98 & 181 & $\begin{array}{l}\text { ACCTGCCAACTCAAA } \\
\text { ATTGC }\end{array}$ & 60,1 & $\begin{array}{l}\text { GCCGCTGAGACTTC } \\
\text { TGTTTT }\end{array}$ & 59,6 & 45 & 50 \\
\hline 703 & BrPe4225 & $\begin{array}{l}\text { Maracuja_ } \\
\text { NoIndex_L } \\
\text { 003_R1_00 } \\
\text { 1_contig_4 } \\
7372\end{array}$ & 4 & 204 & 215 & 20 & 5 & 16 & $\begin{array}{l}\text { TTGTTTGAGATGGCCGGTAAGAATTTCGAGGAAGAAATTCCTAATTA } \\
\text { GGAGGGGAGAGATGTGGAACCTACCTCCGAGTGGAAGAATTGACC } \\
\text { CGAAACCCCACCTTTGACCCGTAGTGTCTCATGCATTGAACATGCAT } \\
\text { TCATAGATGAATTTATTTATTTTATTTTAATTTATCATGCATTGAGTC } \\
\text { TTCATATGCATGGAGAGTGTGAAAAAAAAAATGAAAACATAAAAA } \\
\text { ATTGCTTGAATGACATGTCATCCACCCTTA }\end{array}$ & ATTT & $\mathrm{s}$ & 191,65 & 155 & $\begin{array}{l}\text { AGGGGAGAGATGTGG } \\
\text { AACCT }\end{array}$ & 59,9 & $\begin{array}{l}\text { TCTCCATGCATATG } \\
\text { AAGACTCAA }\end{array}$ & 59,7 & 55 & 39,1 \\
\hline 704 & BrPe4226 & $\begin{array}{l}\text { Maracuja_ } \\
\text { NoIndex_L } \\
\text { 003_R1_00 } \\
\text { 1_contig_4 } \\
7585\end{array}$ & 4 & 3215 & 3226 & 12 & 3 & 8 & $\begin{array}{l}\text { ACTATCTATGGCCTATTGCCAAAAAAGAAAGTTATCGACGTCTGCTT } \\
\text { TGTTCACCTCTGCTGCAAATCTCCCAGACAATAGGTTCTTTCTCAAG } \\
\text { ATTGTTAAATTTCGAAAAGAATGAATCTAATATTTGGTGAGGAGAA } \\
\text { TAGACCTTAACTAGCTAGCTAGGGAGGGACTCTTCCAAGGAATATC } \\
\text { AACTAGGTAGAAGAAAATCTGATATAATTAATAGTAGACTTTCGTA } \\
\text { AAAGATAATGCCGATCGATGCCATTATATATGCGGAGTTGCAGTCTT } \\
\text { AATTCTTTATTTATATATTTATTTGTGACGAAC }\end{array}$ & CTAG & $\mathrm{s}$ & 14,62 & 219 & $\begin{array}{l}\text { TCGACGTCTGCTTTGT } \\
\text { TCAC }\end{array}$ & 60,0 & $\begin{array}{l}\text { GCATCGATCGGCAT } \\
\text { TATCTT }\end{array}$ & 60 & 50 & 45 \\
\hline 705 & BrPe4227 & $\begin{array}{l}\text { Maracuja_ } \\
\text { NoIndex_L } \\
\text { 003_R1_00 } \\
\text { 1_contig_4 } \\
7620\end{array}$ & 4 & 2614 & 2625 & 12 & 3 & 8 & $\begin{array}{l}\text { GGTGGCTTTGGAGGTTTCGTAATGACAGGATTTTTAATGCAAAGGA } \\
\text { ACCATGGCCTGACGCTGTGCAAACCATTAGAAATTATTCAGATATG } \\
\text { GTTTTTGCTCTCAGATCTGTCTCTGACTCGTTAAGAATCAGTCAGAA } \\
\text { AAGAGTAAGGCTGGTTGGTTGGTCTACACCACCAATAACTGGTAC } \\
\text { AAGTTGAACACAGATGGTGCTTTTAAAGGAGATACATATATATGTG } \\
\text { CAGGAGGCATTATCAGAGGCAACCATGGTGAGTGGGTTGGGAGCTT } \\
\text { TACATGTAAATCCATAGGAGCTTCTGCCTATCAGG }\end{array}$ & TGGT & G & 17,84 & 204 & $\begin{array}{l}\text { GTGGCTTTGGAGGTT } \\
\text { TCGTA }\end{array}$ & 60,1 & $\begin{array}{l}\text { GCACCATCTGTGTT } \\
\text { CAACTTGT }\end{array}$ & 60,1 & 50 & 45,5 \\
\hline
\end{tabular}

G: genoma funcional

S: genoma estructural

P: polimórfico

M: monomórfico 
APÉNDICE

Marcadores microssatélites desenhados a partir do sequênciamento parcial e da montagem de novo do genoma de $P$. edulis

\begin{tabular}{|c|c|c|c|c|c|c|c|c|c|c|c|c|c|c|c|c|c|c|c|}
\hline $\mathbf{N}^{\circ}$ & Primer & Contig I & Motivo & Início & Fim & pb & $\begin{array}{c}\mathbf{N}^{\circ} \\
\text { Repet }\end{array}$ & Score & Sequência do contig & Unidade & G/S & Cobertura & pb & Sequência Forward & $\begin{array}{l}\mathrm{T}^{\circ} \mathrm{C} \\
F w d \\
\end{array}$ & Sequência Reverse & $\begin{array}{l}\mathrm{T}^{\circ} \mathrm{C} \\
\operatorname{Rev} \\
\end{array}$ & $\begin{array}{c}\% \mathrm{GC} \\
F w d \\
\end{array}$ & $\begin{array}{cc}\% \mathrm{GC} & \mathrm{P} / \mathrm{M} \\
\operatorname{Rev} & \end{array}$ \\
\hline 706 & BrPe4228 & $\begin{array}{l}\text { Maracuja_ } \\
\text { NoIndex_L } \\
\text { 003_R1_00 } \\
\text { 1_contig_4 } \\
7778\end{array}$ & 4 & 732 & 747 & 16 & 4 & 12 & $\begin{array}{l}\text { ATTTTGTGGGCCGTGTATATATAAATATGTATATACTCAAAATGCTC } \\
\text { TTCAACATCGATCTGGACAATTACGGTCCATATCCAGCCACCTTGCT } \\
\text { TCCAGACTAACTCTCGGTTTTTCTTATTTTCAGCCAAACAATAATATT } \\
\text { TTTACAATTTCCTTCCTTCCTTCCCAGACGATGAGTTTTAACGGTCAA } \\
\text { GGGAACAACACCCTTGTGCTCATTTTACGATTAAAAATTAAGAAATT } \\
\text { CTTAGGATTTTTTCCTTTTTTTTAGAAAACTTGGAATATACATTATAA } \\
\text { TATAAATTCAATTCATTACATTTGAGAGTAA }\end{array}$ & TTCC & $\mathrm{G}$ & 15,77 & 160 & $\begin{array}{l}\text { CATCGATCTGGACAA } \\
\text { TTACGG }\end{array}$ & 60,3 & $\begin{array}{l}\text { TGAGCACAAGGGTG } \\
\text { TTGTTC }\end{array}$ & 59,7 & 47,6 & 50 \\
\hline 707 & BrPe4229 & $\begin{array}{l}\text { Maracuja_ } \\
\text { NoIndex_L } \\
\text { 003_R1_00 } \\
\text { 1_contig_4 } \\
8060\end{array}$ & 4 & 10651 & 10666 & 16 & 4 & 12 & $\begin{array}{l}\text { CGCAAACAATTAACAATTAGTAATGAGAGACTCGAAAAATGTAACC } \\
\text { CAGACATGTAATGGTACCAAATAGAAAAAAGCTTGTCATGCTTCGC } \\
\text { AATCAAGACAATATCCTCTAAAGAACACAGAACAGCCCTCAGACAA } \\
\text { TCACTGGCGCTATCATTCATTCATTCATGATGCCGATGATAAACACA } \\
\text { AAACTGAGATGTCAGTGTTATACTGGGAAAAAATGCGAAAACCATC } \\
\text { TTCTAAATAGCACATGATTTTGTACGCACGACGATTGATTCTGCCGA } \\
\text { TCATAAACACAAATGTACATATTCCTAAATCATGACAA }\end{array}$ & TCAT & $\mathrm{s}$ & 16,82 & 154 & $\begin{array}{l}\text { CACAGAACAGCCCTC } \\
\text { AGACA }\end{array}$ & 60,0 & $\begin{array}{l}\text { AATCAATCGTCGTG } \\
\text { CGTACA }\end{array}$ & 60,1 & 50 & 45 \\
\hline 708 & BrPe4230 & $\begin{array}{l}\text { Maracuja_ } \\
\text { NoIndex_L } \\
\text { 003_R1_00 } \\
\text { 1_contig_4 } \\
8133\end{array}$ & 4 & 435 & 446 & 12 & 3 & 8 & $\begin{array}{l}\text { CTGGGCATCGATAACGTTTCTTCCTAATTTCCTGCAATGGAACACTA } \\
\text { TGGTATCCCCAGAAACTATCCCATTAGCTTCGGTGAAGTCATGAAAC } \\
\text { CCGCTACTGAAATAAACATGGTCGCCCTTGCATGAGACAGTGATGC } \\
\text { AAACAGGCCACTTCCTTCCTTCAGGGTCCTCAATCACCGTGCTTGGC } \\
\text { TTTTTGGCCAGCTCAGTTGCCGCAGCAAAACTAGATGGCATACGCTT } \\
\text { CCAGGAAGAATAATCATAACACATTCGTTATAATCAGAGGGAAATA } \\
\text { TCAAAGGGAATTCAGTTATAATGGGATTTGAC }\end{array}$ & СтTC & $\mathrm{s}$ & 23,37 & 174 & $\begin{array}{l}\text { ATCCCATTAGCTTCG } \\
\text { GTGAA }\end{array}$ & 59,5 & $\begin{array}{l}\text { CTGGAAGCGTATGC } \\
\text { CATCTA }\end{array}$ & 58,9 & 45 & 50 \\
\hline 709 & BrPe4231 & $\begin{array}{l}\text { Maracuja_ } \\
\text { NoIndex_L } \\
\text { 003_R1_00 } \\
\text { 1_contig_4 } \\
8314\end{array}$ & 4 & 350 & 361 & 12 & 3 & 8 & $\begin{array}{l}\text { TGTTTCACGATTCTTCGAGATTTCGATCCCCATGTGGTTATAGGTAC } \\
\text { AGGAGGATACGTTTCTTTCCCTACTTGCCTTGCTGCTTTGCTCCAAG } \\
\text { GAATCAAGATTGTGATCCAGGAACAGAATTCTGTCCCTGGAACAGC } \\
\text { AAATTATATACTTTCTTTCTTTGCTGCGGCAGTCTTTGTGGCTTATAA } \\
\text { TTCGACTGTTGAGTGTTTTCCCCATAATAAGCATAAGTGCGTGGTGA } \\
\text { GTGGCAATCCTATCAGGTTGTCATTAAGACGTTTCGTGTCAAAGGCG } \\
\text { GTGGCGAGGTCAGAGTTCTTTCCAAGGTCC }\end{array}$ & СтTT & G & 15,25 & 160 & $\begin{array}{l}\text { CTGCTTTGCTCCAAG } \\
\text { GAATC }\end{array}$ & 60,0 & $\begin{array}{l}\text { CCACTCACCACGCA } \\
\text { CTTATG }\end{array}$ & 60,2 & 50 & 55 \\
\hline 710 & BrPe4232 & $\begin{array}{l}\text { Maracuja_ } \\
\text { NoIndex_L } \\
\text { 003_R1_00 } \\
\text { 1_contig_4 } \\
8385\end{array}$ & 4 & 2614 & 2625 & 12 & 3 & 8 & $\begin{array}{l}\text { GAAATTACTGGGCTTTGATTTTATGTGTTGGCATTTTGGTTAGGGTTT } \\
\text { CTATTTCAGATGCAATTCTGCACATTTTGTTTGGGTTTCCTTTTTTTTC } \\
\text { CTTCTGCGTTGTTAGTATGTTTAAAATACATAGGATAATGGAGATTT } \\
\text { CTGGTGATTTATTTATTTTTCTATAAAAGACTGACCAAATGACATTA } \\
\text { TAGAGCCTTTGATAATGCTTTAGCCATTTGAGTCCTGGCCGATGTTG } \\
\text { ATCTTCTATTTGAAGTGACCACATTGGTAAAGAACCTAGTAGGATGT } \\
\text { TTTTCTGACTTGAATTCAATGGATGAT }\end{array}$ & Aтtт & $\mathrm{s}$ & 13,73 & 175 & $\begin{array}{l}\text { CCTTCTGCGTTGTTAG } \\
\text { TATGTTT }\end{array}$ & 57,6 & $\begin{array}{l}\text { TCTTTACCAATGTGG } \\
\text { TCACTTCA }\end{array}$ & 59,5 & 39,1 & 39,1 \\
\hline
\end{tabular}

G: genoma funcional

S: genoma estructural

P: polimórfico

M: monomórfico 
APÉNDICE

Marcadores microssatélites desenhados a partir do sequênciamento parcial e da montagem de novo do genoma de $P$. edulis

\begin{tabular}{|c|c|c|c|c|c|c|c|c|c|c|c|c|c|c|c|c|c|c|c|}
\hline $\mathbf{N}^{\circ}$ & Primer & Contig I & Motivo & Início & Fim & pb & $\begin{array}{c}\mathbf{N}^{\circ} \\
\text { Repet }\end{array}$ & Score & Sequência do contig & Unidade & G/S & Cobertura & pb & Sequência Forward & $\begin{array}{l}\mathrm{T}^{\circ} \mathrm{C} \\
F w d \\
\end{array}$ & Sequência Reverse & $\begin{array}{r}\mathrm{T}^{\circ} \mathrm{C} \\
\operatorname{Rev} \\
\end{array}$ & $\begin{array}{c}\% \mathrm{GC} \\
F w d \\
\end{array}$ & $\begin{array}{c}\% \mathrm{GC} \\
\operatorname{Rev}\end{array} \quad \mathrm{P} / \mathrm{M}$ \\
\hline 711 & BrPe4233 & $\begin{array}{l}\text { Maracuja_ } \\
\text { NoIndex_L } \\
\text { 003_R1_00 } \\
\text { 1_contig_4 } \\
\text { 8458 }\end{array}$ & 4 & 468 & 479 & 12 & 3 & 8 & $\begin{array}{l}\text { TTTTTGTTTTTTTTTTTGGCTTTCAATTCAGTGTCCTGTTTGGTAATTA } \\
\text { TGGAGGTGGTGGCCAGTGTGAGTTATGTGGAGAGGGCTTTGTGGGT } \\
\text { TTCCTCTTTAATGGAAACTATGGTGGTTGAGACTGTTTGTGCTGCGG } \\
\text { CAAAGTCTCTTGCTTGCTTGATTTTTGTGGTATAGCTTCCATTTAACT } \\
\text { CTTCTTCCCTGGAGTTATTGTTTCTTAAAATTAGTGCTTTTTGTTTGA } \\
\text { TTGTACTCGTGTGTATGTGGTTTGTGGGTGGTTTTGTGTTCTGAGATG } \\
\text { GTTGGATATTGCTCCTCTTTCGTTGT }\end{array}$ & CTTG & $\mathrm{s}$ & 16,7 & 218 & $\begin{array}{l}\text { GTGGTGGCCAGTGTG } \\
\text { AGTTA }\end{array}$ & 59,6 & $\begin{array}{l}\text { AAACCACCCACAAA } \\
\text { CCACAT }\end{array}$ & 60 & 55 & 45 \\
\hline 712 & BrPe4234 & $\begin{array}{l}\text { Maracuja_ } \\
\text { NoIndex_L } \\
\text { 003_R1_00 } \\
\text { 1_contig_4 } \\
9212\end{array}$ & 4 & 392 & 403 & 12 & 3 & 8 & $\begin{array}{l}\text { CCTTTCAATCCACTGCTTAATAGACAAGACATTGATTCCTGATGCTT } \\
\text { GGTATTCAGAGACTACAATGGAAGATAAAAGTGAAAGATAAAGAA } \\
\text { ACAACTTCCAGATTATATACAAGTAAAAGACTAAAATAGTTAATGC } \\
\text { ATTCCATCACCTTTTGTTTGTTTGAAATCTTTCCTTCCATATAGATTT } \\
\text { TACAGTTTCTGCTGTGACAATGGACGACATACTGAAACATTACGGA } \\
\text { ATCGAAAAAACTACTAACAAGAAGCTGCAGATTTATATATCTTCCTT } \\
\text { AGATCTTTTGCAACATCTATCATGGTTGGTCTA }\end{array}$ & TTTG & $\mathrm{s}$ & 15,95 & 185 & $\begin{array}{l}\text { CATTGATTCCTGATGC } \\
\text { TTGG }\end{array}$ & 59,1 & $\begin{array}{l}\text { GTCGTCCATTGTCA } \\
\text { CAGCAG }\end{array}$ & 60,3 & 45 & 55 \\
\hline 713 & BrPe4235 & $\begin{array}{l}\text { Maracuja_ } \\
\text { NoIndex_L } \\
\text { 003_R1_00 } \\
\text { 1_contig_4 } \\
9604\end{array}$ & 4 & 731 & 742 & 12 & 3 & 8 & $\begin{array}{l}\text { TTTTACTCAGGTTCGCGTGATGTCCGGAGTAAAGTATAATACTACTG } \\
\text { CGGATGAGTATTTTAAATCACGATATCGATTTGGATCCATAACAGTA } \\
\text { GCATCTGAACGCACCACGTAAAAAGGGGACAAACTATAGCAAAT } \\
\text { GCTGCTACTACATTTATTATTTTACCCGGATATATAAAACTATAAC } \\
\text { TCCATAATTTAAAAAAGAAAGAGAGGAGAAGTGATGTGAGGCCTGG } \\
\text { GATTTTTCATATATGGATAGGTTGATTATTAATGATGCAAGAGACTG } \\
\text { CCCGAATTATAAATAACTTTGTATTCCATGTGA }\end{array}$ & ATTT & $\mathrm{s}$ & 14,98 & 175 & $\begin{array}{l}\text { CCACGTAAAAAGGGG } \\
\text { ACAAA }\end{array}$ & 59,8 & $\begin{array}{l}\text { GGGCAGTCTCTTGC } \\
\text { ATCATT }\end{array}$ & 60,2 & 45 & 50 \\
\hline 714 & BrPe4236 & $\begin{array}{l}\text { Maracuja_ } \\
\text { NoIndex_L } \\
\text { 003_R1_00 } \\
\text { 1_contig_4 } \\
9845\end{array}$ & 4 & 568 & 579 & 12 & 3 & 8 & $\begin{array}{l}\text { TGCGTGATAACTGAGCCCATAATCAGTGGTCGTTTTCCCACAATGGC } \\
\text { AGAGGACATTTTCATGGCCACCCAACATCTGAGGTTACCCGAATCT } \\
\text { TCTTCTTCATGCATTACAAAAAGAAAAACTCTATCTTACTTAATGTG } \\
\text { GCGGCAAAATCCTTCCTTCCTGAGAAACTATAGGCCTGAAGTCTATG } \\
\text { CTGATACCCATAAGAGTTATGCTGATACCCGACGTCGTGACCTAGA } \\
\text { GTTCGAGGTTGGGGATATGGTTTTTCTGAGAGTTGCTCCATGGAGGG } \\
\text { GAGTTATACGGTTCAGGCAGCGGGGTAAGCT }\end{array}$ & ТССТ & $\mathrm{s}$ & 260,09 & 173 & $\begin{array}{l}\text { TACTTAATGTGGCGG } \\
\text { CAAAA }\end{array}$ & 59,2 & $\begin{array}{l}\text { CGCTGCCTGAACCG } \\
\text { TATAAC }\end{array}$ & 60,7 & 40 & 55 \\
\hline 715 & BrPe4237 & $\begin{array}{l}\text { Maracuja_ } \\
\text { NoIndex_L } \\
\text { 003_R1_00 } \\
\text { 1_contig_5 } \\
0045\end{array}$ & 4 & 854 & 865 & 12 & 3 & 8 & $\begin{array}{l}\text { TATTTACTGTTGGCGTTAGTAATTATAGTCAGGACTGGTTTTACGTG } \\
\text { CATGTCAACAGGTAGGTGTTTCCCATGTCAATAATCTCCCCTTCTG } \\
\text { TACGTTCGGTGCTAATATCTCTAAATCAAAATGCAGACATACAGGG } \\
\text { GCAAAAACCTACCAACCAACCACATGGCAGGTTATCTTTGAACTCG } \\
\text { AAAACGTGCAACAAAATGGTAACTACACACTCCAATTGGCGTTGGC } \\
\text { ATCAGCTGCCTCATCTGAAATCAAGGTAAAAATACTGAAGATTGGT } \\
\text { AGTGTTACAGGTTGGAAGAACTTCGCAAAATGAA }\end{array}$ & ACCA & G & 17,4 & 169 & $\begin{array}{l}\text { TCTCCССTTCTGTACG } \\
\text { TTCG }\end{array}$ & 60,2 & $\begin{array}{l}\text { TTCAGATGAGGCAG } \\
\text { CTGATG }\end{array}$ & 60,1 & 55 & 50 \\
\hline
\end{tabular}

G: genoma funcional

S: genoma estructural

P: polimórfico

M: monomórfico 
APÉNDICE

Marcadores microssatélites desenhados a partir do sequênciamento parcial e da montagem de novo do genoma de $P$. edulis

\begin{tabular}{|c|c|c|c|c|c|c|c|c|c|c|c|c|c|c|c|c|c|c|c|}
\hline $\mathbf{N}^{\circ}$ & Primer & Contig M & Motivo & Início & Fim & pb & $\begin{array}{c}\mathrm{N}^{\mathbf{o}} \\
\text { Repet }\end{array}$ & Score & Sequência do contig & Unidade & G/S & Cobertura & pb & Sequência Forward & $\begin{array}{l}\mathrm{T}^{\circ} \mathrm{C} \\
\text { Fwd }\end{array}$ & Sequência Reverse & $\begin{array}{l}\mathrm{T}^{\circ} \mathrm{C} \\
\operatorname{Rev} \\
\end{array}$ & $\begin{array}{c}\% \mathrm{GC} \\
F w d \\
\end{array}$ & 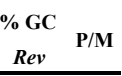 \\
\hline 716 & BrPe4238 & $\begin{array}{l}\text { Maracuja_ } \\
\text { NoIndex_L } \\
\text { 003_R1_00 } \\
\text { 1_contig_5 } \\
0065\end{array}$ & 4 & 1066 & 1077 & 12 & 3 & 8 & $\begin{array}{l}\text { AGTAGGTATGCTTAGTCACTGAGCACTAACCGTTGTTCAAGTTAAAT } \\
\text { GTGATAGTAATGGCATTTGCTTTCACCTTTTTTGTAGGTGAAAAAGG } \\
\text { CATCGCATCGGCTCAAGCAATGGCTCATAGAAAAAGGTTCACGGGA } \\
\text { ATCTGAAGAACCATCCATCCATTAGAGGCGCAACAAGTTTCTCTTAA } \\
\text { CATTAAAGAGCAATCCTCCACCGTTGATGTATGGCATATAGATGTGC } \\
\text { TACCTACTAGTATGGTTGCGTGCAAAACCAAAAACTATTATATTAAA } \\
\text { CACTTCAATCAGTTAATTGTTTTTTATATTG }\end{array}$ & CCAT & $\bar{G}$ & 17,03 & $\begin{array}{r}158 \mathrm{C} \\
\mathrm{C}\end{array}$ & $\begin{array}{l}\text { GCTCAAGCAATGGCT } \\
\text { CATAGA }\end{array}$ & 60,5 & $\begin{array}{l}\text { GTTTTGCACGCAAC } \\
\text { CATACT }\end{array}$ & 58,7 & 47,6 & 45 \\
\hline 717 & BrPe4239 & $\begin{array}{l}\text { Maracuja_ } \\
\text { NoIndex_L } \\
\text { 003_R1_00 } \\
\text { 1_contig_5 } \\
0084\end{array}$ & 4 & 1872 & 1883 & 12 & 3 & 8 & $\begin{array}{l}\text { GCAATGAGCATTCCTAGTGAACAGTATTACAAGATAACTCTTAATA } \\
\text { AGAACAGAGTAAATGTAAAAGGAATTATTACTAGAAAAATATAACC } \\
\text { TACAGAGGGGATTAACAGTCTTCATATCAAAAATTCCATAGACTAA } \\
\text { TAAAGAGAAATGTATCTATCTATCGGCCATATCTTATCACACTATAT } \\
\text { GGTGTACCTGATGCTTCTTCACATTTCTTTCTTACAAGGGTTATATAG } \\
\text { TTAGTCATTTGCCATGCCAAAGCATCTGTTATCCAATAACAAATTTC } \\
\text { CTTCAAATGCCACTTCATTTGTTCTGTCTGTC }\end{array}$ & TATC & $\mathrm{s}$ & 16,2 & $159 \mathrm{C}$ & $\begin{array}{l}\text { CAGAGGGGATTAACA } \\
\text { GTCTTCA }\end{array}$ & 58,3 & $\begin{array}{l}\text { TTGGCATGGCAAAT } \\
\text { GACTAA }\end{array}$ & 60,1 & 45,5 & 40 \\
\hline 718 & BrPe4240 & $\begin{array}{l}\text { Maracuja_ } \\
\text { NoIndex_L } \\
\text { 003_R1_00 } \\
\text { 1_contig_5 } \\
0398\end{array}$ & 4 & 1005 & 1016 & 12 & 3 & 8 & $\begin{array}{l}\text { AGGGTCTTTACTTCAGTTAATTGAATGCCTAAGTTTAACATGTTCTT } \\
\text { ACGTAATCATAGGAGGGCATGCTTGTTCAGTCACGGCTGGAGATGC } \\
\text { TTCAAGGTTAGTAGTTCAACTTACTTTTTTCTTGATTTTCATCAGTCT } \\
\text { ATGGTTGATTTTGTTTGTTTGATTTACACTTGGTTTTGCTTAAAGGGG } \\
\text { TTTGCTTGCGTCTTATGAAGAGAACTTGGGTAGGATAATACTTCAAC } \\
\text { GTGTTATATAAGGAATTTCTCTGCCTAATTTATAAGATCGAAATTTG } \\
\text { AGTTGCATTGCCTAAATTATAGTCATTAA }\end{array}$ & TTTG & $\mathrm{s}$ & 13,81 & $\begin{aligned} 158 \mathrm{C} \\
\mathrm{T}\end{aligned}$ & $\begin{array}{l}\text { CATAGGAGGGGATGC } \\
\text { TTGTT }\end{array}$ & 60,1 & $\begin{array}{l}\text { TCTCTTCATAAGAC } \\
\text { GCAAGCAA }\end{array}$ & 60,2 & 50 & 40,9 \\
\hline 719 & BrPe4241 & $\begin{array}{l}\text { Maracuja_ } \\
\text { NoIndex_L } \\
003 \text { R1_00 } \\
\text { 1_contig_5 } \\
0672\end{array}$ & 4 & 182 & 193 & 12 & 3 & 8 & $\begin{array}{l}\text { AGGGCGAGAGTAGCCATGGTGGTGATGCAGCCAGACTTAGACAATC } \\
\text { TCGATCGAGACAGACCTTGCCCCAGATTCTAGGAGCTCAGCCAGAG } \\
\text { GTTGTGGCACGAGTGCCAGATGAGGATCCTGTTGATAGAGTTTACC } \\
\text { AGGATGGAGATTTGGATGGATGGAGACAGTCAGTTGGCCAGCCAGT } \\
\text { TACTGTGAGGCCATCTAGACCCAGACTCCGAGCCCAGG }\end{array}$ & TGGA & G & 683,54 & $169 \mathrm{~T}$ & $\begin{array}{l}\text { TGGTGATGCAGCCAG } \\
\text { ACTTA }\end{array}$ & 60,4 & $\begin{array}{l}\text { AGTAACTGGCTGGC } \\
\text { CAACTG }\end{array}$ & 60,3 & 50 & 55 \\
\hline 720 & BrPe4242 & $\begin{array}{l}\text { Maracuja_ } \\
\text { NoIndex_L } \\
003 \text { R1_00 } \\
\text { 1_contig_5 } \\
0727\end{array}$ & 4 & 568 & 579 & 20 & 5 & 16 & $\begin{array}{l}\text { AGAGCAAGTATACCGCAAGTTTCTTTTTCAAGTCCCCACGTTCAATG } \\
\text { CATCATTTGGACACTGGTTGCTTCATGTGCAAGCTTGAGCTCTTTCG } \\
\text { TCTGTGACAACAAGATTTAGAAGCTAAAATGAAAGGACTAAAGCGT } \\
\text { TTAAGCCACCACCAACCAACCAGCGGTCAGGCGAATCTGAAACATA } \\
\text { TCCAAGCAGCAGAACTACACCTGCGGTGCCGCTTGGATTACATAA } \\
\text { TTTTGATCTGACAGCCAGAGATTTCCTGAATATCCCAAAAAAGTTAC } \\
\text { CAATATCTGGAACATTTTTATGTAATAACTACA }\end{array}$ & ACCA & G & 16,86 & $169 \mathrm{~T}$ & $\begin{array}{l}\text { TGCATCATTTGGACA } \\
\text { CTGGT }\end{array}$ & 60,0 & $\begin{array}{l}\text { ACCGCAGGTGTAGT } \\
\text { TTCTGC }\end{array}$ & 60,3 & 45 & 55 \\
\hline
\end{tabular}

G: genoma funcional

S: genoma estructural

P: polimórfico

M: monomórfico 
APÉNDICE

Marcadores microssatélites desenhados a partir do sequênciamento parcial e da montagem de novo do genoma de $P$. edulis

\begin{tabular}{|c|c|c|c|c|c|c|c|c|c|c|c|c|c|c|c|c|c|c|c|}
\hline $\mathbf{N}^{\circ}$ & Primer & Contig M & Motivo & Início & Fim & pb & $\begin{array}{c}\mathrm{N}^{\mathbf{o}} \\
\text { Repet }\end{array}$ & Score & Sequência do contig & Unidade & G/S & Cobertura & pb & Sequência Forward & $\begin{array}{l}\mathrm{T}^{\circ} \mathrm{C} \\
F w d \\
\end{array}$ & Sequência Reverse & $\begin{array}{l}\mathrm{T}^{\circ} \mathrm{C} \\
\operatorname{Rev} \\
\end{array}$ & $\begin{array}{c}\% \mathrm{GC} \\
F w d \\
\end{array}$ & 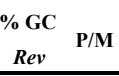 \\
\hline 721 & BrPe4243 & $\begin{array}{l}\text { Maracuja_ } \\
\text { NoIndex_L } \\
\text { 003_R1_00 } \\
\text { 1_contig_5 } \\
0785\end{array}$ & 4 & 962 & 973 & 12 & 3 & 8 & $\begin{array}{l}\text { TCCAATACCTAATATATTTTGTATTTTATAAGATTTACTTCCATGACC } \\
\text { ACTGCAGCGATAATCTCGTTATCTTCAGCAAGATTTTCTTGAGGACT } \\
\text { TGATTGAGGTGGTTGCATTGGATATGCTCTCTGTACATTGTTTCCTTG } \\
\text { TTGGTTATTTGTTTGTTTGCATTAGTATGCTTTATGTCTTGGTTTTCTA } \\
\text { CAAACAAAGCAAACTATCCTTCTCTTTTGAATTCTATTATCATCTCTC } \\
\text { TTGAGTATGCTTGGTTTTTTATATCGCCATGTTAAACTCCTAAAATAT } \\
\text { AGAGTTTAACATGTTAATTTGATA }\end{array}$ & TTTG & $\bar{G}$ & 50,14 & 155 & $\begin{array}{l}\text { TGAGGTGGTTGCATT } \\
\text { GGATA }\end{array}$ & 59,9 & $\begin{array}{l}\text { CCAAGCATACTCAA } \\
\text { GAGAGATGA }\end{array}$ & 58,6 & 45 & 43,5 \\
\hline 722 & BrPe4244 & $\begin{array}{l}\text { Maracuja_ } \\
\text { NoIndex_L } \\
\text { 003_R1_00 } \\
\text { 1_contig_5 } \\
0950\end{array}$ & 4 & 1190 & 1201 & 12 & 3 & 8 & $\begin{array}{l}\text { GACAAGTCCCGTAATATTTCAATATTGTCTGGATCAATTCTTAATGC } \\
\text { ATTTCGATAGCATTTGATGGCCTCTCTATATTCTCTGTCAGACCGAT } \\
\text { AAAGGAGACCATAAACATGCCAGCAAACATGACTTTTAAGGTCATT } \\
\text { CTGCATGGGCAAGAAAGAAAGAGCTCACATCAAGTTACAGAAACA } \\
\text { ATGATATCAAAAAAAAAAAAATTATACAACATTTAGAGAGAGCTTC } \\
\text { TTGACCTTTAAGCCTAGCCTGACAAGTTCATATGCTTCAGATTCATT } \\
\text { GATAAAGTTTCTGGTCAAGGGAGAAGAAAGAATT }\end{array}$ & AAGA & $\mathrm{s}$ & 16,1 & 162 & $\begin{array}{l}\text { TTGTCTGGATCAATTC } \\
\text { TTAATGC }\end{array}$ & 58,3 & $\begin{array}{l}\text { TTGTTTCTGTAACTT } \\
\text { GATGTGAGC }\end{array}$ & 58,5 & 34,8 & 37,5 \\
\hline 723 & BrPe4245 & $\begin{array}{l}\text { Maracuja_ } \\
\text { NoIndex_L } \\
\text { 003_R1_00 } \\
\text { 1_contig_5 } \\
\text { 1153 }\end{array}$ & 4 & 744 & 755 & 12 & 3 & 8 & $\begin{array}{l}\text { AAGTTTTAGTGTTATGGTTGAATTCTTGAGGTTCGGTATCTCAGTTAT } \\
\text { GGTTTCCTAGAGTTGTCTTGGGTTCCATAGGATGTCAGGGAGTGTCT } \\
\text { GAAAGAGTTTACTGAGGATTTTATTTCTGTTGAATTATTTTAGGATA } \\
\text { CTGATATCTTATTTATTTATATTTTAGATGTAAAATTATGACACAGAT } \\
\text { ATCGATGCATATCTCAATAGGACATTGACAACCTAGGTGAGTTGGA } \\
\text { CCTTATTTAAATTGTTTCAAGTATTTTTTTTAAAATTTCTATTTTTA } \\
\text { TTTTGAGATTATTTAACTATTGATATT }\end{array}$ & TTAT & $\mathrm{s}$ & 23,52 & 169 & $\begin{array}{l}\text { GGGTTCCATAGGATG } \\
\text { TCAGG }\end{array}$ & 59,2 & $\begin{array}{l}\text { TCCAACTCACCTAG } \\
\text { GTTGTCA }\end{array}$ & 58,2 & 55 & 47,6 \\
\hline 724 & BrPe4246 & $\begin{array}{l}\text { Maracuja_ } \\
\text { NoIndex_L } \\
\text { 003_R1_00 } \\
\text { 1_contig_5 } \\
\text { 1495 }\end{array}$ & 4 & 2401 & 2412 & 12 & 3 & 8 & $\begin{array}{l}\text { TACAGTAAGGGAGAACTCGAGAAACTTGAGGGTAAAAGATCCGCCAA } \\
\text { AGAGGATACTTGAAACAGAGTGTATCCAGAAGCTATCTACTCAA } \\
\text { TCTATGGCTACAAAATGGACCAACGTATCGATCTACAACACTGGGG } \\
\text { GTAGATATTATCTTTATTTATTTAATTTTTTGTGTGGGTTGGTTGCCT } \\
\text { TTAATATATATTTTGGGTCAGCCTAACAGACTCACTCTTATCATTGC } \\
\text { ATTCTTTAAATATCGGAGCTGTAAACTGGTTGTGTACCTGGCAGAGT } \\
\text { CTGTCCTGTACTTGCTGCGATGCGAATCTACC }\end{array}$ & TTTA & $\mathrm{s}$ & 13,52 & $157^{\circ}$ & $\begin{array}{l}\text { TAAAGATCCGCCAAA } \\
\text { GAGGA }\end{array}$ & 59,8 & $\begin{array}{l}\text { TAAAGGCAACCAAC } \\
\text { CCACAC }\end{array}$ & 60,8 & 45 & 50 \\
\hline 725 & BrPe4247 & $\begin{array}{l}\text { Maracuja_ } \\
\text { NoIndex_L } \\
\text { 003_R1_00 } \\
\text { 1_contig_5 } \\
\text { 1618 }\end{array}$ & 4 & 717 & 728 & 12 & 3 & 8 & $\begin{array}{l}\text { TCACAGTCTCCTGTGCAGACATTCTAGCCATTGCTGCCAGGGATGCA } \\
\text { GTAGCATCGGTAAACATCTATTCTTAAAGAACATGATTCTCCTATCA } \\
\text { TCCATCAACCTCAACATCTTTTTTTCTTTTCCTCTGTAATAATCTGTG } \\
\text { GTTTTCTACATGCATGCATGGAAAGAGAGGTGGCCCAAGCTGGAAA } \\
\text { GTTCTACTCGGCAGGAAGGACTCTCTGAAAGCAAGCTTTGATGGTG } \\
\text { CAAATCAGTTCATACCTGCTCCAAATTCCTCACTGGAGACTCTCATT } \\
\text { GCCAATTTCAAGCAACAGGGTCTTGGAATAG }\end{array}$ & CATG & $\mathrm{s}$ & 15,34 & 180 & $\begin{array}{l}\text { TTCCTCTGTAATAATC } \\
\text { TGTGGTTTTC }\end{array}$ & 59,1 & $\begin{array}{l}\text { ACCCTGTTGCTTGA } \\
\text { AATTGG }\end{array}$ & 60 & 34,6 & 45 \\
\hline
\end{tabular}

G: genoma funcional

S: genoma estructural

P: polimórfico

M: monomórfico 
APÉNDICE

Marcadores microssatélites desenhados a partir do sequênciamento parcial e da montagem de novo do genoma de $P$. edulis

\begin{tabular}{|c|c|c|c|c|c|c|c|c|c|c|c|c|c|c|c|c|c|c|c|}
\hline $\mathbf{N}^{\circ}$ & Primer & Contig I & Motivo & Início & Fim & pb & $\begin{array}{c}\mathbf{N}^{\circ} \\
\text { Repet }\end{array}$ & Score & Sequência do contig & Unidade & G/S & Cobertura & pb & Sequência Forward & $\begin{array}{l}\mathrm{T}^{\circ} \mathrm{C} \\
F w d \\
\end{array}$ & Sequência Reverse & $\begin{array}{r}\mathrm{T}^{\circ} \mathrm{C} \\
\operatorname{Rev} \\
\end{array}$ & $\begin{array}{c}\% \mathrm{GC} \\
F w d \\
\end{array}$ & $\begin{array}{cc}\% \mathrm{GC} & \mathrm{P} / \mathrm{M} \\
\operatorname{Rev} & \end{array}$ \\
\hline 726 & BrPe4248 & $\begin{array}{l}\text { Maracuja_ } \\
\text { NoIndex_L } \\
003 \text { R1_00 } \\
\text { 1_contig_5 } \\
1737\end{array}$ & 4 & 1207 & 1218 & 12 & 3 & 8 & $\begin{array}{l}\text { GAGGTCTTTGTTCCTGCTTCTCTTGGGGCTTGGCCTCCACTGTCTTAG } \\
\text { GCTTTTGGGCAGAATTTGGGCTTTGTCTATTAGGGCCCATGGCAGTC } \\
\text { TTTGGGAGGGTCAACTTTGGTGCAATGGATTTTTCCTTATTTTTGCCC } \\
\text { GAAGAATCTTGCTTGCTTGAGCTTTCCATAACAGTGTCTTGGGGTGA } \\
\text { TTCTCCATCAAGACCCAAATCAAGGATCTCCAAACGGGATCTTGATC } \\
\text { CCCCAATTTTCACTTCTGTCCATTGTGTGTTCTTTGGTTGGCTCTTTG } \\
\text { AACCCCAGACCCAGTTTGGACCGGTC }\end{array}$ & CTTG & $\mathrm{G}$ & 18,49 & 203 & $\begin{array}{l}\text { TTGGCCTCCACTGTCT } \\
\text { TAGG }\end{array}$ & 60,2 & $\begin{array}{l}\text { AGATCCCGTTTGGA } \\
\text { GATCCT }\end{array}$ & 59,9 & 55 & 50 \\
\hline 727 & BrPe4249 & $\begin{array}{l}\text { Maracuja_ } \\
\text { NoIndex_L } \\
\text { 003_R1_00 } \\
\text { 1_contig_5 } \\
\text { 1778 }\end{array}$ & 4 & 1169 & 1180 & 12 & 3 & 8 & $\begin{array}{l}\text { CTCCGCTGCAAAATTATTGAAAAAGTTGCCAAAGTCACCGGCGACA } \\
\text { TCAATCAAAATTCTCAATCAACCACCAACTTGATATTAGTATCATGG } \\
\text { CAGTTGGTCAACTGATTTAATGTTTGGGTTTATATATCAGCAGAGGG } \\
\text { TCCCCGTTATGATCGATCGATCAGGAAAAATCATATCTGTATGATTG } \\
\text { TTTTTCCTTTTCAGTTAGGTTTGATTGTGACAGTAACCAAGACTTGAT } \\
\text { ACTCTATACCACGATTGATATGCAGTTAAAAATAATAGTAACTCGTG } \\
\text { TGAAAATTATAGTTGAAGGGAAGACCAGTA }\end{array}$ & GATC & $\mathrm{s}$ & 14,3 & 225 & $\begin{array}{l}\text { CCGCTGCAAAATTAT } \\
\text { TGAAAA }\end{array}$ & 60,1 & $\begin{array}{l}\text { TTGGTTACTGTCACA } \\
\text { ATCAAACCT }\end{array}$ & 59,8 & 33,3 & 37,5 \\
\hline 728 & BrPe4250 & $\begin{array}{l}\text { Maracuja_ } \\
\text { NoIndex_L } \\
003 \text { R1_00 } \\
\text { 1_contig_5 } \\
2213\end{array}$ & 4 & 3833 & 3844 & 12 & 3 & 8 & $\begin{array}{l}\text { GCTTATGATGGTAACAATAATGCAAATTTGGTCTCTGCTCTTTGATA } \\
\text { AATCCGTTGACAAGAAGCACCATAGGAACAAACAAAGAGAACATA } \\
\text { ACAAAAGATAAAACGAAAAGCATTGTTGTCCATTGATATTGGAACT } \\
\text { ACAGGTCATTAGTGGATGGATGGACCAACACATCCATGGGATTGTG } \\
\text { CCTGATAACATATACAAATTATTAAATTTTAAAAGGAGAAACTCATT } \\
\text { GGAAAGCTGTTTCAAGGAAGTAATTCATTCCCTTTTTTAACTCGGAA } \\
\text { TTGTGAGATCCCAAAAACGAAAAAAAAAAACATA }\end{array}$ & TGGA & G & 16,77 & 191 & $\begin{array}{l}\text { ACGAAAAGCATTGTT } \\
\text { GTCCA }\end{array}$ & 59,2 & $\begin{array}{l}\text { TTTTTGGGATCTCAC } \\
\text { AATTCC }\end{array}$ & 58,9 & 40 & 38,1 \\
\hline 729 & BrPe4251 & $\begin{array}{l}\text { Maracuja_ } \\
\text { NoIndex_L } \\
\text { 003_R1_00 } \\
\text { 1_contig_5 } \\
\text { 2485 }\end{array}$ & 4 & 2323 & 2334 & 12 & 3 & 8 & $\begin{array}{l}\text { ATGAGTCACGCATGAGTTAACGGGGGAGGCTAACTTCAACTCTTCA } \\
\text { ACTCATATATTAGTATCTAATTGGGAAATGAATGGATAAATTATTGT } \\
\text { GTTTATGGGTTTAGTTTGGATTGAAGAAACTGTAATTTAAGTCAACA } \\
\text { GTCGTGGTTCGATAGATAGATATTTGCATCCATGACATTAGGTTGAA } \\
\text { ATGTCATAATTTTGCTCGGAATTTCGATATTGACATCTTAAACTGCG } \\
\text { AATATGTTCGTAGTGGGACATAGATGTTTGGTAATATGAACGCTTTA } \\
\text { AATCCAACACCAATAGTCTTATCATTTAATC }\end{array}$ & GATA & $\mathrm{s}$ & 17,61 & 158 & $\begin{array}{l}\text { TCTAATTGGGAAATG } \\
\text { AATGGA }\end{array}$ & 057 & $\begin{array}{l}\text { CAATATCGAAATTC } \\
\text { CGAGCAA }\end{array}$ & 60 & 33,3 & 38,1 \\
\hline 730 & BrPe4252 & $\begin{array}{l}\text { Maracuja_ } \\
\text { NoIndex_L } \\
\text { 003_R1_00 } \\
\text { 1_contig_5 } \\
\text { 2575 }\end{array}$ & 4 & 2645 & 2656 & 12 & 3 & 8 & $\begin{array}{l}\text { TAATAGTTGCAGGTAGAAAACAATCACATTTACTATTCAATGCCACC } \\
\text { TTTTGAGTATGTTATTAAGAATGTGGGGTTTTTAAAGGCTGAGGAG } \\
\text { GAAGTAGCAGGTTCTTTAAAAATTTGAGTGGATCATCACAAATGAC } \\
\text { TTACCTTTTGTATTTATTTATTCTATTCCTTTTTAAGAATATCCAAA } \\
\text { CATTTTTGGCTTATTGCAGGTCAAAAAATTATTTGCGGCATAGATTG } \\
\text { GAAGATTATAAAATGTGGATGTGGTTGATTCCCATGGTTTTGTACCA } \\
\text { ATGTGTAAGATTTTGATATGCCATTTTGGT }\end{array}$ & TATT & $\mathrm{s}$ & 20,36 & 155 & $\begin{array}{l}\text { AGGCTGAGGAGGAAG } \\
\text { TAGCA }\end{array}$ & 59,2 & $\begin{array}{l}\text { TTCCAATCTATGCC } \\
\text { GCAAAT }\end{array}$ & 60,4 & 55 & 40 \\
\hline
\end{tabular}

G: genoma funcional

S: genoma estructural

P: polimórfico

M: monomórfico 
APÉNDICE

Marcadores microssatélites desenhados a partir do sequênciamento parcial e da montagem de novo do genoma de $P$. edulis

\begin{tabular}{|c|c|c|c|c|c|c|c|c|c|c|c|c|c|c|c|c|c|c|c|}
\hline $\mathbf{N}^{\circ}$ & Primer & Contig & Motivo & Início & Fim & pb & $\begin{array}{c}\mathbf{N}^{\circ} \\
\text { Repet }\end{array}$ & Score & Sequência do contig & Unidade & G/S & Cobertura & pb & Sequência Forward & $\begin{array}{l}\mathrm{T}^{\circ} \mathrm{C} \\
F w d \\
\end{array}$ & Sequência Reverse & $\begin{array}{l}\mathrm{T}^{\circ} \mathrm{C} \\
\operatorname{Rev} \\
\end{array}$ & $\begin{array}{c}\% \mathrm{GC} \\
F w d \\
\end{array}$ & $\begin{array}{r}\% \mathrm{GC} \\
\operatorname{Rev} \\
\end{array}$ \\
\hline 731 & BrPe4253 & $\begin{array}{l}\text { Maracuja_ } \\
\text { Nolndex_L } \\
\text { 003_R1_00 } \\
\text { 1_contig_5 } \\
\text { 2786 }\end{array}$ & 4 & 1661 & 1672 & 12 & 3 & 8 & $\begin{array}{l}\text { TTTGTTTAACAAGTCCTAGGGGCTGTTATTTTGTTTCTTATTTTTACT } \\
\text { ATAAGTATGGAGCTTGTACCCCGAGTTAGACCCAGTCGAAGACCTG } \\
\text { GTTTGACATTTTAGTTGGTTTACCCATCAAGACATGTAGTTTGAGTA } \\
\text { GTCGAGTCACATTCATTCATTGAGCATTGCATGTGTAAGTCGTGCAT } \\
\text { TTTTTATTTTCAAATTGTGCGTGCACATGGATACGTGGAGTTCGAAG } \\
\text { GTTCAAATGGCGAGTGTGTTTCCAAGTCCCGATTGAGACGAGGTG } \\
\text { AGAGCACCCTGAGTATCTTATGAGTGTTTGG }\end{array}$ & $\begin{array}{l}\text { CATT } \\
\end{array}$ & $\bar{s}$ & 25,4 & 202 & $\begin{array}{l}\text { ACCCCGAGTTAGACC } \\
\text { CAGTC }\end{array}$ & 60,4 & $\begin{array}{l}\text { CGGGACTTGGAAAA } \\
\text { CACACT }\end{array}$ & 60 & 60 & 50 \\
\hline 732 & BrPe4254 & $\begin{array}{l}\text { Maracuja_ } \\
\text { NoIndex_L } \\
003 \_R 1 \text { 00 } \\
\text { 1_contig_5 } \\
3021\end{array}$ & 4 & 203 & 214 & 12 & 3 & 8 & $\begin{array}{l}\text { TACTGACACAAACTGCTAGAGCGGCAACCACTTCAGTTGCTTCTGTT } \\
\text { TCTGCGAATGGCTACATCTCTAAGGAGCAGATACGTCGAAACATAC } \\
\text { CAACCCAGAAGCGGTTTGTTGATTCTCATCGACAAGGCCTCATCGTG } \\
\text { GAGGAGAGTTACAGACAGACAGTTGTTATCAGGTCTTACGAAGTCG } \\
\text { GACCTGACAAAACTGCTACCCTCGAAAGCATCCTAAATCTTCTTCAG } \\
\text { GTAATAATAAACTTAAAACTTCTTGTATGGCTGTCCCTTGCACATAA } \\
\text { TAAGCATCGGCTTCGTGCCTTGCTGATATTAT }\end{array}$ & ACAG & G & 15,4 & 179 & $\begin{array}{l}\text { TGCTTCTGTTTCTGCG } \\
\text { AATG }\end{array}$ & 60,1 & $\begin{array}{l}\text { TGCTTTCGAGGGTA } \\
\text { GCAGTT }\end{array}$ & 60 & 45 & 50 \\
\hline 733 & BrPe4255 & $\begin{array}{l}\text { Maracuja_ } \\
\text { Nolndex_L } \\
\text { 003_R1_00 } \\
\text { 1_contig_5 } \\
3162\end{array}$ & 4 & 3129 & 3140 & 12 & 3 & 8 & $\begin{array}{l}\text { GGTATATCTGTGTATTCCTTTCAAAACTTTGTCTGTTCTGTATGGGCA } \\
\text { AAGACACATGTGGGTTAGGTTCGGTTTGAGAACATCGTGACTCTTAT } \\
\text { TCTGTCTCTACGTACCCCACCATTTGGTAAGCTGTGTGAACGAGACA } \\
\text { AAATGCCCACAAACAAACAAGCCACCACCTCGAAAATGATTGATGG } \\
\text { GTTTGCCTCCCTAACAGTATATTAAATACTAAGAAACCGATTCTTTA } \\
\text { TCATGCAATGATAACTAAGCGACAAATGTTCATGAATGTATGGTATT } \\
\text { CGGCTTTTGTTTCTTTTCAGCATCATTATT }\end{array}$ & ACAA & G & 17,38 & 239 & $\begin{array}{l}\text { TGGGTTAGGTTCGGT } \\
\text { TTGAG }\end{array}$ & 60,0 & $\begin{array}{l}\text { AAGAAACAAAAGCC } \\
\text { GAATACCA }\end{array}$ & 60 & 50 & 36,4 \\
\hline 734 & BrPe4256 & $\begin{array}{l}\text { Maracuja_ } \\
\text { NoIndex_L } \\
003 \_R 1 \text { 00 } \\
\text { 1_contig_5 } \\
3501\end{array}$ & 4 & 2114 & 2125 & 12 & 3 & 8 & $\begin{array}{l}\text { AACACTACTTTTCTCTTAATAAAAAAATCAGGAGTTTGATCATTACTT } \\
\text { TTAGCTGGCAACTCCTAATAAAAAGCATATCACTACATGTTCATATC } \\
\text { TACCAAGAATTTGCTTCAGGAATTCTTTATCCTTTTCCGCGCAATTTC } \\
\text { CATCTTCCTTTATTTATTTAATCTTACTGCAGAGGATATGATTACTTA } \\
\text { ATCATTATTATTAATTCATGCAGTAACATTAGTTTTAATATGTGTCG } \\
\text { TCATTGTCAAATCATTTTCGCATATTTGTAAGAAAAACAGACAAACT } \\
\text { AATCAACTCGTAGGAGATTGTGTGGAC }\end{array}$ & TTTA & $\mathrm{s}$ & 17,51 & 165 & $\begin{array}{l}\text { ACCAAGAATTTGCTT } \\
\text { CAGGA }\end{array}$ & 57,4 & $\begin{array}{l}\text { TGCGAAAATGATTT } \\
\text { GACAATG }\end{array}$ & 59,6 & 40 & 33,3 \\
\hline 735 & BrPe4257 & $\begin{array}{l}\text { Maracuja_ } \\
\text { Nolndex_L } \\
003 \_R 1 \text { 00 } \\
\text { 1_contig_5 } \\
3955\end{array}$ & 4 & 342 & 353 & 12 & 3 & 8 & $\begin{array}{l}\text { TACTGATCCAGCAATCCAGTACAAAGCTTACACTGACTATGCATTTG } \\
\text { ATATGGGATTGATTAAACAATCTGAGCACGATCGGATCAACAAGAT } \\
\text { GGTTCCGGTTTGTGAATTGGCGATAAAACTCTGCGGTATTGTGCCAA } \\
\text { CTCTTAACTGTTCTTTCTTTCTGCTTGATGGGTTTCTAATCTTCCTGA } \\
\text { CCTTTCCATTACTTTTAGGACATAATATTCTCATTACTTTGGTATTGG } \\
\text { CTGTTTTCAGCGTTCAATTTAAATTGTTCATGATGCTCTACAGTTCT } \\
\text { ATACTATTGGTATGTCATGCTTGCAGCT }\end{array}$ & ТтСт & $\mathrm{s}$ & 17,61 & 167 & $\begin{array}{l}\text { CAACAAGATGGTTCC } \\
\text { GGTTT }\end{array}$ & 59,8 & $\begin{array}{l}\text { GAACGCTGAAAACA } \\
\text { GCCAAT }\end{array}$ & 60,3 & 45 & 45 \\
\hline
\end{tabular}

G: genoma funcional

S: genoma estructural

P: polimórfico

M: monomórfico 
APÉNDICE

Marcadores microssatélites desenhados a partir do sequênciamento parcial e da montagem de novo do genoma de $P$. edulis

\begin{tabular}{|c|c|c|c|c|c|c|c|c|c|c|c|c|c|c|c|c|c|c|c|}
\hline $\mathbf{N}^{\circ}$ & Primer & Contig I & Motivo & Ińíio & Fim & pb & $\begin{array}{c}\mathbf{N}^{\mathbf{o}} \\
\text { Repet }\end{array}$ & Score & Sequência do contig & Unidade & G/S & Cobertura & pb & Sequência Forward & $\begin{array}{l}\mathrm{T}^{\circ} \mathrm{C} \\
F w d \\
\end{array}$ & Sequência Reverse & $\begin{array}{l}\mathrm{T}^{\circ} \mathrm{C} \\
\operatorname{Rev} \\
\end{array}$ & $\begin{array}{r}\% \mathrm{GC} \\
F w d \\
\end{array}$ & $\begin{array}{cc}\% \mathrm{GC} & \mathbf{P} / \mathbf{M} \\
\operatorname{Rev} & \\
\end{array}$ \\
\hline 736 & BrPe4258 & $\begin{array}{l}\text { Maracuja_ } \\
\text { Nolndex_L } \\
\text { 003_R1_00 } \\
\text { 1_contig_5 } \\
4241\end{array}$ & 4 & 402 & 413 & 12 & 3 & 8 & $\begin{array}{l}\text { CGACATGCAAGTACTGTAGAACTAGTTTCAGTAAAAAAGAGCAAACA } \\
\text { ATGCAGGTTGGAAAATGGACAACTGGCTGTTTCGATTAGACTAATA } \\
\text { AGCAAGTGATATTCGATGACTCACCATCTTTTGCCACTTGTGATATA } \\
\text { TACCAGTGATATCTTTCTTTCTTCCCTCTGCAGATCAAATATATTCAT } \\
\text { CCCAAATGCCCACCCACAGGCATGCGCATCAAAGTGTCTTGCAATA } \\
\text { TGATGATTCGAAAGGTTCCGATGAAAAGTTATACCACATGTTCCACT } \\
\text { GATCCATTCACTTTCCCACGCAAATTCACTGA }\end{array}$ & TCTT & $\bar{G}$ & 16,73 & 207 & $\begin{array}{l}\text { TGCAGGTTTGAAAAT } \\
\text { GGACA }\end{array}$ & 60,1 & $\begin{array}{l}\text { TCGGAACCTTTCGA } \\
\text { ATCATC }\end{array}$ & 60 & 40 & 45 \\
\hline 737 & BrPe4259 & $\begin{array}{l}\text { Maracuja_ } \\
\text { NoIndex_L } \\
003 \_R 1 \_00 \\
\text { 1_contig_5 } \\
4579\end{array}$ & 4 & 1825 & 1836 & 12 & 3 & 8 & $\begin{array}{l}\text { AAAGGCTTACCTCTTTGTACTGCTCACTTGCTGCAAGTGAATACTTT } \\
\text { TTCTGAAAGCTGGCAGCCCGTGATTTCCCAGAAAACGACATTTCTGG } \\
\text { TTGTGCTTTAAGGTTTTCGAACAACAACCAGAATCACGGCCAGAGA } \\
\text { CTTCAATTTTCCGGCCGGCCGGGACAGGGTTCTCGTAAGAAACAAG } \\
\text { TGATCTTGTGACGCTCAACATCAGCAGTAATAACCTTGCAGCCAAA } \\
\text { AGATCTAAGACTAAATTAATATAGTTTTGTAGATATCATCAACTTAC } \\
\text { AAATTAGTCAATCTAGCCGCTATATATACCGAT }\end{array}$ & CCGG & G & 15,4 & 168 & $\begin{array}{l}\text { CGGCCAGAGACTTCA } \\
\text { ATTTT }\end{array}$ & 59,3 & $\begin{array}{l}\text { CGGCTAGATTGACT } \\
\text { AATTTGTAAGTTG }\end{array}$ & 60,7 & 45 & 37 \\
\hline 738 & BrPe4260 & $\begin{array}{l}\text { Maracuja_ } \\
\text { NoIndex_L } \\
003 \_ \text {R1_00 } \\
\text { 1_contig_5 } \\
4613\end{array}$ & 4 & 374 & 385 & 12 & 3 & 8 & $\begin{array}{l}\text { GTCCTCACGAATGCGTAGGTCTCTGTAATTGTAAAGAGATAAATGTA } \\
\text { ATATCAACAAAGGATAAATTGTTTGAATTAATAACCAAGGTAGAGG } \\
\text { ATCCGGAGGAATAGAAAGAGTATCCAGATAGTCTTAAAGAATATGT } \\
\text { GGAACTAAAAGGAAAGAAAGAAAAGGTAGAAGCTTATAGCCTAAA } \\
\text { TGATATATTATTTAGAAAACCTAAAGAGAAAGTGGCAACAACTGAG } \\
\text { GATCTTAGAAACGAAGTATATATACTTAAGGAAGAAATGAAAAATA } \\
\text { TGAAAGAAGATTCGGATCAACTTAAGAGGCAAATAA }\end{array}$ & GAAA & $\mathrm{s}$ & 39,13 & 230 & $\begin{array}{l}\text { CCTCACGAATGCGTA } \\
\text { GGTCT }\end{array}$ & 60,3 & $\begin{array}{l}\text { TCCTCAGTTGTTGCC } \\
\text { ACTTTC }\end{array}$ & 60,3 & 55 & 47,6 \\
\hline 739 & BrPe4261 & $\begin{array}{l}\text { Maracuja_ } \\
\text { Nolndex_L } \\
\text { 003_R1_00 } \\
\text { 1_contig_5 } \\
\text { 5044 }\end{array}$ & 4 & 1415 & 1426 & 12 & 3 & 8 & $\begin{array}{l}\text { TTGTGTATTTTAAAATTGTCCAAATATTAATAAAAAAAATAAACCTG } \\
\text { ATGGAATCATTAACAAGTAGAACAGTTTAGTGCTGCTCTTATCTTTC } \\
\text { ATTGTCAATCGTGCTAAAGGTGTAATGAGTAAGGACAATAGTTTTA } \\
\text { TATTTTAGCTTCTTTCTTTCTCTTGCAAGTTTTCTATGTTTTAGACAG } \\
\text { AACATACAGAAAAAGGGAAAGCAAAAAAGTTCAAATCCTACCTAGT } \\
\text { ATTCCACCTTTTATTTCGGTTGTAGTTTCAGTTGGTTAATTGAAGA } \\
\text { CCCTACTAGTGCTAGATTCTAATTCCATA }\end{array}$ & TTCT & $\mathrm{s}$ & 16,43 & 164 & $\begin{array}{l}\text { TCATTGTCAATCGTGC } \\
\text { TAAAGG }\end{array}$ & 60,1 & $\begin{array}{l}\text { CCGAAATAAAAAGG } \\
\text { TGGGAAT }\end{array}$ & 59,2 & 40,9 & 38,1 \\
\hline 740 & BrPe4262 & $\begin{array}{l}\text { Maracuja_ } \\
\text { NoIndex_L } \\
\text { 003_R1_00 } \\
\text { 1_contig_5 } \\
5048\end{array}$ & 4 & 375 & 386 & 12 & 3 & 8 & $\begin{array}{l}\text { TGCCAACAAGTTAAAGCTGAGCATCAGCGACCGGCAGGCTTGTTAC } \\
\text { AGCCTTTGCCTATCCCAGAGTGGAAATGGGAGCACTTGACGATGGA } \\
\text { CTTCGTCGTAGGACTGCCAAGGACACAATGTGGTCATGATGTTGTTT } \\
\text { GGGTTATAGTGGACTGACTGACTAAGTCGACACACTTCTTGGCTATC } \\
\text { TGGGT }\end{array}$ & GACT & G & 845,66 & 161 & $\begin{array}{l}\text { ACCGGCAGGCTTGTT } \\
\text { ACAG }\end{array}$ & 61,2 & $\begin{array}{l}\text { CCCAGATAGCCAAG } \\
\text { AAGTGTG }\end{array}$ & 59,7 & 57,9 & 52,4 \\
\hline
\end{tabular}

G: genoma funcional

S: genoma estructural

P: polimórfico

M: monomórfico 
APÉNDICE

Marcadores microssatélites desenhados a partir do sequênciamento parcial e da montagem de novo do genoma de $P$. edulis

\begin{tabular}{|c|c|c|c|c|c|c|c|c|c|c|c|c|c|c|c|c|c|c|c|}
\hline $\mathbf{N}^{\circ}$ & Primer & Contig I & Motivo & Início & Fim & pb & $\begin{array}{c}\mathbf{N}^{\mathbf{o}} \\
\text { Repet }\end{array}$ & Score & Sequência do contig & Unidade & G/S & Cobertura & pb & Sequência Forward & $\begin{array}{l}\mathrm{T}^{\circ} \mathrm{C} \\
F w d \\
\end{array}$ & Sequência Reverse & $\begin{array}{r}\mathrm{T}^{\circ} \mathrm{C} \\
\operatorname{Rev} \\
\end{array}$ & $\begin{array}{c}\% \mathrm{GC} \\
F w d \\
\end{array}$ & $\begin{array}{cc}\% \mathrm{GC} & \mathrm{P} / \mathrm{M} \\
\operatorname{Rev} & \end{array}$ \\
\hline 741 & BrPe4263 & $\begin{array}{l}\text { Maracuja_ } \\
\text { NoIndex_L } \\
\text { 003_R1_00 } \\
\text { 1_contig_5 } \\
5480\end{array}$ & 4 & 1090 & 1101 & 12 & 3 & 8 & $\begin{array}{l}\text { TTGTCTCCTGCTCAGGATATTACTTTCAGGTATGAATCTGTCAAGTG } \\
\text { CTTGGTTAGCATCATCAAGTCCATGGGTACTTGGATGGGCCAACAGC } \\
\text { TGAAAGAAGGAGAGGTGTATTTGCCTAAGAGCTCCGACATTGATAC } \\
\text { TCCTACAGAGAATCAATCAATCCTGGGTGGAGAGGATCCAAGTGCC } \\
\text { TTTGAGAATGACTTCCATTCAGAAGTAAACCCAGAAATGTCACCTGC } \\
\text { TGCTACGCTTGAACAGCGTCGAGCTTATAAAATGGAACTCCTGGTA } \\
\text { GTTGTTGCCTACTCATTGTGATATTCAATATT }\end{array}$ & AATC & $\mathrm{G}$ & 16,51 & 184 & $\begin{array}{l}\text { GTCCATGGGTACTTG } \\
\text { GATGG }\end{array}$ & 60,0 & $\begin{array}{l}\text { CTGTTCAAGCGTAG } \\
\text { CAGCAG }\end{array}$ & 60 & 55 & 55 \\
\hline 742 & BrPe4264 & $\begin{array}{l}\text { Maracuja_ } \\
\text { NoIndex_L } \\
003 \text { R1_00 } \\
\text { 1_contig_5 } \\
5655\end{array}$ & 4 & 1481 & 1492 & 12 & 3 & 8 & $\begin{array}{l}\text { CTCCATTCCATAGTATCTTCATCGAAGAGGTAATGATGCATTTCATG } \\
\text { ATCTTTGCAGTGAGAAACTCAAGAATTCCTGTTAATGCAACGTTC } \\
\text { CTCGATGAACTCCCACTTCAGCCTGTCATAGGTTTTTTGTAAGTCAA } \\
\text { TCTTAATAGCCATCCATCCATGTTTTCTGGAATTTTTCCTCATCAAAT } \\
\text { GTATAATCTCTTGCACAATAATAATATTGTGAGTGATTTGTCTCTCCT } \\
\text { TCACAAAATTCGATTATGTATCAGTCACCCAATGATTCACTAGAGGT } \\
\text { TTTAGACGGTGAGTAATTAATTTAGTGA }\end{array}$ & CCAT & G & 20,31 & 150 & $\begin{array}{l}\text { TGCATTTCATGATCTT } \\
\text { TGCAG }\end{array}$ & 59,8 & $\begin{array}{l}\text { TGATGAGGAAAAAT } \\
\text { TCCAGAAAA }\end{array}$ & 59,9 & 38,1 & 30,4 \\
\hline 743 & BrPe4265 & $\begin{array}{l}\text { Maracuja_ } \\
\text { NoIndex_L } \\
003 \text { R1_00 } \\
\text { 1_contig_5 } \\
5657\end{array}$ & 4 & 667 & 678 & 12 & 3 & 8 & $\begin{array}{l}\text { TAGCGGATTTTGGATACGAGAGTGAGGTCAGACTTCTTCCGCAACG } \\
\text { ACGACGATGACATGTTGTGTGCAGTGCGGCCATGTTTGATCTCCTTA } \\
\text { CTCGCGCCCTTAATGTTTCCATTCTCAAGCAGCCAAGGTTCAGCAG } \\
\text { TGAAGCCATGTAGCTAGCTAGCAGATAGGGGCAAGCAACTAAAGCT } \\
\text { CTACTGTCACTATAGCAACTGAATCTAGAAACGGTGTGTGTGATTTT } \\
\text { GTGCTTGGCTAATAACTTTTTGTTGCGTCTCTAAAAGTACGAGTAAC } \\
\text { TGTTATAAATAGGGTACTAGTAGTGCAAATTT }\end{array}$ & TAGC & $\mathrm{s}$ & 12,27 & 151 & $\begin{array}{l}\text { AGTGCGGCCATGTTT } \\
\text { GAT }\end{array}$ & 60,1 & $\begin{array}{l}\text { CGTTTCTAGATTCAG } \\
\text { TTGCTATAGTG }\end{array}$ & 57,9 & 50 & 38,5 \\
\hline 744 & BrPe4266 & $\begin{array}{l}\text { Maracuja_ } \\
\text { NoIndex_L } \\
003 \text { R1_00 } \\
\text { 1_contig_5 } \\
5706\end{array}$ & 4 & 295 & 306 & 12 & 3 & 8 & $\begin{array}{l}\text { TCTGTGTCTCTAATCTCATCAATTTGAGACTGACTCCTACTAGCTTCC } \\
\text { TTAGAAAGGAATTCTATTTCTAGGAAACACCTCCTCTAGAACAAAC } \\
\text { ACTTTGTTGTCTTGTGGGTGGTAGAAATAATATCCTTTCGTTTCCTTA } \\
\text { GGATATCCAACAAACAAACACTTCTTAGACTTGGATTGTAATTTATC } \\
\text { AAGTGTCATACATCTCACGTATGCCTCACAACCCCAAATCTTGAGAT } \\
\text { ATGTGAGGTTGGGACTCTTCCCATACCATATCTCATA }\end{array}$ & AACA & G & 868,32 & 165 & $\begin{array}{l}\text { CTTTGTTGTCTTGTGG } \\
\text { GTGGT }\end{array}$ & 59,9 & $\begin{array}{l}\text { ATGGGAAGAGTCCC } \\
\text { АACCTC }\end{array}$ & 60,3 & 47,6 & 55 \\
\hline 745 & BrPe4267 & $\begin{array}{l}\text { Maracuja_ } \\
\text { NoIndex_L } \\
003 \text { R1_00 } \\
\text { 1_contig_5 } \\
5888\end{array}$ & 4 & 805 & 820 & 16 & 4 & 12 & $\begin{array}{l}\text { GAAAAAACAGAGCAGTAGACATAGTTGTGTACATGAAGCATTACCA } \\
\text { TTACAATGCTAGAGAACTGCTCCAGGTTACTGGCACAGAGTACTAC } \\
\text { GTATACCAACCTTAACTTCCCATGTTGAGCTGATGAACACAGATAGT } \\
\text { TCAAAACGATTGAAAGAAAGAAAGAAACAGAGGGTACTATGCTTTC } \\
\text { ATTTTTGACCAGTTGAAGTTGCATTCTGAACTTCTCCTCGGGTTTAA } \\
\text { ATGCCAGCAGAAATGAGCAAGGAATGAACAGTTGTCTCTCACAGT } \\
\text { GCATAACATGACTAACAGGAAATAAAAGCATGTTTGTT }\end{array}$ & GAAA & $\mathrm{s}$ & 16,09 & 185 & $\begin{array}{l}\text { CTCCAGGTTACTGGC } \\
\text { ACAGAG }\end{array}$ & 59,9 & $\begin{array}{l}\text { GCTCATTTCTGCTGG } \\
\text { CATTT }\end{array}$ & 60,4 & 57,1 & 45 \\
\hline
\end{tabular}

G: genoma funcional

S: genoma estructural

P: polimórfico

M: monomórfico 
APÉNDICE

Marcadores microssatélites desenhados a partir do sequênciamento parcial e da montagem de novo do genoma de $P$. edulis

\begin{tabular}{|c|c|c|c|c|c|c|c|c|c|c|c|c|c|c|c|c|c|c|c|}
\hline $\mathbf{N}^{\circ}$ & Primer & Contig M & Motivo & Início & Fim & pb & $\begin{array}{c}\mathrm{N}^{\mathbf{o}} \\
\text { Repet }\end{array}$ & Score & Sequência do contig & Unidade & G/S & Cobertura & pb & Sequência Forward & $\begin{array}{l}\mathrm{T}^{\circ} \mathrm{C} \\
F w d \\
\end{array}$ & Sequência Reverse & $\begin{array}{l}\mathrm{T}^{\circ} \mathrm{C} \\
\operatorname{Rev} \\
\end{array}$ & $\begin{array}{c}\% \mathrm{GC} \\
F w d \\
\end{array}$ & $\begin{array}{cc}\% \mathrm{GC} & \mathbf{P} / \mathrm{M} \\
\operatorname{Rev} & \end{array}$ \\
\hline 746 & BrPe4268 & $\begin{array}{l}\text { Maracuja_ } \\
\text { NoIndex_L } \\
\text { 003_R1_00 } \\
\text { 1_contig_5 } \\
6093\end{array}$ & 4 & 2144 & 2155 & 12 & 3 & 8 & $\begin{array}{l}\text { TGTGCCACCTAATCGGTTAGAACCTGTTTAAATCTATGTGTTTATCA } \\
\text { AAAAAAAATTATGCTCAACTAAGCCTTAATCCATGGCTTTCAATCCT } \\
\text { CAAGACAGCACAATCGGGCAACAAGTCAAAACAAAGATTAGGGAC } \\
\text { TTGGGTAGTAAAAATAAATAAATTAACATCTATGCACTAGTTTACAA } \\
\text { CGAAATCCAAGACACTTATTGGCAAAAACATCAAGAATGGGGCTGA } \\
\text { AAGGTCCCAATATAGCTTAAATCATCATATTTCTTCTTCTTCCCCTTT } \\
\text { TTTTAACTGCACGCACCTATCAGTTTAACCTG }\end{array}$ & AAAT & $\mathrm{s}$ & 20,38 & $\begin{array}{r}156 \mathrm{~A} \\
\mathrm{C}\end{array}$ & $\begin{array}{l}\text { ATCCATGGCTTTCAAT } \\
\text { CCTC }\end{array}$ & 58,9 & $\begin{array}{l}\text { CAGCCCCATTCTTG } \\
\text { ATGTTT }\end{array}$ & 59,9 & 45 & 45 \\
\hline 747 & BrPe4269 & $\begin{array}{l}\text { Maracuja_ } \\
\text { NoIndex_L } \\
\text { 003_R1_00 } \\
\text { 1_contig_5 } \\
6322\end{array}$ & 4 & 422 & 433 & 12 & 3 & 8 & $\begin{array}{l}\text { AATCAAGAATCAATTCAATATTTCTGTGCGCACATTACGAAGTGATA } \\
\text { ATGCCAAAGAATACTTGTCAGAAGCTTTTCAGGTATATATGAAGCA } \\
\text { ACATGGAATTCTTCACCAATCATCTTGTGTTGATACGCCTTCTCAGA } \\
\text { ATGGAGTGGCAGAAAGAAAGAATAGACACCTTCTTGAGACTACTCG } \\
\text { TGCTTTGTTGTTCCAAGTAAAAGTTCTTAAACAGATGCTATTTCCAC } \\
\text { TGCATGTTTTTTGATTAATCATATGCCATCTATAGTACTTGATGGTGA } \\
\text { CATCCCTTATAATATCCTTTTTCCTCGTAAG }\end{array}$ & AGAA & $\mathrm{s}$ & 61,12 & $177 \mathrm{~T}$ & $\begin{array}{l}\text { TGCGCACATTACGAA } \\
\text { GTGAT }\end{array}$ & 60,3 & $\begin{array}{l}\text { CTTGGAACAACAAA } \\
\text { GCACGA }\end{array}$ & 59,9 & 45 & 45 \\
\hline 748 & BrPe4270 & $\begin{array}{l}\text { Maracuja_ } \\
\text { NoIndex_L } \\
\text { 003_R1_00 } \\
\text { 1_contig_5 } \\
6475\end{array}$ & 4 & 346 & 357 & 12 & 3 & 8 & $\begin{array}{l}\text { GTTGAATTCTTTTACCAGGTTATTATTTGTTTCTCCTGTTATATATGT } \\
\text { AATAATGCTACAACAATGTATCTGGCATTTTAACATACACATGGAA } \\
\text { GCATAATATAATTTCCTCTGCCAAGTACAAGCCGTACCGTAATTAAC } \\
\text { GTTTAATATTAAATAAATAAAAAACGGTCCTTAAATGCAAAATCCA } \\
\text { GAAACTAATACCAATTCAAGGATGCTAAAAATCAGGCCCGAAACTC } \\
\text { GGTTGGAGTTTGGGAGGTCGGTCAGAAGGGGAAGTCCAGCAAGACA } \\
\text { TGTTGAAGGTTTCAGTACGAGTTGCATGGCCTG }\end{array}$ & TAAA & $\mathrm{s}$ & 15,04 & $199 \mathrm{~T}$ & $\begin{array}{l}\text { TCTGCCAAGTACAAG } \\
\text { CCGTA }\end{array}$ & 59,5 & $\begin{array}{l}\text { GCCATGCAACTCGT } \\
\text { ACTGAA }\end{array}$ & 59,9 & 50 & 50 \\
\hline 749 & BrPe4271 & $\begin{array}{l}\text { Maracuja_ } \\
\text { NoIndex_L } \\
\text { 003_R1_00 } \\
\text { 1_contig_5 } \\
6853\end{array}$ & 4 & 590 & 601 & 12 & 3 & 8 & $\begin{array}{l}\text { TTGCTATAGCGAGGAAGGTGGCTGTTGTCAACATGGAGTTTAATCCT } \\
\text { GTGATGATATTTTCTGCAACTGATCGCTGCGGGGTTATTCCGAGAG } \\
\text { GTGACTTGCTGGAGTTTTGAATGGTTTAGTAATAATTGATCCAGGCT } \\
\text { TCATCCGAGAAGAAAGAAAGAGTTGAAAAGATAGATATTATGCAAT } \\
\text { CCAATAATAAAATAAACTGAAATAATTGGTTGTCACAATCTTTCATA } \\
\text { TCAATATTTTCTTGCCAATGGAGTCTGGTCTTGTCTCGTCATTTGTTT } \\
\text { CATTGGTTGGTTTCGTGACTCTCACCATTC }\end{array}$ & AAGA & $\mathrm{s}$ & 13,93 & $186 \mathrm{~A}$ & $\begin{array}{l}\text { ATAGCGAGGAAGGTG } \\
\text { GCTGT }\end{array}$ & 61,2 & $\begin{array}{l}\text { TTGGATTGCATAAT } \\
\text { ATCTATCTTTTC }\end{array}$ & 57,1 & 55 & 26,9 \\
\hline 750 & BrPe4272 & $\begin{array}{l}\text { Maracuja_ } \\
\text { NoIndex_L } \\
\text { 003_R1_00 } \\
\text { 1_contig_5 } \\
6987\end{array}$ & 4 & 2048 & 2067 & 20 & 5 & 16 & $\begin{array}{l}\text { CGTTATGTTGGGTGCTAATTCTGATGCAATTTTACACTGCAGCAGGA } \\
\text { CGGCAAACTTCATTGTTCTTAACATCTTACAGGTCTTTCACCATCTCT } \\
\text { GTAATGAAAATGGAGAGAAACAAATGAAGTCACAAGCTACCATATC } \\
\text { TTCAGAACCTATTTATTATTTATTTATTGTTTTAATAGTTAGCCAG } \\
\text { GTAGCTTTTTTAGTTTTACTGCATGGGGAAGTACCATTGGAGTGATG } \\
\text { GGGCATGATCCACTGAAAAGAAATTGAGGGCTCCTCTGTACCGAA } \\
\text { CAAGCTCTGCTCTTCTAGCTTCCTTAGATGGGGCTCAT }\end{array}$ & ТАTT & $\mathrm{s}$ & 14,02 & $225 \mathrm{C}$ & $\begin{array}{l}\text { GGACGGCAAACTTCA } \\
\text { TTGTT }\end{array}$ & 60,0 & $\begin{array}{l}\text { AGCCCTGCAATTTC } \\
\text { TTTTCA }\end{array}$ & 59,8 & 45 & 40 \\
\hline
\end{tabular}

G: genoma funcional

S: genoma estructural

P: polimórfico

M: monomórfico 
APÉNDICE

Marcadores microssatélites desenhados a partir do sequênciamento parcial e da montagem de novo do genoma de P. edulis

\begin{tabular}{|c|c|c|c|c|c|c|c|c|c|c|c|c|c|c|c|c|c|c|c|}
\hline $\mathbf{N}^{\circ}$ & Primer & Contig $\mathrm{I}$ & Motivo & Início & Fim & pb & $\begin{array}{c}\mathbf{N}^{\circ} \\
\text { Repet }\end{array}$ & Score & Sequência do contig & Unidade & G/S & Cobertura & pb & Sequência Forward & $\begin{array}{l}\mathrm{T}^{\circ} \mathrm{C} \\
F w d\end{array}$ & Sequência Reverse & $\begin{array}{r}\mathrm{T}^{\circ} \mathrm{C} \\
\operatorname{Rev}\end{array}$ & $\begin{array}{r}\% \mathrm{GC} \\
F w d\end{array}$ & $\begin{array}{c}\% \mathrm{GC} \\
\operatorname{Rev}\end{array} \quad \mathrm{P} / \mathbf{M}$ \\
\hline 751 & BrPe4273 & $\begin{array}{l}\text { Maracuja_ } \\
\text { NoIndex_L } \\
\text { 003_R1_00 } \\
\text { 1_contig_5 } \\
7329\end{array}$ & 4 & 907 & 918 & 12 & 3 & 8 & $\begin{array}{l}\text { GAATCAGTTAATAAAGTATCTTTGGCGATATAATTTTCTAGTGTTGA } \\
\text { CTTGTACTGCACACGTCGGATAGCGTAAAAGTCATAAAGCTCCTTC } \\
\text { CCGTTCTGTCTTTATTTCAACTTCTTCCCGGTTTTCAACTCAGAAAAG } \\
\text { AAGTATCTCCCGCCCGCCCGTGGTTTTAGAAAAGCGGGATTTGACC } \\
\text { AACGGCTTCATCTGCCAAACAATGAGCTAATGCTTTTCGTTAAGTCA } \\
\text { TTTTCAATATTCTTTATGTTTATCTTTATATACTAAGAAACTCTTCC }\end{array}$ & CCCG & $\mathrm{s}$ & 17,32 & 164 & $\begin{array}{l}\text { TACTGCACACGTCGG } \\
\text { ATAGC }\end{array}$ & 59,9 & $\begin{array}{l}\text { GCTCATTGTTTGGCA } \\
\text { GATGA }\end{array}$ & 59,8 & 55 & 45 \\
\hline 752 & BrPe4274 & $\begin{array}{l}\text { Maracuja_ } \\
\text { NoIndex_L } \\
\text { 003_R1_00 } \\
\text { 1_contig_5 } \\
7865\end{array}$ & 4 & 334 & 353 & 20 & 5 & 16 & $\begin{array}{l}\text { AAAGGAAAAGGCAAATTATCGAAGAAAAAATAGGGTGGAAAGGAG } \\
\text { CCGTTGCGGTTAGTAATGGCATTTGATTGTGTAATAGCTTGGTTTTC } \\
\text { ACGTTAACTGAGAGAGAGATTGGTGTGGAGGTTAGGGGGATTCATT } \\
\text { TTTTGAAGCTAAGAAGGAAGGAAGGAAGGAAGAGCAAGTCATTAC } \\
\text { CCATCACCATAAGAAAGGAGCAGTAATCATATGCTATTGTTTAAGA } \\
\text { GAGTTTGCTTATCTTTCACAACTATAACAACCCTCCTTTGGGTTGTAT } \\
\text { CGTTCCCCAATCAAAATCCAACGTACACAAAAGCATCAATACT }\end{array}$ & GAAG & G & 19,32 & 184 & $\begin{array}{l}\text { GTGTGGAGGTTAGGG } \\
\text { GGATT }\end{array}$ & 60,1 & $\begin{array}{l}\text { TTGGATTTTGATTGG } \\
\text { GGAAC }\end{array}$ & 59,6 & 55 & 40 \\
\hline 753 & BrPe4275 & $\begin{array}{l}\text { Maracuja_ } \\
\text { NoIndex_L } \\
\text { 003_R1_00 } \\
\text { 1_contig_5 } \\
7893\end{array}$ & 4 & 2861 & 2876 & 16 & 4 & 12 & $\begin{array}{l}\text { AAAATCCTACTGCTAACATGAGAATAACAAGCCCATAAACTCGCAA } \\
\text { ATCCTGGACTTCAGCCTACCTGCAGGTAAATTTGCCATCTACCATTA } \\
\text { TACATATAAGAGAATGCCTGGCCGATCATAAATCAATAGAAAGTTG } \\
\text { CCAAGTATGCCATTTATTTATTTATTTTGAAAACTACTGCTTAGTCTT } \\
\text { TCAACAAAAAGACCAAGCTGCCTTTCTACACATACAGTCATAGTTA } \\
\text { GAATAATACAACATAGCTTCAATTCTATTAGACAATCAGTGTGCAGC } \\
\text { TGTACTACTTTCCTTTCACAAGAGAACAACTATTTA }\end{array}$ & ATTT & $\mathrm{s}$ & 16,89 & 163 & $\begin{array}{l}\text { CCTGGACTTCAGCCT } \\
\text { ACCTG }\end{array}$ & 59,9 & $\begin{array}{l}\text { AAGGCAGCTTGGTC } \\
\text { TTTTTG }\end{array}$ & 59,5 & 60 & 45 \\
\hline 754 & BrPe4276 & $\begin{array}{l}\text { Maracuja_ } \\
\text { NoIndex_L } \\
\text { 003_R1_00 } \\
\text { 1_contig_5 } \\
7983\end{array}$ & 4 & 493 & 504 & 12 & 3 & 8 & $\begin{array}{l}\text { GGTCATCCGCAAAGCTTAGCTGTATGAGTTTACTGTTTGCACATCCA } \\
\text { GAGTGGTACTGGAAAAAATCAGGAGCTTTGGTAAAGCTTCTAGCTA } \\
\text { AATATTCAATGGCCAATACGAAGAGTAGAGGGGACACAGGGTCCCC } \\
\text { CTGTCTCAACCCCTTCCTTCCTTGGAAAAAACCTTCCATGCTTCCATT } \\
\text { CAACATCAAGGTAAAGTGTGTAGTTCGGACACAAGTCATTGTCCAC } \\
\text { TGTATGAACCTGCGAGGGAAGCCAAGAGCCAACAAAACTTCTTCTA } \\
\text { AGAAATCCCATTTAATAGAATCATATGCCTTCC }\end{array}$ & ССТT & G & 25,63 & 159 & $\begin{array}{l}\text { TGTTTGCACATCCAG } \\
\text { AGTGG }\end{array}$ & 60,7 & $\begin{array}{l}\text { TGTTGAATGGAAGC } \\
\text { ATGGAA }\end{array}$ & 60 & 50 & 40 \\
\hline 755 & BrPe4277 & $\begin{array}{l}\text { Maracuja_ } \\
\text { NoIndex_L } \\
\text { 003_R1_00 } \\
\text { 1_contig_5 } \\
\text { 8058 }\end{array}$ & 4 & 509 & 520 & 12 & 3 & 8 & $\begin{array}{l}\text { TGACTGCCTCGACCAAAACATGTAAAATCTGTTCGAGAACCAATCA } \\
\text { AATCAAAATCGAATTGTCTTGCACTGGACAGAACCAAACCAAATTG } \\
\text { TAGGTCTAGCTTAGGCAAAGGCCACATCAGTTTTGGCTGTTTATGAA } \\
\text { CAAAAGAGCGGTGATTGATTGATCGATTAGAGTATTCTGTTCTTCGA } \\
\text { AGCAACTGGCTTCTACCATTTTATGAATTGAATCACTTGCAGCTTTT } \\
\text { CTTTTCAAGAAATAAATTGTTGTGTCTTTGAAGAAATAACAAACGAA } \\
\text { GTTTACAGAATTCCAGTCTGCGATTGACACTG }\end{array}$ & TGAT & $\mathrm{s}$ & 15,27 & 105 & $\begin{array}{l}\text { TAGGCAAAGGCCACA } \\
\text { TCAGT }\end{array}$ & 60,7 & $\begin{array}{l}\text { AAAATGGTAGAAGC } \\
\text { CAGTTGC }\end{array}$ & 58,4 & 50 & 42,9 \\
\hline
\end{tabular}

G: genoma funcional

S: genoma estructural

P: polimórfico

M: monomórfico 
APÉNDICE

Marcadores microssatélites desenhados a partir do sequênciamento parcial e da montagem de novo do genoma de $P$. edulis

\begin{tabular}{|c|c|c|c|c|c|c|c|c|c|c|c|c|c|c|c|c|c|c|c|}
\hline $\mathbf{N}^{\circ}$ & Primer & Contig I & Motivo & Início & Fim & pb & $\begin{array}{c}\mathbf{N}^{\circ} \\
\text { Repet }\end{array}$ & Score & Sequência do contig & Unidade & G/S & Cobertura & pb & Sequência Forward & $\begin{array}{l}\mathrm{T}^{\circ} \mathrm{C} \\
F w d \\
\end{array}$ & Sequência Reverse & $\begin{array}{l}\mathrm{T}^{\circ} \mathrm{C} \\
\operatorname{Rev} \\
\end{array}$ & $\begin{array}{c}\% \mathrm{GC} \\
F w d \\
\end{array}$ & $\begin{array}{cc}\% \mathrm{GC} & \mathrm{P} / \mathrm{M} \\
\operatorname{Rev} & \end{array}$ \\
\hline 756 & BrPe4278 & $\begin{array}{l}\text { Maracuja_ } \\
\text { NoIndex_L } \\
003 \text { _R1_00 } \\
\text { 1_contig_5 } \\
8231\end{array}$ & 4 & 692 & 703 & 12 & 3 & 8 & $\begin{array}{l}\text { TCGTGCTCCTTCCCATGGAATCCAGCATGCGGAAAGTTGAAAATTAT } \\
\text { CCGATCAAATTTTTTCATACCCAAGGCCGAGTGGAACATTTTGGTTG } \\
\text { CATCCACTCCATGTATTATGACAGCTCCCAACTCCTTCAGAATTTCC } \\
\text { AAATTAACTCTTGCTTGCTTGTATTTTTTAATCAGCTCATCTGATTGA } \\
\text { TCGATAGCATTCATACAAAAGGAAAGACCAAAGATGGTAACTTCAG } \\
\text { AAAATAAAGTACTAAATCATCCATTTACAGAGATTCGCCTCAAAAA } \\
\text { GAAAGATTACATGTAGAAAAAAAAACATACA }\end{array}$ & CTTG & $\mathrm{s}$ & 15,57 & 210 & $\begin{array}{l}\text { CCGAGTGGAACATTT } \\
\text { TGGTT }\end{array}$ & 59,8 & $\begin{array}{l}\text { TCTTTTTGAGGCGA } \\
\text { ATCTCTG }\end{array}$ & 59,6 & 45 & 42,9 \\
\hline 757 & BrPe4279 & $\begin{array}{l}\text { Maracuja_ } \\
\text { NoIndex_L } \\
\text { 003_R1_00 } \\
\text { 1_contig_5 } \\
8300\end{array}$ & 4 & 672 & 683 & 12 & 3 & 8 & $\begin{array}{l}\text { TGAAAGGATTTTGTCGACATTACAAGATAACAATTCTGTCTGGTTTA } \\
\text { AGGATACTACAAGCAAAACAGAAGTTCAACAAAACCATTTACAGCA } \\
\text { ATCACATAGGAAAAGAAGCATGAAAGTTCGGTGTGTAACTGATTTA } \\
\text { ATCTCTCGAACATAAATAAATAAGATGCAGCTAACTAATAAACACT } \\
\text { GATTTAATAGGAGAATTAAACCAATAACTAATCAGTAATGCACTCA } \\
\text { AAAACAAAATAAATATTCCTGAATAATCAATTTGTAAATAGCACAA } \\
\text { GTAGAGTATCAGAATGTTGTAAAAATTACTCGTCT }\end{array}$ & ATAA & $\mathrm{s}$ & 16,6 & 169 & $\begin{array}{l}\text { TTCAACAAAACCATT } \\
\text { TACAGCAA }\end{array}$ & 59,6 & $\begin{array}{l}\text { TTTTGTTTTTGAGTG } \\
\text { CATTACTGA }\end{array}$ & 58,9 & 30,4 & 29,2 \\
\hline 758 & BrPe4280 & $\begin{array}{l}\text { Maracuja_ } \\
\text { NoIndex_L } \\
\text { 003_R1_00 } \\
\text { 1_contig_5 } \\
8439\end{array}$ & 4 & 3371 & 3382 & 12 & 3 & 8 & $\begin{array}{l}\text { TCTTAAGTCTAGTTTGTCTAAAAAGAATCTGGATAATGGTCGAGTTT } \\
\text { CCGGTACATCAGAACAAGCAGTAAGTTTTGTCTTGCCTCTTTCTTTTT } \\
\text { CTTTTTGCTTTTAAAAATTGCTCTTTTAATTCTTCTCCATGATAGGAT } \\
\text { CAATAATTAGATAGATAGAGGTTCTTTTCCTAACATTGGTGATGGAT } \\
\text { AAGTTGCCAACTGACTGTGCAGCCATGCTCAGTTACATTGTATTTG } \\
\text { TCATTGATTTTGTGGATAATTCACTCTATCTGACATCCAAAGTCAT } \\
\text { GGCAGGAAGGCATGGTTGAATTATTGG }\end{array}$ & TAGA & $\mathrm{s}$ & 19,06 & 193 & $\begin{array}{l}\text { TGCTCTTTTAATTCTT } \\
\text { CTCCATGA }\end{array}$ & 59,4 & $\begin{array}{l}\text { AATTCAACCATGCC } \\
\text { TTCCTG }\end{array}$ & 59,9 & 33,3 & 45 \\
\hline 759 & BrPe4281 & $\begin{array}{l}\text { Maracuja_ } \\
\text { NoIndex_L } \\
\text { 003_R1_00 } \\
\text { 1_contig_5 } \\
8569\end{array}$ & 4 & 1235 & 1246 & 12 & 3 & 8 & $\begin{array}{l}\text { TACTGTTGAAGGGTCAAGAAGGGACTCTGTGGTGGCATGCTCATAGC } \\
\text { TCATGGCTTAGAGCCACCGTTTACGGTGCTTTGATTATCCATCCAAA } \\
\text { GGAAGGATCCTCGTACCCTTTTGCTATACCGCATAGAGAAACGCCT } \\
\text { ATACTTCTTGGTAATTAATTAATGATGATCAGTACCTTTCCAGAATT } \\
\text { AATCACTTCTTGGTAATTAATTATGACATTTCAATGACTTTGGTTATT } \\
\text { GATCAGGAGAATGGTGGGATGCGAAACCTGTGGATGTCTTGAAGGA } \\
\text { AGCTATTAGAACAGGAGCTGCTCCAAACATAT }\end{array}$ & TAAT & $\mathrm{s}$ & 29,87 & 174 & $\begin{array}{l}\text { CTGTGGTGGCATGCT } \\
\text { CATAG }\end{array}$ & 60,3 & $\begin{array}{l}\text { CCAAGAAGTGATTA } \\
\text { ATTCTGGAAA }\end{array}$ & 58,7 & 55 & 33,3 \\
\hline 760 & BrPe4282 & $\begin{array}{l}\text { Maracuja_ } \\
\text { NoIndex_L } \\
\text { 003_R1_00 } \\
\text { 1_contig_5 } \\
8763\end{array}$ & 4 & 155 & 166 & 12 & 3 & 8 & $\begin{array}{l}\text { GTAGTTTTCCGGGACAAGCGATCCTGTAAATAGATGTATACTGGGTT } \\
\text { TGAGGTTTCCTCCGAGCACGATATTTCCGGGATAAGCTTTTCGAG } \\
\text { GATATTCGTATTCGGATTTGTACCCGATGTTGTGGACTCTGATTTCTA } \\
\text { GATTCTGAGATTGATTGATTCTCGGTTAGGTTTTGTGGGCAGGTCAT } \\
\text { CGTGTGTGGTGGTCCTGTTCCCTTTGATCTTTGAGTGTGGCACGATT } \\
\text { GCCTTCGTCTTGAGGTTTGCTTGAGCATGTTGCACTACTTTCTATATA } \\
\text { TCATGGCTTTACACACGAGTCGTCTGGT }\end{array}$ & GATT & G & 507,71 & 155 & $\begin{array}{l}\text { TTTGTACCCGATGTTG } \\
\text { TGGA }\end{array}$ & 59,8 & $\begin{array}{l}\text { CATGCTCAAGCAAA } \\
\text { CCTCAA }\end{array}$ & 60 & 45 & 45 \\
\hline
\end{tabular}

G: genoma funcional

S: genoma estructural

P: polimórfico

M: monomórfico 
APÉNDICE

Marcadores microssatélites desenhados a partir do sequênciamento parcial e da montagem de novo do genoma de P. edulis

\begin{tabular}{|c|c|c|c|c|c|c|c|c|c|c|c|c|c|c|c|c|c|c|c|}
\hline $\mathbf{N}^{\circ}$ & Primer & Contig I & Motivo & Início & Fim & pb & $\begin{array}{c}\mathbf{N}^{\circ} \\
\text { Repet }\end{array}$ & Score & Sequência do contig & Unidade & G/S & Cobertura & pb & Sequência Forward & $\begin{array}{l}\mathrm{T}^{\circ} \mathrm{C} \\
F w d \\
\end{array}$ & Sequência Reverse & $\begin{array}{l}\mathrm{T}^{\circ} \mathrm{C} \\
\operatorname{Rev} \\
\end{array}$ & $\begin{array}{c}\% \mathrm{GC} \\
F w d \\
\end{array}$ & $\begin{array}{cc}\% \mathrm{GC} & \mathrm{P} / \mathrm{M} \\
\operatorname{Rev} & \end{array}$ \\
\hline 761 & BrPe4283 & $\begin{array}{l}\text { Maracuja_ } \\
\text { NoIndex_L } \\
003 \text { R1_00 } \\
\text { 1_contig_5 } \\
8838\end{array}$ & 4 & 349 & 364 & 16 & 4 & 12 & $\begin{array}{l}\text { AAGGGGACGGGTAGAAGCAGAACAGTGAGCGTTGAAGGTGGATGT } \\
\text { TATAATTTATAGCTAAACCCTAAAGCGAGGCACCAACTACAGCGGT } \\
\text { CGGATTTACAATGGACGGCTCAGTTCACCGCTTCTATTTATGGTATT } \\
\text { CTTTAGTGGAGGTTTATTTATTTATTTAAAAGTTATCTATTTATGCTG } \\
\text { AATTGTAAGACGACGAGATAGGAGAATATTTTTGTAAAAATATAG } \\
\text { AGAAATTTAATGTACCTGTTATTAGTGAGCAAACAACATTTAATATG } \\
\text { GTAGAAAAATGAGGATTAAACACTAGAATCCTAGAAG }\end{array}$ & TTTA & $\mathrm{s}$ & 15,26 & 176 & $\begin{array}{l}\text { GAGCGTTGAAGGTGG } \\
\text { ATGTT }\end{array}$ & 60,1 & $\begin{array}{l}\text { TCGTCGTCTTACAAT } \\
\text { TCAGCA }\end{array}$ & 59,5 & 50 & 42,9 \\
\hline 762 & BrPe4284 & $\begin{array}{l}\text { Maracuja_ } \\
\text { NoIndex_L } \\
\text { 003_R1_00 } \\
\text { 1_contig_5 } \\
\text { 8962 }\end{array}$ & 4 & 487 & 498 & 12 & 3 & 8 & $\begin{array}{l}\text { AGAATTCATTACCAGTCACATATTTTTGGAACCTTGTTCCTTTCCAA } \\
\text { AGGGGATACCGAATAGGAAGCACCGTCACTCCACGTGCATTTGAAG } \\
\text { TAATGAAAGGCCCCTCCACTTGCATGTGCCCTTGTATAATACAAGAA } \\
\text { CCCCATCAGTGTACGTACGTACAACCTTGATTGAATAGTCTCAGAAA } \\
\text { AGTTATAAATAATTATCCAAATCTAAGCCATCATTCCGAATATCTGT } \\
\text { TAAATTTCAGATTAAGAATATGGTGGTCACTGTTTTTTACTGTTGG } \\
\text { ACTCTGCTATTTTGCTACTCCCTAAACCAGA }\end{array}$ & GTAC & $\mathrm{s}$ & 32,48 & 177 & $\begin{array}{l}\text { GGGGATACCGAATAG } \\
\text { GAAGC }\end{array}$ & 59,8 & $\begin{array}{l}\text { CGGAATGATGGCTT } \\
\text { AGATTTG }\end{array}$ & 59,6 & 55 & 42,9 \\
\hline 763 & BrPe4285 & $\begin{array}{l}\text { Maracuja_ } \\
\text { NoIndex_L } \\
\text { 003_R1_00 } \\
\text { 1_contig_5 } \\
\text { 9244 }\end{array}$ & 4 & 959 & 974 & 16 & 4 & 12 & $\begin{array}{l}\text { TTTCATGCTTTCTTTCACCTACAGTAACATCAAATACTTTTCAGAGCT } \\
\text { TCTACCCTAAGTCTCTAACTAGCCTCTGTGTCCTATGTTCAGGAAAT } \\
\text { GTTTTCCATCAAATTCTGATTCGTATTCTGAGCAGAATCCCAAATTT } \\
\text { ATATTTGTTTTATTTATTTATTTACTGTGTCGATGGAGATGTATCCGC } \\
\text { ACTCTGGAGTGCTTCGATTGTGTCCTTAGATGTGTTTATGCACCCG } \\
\text { CACTGCATGCAAATCAGAATTGTACCTGGAATTTAATAGTGGCCTGT } \\
\text { ACATATTCCTCGACAAGATGTTTGGAGTTTGA }\end{array}$ & TTTA & $\mathrm{s}$ & 17,92 & 224 & $\begin{array}{l}\text { TCAGGAAATGTTTTC } \\
\text { CATCAAA }\end{array}$ & 59,4 & $\begin{array}{l}\text { TCCAAACATCTTGT } \\
\text { CGAGGA }\end{array}$ & 59,2 & 31,8 & 45 \\
\hline 764 & BrPe4286 & $\begin{array}{l}\text { Maracuja_ } \\
\text { NoIndex_L } \\
\text { 003_R1_00 } \\
\text { 1_contig_5 } \\
9261\end{array}$ & 4 & 798 & 809 & 12 & 3 & 8 & $\begin{array}{l}\text { TCCTTCTGCTTGCAGAGTTAATGGGCGTGCAAATAAAAAACTTAGGC } \\
\text { TAGAAGCAAGCAGTCATTCAAGGAGCACAAGAGTAGAAATTCAAA } \\
\text { GTGATTCAATTGCAGGGAGAATTGATACTGGAGCCAAGTTGAGAAA } \\
\text { TTTTCAAGCTGTAGAAAGAAAGAATGCGACTGTTGCAAGAGATAGG } \\
\text { CAAAAGGAATTGACTGATCTTGTTTCACGTAGAGCTAATGGACACA } \\
\text { CAGGAAAATGCCGCAGTCTGAAAGTTTGTTGTCGAAAAGGTCCCAA } \\
\text { TGGTGCTAATCCACTTTTGCTGGATAGAGACTACGA }\end{array}$ & AGAA & G & 13,71 & 218 & $\begin{array}{l}\text { GCAGTCATTCAAGGA } \\
\text { GCACA }\end{array}$ & 60,0 & $\begin{array}{l}\text { GGGACCTTTTCGAC } \\
\text { AACAAA }\end{array}$ & 59,9 & 50 & 45 \\
\hline 765 & BrPe4287 & $\begin{array}{l}\text { Maracuja_ } \\
\text { NoIndex_L } \\
\text { 003_R1_00 } \\
\text { 1_contig_5 } \\
9380\end{array}$ & 4 & 457 & 468 & 12 & 3 & 8 & $\begin{array}{l}\text { ATTTTTTTACTGATAGAAGCCATCCGACTTATTGTGCATTGTAATAC } \\
\text { AAACCGATCGGATTACACTTTTGAGGTTGCAAAATTATCTTCCTTCA } \\
\text { TCCATTTAAACCCACTCTTCCCTCCTGATACCTAGACATACCCTCTG } \\
\text { GCATCTGAGGCCAGCCAGCCACGACCAAAAAGCCAAGTGGAGCACT } \\
\text { TCCTTTTGCCTTTTTGTTTTATTTTGTGCACTTGGAAGGAAAATAAGA } \\
\text { AAAGAGAGGTGGTGAAGGAGAGGAAAGAAGAGAGAAAGCTTGAGG } \\
\text { GAGAGTGAGCTGATTATGTTGAGGGCTGAGAG }\end{array}$ & GCCA & G & 41,82 & 189 & $\begin{array}{l}\text { АСССАСТСТTСССТCC } \\
\text { TGAT }\end{array}$ & 59,9 & $\begin{array}{l}\text { CAGCTCACTCTCCCT } \\
\text { CAAGC }\end{array}$ & 60,3 & 55 & 60 \\
\hline
\end{tabular}

G: genoma funcional

S: genoma estructural

P: polimórfico

M: monomórfico 
APÉNDICE

Marcadores microssatélites desenhados a partir do sequênciamento parcial e da montagem de novo do genoma de $P$. edulis

\begin{tabular}{|c|c|c|c|c|c|c|c|c|c|c|c|c|c|c|c|c|c|c|c|}
\hline $\mathbf{N}^{\circ}$ & Primer & Contig I & Motivo & Início & Fim & pb & $\begin{array}{c}\mathbf{N}^{\circ} \\
\text { Repet }\end{array}$ & Score & Sequência do contig & Unidade & G/S & Cobertura & pb & Sequência Forward & $\begin{array}{l}\mathrm{T}^{\circ} \mathrm{C} \\
F w d \\
\end{array}$ & Sequência Reverse & $\begin{array}{r}\mathrm{T}^{\circ} \mathrm{C} \\
\operatorname{Rev} \\
\end{array}$ & $\begin{array}{c}\% \mathrm{GC} \\
F w d \\
\end{array}$ & $\begin{array}{c}\% \mathrm{GC} \\
\operatorname{Rev}\end{array} \quad \mathrm{P} / \mathrm{M}$ \\
\hline 766 & BrPe4288 & $\begin{array}{l}\text { Maracuja_ } \\
\text { NoIndex_L } \\
\text { 003_R1_00 } \\
\text { 1_contig_5 } \\
9445\end{array}$ & 4 & 2936 & 2947 & 12 & 3 & 8 & $\begin{array}{l}\text { TTTACGCTCCCAAGTCACCAATTTGTCAAAATCTACACTCACACTGT } \\
\text { AAACGGCATCAGAAACTCAAAATACCCATCCGAGAACAGCAGCAAT } \\
\text { TTGAAACATTAGCGCTTCAAAAACTCAAGTGAATTCAGTACAGGCA } \\
\text { AACAAAACGCACTTGCTTGCTTGTGTCTATGAGTTTTATGTTATGA } \\
\text { ATGCCCAAAGCGTCAGGAAGGTCCGGCTAAATGAATAGGAACAAG } \\
\text { AAGAGACACAAAACCATAACAAGAAAAAAGAAAGAGCAAATGAAT } \\
\text { GTAACAAAGATAAACACTAAACAGCAAAGAAATAAC }\end{array}$ & CTTG & $\mathrm{s}$ & 19,19 & 197 & $\begin{array}{l}\text { TACGCTCCCAAGTCA } \\
\text { CCAAT }\end{array}$ & 60,5 & $\begin{array}{l}\text { ACGCTTTGGGCATT } \\
\text { CATAAC }\end{array}$ & 60 & 50 & 45 \\
\hline 767 & BrPe4289 & $\begin{array}{l}\text { Maracuja_ } \\
\text { NoIndex_L } \\
003 \text { R1_00 } \\
\text { 1_contig_6 } \\
0263\end{array}$ & 4 & 529 & 540 & 12 & 3 & 8 & $\begin{array}{l}\text { AAAAAAATAAGGTGCTCAAAATTAGCTCAAAAATCAAGAAATTTGA } \\
\text { AACAAAAAAATGCTCATCGGTACTGGAATCTGACGAGAAAAGTAGC } \\
\text { AAGCTCAGTATGTAAAGAATGATGATGTTGAGAAGGTTCCAATGTG } \\
\text { ATAAGAATTGCCTTGATTGATTGAGTGTGGAGGGAATTATGAGTGTT } \\
\text { TTTGTGTTTAGGGCTCCAAAGGGATAAAGAGATAAGGAGACAGAAA } \\
\text { GAGAGAGGAAGCTTGGGAAGAATAGTCAACAAAATAAAAATTTGA } \\
\text { AATTTATGAAAAAAAGCTAAACAAAGCCTAGTAAGT }\end{array}$ & TTGA & $\mathrm{s}$ & 28,91 & 101 & $\begin{array}{l}\text { GGTTCCAATGTGATA } \\
\text { AGAATTGC }\end{array}$ & 59,7 & $\begin{array}{l}\text { TGTCTCCTTATCTCT } \\
\text { TTATCCCTTT }\end{array}$ & 58 & 39,1 & 36 \\
\hline 768 & BrPe4290 & $\begin{array}{l}\text { Maracuja_ } \\
\text { NoIndex_L } \\
003 \text { _R1_00 } \\
\text { 1_contig_6 } \\
0400\end{array}$ & 4 & 3333 & 3344 & 12 & 3 & 8 & $\begin{array}{l}\text { GCATAGTGTCACAACTTCCAAACATGTAAGAAGTAATTCCTTCCTGA } \\
\text { CTTAGCACAGTGGAAAAAGCTCCGCTATAAATGAAGCAAGGCACTC } \\
\text { AAATTACAAGAAGCTAAGTTAACAGTCAGTCATCTCAATCCATGGG } \\
\text { CCAAAGACCAAGCATGCATGCATTCTCTCAACTGATATTTTTCATTT } \\
\text { CACATGATGCCTAAAATAACTAAACAACCTGACTAATTCTTTTAGAT } \\
\text { GTAACACATTTTCATCCCAAAAATATGAAAAGAAATTAACATCAAC } \\
\text { AACAAAATTTGTAATAGACAAAGAATGACTTTT }\end{array}$ & GCAT & $\mathrm{s}$ & 17,46 & 128 & $\begin{array}{l}\text { CAATCCATGGGCCAA } \\
\text { AGAC }\end{array}$ & 61,3 & $\begin{array}{l}\text { TTTTTGGGATGAAA } \\
\text { ATGTGTT }\end{array}$ & 57 & 52,6 & 28,6 \\
\hline 769 & BrPe4291 & $\begin{array}{l}\text { Maracuja_ } \\
\text { NoIndex_L } \\
003 \text { 1_1_00 } \\
\text { 1_contig_6 } \\
0616\end{array}$ & 4 & 4340 & 4351 & 12 & 3 & 8 & $\begin{array}{l}\text { ATAGTGAAAACTCAATTGCTTACATGTTAAAATTCCAATTTTGCTGG } \\
\text { CTGGTATACTCCATCATGATGTGCTATCTATTTGCTTCATAGGATAA } \\
\text { GCTTCTAGATCTGTTAGAAAGGACAAGAGGAATTGAACAGGAAATA } \\
\text { AGGGAAATGATTGCTTGCTTGCCAGCCATGGAAATGACAACTAACA } \\
\text { GTAATCAGAATCCTAAAGTGAGAGCAGTGCCAAAAATCCCTGAATA } \\
\text { TGAGCACCAAATACTTCCATGTCCTGCTTATGTACAAGCAGACTCAA } \\
\text { TGCAGCATGACCAAAATCAGGAAACTGAGCTTC }\end{array}$ & TTGC & G & 17,19 & 191 & $\begin{array}{l}\text { CCAATTTTGCTGGCTG } \\
\text { GTAT }\end{array}$ & 60,0 & $\begin{array}{l}\text { GGATTTTTGGCACT } \\
\text { GCTCTC }\end{array}$ & 59,8 & 45 & 50 \\
\hline 770 & BrPe4292 & $\begin{array}{l}\text { Maracuja_ } \\
\text { NoIndex_L } \\
\text { 003_R1_00 } \\
\text { 1_conti__6 } \\
0667\end{array}$ & 4 & 261 & 272 & 12 & 3 & 8 & $\begin{array}{l}\text { GTACAACCGGTCGAGTGAGCGTGTCGAGCTCATTATGCCTTTTTCTC } \\
\text { CTCCTCTATCTTGTTCCATCCTTTTTGTGCCACTTGTACACATCCCTA } \\
\text { GGGAGTATTCCTAGTCACCCCCATGACCAGAAATCACATTCATACCT } \\
\text { TTTTAAAGCTTCCTTCCTTCATCGAGAGAAAAACCAAATGGTGAATG } \\
\text { TGTTTCTTGAATTGGAGAGTGCAACCTTTGCTTCTGGTGATTACCTTG } \\
\text { TGGTCCAGGTGAGTTGTTGTGGTGATGGTTATGGCCAGAAAAGAGG } \\
\text { GAGGAGGTGTCCCCATGCATGTTTCTCTA }\end{array}$ & СтTC & G & 172,22 & 150 & $\begin{array}{l}\text { TTCCTAGTCACCCCC } \\
\text { ATGAC }\end{array}$ & 59,8 & $\begin{array}{l}\text { AACTCACCTGGACC } \\
\text { ACAAGG }\end{array}$ & 60 & 55 & 55 \\
\hline
\end{tabular}

G: genoma funcional

S: genoma estructural

P: polimórfico

M: monomórfico 
APÉNDICE

Marcadores microssatélites desenhados a partir do sequênciamento parcial e da montagem de novo do genoma de $P$. edulis

\begin{tabular}{|c|c|c|c|c|c|c|c|c|c|c|c|c|c|c|c|c|c|c|c|}
\hline $\mathbf{N}^{\circ}$ & Primer & Contig I & Motivo & Início & Fim & pb & $\begin{array}{c}\mathbf{N}^{\circ} \\
\text { Repet }\end{array}$ & Score & Sequência do contig & Unidade & G/S & Cobertura & pb & Sequência Forward & $\begin{array}{l}\mathrm{T}^{\circ} \mathrm{C} \\
F w d \\
\end{array}$ & Sequência Reverse & $\begin{array}{l}\mathrm{T}^{\circ} \mathrm{C} \\
\operatorname{Rev} \\
\end{array}$ & $\begin{array}{c}\% \mathrm{GC} \\
F w d \\
\end{array}$ & $\begin{array}{cc}\% \mathrm{GC} & \mathrm{P} / \mathrm{M} \\
\operatorname{Rev} & \end{array}$ \\
\hline 771 & BrPe4293 & $\begin{array}{l}\text { Maracuja_ } \\
\text { NoIndex_L } \\
\text { 003_R1_00 } \\
\text { 1_contig_6 } \\
\text { 0952 }\end{array}$ & 4 & 175 & 186 & 12 & 3 & 8 & $\begin{array}{l}\text { ACTCCAAACTCATTAGAAGCCTTACCTCAAACACCAACAAACTCCA } \\
\text { GGAATCAAGAAAGCCAAGGTTAGGGCACAAATGCTCTCAATTCTCC } \\
\text { AAAGTGAAAAGAAAATGGAAATGAAGGGAAAAATGAGCAAAGTGG } \\
\text { GGAGGAAGTGTCGTGGCTGGCTGGCCATAACCCAGGAGAAAAGTTC } \\
\text { CAGGTGTCAAGCCAGCATAGGGAAGCAGAAAGCAAGGTTGAAAAA } \\
\text { TTCAGCCATGCATTTATTAAAGCTTCGACCGGTCGAA }\end{array}$ & TGGC & G & 96,42 & 173 & $\begin{array}{l}\text { AGGGCACAAATGCTC } \\
\text { TCAAT }\end{array}$ & 59,7 & $\begin{array}{l}\text { TGCATGGCTGAATT } \\
\text { TTTCAA }\end{array}$ & 60,2 & 45 & 35 \\
\hline 772 & BrPe4294 & $\begin{array}{l}\text { Maracuja_ } \\
\text { NoIndex_L } \\
\text { 003_R1_00 } \\
\text { 1_contig_6 } \\
1839\end{array}$ & 4 & 1127 & 1138 & 12 & 3 & 8 & $\begin{array}{l}\text { CACCAAAGAACACGTGGCAAATCTCTTTTTGGCATCCCAGTAGGTA } \\
\text { GCTAGCTATCATCAATAATTATACAAACTCTCATCATACAATTTCTG } \\
\text { TCATTTTCTTTCTACCTTTGACCTGATCTCTAATCCTTACAGCTTTCA } \\
\text { CGGATGGATGAAGGAAGGAAGCTTGTCACGGAAATTCCCTGCCTTC } \\
\text { ACTGAAGTCTTCAGTCGCAAATCATCCAACAGACCATTGGAAATTA } \\
\text { ATGCTTTCAACCTCTTGACGCCACCAAAAAAAGGCAACCCCATTTTT } \\
\text { TTGGGATTCAAACGTTGCGCTGTCGCTTTGAT }\end{array}$ & GAAG & G & 15,71 & 150 & $\begin{array}{l}\text { CCTTTGACCTGATCTC } \\
\text { TAATCCTT }\end{array}$ & 59,2 & $\begin{array}{l}\text { GTGGCGTCAAGAGG } \\
\text { TTGAA }\end{array}$ & 59,8 & 41,7 & 52,6 \\
\hline 773 & BrPe4295 & $\begin{array}{l}\text { Maracuja_ } \\
\text { NoIndex_L } \\
003 \text { R1_00 } \\
\text { 1_contig_6 } \\
1947\end{array}$ & 4 & 4109 & 4120 & 12 & 3 & 8 & $\begin{array}{l}\text { ATACAATAAAGAAGTTGATCATGGTCGTGCAGTTTATGACCCTTGTT } \\
\text { GGTTCAATTAATGTAGGAGTCAAAGTTAGATTAGTGGTAGGTTCATT } \\
\text { TATGTGGAGATGGATGTTTCTAACAATTGTGGGTCCAATTTTGTTTC } \\
\text { TTCCACACAAAATAAATAAATGAATAAAAATACTTGTATAATCGAT } \\
\text { GATATCATATGATGTAAATATTTAATTCCTCTCTTACCTACAGCACT } \\
\text { CCACCGCTTGGACTCCATTCTATATATTTTATTTCGTTCGTATGTTTG } \\
\text { TACTTTATAAGTGTATTGTACACTTAGGAC }\end{array}$ & AAAT & $\mathrm{s}$ & 16,48 & 225 & $\begin{array}{l}\text { TGATCATGGTCGTGC } \\
\text { AGTTT }\end{array}$ & 60,1 & $\begin{array}{l}\text { CGGTGGAGTGCTGT } \\
\text { AGGTAAG }\end{array}$ & 59,8 & 45 & 57,1 \\
\hline 774 & BrPe4296 & $\begin{array}{l}\text { Maracuja_ } \\
\text { NoIndex_L } \\
\text { 003_R1_00 } \\
\text { 1_contig_6 } \\
\text { 2552 }\end{array}$ & 4 & 5738 & 5749 & 12 & 3 & 8 & $\begin{array}{l}\text { TGGTAAGCAGACCAGCATGGATGAAGAGTTTTTTCTGCTCTCTCATC } \\
\text { TAAACCTCCTTCCTCTGCTACAGACATCCAGTACAGAGCTTGTTTCT } \\
\text { GATATGGCTTTAGTTCACAAGTGAGTTTCATGGATGGCTCCATCTGC } \\
\text { TGCATGATCAAGAAAGAAAGATCAGCAAAGACAATATAATCGTATA } \\
\text { TTCCTGGCATTCAGAATGTAAAACAGAAAAAAAGAGAAAAGAATTTA } \\
\text { AAAGAAAAAAACTGAACTTTCTTGACAAAGTGAGTTAACGATGATT } \\
\text { GTCCAATCCAGGTCTATGTAAAGGCTCACATAT }\end{array}$ & AAGA & $\mathrm{s}$ & 19,64 & 195 & $\begin{array}{l}\text { CAGACCAGCATGGAT } \\
\text { GAAGA }\end{array}$ & 59,8 & $\begin{array}{l}\text { TCTGAATGCCAGGA } \\
\text { ATATACGA }\end{array}$ & 59,6 & 50 & 40,9 \\
\hline 775 & BrPe4297 & $\begin{array}{l}\text { Maracuja_ } \\
\text { NoIndex_L } \\
003 \text { 181_00 } \\
\text { 1_conti__6 } \\
\text { 2636 }\end{array}$ & 4 & 1002 & 1013 & 12 & 3 & 8 & $\begin{array}{l}\text { TAAGATCTCCGAAACATTCTCCTATTACGAGCCTACGCTCGAAACGC } \\
\text { TAATCTCGCTCTCACACGGCACTCTAGGTGCCCTCAAACTCCAAAAA } \\
\text { CCTAAGATCTCGGAAAATTGCCAACTGACCCCTGAAACCTCCGATC } \\
\text { ACCATAAACACATGCATGCATGACTCGAAAATAAATGAAACGACTC } \\
\text { AACACATGCAAGAACTCGAAATAAAGCATAACCCAACTCCCTCGGC } \\
\text { TTGAAAGCTCTAGACTAACATCGACACCTAAGATGACCAACTAGGG } \\
\text { ATACCGAACTAAACCTCTATGTCCAAACATGGTC }\end{array}$ & CATG & $\mathrm{s}$ & 17,15 & 167 & $\begin{array}{l}\text { CGAAACGCTAATCTC } \\
\text { GCTCT }\end{array}$ & 59,8 & $\begin{array}{l}\text { TTCGAGTTCTTGCAT } \\
\text { GTGTTG }\end{array}$ & 59,9 & 50 & 42,9 \\
\hline
\end{tabular}

G: genoma funcional

S: genoma estructural

P: polimórfico

M: monomórfico 
APÉNDICE

Marcadores microssatélites desenhados a partir do sequênciamento parcial e da montagem de novo do genoma de $P$. edulis

\begin{tabular}{|c|c|c|c|c|c|c|c|c|c|c|c|c|c|c|c|c|c|c|c|}
\hline $\mathbf{N}^{\circ}$ & Primer & Contig I & Motivo & Início & Fim & pb & $\begin{array}{c}\mathbf{N}^{\circ} \\
\text { Repet }\end{array}$ & Score & Sequência do contig & Unidade & G/S & Cobertura & pb & Sequência Forward & $\begin{array}{l}\mathrm{T}^{\circ} \mathrm{C} \\
F w d \\
\end{array}$ & Sequência Reverse & $\begin{array}{l}\mathrm{T}^{\circ} \mathrm{C} \\
\operatorname{Rev} \\
\end{array}$ & $\begin{array}{r}\% \mathrm{GC} \\
F w d \\
\end{array}$ & $\begin{array}{cc}\% \mathrm{GC} & \mathrm{P} / \mathrm{M} \\
\operatorname{Rev} & \end{array}$ \\
\hline 776 & $\begin{array}{ll}\text { BrPe4298 } \\
\end{array}$ & $\begin{array}{l}\text { Maracuja_ } \\
\text { NoIndex_L } \\
\text { 003_R1_00 } \\
\text { 1_contig_6 } \\
\text { 2931 }\end{array}$ & 4 & 1442 & 1453 & 12 & 3 & 8 & $\begin{array}{l}\text { CCTGTTATATCCCTACGAGGAAAACAAAATCTTCCTGTGGACTTTTT } \\
\text { GCCTCATAGAAAGAATGCAACAGAGAAGGCAAAAGATGTGCCCGT } \\
\text { GACAAAGATTGAGCAGCATAAAAGGAAAACACATGGCCAGGAGTC } \\
\text { AAAAGAGGAGAAAAAAAGAAAGAAAGGTATGGATATCTGTCTGTTG } \\
\text { CCATTTGTCTCCTTTTGTTCTTGTATCTTAATCTGCAATTCGTTACTC } \\
\text { TTGGGGTCATGTTTTCTTGGATCGATTAAAGATGAAAAAACTCTTTC } \\
\text { ACTGACAGCAGCTGTCATATTGTAATCTCCCGTC }\end{array}$ & AAAG & $\mathrm{G}$ & 14,15 & 160 & $\begin{array}{l}\text { ATGTGCCCGTGACAA } \\
\text { AGATT }\end{array}$ & 60,4 & $\begin{array}{l}\text { CATGACCCCAAGAG } \\
\text { TAAACGA }\end{array}$ & 60 & 45 & 47,6 \\
\hline 777 & BrPe4299 & $\begin{array}{l}\text { Maracuja_ } \\
\text { NoIndex_L } \\
\text { 003_R1_00 } \\
\text { 1_contig_6 } \\
3256\end{array}$ & 4 & 1103 & 1114 & 12 & 3 & 8 & $\begin{array}{l}\text { ATATTTACTCATCCTTAATAGTTAAGTAGCCAAGTTTTTTTAAGCATT } \\
\text { TTTTTTCTATTCTCATATAGCCCATACAGATATTGGAATAATTTTTTA } \\
\text { ATCTCTTTTCGCCACTGTAATTATGAAAATGAACATTGAAATGTACC } \\
\text { TCAGAATTAAATAAATAAACCAAAAACATATAAAATGCAGTTAATC } \\
\text { CTATTGTCCCACATGTTAAATCAAATATGTTAGAATACCACCAACGA } \\
\text { GCCTTGGTTCAATAGGTACCTCCTCAGGTTTTAAGATTTGGGTGTTA } \\
\text { GGAGAAGTCCTGAGTTCGAATTGACTTTA }\end{array}$ & TAAA & $\mathrm{s}$ & 15,1 & 152 & $\begin{array}{l}\text { TTTTTAATCTCTTTTC } \\
\text { GCCACTG }\end{array}$ & 59,8 & $\begin{array}{l}\text { CAAGGCTCGTTGGT } \\
\text { GGTATT }\end{array}$ & 60 & 34,8 & 50 \\
\hline 778 & BrPe4300 & $\begin{array}{l}\text { Maracuja_ } \\
\text { NoIndex_L } \\
\text { 003_R1_00 } \\
\text { 1_contig_6 } \\
\text { 3395 }\end{array}$ & 4 & 3132 & 3143 & 12 & 3 & 8 & $\begin{array}{l}\text { AGTTTCAAAATTGATCTCAAATATGAAACAGGGCCAAAACTTTAGG } \\
\text { AAACACAGGAGGGATAACCATTGCACACAAAATAAAAATCTCAAAT } \\
\text { GAAAAAAATAAACCATAAAATTAAATTCTTTACCAACCATATACAA } \\
\text { AGTTCCAAAAAAGAATGAATGAATCGGCATGGTGAAACAAATTGAA } \\
\text { CTCAGGCAACTTTGACATATGAAACAAAACATTTCAGCCAAACTGGT } \\
\text { AACTAAAAGAGTTTAAAAAATTAGAGAAAGAGATGGCCAACAATC } \\
\text { AAGCTAGTAAAAACTCAGGATGAAAGGAGTGAAAGAT }\end{array}$ & GAAT & $\mathrm{s}$ & 19,1 & 155 & $\begin{array}{l}\text { CCAACCATATACAAA } \\
\text { GTTCCAAAA }\end{array}$ & 59,2 & $\begin{array}{l}\text { GCTTGATTGTTGGCC } \\
\text { ATCTC }\end{array}$ & 60,6 & 33,3 & 50 \\
\hline 779 & BrPe4301 & $\begin{array}{l}\text { Maracuja_ } \\
\text { NoIndex_L } \\
003 \text { 1_1_00 } \\
\text { 1_contig_6 } \\
3733\end{array}$ & 4 & 1086 & 1097 & 12 & 3 & 8 & $\begin{array}{l}\text { AACAGGTCTTGAGTTCCATTAAATTCGGATGTGCCAAGTGCTGGCGG } \\
\text { TCTGAATTGAGTAGATGGCGGCGGAGCTGTAAGGGCATAAGTCAAT } \\
\text { CTAGTTGAAGAATTCTCAATTAGACCGGCAACTCCCGCAGCTGCAG } \\
\text { ATTGGGCACTCGAAGGAAGGAAGAGATCATGTTTCTGGTCCTTATA } \\
\text { GGCGCTCCAAACCTACAAAATGGAAGAAACATTCGTCCCTTCTTAA } \\
\text { AAAATCTCCATGGAAATGCTCAGCATACAGAAACTACGGTTGCATA } \\
\text { AAATGAACCAACTACATCTATTATTGTCAAAATCT }\end{array}$ & GAAG & G & 18,14 & 182 & $\begin{array}{l}\text { AAATTCGGATGTGCC } \\
\text { AAGTG }\end{array}$ & 60,9 & $\begin{array}{l}\text { TGTAGGTTTGGAGC } \\
\text { GCCTAT }\end{array}$ & 59,7 & 45 & 50 \\
\hline 780 & BrPe4302 & $\begin{array}{l}\text { Maracuja_ } \\
\text { NoIndex_L } \\
003 \text { 181_00 } \\
\text { 1_conti__6 } \\
3733\end{array}$ & 4 & 2968 & 2979 & 12 & 3 & 8 & $\begin{array}{l}\text { AAGATTGTTGTAGCTTACTTCACAAGAAACTTTGTCGTTCTATAAAA } \\
\text { GTTCTATTGATTTCGAAGATCTATAACCCTAAATTTTTTATATTTTAC } \\
\text { TCTAGCTTCAATATTCATTGAATTTAGGCTATTGTTTCCTGATGATT } \\
\text { AATTGAATTCTTTCTTTCTAGTCTATGTCATGTTTGCAGATCAAAAAC } \\
\text { AGGAAAAAGCTTTTCAAATGAATTGACACCTGCAAGCTTTGTATAA } \\
\text { CCCAATGGAAACATGAAACATGATATTGGTTAATTAATTAATGTTTC } \\
\text { TAGACAGGAAAAAAGAAGAAGAAAGAAA }\end{array}$ & ТTCT & $\mathrm{s}$ & 18,14 & 214 & $\begin{array}{l}\text { TTCACAAGAAACTTT } \\
\text { GTCGTTCT }\end{array}$ & 58,1 & $\begin{array}{l}\text { CAAAGCTTGCAGGT } \\
\text { GTCAAT }\end{array}$ & 58,9 & 34,8 & 45 \\
\hline
\end{tabular}

G: genoma funcional

S: genoma estructural

P: polimórfico

M: monomórfico 
APÉNDICE

Marcadores microssatélites desenhados a partir do sequênciamento parcial e da montagem de novo do genoma de $P$. edulis

\begin{tabular}{|c|c|c|c|c|c|c|c|c|c|c|c|c|c|c|c|c|c|c|c|}
\hline $\mathbf{N}^{\circ}$ & Primer & Contig & Motivo & Início & Fim & pb & $\begin{array}{c}\mathbf{N}^{\circ} \\
\text { Repet }\end{array}$ & Score & Sequência do contig & Unidade & G/S & Cobertura & pb & Sequência Forward & $\begin{array}{l}\mathrm{T}^{\circ} \mathrm{C} \\
F w d \\
\end{array}$ & Sequência Reverse & $\begin{array}{l}\mathrm{T}^{\circ} \mathrm{C} \\
\operatorname{Rev} \\
\end{array}$ & $\begin{array}{c}\% \mathrm{GC} \\
F w d \\
\end{array}$ & $\begin{array}{r}\% \mathrm{GC} \\
\operatorname{Rev} \\
\end{array}$ \\
\hline 781 & BrPe4303 & $\begin{array}{l}\text { Maracuja_ } \\
\text { NoIndex_L } \\
\text { 003_R1_00 } \\
\text { 1_contig_6 } \\
4349\end{array}$ & 4 & 368 & 379 & 12 & 3 & 8 & $\begin{array}{l}\text { GTCTTTGAAGAATCATCAATCCTGATTTATCTTCGTGTTGCCGGTTCT } \\
\text { TTGATTCCTATGCGGGTTTGGAGTCTGATTCCATAGCTTCGGTGAA } \\
\text { GCTACGGATCCAGACGTCTGAAGGGTTCGTGGTGAAGAAACAAAAG } \\
\text { CTTGTTTTTGGAGGGAGGGAGTTGGCAAGGAATGATTCGCTTGTTAA } \\
\text { GGACTATGGTGTTGATAACGGAAATGTTTTACATTTGGTTCTTAAGC } \\
\text { TCTCCGATCTCTTGGTGATTAACGCGAGGACCACTTGTGGGAAGGA } \\
\text { ATTTGAGTTTAAGGTGGACAGATATAGGAAT }\end{array}$ & GGAG & $\bar{G}$ & 11,86 & 238 & $\begin{array}{l}\text { GTGTTGCCGGTTCTTT } \\
\text { GATT }\end{array}$ & 60,0 & $\begin{array}{l}\text { CAAGTGGTCCTCGC } \\
\text { GTTAAT }\end{array}$ & 60,1 & 45 & 50 \\
\hline 782 & BrPe4304 & $\begin{array}{l}\text { Maracuja_ } \\
\text { NoIndex_L } \\
003 \_R 1 \text { 00 } \\
\text { 1_contig_6 } \\
4351\end{array}$ & 4 & 1451 & 1462 & 12 & 3 & 8 & $\begin{array}{l}\text { TGCTTCTGTCATGGCAGGGTATCAAGCAATTCTTCGTTGCAGTGGAA } \\
\text { AGAGAGGAGTGGAAATTTGATACTCTCTGTGACCTTTATGATACACT } \\
\text { TACCATCACCCAAGCTGTTATTTTCTGCAACACAAAGCGGAAGGTA } \\
\text { ATGCTTTAACTTGTTTGTTTGTGGATTAGATGTATAATTTGTTATTTT } \\
\text { CTTTGCTTAATTTCTGCCATGCGACTGAATTTTATTTGATTTTACCAT } \\
\text { TTCTCTAATATCTGTACTTGGAATGACACGAAGTGTGTTCTTTCTAA } \\
\text { ATTGAAATATTTGAGGTTGCCTTCTAAAT }\end{array}$ & TTGT & G & 19,19 & 211 & $\begin{array}{l}\text { TCTGTCATGGCAGGG } \\
\text { TATCA }\end{array}$ & 60,1 & $\begin{array}{l}\text { CAGTCGCATGGCAG } \\
\text { AAATTA }\end{array}$ & 59,8 & 50 & 45 \\
\hline 783 & BrPe4305 & $\begin{array}{l}\text { Maracuja_ } \\
\text { NoIndex_L } \\
\text { 003_R1_00 } \\
\text { 1_contig_6 } \\
4985\end{array}$ & 4 & 879 & 890 & 12 & 3 & 8 & $\begin{array}{l}\text { GGCTCTTCACCTTCTTTGCAGTGCACAGATTTTGCCAATGGAGGATT } \\
\text { AGGATTGGGTATTTGCACTGTAGAATGTGGAGATGAACCACTATTC } \\
\text { AATATCGACTCCATAACCAGATTCTTGCTTCATACTTGTATAGGAAT } \\
\text { ATTTCTTGTCCAGTCAGTCAGTTAATATGACATGATGAACCTGCCA } \\
\text { TAAGTTTAGATATGTGTGTTGATGGAAATTGGGGAGGTAAGTTTGT } \\
\text { CTTCATTTGGGCCTGATTCCATTGGTTCACTTCTGTTTCTTTCACAAA } \\
\text { ACTGGGAATGTAACGCAGGCTTCCTTGTTT }\end{array}$ & CAGT & $\mathrm{s}$ & 12,95 & 198 & $\begin{array}{l}\text { CCATAACCAGATTCT } \\
\text { TGCTTCA }\end{array}$ & 59,2 & $\begin{array}{l}\text { CCTGCGTTACATTCC } \\
\text { CAGTT }\end{array}$ & 60 & 40,9 & 50 \\
\hline 784 & BrPe4306 & $\begin{array}{l}\text { Maracuja_ } \\
\text { NoIndex_L } \\
003 \_R 1 \text { 00 } \\
\text { 1_contig_6 } \\
5781\end{array}$ & 4 & 2799 & 2810 & 12 & 3 & 8 & $\begin{array}{l}\text { TTTCGAAAACAAGGCAAGAGATTAGTTATGGATATTCGATATTTCTAT } \\
\text { ATTATAAGAAATTAAGGTTAATATTGGAAACACACTCCCAGCTTAG } \\
\text { GAATTTTGGATGATAAAATGTTCATTTTAAGAAATTTTAATTGAAAT } \\
\text { CCGAAAAGAAATTTATTTATTTTTTGTTCATCTGGACATGCCATAAC } \\
\text { AACAATTCTGAGCAAGAGAGAATACTTGAATACAAAATCTAGCAGT } \\
\text { GTAATAAAACATAAACTCCAAACCATACATGACCCTTCTGTTTCTA } \\
\text { CCCATAAAACATCTTTGGTATGAAGTGTCGGC }\end{array}$ & ATTT & $\mathrm{s}$ & 15,06 & 241 & $\begin{array}{l}\text { TGGAAACACACTCCC } \\
\text { AGCTT }\end{array}$ & 60,7 & $\begin{array}{l}\text { GCCGACACTTCATA } \\
\text { CCAAAGA }\end{array}$ & 60,1 & 50 & 47,6 \\
\hline 785 & BrPe4307 & $\begin{array}{l}\text { Maracuja_ } \\
\text { NoIndex_L } \\
003 \text { 1_1_00 } \\
\text { 1_contig_6 } \\
6012\end{array}$ & 4 & 183 & 194 & 12 & 3 & 8 & $\begin{array}{l}\text { CCTCGAATTTCAAAATTACACTACTCCCTTTCACTTGTCTCTTCCTAA } \\
\text { ACTCCAAAGTAATCCGGATCTCTGCCTTAAAACAACATTACCGAAA } \\
\text { GAATCCCCATCTGCCAAGTCAGTAGTCACCTGTAAATAGCGAAAAG } \\
\text { ATTTCCTGGCTCGATCGATCGAATCCAATATCCACTAATGGACAGCT } \\
\text { CGGATTCCGCTACGCATCCTGTCCCCGCCACCATTCCGCTGGCTCCT } \\
\text { GTATCCTCTCATTCTCTTCTCTCTCTATGCCGTTTGTTGTATAGGCTC } \\
\text { TTAAATTATGTGTTTTTGTTTGTGTTTTTG }\end{array}$ & TCGA & $\mathrm{s}$ & 17,87 & 178 & $\begin{array}{l}\text { TCCGGATCTCTGCCTT } \\
\text { AAAA }\end{array}$ & 59,8 & $\begin{array}{l}\text { ATACAGGAGCCAGC } \\
\text { GGAAT }\end{array}$ & 59,7 & 45 & 52,6 \\
\hline
\end{tabular}

G: genoma funcional

S: genoma estructural

P: polimórfico

M: monomórfico 
APÉNDICE

Marcadores microssatélites desenhados a partir do sequênciamento parcial e da montagem de novo do genoma de $P$. edulis

\begin{tabular}{|c|c|c|c|c|c|c|c|c|c|c|c|c|c|c|c|c|c|c|c|}
\hline $\mathbf{N}^{\circ}$ & Primer & Contig & Motivo & Início & Fim & pb & $\begin{array}{c}\mathbf{N}^{\circ} \\
\text { Repet }\end{array}$ & Score & Sequência do contig & Unidade & G/S & Cobertura & pb & Sequência Forward & $\begin{array}{l}\mathrm{T}^{\circ} \mathrm{C} \\
F w d \\
\end{array}$ & Sequência Reverse & $\begin{array}{l}\mathrm{T}^{\circ} \mathrm{C} \\
\operatorname{Rev} \\
\end{array}$ & $\begin{array}{c}\% \mathrm{GC} \\
F w d \\
\end{array}$ & $\begin{array}{c}\% \mathrm{GC} \\
\operatorname{Rev}\end{array}$ \\
\hline 786 & $\begin{array}{ll}\text { BrPe4308 } \\
\end{array}$ & $\begin{array}{l}\text { Maracuja_ } \\
\text { NoIndex_L } \\
\text { 003_R1_00 } \\
\text { 1_contig_6 } \\
6123\end{array}$ & 4 & 838 & 849 & 12 & 3 & 8 & $\begin{array}{l}\text { CTGTTCAGCAGCATGGCTTCAATTTTACGTATCAGTTGGAGAGTGGC } \\
\text { AAAGGGGGTGATCTACCCAGCTCTGGCCAGGTCTCTTGATTCCCTTT } \\
\text { TACCTTTGATTCTAAATGGAACAAGTGAATTATGCACTAGTAGTTGC } \\
\text { GTTCTTTTATTTGTTTGTTTGCAATGCCGGGAGCTCTTATTTTGGTGC } \\
\text { TGCTGCAGTTTTTTCAAACTTAGTAATAAAACAGTGGTACTTCACGT } \\
\text { TTTTTTAATAATTTGGTAATTTCTTGATCAAGAACTTCAGGACTTGTT } \\
\text { TCTGATTGCTTTCTAGTGGACCACCATA }\end{array}$ & TTTG & $\mathrm{s}$ & 15,68 & 177 & $\begin{array}{l}\text { AGCAGCATGGCTTCA } \\
\text { ATTTT }\end{array}$ & 59,9 & $\begin{array}{l}\text { AAATAAGAGCTCCC } \\
\text { GGCATT }\end{array}$ & 60,1 & 40 & 45 \\
\hline 787 & BrPe4309 & $\begin{array}{l}\text { Maracuja_ } \\
\text { NoIndex_L } \\
003 \text { R1_00 } \\
\text { 1_contig_6 } \\
6492\end{array}$ & 4 & 456 & 475 & 20 & 5 & 16 & $\begin{array}{l}\text { TAAAGCGTTTGATCGAAGGTATTATATTCGCCCTTCGATCTTCTGAC } \\
\text { AACTCTATTCACATGGCCATGTAAACAACTACAATCATTGTGTTGGG } \\
\text { TCTTCTTCTGCATTGAGCAGGTACAATCTCACGGTCTTTGGTCCTGAT } \\
\text { GCAATGTCTCTTTCTTTCTTTCTTTCTTCTTAATCCGTAGTCATAATA } \\
\text { CAGTATTAATTCAAGCATCTCCACCATTGAACTTCGAGACTTTTTCA } \\
\text { ACTGTTTAAAGAGATACTCAGTTAACACGCGGTCAGATCTAATTTA } \\
\text { CGGCGGGCCAGGGGATCGAGATGCCACCTCAAGGTA }\end{array}$ & TCTT & G & 17,16 & 177 & $\begin{array}{l}\text { TCTTTGGTCCTGATGC } \\
\text { AATG }\end{array}$ & 59,6 & $\begin{array}{l}\text { TTAGATCTGGACCG } \\
\text { CGTGTT }\end{array}$ & 60,7 & 45 & 50 \\
\hline 788 & BrPe4310 & $\begin{array}{l}\text { Maracuja_ } \\
\text { NoIndex_L } \\
003 \_R 1 \text { 00 } \\
\text { 1_contig_6 } \\
6537\end{array}$ & 4 & 1473 & 1488 & 16 & 4 & 12 & $\begin{array}{l}\text { TGTTGTTTAACCATTAACATTGATATCAGTTCAGGTGGAGCATGCGG } \\
\text { AAACTACTTTGTTGATTCGCCAAGGAGAGACAAGACGGCAGAGGT } \\
\text { TGCACTACGGAAGTTAGATGCTGAAATTGACATGTGAACCAATAT } \\
\text { GTATGTCTGAGATTTATTTATTTATTTTTTCAAGTTGGGATACTTTTC } \\
\text { CTCAGTACCGGCGGTAAAGCTTTATAACTACCCATTTTAGAAACCTA } \\
\text { AGCAAAAAAAAGTGTTTGCATCTGGGAGATTTATAGTTGAGGTATT } \\
\text { GCTCGCAGGCATGCCAAATGGAGGAGGATGTGCAAC }\end{array}$ & ATTT & $\mathrm{s}$ & 17,57 & 219 & $\begin{array}{l}\text { AGGAGAGACAAGAC } \\
\text { GGCAGA }\end{array}$ & 60,1 & $\begin{array}{l}\text { CCTGCGAGCAATAC } \\
\text { CTCAAC }\end{array}$ & 60,8 & 55 & 55 \\
\hline 789 & BrPe4311 & $\begin{array}{l}\text { Maracuja_ } \\
\text { Nolndex_L } \\
\text { 003_R1_00 } \\
\text { 1_contig_6 } \\
6652\end{array}$ & 4 & 268 & 279 & 12 & 3 & 8 & $\begin{array}{l}\text { AAAGCATTCTGACCTCCAGAACACTCGTGAAACACAACCCTCATAC } \\
\text { CTAAAGGTACGAAAACACCAACAAGACAACAATCCACCCTAAAAA } \\
\text { ACATCTCCAAATAGTCAGGGTTCGGGAATTACGCTCTCTATCCGAAC } \\
\text { CTCTGAATCACCATGTATGTATGTGCACGCACGACTTAAAAACTGAA } \\
\text { AATACGAGACTCAGCACATGCAATGTATGATCATGAATATGACTCG } \\
\text { ACAAAATCTAAACATGCGATGCAAGGGTTTATTTAATCAAAACTCG } \\
\text { AACCAGGTCCTCGACCGGGTTCAACTCGGGAGCAG }\end{array}$ & ATGT & $\mathrm{s}$ & 64,4 & 186 & $\begin{array}{l}\text { CTCGTGAAACACAAC } \\
\text { CCTCA }\end{array}$ & 59,7 & $\begin{array}{l}\text { ATTGCATGTGCTGA } \\
\text { GTCTCG }\end{array}$ & 60 & 50 & 50 \\
\hline 790 & BrPe4312 & $\begin{array}{l}\text { Maracuja_ } \\
\text { Nolndex_L } \\
\text { 003_R1_00 } \\
\text { 1_contig_6 } \\
6761\end{array}$ & 4 & 156 & 167 & 12 & 3 & 8 & $\begin{array}{l}\text { GGTTAGAGATGTTTTTGAGAGTGTTTTCATGCCTTCGAGTACGAGGG } \\
\text { ATGGTCGTCATGGAAGTTTCGGAGGTCGAAGCGTGTTTTCGGAAAA } \\
\text { ATTTTCCAAGATGCAAGCCGACCAGTCGAAACACCGCCTTCAACCA } \\
\text { CCTCTTGCTTTTTTCTTTCTTTCCAGCTCACCACCCCTTTCCCTGCCAC } \\
\text { CTGGACATCATCTGGAAGGTAAGTTGGACTCCTTTTCCATGTCCCAA } \\
\text { AGCCACCAG }\end{array}$ & TTTC & $\mathrm{s}$ & 53,72 & 182 & $\begin{array}{l}\text { TCATGGAAGTTTCGG } \\
\text { AGGTC }\end{array}$ & 60,0 & $\begin{array}{l}\text { TTTGGGACATGGAA } \\
\text { AAGGAG }\end{array}$ & 59,9 & 50 & 45 \\
\hline
\end{tabular}

G: genoma funcional

S: genoma estructural

P: polimórfico

M: monomórfico 
APÉNDICE

Marcadores microssatélites desenhados a partir do sequênciamento parcial e da montagem de novo do genoma de $P$. edulis

\begin{tabular}{|c|c|c|c|c|c|c|c|c|c|c|c|c|c|c|c|c|c|c|c|}
\hline $\mathbf{N}^{\circ}$ & Primer & Contig & Motivo & Início & Fim & pb & $\begin{array}{c}\mathbf{N}^{\circ} \\
\text { Repet }\end{array}$ & Score & Sequência do contig & Unidade & G/S & Cobertura & pb & Sequência Forward & $\begin{array}{l}\mathrm{T}^{\circ} \mathrm{C} \\
F w d \\
\end{array}$ & Sequência Reverse & $\begin{array}{l}\mathrm{T}^{\circ} \mathrm{C} \\
\operatorname{Rev} \\
\end{array}$ & $\begin{array}{c}\% \mathrm{GC} \\
F w d \\
\end{array}$ & $\begin{array}{r}\% \mathrm{GC} \\
\operatorname{Rev} \\
\end{array}$ \\
\hline 791 & BrPe4313 & $\begin{array}{l}\text { Maracuja_ } \\
\text { NoIndex_L } \\
\text { 003_R1_00 } \\
\text { 1_contig_6 } \\
6945\end{array}$ & 4 & 936 & 947 & 12 & 3 & 8 & $\begin{array}{l}\text { CTTATGTAGTTCGGTAGCAAAGAACTCAACACACTTTAATGCTTGTT } \\
\text { ACAGTTTTAGAAGACATCCTTCCTTTCATCCGAGCTTCATGACTTCTT } \\
\text { ATCTTCTCTGGCTAATTACGATTCTTACATTTCTCCATGGTCCTTGGA } \\
\text { GCTGCAAAAAGAAAGAAAGCAGAGGCTCTAAAATCATTTTCAAGAA } \\
\text { GATGTACCGTTTGAACATGAAAATAAGGCAAATTTATTCCAACATT } \\
\text { CCCAGATATAAGTAGAGATGTTTGAAGACATGCGAGTTCAGGAAAC } \\
\text { GAGAAGATTTCAGGTGTTATCTTTTGCAAA }\end{array}$ & AAAG & $\mathrm{s}$ & 16,48 & 211 & $\begin{array}{l}\text { TCCTTTCATCCGAGCT } \\
\text { TCAT }\end{array}$ & 59,8 & $\begin{array}{l}\text { CCTGAACTCGCATG } \\
\text { TCTTCA }\end{array}$ & 60 & 45 & 50 \\
\hline 792 & BrPe4314 & $\begin{array}{l}\text { Maracuja_ } \\
\text { NoIndex_L } \\
003 \text { R1_00 } \\
\text { 1_contig_6 } \\
7127\end{array}$ & 4 & 3615 & 3626 & 12 & 3 & 8 & $\begin{array}{l}\text { TGGGTGCTAAGAACAAAGTTGCAGTGGCTTGCCTATACACTACAAA } \\
\text { GACCCTAGGGCTCATTCCTTGCAGAAGAGCCGCTCTTGTGATGAGG } \\
\text { GAAACTCCTGCGTAAGTGAATTGTAGACCAAACATAGCCATTTCTG } \\
\text { GCTTGAGATCGGCCCACCCACCCATATTTGGCATTCCAAGATATATA } \\
\text { GGGATTAGCTTTGCAGTCTACTATACATACCCTTACACACACGTATA } \\
\text { TATAGCCCGCAGAAATAAGTTTGTCAGCACATACGCTTCGTACACTA } \\
\text { CACATGCATGGTACAGATAAGAAGGTAGCTGAA }\end{array}$ & $\mathrm{CCCA}$ & $\mathrm{s}$ & 15,39 & 191 & $\begin{array}{l}\text { AGTTGCAGTGGCTTG } \\
\text { СCTAT }\end{array}$ & 59,9 & $\begin{array}{l}\text { AGTAGACTGCAAAG } \\
\text { CTAATCCCTA }\end{array}$ & 57,9 & 50 & 41,7 \\
\hline 793 & BrPe4315 & $\begin{array}{l}\text { Maracuja_ } \\
\text { NoIndex_L } \\
\text { 003_R1_00 } \\
\text { 1_contig_6 } \\
7330\end{array}$ & 4 & 2497 & 2508 & 12 & 3 & 8 & $\begin{array}{l}\text { GGGAGAAGTCCAATCTGTGGTGGCTCCAATTTGATGTAGTTGGCTTT } \\
\text { TTTGGGATCTTGGTATTGACACCGCTAGAAAGAATACAAGTTATGC } \\
\text { CGTAAATGGCACGGAATTATTAATAAAAAACACTGCATGTCTTCCTG } \\
\text { TGTTTCAGCTACGTACGTACGGTGTAGGAGAGATTCAGCGAGAGGT } \\
\text { GGCTGCTGTGTATTTGCGTTGTTTATTCGTATCCGCATGAATAAAGC } \\
\text { TTCAATATTTTGTATAGAATAATTTAGCACTATACATATCAATCGAT } \\
\text { TTTATATCAATTATATAATACCGAATGCTCT }\end{array}$ & TACG & $\mathrm{s}$ & 20,73 & 189 & $\begin{array}{l}\text { GGGAGAAGTCCAATC } \\
\text { TGTGG }\end{array}$ & 59,5 & $\begin{array}{l}\text { ССАССТCTCGCTGA } \\
\text { АТСТCT }\end{array}$ & 59,6 & 55 & 55 \\
\hline 794 & BrPe4316 & $\begin{array}{l}\text { Maracuja_ } \\
\text { NoIndex_L } \\
\text { 003_R1_00 } \\
\text { 1_contig_6 } \\
7794\end{array}$ & 4 & 1026 & 1037 & 12 & 3 & 8 & $\begin{array}{l}\text { CAAAATATTTGCATGCCTAAGATCTTTGCACCTACAATACATAGTAA } \\
\text { TCAATGCATTTCTTACATTATCAATTCATAAAAACAGCTCAGGATT } \\
\text { GTAGAACCATGAATATCAGCTCCTAATTTAAGAGTACCAATATGGA } \\
\text { AACATGTACCCAAACAAACAAATATTGCTACCGTATCCAAATAAAT } \\
\text { GCCACATCTTCTCATTTGAGAAAGCAACTCAAGCACCCCTTTGAAAT } \\
\text { TGTCGGTCCTCAAGCACCCTCTCTTATAGTATTCCAAGTCAAAATA } \\
\text { TTGGCTTCAACACCCTCTGTCCTCATTTTTTC }\end{array}$ & CAAA & $\mathrm{s}$ & 33,75 & 218 & $\begin{array}{l}\text { TGCCTAAGATCTTTGC } \\
\text { ACCT }\end{array}$ & 57,6 & $\begin{array}{l}\text { TTCAAAGGGGTGCT } \\
\text { TGAGTT }\end{array}$ & 59,7 & 45 & 45 \\
\hline 795 & BrPe4317 & $\begin{array}{l}\text { Maracuja_ } \\
\text { NoIndex_L } \\
003 \_R 1 \text { 00 } \\
\text { 1_contig_6 } \\
8112\end{array}$ & 4 & 990 & 1001 & 12 & 3 & 8 & $\begin{array}{l}\text { CTTTCCTTTCGAGAGTGGAGTGTAAATCCAAGAATTCAAGACAAAG } \\
\text { GTGTCTTTTGATATTATGTAAAAAAAAACAAAAATATGAGACTCCA } \\
\text { GTAGAATAAGAACACCCTGGTAAAGTTATGCGTTGTTGTAGGAATTT } \\
\text { AACATAGACGGAAAGAAAGAAATCACCTCTCAAACCTGTGGGACAT } \\
\text { CCAACATCCTCGGACAAGATTGGCAAAGATAACAACAATCACATAC } \\
\text { TAATTAACCAGTCATTCAAACCATGATGCACCCATTTAATTAAAATT } \\
\text { AAAGTGTTATTCCCGGTCAAATTATTATATTTT }\end{array}$ & GAAA & G & 13,29 & 162 & $\begin{array}{l}\text { CCCTGGTAAAGTTAT } \\
\text { GCGTTG }\end{array}$ & 59,5 & $\begin{array}{l}\text { AAATGGGTGCATCA } \\
\text { TGGTTT }\end{array}$ & 60,1 & 47,6 & 40 \\
\hline
\end{tabular}

G: genoma funcional

S: genoma estructural

P: polimórfico

M: monomórfico 
APÉNDICE

Marcadores microssatélites desenhados a partir do sequênciamento parcial e da montagem de novo do genoma de $P$. edulis

\begin{tabular}{|c|c|c|c|c|c|c|c|c|c|c|c|c|c|c|c|c|c|c|c|}
\hline $\mathbf{N}^{\circ}$ & Primer & Contig & Motivo & Início & Fim & pb & $\begin{array}{c}\mathbf{N}^{\circ} \\
\text { Repet }\end{array}$ & Score & Sequência do contig & Unidade & G/S & Cobertura & pb & Sequência Forward & $\begin{array}{l}\mathrm{T}^{\circ} \mathrm{C} \\
F w d \\
\end{array}$ & Sequência Reverse & $\begin{array}{l}\mathrm{T}^{\circ} \mathrm{C} \\
\operatorname{Rev} \\
\end{array}$ & $\begin{array}{c}\% \mathrm{GC} \\
F w d \\
\end{array}$ & $\begin{array}{r}\% \mathrm{GC} \\
\operatorname{Rev} \\
\end{array}$ \\
\hline 796 & BrPe4318 & $\begin{array}{l}\text { Maracuja_ } \\
\text { NoIndex_L } \\
\text { 003_R1_00 } \\
\text { 1_contig_6 } \\
8898\end{array}$ & 4 & 1910 & 1921 & 12 & 3 & 8 & $\begin{array}{l}\text { CTATCACTGATAACATGGAGGAGGAATATCGAGCTTGAAGAAATTGT } \\
\text { TGTAATTAGGGAGACGCCGAAAGGAACTGGAGCTTTGGTACAGTGG } \\
\text { AAAGGCTTCTGTCATTTGAAGCAACTTGGCAGCCCGTTGAAGAACTT } \\
\text { TGACAGCAATTTCCATCCATCCACCGTTGAGGACAAGGTCACTCTTA } \\
\text { GAATGACAGGGAATGATAGGCCCCAGATTAAGTTTGTCTAGCGTAG } \\
\text { AAGAGAGAGAAAGGAGTAAATTGTCTCTAGTTAATTACATGTCTCT } \\
\text { GGACAAATAAAGGAATGTTTCTGACATGCCAGAT }\end{array}$ & TCCA & $\bar{G}$ & 19,02 & 152 & $\begin{array}{l}\text { CGAAAGGAACTGGAG } \\
\text { CTTTG }\end{array}$ & 60,0 & $\begin{array}{l}\text { AATCTGGGGCCTAT } \\
\text { CATTCC }\end{array}$ & 60,1 & 50 & 50 \\
\hline 797 & BrPe4319 & $\begin{array}{l}\text { Maracuja_ } \\
\text { NoIndex_L } \\
003 \_R 1 \text { 00 } \\
\text { 1_contig_6 } \\
9045\end{array}$ & 4 & 3515 & 3530 & 16 & 4 & 12 & $\begin{array}{l}\text { ATTGATGTAAATATATACCTTGTATTTTGTTCATCATAATAAGTTGTA } \\
\text { TTATTTTCTATGTGTTAATTTCCATACATGCCATGAGTATTCTATATT } \\
\text { AATTATGTATATATGCTTTTATATGATCTATGCAAATTATCTAACATC } \\
\text { GTAACATAATTAATTAATTAATACTTTATGCAACTCAACATTTGATA } \\
\text { AAACAATTATGCTTGAAATTACATAATTGATCATATAATAAAATTTC } \\
\text { ACATGCAAATTAATTAAACATGTGTGTAGGTAGTTAGTGTGTGCTTA } \\
\text { AAACTTAATCCTGGTCCTTAATTATGGATGG }\end{array}$ & TAAT & s & 16,45 & 238 & $\begin{array}{l}\text { AATTTCCATACATGC } \\
\text { CATGAG }\end{array}$ & 57,4 & $\begin{array}{l}\text { GGACCAGGATTAAG } \\
\text { TTTTAAGCA }\end{array}$ & 58,7 & 38,1 & 39,1 \\
\hline 798 & BrPe4320 & $\begin{array}{l}\text { Maracuja_ } \\
\text { NoIndex_L } \\
\text { 003_R1_00 } \\
\text { 1_contig_6 } \\
9215\end{array}$ & 4 & 609 & 620 & 12 & 3 & 8 & $\begin{array}{l}\text { GAGGATAGTTGTCAAAGCCTCAGAGAAAGAACAGATATGAAGATG } \\
\text { ATAAGAAGAGATAAGAAAGTTGTCAAAGAAAAAGCAATGGATGAC } \\
\text { ATTCAAAGCAGAAGGAATCTCCACTTTTCTACAAAGGGCATCAATA } \\
\text { ATTGTACTTTCTGTAAAGAAAGAAAGGGTAAAATGTAATAGATATA } \\
\text { TAAGGATCCGAGCTATAAAAGAGGCATGAAGCCTAGAATGTAATCG } \\
\text { AACTCATTTTAGAAAATGAAAACCTTTGTTTGATCAATCTTGAGATG } \\
\text { TCTCATCTTTTAGTTTCAATTACTTTAATATATCCAT }\end{array}$ & AAAG & G & 20,58 & 155 & $\begin{array}{l}\text { TCAAAGAAAAAGCAA } \\
\text { TGGATGA }\end{array}$ & 59,7 & $\begin{array}{l}\text { CATTCTAGGCTTCAT } \\
\text { GCCTCTT }\end{array}$ & 59,9 & 31,8 & 45,5 \\
\hline 799 & BrPe4321 & $\begin{array}{l}\text { Maracuja_ } \\
\text { NoIndex_L } \\
003 \_R 1 \text { 00 } \\
\text { 1_contig_6 } \\
9267\end{array}$ & 4 & 3281 & 3292 & 12 & 3 & 8 & $\begin{array}{l}\text { CGGGGAGAACAAAAAAGGAAGGAACAATACCCCATGTGGGATTTCAT } \\
\text { AAAATACTGGAAAGACATCGTTTCATACCATCAAAATCAATGATTC } \\
\text { ATCCTCGAATGGAGCATAGCAACTTTCGGATTCCAGCACCGGAACT } \\
\text { AAACAATAAACAGAATGAATGAATTAGTCGACGTTACCAGTCACAA } \\
\text { AGGGTGTTTCATTTTTTATTTGTTTTTTCCGTTTGAGAGGTTCATCTA } \\
\text { CCCGGATAAATGTTACAGGGACATGAAATCTCCAAAGAAACCGATC } \\
\text { TCCGGCGATGCTGACTCCAGGTAGGTTGGGAAAC }\end{array}$ & T GAAT & $\mathrm{s}$ & 15,8 & 187 & $\begin{array}{l}\text { GATTCCAGCACCGGA } \\
\text { ACTAA }\end{array}$ & 60,1 & $\begin{array}{l}\text { CCAACCTACCTGGA } \\
\text { GTCAGC }\end{array}$ & 59,7 & 50 & 60 \\
\hline 800 & BrPe4322 & $\begin{array}{l}\text { Maracuja_ } \\
\text { NoIndex_L } \\
003 \_R 1 \text { 00 } \\
\text { 1_contig_6 } \\
9378\end{array}$ & 4 & 1871 & 1882 & 12 & 3 & 8 & $\begin{array}{l}\text { ATGAATCAAATTTGGATACCAATTAAAAGATTATAGCTAACATTTTA } \\
\text { TTGGTTCATCTTTGCGACTTTTCACCTCCTAGTAAGTTTTGGTGATAC } \\
\text { ATAACCACCATTCAGCAAAAGAGGGCATCTTGTTAGGTCCGCCAAT } \\
\text { AATGTGATTATTAATTAATTATCAGAAACTGCATTTACTTTCTGCGC } \\
\text { AGCATTTCCTGAGCCGACAGGAATTCGGTAAGACCTCGACGATATG } \\
\text { CACCTAAACTTTTACTCTGCTTCATCAAGATAACAAACGTCGATGTC } \\
\text { GATACTTCAGATTTAACACTCTTGCCATTTA }\end{array}$ & ATTA & $\mathrm{s}$ & 15,72 & 181 & $\begin{array}{l}\text { TTTGCGACTTTTCACC } \\
\text { TCCT }\end{array}$ & 59,9 & $\begin{array}{l}\text { GGTGCATATCGTCG } \\
\text { AGGTCT }\end{array}$ & 60,1 & 45 & 55 \\
\hline
\end{tabular}

G: genoma funcional

S: genoma estructural

P: polimórfico

M: monomórfico 
APÉNDICE

Marcadores microssatélites desenhados a partir do sequênciamento parcial e da montagem de novo do genoma de $P$. edulis

\begin{tabular}{|c|c|c|c|c|c|c|c|c|c|c|c|c|c|c|c|c|c|c|c|}
\hline $\mathbf{N}^{\circ}$ & Primer & Contig I & Motivo & Início & Fim & pb & $\begin{array}{c}\mathbf{N}^{\circ} \\
\text { Repet }\end{array}$ & Score & Sequência do contig & Unidade & G/S & Cobertura & pb & Sequência Forward & $\begin{array}{l}\mathrm{T}^{\circ} \mathrm{C} \\
F w d \\
F\end{array}$ & Sequência Reverse & $\begin{array}{l}\mathrm{T}^{\circ} \mathrm{C} \\
\operatorname{Rev} \\
\end{array}$ & $\begin{array}{c}\% \mathrm{GC} \\
F w d \\
\end{array}$ & $\begin{array}{cc}\% \mathrm{GC} & \mathbf{P} / \mathbf{M} \\
\operatorname{Rev} & \\
\end{array}$ \\
\hline 801 & BrPe4323 & $\begin{array}{l}\text { Maracuja_ } \\
\text { NoIndex_L } \\
\text { 003_R1_00 } \\
\text { 1_contig_7 } \\
0721\end{array}$ & 4 & 469 & 480 & 12 & 3 & 8 & $\begin{array}{l}\text { GAAAGAGAGGTACGATGAAAAATCTTGTGGAGCACATGAGGGTAGA } \\
\text { ATTGGACTGATAGAAGTTGGAGGCTGATGATGGTCGTCTTCCTGAG } \\
\text { GGGTTTGAAGCATGAAATTTGCCTGGAAGAAGGCCATTCCATTGCA } \\
\text { AGTCATCACCTACCTAGCTAGCTAGACCTGTGCCACCAATCTCAAAA } \\
\text { CCTGTGGTGAAACTCTAGCTGGCATGCTATGCTTTTAGGCAGAAGAA } \\
\text { AAGTGATAGAAGCCAGGAGTGGGCAGAGTTTAGTGTAGAAGAAGC } \\
\text { AATGGAGAGACCCAATATCACACACCACGGAGAAAA }\end{array}$ & $\begin{array}{c}\text { CTAG } \\
\end{array}$ & $\bar{s}$ & 18,14 & 233 & $\begin{array}{l}\text { AAGTTGGAGGCTGAT } \\
\text { GATGG }\end{array}$ & 60,1 & $\begin{array}{l}\text { TTGGGTCTCTCCATT } \\
\text { GCTTC }\end{array}$ & 60,2 & 50 & 50 \\
\hline 802 & BrPe4324 & $\begin{array}{l}\text { Maracuja_ } \\
\text { NoIndex_L } \\
003 \text { R1_00 } \\
\text { 1_contig_7 } \\
0812\end{array}$ & 4 & 1618 & 1629 & 12 & 3 & 8 & $\begin{array}{l}\text { AAGAAAAGCATCTTAAATACCAAAATCTCAATAACAAAACTCCGTA } \\
\text { AAAACCTTAGCAACAACGATTTTTTCCTAGAAATTGTAAGAGCGTG } \\
\text { AAGATGAGGGAGGCGGCGGTTAAAAGCTTAACGCGAAATGACACA } \\
\text { GAGAAAATAGAAAAAGAAAGAAAGTGGTAAAATCCCCACGGAGAA } \\
\text { AACGCCTACTTGAGAGTCTATAGAGACGGAAAATTTAGCGGAAT } \\
\text { TCGAAAAATAAAATTCATATGCTCCAACGCGCATCATTTCTTGTCAA } \\
\text { AAGTGGGTTTCCAGGAAAAAAATATGAAAGCATTTT }\end{array}$ & AAAG & G & 17,92 & 167 & $\begin{array}{l}\text { CGCGAAATGACACAG } \\
\text { AGAAA }\end{array}$ & 60,0 & $\begin{array}{l}\text { CCTGGAAACCCACT } \\
\text { TTTGAC }\end{array}$ & 59,4 & 45 & 50 \\
\hline 803 & BrPe4325 & $\begin{array}{l}\text { Maracuja_ } \\
\text { Nolndex_L } \\
\text { 003_R1_00 } \\
\text { 1_contig_7 } \\
\text { 2177 }\end{array}$ & 4 & 2923 & 2934 & 12 & 3 & 8 & $\begin{array}{l}\text { GGCAAACAAAACCCAACAGCTGAATCTTTTCAGTTAACAACTTCTA } \\
\text { CGCCCGATCAACATAAACATCCAAAAACAACAGCAAACAAGTTAAG } \\
\text { AGTGAGCTAGTTAGGAAGAAAGAAACAACGTCCACACCAAATTGAT } \\
\text { AAACATGCAAAGAAACAAACAAACGGTAACAAATAACCCAGTTCA } \\
\text { TTATGTTAACAGAAACAACAATTCAGTAAACGGAGACTTACCAATT } \\
\text { TATAAACGTGATTCTGATTAACAAAAAGCAACAGAAGATCAAGAAG } \\
\text { AAGAAGAAGAAGAAACGCTGACTAAGCCTGTGATATA }\end{array}$ & AAAC & $\mathrm{s}$ & 18,22 & 150 & $\begin{array}{l}\text { CAACGTCCACACCAA } \\
\text { ATTGA }\end{array}$ & 60,4 & $\begin{array}{l}\text { TCTTCTGTTGCTTTT } \\
\text { TGTTAATCAG }\end{array}$ & 59,1 & 45 & 32 \\
\hline 804 & BrPe4326 & $\begin{array}{l}\text { Maracuja_ } \\
\text { NoIndex_L } \\
\text { 003_R1_00 } \\
\text { 1_contig_7 } \\
2619\end{array}$ & 4 & 5368 & 5379 & 12 & 3 & 8 & $\begin{array}{l}\text { AAATATGCAGGAGGTGGGGGAGGCAAAATGACATCTCTAAATATTC } \\
\text { CACTGATGAAAGAAGTCTTGTTCTCAGTATCCATAAAGGACACGTTT } \\
\text { ACACTGAAATTAAAACTATTATTTGCGACATTCCCAGCTTTTCCTGT } \\
\text { ATCTTCACCTGCAAGCAAGCAAAATGATTGCATTACCCCCACAAAC } \\
\text { CCAATAAATGATGATATCATAAATAGCTGCTAGAATCAAACTTAAA } \\
\text { CCGTCACACTAGAAATCACACTTCCCAAATGTAGCAAACTTGATGA } \\
\text { ATATCTCCTCAATGAGATGATTGTCATTAATCTC }\end{array}$ & GCAA & $\mathrm{s}$ & 16,61 & 176 & $\begin{array}{l}\text { GGGGAGGCAAAATGA } \\
\text { CATC }\end{array}$ & 60,3 & $\begin{array}{l}\text { TATTGGGTTTGTGG } \\
\text { GGGTAA }\end{array}$ & 59,9 & 52,6 & 45 \\
\hline 805 & BrPe4327 & $\begin{array}{l}\text { Maracuja_ } \\
\text { NoIndex_L } \\
003 \_R 1 \text { _00 } \\
\text { 1_contig_7 } \\
3155\end{array}$ & 4 & 1681 & 1692 & 12 & 3 & 8 & $\begin{array}{l}\text { AGGCCCGGCCAGAAAGGGTTTAATTGATGAGGTTTCAGAGAGTGAG } \\
\text { TAGTTAACAAGACCTGACCATAAAGAGGTGTCGAATGAAGCTCTCA } \\
\text { TCCACCAGAAAGAAATAATGGCGTGAAGGCAACTGATATAGAGAG } \\
\text { GAGGGGGTACGATAAGGAAGGAAGGGCGGAGATTTAACACTCAGA } \\
\text { TGATATATGGCATCTTATGGCAGTTCTGGCTTGTACAGTAATAATTA } \\
\text { TACAGACGATATTTCAAACAAATATTAATATATTATTTATAATAATA } \\
\text { TTGTTATTTAATTCATACACATTTTCAAATACTTG }\end{array}$ & AAGG & $\mathrm{s}$ & 13,35 & 157 & $\begin{array}{l}\text { CCTGACCATAAAGAG } \\
\text { GTGTCG }\end{array}$ & 59,6 & $\begin{array}{l}\text { CAAGCCAGAACTGC } \\
\text { CATAAGA }\end{array}$ & 60,4 & 52,4 & 47,6 \\
\hline
\end{tabular}

G: genoma funcional

S: genoma estructural

P: polimórfico

M: monomórfico 
APÉNDICE

Marcadores microssatélites desenhados a partir do sequênciamento parcial e da montagem de novo do genoma de $P$. edulis

\begin{tabular}{|c|c|c|c|c|c|c|c|c|c|c|c|c|c|c|c|c|c|c|c|}
\hline $\mathbf{N}^{\circ}$ & Primer & Contig I & Motivo & Início & Fim & pb & $\begin{array}{c}\mathbf{N}^{\circ} \\
\text { Repet }\end{array}$ & Score & Sequência do contig & Unidade & G/S & Cobertura & pb & Sequência Forward & $\begin{array}{l}\mathrm{T}^{\circ} \mathrm{C} \\
F w d \\
\end{array}$ & Sequência Reverse & $\begin{array}{l}\mathrm{T}^{\circ} \mathrm{C} \\
\operatorname{Rev} \\
\end{array}$ & $\begin{array}{c}\% \mathrm{GC} \\
F w d \\
\end{array}$ & $\begin{array}{cc}\% \mathrm{GC} & \mathrm{P} / \mathrm{M} \\
\operatorname{Rev} & \end{array}$ \\
\hline 806 & BrPe4328 & $\begin{array}{l}\text { Maracuja_ } \\
\text { NoIndex_L } \\
\text { 003_R1_00 } \\
\text { 1_contig_7 } \\
3740\end{array}$ & 4 & 460 & 471 & 12 & 3 & 8 & $\begin{array}{l}\text { CACTAAATTTAGTCCGTCCAAACTGATTACAAATTGACAGTAGGAG } \\
\text { ACGTGTCAATCGTATTCATAGTAGGAATTGGTCAACTATTAGGAATC } \\
\text { CGTCATTCAATCCATCCATGCCGTGCACCCATAAAGACGAGCACCA } \\
\text { TCTATCCTTGACTTGCTTGCTTGTCAAATCCAACGGATGACATAACC } \\
\text { TTCAAACTCATAAACCATGATTAACCAAGTTGTTCGGCTATTTAAAG } \\
\text { AAAAAGAACAACATACTAAAGCTAGCAAAATTTAAGCACAAGCATA } \\
\text { ATTATCCAATATTAGAGAAAATGGAATTTGAT }\end{array}$ & CTTG & $\mathrm{G}$ & 18,76 & 109 & $\begin{array}{l}\text { CCCATAAAGACGAGC } \\
\text { ACCAT }\end{array}$ & 60,0 & $\begin{array}{l}\text { AAATAGCCGAACAA } \\
\text { CTTGGTTA }\end{array}$ & 57,9 & 50 & 36,4 \\
\hline 807 & BrPe4329 & $\begin{array}{l}\text { Maracuja_ } \\
\text { NoIndex_L } \\
\text { 003_R1_00 } \\
\text { 1_contig_7 } \\
3836\end{array}$ & 4 & 297 & 308 & 12 & 3 & 8 & $\begin{array}{l}\text { ATGAAACAATTGCACATTCTTTCTTGGGAGAAGTAAACAATTCCGAC } \\
\text { ATAAAATGTTACTCAACAATTATAACATTGTTGGTTTCAAAATCCCA } \\
\text { TGAAACATTAATATCGATGAGAAGGTTCTTAATTAATATAAGATATC } \\
\text { GAGGTGATGACATACATACATGCATCCTTTGATCACATCTTGGATAC } \\
\text { TGGTGACGAGATCTTGTTTATTCAACCTAACAAATCACAATACATGG } \\
\text { GTAATTTTATTATAAAAGA }\end{array}$ & ACAT & $\mathrm{s}$ & 18,54 & 188 & $\begin{array}{l}\text { TGCACATTCTTTCTTG } \\
\text { GGAGA }\end{array}$ & 60,8 & $\begin{array}{l}\text { CTCGTCACCAGTAT } \\
\text { CCAAGATG }\end{array}$ & 59,6 & 42,9 & 50 \\
\hline 808 & BrPe4330 & $\begin{array}{l}\text { Maracuja_ } \\
\text { NoIndex_L } \\
003 \text { R1_00 } \\
\text { 1_contig_7 } \\
4180\end{array}$ & 4 & 1085 & 1112 & 28 & 7 & 24 & $\begin{array}{l}\text { CACTATACTATATACGAATGATAATTCAAGTACACTGCATGAAACA } \\
\text { AAAAAAAAATGCCTCTCTTTCGAGTATTAATTCCATTCATTGACCCC } \\
\text { TCTCGAGACCTATTGTTGTATTGAACCTTCAATTTTATCATTAAACA } \\
\text { GAAAAGGGAAGAAGGAAGGAAGGAAGGAAGGAAGGAAGTATAGT } \\
\text { GGTGTGTTAAGACAAATGCGAGTGAGAGACAAAACACATAGACAAT } \\
\text { AAATACGAATTCAAAAATAAACCGAAATTCCCACCTCATAAACAAA } \\
\text { CAACAAGCAGAAGAGGACAAACAGAGAGACGAGTAAAAGAGAAA }\end{array}$ & GAAG & G & 17,62 & 183 & $\begin{array}{l}\text { ATTGACCCCTCTCGA } \\
\text { GACCT }\end{array}$ & 60,1 & $\begin{array}{l}\text { GAGGTGGGAATTTC } \\
\text { GGTTTA }\end{array}$ & 58,9 & 55 & 45 \\
\hline 809 & BrPe4331 & $\begin{array}{l}\text { Maracuja_ } \\
\text { NoIndex_L } \\
\text { 003_R1_00 } \\
\text { 1_contig_8 } \\
5906\end{array}$ & 4 & 793 & 804 & 12 & 3 & 8 & $\begin{array}{l}\text { TTGGCCGAGGTAACACCAAATGCACTGCACTTCTGCATACTAAGAC } \\
\text { GTAAAGCTTGGTTCTCTGCAGTAAAAAACTGGAGCAACCGGTCCAG } \\
\text { CCTCCTACATTCCCCTTCCAAATACTTACTCTTCAATTCTAGATCTCT } \\
\text { CACATACTCCTTCTTTCTTTCTCTTGATCGCACCGCCGCATCTCTATT } \\
\text { TCTCAACTGCCTGAAAATTAAACTCCATAATCATATATGATATACAC } \\
\text { TGAACTCGAATTTATAAAGGAACAGCATACTCCACCAGTTTGTACTG } \\
\text { TCTTCAGACCTCAGATATTGTGCTCAAACA }\end{array}$ & ТTCT & G & 18,75 & 182 & $\begin{array}{l}\text { AGCCTCCTACATTCC } \\
\text { CCTTC }\end{array}$ & 59,5 & $\begin{array}{l}\text { TGGTGGAGTATGCT } \\
\text { GTTCCTT }\end{array}$ & 59,6 & 55 & 47,6 \\
\hline 810 & BrPe4332 & $\begin{array}{l}\text { Maracuja_ } \\
\text { NoIndex_L } \\
003 \text { 181_00 } \\
\text { 1_contig_1 } \\
42735\end{array}$ & 4 & 838 & 849 & 12 & 3 & 8 & $\begin{array}{l}\text { TTCGACACGGGAAGTTCTGATCTTTGGGTGCCTTCATCTAAATGTTA } \\
\text { TTTCTCGGTCAGTGTTGCTAGCTTTTGGATCGTGTTACTTGATTACTA } \\
\text { TTTGTTTGCCTTGGATTGACGTGAGGTTACATGCTCATGGTTTATGT } \\
\text { GACCGCAGCTTGCTTGCTTTTTCCATCCCAAGTATAAGTCCAGTGAA } \\
\text { TCAAGCACCTACAAGAAGAATGGTGTGTTGTTTTTCTCGGGTTGAAA } \\
\text { GAATATAATTTCTAGTTGGATCATAACTCTTATAAAAATAATAATAA } \\
\text { TAAACACTTTCACAGACATCACTAGTTC }\end{array}$ & GCTT & G & 15,34 & 216 & $\begin{array}{l}\text { TCTGATCTTTGGGTGC } \\
\text { CTTC }\end{array}$ & 60,2 & $\begin{array}{l}\text { CCCGAGAAAAACAA } \\
\text { CACACC }\end{array}$ & 60,4 & 50 & 50 \\
\hline
\end{tabular}

G: genoma funcional

S: genoma estructural

P: polimórfico

M: monomórfico 
APÉNDICE

Marcadores microssatélites desenhados a partir do sequênciamento parcial e da montagem de novo do genoma de $P$. edulis

\begin{tabular}{|c|c|c|c|c|c|c|c|c|c|c|c|c|c|c|c|c|c|c|c|}
\hline $\mathbf{N}^{\circ}$ & Primer & Contig I & Motivo & Início & Fim & pb & $\begin{array}{c}\mathbf{N}^{\circ} \\
\text { Repet }\end{array}$ & Score & Sequência do contig & Unidade & G/S & Cobertura & $\mathrm{pb}$ & Sequência Forward & $\begin{array}{l}\mathrm{T}^{\circ} \mathrm{C} \\
F w d \\
\end{array}$ & Sequência Reverse & $\begin{array}{l}\mathrm{T}^{\circ} \mathrm{C} \\
\operatorname{Rev} \\
\end{array}$ & $\begin{array}{c}\% \mathrm{GC} \\
F w d \\
\end{array}$ & $\begin{array}{cc}\% \mathrm{GC} & \mathrm{P} / \mathrm{M} \\
\operatorname{Rev} & \end{array}$ \\
\hline 811 & BrPe4333 & $\begin{array}{l}\text { Maracuja_ } \\
\text { NoIndex_L } \\
003 \text { R1_00 } \\
\text { 1_contig_1 } \\
48706\end{array}$ & 4 & 2456 & 2467 & 12 & 3 & 8 & $\begin{array}{l}\text { TATAGCCTCACTCCTCTCTTCTCTGCAACCTTTTCATGTGTGCATGTT } \\
\text { CTGATTGTCCAATCCCGGGAATATGTTGAGGTCTGGAAGTCCTTGTT } \\
\text { CTCATATTTTAATTTTCCATCATAGTTGGATCTAGATATTTTTAATCT } \\
\text { GTTATCTTTTATTTATTTACTTTTCCTTCTAGCCCAGGAGGGGTTTTT } \\
\text { TGTTGGTTTTTTCCCGGTGGTTGTCAACGGTTTGTTCTCCGCTTCTA } \\
\text { TTGTTCTTACTCTTCTCTTCAAATTTTTTGTCACTTCCTTTTTCTTCAG } \\
\text { TTGGTTGTCTTCAAGTTTACCAGG }\end{array}$ & TTTA & $\mathrm{G}$ & 18,98 & 161 & $\begin{array}{l}\text { TGCAACCTTTTCATGT } \\
\text { GTGC }\end{array}$ & 60,7 & $\begin{array}{l}\text { CCTCCTGGGCTAGA } \\
\text { AGGAAA }\end{array}$ & 60,7 & 45 & 55 \\
\hline 812 & BrPe4334 & $\begin{array}{l}\text { Maracuja_ } \\
\text { NoIndex_L } \\
\text { 003_R1_00 } \\
\text { 1_contig_1 } \\
\text { 55236 }\end{array}$ & 4 & 423 & 434 & 12 & 3 & 8 & $\begin{array}{l}\text { ATTCAAGTTATCTTGTATTCTCTTATGGGCATTCAACAGCATTTATAA } \\
\text { CTTAGGCTTTATATTCTAATTCTGCAAGTAAGACACCACAAGTTAAT } \\
\text { TGACACTATGGCTTTCTGCTTCTATTAACTTTGATTCATTCAACAAAT } \\
\text { TTGCTACTTATTTATTTATCACTCTTTCATTGGCTCGTGGATATTCCT } \\
\text { AATTTGATGCGTAATGTTTTAGGTAGGCAATCTTTCATAAACACCTC } \\
\text { CAAGTGGATCGAAGAAGTCCGAACTGAGAGAGGCACCGATGTTATC } \\
\text { ATTGTCCTTGTTGGGAACAAAACTGACC }\end{array}$ & ТTAT & G & 18,79 & 224 & $\begin{array}{l}\text { TGGGCATTCAACAGC } \\
\text { ATTTA }\end{array}$ & 60,1 & $\begin{array}{l}\text { CGATCCACTTGGAG } \\
\text { GTGTTT }\end{array}$ & 60 & 40 & 50 \\
\hline 813 & BrPe4335 & $\begin{array}{l}\text { Maracuja_ } \\
\text { NoIndex_L } \\
003 \text { R1_00 } \\
\text { 1_contig_6 } \\
0202\end{array}$ & 4 & 1859 & 1870 & 12 & 3 & 8 & $\begin{array}{l}\text { ACTTTGTACTGATAAAACAGAACTTGCACCTGTTCTTGATAGATATA } \\
\text { AAACCCTTAATGTATACTTTCCAGAACTTGTTGAACCTATGCAACAT } \\
\text { GAAAATAATGAAGAAAATATTCAGACCCAGCAAGATGAACAATCA } \\
\text { AACCTTGAGAGCAACCAACCAACACCTCAGGATAGTTCTAGTAACT } \\
\text { TAAATACCTCACCTGCAACTAGAAAAAAAAATCAGCAAAATGCTAGG } \\
\text { GAAAGTCCTAGGAAAATTAATGATTACCAATTAGTAAGGGACAGAG } \\
\text { AAAAGAAGAACTATCCCAAATAAGAAATACTGATA }\end{array}$ & CAAC & G & 24,36 & 222 & $\begin{array}{l}\text { CAGAACTTGCACCTG } \\
\text { TTCTTGA }\end{array}$ & 60,5 & $\begin{array}{l}\text { GGACTTTCCCTAGC } \\
\text { ATTTTGC }\end{array}$ & 60,1 & 45,5 & 47,6 \\
\hline 814 & BrPe4336 & $\begin{array}{l}\text { Maracuja_ } \\
\text { NoIndex_L } \\
003 \text { R1_00 } \\
\text { 1_contig_1 } \\
6\end{array}$ & 4 & 7900 & 7911 & 12 & 3 & 8 & $\begin{array}{l}\text { AGTCTTATTAAAATCCCTAAGAGAGTAGATGTTGAGGAATGAAGGG } \\
\text { GAGAAGAGGAGCCGTCCACTTTAGGGAAAGGGCTTTGATCAAGAGC } \\
\text { CTTTCTTCTTTCTCAAAGTCTAGATGGAAAGAAGGATTGAGAACAGC } \\
\text { TGCTAAGAAACCAAGCAAGCAAGAAAGAGTAAGTCATTATCGAAG } \\
\text { AAAGCTCCGTCTTCGATCTCTCACTGGACATAGGATCAAGGGACGA } \\
\text { GAGAAGGTCGTAGGGTACCTACCCCAAGCAAAGAGAAAAGTAGAA } \\
\text { AAGGTCATAGTCCGAGCTCTCTAAGCACGAAATAAGG }\end{array}$ & CAAG & G & $3.892,26$ & 194 & $\begin{array}{l}\text { GGAATGAAGGGGAG } \\
\text { AAGAGG }\end{array}$ & 60,0 & $\begin{array}{l}\text { CGTCCCTTGATCCTA } \\
\text { TGTCC }\end{array}$ & 59,4 & 55 & 55 \\
\hline 815 & BrPe4337 & $\begin{array}{l}\text { Maracuja_ } \\
\text { NoIndex_L } \\
\text { 003_R1_00 } \\
\text { 1_contig_2 } \\
6242\end{array}$ & 4 & 200 & 219 & 20 & 5 & 16 & $\begin{array}{l}\text { GACCACCGCCAAGATCCACCTGGCTCCTCAAGTCAATCACCATGGA } \\
\text { GCCGTCTAAACAATTCTTGTAATCCAAAATCTCAGTCTGCAATACAG } \\
\text { ATGATGAGAGAAAAGAAAATGGACAAAAAGTAAACAACACAAATG } \\
\text { TATATGTCTACGTATCTATCTATCTATCTATCAGAGAATTTTTCATCT } \\
\text { TTGAAAGAGAAAAGATTCCCACGAGGAGAAGAGAATTGCATGCATT } \\
\text { ACATTTATTTACATACACATGCTCGTTTTAGTTGGAGAGACAGATT } \\
\text { AAAAAACGGAGATCTAACCATCAGATCATAGCAGCGCTCCC }\end{array}$ & TATC & $\mathrm{s}$ & 14,67 & 205 & $\begin{array}{l}\text { TGGACAAAAAGGTAAA } \\
\text { CAACACAAA }\end{array}$ & 58,7 & $\begin{array}{l}\text { AGCGCTGCTATGAT } \\
\text { CTGATG }\end{array}$ & 59,2 & 29,2 & 50 \\
\hline
\end{tabular}

G: genoma funcional

S: genoma estructural

P: polimórfico

M: monomórfico 
APÉNDICE

Marcadores microssatélites desenhados a partir do sequênciamento parcial e da montagem de novo do genoma de P. edulis

\begin{tabular}{|c|c|c|c|c|c|c|c|c|c|c|c|c|c|c|c|c|c|c|c|}
\hline $\mathbf{N}^{\circ}$ & Primer & Contig & Motivo & Início & Fim & pb & $\begin{array}{c}\mathbf{N}^{\circ} \\
\text { Repet }\end{array}$ & Score & Sequência do contig & Unidade & & Cobertura & pb & Sequência Forward & $\begin{array}{l}\mathrm{T}^{\circ} \mathrm{C} \\
F w d \\
\end{array}$ & Sequência Reverse & $\begin{array}{l}\mathrm{T}^{\circ} \mathrm{C} \\
\operatorname{Rev} \\
\end{array}$ & $\begin{array}{r}\% \mathrm{GC} \\
F w d \\
\end{array}$ & $\begin{array}{cc}\% \mathrm{GC} & \mathrm{P} / \mathrm{M} \\
\operatorname{Rev} & \end{array}$ \\
\hline 816 & BrPe4338 & Maracuja_ & 4 & 6182 & 6193 & 12 & 3 & 8 & $\begin{array}{l}\text { CTGTCCATATCCAAGGCTGATAAGCAACACTTCTCTCCACAAACCTT } \\
\end{array}$ & AGTG & $\mathrm{G}$ & 17,16 & 154 & CTTCCCCAGGTATCC & 60,1 & CAGGGGATCTTGGT & 59,1 & 55 & $\frac{55}{55}$ \\
\hline & & NoIndex_L & & & & & & & CCCCAGGTATCCCATCTCGCATTGTCATGATATGGATAGTTATCTGC & & & & & САTCT & & CAGAGT & & & \\
\hline & & 003_R1_00 & & & & & & & ATAAGAGAGGTCTCCAACGAACAATACCGCCTGGCCTTTTTGTGGGT & & & & & & & & & & \\
\hline & & 1_contig_1 & & & & & & & TCATTTCGTAGTGAGTGAGTGTTTTGTTTGAATCAAAACTCTGACCA & & & & & & & & & & \\
\hline & & 4659 & & & & & & & AGATCCCCTGCAATCATAACATACAATATGCACTTCCTTACCAACAA & & & & & & & & & & \\
\hline & & & & & & & & & CTTCCCAGAAACACCAGTACCAAATTTGCTCAGAGAACTATGCAGA & & & & & & & & & & \\
\hline & & & & & & & & & AATTTAAGCAAAACTGAAGTTCTTGGCACAA & & & & & & & & & & \\
\hline
\end{tabular}

